\title{
Wilson-Leonard An 11,000-year Archeological Record of Hunter- Gatherers in Central Texas Volume IV: Archeological Features and Technical Analyses
}

Michael B. Collins

Texas Archeological Research Laboratory

Paul Goldberg

Texas Archeological Research Laboratory

Wulf A. Gose

Texas Archeological Research Laboratory

Jan Guy

Texas Archeological Research Laboratory

Thomas W. Stafford Jr.

Texas Archeological Research Laboratory

See next page for additional authors

Follow this and additional works at: https://scholarworks.sfasu.edu/ita

Part of the American Material Culture Commons, Archaeological Anthropology Commons, Environmental Studies Commons, Other American Studies Commons, Other Arts and Humanities Commons, Other History of Art, Architecture, and Archaeology Commons, and the United States History Commons

Tell us how this article helped you.

This Article is brought to you for free and open access by the Center for Regional Heritage Research at SFA ScholarWorks. It has been accepted for inclusion in Index of Texas Archaeology: Open Access Gray Literature from the Lone Star State by an authorized editor of SFA ScholarWorks. For more information, please contact cdsscholarworks@sfasu.edu. 


\section{Wilson-Leonard An 11,000-year Archeological Record of Hunter-Gatherers in Central Texas Volume IV: Archeological Features and Technical Analyses}

Authors

Michael B. Collins, Paul Goldberg, Wulf A. Gose, Jan Guy, Thomas W. Stafford Jr., and Paul R. Takac

Creative Commons License

(c) (i) (8)

This work is licensed under a Creative Commons Attribution-NonCommercial-No Derivative Works 4.0 International License. 


\title{
WILSON-LEONARD
}

\section{An 11,000-year Archeological Record of Hunter-Gatherers in Central Texas}

\section{Volume IV: Archeological Features and Technical Analyses}

\author{
Assembled and Edited by Michael B. Collins
}

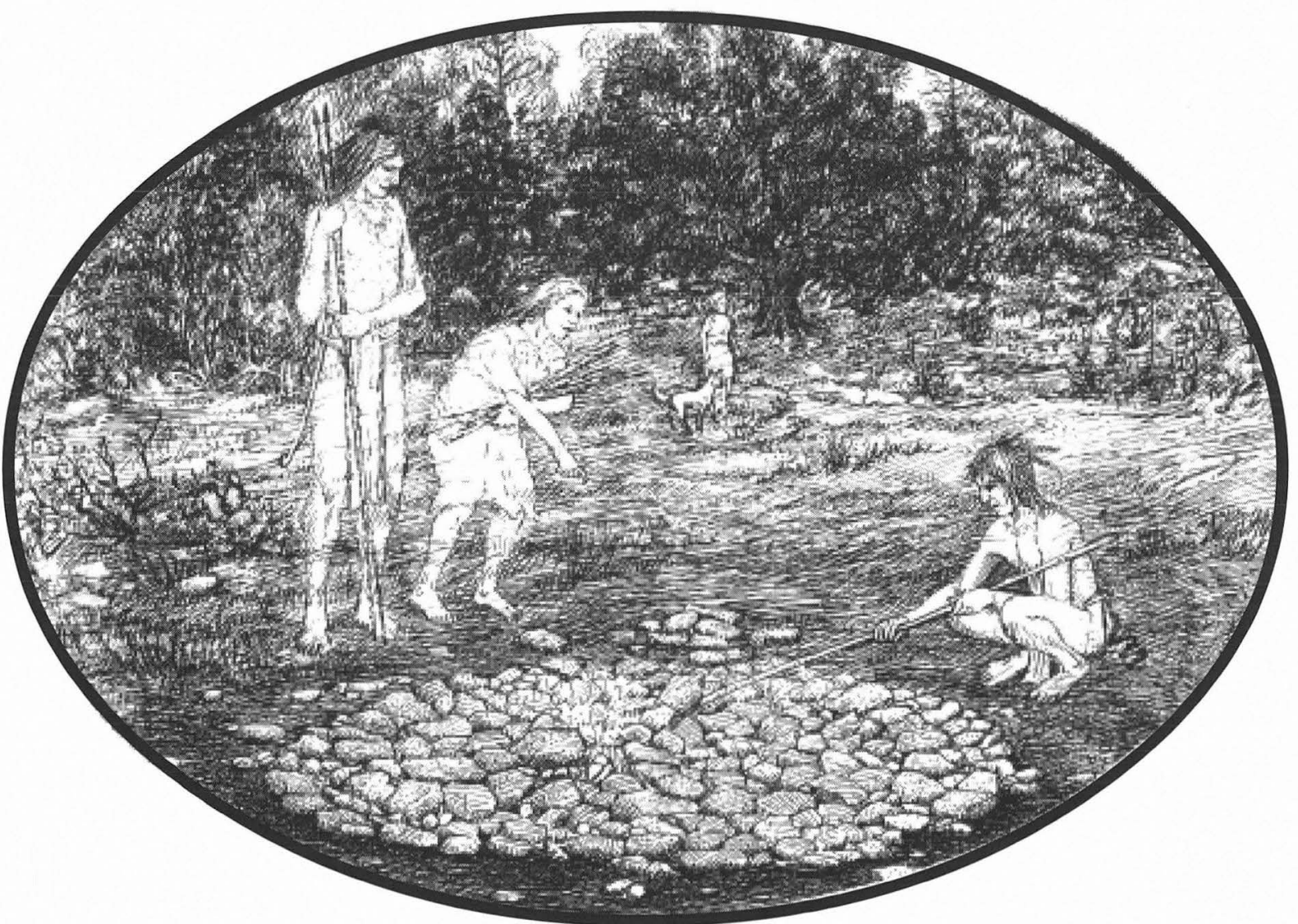

Studies in Archeology 31

Texas Archeological Research Laboratory The University of Texas at Austin
Archeology Studies Program, Report 10

Texas Department of Transportation Environmental Affairs Division 


\title{
WILSON-LEONARD
}

\author{
An 11,000-year Archeological Record \\ of Hunter-Gatherers in Central Texas
}

\section{Volume IV: Archeological Features and Technical Analyses}

\author{
assembled and edited by \\ Michael B. Collins \\ with contributions by \\ Michael B. Collins \\ Paul Goldberg \\ Wulf A. Gose \\ Jan Guy \\ Thomas W. Stafford, Jr. \\ Paul R. Takac
}

Principal Investigator: Nancy Kenmotsu

Frank Weir (1982-1998)

Texas Antiquities Committee Permit No. 300

Studies in Archeology 31

Texas Archeological Research Laboratory

The University of Texas at Austin

Archeology Studies Program, Report 10

Texas Department of Transportation

Environmental Affairs Division 
Cover drawing by Frank Weir

The University of Texas at Austin Texas Archeological Research Laboratory J. J. Pickle Research Campus 5

Austin, Texas 78712-1100

Printed 1998, on acid-free, 60-pound paper

ISBN 1-887072-28-4(Volume IV)

ISBN 1-887072-24-1 (5-Volume Set) 


\section{TABLE OF CONTENTS \\ Volume IV}

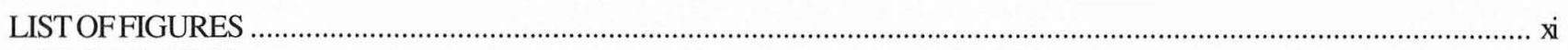

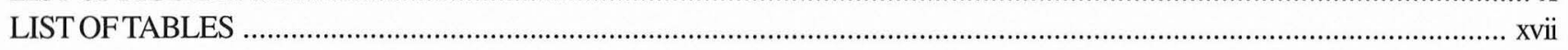

\section{CHAPTER 24: INTRODUCTIONTO VOLUMEIV}

by Michael B. Collins

\section{CHAPTER 25: RADIOCARBONCHRONOSTRATIGRAPHY}

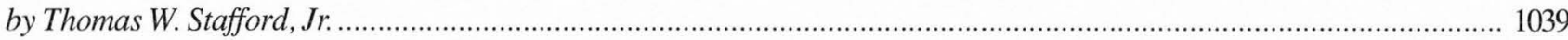

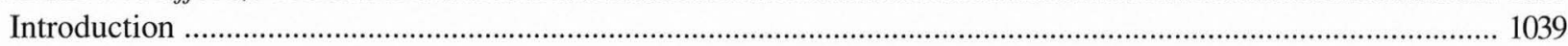

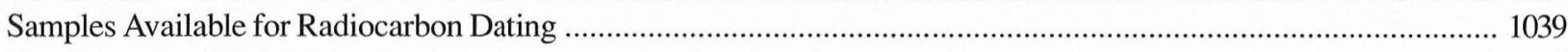

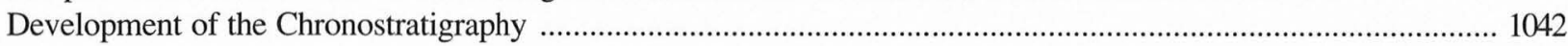

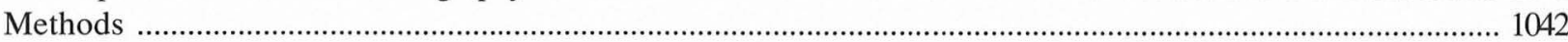

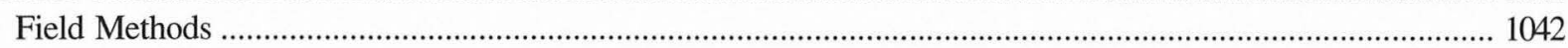

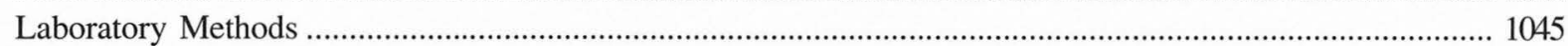

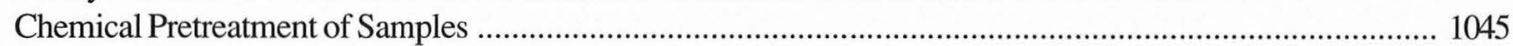

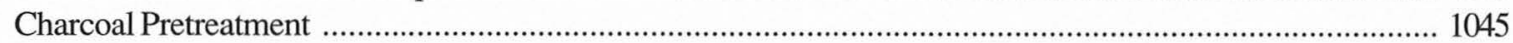

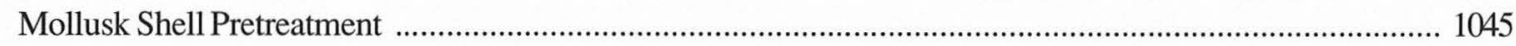

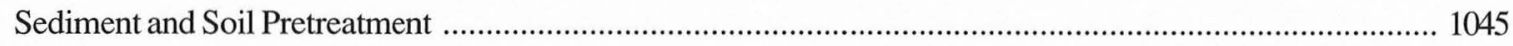

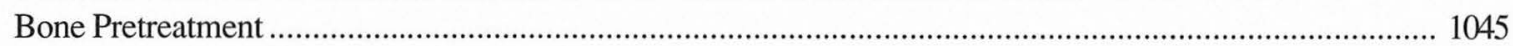

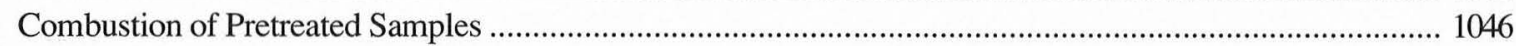

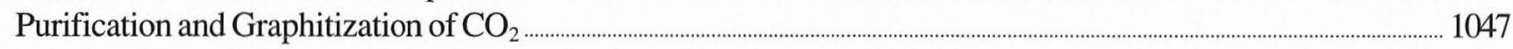

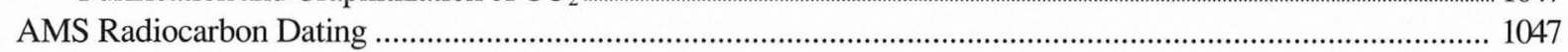

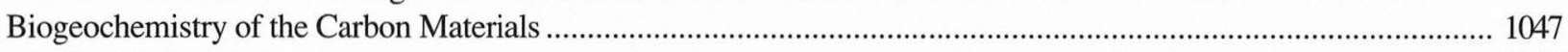

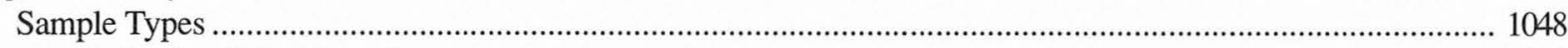

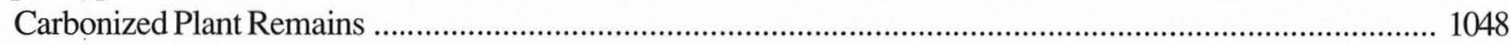

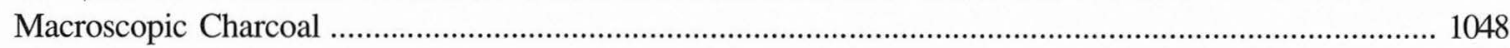

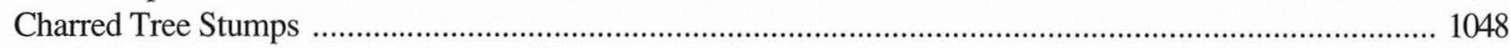

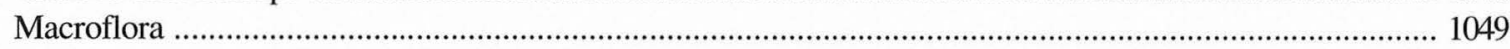

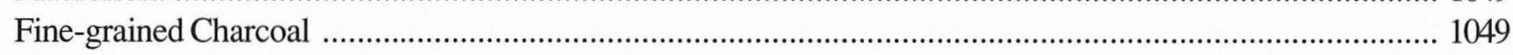

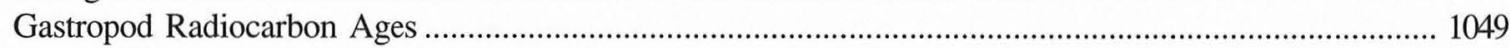

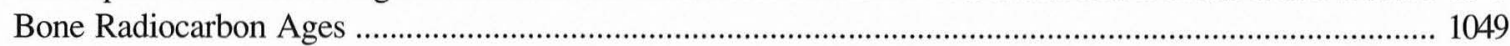

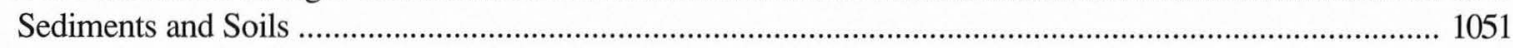

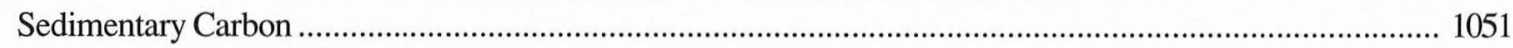

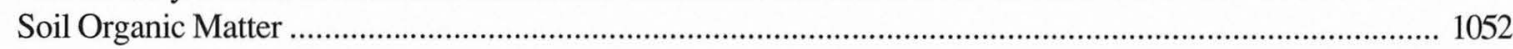

Physical and Chemical Postdepositional Alterations of Soils and Sediments ................................................... 1052

Results

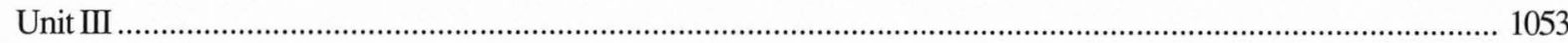

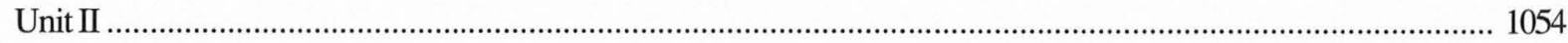

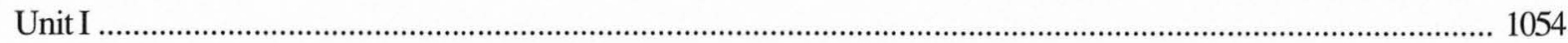

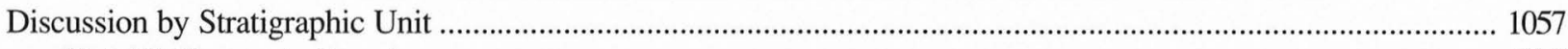

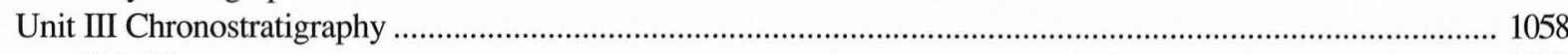

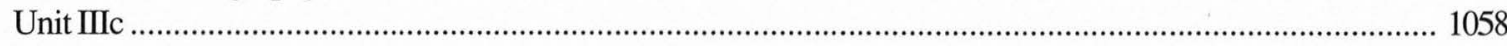

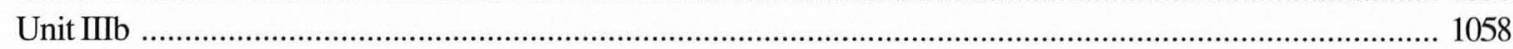

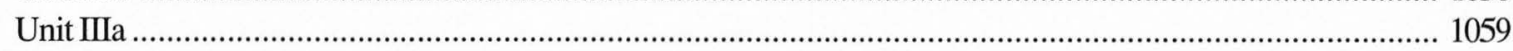

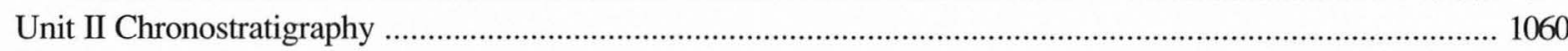

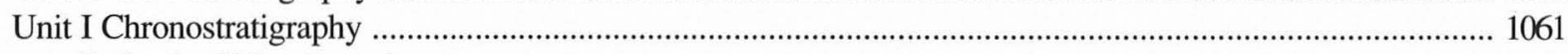

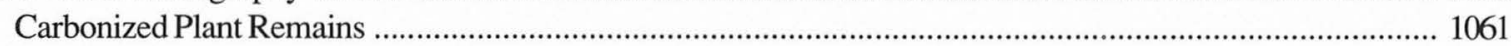

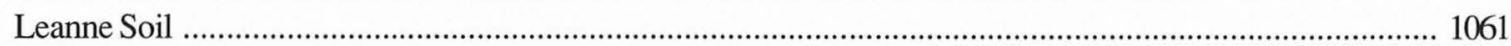

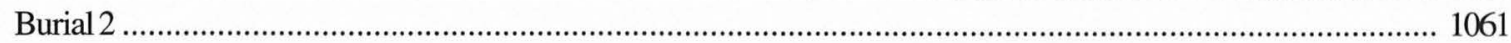

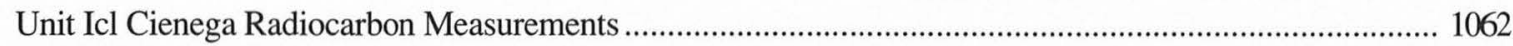

Developing Radiocarbon Chronologies at Alluvial Archeological Sites ................................................................ 1063 


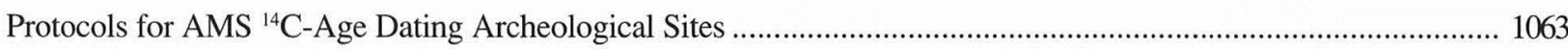

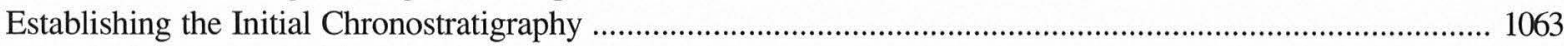

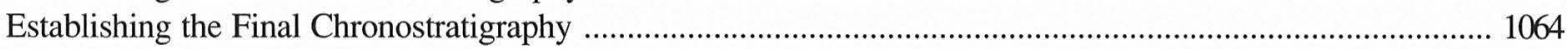

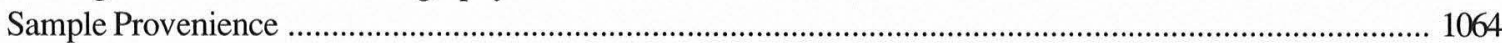

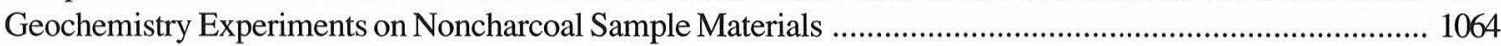

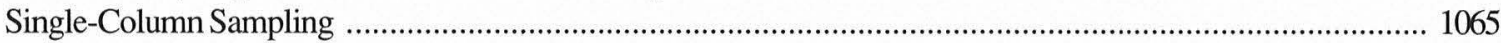

Using AMS Measurements to Distinguish between Similar-Age Events ................................................... 1065

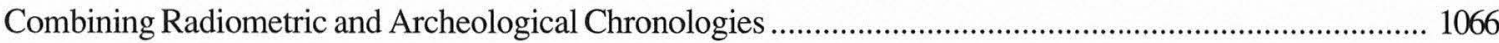

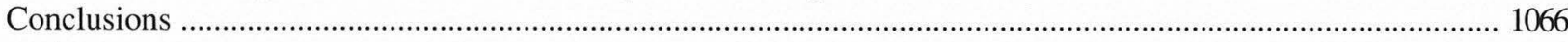

\section{CHAPTER 26: ANALYSIS OF CULTURAL AND NONCULTURALFEATURES}

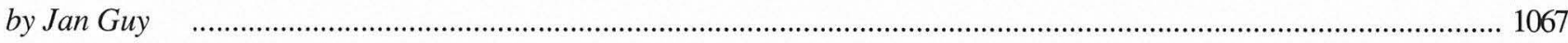

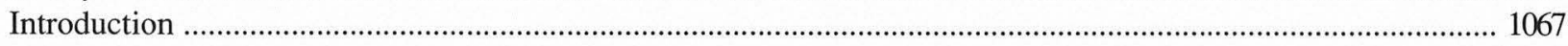

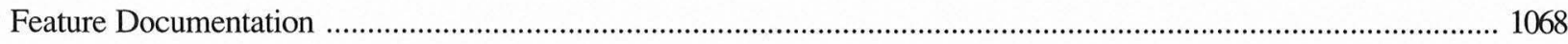

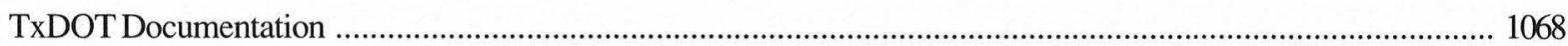

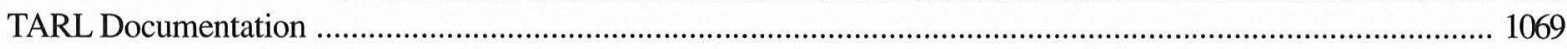

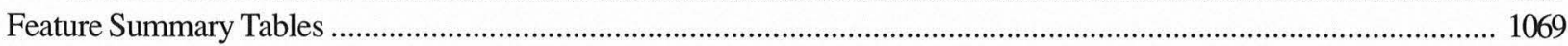

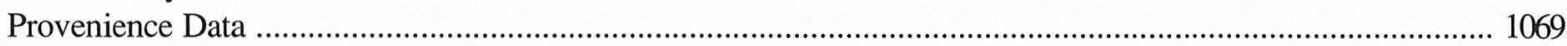

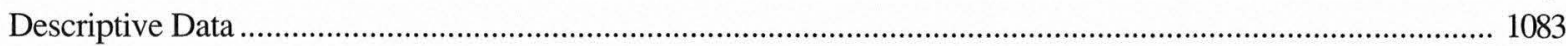

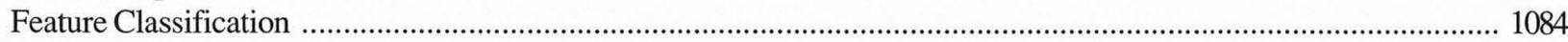

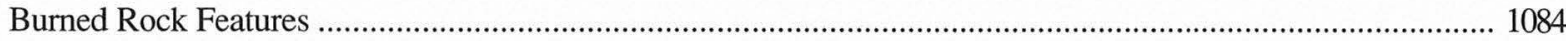

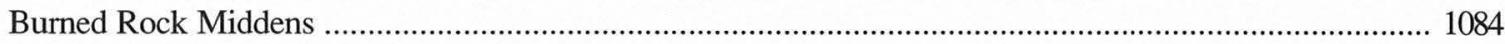

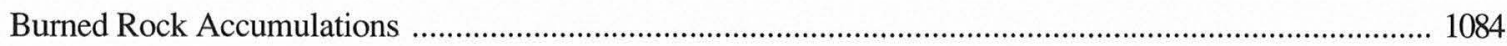

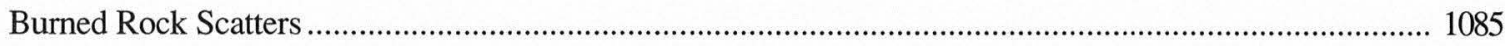

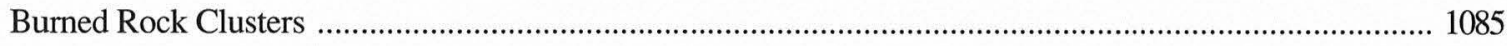

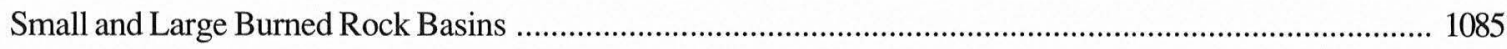

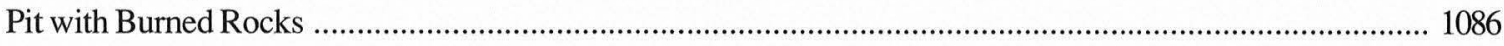

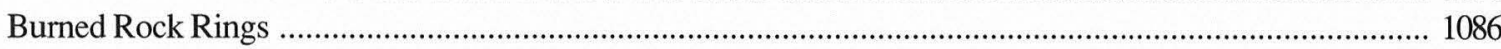

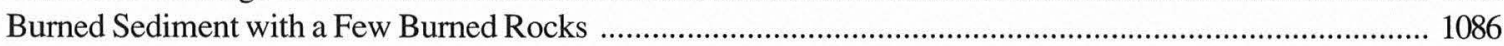

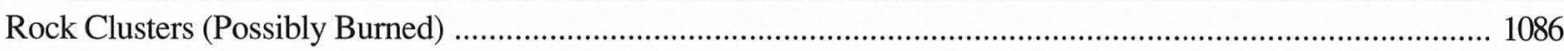

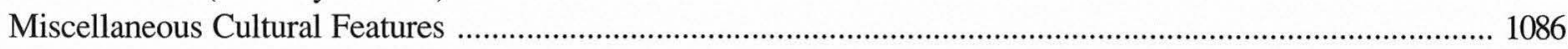

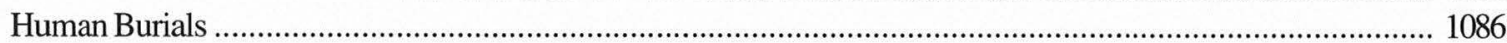

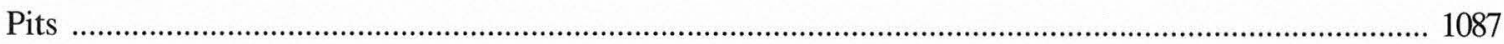

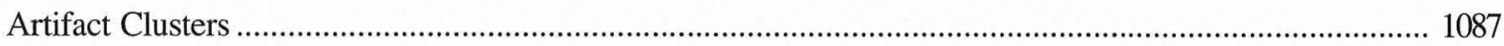

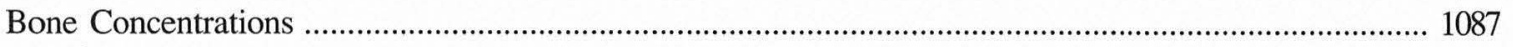

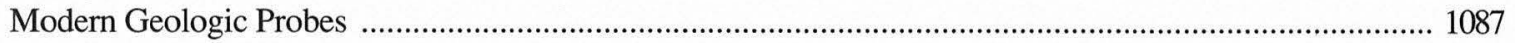

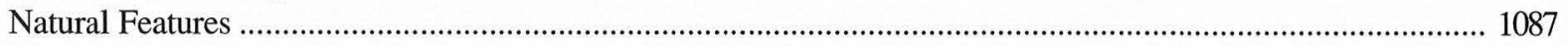

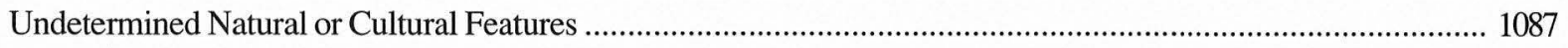

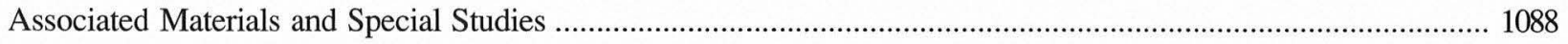

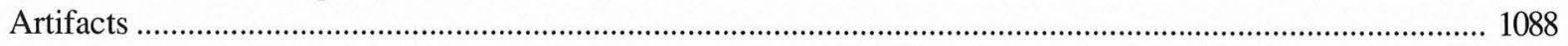

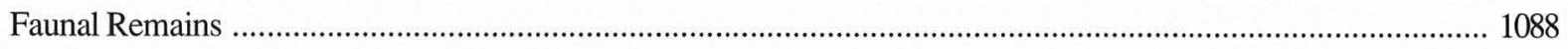

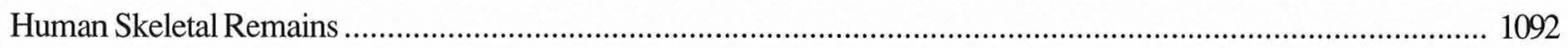

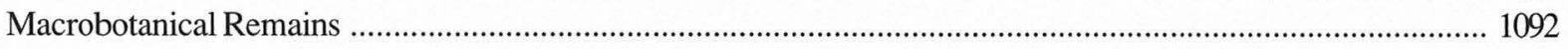

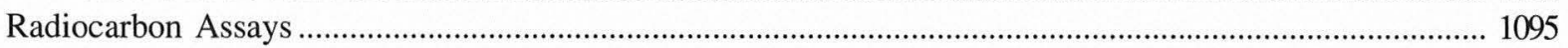

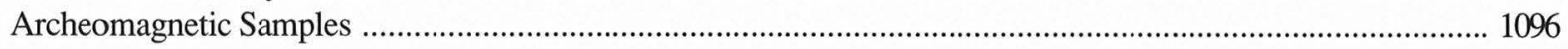

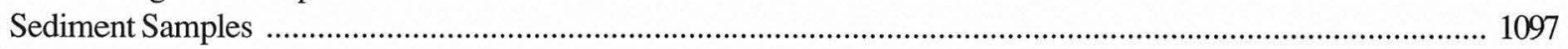

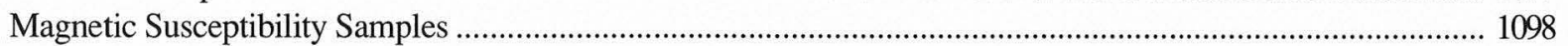

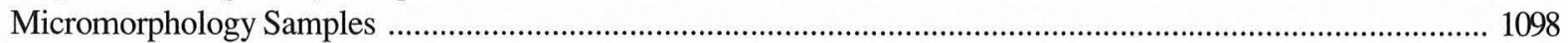

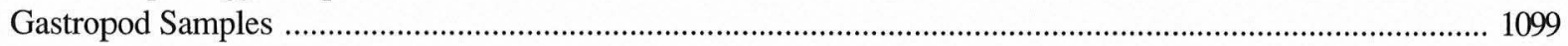

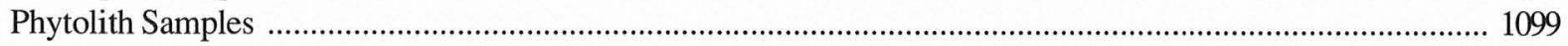

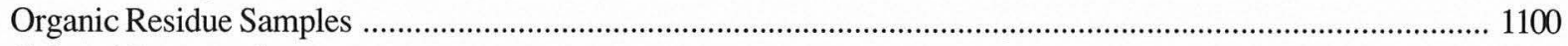

The Cultural Features Sequence ……........................................................................................................... 1100

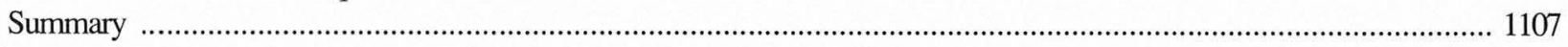

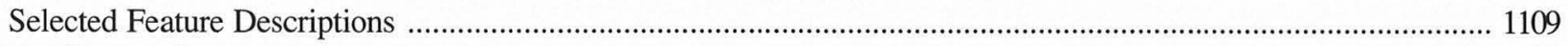

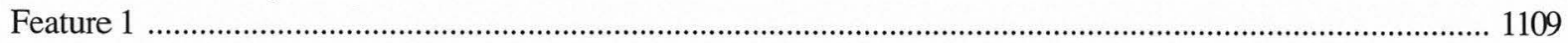




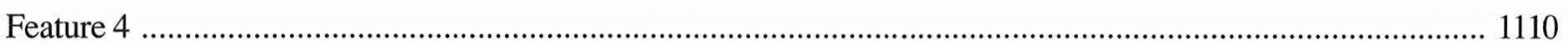

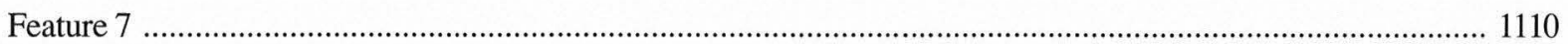

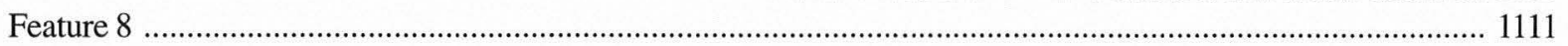

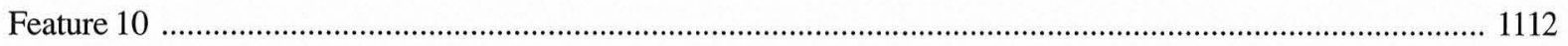

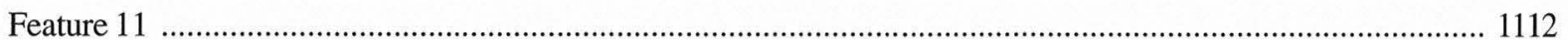

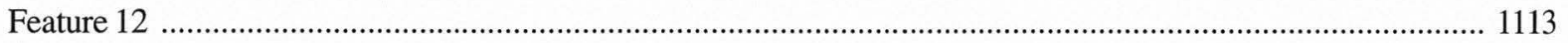

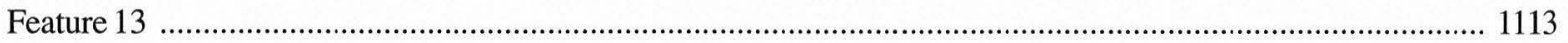

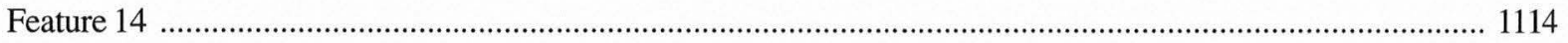

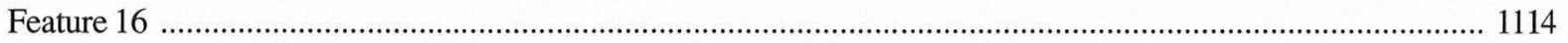

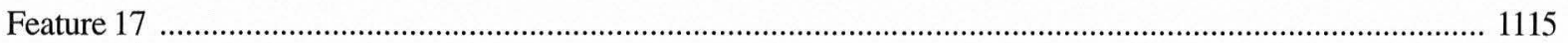

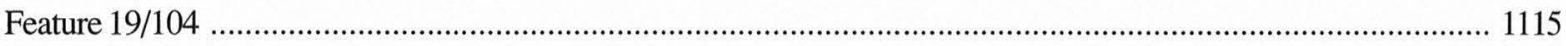

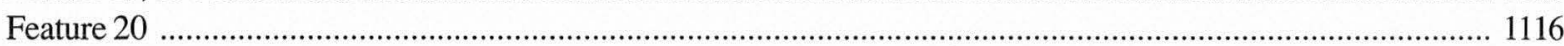

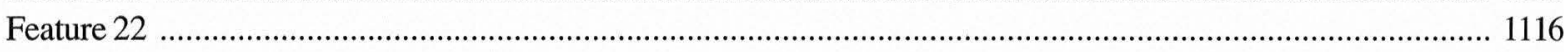

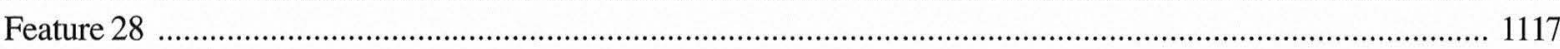

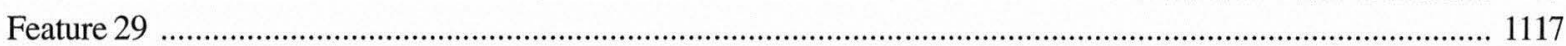

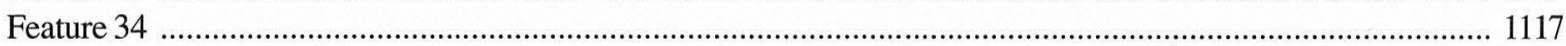

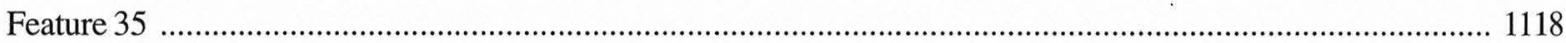

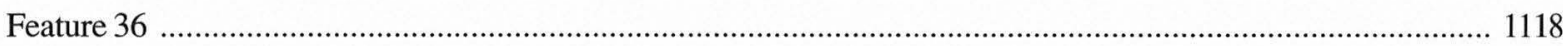

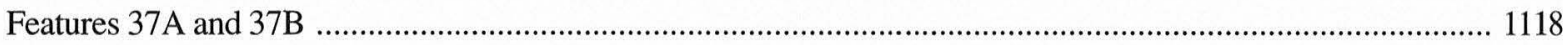

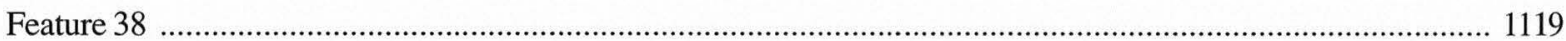

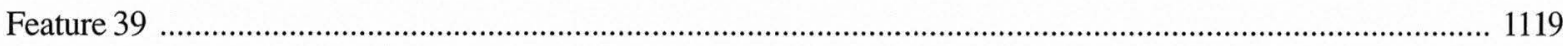

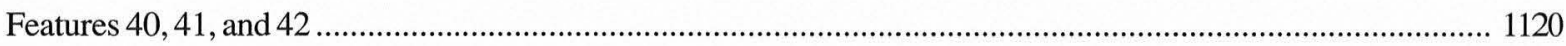

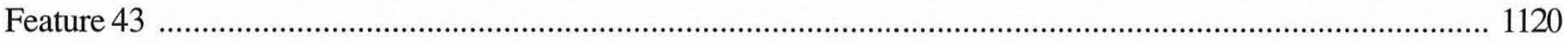

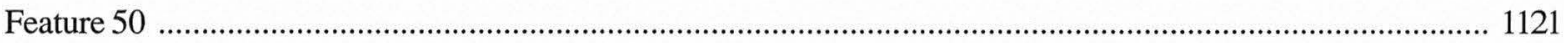

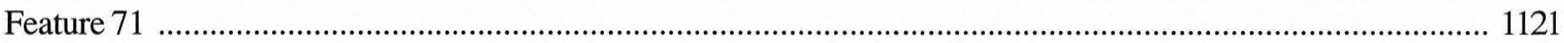

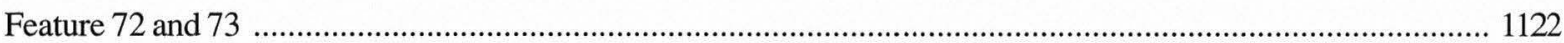

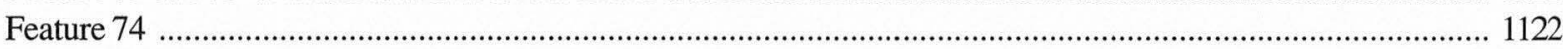

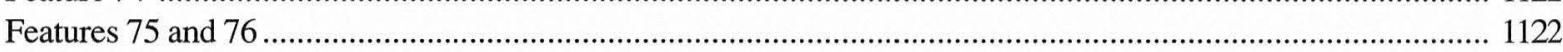

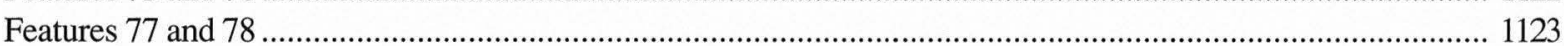

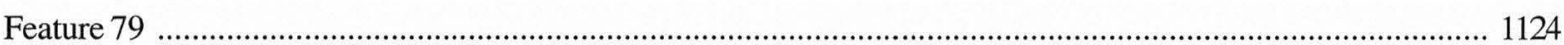

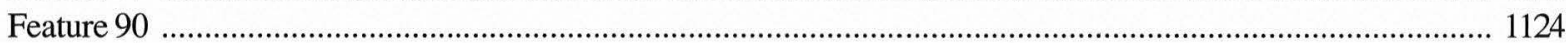

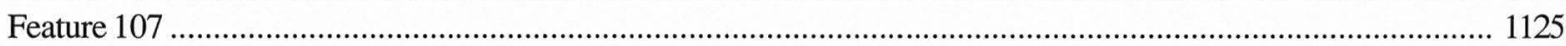

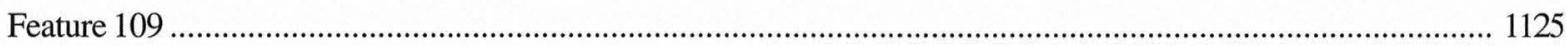

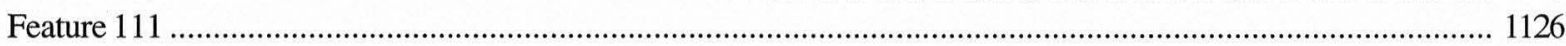

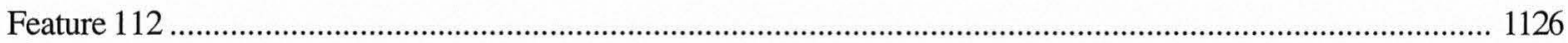

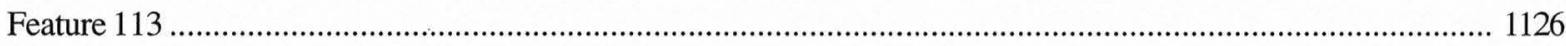

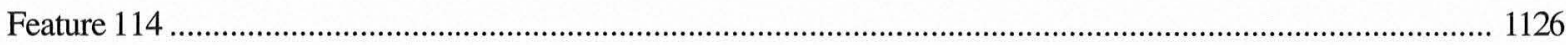

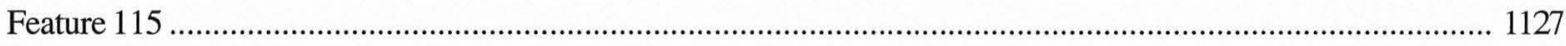

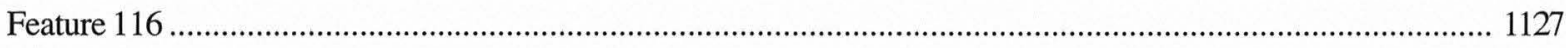

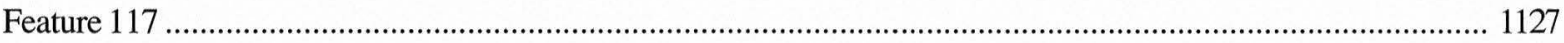

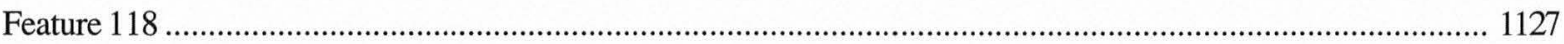

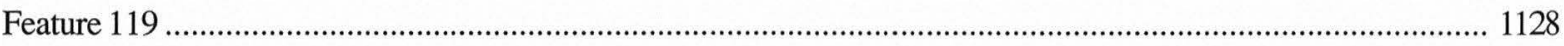

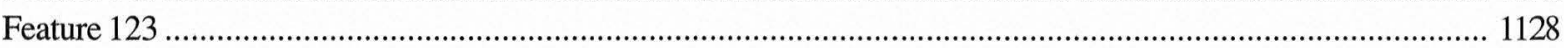

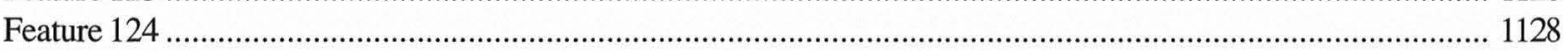

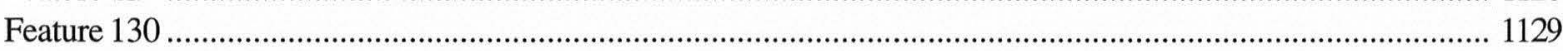

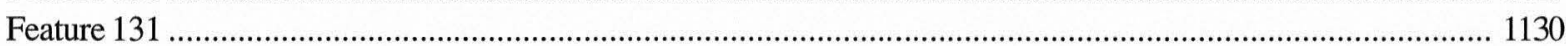

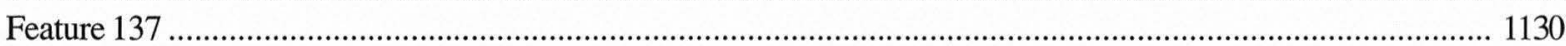

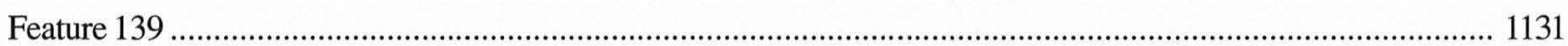

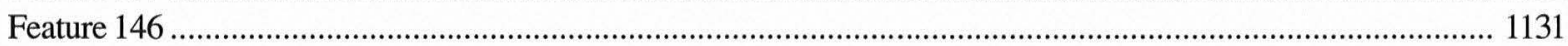

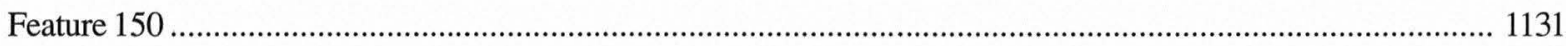

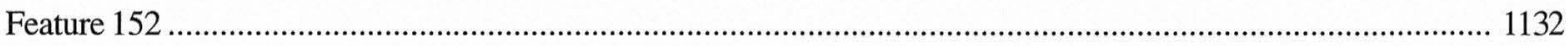

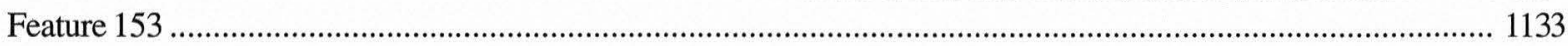

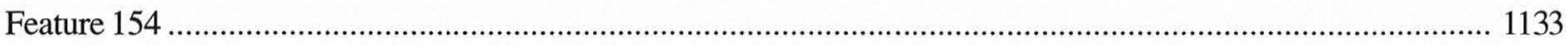

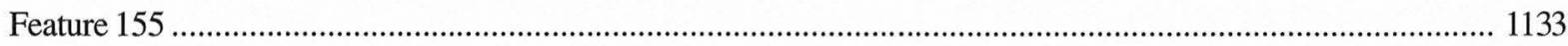

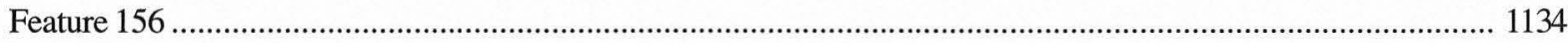




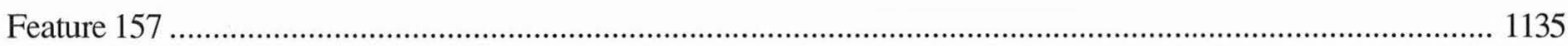

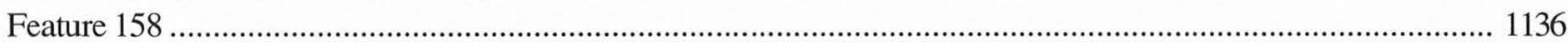

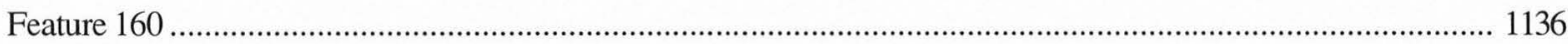

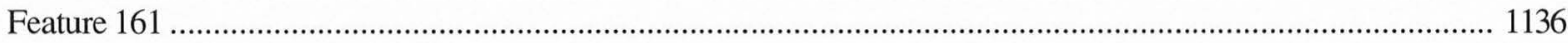

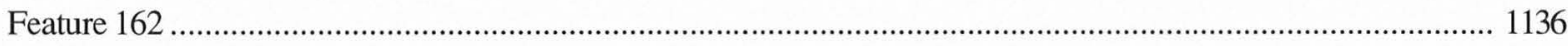

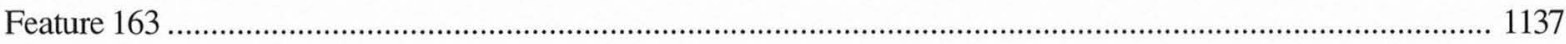

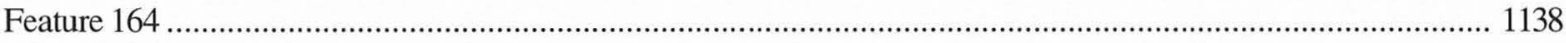

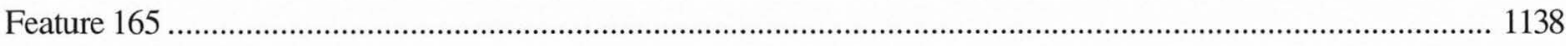

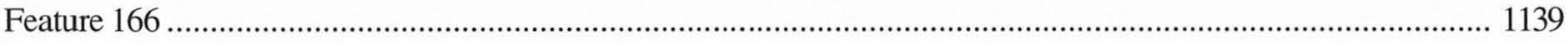

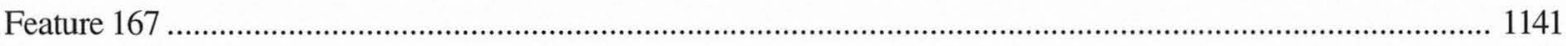

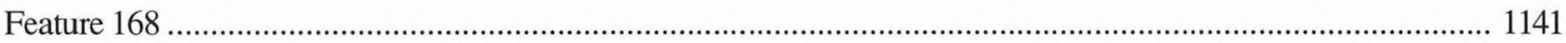

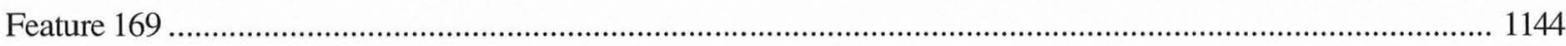

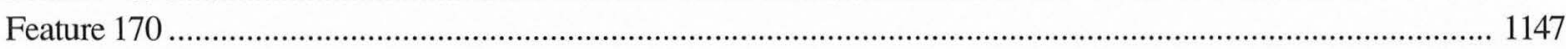

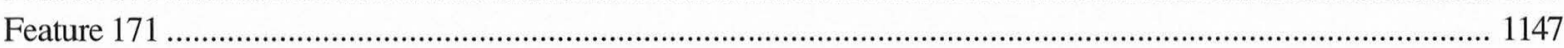

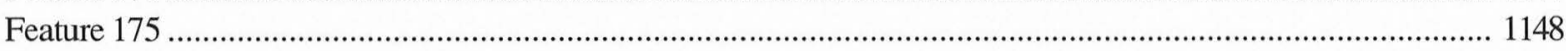

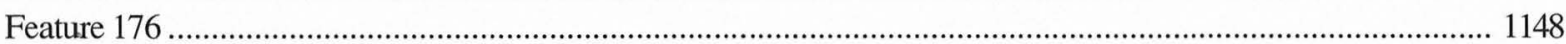

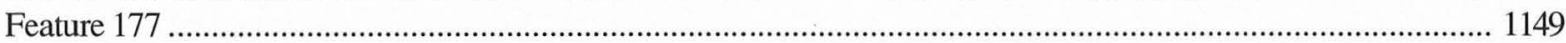

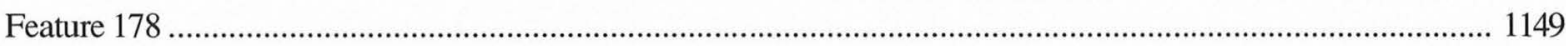

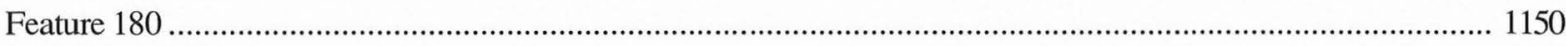

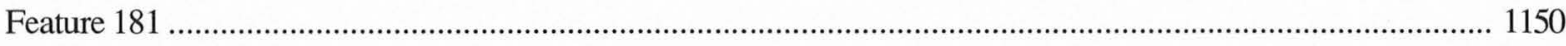

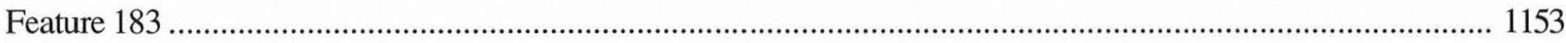

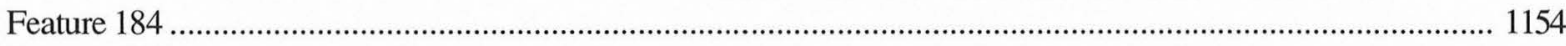

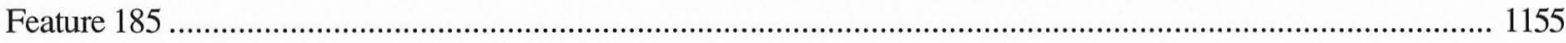

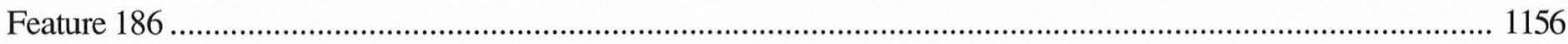

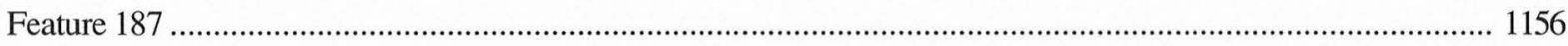

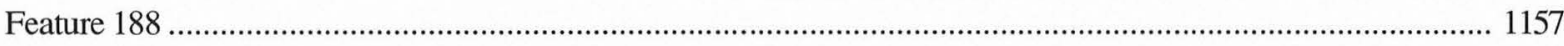

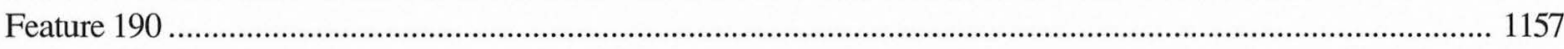

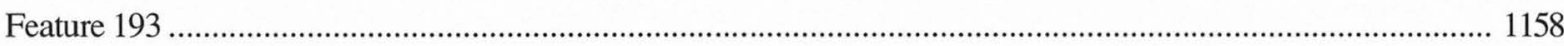

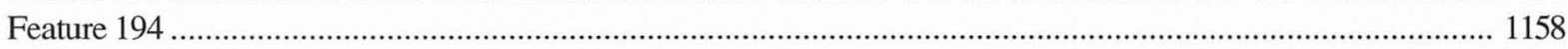

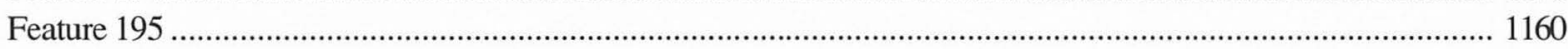

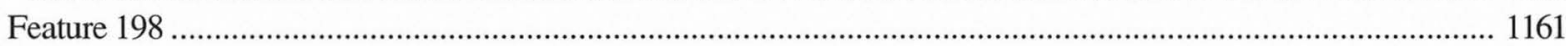

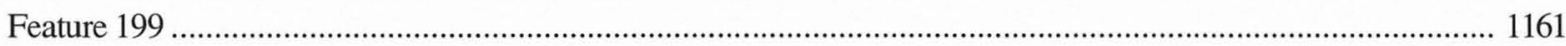

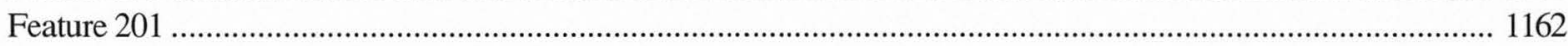

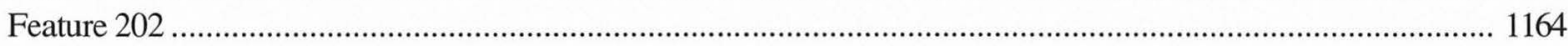

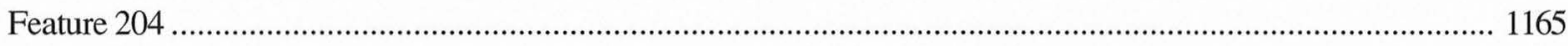

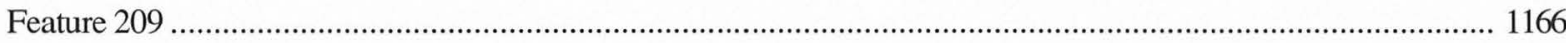

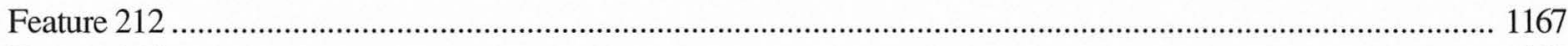

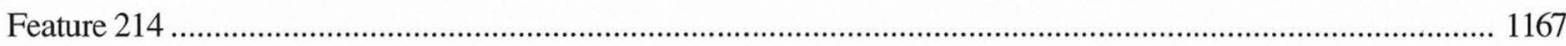

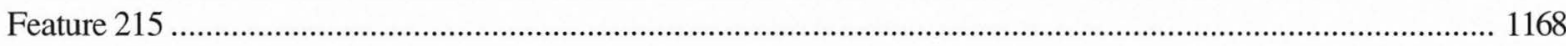

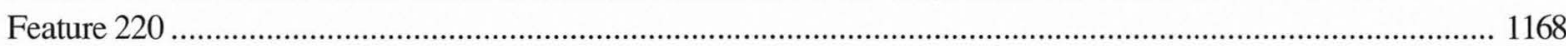

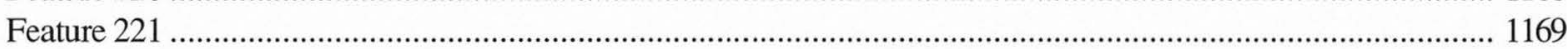

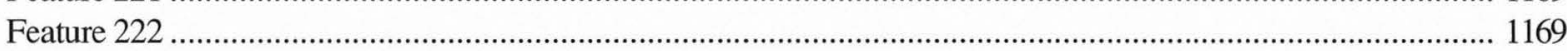

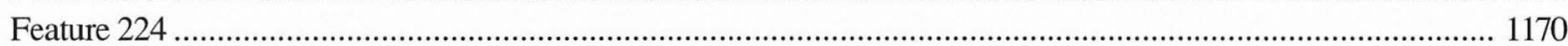

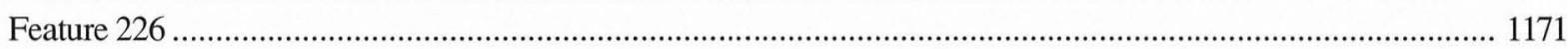

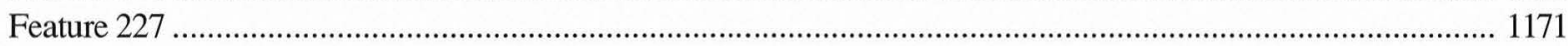

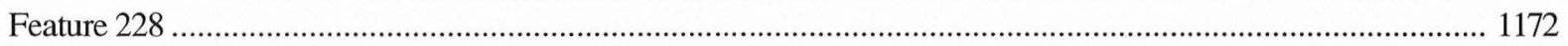

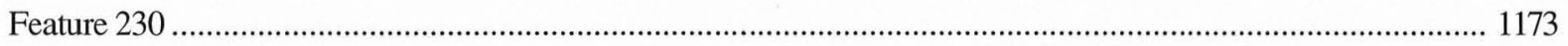

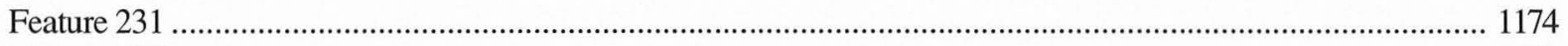

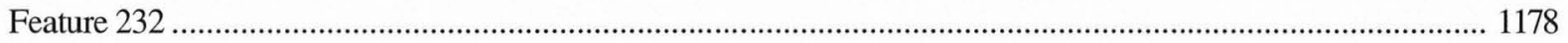

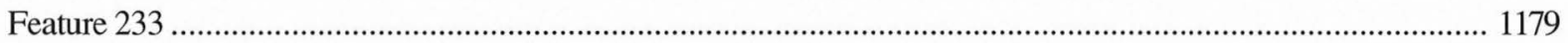

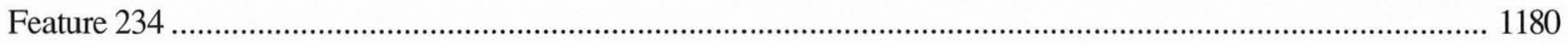

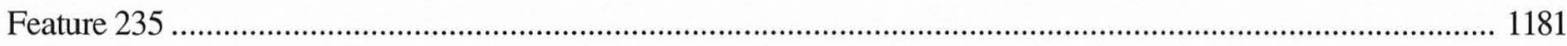

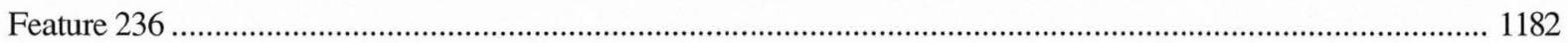

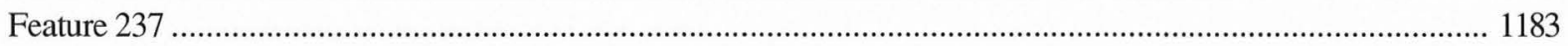

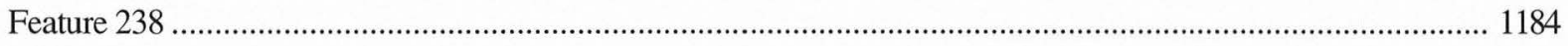




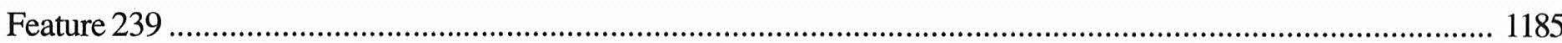

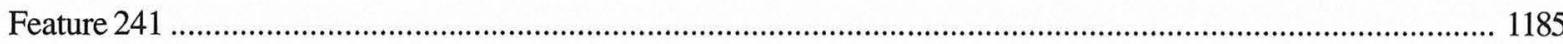

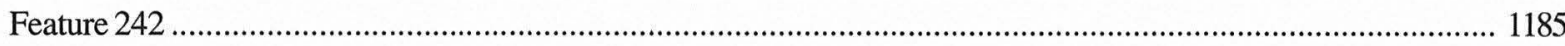

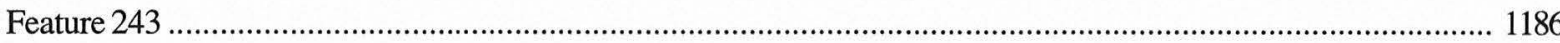

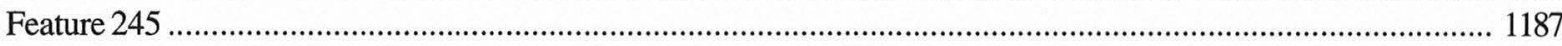

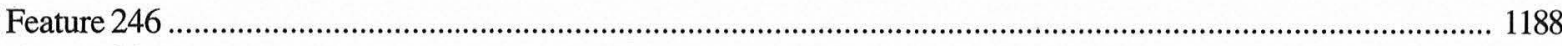

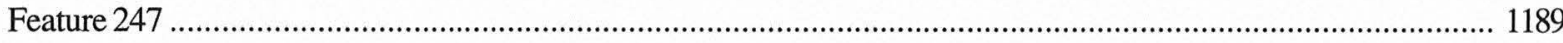

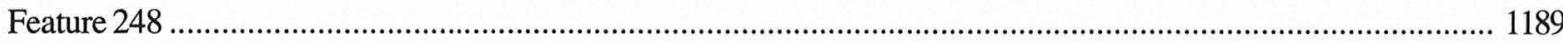

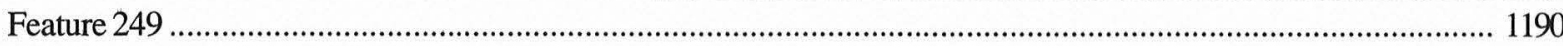

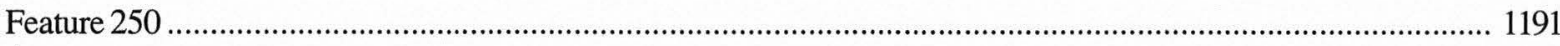

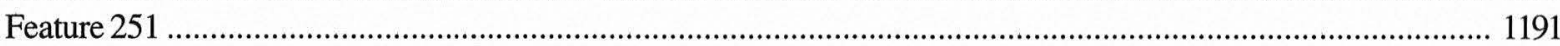

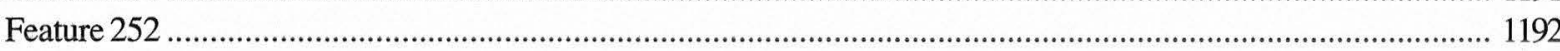

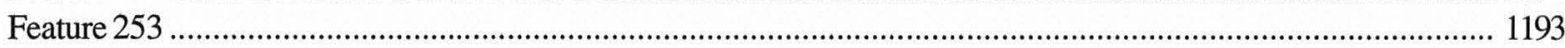

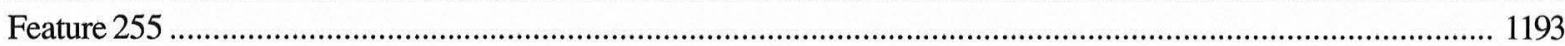

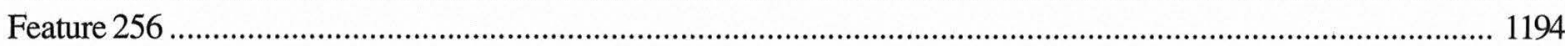

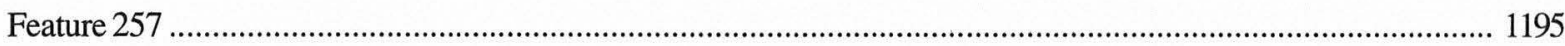

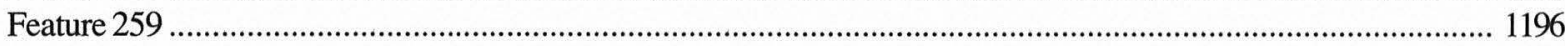

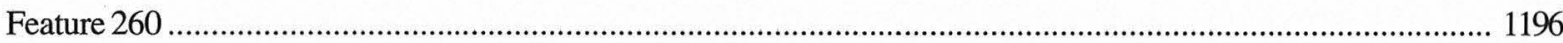

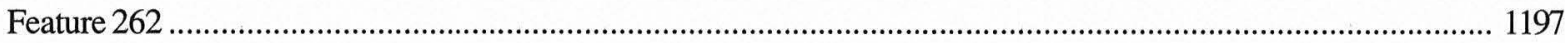

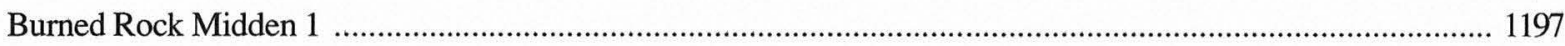

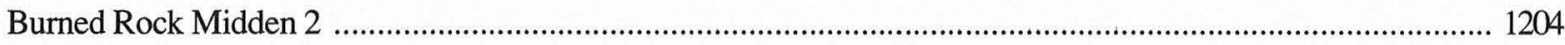

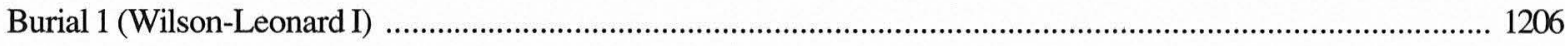

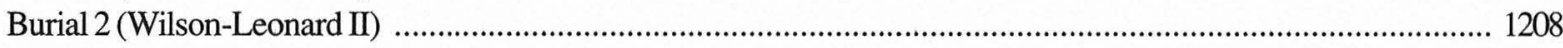

\section{CHAPTER 27: ARCHEOMAGNETIC ANALYSIS OFBURNED LIMESTONEROCKS}

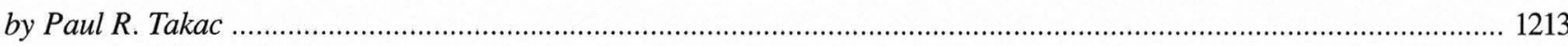

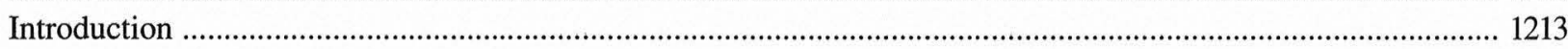

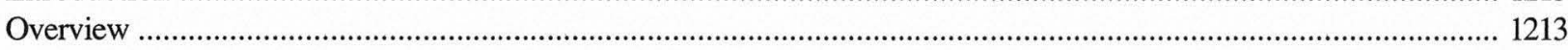

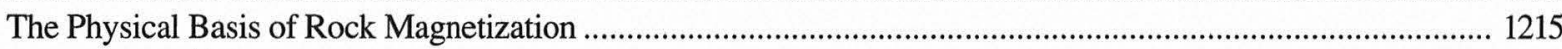

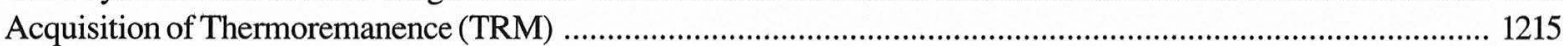

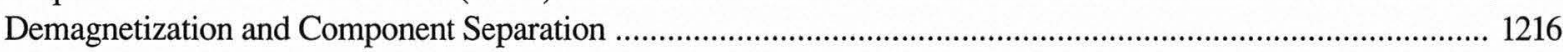

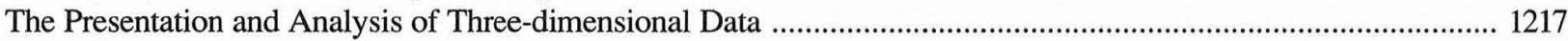

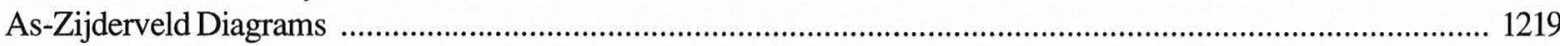

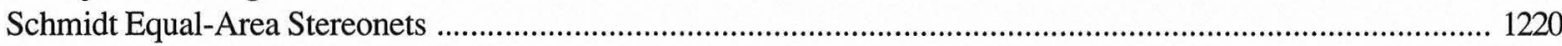

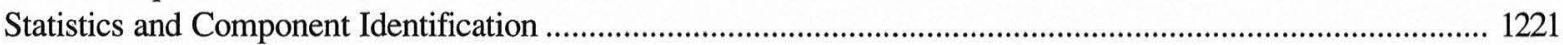

Principal Component Analysis .............................................................................................................. 1221

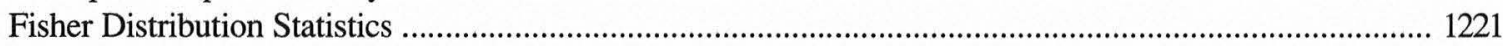

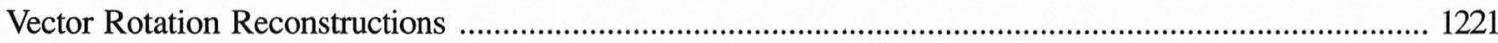

Summary: Modeling TRM in Burned Rocks .................................................................................................... 1223

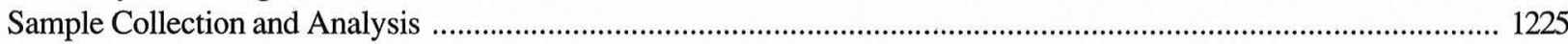

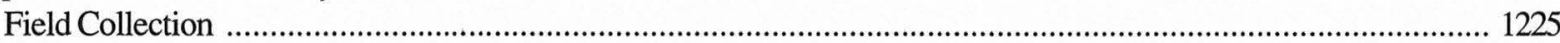

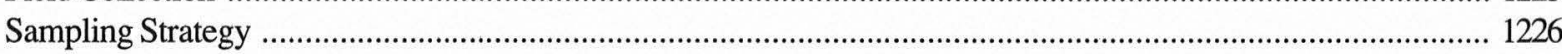

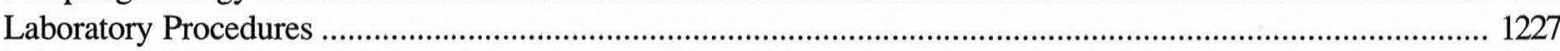

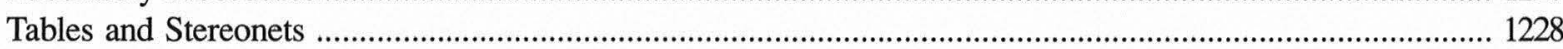

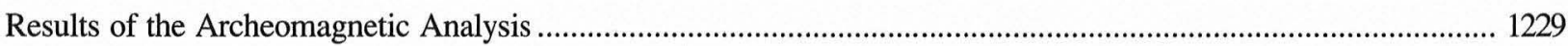

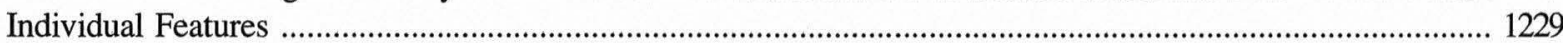

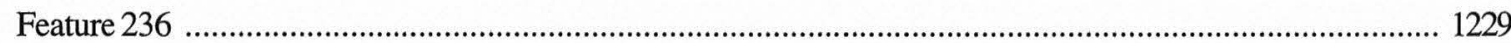

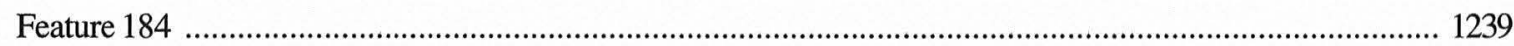

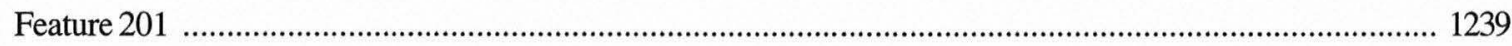

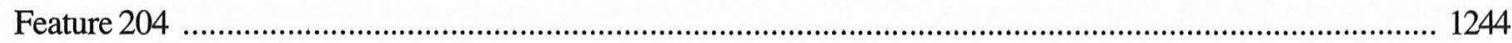

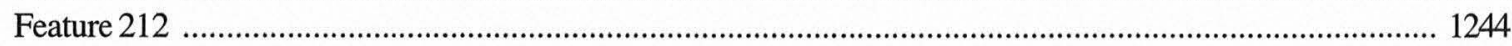

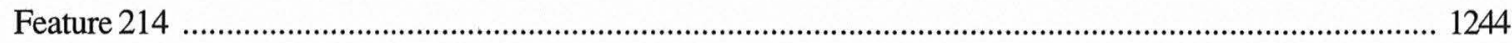

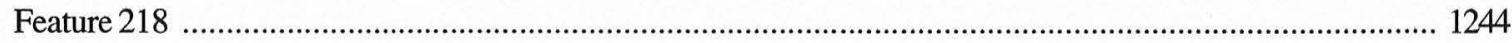

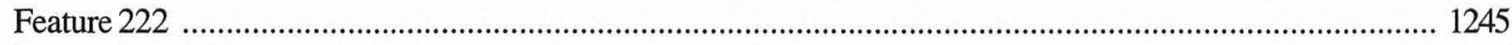

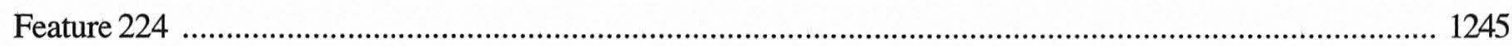




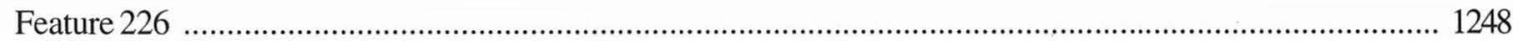

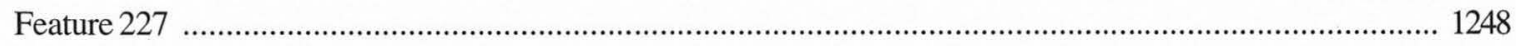

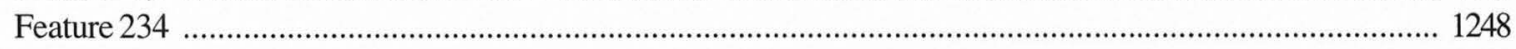

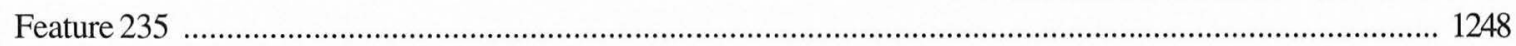

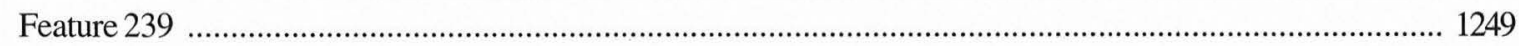

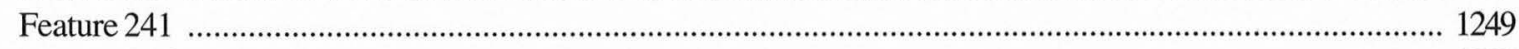

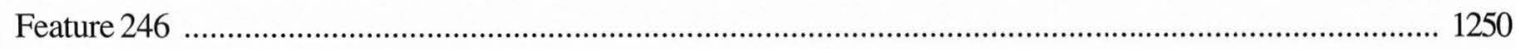

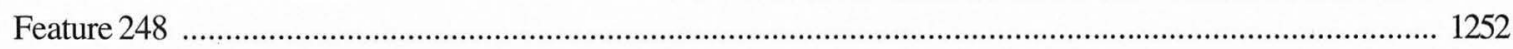

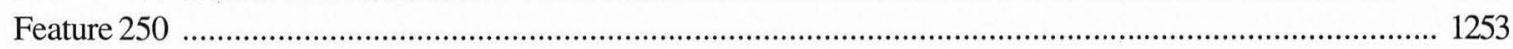

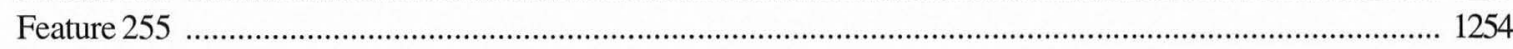

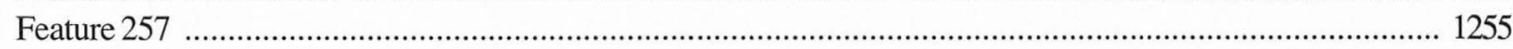

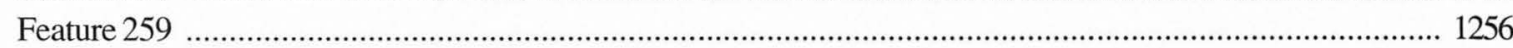

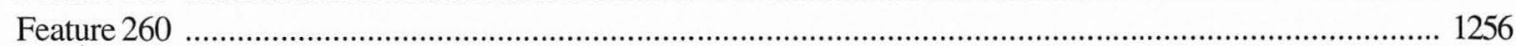

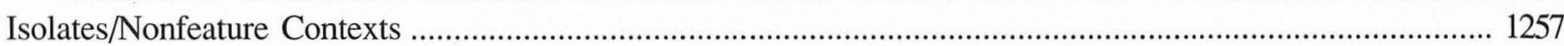

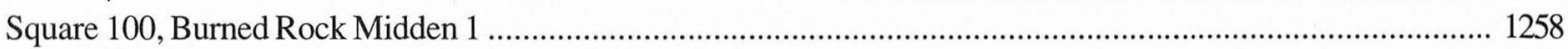

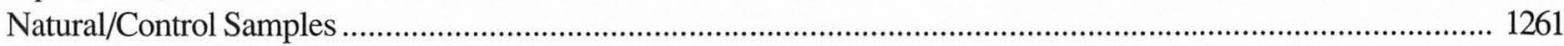

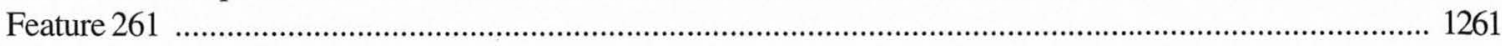

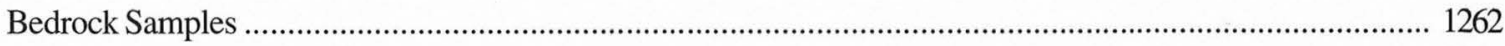

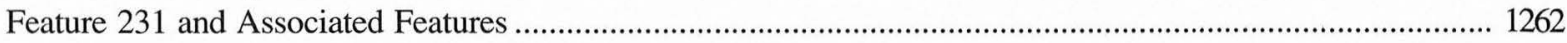

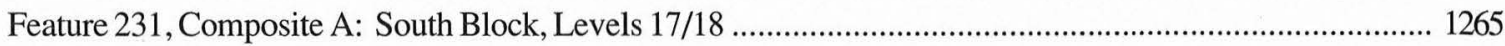

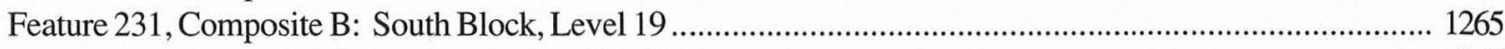

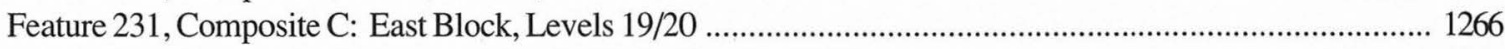

Feature 231, Composite D: East and South Blocks, Levels 20/21 ............................................................. 1267

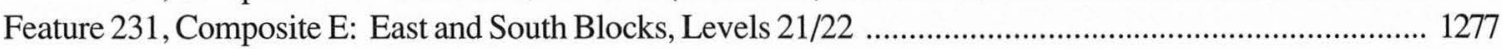

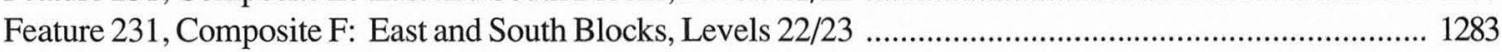

Feature 231, Composite G: East end of South Block, Level 23 ................................................................. 1295

Feature 231, Composite H: East and South Blocks, Level 24 .................................................................... 1300

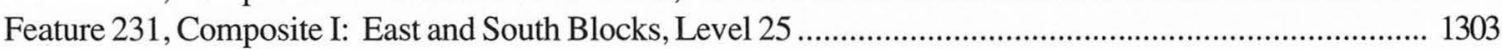

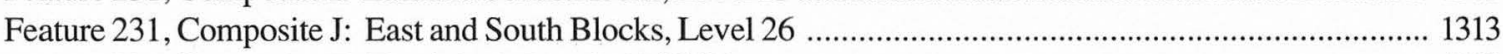

Feature 231, Composite K: East Block, Levels 27/28/29 ……….............................................................. 1318

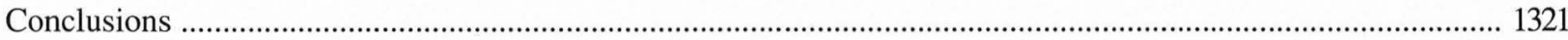

Paleomagnetism of Burned Rocks at Wilson-Leonard ................................................................................... 1321

Current and Future Paleomagnetic Research on Burned Rocks ...................................................................... 1325

\section{CHAPTER 28: MAGNETICSUSCEPTIBILITY OF SEDIMENTS}

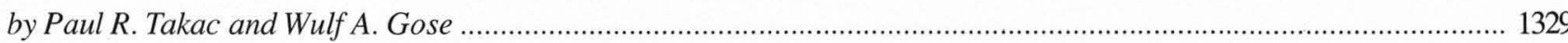

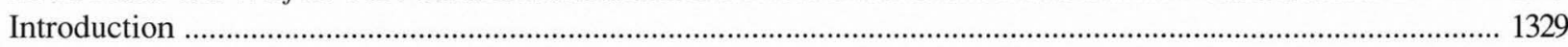

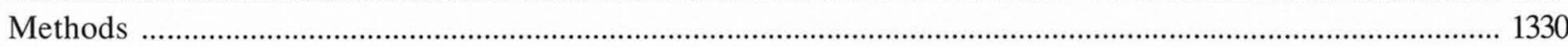

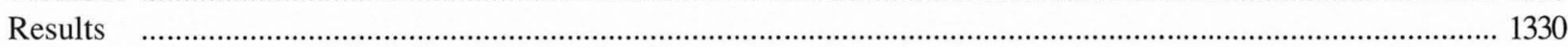

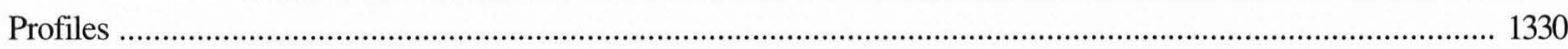

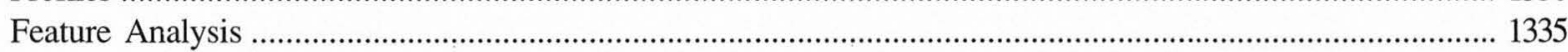

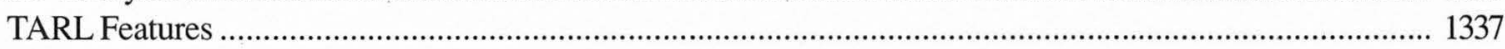

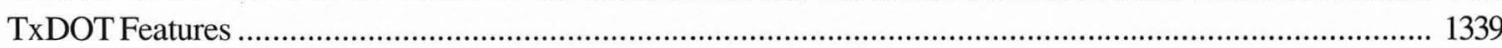

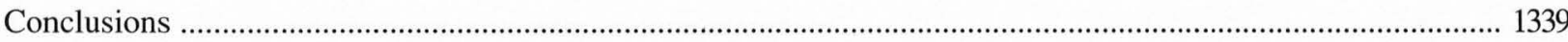

CHAPTER 29: MICROMORPHOLOGICAL ANALYSIS OF SEDIMENTS
by Paul Goldberg
Introduction
Methods
Micromorphological Analysis
Terms and Elements Used or Identified in the Study of the Thin Sections
Groundmass/Matrix
Postdepositional Effects




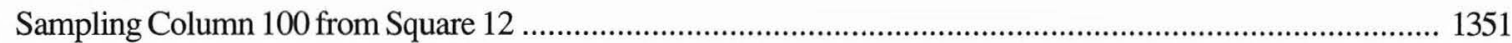

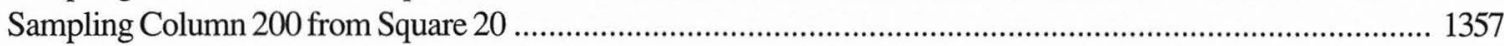

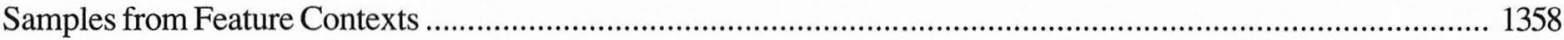

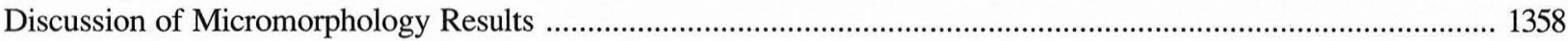

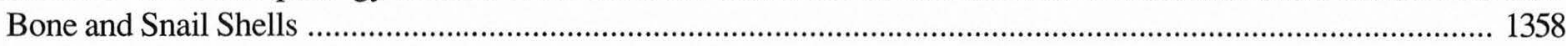

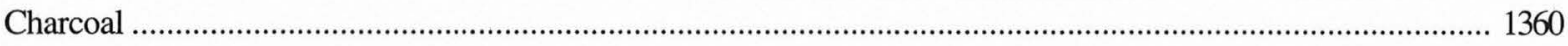

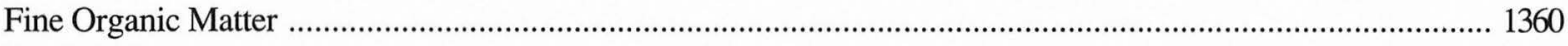

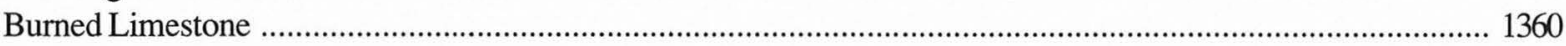

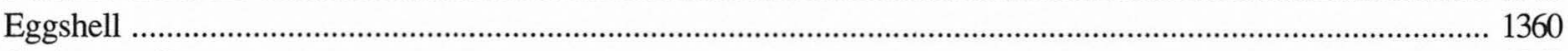

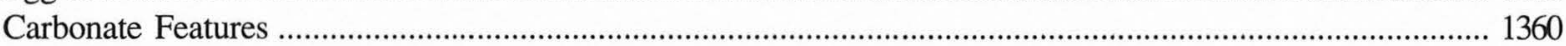

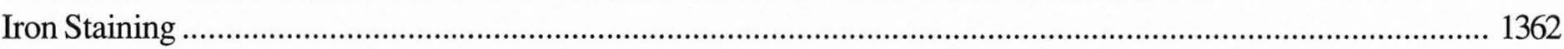

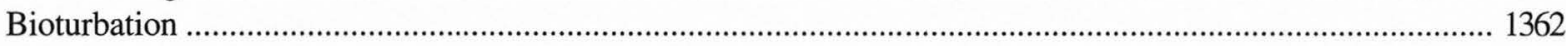

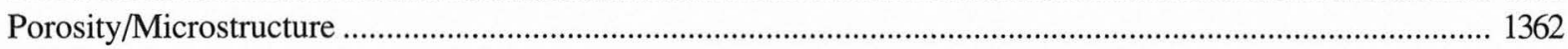

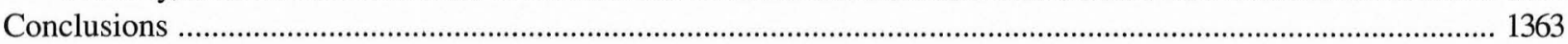

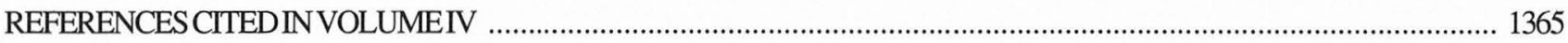

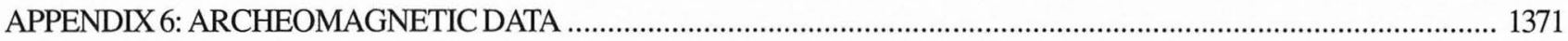

APPENDIX 7: DESCRIPTIONS OF MICROMORPHOLOGICAL THIN SECTIONS …............................................... 1415 


\section{LIST OF FIGURES \\ Volume IV}

25-1. Schematic profile showing relative stratigraphic positions of radiocarbon samples

25-2. Comparison of apparent radiocarbon ages versus sample size for the synthetic amino acid alanine

$\left(\mathrm{NH}_{2} \mathrm{CH}_{2} \mathrm{CH}_{2} \mathrm{COOH}\right)$

25-3. Comparison of apparent radiocarbon age versus sample size for $\mathrm{CO}$ derived from Harding Calcite

25-4. Change in total amino acid content of Wilson-Leonard fossil bone âs a function of geologic age .................... 1050

25-5. Proportional changes among five diagnostic amino acids in bone protein

25-6. Summary of the relative proportional changes undergone by the five most characteristic amino acids in bone collagen ......

25-7. Radiocarbon ages for three chemical fractions (decalcified sediment, humic acids, and humins) isolated from the Unit Icl cienega sediment collected in Squares 27 and 28, south wall

25-8. Age versus depth comparison for humic acid fractions dated from the Unit Icl cienega sediments from Square 20, south wall

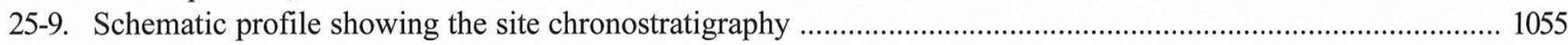

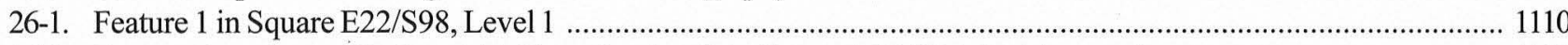

26-2. Feature 4 as exposed in Level 11 (detection level) in Square E20/S94, looking northwest .............................. 1110

26-3. Feature 7 in Squares E20/S82 and E20/S84, Level 2, Block 3, looking south .................................................. 1111

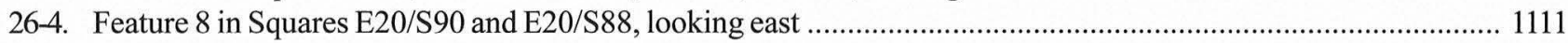

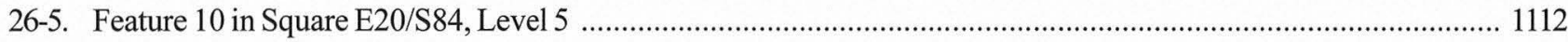

26-6. Feature 11 in Square E20/S86, Level 5, looking west ................................................................................ 1113

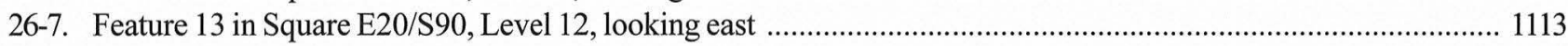

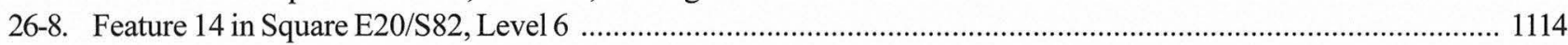

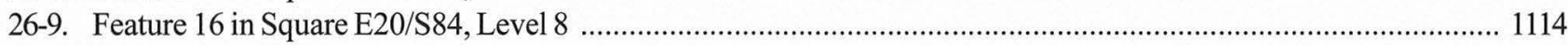

26-10. Feature 19/104 as exposed in Square E22/S90, Levels 16 and 17, looking west ............................................. 1115

26-11. Western half of Feature 20 as exposed at the base of Level 12 in Square E20/S86, looking south ...................... 1116

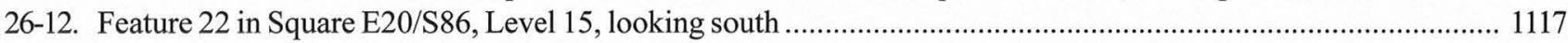

26-13. Features 34 (right) and 38 (left) in Square E20/S74, Level 3, looking south ................................................. 1117

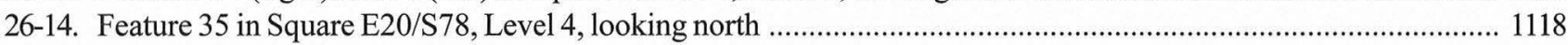

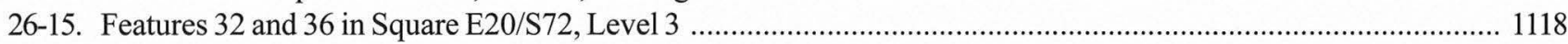

26-16. Feature 37A in Square E20/S78, Level 6, looking east ............................................................................. 1119

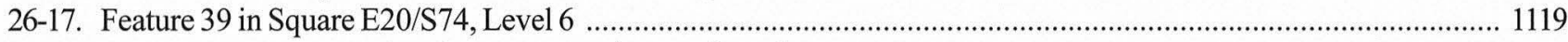

26-18. Features 40-42 in Level 8 of Squares E20/S78 and E20/S76 ................................................................. 1120

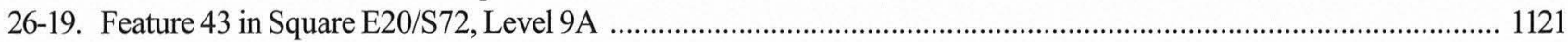

26-20. Feature 50 in Square E20/S78, Level 12A, looking west ............................................................................ 1121

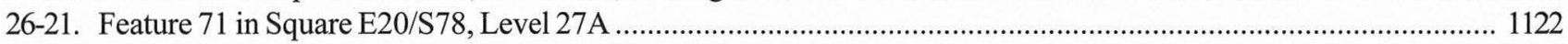

26-22. Features 75-78 in Squares E22/S82 and E22/S80, Level 6 .................................................................. 1123

26-23. Feature 79 in Squares E22/S90 and E22/S88, Level 9, looking west ............................................................ 1124

26-24. Feature 90 in Square E22/S90, Level 12, looking south ............................................................................... 1124

26-25. Eastern half of Feature 107 in Square E22/S82, looking west ...................................................................... 1125

26-26. Feature 109 in Square E22/S82, Level 17, looking west ............................................................................. 1125

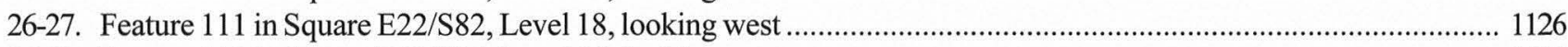

26-28. Feature 113 in Square E22/S84, Level 20, looking east ............................................................................. 1126

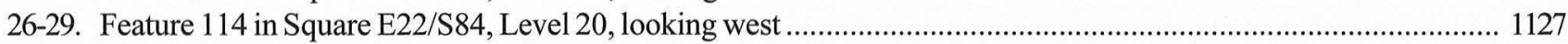

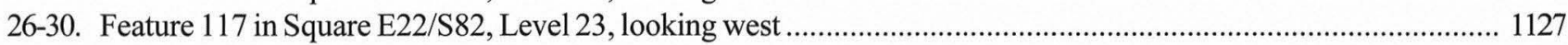

26-31. Feature 118 in Square E22/S86, Level 23, looking south ................................................................................. 1128

26-32. Feature 119 in Square E22/S82, Level 24 ........................................................................................... 1128

26-33. Feature 123 as exposed in Square E22/S78, Level 16A, looking west ......................................................... 1128

26-34. Feature 124 as exposed at the base of Level 16B in the southeast corner of Block 6, looking south ................. 1129

26-35. Feature 130 as exposed in Squares E24/S74, E24/S76, E26/S74, and E26/S76 at the base of Level 17B,

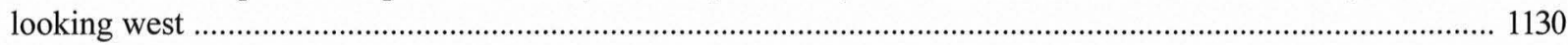

26-36. Features 130 and 131 as exposed in the southeast corner of Block 6 at the base of Level 18A ....................... 1130

26-37. Feature 131 as exposed in Squares E24/S76, E24/S78, E26/S76, and E26/S78 at the base of Level 18A, looking north ...... 
26-38. Feature 137 in Square E22/S76, Level 19A, looking east

26-39. Feature 139 as exposed in Squares E24/S74 and E22/S74, Level 19A, looking west ......................................... 1131

26-40. Feature 146 as exposed in Squares E26/S74 and E26/S72, Level 20A, looking west ........................................ 1132

26-41. Feature 146 and Feature 150 as exposed in Squares E26/S74, E26/S72, E24/S74, and E24/S72, Level 21A, looking east

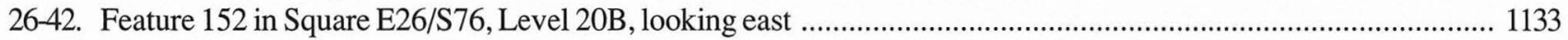

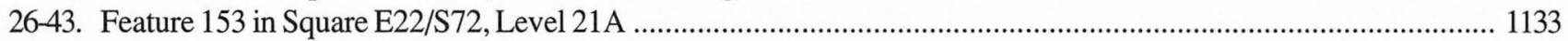

26-44. Feature 155 in Square E24/S76, Level 22B, looking east ............................................................................... 1134

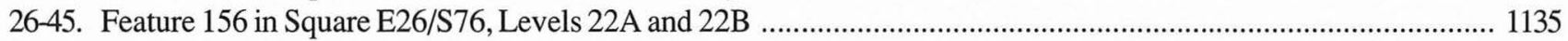

26-46. Feature 157 as exposed in Square E26/S72, Level 22B, looking east ............................................................. 1135

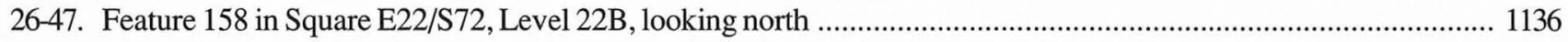

26-48. Feature 161 (debitage concentration) in Square E24/S78, Level 24A ……........................................................ 1136

26-49. Feature 162 in Square E26/S76, Level 24B ................................................................................................ 1137

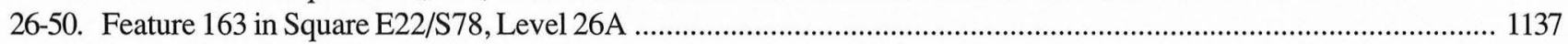

26-51. Feature 164 in Square E26/S76, Levels 26B-28B, looking east ....................................................................... 1138

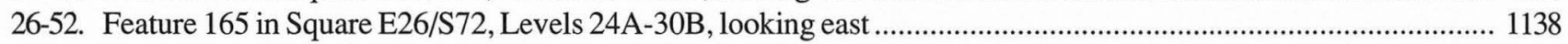

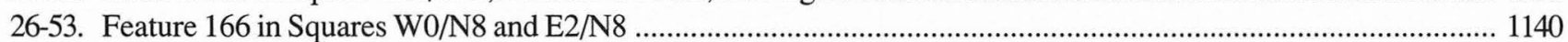

26-54. Feature 167 as exposed at the base of Level 31A in Block 6, looking west ...................................................... 1141

26-55. Features 168 and 169 at detection level in Squares E20/S76 and E20/S78, looking south ............................... 1142

26-56. Feature 168 as it appeared at detection level (base of Level 31A) in Square E20/S76, looking west .................. 1142

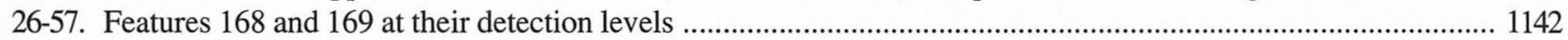

26-58. Feature 168 after fill was removed from south half of pit, looking south .......................................................... 1143

26-59. Feature 168 after fill was removed, looking west ................................................................................... 1143

26-60. South wall of Feature 168 after fill removal, looking south ........................................................................... 1143

26-61. Feature 169 as it appeared at detection level, looking south ......................................................................... 1144

26-62. Feature 169 after fill was removed from the northern half in July 1983, looking south .................................... 1145

26-63. Feature 169 after additional fill was removed from northern half in December 1983, looking south .................... 1145

26-64. Profile of the south half of Feature 169 showing the limestone cobbles found in the "brown silty clay"

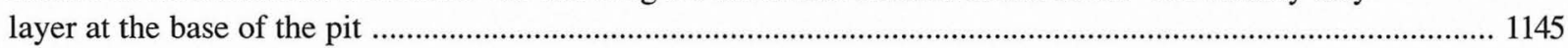

26-65. Feature 169 after fill was removed from the south half of the pit, looking south ............................................. 1145

26-66. Feature 170 as exposed in Square E24/S78, Level 31B, looking south .............................................................. 1147

26-67. Feature 171 in Squares E24/S78 and E26/S78, Level 32B, looking south ........................................................... 1148

26-68. Feature 175 in Squares E26/S76 and E26/S78, Levels 36A-37B, looking north ................................................ 1148

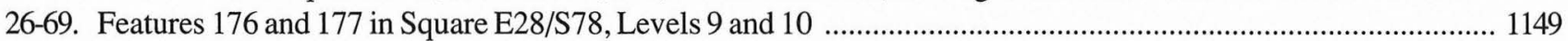

26-70. Feature 178 in Square E24/S72, Level 37B, looking north ............................................................................... 1149

26-71. Feature 180 in Square E28/S78, Level 13, looking south ........................................................................... 1150

26-72. Feature 181 as exposed in Levels 16B/17A of Square E28/S78, looking east ................................................... 1150

26-73. Feature 181 as exposed in Levels 16B/17A of Square E28/S78, looking north ................................................. 1151

26-74. Features 181 and 245 exposed at about $95.70 \mathrm{~m}$ (base of Levels 22/23) in the TARL East Block,

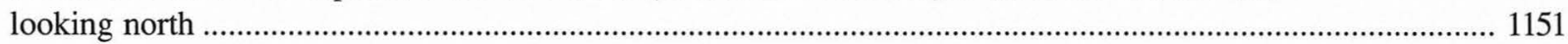

26-75. Feature 181 cross-sectioned in Square E28/S78, looking east .......................................................................... 1151

26-76. Feature 181 in the east and north walls of Square E28/S78, looking northeast ............................................. 1151

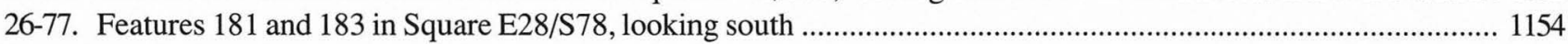

26-78. Feature 181 in the south, east, and north walls of Square E28/S78, looking east ......................................... 1154

26-79. Feature 184 on the Level 20A pedestal in Square E28S78, looking southeast ................................................ 1155

26-80. Features 184, 185, and 186 in Square E28/S78, looking west...................................................................... 1155

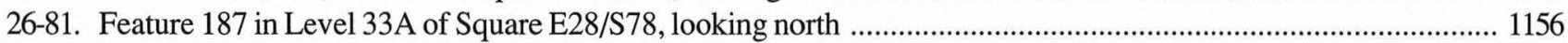

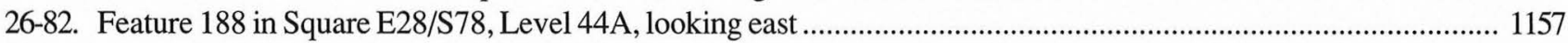

26-83. Feature 190 in the east wall of Square E26/S74, looking east ....................................................................... 1158

26-84. East wall profile of Square W0/S8 showing Burned Rock Midden 2, Feature 194, and Feature 195 ................... 1159

26-85. Eastern half of Square W0/N8, with the southeast quad at the base of Level 10 and the northeast quad

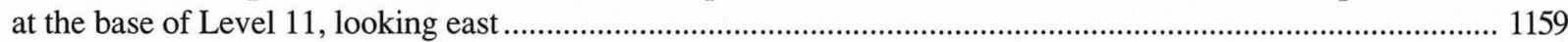

26-86. Feature 194 in Square W0/N8 after fill was removed, looking south ........................................................... 1159

26-87. Feature 198 in Square W0/N8, Level 28B, looking north ............................................................................... 1161

26-88. Feature 199 (burned tree) in the west wall of Block 4 (Squares E20/S74, E20/S72), look west ............................ 1161 
26-89. Portion of Feature 201 exposed in Square 21, Level 6, looking west ............................................................... 1162

26-90. Portion of Feature 201 exposed in Square 17, Level 7, looking north ........................................................... 1162

26-91. Portions of Feature 201 exposed in the TARL East Block, looking south ....................................................... 1162

26-92. Feature 206 in Level 5 of Squares 15 (left) and 16 (right), looking north ...................................................... 1163

26-93. Feature 211 in Level 8 of Square 17, looking west ................................................................................ 1163

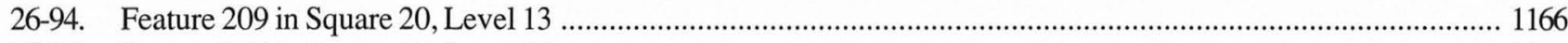

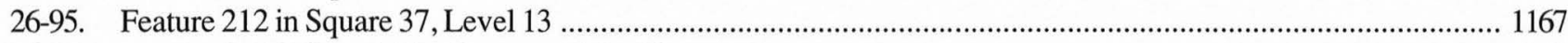

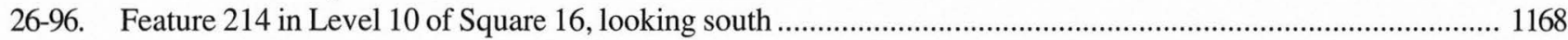

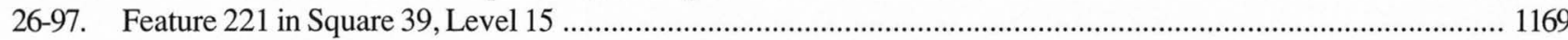

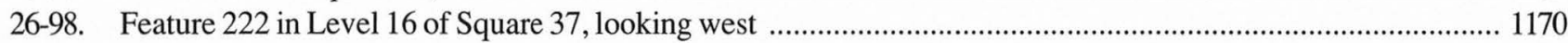

26-99. Feature 224 as exposed at the base of Level 19 in Square 12, looking east .................................................. 1170

26-100. Feature 226 as exposed at the base of Level 20 in Square 46, looking north ................................................ 1171

26-101. Feature 227 in Level 20 of Square 30, looking east ............................................................................... 1172

26-102. Feature 227 on Level 22A pedestal in Square 30, looking south .................................................................. 1172

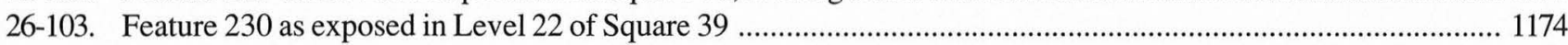

26-104. Composite plan map illustrating recorded extent of the Feature 124/231 burned rock accumulation

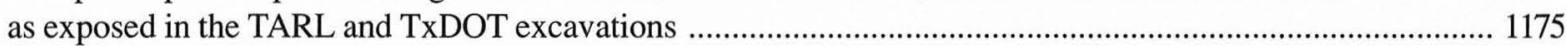

26-105. Excavation of upper layers of Feature 231 in the TARL East Block, looking east ............................................ 1176

26-106. Feature 231 as exposed in Levels 22/23 (ca. 95.80-95.75 m) in the TARL East Block ...................................... 1176

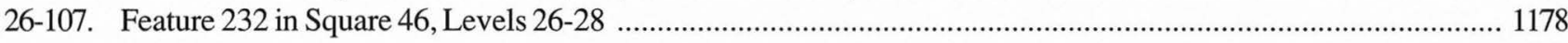

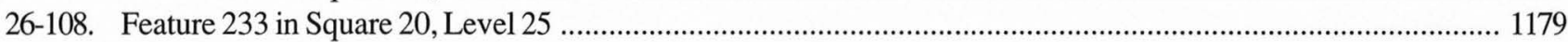

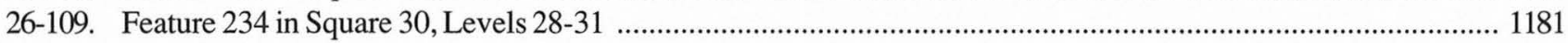

26-110. Feature 235 in Square 32, Level 28, looking south ................................................................................. 1181

26-111. Feature 236 as exposed in Level 29 of Square 33 and Level 30 of Square 48, looking south .......................... 1182

26-112. Feature 236 after cross sectioning in Square 33, Levels 29-31, looking east ................................................. 1182

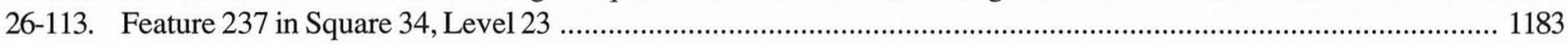

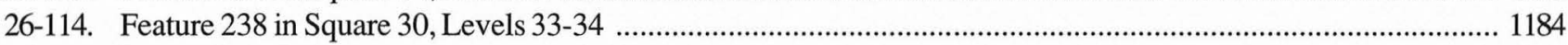

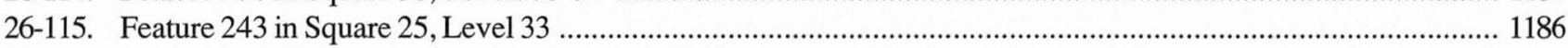

26-116. Feature 245 (right) and Feature 181 (left) as exposed at an elevation of approximately $95.70 \mathrm{~m}$

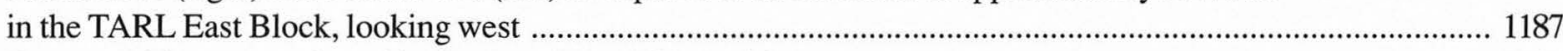

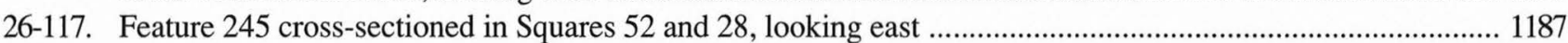

26-118. Feature 246 in Level 32 of Squares 34 and 49, looking east ................................................................. 1188

26-119. Feature 248 as exposed at the base of Level 28 in Squares 28, 44, 52, and 53, looking east ............................ 1189

26-120. Features 181, 184, and 249 exposed in the east wall of TxDOT Square E28/S78 after backfill was removed during the TARL investigations, looking east ........................................................................ 1190

26-121. Feature 252 in the floor and west wall of Square 55, looking west ............................................................. 1192

26-122. Feature 252 in the floor of Square 55 after the fill was removed from the lower portion of the feature ............. 1192

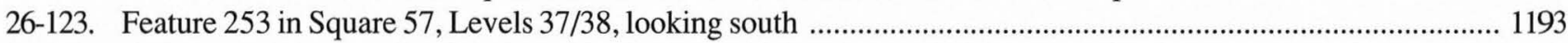

26-124. Feature 255 in Level 42 of Squares 35 and 59, looking north .................................................................. 1194

26-125. Feature 256 in Square 28, Levels 41-42 ............................................................................................. 1195

26-126. Feature 260 in Squares 39 and 52, Level 42, looking south ..................................................................... 1196

26-127. Burned Rock Midden 1 during the excavation of the Block 3 squares, looking north .................................... 1199

26-128. Plan map illustrating the approximate extent of Burned Rock Midden 1 and the excavation squares that sampled the midden.

26-129. Burned Rock Midden 1 deposits as exposed in the east walls of the Block 2 and

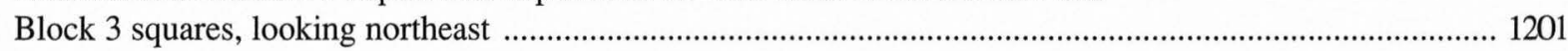

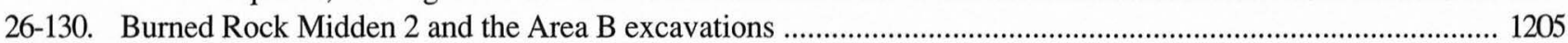

26-131. Looking southeast across Burned Rock Midden 2 ............................................................................. 1205

26-132. Looking east across the area with potholes excavated by relic collectors in the northern end

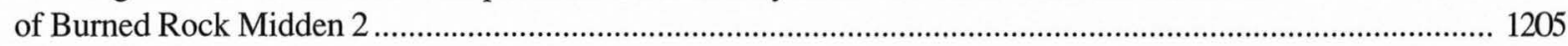

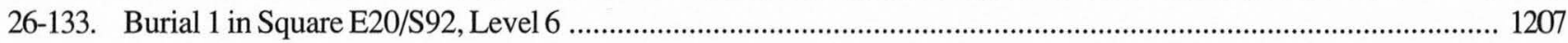

26-134. Plan of Burial 2 and outline profiles of the burial pit ................................................................................. 1209

27-1. Three idealized burned rocks features .......................................................................................... 1214

27-2. The progression of remanence in a hypothetical group of ferromagnetic grains as either the ambient temperature or electromagnetic field strength is increased 
27-3. Changes in the direction and intensity of measured remanence during demagnetization .............................. 1218

27-4. The construction of an As-Zijderveld or vector component diagram for a hypothetical burned rock sample .. 1219

27-5. How to read a Schmidt Equal-area stereonet .......................................................................................... 1220

27-6. The major components and conventions of Vector Rotation Reconstructions ............................................... 1222

27-7. As-Zijderveld and stereonet plots to accompany self-demonstration described in text ............................... 1224

27-8. Collecting and orienting archeomagnetic samples .................................................................................. 1225

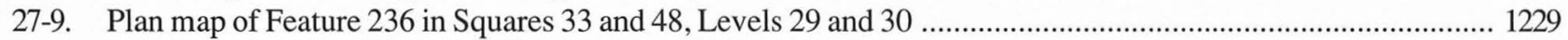

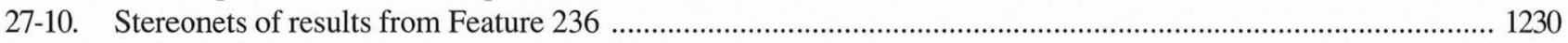

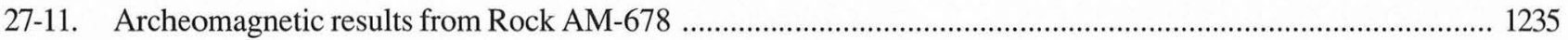

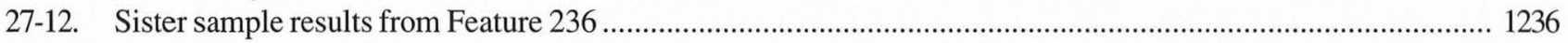

27-13. Stereonet plot of the single remanence component calculated for AM-673/935

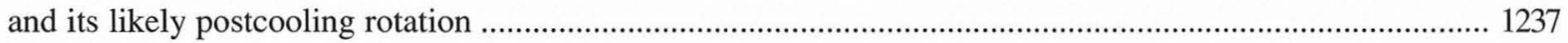

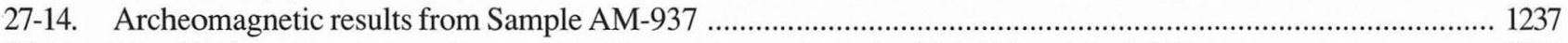

27-15. Identified components and vector rotation reconstructions for AM-680 and AM-938 …............................ 1238

27-16. Plan map of Feature 184 in TARL Square 50 and TxDOT Square E28/S78 …............................................ 1240

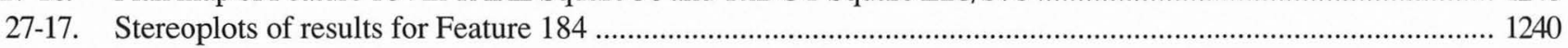

27-18. Composite plan map of Feature 201 and associated features in East Block, Levels 6-8 ................................. 1241

27-19. Composite plan map of Feature 201 and associated features in South Block, Levels 5-8 ............................. 1242

27-20. Stereoplots of results for Feature 201, East and South Block, as well as for Features 204 and 212 ................ 1243

27-21. Plan map of Feature 204 in Square 20, Level 11B ..................................................................................... 1244

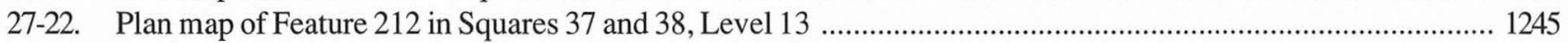

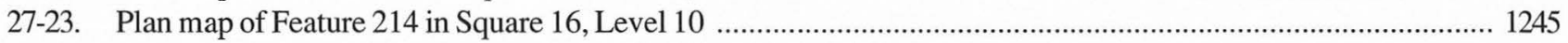

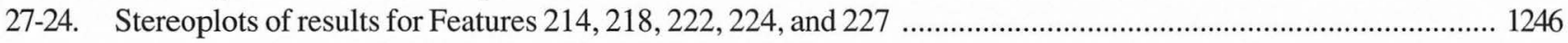

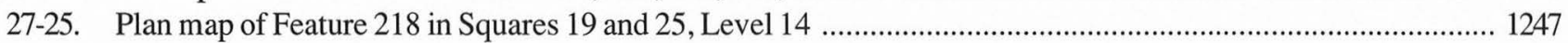

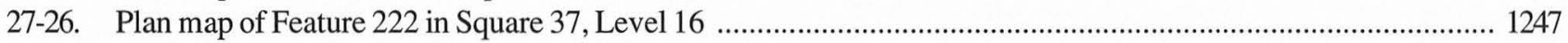

27-27. Plan map of Feature 224 in Square 12, Levels 18 and 19 ........................................................................ 1247

27-28. Plan map of Feature 226 in Square 46, Level 20B ................................................................................ 1248

27-29. Plan map of Feature 227 in Square 30, Levels 20B and 21B ............................................................... 1248

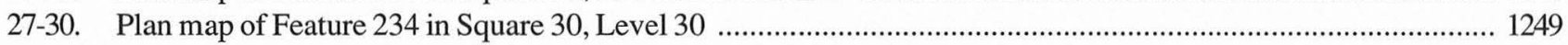

27-31. Plan map of Feature 235 in Square 32, Levels 28B and 29 ......................................................................... 1249

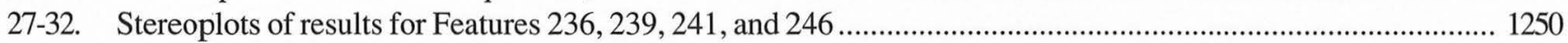

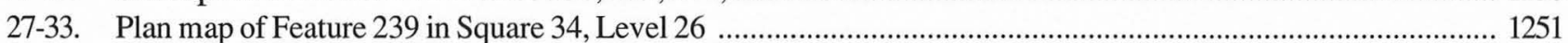

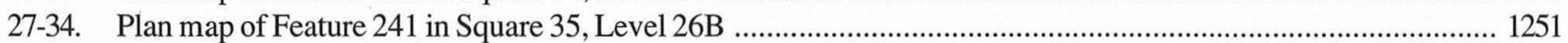

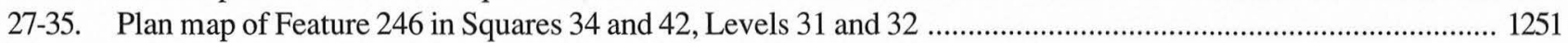

27-36. Figure showing the loss of remanent magnetization during demagnetization in two samples from AM-1100 .. 1252

27-37. Plan map of Feature 248 in Squares 28, 44, 52 and 53, Levels 28 and 29 .................................................. 1253

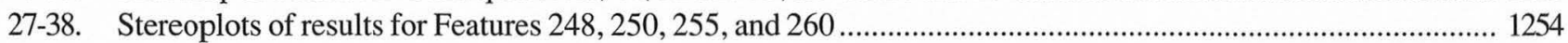

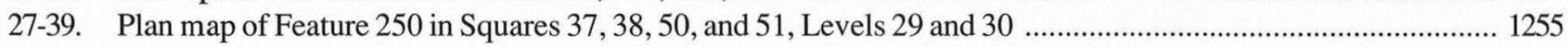

27-40. Plan map of Feature 255 in Square 59, Level 42 ................................................................................ 1256

27-41. Plan map of Feature 257 in Square 53, Level 39B .................................................................................... 1256

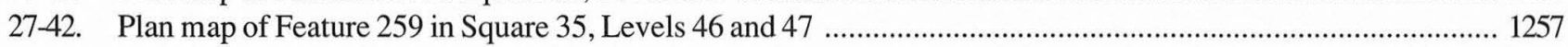

27-43. Plan map of Feature 260 in Squares 39 and 52, Level 42B ..................................................................... 1257

27-44. Photographs and schematic plan maps of sample locations and results for Levels 3 and 4

27-45. Photographs and schematic plan maps of sample locations and results for Levels 7 and 8

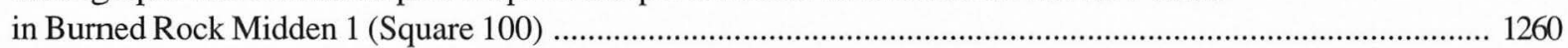

27-46. Stereoplots of results for Levels 2, 3, and 4 in Burned Rock Midden 1 (Square 100) ................................... 1261

27-47. Stereoplots of results for Levels 5, 6, and 7 in Burned Rock Midden 1 (Square 100) .................................... 1262

27-48. Stereoplots of results for Levels 8, 9, 10, and 11 in Burned Rock Midden 1 (Square 100) .............................. 1263

27-49. Feature 231, Composite A: Subfeature 217 in Squares 33 and 48, Levels 17/18 (ca. $95.95 \mathrm{~m}$ ) ........................ 1265

27-50. Stereoplots of results for Feature 231, Composites A, B, and C ….......................................................... 1267

27-51. Feature 231 and associated subfeatures, Composite B: South Block, Level 19 (ca. $95.90 \mathrm{~m})$......................... 1268

27-52. Detail from Composite B: Feature 223 in Squares 34 and 49, Level 19 (ca. $95.90 \mathrm{~m})$...................................... 1268

27-53. Detail from Composite B: Squares 33 and 48, Level $19(\mathrm{ca} .95 .90 \mathrm{~m})$....................................................... 1268

27-54. Feature 231, Composite C: East Block, Levels 19 and 20 (ca. 95.85 m) ………............................................ 1270 
27-55. Feature 231 and associated subfeatures, Composite D: East and South Blocks,

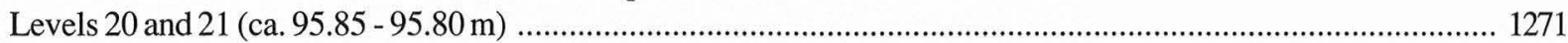

27-56. Stereoplots of results for Composite D, including subfeatures ................................................................... 1274

27-57. Detail from Composite D: Squares 33, 34, 48, and 49, Level 20 (ca. 95.85 m) …........................................... 1275

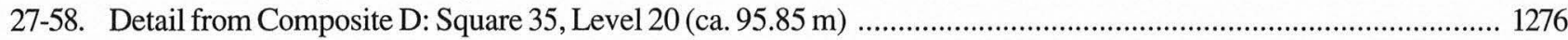

27-59. Detail of Composite E: Squares 37,38, 50, and 51, Level 21 (ca. $95.80 \mathrm{~m}$ ), including Feature 228 .................... 1276

27-60. Detail from Composite D: Feature 230 in Square 39, Level 21 (ca. 95.80 m) ………...................................... 1277

27-61. Detail from Composite D: Squares 52 and 53, Level 21 (ca. 95.80 m) ……................................................. 1277

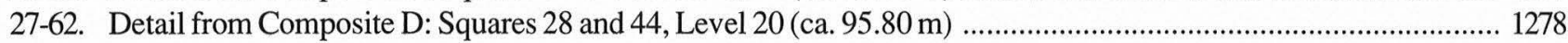

27-63. Detail from Composite D: Squares 27 and 43, Level 20 (ca. $95.80 \mathrm{~m})$....................................................... 1278

27-64. Feature 231 and associated subfeatures, Composite E: East and South Blocks, Levels 21 and 22

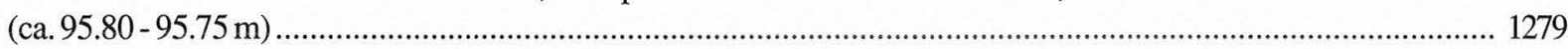

27-65. Stereoplots of results for Composite E, including subfeatures ................................................................ 1280

27-66. Stereoplots of results for Composite E subfeatures .................................................................................... 1281

27-67. Detail of Composite E:Squares 37, 38, 50, and 51, Level 21 (ca. $95.80 \mathrm{~m}$ ), including Feature 228 ...................... 1284

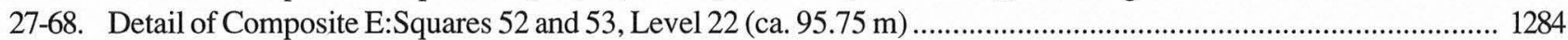

27-69. Detail of Composite E:Feature 230 in Square 39, Level 22 (ca. 95.75 m) ...................................................... 1284

27-70. Detail of Composite E:Squares 28 and 44, Level 21 (ca. $95.75 \mathrm{~m}$ ) ............................................................ 1285

27-71. Detail of Composite E:Squares 26, 27, 42, and 43, Level 21 (ca. $95.75 \mathrm{~m}$ ) …............................................. 1285

27-72. Feature 231 and associated subfeatures, Composite F: East and South Blocks, Levels 22 and 23

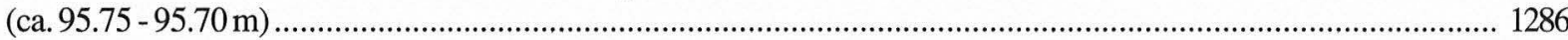

27-73. Stereoplots of results for Composite F, including subfeatures .................................................................... 1290

27-74. Stereoplots of results for Composite F subfeatures .................................................................................. 1291

27-75. Detail of Composite F: Squares 37, 38, 50, and 51, Level 22 (ca. $95.75 \mathrm{~m})$..................................................... 1292

27-76. Detail of Composite F: Squares 52 and 53, Level 23 (ca. 95.70 m) ............................................................ 1293

27-77. Detail of Composite F: Feature 230 in Square 39, Level $23(\mathrm{ca} .95 .70 \mathrm{~m})$....................................................... 1293

27-78. Detail of Composite F: Squares 28 and 44, Level 22 (ca. $95.70 \mathrm{~m})$.......................................................... 1294

27-79. Detail of Composite F: Feature 225 in Squares 27 and 43, Level 22 (ca. 95.70 m) ............................................ 1294

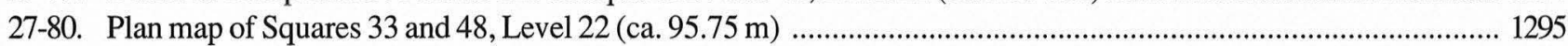

27-81. Feature 231 and associated subfeatures, Composite G: South Block, Level 23 (ca. $95.70 \mathrm{~m}$ ) .......................... 1296

27-82. Stereoplots of results for Composite $\mathrm{G}$, including subfeatures ................................................................. 1298

27-83. Detail of Composite G: Feature 181 in Squares 37 and 50, Level 23 (ca. 95.70 m) .......................................... 1299

27-84. Detail of Composite G: Feature 181 in Squares 38 and 51, Level 23 (ca. $95.70 \mathrm{~m}$ ) ........................................ 1299

27-85. Feature 231 and associated subfeatures, Composite H: East and South Blocks, Level 24 (ca. 95.65 m) ............ 1301

27-86. Stereoplots of results for Composite $\mathrm{H}$, including subfeatures .................................................................... 1302

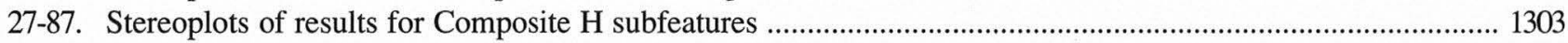

27-88. Detail of Composite H: Feature 181 in Squares 37, 38, 50, and 51, Level 24 (ca. 95.65 m) ............................ 1306

27-89. Detail of Composite H: Features 181 and 231/245 in Squares 52 and 53, Level 24 (ca. $95.65 \mathrm{~m}$ ) ....................... 1307

27-90. Detail of Composite H: Square 39, Level 24 (ca. 95.65 m) .......................................................................... 1307

27-91. Detail of Composite H: Feature 245 in Squares 27, 28, and 44, Level 24 (ca. $95.65 \mathrm{~m}$ ) ..................................... 1308

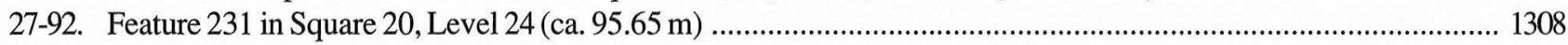

27-93. Feature 231 in Squares 34 and 49, Level 24 (ca. 95.65 m) ........................................................................ 1309

27-94. Feature 231 and associated subfeatures, Composite I: East and South Blocks, Level 25 (ca. $95.60 \mathrm{~m}$ ) ............. 1310

27-95. Stereoplots of results for Composite I, including subfeatures ...................................................................... 1312

27-96. Stereoplots of results for Composite I subfeatures .................................................................................... 1313

27-97. Detail of Composite I: Features 181 and 258 in Squares 37, 38, 50, and 51, Level 25 (ca. $95.60 \mathrm{~m}$ ) .................... 1314

27-98. Detail of Composite I: Features 181 and 231/245 in Square 52, Level 25 (95.60 m) .......................................... 1314

27-99. Detail of Composite I: Feature 245 in Squares 28 and 44, Level 25 (ca. 95.60 m) .............................................. 1314

27-100. Detail of Composite I: Feature 231/245 in Squares 27 and 43, Level 25 (ca. 95.60 m) ....................................... 1314

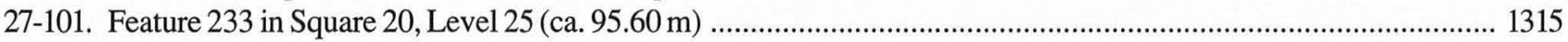

27-102. Feature 231 in Squares 25, 26, 41, and 42, Level 25 (ca. $95.60 \mathrm{~m}$ ) .............................................................. 1315

27-103. Feature 231 and associated subfeatures, Composite J: East and South Blocks, Level 26 (ca. $95.55 \mathrm{~m}$ ) .............. 1316

27-104. Stereoplots of results for Composite J, including subfeatures ..................................................................... 1317

27-105. Stereoplots of results for Composite J subfeatures ............................................................................... 1318

27-106. Detail of Composite J: Features 181, 258, and 184 in Squares 37, 38, 50, and 51, Level 26 (ca. $95.55 \mathrm{~m}$ ) ............. 1320 
27-107. Detail of Composite J: Feature 245 in Squares 28, 44, 52, and 53, Level 26 (ca. $95.55 \mathrm{~m}$ )

27-108. Detail and extension of Composite J: Squares 25, 26, 27, 41, 42, and 43, Level 26 (ca. $95.55 \mathrm{~m}$ )

27-109. Feature 231 and associated Subfeature 242, Composite K: East Block, Squares 20, 25, 26, 41, and 42,

Levels 27 - 29 (ca. $95.50-95.40 \mathrm{~m}$ )

27-110. Stereoplots of results for Composite K, including Feature242 and 249 …...................................................... 1326

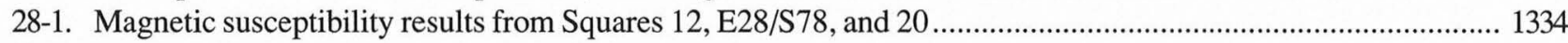

28-2. Magnetic susceptibility results from Square 33/56 ................................................................................... 1335

28-3. Isothermal remanence acquisition curves for magnetite and hematite .......................................................... 1335

28-4. Results of IRM analyses from eight selected samples from the Square 20 profile ......................................... 1336

28-5. The ratio of low coercivity ferromagnetic minerals to high coercivity minerals in TARL sediment columns from Squares 12, 20, and 33/56

29-1. Photomicrographs of micromorphological samples .................................................................................. 1352

29-2. Photomicrograph of micromorphological Sample WL-92-105 ....................................................................... 1353

29-3. Photomicrograph of micromorphological Sample WL-92-208 .................................................................... 1353

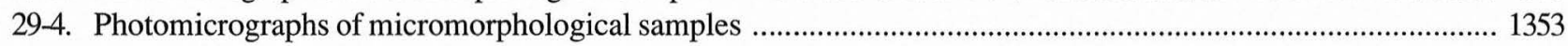

29-5. Photomicrographs of micromorphological samples ...................................................................................... 1354

29-6. Photomicrographs of micromorphological samples .............................................................................. 1355

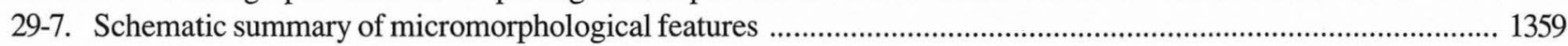




\section{LIST OF TABLES \\ Volume IV}

25-1. Wilson-Leonard data by laboratory number

25-2. Quantitative amino acid analysis of human bone from Burial 2 and cortical bone

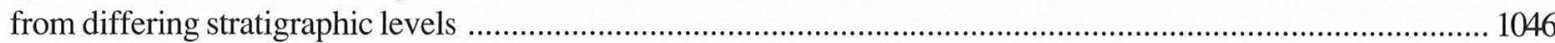

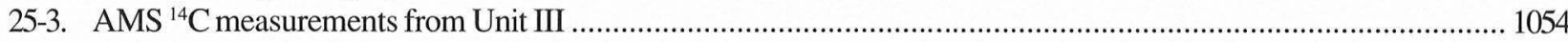

25-4. Carbonized Camassia scilloides bulbs from Feature 181, Unit IIIa .................................................................. 1057

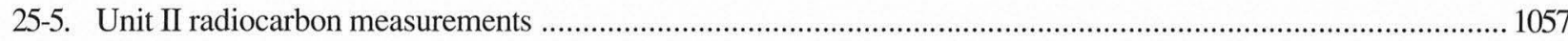

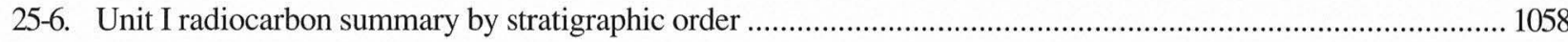

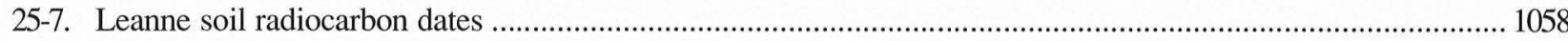

25-8. AMS radiocarbon measurements on tree ring positions within Feature 253 .................................................... 1059

25-9. AMS radiocarbon measurements on Burial 2 bone and pit fill ........................................................................ 1059

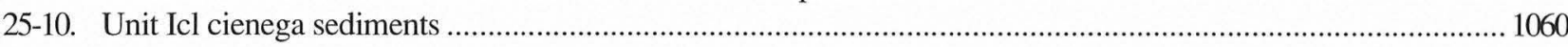

25-11. Summary of Wilson-Leonard chronostratigraphy in order of youngest to oldest sediments ............................. 1061

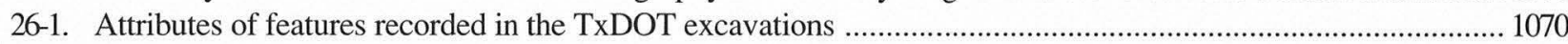

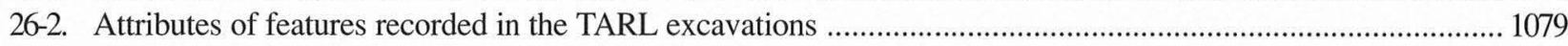

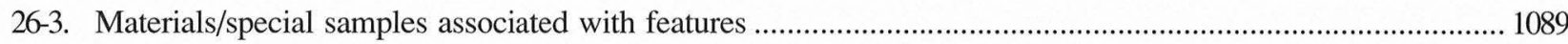

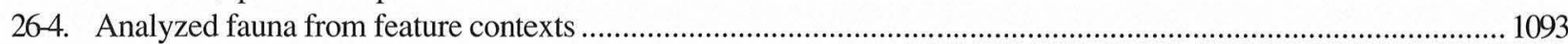

27-1. Individual features and Burned Rock Midden 1 archeomagnetic interpretation of vectoral data .................... 1231

27-2. Summary of TARL Square 100 archeomagnetic results by level ................................................................. 1264

27-3. Archeomagnetic interpretation of vectoral data, Composite A ........................................................................ 1266

27-4. Archeomagnetic interpretation of vectoral data, Composite B ..................................................................... 1269

27-5. Archeomagnetic interpretation of vectoral data, Composite C .................................................................... 12270

27-6. Archeomagnetic interpretation of vectoral data, Composite D ................................................................... 1272

27-7. Summary of archeomagnetic results for Composite D .............................................................................. 1227

27-8. Archeomagnetic interpretation of vectoral data, Composite E ........................................................................ 1282

27-9. Summary of archeomagnetic results for Composite E .................................................................................. 1283

27-10. Archeomagnetic interpretation of vectoral data, Composite F .................................................................. 1287

27-11. Summary of archeomagnetic results for Composite F ............................................................................... 1289

27-12. Archeomagnetic interpretation of vectoral data, Composite G ................................................................. 1297

27-13. Summary of archeomagnetic results for Composite G ............................................................................... 1297

27-14. Archeomagnetic interpretation of vectoral data, Composite $\mathrm{H}$.................................................................... 1304

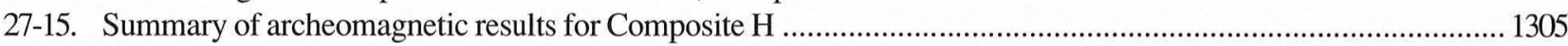

27-16. Archeomagnetic interpretation of vectoral data, Composite I........................................................................ 1311

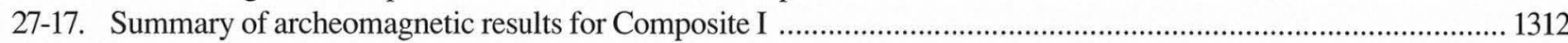

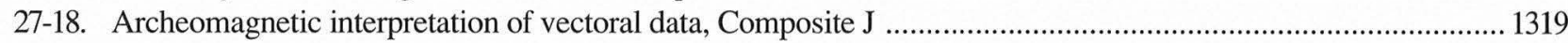

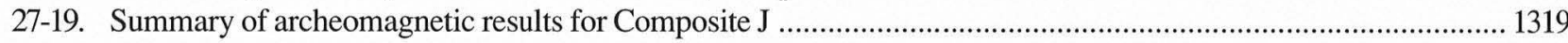

27-20. Archeomagnetic interpretation of vectoral data, Composite K …................................................................... 1324

27-21. Summary of archeomagnetic results for Composite K …….......................................................................... 1325

28-1. General provenience of analyzed magnetic susceptibility samples ................................................................. 1330

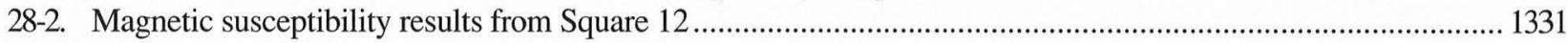

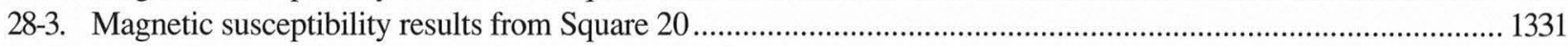

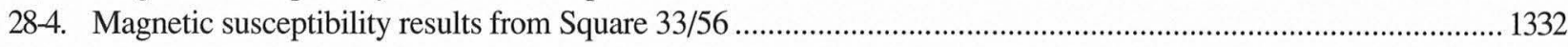

28-5. Magnetic susceptibility results from Square E28/S78 ………....................................................................... 1333

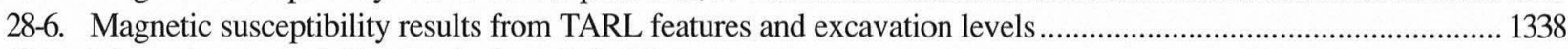

28-7. Magnetic susceptibility results from TxDOT features ………........................................................................ 1340

28-8. Magnetic susceptibility results of Burial 2 sediment samples ........................................................................ 1341

29-1. Micromorphological samples analyzed from Wilson-Leonard .......................................................................... 1345

29-2. Summary of Wilson-Leonard geological samples ............................................................................................. 1346

A6-1. Individual feature, Burned Rock Midden 1, and nonfeature archeomagnetic samples ................................... 1374

A6-2. Feature 231, 181, and 245 archeomagnetic samples ................................................................................ 1387

A6-3. Archeomagnetic interpretation of vectoral data samples not illustrated or discussed in Chapter 27 .............. 1409

A6-4. Archeomagnetic samples collected but not analyzed, individual features and BRM $1 \ldots \ldots \ldots \ldots \ldots \ldots \ldots \ldots \ldots \ldots \ldots . . . . . . . . . . .1410$

A6-5. Archeomagnetic samples collected by not analyzed, Features 231, 181, and 245 ....................................... 1412 


\section{Chapter 24}

\section{INTRODUCTION TO VOLUME IV}

by Michael B. Collins

Archeology depends ultimately on context. The salient aspect of context at Wilson-Leonard is an 11,000-year stratified sequence of occupations covering most of the known local archeological chronology. Stratification is critically important for establishing the sequential order of events in the archeological record, information that can never be as reliably determined by seriation or cross dating. Once a sequence is established, its value is determined by how well it is dated and by the amount of information it yields on the events documented in the sequence. The outcome of the 1982-1984 investigations at Wilson-Leonard included the outline of an important stratified sequence of prehistoric events with minimal chronometric control and a fairly coarsegrained geologic interpretation of the depositional environment responsible for that sequence.

The five chapters in this volume report aspects of the concerted effort during the 1992-1993 investigations and subsequent analyses to (1) establish more-precise chronological control on the deposits and the cultural events represented, (2) maximize the information that could be extracted on the cultural behavior responsible for each archeological component in the sequence, and (3) attain a finer-grained understanding of the geologic processes contributing to the formation of the site.

Radiocarbon dating based on the 1982-1983 excavation was of limited utility. Only 14 radiocarbon assays had been completed prior to the second excavation. The majority of those were selected in an effort to ascertain the age of Burial 2, but the results were not satisfactory. Holliday (1992) depicted sedimentation rates for the site using available radiocarbon determinations as well as estimated ages of diagnostic artifacts. The lowest and best-defined cultural levels (early Paleoindian) of the site, where Holliday identified the most rapid rates of deposition, were not datable given the results of the 1982-1984 excavations. Late Paleoindian through Late Prehistoric components could only be dated within relatively broad limits using standard radiocarbon decay-event counting techniques. Although AMS dating had debuted in the late 1970s, it was not a mainstream technique in 1982-1984. The small sample size requirements of the AMS method, which had become a standard technique by the time of the 1992-1993 fieldwork, improved the prospect for establishing better chronometric controls on the site, but much more pertinent to the dating problems encountered at Wilson-Leonard was the vastly improved understanding of the geochemical processes affecting radiocarbon dating. The accompanying report by Stafford (Chapter 25) sets out the problems in, approaches to, and results of using AMS radiocarbon techniques to establish an accurate chronostratigraphy for the site. Stafford's results, based on a total of 96 radiocarbon determinations, provide (1) an important site chronology with regional applications - especially for the period 8000 to 12,000 в.P., which previously had been the least well-dated segment of the regional chronology, and (2) an exemplary case study for overcoming many limitations to radiocarbon dating of charcoal, sediment, soil, bone, and shell recovered from open sites with adverse conditions for the preservation of organic materials.

The next two chapters ( 26 by Guy describing features and 27 by Takac reporting archeomagnetic investigations) draw upon the numerous archeological features at WilsonLeonard to enrich the yield of interpretive information about the site and its former inhabitants. A majority of the prehistoric features (226 of 260) documented at Wilson-Leonard are the direct result of human activities at the site, and of these, most (212) contain burned rocks. These we believe to have resulted almost exclusively from domestic activities and primarily from food preparation. Besides those with burned rocks, cultural features include two human burials, an isolated human skull, bone clusters, pits, and artifact clusters. The 34 features considered to be natural (or probably natural) include 12 burned trees or other woody vegetation which proved to be extremely valuable in the radiocarbon 
dating of the site. Other natural anomalies designated as features were such things as burrows, a mineralized root, and pockets or lenses of gravel. The diverse sizes and forms of the 212 burned rock features reflect change over time as well as variation among features within the same component. Besides the two large burned rock middens exposed in the excavations, more than 140 features are "clusters" of burned rocks, more than 20 are "scatters," and 5 are "accumulations." Other categories of burned rock features are large basins, small basins, and rings.

TxDOT and TARL excavations differed in the way in which features were excavated, documented, and controlled for the proveniences of samples and of associated artifacts. This resulted in significant differences in the data recovered and renders the two sets of data less than completely comparable, in spite of the fact that the two excavations encountered similar features. Slightly more than three-quarters of the features were found in the 1982-1984 excavations (of the total of 260 features, $77 \%$ were excavated during the TxDOT work and $23 \%$ were dug in the TARL season; of the 226 total cultural features, $78 \%$ were dug by TxDOT and $22 \%$ by TARL). For those kinds of features that were numerous, these proportions were fairly comparable (TxDOT work documented $79 \%$ of the 212 burned rock features and $83 \%$ of the 12 burned trees); for those kinds of features that occurred infrequently, percentages are not as comparable, and the larger excavation produced the greater number. In spite of these indications that the two excavations were sampling the same population of features, the results were noticeably different. At least one artifact was provenienced to $80 \%$ of the 61 features excavated by TARL compared to $35 \%$ of the 199 excavated by TxDOT. Bone was provenienced to $75 \%$ of TARL features and $16 \%$ of TxDOT features. Mussel shell was found in $13 \%$ of TARL features and $9 \%$ of TxDOT features. Macroplant remains were documented for $57 \%$ of TARL features and $20 \%$ of TxDOT features. Bulk sediment samples were recovered for laboratory analysis from $79 \%$ of TARL features and $12 \%$ of TxDOT features. Beyond these differences, field data on many TxDOT features are imprecise or lacking. For these reasons, the full potential of the sample of features from Wilson-Leonard cannot be achieved, however, data from several features, in both the TxDOT and TARL excavations, yielded very significant information about subsistence activities at the site, especially for the Early Archaic.

Because archeological features commonly reflect relatively short-term and behaviorally specific events, it behooves investigators to learn as much as possible about those behaviors. One approach that was being developed at the time of the 1992-1993 fieldwork is to determine detailed archeomagnetic histories of burned rocks, especially those in features. Several kinds of information can be derived from patterns in archeomagnetic data on burned rocks, and a large number of samples (over 1,200) were collected at Wilson-Leonard in 1992 and 1993. Detailed analyses of 725 such samples provided data on the temperatures to which rocks were heated, whether they had cooled in the place where they last heated, had moved during cooling, or had moved since last cooling. In some instances, even the direction of movements could be inferred. Piecing information of this kind together permits sound inferences to be made about the function and the integrity of burned rock features. Ovens can be distinguished from simple hearths and heaps of rocks discarded from fireplaces no longer are to be confused with in-place features. Disturbed portions of otherwise intact features can be identified. These findings viewed sequentially over the time of occupation of the site are the basis for inferring aspects of the fundamental cooking technology of prehistoric hunter-gatherers. It is especially fortunate that a number of Early Archaic features, a few of which yielded charred plant food remains, were well preserved and could be investigated using the archeomagnetic approach. The principles, methods, results, and interpretations of the Wilson-Leonard archeomagnetic investigations are presented in Chapter 27.

Two other comparatively recent investigative techniques are reported in the next two chapters. These are magnetic susceptibility (Chapter 28 by Takac) and micromorphology (Chapter 29 by Goldberg) of soils and sediments. Both of these approaches contribute to more-detailed understanding of the earthen matrix in which archeological materials are found. Magnetic susceptibility is the potential a rock or an earthen material has for becoming magnetized. Measurement of magnetic susceptibility is a technique borrowed from soil science where it has been determined that natural soil processes as well as aspects of human habitation increase magnetic susceptibility. By detecting with an instrument relative levels of magnetic susceptibility horizontally across a surface or vertically on a profile, patterns in the data can indicate varying intensities of natural or anthropic pedogenesis. At Wilson-Leonard, the investigation was oriented along the temporal axis for the most part, but some use of magnetic susceptibility was made in diagnosing individual features. Magnetic susceptibility contributed to better definition of anthropogenic and pedogenic aspects of the site stratigraphy and in a few cases aided in the interpretation of features. This latter effort was not anticipated during the fieldwork, and samples were not collected specificially for that purpose. It is apparent that with better field sampling, this technique could be very useful in the interpretation of features.

Microscopic study of specially prepared thin sections of soils or sediments ("micromorphology") is another borrowing from soil science that has proven extremely valuable to archeological inquiry. Applied to several problems at Wilson-Leonard, micromorphology revealed details on the formation and diagenesis of sediments, soils, and cultural features. The value of this approach derives from the fact that soil or sediment is studied intact, not disaggregated. Constituents can be identified and their relationships in 
the structure of the sample can be determined. These relationships often show sequential events in the formation or diagenesis of the sampled matrix. The events may be natural or cultural in origin. Sampling for micromorphological analysis at Wilson-Leonard was primarily along vertical sections, but some sampling of features was also done. Small-scale turbation, mostly by earthworms, has been pervasive in the site, resulting in the destruction of organic material and disruption of the sedimentary fabric. Much of the presentation in Chapter 29 is concerned with the particulars of sample micromorphology, but these details lead to broader conclusions. Goldberg notes, for example, that the similar patterns of decreasing abundance of charcoal, snail shell, and bone with depth in the site result from different mechanisms-solely depositional in the case of snail shell, depositional combined with postdepositonal in the cases of bone and charcoal. Precipitation of carbonates in various forms and amounts in the sequence reflects complex ground water and pedogenic factors. Insights into these and other sedimen- tary characteristics of the site could not have been achieved using more-traditional techniques.

The appendices in this volume include two that are supporting data for chapters in the volume; Appendix 6 itemizes the raw archeomagnetic data and Appendix 7 contains the descriptions of micromorphological samples. Appendix 8, on the other hand, is an independent set of data. Joy Becker, a graduate student at The University of Texas undertook a project in 1994 and 1995 to sort fine-screen matrix samples from selected features and organize the materials recovered. Becker accomplished this and also provided preliminary identifications of the recovered specimens with consultation from Lundelius and Masson. The results proved valuable and were utilized by other analysts, especially by Guy in describing the content of features (see Chapter 26). There are limitations to Becker's study - the principal one being that no more experienced analyst verified all of her identifications-and the data cannot be taken to be as rigorous as those generated by the more formal analyses, however, the raw findings are presented in tabular form in this appendix. 


\section{Chapter 25}

\section{RADIOCARBON CHRONOSTRATIGRAPHY}

by Thomas W. Stafford, Jr.

\section{INTRODUCTION}

The Wilson-Leonard archeological site consists of more than $5 \mathrm{~m}$ of stratified alluvium and colluvium containing evidence for human habitation spanning at least the last 11,000 radiocarbon years. The site is important because (1) Archaic and Paleoindian components dating 8000-11,500 B.P. are better differentiated in Wilson-Leonard deposits than at any reported site in Texas; (2) a human burial excavated in 1983 was dated stratigraphically to ca. 10,000 в.P.; (3) the sediments record human occupations representing the most complete sequence known from Central Texas during the last 11,500 years; and (4) there are data contributing to the regional paleoecological record for the Holocene and Late Pleistocene.

Despite the site's obvious archeological and paleoecological importance, the chronology of the deposits was difficult to establish because the sediments were oxidized, charcoal was uncommon, fossil bone and shells were diagenetically altered, and stratigraphic correlations were hampered by bioturbation and poor stratification within the colluvium. This chapter reports a concerted effort to use radiocarbon dating to establish the chronological framework for the Wilson-Leonard site. The resulting radiocarbon chronology from Wilson-Leonard demonstrates how accelerator mass spectrometry (AMS) radiocarbon dating was combined with lithostratigraphy, biostratigraphy, and archeology to yield a final chronostratigraphy for a complex stratified site. Although the Wilson-Leonard site does not contain abundant carbon sources, the chronostratigraphy was established accurately by using AMS ${ }^{14} \mathrm{C}$ dates on charcoal, sediments, soils, bone, and shell carbonate.

As detailed in Volume I, the Wilson-Leonard site is situated on the floor and adjacent margin of the alluvial valley of Brushy Creek. The soils and sediments are carbonate-rich and the dominant regional vegetation is oak-juniper savanna with riparian floral species. This part of Texas supports a diverse vertebrate and invertebrate fauna. Carbon at the site is derived from these inorganic and organic sources via natural and cultural processes.

\section{SAMPLES AVAILABLE FOR RADIOCARBON DATING}

Table 25-1 summarizes 96 radiocarbon measurements made on samples collected during the 1982-1984 TxDOT and 1992-1993 TARL excavations. The 14 TxDOT 1982-1984 samples include 3 conventional (Beta-decay counting) radiocarbon dates on soils and charcoal associated with Burial 2 fill, 6 AMS radiocarbon measurements made directly on Burial 2 human bone (Stafford et al. 1987), and 5 conventional radiocarbon dates on charcoal from other contexts. The radiocarbon measurements are presented as $\mathrm{d}^{13} \mathrm{C}$-corrected values with their fraction modern value. Calendarcorrected ${ }^{14} \mathrm{C}$ ages are not given because (1) calendar corrections are not presently available for the full time range ( 0 12,000 years), and (2) Paleoindian chronologies are presently known and discussed as uncalibrated ${ }^{14} \mathrm{C}$ ages. Discussing an 11,000 cal B.P. age would be immediately confused with an 11,000 year ${ }^{14} \mathrm{C}$ age. Until cal corrections are known for the last 20,000 years or more, confusion is minimized if ages are discussed in ${ }^{14} \mathrm{C}$ years instead of calendar years.

Sixty-four radiocarbon measurements were on samples collected during the 1992-1993 field season. Eighteen dates measured in 1995 were from charcoal collected during the 1982-1984 excavations. Radiocarbon measurements include conventional ${ }^{14} \mathrm{C}$ analyses made by The University of Texas at Austin Radiocarbon Laboratory (Tx- ), conventional and AMS ${ }^{14} \mathrm{C}$ dates made by Beta Analytic Laboratories, Inc., Florida (Beta-, CAMS- ) and AMS ${ }^{14} \mathrm{C}$ analyses made by the Lawrence Livermore National Laboratory's Center for Accelerator Mass Spectrometry, California (CAMS- ) on targets provided by the Institute of Arctic and Alpine Research 
TABLE 25-1

\begin{tabular}{|c|c|c|c|c|c|c|c|c|c|c|c|c|}
\hline Lab No. & Elevation $(\mathrm{m})$ & Feature No. & Unit & Location & Field No. & Sample Type & Common Name & Fraction Dated & $\mathrm{Fm}$ & $\mathrm{Fm} \sigma$ & ${ }^{14} \mathrm{C}$ Age & $\sigma$ \\
\hline AA-171 & ca. $94.31-94.11$ & Burial 2 & Isi//cl//si-c & E20/S74, Level 32 & None & Charcoal & N/A & Pretreated charcoal & * & * & 13,000 & 3,000 \\
\hline AA-747 & ca. $94.31-94.11$ & Burial 2 & Isi//cl//si-c & E20/S74, Level 32 & None & Bone & Human & Apatite $\mathrm{CO}_{2}$ & * & * & 4,650 & 310 \\
\hline AA-748 & ca. $94.31-94.11$ & Burial 2 & $\mathrm{Isi} / / \mathrm{cl} / / \mathrm{si}-\mathrm{c}$ & E20/S74, Level 32 & None & Bone & Human & $\mathrm{HCl}$ soluble carbon & * & * & 5,940 & 520 \\
\hline AA-749 & ca. $94.31-94.11$ & Burial 2 & Isi/Icl//si-c & E20/S74, Level 32 & None & Bone & Human & $\mathrm{HCl}$ soluble carbon & * & * & 6,700 & 460 \\
\hline AA-751 & са. $94.31-94.11$ & Burial 2 & Isi//cl//si-c & E20/S74, Level 32 & None & Bone & Human & Gelatin & * & * & 5,860 & 270 \\
\hline AA-752 & ca. $94.31-94.11$ & Burial 2 & $\mathrm{Isi} / / \mathrm{cl} / / \mathrm{si}-\mathrm{c}$ & E20/S74, Level 32 & None & Bone & Human & $\mathrm{H}_{2} 0$ Insoluble & * & * & 5,440 & 420 \\
\hline AA-753 & ca. $94.31-94.11$ & Burial 2 & Isi//lcl/Isi-c & E20/S74, Level 32 & None & Bone & Human & Gelatin & $*$ & $*$ & 1,270 & 280 \\
\hline Beta-79699 & 96.32 & 199 & 파 b & E20/S74, Level 12 & СH-1085 & Tree stump & Red mulberry & Pretreated charcoal & * & * & 5,560 & 60 \\
\hline Beta-79700 & са. 96.49-96.39 & 50 & IIIlb & E20/S78, Level 12a & CH-1054 & Tree stump & Live oak & Pretreated charcoal & * & * & 5,520 & 80 \\
\hline Beta-79803 & 96.43 & 214 & IIIb & Square 16 , Level $12 \mathrm{~b}$ & C14-15 & Charcoal & Juniper & Pretreated charcoal & * & * & 4,880 & 70 \\
\hline CAMS-03131 & Modern surface. & & Modern & Modern ground surface & None & Modern snail & Unknown & & 0.6289 & 0.0047 & 3,730 & 60 \\
\hline CAMS-05881 & $93.20-93.13$ & & Icl & Unit 28, Level 52-53 & C14-419 & Sediment & N/A & Humic acids & 0.2707 & 0.0024 & 10,500 & 80 \\
\hline CAMS-05882 & $93.59-93.55$ & & Icl & Unit 28, Level 49 & $\mathrm{C} 14-420$ & Sediment & N/A & Humic acids & 0.3979 & 0.0023 & 9,730 & 70 \\
\hline CAMS-05883 & 93.59-93.55 & & Icl & Unit 28 , Level 49 & C14-420 & Sediment & N/A & Decalcified sediment & 0.3098 & 0.0024 & 9,410 & 70 \\
\hline CAMS-05884 & $93.16-93.12$ & & Icl & Unit 27, Level 53 & C14-418 & Sediment & $\mathrm{N} / \mathrm{A}$ & Decalcified sediment & 0.3210 & 0.0025 & 9,130 & 70 \\
\hline CAMS-05886 & $93.16-93.12$ & & Icl & Unit 27 , Level 53 & C14-418 & Sediment & $\mathrm{N} / \mathrm{A}$ & Humic acids & 0.2893 & 0.0037 & 9,960 & 110 \\
\hline CAMS-05887 & $93.20-93.13$ & & Icl & Unit 28 , Levels $52-53$ & C14-419 & Sediment & N/A & Decalcified sediment & 0.2878 & 0.0023 & 10,000 & 70 \\
\hline CAMS-05993 & $93.20-93.13$ & & Icl & Unit 28, Levels $52-53$ & C14-419 & Sediment & N/A & Humins & 0.2813 & 0.0025 & 10,190 & 80 \\
\hline CAMS-05994 & $93.16-93.12$ & & Icl & Unit 27 , Level 53 & C14-418 & Sediment & N/A & Humins & 0.2996 & 0.0033 & 9,680 & 90 \\
\hline CAMS-05995 & $93.59-93.55$ & & Ict & Unit 28, Level 49 & C14-420 & Sediment & $\mathrm{N} / \mathrm{A}$ & Humins & 0.3354 & 0.0034 & 8,780 & 90 \\
\hline CAMS-06348 & 94.63 & 253 & Isi-c & Unit 57, Level 38 & C14-291 & Tree stump & Live oak & Pretreated charcoal & 0.3051 & 0.0024 & 9,540 & 70 \\
\hline CAMS-06349 & 94.64 & 253 & Isi-c & Unit 57 , Level 38 & C14-287 & Tree stump & Live oak & Pretreated charcoal & 0.3063 & 0.0027 & 9,500 & 80 \\
\hline CAMS-06350 & 94.63 & 253 & Isi-c & Unit 57, Level 38 & C14-290 & Tree stump & Live oak & Pretreated charcoal & 0.3022 & 0.0023 & 9,610 & 70 \\
\hline CAMS-06373 & 94.63 & 253 & Isi-c & Unit 57, Level 38 & C14-286 & Tree stump & Live oak & Pretreated charcoal & 0.3048 & 0.0028 & 9,540 & 80 \\
\hline CAMS-06374 & 94.63 & 253 & Isi-c & Unit 57, Level 38 & C14-289 & Tree stump & Live oak & Pretreated charcoal & 0.3072 & 0.0038 & 9,480 & 100 \\
\hline CAMS-06377 & 94.65 & 253 & Isi-c & Unit 57, Level 38 & C14-295 & Snail & N/A & Snail (HCl-leached) & 0.2700 & 0.0025 & 10,520 & 80 \\
\hline CAMS-06382 & 94.63 & 253 & Isi-c & Unit 57 , Level 38 & C14-288 & Tree stump & Live oak & Pretreated charcoal & 0.3029 & 0.0027 & 9,590 & 80 \\
\hline CAMS-06911 & 95.09 & & Isi-c & Unit 12, Level 33 & $\mathrm{C} 14-282$ & Soil A-horizon & $\mathrm{N} / \mathrm{A}$ & Decalcified sediment & 0.3562 & 0.0027 & 8,290 & 70 \\
\hline CAMS-06912 & 95.25 & & Isi-c & Unit 12, Level 32 & C14-283 & Soil A-horizon & N/A & Decalcified sediment & 0.4500 & 0.0033 & 6,410 & 60 \\
\hline CAMS-06913 & 95.40 & & Isi-c & Unit 12, Level 30 & C14-284 & Soil A-horizon & N/A & Decalcified sediment & 0.4418 & 0.0032 & 6,560 & 60 \\
\hline CAMS-06914 & 95.51 & & Isi-c & Unit 12, Level 28 & C14-285 & Soil A-horizon & N/A & Decalcified sediment & 0.5562 & 0.0064 & 4,710 & 100 \\
\hline CAMS-06915 & 95.09 & & Isi-c & Unit 12, Level 33 & C14-282 & Soil A-horizon & $\mathrm{N} / \mathrm{A}$ & Sedimentary humins & 0.3646 & 0.0040 & 8,110 & 90 \\
\hline CAMS-06916 & 95.25 & & Isi-c & Unit 12, Level 32 & Cl4-283 & Soil A-horizon & N/A & Sedimentary humins & 0.3960 & 0.0036 & 7,440 & 80 \\
\hline CAMS-06917 & 95.40 & & Isi-c & Unit 12, Level 30 & C14-284 & Soil A-horizon & N/A & Sedimentary humins & 0.4040 & 0.0037 & 7,280 & 80 \\
\hline CAMS-06918 & 95.51 & & Isi-c & Unit 12, Level 28 & C14-285 & Soil A-horizon & N/A & Sedimentary humins & 0.5123 & 0.0054 & 5,370 & 90 \\
\hline CAMS-06919 & 95.25 & & Isi-c & Unit 12, Level 32 & C14-283 & Soil A-horizon & N/A & Humic acids & 0.4183 & 0.0037 & 7,000 & 80 \\
\hline CAMS-06920 & 95.40 & & Isi-c & Unit 12 , Level 30 & C14-284 & Soil A-horizon & N/A & Humic acids & 0.3945 & 0.0039 & 7,470 & 90 \\
\hline CAMS-07198 & 95.51 & & Isi-c & Unit 12, Level 28 & C14-285 & Soil A-horizon & N/A & Humic acids & 0.5040 & 0.0041 & 5,500 & 70 \\
\hline CAMS-07201 & 95.09 & & Isi-c & Unit 12, Level 33 & Cl4-282 & Soil A-horizon & N/A & Humic acids & 0.3355 & 0.0029 & 8,770 & 70 \\
\hline CAMS-07207 & 95.32 & 247 & II & Unit 34, Level 31c & $\mathrm{C} 14-200$ & Charcoal & Unknown & Charcoal & 0.3654 & 0.0031 & 8,090 & 70 \\
\hline CAMS-07558 & Modern surface & & Modern & Modern ground surface & None & Modern Snail & Unknown & Shell carbonate & 0.6909 & 0.0049 & 2,970 & 60 \\
\hline CAMS-07559 & Modern surface & & Modern & Modern ground surface & None & Modern Snail & Unknown & Shell carbonate & 1.4448 & 0.0101 & Modern & $\mathrm{NA}$ \\
\hline CAMS-07560 & 95.32 & 236 & II & Unit 48, Level 31b & C14-156a & Charcoal & Unknown & Pretreated charcoal & 0.3007 & 0.0026 & 9,650 & 80 \\
\hline CAMS-07561 & 95.32 & 236 & II & Unit 48 , Level 31b & $\mathrm{C} 14-156 \mathrm{~b}$ & Charred Bone & N/A & Charred bone protein & 0.2739 & 0.0095 & 10,400 & 280 \\
\hline CAMS-08355 & 95.6 & 181 & IIIa & Square 52, Level 25 & C14-219 & Bulb & Wild hyacinth & Pretreated charcoal & 0.3700 & 0.0026 & 7,990 & 60 \\
\hline CAMS-10194 & 95.66 & 245 & IIIa & Unit 52, Level 24 & C14-113 & Charcoal & Unknown & Pretreated charcoal & 0.3643 & 0.0028 & 8,110 & 70 \\
\hline CAMS-10195 & 94.21 & 255 & Isi-c & Unit 39, Level 42 & C14-321 & Charcoal & Unknown & Pretreated charcoal & 0.2882 & 0.0023 & 9,990 & 70 \\
\hline CAMS-10196 & 96.42 & 204 & IIIb & Unit 20, Level $12 b$ & Cl4-5 & Charcoal & Unknown & Pretreated charcoal & 0.5757 & 0.0037 & 4,440 & 60 \\
\hline CAMS-10197 & 95.68 & 245 & IIIa & Unit 52, Level 24 & C14-152 & Charcoal & Unknown & Pretreated charcoal & 0.3633 & 0.0025 & 8,130 & 60 \\
\hline
\end{tabular}




\begin{tabular}{|c|c|c|c|c|c|c|c|c|c|c|c|c|}
\hline Lab No. & Elevation $(\mathrm{m})$ & Feature No. & Unit & Location & Field No. & Sample Type & Common Name & Fraction Dated & $\mathrm{Fm}$ & $\mathrm{Fm} \sigma$ & ${ }^{14} \mathrm{C}$ Age & $\sigma$ \\
\hline CAMS-10201 & 95.63 & 181 & IIIa & Unit 51, Level 24 & $\mathrm{C} 14-354$ & Bulb & Wild hyacinth & Pretreated charcoal & 0.3659 & 0.0026 & 8,080 & 60 \\
\hline CAMS-10206 & 95.63 & 245 & IIIa & Unit 52, Level 25 & C14-143 & Charcoal & Unknown & Pretreated charcoal & 0.3505 & 0.0085 & 8,420 & 200 \\
\hline CAMS-10207 & 95.12 & 238 & Isi-c/II & Unit 30, Level 33b & C14-82 & Charcoal-root & Unknown & Pretreated charcoal & 0.3330 & 0.0034 & 8,830 & 90 \\
\hline CAMS-13025 & 95.61 & 231 & IIIa & Unit 52, Level 25 & C14-199 & Charcoal & Unknown & Pretreated charcoal & 0.6520 & 0.0059 & 3,440 & 80 \\
\hline CAMS-13509 & ca. $95.51-95.46$ & 181 & IIIIa & NW1/4 E28/S78, Level 20a & CH-1480 & Bulb & Wild hyacinth & Pretreated charcoal & 0.3635 & 0.0031 & 8,130 & 70 \\
\hline CAMS-13512 & ca. $95.74-95.67$ & 181 & IIIa & NE 1/4 E28/S78, Level 17b & CH-1482 & Bulb & Wild hyacinth & Pretreated charcoal & 0.3688 & 0.0025 & 8,010 & 60 \\
\hline CAMS-13513 & ca. 95.69-95.66 & 181 & IIIIa & E28/S78 Level 18a, NE 1/4 & CH-1483-2 & Bulb & Wild hyacinth & Pretreated charcoal & 0.3679 & 0.0025 & 8,030 & 60 \\
\hline CAMS-13514 & ca. $95.81-95.78$ & 181 & IIIIa & E28/S78 Level 16b, SE 1/4 & CH-1484 & Bulb & Wild hyacinth & Pretreated charcoal & 0.3658 & 0.0029 & 8,080 & 70 \\
\hline CAMS- 13840 & са. $95.69-95.66$ & 181 & ІІІа & E28/S78 Level 18a, NE 1/4 & CH-1483-1 & Bulb & Wild hyacinth & Pretreated charcoal & 0.3756 & 0.0026 & 7,870 & 60 \\
\hline CAMS-13841 & ca. $95.78-95.76$ & 181 & IIIa & SE QUAD, E28/S78 Level 17a & CH-1479 & Bulb & Wild hyacinth & Pretreated charcoal & 0.3746 & 0.0026 & 7,890 & 60 \\
\hline CAMS-13842 & ca. $94.75-94.68$ & & Isi-c & E22/S78, Level 29a & CH-1481 & Nutshell & Black walnut & Pretreated charcoal & 0.2971 & 0.0020 & 9,750 & 60 \\
\hline CAMS-13844 & са. $95.59-95.53$ & 181 & IIIa & E28/S78, Level 18b, NE 1/4 & CH-1478 & Bulb & Wild hyacinth & Pretreated charcoal & 0.3743 & 0.0034 & 7,890 & 80 \\
\hline CAMS-14805 & ca. 94.62-94.55 & 167 & Isi-c & E22/S74, Level 30a & CH-1217 & Tree Root & Live oak & Pretreated charcoal & 0.3098 & 0.0022 & 9,410 & 60 \\
\hline CAMS-14806 & ca. 94.73-94.68 & 164 & Id/II & E26/S76, Level 28b & CH-558 & Tree stump & Unknown & Pretreated charcoal & 0.3057 & 0.0022 & 9,520 & 60 \\
\hline CAMS-14807 & ca. 94.73 & 72 & Isi-c & E20/S74, Level, 27a & CH-1071 & Tree Root & Unknown & Pretreated charcoal & 0.3090 & 0.0023 & 9,430 & 60 \\
\hline CAMS-18375 & ca. $97.36-97.08$ & 8 & IIII/y & E20/S90, Level 10 & CH-998 & Bulb & Wild hyacinth & Pretreated charcoal & 0.3580 & 0.0032 & 8,250 & 80 \\
\hline CAMS-18639 & са. $97.32-97.27$ & 10 & IIIc & E20/S84, Level 5 & CH-1024 & Charcoal & Hackberry & Pretreated charcoal & * & * & 1,990 & 60 \\
\hline CAMS-18640 & ca. 95.22 & 157 & II & E26/S72, Level 22a & $\mathrm{CH}-740$ & Charcoal & Unknown & Pretreated charcoal & * & * & 9,340 & 60 \\
\hline CAMS-19080 & ca. 94.57 & 198 & $\mathrm{I} / \mathrm{II}$ & W0/N8, Level 29b & CH-921 & Tree stump & Live oak & Pretreated charcoal & * & * & 9,240 & 70 \\
\hline CAMS-19252 & $93.45-93.43$ & & Icl & Square 20, Level 49 & WL92-234 & Sediment & N/A & Humic acids & 0.2517 & 0.0020 & 11,080 & 70 \\
\hline CAMS-19256 & 94.05-94.02 & & Icl//si-c & Square 20, Level 44 & WL92-229 & Sediment & N/A & Humic acids & 0.2746 & 0.0020 & 10,380 & 60 \\
\hline CAMS-19257 & 93.63-93.61 & & Icl & Square 20, Level 48 & WL92-233 & Sediment & N/A & Humic acids & 0.2656 & 0.0019 & 10,650 & 60 \\
\hline CAMS-19258 & $94.07-94.05$ & & Icl/Isi-c & Square 20, Level 44 & WL92-229 & Sediment & N/A & Humic acids & 0.2754 & 0.0020 & 10,360 & 60 \\
\hline CAMS-19259 & 93.17-93.14 & & Isi//Icl & Square 20, Level 53 & WL92-236 & Sediment & N/A & Humic acids & 0.2568 & 0.0021 & 10,920 & 70 \\
\hline CAMS-19260 & $93.14-93.12$ & & $\mathrm{Isi} / \mathrm{Icl}$ & Square 20, Level 53 & WL92-236 & Sediment & N/A & Humic acids & 0.2485 & 0.0029 & 11,190 & 100 \\
\hline CAMS-19261 & $94.02-94.01$ & & $\mathrm{Icl} / / \mathrm{si}-\mathrm{c}$ & Square 20, Level 44 & WL92-229 & Sediment & N/A & Humic acids & 0.2671 & 0.0020 & 10,610 & 60 \\
\hline CAMS-19262 & 93.18-93.16 & & Isi//Icl & Square 20, Level 53 & WL92-236 & Sediment & N/A & Humic acids & 0.2418 & 0.0031 & 11,400 & 110 \\
\hline CAMS-19481 & $93.89-93.87$ & & Icl & Square 20, Level 46 & WL92-231 & Sediment & N/A & Humic acids & 0.2813 & 0.0038 & 10,190 & 110 \\
\hline CAMS-19482 & $93.66-93.64$ & & Icl & Square 20, Level 48 & WL92-233 & Sediment & N/A & Humic acids & 0.2727 & 0.0042 & 10,440 & 130 \\
\hline CAMS-19483 & 93.73-93.71 & & Icl & Square 20, Level 47 & WL92-232 & Sediment & N/A & Humic acids & 0.2932 & 0.0025 & 9,860 & 70 \\
\hline CAMS-19484 & $93.60-93.59$ & & Icl & Square 20, Levels $48-49$ & WL92-233 & Sediment & N/A & Humic acids & 0.2652 & 0.0029 & 10,660 & 90 \\
\hline CAMS-19485 & 93.53-93.51 & & Icl & Square 20, Level 49 & WL92-234 & Sediment & N/A & Humic acids & 0.2762 & 0.0020 & 10,330 & 60 \\
\hline CAMS-19486 & $93.40-93.38$ & & Icl & Square 20, Level 51 & WL92-235 & Sediment & N/A & Humic acids & 0.2546 & 0.0020 & 10,990 & 70 \\
\hline CAMS-19487 & 93.49-93.46 & & Icl & Square 20, Level 50 & WL92-234 & Sediment & N/A & Humic acids & 0.2652 & 0.0056 & 10,660 & 170 \\
\hline CAMS-19488 & 93:86-93.84 & & $\mathrm{Icl} / / \mathrm{si}-\mathrm{c}$ & Square 20, Level 46 & WL92-231 & Sediment & N/A & Humic acids & 0.3134 & 0.0022 & 9,320 & 60 \\
\hline CAMS-19489 & 93.93-93.91 & & $\mathrm{Icl} / / \mathrm{si}-\mathrm{c}$ & Square 20, Level 45 & WL92-230 & Sediment & N/A & Humic acids & 0.2785 & 0.0025 & 10,270 & 80 \\
\hline CAMS-19490 & 94.01-93.99 & & $\mathrm{Icl} / / \mathrm{si}-\mathrm{c}$ & Square 20, Level 44 & WL92-229 & Sediment & N/A & Humic acids & 0.2780 & 0.0020 & 10,280 & 60 \\
\hline CAMS-19492 & 93.97-93.95 & & Icl & Square 20, Level 45 & WL92-230 & Sediment & N/A & Humic acids & 0.2841 & 0.0021 & 10,110 & 70 \\
\hline CAMS-19493 & $93.77-93.75$ & & Icl & Square 20, Level 47 & WL92-232 & Sediment & N/A & Humic acids & 0.2700 & 0.0022 & 10,520 & 70 \\
\hline ETH-14115* & $96.77-96.67$ & BRM-2 & IIIc-base & W0/N8 Level 8 & CH-925 & Bulb & Wild hyacinth & Pretreated charcoal & * & $*$ & 3,780 & 70 \\
\hline Tx-4784a & 95.49 & & II & E24/S78, Level 21a-b & CH-1311 & Charcoal & Unknown & Pretreated charcoal & * & * & 8,820 & 120 \\
\hline Tx-4784b & 95.49 & & II & E24/S78, Level 21a-b & CH-1311 & Charcoal & Unknown & Humic acids & * & * & 8,940 & 100 \\
\hline$T x-4784 c$ & 95.49 & & II & E24/S78, Level 21a-b & CH-1311 & Charcoal & Unknown & Humic acids & * & * & 8,860 & 150 \\
\hline Tx-4787 & 94.29-94.24 & Burial 2 & Isi//cl//si-c & E20/S74, Level 32 & None & Burial Pit Sediment & $\mathrm{N} / \mathrm{A}$ & Decalcified sediment & * & * & 9,470 & 170 \\
\hline Tx-4793 & ca. $94.31-94.11$ & Burial 2 & Isi//cl//si-c & E20/S74, Level 32 & None & Burial Pit Sediment & N/A & Decalcified sediment & $*$ & $*$ & 9,650 & 124 \\
\hline Tx-4798 & $96.58-96.43$ & 19 & $\mathrm{X}$ & E22/S90, Level 17 & None & Charcoal & Unknown & Pretreated charcoal & * & * & 7,470 & 230 \\
\hline Tx-4828 & $94.79-94.64$ & 165 & Isi-c/II & E26/S72, Level 27a-b & None & Tree stump & Live oak & Pretreated charcoal & * & * & 9,530 & 88 \\
\hline
\end{tabular}


(INSTAAR) Laboratory for AMS Radiocarbon Research, Boulder, Colorado.

\section{DEVELOPMENT OF THE CHRONOSTRATIGRAPHY}

Developing an accurate chronological framework for geological and archeological events at the Wilson-Leonard site was complicated by sedimentological, stratigraphic, and geochemical circumstances. Intact charcoal was rare, and it was commonly silt-sized carbon dispersed within burned rock features. Pervasive, postdepositional oxidation either adversely altered samples such as bone and shell, or it destroyed wood and more-perishable organic materials. Finally, poorly differentiated stratigraphic contacts, combined with pervasive bioturbation, yielded strata that were difficult to correlate laterally (see Chapter 6).

The approach for developing a radiocarbon chronology was to test stratigraphically the accuracy of ${ }^{14} \mathrm{C}$ dates on as many carbon sources as possible. Materials used for dating included (1) small charred plant macrofossils (wild hyacinth bulbs, nutshell, and wood charcoal) collected mostly from features; (2) carbonized, in situ tree stumps; (3) disseminated, silt-sized charcoal dispersed within interstitial sediments of burned rock features; (4) pedogenic organic carbon in buried, cumulic soil A-horizons; (5) primary, aquatic plant-derived carbon from cienega muds; (6) human and animal bone; and (7) terrestrial gastropods. The accuracy of dates on these sample types depends upon the material's geochemical origin, susceptibility to postdepositional alteration, and stratigraphic displacement after deposition.

Charcoal and carbonized macroflora have the least susceptibility to diagenetic chemical alteration and are easily pretreated chemically to remove secondary humate contamination. However, unless charcoal samples are physically large ( $>2-4 \mathrm{~mm}$ ), they are susceptible to vertical dislocation by bioturbation. AMS ${ }^{14} \mathrm{C}$ technology enables dating of milligram-sized charcoal fragments, but physical dislocation of small charcoal fragments may negate the value of this strategy. Carbonate samples such as snails can be dislocated physically, but their dominant dating problems are from reservoir effects caused by the animal's diet (Goodfriend and Hood 1983; Goodfriend and Stipp 1983) and postdepositional exchange of their carbonate with exogenous geologic carbonate.

Soil organic matter yields an average radiocarbon age for pedogenesis unless the A-horizon is accreting rapidly. Bioturbation further mixes different ages of carbon into the soil. These effects are partially compensated for by dating multiple, 1- to 2-cm-thick horizons within the soil and measuring ${ }^{14} \mathrm{C}$ in different organic chemical fractions, e.g., humates, humic acids, and humins.

Sedimentary organic carbon is also affected by postdepositional bioturbation; however, depositional environments such as cienegas contain primary, aquatic vegeta- tion-derived carbon that often retains its stratigraphic integrity. Lacustrine and marsh sediment dating is successful when multiple chemical fractions are dated from thin, closely spaced intervals from one vertical stratigraphic column.

Fine, dispersed charcoal and carbonized organic matter within hearths and other burned rock features have the combined problems of sediments, soils, and charcoal. The carbon's source is multigenetic, the carbon can migrate physically, and pedogenesis alters the carbon ${ }^{14} \mathrm{C}$ composition.

Large bones, such as Burial 2 human remains, are least likely to have moved vertically; however, their postdepositional oxidation and leaching by groundwaters diminished substantially their suitability for dating. Bone protein was extensively leached except from bone in the youngest sediments.

Carbonized tree stumps in growth position were the most reliable material for dating because the tree remains were large, in situ, and the carbon could be treated chemically to remove humate contamination. Establishing the tree's exact living (germination) surface within the sediments was the only uncertainty.

Each of the seven possible carbon sources for ${ }^{14} \mathrm{C}$ dating has inherent limits and strengths over other materials. The chronology developed for the Wilson-Leonard site is based on a thorough understanding of the limitations of each sample and how dating accuracy depends upon the sample's sediment matrix, its susceptibility for chemical alteration, and how dates compare stratigraphically. These circumstances are not unique to this site. Many sites in Texas and throughout the arid and semiarid southwestern United States share all or some of the limitations and possibilities for ${ }^{14} \mathrm{C}$ dating discussed here. It follows that establishing accurate chronologies for such sites requires all sample types be considered instead of restricting the chronology to dates on wood and charcoal.

\section{METHODS}

\section{Field Methods}

Samples collected during the 1982-1984 field seasons were evaluated and stratigraphically relocated before dating in 1995 . The previously excavated TxDOT samples included six charred tree stumps, nine charred wild hyacinth (Camassia scilloides) bulbs, one walnut shell, and two wood charcoal samples.

Samples dated from the 1992-1993 field season were collected by TARL excavators, the author, or both during the TARL fieldwork. Carbon samples collected during the recent TARL excavations were located to $\pm 1 \mathrm{~cm}$ within XYZ coordinates; their relative stratigraphic positions are plotted schematically on cross section Figure 25-1. Samples collected in situ by the author (Features 181 and 245, the Leanne soil, and Unit Icl sediments) were removed from 


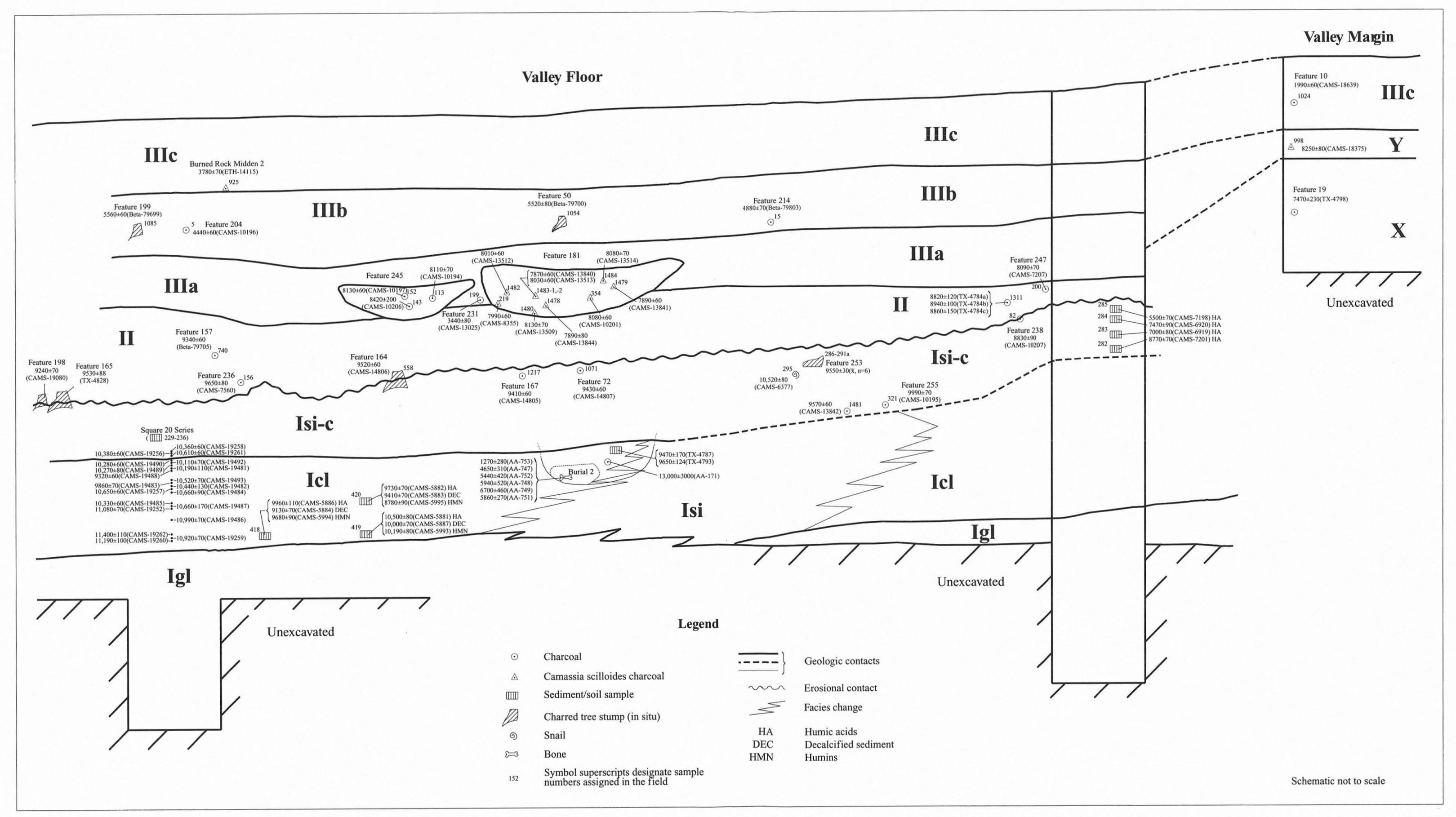

FIGURE 25-1. Schematic profile showing relative stratigraphic positions of radiocarbon samples. 
vertical stratigraphic sections and were fully documented as well as recorded photographically. No ex situ carbon, for example, screen-derived charcoal, was dated from either the TARL or the TxDOT excavations.

Because stratigraphic separation of natural units and their cultural content was better in the valley fill than along the valley margin, sampling for ${ }^{14} \mathrm{C}$ dating primarily focused on exposures in the valley fill. Also, the early fluvial deposits were found only in the valley floor part of the site.

\section{Laboratory Methods}

\section{Chemical Pretreatment of Samples}

The laboratory methods include chemical pretreatment to remove exogenous carbon contaminants, combustion or hydrolysis of the sample and purification of its $\mathrm{CO}_{2}$, and conversion of the $\mathrm{CO}_{2}$ into graphite. Depending upon a sample's geologic age and its carbon content, the optimum amount of pretreated carbon needed for AMS ${ }^{14} \mathrm{C}$ dating is 0.5 to $2 \mathrm{mg}$, which can require processing 1 to $20 \mathrm{mg}$ of charcoal, 12 to $100 \mathrm{mg}$ of shell carbonate, 0.1 to $2 \mathrm{~g}$ of bone, and 1 to $10 \mathrm{~g}$ of soil or sediment.

Four factors determine the size of a sample needed for radiocarbon dating. These are (1) each sample's characteristic carbon content, e.g., $>95 \%$ in charcoal, $12 \%$ in calcite, about $8 \%$ organic carbon in bone, and $0.5-20 \%$ in soils and sediments; (2) the amount of carbon remaining in the sample after burial and diagenesis; (3) the percent carbon remaining after rigorous chemical pretreatment in the laboratory; and (4) the sample's absolute geologic age.

\section{Charcoal Pretreatment}

Charcoal samples were pretreated to remove rootlets, secondary carbonate (predominately $\mathrm{CaCO}_{3}$ ), occluded sediment, and exogenous humates (humic and fulvic acids). At the INSTAAR AMS Laboratory, charcoal pretreatment is automated to standardize the procedures and improve yields (Bradley and Stafford 1995). Approximately 2 to $20 \mathrm{mg}$ of charcoal were weighed into Pyrex tubes through which $0.5 \mathrm{~N}$ $\mathrm{HCl}, 0.5 \% \mathrm{KOH}$, deionized $\mathrm{H}_{2} \mathrm{O}$, and $\mathrm{pH} 1 \mathrm{H}_{2} \mathrm{O}$ flowed under computer control. Acid decalcification of charcoal removes $\mathrm{CaCO}_{3}$, which comprises two important contaminates $-\mathrm{Ca}^{+2}$, which complexes humates and retards their removal during $\mathrm{KOH}$ pretreatment, and the carbonate ion $\left(\mathrm{CO}_{3}^{-2}\right)$, which contributes foreign carbon derived from groundwater and enclosing sediments.

Following $\mathrm{HCl}$ decalcification, at least three cycles of $0.5 \% \mathrm{KOH}$ were used to remove humates, which produce solutions ranging from clear or pale yellow, to opaque and very dark brown, depending on humate content. Finegrained $(<500 \mu \mathrm{m})$, incompletely carbonized charcoal is very soluble in $\mathrm{KOH}$. Because it is impossible to determine from a solution's color when humate removal ceases and sample disintegration begins, $\mathrm{KOH}$ extraction continued until the solution was clear and colorless. Although hydroxide extraction can be terminated to avoid total sample loss and retain some carbon for dating, exogenous humates can remain and yield incorrect radiocarbon ages. If $100 \%$ dissolution occurred during $\mathrm{KOH}$ extraction, the sample was designated not datable.

\section{Mollusk Shell Pretreatment}

Gastropod samples were pretreated physically by removing adhering sediment, then broken open to remove occluded sediment. Only the thick, innermost whorl was retained for further processing. Approximately $50-100 \mathrm{mg}$ of clean shell were leached at room conditions with $0.2 \mathrm{~N} \mathrm{HCl}$ to remove $50 \%$ of the initial mass. Preliminary acid leaching removes surficial, diagenetic carbonate. The acid-etched shell was reacted with $95 \% \mathrm{H}_{3} \mathrm{PO}_{4}$ in vacuo to remove another $10 \%$ of the shell's mass. The final hydrolysis in $\mathrm{H}_{3} \mathrm{PO}_{4}$ dissolved the shell completely, and the $\mathrm{CO}_{2}$ was purified for graphitization.

\section{Sediment and Soil Pretreatment}

Sediment and soil samples were freeze dried (lyophilized), then sieved through $63 \mu \mathrm{m}$ stainless steel screen to remove rootlets and clastic detritus. Approximately 1 to $5 \mathrm{~g}$ of the $<63-\mu \mathrm{m}$-sized fraction were decalcified at room temperature with $1 \mathrm{~N} \mathrm{HCl}$. The acid-insoluble residue was washed to neutrality with deionized $\mathrm{H}_{2} \mathrm{O}$ and freeze dried. This first, decalcified fraction was radiocarbon dated as "decalcified sediment" or "decalcified soil." The humic acid and humin fractions were isolated by extracting the decalcified sediment or soil with $0.5 \% \mathrm{KOH}$ at room temperature, thereby separating the base-soluble humic acids from baseinsoluble humins. The $\mathrm{KOH}$-soluble phase is usually opaque, dark brown to dark reddish brown and contains humic acids and fulvic acids. The $\mathrm{KOH}$-insoluble fraction contains the humin fraction. The $\mathrm{KOH}$ solution of dissolved humates was centrifuged to remove clays and fine silts before filtering through $0.45-\mu \mathrm{m}$ Millipore Teflon filters. The solution was acidified with $6 \mathrm{~N} \mathrm{HCl}$ to precipitate humic acids; the smaller-molecular-weight fulvic acids remained in solution. The humins and humic acids were washed with $\mathrm{pH} 1 \mathrm{H}_{2} \mathrm{O}$ and freeze dried. Approximately 100 to $200 \mathrm{mg}$ of decalcified sediment or soil, 20 to $50 \mathrm{mg}$ of humins, and 5 to $15 \mathrm{mg}$ of humic acids were combusted for radiocarbon dating.

\section{Bone Pretreatment}

Bone was examined twice for radiocarbon dating, first during the 1982-1984 fieldwork and again in 1995. The first bone dating was performed in 1983 on the Burial 2 human skeleton and those data were summarized in a date list 
published in 1987 (Stafford et al. 1987). The chemical pretreatments used on this skeletal bone drastically differed from methods developed later (Stafford et al. 1991). Also, in the decade following the original dating of the Burial $2 \mathrm{hu}-$ man bone, better understanding of fossil bone chemistry indicates that the Burial 2 human bone would be considered unsuitable for radiocarbon dating because the bone's protein content is unacceptable for accurate AMS ${ }^{14} \mathrm{C}$ dating (Stafford 1990; Stafford et al. 1991). The second examination of Wilson-Leonard bone for possible radiocarbon dating is summarized in Table 25-2, a tabulation of each bone's quantitative amino acid analyses - the definitive analysis for determining whether or not a bone is suitable for accurate radiocarbon measurement.

In 1983, Burial 2 bone was pretreated as described by Stafford et al. (1987). After initial physical cleaning, $26 \mathrm{~g}$ of powdered human bone were decalcified in $4^{\circ} \mathrm{C}, 0.2 \mathrm{~N} \mathrm{HCl}$ over 4-5 days. The $\mathrm{HCl}$ soluble fraction, " $\mathrm{HCl}$ soluble carbon," was evaporated to dryness in a rotary evaporator. After freeze drying, the weak-acid-insoluble protein was dissolved in $\mathrm{pH} 2 \mathrm{H}_{2} \mathrm{O}$ at $110^{\circ} \mathrm{C}$. The soluble phase of the hot water fraction was dated as "gelatin" and the hot water insoluble material was dated as " $\mathrm{H}_{2} \mathrm{O}$ insoluble carbon." The bone apatite fraction was dated by first extracting $5 \mathrm{~g}$ of bone powder with $1 M$ acetic acid in vacuo to remove secondary carbonate. The resulting bone powder was reacted in vacuo with $\mathrm{HCl}$ to release bone apatite $\mathrm{CO}_{2}$.

\section{Combustion of Pretreated Samples}

After chemical pretreatment and isolation of specific chemical fractions, samples were combusted or hydrolyzed,

TABLE 25-2

Quantitative Amino Acid Analyses (AAA- ) of Human Bone from Burial 2, and Cortical Bone from Different Stratigraphic Levels

\begin{tabular}{|c|c|c|c|c|c|c|c|c|c|c|c|}
\hline & \begin{tabular}{|l} 
Cow \\
Bone
\end{tabular} & $\begin{array}{l}\text { AAA- } \\
837\end{array}$ & $\begin{array}{l}\text { AAA- } \\
838\end{array}$ & $\begin{array}{l}\text { AAA- } \\
834\end{array}$ & $\begin{array}{l}\text { AAA- } \\
840\end{array}$ & $\begin{array}{l}\text { AAA- } \\
836\end{array}$ & $\begin{array}{l}\text { AAA- } \\
833\end{array}$ & $\begin{array}{l}\text { AAA- } \\
826\end{array}$ & $\begin{array}{c}\text { AAA- } \\
839\end{array}$ & $\begin{array}{l}\text { AAA- } \\
827\end{array}$ & $\begin{array}{c}\text { AAA- } \\
835\end{array}$ \\
\hline & \multicolumn{11}{|c|}{ Estimated Age (Years) } \\
\hline & Modern & 1,500 & 4,000 & 4,500 & 8,000 & 9,000 & 9,700 & 10,000 & 10,700 & 11,000 & 11,000 \\
\hline & - & $\begin{array}{c}\text { IIIc } \\
\text { (Upper) }\end{array}$ & $\begin{array}{l}\text { IIIb, IIIc } \\
\text { Contact }\end{array}$ & $\begin{array}{c}\text { IIIb } \\
\text { Upper }\end{array}$ & IIIa & II & Isi-c & $\begin{array}{l}\text { Isi, Isi-c } \\
\text { Contact }\end{array}$ & Icl & $\begin{array}{c}\text { Isi, Icl } \\
\text { Contact }\end{array}$ & $\begin{array}{l}\text { Isi-c, Icl } \\
\text { Contact }\end{array}$ \\
\hline Hydroxyproline & 93 & 94 & 95 & 91 & 0 & 84 & 58 & 0 & 0 & 64 & 81 \\
\hline Aspartic acid & 50 & 58 & 55 & 73 & 221 & 72 & 142 & 229 & 132 & 157 & 92 \\
\hline Threonine & 19 & 22 & 20 & 20 & 20 & 20 & 23 & 30 & 0 & 13 & 22 \\
\hline Serine & 33 & 30 & 28 & 27 & 20 & 24 & 33 & 31 & 0 & 55 & 29 \\
\hline Glutamic acid & 79 & 84 & 85 & 96 & 172 & 96 & 117 & 136 & 44 & 104 & 105 \\
\hline Proline & 115 & 116 & 120 & 113 & 56 & 111 & 83 & 10 & 0 & 31 & 94 \\
\hline Glycine & 327 & 314 & 324 & 319 & 199 & 304 & 280 & 203 & 305 & 188 & 303 \\
\hline Alanine & 113 & 108 & 111 & 113 & 86 & 118 & 103 & 85 & 150 & 87 & 115 \\
\hline Valine & 20 & 26 & 26 & 27 & 60 & 32 & 39 & 61 & 95 & 60 & 33 \\
\hline Methionine & 11 & 0 & 0 & 8 & 0 & 0 & 0 & 0 & 0 & 0 & 0 \\
\hline Isoleucine & 14 & 14 & 15 & 13 & 37 & 16 & 20 & 38 & 34 & 27 & 19 \\
\hline Leucine & 31 & 31 & 28 & 25 & 60 & 29 & 30 & 50 & 49 & 53 & 30 \\
\hline Tyrocine & 6 & 5 & 2 & 1 & 6 & 0 & 3 & 8 & 11 & 5 & 1 \\
\hline Phenylalanine & 14 & 15 & 13 & 12 & 12 & 14 & 10 & 21 & 33 & 34 & 9 \\
\hline Histidine & 8 & 4 & 3 & 2 & 8 & 3 & 6 & 25 & 41 & 26 & 5 \\
\hline Hydroxylysine & 8 & 7 & 6 & 5 & 0 & 3 & 0 & 0 & 0 & 0 & 4 \\
\hline Lysine & 28 & 22 & 22 & 20 & 38 & 33 & 38 & 47 & 65 & 47 & 21 \\
\hline Arginnine & 31 & 48 & 46 & 36 & 7 & 41 & 14 & 24 & 41 & 48 & 38 \\
\hline Nanomoles of amino & & & & & & & & & & & \\
\hline acids per $\mathrm{mg}$ of bone & 2,170 & 844 & 391 & 50 & 7 & 30 & 7 & 3 & 1 & 2 & 12 \\
\hline$\%$ Modern & 100 & 38.90 & 18.00 & 2.30 & 0.30 & 1.40 & 0.60 & 0.10 & 0.05 & 0.10 & 0.40 \\
\hline Datable & Yes & Yes & Yes & No & No & No & No & No & No & No & No \\
\hline
\end{tabular}

Note: The geologic age ("estimated age, yr.") is a very approximate estimate based on the fossils' stratigraphic position. The values for each amino acid are expressed as residues of each amino acid per 1,000 total amino acids (R/1,000). The value "Nanomoles of amino acids per mg of bone" is the bone's total amino acid content, derived almost exclusively from the bone protein,

"\% Modern" is the percentage of amino acids (approximately collagen) remaining in the fossil bone relative to modern bone; the percentage is calculated by dividing "total nm AA's" by $2,170 \mathrm{~nm}$. The term "Datable" refers to whether or not that bone, with the indicated amino acid composition, should be used for radiocarbon dating. 
and the $\mathrm{CO}_{2}$ was converted into graphite. Samples for combustion were transferred into $820^{\circ} \mathrm{C}$ pretreated, 6-mm O.D. quartz tubes containing $0.5 \mathrm{~g}$ of $\mathrm{CuO}$ wire, $0.2 \mathrm{~g}$ of $\mathrm{Cu}$ granules and $0.1 \mathrm{mg} \mathrm{Ag}$ powder. The tubes were evacuated to $\leq 1$ millitorr on a liquid nitrogen-trapped vacuum line, sealed with a gas torch and combusted for three hours at $820^{\circ} \mathrm{C}$. The tubes were cooled from $820^{\circ} \mathrm{C}$ to $150^{\circ} \mathrm{C}$ at $50^{\circ} \mathrm{C}$ per hour. During combustion, copper oxide yields $\mathrm{O}_{2}$ to convert organic carbon to $\mathrm{CO}_{2}$; the copper and silver reagents remove sulfur and halide $\left(\mathrm{Cl}^{-}, \mathrm{F}^{-}\right)$contamination that would inhibit subsequent $\mathrm{CO}_{2}$ graphitization. Pretreated shell carbonate was reacted with $95 \%$ phosphoric acid in vacuo to hydrolyze $\mathrm{CaCO}_{3}$ to $\mathrm{CO}_{2}$.

\section{Purification and Graphitization of $\mathrm{CO}_{2}$}

The $\mathrm{CO}_{2}$ gas was purified cryogenically and aliquots were separated for graphitization, ${ }^{13} \mathrm{C}$ analysis, and archiving. Approximately $1 \pm 0.3 \mathrm{mg}$ of carbon as $\mathrm{CO}_{2}$ was converted catalytically into graphite by a modification of the Slota et al. (1987) method. A 9-mm O.D. Pyrex tube containing $\mathrm{Zn}$ powder at the base and an inner, 6-mm O.D. Pyrex tube with $0.5 \mathrm{mg}$ of Fe powder was used for graphitization. The zinc powder was degassed under vacuum at $400^{\circ} \mathrm{C}$ before both the $\mathrm{Fe}$ and $\mathrm{Zn}$ reagents were hydrogenated 30 minute with 300 torr of $\mathrm{H}_{2}$ at $400^{\circ} \mathrm{C}$. After the catalysts were pretreated, $\mathrm{CO}_{2}$ was transferred cryogenically into the Pyrex reaction tube and the $\mathrm{Fe}$ and $\mathrm{Zn}$ reagents were heated with furnaces at $520^{\circ} \mathrm{C}$ and $450^{\circ} \mathrm{C}$, respectively. Over a 6-8-hour period, hot $\mathrm{Zn}$ converts $\mathrm{CO}_{2}$ to $\mathrm{CO}$ that reacts with $\mathrm{Fe}$ to ultimately form graphitic carbon (graphite). Graphite was packed into aluminum target holders and analyzed at the Lawrence Livermore Laboratory's Center for Accelerator Mass Spectrometry.

\section{AMS Radiocarbon Dating}

Analyses reported by the Lawrence Livermore accelerator facility are fraction modern of ${ }^{14} \mathrm{C}(\mathrm{Fm} \pm 1 \sigma)$ and ${ }^{14} \mathrm{C}$ age $\left({ }^{14} \mathrm{C} \pm 1 \sigma\right)$ corrected for the sample's $\delta^{13} \mathrm{C}$ value. Primary and secondary Modern standards were provided by INSTAAR and include National Bureau of Standards's (NBS) Oxalic acids I and II (Ox-I, Ox-II), ANU sucrose, and radiocarbon-free alanine and wood backgrounds used at INSTAAR. Modern standards and backgrounds were prepared in the same mass range $(0.02$ to $3.0 \mathrm{mg} \mathrm{C})$ as unknownage samples.

Accelerator mass spectrometry measurements were made by analyzing 60 unknown-age samples, 20 primary and secondary standards, and backgrounds in an 80 target wheel (Vogel et al. 1993). Unknown-age samples were analyzed for two minutes during each of four cycles or until approximately $0.8 \%$ measurement precision was obtained. Backgrounds for AMS measurements were determined by sample type and carbon mass and were 48,000 to 50,000 years for $>1$ $\mathrm{mg}$ of carbon derived by combustion of organic matter (Fig- ure 25-2) and 50,000 to 52,000 years for $>2 \mathrm{mg}$ of inorganic carbon from calcite (Figure 25-3). Inorganic and organic carbon are converted into $\mathrm{CO}_{2}$ by two different methods, which yield different backgrounds for each of the two carbon types. Inorganic carbon from carbonates is derived by hydrolysis with phosphoric acid, or less commonly with $\mathrm{HCl}$. Acid hydrolysis contributes less modern carbon than combustion with copper oxide and therefore theoretically older ages are attainable from carbonates than from combusted samples.

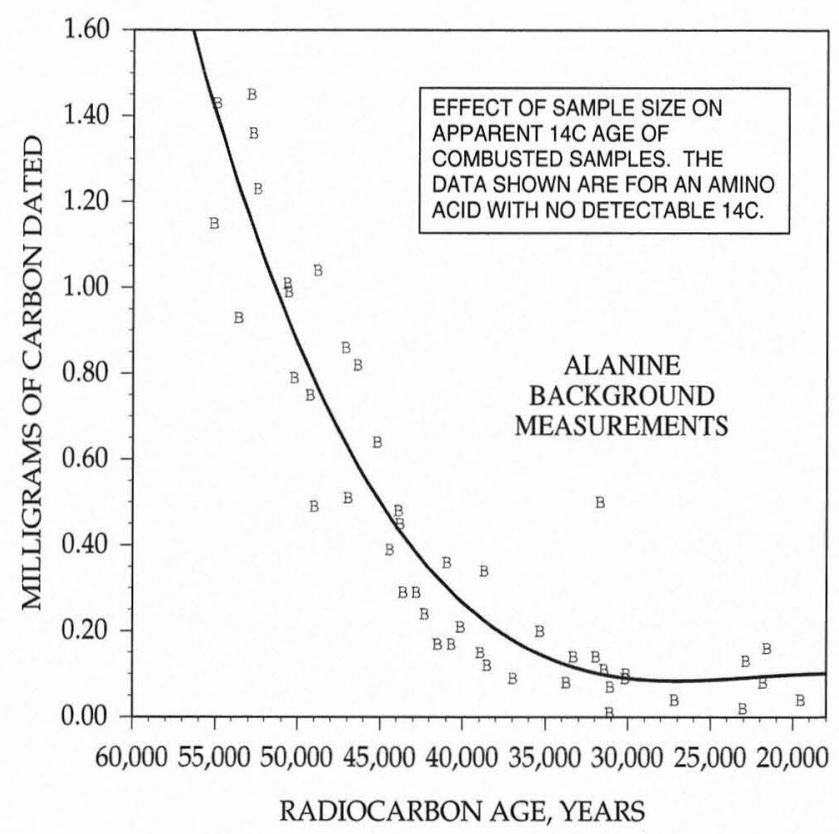

FIGURE 25-2. Comparison of apparent radiocarbon ages versus sample size for the synthetic amino acid alanine $\left(\mathrm{NH}_{2} \mathrm{CH}_{2} \mathrm{CH}_{2} \mathrm{COOH}\right)$ from Sigma Chemical Company.

Sample size establishes the maximum age attainable by ${ }^{14} \mathrm{C}$ dating. As sample carbon mass decreases, the fraction of modern carbon (Fm) increases because a relatively constant mass of modern background carbon ( 1 to $5 \mu \mathrm{g}$ ) is diluted with progressively less sample carbon. Figure 25-2 contains ${ }^{14} \mathrm{C}$ measurements on decreasing masses of Sigma Chemical Company alanine, a synthetic amino acid that contained no measurable radiocarbon and is used as an internal standard at INSTAAR. Whereas combusting large amounts of alanine ( $>8 \mathrm{mg}$ ) yielded ${ }^{14} \mathrm{C}$ ages $>50,000$ years, the oldest age theoretically possible from $20 \mu \mathrm{g}$ of alanine carbon is about 20,000 years. Because the Wilson-Leonard samples were less than 15,000 years old and they yielded at least 0.5 mg of carbon, size-controlled age constraints did not affect the Wilson-Leonard results.

\section{BIOGEOCHEMISTRY OF THE CARBON MATERIALS}

Five different sample types were used for radiocarbon dating: charcoal, bone, sediment, soil, and mollusk shell. Each material has strengths and weaknesses based on how 


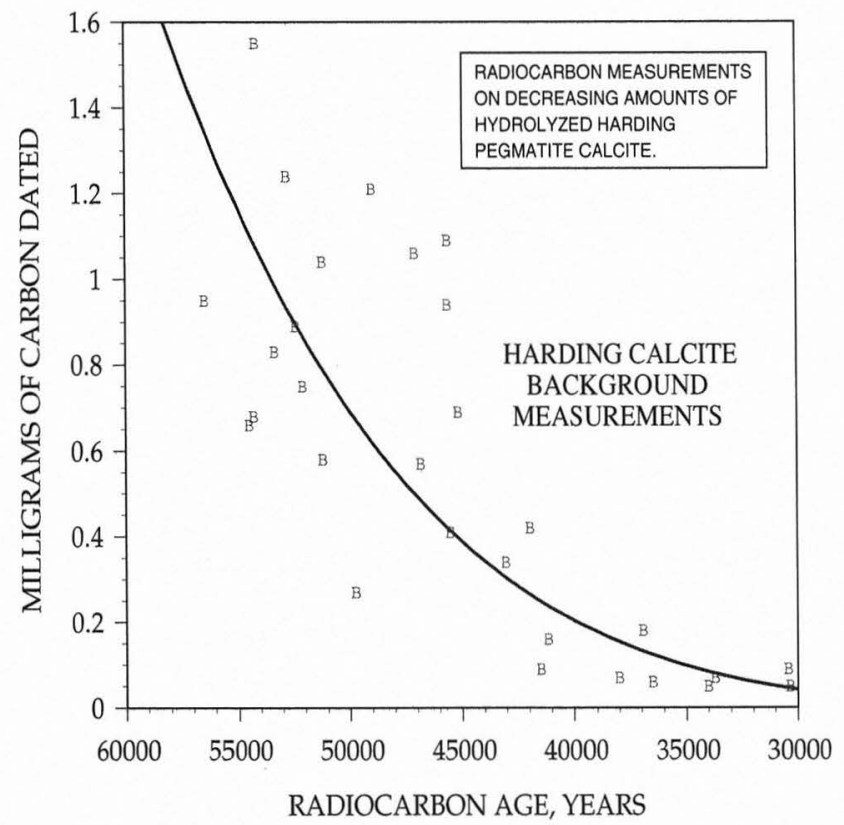

FIGURE 25-3. Comparison of apparent radiocarbon age versus sample size for $\mathrm{CO}_{2}$ derived from Harding Calcite, an optical-quality geological calcite with no detectable radiocarbon. The background for calcite is approximately 500 to 1,000 years older than for combusted organic matter because the phosphoric acid hydrolysis of calcite adds less modern carbon than does the combustion process used for organic carbon.

its carbon was fixed biologically and subsequently modified by chemical and physical processes after deposition. The following sections outline the inherent biogeochemical characteristics of each sample material and how they affect radiocarbon accuracy.

\section{Sample Types}

\section{Carbonized Plant Remains}

Carbonized plant remains, often from archeological contexts, are used typically for developing radiocarbon chronologies. The benefits of using charred organic matter are that charcoal is very inert chemically and secondary physical contaminants (e.g., modern rootlets) and chemical contaminants (humates) can be removed by adequate pretreatment; plant remains often provide paleoenvironmental data when identified to genus; and charcoals are often from welldefined stratigraphic contexts-cultural features or in situ trees. Problems with conventional radiocarbon dates on charcoal are usually resolvable and include stratigraphic correlation errors, redeposition of older charcoal, human use of old wood, or pervasive bioturbation.

AMS technology enables dating of samples at least one thousand times smaller than those required for conventional radiocarbon methods. A few milligrams of charcoal, individual macrofloral remains, or individual tree rings are datable by AMS; however, using small samples necessi- tates greater vigilance when collecting samples and interpreting the results. First, bioturbation effects are magnified because processes that would not affect centimeter and larger fragments will readily move millimeter-diameter charcoal. Verifying a sample's stratigraphic position is the most important consideration when AMS dating small charcoal fragments. Second, 50 - to $1,000-\mu \mathrm{m}$-diameter charcoal is often poorly carbonized and is very soluble in $\mathrm{KOH}$ during pretreatment. Consequently, samples ostensibly large enough for AMS dating may yield too little carbon for analysis, or their ages will have $2-10 \%$ standard errors because there was less than 200-300 $\mu \mathrm{g}$ of carbon.

\section{Macroscopic Charcoal}

Macroscopic, anthropogenic charcoal larger than $5 \mathrm{~mm}$ was rare at Wilson-Leonard despite abundant archeological evidence for human occupation over the last 11,000 years or more. Charcoal is rare, because the site's alluvial and colluvial environments were not conducive to charcoal's physical preservation (see discussions in Chapters 6 and 40). Fluvial environments were not conducive to charcoal accumulation and the cienega areas would have been unfavorable for habitation except along their margins. The colluvial strata at Wilson-Leonard were deposited by sporadic sedimentation that was unfavorable to preserving in situ charcoal.

\section{Charred Tree Stumps}

The largest and most stratigraphically reliable charcoal was from seven tree stumps that had burned in situ. These fossil trees (five live oaks, one red mulberry, and one unidentified species) gave the most reliable age estimates for land surfaces because the trees' growth positions could be closely approximated. Some of the live oaks may have been killed (smothered) when colluvial or flood plain sediments covered their root systems. The stumps may have burned after the tree's death, but when the tree was still at or near its original growth position. There were three stratigraphic occurrences of charred tree stumps: two stumps in Unit IIIb, three stumps in lower Unit II, and two at or near the top of Unit I. Because two sets of dates were within one standard deviation, the stumps may represent wooded landscapes where several trees burned — once at ca. 9500 B.P. and again at ca. 5500 B.P.

It was more difficult to reconstruct original growth surfaces for isolated, charred tree roots that were not traceable to tree stumps. For example, ${ }^{14} \mathrm{C}$ dates were obtained on charcoal from an extensive burned root mass in Unit Isi-c (collected as Feature 72 and Feature 167), but the radiocarbon ages (9430 \pm 60 [CAMS-14807] and $9410 \pm 60$ [CAMS$14805]$ ), respectively, suggest that the germination surface of the trees was actually at a higher elevation in Unit II. These two samples are particularly significant as the root mass from which they were collected extends over Burial 2 
with no indication that the burial pit was dug through the root mass. By superposition, the stratigraphic position of the root mass gives a direct, minimum age of ca. 9400 B.P. for Burial 2.

\section{Macroflora}

Samples with the next best stratigraphic control were charred macroflora-seven carbonized bulbs of wild hyacinth (Camassia scilloides) from the Feature 181 burned rock oven in Unit IIIa. The oven's interlocking matrix of limestone cobbles and sediment prevented the tubers from being dislocated vertically by bioturbation. The age similarity of the Camassia radiocarbon dates suggests that the bulbs were from a single archeological event and that their physical locations were stratigraphically intact.

\section{Fine-grained Charcoal}

In contrast to the charred tree stumps and individual fragments of coarse charcoal were fine-grained $(<100-200$ $\mu \mathrm{m}$ ) disseminated charcoal and carbonized plant remains that were dispersed throughout Feature 245, another burned rock oven found in Unit IIIa. The fine-grained carbonaceous sediment within the oven was not dated because vertical dislocation was likely. Physically pretreating the oven's millimeter-sized charcoal was largely unsuccessful because 80 to $100 \%$ of the sample dissolved during the $\mathrm{KOH}$ pretreatment. Dissolution in $\mathrm{KOH}$ indicates incomplete carbon reduction and carbon yields that can be too small for even AMS techniques. Although the acid-base pretreatment can be terminated to retain sufficient carbon for dating, humates can remain and the sample will date younger than its actual age. Dating the $\mathrm{KOH}$ soluble fraction is not tenable because it is unknown what percentage of the charcoal "humates" is original and what fraction is foreign pedogenic contamination.

Except for the charred tree stumps and Camassia bulbs, charcoal preservation was very poor. Many individual occurrences of small ( $<3 \mathrm{~mm}$ diameter) charcoal were not selected for dating because their stratigraphic position was not $100 \%$ certain. Although the fragments could have been the last remnants of a small hearth, the charcoal was small enough to have been dislocated vertically by burrowing animals, including earthworms (see Chapter 29). Avoiding these small, poorly documented samples undoubtedly prevented many spurious ages from being measured.

\section{Gastropod Radiocarbon Ages}

The carbonate fractions of modern and fossil gastropods were dated to establish potential reservoir corrections for modern specimens and for absolute age estimates in Unit I. Two problems are encountered when dating gastropod inorganic carbon. First, the snail can ingest geologically old carbon from limestone substrates, yielding shell carbonate that is depleted in ${ }^{14} \mathrm{C}$ relative to the contemporaneous atmosphere (Goodfriend and Hood 1983; Goodfriend and Stripp 1983). Apparent radiocarbon ages for living snails can range from Modern to $>2,000$ years. Second, a gastropod's carbonate can exchange with groundwater-borne carbonate after burial. Secondary carbonate exchange usually causes gastropod ages to become older than expected; however, shell carbonate ages can become younger if waters contain more recent, atmospherically derived dissolved $\mathrm{CO}_{2}$.

\section{Bone Radiocarbon Ages}

Direct dates on fossil bone would have resolved several chronological problems, including the absolute age of Burial 2 and the Bison in the Early Paleoindian bone bed. Direct dating of bone eliminates the uncertainty inherent in dates on associated charcoal or ages based on stratigraphic correlation. However, the very poor chemical preservation of bone organic matter at Wilson-Leonard precluded dating bone older than an estimated 4,000 years. Because approximately 4,000 radiocarbon years were represented by $<70 \mathrm{~cm}$ of Unit IIIc sediment and the bones were unidentifiable cortical fragments, dating these bone fragments was not justified.

Quantitative amino acid analyses were used to assess the amount of protein remaining in bone and whether or not the bone was datable. The two most common methods for assaying a bone's protein composition are quantitative amino acid analysis and carbon-hydrogen-nitrogen ( $\mathrm{CHN}$ ) analysis. A CHN analysis is less definitive than an amino acid analysis because CHN measures total carbon, hydrogen, and nitrogen; the analysis does not distinguish amino acid derived $\mathrm{C}$ and $\mathrm{N}$ from inorganic species such as inorganic carbon from carbonate $\left(\mathrm{CO}_{3}^{-2}\right)$ and inorganic nitrogen in nitrate or ammonia. Amino acid analysis is a definitive measure of bone protein content because the exact nanomole $\left(10^{-9}\right.$ mole $)$ quantity of each amino acid is determined per milligram of bone. Nonamino acid nitrogen, from nitrates and ammonia and carbonate carbon are not measured by the amino acid analysis.

Table 25-2 compiles amino acid analyses from WilsonLeonard fossil bones and compares those values against modern bone samples. The most important data from Table 25-2 are the nanomoles ( $\mathrm{nm}$ ) of amino acids per milligram of bone (nm AA's/mg bone), the bone's percent of preserved protein relative to modern bone, and the proportional ratios for the five most diagnostic amino acids in collagen: hydroxyproline (HYP), aspartic acid (ASP), glutamic acid (GLU), proline (PRO), and glycine (GLY). The proportional ratios are reported as the number of residues (molecules) of amino acids per thousand residues (R/1000) of all amino acids.

The fossil bone analyses are interpreted by comparing them to modern cow (Bos taurus) bone (AAA-578), which contained 2,170 nanomoles of amino acids per $\mathrm{mg}$ of bone. These amino acids are predominately from the bone protein 
collagen, which comprises the majority of bone's $20 \%$ organic matter. The amino acid composition for modern bone collagen is unusual in nature and is characterized by $9 \%$ hydroxyproline, $5 \%$ aspartic acid, $7 \%$ glutamic acid, 33\% glycine, and $12 \%$ proline. Hydroxyproline is rare in nature except in collagen (Stafford et al. 1991).

As bone collagen degrades chemically, total protein decreases (Figure 25-4), and the relative proportions of amino acids change predictably (Figures 25-5 and 25-6). By determining the amount of protein remaining in a bone and the amino acid spectrum of the protein, fossil bones can be ranked quantitatively for their dating suitability. Bones with less than $5 \%$ of their original collagen or with noncollagenous amino acid compositions are not datable by any present radiocarbon method (Stafford et al. 1991). A 5\% protein content is indicated by either $<0.2 \%$ nitrogen content by $\mathrm{CHN}$ analysis, or $<100$ nanomoles of amino acids per $\mathrm{mg}$ of bone. A noncollagenous amino acid composition (see Figure 25-5) is characterized by hydroxyproline decreasing to $0-5 \%$, aspartic and glutamic acids increasing two to three times of their normal $5 \%$ and $7 \%$, and glycine decreasing from $33 \%$ to $20-25 \%$; proline can decrease to zero, but more commonly decreases to $1-5 \%$ from its normal $12 \%$.

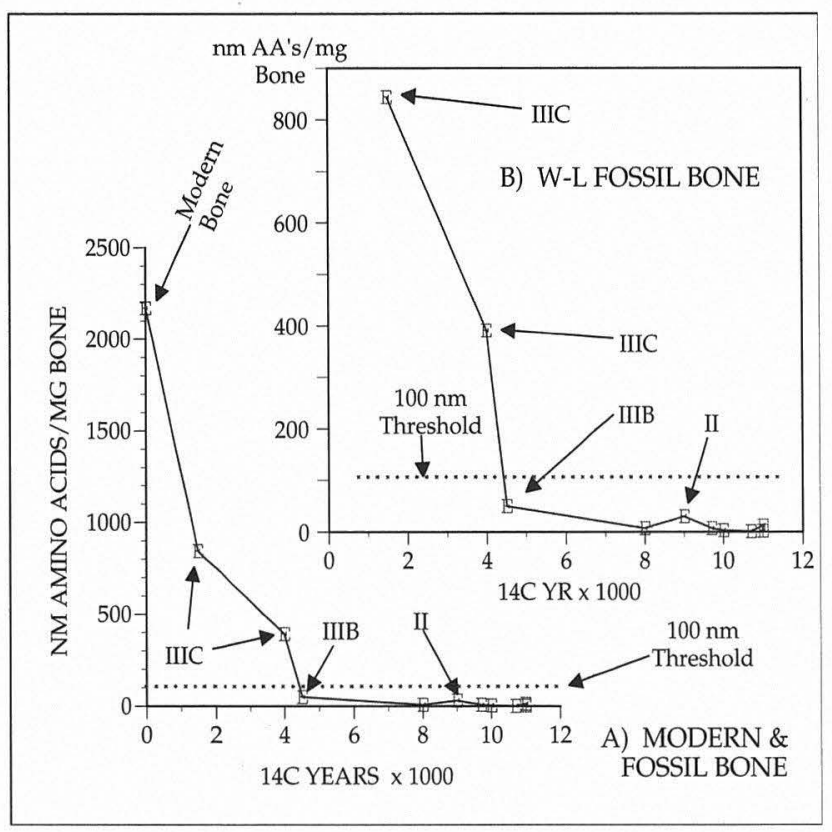

FiguRE 25-4. Change in total amino acid content of Wilson-Leonard fossil bone as a function of geologic age. Modern bone contains approximately 2,170 nanomoles of amino acids per $\mathrm{mg}$ of bone. Bones with less than about $100 \mathrm{nmAA}$ 's/mg bone are not considered datable.

Table 25-2 and Figure 25-4 indicate how total bone collagen varies with geologic age and how rapidly the bone protein was degraded and lost to oxidation and leaching processes at the Wilson-Leonard site. The degradation of Wilson-Leonard bone was caused by oxidizing waters in the

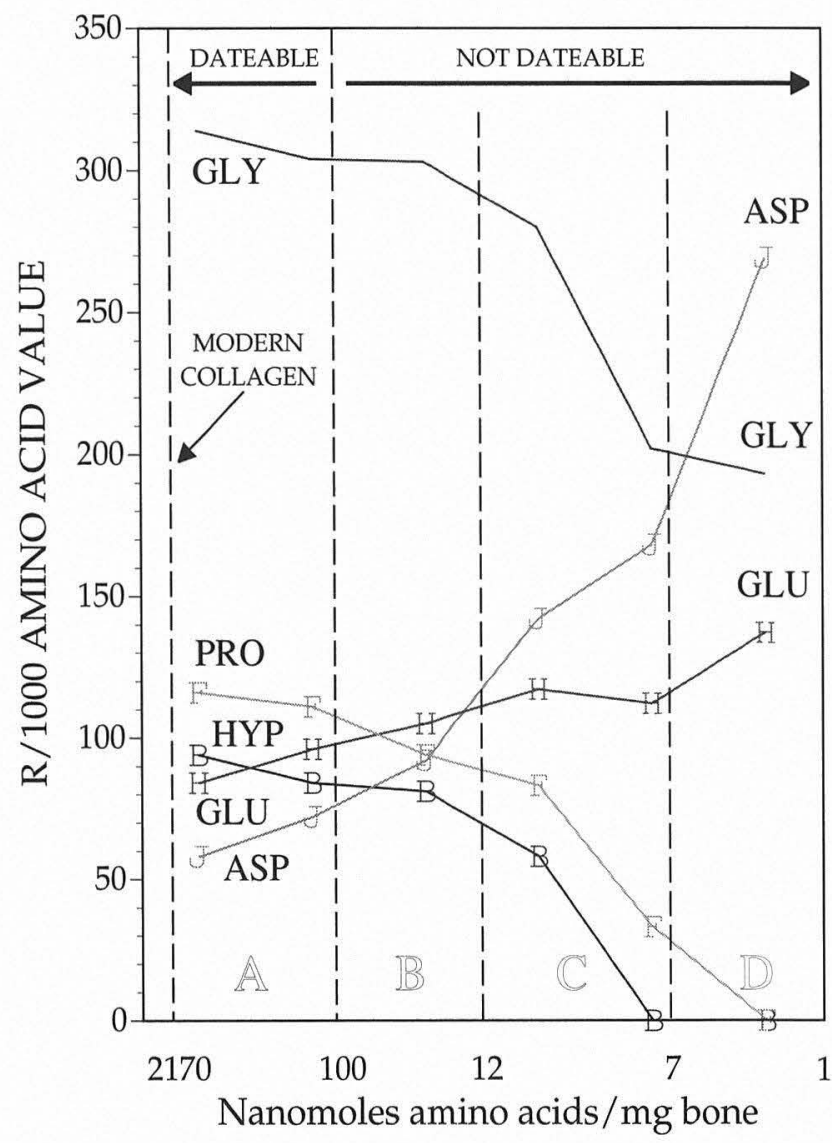

FIGURE 25-5. Proportional changes among five diagnostic amino acids in bone protein. As protein content decreases, there are predictable changes in the different amino acid ratios $(\mathrm{R} / 1,000$ values). The amino acids hydroxyproline, proline, and glycine decrease proportionally, while aspartic and glutamic acids increase relative to all other amino acids remaining in the bone. The composition within column $\mathrm{A}$ is that of collagen and all bones within this category $(2,170$ to 100 nanomoles amino acids $/ \mathrm{mg}$ of bone) are datable. Columns B, C, and D are for bones with less than $100 \mathrm{~nm}$ amino acids/mg of bone; the fossils are not considered datable, although their amino acid compositions range from collagenlike to noncollagenous.

vadose zone. Porous sediments, for example, Unit Igl sands and gravels and the colluvium of Units II and III were especially susceptible to leaching. The Unit Igl gravels contain abundant evidence of postdepositional oxidation - pyrolusite $\left(\mathrm{MnO}_{2}\right)$ and limonite coatings on the gravel clasts. The result was rapid and extensive degradation and leaching of collagen from bone in all but the geologically youngest strata.

Only two specimens, AAA-837 and AAA-838, contained sufficient collagenous protein for dating (see Table 25-2). The specimens were from the base and somewhat higher in Unit IIIc, which dates less than 4,000 years old. A third specimen, AAA-834 from upper Unit IIIb, had a collagen-like composition, that is the amino acid composition was similar to collagen and the amino acids were derived from degrading collagen; however, two significant changes 


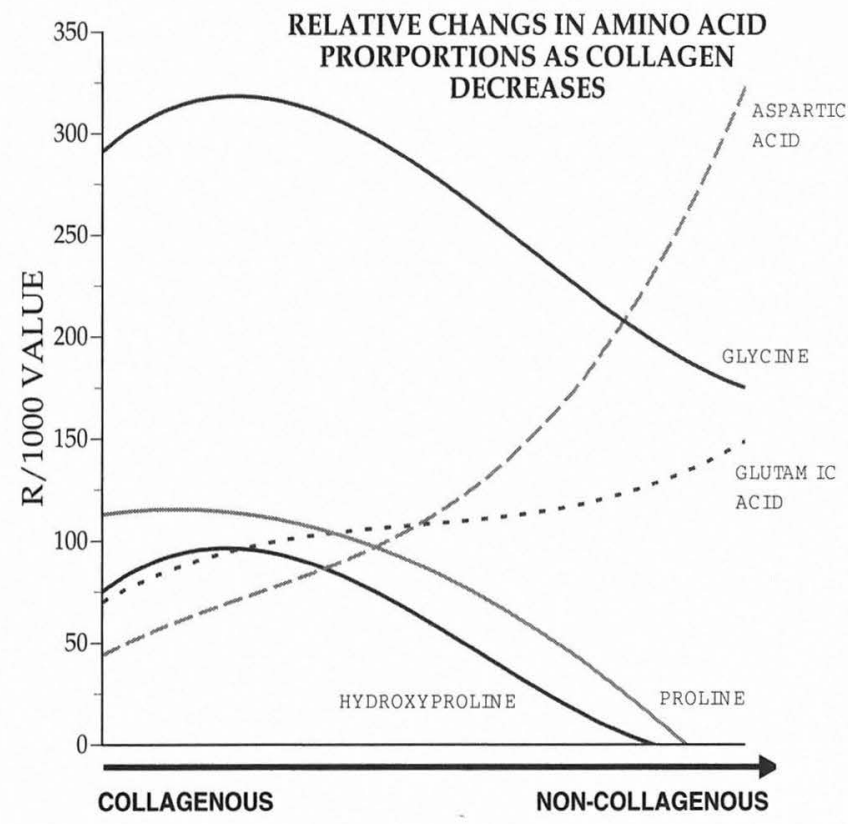

FIGURE 25-6. Summary of the relative proportional changes undergone by the five most characteristic amino acids in bone collagen. The original collagen composition eventually changes to a noncollagenous one that can reflect either the decomposition of collagen, the addition of exogenous amino acids and proteins, or a combination of both processes.

had occurred during diagenesis. First, bone sample AAA834 contained only $1.6 \%$ of its original protein. Second, amino acid analysis of the remaining organic matter indicated that the proportions of aspartic and glutamic acids had increased, although values for hydroxyproline and proline were similar to modern collagen. Increasing proportions of aspartic and glutamic acids are characteristic degradation patterns for bone diagenesis (see Figures 25-5 and 25-6). Despite the collagen-like amino acid composition, bone AAA- 834 was not datable because total protein was less than the $5 \%$ threshold. The older fossil bones have much less than $100 \mathrm{~nm}$ amino acids per mg of bone, either noncollagenous compositions, or amino acid compositions that represent significant collagen degradation.

Human bone from Burial 2 had been dated in 1983 by the author at the University of Arizona. The Burial 2 bone contained extremely small amounts of amino acids and the bone had a noncollagenous amino acid composition (see Table 25-2). The CHN composition for whole bone from Burial 2 was $4.01 \% \mathrm{C}, 0.54 \% \mathrm{H}$ and $0.09 \% \mathrm{~N}$ on cortical bone and $3.48 \% \mathrm{~N}, 0.56 \% \mathrm{C}$, and $0.06 \% \mathrm{~N}$ on cancellous bone (Stafford et al. 1987). Further evidence for severe chemical degradation of Burial 2 bone protein was the bone's behavior during chemical pretreatment. The decalcified bone yielded an amorphous, insoluble residue instead of a pseudomorph of the bone's physical structure. The gelatin fractions had none of the properties of modern collagen (Stafford et al. 1987).
Had Burial 2 been found during the 1992-1993 TARL excavations, the human bone would not have been radiocarbon dated because the bone had a noncollagenous amino acid composition and much less than $5 \%$ of its original organic matter. Those results are evidence that Burial 2 bone would not be expected to yield an accurate radiocarbon age (Stafford et al. 1991). Subsequent to the dating of Burial 2 in 1983, we have learned that no present radiocarbon technique provides accurate dates for bone having less than 5\% of its original protein content. The chemical results, combined with the low organic matter content and a noncollagenous composition, indicate that the AMS radiocarbon dates from Burial 2 are minimum ages for the human remains.

\section{Sediments and Soils}

Sediments and soils contain substantial amounts of organic carbon that can be dated with varying levels of accuracy. Sediment and soil carbon is the macromolecular- to micron-sized carbon fraction derived from plant growth and decomposition; this carbon contrasts with macroscopic plant and animals remains that are identifiable taxonomically or morphologically. Macerated plant remains, humic acids and fulvic acids, and lipids are some examples of organic carbon isolated from sediments for radiocarbon dating. Sedimentary carbon frequently yields accurate depositional ages because plant growth and its deposition were contemporaneous within a year's time span. In contrast, pedogenic carbon usually reflects an average or mean residence time for the pedogenesis because carbon is continuously mixed within and added to a soil profile. If some fundamental stratigraphic and geochemical principles are understood and applied judiciously, carbon from sediments and soils can provide valuable chronological data.

\section{Sedimentary Carbon}

Sedimentary carbon will yield depositional ages for a stratum if well-defined bedding exists; carbon fixed by photosynthesis is deposited immediately and is removed from the carbon cycle; the depositional rates are slow enough to allow good time resolution; and carbon reservoir effects are minimal or absent. At Wilson-Leonard, the only sedimentary carbon suitable for dating was from the Unit Icl cienega muds. The Unit Igl fluvial sands and gravels were not datable because those sediments contained minimal organic carbon; the colluvial sediments from Units II and III were poorly stratified and their carbon was from numerous, unidentified sources; the Isi complex of alluvial and some colluvial material contained carbon from undetermined sources.

The rationale for dating cienega clays is that the sedimentary carbon was derived largely from plants growing contemporaneously with the cienega's formation. Because 
a cienega is both a sedimentary deposit and a soil (Histosol), four geochemical processes must be understood when cienega sediments are dated.

First, marsh muds could contain particulate carbon reworked from geologically older strata within the marsh or the fluvial basin. This earlier-cycle, geologically ancient carbon, will cause cienega sediments to date older than their time of deposition.

Second, the carbon of growing plants could be out of equilibrium with atmospheric carbon if waters contained substantial amounts of ancient, limestone-derived carbonate and the cienega had a large fraction of submerged aquatic plants. The result is a "reservoir effect," where living plants have ${ }^{14} \mathrm{C}$ contents less than contemporaneous terrestrial plants. Dissolved carbonate from geological (ancient) limestone sources will have no measurable radiocarbon and will cause living aquatic plants to date "older" than plants photosynthesizing atmospheric $\mathrm{CO}_{2}$. A second mechanism for incorporating older carbon into plants is when living, aquatic plants use $\mathrm{CO}_{2}$ or bicarbonate derived from microbial digestion of preexisting plant remains. Reservoir age corrections can range from a few tens to several hundred years. Shallow, well-agitated waters will have the smallest reservoir effects because atmospheric $\mathrm{CO}_{2}$ will exchange rapidly with the limestone-derived carbon species. The reservoir effect will be substantially greater in deeper, more stagnant waters and those waters nearest to limestone-terrain spring vents.

Third, during deposition, a certain thickness of sediment is homogenized by physical and biological processes at the sediment-water interface. This time-averaging results from plant growth, bioturbation by invertebrates such as crayfish and snails, and by vertebrate animals, especially large herbivores. The thickness of sediment bioturbated during deposition depends upon the sedimentation rate, the abundance of animal activity, and whether the depositional site was in the center of a cienega or near the shore where animal activity was greater. Depositional bioturbation reduces the age resolution within a stratum because a certain thickness of sediment, i.e., time interval, was homogenized physically.

Fourth, the accuracy of cienega radiocarbon dates depends upon which chemical fraction is dated. Decalcified sediment, humic acids, and humins are the fractions most commonly used (Abbott and Stafford 1996). Humic acids are usually preferred because their extraction process $(\mathrm{KOH}$ extraction, filtration, and precipitation) excludes particulate contamination by modern carbon, they are far less mobile in carbonate terrains, and they would be derived from plant decomposition occurring within the cienega during and shortly after plant growth. Decalcified sediments and humins are too heterogeneous chemically for reliable dating, and these fractions have the greatest chance to contain modern rootlet and other cellulose contamination.

\section{Soil Organic Matter}

Radiocarbon dates from soils are inherently less accurate than those from sediments because soil carbon is continually refluxed by plant growth and animal burrowing. The bioturbation homogenizes the matrix (A-horizon) and continually adds modern carbon throughout the soil's genesis. At the minimum, a soil date is an average age or "mean residence time" of the carbon accumulated during pedogenesis. However, soil radiocarbon dates approach absolute ages if the soil is weakly developed and thin, e.g., Entisols or Inceptisols, or the soil has a thick, rapidly aggrading (cumulic) A-horizon where carbon mixing is minimized. The Leanne soil (Unit Isi-c) is cumulic and was deposited over a short (ca. 500 years) time interval. Consequently, dating its organic carbon fractions could theoretically yield ages relevant to its formation.

\section{Physical and Chemical Postdepositional Alterations of Soils and Sediments}

The accuracy of soil and sediment dates is determined ultimately by the amount of postdepositional chemical and physical alteration. There are two dominant processes: bioturbation and later pedogenesis. Bioturbation by animals ranging from earthworms to gophers will mix carbon hundreds or thousands of years younger into the preexisting sediments. Postdepositional bioturbation is evident macroscopically in many sections of the Unit Icl cienega muds, and earthworm disturbance is evident in thin sections of the Burial 2 pit fill (see Chapter 29). Despite the bioturbation of Icl cienega sediments, a reliable AMS radiocarbon chronology was obtained by sampling 1-2-cm-thick sediment blocks from a single vertical section.

The most common postdepositional chemical alteration is overprinting of a stratum's indigenous carbon by later pedogenesis. Humic acids from overlying soils will be indistinguishable chemically from humic acids in the sediment or soil being dated. This chemical overprinting occurred in the Leanne soil.

Separating sedimentary processes from pedogenic ones was often problematic because no stratigraphic unit was monogenetic. Each of the three sediment or soil deposits overlapped genetically and each contained both sedimentary and pedogenic carbon. For example, the fill in the Burial 2 pit was a mixture of sediment from Unit Icl cienega muds, the Leanne soil (Unit Isi-c), and possibly charred tree stump carbon added by bioturbation. Also, the Leanne soil A-horizon contains carbon from three sources: (1) indigenous, sedimentary organic carbon in the soil C-horizon in which the Leanne soil developed; (2) eolian and anthropogenic carbon sources, which increase in volume upward and contribute to the Leanne soil's cumulic appearance; and (3) postLeanne soil carbon that was added by pedogenesis significantly postdating the Leanne soil pedogenesis. Finally, Unit 
Icl cienega carbon is multigenetic because the sediments are comprised of fluvial overbank muds, to which were added increasing amounts of colluvial and eolian silt over time and aquatic plant carbon that accumulated as a Histosol or marsh soil. Unit Icl is sedimentary because over a meter of silt and clay accumulated in 1,000 years; it is also pedogenic because much of the carbon was from marsh plants whose root systems penetrated and bioturbated older marsh deposits.

Three major chemical fractions can be dated readily from sediments: decalcified sediment, humic acids, and humins. Decalcified sediment contains the total organic carbon content of the sediment after inorganic carbonates have been removed with $\mathrm{HCl}$. Fulvic and humic acids are the $\mathrm{KOH}-$ soluble compounds extracted from the decalcified sediment and represent most of the decomposed organic matter. Humic acids are the larger molecular fraction and are the least mobile of the base-soluble isolates. The insoluble residues remaining after $\mathrm{HCl}$ and $\mathrm{KOH}$ extraction are operationally termed "humins," which are the most insoluble organic carbon residues. Humic acids were used for the final chronology for Unit Icl based on experimental and theoretical reasons. When age measurements were made on each of the three fractions from Squares 27 and 28, humic acids were the oldest fraction and presumably the one least affected by younger carbon contamination (Figures 25-7 and 25-8). Decalcified sediment and humins have the greatest chance to contain younger carbon from rootlets and other particulate carbon, while humic acids have the least possibility for containing younger carbon. Although humic acids are mobile in certain environments, calcium carbonate-rich sedimentary conditions markedly lower humate translocation by forming relatively immobile calcium complexes with humic acids.

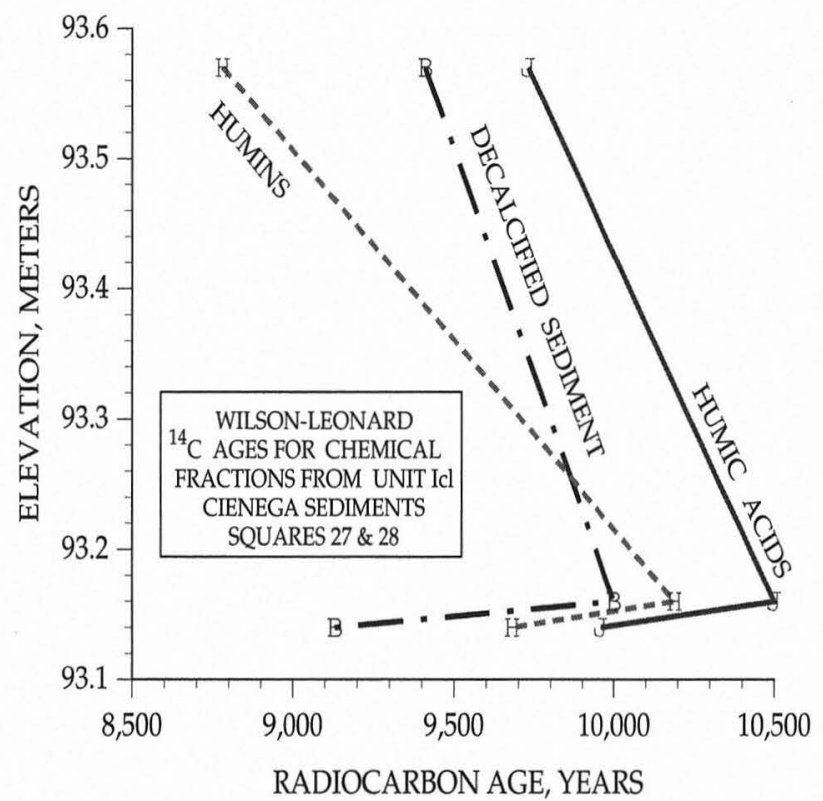

FIgURE 25-7. Radiocarbon ages for three chemical fractions (decalcified sediment, humic acids, and humins) isolated from the Unit Icl cienega sediment collected in Squares 27 and 28, south wall.

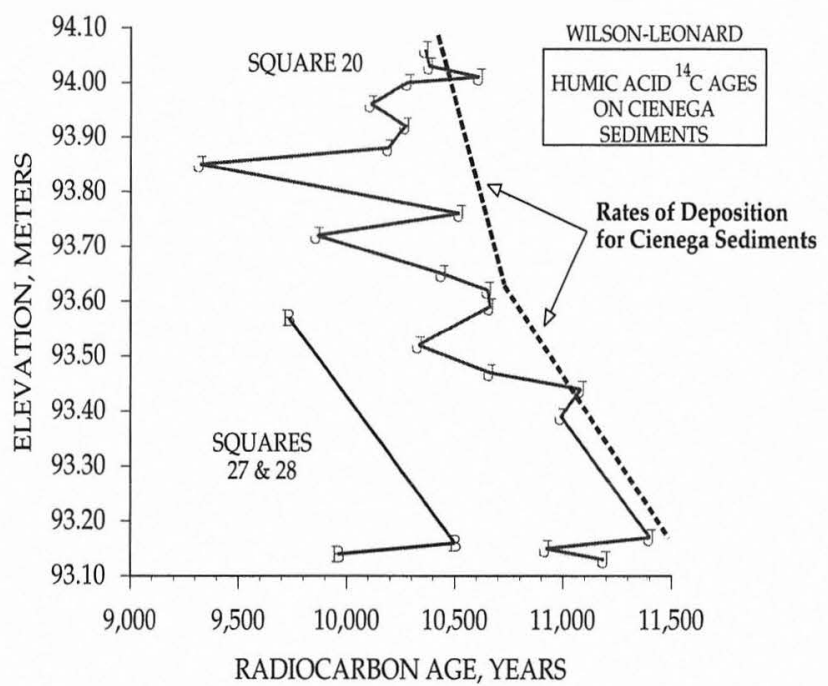

FigURE 25-8. Age versus depth comparison for humic acid fractions dated from the Unit Icl cienega sediments from Square 20, south wall.

\section{RESULTS}

The radiocarbon measurements are tabulated as a date list arranged by radiocarbon laboratory number (see Table 25-1), by individual strata and features, and by individual samples located stratigraphically (see Figure 25-1). Finally, interpreted time lines for all geologic units are summarized in Figure 25-9.

The results are presented starting with the uppermost unit, Unit IIIc, and conclude with Unit Icl cienega, the oldest unit dated. Except for the soil at the top of Unit Isi-c, neither the basal gravels (Igl) nor the remaining sediments of Isi contained suitable carbon for radiocarbon dating of Unit I.

\section{Unit III}

Table 25-3 lists 21 radiocarbon measurements from Unit III, which was divided into Units IIIc, IIIb, and IIIa within the valley fill, and Units IIIc, $\mathrm{X}$, and $\mathrm{Y}$ along the valley margin (see Figure 25-1). All Unit III dates were on charcoal, either from tree stumps, hearths, or wild hyacinth bulbs. The samples with the most reliable stratigraphic locations were the charred tree stumps in Unit IIIb and charred Camassia bulbs in a burned rock oven, Feature 181, originating in upper Unit IIIa. Age control on Feature 181, and an adjacent burned rock oven, Feature 245, was very good because numerous charcoal samples were present from each feature (Table 25-4).

The age range for Unit III is from the present (late twentieth century) at the top of Unit IIIc to ca. 8700 B.P. at the base of Unit IIIa. Age control for Unit IIIIa is good because 13 dates are available from reliable stratigraphic contexts. The contact of Unit IIIa and IIIb is the least well-known 
TABLE 25-3

AMS ${ }^{14} \mathrm{C}$ Measurements from Unit III

\begin{tabular}{|c|c|c|c|c|}
\hline \multirow[b]{2}{*}{${ }^{14} \mathrm{C}$ Sample No. } & \multirow[b]{2}{*}{ Sample Description } & \multicolumn{3}{|c|}{${ }^{14} \mathrm{C}$ Age, yr. } \\
\hline & & Elevation $(\mathrm{m})$ & & Radiocarbon Lab No. \\
\hline \multicolumn{5}{|l|}{ UNIT IIIIc } \\
\hline CH-1024 & Hearth Charcoal (Feature 10) (Hackberry, Celtis spp.) & $\sim 97.32-97.27$ & $1990 \pm 60$ & Beta-79698 \\
\hline CH-925 & Charred Camassia scilloides & $\sim 96.77-96.67$ & $3780 \pm 70$ & Beta-81106 \\
\hline \multicolumn{5}{|l|}{ UNIT IIII } \\
\hline $\mathrm{C} 14-5$ & Hearth Charcoal (Feature 204) & 96.42 & $4440 \pm 60$ & CAMS-10196 \\
\hline $\mathrm{CH}-1054$ & Charred Live Oak stump (Feature 50) & $\sim 96.49-96.39$ & $5520 \pm 80$ & Beta- 79700 \\
\hline $\mathrm{CH}-1085$ & Charred Red Mulberry Stump (Feature 199) & 96.32 & $5560 \pm 60$ & Beta-79699 \\
\hline C14-15 & $\begin{array}{l}\text { Hearth Charcoal (Feature 214) Juniper, Juniperus } \\
\text { spp. }\end{array}$ & 96.43 & $4880 \pm 70$ & Beta-79803 \\
\hline \multicolumn{5}{|l|}{ UNIT IIIa } \\
\hline $\mathrm{CH}-1484$ & Charred C. scilloides bulb (Feature 181) & $\sim 95.81-95.78$ & $8080 \pm 70$ & CAMS-13514 \\
\hline $\mathrm{CH}-1479$ & Charred C. scilloides bulb (Feature 181) & $\sim 95.78-95.76$ & $7890 \pm 60$ & CAMS-13841 \\
\hline $\mathrm{CH}-1482$ & Charred C. scilloides bulb (Feature 181) & $\sim 95.74-95.67$ & $8010 \pm 60$ & CAMS-13512 \\
\hline CH-1483-1 & Charred C. scilloides bulb (Feature 181) & $\sim 95.69-95.66$ & $7870 \pm 60$ & CAMS-13840 \\
\hline CH-1483-2 & Charred C. scilloides bulb (Feature 181) & $\sim 95.69-95.66$ & $8030 \pm 60$ & CAMS-13513 \\
\hline C14-354 & Charred C. scilloides bulb (Feature 181) & 95.63 & $8080 \pm 60$ & CAMS-10201 \\
\hline C14-219 & Charred C. scilloides bulb (Feature 181) & 95.595 & $7990 \pm 60$ & CAMS- 8355 \\
\hline CH-1478 & Charred C. scilloides bulb (Feature 181) & $\sim 95.59-95.53$ & $7890 \pm 80$ & CAMS-13844 \\
\hline \multirow[t]{2}{*}{$\mathrm{CH}-1480$} & Charred C. scilloides bulb (Feature 181) & $\sim 95.51-95.46$ & $8130 \pm 70$ & CAMS-13509 \\
\hline & Average Age of Feature 181 & & $7997 \pm 21$ & - \\
\hline $\mathrm{C} 14-152$ & Charcoal (Feature 245) & 95.68 & $8130 \pm 60$ & CAMS-10197 \\
\hline C14-113 & Charcoal (Feature 245) & 95.66 & $8110 \pm 70$ & CAMS-10194 \\
\hline C14-143 & Charcoal (Feature 245) & 95.63 & $8420 \pm 200$ & CAMS-10206 \\
\hline C14-199 & Charcoal (Feature 231) & 95.61 & $* 3440 \pm 80$ & CAMS-13025 \\
\hline \multicolumn{5}{|l|}{$\overline{\text { STRATUM IIIC/Y }}$} \\
\hline CH-998 & Charred Camassia scilloides (Feature 8) & $97.36-97.08$ & $8250 \pm 80$ & CAMS-18375 \\
\hline \multicolumn{5}{|l|}{ STRATUM X } \\
\hline NA & Oven Charcoal (Feature 19/104) & $\sim 96.58-96.43$ & $7470 \pm 230$ & Tx-4798 \\
\hline $\begin{array}{l}\text { Note: AMS Radioce } \\
\text { margin. Radiocarbo } \\
\text { carbonized root tub } \\
\text { An average was det } \\
\text { periods of use. Sa } \\
\text { discussions. }\end{array}$ & $\begin{array}{l}\text { n measurements on carbonized organic matter from } \\
\text { amples from IIIa are from two Early Archaic burne } \\
\text { of the wild hyacinth (Camassia scilloides). Samples } \\
\text { ined for Feature 181; the ages from Feature } 245 \text { we } \\
\text { e C14-199 (CAMS-13025) is considered stratigra }\end{array}$ & $\begin{array}{l}\text { III and its eq } \\
\mathrm{k} \text { middens, F } \\
\text { resented in st } \\
\text { t averaged be } \\
\text { ally displacec }\end{array}$ & $\begin{array}{l}\text { lent Units } \\
\text { res } 181 \text { and } \\
\text { raphic orde } \\
\text { e the featur } \\
\text { d was excl }\end{array}$ & $\begin{array}{l}\text { and Y along the valley } \\
245 \text {. Charred bulbs are } \\
\text { from highest to lowest. } \\
\text { may have had multiple } \\
\text { ded from Unit III age }\end{array}$ \\
\hline
\end{tabular}

because carbon samples are rare in sediments above the Unit IIIa burned rock features. The chronology for Units IIIb and IIIc is also hampered by a very slow depositional rate for the past 5,000 to 6,000 years.

\section{Unit II}

Unit II yielded 10 dates on hearth and charred tree stump or root charcoal and 1 date from charred bone (Table 25-5). The charcoal radiocarbon measurements from Unit II range from $8090 \pm 70$ (CAMS-7207) to $9650 \pm 80$ (CAMS-7560). The stratigraphic positions of the hearth and charred tree samples were located precisely and are the best estimates for stratigraphic ages.

\section{Unit I}

Unit I yielded the most types of samples and individual measurements for radiocarbon dating. Sixty-one radiocarbon measurements were made on hearth charcoal, charred tree stumps, charred plant remains, gastropod carbonate, human bone, and three types of organic carbon from soil and sedimentary matrices. The age measurements indicate a Unit I time range of ca. 9,500 to $>11,500$ years. 


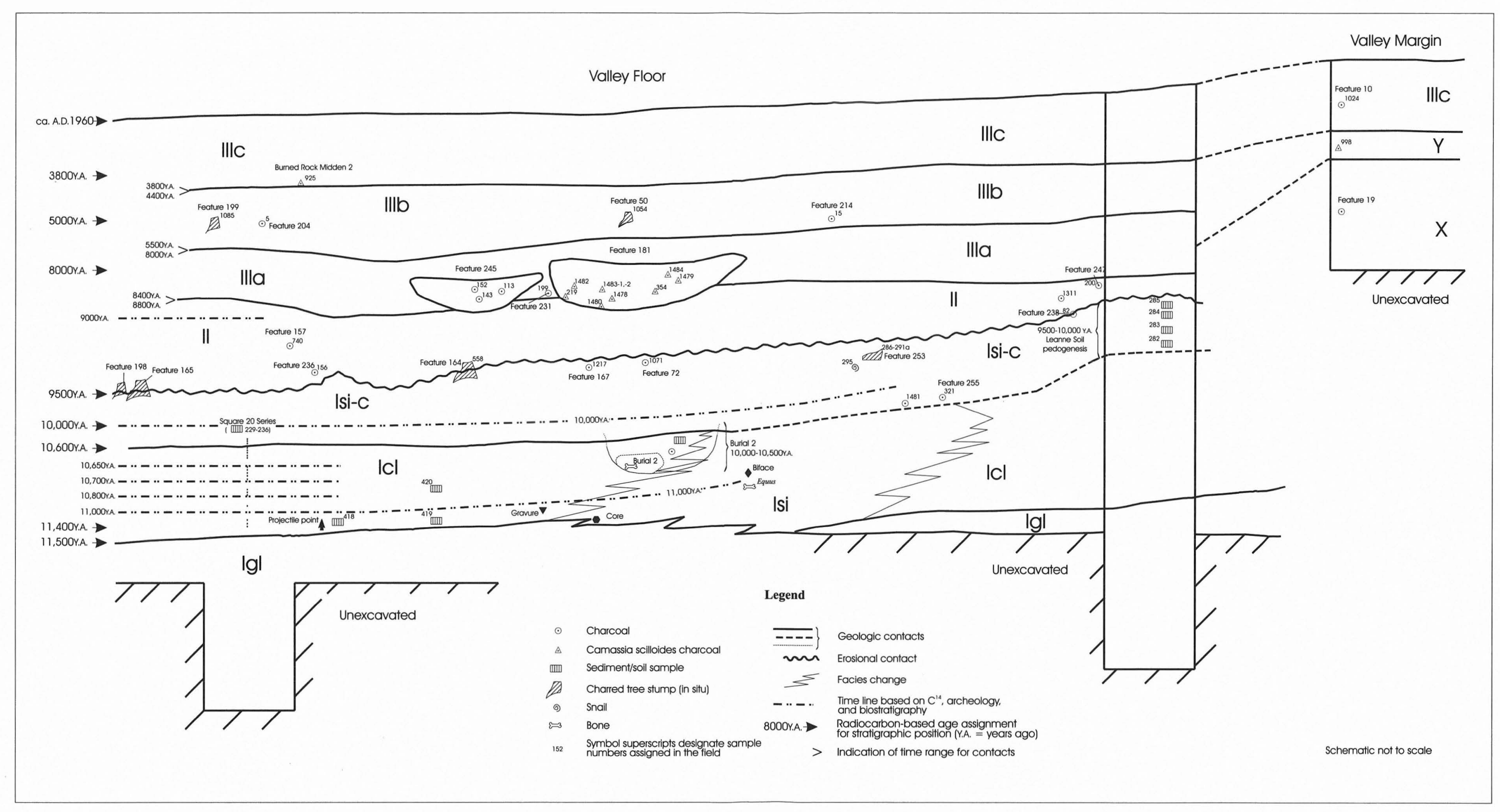

FIGURE 25-9. Schematic profile showing the site chronostratigraphy. 
TABLE $25-4$

Carbonized Camassia scilloides Bulbs from Feature 181, Unit IIIa

\begin{tabular}{|c|c|c|c|}
\hline $\begin{array}{l}\text { Excavation Level and } \\
{ }^{14} \mathrm{C} \text { Sample No. }\end{array}$ & Sample Dated & $\begin{array}{l}{ }^{14} \mathrm{C} \text { Age, } \\
\text { yr. } \pm 1 \sigma\end{array}$ & Radiocarbon Lab No. \\
\hline \multicolumn{4}{|c|}{$\begin{array}{l}\text { 1ST AMS Measurement SERIES } \\
\text { (June 16, 1994) }\end{array}$} \\
\hline Level 20a CH-1480 & Charred C. scilloides bulb & $8130 \pm 70$ & CAMS-13509 \\
\hline Level 17b CH-1482 & Charred C. scilloides bulb & $8010 \pm 60$ & CAMS-13512 \\
\hline Level 18a CH-1483-2 & Charred $C$. scilloides bulb & $8030 \pm 60$ & CAMS-13513 \\
\hline Level 16b CH-1484 & Charred C. scilloides bulb & $8080 \pm 70$ & CAMS-13514 \\
\hline Series 1 Average: & & $8063 \pm 33$ & - \\
\hline \multicolumn{4}{|c|}{$\begin{array}{l}\text { 2ND AMS Measurement SERIES } \\
\text { (June 26, 1994) }\end{array}$} \\
\hline Level 18a CH-1483-1 & Charred C. scilloides bulb & $7870 \pm 60$ & CAMS-13840 \\
\hline Level 17a CH-1479 & Charred C. scilloides bulb & $7890 \pm 60$ & CAMS-13841 \\
\hline Level 18b CH-1478 & Charred C. scilloides bulb & $7890 \pm 80$ & CAMS-13844 \\
\hline Series 2 Average: & & $7883 \pm 38$ & - \\
\hline Average of All Analyses: & & $7985 \pm 25$ & - \\
\hline \multicolumn{4}{|c|}{$\begin{array}{l}\text { Note: AMS Radiocarbon measurements on charred Camassia scilloides (wild hyacinth) bulbs from the Early Archaic burned rock } \\
\text { oven, Feature 181, in Unit IIIa. Each of the two series of dates was analyzed on the same accelerator wheel of graphite targets; } 10 \\
\text { days separated the two analysis series. One sample (CH-1483) was analyzed twice and enables variation to be compared between } \\
\text { each sample set for the two different measurement periods. }\end{array}$} \\
\hline
\end{tabular}

TABLE 25-5

Unit II Radiocarbon Measurements

\begin{tabular}{clccc}
\hline \multicolumn{1}{c}{ Sample No. } & \multicolumn{1}{c}{ Sample Description } & Elevation $(\mathrm{m})$ & yr. $\pm 1 \sigma$ & Radiocarbon Lab No. \\
\hline UNIT II & & & & \\
CH-1311 & Charcoal & 95.485 & $8820 \pm 120$ & Tx-4784a \\
CH-1311 & Charcoal \& Humic Acids & 95.485 & $8940 \pm 100$ & Tx-4784b \\
CH-1311 & Charcoal \& Humic Acids & 95.485 & $8860 \pm 150$ & Tx-4784c \\
Average of CH-1311 Measurements & & $8870 \pm 70$ & - \\
CH-740 & Hearth Charcoal Feature 157 & $\sim 95.22$ & $9340 \pm 60$ & CAMS-18640 \\
CH-558 & Charred Stump Feature 164 & $\sim 94.73-94.68$ & $9520 \pm 60$ & CAMS-14806 \\
NA & Charred Live Oak Stump Feature 165 & $94.79-94.64$ & $9530 \pm 88$ & Tx-4828 \\
C14-156a & Hearth Charcoal Feature 236 & 95.32 & $9650 \pm 80$ & CAMS-7560 \\
C14-156b & Bone Humins Feature 236 & 95.32 & $10,400 \pm 280$ & CAMS-7561 \\
CH-921 & Charred Live Oak Stump Feature 198 & 94.57 & $9240 \pm 70$ & Beta-80859 CAMS-19080 \\
\hline UNIT II/I & $\quad$ Charred Root Feature 238 (originated in Unit II & 95.12 & $8830 \pm 90$ & CAMS-10207 \\
C14-82 & and intruding into Unit I) & & & \\
C14-200 & Hearth Charcoal Feature 247 & 95.32 & $8090 \pm 70$ & CAMS-7207 \\
\hline
\end{tabular}

Note: Conventional and AMS radiocarbon measurements from Unit II. Sample CH-1311 was hearth-derived charred organic matter that was dated using different chemical fractions. The charred stumps were in situ.

Table 25-6 lists the Unit I samples by stratigraphic position, from highest to lowest. Units with multiple dates are Isi-c, the Leanne soil (Table 25-7), the charred tree stump from Feature 253 (Table 25-8), Burial 2 (Table 25-9), and the Icl cienega (Table 25-10). Units Isi and the basal, Igl gravels yielded no suitable organic carbon for analysis, therefore the Unit I basal age is unknown.

\section{DISCUSSION BYSTRATIGRAPHIC UNIT}

The accuracy of radiocarbon measurements is discussed beginning with the geochemistry of each sample and concludes in the context of the entire site. This section's chronostratigraphy is based exclusively on the radiocarbon measurements and does not include archeological and 
TABLE 25-6

Unit I Radiocarbon Summary by Stratigraphic Order

\begin{tabular}{cclcc}
\hline Ring No. & Sample No. & \multicolumn{1}{c}{ Description of Sample Dated } & ${ }^{14}$ C Age, Yr. B.P. & Radiocarbon Lab No. \\
\hline 1 & NA & Leanne soil (12 analyses on 3 chemical fractions) & - & (See Table 25-7) \\
2 & NA & Charred tree stump (Feature 253) average, n=6 & $9550 \pm 30$ & (See Table 25-8) \\
3 & NA & Gastropod associated with Feature 253 & $10,520 \pm 80$ & (See Table 25-8) \\
4 & CH-1071 & Charred tree root (Feature 72) & $9430 \pm 60$ & CAMS-14807 \\
5 & CH-1217 & Charred tree root (Feature 167) & $9410 \pm 60$ & CAMS-14805 \\
6 & CH-1481 & Charred black walnut shell & $9750 \pm 60$ & CAMS-13842 \\
7 & NA & Burial 2 (9 analyses on sediment, charcoal, and human & - & (See Table 25-9) \\
& & bone) & $9990 \pm 70$ & CAMS-10195 \\
9 & C14-321 & Hearth charcoal (Feature 255) & - & (See Table 25-10) \\
\hline
\end{tabular}

Note: The radiocarbon dates are listed in stratigraphic order from top to bottom. Samples with multiple dates are the Leanne soil, the charred in situ tree stump, Burial 2, and the Icl cienega sediments. These analyses are placed in stratigraphic order in respect to charcoal analyses within Unit I and the table number is designated where their individual dates are presented. Three different chemical fractions were dated from four stratigraphic positions within the Leanne soil's A-horizon (Table 25-7). The top and bottom samples were $40 \mathrm{~cm}$ apart vertically. At each of the four elevations, a 5-cm-thick sample was collected and the soil was chemically pretreated to isolate decalcified sediment, humic acid, and humin chemical fractions for radiocarbon dating. The age ranges from the A-horizon were from 4,710 to 8,770 years with the humic acid fraction being the oldest fraction.

TABLE $25-7$

Leanne Soil Radiocarbon Dates

\begin{tabular}{cccc}
\hline Elevation $(\mathrm{m})$ & Decalcified Soil & Humic Acids & Humins \\
\hline $95.51 \mathrm{~m}$ & $4710 \pm 100$ CAMS-6914 & $* 5500 \pm 70$ CAMS-7198 & $5370 \pm 90$ CAMS-6918 \\
$95.40 \mathrm{~m}$ & $6560 \pm 60$ CAMS-6913 & $* 7470 \pm 90$ CAMS-6920 & $7280 \pm 80$ CAMS-6917 \\
$95.25 \mathrm{~m}$ & $6410 \pm 60$ CAMS-6912 & $7000 \pm 80$ CAMS-6919 & $* 7440 \pm 80$ CAMS-6916 \\
$95.09 \mathrm{~m}$ & $8290 \pm 70$ CAMS-6911 & $* 8770 \pm 70$ CAMS-7201 & $8110 \pm 90$ CAMS-6915 \\
\hline
\end{tabular}

* the oldest fraction at each elevation

Note: Decalcified soil is total, decalcified organic matter, from which humic acids are extracted. Humins are the insoluble residue remaining after humic acids are removed from decalcified sediment.

biostratigraphic data that were used to refine these age estimates and to develop a final chronostratigraphy. The absolute site chronology is presented in the conclusions section.

In order from youngest to oldest, the following discussion outlines how the geologic ages were assigned to each stratigraphic unit. The results are discussed as outlined in Table 25-11.

\section{Unit III Chronostratigraphy}

\section{Unit IIIc}

The paucity of charcoal and the compression of 5,600 years into $1.5 \mathrm{~m}$ of sediment hampered establishing time lines within Units IIIc and IIIb. The upper surface of Unit IIIc dates to the late twentieth century based on historic artifacts found in the upper $10 \mathrm{~cm}$. The base of Unit IIIc dates to ca. 4000 B.P. based on the age of a wild hyacinth bulb $(3780 \pm 70$
[Beta-81106]) from a feature slightly above the base of Unit IIIc. One additional radiocarbon date from IIIc is $1990 \pm 60$ (Beta-79698) on charcoal collected from mid-IIIc along the valley margin. Because Unit IIIc represents approximately 4,000 years of time and the stratum is less than $80 \mathrm{~cm}$ thick, calculating depositional rates is not justified.

\section{Unit IIIb}

The contact of Units IIIc and IIIb is bracketed by two ages, $3780 \pm 70$ (Beta-81106) from the base of Unit IIIc and an age of $4440 \pm 60$ (CAMS-10196) from the middle of Unit IIIb. Age control within Unit IIIb is also poor because only four dates are available and three of the four are from the middle of the stratum. Based strictly on radiocarbon results, the time range of Unit IIIb is from ca. 3800 to ca. 5560 B.P. This estimate was better established by using archeological typologies from Units IIIb and IIIa as ca. 4000 to 6000-6500 B.P. 
TABLE 25-8

AMS Radiocarbon Measurements on Tree Ring Positions within Feature 253

\begin{tabular}{lcc}
\hline Sample Description & $\begin{array}{c}{ }^{14} \text { C Age, yr. } \\
\pm 1 \sigma\end{array}$ & $\begin{array}{c}\text { Radiocarbon } \\
\text { Lab No. }\end{array}$ \\
\hline $\begin{array}{c}\text { Stump position } 1 \\
\text { Stump position } 2\end{array}$ & $9540 \pm 80$ & CAMS-6373 \\
Stump position 3 & $9500 \pm 80$ & CAMS-6349 \\
Stump position 4 & $9480 \pm 100$ & CAMS-6382 \\
Stump position 5 & $9610 \pm 70$ & CAMS-6350 \\
Stump position 6 & $9540 \pm 70$ & CAMS-6348 \\
\hline Average & $9550 \pm 30$ & - \\
\hline Gastropod & $10,520 \pm 80$ & CAMS-6377 \\
\hline $\begin{array}{l}\text { Note: Samples 1 to 6 were taken incrementally and perpendicular } \\
\text { to the tree's circumference. Sample 1 is the outermost ring and }\end{array}$ \\
number 6 is nearest the center of the tree stump. The gastropod \\
was collected in situ and was from sediments enclosing the \\
charred tree. The charcoal and gastropod AMS measurements \\
were analyzed in the same target wheel. \\
\hline \hline
\end{tabular}

TABLE 25-9

AMS Radiocarbon Measurements on Burial 2 Bone and Pit Fill

\begin{tabular}{lcc}
\hline \multicolumn{1}{c}{ Fraction Dated } & $\begin{array}{c}{ }^{14} \mathrm{C} \mathrm{Age}, \mathrm{yr} . \\
\pm 1 \sigma\end{array}$ & $\begin{array}{c}\text { Radiocarbon } \\
\text { Lab No. }\end{array}$ \\
\hline Human Bone & $1270 \pm 280$ & AA-753 \\
Gelatin & $4650 \pm 310$ & AA-747 \\
Apatite $\mathrm{CO}_{2}$ & $5440 \pm 420$ & AA-752 \\
$\mathrm{H}_{2} \mathrm{O}$ insoluble carbon & $5940 \pm 520$ & AA-748 \\
$\mathrm{HCl}$ soluble fraction & $6700 \pm 460$ & AA-749 \\
$\mathrm{HCl}$ soluble fraction & $9470 \pm 170$ & Tx-4787 \\
\hline Burial Pit Fill & $9650 \pm 124$ & Tx-4793 \\
$\begin{array}{l}\text { Decalcified sediment } \\
\text { Decalcified sediment }\end{array}$ & $13,000 \pm 3000$ & AA-171 \\
\hline $\begin{array}{l}\text { Disseminated Charcoal within Burial Fill } \\
\text { Acid-base pretreated } \\
\text { charcoal }\end{array}$ & & \\
\hline
\end{tabular}

Note: AMS Radiocarbon measurements on Burial 2 human bone, burial fill enclosing the skeleton, and disseminated charcoal within the burial fill. Sediment radiocarbon measurements were made during 1983-1984 by the University of Texas at Austin conventional radiocarbon laboratory (Tx-) and by T. Stafford, Jr. on bone in 1983 at the University of Arizona AMS Radiocarbon Laboratory (AA-).

\section{Unit IIIa}

The radiocarbon estimate for the contact of Units IIIb and IIIa is between 5560 and 8000 в.P. This approximation is based on the earliest Unit IIIb age of 5560 60 (Beta-79699) and the average age of $7985 \pm 30$ assigned to Feature 181, a burned rock oven that was probably dug from an occupational surface in the upper part of IIIa. The base of Unit IIIa dates at least $8420 \pm 200$ years old (CAMS-10206), the oldest age from the burned rock oven, Feature 245.

The radiocarbon estimate of 5,560-8,000 years for the contact of Units IIIb and IIIa is better estimated by including artifact typologies from above and below the contact (see Chapters 4, 9, and 13). The lower sediments of Unit IIIa contain Angostura, Hoxie, and Gower-like projectile point types primarily dating earlier than 8000 B.P. At the Unit IIIa/IIIb contact and above were Bandy, Martindale, and Uvalde projectile point types that date ca. $6000-6500$ в.P. (Collins 1995). Therefore, a possible time range for the contact of Units IIIa and IIIb is $6000-6500$ B.P.

Radiocarbon time ranges are different for the two burned rock ovens in Unit IIIa, Features 245 and 181. Because the three radiocarbon analyses from Feature 245 do not overlap at 1 sigma they should not be averaged (Long and Rippeteau 1974). Consequently, Feature 245 spans from $8110 \pm 70$ to $8420 \pm 200$ years and appears to predate Feature 181 by 100 years or more.

Camassia charcoal samples from Feature 181 provided excellent time control for the burned rock oven; the average age of the feature's nine radiocarbon measurements was $7997 \pm 21$ years. Furthermore, the feature yielded data regarding the accuracy and precision attainable for dating shorttime occupations at archeological sites. The Camassia samples were submitted on four different times to the INSTAAR radiocarbon laboratory. A total of nine AMS ${ }^{14} \mathrm{C}$ ages were measured on eight different samples in four separate accelerator runs (see Tables 25-3 and 25-4). Seven of the Camassia samples provided an inadvertent age-control experiment from the last two sample submissions to Colorado. On the third and fourth sets of Camassia charcoals, one sample had been divided physically into two parts (CH-14831 and $\mathrm{CH}-1483-2$ ). Because each half was processed as a unique sample and then analyzed in a different target wheel, internal variation between AMS analyses could be assessed. The experiment was strengthened by the presence of two previous charcoal analyses (CAMS-8355 and 10201) and because all nine analyses provided an overall average of $7997 \pm 21$ years. The first series of Camassia measurements averaged $8063 \pm 33$ years $(n=4)$ and the second series averaged $7883 \pm 38$ years $(n=3)$ (see Table $25-4)$. The average of all Feature 181 samples, rounded to the nearest five radiocarbon years, is $7985 \pm 30$ years. If the one charcoal sample had not been analyzed in both wheels, the 180 years difference between the averages could have been interpreted as two different episodes of oven use. This replication experiment is a caution against overinterpreting small age differences between populations of sample dates unless precautions are taken to minimize analytical variation by pretreating, combusting and graphitizing, and performing the AMS analyses as a single, internally coherent series. If samples representing short-time events are processed and dated in the same 
TABLE $25-10$

Unit Icl Cienega Sediments

\begin{tabular}{|c|c|c|c|c|c|}
\hline \multirow{2}{*}{$\begin{array}{c}\text { Elevation } \\
\text { (m above datum) }\end{array}$} & \multirow{2}{*}{$\begin{array}{c}\text { Square } 20 \\
\text { Humic Acids }\end{array}$} & \multicolumn{3}{|c|}{ Squares 27 and 28} & \multirow[t]{2}{*}{ CAMS No. } \\
\hline & & Humic Acids & Decalcified Sediment & Humins & \\
\hline $94.07-94.05$ & $10,360 \pm 60$ & - & - & - & CAMS-19258 \\
\hline $94.05-94.02$ & $10,380 \pm 60$ & - & - & - & CAMS-19256 \\
\hline $94.02-94.01$ & $10,610 \pm 60$ & - & - & - & CAMS-19261 \\
\hline 94.01-93.99 & $10,280 \pm 60$ & - & - & - & CAMS-19490 \\
\hline $93.97-93.95$ & $10,110 \pm 70$ & - & - & - & CAMS-19492 \\
\hline $93.93-93.91$ & $10,270 \pm 80$ & - & - & - & CAMS-19489 \\
\hline $93.89-93.87$ & $10,190 \pm 110$ & - & - & - & CAMS-19481 \\
\hline $93.86-93.84$ & $9,320 \pm 60$ & - & - & - & CAMS-19488 \\
\hline $93.77-93.75$ & $10,520 \pm 70$ & - & - & - & CAMS-19493 \\
\hline $93.73-93.71$ & $9,860 \pm 70$ & 一 & - & - & CAMS-19483 \\
\hline $93.66-93.64$ & $10,440 \pm 130$ & 一 & - & - & CAMS-19482 \\
\hline $93.63-93.61$ & $10,650 \pm 60$ & - & - & - & CAMS-19257 \\
\hline $93.60-93.59$ & $10,660 \pm 90$ & - & - & - & CAMS-19484 \\
\hline 93.59-93.55 (C14-420) & - & $\begin{array}{c}9,730 \pm 70 \\
(\mathrm{CAMS}-5882)\end{array}$ & $\begin{array}{c}9,410 \pm 70 \\
(\mathrm{CAMS}-5883)\end{array}$ & $\begin{array}{c}8,780 \pm 90 \\
\text { (CAMS-5995) }\end{array}$ & - \\
\hline $93.53-93.51$ & $10,330 \pm 60$ & - & - & 一 & CAMS-19485 \\
\hline $93.49-93.46$ & $10,660 \pm 170$ & - & - & - & CAMS-19487 \\
\hline $93.45-93.43$ & $11,080 \pm 70$ & - & - & - & CAMS-19252 \\
\hline $93.40-93.38$ & $10,990 \pm 70$ & - & - & 一 & CAMS-19486 \\
\hline $93.20-93.13$ (C14-419) & 一 & $\begin{array}{c}10,500 \pm 80 \\
(\mathrm{CAMS}-5881)\end{array}$ & $\begin{array}{c}10,000 \pm 70 \text { (CAMS- } \\
5887)\end{array}$ & $\begin{array}{c}10,190 \pm 80 \\
(\text { CAMS-5993) }\end{array}$ & - \\
\hline $93.18-93.160$ & $11,400 \pm 110$ & - & - & - & CAMS-19262 \\
\hline $93.17-93.14$ & $10,920 \pm 70$ & - & - & - & CAMS-19259 \\
\hline $93.16-93.12(\mathrm{C} 14-418)$ & 一 & $\begin{array}{c}9,960 \pm 110 \\
(\mathrm{CAMS}-5886)\end{array}$ & $\begin{array}{c}9,130 \pm 70(\mathrm{CAMS}- \\
5884)\end{array}$ & $\begin{array}{c}9680 \pm 90 \\
\text { (CAMS-5994) }\end{array}$ & - \\
\hline $93.14-93.12$ & $11,190 \pm 100$ & - & - & - & CAMS-19260 \\
\hline
\end{tabular}

Note: AMS radiocarbon dates on sedimentary carbon from Unit Icl cienega deposits. Two collections were made of in situ sediment. Square 20 samples are from a single, vertical profile where samples were collected between 94.07 and $9312 \mathrm{~m}$ elevation. Samples from Squares 27 and 28 are from a vertical exposure $2 \mathrm{~m}$ wide.

accelerator target wheel, these laboratory and measurement variations are minimized.

\section{Unit II Chronostratigraphy}

The contact of Units IIIa and II dates between 8,420 and 8,870 years. This range is based on the oldest charcoal radiocarbon age from Unit IIIa ( $8420 \pm 200$, CAMS-10206) and the average of three ages from sample CH-1311 $(8870 \pm 70)$ in upper Unit II sediments.

Unit II probably spans less than 1,000 radiocarbon years and is bracketed by $8870 \pm 70$ years in upper Unit II and by three charred tree stumps that date the erosional surface upon which Unit II was deposited. The tree stumps from lower Unit II (Features 164, 165, and 198) and Feature 253 from uppermost Unit I may have been killed by the erosion and subsequent deposition that define the Isi-c/II contact and the basal sediments of Unit II. The trees' ages $(9530 \pm 88$ years [Feature 165], $9520 \pm 60$ years [Feature 164], $9240 \pm 70$ years [Feature 198], and $9550 \pm 30$ years [Feature 253]) are evidence that the trees may have belonged to one or two woodlands that burned during a short time interval.

Three additional charcoal samples constrain the age of the erosional surface at the base of Unit II. Hearth charcoal (Feature 157) from upper Unit II dated $9340 \pm 60$ years (Beta79705). Charred root charcoal was also collected from two other features in upper Unit Isi-c (Features 72 and 167). These samples dated $9430 \pm 60$ years (CAMS-14807) and $9410 \pm 60$ years (CAMS-14805). These samples probably represent different roots from one live oak tree growing on approximately the same surface containing Feature 253 . Consequently, the erosional contact separating Units Isi-c and II is bracketed by the youngest Unit II stump charcoal age 
TABLE 25-11

Summary of Wilson-Leonard Chronostratigraphy in Order of Youngest to Oldest Sediments

\begin{tabular}{ll}
\hline Geological Event & Age Range, ${ }^{14}$ C years \\
\hline Unit IIIc deposition & $3780-4440$ B.P. to Modern \\
Unit IIIb deposition & $5500-8000$ to $3780-4440$ B.P. \\
Unit IIIa deposition & $8420-8870$ to $5500-8000$ B.P. \\
Unit II deposition & 9500 to $8420-8870$ B.P. \\
Erosion (I/II disconformity) & 9500 B.P. \\
Leanne soil pedogenesis & ca. 10,000 to 9600 B.P. \\
Burial 2 interment & ca. 10,000 to 10,500 B.P. \\
Cienega deposition, Icl & ca. 11,000 to $10,600-$ \\
Fluvial/colluvial deposition, Isi & 10,000 B.P. \\
Fluvial deposition, Igl 11,500 to 9,500 B.P. \\
\hline \hline
\end{tabular}

(9240 \pm 70 , Beta-80859) and the oldest stump charcoal at the base of Unit II ( $9530 \pm 88$, Tx-4828).

\section{Unit I Chronostratigraphy}

\section{Carbonized Plant Remains}

The only large carbonized macrofossils recovered for dating from Unit I were from the Leanne soil (Isi-c). An in situ, carbonized live oak tree stump (Feature 253) from uppermost Unit Isi-c yielded six AMS ${ }^{14} \mathrm{C}$ ages that averaged $9550 \pm 30$ years (see Table $25-8$ ). The stump was sampled at six tree-ring positions; the innermost sample (Position 6) being closest to the tree's center. The top of the tree stump probably represented the level at or a few centimeters below the land surface when the tree burned. This tree stump probably belonged to the same vegetation community as the three charred stumps in basal Unit II. A gastropod $10 \mathrm{~cm}$ horizontally from the tree stump and at the elevation of the stump was removed from sediments enclosing the tree. The snail carbonate date $(10,520 \pm 80$, CAMS-6377) is 1,000 years older than the stump, either because the snail's reservoir age was 1,000 years or the snail shell's carbonate had exchanged with geologically ancient carbonate during burial. Two additional charcoal samples were collected from Unit Isi-c. A charred walnut shell found in lower Isi-c dated $9750 \pm 60$ years, and hearth charcoal from the base of Isi-c (Feature 255) dated $9990 \pm 70$ years. The latter sample was located in approximately the same stratigraphic position as the top of the Burial 2 interment pit.

\section{Leanne Soil}

The Leanne soil (Isi-c) was dated to assess how ${ }^{14} \mathrm{C}$ content varied with soil profile depth and among chemical fractions, and whether the soil ${ }^{14} \mathrm{C}$ ages were residence-time, absolute ages, or neither. The results are consistent with the soil A-horizon being cumulic (i.e., sedimentation was fast enough to raise the soil surface over time but was slow enough that soil biological processes were not stopped) and all elevations within the A-horizon, but especially the upper $35 \mathrm{~cm}$ of the soil, containing geologically younger carbon that had been added after Leanne soil pedogenesis ended.

The cumulic nature of the Leanne soil is expressed chronometrically - radiocarbon ages became older with increasing depth in the soil profile. This age versus depth relationship results when sedimentation continues during pedogenesis, yet the sediment accumulation rate is not fast enough to stop plant growth. The result is an aggrading soil profile where carbon refluxing affects only the most active, uppermost soil horizons. Lower sections in a cumulic A-horizon have less and less modern carbon added as the profile increases in thickness. Consequently, carbon averaging is not homogeneous throughout the entire soil profile. As cumulic pedogenesis continues, less and less carbon from the active soil-air interface is mixed into older levels.

The evidence indicating younger-carbon contamination of the Leanne soil is soil radiocarbon ages consistently younger than the 9,500-year-old disconformity overlying the soil. Cumulic soils rarely yield ages as old as their earliest pedogenesis; however, all ages should be at least as old as the soil's termination date. Ages for Leanne soil fractions range from 4,710 to 8,770 years and are 700 to 4,800 years younger than its 9500 B.P. termination date (see Table 25-7).

Contamination by younger carbon is evident in all three chemical fractions but is less for humic acids than for decalcified sediment or humins. Humic acids were the oldest fraction in three of four horizons (see Table 25-7); this relationship indicates that particulate carbon is the prominent contaminant rather than translocated humic acids. However, humic acid ages were 700 to 4,000 years younger than the soil's termination date. It is unknown whether these humates were added physically by bioturbation or by the downward, chemical translocation of geologically younger humates.

\section{Burial 2}

Conventional and AMS radiocarbon measurements for Burial 2 were determined during 1983 (see Table 25-9). No additional age dating of the bone or the burial pit fill was performed during later field seasons. Direct AMS ${ }^{14} \mathrm{C}$ ages on the human bone ranged from 1,270 to 6,700 years (Stafford et al. 1987). The large standard deviations (approximately $\pm 10 \%$ but over $20 \%$ in one case) were caused by the fact that AMS technology was being developed in 1983 and $10 \%$ precisions were customary, and the amount of carbon dated was smaller than optimal because the human bone was very poorly preserved and the carbon yields were very low. 
Three age estimates exist for the sediments filling the burial pit. Two ages, $9470 \pm 170$ years (Tx-4787) and $9650 \pm 124$ years $(\mathrm{Tx}-4793)$ were on total organic matter from the pit sediments. The third age, $13,000 \pm 3000$ years (AA-171), was on dispersed charcoal within the burial fill. The large standard deviation ( $>23 \%$ ) resulted from the sample's extremely small size.

The interment pit for Burial 2 originated in the lower few centimeters of the Leanne soil and extended laterally and downward into Unit Icl cienega muds. The burial pit was subsequently covered by continuing cumulic pedogenesis, which would deposit an additional 70 or more centimeters of Leanne soil above Burial 2 (see Figure 25-1). Consequently, the burial pit carbon may represent a mixture of carbon from different sources and ages-Leanne soil carbon contemporaneous with the burial; older, preexisting cienega carbon; and younger carbon from post-Leanne pedogenesis. Finally, the burial pit sediments may have contained younger, disaggregated tree stump carbon mixed into the burial fill by bioturbation.

The radiocarbon age range assigned to Burial 2 is 10,000 to 10,500 years. This estimate is based on the burial's stratigraphic position and associated charcoal dates. All direct bone dates on the burial were too young because the bone's chemical preservation was not acceptable for radiocarbon dating. The oldest age on the human bone, $6700 \pm 460$ years (AA-749), is at least 3,000 years too young, based on the 9,500-year disconformity stratigraphically above Burial 2. In addition, charred roots (Feature 72/167) extending over the burial have an age of approximately 9,420 years. The date on dispersed charcoal from the burial pit $(13,000 \pm 3000$ years, AA-171), is unusable because the standard deviation is too large. The best constraints for the burial pit's youngest age are the $9470 \pm 170(\mathrm{Tx}-4787)$ and $9650 \pm 124(\mathrm{Tx}-4793)$ ages on burial pit fill and the $9990 \pm 70$ (CAMS-10195) age for charcoal from Feature 255 from lower Unit Isi-c. The stratigraphic position of Feature 255 is comparable to that of the top of the Burial 2 pit. Because the burial pit's fill contained younger carbon from overlying tree stumps, these 9470- and 9650year age estimates are probably too young. Consequently, the $9990 \pm 70$-year age is used for the younger age date for Burial 2.

The older constraining age estimate for Burial 2 is based on the stratigraphic position of the burial pit, whose base intersects the 10,650-year time line within Unit Icl. Consequently, the age range assigned to Burial 2 is 10,000 to 10,500 radiocarbon years.

\section{Unit Icl Cienega Radiocarbon Measurements}

Determining the age of cienega deposition was important for paleoenvironmental reconstructions because cienega formation marked the change from Late Pleistocene fluvial conditions toward less-mesic Holocene conditions. The drying cycle culminated in the erosional event terminating
Leanne soil pedogenesis. Dating the cienega muds was hampered by the absence of plant macrofossils and charcoal and the paucity and poor preservation of bone. General age brackets for upper and lower Unit Icl were 9500 years from charred trees in lower Unit II, and 10,500-11,200 years based on Paleoindian artifact typologies from in and below the base of Unit Icl. A bison bone bed in Unit Isi was not datable directly because the bones contained no suitable protein for ${ }^{14} \mathrm{C}$ measurement (see Table $25-2$ ). The only appropriate method for dating the cienega was to analyze the sediments directly.

Age estimates for Unit Icl deposition were determined by dating decalcified sediment, humic acids, and humins (see Table 25-10, Figures 25-7 and 25-8). Sedimentary organic matter was dated because the carbon was derived predominately from marsh plants. One uncertainty with dating aquatic plant carbon is not knowing if the cienega waters contained ancient dissolved carbonate (a reservoir effect) that would cause the plants to date older than expected. Also unknown is what thickness of sediment was homogenized during cienega formation. This zone of physical sediment mixing is caused by bioturbation affects from marsh plant roots, large mammals, especially ungulates, and aquatic invertebrates. These processes mixed a finite thickness of sediments during or shortly after sediment accumulation.

Considerably more disruptive was burrowing that occurred hundreds to thousands of years after cienega deposition. Bioturbation during deposition is difficult to identify physically because growth-period bioturbation mixes younger and older muds that often have nearly identical lithologies and colors. Postdepositional bioturbation should be more evident because younger burrows usually contain sediment with different colors and lithologies; however, after several thousand years, even postdepositional bioturbation can become obscured. Consequently, if 11,000year-old sediments were burrowed 2,000 years later, that is at 9,000 years ago, the bioturbation may be physically and visually unrecognizable today. The presence of age inversions in the Square 20 humic acid dates (see Figure 25-8) is interpreted as postdepositional bioturbation that was obscured physically over time.

Two series of radiocarbon dates on sediment were made for Unit Icl. These sediments comprised the base of the Leanne soil and the entire thickness of Unit Icl (see Table 2510). The first series of samples was from Squares 27 and 28 , where sediment was removed from three locations (see Figure 25-1). Three chemical fractions were dated to determine age differences among fractions and to establish which fraction was best suited for additional dating. The dates from this first series had 500-1,000-year differences among the three fractions at each elevation, with humic acids being the oldest for all locations.

In the second series, humic acids were dated from a 95$\mathrm{cm}$-thick stratigraphic section in Square 20 (see Figures 25-1 
and 25-8, Table 25-10). Because the cienega sediments were from a $7-\mathrm{cm}$-wide column on one vertical plane, lateral correlation errors were eliminated and time-averaging was minimized by the small vertical thickness sampled for dating. The Square 20 dates ranged from 9320 to 11,400 B.P. and are plotted in Figure 25-8 as depth versus humic acid radiocarbon age.

Based on humic acid dates from Square 20, the age range for Unit Icl deposition is from 11,500-11,000 to 10,600-10,000 years. Square 20 data were used instead of those from Squares 27 and 28 because the single-column data have no lateral correlation errors, and the Square 20 ages are more consistent with the artifact typologies from the lower onethird of Unit Icl. Radiocarbon ages from Squares 27 and 28 were 1,000 years younger than ages from the same elevation in Square 20. These 1,000-year younger ages are inconsistent with Folsom and Clovis artifacts excavated in and below Unit Icl and may indicate that Unit Icl time lines dip more steeply than expected. The Square 20 ages range from 10,920 to 11,400 years and are consistent with Clovis chronologies at the base of Unit Icl. In contrast, sediments from the same elevation in Square 27 dated 10,500 years, an age estimate younger than ones generally accepted from Clovis chronologies.

The estimated age for the end of cienega sedimentation, at $94.07 \mathrm{~cm}$, is equal to or younger than $10,610 \pm 60$ years (CAMS-19261). The physical termination of cienega sediments is uncertain because Leanne pedogenesis obscured the cienega sediments' upper boundary, which is higher than the contact of Units Isi-c and Icl. Although the contact of Units Isi-c and Icl is interpreted as dating 10,600 B.P., cienega deposition may have continued until $10,000{ }^{14} \mathrm{C}$ years B.P.

The transition from fluvial to cienega deposition at the contact of Units Icl and Isi or Igl dates approximately 11,500 B.P., based on the cienega radiocarbon dates and Clovis artifact typologies. The 11,500-year estimate is based on humic acids $25 \mathrm{~cm}$ above the Igl//si contact dating 11,400土110 years (CAMS-19262) and Clovis-style artifacts, which date between 10,800 and 11,500 radiocarbon years B.P. (Taylor et al. 1996), present in the upper portion of Units Igl, Isi, and in the lower few centimeters of Icl.

The oldest age that could be suggested for the Igl/Isi contact is ca. 11,800 years based on depositional rates. Using a depositional rate of $1 \mathrm{~cm}$ per 15 years for the lower twothirds of Unit Icl (see Figure 25-8), the $25 \mathrm{~cm}$ underlying the 11,400 -year age could represent 375 radiocarbon years, or an age of 11,775 years for the Isi/Icl contact. An age of 11,500 to 11,800 years is hypothesized because (1) the depositional positions of the Clovis artifacts are not known, and they may be higher than the artifacts' recovered elevations due to downward migration of the lithic artifacts; and (2) reservoir corrections for the cienega organic matter are unknown; the marsh plants could have grown in waters containing geologically ancient carbonate and could have had reservoir ages of a few hundred years. Consequently, the best interpreted ${ }^{14} \mathrm{C}$ age for the base of Unit Isi sedimentation is 11,500 to 11,800 B.P.

\section{DEVELOPING RADIOCARBON CHRONOLOGIES AT ALLUVIALARCHEOLOGICAL SITES}

Few alluvial sites can be dated by using small numbers of charcoal samples. The reasons for this include (1) the paucity of charcoal or other abundant sample types; (2) poor chemical preservation of organic samples; (3) resistance by stratigraphers to use carbon sources other than charcoal for dating; (4) depositional environments that are not conducive for accumulating or physically preserving charcoal or macrofossils; (5) inherent geochemical constraints that inflict considerable dating uncertainties - residence-times for soils and reservoir-age uncertainties in aquatic systems; (6) pervasive bioturbation; (7) simple excavation and laboratory errors; and (8) poor communication between scientific disciplines and resistance to combining archeological, paleontological, and stratigraphic data to refine absolute-age chronologies.

\section{PROTOCOLS FORAMS ${ }^{14} \mathrm{C}$-AGE DATING ARCHEOLOGICAL SITES}

The field and laboratory studies used for dating the Wilson-Leonard site yielded improved understandings for establishing accurate radiocarbon chronologies. The protocols below cover topics as complex as sediment chemistry and AMS radiocarbon physics to the simple procedures of assigning sample numbers. However, from the most esoteric to the most elementary, these suggestions address errors and problems that are ubiquitous at archeological and paleontological sites.

Dating stratified alluvial sites should be done in three stages. First, an initial series of dates should establish the overall time span for the site. Second, chemical experiments should determine what sample types and chemical fractions will yield the most accurate ages, and third, the final chronology should be based on dating of single stratigraphic sections and features.

\section{Establishing the Initial Chronostratigraphy}

The site's overall age range and ages for major strata and their boundaries should be established immediately to guide excavations and later chronological work. For example, one date each from Units IIIc, IIIa, the Leanne soil, and Unit Icl established that the Wilson-Leonard site dates from Modern to at least the Late Pleistocene and that sedimentation rates were higher in the lower half of the site than in the upper half.

By measuring a few (5 to 10 ) radiocarbon ages initially, the overall chronology is established without generating excessive numbers of dates that may have to be reinterpreted once the stratigraphy and geochemistry are known 
properly. This approach saves considerable money, minimizes the number of "poor analyses" requiring interpretation, and encourages dating samples only after the site's stratigraphy and geochemistry are understood. Burial 2 best illustrates these rationales. The skeleton's radiocarbon analyses were the first age determinations from the site. Unfortunately, the bone was not chemically suitable for dating and the burial's stratigraphic context was uncertain. The age of the burial was established only after later excavations and dating of the entire stratigraphic column. Despite the welldocumented problems of the Burial 2 bone dates, the results cannot simply be dismissed and discarded as "bad dates." These problems would have been eliminated if the Burial 2 dating had been postponed until the stratigraphy and geochemistry were better understood.

\section{Establishing the Final Chronostratigraphy}

The final site chronology should be accomplished in five steps:

(1) The provenience of all potentially datable materials should have XYZ coordinates accurate to at least $\pm 1-2 \mathrm{~cm}$.

(2) Laboratory dating experiments should establish which chemical fractions are most appropriate for each sample type. These materials are often sediments, soils, and biological carbonates that have geochemical characteristics unique to each site.

(3) The final chronology should be based on individual stratigraphic columns that minimize bioturbation effects and stratigraphic correlation problems.

(4) The contemporaneity or age difference for important geological or archeological events should be established by performing the chemical pretreatment, graphitization, and AMS dating as a single submission to the accelerator laboratory, which then measures the graphite targets in the same accelerator run.

(5) There should be continual feedback between the radiometric chronology and the archeological and biostratigraphic chronologies.

\section{Sample Provenience}

One reason that the Wilson-Leonard dating was successful is that most carbon samples were located to \pm 1 $2 \mathrm{~cm}$ and no screen charcoal was used. These precautions overcame or minimized several common problems: i.e., new correlations that change stratigraphic assignments, depth differences between a macrofossil's location and its growth surface, and previously unidentified bioturbation. At Wilson-Leonard, several of these circumstances existed: the top of the Burial 2 pit was not identified when first exposed in 1983 and an unknown thickness of the burial pit was excavated before the burial was identified as such; charred roots and tree stumps in Unit I were later identified as having originated from Unit II, and the extent of Unit Icl bioturbation was evident only after excavations were completed.

Often overlooked are the apparently innocuous methods of sample numbering in the field and laboratory, specifically when multiple samples are collected at one time from a single stratum or a thick stratigraphic column. Number reversals and transcription mistakes cause more laboratory errors than all other laboratory mistakes combined. Human errors will decrease if samples are numbered in stratigraphic order, starting with the smallest number at the top and the largest at the bottom. When radiocarbon dated, samples will increase in age as their sample number increases. For example, the Leanne soil samples were numbered $\mathrm{CH}-285$ on top and $\mathrm{CH}-282$ at the bottom. Reversing this numbering would have more properly matched increasing ages with increasing sample numbers deeper in the soil profile. Another source of error is laboratory numbering of field samples. Internal laboratory numbers should mimic the pattern used in the field, i.e., numbers increasing with stratigraphic depth should be numbered likewise in the laboratory. Using the Leanne series again, field numbers $285,284,283$, and 282 should not be assigned internal laboratory numbers of 100 , $101,102,103$, respectively.

\section{Geochemistry Experiments on Noncharcoal Sample Materials}

Unless natural or charred plant remains are physically dislocated, their dating presents few problems. Unfortunately, it is rare that site chronologies are established exclusively on charcoal. To augment charcoal-based chronologies, nonstandard materials must be used, including bone, sediments, soils, and inorganic and biological carbonates. Although these latter materials have complicated geochemical and stratigraphic considerations, they may provide a more complete and accurate chronology than charcoal alone could provide. Successfully using sediments, soils, and carbonates requires understanding their geochemical properties and their efficacy for radiocarbon dating. The suitability of each sample varies between sites and even among strata at the same site. Consequently, the suitability of each sample type and chemical fraction should be based on geochemical and chronological experiments.

\section{FOSSILBONEGEOCHEMISTRY}

It is easy to identify fossil bones that will yield accurate radiocarbon ages. Quantitative amino acid analyses separate bones into those with and without collagenous protein compositions. Suitable bones are those with $>0.2 \%$ $\mathrm{N}$ by total $\mathrm{CHN}$ analysis, or those with $>100$ nanomoles of amino acids per mg of bone and a collagenous amino acid composition. Bones with $>5 \%$ of their original organic matter date accurately when they are chemically pretreated to remove humates and other exogenous organic matter 
(Stafford et al. 1991). Bones with less than 5\% of their original organic matter have noncollagenous compositions and yield spurious ages. The amino acids most sensitive to degradation are aspartic and glutamic acids, whose proportional increases are evident before degradational changes in glycine and hydroxyproline. Specimens such as Burial 2 human bones, which have noncollagenous compositions, will date hundreds to several thousands of years too young depending on which chemical fraction is isolated.

\section{SEDIMENT AND SOIL GEOCHEMISTRY}

There are strong geochemical reasons for dating specific materials or chemical fractions from sediments and soils, for example, using macrofloral remains or humic acids instead of humins. However, experimental data from the site must corroborate the theoretical assumptions. Geochemical idiosyncrasies at each site might preclude dating any chemical fraction, or a nontypical chemical fraction might be required, for example fulvic acids instead of humic acids or humins. The appropriate chemical fraction for each stratum cannot be identified until initial radiocarbon experiments are completed on the sediments or soils.

After establishing that a sediment or soil will yield reliable age estimates, chemical experiments establish if humic acids or another fraction should be used for the final chronology. Three chemical fractions, decalcified sediment, humic acids, and humins were dated from the Leanne soil and the Icl cienega muds. In three of four Leanne soil levels, and all of three Icl cienega horizons, humic acids yielded the oldest age estimates. If no chemical fraction dates youngest or oldest consistently, further dating is probably not warranted.

Dating the oldest of any chemical fraction is probably the best protocol because most geochemical processes introduce modern carbon over time and yield younger radiocarbon dates. However, using the oldest chemical fraction must be compatible with the biogeochemistry of the depositional environment and subsequent geochemical changes at the site. Humic acids are usually selected because their chemical isolation minimizes, if not precludes, their contamination with younger, particulate carbon, especially cellulose. Humic acids should not be dated without prior experimentation because in environments such as acidic bogs, humic acids are more mobile, and the humin fraction may be the better choice. Finally, using the oldest chemical fraction may not be acceptable for humins from some depositional environments. The humin fraction contains the most residual carbon, which could derive from geologically ancient charcoal, coal, or similar residues. These examples demonstrate why no one chemical fraction can be dated in all situations and why the oldest fraction is not always the one producing the most accurate age.

\section{Single-Column Sampling}

Most archeological and paleontological site chronologies are established by interpreting dates on samples collected incrementally over the excavation season. Often, these results are difficult to compile because strata and their samples cannot be correlated accurately. Second, geochemical anomalies or bioturbation may be discovered long after the samples are dated. These interpretation problems can be reduced substantially by dating single stratigraphic columns from well-exposed stratigraphic sections.

A "single-column chronology" means that numerous samples are collected from one vertical plane and from a narrow-as-possible width along that stratigraphic section. This approach has several benefits: (1) stratigraphic correlation problems are minimized or eliminated - all samples are collected in stratigraphic superposition; (2) dating the same chemical fraction eliminates cross-fraction correlations - discrepancies between chemical fractions are eliminated and the stratum's age accuracy can be evaluated on the strengths or limitations of a single chemical component; (3) chronologies for one stratum are internally consistent; and (4) bioturbation effects are minimized because a narrow (1-4-cm wide) sediment interval was sampled. Close vertical spacing of samples, e.g., collecting one sample every $5-10 \mathrm{~cm}$, decreases the affect of any one erroneous date. Using a single stratigraphic column is most useful for dating sediments and soils because these materials contain sufficient carbon throughout their vertical section. It is more difficult to sample charcoal, macrofossils, or bones from a vertical section because their abundance is lower and distribution is not uniform.

Figure 25-8 illustrates why dating one chemical fraction from a single stratigraphic column minimizes the effects of bioturbation and stratigraphic correlation. Sediments from Squares 27 and 28 were dated initially to determine age relationships among the three chemical fractions (see Figure 257). After humic acids were selected for dating, one vertical column in Square 20 was sampled. The two curves (Squares 27 and 28 versus Square 20) are parallel and have similar agedepth trends and age inversions. However, there is a 900year offset between the two sampling sites, despite the profiles being 1 to $2 \mathrm{~m}$ laterally apart. The chronology for Unit Icl is based on the dates from Square 20 because the ages are from a single chemical fraction (humic acids) from sediments collected in unquestionable stratigraphic superposition. Bioturbation effects are still evident and these would exist throughout the stratum; however, lateral correlation errors within the stratum were eliminated by using only the Square 20 results for the final chronostratigraphy.

\section{Using AMS Measurements to Distinguish between Similar-Age Events}

Radiocarbon analyses are used frequently to determine whether or not archeological events were coeval. Hearths, 
burials, and butchering or habitation features can be contemporaneous at a site or they may represent multiple, recurring occupations separated by a few tens to hundreds of years. Because the age differences among habitations may be within one standard error of a radiocarbon age, variation between dates must be minimized. The best protocol to eliminate analytical variation is to process simultaneously all samples that may belong to a single time event. These samples should be chemically processed, combusted, and graphitized at the same time. Finally, their AMS targets should be run on the same wheel during the accelerator analysis. These steps minimize pretreatment differences among sample suites and the small weekly to monthly variations that may or may not exist among accelerator runs.

\section{Combining Radiometric and Archeological Chronologies}

There should be continual feedback between the radiometric results and archeological and biostratigraphic chronologies. Each chronology should augment the other to produce a final geological and cultural chronology that is more exact than ages based exclusively on radiocarbon assays. At Wilson-Leonard, archeological and biostratigraphic data helped to refine the dating of Units III and Icl. In Unit III, the contact of Units IIIb and IIIa dated 5,500-8,800 years based only on radiocarbon analyses. By using the typologies of Early Archaic artifact types, the contact was more precisely dated as $6000-6500$ B.P. Time lines in the lower $40 \mathrm{~cm}$ of Unit Icl were not absolutely determined because different locations within the cienega muds yielded inconsistent dating results, especially for the Early Paleoindian period. By using the highest stratigraphic occurrences of Clovis- and Folsomstyle artifacts and the position of extinct Pleistocene megafauna (Equus), locating time lines from 10,800 and 11,500 years were better estimated.

There is one caution regarding using archeological typologies and biostratigraphy to augment radiocarbon chronologies and that is the possibility of circular reasoning. The Clovis and Folsom artifact types are accurately and precisely dated across the United States (Taylor et al. 1996); however, other artifact typologies may have poor time control, and their use will lend false credence to a site's chronology. The best biostratigraphic species are extinct ones whose last occurrence has been dated throughout North America. The late Pleistocene megafauna are appropriate time markers and have terminal ages no younger than 10,850 B.P. (Stafford 1990; Stafford et al. 1991). In contrast are full-glacial-age rodent and ungulate species that are missing from a region due to local extinction or climate-induced emigration. These latter species should be used with extreme caution because their migration histories are not dated accurately.

\section{CONCLUSIONS}

The natural genetic units of the Wilson-Leonard stratigraphy are demonstrated by the sediments' tripartite division into Units I, II, and III. These lithostratigraphic units represent three internally cohesive, distinct deposition episodes that date from at least 12,000 в.P. to present. The principal sedimentological events were:

(1) Unit I was deposited from at least 12,000 to 9500 B.P., and reflects a progression from fluvial to cienega, and finally to elevated soil (upland) environments.

(2) A 9500 B.P. disconformity separates Units I and II, and is interpreted to represent the culmination of a drying cycle begun during Unit I time. The erosion terminated deposition of Unit Id as well as Leanne soil pedogenesis, and truncated that soil and Unit Id.

(3) Unit II deposition was from 9500 to ca. 8700 B.P. and comprised primarily coarse, upland-derived, colluvial sediments. After Unit II time, sedimentation rates decreased markedly and while variable, continued to be low until the present.

(4) Unit III strata recorded slow accumulation of primarily fine colluvial and eolian sediments that were intermixed with substantial amounts anthropogenic burned rocks, artifacts, and organic carbon from numerous human occupations. Unit III deposition dates from 8700 years ago to the middle twentieth century.

The chronostratigraphic analyses at the WilsonLeonard site demonstrate how AMS radiocarbon dating, geochemistry, archeology, and paleontology combine to yield a site chronology that is far more accurate than achievable by any one single method. The foundation of this chronology is the ability of AMS techniques to date 0.1 to $1 \mathrm{mg}$ of carbon. This capability means that individual macrofossils, charcoal fragments, separate tree rings, thin sediment horizons, and specific organic compounds can be dated with precisions never before possible. However, the effective use of AMS dating necessitates that there is an even greater understanding of taphonomic, sedimentological, and geochemical processes at each geological site. When the advances of AMS physics are combined with a commensurate improvement in stratigraphic and geochemical knowledge, site chronologies will be far more accurate than when conventional dating and sedimentology practices are used. 


\title{
Chapter 26
}

\section{ANALYSIS OF CULTURAL AND NATURAL FEATURES}

\author{
by Jan Guy
}

\section{INTRODUCTION}

The various peoples who camped on the WilsonLeonard terrace for 11,000 years left us many clues to the activities they engaged in during their visits. Other chapters have detailed an impressive, stratified sequence of stone tools and animal and plant remains spanning numerous Paleoindian through Late Prehistoric occupations. This chapter considers another line of evidence: a rather tantalizing yet perplexing suite of clues we refer to as the feature evidence.

The body of data analyzed in the present study consists of 260 features recorded during the 1982-1993 TxDOT and TARL investigations. The vast majority of these ( 226 or ca. $87 \%$ ) are cultural (or probably cultural) features, but the sample also includes 21 natural features and 13 features of undetermined cultural or natural origin.

The cultural feature sample is strongly dominated by burned rock features. They comprise approximately $94 \%$ of this sample (212 of 226). This dominance is not surprising given the general high frequency of burned rock features in Central Texas sites (Collins 1991; Prewitt 1981; Weir 1976), but it should also be noted that burned rock features often have a higher archeological visibility than do other types (e.g., hearths lacking burned rocks or small postholes). The nonperishable rock constituents of these features also have a higher survival rate in an open terrace site than features comprised of entirely perishable materials. Since the stratified sequence of burned rock features is one of the strongest data sets in the present sample, much of the feature analysis focused on data collected from burned rock features.

Cultural features were found in all major stratigraphic units at the Wilson-Leonard site, and they reflect a long sequence of human occupations. In addition to a highly significant, early human burial (estimated to date to ca. 10,000 B.P.), the cultural features found in Paleoindian-age deposits (ca.
11,500-8800 B.P.) include several intriguing pit features, a few artifact or bone clusters, and several dozen burned rock features. The burned rock features are primarily small "hearthlike" configurations, but they also include several larger features that may reflect earth/rock oven cooking technology.

The cultural features found in Archaic-age deposits (ca. 8800-1300 B.P.) include one or two disturbed human burials, a possible biface cache, and at least 158 burned rock features. The Archaic burned rock features encompass a greater range of variation than the Paleoindian features. At the larger end of the scale, they include massive, domed mounds of concentrated burned rocks (or "burned rock middens"); extensive, flat accumulations of burned rocks; large, basinshaped pits filled with burned rocks (probable rock/earth ovens); and large, flat clusters of burned rocks. The smaller burned rock features include small basin-shaped pits filled with burned rocks; small, flat clusters of burned rocks; burned rock rings; and small patches of burned sediment with a few burned rocks.

Only four features were judged potentially associated with use of the site in the Late Prehistoric period (ca. 1300800 в.P.). Some evidence suggests there may have been a relatively minor Late Prehistoric contribution to one of the burned rock middens, and three small burned rock features found in the upper levels may date to this period as well.

The natural features consist primarily of burned trees (or other large plants) and burrows (or other filled depressions). Many of the natural features were initially documented as potential cultural features (e.g., hearths or pits).

The process of collecting and interpreting feature evidence is fraught with subjective bias, and archeologists often engage in heated debate over the significance of the features they identify. This is especially true of the poorly preserved remains of open campsites used by nomadic hunter-gatherer groups for relatively short periods of time. The physical evidence of the individual components (e.g., hearths, domiciles, and dedicated work areas) and overall 
structure of the various camps may consist of rather ephemeral clues that are easily obliterated (or reconfigured) during the initial occupation, subsequent occupations, and postabandonment. The transient nature of this evidence is also affected by natural site formation processes and preservation conditions which may vary throughout a site's history. The evidence is further biased by archeological sampling strategies and the types of data archeologists collect and record.

Nonetheless, it is among these remains that we find some of the most revealing clues to the prehistoric past. Feature data played several very important roles in the overall Wilson-Leonard site analysis: the clues gleaned from cultural features enhanced our efforts to reconstruct the lifeways of the various peoples who utilized this site; the faunal and botanical remains from feature contexts provided important clues to the biohabitats these people occupied and the resources available for their consumption; selected radiocarbon samples from feature contexts provided many of the key anchor points in the development of the Wilson-Leonard chronostratigraphy (see Chapter 25); and feature data contributed significantly to the ellucidation of both cultural and natural site formation processes.

Behavioral implications/interpretations of feature data are discussed primarily in the synthesis chapters in Volume I (see Chapters 7-11) where they are considered along with supporting lines of evidence drawn from other studies of the Wilson-Leonard data as well as relevant comparative data from other sites. This chapter focuses primarily on the more objective, descriptive data from which interpretive conclusions are drawn, especially the morphological and contextual data.

The results of the feature analysis are summarized in seven major sections. The first section discusses some of the strengths and limitations of the field documentation upon which much of this analysis was based. The second section presents tabular summaries of all features recorded in the TxDOT and TARL excavations. This is followed by a section discussing the various classes of features identified in the analysis and the criteria upon which these classifications were based. The next section summarizes the various materials recovered from feature contexts and the special studies performed on some of these materials. This is followed by sections summarizing the results of this analysis and interpretive conclusions drawn from these results. The last section presents detailed descriptions of 140 selected features.

\section{FEATUREDOCUMENTATION}

Since archeological features are usually dismantled as they are excavated, feature analysis is largely dependent on the data collected during the excavation/investigation process. These data include both the field documentation (i.e., written descriptions, drawings, and photographs) and the physical materials collected from feature contexts (e.g., artifacts, stones, sediment, faunal/plant remains, and special samples).

In the present Wilson-Leonard sample, there is a tremendous range of variation in both the quantity and quality of the data collected from each of the 260 recorded features. Since more analytical effort has been devoted to the better documented features, it is important to note some of the critical strengths and limitations identified in the collected data. The various materials collected from feature contexts in the TxDOT and TARL investigations are summarized in a later section. This section summarizes the range of variation encountered in the field records and the implications for this analysis.

\section{TxDOT Documentation}

A detailed summary and assessment of the TxDOT feature documentation was presented in the 1991 TARL evaluation of the TxDOT field records (Collins et al. 1991). This study inventoried and assessed five major sources of feature documentation: (1) individual sets of "feature" or "burial notes" (including both written descriptions and/or drawings); (2) level records and associated feature drawings/ floor plans; (3) photographs (color slides; black and white prints; color Polaroids) and corresponding photo log descriptions; (4) daily journal references; and (5) "Feature Data Forms." The latter source consists of a typed set of brief feature descriptions that were apparently generated in the TxDOT lab. Whereas the first four sources constitute primary field data, the Feature Data Forms clearly represent a secondary source based on field data. The latter include numerous provenience errors and generally represent a rather unreliable source. Although they were not identified as a source of feature data in the 1991 study, the TxDOT profile drawings (geologic/stratigraphic) were another important source of primary field data for the feature analysis.

Written descriptions in either the level records or feature notes were found for approximately $87 \%$ of the features. These descriptions range from very brief notations to comprehensive summaries. Most features were only described in the level records, with separate sets of "feature notes" compiled for only about $17 \%$. Approximately $10 \%$ of the recorded features were only described in very brief daily journal entries. Most features (ca. 93\%) were documented with at least one drawing (usually a plan drawing), and the more complex features were usually documented with multiple drawings (these include a few profile or cross-section drawings). Most features (ca. 94\%) were also documented with at least one photograph, with numerous photographs taken of most of the more significant features.

Overall, the TxDOT feature documentation improved dramatically as the investigations progressed. The poorest data derive from the testing phase and the first several months of the mitigation phase (see Chapter 3). Few or no 
useful feature data were collected from the three test pits and the Block 1 and 2 excavations. Although feature documentation generally improved during the excavation of Blocks 3, 4, and 5, the data are highly variable. The best feature documentation derived from the Block 6 excavations, the Fine-Screened Square (E28/S78), the Area B squares, and the lower levels of the Block 4 squares. Some of the most significant features (notably Burial 2, the Paleoindian burial) were found in the better-documented excavations.

The most critical problems identified in the TxDOT feature documentation include contradictory and incomplete provenience data (especially elevation data) for many features; poor documentation of the stratigraphic context of most features; nonexistent or very limited verbal descriptions for many features; no drawings of some features; no photographs of some features; poor documentation of associated materials (especially special samples); and the lack of comprehensive, accurate indexes listing the provenience of all recorded features and special samples collected from these features (especially charcoal samples intended for radiocarbon dating).

Some of these problems had serious implications for this analysis. A tremendous amount of time and effort was expended trying to resolve contradictory and/or incomplete provenience data (especially elevation data); reconstructing stratigraphic contexts; and reconstructing feature provenience for associated materials. These efforts were more successful for some data sets than others. For example, almost all problems associated with excavation provenience (square, level, etc.) were resolved, but complete elevation data could not be reconstructed for many features (ca. $75 \%$ of the recorded features have incomplete elevation data). Stratigraphic context was successfully reconstructed for most features, but feature provenience could not be retrieved for many of the associated materials (this is discussed further in the associated materials section below).

Ultimately, these efforts led to the identification of the most reliable and thorough sets of feature records. It is these features that have played the most important roles in the overall site analysis.

\section{TARL Documentation}

The methods employed in the excavation and documentation of features during the TARL investigations are briefly summarized in Chapter 3 . The most important sources of feature data in the TARL field records include (1) individual sets of "feature notes" (completed for every feature); (2) level records and associated feature drawings/floor plans; (3) photographs (color slides, black and white prints; color Polaroids) and corresponding photo log descriptions; (4) geologic profile drawings (documenting stratigraphic context); (5) daily journal references; (6) the field "Feature Index" listing the excavation provenience of all the recorded features; and (7) the various special sample indexes (compiled in the field) listing the excavation provenience for all special samples (including those from feature contexts).

Verbal descriptions were made for all the TARL features in either the feature notes or the level notes (the two sets of notes are usually cross-referenced). Some of the feature descriptions are rather brief, but for the most part they range from adequate to comprehensive. There are photographs of all features, and almost all are also documented with one or more drawings (primarily plan drawings; a few profile or cross-section drawings). Both detection level and base elevations were recorded for almost all TARL features (the only features with incomplete data are a modern auger hole and a probable burrow).

A few problems were identified in the TARL feature documentation. There were a few cases of contradictory or incomplete provenience data, but most of these problems were resolved by consulting an alternate source of field data. Since a large number of special samples were collected from TARL features, many of the provenience problems concerned the location of special samples. The field indexes listing special sample provenience and the field bag logs were invaluable in sorting out these sorts of problems.

Probably the single greatest problem with the TARL feature documentation was a somewhat overly cautious tendency to assign feature designations to some poorly defined entities that arguably did not warrant recording as "features." Since special samples were also collected from some of these problematical features, they may appear to be more significant than they are.

\section{FEATURESUMMARY TABLES}

Provenience and basic descriptive data are summarized for all recorded features in Tables 26-1 and 26-2. Table 26-1 lists the 199 features identified in the 1982-1984 TxDOT excavations and Table 26-2 lists the 61 features recorded in the 1992-1993 TARL excavations. During the latter investigations, additional work was performed on three features initially recorded in the TxDOT investigations (Features 181, 184, and Burned Rock Midden 1). These features are listed only on Table 26-1, but the TARL excavation provenience is included. The tables are ordered by feature number, and they list the following data for each feature: excavation provenience (block, square, level, etc.), documented elevation range, stratigraphic context, archeological chronology, feature type, dimensions, and number of rocks recorded (where applicable). The last column on each of these tables indicates which features are described in the Selected Feature Descriptions section presented at the end of the chapter.

\section{Provenience Data}

The excavation provenience is listed slightly differently in the two tables to accommodate the different sampling strategies employed in the TxDOT and TARL excavations 
TABLE 26-1

Attributes of Features Recorded in the TxDOT Excavations

\begin{tabular}{|c|c|c|c|c|c|c|c|c|c|c|c|}
\hline Feature & Block & Square (Quad) & Level & $\begin{array}{l}\text { Elevation Range } \\
\text { (m) }\end{array}$ & $\begin{array}{l}\text { Stratigraphic } \\
\text { Unit }\end{array}$ & $\begin{array}{l}\text { Archeological } \\
\text { Chronology }\end{array}$ & Feature Type & $\begin{array}{l}\text { Horizontal } \\
\text { Extent }(\mathrm{cm})\end{array}$ & \begin{tabular}{|c|} 
Vertical \\
Extent $(\mathrm{cm})$
\end{tabular} & $\begin{array}{l}\text { No. of } \\
\text { Rocks }\end{array}$ & Described \\
\hline 1 & 1 & E22/S98 (SW) & 1 & no data & IIII & Late Prehistoric & burned rock cluster & $40-x-40$ & ca. 5-10 & 11 & $\mathrm{X}$ \\
\hline 2 & 1 & E22/S100 (SE, SW) & 10 & no data & $\mathrm{Y}$ & Early Archaic & burned rock cluster & $100-x-120$ & ca. $5-10$ & 29 & \\
\hline 3 & 1 & E22/S98 (NE, SE) & 10 & no data & $\mathrm{Y}$ & Early Archaic & burned rock cluster & $\begin{array}{c}140-x-60+ \\
\text { (extended into } \\
\text { wall) }\end{array}$ & ca. $5-10$ & over 34 & \\
\hline 4 & 2 & E20/S94 (NW, SW) & 11 to 13 & $97.67-97.27$ & $\mathrm{X} / \mathrm{Y}$ & Early Archaic & large burned rock basin & $\begin{array}{c}170-\mathrm{x}-60+ \\
\text { (extended into } \\
\text { wall) }\end{array}$ & 40 & over 90 & $\mathrm{x}$ \\
\hline 5 & 2 & E20/S96 (NE) & 13 & $97.47-97.45^{*}$ & $\mathrm{X} / \mathrm{Y}$ & Early Archaic & burned rock cluster & $40-x-30$ & ca. $5-10$ & 10 & \\
\hline 6 & 2 & E20/S94 (SE) & 13 & $97.36-97.29 *$ & $\mathrm{X} / \mathrm{Y}$ & Early Archaic & burned rock cluster & $40-x-50$ & ca. $5-10$ & 6 & \\
\hline 7 & 3 & $\begin{array}{l}\text { E20/S82 (all quads) } \\
\text { E20/S84 (NE, NW) }\end{array}$ & 2 & $97.62-97.51$ & IIIc & $\begin{array}{l}\text { Late Archaic or } \\
\text { Late Prehistoric }\end{array}$ & burned rock scatter & $200-x-180$ & ca. 11 & ca. 100 & $\mathrm{x}$ \\
\hline 8 & 3 & $\begin{array}{l}\text { E20/S88 (all quads) } \\
\text { E20/S90 (all quads) }\end{array}$ & 11 to 13 & $97.15-96.78$ & $\mathrm{X} / \mathrm{Y} / \mathrm{IIIb}$ & Early Archaic & burned rock accumulation & $400-x-200$ & ca. $30-40$ & over 500 & $\mathrm{x}$ \\
\hline 9 & 3 & E20/S86 (NE,NW) & 17 & $96.27 *$ & $\mathrm{X} / \mathrm{II} / \mathrm{III}$ & $\begin{array}{l}\text { Late Paleoindian or } \\
\text { Early Archaic }\end{array}$ & burned rock cluster & $70-x-50$ & ca. $5-10$ & 32 & \\
\hline 10 & 3 & E20/S84 (NE, NW) & 5 & $97.32-97.27 *$ & IIIc & Late Archaic & $\begin{array}{l}\text { burned rock cluster (small } \\
\text { burned rock basin?) }\end{array}$ & $90-x-60$ & ca. $5-10$ & ca. 80 & $\mathrm{X}$ \\
\hline 11 & 3 & E20/S86 (NE, SE) & 5 & no data & IIIc & Late Archaic? & artifact cluster (biface cache?) & $25-x-15$ & ca. $5-10$ & $\mathrm{n} / \mathrm{a}$ & $\mathrm{x}$ \\
\hline 12 & 35 & $\begin{array}{l}\text { E20/S88 (NE, SE) } \\
\text { E22/S88 (NW,SW) }\end{array}$ & $\begin{array}{l}12 \text { to } 1411 \text { to } \\
13\end{array}$ & $96.96-96.72$ & $\mathrm{X} / \mathrm{Y} / \mathrm{IIIb}$ & Early Archaic & large burned rock basin & $150-x-105$ & ca. 30 & over 200 & $\mathrm{X}$ \\
\hline 13 & 3 & E20/S90 (NE, SE) & 12 to 13 & no data & $\mathrm{X} / \mathrm{Y}$ & Early Archaic & small burned rock basin & $90-x-70$ & ca. 20 & over 100 & $\mathrm{x}$ \\
\hline 14 & 3 & E20/S82 (all quads) & 6 & $97.22-97.12^{*}$ & IIIc & $\begin{array}{l}\text { Middle or Late } \\
\text { Archaic }\end{array}$ & burned rock cluster & $45-x-35$ & ca. 10 & ca. 25 & $\mathrm{X}$ \\
\hline 15 & 3 & E20/S88 (NE, SE) & 15,16 & $96.77-96.52^{*}$ & $\mathrm{x}$ & Early Archaic & burned rock scatter & $180-x-60$ & 25 & ca. 75 & \\
\hline 16 & 3 & E20/S84 (NE, SE) & 8 & 97.07-97.03* & IIIb/IIIc & $\begin{array}{l}\text { Middle or Late } \\
\text { Archaic }\end{array}$ & $\begin{array}{l}\text { burned rock cluster (small } \\
\text { burned rock basin?) }\end{array}$ & $55-x-40$ & ca. $5-10$ & ca. 20 & $\mathrm{X}$ \\
\hline 17 & 3 & E20/S90 (NE, SE) & 16 & $96.68-96.55^{*}$ & $\mathrm{x}$ & Early Archaic & $\begin{array}{l}\text { burned rock scatter (with } \\
\text { concentration of burned } \\
\text { sediment) }\end{array}$ & $130-x-130$ & ca. $10-15$ & ca. 50 & $\mathrm{X}$ \\
\hline 18 & 3 & E20/S82 (NW, SW) & 10 & 96.84-96.78* & IIIlb & $\begin{array}{l}\text { Early or Middle } \\
\text { Archaic }\end{array}$ & burned rock cluster & $\begin{array}{c}50-x-25+ \\
\text { (extended into } \\
\text { wall) }\end{array}$ & ca. $5-10$ & over 14 & \\
\hline $19 / 104$ & 35 & $\begin{array}{l}\text { E20/S90 (NE, SE) } \\
\text { E22/S90 (all quads) }\end{array}$ & $15-18$ & $96.77-96.37$ & $\mathrm{x}$ & Early Archaic & large burned rock basin & $220-x-190$ & ca. 40 & over 500 & $\mathrm{X}$ \\
\hline 20 & 35 & $\begin{array}{l}\text { E20/S86 (NE, SE) } \\
\text { E22/S86 (NW,SW) }\end{array}$ & $\begin{array}{c}10 \text { to } 129 \text { to } \\
13\end{array}$ & $97.02-96.78$ & $\mathrm{X} / \mathrm{IIIb} / \mathrm{IIIC}$ & $\begin{array}{l}\text { Middle or Late } \\
\text { Archaic }\end{array}$ & $\begin{array}{l}\text { burned sediment and charcoal } \\
\text { (burned plant?) }\end{array}$ & $160-x-85$ & ca. 25 & $\mathrm{n} / \mathrm{a}$ & $\mathrm{x}$ \\
\hline 21 & 3 & $\mathrm{E} 20 / \mathrm{S} 82(\mathrm{NW}, \mathrm{SW})$ & 12 & 96.69-96.57* & IIIlb & Early Archaic & burned rock scatter & $150-x-80$ & ca. $10-15$ & ca. 70 & \\
\hline 22 & 3 & $\mathrm{E} 20 / \mathrm{S} 86(\mathrm{SW})$ & 15 & 96.63-96.54* & $\mathrm{X} / \mathrm{IIIa}$ & Early Archaic & burned rock cluster & $40-x-35$ & ca. $5-10$ & 12 & $\mathrm{X}$ \\
\hline
\end{tabular}

*Incomplete elevation data 
Table 26-1, continued

\begin{tabular}{|c|c|c|c|c|c|c|c|c|c|c|c|}
\hline Feature & Block & Square (Quad) & Level & $\begin{array}{l}\text { Elevation Range } \\
(\mathrm{m})\end{array}$ & $\begin{array}{l}\text { Stratigraphic } \\
\text { Unit }\end{array}$ & $\begin{array}{l}\text { Archeological } \\
\text { Chronology }\end{array}$ & Feature Type & $\begin{array}{l}\text { Horizontal } \\
\text { Extent }(\mathrm{cm})\end{array}$ & \begin{tabular}{|c|} 
Vertical \\
Extent $(\mathrm{cm})$
\end{tabular} & $\begin{array}{l}\text { No. of } \\
\text { Rocks }\end{array}$ & Described \\
\hline 23 & 3 & $\begin{array}{l}\text { E20/S84 (SW) } \\
\text { E20S86(NW) }\end{array}$ & $15-1616$ & 96.46-96.33* & IIIa/IIIb & Early Archaic & burned rock cluster & $\begin{array}{c}\text { 95-x-55+ } \\
\text { (extended into }\end{array}$ & ca. $10-15$ & over 60 & \\
\hline 24 & 3 & E20/S84 (NE, NW, SE) & 16 & 96.21-96.17* & IIIa & Early Archaic & burned rock cluster & $\begin{array}{l}\text { wall) } \\
80-\mathrm{x}-60\end{array}$ & ca. $5-10$ & ca. 30 & \\
\hline 25 & 3 & E20/S86 (NW, SW) & 16 & $96.45-96.37 *$ & $\mathrm{X} / \mathrm{II} / \mathrm{III}$ & Early Archaic & burned rock cluster & $95-x-85$ & ca. 10 & ca. 40 & \\
\hline 26 & 3 & E20/S82 (SW) & 16,17 & $96.17-96.07 *$ & II/IIIa & Early Archaic & burned rock cluster & $100-x-50$ & ca. $10-15$ & ca. 90 & \\
\hline 27 & 3 & $\mathrm{E} 20 / \mathrm{S} 84(\mathrm{SW})$ & 17 & $96.14-96.08 *$ & IIIIa & Early Archaic & burned rock cluster & $65-x-60$ & ca. $5-10$ & 15 & \\
\hline 28 & 3 & E20/S84 (SE) & 17,18 & $96.21-96.14 *$ & II/IIIa & Early Archaic & $\begin{array}{l}\text { burned rock cluster (possibly in } \\
\text { a pit) }\end{array}$ & $\begin{array}{c}65-x-55+ \\
\text { (extended into } \\
\text { wall) }\end{array}$ & ca. $20-25$ & 35 & $\mathrm{x}$ \\
\hline 29 & 3 & E20/S86 (SE) & 17 & $96.30-96.24 *$ & $\mathrm{X} / \mathrm{II} / \mathrm{III}$ & Early Archaic & burned rock cluster & $130-x-75$ & ca. $5-10$ & ca. 55 & $\mathrm{x}$ \\
\hline $\begin{array}{l}30 \\
31\end{array}$ & 3 & $\begin{array}{l}\text { E20/S84 (SW) } \\
\text { number skipped }\end{array}$ & 18,19 & $96.12-95.96^{*}$ & II/IIIa & $\begin{array}{l}\text { Late Paleoindian or } \\
\text { Early Archaic }\end{array}$ & burned rock cluster & $80-x-75$ & ca. $15-20$ & ca. 32 & \\
\hline 32 & 4 & E20/S72 (NE, NW) & 3 & $97.02-96.99 *$ & IIIc & Late Archaic & burned rock cluster & $90-x-75$ & ca. $5-10$ & 22 & \\
\hline 33 & 35 & $\begin{array}{c}\text { E20/S86 (NE,SE) } \\
\text { E22/S86 (NW, SW) }\end{array}$ & 18,1919 & $96.20-95.93^{*}$ & $\mathrm{X} / \mathrm{II}$ & $\begin{array}{c}\text { Late Paleoindian or } \\
\text { Early Archaic }\end{array}$ & burned rock cluster & $160-x-80$ & ca. $20-30$ & ca. 50 & \\
\hline 34 & 4 & $\begin{array}{c}\mathrm{E} 20 / \mathrm{S} 74(\mathrm{SE}, \mathrm{SW}) \\
\mathrm{E} 20 / \mathrm{S} 76(\mathrm{NE})\end{array}$ & 3 & $97.22-97.17 *$ & IIIc & Late Archaic & burned rock cluster & $85-x-45$ & ca. $5-10$ & 38 & $\mathrm{x}$ \\
\hline 35 & 4 & E20/S78 (SE, SW) & 3,4 & 97.16-97.08* & IIIC & Late Archaic & burned rock ring & $100-x-50$ & ca. $10-15$ & 20 & $\mathrm{X}$ \\
\hline 36 & 4 & $\mathrm{E} 20 / \mathrm{S} 72$ (SE) & 3 & 97.05-96.97* & IIIC & Late Archaic & burned rock cluster & $60-x-40$ & ca. 10 & ca. 16 & $X$ \\
\hline $37 \mathrm{~A}$ & 4 & E20/S78 (NE) & 6 & 97.03-96.91* & IIIc & $\begin{array}{l}\text { Middle or Late } \\
\text { Archaic }\end{array}$ & burned rock cluster & $80-x-75$ & ca. $10-15$ & 40 & $\mathrm{X}$ \\
\hline $37 \mathrm{~B}$ & 4 & $\mathrm{E} 20 / \mathrm{S} 78$ (SW) & 6 & 97.09-97.04* & IIIc & $\begin{array}{l}\text { Middle or Late } \\
\text { Archaic }\end{array}$ & burned rock cluster & $65-x-15$ & ca. $5-10$ & 11 & $\mathrm{X}$ \\
\hline 38 & 4 & E20/S74 (SE) & 3,4 & $97.19-97.17 *$ & IIIc & Late Archaic & burned rock cluster & $\begin{array}{c}55-\mathrm{x}-30+ \\
\text { (extended into } \\
\text { wall) }\end{array}$ & ca. $10-15$ & 18 & $\mathrm{x}$ \\
\hline 39 & 4 & E20/S74 (NW) & 6 & $96.92-96.85^{*}$ & IIIc & $\begin{array}{l}\text { Middle or Late } \\
\text { Archaic }\end{array}$ & $\begin{array}{l}\text { burned rock cluster (small } \\
\text { burned rock basin?) }\end{array}$ & $60-x-60$ & ca. 10 & ca. 45 & $\mathrm{X}$ \\
\hline 40 & 4 & $\begin{array}{c}\mathrm{E} 20 / \mathrm{S} 76(\mathrm{NE}) \mathrm{E} 20 / \mathrm{S} 74 \\
(\mathrm{SE})\end{array}$ & 8 & $96.77-96.75^{*}$ & $\mathrm{IIIb} / \mathrm{III} \mathrm{c}$ & Middle Archaic? & burned rock cluster & $40-x-40$ & ca. $5-10$ & 25 & $\mathrm{x}$ \\
\hline 41 & 4 & $\begin{array}{l}\mathrm{E} 20 / \mathrm{S} 78(\mathrm{NW}, \mathrm{NE}) \\
\mathrm{E} 20 / \mathrm{S} 76(\mathrm{SW})\end{array}$ & 8 & 96.79-96.78* & $\mathrm{IIIb} / \mathrm{IIIc}$ & Middle Archaic? & burned rock cluster & $50-x-50$ & ca. $5-10$ & 25 & $\mathrm{x}$ \\
\hline 42 & 4 & $\mathrm{E} 20 / \mathrm{S} 78(\mathrm{NE})$ & 8 & 96.81-96.79* & $\mathrm{IIIb} / \mathrm{IIIc}$ & Middle Archaic? & burned rock cluster & $70-x-50$ & ca. $5-10$ & 15 & $\mathrm{X}$ \\
\hline 43 & 4 & E20/S72 (NW) & $9 \mathrm{~A}$ & 96.63-96.57* & $\mathrm{IIIb} / \mathrm{III}$ & Middle Archaic? & burned rock cluster & $75-x-75$ & ca. $5-10$ & ca. 60 & $\mathrm{X}$ \\
\hline 44 & 4 & E20/S76 (NW, SW) & $9 \mathrm{~A}$ & 96.73-96.71* & $\mathrm{IIIb} / \mathrm{III}$ & Middle Archaic? & burned rock cluster & $45-x-30$ & ca. $5-10$ & 4 & \\
\hline 45 & 4 & E20/S72 (NE, SE) & $10 \mathrm{~A}$ & $96.48-96.44 *$ & $\mathrm{IIIb} / \mathrm{IIIc}$ & Middle Archaic? & burned rock cluster & $95-x-55$ & ca. $5-10$ & 20 & \\
\hline 46 & 4 & E20/S74 (NW, SW) & $11 \mathrm{~B}$ & $96.50-95.46^{*}$ & IIIlb & Middle Archaic? & burned rock cluster & $130-x-120$ & ca. $5-10$ & ca. 70 & \\
\hline 47 & 4 & E20/S76 (SE) & 11B & $96.47 *$ & IIIlb & Middle Archaic? & burned rock cluster & $40-x-25$ & ca. $5-10$ & 10 & \\
\hline 48 & 4 & E20/S76 (SW) & $11 \mathrm{~B}$ & 95.95-95.81* & IIIlb & Middle Archaic? & burned rock cluster & $40-x-30$ & ca. 15 & 6 & \\
\hline
\end{tabular}


Table 26-1, continued

\begin{tabular}{|c|c|c|c|c|c|c|c|c|c|c|c|}
\hline Feature & Block & Square (Quad) & Level & $\begin{array}{c}\begin{array}{c}\text { Elevation Range } \\
(\mathrm{m})\end{array} \\
\end{array}$ & $\begin{array}{l}\text { Stratigraphic } \\
\text { Unit } \\
\end{array}$ & $\begin{array}{l}\text { Archeological } \\
\text { Chronology }\end{array}$ & Feature Type & $\begin{array}{l}\text { Horizontal } \\
\text { Extent }(\mathrm{cm}) \\
\end{array}$ & \begin{tabular}{|c|} 
Vertical \\
Extent $(\mathrm{cm})$ \\
\end{tabular} & $\begin{array}{l}\text { No. of } \\
\text { Rocks }\end{array}$ & Described \\
\hline 49 & 4 & E20/S78 (NE) & $11 \mathrm{~B}$ & $96.49 *$ & IIIb & Middle Archaic & $\begin{array}{l}\text { burned sediment (probably } \\
\text { associated with Feature 50) }\end{array}$ & $40-x-20$ & ca. 5 & $\mathrm{n} / \mathrm{a}$ & \\
\hline 50 & 4 & E20/S78 (NE) & $12 \mathrm{~A}-16 \mathrm{~A}$ & ca. 96.44-96.04 & $\mathrm{IIIa} / \mathrm{IIIb}$ & Middle Archaic & burned tree & $70-x-90$ & 40 & $\mathrm{n} / \mathrm{a}$ & $\mathrm{x}$ \\
\hline 51 & 4 & E20/S72 (SE) & $13 \mathrm{~A}$ & $96.22-96.20 *$ & IIIb & Early Archaic & burned rock cluster & $\begin{array}{c}50-x-25+ \\
\text { (extended into } \\
\text { wall) }\end{array}$ & ca. $5-10$ & 15 & \\
\hline 52 & 4 & E20/S76 (SW, NW) & $16 \mathrm{~A}$ & $\begin{array}{c}\text { no data; level } \\
\text { was } 96.06-95.96\end{array}$ & IIIa & Early Archaic & burned rock cluster & $\begin{array}{c}60-x-30+ \\
\text { (extended into } \\
\text { wall) }\end{array}$ & ca. $5-10$ & over 25 & \\
\hline 53 & 4 & $\mathrm{E} 20 / \mathrm{S} 78(\mathrm{NW})$ & $16 \mathrm{~A}$ & $\begin{array}{c}\text { no data; level } \\
\text { was } 96.12-95.97\end{array}$ & IIIa & Early Archaic & burned rock cluster & $90-x-80$ & ca. $5-10$ & ca. 50 & \\
\hline 54 & 4 & $\begin{array}{l}\text { E20/S74 (SE, SW) } \\
\text { E20/S76 (NE, NW) }\end{array}$ & $16 \mathrm{~A}$ & $\begin{array}{c}\text { no data; level } \\
\text { was } 96.06-95.90\end{array}$ & IIIa & Early Archaic & burned rock scatter & $180-x-140$ & ca. $5-10$ & ca. 100 & \\
\hline 55 & 4 & E20/S72 (NE) & $16 \mathrm{~A}$ & $\begin{array}{c}\text { no data; level } \\
\text { was } 95.97-95.87\end{array}$ & IIIa & Early Archaic & burned rock cluster & $90-x-50$ & ca. $5-10$ & 23 & \\
\hline 56 & 4 & E20/S72 (NW) & $16 \mathrm{~A}$ & $\begin{array}{c}\text { no data; level } \\
\text { was } 95.97-95.87\end{array}$ & ШІа & Early Archaic & burned rock cluster & $30-x-20$ & ca. $5-10$ & 12 & \\
\hline 57 & & number skipped & & & & & & & & & \\
\hline 58 & 4 & $\begin{array}{l}\mathrm{E} 20 / \mathrm{S} 78(\mathrm{NW}, \mathrm{SW}) \\
\mathrm{E} 20 / \mathrm{S} 76(\mathrm{SW})\end{array}$ & 17B & 95.94-95.87* & ШII & Early Archaic & $\begin{array}{c}\text { burned rock cluster (possibly in } \\
\text { a large basin?) }\end{array}$ & $\begin{array}{c}120-\mathrm{x}-65+ \\
\text { (extended into } \\
\text { wall) }\end{array}$ & ca. 10 & ca. 150 & \\
\hline 59 & 4 & $\mathrm{E} 20 / \mathrm{S} 72(\mathrm{NW})$ & $18 \mathrm{~A}$ & 95.73-95.72* & IIIa & Early Archaic & burned rock scatter & $70-x-65$ & ca. $5-10$ & 20 & \\
\hline 60 & 4 & $\mathrm{E} 20 / \mathrm{S} 72(\mathrm{NE})$ & $18 \mathrm{~A}$ & $95.68-95.66^{*}$ & IIIa & Early Archaic & burned rock cluster & $35-x-30$ & ca. $5-10$ & 14 & \\
\hline 61 & 4 & E20/S74 (SE, NE, NW) & $18 \mathrm{~A}$ & 95.82-95.69* & ШІа & Early Archaic & burned rock cluster & $100-x-70$ & ca. $10-15$ & ca. 50 & \\
\hline 62 & 4 & E20/S76 (SW) & $18 \mathrm{~A}$ & 95.87-95.84* & IIIa & Early Archaic & burned rock cluster & $40-x-35$ & ca. $5-10$ & 16 & \\
\hline 63 & 4 & E20/S78 (NE, NW) & $18 \mathrm{~A}$ & ca. $95.87 *$ & ПIIIIIa & Early Archaic & burned rock cluster & $55-\mathrm{x}-30$ & ca. $5-10$ & 19 & \\
\hline 64 & 4 & E20/S78 (SW) & $18 \mathrm{~A}$ & 95.96-95.84* & II/IIIa & Early Archaic & burned rock cluster & $75-x-40$ & ca. $10-15$ & 13 & \\
\hline 65 & 4 & E20/S78 (SW) & $18 \mathrm{~B}, 19 \mathrm{~A}$ & $95.83-95.78^{*}$ & II/IIIIa & Early Archaic & burned rock scatter & $150-x-30$ & ca. $5-10$ & 21 & \\
\hline 66 & 4 & E20/S74 (NE) & $19 \mathrm{~A}$ & $95.71-95.65^{*}$ & IIIa & Early Archaic & burned rock cluster & $50-x-40$ & ca. $5-10$ & 11 & \\
\hline 67 & 4 & $\begin{array}{c}\mathrm{E} 20 / \mathrm{S} 74 \text { (NE) E20/S72 } \\
\text { (SE) }\end{array}$ & $19 \mathrm{~A}$ & $95.60-95.58^{*}$ & IIIa & Early Archaic & burned rock cluster & $90-x-40$ & ca. $5-10$ & 16 & \\
\hline 68 & 4 & E20/S72 (NE) & 19B & $95.62-95.54$ & ШII & Early Archaic & burned rock cluster & $65-x-55$ & 8 & 28 & \\
\hline 69 & 4 & E20/S74 (NW, SW) & $19 \mathrm{~B}, 20 \mathrm{~A}$ & $95.92-95.43$ & II/IIIa & Early Archaic & $\begin{array}{l}\text { burned sediment and charcoal } \\
\text { (burned plant?) }\end{array}$ & $85-x-60$ & 49 & $\mathrm{n} / \mathrm{a}$ & \\
\hline 70 & 4 & E20/S78 (NE) & 19B & $95.66-95.62 *$ & II/IIIa & Early Archaic & burned rock cluster & $70-x-55$ & ca. $5-10$ & 24 & \\
\hline 71 & 4 & $\mathrm{E} 20 / \mathrm{S} 78(\mathrm{NW}, \mathrm{SW})$ & $27 \mathrm{~A}$ & $94.80-94.75^{*}$ & Isi-c & Late Paleoindian & burned rock ring? & $70-x-35$ & ca. $5-10$ & 6 & $\mathrm{X}$ \\
\hline 72 & 4 & E20/S74 (all quads) & $27 \mathrm{~A}, \mathrm{~B}$ & $94.73 *$ & Isi-c & Late Paleoindian & burned tree root (part of F167) & $110-x-110$ & no data & $\mathrm{n} / \mathrm{a}$ & $\mathrm{X}$ \\
\hline 73 & 4 & E20/S74 (all quads) & $28 \mathrm{~B}-30 \mathrm{~A}$ & $94.57^{*}$ & Isi/Icl/Isi-c & Late Paleoindian & burned tree root (part of F167) & $80-\mathrm{x}-80$ & no data & $\mathrm{n} / \mathrm{a}$ & $\mathrm{X}$ \\
\hline 74 & 4 & E20/S76 (NE) & $29 \mathrm{~A}, \mathrm{~B}$ & $\begin{array}{c}\text { no data; level } \\
\text { was } 94.53-94.44\end{array}$ & Isi/Icl/Isi-c & $\begin{array}{l}\text { Early or Late } \\
\text { Paleoindian }\end{array}$ & gravel pocket & $40-x-35$ & 9 & $\mathrm{n} / \mathrm{a}$ & $\mathrm{X}$ \\
\hline 75 & 5 & $\mathrm{E} 22 / \mathrm{S} 82$ (SW) & 6 & $97.20-97.19^{*}$ & $\mathrm{IIIb} / \mathrm{IIIc}$ & Late Archaic? & small burned rock basin & $40-x-30$ & ca. $5-10$ & 4 & $\mathrm{X}$ \\
\hline 76 & 5 & $\mathrm{E} 22 / \mathrm{S} 82(\mathrm{SE})$ & 6 & 97.18-97.14* & $\mathrm{IIIb} / \mathrm{III} \mathrm{c}$ & Late Archaic? & burned rock cluster & $60-x-60$ & ca. $5-10$ & 40 & $\mathrm{X}$ \\
\hline
\end{tabular}


Table 26-1, continued

\begin{tabular}{|c|c|c|c|c|c|c|c|c|c|c|c|}
\hline Feature & Block & Square (Quad) & Level & $\begin{array}{c}\text { Elevation Range } \\
(\mathrm{m})\end{array}$ & $\begin{array}{l}\text { Stratigraphic } \\
\text { Unit }\end{array}$ & $\begin{array}{l}\text { Archeological } \\
\text { Chronology }\end{array}$ & Feature Type & $\begin{array}{l}\text { Horizontal } \\
\text { Extent }(\mathrm{cm})\end{array}$ & \begin{tabular}{|c|} 
Vertical \\
Extent $(\mathrm{cm})$
\end{tabular} & $\begin{array}{l}\text { No. of } \\
\text { Rocks }\end{array}$ & Described \\
\hline 77 & 5 & $\mathrm{E} 22 / \mathrm{S} 80(\mathrm{SE})$ & 6 & $97.12-97.08^{*}$ & IIII & Late Archaic? & burned rock cluster & $25-x-20$ & ca. 5-10 & 7 & $\mathrm{X}$ \\
\hline 78 & 5 & $\mathrm{E} 22 / \mathrm{S} 80(\mathrm{NW}, \mathrm{SW})$ & 6 & $97.07-97.00^{*}$ & IIIc & Late Archaic? & $\begin{array}{l}\text { burned rock cluster (small } \\
\text { burned rock basin?) }\end{array}$ & $90-x-80$ & ca. $10-15$ & ca. 60 & $\mathrm{x}$ \\
\hline 79 & 5 & $\begin{array}{c}\text { E22/S88 (SW) } \\
\text { E22/S90 (NW, NE) }\end{array}$ & 9 & $\begin{array}{c}\text { no data; level } \\
\text { was } 97.34-97.18\end{array}$ & $\mathrm{Y} / \mathrm{IIIc}$ & $\begin{array}{l}\text { Early or Middle } \\
\text { Archaic }\end{array}$ & $\begin{array}{l}\text { depression filled with charcoal- } \\
\text { stained sediment and ash }\end{array}$ & $130-x-105$ & no data & $\mathrm{n} / \mathrm{a}$ & $\mathrm{x}$ \\
\hline 80 & 5 & $\begin{array}{l}\mathrm{E} 22 / \mathrm{S} 84(\mathrm{NW}) \\
\mathrm{E} 22 / \mathrm{S} 82(\mathrm{SW})\end{array}$ & 9 & 96.94-96.83* & ШІІb/ШІ & $\begin{array}{l}\text { Early or Middle } \\
\text { Archaic }\end{array}$ & burned rock cluster & $90-x-60$ & ca. $10-15$ & 46 & \\
\hline 81 & 5 & E22/S84 (NE, SE) & 9,10 & $96.87-96.72 *$ & $\mathrm{IIIb} / \mathrm{III}$ & $\begin{array}{l}\text { Early or Middle } \\
\text { Archaic }\end{array}$ & burned rock scatter & $\begin{array}{c}200-\mathrm{x}-50+ \\
\text { (extended into } \\
\text { wall) }\end{array}$ & ca. $15-20$ & over 100 & \\
\hline 82 & 5 & E22/S84 (NW, SW) & 10 & $96.81-96.73 *$ & IIIb & Early Archaic? & burned rock cluster & $130-x-60$ & ca. $5-10$ & 43 & \\
\hline 83 & 5 & $\mathrm{E} 22 / \mathrm{S} 80(\mathrm{NW}, \mathrm{SW})$ & 9 & 96.81-96.74* & IIIb & Middle Archaic? & burned rock cluster & $65-x-30$ & ca. $5-10$ & 19 & \\
\hline 84 & 5 & E22/S82 (NE, SE) & 10,11 & $96.68-96.61^{*}$ & IIIlb & $\begin{array}{l}\text { Early or Middle } \\
\text { Archaic }\end{array}$ & burned rock cluster & $90-x-90$ & ca. $10-15$ & ca. 40 & \\
\hline 85 & 5 & $\mathrm{E} 22 / \mathrm{S} 90(\mathrm{SW})$ & 11 & $97.17-97.15^{*}$ & $\mathrm{Y}$ & Early Archaic & burned rock cluster & $70-x-70$ & ca. $5-10$ & ca. 25 & \\
\hline 86 & 5 & E22/S88 (NE) & 11 & 96.96-96.88* & $\mathrm{Y} / \mathrm{IIIb}$ & Early Archaic & burned rock cluster & $\begin{array}{c}80-x-50+ \\
\text { (extended into } \\
\text { wall) }\end{array}$ & ca. 10 & over 19 & \\
\hline 87 & 5 & E22/S88 (all quads) & 11,12 & $96.96-96.89 *$ & $\mathrm{X} / \mathrm{Y} / \mathrm{IIL}$ & Early Archaic & burned rock cluster & $45-x-35$ & ca. 10 & 23 & \\
\hline 88 & 5 & $\begin{array}{l}\text { E22/S86 (NE, NW) } \\
\text { E22/S84 (all quads) }\end{array}$ & 11 & $96.85-96.70^{*}$ & IIIb & Early Archaic & burned rock scatter & $200-x-170$ & ca. 15 & ca. 250 & \\
\hline 89 & 5 & E22/S82 (NE, SE) & 11 & $96.63-96.60^{*}$ & IIIIb & $\begin{array}{l}\text { Early or Middle } \\
\text { Archaic }\end{array}$ & burned rock ring & $70-x-70$ & ca. $5-10$ & 25 & \\
\hline 90 & 5 & $\mathrm{E} 22 / \mathrm{S} 90$ (SW) & 12 & $97.15-97.07$ & $\mathrm{X} / \mathrm{Y}$ & Archaic? & $\begin{array}{c}\text { isolated human skull (disturbed } \\
\text { burial?) }\end{array}$ & $25-\mathrm{x}-20$ & 8 & $\mathrm{n} / \mathrm{a}$ & $\mathrm{X}$ \\
\hline 91 & 5 & E22/S82 (NE) & 12 & $\begin{array}{c}\text { no data; level } \\
\text { was } 97.47-97.12\end{array}$ & IIIb & Early Archaic & burned rock cluster & $75-x-65$ & ca. 5-10? & 38 & \\
\hline 92 & 5 & $\mathrm{E} 22 / \mathrm{S} 90(\mathrm{SW})$ & 13 & $96.94-96.85 *$ & $\mathrm{X} / \mathrm{Y}$ & Early Archaic & burned rock cluster & $90-x-90$ & ca. 10 & ca. 60 & \\
\hline 93 & 5 & E22/S88 (all quads) & 13 & $96.78-96.73 *$ & $\mathrm{X} / \mathrm{IIIb}$ & Early Archaic & burned rock cluster & $65-x-35$ & ca. $5-10$ & 25 & \\
\hline 94 & 5 & $\begin{array}{l}\mathrm{E} 22 / \mathrm{S} 84(\mathrm{SW}) \\
\mathrm{E} 22 / \mathrm{S} 86(\mathrm{NW})\end{array}$ & 13 & $96.67-96.55$ & $\mathrm{X} / \mathrm{IIIb}$ & Early Archaic & burned rock cluster & $85-x-30$ & ca. $10-15$ & 23 & \\
\hline 95 & 5 & $\mathrm{E} 22 / \mathrm{S} 80$ (SE) & 13 & $96.37 *$ & IIIa/IIIlb & Early Archaic & $\begin{array}{l}\text { burned sediment (burned } \\
\text { plant?) }\end{array}$ & $50-x-40$ & no data & $\mathrm{n} / \mathrm{a}$ & \\
\hline 96 & 5 & $\mathrm{E} 22 / \mathrm{S} 90(\mathrm{SW})$ & 14 & $96.84-96.81^{*}$ & $\mathrm{X}$ & Early Archaic & burned rock cluster & $75-x-70$ & ca. $5-10$ & 22 & \\
\hline 97 & 5 & $\mathrm{E} 22 / \mathrm{S} 90(\mathrm{NW})$ & 14 & 96.80 - $96.73^{*}$ & $\mathrm{X}$ & Early Archaic & burned rock cluster & $60-x-55$ & ca. $5-10$ & 20 & \\
\hline 98 & 5 & $\mathrm{E} 22 / \mathrm{S} 90$ (SE) & 14 & $96.86-96.81^{*}$ & $\mathrm{X}$ & Early Archaic & burned rock cluster & $50-x-35$ & ca. $5-10$ & 11 & \\
\hline 99 & 5 & E22/S90 (NE, SE) & 14 & $96.77-96.71^{*}$ & $\mathrm{X}$ & Early Archaic & burned rock cluster & $80-x-80$ & ca. $5-10$ & 45 & \\
\hline 100 & 5 & E22/S88 (NW, NE) & 14 & $96.71-96.62 *$ & $\mathrm{X} / \mathrm{IIIb}$ & Early Archaic & burned rock cluster & $100-x-50$ & ca. $5-10$ & 50 & \\
\hline 101 & 5 & E22/S84 (NE, SE) & 15 & $96.35-96.25 *$ & IIIIa & Early Archaic & burned rock cluster & $\begin{array}{c}120-\mathrm{x}-100 \\
\text { (extended into } \\
\text { wall) }\end{array}$ & ca. $10-15$ & 75 & \\
\hline
\end{tabular}


Table 26-1, continued

\begin{tabular}{|c|c|c|c|c|c|c|c|c|c|c|c|}
\hline Feature & Block & Square (Quad) & Level & \begin{tabular}{|c|}
$\begin{array}{c}\text { Elevation Range } \\
(\mathrm{m})\end{array}$ \\
\end{tabular} & $\begin{array}{l}\text { Stratigraphic } \\
\text { Unit }\end{array}$ & $\begin{array}{c}\text { Archeological } \\
\text { Chronology }\end{array}$ & Feature Type & $\begin{array}{c}\text { Horizontal } \\
\text { Extent }(\mathrm{cm})\end{array}$ & $\begin{array}{c}\text { Vertical } \\
\text { Extent }(\mathrm{cm})\end{array}$ & $\begin{array}{l}\text { No. of } \\
\text { Rocks }\end{array}$ & Described \\
\hline 102 & 5 & E22/S86 (NE, SE) & 15 & 96.49-96.44* & $\mathrm{X} / \mathrm{IIIa}$ & Early Archaic & burned rock cluster & $\begin{array}{c}70-\mathrm{x}-30+ \\
\text { (extended into } \\
\text { wall) }\end{array}$ & ca. $5-10$ & 11 & \\
\hline 103 & 5 & $\begin{array}{l}\text { E22/S86 (SW) } \\
\text { E22/S88 (NW) }\end{array}$ & 15 & $96.64-96.47^{*}$ & X/IIIa & Early Archaic & burned rock cluster & $190-x-95$ & ca. $15-20$ & 85 & \\
\hline $\begin{array}{l}104 \text { (see } \\
19 / 104)\end{array}$ & & & & & & & & & & & \\
\hline 105 & 5 & $\mathrm{E} 22 / \mathrm{S} 80(\mathrm{NE})$ & 16 & $96.05-96.02 *$ & IIIa & Early Archaic & burned rock cluster & $\begin{array}{c}120-\mathrm{x}-70+ \\
\text { (extended into } \\
\text { wall) }\end{array}$ & ca. $5-10$ & 45 & \\
\hline 106 & 5 & $\mathrm{E} 22 / \mathrm{S} 80$ (SE) & 16 & $96.10-96.06^{*}$ & IIIa & Early Archaic & burned rock cluster & $50-x-50$ & ca. $5-10$ & 14 & \\
\hline 107 & 35 & $\begin{array}{c}\text { E20/S82 (NE, SE) } \\
\text { E22/S82 (NW, SW) }\end{array}$ & 1716 & 96.13-95.96* & II/IIIa & Early Archaic & burned rock cluster & $160-x-130$ & ca. $10-20$ & 45 & $\mathrm{X}$ \\
\hline 108 & 5 & $\mathrm{E} 22 / \mathrm{S} 80(\mathrm{SW}, \mathrm{SE})$ & 17 & \begin{tabular}{|c|} 
no data; level \\
was $96.17-95.92$
\end{tabular} & II/IIIa & $\begin{array}{c}\text { Late Paleoindian or } \\
\text { Early Archaic }\end{array}$ & burned rock cluster & $70-x-40$ & ca. $5-10$ & 17 & \\
\hline 109 & 5 & E22/S82 (NE) & 17 & $96.00-95.96^{*}$ & II & Late Paleoindian & burned rock cluster & $50-x-40$ & ca. $5-10$ & 15 & $\mathrm{x}$ \\
\hline 110 & 5 & $\begin{array}{l}\text { E22/S84 (SW) } \\
\text { E22/S86 (NW) }\end{array}$ & 17 & $96.19-96.09 *$ & X/II/ШII & $\begin{array}{c}\text { Late Paleoindian or } \\
\text { Early Archaic }\end{array}$ & burned rock scatter & $220-x-110$ & ca 10 & 90 & \\
\hline 111 & 5 & $\mathrm{E} 22 / \mathrm{S} 82$ (SW) & 18 & 95.90-95.87* & II & Late Paleoindian & burned rock cluster & $90-x-65$ & ca. $5-10$ & 26 & $\mathrm{X}$ \\
\hline 112 & 5 & E22/S88 (NE) & 20 & 96.13-96.01* & $\mathrm{X}$ & Late Paleoindian & burned rock cluster & $45-x-10$ & ca. $10-15$ & 6 & $X$ \\
\hline 113 & 5 & $\mathrm{E} 22 / \mathrm{S} 84$ (SE) & 20 & $95.90-95.84 *$ & $\mathrm{X} / \mathrm{II}$ & Late Paleoindian & burned rock cluster & $\begin{array}{c}15-\mathrm{x}-18+ \\
\text { (extended into } \\
\text { wall) }\end{array}$ & ca. $5-10$ & 8 & $\mathrm{X}$ \\
\hline 114 & 5 & E22/S84 (all quads) & 20 & 95.79-95.76* & $\mathrm{X} / \mathrm{II}$ & Late Paleoindian & burned rock cluster & $40-x-15$ & ca. $5-10$ & 6 & $\mathrm{X}$ \\
\hline 115 & 5 & $\mathrm{E} 22 / \mathrm{S} 88$ (NE) & $22-23$ & $95.99-95.98 * *$ & $\mathrm{X}$ & Late Paleoindian & burned rock cluster & $95-x-30$ & ca. $5-10$ & 15 & $\mathrm{X}$ \\
\hline 116 & 5 & $\mathrm{E} 22 / \mathrm{S} 86$ (NE) & 22 & $95.80^{*}$ & $\mathrm{X}$ & Late Paleoindian & burned rock cluster & $40-x-40$ & ca. $5-10$ & 6 & $\mathrm{X}$ \\
\hline 117 & 5 & $\mathrm{E} 22 / \mathrm{S} 82$ (SW) & 23 & 95.64- $95.53 *$ & $\mathrm{Id} / \mathrm{II}$ & Late Paleoindian & burned rock cluster & $120-x-53$ & ca. $10-15$ & 11 & $\mathrm{X}$ \\
\hline 118 & 5 & E22/S86 (NE) & 23 & 95.81 to $95.77 *$ & $\mathrm{X}$ & Late Paleoindian & burned rock cluster & $110-x-50$ & ca. $5-10$ & 10 & $\mathrm{x}$ \\
\hline 119 & 5 & $\mathrm{E} 22 / \mathrm{S} 82(\mathrm{SE})$ & 24 & 95.48 to $95.42^{*}$ & Isi-c/Id & Late Paleoindian & burned rock cluster & $65-x-60$ & ca. $5-10$ & 12 & $\mathrm{X}$ \\
\hline 120 & & E40/S70 (all quads) & 3,4 & $96.56-96.51^{*}$ & IIIc & Late Archaic & burned rock scatter & $200-x-200$ & ca. $10-20$ & over 300 & \\
\hline 121 & & $\begin{array}{l}\mathrm{E} 40 / \mathrm{S} 70 \text { (quad } \\
\text { unknown) }\end{array}$ & 5,6 & no data & IIIc & Late Archaic & $\begin{array}{l}\text { burned rock scatter (possible } \\
\text { continuation of Feature 120) }\end{array}$ & no data & no data & $\begin{array}{c}\text { not } \\
\text { recorded }\end{array}$ & \\
\hline 122 & 6 & E24/S74 (NE, SE) & 15 & ca. $95.45^{*}$ & IIIa/IIIb & Early Archaic & burned rock cluster & $33-x-25$ & ca. $5-10$ & 8 & \\
\hline 123 & 6 & $\mathrm{E} 22 / \mathrm{S} 78(\mathrm{NE})$ & $16 \mathrm{~A}, 16 \mathrm{~B}$ & 96.02-95.94* & IIIa & Early Archaic & small burned rock basin & $100-x-70$ & ca. $10-15$ & ca. 100 & $\mathrm{X}$ \\
\hline 124 & 6 & $\begin{array}{l}\text { E26/S78 (all quads) } \\
\text { E26/S76 (all quads) } \\
\text { E26/S74 (all quads) }\end{array}$ & $\begin{array}{c}15 \text { to } 17 \mathrm{~B} 15 \\
\text { to } 17 \mathrm{~B} 17 \mathrm{~A} \text {, } \\
17 \mathrm{~B}\end{array}$ & $96.02-95.73^{*}$ & IIIIa & Early Archaic & burned rock accumulation & $\begin{array}{c}\text { over } 600-\mathrm{x}-200 \\
\text { (extended into } \\
\text { walls) }\end{array}$ & ca. $20-30$ & ca. 2,000 & $\mathrm{x}$ \\
\hline 125 & 6 & E26/S76 (SW) & 15 & $95.94 *$ & IIIa & Early Archaic & burned rock cluster & $25-x-30$ & ca. $5-10$ & 5 & \\
\hline 126 & 6 & $\mathrm{E} 22 / \mathrm{S} 74(\mathrm{SE})$ & $16 \mathrm{~A}$ & $95.93-95.89 *$ & IIIIa & Early Archaic & burned rock cluster & $70-x-40$ & ca. $5-10$ & ca. 20 & \\
\hline 127 & 6 & E24/S78 (all quads) & $16 \mathrm{~A}$ & $96.01-95.89 *$ & IIIa & Early Archaic & burned rock cluster & $90-x-70$ & ca. $10-15$ & ca. 40 & \\
\hline 128 & 6 & E22/S76 (NW quad) & $16 \mathrm{~B}$ & $95.89-95.85^{*}$ & IIIa & Early Archaic & burned rock cluster & $100-x-70$ & ca. $5-10$ & ca. 20 & \\
\hline 129 & & number skipped & & & & & & & & & \\
\hline
\end{tabular}




\begin{tabular}{|c|c|c|c|c|c|c|c|c|c|c|c|}
\hline Feature & Block & Square (Quad) & Level & \begin{tabular}{|c|}
$\begin{array}{c}\text { Elevation Range } \\
(\mathrm{m})\end{array}$ \\
\end{tabular} & $\begin{array}{l}\text { Stratigraphic } \\
\text { Unit }\end{array}$ & $\begin{array}{l}\text { Archeological } \\
\text { Chronology }\end{array}$ & Feature Type & $\begin{array}{l}\text { Horizontal } \\
\text { Extent }(\mathrm{cm})\end{array}$ & $\begin{array}{c}\text { Vertical } \\
\text { Extent }(\mathrm{cm})\end{array}$ & $\begin{array}{l}\text { No. of } \\
\text { Rocks }\end{array}$ & Descril \\
\hline 130 & 6 & $\begin{array}{l}\text { E24/S74 (SE) } \\
\text { E24/S76 (NE) } \\
\text { E26/S74 (SW) } \\
\text { E26/S76 (NW) }\end{array}$ & 17B-18B & $95.75-95.66^{*}$ & IIIa & Early Archaic & large burned rock basin & $150-x-150$ & ca. $10-15$ & ca. 500 & $\bar{X}$ \\
\hline 131 & 6 & $\begin{array}{c}\text { E24/S76 (SE) } \\
\text { E24/S78 (NE, SE) } \\
\text { E26/S76 (SW) } \\
\text { E26/S78 (NW, SW) }\end{array}$ & 17B-18B & $95.84-95.66^{*}$ & ШШа & Early Archaic & large burned rock basin & $160-x-150$ & ca. 20 & ca. 700 & $\mathrm{X}$ \\
\hline 132 & 6 & $\begin{array}{l}\text { E26/S76 (SE) } \\
\text { E26/S78 (NE) }\end{array}$ & $\begin{array}{c}17 \mathrm{~B}-18 \mathrm{~A} \\
18 \mathrm{~A}\end{array}$ & $95.76-95.69 *$ & IIIa & Early Archaic & burned rock cluster & $60-x-60$ & ca. $5-10$ & ca. 45 & \\
\hline 133 & 6 & E26/S72 (SE) & $18 \mathrm{~A}$ & $95.65-95.61 *$ & IIIIa & Early Archaic & burned rock cluster & $35-x-20$ & ca. $5-10$ & 11 & \\
\hline 134 & 6 & $\begin{array}{c}\text { E24/S76 (SE, SW, } \\
\text { NW) }\end{array}$ & $18 \mathrm{~A}$ & $95.82-95.79 *$ & ПIIa & Early Archaic & burned rock cluster & $65-x-35$ & ca. $5-10$ & ca. 40 & \\
\hline 135 & 6 & E24/S72 (NE, NW) & 18B & $95.57-95.52 *$ & IIIIa & Early Archaic & burned rock cluster & $60-x-40$ & ca. $5-10$ & 10 & \\
\hline 136 & 6 & E24/S74 (all quads) & $18 \mathrm{~B}$ & $95.67-95.62 *$ & IIIa & Early Archaic & burned rock cluster & $40-x-35$ & ca. $5-10$ & 16 & \\
\hline $\begin{array}{l}137 \\
138\end{array}$ & 6 & $\begin{array}{l}\text { E22/S76 (NE, SE) } \\
\text { E40/S70 (all quads) }\end{array}$ & $\begin{array}{c}18 \mathrm{~B}, 19 \mathrm{~A} \\
14-15\end{array}$ & $\begin{array}{l}\text { 95.71-95.69* } \\
\text { 95.53-95.38* }\end{array}$ & $\begin{array}{l}\text { IIIa } \\
\text { IIIIa }\end{array}$ & $\begin{array}{l}\text { Early Archaic } \\
\text { Early Archaic }\end{array}$ & $\begin{array}{l}\text { burned rock ring } \\
\text { burned rock scatter }\end{array}$ & $\begin{array}{c}60-x-50 \\
200-x-200\end{array}$ & $\begin{array}{l}\text { ca. } 5-10 \\
\text { ca. } 10-15\end{array}$ & $\begin{array}{l}\text { ca. } 20 \\
\text { ca. } 60\end{array}$ & $\mathrm{X}$ \\
\hline 139 & 6 & $\begin{array}{l}\text { E22/S74 (NE) } \\
\text { E24/S74 (NW) }\end{array}$ & $\begin{array}{c}19 \mathrm{~A}, 19 \mathrm{~B} 19 \\
\mathrm{~A}\end{array}$ & $95.60-95.48 *$ & IIIa & Early Archaic & small burned rock basin & $70-x-70$ & ca. $10-15$ & ca. 50 & $\mathrm{X}$ \\
\hline 140 & 6 & E26/S74 (NE, SE) & $19 \mathrm{~A}, 19 \mathrm{~B}$ & 95.59-95.54* & ШII & Early Archaic & burned rock cluster & $70-x-70$ & ca. $5-10$ & ca. 50 & \\
\hline 141 & 6 & E26/S76 (NE, SE) & $18 \mathrm{~B}$ & $95.67-95.66^{*}$ & ш/Ша & Early Archaic & burned rock cluster & $70-x-50$ & ca. $5-10$ & 25 & \\
\hline 142 & 6 & E26/S76 (NW, SW) & $19 \mathrm{~A}$ & $95.67-95.65 *$ & II/IIIa & Early Archaic & burned rock cluster & $60-x-40$ & ca. $5-10$ & ca. 20 & \\
\hline 143 & 6 & E24/S72 (SW) & 19B & $95.51-95.46^{*}$ & П/ШІа & Early Archaic & burned rock cluster & $100-x-70$ & ca. $5-10$ & ca. 30 & \\
\hline 144 & 6 & E24/S78 (SW) & $19 \mathrm{~B}, 20 \mathrm{~A}$ & $95.70-95.62 *$ & п/Ша & $\begin{array}{c}\text { Late Paleoindian or } \\
\text { Early Archaic }\end{array}$ & $\begin{array}{l}\text { burned rock cluster (small } \\
\text { burned rock basin?) }\end{array}$ & $\begin{array}{c}60-\mathrm{x}-45+ \\
\text { (extended into } \\
\text { wall) }\end{array}$ & ca. $10-15$ & over 40 & \\
\hline 145 & 6 & $\begin{array}{c}\text { E26/S74 (SE) E26/S76 } \\
\text { (NE) }\end{array}$ & $19 \mathrm{~B}, 20 \mathrm{~A}$ & $95.55-95.52 *$ & ПI/ШIIa & Early Archaic & burned rock cluster & $50-x-50$ & ca. $5-10$ & 13 & \\
\hline 146 & 6 & $\begin{array}{l}\text { E26/S74 (NE, NW) } \\
\text { E26/S72 (SE) }\end{array}$ & $\begin{array}{l}19 \mathrm{~B} \text { to } 21 \mathrm{~A} \\
20 \mathrm{~A} \text { to } 21 \mathrm{~A}\end{array}$ & 95.51-95.41* & П/Ша & Early Archaic & large burned rock basin & $130-x-120$ & ca. $10-20$ & ca. 500 & $\mathrm{X}$ \\
\hline 147 & 6 & $\begin{array}{l}\text { E24/S76 (SE) } \\
\text { E26/S76 (SW) }\end{array}$ & $20 \mathrm{~A}, 20 \mathrm{~B}$ & 95.63-95.55* & П/Ша & $\begin{array}{c}\text { Late Paleoindian or } \\
\text { Early Archaic }\end{array}$ & burned rock cluster & $90-\mathrm{x}-40$ & ca. 10 & ca. 35 & \\
\hline 148 & & $\mathrm{E} 40 / \mathrm{S} 70(\mathrm{NW}, \mathrm{SW})$ & 19 & 95.21-95.08* & II/IIIa & $\begin{array}{c}\text { Late Paleoindian or } \\
\text { Early Archaic }\end{array}$ & burned rock cluster & $80-x-60$ & ca. $10-15$ & 30 & \\
\hline 149 & 6 & E24/S74 (NW, SW) & $20 \mathrm{~B}$ & 95.46-95.42* & II/IIIa & Early Archaic & burned rock cluster & $60-x-45$ & ca. $5-10$ & 15 & \\
\hline 150 & 6 & $\begin{array}{c}\text { E24/S74 (NE, SE) } \\
\text { E26/S74 (NW, SW) } \\
\text { E24/S72 (SE) } \\
\text { E26/S72 (SW) }\end{array}$ & $20 B-21 B$ & 95.43-95.35* & II/IIa & Early Archaic & large burned rock basin & $130-x-120$ & ca. $10-15$ & ca. 400 & $\mathrm{X}$ \\
\hline 151 & 6 & E26/S74 (NW) & 20B & no data & II/IIIa & Early Archaic & $\begin{array}{c}\text { burned rock cluster (part of } \\
\text { Feature 150) }\end{array}$ & $\mathrm{n} / \mathrm{a}$ & $\mathrm{n} / \mathrm{a}$ & $\mathrm{n} / \mathrm{a}$ & \\
\hline 152 & 6 & E26/S76 (SE) & $20 \mathrm{~B}$ & $95.48-95.43 *$ & II/IIIa & $\begin{array}{c}\text { Late Paleoindian or } \\
\text { Early Archaic }\end{array}$ & burned rock ring & $60-x-45$ & ca. $5-10$ & 9 & $\mathrm{X}$ \\
\hline 153 & 6 & E22/S72 (all quads) & $21 \mathrm{~A}$ & 95.45-95.41* & II & Late Paleoindian & burned rock ring & $90-x-90$ & ca. 5 & 18 & $\mathrm{X}$ \\
\hline
\end{tabular}


Table 26-1, continued

\begin{tabular}{|c|c|c|c|c|c|c|c|c|c|c|c|}
\hline Feature & Block & Square (Quad) & Level & \begin{tabular}{|c|}
$\begin{array}{c}\text { Elevation Range } \\
(\mathrm{m})\end{array}$
\end{tabular} & $\begin{array}{l}\text { Stratigraphic } \\
\text { Unit }\end{array}$ & $\begin{array}{l}\text { Archeological } \\
\text { Chronology }\end{array}$ & Feature Type & $\begin{array}{l}\text { Horizontal } \\
\text { Extent }(\mathrm{cm})\end{array}$ & $\begin{array}{c}\text { Vertical } \\
\text { Extent }(\mathrm{cm})\end{array}$ & $\begin{array}{l}\text { No. of } \\
\text { Rocks }\end{array}$ & Descril \\
\hline 154 & & $\mathrm{E} 40 / \mathrm{S} 70$ (SW, SE) & 23 to 26 & $94.71-94.32$ & I & Late Paleoindian? & burned tree (juniper?) & $180-x-80$ & 39 & $\mathrm{n} / \mathrm{a}$ & $\bar{X}$ \\
\hline 155 & 6 & E24/S76 (NW, NE) & $21 \mathrm{~B}$ to $22 \mathrm{~B}$ & $95.43-95.29 *$ & II & Late Paleoindian & $\begin{array}{l}\text { burned rock cluster (small } \\
\text { burned rock basin?) }\end{array}$ & $100-x-80$ & ca. 14 & 80 & $x$ \\
\hline 156 & 6 & E26/S76 (NE) & $22 \mathrm{~A}, 22 \mathrm{~B}$ & $95.35-95.29 *$ & II & Late Paleoindian & burned rock ring & $70-x-50$ & ca. $6-10$ & 16 & $\mathrm{X}$ \\
\hline 157 & 6 & E26/S72 (all quads) & $21 \mathrm{~B}-22 \mathrm{~B}$ & $95.32-95.15$ & II & Late Paleoindian & burned rock cluster & $160-x-140$ & 17 & over 100 & $\mathrm{X}$ \\
\hline 158 & 6 & $\mathrm{E} 22 / \mathrm{S} 72(\mathrm{NE}, \mathrm{SE})$ & $22 \mathrm{~B}$ & $95.28-95.25 *$ & II & Late Paleoindian & burned rock ring? & $50-x-40$ & ca. $5-10$ & 7 & $\mathrm{X}$ \\
\hline 159 & 6 & $\begin{array}{l}\text { E26/S78 (NE) } \\
\text { E26/S76 (SE) }\end{array}$ & $23 \mathrm{~A}$ & 95.22 & II & Late Paleoindian & mineralized root & $120-x-3$ & $<5$ & $\mathrm{n} / \mathrm{a}$ & \\
\hline 160 & 6 & E24/S72 (NE, NW) & $23 \mathrm{~B}, 24 \mathrm{~A}$ & $95.11-95.02$ & II & Late Paleoindian & $\begin{array}{c}\text { burned sediment and charcoal } \\
\text { (burned plant?) }\end{array}$ & $70-x-40$ & 9 & $\mathrm{n} / \mathrm{a}$ & $\mathrm{X}$ \\
\hline 161 & 6 & E24/S78 (all quads) & $24 \mathrm{~A}$ & 95.24 & Id/II & Late Paleoindian & artifact cluster (debitage) & $30-x-30$ & 7 & $\mathrm{n} / \mathrm{a}$ & $\mathrm{X}$ \\
\hline 162 & 6 & E26/S76 (NE) & $24 \mathrm{~B}$ & $95.09-95.04 *$ & II & Late Paleoindian & $\begin{array}{l}\text { burned sediment with a few } \\
\text { burned rocks }\end{array}$ & $40-x-30$ & ca. $5-10$ & 5 & $\mathrm{X}$ \\
\hline 163 & 6 & E22/S78 (all quads) & $25 \mathrm{~A}$ to $26 \mathrm{~A}$ & 95.13-95.01* & Isi-c/Id & $\begin{array}{c}\text { Late Paleoindian } \\
\text { (Wilson } \\
\text { Component) }\end{array}$ & $\begin{array}{l}\text { burned rock cluster (with } \\
\text { surrounding scatter) }\end{array}$ & $\begin{array}{c}60-x-30 \\
(150-x-150)\end{array}$ & $\begin{array}{l}\text { ca. } 5-10 \\
\text { (ca. } 10-15)\end{array}$ & $\begin{array}{c}17 \\
(20)\end{array}$ & $\mathrm{x}$ \\
\hline 164 & 6 & $\mathrm{E} 26 / \mathrm{S} 76$ (SE) & $26 \mathrm{~B}$ to $28 \mathrm{~B}$ & $94.90-94.67$ & Isi-c/Id/II & Late Paleoindian & burned tree or other large plant & $\begin{array}{c}50-\mathrm{x}-40+ \\
\text { (extended into } \\
\text { wall) }\end{array}$ & 23 & $\mathrm{n} / \mathrm{a}$ & $\mathrm{X}$ \\
\hline 165 & 6 & E26/S72 (NE, SE) & $24 \mathrm{~A}$ to $30 \mathrm{~B}$ & $94.98-94.53$ & Isi-c/II & Late Paleoindian & burned live oak tree & $\begin{array}{c}\text { over } 120-\mathrm{x}-130 \\
\text { (extended into } \\
\text { walls) }\end{array}$ & 45 & $\mathrm{n} / \mathrm{a}$ & $\mathrm{X}$ \\
\hline 166 & Area B & $\begin{array}{c}\text { W0/N8 (NE, SE) } \\
\text { E2/N8 (NW, SW, SE) }\end{array}$ & $25 \mathrm{~A}$ to $27 \mathrm{~A}$ & $95.05-94.83$ & $\mathrm{I} / \mathrm{II}$ ? & Late Paleoindian & large burned rock basin & $\begin{array}{c}160 \mathrm{x} \text { over } 120 \\
\text { (extended into } \\
\text { wall) }\end{array}$ & 22 & 75 & $\mathrm{X}$ \\
\hline 167 & 6 & $\begin{array}{c}\text { E22/S72 (NE, NW, } \\
\text { SE) } \\
\text { E22/S74 (all quads) } \\
\text { E22/S76 (NE, NW) } \\
\text { E24/S72 (NW, SW) } \\
\text { E24/S74 (all quads) } \\
\text { E24/S76(NW) } \\
\text { E26/S74 (SW) }\end{array}$ & $\begin{array}{l}29 \mathrm{~B} \text { to } 33 \mathrm{~B} \\
29 \mathrm{~A} \text { to } 33 \mathrm{~B} \\
28 \mathrm{~B} \text { to } 31 \mathrm{~B} \\
30 \mathrm{~A} \text { to } 33 \mathrm{~B} \\
30 \mathrm{~B} \text { to } 32 \mathrm{~B} \\
31 \mathrm{~A} \\
31 \mathrm{~A}\end{array}$ & 94.69-94.11 & Isi/Icl/Isi-c & Late Paleoindian & burned live oak tree & $400-x-300$ & 58 & $\mathrm{n} / \mathrm{a}$ & $\mathrm{X}$ \\
\hline 168 & 4 & E20/S76 (NE, NW) & $31 \mathrm{~A}$ to $35 \mathrm{~B}$ & $94.30-93.90$ & Isi/Icl/Isi-c & $\begin{array}{l}\text { Late Paleoindian } \\
\text { (Wilson } \\
\text { Component) }\end{array}$ & pit & $87-x-70$ & 40 & $\mathrm{n} / \mathrm{a}$ & $\mathrm{X}$ \\
\hline 169 & 4 & $\begin{array}{l}\mathrm{E} 20 / \mathrm{S} 76(\mathrm{SW}) \\
\mathrm{E} 20 / \mathrm{S} 78(\mathrm{NW})\end{array}$ & $\begin{array}{l}31 \mathrm{~A}-34 \mathrm{~A} \\
30 \mathrm{~A}-34 \mathrm{~A}\end{array}$ & $94.63-94.08$ & Isi/Isi-c & $\begin{array}{l}\text { Late Paleoindian } \\
\text { (Wilson } \\
\text { Component) }\end{array}$ & pit & $65-x-60$ & 55 & $\mathrm{n} / \mathrm{a}$ & $\mathrm{X}$ \\
\hline 170 & 6 & $\mathrm{E} 24 / \mathrm{S} 78(\mathrm{SW})$ & $31 \mathrm{~A}$ to $32 \mathrm{~A}$ & $94.51-94.40$ & Isi & Early Paleoindian & bone cluster & $40-x-40$ & 10 & $\mathrm{n} / \mathrm{a}$ & $\mathrm{X}$ \\
\hline 171 & 6 & $\begin{array}{l}\text { E24/S78 (NE) } \\
\text { E26/S78 (NW) }\end{array}$ & $32 \mathrm{~B}$ & $94.38-94.30$ & Isi-c & $\begin{array}{l}\text { Late Paleoindian } \\
\text { (Wilson } \\
\text { Component) }\end{array}$ & burned rock cluster & $135-x-80$ & 8 & 9 & $\mathrm{X}$ \\
\hline 172 & $\mathrm{n} / \mathrm{a}$ & $\begin{array}{c}\text { North wall of Gradall } \\
\text { Trench \#2 }\end{array}$ & $\begin{array}{c}\text { ca. } 62 \mathrm{~cm} \\
\text { below surface }\end{array}$ & no data & ШlШ $/ \mathrm{IIIc} ?$ & $\begin{array}{l}\text { Middle or Late } \\
\text { Archaic? }\end{array}$ & burned rock cluster & $59 \mathrm{~cm}(\mathrm{E}-\mathrm{W})$ & no data & no data & \\
\hline 173 & FSU & E28/S78 (all quads) & 4,5 & 97.05-96.92* & IIIc & Late Archaic & burned rock scatter & $200-x-200$ & ca. $10-20$ & over 200 & \\
\hline
\end{tabular}




\begin{tabular}{|c|c|c|c|c|c|c|c|c|c|c|c|}
\hline Feature & Block & Square (Quad) & Level & \begin{tabular}{|c|}
$\begin{array}{c}\text { Elevation Range } \\
(\mathrm{m})\end{array}$ \\
\end{tabular} & $\begin{array}{l}\text { Stratigraphic } \\
\text { Unit }\end{array}$ & $\begin{array}{l}\text { Archeological } \\
\text { Chronology }\end{array}$ & Feature Type & $\begin{array}{l}\text { Horizontal } \\
\text { Extent }(\mathrm{cm})\end{array}$ & $\begin{array}{c}\text { Vertical } \\
\text { Extent }(\mathrm{cm})\end{array}$ & $\begin{array}{l}\text { No. of } \\
\text { Rocks }\end{array}$ & Descril \\
\hline 174 & FSU & E28/S78 (NW, SW) & 8 & $96.85-96.61$ & $\mathrm{IIIb} / \mathrm{IIIC}$ & $\begin{array}{l}\text { Middle or Late } \\
\text { Archaic }\end{array}$ & burned rock cluster & $70-x-60$ & 24 & $25-30$ & \\
\hline 175 & 6 & $\begin{array}{l}\text { E26/S76 (SW) } \\
\text { E26/S78 (NW) }\end{array}$ & $36 \mathrm{~A}$ to $37 \mathrm{~B}$ & 93.93-93.68 & Isi/Icl & $\begin{array}{l}\text { Early or Late } \\
\text { Paleoindian }\end{array}$ & probable burrow & $80-x-70$ & 25 & $\mathrm{n} / \mathrm{a}$ & $\mathrm{X}$ \\
\hline 176 & FSU & E28/S78 (NE) & 9,10 & $96.50-96.40$ & $\mathrm{IIIb} / \mathrm{IIC}$ & $\begin{array}{l}\text { Middle or Late } \\
\text { Archaic }\end{array}$ & $\begin{array}{l}\text { burned sediment with a few } \\
\text { burned rocks }\end{array}$ & $80-x-60$ & 10 & 8 & $\mathrm{X}$ \\
\hline 177 & FSU & $\begin{array}{l}\text { E28/S78 (NW, SW, } \\
\text { SE) }\end{array}$ & 10 & $96.52-96.39$ & $\mathrm{IIIb} / \mathrm{III} \mathrm{c}$ & $\begin{array}{l}\text { Middle or Late } \\
\text { Archaic }\end{array}$ & burned rock cluster & $130-x-90$ & 13 & ca. 100 & $\mathrm{X}$ \\
\hline 178 & 6 & E24/S72 (NE) & $37 \mathrm{~A}-37 \mathrm{~B}$ & $93.82-93.60$ & Icl & $\begin{array}{l}\text { Early or Late } \\
\text { Paleoindian }\end{array}$ & probable burrow & $75-x-50$ & 22 & $\mathrm{n} / \mathrm{a}$ & $\mathrm{X}$ \\
\hline 179 & FSU & $\begin{array}{c}\text { E28/S78 (SW, SE, } \\
\text { NW) }\end{array}$ & 11,12 & $96.42-96.30$ & IIIb & $\begin{array}{l}\text { Early or Middle } \\
\text { Archaic }\end{array}$ & burned rock scatter & $200-x-180$ & 12 & ca. 200 & \\
\hline 180 & FSU & E28/S78 (NW, NE) & 13,14 & $96.16-96.06$ & IIIa/IIIb & Early Archaic & burned rock ring & $60-x-50$ & 10 & 15 & $\mathrm{X}$ \\
\hline 181 & FSU & $\begin{array}{l}\text { E28/S78 (all quads) } \\
\text { TARL } 37-39,50-53\end{array}$ & $\begin{array}{l}\text { 15A to } 20 \mathrm{~A} \\
\text { TARL } 19-27\end{array}$ & $95.95-95.45$ & $\begin{array}{l}\text { IIIa } \\
\text { II/IIIa }\end{array}$ & Early Archaic & large burned rock basin & $260-x-260$ & 50 & $\begin{array}{c}\text { not } \\
\text { recorded }\end{array}$ & $\mathrm{X}$ \\
\hline 182 & 6 & $\begin{array}{c}\text { E24/S78 } \\
\text { E26/S78 (north wall) }\end{array}$ & $\begin{array}{l}\text { recorded in } \\
\text { profile }\end{array}$ & $96.47-96.29$ & $\begin{array}{l}\text { IIIa } \\
\text { II/IIIa }\end{array}$ & Early Archaic & burned rock cluster & $\begin{array}{l}90(\mathrm{E}-\mathrm{W} \\
\text { dimension) }\end{array}$ & 18 & ca. 20 & \\
\hline 183 & FSU & E28/S78 (all quads) & $17 \mathrm{~A}$ to $18 \mathrm{~B}$ & $95.74-95.66$ & IIIIa & Early Archaic & burned rock cluster & $140-x-75 \mathrm{~cm}$ & 8 & ca. 200 & $\mathrm{X}$ \\
\hline 184 & FSU & $\begin{array}{l}\text { E28/S78 (SE) } \\
\text { TARL } 50\end{array}$ & $\begin{array}{l}18 \mathrm{~B} \text { to } 20 \mathrm{~B} \\
\text { TARL } 26-27\end{array}$ & $95.60-95.45$ & II & Late Paleoindian & $\begin{array}{l}\text { burned rock cluster (large } \\
\text { burned rock basin?) }\end{array}$ & $\begin{array}{c}135-\mathrm{x}-75+ \\
\text { (extended into } \\
\text { wall) }\end{array}$ & 15 & over 60 & $\mathrm{X}$ \\
\hline 185 & FSU & E28/S78 (all quads) & $20 \mathrm{~A}, 20 \mathrm{~B}$ & $95.51-95.39$ & II & Late Paleoindian & $\begin{array}{c}\text { burned rock cluster (associated } \\
\text { with Feature 184?) }\end{array}$ & $70-x-35$ & 12 & 21 & $\mathrm{X}$ \\
\hline 186 & FSU & E28/S78 (NE, SE) & $20 \mathrm{~A}$ to $23 \mathrm{~A}$ & $95.46-95.16$ & II/IIIa & Early Archaic & burrow & $95-x-45$ & ca. 30 & $\mathrm{n} / \mathrm{a}$ & $\mathrm{X}$ \\
\hline 187 & FSU & E28/S78 (NE) & $32 \mathrm{~A}, 32 \mathrm{~B}$ & $94.26-94.17$ & Isi-c & $\begin{array}{l}\text { Late Paleoindian } \\
\text { (Wilson } \\
\text { Component) }\end{array}$ & $\begin{array}{l}\text { burned rock cluster (small } \\
\text { burned rock basin?) }\end{array}$ & $70-x-55$ & ca. 9 & 45 & $\mathrm{X}$ \\
\hline 188 & FSU & E28/S78 (NE) & $43 \mathrm{~B}, 44 \mathrm{~A}$ & $93.09-93.04$ & Isi & Early Paleoindian & $\begin{array}{l}\text { artifact cluster (tested and } \\
\text { battered cobbles) }\end{array}$ & $25-x-10$ & 5 & $\mathrm{n} / \mathrm{a}$ & $\mathrm{X}$ \\
\hline 189 & 4 & E20/S76 (SW) & $32 \mathrm{~B}$ & $\begin{array}{c}\text { detected at ca. } \\
94.26\end{array}$ & $\begin{array}{l}\text { detected in } \\
\text { Isi/Icl/Isi-c }\end{array}$ & modern & $\begin{array}{c}1982 \text { geologic probe (auger } \\
\text { hole?) }\end{array}$ & $20-x-20$ & no data & $\mathrm{n} / \mathrm{a}$ & \\
\hline $\begin{array}{l}190 \\
191\end{array}$ & 6 & $\begin{array}{l}\text { E26/S74 (east wall) } \\
\text { number skipped }\end{array}$ & no data & no data & Isi/Icl? & Early Paleoindian & possible pit or burrow? & $60-x-60$ & ca. 20 & $\mathrm{n} / \mathrm{a}$ & $\mathrm{X}$ \\
\hline 192 & 35 & $\begin{array}{c}\mathrm{E} 20 / \mathrm{S} 90(\mathrm{SE}) \\
\mathrm{E} 22 / \mathrm{S} 90(\mathrm{SE}, \mathrm{SW}, \\
\mathrm{NW})\end{array}$ & 2019,20 & $96.35-96.22 *$ & $\mathrm{x}$ & $\begin{array}{l}\text { Late Paleoindian or } \\
\text { Early Archaic }\end{array}$ & burned rock cluster & $140-x-90$ & ca. $10-15$ & 30 & \\
\hline 193 & FSU & E28/S78 (NW, SW) & 29B-30B & $\begin{array}{c}\text { no data; level } \\
\text { was } 94.56-94.41\end{array}$ & Isi-c & $\begin{array}{l}\text { Late Paleoindian } \\
\text { (Wilson } \\
\text { Component) }\end{array}$ & burned rock cluster & $35-x-30$ & ca. 15 & 14 & $\mathrm{X}$ \\
\hline 194 & Area B & W0/N8 (SE) & 9 to 12 & $96.58-96.31$ & III/IIIc & $\begin{array}{l}\text { Middle or Late } \\
\text { Archaic }\end{array}$ & pit with burned rock & $\begin{array}{c}\text { over } 70-\mathrm{x}-70 \\
\text { (extended into } \\
\text { walls) }\end{array}$ & 27 & $\begin{array}{c}\text { not } \\
\text { recorded }\end{array}$ & $\mathrm{x}$ \\
\hline 195 & Area B & $\begin{array}{l}\text { W0/N8 (NE, SE) } \\
\text { E2/N8 (NW, NE) }\end{array}$ & 10,11 & $96.57-96.47$ & III & Middle Archaic? & $\begin{array}{l}\text { burned rock accumulation } \\
\text { (lowest layer of Burned Rock } \\
\text { Midden 2) }\end{array}$ & $\begin{array}{l}\text { over } 270-x-140 \\
\text { (extended into } \\
\text { walls) }\end{array}$ & 10 & $\begin{array}{c}\text { not } \\
\text { recorded }\end{array}$ & $\mathrm{X}$ \\
\hline 196 & Area B & $\begin{array}{l}\text { W0/N8 (NE, SE) } \\
\text { E2/N8 (NW, SW) }\end{array}$ & 14 & ca. $96.15^{*}$ & III & $\begin{array}{c}\text { Early or Middle } \\
\text { Archaic }\end{array}$ & $\begin{array}{l}\text { burned sediment and charcoal } \\
\text { (burned plant?) }\end{array}$ & $80-x-50$ & ca. $10-15$ & $\mathrm{n} / \mathrm{a}$ & \\
\hline
\end{tabular}


Table 26-1, continued

\begin{tabular}{|c|c|c|c|c|c|c|c|c|c|c|c|}
\hline Feature & Block & Square (Quad) & Level & \begin{tabular}{|c|} 
Elevation Range \\
$(\mathrm{m})$
\end{tabular} & $\begin{array}{c}\text { Stratigraphic } \\
\text { Unit }\end{array}$ & $\begin{array}{l}\text { Archeological } \\
\text { Chronology }\end{array}$ & Feature Type & $\begin{array}{l}\text { Horizontal } \\
\text { Extent }(\mathrm{cm})\end{array}$ & $\begin{array}{c}\text { Vertical } \\
\text { Extent }(\mathrm{cm})\end{array}$ & $\begin{array}{l}\text { No. of } \\
\text { Rocks }\end{array}$ & Descri \\
\hline 197 & Area B & W0/N8 (NE, SE) & 14 & $96.16-96.10$ & III & Early Archaic & burned rock cluster & $45-x-35$ & 6 & 20 & \\
\hline 198 & Area B & W0/N8 (NE, NW) & $26 \mathrm{~B}$ to 30 & $94.86-94.47$ & I/II? & Late Paleoindain & burned live oak tree & $\begin{array}{c}\text { over } 170-\mathrm{x}-80 \\
\text { (extended into } \\
\text { walls) }\end{array}$ & 39 & $\mathrm{n} / \mathrm{a}$ & $\mathrm{x}$ \\
\hline 199 & 4 & $\begin{array}{l}\text { E20/S92 (west wall) } \\
\text { E20/S74 (west wall) }\end{array}$ & $\begin{array}{l}\text { recorded in } \\
\text { profile }\end{array}$ & $96.40-96.30$ & IIItb & Middle Archaic & burned mulberry tree & $20(\mathrm{~N}-\mathrm{S})$ & over 10 & $\mathrm{n} / \mathrm{a}$ & $\mathrm{x}$ \\
\hline BRM 1 & $\begin{array}{l}1 \\
2 \\
3 \\
5\end{array}$ & $\begin{array}{c}\mathrm{E} 20,22 / \mathrm{S} 98,100 \\
\mathrm{E} 20 / \mathrm{S} 92,94,96 \\
\mathrm{E} 20 / \mathrm{S} 84,86,88,90 \\
\mathrm{E} 22 / \mathrm{S} 84,86,88,90\end{array}$ & $\begin{array}{c}3-5 \\
2-8 \\
2-10 \\
6-10\end{array}$ & $98.96-96.82$ & $\begin{array}{l}\mathrm{Y}, \mathrm{Y} / \mathrm{IIIc}, \\
\mathrm{Y} / \mathrm{HIl} / \mathrm{IIc}, \\
\mathrm{IIl} / \mathrm{IIIc}, \mathrm{IIIc}\end{array}$ & $\begin{array}{l}\text { Early through Late } \\
\text { Archaic (possibly } \\
\text { Late Prehistoric) }\end{array}$ & burned rock midden & $16-x-16 m$ & ca. 100 & $\begin{array}{c}\text { not } \\
\text { recorded }\end{array}$ & $\mathrm{x}$ \\
\hline BRM 2 & Area B & $\begin{array}{l}\text { W0/N8 } \\
\text { E2/N8 }\end{array}$ & $1-11$ & $97.47-96.47$ & $\begin{array}{c}\text { III } \\
\text { II/IIIc } \\
\text { IIIc }\end{array}$ & $\begin{array}{l}\text { Middle through } \\
\text { Late Archaic }\end{array}$ & burned rock midden & $20-x-18 m$ & ca. 100 & $\begin{array}{c}\text { not } \\
\text { recorded }\end{array}$ & $\mathrm{x}$ \\
\hline Burial 1 & 2 & E20/S92 (NE) & 6 & $\begin{array}{c}\text { no data; } \\
\text { detection level } \\
\text { estimated } \\
\text { between } 97.92 \\
\text { and } 97.66\end{array}$ & IIIc(pot) & Late Archaic? & human burial & over $60-x-60$ & no data & $\mathrm{n} / \mathrm{a}$ & $\mathrm{X}$ \\
\hline Burial 2 & 4 & $\begin{array}{l}\text { E20/S74 (NE, NW) } \\
\text { E20/S72 (SE, SW) }\end{array}$ & $\begin{array}{c}31 \mathrm{~A} \\
31 \mathrm{~A}-34 \mathrm{~B}\end{array}$ & $94.37-94.11$ & Isi/Icl/Isi-c & $\begin{array}{l}\text { Late Paleoindian } \\
\text { (Wilson } \\
\text { component) }\end{array}$ & human burial & $104-x-52$ & ca. $22-26$ & $\mathrm{n} / \mathrm{a}$ & $\mathrm{X}$ \\
\hline
\end{tabular}


TABLE 26-2

Attributes of Features Recorded in the TARL Excavations

\begin{tabular}{|c|c|c|c|c|c|c|c|c|c|c|c|}
\hline Feature & Block & Square & Level & $\begin{array}{c}\text { Documented } \\
\text { Elevation Range }\end{array}$ & $\begin{array}{c}\text { Stratigraphic } \\
\text { Context }\end{array}$ & $\begin{array}{l}\text { Archeological } \\
\text { Chronology }\end{array}$ & Feature Type & $\begin{array}{c}\text { Horizontal Extent } \\
(\mathrm{cm})\end{array}$ & $\begin{array}{c}\text { Vertical } \\
\text { Extent }(\mathrm{cm})\end{array}$ & $\begin{array}{l}\text { No. of } \\
\text { Rocks }\end{array}$ & Described \\
\hline 201 & $\begin{array}{c}\text { South, } \\
\text { East }\end{array}$ & $14-22$ & $\begin{array}{c}\text { portions of } \\
\text { Levels 5-9 } \\
\text { (varies in each } \\
\text { square) }\end{array}$ & $\begin{array}{l}\text { South Block: } 97.20 \\
96.80 \text {; East Block: } \\
97.10-96.70\end{array}$ & $\begin{array}{c}\text { IIIb/IIIc } \\
\text { IIIc }\end{array}$ & Late Archaic & $\begin{array}{l}\text { burned rock accumulation with } \\
\text { subfeatures: F203, F205, F206, } \\
\text { F207, F208, F211 }\end{array}$ & $\begin{array}{l}\text { over } 10-\mathrm{x}-4 \mathrm{~m} \\
\text { (extended into } \\
\text { walls) }\end{array}$ & ca. $20-40$ & $\begin{array}{c}\text { not } \\
\text { recorded }\end{array}$ & $\mathrm{X}$ \\
\hline 202 & South & 14 & 4 & $97.33-97.23$ & IIIc & $\begin{array}{l}\text { Late Archaic or Late } \\
\text { Prehistoric }\end{array}$ & burned rock cluster & $40-x-35$ & 10 & 7 & $\mathrm{X}$ \\
\hline 203 & East & 19 & $8-9$ & $96.89-96.76$ & $\mathrm{IIlb} / \mathrm{IIIc}$ & Late Archaic & $\begin{array}{l}\text { burned rock scatter } \\
\text { (within Feature 201) }\end{array}$ & $100-x-100$ & 13 & ca. 100 & $\begin{array}{l}\text { see Feature } \\
201\end{array}$ \\
\hline 204 & East & 20 & $11-12$ & $96.59-96.47$ & $\mathrm{IIlb}$ & Middle Archaic & burned rock cluster & $70-x-50$ & 12 & ca. 50 & $\mathrm{x}$ \\
\hline 205 & East & 22 & 8 & $96.90-96.80$ & $\mathrm{IIIb} / \mathrm{IIIc}$ & Late Archaic & $\begin{array}{l}\text { burned rock scatter } \\
\text { (within Feature 201) }\end{array}$ & $100-x-60$ & 10 & ca. 30 & $\begin{array}{l}\text { see Feature } \\
201\end{array}$ \\
\hline 206 & South & 15,16 & $5-6$ & $97.20-97.03$ & IIIc & Late Archaic & $\begin{array}{l}\text { burned rock cluster or small } \\
\text { burned rock basin (within } \\
\text { Feature 201) }\end{array}$ & $65-x-50$ & 17 & 25 & $\begin{array}{c}\text { see Feature } \\
201\end{array}$ \\
\hline 207 & South & 14 & $5-6$ & $97.10-97.00$ & IIIc & Late Archaic & $\begin{array}{l}\text { burned rock cluster (within } \\
\text { Feature 201) }\end{array}$ & $55-x-45$ & 10 & 20 & $\begin{array}{l}\text { see Feature } \\
201\end{array}$ \\
\hline 208 & South & 16,17 & 7 & $97.05-96.90$ & $\mathrm{IIIb} / \mathrm{IIIc}$ & Late Archaic & $\begin{array}{l}\text { burned rock cluster (within } \\
\text { Feature 201) }\end{array}$ & $100-x-70$ & 15 & 40 & $\begin{array}{l}\text { see Feature } \\
201\end{array}$ \\
\hline 209 & East & 20 & 13 & $96.38-96.30$ & IIIb & Middle Archaic & $\begin{array}{l}\text { burned (?) sediment with a few } \\
\text { burned rocks }\end{array}$ & $40-x-40$ & 8 & 3 & $\mathrm{X}$ \\
\hline 210 & East & 22 & $9-10$ & $96.82-96.67$ & $\mathrm{IIIb} / \mathrm{IIIc}$ & $\begin{array}{l}\text { Middle or Late } \\
\text { Archaic }\end{array}$ & $\begin{array}{l}\text { burned rock scatter (possibly } \\
\text { associated with Feature 201) }\end{array}$ & $75-x-40$ & 15 & $50-75$ & \\
\hline 211 & East & 17 & 8 & $96.89-96.80$ & IIIb/IIIc & Late Archaic & $\begin{array}{l}\text { burned rock cluster (within } \\
\text { Feature 201) }\end{array}$ & $55-x-50$ & 9 & 18 & $\begin{array}{l}\text { see Feature } \\
201\end{array}$ \\
\hline 212 & East & $\begin{array}{l}37 \\
38\end{array}$ & 12,13 & $96.48-96.32$ & IIIlb & Middle Archaic & burned rock cluster & $\begin{array}{l}75 \times \text { over } 55 \\
\text { (extended into } \\
\text { wall) }\end{array}$ & 16 & 30 & $\mathrm{x}$ \\
\hline 213 & South & $\begin{array}{l}12 \\
13\end{array}$ & $\begin{array}{l}11-12 \\
10-13\end{array}$ & $96.65-96.30$ & Шаa/IIIb & $\begin{array}{l}\text { Early or Middle } \\
\text { Archaic }\end{array}$ & burned plant & $80-x-75$ & 35 & $\mathrm{n} / \mathrm{a}$ & \\
\hline 214 & South & 16 & $10-12 ?$ & $96.70-96.64$ & IIIb & Middle Archaic & burned rock cluster & $75-x-35$ & 6 & 9 & $\mathrm{X}$ \\
\hline 215 & East & 20 & $15-16$ & $96.09-96.01$ & IIIa/IIIb & $\begin{array}{l}\text { Early or Middle } \\
\text { Archaic }\end{array}$ & burned rock cluster & $55-x-40$ & 8 & 26 & $\mathrm{x}$ \\
\hline 216 & East & 22 & 12 & $96.46-96.405$ & IIIb & Middle Archaic & rock cluster (possibly burned?) & $65-x-50$ & 5 & 7 & \\
\hline 217 & South & $\begin{array}{l}14 \\
33\end{array}$ & $\begin{array}{c}16 \\
16-17\end{array}$ & 96.04-95.95 & IIIa & Early Archaic & $\begin{array}{l}\text { burned rock scatter (within } \\
\text { Feature 231) }\end{array}$ & $100-x-100$ & 9 & ca. 100 & $\begin{array}{l}\text { see Feature } \\
231\end{array}$ \\
\hline
\end{tabular}




\begin{tabular}{|c|c|c|c|c|c|c|c|c|c|c|c|}
\hline Feature & Block & Square & Level & $\begin{array}{c}\text { Documented } \\
\text { Elevation Range }\end{array}$ & $\begin{array}{c}\text { Stratigraphic } \\
\text { Context }\end{array}$ & $\begin{array}{l}\text { Archeological } \\
\text { Chronology }\end{array}$ & Feature Type & $\begin{array}{c}\text { Horizontal Extent } \\
(\mathrm{cm})\end{array}$ & $\begin{array}{c}\text { Vertical } \\
\text { Extent }(\mathrm{cm})\end{array}$ & $\begin{array}{l}\text { No. of } \\
\text { Rocks } \\
\end{array}$ & Described \\
\hline 218 & East & $\begin{array}{l}19 \\
25\end{array}$ & 14 & $96.23-96.17$ & IIIb & Middle Archaic & burned rock scatter & $150-x-90$ & 6 & ca. 50 & \\
\hline 219 & East & 39 & $15-37$ & $96.13-94.70^{*}$ & $\mathrm{n} / \mathrm{a}$ & modern & 1992 TARL auger hole & $10-x-10$ & no data & $\mathrm{n} / \mathrm{a}$ & \\
\hline 220 & East & 52 & $15-16$ & $96.20-96.09$ & IIIa/Шlb & Early Archaic & burned rock cluster & $65-x-50$ & 11 & 20 & $\mathrm{X}$ \\
\hline 221 & East & 39 & 15 & $96.15-96.10$ & $\mathrm{IIIa} / \mathrm{IITb}$ & Early Archaic & $\begin{array}{l}\text { burned sediment with a few } \\
\text { burned rocks }\end{array}$ & $60-x-30$ & 5 & 3 & $\mathrm{X}$ \\
\hline 222 & East & 37 & 16 & $96.10-96.04$ & IIIIa & Early Archaic & burned rock cluster & $45-x-35$ & 6 & 7 & $\mathrm{X}$ \\
\hline 223 & South & 34 & $18-19$ & $96.00-95.90$ & IIIIa & Early Archaic & $\begin{array}{l}\text { burned rock scatter (within } \\
\text { Feature 231) }\end{array}$ & $100-\mathrm{x}-100$ & 6 & over 100 & $\begin{array}{c}\text { see Feature } \\
231\end{array}$ \\
\hline 224 & South & 12 & $18-21$ & $95.98-95.81$ & П/ІІІа & Early Archaic & small burned rock basin & $50-x-45$ & 17 & ca. 25 & $\mathrm{X}$ \\
\hline 225 & East & 27 & 22 & $95.75-95.70$ & IIIIa & Early Archaic & $\begin{array}{l}\text { burned rock scatter (within } \\
\text { Feature 231) }\end{array}$ & $100-x-100$ & 12 & ca. 75 & $\begin{array}{c}\text { see Feature } \\
231\end{array}$ \\
\hline 226 & South & 46 & $20-21$ & $95.87-95.80$ & II/IIIa & $\begin{array}{l}\text { Late Paleoindian or } \\
\text { Early Archaic }\end{array}$ & burned rock cluster & $60-x-20$ & 7 & 10 & $\mathrm{X}$ \\
\hline 227 & South & 30 & $20-22$ & $95.90-95.75$ & II, II/IIIa & $\begin{array}{l}\text { Late Paleoindian or } \\
\text { Early Archaic }\end{array}$ & small burned rock basin & $65-x-65$ & 15 & 26 & $\mathrm{x}$ \\
\hline 228 & East & 38 & $20-21$ & $95.85-95.80$ & IIII & Early Archaic & $\begin{array}{l}\text { pit or burrow? (within Feature } \\
\text { 231) }\end{array}$ & $40-x-35$ & 5 & $\mathrm{n} / \mathrm{a}$ & $\mathrm{x}$ \\
\hline 229 & & $\begin{array}{l}\text { number } \\
\text { skipped }\end{array}$ & & & & & & & & & \\
\hline 230 & East & 39 & $21-23$ & $95.84-95.70$ & IIIa & Early Archaic & $\begin{array}{l}\text { small burned rock basin (within } \\
\text { Feature 231) }\end{array}$ & $75-x-70$ & 14 & ca. 100 & $\mathrm{X}$ \\
\hline 231 & $\begin{array}{c}\text { East \& } \\
\text { South }\end{array}$ & $\begin{array}{c}27,28 \\
33-35 \\
37-39 \\
43-44 \\
49-53\end{array}$ & $\begin{array}{c}\text { portions of } \\
\text { Levels } 16-27 \\
\text { (varies in each } \\
\text { square) }\end{array}$ & $\begin{array}{l}\text { East Block: } 95.95- \\
\text { 95.50; South } \\
\text { Block: } 96.05-95.65\end{array}$ & IIIa, II/IIIa & Early Archaic & $\begin{array}{l}\text { burned rock accumulation with } \\
\text { various subfeatures: 181, F217, } \\
\text { F223, F225, F228, F230, F237, } \\
\text { F245 }\end{array}$ & $\begin{array}{c}650-\mathrm{x}-350 \\
\text { (extended into } \\
\text { walls) }\end{array}$ & $20-40$ & $\begin{array}{c}\text { not } \\
\text { recorded }\end{array}$ & $\mathrm{X}$ \\
\hline 232 & South & 46 & $26-28$ & 95.54-95.45 & II & Late Paleoindian & $\begin{array}{l}\text { burned sediment with a few } \\
\text { burned rocks }\end{array}$ & $\begin{array}{l}75 \times \text { over } 100 \\
\text { (extended into } \\
\text { wall) }\end{array}$ & 9 & 3 & $\mathrm{x}$ \\
\hline 233 & East & 20 & $25-26$ & $95.67-95.56$ & II/IIIa & Early Archaic & $\begin{array}{l}\text { burned rock cluster and scatter } \\
\text { (possibly associated with Feature } \\
231 \text { ) }\end{array}$ & $90-x-90$ & 9 & 45 & $\mathrm{x}$ \\
\hline 234 & South & 30 & $28-31$ & $95.46-95.30$ & Isi-c/II & Late Paleoindian & $\begin{array}{l}\text { burned sediment and charcoal } \\
\text { (burned plant?) }\end{array}$ & $100-x-100$ & 16 & $\mathrm{n} / \mathrm{a}$ & $\mathrm{x}$ \\
\hline
\end{tabular}




\begin{tabular}{|c|c|c|c|c|c|c|c|c|c|c|c|}
\hline Feature & Block & Square & Level & Elevation Range & $\begin{array}{l}\text { Stratigraphic } \\
\text { Context }\end{array}$ & $\begin{array}{l}\text { Archeological } \\
\text { Chronology }\end{array}$ & Feature Type & \begin{tabular}{|c|}
$\begin{array}{c}\text { Horizontal Extent } \\
(\mathrm{cm})\end{array}$ \\
\end{tabular} & $\begin{array}{c}\text { Vertical } \\
\text { Extent }(\mathrm{cm})\end{array}$ & $\begin{array}{l}\text { No. of } \\
\text { Rocks }\end{array}$ & Described \\
\hline 235 & South & 32 & $28-29$ & $95.49-95.43$ & Isi-c/II & Late Paleoindian & burned rock cluster & $65-x-60$ & 6 & 26 & $\mathrm{X}$ \\
\hline 236 & South & $\begin{array}{l}33 \\
48\end{array}$ & $29-31$ & $95.46-95.30$ & $\mathrm{Id} / \mathrm{II}$ & Late Paleoindian & small burned rock basin & $60-x-60$ & 16 & 20 & $\mathrm{x}$ \\
\hline 237 & South & 34 & 23 & $95.74-95.72$ & п/ІІІа & Early Archaic & $\begin{array}{l}\text { burned sediment with a few } \\
\text { burned rocks (within Feature } \\
\text { 231) }\end{array}$ & $15-x-15$ & 2 & $\mathrm{n} / \mathrm{a}$ & $x$ \\
\hline 238 & South & 30 & $33-34$ & $95.13-95.00$ & Isi-c/II & Late Paleoindian & $\begin{array}{l}\text { burned sediment and charcoal } \\
\text { (burned plant?) }\end{array}$ & $90-x-40$ & 13 & $\mathrm{n} / \mathrm{a}$ & $\mathrm{X}$ \\
\hline 239 & South & 34 & $25-27$ & $95.63-95.50$ & II & Late Paleoindian & burned rock cluster & $\begin{array}{c}65-\mathrm{x}-60 \text { (extends } \\
\text { into wall) }\end{array}$ & 13 & 15 & $\mathrm{x}$ \\
\hline 240 & East & 27 & $27-28$ & 95.54-95.47 & ш/Ша & $\begin{array}{l}\text { Late Paleoindian or } \\
\text { Early Archaic }\end{array}$ & burned rock scatter & $80-x-60$ & 7 & 20 & \\
\hline 241 & South & 35 & $25-26$ & $95.65-95.52$ & II & Late Paleoindian & burned rock cluster & $55-\mathrm{x}-45$ & 13 & 13 & $\mathrm{x}$ \\
\hline 242 & East & 20 & $28-29$ & $95.49-95.41$ & II/IIIa & $\begin{array}{l}\text { Late Paleoindian or } \\
\text { Early Archaic }\end{array}$ & burned rock cluster & $60-x-30$ & 8 & 16 & $\mathrm{X}$ \\
\hline 243 & East & 25 & 33 & $95.22-95.12$ & II & Late Paleoindian & $\begin{array}{l}\text { burned sediment with a few } \\
\text { burned rocks }\end{array}$ & $50-x-25$ & 10 & 5 & $x$ \\
\hline 244 & South & 32 & $35-37$ & $94.89-94.74$ & Isi/Isi-c & $\begin{array}{l}\text { Early or Late } \\
\text { Paleoindian }\end{array}$ & stratigraphic contact & $\mathrm{n} / \mathrm{a}$ & $\mathrm{n} / \mathrm{a}$ & $\mathrm{n} / \mathrm{a}$ & \\
\hline 245 & East & $\begin{array}{l}27,28, \\
39,44, \\
52,53\end{array}$ & $22,24-27$ & $95.78-95.53$ & ШІа, П/ШІа & Early Archaic & large burned rock basin & ca. $150-x-150$ & 25 & over 500 & $\mathrm{X}$ \\
\hline 246 & South & $\begin{array}{l}34 \\
49\end{array}$ & $\begin{array}{c}31-32 \\
32\end{array}$ & $95.36-95.20$ & II & Late Paleoindian & burned rock cluster & $60-x-55$ & 16 & 20 & $\mathrm{X}$ \\
\hline 247 & South & $\begin{array}{l}34 \\
35\end{array}$ & $\begin{array}{c}31 \\
30-31\end{array}$ & $95.35-95.30$ & II & Late Paleoindian & $\begin{array}{l}\text { burned sediment with a few } \\
\text { burned rocks }\end{array}$ & $25-x-20$ & 5 & 4 & $\mathrm{x}$ \\
\hline 248 & East & $\begin{array}{l}52,53 \\
28,44\end{array}$ & $28-29$ & $95.48-95.40$ & II & Late Paleoindian & burned rock cluster & $55-\mathrm{x}-40$ & 8 & 37 & $\mathrm{x}$ \\
\hline 249 & East & $\begin{array}{l}50 \\
51\end{array}$ & $\begin{array}{l}27-32 \\
26-31\end{array}$ & $95.55-95.30$ & ПIIа, Пт/IIIа & Early Archaic & probable burrow & $80-x-35$ & 25 & $\mathrm{n} / \mathrm{a}$ & $\mathrm{X}$ \\
\hline 250 & East & $\begin{array}{c}37,50 \\
38\end{array}$ & $\begin{array}{c}29-31 \\
30\end{array}$ & $95.43-95.29$ & II & Late Paleoindian & $\begin{array}{l}\text { burned rock cluster } \\
\text { (small burned rock basin?) }\end{array}$ & $55-x-50$ & 14 & 20 & $\mathrm{x}$ \\
\hline 251 & East & 58 & $40-41$ & $94.40-94.39$ & Isi-c & Late Paleoindian & burned sediment (burned plant?) & $13-x-9$ & 1 & $\mathrm{n} / \mathrm{a}$ & $\mathrm{x}$ \\
\hline 252 & South & $\begin{array}{l}55 \\
46\end{array}$ & $\begin{array}{l}42-43 \\
41-43\end{array}$ & $94.33-94.14$ & Isi/Isi-c & $\begin{array}{l}\text { Late Paleoindian } \\
\text { (Wilson Component) }\end{array}$ & pit or burrow? & $50-x-45$ & 19 & $\mathrm{n} / \mathrm{a}$ & $\mathrm{X}$ \\
\hline
\end{tabular}




\begin{tabular}{|c|c|c|c|c|c|c|c|c|c|c|c|}
\hline Feature & Block & Square & Level & Elevation Range & $\begin{array}{l}\text { Stratigraphic } \\
\text { Context }\end{array}$ & $\begin{array}{l}\text { Archeological } \\
\text { Chronology }\end{array}$ & Feature Type & \begin{tabular}{|c|}
$\begin{array}{c}\text { Horizontal Extent } \\
(\mathrm{cm})\end{array}$ \\
\end{tabular} & $\begin{array}{c}\text { Vertical } \\
\text { Extent }(\mathrm{cm})\end{array}$ & $\begin{array}{l}\text { No. of } \\
\text { Rocks }\end{array}$ & Described \\
\hline 253 & South & 57 & $37-39$ & $94.72-94.50$ & Isi-c & $\begin{array}{l}\text { Late Paleoindian } \\
\text { (Wilson Component) }\end{array}$ & burned live oak tree & $\begin{array}{l}\text { over } 31-x-31 \\
\text { (extended into } \\
\text { wall) }\end{array}$ & 22 & $\mathrm{n} / \mathrm{a}$ & $\bar{X}$ \\
\hline 254 & East & 28 & 31 & 95.50-95.30* & I/Wa & Early Archaic & probable burrow? & $50 \times 45$ & over $20 ?$ & $\mathrm{n} / \mathrm{a}$ & \\
\hline 255 & $\begin{array}{c}\text { East \& } \\
\text { South }\end{array}$ & $\begin{array}{l}35 \\
59\end{array}$ & 42 & $94.26-94.19$ & Isi-c & $\begin{array}{l}\text { Late Paleoindian } \\
\text { (Wilson Component) }\end{array}$ & burned rock cluster & $50-x-30$ & 7 & 15 & $\mathrm{X}$ \\
\hline 256 & East & 28 & $41-42$ & $94.32-94.20$ & Isi-c & $\begin{array}{l}\text { Late Paleoindian } \\
\text { (Wilson Component) }\end{array}$ & $\begin{array}{l}\text { burned sediment with a few } \\
\text { burned rocks }\end{array}$ & $50-x-50$ & 12 & 6 & $\mathrm{x}$ \\
\hline 257 & East & 53 & $38-39$ & $94.69-94.50$ & Isi-c & $\begin{array}{l}\text { Late Paleoindian } \\
\text { (Wilson Component) }\end{array}$ & burned rock cluster & $20-x-10$ & 19 & 4 & $\mathrm{x}$ \\
\hline 258 & East & 38 & $25-27$ & $95.65-95.50$ & ПI/IIIa & Early Archaic & probable burrow & $\begin{array}{c}65 \mathrm{x} \text { over } 30 \\
\text { (extended into } \\
\text { wall) }\end{array}$ & 15 & $\mathrm{n} / \mathrm{a}$ & \\
\hline 259 & South & 35 & $46-47$ & $93.89-93.69$ & Icl/Isi-c & $\begin{array}{l}\text { Early or Late } \\
\text { Paleoindian }\end{array}$ & possibly burned rock cluster & $55-x-80$ & 20 & 9 & $\mathrm{x}$ \\
\hline 260 & East & $\begin{array}{l}52 \\
39\end{array}$ & $42-43$ & $94.30-94.18$ & Isi-c & $\begin{array}{l}\text { Late Paleoindian } \\
\text { (Wilson Component) }\end{array}$ & $\begin{array}{l}\text { burned rock cluster? (burned } \\
\text { rock ring?) }\end{array}$ & $100-x-100$ & 12 & 22 & $\mathrm{x}$ \\
\hline 261 & East & 20 & $54-56$ & $93.10-93.00$ & Igl & Early Paleoindian & top of gravel bar & $\mathrm{n} / \mathrm{a}$ & $\mathrm{n} / \mathrm{a}$ & $\mathrm{n} / \mathrm{a}$ & \\
\hline 262 & East & 27 & $51-52$ & $93.35-93.20$ & Isi/Icl & Early Paleoindian & $\begin{array}{l}\text { bone scatter (with possible } \\
\text { burned rock) }\end{array}$ & $100-x-80$ & 15 & $6 ?$ & $\mathrm{X}$ \\
\hline
\end{tabular}


(i.e., 1-x-1-m quad provenience is listed on the TxDOT table). In both tables, elevation data are expressed as documented elevation range (highest to lowest recorded elevation), but there are some important differences in the quality of elevation data presented in these two tables. Both detection level (highest recorded point) and base elevations were recorded for all features identified in the TARL excavations so the elevation ranges presented on Table 26-2 are reasonably accurate. The TxDOT data are less consistent and many of the elevation ranges listed on Table 26-1 reflect incomplete data. No elevations were recorded for some features encountered in the TxDOT excavations, but in some of these cases, feature elevations could be estimated using level elevations and other data (estimated elevations are so noted on the table). In a few cases, there were insufficient data to estimate elevations, and for these features, "no data" is entered in the elevation column. In many other cases, elevations were recorded for one or more points within the feature, but the full range was not recorded. For example, many of the burned rock features have elevation data recorded only on plan drawings, and these drawings may have elevations listed for rocks without any indication if they are base or top elevations. In such cases, the highest and lowest recorded elevations were listed as the range along with an asterisk $(*)$ indicating incomplete data. It is also important to note that the primary elevation datum (arbitrary 100-m point) used in the TARL excavations was $63 \mathrm{~cm}$ below the primary datum used in the TxDOT excavations (as discussed in Chapter 3, no TxDOT elevation reference point was located until after TARL excavations were underway). As noted elsewhere in this report, all TxDOT elevations were converted to the TARL datum by subtracting $63 \mathrm{~cm}$. The converted elevations are presented in Tables 26-1 and 26-2 (and in the individual feature descriptions at the end of this chapter).

The next column lists the stratigraphic context for each feature using the TARL stratigraphic scheme described in Chapter 6. The stratigraphic context was documented in the field for all TARL features (although a few were revised slightly during this analysis). Stratigraphic context was documented in the field for only a few TxDOT features and these tentative assignments were based on provisional stratigraphic schemes (devised by the field crew) that were never correlated to the formal system developed by Holliday (see Chapters 3 and 6). During the TARL analysis, all unique TxDOT excavation proveniences were correlated to the TARL stratigraphic system through careful study of TxDOT level records, feature notes, stratigraphic notes, profile drawings, and photographs. The stratigraphic assignments listed for TxDOT features on Table 26-1 were determined during this process, and in some cases only tentative correlations could be made. Tentative stratigraphic assignments are followed by a question mark.

Archeological chronology placement was derived from stratigraphic position, radiocarbon dates (individual feature dates as well as the chronostratigraphy presented in Chapter 25), and the distribution of temporally diagnostic artifacts. Tentative chronology assignments are followed by a question mark.

\section{Descriptive Data}

The "feature type" column follows the feature classification scheme discussed in the following section. This same classification scheme was followed in the individual feature descriptions presented at the end of the chapter.

Maximum horizontal and vertical dimensions are listed in the next two columns. The horizontal dimensions represent maximum length (or longest axis) and maximum width at a roughly perpendicular axis. Partially exposed features (with incomplete length and/or width data) are so noted. As is the case with all deep excavations, it was not practical to expand the excavated areas to expose portions of features that extended outside the excavated areas. This resulted in a fair number of features that are known from only partial exposures.

The maximum vertical extent was generally derived from either the documented elevation range or, when elevation data were incomplete, this dimension was estimated (and so noted). These estimates were based on the vertical extent of the excavation levels encompassing the features and from other clues gleaned from the field documentation (especially drawings and photographs). In a few cases, the vertical extent is less than the documented elevation range would indicate. This occurred with large features located in sloping deposits (e.g., the large burned rock middens and burned rock accumulations). The thickness of the deposits in these cases was generally less than the difference between the highest and lowest elevations.

The next column applies primarily to the burned rock features that dominate this sample. This column lists the actual or estimated count of the number of rocks found in features (where relevant). Burned rock fragments less than $2 \mathrm{~cm}$ in length/diameter were seldom documented by the excavators so the number listed in this column generally reflects rocks $2 \mathrm{~cm}$ or larger in size. Total burned rock weight is undoubtedly a better way to examine this variable, but weight was not consistently measured. Total burned rock weight was documented for only a few of the TxDOT features, and in the TARL investigations, efforts to consistently record this information were complicated by the archeomagnetic investigation/sampling strategies and other variables. For some of the burned rock features listed on Tables 26-1 and 26-2, a rock count was not documented in the field notes. The number was estimated for some of these features (based on photographs and plan drawings) and for others "not recorded" is entered in this column. The latter group primarily consists of the large burned rock middens and burned rock accumulations encompassing thousands of burned rocks. This group also 
includes a few smaller features that included insufficient documentation to estimate the burned rock count.

The last column on each of these tables indicates the features that are described in the Selected Feature Descriptions section presented at the end of the chapter. The criteria used to select these features are discussed in that section.

\section{FEATURECLASSIFICATION}

All the recorded features were classified by descriptive feature types, and these are referenced in both the provenience tables discussed above and the individual feature descriptions presented at the end of this chapter. The criteria for some of these types are self-evident (e.g., mineralized root, modern auger hole), but for others the criteria are summarized in the following discussions.

\section{Burned Rock Features}

Virtually all of the burned rocks found in cultural features at the Wilson-Leonard site were limestone fragments, and most (if not all) were probably derived from local sources. Limestone is readily available from either bedrock exposures along the valley margin or from gravel deposits in the stream beds. Lithologic aspects of most of these rocks visually match those of the Comanche Peak limestone that crops out in the site area and along Brushy and Spanish Oak creeks. A few pieces of burned chert or sandstone (apparently unmodified) were found among the limestone fragments in several burned rock features, but this was a rather rare occurrence.

Burned or heat-altered limestone was generally identified in the field on the basis of either visual (e.g., discoloration and/or fracture patterns) or contextual clues (e.g., location within an obvious burned rock feature). Although the definitive identification of heat-altered stone is problematical at many sites, the visual and contextual clues are fairly reliable indicators at the Wilson-Leonard site. This opinion is supported by the archeomagnetic results obtained on burned limestone identified during the TARL investigations (see Chapter 27). The archeomagnetic results supported the field identifications in almost all cases.

The 212 burned rock features found in the WilsonLeonard investigations were classified into nine descriptive categories in this analysis: burned rock midden, burned rock accumulation, burned rock scatter, burned rock cluster, large burned rock basin, small burned rock basin, pit with burned rocks, burned rock ring, and burned sediment with a few burned rocks. These categories were defined on the basis of key morphological attributes rather than functional/interpretive criteria. Morphological/descriptive types rather than functional/interpretative types (such as "hearth" or "oven") were used for several reasons. First, an effort was made to present the descriptive data in an objective format that would facilitate both comparative studies and alternative interpretations. Second, insufficient evidence was preserved in most of these features to support very convincing functional interpretations. Finally, this simple classification system was also designed to overcome some of the deficiencies in the data collected on many features. For example, early in the TxDOT excavations burned rock features were recorded primarily with plan drawings and/or photographs and little additional documentation. These sources typically provide important data on the configuration of burned rock features (e.g., number of rocks, spacing, overall shape) but they usually lacked documentation of other important attributes (e.g., evidence of in situ burning). In the sections that follow, the nine categories of burned rock features are briefly described.

\section{Burned Rock Middens}

Burned rock middens are the largest and most visually prominent cultural features found at the Wilson-Leonard site. Two burned rock middens (designated Burned Rock Midden 1 and Burned Rock Midden 2) were sampled in the excavations and several others are located in or very near the site area (see Chapter 2). These features are large, mounded (or domed) accumulations of densely packed burned limestone fragments, mixed with dark organically enriched sediment, charcoal, ash, faunal remains, and assorted artifacts. The excavated middens ranged from ca. $16-20 \mathrm{~m}$ in diameter with maximum vertical extents of ca. $1 \mathrm{~m}$. "Central depressions" or "central pit features" were not documented for either of these middens, and they are comparable to the "domed burned rock middens" identified at other Central Texas sites (cf. Black and Ellis 1997:7-9; Collins 1991:2; Prewitt 1991:25; Type 1 in Weir 1976:34-35). These middens are also comparable to Howard's (1991:57-58) "partly buried middens in stratified contexts." Although the upper portions of the mounds were visible on the surface, most of the midden deposits were buried.

\section{Burned Rock Accumulations}

Five features were classified as burned rock accumulations (Features 8, 124, 195, 201, and 231). The deposits found within these accumulations closely resemble the burned rock midden deposits (multiple layers of densely packed burned rocks and other cultural debris buried in dark, organically enriched sediments), but they are flat rather than mounded and are no more than $40 \mathrm{~cm}$ thick. All five accumulations were only partially exposed, but the documented portions had horizontal extents of at least 4-10 m and vertical extents ranging from ca. $10-40 \mathrm{~cm}$. Two of the accumulations (Feature 8 and Feature 195) probably represent the lowest layers of Burned Rock Middens 1 and 2 (respectively). They were separated from the overlying mounded midden deposits by thin layers of relatively rock-free sediments. These layers apparently represented 
depositional episodes that interrupted the accumulation of the burned rock deposits.

The other accumulations (Features 124, 201, and 231) were buried in the Valley Floor deposits and do not underlie mounded accumulations. The latter group are probably comparable to the "incipient burned rock middens," or "sheet burned rock middens" identified at other Central Texas sites (cf. Black and Ellis 1997:9; Collins 1991:16; Type 4 in Weir 1976:40). They are also comparable to Howard's (1991:57-58) "buried middens" in stratified contexts.

\section{Burned Rock Scatters}

Twenty-three features were classified as burned rock scatters. Generally, these appeared to be randomly distributed (or unpatterned) concentrations of burned stones, usually composed of no more than one or two layers of rocks. Maximum horizontal dimensions (as recorded) ranged from ca. $70-200 \mathrm{~cm}$, with vertical extents of ca. $6-20 \mathrm{~cm}$.

Several of the burned rock scatters (e.g., Features 7 and 15) looked like they might represent the disrupted remains of one or more discrete burned rock clusters. Others (e.g., Features 203, 205, 210, 217, 223, and 225) were recorded within the boundaries of larger burned rock accumulations (before they were recognized as extensive accumulations). Effectively, these burned rock scatters represent a "slice" or "sample" of the larger accumulation (which may represent, at least in part, a palimpsest of burned rock scatters).

\section{Burned Rock Clusters}

The burned rock cluster category encompassed a wide range of variation. This was the largest burned rock feature category, with a total of 145 features so classified. This classification was generally used for groups (or clusters) of burned rocks that looked like they might represent the remains of an intentional construction (e.g., a rock hearth or cooking feature) or some other patterned behavior (e.g., a disposal pile). There was considerable variation in the size of these clusters, with horizontal dimensions ranging from ca. $40-140 \mathrm{~cm}$ (majority fell within the 50-100-cm size range) and vertical extents ranging from ca. $5-25 \mathrm{~cm}$ (majority fell within the 5-15-cm size range). Most of the clusters were composed of a single layer of rocks, although a few multiplelayer clusters were identified as well (ca. 2-3 layers). The smaller clusters included anywhere from 5 to 50 rocks and the larger clusters included up to 150 rocks. Rock spacing varied considerably, with the category encompassing both compact and loose groupings of stones. Unlike the rockfree interiors of burned rock rings (see below), burned rock clusters included rocks in their central or interior areas.

Some of the burned rock clusters exhibited relatively distinct parameters, while others were less clearly circumscribed. There were many variations in overall shape (e.g., circular, oval, triangular, irregular), but most appeared to be resting on a relatively flat surface. When one or more lines of evidence indicated a cluster of rocks was probably resting in a basin-shaped pit, the feature was classified as a burned rock basin (see below). When the evidence was more ambiguous, the feature was classified as a burned rock cluster with a parenthetical note suggesting an alternative classification (e.g., "small burned rock basin?").

Some of the burned rock clusters included definitive evidence of in situ burning. Sizable patches of burned sediment were observed in situ in some clusters, and some of these included concentrations of charcoal and/or ash. Evidence of in situ burning was also obtained in the lab from micromorphology thin-sections of feature sediment and archeomagnetic samples collected from burned rocks. For many of the other clusters, this sort of evidence was either not present, not preserved, or not collected.

Many (or most?) of the Wilson-Leonard burned rock clusters fall within the broad range of variation encompassed by the "hearth" or "flat hearth" classifications used in many Central Texas site reports and syntheses (Howard 1991; Prewitt 1974, 1981; Ricklis and Collins 1994; Sorrow et al. 1967; Weir 1976). The term "hearth" has been used very selectively in the present analysis. It has only been used in interpretive discussions, and it has been confined primarily to burned rock clusters with definitive evidence of in situ burning and at least some degree of structural integrity (archeomagnetic and micromorphology data providing the strongest lines of evidence). There are a number of alternative behaviors that can result in clusters of burned or heataltered stones (e.g., disposal piles from stone-boiling or hearth/oven clean-out).

\section{Small and Large Burned Rock Basins}

The burned rock basin categories were used for basinshaped pits filled or lined with burned rocks. The basinshaped pits were wider than they were deep with gently sloping walls. The actual pit outlines were difficult to discern in the Wilson-Leonard deposits, and the pits were usually recognized/defined by the rocks resting on the walls and base (i.e., basin-shaped configurations of stones).

The eight features classified as small burned rock basins (Features 13, 75, 123, 139, 224, 227, 230, and 236) ranged from ca. $40-100 \mathrm{~cm}$ in diameter and ca. $10-20 \mathrm{~cm}$ in vertical extent (though actual depth may have been greater than documented extent). The smallest basin (Feature 75) was lined with only 4 rocks; the others were filled with ca. 20-100 rocks. Evidence of in situ burning was documented for some of these basins (usually at or near the base).

The nine features classified as large burned rock basins (Features 4, 19/104, 130, 131, 146, 150, 166, 181, and 245) ranged from ca. $130-260 \mathrm{~cm}$ in diameter and ca. $15-50 \mathrm{~cm}$ in vertical extent (though actual depth may have been greater than documented extent). Some of the large burned rock basins apparently had layers of larger (less-intensively 
fractured) stones at or near the base of the pit, but for the most part these features were filled with a dense jumble of fractured rocks (ranging from several hundred to a few thousand rocks). Evidence of in situ burning was documented for some of these features.

Both the large and small burned rock basins found at Wilson-Leonard are comparable to "basin-shaped hearths" reported at other Central Texas sites (Howard 1991:57-62; Prewitt 1974:72, 1981:77-83; Weir 1976:41). The large burned rock basins are also comparable to features classified as "rock ovens" or "earth ovens" in other studies (Black et al. 1993; Black et al. 1997; Collins 1995).

\section{Pit with Burned Rocks}

This category was used for a single problematical feature, Feature 194. This feature was partially exposed in the lower levels of Burned Rock Midden 2. Although it very likely represents either a large or a small burned rock basin, there was insufficient evidence to confidently assign it to either category. Its documented portion was ca. $70-x-70 \mathrm{~cm}$ in diameter, but it extended into two walls and was almost certainly larger. It had a documented depth of $27 \mathrm{~cm}$, but was very likely deeper (it probably originated from a surface above its detection level). It appears to have had a circular outline, but the boundaries were obscured by intrusive burrows. The pit fill apparently contained at least some burned rocks, but it is not clear how many. The largest rocks were apparently found at the base of the pit along with some burned sediment and charcoal.

\section{Burned Rock Rings}

The burned rock ring category was used for circular, oval, or semicircular configurations of burned rocks surrounding rock-free interiors. The nine features classified as burned rock rings (Features 35, 71, 89, 137, 152, 153, 156, 158, and 180) range from ca. $50-100 \mathrm{~cm}$ in diameter and no more than $5-15 \mathrm{~cm}$ thick. They were composed of ca. 6 to 20 rocks that appeared to rest on relatively flat surfaces. At least some of these features exhibited evidence of in situ burning in the interior, suggesting they might have been containment or hearth rings encircling a campfire. Others may simply represent fortuitous (rather than intentional) configurations (e.g., burned rock clusters where interior stones were displaced).

\section{Burned Sediment with a Few Burned Rocks}

This category describes a group of nine features (Features 162, 176, 209, 221, 232, 237, 243, 247, and 256) sharing the following key attributes: they encompassed patches of in situ burned sediment (usually oxidized) with a rather limited areal extent, and they included relatively small numbers of burned rocks (ca. 3-8) that appeared to be randomly scattered across and around the patches of burned sediment (no patterned configurations apparent), with the rocks apparently resting on relatively flat surfaces (no evidence of pits). These were relatively small features, encompassing areas no more than ca. $25-80 \mathrm{~cm}$ in diameter and no more than ca. 5-10 cm thick. Other evidence of burning included scattered charcoal, ash, burned bones, burned snail shells, and/or burned artifacts (not all present in all features). The areas of burned sediment and charcoal found in these features were distinguished from the definite (and probable) burned plants on the basis of their overall appearance/configuration, their horizontal and vertical extent (they were generally smaller than the burned plants, especially in their vertical extent), and the quantity of woody charcoal present (most of the burned plants had larger concentrations of woody charcoal).

\section{Rock Clusters (Possibly Burned)}

This category encompasses two problematical features recorded during the TARL investigations. Both appeared to be cultural rock clusters, but the rocks exhibited no obvious signs of burning (and no other evidence of burning was found in the feature areas). Feature 216 was a ca. $75-x-35-x-6-$ $\mathrm{cm}$ cluster of seven closely spaced rocks. Feature 259 was a somewhat looser grouping of ca. nine rocks within an area measuring ca. $80-\mathrm{x}-55-\mathrm{x}-20 \mathrm{~cm}$.

\section{Miscellaneous Cultural Features}

In addition to the rock features discussed above, five additional categories of cultural features were identified in this analysis: human burials, pits (without burned rocks), artifact clusters, bone concentrations, and modern geologic probes.

\section{Human Burials}

The human burial category was assigned to two flexed inhumations and an isolated skull that was probably displaced from an unidentified third burial. Burial 1 (or WilsonLeonard I) was a disturbed burial found in the lower portion of Burned Rock Midden 1 (in Unit IIIc). Although the upper half of the burial was missing, the surviving portion appeared to be in primary context. The individual was apparently interred in a flexed position (possibly face up) with the lower legs folded beneath the upper legs. The sex could not be determined, and the age could only be estimated as adolescent or adult.

Feature 90 was a fragmentary skull (cranial vault) found in stratigraphic Unit Y. It was tentatively identified as an adolescent or young adult female. Although the skull was initially thought to be part of Burial 1, the stratigraphic position of Feature 90 suggests it probably predates Burial 1. 
Burial 2 (or Wilson-Leonard II) was a relatively undisturbed primary inhumation of a young adult female. She was buried in semiflexed position, lying on her right side with her head pointing to the northeast. Burial 2 was found about $3 \mathrm{~m}$ below surface, near the base of the Leanne soil (Unit Isi-c).

\section{Pits}

Only two features were confidently classified as pits (Features 168 and 169). They were found about 1-2 m south of Burial 2 in approximately the same stratigraphic context. Both pits exhibited very regular, symmetrical outlines, being oval in plan view and roughly $\mathrm{U}$-shaped in profile. They measured 65 to $87 \mathrm{~cm}$ in maximum diameter and 40 to $55 \mathrm{~cm}$ deep. Two possibly burned limestone cobbles were found at the very base of one of these pits, but otherwise their fill was relatively clean and provided no definitive clues to their function.

\section{Artifact Clusters}

The three features classified as artifact clusters include a possible biface cache (Feature 11) found in the upper portion of Burned Rock Midden 1 (Unit IIII), a debitage cluster (Feature 161) found in Unit II, and a pair of battered and tested cobbles (Feature 188) found in Unit Isi.

\section{Bone Concentrations}

Both of the features in this category are probably associated with the Early Paleoindian "bone bed" described in Chapter 7. Feature 170 was a small tight cluster of at least 63 bone fragments found within a ca. 40-cm-diameter area. The identifiable bone included large mammal (probable bison) and medium/large mammal. Feature 262 consisted of a moredispersed scatter of ca. 50 bone fragments within a ca. 100-x$80-\mathrm{cm}$ area. The identifiable bone included large mammal, medium/large mammal, and rabbit. Additional bone from a fine-screen sample included mammal, rabbit, fish, snake, and turtle. A few limestone fragments were also found among the Feature 262 bones, but they exhibited no obvious signs of burning.

\section{Modern Geologic Probes}

Two geologic probes were assigned feature designations before they were recognized as modern features. Feature 189 was a ca. 20 -cm-diameter posthole or auger hole excavated during the TxDOT investigations and Feature 219 was a ca. $10-\mathrm{cm}$-diameter auger hole excavated during the TARL investigations.

\section{Natural Features}

The 21 definitely natural features recorded include 11 burned trees (or other large plants), 6 animal burrows, and 4 geologic features. Many of these features were initially recorded as possible cultural features before they were recognized as natural phenomena. Some of the burned plants were initially interpreted as hearths, and some of the animal burrows were investigated as possible pits. In these cases, careful examination of the overall morphology of the feature (especially asymmetrical elements) elucidated the probable natural origins.

The burned trees include eight located at or near the Unit I/II contact in lower Unit II or upper Unit I (Features 72, $73,154,164,165,167,198$, and 253). Radiocarbon dates obtained on wood charcoal from six of these features (all but Features 73 and 154) were used to estimate the age of the Unit I/II contact (see Chapter 25). Radiocarbon dates obtained on two burned trees found in Unit IIIb (Features 50 and 199) were also used to estimate the age of this stratigraphic unit (see Chapter 25).

Most of the burrows were initially recorded as possible pit features. Two were located in Unit I (Feature 175 and Feature 178), and four were located in Unit III (Features 186, 249,254 , and 258).

The four geologic features include a gravel pocket recorded in Unit I (Feature 74), a mineralized root or rhyzolith recorded in Unit II (Feature 159), and two stratigraphic contacts recorded in Unit I (Feature 244, the Unit Isi/Isi-c contact; and Feature 261, the top of a gravel bar in Unit Igl). The stratigraphic contacts were recorded as features, because they were initially misinterpreted as possible cultural phenomena.

\section{Undetermined Natural or Cultural Features}

Thirteen features could not be confidently identified as either cultural or natural. These include nine concentrations of burned sediment and/or charcoal (Features 20, 49, 69, 95, $160,196,234,238$, and 251); three possible pits or burrows (Features 190, 228, and 252); and a large depression filled with ash and charcoal stained sediment (Feature 79; found at the base of Burned Rock Midden 1).

Most of the burned sediment and charcoal concentrations probably represent burned plants, but the evidence was somewhat ambiguous. Horizontal dimensions ranged from ca. 50-160 cm, and vertical extents ranged from ca. 9$49 \mathrm{~cm}$.

The possible pits or burrows were all filled depressions, but their shapes could not be confidently assessed as either cultural or natural. Their horizontal dimensions ranged from ca. $40-60 \mathrm{~cm}$, and they ranged from ca. $5-20 \mathrm{~cm}$ in vertical extent.

Feature 79 was a large shallow depression found below the base of Burned Rock Midden 1. It had horizontal dimensions of ca. 130-x-105 cm, but the depth was not documented. The depression was filled with ash and charcoal-stained sediment that may have filtered down from the overlying midden deposits. The excavators initially thought it was a 
large shallow pit, but ultimately decided it was a natural topographic depression that had filled with ash and charcoal.

\section{ASSOCIATED MATERIALS AND SPECIAL STUDIES}

Table 26-3 summarizes six additional categories of feature data. It lists the 142 features ( 83 TxDOT; 59 TARL) with associated artifacts, faunal remains, macroplant remains, sediment samples, and/or special samples. The latter category includes organic residue, radiocarbon, archeomagnetic, magnetic susceptibility, micromorphology, gastropod, flotation, and phytolith samples.

The 118 features with no associated materials are not listed on this table. Only two TARL features have no associated materials: Feature 219, a modern auger hole; and Feature 251, a patch of burned sediment that may represent a burned plant. Most of the 116 TxDOT features with no associated materials were burned rock clusters, but this group also includes some small burned rock basins, burned rock rings, burned rock scatters, a modern auger hole, and several natural (or possibly natural) features.

Although the field records clearly indicate no materials were collected from the two TARL features, this is not the case for all the TxDOT features. The field records indicate that artifacts, faunal, and/or macroplant remains were actually collected from some of these features, but the feature provenience was not maintained (materials were combined with level recovery). For many of the other features, the field documentation does not indicate if any materials were found in the feature ("no recovery" was explicitly documented for only a few of these features).

Some feature-associated materials were combined with general level recovery in the field and some were combined in the laboratory. As discussed in Chapter 3, the lot number system used in the TxDOT lab did not easily accomodate proveniences that were more specific than square, quad, and level (e.g., feature provenience or point-plotted items). In this system, feature provenience is only maintained if materials are bagged and tagged separately, or if the feature number is written on the artifact in addition to the lot number. Very few artifacts were labeled with feature numbers, and the separate bags and tags were apparently not maintained for many of the featureassociated materials.

Feature provenience was reconstructed for some of the TxDOT-associated materials during the TARL analysis, but not all materials mentioned in the feature records could be accurately identified and/or segregated in the collections (especially the less distinctive materials). In many cases, feature provenience was maintained and/or reconstructed for only some of the materials actually collected from any one feature context. For example, feature provenience might be reconstructed for distinctive stone tools mentioned in the feature notes but not the debitage, bone fragments, or charcoal samples (which in many cases could not be distinguished from the general recovery materials).

The nature of the associated material samples from both the TXDOT and TARL features is briefly summarized in the sections that follow. The general scope of the special studies conducted on these materials is summarized as well.

\section{Artifacts}

Artifact associations were documented for 69 (ca. 35\%) of the TxDOT features and 49 (ca. 80\%) of the TARL features (see Table 26-3). As noted above, the much lower percentage for the TxDOT features reflects the loss of feature provenience for many associated artifacts. The TARL recovery was enhanced by the use of $1 / 8$-inch mesh water screening (as opposed to the 1/4-inch dry screening used for most of the TxDOT work; see Chapter 3). The TARL investigations also involved fine-screening and flotation of a larger volume of sediment from feature contexts, and this may have enhanced the recovery as well (especially of microdebitage).

As with the overall site recovery, the vast majority of artifacts from feature contexts are chipped stone tools and debitage. A relatively small number of ground and battered stone artifacts were also provenienced to features, along with a few modified shell and bone artifacts.

The artifact recovery from $54 \mathrm{TxDOT}$ and $38 \mathrm{TARL}$ features is summarized in the individual feature descriptions presented at the end of this chapter. All of the lithic artifacts from feature contexts (as well as nonfeature contexts) are also listed in Appendix 5. Although Appendix 5 is sorted by square and level, feature provenience is listed as well. The modifed bone and shell artifacts from feature contexts are listed in Table 21-1 in Chapter 21.

\section{Faunal Remains}

Associated faunal remains (including bone and/or mussel shell) were documented for 34 (ca. 20\%) of the TxDOT features and 47 (ca. 77\%) of the TARL features (see Table 26-3). Like the artifact recovery, the low TxDOT percentage reflects the loss of feature provenience for many faunal materials found in feature contexts. The TARL faunal recovery was also enhanced by both the $1 / 8$-inch mesh water-screening and a larger volume of both fine-screen and flotation samples from feature contexts.

The various faunal samples from feature contexts are summarized in Table 26-4. These samples were studied by five analysts. Baker analyzed the 1/4-inch-mesh bone from the TxDOT excavations and the 1/8-inch-mesh bone from the TARL excavations (see Chapter 33, Appendixes 9 and 10). He reports data from 28 TxDOT features and 39 TARL features. Although most of the feature samples were dominated by unidentifiable fragments, the identifiable bone included a wide variety of taxa. The mammal bone included 
TABLE 26-3

\begin{tabular}{|c|c|c|c|c|c|c|c|c|c|c|c|c|c|c|c|c|}
\hline \multirow{3}{*}{ Feature } & \multicolumn{16}{|c|}{ Materials/Special Samples Associated with Features } \\
\hline & 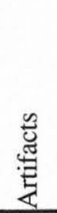 & $\begin{array}{l}\text { ]ี } \\
\text { हี } \\
\text { ల }\end{array}$ & 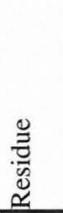 & 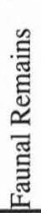 & 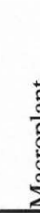 & & 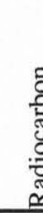 & & 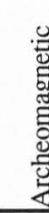 & & 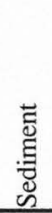 & 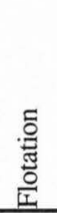 & 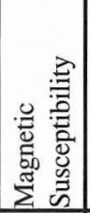 & 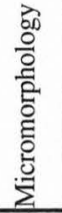 & 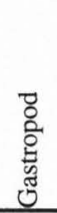 & 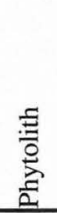 \\
\hline & & A & $\mathrm{U}$ & & A & $\mathrm{U}$ & A & $\mathrm{U}$ & A & $\mathrm{U}$ & & & & & & \\
\hline 4 & $\mathrm{X}$ & & & $\mathrm{X}$ & $\mathrm{X}$ & & & & & & & & & & & \\
\hline 6 & $\mathrm{X}$ & & & & & & & & & & & & & & & \\
\hline 7 & $\mathrm{X}$ & & & $\mathrm{X}$ & $\mathrm{X}$ & & & & & & & & & & & \\
\hline 8 & $\mathrm{X}$ & & & $\mathrm{X}$ & $\mathrm{X}$ & & $\mathrm{X}$ & & & & & & & & & \\
\hline 10 & & & & & $\mathrm{X}$ & & $\mathrm{X}$ & & & & & & & & & \\
\hline 11 & $\mathrm{X}$ & & & & & & & & & & & & & & & \\
\hline 12 & $\mathrm{X}$ & $\mathrm{X}$ & & & $\mathrm{X}$ & & & & & & & & & & & \\
\hline 14 & $\mathrm{X}$ & & & & & & & & & & & & & & & \\
\hline 17 & $\mathrm{X}$ & & & $\mathrm{X}$ & $\mathrm{X}$ & & & & & & & & & & & \\
\hline $19 / 104$ & $\mathrm{X}$ & & & $\mathrm{X}$ & $\mathrm{X}$ & & $\mathrm{X}$ & & & & $X$ & $X$ & $X$ & $\mathrm{X}$ & $\mathrm{X}$ & \\
\hline 20 & $X$ & & & & & & & & & & $\mathrm{X}$ & & & & & \\
\hline 22 & & & & $\mathrm{X}$ & & & & & & & & & & & & \\
\hline 28 & & & & $\mathrm{X}$ & & & & & & & & & & & & \\
\hline 29 & $X$ & & & & & & & & & & & & & & & \\
\hline 33 & & & & & $\mathrm{X}$ & & & & & & & & & & & \\
\hline 36 & $X$ & & & & & & & & & & & & & & & \\
\hline 46 & $\mathrm{X}$ & & & & & & & & & & & & & & & \\
\hline 50 & $\mathrm{X}$ & & & $\mathrm{X}$ & $\mathrm{X}$ & & $\mathrm{X}$ & & & & $X$ & & & & & \\
\hline 69 & & & & & & & & & & & $\mathrm{X}$ & & & & & \\
\hline 72 & & & & & $X$ & & $\mathrm{X}$ & & & & & & & & & \\
\hline 73 & & & & & $\mathrm{X}$ & & & & & & $\mathrm{X}$ & & & & & \\
\hline 76 & $X$ & & & & & & & & & & & & & & & \\
\hline 78 & $\mathrm{X}$ & & & & & & & & & & & & & & & \\
\hline 82 & $\mathrm{X}$ & & & & & & & & & & & & & & & \\
\hline 88 & $\mathrm{X}$ & & & & & & & & & & & & & & & \\
\hline 103 & $\mathrm{X}$ & & & & & & & & & & & & & & & \\
\hline 107 & $X$ & & & & & & & & & & & & & & & \\
\hline 110 & $X$ & & & & & & & & & & & & & & & \\
\hline 115 & $X$ & & & & & & & & & & & & & & & \\
\hline 118 & $\mathrm{X}$ & & & & & & & & & & & & & & & \\
\hline 120 & $\mathrm{X}$ & & & & & & & & & & & & & & & \\
\hline 121 & $\mathrm{X}$ & & & & & & & & & & & & & & & \\
\hline 123 & $X$ & & & $X$ & & & & & & & & & & & & \\
\hline 124 & $\mathrm{X}$ & & & $X$ & & & & & & & & & & & & \\
\hline 130 & $X$ & & & & $\mathrm{X}$ & & & & & & & & & & & \\
\hline 131 & $\mathrm{X}$ & & & & $\mathrm{X}$ & & & & & & & & & & & \\
\hline 133 & $X$ & & & & & & & & & & & & & & & \\
\hline 139 & $\mathrm{X}$ & & & & & & & & & & & & & & & \\
\hline 140 & & & & $X$ & & & & & & & & & & & & \\
\hline 141 & $X$ & & & & & & & & & & & & & & & \\
\hline 146 & $X$ & & & $X$ & $X$ & & & & & & & & & & & \\
\hline 150 & $X$ & & & $\mathrm{X}$ & $\mathrm{X}$ & & & & & & & & & & & \\
\hline 153 & $\mathrm{X}$ & & & & & & & & & & & & & & & \\
\hline
\end{tabular}


Table 26-3, continued

\begin{tabular}{|c|c|c|c|c|c|c|c|c|c|c|c|c|c|c|c|c|}
\hline 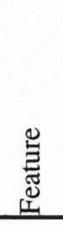 & 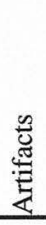 & & $\begin{array}{l}\stackrel{\Xi}{\tilde{W}} \\
\stackrel{\mathscr{Q}}{\mathscr{U}}\end{array}$ & 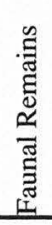 & ב & & 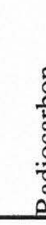 & & $\begin{array}{l}. \\
\\
5 \\
5 \\
5 \\
0 \\
0 \\
5\end{array}$ & & 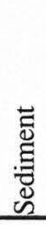 & 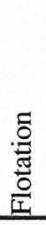 & 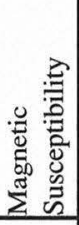 & 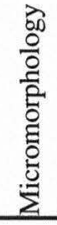 & 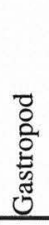 & 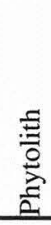 \\
\hline & & A & $\mathrm{U}$ & & A & $\mathrm{U}$ & A & $\mathrm{U}$ & A & $\mathrm{U}$ & & & & & & \\
\hline 154 & $X$ & & & $\mathrm{X}$ & & & & & & & $\mathrm{X}$ & & & & & \\
\hline 155 & $\mathrm{X}$ & & & $X$ & & & & & & & $X$ & $\mathrm{X}$ & $\mathrm{X}$ & $X$ & $X$ & \\
\hline 157 & $\mathrm{X}$ & & & $X$ & $\mathrm{X}$ & & $\mathrm{X}$ & & & & $X$ & $\mathrm{X}$ & $\mathrm{X}$ & $X$ & & \\
\hline 158 & $\mathrm{X}$ & & & & & & & & & & & & & & & \\
\hline 160 & & & & & & & & & & & $\mathrm{X}$ & & & & & \\
\hline 161 & $\mathrm{X}$ & & & & & & & & & & & & & & & \\
\hline 162 & & & & & $X$ & & & & & & & & & & & \\
\hline 163 & $\mathrm{X}$ & & & $\mathrm{X}$ & $X$ & & & & & & & & & & & \\
\hline 164 & $\mathrm{X}$ & & & & $X$ & & $\mathrm{X}$ & & & & $X$ & & & & & \\
\hline 165 & $\mathrm{X}$ & & & & $X$ & $X$ & $\mathrm{X}$ & & & & $\mathrm{X}$ & & & & & \\
\hline 166 & $\mathrm{X}$ & & & $\mathrm{X}$ & $\mathrm{X}$ & $\mathrm{X}$ & & & & & $\mathrm{X}$ & $\mathrm{X}$ & $X$ & $\mathrm{X}$ & $\mathrm{X}$ & \\
\hline 167 & & & & & $X$ & $\mathrm{X}$ & $\mathrm{X}$ & & & & & & & & & \\
\hline 168 & $\mathrm{X}$ & & & $\mathrm{X}$ & $\mathrm{X}$ & & & & & & $\mathrm{X}$ & $\mathrm{X}$ & $X$ & $X$ & $X$ & $\mathrm{X}$ \\
\hline 169 & $X$ & & & $\mathrm{X}$ & $X$ & $\mathrm{X}$ & & & & & $\mathrm{X}$ & $\mathrm{X}$ & $X$ & $\mathrm{X}$ & $\mathrm{X}$ & $\mathrm{X}$ \\
\hline 170 & & & & $\mathrm{X}$ & & & & & & & & & & & & \\
\hline 171 & $\mathrm{X}$ & & & & & & & & & & & & & & & \\
\hline 172 & $\mathrm{X}$ & & & & & & & & & & & & & & & \\
\hline 173 & $\mathrm{X}$ & & & $\mathrm{X}$ & & & & & & & & & & & & \\
\hline 175 & $X$ & & & $\mathrm{X}$ & $X$ & & & & & & $X$ & $X$ & $X$ & & & \\
\hline 176 & $\mathrm{X}$ & & & & & & & & & & $\mathrm{X}$ & $\mathrm{X}$ & $X$ & $X$ & & \\
\hline 177 & $\mathrm{X}$ & & & $\mathrm{X}$ & & $\mathrm{X}$ & & & & & & & & & & \\
\hline 178 & $X$ & & & & & & & & & & & & & & & \\
\hline 179 & $\mathrm{X}$ & & & & & & & & & & & & & & & \\
\hline 181 & $\mathrm{X}$ & & $X$ & $\mathrm{X}$ & $X$ & & $\mathrm{X}$ & $X$ & $\mathrm{X}$ & $\mathrm{X}$ & $X$ & $\mathrm{X}$ & $X$ & $X$ & & $X$ \\
\hline 183 & $\mathrm{X}$ & & & $X$ & $\mathrm{X}$ & & & & & & & & & & & \\
\hline 184 & $X$ & & $X$ & $X$ & & & & & $X$ & & $\mathrm{X}$ & $X$ & $X$ & & & \\
\hline 185 & $\mathrm{X}$ & & & $X$ & & & & & & & $\mathrm{X}$ & $\mathrm{X}$ & $X$ & $X$ & & \\
\hline 186 & & & & $\mathrm{X}$ & & $\mathrm{X}$ & & & & & $X$ & & & & & \\
\hline 187 & $\mathrm{X}$ & & & $\mathrm{X}$ & $\mathrm{X}$ & & & & & & $X$ & $X$ & $X$ & $X$ & & \\
\hline 188 & $\mathrm{X}$ & & & & & & & & & & & & & & & \\
\hline 192 & $\mathrm{X}$ & & & & & & & & & & & & & & & \\
\hline 193 & $X$ & & & & $\mathrm{X}$ & & & & & & & & & & & \\
\hline 194 & $X$ & & & & $X$ & & & & & & & & & & & \\
\hline 196 & $\mathrm{X}$ & & & & $X$ & & & & & & & & & & & \\
\hline 198 & & & & & $X$ & $\mathrm{X}$ & $\mathrm{X}$ & & & & $\mathrm{X}$ & & & & & \\
\hline 199 & & & & & $X$ & & $\mathrm{X}$ & & & & & & & & & \\
\hline 201 & $\mathrm{X}$ & & $X$ & $\mathrm{X}$ & $\mathrm{X}$ & & & $\mathrm{X}$ & $\mathrm{X}$ & $X$ & $\mathrm{X}$ & & & & & \\
\hline 202 & $\mathrm{X}$ & & $X$ & $\mathrm{X}$ & & & & & & & & & & & & \\
\hline 203 & $\mathrm{X}$ & & $X$ & $X$ & & & & & $\mathrm{X}$ & $\mathrm{X}$ & $X$ & $\mathrm{X}$ & $X$ & & & \\
\hline 204 & $X$ & & & $\mathrm{X}$ & & & $\mathrm{X}$ & & $X$ & $\mathrm{X}$ & $\mathrm{X}$ & $\mathrm{X}$ & $X$ & $X$ & $\mathrm{X}$ & $\mathrm{X}$ \\
\hline 205 & $X$ & & & $\mathrm{X}$ & $X$ & & & & $X$ & $X$ & $\mathrm{X}$ & $\mathrm{X}$ & $X$ & & & \\
\hline 206 & $\mathrm{X}$ & & $X$ & $\mathrm{X}$ & $X$ & & & & $\mathrm{X}$ & $\mathrm{X}$ & $\mathrm{X}$ & $\mathrm{X}$ & $X$ & $X$ & $\mathrm{X}$ & \\
\hline 207 & & & & $\mathrm{X}$ & & & & & $\mathrm{X}$ & & $X$ & $\mathrm{X}$ & $X$ & & & \\
\hline 208 & $\mathrm{X}$ & & & & $\mathrm{X}$ & & & & & $\mathrm{X}$ & $\mathrm{X}$ & $\mathrm{X}$ & $\mathrm{X}$ & & & \\
\hline
\end{tabular}


Table 26-3, continued

\begin{tabular}{|c|c|c|c|c|c|c|c|c|c|c|c|c|c|c|c|c|}
\hline \multirow[t]{2}{*}{ 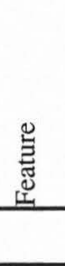 } & \multirow[t]{2}{*}{ 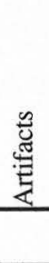 } & \multicolumn{2}{|c|}{ 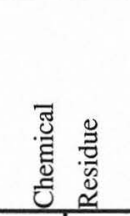 } & \multirow[t]{2}{*}{ 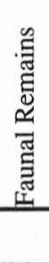 } & \multicolumn{2}{|c|}{ 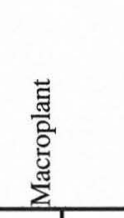 } & \multicolumn{2}{|c|}{ 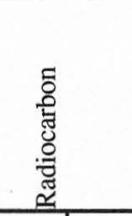 } & \multicolumn{2}{|c|}{ 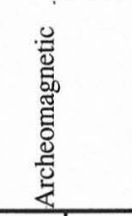 } & \multirow[t]{2}{*}{ 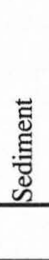 } & \multirow[t]{2}{*}{ 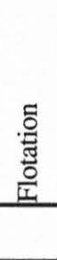 } & \multirow[t]{2}{*}{ 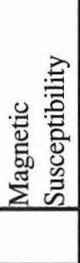 } & \multirow[t]{2}{*}{ 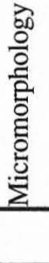 } & \multirow[t]{2}{*}{ 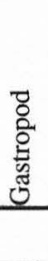 } & \multirow[t]{2}{*}{ : } \\
\hline & & A & $\mathrm{U}$ & & A & $\mathrm{U}$ & A & $\mathrm{U}$ & A & $\mathrm{U}$ & & & & & & \\
\hline 209 & $\mathrm{X}$ & & $X$ & $\mathrm{X}$ & $\mathrm{X}$ & & & $X$ & & & $X$ & $\mathrm{X}$ & $\mathrm{X}$ & $\mathrm{X}$ & $\mathrm{X}$ & \\
\hline 210 & $\mathrm{X}$ & & & $X$ & $\mathrm{X}$ & & & & & & $X$ & $\mathrm{X}$ & $X$ & & & \\
\hline 211 & $\mathrm{X}$ & & & & & & & & $\mathrm{X}$ & $X$ & $X$ & $\mathrm{X}$ & $X$ & & & \\
\hline 212 & $\mathrm{X}$ & & $X$ & $X$ & & & & & $\mathrm{X}$ & $X$ & $\mathrm{X}$ & $\mathrm{X}$ & $X$ & & & \\
\hline 213 & $\mathrm{X}$ & & $X$ & $X$ & $\mathrm{X}$ & & & $X$ & & $X$ & $X$ & $\mathrm{X}$ & $\mathrm{X}$ & $X$ & & \\
\hline 214 & $\mathrm{X}$ & & $X$ & $X$ & $\mathrm{X}$ & & $X$ & & $\mathrm{X}$ & $\mathrm{X}$ & $X$ & $\mathrm{X}$ & $X$ & & & \\
\hline 215 & $\mathrm{X}$ & & & $\mathrm{X}$ & & & & & & & $\mathrm{X}$ & $\mathrm{X}$ & $\mathrm{X}$ & & & \\
\hline 216 & & & & & & & & & & $X$ & $\mathrm{X}$ & $\mathrm{X}$ & $X$ & $X$ & & \\
\hline 217 & $\mathrm{X}$ & & & $X$ & $\mathrm{X}$ & & & $\mathrm{X}$ & $\mathrm{X}$ & $X$ & & & & & & \\
\hline 218 & & & & & & & & & $\mathrm{X}$ & $\mathrm{X}$ & & & & & & \\
\hline 220 & $X$ & & $X$ & $X$ & $X$ & & & $X$ & & & $\mathrm{X}$ & $X$ & $X$ & $X$ & & \\
\hline 221 & $\mathrm{X}$ & & & $X$ & $\mathrm{X}$ & & & $X$ & & & $X$ & & $X$ & & & \\
\hline 222 & $\mathrm{X}$ & & & $X$ & & & & & $\mathrm{X}$ & $\mathrm{X}$ & $\mathrm{X}$ & $\mathrm{X}$ & $\mathrm{X}$ & $X$ & & \\
\hline 223 & $\mathrm{X}$ & & $X$ & $X$ & & & & & $X$ & $\mathrm{X}$ & & & & & & \\
\hline 224 & $\mathrm{X}$ & & $X$ & $X$ & & & & & $X$ & $X$ & $X$ & $\mathrm{X}$ & $\mathrm{X}$ & $X$ & $X$ & \\
\hline 225 & $\mathrm{X}$ & $X$ & $X$ & $X$ & & & & $X$ & $\mathrm{X}$ & $X$ & $X$ & & $\mathrm{X}$ & & & \\
\hline 226 & $\mathrm{X}$ & & & $X$ & & & & & $\mathrm{X}$ & $X$ & $X$ & $\mathrm{X}$ & $X$ & $X$ & & \\
\hline 227 & $\mathrm{X}$ & $X$ & $X$ & $X$ & & & & & $X$ & $X$ & $X$ & $\mathrm{X}$ & $X$ & $\mathrm{X}$ & & \\
\hline 228 & $\mathrm{X}$ & & & $\mathrm{X}$ & & & & $X$ & $\mathrm{X}$ & & $\mathrm{X}$ & $\mathrm{X}$ & $\mathrm{X}$ & $\mathrm{X}$ & & \\
\hline 230 & $\mathrm{X}$ & & $X$ & $X$ & & & & & $\mathrm{X}$ & $\mathrm{X}$ & $\mathrm{X}$ & $\mathrm{X}$ & $\mathrm{X}$ & $\mathrm{X}$ & & \\
\hline 231 & $X$ & $X$ & $X$ & $X$ & $\mathrm{X}$ & $X$ & $X$ & $\mathrm{X}$ & $\mathrm{X}$ & $\mathrm{X}$ & $\mathrm{X}$ & $\mathrm{X}$ & $X$ & & $X$ & \\
\hline 232 & $\mathrm{X}$ & & & $X$ & & & & & & & & & & $\mathrm{X}$ & & \\
\hline 233 & $X$ & & $\mathrm{X}$ & $\mathrm{X}$ & $\mathrm{X}$ & & & $\mathrm{X}$ & $\mathrm{X}$ & $\mathrm{X}$ & $\mathrm{X}$ & $\mathrm{X}$ & $X$ & $\mathrm{X}$ & $\mathrm{X}$ & \\
\hline 234 & $X$ & & $X$ & $X$ & $X$ & & & $X$ & $X$ & $X$ & $X$ & $\mathrm{X}$ & $X$ & & & \\
\hline 235 & $\mathrm{X}$ & & $X$ & $X$ & $X$ & & & $X$ & $\mathrm{X}$ & $X$ & $X$ & $\mathrm{X}$ & $\mathrm{X}$ & & & \\
\hline 236 & $X$ & $\mathrm{X}$ & $X$ & $\mathrm{X}$ & $\mathrm{X}$ & & $X$ & $\mathrm{X}$ & $\mathrm{X}$ & $\mathrm{X}$ & $\mathrm{X}$ & $\mathrm{X}$ & $X$ & $X$ & $X$ & $\mathrm{X}$ \\
\hline 237 & & & & & & & & & $X$ & $X$ & $X$ & & $\mathrm{X}$ & $\mathrm{X}$ & & \\
\hline 238 & $\mathrm{X}$ & & $X$ & $X$ & $\mathrm{X}$ & & $X$ & $X$ & & & $X$ & & $X$ & & & \\
\hline 239 & $\mathrm{X}$ & & & $\mathrm{X}$ & $\mathrm{X}$ & $\mathrm{X}$ & & $\mathrm{X}$ & $\mathrm{X}$ & $\mathrm{X}$ & $\mathrm{X}$ & $\mathrm{X}$ & $\mathrm{X}$ & $\mathrm{X}$ & & \\
\hline 240 & $\mathrm{X}$ & & $\mathrm{X}$ & $X$ & & & & & $\mathrm{X}$ & $\mathrm{X}$ & & & & & & \\
\hline 241 & $\mathrm{X}$ & & $X$ & & & & & & $\mathrm{X}$ & $X$ & $X$ & $\mathrm{X}$ & $X$ & $X$ & & \\
\hline 242 & & & & & & & & & $\mathrm{X}$ & $\mathrm{X}$ & $X$ & $\mathrm{X}$ & $\mathrm{X}$ & & & \\
\hline 243 & & & & & & & & & & & $\mathrm{X}$ & & $X$ & $X$ & & \\
\hline 244 & & & & & & $X$ & & $\mathrm{X}$ & & & $\mathrm{X}$ & & $X$ & & & \\
\hline 245 & $\mathrm{X}$ & $X$ & $\mathrm{X}$ & $X$ & $X$ & $X$ & $X$ & $\mathrm{X}$ & $\mathrm{X}$ & $X$ & $\mathrm{X}$ & $\mathrm{X}$ & $\mathrm{X}$ & $\mathrm{X}$ & $X$ & $\mathrm{X}$ \\
\hline 246 & $\mathrm{X}$ & & & $X$ & $X$ & & & $\mathrm{X}$ & $\mathrm{X}$ & $\mathrm{X}$ & $\mathrm{X}$ & $X$ & $\mathrm{X}$ & $\mathrm{X}$ & & \\
\hline 247 & $\mathrm{X}$ & & $\mathrm{X}$ & $X$ & $X$ & & $\mathrm{X}$ & $\mathrm{X}$ & & $X$ & & & & & & \\
\hline 248 & $\mathrm{X}$ & & $X$ & $\mathrm{X}$ & $X$ & & & $\mathrm{X}$ & $\mathrm{X}$ & $\mathrm{X}$ & $\mathrm{X}$ & $\mathrm{X}$ & $X$ & $\mathrm{X}$ & $X$ & \\
\hline 249 & $\mathrm{X}$ & & $\mathrm{X}$ & $\mathrm{X}$ & & $X$ & & $\mathrm{X}$ & $\mathrm{X}$ & & $\mathrm{X}$ & $\mathrm{X}$ & $X$ & $\mathrm{X}$ & & \\
\hline 250 & & & & & & & & & $\mathrm{X}$ & $\mathrm{X}$ & & & & & & \\
\hline 252 & $\mathrm{X}$ & & & $X$ & & & & & & & $\mathrm{X}$ & $X$ & $X$ & $X$ & & $\mathrm{X}$ \\
\hline 253 & & & & & $\mathrm{X}$ & $X$ & $\mathrm{X}$ & $\mathrm{X}$ & & & & & & & & \\
\hline 254 & $\mathrm{X}$ & & & $X$ & & & & & & $X$ & & & & & & \\
\hline 255 & $\mathrm{X}$ & & & $\mathrm{X}$ & $X$ & & $\mathrm{X}$ & $\mathrm{X}$ & $\mathrm{X}$ & $\mathrm{X}$ & $\mathrm{X}$ & $\mathrm{X}$ & $X$ & $\mathrm{X}$ & $\mathrm{X}$ & $\mathrm{X}$ \\
\hline 256 & & & & & & $X$ & & $\mathrm{X}$ & & $\mathrm{X}$ & $X$ & $\mathrm{X}$ & $X$ & $\mathrm{X}$ & & \\
\hline
\end{tabular}


Table 26-3, continued

\begin{tabular}{|c|c|c|c|c|c|c|c|c|c|c|c|c|c|c|c|c|}
\hline \multirow[t]{2}{*}{ 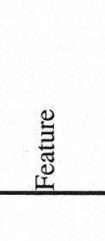 } & \multirow[t]{2}{*}{ 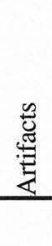 } & \multicolumn{2}{|c|}{ 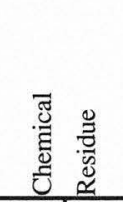 } & \multirow[t]{2}{*}{ 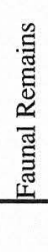 } & \multicolumn{2}{|c|}{ 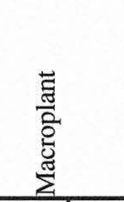 } & \multicolumn{2}{|c|}{ 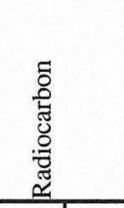 } & \multicolumn{2}{|c|}{ 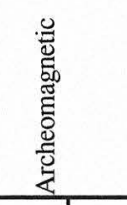 } & \multirow[t]{2}{*}{ 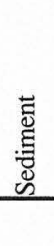 } & \multirow[t]{2}{*}{ 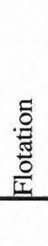 } & \multirow[t]{2}{*}{ 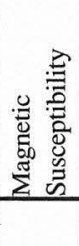 } & \multirow[t]{2}{*}{ 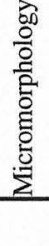 } & \multirow[t]{2}{*}{ 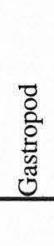 } & \multirow[t]{2}{*}{ 氞 } \\
\hline & & A & U & & A & $\mathrm{U}$ & A & $\mathrm{U}$ & A & $\mathrm{U}$ & & & & & & \\
\hline 257 & $\mathrm{X}$ & & & $\mathrm{X}$ & $X$ & $\mathrm{X}$ & & $\mathrm{X}$ & $\mathrm{X}$ & & $X$ & $\mathrm{X}$ & $\mathrm{X}$ & & & \\
\hline 258 & $\mathrm{X}$ & & $\mathrm{X}$ & $\mathrm{X}$ & & $\mathrm{X}$ & & $\mathrm{X}$ & $\mathrm{X}$ & & $X$ & $\mathrm{X}$ & $\mathrm{X}$ & & & \\
\hline 259 & $\mathrm{X}$ & & $\mathrm{X}$ & $\mathrm{X}$ & & $\mathrm{X}$ & & $\mathrm{X}$ & $\mathrm{X}$ & $\mathrm{X}$ & & & & & & \\
\hline 260 & $\mathrm{X}$ & & & $\mathrm{X}$ & $\mathrm{X}$ & & & $\mathrm{X}$ & $\mathrm{X}$ & $\mathrm{X}$ & $\mathrm{X}$ & $\mathrm{X}$ & $\mathrm{X}$ & $X$ & $X$ & \\
\hline 261 & $\mathrm{X}$ & & & & & & & & $\mathrm{X}$ & $\mathrm{X}$ & $X$ & $\mathrm{X}$ & $\mathrm{X}$ & & & \\
\hline 262 & $\mathrm{X}$ & & $\mathrm{X}$ & $\mathrm{X}$ & $X$ & & & $\mathrm{X}$ & & $\mathrm{X}$ & $\mathrm{X}$ & $\mathrm{X}$ & $\mathrm{X}$ & $\mathrm{X}$ & & \\
\hline BRM 1 & $\mathrm{X}$ & $\mathrm{X}$ & & $\mathrm{X}$ & $\mathrm{X}$ & $\mathrm{X}$ & & & $\mathrm{X}$ & $\mathrm{X}$ & $\mathrm{X}$ & $\mathrm{X}$ & $\mathrm{X}$ & $\mathrm{X}$ & $\mathrm{X}$ & \\
\hline BRM 2 & $\mathrm{X}$ & & & $\mathrm{X}$ & $\mathrm{X}$ & & $\mathrm{X}$ & & & & & & & & & \\
\hline Burial 1 & $\mathrm{X}$ & $X$ & & & & & & & & & & & & & & \\
\hline Burial 2 & $\mathrm{X}$ & $\mathrm{X}$ & & $\mathrm{X}$ & $\mathrm{X}$ & $\mathrm{X}$ & $\mathrm{X}$ & & & & $\mathrm{X}$ & $\mathrm{X}$ & $\mathrm{X}$ & $\mathrm{X}$ & & $\mathrm{X}$ \\
\hline
\end{tabular}

bison, deer, antelope, Canis sp., unidentified carnivore, jackrabbit, cottontail rabbit and miscellaneous rodents. He also found turtle and snake remains and small quantities of bird, fish, and toad or frog bone.

Balinsky analyzed bone recovered from Square 20, one of the two TARL fine-screen squares (see Chapter 35). Her study, which focused primarily on microvertebrate fauna, included samples from five features found in Square 20 (Features 201, 204, 210, 217, and 233). These samples were also dominated by unidentifiable fragments, but the identifiable bone included larger percentages of smaller animals than Baker's samples (especially rodents, rabbits, turtles, snakes, and fish). The sample from Feature 233 (an Early Archaic burned rock cluster/scatter) was particularly interesting, because it included a relatively high percentage of fish bone (fish bone comprised ca. $40-50 \%$ of the identifiable taxa).

Balinsky's samples were recovered using the fine-screen method described in Chapter 34. This same method was used to process some bulk sediment samples that were collected from feature contexts during both the TxDOT and TARL investigations (not constant-volume samples). The bone recovered from these samples was studied by Becker (see Appendix 8), and the eggshell was analyzed by Decker (see Chapter 36). Becker examined samples from 8 TxDOT features and 12 TARL features. Although she did not conduct a full analysis of these materials, the summary table presented in Appendix 8 includes useful taxon counts. Like the other faunal samples, these samples were all dominated by unidentifiable bone. The identifiable bone included mammal, rabbit, rodent, reptile, turtle, snake, amphibian, and fish bone.

Decker performed a full analysis of eggshell fragments recovered from $7 \mathrm{TxDOT}$ and 11 TARL features (see Chapter 36). The number of eggshell fragments ranged from 1 to 105 per feature (the volume of the fine-screen samples varied considerably). Decker used thickness measurements to esti- mate the minimum number of species, ranging from 1 to 5 , represented by the eggshells found in each feature.

Most of the mussel shell found in the TxDOT investigations was initially analyzed by Neck (1988). Neck's results were ultimately incorporated into a study by Shaw that also included the shell recovered from the TARL investigations (see Chapter 37). Shaw reports mussel shell from 17 TxDOT and 8 TARL features. Most of the mussel shell fragments could not be identified to species. The identifiable specimens from feature contexts include Amblema plicata, Lampsilis teres, Leptodea fragilis, Potamilus purpuratus, Toxolasma texasensis, and Uniomerus tetralasmus.

Of the 81 features with associated faunal remains, 68 are described in the last section of this chapter. These descriptions include summaries of all the faunal remains recovered from each of the features. For the 13 features that are not described, these data can be obtained from the faunal chapters and appendixes cited above.

\section{Human Skeletal Remains}

Human skeletal remains were recovered from three features during the TxDOT investigations (Burial 1, Burial 2, and Feature 90). An analysis of all these skeletal remains was performed by Steele (see Chapter 31). Wilson also conducted stable carbon isotope analyses on small samples of bone from both Burial 1 and Burial 2 (see Chapter 32). The results of these analyses are summarized in the descriptions presented for each of these features in the last section of this chapter.

\section{Macrobotanical Remains}

Associated macroplant samples (charcoal collected in situ or from the screen) were documented for 38 (ca. 19\%) of the TxDOT features and 32 (ca. 53\%) of the TARL features. 
TABLE 26-4

Analyzed Fauna from Feature Contexts*

\begin{tabular}{|c|c|c|c|c|c|c|}
\hline Feature No. & 1/4-inch Bone & 1/8-inch Bone & $\begin{array}{l}\text { Fine-Screen } \\
\text { Bone }\end{array}$ & $\begin{array}{c}\text { Fine-Screen } \\
\text { Eggshell }\end{array}$ & Mussel Shell & Comments \\
\hline 4 & $\mathrm{X}$ & & & & & \\
\hline 7 & $\mathrm{X}$ & & & & $\mathrm{X}$ & \\
\hline 8 & $\mathrm{x}$ & & & & $\mathrm{x}$ & \\
\hline 17 & $\mathrm{x}$ & & & & $\mathrm{X}$ & \\
\hline 19/104 & $\mathrm{X}$ & & & & $\mathrm{x}$ & \\
\hline 22 & & & & & $\mathrm{x}$ & \\
\hline 28 & & & & & $\mathrm{x}$ & \\
\hline 50 & $\mathrm{X}$ & & & & $\mathrm{X}$ & \\
\hline 123 & $\mathrm{X}$ & & & & & \\
\hline 124 & $\mathrm{X}$ & & & & $\mathrm{x}$ & \\
\hline 140 & $\mathrm{X}$ & & & & & \\
\hline 146 & $\mathrm{x}$ & & & & & \\
\hline 150 & $\mathrm{x}$ & & & & $\mathrm{x}$ & \\
\hline 154 & $\mathrm{X}$ & & & & & \\
\hline 155 & $\mathrm{X}$ & & $\mathrm{X}$ & & & Becker analyzed TARL fine-screen bone \\
\hline 157 & $\mathrm{X}$ & & $\mathrm{X}$ & $\mathrm{x}$ & $\mathrm{X}$ & Becker analyzed TARL fine-screen bone \\
\hline 163 & $\mathrm{X}$ & & & & $\mathrm{x}$ & \\
\hline 166 & $\mathrm{X}$ & & $\mathrm{X}$ & & & Becker analyzed TARL fine-screen bone \\
\hline 168 & $\mathrm{x}$ & & $\mathrm{X}$ & & & Becker analyzed TARL fine-screen bone \\
\hline 169 & $\mathrm{x}$ & & $\mathrm{x}$ & $\mathrm{X}$ & & Becker analyzed TARL fine-screen bone \\
\hline 170 & $\mathrm{X}$ & & & & & \\
\hline 173 & $\mathrm{X}$ & & & & $\mathrm{X}$ & \\
\hline 175 & $\mathrm{x}$ & & $\mathrm{x}$ & & & Becker analyzed TARL fine-screen bone \\
\hline 177 & $\mathrm{x}$ & & & & & \\
\hline 181 & $\mathrm{x}$ & $\mathrm{x}$ & $\mathrm{x}$ & $\mathrm{x}$ & $\mathrm{x}$ & Becker analyzed TARL fine-screen bone \\
\hline 183 & & & & & $\mathrm{X}$ & \\
\hline 184 & & $\mathrm{X}$ & collected but & $\mathrm{X}$ & & \\
\hline 185 & & & $\begin{array}{l}\text { not analyzed } \\
\text { collected but }\end{array}$ & & & \\
\hline & & & not analyzed & & & \\
\hline 186 & $\mathrm{x}$ & & & & & \\
\hline 187 & $\mathrm{x}$ & & $\mathrm{x}$ & & & Becker analyzed TARL fine-screen bone \\
\hline 195 & $\mathrm{X}$ & & & & $\mathrm{X}$ & Bone and shell are provenienced to $\mathrm{BRM} 2$ in \\
\hline 201 & & $\mathrm{X}$ & & & & Chapters 33 and 37 \\
\hline 201 & & $\mathrm{X}$ & $\mathrm{X}$ & & & Balinsky analyzed TARL fine-screen bone \\
\hline 202 & & $\mathrm{X}$ & & & & \\
\hline 203 & & $\mathrm{X}$ & & & & \\
\hline 204 & & & $\mathrm{x}$ & $\mathrm{x}$ & & Balinsky analyzed TARL fine-screen bone \\
\hline 205 & & $\mathrm{x}$ & & & & \\
\hline 206 & & $\mathrm{X}$ & $\mathrm{x}$ & $\mathrm{x}$ & & Becker analyzed TARL fine-screen bone \\
\hline 207 & & $\mathrm{X}$ & & & & \\
\hline 209 & & & $\mathrm{X}$ & $\mathrm{X}$ & & Balinsky analyzed TARL fine-screen bone \\
\hline 210 & & $\mathrm{X}$ & & & & \\
\hline 212 & & $\mathrm{X}$ & & & $\mathrm{X}$ & \\
\hline 213 & & $\mathrm{x}$ & $\mathrm{x}$ & $\mathrm{x}$ & & Becker analyzed TARL fine-screen bone \\
\hline 214 & & $\mathrm{X}$ & & & & \\
\hline 215 & & & $\mathrm{x}$ & $\mathrm{x}$ & & Balinsky analyzed TARL fine-screen bone \\
\hline 217 & & $\mathrm{X}$ & & & & \\
\hline 220 & & $\mathrm{x}$ & & & & \\
\hline 221 & & $\mathrm{x}$ & & & & \\
\hline 222 & & $\mathrm{X}$ & & & & \\
\hline 223 & & $\mathrm{x}$ & & & & \\
\hline 224 & & & $\mathrm{X}$ & $\mathrm{x}$ & & Becker analyzed TARL fine-screen bone \\
\hline 225 & & $\mathrm{x}$ & & & $\mathrm{X}$ & \\
\hline 226 & & $\mathrm{x}$ & collected but & & & \\
\hline 227 & & $\mathrm{X}$ & not analyzed & & & \\
\hline 227 & & $X$ & $\begin{array}{l}\text { collected but } \\
\text { not analyzed }\end{array}$ & & & \\
\hline 228 & & $\mathrm{x}$ & & & & \\
\hline 230 & & $\mathrm{x}$ & & & $\mathrm{X}$ & \\
\hline
\end{tabular}

See Chapter 33 for 1/8- and 1/4-inch sample analyses; Chapter 35, Appendix 8, and Appendix 11 for fine-screen bone analyses; Chapter 36 for finescreen eggshell analysis; and Chapter 37 for mussel shell analysis. 


\begin{tabular}{|c|c|c|c|c|c|c|}
\hline Feature No. & 1/4-inch Bone & 1/8-inch Bone & $\begin{array}{c}\text { Fine-Screen } \\
\text { Bone }\end{array}$ & $\begin{array}{c}\text { Fine-Screen } \\
\text { Eggshell }\end{array}$ & Mussel Shell & Comments \\
\hline $\begin{array}{c}231 \\
232 \\
233 \\
234 \\
235 \\
236 \\
238 \\
239 \\
240 \\
242 \\
\\
245 \\
246 \\
\\
247 \\
248 \\
249 \\
252 \\
254 \\
255 \\
257 \\
258 \\
259 \\
260 \\
262 \\
B R M \\
B R M \\
\text { Burial } 2\end{array}$ & $\begin{array}{l}X \\
X\end{array}$ & $\begin{array}{l}\mathrm{X} \\
\\
\mathrm{X} \\
\mathrm{X} \\
\mathrm{X} \\
\mathrm{X} \\
\\
\mathrm{X} \\
\mathrm{X} \\
\mathrm{X} \\
\mathrm{X} \\
\mathrm{X}\end{array}$ & $\begin{array}{c}\mathrm{X} \\
\mathrm{X} \\
\mathrm{X} \\
\mathrm{X} \\
\\
\text { collected but } \\
\text { not analyzed } \\
\mathrm{X} \\
\text { collected but } \\
\text { not analyzed } \\
\\
\\
\mathrm{X} \\
\mathrm{X} \\
\mathrm{X} \\
\\
\mathrm{X} \\
\mathrm{X} \\
\mathrm{X} \\
\mathrm{X}\end{array}$ & $\begin{array}{l}\text { X } \\
\mathrm{X}\end{array}$ & $\begin{array}{l}X \\
X\end{array}$ & $\begin{array}{l}\text { Becker analyzed TARL fine-screen bone } \\
\text { Balinsky analyzed TARL fine-screen bone } \\
\text { Becker analyzed TARL fine-screen bone } \\
\text { Becker analyzed TARL fine-screen bone } \\
\text { Becker analyzed TARL fine-screen bone } \\
\text { Becker analyzed TARL fine-screen bone } \\
\text { Becker analyzed TARL fine-screen bone } \\
\text { Becker analyzed TARL fine-screen bone } \\
\text { Becker analyzed TARL fine-screen bone } \\
\text { Becker analyzed TARL fine-screen bone } \\
\text { Becker analyzed TARL fine-screen bone }\end{array}$ \\
\hline
\end{tabular}

Many of the TARL samples were collected in situ as "C14" samples. The $\mathrm{C} 14$ sample numbers were assigned in the field, with their X-Y-Z coordinates (horizontal and vertical positions) consistently recorded in a field log. Frequently, the C14 samples were also point-plotted in the feature plan drawings. The TARL samples found on the screen were assigned lot numbers.

The TxDOT macroplant samples include charcoal apparently collected in situ as radiocarbon samples and charcoal apparently collected from the screen. The former were wrapped in foil and were sometimes described as " $\mathrm{C} 14$ samples" or "radiocarbon samples" in the field notes. Unfortunately these samples were not numbered in the field, there was no field log documenting their position, and they were not consistently documented in either the level or feature notes. Sample numbers were assigned to the foilwrapped charcoal samples during the TARL analysis, but they were assigned " $\mathrm{CH}$ " numbers to avoid confusion with the better-documented TARL "C14" samples. The TxDOT charcoal that was apparently found on the screen was assigned TxDOT lot numbers.

The macroplant samples analyzed by Dering (see Chapter 40) include ca. 194 samples from definite feature contexts (and others for which the feature provenience could not be retrieved). These samples represent 36 TxDOT and 27 TARL features. Most of these were burned rock features, but the group also includes at least 7 burned trees, 2 pits, a burrow, a bone scatter, and a human burial (Burial 2).
Over half of these samples were very poorly preserved and could not be identified. Most of the identifiable samples were various types of wood-arboreal legume, elm, hackberry, juniper, live oak, mulberry, rose family, walnut, willow family, and unknown hardwood. Most of the identifiable samples from the definite burned trees were identified as live oak (including samples from Features 50, $165,167,198$, and 253) with one identified as red mulberry (Feature 199).

In addition to the wood samples, Dering identified 4 samples ( 3 from Burned Rock Midden 1 and 1 from Feature 201 ) as walnut nutshell and 12 samples as wild hyacinth or Camassia scilloides bulbs. The wild hyacinth bulbs were clearly the most significant finding. Ten of the bulbs were found in Feature 181, a large burned rock basin found in an Early Archaic context in Unit IIIa. One was found in a Late Archaic context near the base of Burned Rock Midden 2, and another was found in Feature 8, an Early Archaic burned rock accumulation that probably represents the earliest layer of Burned Rock Midden 1.

In a concerted effort to increase the recovery of macrobotanical remains, 170 flotation samples from feature contexts were processed during the TARL analysis (see Chapter 40 ). These 170 samples represent only 55 features (multiple samples were processed from some features). Individual sample sizes ranged from ca. 0.15 to 5 liters (though most were in the 2-5-liter range). The total volume processed from feature contexts was ca. 515 liters. 
Unfortunately, the preservation was quite poor and only 62 of the processed feature samples (from 31 features) yielded enough visible material to warrant further study by Dering. Dering found identifiable plant remains in only 3 of these samples (from Features 209, 213, and 233). Feature 209 was a Middle Archaic burned rock feature found in Unit IIIb. It consisted of a small patch of charcoal-stained (possibly burned?) sediment and a few burned rocks. The ca. 5-liter flotation sample from this feature yielded Juniper and Rosaceae wood charcoal and seven carbonized grass seeds. The grass seeds represented three genera: Panicum, Setaria, and Paspalum. A macroplant sample from this feature was identified as elm family wood. Feature 213 was a burned plant found in the Unit IIIa/IIIb transition. The flotation sample from this feature (processed before it was identified as a burned plant) yielded some oak wood charcoal. Feature 233 was an Early Archaic burned rock feature found in the Unit II/IIIa transition. Two flotation samples from this feature were nonproductive but some juniper wood charcoal was recovered from the third sample.

Of the 72 features with associated macrobotanical remains (see Table 26-3), 66 are described in the feature descriptions section at the end of this chapter. Both the analyzed and unanalyzed macrobotanical samples are summarized in each of these descriptions. The analyzed macrobotanical samples from the 6 features that are not described are reported in Chapter 40.

\section{Radiocarbon Assays}

Forty-eight radiocarbon assays were obtained on samples from feature contexts. Forty-one were AMS determinations and 7 were conventional (Beta-decay counting) dates. The dated samples were collected from 14 TxDOT features and 9 TARL features (see Table 26-3 and Table 25-1 in Chapter 25). These include 24 samples from 13 burned rock features, 15 samples from 9 burned trees or roots, and 9 samples from Burial 2. Descriptions of all the 23 dated features are included in the feature descriptions section at the end of this chapter.

Almost all the dated samples from feature contexts were charcoal samples (wood charcoal or bulbs). The exceptions were a carbonized bone fragment from Feature 236, a snail shell from Feature 253, six human bone samples from Burial 2 (or Wilson-Leonard II), and two sediment samples from Burial 2 pit fill.

In Chapter 25, Stafford presents a detailed assessment of all the radiocarbon assays obtained from both feature and nonfeature contexts. He also uses the most reliable of these determinations to develop a chronostratigraphy for the site deposits. Some of the radiocarbon dates on feature samples were very problematical and they were ultimately disregarded in the development of the site chronostratigraphy. Other dates from feature contexts were judged to be very reliable and some of these determinations served as key anchor points in the chronostratigraphic reconstruction.

The problematical determinations include most of the dates obtained from Burial 2 samples. Assessing the age of this highly significant Paleoindian burial proved to be one of the greatest challenges in the site analysis. Six AMS dates were obtained on human bone samples from this burial in ca. 1983 (Stafford et al. 1987), but the bone was too poorly preserved and all the determinations were clearly too young (see Chapter 25). A charcoal sample from the burial pit fill was also AMS-dated in ca. 1983 (Stafford et al. 1987), but the sample was apparently too small for an accurate date and the resulting determination $(13,000 \pm 3000$ B.P., AA-171) had too large a standard deviation to be very informative (see Chapter 25). Two conventional radiocarbon dates were also obtained in ca. 1982-1983 on sediment samples from the pit fill. These determinations ( $9470 \pm 170$ B.P., Tx-4787 and 9650 \pm 124 B.P., $T x-4793$ ), also appear to be a little young and may reflect the presence of stratigraphically displaced (younger) charcoal in the pit fill. Charcoal from the roots of an overlying burned live oak tree, Feature 167, was dispersed throughout the upper portion of Unit I deposits in this area of the site (see descriptions for Features 72/73 and 167; Features 72 and 73 are roots associated with the Feature 167 tree). This live oak tree apparently grew from a surface at or near the Unit I/II contact (ca. $70 \mathrm{~cm}$ above Burial 2), and reliable AMS dates obtained on charcoal collected from the burned roots of this tree $(9410 \pm 60$ B.P., CAMS-14805 from Feature 167; and $9430 \pm 60$ B.P., CAMS-14807 from Feature 72) are quite close to the Burial 2 sediment dates.

An AMS date from another feature was also considered in refining the age estimate of Burial 2. Feature 255 was a small hearth constructed on an occupational surface in the lower portion of the Leanne soil (see Feature 255 description). Archeomagnetic results indicate this hearth is in primary context (relatively undisturbed), and its stratigraphic position (slightly above the base of the Leanne soil) is comparable to the stratigraphic reconstruction for the top of the burial pit (see Burial 2 description). An AMS date of $9990 \pm$ 70 B.P. (CAMS-10195) obtained on some wood charcoal collected from this hearth was judged to be a reliable determination. Considering this date, the two Burial 2 pit fill dates, and other reliable determinations from the upper portion of Unit I (see Chapter 25), the age of Burial 2 has been estimated in this analysis as ca. 10,000 B.P. (although Stafford has assigned a more-conservative age estimate of ca. 10,000-10,500 B.P., see Chapter 25).

Other reliable feature assays from Unit I/II contexts include determinations on nine additional wood charcoal samples collected from burned trees/roots. These samples were collected from three live oak trees (Features 165, 198, and 253) and an unidentified tree or other large plant (Feature 164). Like Feature 167, all four of these plants apparently grew on surfaces at or near the Unit I/II contact, and the dates were quite close to one another: the Feature 164 charcoal sample was AMS-dated to $9520 \pm 60$ B.P. (CAMS- 
14806); the Feature 165 charcoal sample was conventionally dated to $9530 \pm 88$ B.P. (Tx-4828); the Feature 198 charcoal sample was AMS-dated to $9240 \pm 70$ B.P. (CAMS19080); and six charcoal samples from Feature 253 were AMS-dated to $9480 \pm 100$ B.P. (CAMS-06374), $9500 \pm 80$ B.P. (CAMS-06349), $9540 \pm 70$ B.P. (CAMS-06348), $9540 \pm 80$ B.P. (CAMS-06373), $9590 \pm 80$ B.P. (CAMS-06382), and $9610 \pm$ 70 B.P. (CAMS-06350). A less-reliable AMS date was obtained on a snail shell collected from Feature 253 (10,520 \pm 80 B.P., CAMS-06377). Stafford used the charcoal dates from Features $164,165,167$, and 253 to estimate the age of the Unit I/II contact at ca. 9500 B.P. Since the stratigraphic position of Feature 198 was less certain (see Feature 198 description), the slightly younger date obtained on this sample was considered but not emphasized in dating the Unit I/II contact.

The dated feature samples include four from features in Unit II (all were burned rock features). Reliable AMS dates were obtained on charcoal from Feature 157, a large burned rock cluster found in upper Unit II (9340 \pm 60 B.P., CAMS18640), and Feature 236, a small burned rock basin found in lower Unit II (9650 \pm 80 B.P., CAMS-07560). Less-reliable dates were derived from carbonized bone found in Feature $236(10,400 \pm 280$ B.P., CAMS-07561), and from charcoal found in Feature 247, a burned rock cluster located in upper Unit II ( $8090 \pm 70$ B.P.). The latter date appears to be too young for this stratigraphic context, suggesting the dated charcoal may have been stratigraphically displaced from overlying Unit IIIa deposits (see Feature 247 description).

The most significant radiocarbon dates for Unit IIIa were derived from carbonized wild hyacinth bulbs found in the Feature 181 large burned rock basin. Nine of these bulbs were AMS-dated and the determinations were judged to be very reliable (see discussion by Stafford in Chapter 25): 7870 \pm 60 B.P. (CAMS-13840); $7890 \pm 60$ B.P. (CAMS-13841); 7890 \pm 80 B.P. (CAMS-13844); $7990 \pm 60$ B.P. (CAMS-08355); 8010 \pm 60 B.P. (CAMS-13512); $8030 \pm 60$ B.P. (CAMS-13513); 8080 \pm 70 B.P. (CAMS-13514); $8080 \pm 60$ B.P. (CAMS-10201); and $8130 \pm 70$ B.P. (CAMS-13509). Other reliable AMS determinations from Unit IIIa were made on three charcoal samples collected from Feature 245, another large burned rock basin found immediately north of Feature 181 (see Feature 245 description). The dates on these samples were $8110 \pm 70$ B.P. (CAMS-10194), $8130 \pm 60$ B.P. (CAMS-10197), and $8420 \pm$ 200 B.P. (CAMS-10206). An unreliable AMS date of $3440 \pm$ 80 B.P. (CAMS-13025) was derived from some poorly preserved charcoal found in the Feature 231 burned rock accumulation.

Four features were dated in Unit IIIb, and all of these dates appear to be reliable. Conventional dates were obtained on wood charcoal samples collected from a burned live oak tree (Feature 50: $5520 \pm 80$ B.P., Beta-79700), a burned red mulberry tree (Feature 199: $5560 \pm 60$ B.P., Beta-79699), and a burned rock cluster (Feature 214: $4880 \pm 70$ B.P., Beta79803). An AMS measurement was made on wood charcoal collected from another burned rock cluster (Feature 204: 4440 \pm 60 B.P., CAMS-10196).

The two dates from Unit IIIc features appear reliable as well. A carbonized wild hyacinth found in the lower portion of Burned Rock Midden 2 yielded an AMS date of $3780 \pm$ 70 B.P. (ETH-14115). A wood charcoal sample from Feature 10 , a burned rock cluster found in the upper portion of Unit IIIc, was AMS dated to $1990 \pm 60$ B.P.

Two dates were also obtained on feature samples from poorly defined stratigraphic contexts in the Valley Margin. A charcoal sample from a large burned rock basin in Unit X, Feature 19/104, yielded a conventional date of $7470 \pm 230$ B.P. (Tx-4798). A carbonized wild hyacinth bulb provenienced to the Feature 8 burned rock accumulation (Unit Y/IIIc transition) was AMS-dated to $8250 \pm 80$ B.P. (CAMS-18375). Although the chronostratigraphy of the Valley Margin deposits was not defined as well as the Valley Floor deposits, these dates appear to be consistent with the Early Archaic artifacts found in and near these two features.

\section{Archeomagnetic Samples}

Archeomagnetic samples were collected from limestone fragments found in 49 features during the TARL investigations, and samples from 43 of these features were analyzed by Takac (see Table 26-3, Chapter 27, and Appendix 6). Almost all the sampled rocks were identified as burned or probably burned in the field (based on thermal fractures, discoloration, and/or context), and the archeomagnetic results generally supported the field observations of burning. A relatively small number of samples were collected from rocks that did not appear to have been burned, and the archeomagnetic results generally supported (or did not contradict) these field assessments (see Chapter 27)

The analyzed samples were collected from 13 Paleoindian-age features (in Units I and II), 3 Late Paleoindian or Early Archaic-age features (in the Unit II/IIIa transition), and 27 Archaic-age features (in Unit III). Most of these features are included in the Selected Feature Descriptions section at the end of the chapter, and each of these descriptions includes a summary of the archeomagnetic results. The results from the four features that are not described (Features 218, 240, 258, and 261) can be found in Chapter 27.

The Paleoindian-age features with archeomagnetic data include a small burned rock basin in lower Unit II (Feature 236), six burned rock clusters in Unit II (Features 235, 239, $241,246,248$, and 250), three burned rock clusters in Unit Isic $(255,257$, and 260$)$, a possible burned rock cluster in the Unit Icl/Isi-c transition (Feature 259), a probable burned plant in the Unit Isi-c/II transition (Feature 234), and a natural gravel bar deposit in upper Unit Igl (Feature 261). The samples from the gravel bar and the possible burned rock cluster exhibited very weak magnetic remanence. These rocks do not appear to have been heated. The most significant results were obtained from Features 235, 236, 246, 248, and 
255. All of these were relatively small, compact burned rock features measuring ca. $50-60 \mathrm{~cm}$ in diameter, no more than 16 $\mathrm{cm}$ deep, and containing no more than ca. 15-40 rocks. The archeomagnetic data obtained from rocks in these features suggest they are relatively undisturbed. The rocks were definitely heated (some to very high temperatures), and many appear to have cooled in place, with little or no postcooling displacement. Burned sediment, ash, and/or charcoal were also found in some of these features.

Most of the analyzed samples from Archaic contexts were from Early Archaic features found in Unit IIIa (the burned rock feature density was extremely high in Unit IIIa). Many of these samples were collected within Feature 231, an extensive burned rock accumulation that encompassed several internal subfeatures (see Feature 231 description). The internal subfeatures included two large burned rock basins (Features 181 and 245), a small burned rock basin (Feature 230), a possible pit or burrow (Feature 228), a patch of burned sediment surrounded by a few rocks (Feature 237), and three burned rock scatters (Features 217, 223, and 225). Over 800 archeomagnetic samples were collected from burned rocks within Feature 231 (and subfeatures), and approximately 525 of these samples were analyzed. The results were quite complex and are discussed in some detail in Chapter 27 . Generally, the results indicate all the rocks were heated (many to very high temperatures), and many have very complex heating and cooling histories (suggesting multiple events are represented). An overall higher percentage of rocks within the basin-shaped subfeatures (Feature 181, 230, and 245) remained in or near their final cooling positions, and a higher percentage of rocks in the surrounding scatter experienced more significant displacements (both during cooling and after they were completely cooled). It also appears that many of the rocks that surrounded the large burned rock basins (Features 181 and 245) were probably displaced from these pit features. Some of these rocks were apparently moved while still hot (possibly when cooked food was removed from a pit that was still hot), and others were moved after they were completely cooled (perhaps when the pit was cleaned out prior to reuse).

The analyzed archeomagnetic samples also include three Early Archaic burned rock features- two small burned rock basins (Features 224 and 227) and a small burned rock cluster (Feature 222) - found outside Feature 231 in Unit IIIa. The results indicate these were relatively undisturbed features (i.e., many of the rocks were not significantly displaced after final cooling).

Archeomagnetic results from Middle Archaic contexts include samples collected from three burned rock clusters (Features 204, 212, and 214). These features were small, compact clusters measuring ca. $70-75 \mathrm{~cm}$ in diameter, ca. 6$16 \mathrm{~cm}$ thick, and containing no more than 50 rocks. Only a few samples were analyzed from each of the clusters, but the results indicate the analyzed rocks were definitely heated, and they generally experienced only minor postcooling displacement. A single archeomagnetic sample was also analyzed from a Middle Archaic burned rock scatter (Feature 218), but the results were not very informative.

The archeomagnetic results from Late Archaic contexts include a suite of samples collected from Burned Rock Midden 1, and a suite of samples collected from Feature 201, an extensive burned rock accumulation found in the lower portion of Unit IIIc. Archeomagnetic samples were collected from 100 rocks within Burned Rock Midden 1, and 62 of these were analyzed. The samples span the full vertical extent of the midden (including Early through Late Archaic deposits), but most of the mound appears to have accumulated during Late Archaic occupations. The midden deposits generally appeared to be an undifferentiated mass of densely packed burned rocks. Given this unpatterned appearance, it was expected that the archeomagnetic results would demonstrate that most (if not all) of the rocks were displaced after final cooling. The results were quite surprising, for they indicated approximately a third of the analyzed rocks (from all levels) cooled in place, and another third cooled near their find positions. The remaining third was significantly displaced after the rocks were completely cooled. Although no significant patterns (internal features) were identified among these rocks, the results clearly indicate the midden deposits are not composed entirely (or even primarily) of displaced refuse.

The Feature 201 burned rock accumulation encompassed six internal subfeatures (see Feature 201 description). These subfeatures included four burned rock clusters (Feature 206, 207, 208, and 211) and two burned rock scatters (Features 203 and 205). Fifty archeomagnetic samples were collected from Feature 201 (and subfeatures 203, 205-207, and 211) and 22 of these were analyzed. The sampling intensity was too low to be very informative, but the results indicate all the analyzed rocks were definitely heated and a relatively large percentage cooled in or near their find positions (with relatively little postcooling displacement).

\section{Sediment Samples}

Sediment samples were collected from 24 (or ca. $12 \%$ ) of the TxDOT features and 48 (or ca. 79\%) of the TARL features (see Table 26-3). Some of these were collected with specific studies in mind, but the vast majority were collected as general-purpose samples with specific use to be determined in the analysis phase.

A few of the TxDOT samples were intact blocks of sediment, but the majority were bags of loose sediment (bulk matrix samples). All the intact blocks were composed of burned sediment (primarily collected from burned trees), and at least some of these were apparently intended for thermoluminescence analysis (to date, none has been used for this purpose). No field inventories were maintained for the TxDOT sediment samples, and they were rarely mentioned 
in the feature or level records (many lack critical provenience data).

With the exception of the micromorphology block samples discussed below, all the TARL sediment samples from feature contexts were bags of loose sediment. Some of these were collected in the field as gastropod samples, but the majority were collected as general-purpose samples. The provenience of all these samples was documented in the field notes, but the locations of some of the samples were documented in greater detail than others (e.g., some were point-plotted and some were only provenienced to the square, level, and feature).

During the TARL analysis, most of the sediment samples collected from both the TxDOT and TARL features were divided into subsamples for various special studies. Subsamples were also curated for each of the features represented by these samples. The special studies samples include the faunal fine-screen and macrobotanical flotation samples discussed above and the magnetic susceptibility, micromorphology, gastropod, and phytolith samples discussed below.

\section{Magnetic Susceptibility Samples}

The magnetic susceptibility samples from feature contexts represent 14 (or ca. 7\%) of the TxDOT features and 49 (or ca. $80 \%$ ) of the TARL features. All of these were analyzed (see Chapter 28) as a rather experimental effort. The magnetic susceptibility samples collected from stratigraphic columns during the TARL excavations were a planned research objective, and they were collected in situ with their locations carefully documented in the field notes. The feature samples were added to this analytical effort in the laboratory and, as noted above, they were pulled from bags of loose sediment with variable provenience documentation.

This experimental effort had two primary objectives. The first was to determine if the presence of burned sediment and/or ash in feature sediments might be reflected in enhanced magnetic susceptibility values (relative to background values for comparable stratigraphic contexts). The second objective was relevant to only a portion of the samples. These were samples from several of the TxDOT features with problematical stratigraphic contexts. It was hoped that the stratigraphic context of these features could be clarified by comparing the magnetic susceptibility values obtained from the feature samples to the results obtained from the stratigraphic columns.

Ultimately, the second objective met with greater success than the first. Very few of the samples exhibited significant enhancement over comparable "background" samples from similar stratigraphic contexts. This may, however, reflect the significant degree to which the "background" sediments have also been enhanced by anthropogenic contributions.
The stratigraphic context questions pertained to samples collected from the Burial 2 pit fill and from the fill of adjacent pit Features 168 and 169 (see descriptions for each of these features). All three features were detected slightly below the base of the Leanne soil (Unit Isi-c), but field observations and other lines of evidence suggested all three were probably excavated from surfaces in the lower portion of the Leanne soil. The fill of all three features was significantly darker than the surrounding matrix, and it was suspected that they were filled with at least some organically enriched Leanne soil sediment. Takac interprets the magnetic susceptibility results he obtained from the Feature 168, 169, and Burial 2 samples as an indication that each of these pits was filled with a mixture of both Leanne soil sediments and underlying (lower susceptibility) Unit Isi and/or Unit Icl sediments. This interpretation generally agrees with attributes observed in micromorphology samples made from the fill of each of these features (discussed below).

Most of the features with magnetic susceptibility samples are included in the Selected Feature Descriptions section, and the relevant results are summarized in each of these descriptions. The results for the six features that are not described (Features 210, 213, 216, 244, 258, and 261) can be found in Chapter 28.

\section{Micromorphology Samples}

During the TARL excavations, 27 micromorphology block samples were collected in situ from 9 features (Features $181,232,236,243,245,249,252,256$, and 260). These samples consisted of oriented, small blocks of sediment, usually measuring ca. $10-15 \mathrm{~cm}$ long, ca. $5-10 \mathrm{~cm}$ wide, and ca. $5-10 \mathrm{~cm}$ thick (some were a little smaller). These samples were numbered in the field, point-plotted in feature plan drawings, and their horizontal and vertical coordinates were documented in a field log. Goldberg subsequently impregnated most of these blocks in polyester resin and analyzed petrographic thin-section slides made from 22 of the blocks (representing the same 9 features listed above; see Chapter 29 and Appendix 7).

The samples from Features 181, 236, 243, and 245 were the most informative. These samples exhibited clear evidence of in situ burning in the form of relatively intact areas of burned (reddened) sediment. Other evidence of burning included ash, charcoal, burned/calcined limestone, burned snail shell, and/or burned bone. Some of the samples from Features 181 and 245 also exhibited evidence of extensive earthworm disturbance. Some of the areas of burned sediment had been riddled by earthworms, and they appeared to have shredded much of the charcoal observed in these samples.

During the TARL analysis, additional micromorphology samples were made from bags of loose sediment collected from feature contexts during both the TxDOT and TARL excavations. Fifty-three block samples were made, 
but 7 of these did not harden properly, and they were rejected for further analysis. Thin-section slides were subsequently made from 35 blocks, and the remaining 11 blocks were described but not thin-sectioned (see Chapter 29 and Appendix 7). This group of samples represents 10 TxDOT features and 20 TARL features.

These samples were far less informative than the block samples that were collected in situ. Nonetheless, some of them yielded extremely useful data. The most informative samples fell into two groups: those that included some evidence of in situ burning and those that provided useful data on stratigraphic contexts. The samples with evidence of in situ burning were from Features 104, 176, 206, 220, 224, and 248 . The samples that provided the most useful stratigraphic data were from Features 168, 169, and Burial 2. As noted above (in the discussion of magnetic susceptibility results), several lines of evidence were explored to clarify the stratigraphic position of these three features. When Goldberg analyzed the thin-sections made from the fill of these three features he concluded that the Burial 2 pit and Feature 168 were filled with a mixture of Unit Isi, Unit Icl, and Unit Isi-c (or Leanne soil) sediments. The samples from Feature 169 resembled Leanne soil samples, but they also included unusual reddish areas that he could not identify.

Most of the 39 features with analyzed micromorphology samples are included in the Selected Feature Descriptions section at the end of this chapter. The salient micromorphology results are summarized in each of these descriptions. The results for the two features that are not described (Features 213 and 216) can be found in Appendix 7.

\section{Gastropod Samples}

Gastropod samples were analyzed from 4 TxDOT and 11 TARL features (see Table 26-3). Neck analyzed 18 samples from 4 features (Features 231, 245, 260, and Burned Rock Midden 1) and Theler analyzed 12 samples from 12 features (Features 19/104, 155, 166, 204, 206, 209, 224, 233, 236, 248, 255, and Burned Rock Midden 1). Neck's and Theler's results are reported in Chapter 37, and they are also summarized in the feature descriptions presented for each of these features in the last section of this chapter (all of these features are described).

The gastropod samples from feature contexts generally reflect the same patterns observed in the stratigraphic column samples. Namely, a relatively small number of species with wide habitat tolerances dominate most of the samples, but there appear to be significant fluctuations in the relative frequencies of species with more-restricted habitat tolerances. Species indicative of more-mesic conditions are slightly more abundant in feature samples from Units Isi-c and II (Features 155, 166, 236, 248, and 255) and Unit IIIc (Burned Rock Midden 1 and Feature 206). Species that tolerate more-xeric conditions increase slightly in Unit IIIa samples (Features 224, 231,233, and 245), but they occur in the highest frequencies in the samples from Unit IIIb (Features 204 and 209).

Most of the snails found in these samples (and in the stratigraphic columns) were terrestrial taxa, but small quantities of aquatic snails were recovered as well. Theler found a few aquatic snails in his samples from Unit Isi-c (Feature 255), Unit II (Features 155, 166, 236, and 248), and Unit IIIa (Features 224 and 233), but he found none in the Unit IIIb and Unit IIIc samples (Features 204, 206, 209, and Burned Rock Midden 1). Of particular interest were the presence of a few Phreatodrobia nugax nugax snails in three samples from Unit II (Features 166, 236, and 248) and one from Unit $\mathrm{IIIa}$ (Feature 233). According to Theler, this snail is typically found in the deep artesian waters of the Edwards aquifer, but it is sometimes expelled through spring vents into local streams (see Chapter 37). He feels that these snails (as well as the other aquatic snails) were most likely deposited on the terrace surface during overbank flooding. He attributes the absence of aquatic snails in his Unit IIIb and IIIc samples to a probable cessation (or significant reduction) in overbank fluvial deposition. Neck, however, reports a number of aquatic snails in Burned Rock Midden 1 samples from Unit IIIc. Since Burned Rock Midden 1 is buried in Valley Margin deposits (primarily colluvium), these aquatic snails may very well represent anthropogenic deposition. It does not seem unlikely that at least some of the aquatic snails may reflect human collection of water, aquatic plants, and/or aquatic animals. Fish remains were found in Burned Rock Midden 1 and in three of Theler's samples with aquatic snails (Features 224, 233 , and 236). It is possible that some of the aquatic snails were introduced via fish entrails. It should also be noted that Goldberg believes the significant reduction in overbank deposition occurred around 9500 B.P., with Unit II and all of the Unit III subunits comprised primarily of colluvium and anthropogenic deposits (with a relatively minor alluvial contribution, see Chapter 6)

\section{Phytolith Samples}

Phytolith samples were analyzed from four TxDOT features (Features 168, 169, 181, and Burial 2) and five TARL features (Features 204, 236, 245, 252, and 255). Burial 2 was represented by five samples, but only one sample was analyzed from each of the other features. All of the samples were analyzed by Fredlund (see Chapter 41).

Only three of the samples contained reasonably wellpreserved phytolith assemblages: the samples from Features 181 and 245 in Unit IIIIa and the sample from Feature 204 in Unit IIIb. The grass short-cell assemblages identified in the Feature 204 and 245 samples fell within the expected ranges for these stratigraphic contexts (no significant differences were detected). The Feature 181 sample, however, differed from other Unit IIIIa samples, exhibiting relatively high percentages of conical form phytoliths and relatively low percentages of saddle forms. Fredlund suggests this difference 
may be related to feature function, but he could not infer what grasses were responsible for this aberrant pattern (the conical form is not particularly diagnostic). All of the features with phytolith samples are included in the feature descriptions section at the end of this chapter.

\section{Organic Residue Samples}

Approximately 167 organic residue (OR) samples were collected from feature contexts during the TARL investigations. These samples were exposed and point-plotted in situ, collected with clean metal tools, and wrapped in aluminum foil (see Chapters 3 and 23). Since multiple samples were collected from some features (especially the larger features), only 29 features are represented in this group. The majority of these samples are chipped stone artifacts (e.g., projectile points, perforators, bifaces, unifaces, and debitage), but also included are a few ground and/or battered stones and about 20 burned rocks. The vast majority of these have been curated (unanalyzed) for future research with only 11 samples (representing 6 features) ultimately included in the chemical residue studies presented in Chapter 23.

These samples were studied (along with samples from nonfeature contexts) by two analysts (see Chapter 23). Beck analyzed six of the samples: a burned rock from Feature 227, four chipped stone artifacts from Feature 231 (projectile point, perforator, biface, and flake), and a biface from Burned Rock Midden 1. He subjected the residues he extracted from these samples to gas chromatography-mass spectrometry analysis and found small quantities of fatty acid residues on all of them. He was unable, however, to identify the specific source(s). The most interesting finding was an unusual component found on the perforator from Feature 231 (OR419) and on five other artifacts from nonfeature contexts. He identified this component as pentadecanoic acid, a rare saturated fatty acid that has been reported from only three North American genera: the genus Zanthoxylum (which includes the prickly ash or "toothache tree" which grows in the site area); the genus Lonicera (honeysuckle); and unspecified lichens. Beck favors the prickly ash as the source of the acid primarily because the bark and leaves of this tree are known to have been used medicinally by many Native American groups. He does not, however, rule out other potential sources.

Hurst analyzed five organic residue samples from TARL features and three artifacts from TxDOT features. The latter group had not been collected as organic residue samples (they had been washed and handled), and they were included in Hurst's analysis on an experimental basis. The TARL samples include three burned rocks (from Features 225, 236, and 245) and two chipped stone tools from Feature 231 (a projectile point and a Clear Fork biface). The TxDOT samples include a mano fragment from Feature 12, a metate fragment from Burial 1, and a mano/chopper from Burial 2. Hurst subjected residues he extracted from these artifacts to both capillary ion analysis (for the determination of inorganic ions) and high performance liquid chromatography (to identify amino acid residues). In the capillary ion analysis, Hurst identified chloride, nitrate, sulfate, phosphate, and/ or carbonate anions on these specimens. Although he interprets the chloride and carbonate as pedogenic products with no cultural significance, he believes the nitrate and phosphate may be derived from cultural sources. The potential source of the sulfate is unknown. Both phosphate and nitrate were found on the burned rock from Feature 236 (OR540), nitrate was found on the Clear Fork biface (OR372), and phosphate was found on the metate fragment (7F-5). Hurst also found amino acid residues on two of the specimens. He identified 12 amino acids on the burned rock from Feature 236 (OR540) and 11 on the mano/chopper (FBU2-2) from Burial 2.

\section{THE CULTURALFEATURE SEQUENCE}

This section presents an overview of some of the most significant findings of the feature analysis. It emphasizes data gleaned from the most informative cultural features, and these data are summarized with a primarily diachronic perspective; that is, the cultural features are examined as a sequence of behavioral clues spanning roughly 11,000 years. Synchronic spatial patterns are difficult to address given the nature of the excavated sample (rather limited horizontal exposures), and the greatest strength of the present feature sample derives from the deep, stratified nature of the Wilson-Leonard deposits and the long sequence of occupations that are represented by these features. Much of this discussion focuses on the large, stratified sample of burned rock features, since they provide some of the most useful comparative data.

Feature evidence is rather sparse for the site's earliest inhabitants. Only five features were recorded in Early Paleoindian contexts (ca. 11,500-10,000 B.P.), and only three were definitely cultural. One of these, Feature 188 , is an artifact cluster that may be associated with the Clovis component (see Chapter 7). This feature was found in Unit Isi, slightly below the bone and artifact scatter that has been designated the Bone Bed component (see Chapter 7). Feature 188 consisted of a tested chert cobble (or chert core) and a battered limestone cobble (probable hammerstone) found about $5-7 \mathrm{~cm}$ apart. No debitage from the tested cobble or other artifacts were found in the feature area, but a small amount of splintered bone was recovered. The bone included a large mammal bone (possibly bison?) with spiral fractures. Collins (see Chapter 7) believes the limestone cobble was too soft to effectively flake the chert cobble and suspects the core was flaked elsewhere. He also suspects the core may have been employed in this context (along with the hammerstone) as an anvil for breaking bone (perhaps bison bone).

The other Early Paleoindian cultural features (Features 170 and 262) were bone concentrations associated with the 
Bone Bed component (see Chapter 7). Feature 170 was found in Unit Isi, near the southwest edge of the main concentration of materials provenienced to this component. This cluster included at least 63 bone fragments found within a ca. 40$\mathrm{cm}$-diameter area. When it was first exposed, the cluster included 3 large fragments that were tentatively identified in the field as humerus, tibia, and unidentified long-bone fragments of a large mammal (possibly a bison). The larger fragments apparently splintered further when they were collected, and when they were analyzed by Baker most were unidentifiable. He identified only 2 specimens as very large mammal long bone (the others were medium/large mammal or unidentified). Only angular (dry bone) breaks were observed on these fragments and none appeared burned. No artifacts were associated with this feature.

Feature 262 was found in the Unit Isi/Icl transition zone, just east of the greatest concentration of bone associated with the Bone Bed component. It consisted of a dispersed scatter of bone fragments and a few possibly burned rocks. The scatter, which encompassed a ca. 100-x-80-cm area, included ca. 9 point-plotted bones, ca. 50 smaller bone fragments, and 6 small limestone fragments. Although this feature was initially recorded as a possible hearth, no definitive evidence of burning was identified. The rocks were angular fragments, but they exhibited no obvious discoloration or thermal fractures. No burned sediment was observed in the field or in micromorphology samples made from feature-associated sediment. A few charcoal flecks were observed, but no significant concentrations were found. The only artifact found within Feature 262 was a distal fragment of an ultrathin biface. Feature 262 does not appear to have been a hearth. It most likely represented an unpatterned scatter of debris associated with the Bone Bed component. Although a few possible burned rocks were recorded within this component, no definitive hearths were documented. The other features recorded in Early Paleoindian contexts include Feature 190, a poorly documented feature that most likely represents a burrow, and Feature 261, a natural gravel bar deposit.

The Late Paleoindian Wilson component, which dates from roughly 10,000 to 9500 B.P., represents the next significant cultural interval (see Chapter 8). The evidence for this component was found primarily within the Leanne soil (Unit Isi-c), but the vertical distribution suggests the Wilson component encompasses the remains of several successive occupations. The Leanne soil was apparently enriched by a fairly substantial human contribution of organic material, and coupled with a significant increase in artifact and feature densities, it appears that the Wilson component may represent more-intensive utilization of the site than was seen in the Early Paleoindian occupations.

Burial 2 (or Wilson-Leonard II) is the most significant feature attributed to this component. The burial pit appears to have been dug from an occupational surface in the lower portion of the Leanne soil, and the pit fill apparently included some of this soil. Burial 2 was a primary inhumation of a young adult female (ca. 18-25 years old). She was interred in a semiflexed position with her head to the northeast and her face to the west. The burial pit included at least two intentional inclusions: a mano/chopper made from a round, pink sandstone cobble (ca. 14-cm diameter); and an apparently unmodified limestone slab (ca. 22-x-17-x-10 cm). The ritual or functional significance of these inclusions is unknown. It has been speculated that the stones possibly served as weights, holding a wrapping around the body in place, or they may have been used to dig the grave (the slab had a wedge-like point at one end). A fossil shark tooth found in the neck area was initially interpreted as an ornament, but it may represent a natural (unintentional) inclusion. Nine radiocarbon determinations have been made on Burial 2 (six human bone dates, two sediment dates, and a charcoal date from pit fill), but as previously noted, most of these dates are problematical. Considering various lines of evidence, the age of Burial 2 has been estimated at ca. 10,000 B.P.

The Wilson component also includes two very interesting pit features found very near Burial 2 in approximately the same stratigraphic position. They may have been excavated from the same occupational surface as the burial pit. Feature 168 was located about $85 \mathrm{~cm}$ south of Burial 2, and Feature 169 was ca. $1 \mathrm{~m}$ south of Feature 168. Both were oval-shaped pits with relatively straight sides and slightly rounded bases. Feature 168 measured ca. $87-x-70-x-40 \mathrm{~cm}$, and Feature 169 measured ca. $65-x-60-x-55 \mathrm{~cm}$. The fill of Feature 168 was relatively clean, with no evidence of burning and no definitive clues to the pit's function. Two tabular limestone cobbles (ca. 10-15-cm diameter) were found in a layer of "brown clay" at the base of the Feature 169 pit. The rocks appeared to have been placed (side by side) in the base of the pit. They were not collected and the field notes do not indicate if they appeared burned. The fill above this was described as having a layered appearance with lenses of dark and light gravelly sediment. It had an overall reddish cast that may have been derived from iron-oxide staining. Although the fill included some tiny burned limestone fragments and scattered bits of ash and charcoal, there was no definitive evidence of in situ burning.

Although the function of these pits is unknown, they probably represent some type of domestic feature. The limestone cobbles in Feature 169 may be important functional clues. They may represent heated stones used in food preparation or basal supports for a hide or basketry container that rested inside the pit. Plausible hypotheses for the function of these pits include storage and food processing and/or cooking (e.g., hide-lined stone-boiling pits, leaching pits, etc.).

Another possible pit feature (or large burrow?) was found in approximately the same stratigraphic position as Features 168 and 169. Feature 252 was detected slightly below the base of the Leanne soil, but it probably originated from a surface within the soil. The outlines of this 
feature were obscured though bioturbation, but it appears to have been a roughly oval shaped anomaly measuring ca. $50-\mathrm{x}-45 \mathrm{~cm}$. In cross-section, it was somewhat U-shaped with an irregular base and a depth of at least $19 \mathrm{~cm}$ (probably greater). The fill provided no clues to the feature's origin or possible function, and the boundaries were too disturbed for a definitive classification. It is possible that Feature 252 was a cultural pit that was disturbed by intrusive burrows.

Definitive burned rock features make their first appearance at the site in the Wilson component. Feature 255 was a small burned rock cluster found in the lower portion of the Leanne soil (near the base). It measured ca. 50-x-30-x-7 cm and included about 15 heavily burned, small limestone fragments. Although Feature 255 had a rather unimpressive appearance, it was an important feature for several reasons. First, archeomagnetic results indicate a significant number of the rocks cooled in place after their final heating, thus it can be considered a relatively undisturbed feature. Second, wood charcoal collected from the intact central portion yielded a reliable AMS radiocarbon date of $9990 \pm 70$ B.P. (CAMS-10195), making it the earliest dated burned rock feature at the site. Finally, since it is located in approximately the same stratigraphic position as Burial 2, the two pits, and several other burned rock features, this radiocarbon date provides a rough age approximation for these other important Wilson component features.

Eight additional burned rock features (Features 71, 163, $171,187,193,256,257$, and 260) were associated with the Wilson component, and all were relatively small-scale burned rock features. Most were less than a meter in diameter, no more than $15 \mathrm{~cm}$ thick, and composed of no more than 20 rocks. Feature 256 consisted of a patch of burned sediment and 6 small rocks within a ca. $50 \mathrm{~cm}$ diameter area. Feature 71, tentatively classified as a burned rock ring, consisted of a semicircular configuration of 6 rocks within a $70-x-35-\mathrm{cm}$ area. Feature 257 was a 2-rock remnant of what was probably a slightly larger (ca. 6-rock?) cluster. Features 163, 171, 193, and 260 were burned rock clusters ranging from ca. 35-135 $\mathrm{cm}$ in diameter and including 9-22 rocks. Feature 187 included the most rocks (ca. 45), and this compact cluster (measuring ca. $70-x-55-x-9 \mathrm{~cm}$ ) looked like it might be resting in a small shallow basin.

Most of these Wilson component burned rock features were probably small, simple hearths constructed with minimal effort on a relatively flat surface. Feature 187 may represent a slightly more-specialized cooking feature. The larger number of rocks and the possible basin shape suggest it may represent a layer of rocks placed over a bed of coals in a shallow basin. This sort of construction provides a heated platform of rocks that can be used to cook foods that cannot be cooked directly in flames or coals. A mass of hot rocks confined in a small basin also retains more heat than a campfire built directly on the ground. This sort of feature can be used for small-scale roasting and the baking of foods that require a longer, more-controlled cooking process (Wandsnider 1997).

Of the various Wilson component features, significant quantities of faunal remains were recovered from only Features $163,187,255,257$, and 260 . The identifiable specimens included deer/antelope, rabbit, rodent, reptile, turtle, fish, eggshell, and mussel shell. Approximately $40-80 \%$ of the bone found in these features was burned. Small quantities of poorly preserved charcoal were also found in a number of the features, but all the analyzed macroplant samples from these contexts were unidentifiable to species.

The most informative group of natural features was a suite of six burned trees found at/or near the Unit I/II contact (in the upper portion of Unit $I$ and the lower portion of Unit II). This group included four live oaks (Features 165, 167,198 , and 253), a possible juniper tree (Feature 154), and an unidentified tree/large plant (Feature 164). As previously noted, nine radiocarbon determinations were obtained on five of these (all but Feature 154), and these dates (which were quite close to one another) were used to estimate the age of the Unit I/II contact at ca. 9500 B.P. Four of the trees (Features 164, 165, 167, and 253) were found within a ca. 8-mdiameter area. Given their proximity to one another and the age similarities, they may have burned in a single event.

The next series of cultural features is associated with the various Late Paleoindian occupations represented in Unit II (see Chapter 8). This relatively thin stratigraphic unit accumulated between ca. 9500 and 8800 B.P., and it encompasses the intermingled remains of several components that could not be clearly segregated during the TARL analysis (primarily Golondrina-Barber and St. Mary's Hall occupations). Features of comparable age were also found in stratigraphic Unit $\mathrm{X}$ in the Valley Margin, but most of these features were poorly documented and not very informative. The most useful data for this time interval were derived from the Unit II features found in the Valley Floor portion of the site (especially those found in the TxDOT Block 6 excavations and the TARL excavations).

The cultural features found in Unit II consist of 22 burned rock features and a cluster of debitage (Feature 161). The natural features include a mineralized root and three burned plants (Features 160, 234, and 238). Like the burned rock features associated with the Wilson component, most of the Late Paleoindian burned rock features found in Unit II are relatively small-scale entities, measuring less than $1 \mathrm{~m}$ in diameter and encompassing no more than ca. 20 rocks. However, a few of the features were significantly larger, measuring ca. $130-160 \mathrm{~cm}$ in diameter and encompassing ca. 60-100 burned rocks. These larger-scale Late Paleoindian features may reflect an increase in the amount of food being cooked in a single event. In this regard, they foreshadow the still larger features built in subsequent Archaic occupations.

Four of the smaller burned rock features (Features 162, 232,243 , and 247) consisted of small patches of burned sediment surrounded by a few (ca. 3-5) burned rocks. This group 
measured ca. $25-100 \mathrm{~cm}$ in diameter and ca. $5-10 \mathrm{~cm}$ thick. Three small features were classified as burned rock rings (Features 153,156, and 158). They ranged from ca. $50-90 \mathrm{~cm}$ in diameter, were 5-10 cm thick, and encompassed 7-18 rocks. Only one of these rings (Feature 156) exhibited burned sediment in the rock-free interior.

Only one feature was confidently classified as a small burned rock basin (Feature 236), but two burned rock clusters (Features 155 and 250) looked like they might belong in this category as well. These three features ranged from ca. $55-100 \mathrm{~cm}$ in diameter, were $14-16 \mathrm{~cm}$ deep, and encompassed 20-80 rocks.

Archeomagnetic and micromorphology samples from Feature 236 indicate it was a relatively undisturbed feature with clear evidence of in situ burning. The rocks were apparently heated to relatively high temperatures and then cooled in place with relatively little postcooling displacement. Several charcoal samples were recovered, but none of the analyzed samples could be identified to species. One of the charcoal samples was AMS-dated to $9650 \pm 80$ B.P. (CAMS07560). A less reliable AMS date $(10,400 \pm 280$ B.P., CAMS07561) was obtained on a carbonized bone fragment found in this feature. A large quantity of bone ( 542 specimens) and some eggshell fragments were recovered in a fine-screen sample from this feature. The identifiable bone included mammal, rodent, rabbit, fish, reptile, and turtle. At least half of this bone was burned.

Unit II features also included nine relatively small burned rock clusters (Features 109, 111, 117, 185, 235, 239, 241, 246, and 248 ) and two relatively large burned rock clusters (Features 157 and 184). The smaller clusters ranged from 50-120 $\mathrm{cm}$ in diameter, were 6-15 $\mathrm{cm}$ thick, and encompassed 13-37 rocks. The two larger clusters measured ca. $135-160 \mathrm{~cm}$ in diameter, were ca. 15-17 cm thick, and encompassed at least 60-100 rocks. These large clusters may have been large burned rock basins, but there was insufficient evidence to confidently place them in this category. A charcoal sample from Feature 157 yielded an AMS date of $9340 \pm 60$ B.P. (CAMS-18640).

Only one feature in Unit II, Feature 166, was confidently classified as a large burned rock basin. This was a roughly circular pit measuring ca. $160 \mathrm{~cm}$ in diameter and ca. $22 \mathrm{~cm}$ deep. The pit contained at least 15 large slabs $(20-30-\mathrm{cm}$ size) and about 60 smaller rocks. The rocks were clustered primarily along the sloping walls of the pit with relatively few found in the center. Although no burned sediment or ash was observed in situ, both were observed in micromorphology thin-sections made from a sample of the pit fill. Small amounts of charcoal were scattered throughout the fill but none of the analyzed samples could be identified to species. Two Golondrina-Barber points were found in Feature 166 along with a Clear Fork biface, several biface fragments, some debitage, and some bone fragments. Most of the bone was unidentifiable fragments, but there were a few mammal bones. Much of the bone was burned. Feature 166 was found in the lower portion of Unit II and it probably dates to ca. $9500-9000$ B.P. It is the earliest of the large burned rock basins found at the Wilson-Leonard site and, like the subsequent Archaic versions, it very likely represents an earth/rock oven.

Of the Unit II features, significant quantities of faunal remains were recovered from only six features (Features 155, $166,235,236,239$, and 248). The identifiable remains include mammal, rabbit, rodent, reptile, turtle, and fish bone as well as small amounts of mussel shell and eggshell. Most of the analyzed macroplant samples from Unit II features could not be identified, with only Features 243 and 248 containing identifiable plant remains. Both of these contained wood charcoal identified as live oak and unidentified hardwood.

The next significant group of cultural features dates to the Early Archaic interval in the site's history (ca. 8800-6000 B.P.; see Chapter 9). The best Early Archaic feature data are derived from the Unit IIIa deposits in the Valley Floor (especially the samples from the TxDOT Block 6 and TARL excavation areas). Evidence of Early Archaic occupations was also found in the lower portion of Unit IIIb, but there is considerable mixing of Early and Middle Archaic remains in much of this stratigraphic unit. Deposits of comparable age in the Valley Margin (roughly upper Unit X and lower Unit Y) also contain numerous Early Archaic-age features, but much of the evidence is overprinted with younger remains.

The Early Archaic deposits at the Wilson-Leonard site include a very dramatic increase in the density of both scattered burned rocks and more-circumscribed burned rock features. In part, this reflects the slower rate at which the terrace aggraded after ca. 8800 B.P., but it also reflects a greater use of burned rocks by the Early Archaic inhabitants and apparently more-intensive occupations (perhaps larger groups and/or longer stays). In the Early Archaic feature sample this is reflected by a significant increase in the number and size of large burned rock basins, by the first appearance of burned rock accumulations, a significant increase in the number of burned rock scatters (which are first documented in transitional Late Paleoindian/Early Archaic contexts), and by a significant increase in the number of larger burned rock clusters (greater than $1 \mathrm{~m}$ in diameter). Smallerscale burned rock features, similar to those found in Late Paleoindian contexts, are also found in the Early Archaic deposits indicating continued use of these types of features.

Cultural features from the Early Archaic period include 3 burned rock accumulations; 9 burned rock scatters; 8 large burned rock basins; 5 small burned rock basins; 70 burned rock clusters; 1 burned rock ring; and 2 of the small, burned sediment/burned rock features. Natural (and possibly natural) features from this time interval include 4 burrows, 1 pit or burrow, and 2 probable burned plants. These features are associated with diagnostics that include Angostura, Thrall, Early Split Stem (i.e., Hoxie, Gower, Jetta), Martindale, and Uvalde points (see Chapter 9). 
One of the burned rock accumulations, Feature 8, is buried in the upper portion of Unit $\mathrm{Y}$ in the Valley Margin. It lies slightly below the recorded base of the Burned Rock Midden 1 mound and is separated from the base of the mounded deposits by a thin (ca. 10-20-cm thick) layer of relatively rock-free sediment. Although it was not recorded as part of Burned Rock Midden 1, Feature 8 effectively represents the lowest layer of the midden, with the thin layer of rock-free sediment apparently representing a depositional event that interrupted the accumulation of the burned rock deposits.

Feature 8 surrounds and overlies at least two burned rock basins, Features 12 and 13 . Feature 12 was a large burned rock basin (ca. 150-x-105-x-30 cm) and Feature 13 was a slightly smaller basin $(90-x-70-x-20 \mathrm{~cm})$. A third basin may have been located within the accumulation as well, but no feature number was assigned, and it was incompletely documented. A carbonized Camassia scilloides (or wild hyacinth) bulb from Feature 8 may have been baked in one of these basins. This bulb yielded an AMS radiocarbon date of $8250 \pm 80$ B.P. (CAMS-18375).

Another large burned rock basin, Feature 19/104, was found about $40 \mathrm{~cm}$ below the recorded base of Burned Rock Midden 1 and about 10-20 $\mathrm{cm}$ below the base of Feature 8 . This pit measured over $2 \mathrm{~m}$ in diameter with a recorded depth of ca. $40 \mathrm{~cm}$. If the top of this large pit actually originated above its detection level, then it may have originated from a surface somewhere within the Feature 8 layer. A wood charcoal sample collected from the fill of Feature 19/104 yielded a conventional radiocarbon date of $7470 \pm 230$ B.P. (Tx-4798).

The Feature 124 and 231 designations were assigned to portions of a single, large burned rock accumulation that were investigated in both the TxDOT (Feature 124) and TARL (Feature 231) investigations. The combined exposure indicates an areal extent of at least $7.5-\mathrm{x}-5.5 \mathrm{~m}$. The accumulation was composed of several layers of closely spaced burned rocks mixed with an assortment of other cultural debris (primarily lithic artifacts, faunal remains, and macrobotanical remains). These deposits surrounded and covered at least six large burned rock basins, and much of the burned rock comprising the accumulation was probably derived from repeated use of these cooking pits. The largest of these, Feature 181 , measured about $2.6 \mathrm{~m}$ in diameter and $50 \mathrm{~cm}$ deep. Another large burned rock basin, Feature 245, was found immediately north of Feature 181 . This pit was significantly smaller than Feature 181, measuring ca. $1.5 \mathrm{~m}$ in diameter and ca. $25 \mathrm{~cm}$ deep. The other four (Features 130, 131, 146, and 150 ) were about the same size as Feature 245 , measuring ca. 1.3 to $1.6 \mathrm{~m}$ in diameter.

The recovery and subsequent identification of 10 wild hyacinth (Camassia scilloides) bulbs ( 9 of which were AMS dated) from Feature 181 was one of the most significant findings of the feature investigations at the Wilson-Leonard site. Dering notes that wild hyacinth (also known as eastern camas or blue camas) is a geophyte, or a plant that stores carbohydrates in subsurface structures (see Chapter 40). Although they can be eaten raw in small quantities, the bulbs contain inulin, an indigestible carbohydrate that must be broken down before they can be eaten in any quantity. Dering also points out that Camassia scilloides is closely related to the camas of the Pacific northwest, a plant that was an important staple for the indigenous peoples of that area. Thoms (1989) reports that in the Pacific northwest, camas bulbs were baked for ca. 24-48 hours in steaming earth/rock ovens. The steam breaks down the inulin (through hydrolysis) and converts it to digestible simple sugars (Thoms 1989:157). The recovery of 10 Camassia bulbs from Feature 181 provides strong support for the hypothesis that the large burned rock basins found in many Central Texas sites very likely represent earth/rock ovens used primarily for the bulk processing and slow controlled cooking of various starchy plant foods (Black and Potter 1993; Collins 1995; Black et. al 1997).

Archeomagnetic and micromorphological evidence collected from Features 181 and 245 during the TARL investigations lend additional support to this hypothesis. The archeomagnetic results indicate (among other things) that: (1) these are largely undisturbed/intact features with relatively complex heating and cooling histories (perhaps suggesting multiple episodes of use); (2) most of the rocks were heated to very high temperatures and many were moved while quite hot (especially those in the upper portion of the basins which may have been manipulated before and after food was cooked); (3) many of the rocks in the lower portions of the basins cooled in place with little or no movement (suggesting an intact "heating element" of rocks at the base of these pits); and (4) many rocks found in the burned rock accumulation surrounding these pits appear to have been displaced, both after they were completely cooled and while they were still cooling. Some of these probably reflect displacement of rocks from the ovens when the cooked food was removed and some probably represent clean-out episodes prior to oven reuse. The micromorphology evidence indicates the best evidence of in situ burning (primarily intact areas of burned sediment) was found at the very base of both of these features, underneath the lowest layer of rocks. This evidence suggests fires may have been built in the bases of the pits or before the lowest layer of rocks was placed in the pit. Some ash and charcoal was also observed in these thin-sections, but much of the evidence of burning had been extensively bioturbated, especially by earthworm activity. This suggests that the apparent absence of burned sediment in some of the other burned rock features at the site (especially the other large burned rock basins) may represent a significant preservation bias.

Although charcoal was generally very poorly preserved in the Early Archaic features, so many more samples were collected (compared to Late Paleoindian contexts) that significantly more macroplant identifications were obtained. In addition to the wild hyacinth bulbs, identifiable wood charcoal from Early Archaic features includes arboreal legume 
from Feature 17 (burned rock scatter); live oak from Feature 217 (burned rock scatter); willow family and juniper from Feature 220 (burned rock cluster); juniper from Feature 221; live oak, juniper, and unknown hardwood from Feature 231; juniper from Feature 233; and juniper and unknown hardwood from Feature 245.

A tremendous variety of faunal remains was also recovered from Early Archaic features. Basically the same taxa found in Late Paleoindian contexts were also found in these features (primarily deer, rabbit, rodent, reptile, turtle, fish, eggshell, and mussel shell), but much larger amounts were recovered. Some of the Early Archaic features (notably Features 181 and 233) also exhibited very high percentages of fish and turtle remains.

Relatively few features could be confidently assigned to the Middle Archaic period (ca. $6000-4000$ B.P.; see Chapter 9). Evidence of Middle Archaic occupations was best segregated in the upper portion of Unit IIIb (in the Valley Floor portion of the site), but cultural deposits from this time interval were also found in lower Unit IIIb (where they were generally mixed with Early Archaic remains); the Unit IIIb/ IIIc transition zone and lower Unit IIIc (where they were often mixed with Late Archaic remains); and in upper Unit Y in the Valley Margin (where they were mixed with both Early and Late Archaic remains). The Middle Archaic-age deposits include relatively small numbers of Bell-Andice and Early Triangular points with larger numbers of Nolan and Travis points recovered, especially in the deposits found at/or near the Unit IIIb/IIIc contact (see Chapter 9).

Cultural features assigned to the Middle Archaic interval include 14 burned rock clusters (Features 40-48, 83, 204, 212, 214 and 216), 1 burned rock scatter (Feature 218), 1 of the small burned sediment/burned rock features (Feature 209), and portions of both Burned Rock Middens 1 and 2. Natural features from this time interval include a burned live oak tree (Feature 50) and a burned red mulberry tree (Feature 199). The burned trees were found quite close to one another (ca. $4 \mathrm{~m}$ apart) at approximately the same elevation (within mid Unit IIIb). Conventional radiocarbon dates obtained on samples from each of these features are quite close to one another (Feature 50 was dated to $5520 \pm 80$ B.P., Beta79700; Feature 199 was dated to $5560 \pm 60$ B.P., Beta-79699) and suggest they may have burned in the same event.

Radiocarbon dates were also obtained on wood charcoal found in two of the Middle Archaic burned rock clusters. A sample from Feature 214 was conventionally dated to $4880 \pm 70$ B.P. (Beta-79803), and an AMS measurement of $4440 \pm 60$ B.P. (CAMS-10196) was made on a sample from Feature 204.

The Middle Archaic burned rock clusters are generally small, compact, and apparently flat (no evidence of basin shapes). Most are relatively circular (or oval) clusters measuring less than $1 \mathrm{~m}$ in diameter and no more than $15 \mathrm{~cm}$ thick. These small clusters generally contained less than 25 rocks, although four of the largest (measuring $70-130 \mathrm{~cm}$ in diameter) contained 30-70 rocks. Archeomagnetic samples were analyzed from rocks found in three of these clusters (Features 204, 212, and 214) and all appear to be relatively intact, small hearths. Most of the analyzed rocks were apparently heated to relatively high temperatures and then cooled in place with little or no postcooling displacement. Charcoal was found in all three of these features, but most of it was unidentifiable. One macroplant sample from Feature 214 was identified as juniper wood. Additional juniper wood was recovered in a flotation sample from this feature.

The most productive flotation sample identified in the macrobotanical analysis was collected from Feature 209. This feature consisted of a small, ca. 40-cm diameter area of charcoal-stained (possibly burned) sediment surrounded by three small burned rocks. A macroplant sample from this feature was identified as elm family wood. The flotation samples yielded seven carbonized seeds representing three genera of grasses (Panicum, Setaria, Paspalum), and wood charcoal classified as juniper and Rosaceae. The grass seeds are particularly interesting given the paleoenvironmental evidence suggesting more-xeric conditions (with a concomitant expansion of grasslands) may have prevailed in the site area during this interval of time (see Chapter 9). Some indication of this may also be reflected in gastropod samples from Features 204 and 209, which appear to include a slight increase in species that tolerate more-xeric conditions. A phytolith sample from Feature 204 also contains a higher percentage of phytoliths considered indicative of the short and tall $\mathrm{C}_{4}$ grasses (which may reflect more-xeric conditions as well, see Chapter 41).

The lower portion of Burned Rock Midden 1 contained numerous Middle Archaic diagnostics (primarily Travis and Nolan points), but they are intermingled with slightly younger Late Archaic remains. The Middle Archaic deposits appear to be better separated in Burned Rock Midden 2. As previously noted, the Feature 195 burned rock accumulation apparently represents the lowest layer of Burned Rock Midden 2, and this layer has been somewhat tentatively dated to the Middle Archaic period. Although a few Early and Late Archaic diagnostics were found in this layer, a larger number of Middle Archaic types were recovered (Nolan, Travis, and Early Triangular). No pit features were identified within the Feature 195 layer, but it was only partly exposed (ca. 2-x-4-m exposure). Identifiable plant remains recovered from Feature 195 include wood charcoal classified as live oak, walnut, and elm. Identifiable faunal remains include deer/antelope, rabbit, and turtle.

A thin (ca. 10-cm thick) layer of relatively rock-free sediment separated the Feature 195 layer from the overlying mound of burned rocks. The mounded burned rock deposits contained a mixture of Middle and Late Archaic deposits, but the lower portion of the mound contained relatively more Middle Archaic points (primarily Nolan points). A partially exposed pit, Feature 194, was found in this portion of the mound, and it has been tentatively assigned a Middle or 
Late Archaic age estimate. This pit very likely represents either a large or small burned rock basin, but there was insufficient evidence to confidently classify it as either. It was definitely a pit and it measured at least $70 \mathrm{~cm}$ in diameter (and possible greater). The pit was at least $27 \mathrm{~cm}$ deep (probably deeper) and contained at least some burned rocks (although it was apparently not densely filled with burned rocks). Some burned sediment and charcoal were found beneath some rocks at the base of this pit. A carbonized wild hyacinth bulb was found about $10 \mathrm{~cm}$ above Feature 194 in the same square. It is possible that the bulb was baked in this pit, but it cannot be confidently associated with this feature. The bulb yielded an AMS date of $3780 \pm 70$ B.P. (ETH-14115).

On the basis of the rather limited sample of Middle Archaic-age features, it appears that the occupations in the earlier portion of this cultural period (roughly 60005000 B.P.) may have differed in some significant ways from the occupations that preceded and followed. Notably, there appears to have been a significant reduction in the amount of burned rocks deposited on the site during the early portion of the Middle Archaic period, and this is reflected in the apparent absence of both burned rock accumulations and large burned rock basins during this approximate time interval. Subjectively, the burned rock feature density appears to decrease during this interval and the features tend to be a little smaller. If the large burned rock basins (and associated burned rock accumulations) reflect bulk processing of starchy plant foods, then perhaps these activities did not occur at the Wilson-Leonard site during the ca. 6000-5000 B.P. interval. The paleoenvironmental data from Unit IIIb suggest this may have been one of the most xeric intervals in the site's history. These conditions may have adversely affected the key plant resources (e.g., the wild hyacinth stands) that were processed in these bulk processing facilities.

The paleoenvironmental data gleaned from the site deposits also suggest a gradual return to more-mesic conditions during the Late Archaic period (4000-1300 B.P.). This may be manifested in the feature sample by the large domed burned rock middens that appear to have accumulated much of their mass during the Late Archaic period. These mounds appear to have accumulated primarily between ca. 4000 and 1000 B.P.

The lower $40 \mathrm{~cm}$ of Burned Rock Midden 1 (the mounded deposits) include a mixture of Marcos, Marshall, Bulverde, Nolan, and Travis points. Diagnostics in the upper $40 \mathrm{~cm}$ are dominated by Darl and Ensor points (with a possible Late Prehistoric contribution that is discussed below). Although no internal pit features were recorded within the Late Archaic portion of Burned Rock Midden 1, it is very likely that they were present but not recognized. Two intrusive features found within Burned Rock Midden 1 are probably unrelated to the midden's function, but they have been tentatively assigned to the Late Archaic period. These include a disturbed human burial (Burial 1) and a biface cache (Feature 11).

The upper $60-80 \mathrm{~cm}$ of the Burned Rock Midden 2 mound contained relatively few artifacts, but the recovered diagnostics consist primarily of Bulverde, Bulverde-like, miscellaneous rectangular stem, Nolan, and Travis points. No internal pit features were identified in this portion of the mound. The carbonized hyacinth bulb that yielded the date of $3780 \pm$ 70 B.P. (ETH-14115) was found in the lower $20 \mathrm{~cm}$ of the mounded deposits. The upper $60-80 \mathrm{~cm}$ of Burned Rock Midden 2 was extremely ashy and contained a relatively low artifact density and almost no bone or charcoal. It may have accumulated within a relatively short period of time (as evidenced by the dominance of Bulverde and Bulverde-like points in the upper $60 \mathrm{~cm}$ ).

Other cultural features assigned to the Late Archaic period include a burned rock accumulation (Feature 201), five burned rock scatters (Features 120, 121, 173, 203, and 205), a burned rock ring (Feature 35), and 12 burned rock clusters (Features 10, 32, 34, 36, 38, 76, 77, 78, 206, 207, 208, and 211).

Three of the scatters (Features 173, 203, and 205) and four of the clusters (Features 206, 207, 208, and 211) are apparently associated with the Feature 201 burned rock accumulation. This accumulation, found in the lower portion of Unit IIIc, was partly exposed during the TARL investigations. It was completely buried in the Valley Floor portion of Unit IIIc, but it may have accumulated on a surface that was stratigraphically equivalent to the base of the Burned Rock Midden 1 mound (roughly the IIIb/IIIc contact and lower IIIc). The exposed portion measured ca. $10-\mathrm{x}-4 \mathrm{~m}$, but it was almost certainly larger. No large burned rock basins were found within this accumulation, but one of the burned rock clusters (Feature 206) may have been a small burned rock basin. Several of the other clusters appeared to be relatively undisturbed small hearth features. Diagnostics found within Feature 201 include Scallorn, Ensor, Marcos, Marshall, Castroville, Montell, Williams, Pedernales, and Uvalde. This range of types indicates Feature 201 probably accumulated on a very slowly aggrading surface. Feature 201 may represent either an occupational midden containing a relatively large number of burned rocks or it may represent the margins of a much larger burned rock midden (either an incipient/sheet midden or a mounded midden that lay buried outside the TARL excavation block).

Most of the other Late Archaic burned rock features appear to represent small, relatively discrete hearth-like features. Most are less than a meter in diameter, no more than 15 $\mathrm{cm}$ thick, and they include anywhere from 4 to 80 rocks. Wood charcoal from one of the burned rock clusters, Feature 10, yielded an AMS date of $1990 \pm 60$ B.P. (CAMS18639).

The last cultural features to consider are the three judged potentially associated with Late Prehistoric use of the site (ca. 1300-800 B.P.; see Chapter 10). Only one feature was 
confidently assigned to the Late Prehistoric period, and two others were classified as either Late Prehistoric or Late Archaic in age. The confident assignment was given to Feature 1, a small burned rock cluster measuring ca. $40 \mathrm{~cm}$ in diameter. It was described as a "flat hearth" in the field notes and was composed of only 11 tightly clustered rocks. A considerable amount of bone was found near Feature 1, and much of this appears to be deer or antelope bone. This feature was found in Level 1 (upper $10 \mathrm{~cm}$ of Unit IIIc), and the level recovery included a Scallorn arrow point and an arrow point preform (there were no Archaic diagnostics in this level).

The two features classified as Late Prehistoric or Late Archaic include Feature 7 (a disturbed burned rock scatter) and Feature 202 (a small burned rock cluster). Both were found in problematical contexts (for assessing their age), but neither appeared to be very significant/informative features.

There was also some evidence to suggest there may have been a relatively minor Late Prehistoric contribution to Burned Rock Midden 1. Arrow points were primarily found in the levels encompassing the upper surface of the midden, and they may well postdate the midden. All of the identifiable points $(\mathrm{N}=7)$ were classified as Scallorn points. Thirteen of the 15 arrow points from Burned Rock Midden 1 were found in the very first levels of the midden. These levels represent the highest surface of the mound exposed in the excavations. The arrow points may reflect Late Prehistoric use of a small portion of the midden (most of it appears to have been buried by that time), or the points may postdate the midden.

\section{SUMMARY}

Much of this chapter is devoted to highly descriptive presentations of the key morphological, contextual, and special studies data gleaned from an analysis of the 260 features recorded in the Wilson- Leonard excavations. Although these dry summaries are rather tedious to read, they provide critical supporting evidence for some of the more inferential conclusions drawn in other chapters, especially the synthetic studies presented in Volume I. Since there was considerable variation in the quantity and quality of field data collected from each feature, much analytical effort was expended in the identification of the most reliable and informative feature data. These data ultimately played the most important roles in the overall site analysis.

With the exception of some burned trees that provided critical chronostratigraphic evidence, the feature analysis focused primarily on the 226 features judged to be cultural in origin. The vast majority ( 212 or ca. $94 \%$ ) were burned rock features, and they varied considerably in both size and form. Although important functional differences are clearly represented by this variation, the burned rock features were classified into morphological/descriptive (rather than functional/ interpretative) categories in this analysis in an effort to overcome critical deficiencies in the data collected from many features and to facilitate comparative studies and/or alternative interpretations. Where the evidence was judged to be strong enough to support functional interpretations, these are discussed in analytical commentaries.

The burned rock features were classified into nine descriptive categories: burned rock midden, burned rock accumulation, burned rock scatter, burned rock cluster, large burned rock basin, small burned rock basin, pit with burned rocks, burned rock ring, and burned sediment with a few burned rocks. Most of the burned/heated rocks found in these features were probably used as heat retention elements in various domestic/utilitarian activities (especially food preparation) and they were found in primary, secondary, or undetermined heating contexts. The primary contexts consist of locales (or facilities) with evidence of in situ burning/heating of stones. The secondary contexts consist of heated stones that were displaced significantly from the heating locale (usually after they had cooled). Both contexts were identified primarily on the basis of archeomagnetic data collected from the stones, although the presence/absence of burned sediment, charcoal, and/or ash was used as supporting evidence when appropriate. For the burned rock features lacking archeomagnetic data, primary context was sometimes inferred on the basis of strong supporting evidence. The burned rock features encompassing at least some evidence of in situ burning/heating were generally the most informative.

A wide variety of artifacts, faunal remains, and carbonized botanical remains were found in and around burned rock features, but in most cases definitive and/or specific functional associations could not be demonstrated. As Black (1997:255-257) has argued, materials found within and around burned rock features may be deposited through a variety of mechanisms and potential temporal/functional associations should be examined with great caution. Ethnographic analogues suggest a myriad of activities were conducted around these hearths, but the heated stones were probably used primarily in food preparation/cooking (see, for example, discussion by Ellis 1997). The most convincing functional associations identified in the WilsonLeonard burned rock features include the carbonized remains of various fuel woods (especially live oak and juniper; see Chapter 40) and carbonized wild hyacinth bulbs that appear to have been baked in Archaic burned rock/ earth ovens. At least some of the faunal remains found in the burned rock features probably represent the remains of meals prepared in these facilities, however, convincing temporal/functional associations were difficult to demonstrate given the relative abundance of faunal remains throughout the site deposits.

Although burned rock features strongly dominate the cultural feature samples from Late Paleoindian through Late Prehistoric contexts, none was identified in the Early 
Paleoindian-age deposits at Wilson-Leonard (ca. 11,50010,000 в.P.). Three definite cultural features were recorded in these deposits, but they were not very informative. A small artifact and bone cluster (Feature 188) was tentatively attributed to the Clovis component, and two concentrations of fractured bone (Features 170 and 262) were more confidently attributed to the slightly younger Bone Bed component (see Chapter 7). Although the sparse feature evidence suggests both components represent relatively discrete, short-term occupations, it is important to remember that the excavated sample for the Early Paleoindian period is relatively small. Despite this possible sampling bias, it is quite significant that no burned rock features were identified in Early Paleoindian contexts at Wilson-Leonard. Since burned rock features dominate the feature samples for all subsequent cultural intervals, their apparent absence during the Early Paleoindian period suggests heated rock technology was not in use (or very important) at that time.

The earliest burned rock features from Wilson-Leonard are attributed to the Late Paleoindian Wilson component (ca. 10,000-9500 B.P.). Nine burned rock features date to this interval and most appear to have been relatively small (no more than $1 \mathrm{~m}$ diameter) rock hearths constructed directly on the ground surface. The notable exception (Feature 187) may represent a small ( $<1$-m diameter) earth/rock oven constructed in a shallow, basin-shaped pit. In addition to the burned rock features, a highly significant human burial (Wilson-Leonard II or Burial 2) and two intriguing pits (Features 168 and 169) are attributed to the Wilson component. The burial pit appears to have been excavated from an occupational surface in the lower portion of the Leanne soil around 10,000 в.P. The two pit features appear to have been excavated from approximately the same surface and may be roughly contemporaneous with the burial. Their function is unknown but they were likely used for some domestic/utilitarian purpose (e.g., food storage or preparation). Several of the Wilson component burned rock features also appear to be roughly contemporaneous with the burial while others were clearly constructed on slightly younger occupational surfaces (in the upper portion of the Leanne soil).

The cultural features relating to subsequent Late Paleoindian occupations (ca. $9500-8800$ в.P.) could not be confidently attributed to specific components due to the compressed nature of the deposits and the lack of clear stratigraphic separation. Cultural features from this interval include a debitage concentration and a variety of burned rock features. The latter consisted primarily of relatively flat, hearth-like groupings of stones (most were less than $1 \mathrm{~m}$ diameter), but the sample also included at least six features that may have been earth/rock ovens constructed in shallow pits. Half of these were relatively small (no more than $1 \mathrm{~m}$ diameter), but the others were constructed on a significantly larger scale (measuring 1.4-1.6 $\mathrm{m}$ in diameter and encompassing ca. 60-100 rocks). These larger-scale features were probably used to process larger quantities of food in a single event, and they are thought to reflect important changes in subsistence practices and/or group/economic structure (see Chapter 8).

The Early Archaic interval at Wilson-Leonard (ca. 88006000 в.P.) is characterized by a dramatic increase in the intensity of occupation (see Chapter 9). This is best reflected in the feature data by significant increases in both the density and size of burned rock features. Although discrete components could not be identified in the Early Archaic-age deposits, features dating to this time interval were somewhat easier to segregate than those relating to subsequent Middle Archaic through Late Prehistoric occupations.

In addition to 3 extensive burned rock accumulations, the Early Archaic sample includes 8 large burned rock basins/ovens (measuring ca. 1.3-2.6 $\mathrm{m}$ in diameter), 5 smaller basin-shaped features (possible ovens), and over 80 other burned rock features (primarily flat clusters or scatters). All of the large basins/ovens were found within or directly beneath burned rock accumulations, and much of the debris found in the latter appears to be derived from repeated use of the ovens. These accumulations and the more circumscribed features found within them are interpreted as incipient burned rock middens that were buried before they accumulated into mounded middens. The ovens and associated middens are also thought to reflect an emphasis on bulk processing of plant foods, especially starchy plants that require slow baking. This notion is supported by the recovery of 10 carbonized wild hyacinth (Camassia scilloides) bulbs from one of the larger ovens (Feature 181).

Evidence of Middle and Late Archaic occupations was difficult to separate in the Wilson-Leonard deposits due primarily to slow deposition rates and subsequent mixing of cultural deposits (see Chapter 9). Only 19 cultural features were confidently assigned Middle Archaic age estimates (ca. $6000-4000$ B.P.) and all were burned rock features. Most were relatively small (less than $1 \mathrm{~m}$ diameter), flat, hearth-like clusters, but the sample also includes the lower layers of two burned rock middens. Stratigraphic positions and associated radiocarbon dates suggest the majority of the Middle Archaic-age features at WilsonLeonard date to the latter portion of this period (ca. 50004000 B.P.). Fewer burned rocks were deposited on the site in the early portion of this period (ca. $6000-5000$ в.P.) and this may reflect a decreased emphasis on the bulk processing/cooking of plant foods using heated rock technology (see Chapter 9). Paleoenvironmental data indicate this was one of the most xeric intervals in the site's history, and these conditions may have had an adverse effect on critical plant resources in the site area.

Late Archaic age estimates (ca. $4000-1300$ B.P.) were confidently assigned to a disturbed human burial (WilsonLeonard I or Burial 1), a biface cache, and 21 burned rock features. The latter include 2 domed burned rock middens, an extensive burned rock accumulation, and 18 smaller 
burned rock features. The domed middens first began to accumulate in the latter portion of the Middle Archaic period, however, they appear to have accumulated most of their mounded mass during the Late Archaic period. Paleoenvironmental data suggest this may reflect a return to more favorable mesic conditions in the site area during this interval and a concomitant increase in the intensity of occupation. The relatively high density of burned rocks in the Late Archaic deposits at Wilson-Leonard may also reflect a renewed emphasis on the use of heated rocks for bulk processing/cooking certain key plant foods. Although no large pits or oven-like features were recorded in the Late Archaic portion of either burned rock midden, this likely represents sampling and/or recording biases (see Burned Rock Midden 1 and 2 descriptions at the end of this chapter). A carbonized wild hyacinth bulb found in the lower portion of Burned Rock Midden 2 yielded an AMS date of $3780 \pm 70$ в.P. (ETH-14115). This bulb was probably cooked in a Late Archaic-age earth/rock oven encompassed within Burned Rock Midden 2.

No large, oven-like features were found within the Late Archaic burned rock accumulation (Feature 201) either, but this extensive feature was only partially exposed. Subfeatures recorded within this accumulation included a possible small burned rock basin and three small, hearth-like clusters. The Feature 201 accumulation may represent a portion of a buried burned rock midden, or it may simply represent an occupation midden containing a relatively high density of burned rocks.

Only one feature, a small flat hearth, was confidently assigned a Late Prehistoric age estimate (ca. 1300-800 B.P.), but there may have been a minor Late Prehistoric contribution to the upper portion of Burned Rock Midden 1. At least seven Scallorn arrow points were recovered from levels encompassing the upper surface of the midden, but it could not be determined if the points postdated the midden (see Burned Rock Midden 1 description and discussion in Chapter 10).

This analysis is intended to demonstrate the tremendous research potential of both the existing sample of feature data from the Wilson-Leonard site and new data that may be obtained in future investigations. Very few excavated sites in Texas, and relatively few in North America, have stratified feature samples of comparable time depth. Evidence recovered from the Paleoindian and Early Archaicage deposits at Wilson-Leonard is perhaps the most significant, given the relative paucity of feature data from these intervals in the extant record. The large, stratified sequence of burned rock features is also a great strength of this data set, since it provides an invaluable opportunity to explore diachronic patterns in the use of heated rock technology. Although this feature analysis has yielded some highly significant results, the potential of the existing sample clearly exceeds the limitations of the present study. Some important lines of inquiry have been identified, but much has been left on the table for other researchers to pursue.

\section{SELECTEDFEATUREDESCRIPTIONS}

Detailed descriptions of 140 features are presented in the following section. These include 98 (or ca. 49\%) of the 199 features recorded in the TxDOT investigations and 42 (or ca. $69 \%$ ) of the 61 features recorded during the TARL investigations. Features were selected for more-detailed presentations on the basis of several key criteria. These criteria include: feature type (all of the more-unusual and informative features are described along with a representative sample of the more-abundant and/or less-informative features); excavation context (representative samples from each major excavation area are included); stratigraphic context (most features from Units I and II are described and representative samples were selected from Units IIIa, IIIb, and IIIc); cultural chronology (all Paleoindian-age cultural features are described as are representative samples of the more numerous Archaic features); associated materials; and special studies results (most features with associated artifacts, faunal remains, macrobotanical remains, and/or special studies results are described).

These descriptions are organized in feature number order and present the following data for each feature: type; provenience; stratigraphic context; archeological chronology; summary list of special samples; and a detailed description. In additon to morphological data, the description includes a summary of associated materials and special studies results.

\section{Feature 1}

Feature Type: burned rock cluster Provenience: Square E22/S98 (SW quad), Level 1; no elevations were recorded for either the feature or the level

Stratigraphic Context: Unit IIIc

Archeological Chronology: Late Prehistoric?

Figure: 26-1

Description: Feature 1 was a roughly circular, single-layer cluster of 11 burned rocks ( $4-15 \mathrm{~cm}$ size). The cluster measured about $40 \mathrm{~cm}$ in diameter, and it probably had a vertical extent of no more than $5-10 \mathrm{~cm}$. It was described as a "flat hearth" in the field notes, indicating the rocks probably rested on a relatively flat surface. No burned sediment or charcoal were reported, and no artifacts or other materials were provenienced to Feature 1. The level notes indicate a considerable amount of bone was found near Feature 1 but no bone was provenienced to this feature. Approximately 119 bones and bone fragments were found in general level recovery, and some of these may have been associated with the feature. Most were classified as mammal (large or medium/large) or Vertebrata indeterminate fragments, but the sample also included 11 deer or antelope elements (see Appendix 9).

Comments: The stratigraphic position of Feature 1 (in the upper $10 \mathrm{~cm}$ of Unit IIIc) suggests it probably dates to either 


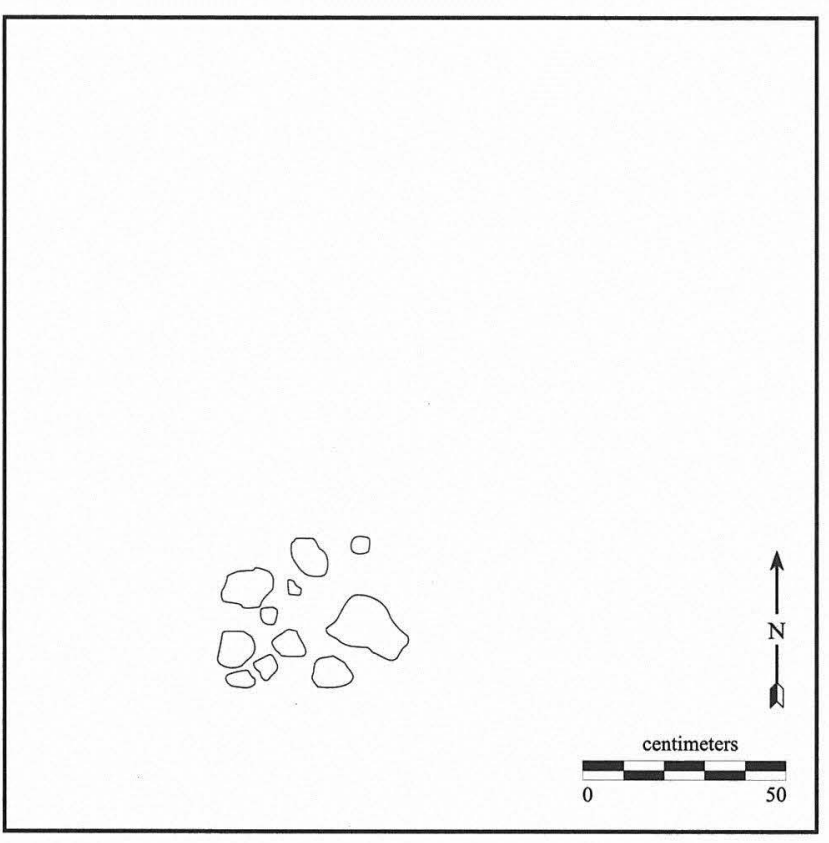

FIGURE 26-1. Feature 1 in Square E22/S98, Level 1.

the Late Prehistoric period or the latter part of the Late Archaic period. Since a Scallorn arrow point (4A-1) and an arrow point preform (4A-3) were found in the same level (and no Archaic diagnostics were recovered), Feature 1 has been tentatively classified as a probable Late Prehistoricage feature.

\section{Feature 4}

Feature Type: large burned rock basin

Provenience: Square E20/S94 (NW and SW quads); Levels 11-13; detection elevation $97.67 \mathrm{~m}$; base elevation $97.27 \mathrm{~m}$ Stratigraphic Context: Apparently originated in Unit $Y$ and intruded Unit X

Archeological Chronology: Early Archaic

\section{Special Studies:}

Macrobotanical: 1 macroplant sample analyzed (see Chapter 40)

\section{Figure: $26-2$}

Description: Feature 4 was a large, basin-shaped pit filled with a dense concentration of burned rocks. Like Feature 3, it was only partially exposed (over half extended into the west wall) and the exposed portion measured ca. $60-\mathrm{x}-170 \mathrm{~cm}$. Feature 4 contained several layers of burned rocks (over 90 exposed) with a documented depth of at least $40 \mathrm{~cm}$. Rock sizes ranged from $5-20 \mathrm{~cm}$ with the basin containing quite a few 10-20-cm-size rocks. Sediment within the central and lower portion of the basin was much darker in color and exhibited a higher ash content. The rocks in this area also appeared to be more intensively fractured with a notable increase in the density of the smaller (ca. 5-cm-size) fragments. A bifurcate stem point (6K-10) was found among the rocks along with 3 unifacial tools (6K-11, 6L-1, 6L-2), 157

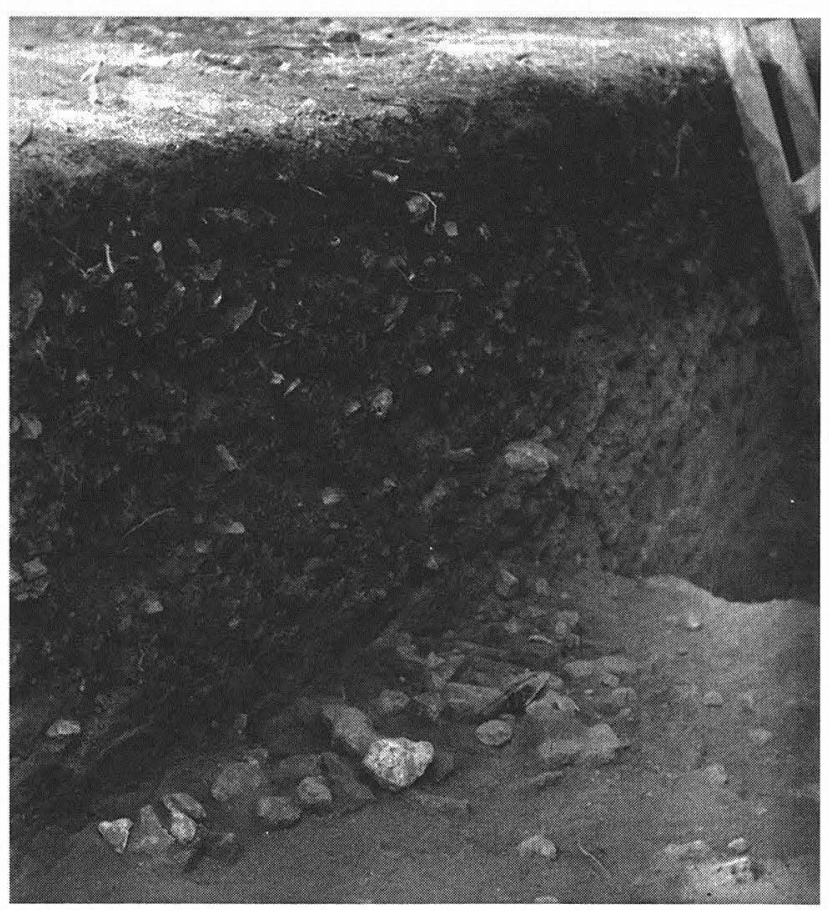

FIGURE 26-2. Feature 4 as exposed in Level 11 (detection level) in Square E20/S94, looking northwest.

pieces of debitage, 9 bone fragments (all Vertebrata indeterminate; see Chapter 33), and small quantities of charcoal. The only charcoal sample provenienced to Feature $4(\mathrm{CH}-$ 993) was classified as indeterminate wood charcoal.

\section{Feature 7}

Feature Type: burned rock scatter

Provenience: Squares E20/S82 (all quads) and E20/S84 (NE and NW quads), Level 2; detection elevation $97.62 \mathrm{~m}$; base elevation $97.51 \mathrm{~m}$

Stratigraphic Context: Unit IIIc

Archeological Chronology: Late Prehistoric or Late Archaic Special Studies:

Macrobotanical: 1 macroplant sample analyzed (see Chapter 40)

Figure: 26-3

Description: Feature 7 was a single-layer scatter of about 100 burned rocks. It was located about $20 \mathrm{~cm}$ below surface and may have been dispersed through plowing. The scatter covered an area measuring about $180-\mathrm{x}-200 \mathrm{~cm}$, and it had a maximum thickness of ca. $11 \mathrm{~cm}$. The rocks included both tabular cobbles (6-15-cm size) and smaller, angular fragments (ca. 2-6 cm). Some of the larger cobbles were fractured in place. Although the scatter generally had a dispersed appearance, some of the rocks were clustered in groups that may have represented the remains of several smaller, more discrete features. No burned sediment was reported within Feature 7, but a small amount of charcoal was found. 


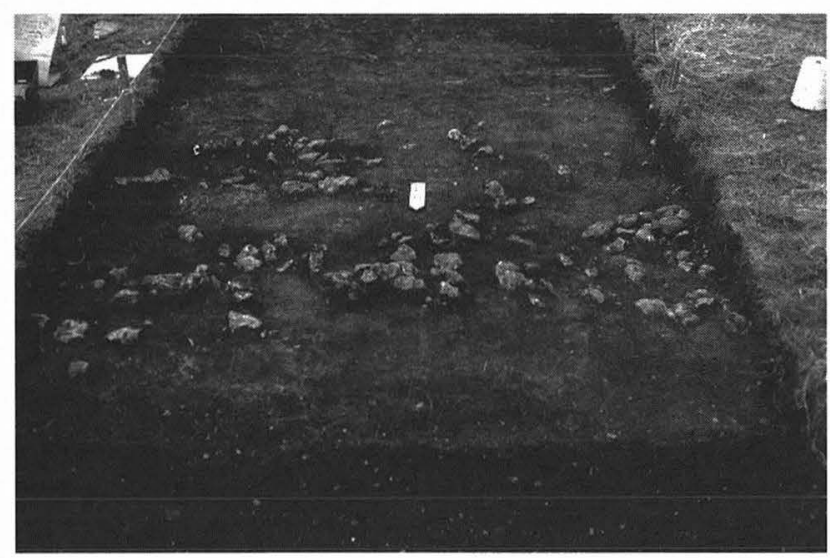

FIGURE 26-3. Feature 7 in Squares E20/S82 and E20/S84, Level 2, Block 3, looking south.

The only charcoal collected from Feature 7 (Lot 12B) was identified as Ulmaceae wood. Other materials found within the scatter include a stemmed arrow point (12B-1), a side-notched dart point (12B-2), 330 pieces of debitage, 2 mussel shell fragments (see Chapter 37), and 65 pieces of bone (see Chapter 33). Most of the bone was identified as medium/large mammal or Vertebrata indeterminate fragments, but the sample also included several deer or antelope elements.

Comments: The stratigraphic position of Feature 7 suggests it probably dates to either the Late Prehistoric period or very late in the Late Archaic period. It was located about $20-30 \mathrm{~cm}$ above the extreme northern edge of Burned Rock Midden 1, and the elevation data indicate it probably postdates the accumulation of most (if not all) of the mounded debris comprising this midden. The apparent clustering of some of the rocks within Feature 7 suggests it may represent the scattered remains of several burned rock features that were disturbed by plowing.

\section{Feature 8}

Feature Type: burned rock accumulation

Provenience: Squares E20/S88 (all quads) and E20/S90 (all quads), Levels 11-13; detection elevation ca. $97.15 \mathrm{~m}$; base elevation ca. $96.78 \mathrm{~m}$

Stratigraphic Context: the Unit X/Y/IIIb transition Archeological Chronology: Early Archaic Special Studies:

Radiocarbon: 1 sample (a carbonized bulb) that is possibly associated with Feature 8 was AMS-dated to $8250 \pm 80$ B.P. (CAMS-18375; see Chapter 25).

Macrobotanical: 1 macroplant sample analyzed (the bulb discussed above; see Chapter 40)

Figure: $26-4$

Description: Feature 8 consisted of an extensive accumulation of burned limestone fragments and other cultural debris. This accumulation apparently represented a sheet

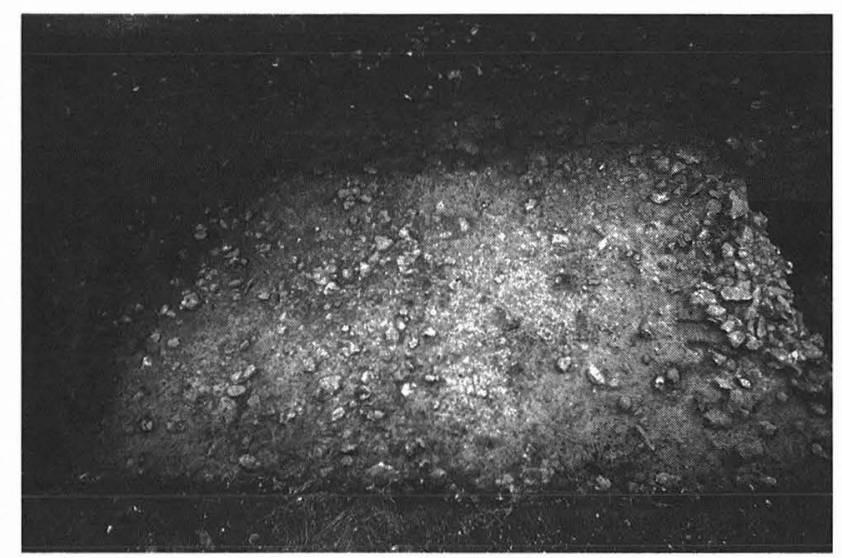

FIGURE 26-4. Feature 8 in Squares E20/S90 and E20/S88, looking east.

midden that surrounded at least three burned rock basins. Feature 8 was comprised of several layers of burned rocks (at least 500 mapped) with a combined thickness of ca. 30-40 $\mathrm{cm}$. It had a documented horizontal extent of at least 2-x-4 m but was probably a little larger than recorded. It probably extended southward into E20/S92, but this square was excavated much earlier than the others, and Feature 8 was not recognized as such at that time. It apparently extended eastward into Squares E22/S88 and E22/S90 as well, but the extension was not documented as Feature 8. Most of the burned rocks within Feature 8 fell within the $5-10$-cm size range but rock size ranged from $2-25 \mathrm{~cm}$. Small patches of burned sediment and dispersed charcoal were found within Feature 8 along with an assortment of lithic artifacts and some faunal remains.

No charcoal samples were provenienced to Feature 8; however, a wild hyacinth bulb (Camassia scilloides) found slightly above the feature's detection level is probably associated (see comments below). The lithic artifacts provenienced to Feature 8 include a Clear Fork uniface (9M2), a bifurcate stem dart point (9M-1), a projectile point barb fragment (8L-3), a Stage 2 biface (9L-4), 2 Stage 1 bifaces (9L6 and 9M-3), 2 biface fragments (9L-5 and 9M-5), 8 unifacial tools (8L-4, 8L-5, 8L-6, 8L-7, 8L-8, 9L-7, 9L-8, and 9M-4), and 1,095 pieces of debitage. The faunal remains include 4 mussel shell fragments (see Chapter 37 ) and 35 pieces of bone (see Chapter 33). Most of the bone was classified as either Vertebrata or medium/large mammal fragments, but the sample also included 3 turtle shell fragments, a snake vertebra, 2 rabbit elements, and 2 fragments of a deer or antelope pelvis.

As previously noted, at least three burned rock basins were found within Feature 8. Feature 12 was a large basin (ca. 30-x-105-x-150 cm) found in Squares E20/S88 and E22/ S88 (see Feature 12 description). Feature 13 was a slightly smaller basin (90-x-70-x-20 cm) found in Squares E20/S90 and E22/S90 (see Feature 13 description). A third basin was apparently represented by a semicircular concentration of stones mapped at the south end of E20/S90 (no 
feature number assigned). The latter feature probably represented the northern half of a basin that was not recognized when the south half was removed in the earlier Square E20/ S92 excavations. This feature had an estimated diameter of ca. $180 \mathrm{~cm}$ and a depth of ca. $30 \mathrm{~cm}$.

Comments: Feature 8 is quite similar to Features 124 and 231 identified in the Block 6 and TARL excavations. All three of these features represent burned rock sheet middens that accumulated in areas where a number of large burned rock basins were constructed. These burned rock accumulations probably represent refuse scatters associated with repeated use of these basin-shaped cooking features. The top of Feature 8 was located about $10-30 \mathrm{~cm}$ below the base of Burned Rock Midden 1, but there was clear stratigraphic separation between these two episodes of burned rock accumulation. The dated wild hyacinth bulb cited above (CH-998) was recovered from Level 10 of Square E20/S90. This level was located in the transition zone between the base of Burned Rock Midden 1 and the top of Feature 8. The cultural stratigraphy is very compressed in this area of the site, and the bulb could conceivably relate to either Burned Rock Midden 1 or Feature 8 . Since 10 carbonized wild hyacinth bulbs were found in another Early Archaic burned rock basin (Feature 181) this bulb may have been cooked in one of the basins found within Feature 8. The AMS dates on 9 of the Feature 181 bulbs are very similar to the CH-998 date cited above, ranging from ca. 7870 to 8130 в.P. (see Feature 181 description and discussion of these dates in Chapter 25).

\section{Feature 10}

Feature Type: burned rock cluster (or small burned rock ba$\sin$ ?)

Provenience: Square E20/S84 (NE and NW quads), Level 5; elevations recorded for 6 rocks range from 97.32 to $97.27 \mathrm{~m}$

Stratigraphic Context : Unit IIIc

Archeological Chronology: Late Archaic

\section{Special Studies:}

Radiocarbon: 1 wood charcoal sample was AMS-dated to $1990 \pm 60$ в.P. (CAMS-18639; see Chapter 25)

Macrobotanical: 1 macroplant sample analyzed (the dated sample cited above; see Chapter 40)

Figure: 26-5

Description: Feature 10 consisted of a relatively tight, ovalshaped cluster of approximately 80 burned rocks. It measured about $60-x-90 \mathrm{~cm}$ with a vertical extent of ca. $5-10 \mathrm{~cm}$. About 50 additional burned rocks were scattered to the north and east of Feature 10, and at least some of these may have been displaced from the main cluster. The cluster was composed of a single layer of closely spaced rocks that may have rested in a shallow depression (or excavated basin?). Feature 10 was not cross-sectioned but rocks on the perimeter of the cluster were a few centimeters higher than rocks in the center. Most of the rocks in the cluster were small angular fragments (ca. $2-5 \mathrm{~cm}$ ), but also included were some

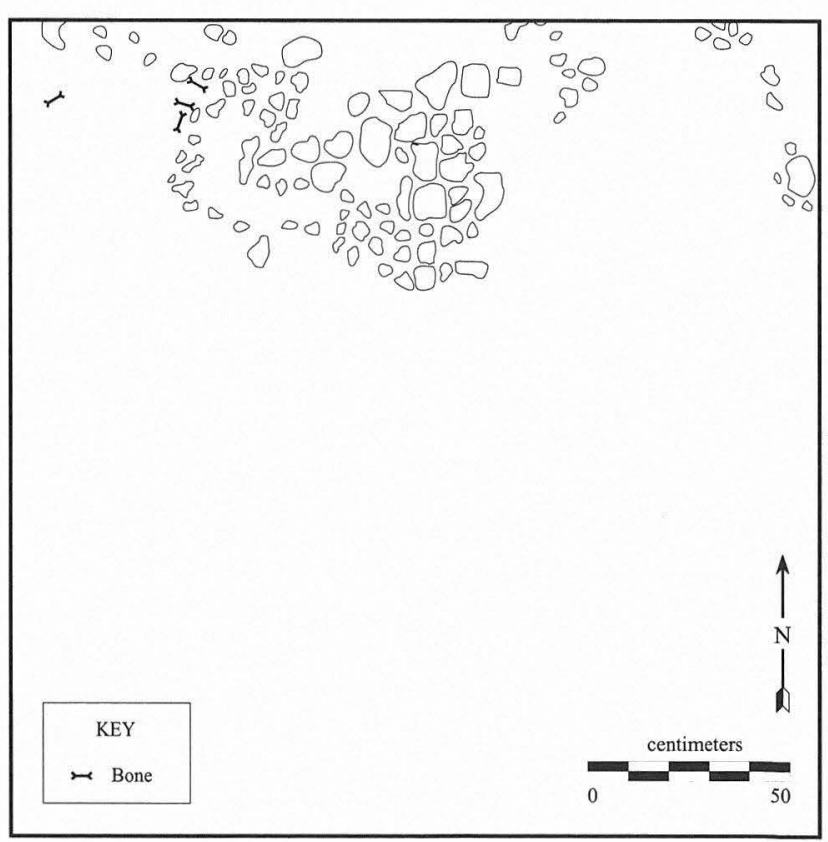

FIGURE 26-5. Feature 10 in Square E20/S84, Level 5.

small cobbles in the 6-12-cm size range. A few of the cobbles were fractured in place. No burned sediment was observed within Feature 10, but a relatively large sample of hackberry wood charcoal (CH-1024) was collected and subsequently dated (see date above). Apart from the charcoal sample, no other materials were provenienced to Feature 10. Field notes indicate some unburned bone was found within the feature, but it was apparently combined with general level recovery. Sixty pieces of bone were provenienced to this level, and though most was identified as mammal or Vertebrata indeterminate fragments, the sample also included 5 deer elements, 2 deer or antelope elements, and 3 large or medium/large mammal long-bone fragments (see Chapter 33).

Comments: Feature 10 clearly dates to the Late Archaic period and the morphological evidence suggests it may represent a small, basin-shaped hearth or cooking feature. This feature was located about $1 \mathrm{~m}$ north of the northern edge of Burned Rock Midden 1 and it may be contemporaneous with a portion of this larger feature's use history.

\section{Feature 11}

Feature Type: biface cache

Provenience: Square E20/S86 (NE and SE quads), Level 5; no elevations were recorded for either the feature or the level

\section{Stratigraphic Context: Unit IIIc}

Archeological Chronology: Late Archaic?

Figure: 26-6

Description: Feature 11 consisted of a cache of three Stage 1 bifaces (Specimens 10E-1, 10E-2, and 10E-3) and a quartz core (Specimen 10E-4). The cache measured about $25-\mathrm{x}-15 \mathrm{~cm}$ 


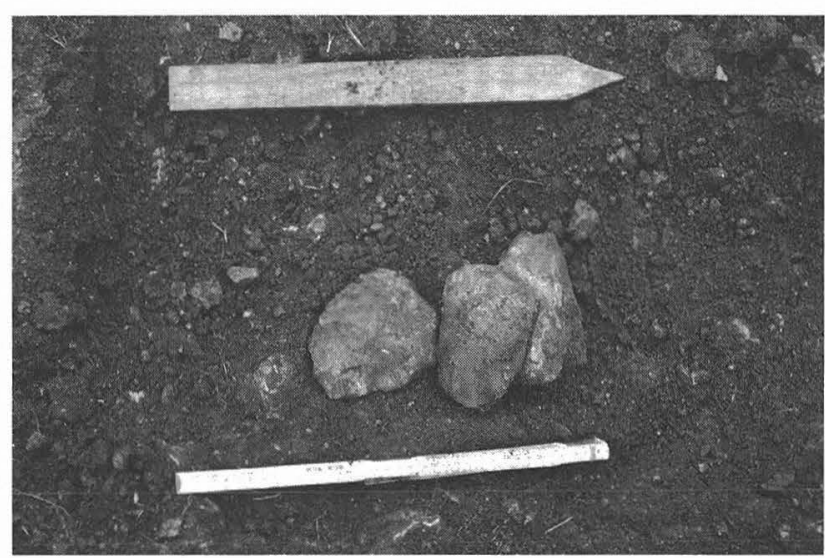

FIGURE 26-6. Feature 11 in Square E20/S86, Level 5, looking west. Field notes indicate these artifacts were moved and then re-staged in their approximate find positions for this photograph.

with a vertical extent of about $8 \mathrm{~cm}$. Although several of the bifaces were apparently moved before their exact position was documented, they were placed back in their approximate find positions for photographs and a plan drawing. These documents show two of the bifaces stacked on top of the core and the third biface lying immediately south (but still touching) the stacked group. There was no evidence to indicate if these artifacts had been placed in a pit. The cache was located in the upper portion of Burned Rock Midden 1 (upper $20 \mathrm{~cm}$ of the northern edge), but it may have been intrusive (i.e., postdating midden accumulation).

Comments: Feature 11 probably represents a deliberate artifact cache dating to the Late Archaic period. Although its stratigraphic position (mid IIIc, upper portion of Burned Rock Midden 1) suggests a Late Archaic age, it is also possible that the artifacts were placed in a pit excavated from a Late Prehistoric occupational surface. When the artifacts were considered with this possibility in mind, the bifaces were judged to be more consistent with Late Archaic than Late Prehistoric lithic technology. A small quartz blade (Specimen 274-2) possibly made from the same raw material as the Feature 11 core was found in a Late Archaic context about 4$5 \mathrm{~m}$ northeast of Feature 11 (TARL Square 12, Level 5; mid Unit IIIc). Although the blade looked like it could have come from the core, refitting attempts were unsuccessful.

\section{Feature 12}

Feature Type: large burned rock basin

Provenience: Square E20/S88 (NE and SE quads), Levels 1214; Square E22/S88 (NW and SW quads), Levels 11-13; detection elevation ca. $96.96 \mathrm{~m}$; base elevation ca. $96.72 \mathrm{~m}$

Stratigraphic Context: the Unit X/Y/IIIb transition

Archeological Chronology: Early Archaic

Special Studies:

Organic Residue: 1 artifact analyzed by Hurst (see Chapter

23)
Macrobotanical: 2 macroplant samples analyzed (see Chapter 40)

Description: Feature 12 was one of three basin-shaped, rockfilled pits found within the Feature 8 burned rock accumulation (see Feature 8 description). The Feature 12 pit was roughly oval shaped, measuring $\mathrm{ca} .105-\mathrm{x}-150 \mathrm{~cm}$ with a depth of at least $30 \mathrm{~cm}$. Sediment within the pit was slightly darker in color and less compact than the surrouriding matrix. The pit fill also included numerous burned limestone fragments (over 200 mapped), scattered charcoal, small quantities of burned sediment, some bone fragments, and a quartzite mano fragment $(9 \mathrm{~N}-3)$. Most of the feature fill was combined with general level recovery but feature provenience was maintained for the mano fragment and two charcoal samples $(\mathrm{CH}-$ 1008, and CH-1009; both classified as indeterminate wood). The mano fragment was analyzed as an organic residue sample, but no significant residues were identified.

\section{Feature 13}

Feature Type: small burned rock basin

Provenience: Square E20/S90 (NE and SE quads), Levels 1213; no elevations were recorded for either the feature or the level

Stratigraphic Context: the Unit X/Y transition

Archeological Chronology: Early Archaic

Figure: 26-7

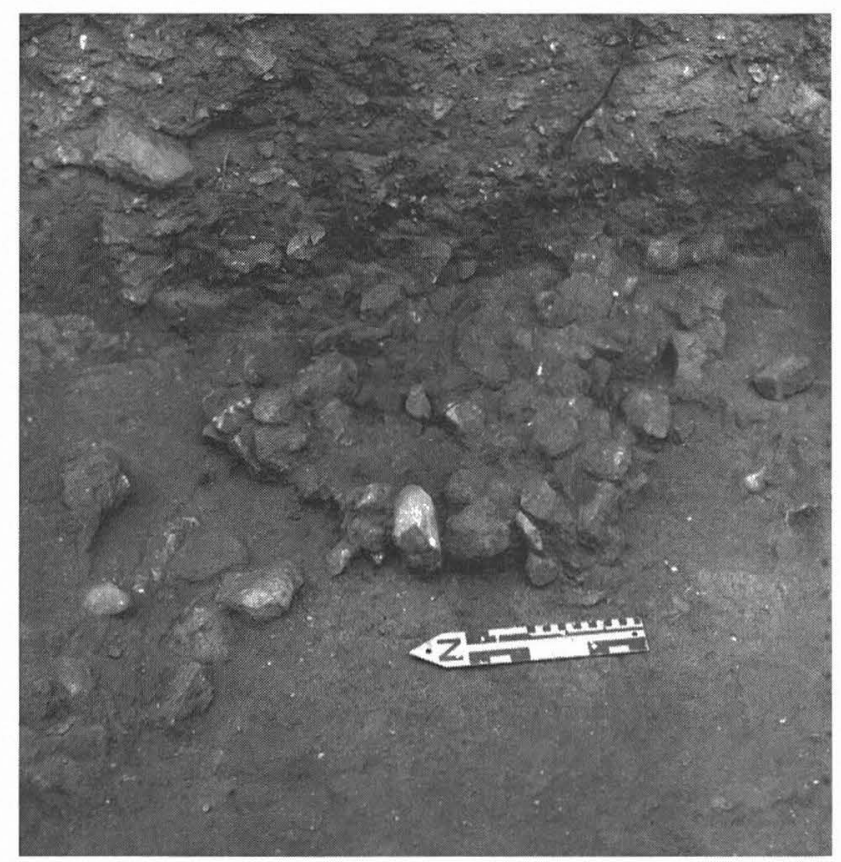

Figure 26-7. Feature 13 in Square E20/S90, Level 12, looking east.

Description: Feature 13 was the smallest of the three basinshaped, rock-filled pits found within the Feature 8 burned rock accumulation (see Feature 8 description). The eastern edge of Feature 13 extended into the east wall of Square E20/ 
S90, but this portion was apparently not documented when the adjacent square (E22/S90) was excavated several months later. The documented portion of this feature measured ca. $70-x-90 \mathrm{~cm}$ with an estimated depth of at least $20 \mathrm{~cm}$. The pit fill included numerous burned rocks (over 100 mapped) as well as some charcoal and bone fragments. Rock size ranged from ca. $2-15 \mathrm{~cm}$ with the larger rocks concentrated primarily in the lower portion of the pit. The field notes do not describe the sediment within the pit or note any evidence of in situ burning. The bone found in Feature 13 fill was apparently combined with general level recovery. No artifacts or other cultural materials were provenienced to this feature.

\section{Feature 14}

Feature Type: burned rock cluster

Provenience: Square E20/S82 (all quads), Level 6; elevations recorded for 3 rocks range from $97.22-97.12 \mathrm{~m}$

Stratigraphic Context: Unit IIIc

Archeological Chronology: Middle or Late Archaic Figure: $26-8$

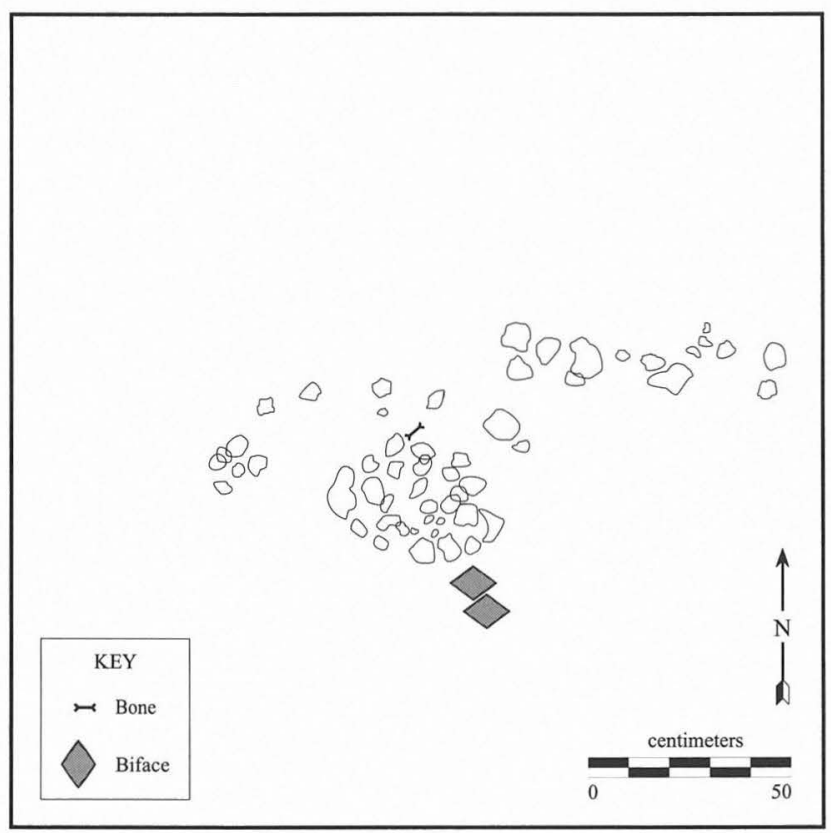

FIGURE 26-8. Feature 14 in Square E20/S82, Level 6.

Description: Feature 14 was an oval-shaped, single layer cluster of about 25 burned rocks. The cluster measured approximately $35-\mathrm{x}-45 \mathrm{~cm}$ with a vertical extent of ca. $10 \mathrm{~cm}$. It was described as a "flat hearth" in the field notes, indicating the rocks probably rested on a relatively flat surface. Rocks within the cluster were very closely spaced, and they ranged from about 3-12 cm in length. A somewhat linear scatter of 25 additional burned rocks formed a $20-\mathrm{x}-150-\mathrm{cm}$ band immediately north of Feature 14, and at least some of these rocks may have been displaced from the cluster.
No burned sediment was observed in Feature 14 but a small amount of charcoal was found (not collected). Some bone was also found within the cluster, but it was apparently combined with general level recovery. Sixty-eight pieces of bone were provenienced to this level, and though most of these were classified as Vertebrata or medium/large mammal fragments, the sample also included 4 deer or antelope elements, 1 rabbit radius, and 3 turtle elements (see Chapter 33). Two bifaces were found at the southern edge of the cluster. One of these specimens (12F-2) was a thin, well-made bifacial tool (knifelike), and the other (12F-4) was a Stage 2 biface (field notes indicate that biface fragment $12 \mathrm{~F}-3$ was chipped off of biface $12 \mathrm{~F}-2$ during excavation).

Comments: Feature 14 was located ca. 1-2 m north of the northern edge of Burned Rock Midden 1, and it may be contemporaneous with a portion of the midden's use history. Although the stratigraphic position of this feature suggests it most likely dates to the Late Archaic period, there was considerable mixing of Middle and Late Archaic diagnostics in this area.

\section{Feature 16}

Feature Type: burned rock cluster (or small burned rock ba$\sin ?)$

Provenience: Square E20/S84 (NE and SE quads), Level 8; elevations recorded for 5 rocks range from 97.07 to $97.03 \mathrm{~m}$ Stratigraphic Context: the Unit IIIb/IIIc transition Archeological Chronology: Middle or Late Archaic Figure: 26-9

Description: Feature 16 was a relatively tight cluster of about 20 burned rocks (5-20-cm size range). The cluster measured

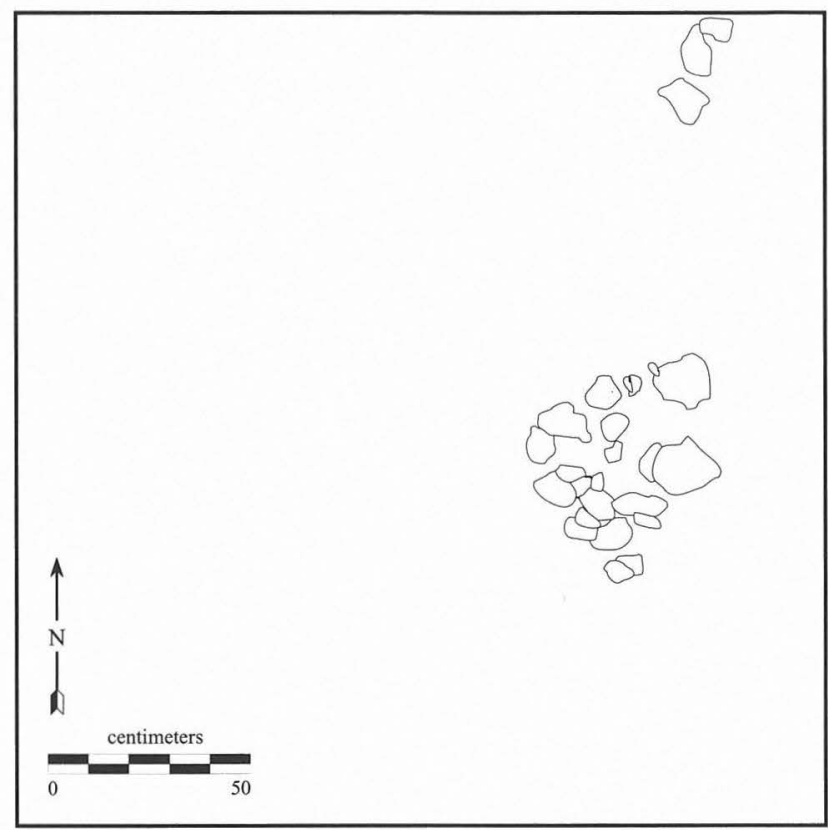

Figure 26-9. Feature 16 in Square E20/S84, Level 8. 
ca. 40-x-55 cm with an estimated thickness of ca. $5-10 \mathrm{~cm}$. There was a small rock-free space $(15-\mathrm{x}-15 \mathrm{~cm})$ at the east end of the cluster where a rock may have been displaced. Although no evidence of a basin was reported in the field notes, the photographs of Feature 16 suggest this possibility. Some of the perimeter rocks appear to be sloping downward toward the center of the cluster, and the center appears to be at least several centimeters lower than the perimeter. Elevations were recorded for 4 of the perimeter rocks and 1 of the center rocks. The center rock had the lowest elevation, but it was only a few centimeters lower than the perimeter stones. No burned sediment or charcoal was observed in the cluster, and no artifacts or other materials were provenienced to Feature 16.

Comments: Feature 16 was located about a meter north of Burned Rock Midden 1, and it may be contemporaneous with a portion of the midden's use.

\section{Feature 17}

Feature Type: burned rock scatter

Provenience: Square E20/S90 (NE and SE quads), Level 16; elevations recorded for 6 rocks range from $96.68-96.55 \mathrm{~m}$

Stratigraphic Context: Unit X

Archeological Chronology: Early Archaic

\section{Special Studies:}

Macrobotanical: 2 macroplant samples analyzed (see Chapter 40)

Description: Feature 17 was a dispersed scatter of ca. 50 burned rocks within an area measuring approximately 130 $\mathrm{cm}$ in diameter. The scatter consisted of a single layer of rocks with a vertical extent of no more than $10-15 \mathrm{~cm}$. Most of the rocks were relatively small angular fragments (ca. 3-8$\mathrm{cm}$ size) but the scatter included a few larger fragments in the 10-20-cm size range. A patch of burned sediment (ca. 25$\mathrm{cm}$ diameter) was found in the southwest quadrant of the scatter, and the rocks were clustered a little more tightly in this area. This burned area looked as if it might represent the in situ remnant of a disturbed hearth with some of the dispersed rocks having been displaced from this core area. Two charcoal samples (CH-1001 and CH-1002) were collected from Feature 17, and both were classified as arboreal legume wood. Other materials found within the scatter include a Thrall point (8P-1), a burin (8P-2), 2 edge-modified flakes (8P-3, 8P-4), 547 pieces of debitage, a mussel shell fragment (Amblema plicata; see Chapter 37), and 8 bone fragments (see Chapter 33). The bone included a burned femur fragment (medium mammal), an unburned rib fragment (medium/large mammal), an unburned rodent femur, and 5 indeterminate fragments (medium/large mammal or Vertebrata).

\section{Feature 19/104}

Feature Type: large burned rock basin

Provenience: Square E20/S90 (NE and SE quads), Levels 15-
18; E22/S90 (all quads), Levels 15-18; detection elevation ca. $96.77 \mathrm{~m}$; base elevation ca. $96.37 \mathrm{~m}$

Stratigraphic Context: Unit X

Archeological Chronology: Early Archaic Special Studies:

Radiocarbon: 1 wood charcoal sample was conventionally dated to $7470 \pm 230$ B.P. (Tx 4798 ; see Chapter 25)

Magnetic Susceptibility: 2 samples analyzed (see Chapter 28)

Micromorphology: 1 sample analyzed (see Chapter 29 and Appendix 7)

Gastropods: 1 sample analyzed (see Chapter 37)

Macrobotanical: 2 macroplant samples analyzed; 1 flotation sample processed (see Chapter 40)

Figure: 26-10

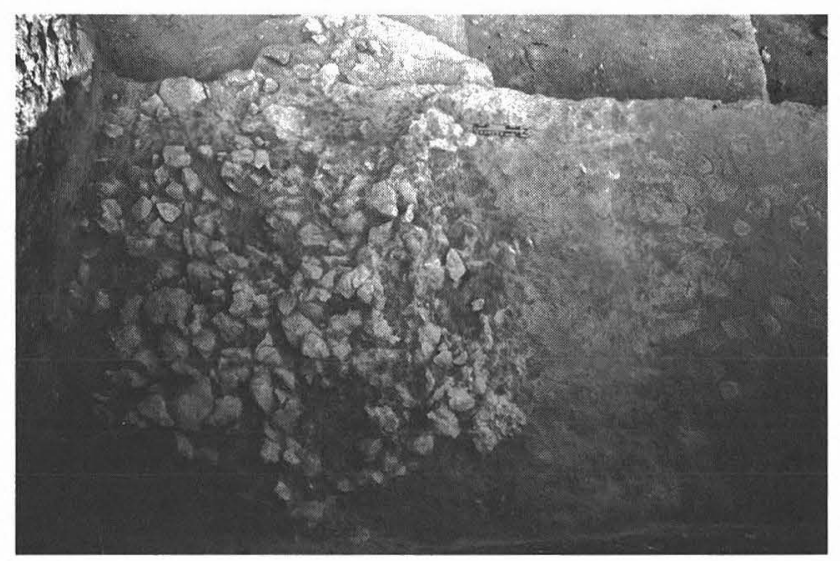

FIGURE 26-10. Feature 19/104 as exposed in Square E22/S90, Levels 16 and 17, looking west. The portion of this feature that extended into Square E20/S90 is visible at the top edge of the photo.

Description: Feature 19/104 was a large, basin-shaped pit containing numerous burned rocks (over 500 mapped) and other cultural debris. The western edge of this feature was first exposed in Square E20/S90 (where it was recorded as Feature 19) and the remainder was exposed several months later in Square E22/S90 (where it was recorded as Feature 104 ; hence, the compound feature designation). The pit measured ca. $190-\mathrm{x}-220 \mathrm{~cm}$ in diameter with a documented depth of at least $40 \mathrm{~cm}$. The pit contained numerous large slabs (15-35-cm size) as well as smaller rocks in the $2-10-\mathrm{cm}$ size range. The larger rocks were concentrated primarily in the lower portion of the feature.

A few isolated patches of burned sediment were observed at or near the base of the pit, and a small amount was collected as a thermoluminescence sample. Although the sample was not used for this purpose, a portion was used for a micromorphology thin-section (WL95-3). This sample exhibited traces of rubified sediment, a few ash rhombs, and some burned (partially calcined) limestone fragments. Small amounts of charcoal were found throughout the pit fill, and at least three samples were collected. One of the samples 
was radiocarbon dated (no $\mathrm{CH}$ number; see date above) and the others (CH-1113 and $\mathrm{CH}-1114)$ were analyzed as macroplant samples (identified as indeterminate wood).

The pit fill also contained assorted lithic artifacts, bone, and mussel shell. The artifacts include a Baker point (1801), a Thrall point (18P-1), 6 bifaces or biface fragments (18O$2,8 \mathrm{O}-3,18 \mathrm{O}-5,18 \mathrm{O}-13 ; 18 \mathrm{R}-1$, and 18R-2); 6 unifacial tools (8O-9, 18O-11, 18O-14, 18O-16, 18RA-8, and 18RB-10); 9 edge-modified flakes (18O-7, 18O-10, 180-15, 18O-18, 18R3, 18RA-6, 18RB-9, 18RC-14, and 18RD-16); 1 core fragment (180-4); 2 burins (18O-17, and 18RA-8); 2 burin spalls (18P2 , and 18RC-13), and 1,765 pieces of debitage. The faunal remains include 9 mussel shell fragments (see Chapter 37) and 16 bone fragments (see Chapter 33). Most of the bone was classified as either Vertebrata or mammal indeterminate fragments, but the sample also included an antelope or deer phalanx, several mammal long-bone fragments, and a turtle shell fragment. Only 6 of these specimens were burned.

A bulk matrix sample was also collected from the pit fill, and most of this sediment was used for magnetic susceptibility, gastropod, and flotation samples (remainder was curated). The magnetic susceptibility results are difficult to interpret, because there are no samples from nonfeature contexts in Unit X to which these samples can be compared. When they are compared to both feature and nonfeature samples from other stratigraphic contexts, the Feature 19/ 104 samples most closely resemble those from the lower portion of Unit II.

The flotation sample was not productive (no identifiable plant remains), but the gastropod sample yielded 231 identifiable terrestrial snails (representing at least 10 taxa) and 58 terrestrial juveniles. Most of the identifiable snails were taxa commonly found throughout the site deposits; however a few less common specimens were recovered as well (e.g., Gastrocopta pellucida, Gastrocopta procera, Gastrocopta contracta, Glyphyalinia umbilicata, and Glyphyalinia roemeri). On the whole, the species found in this sample suggest a woodland setting for Feature 19/104 (see Chapter 37).

\section{Feature 20}

Feature Type: burned sediment and charcoal (burned plant?)

Provenience: Square E20/S86 (NE and SE quads), Levels 1012; Square E22/S86 (NW, and SW quads), Levels 9-13; detection elevation $97.02 \mathrm{~m}$; base elevation $96.78 \mathrm{~m}$

Stratigraphic Context: the Unit X/IIIb/IIIc transition Archeological Chronology: Middle or Late Archaic Figure: 26-11

Description: Feature 20 was a large area of intensely burned sediment found at the base of Burned Rock Midden 1 (very near its northern edge). It had an irregular, oblong outline measuring ca. $85-\mathrm{x}-160 \mathrm{~cm}$ and a documented vertical extent

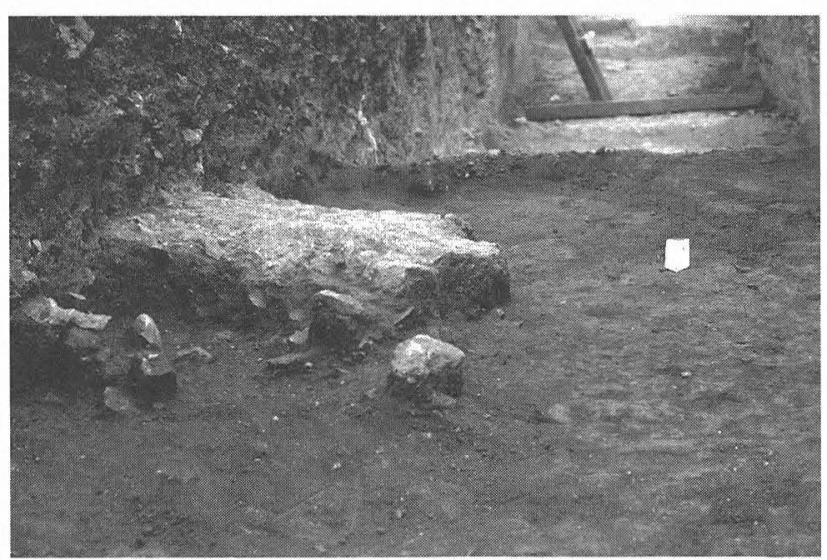

FIGURE 26-11. Western half of Feature 20 as exposed at the base of Level 12 in Square E20/S86, looking south. Note the overlying Burned Rock Midden 1 deposits.

of ca. $25 \mathrm{~cm}$. Sediment in this area was thermally hardened and discolored (red, orange, yellow, gray, black), and though charcoal was apparently scattered throughout the area, no significant concentrations were documented. At least 25 burned rocks were scattered in and around the burned area but no patterning or distinctive groupings were evident. Although the excavators initially thought Feature 20 represented some sort of pit feature, a distinctive pit outline was not identified when the feature was cross-sectioned. The cross-sectioning effort was not documented very thoroughly but the available data suggest Feature 20 probably represents a burned tree (or other large plant).

At least one small charcoal sample was collected from Feature 20, but feature provenience was not maintained in the lab. Four charcoal samples are provenienced to the levels encompassing Feature 20, and three were analyzed as macroplant samples. One (CH-1120) was identified as Rosaceae wood and the others (CH-1118 and CH-1119) as indeterminate wood (see Chapter 40). Four sediment samples, 200 pieces of debitage, and a few bone fragments were also collected from the feature area (feature provenience was not maintained for the bone).

Comments: The stratigraphic relationship between the base of Burned Rock Midden 1 and Feature 20 was not well documented, but photographs suggest the Feature 20 burning event predated the accumulation of the overlying midden deposits.

\section{Feature 22}

Feature Type: burned rock cluster Provenience: Square E20/S86 (SW quad), Level 15; elevations recorded for 4 rocks range from 96.63 to $96.54 \mathrm{~m}$

Stratigraphic Context: the Unit X/IIIa transition

Archeological Chronology: Early Archaic

Figure: 26-12

Description: Feature 22 was a tight single-layer cluster of 12 


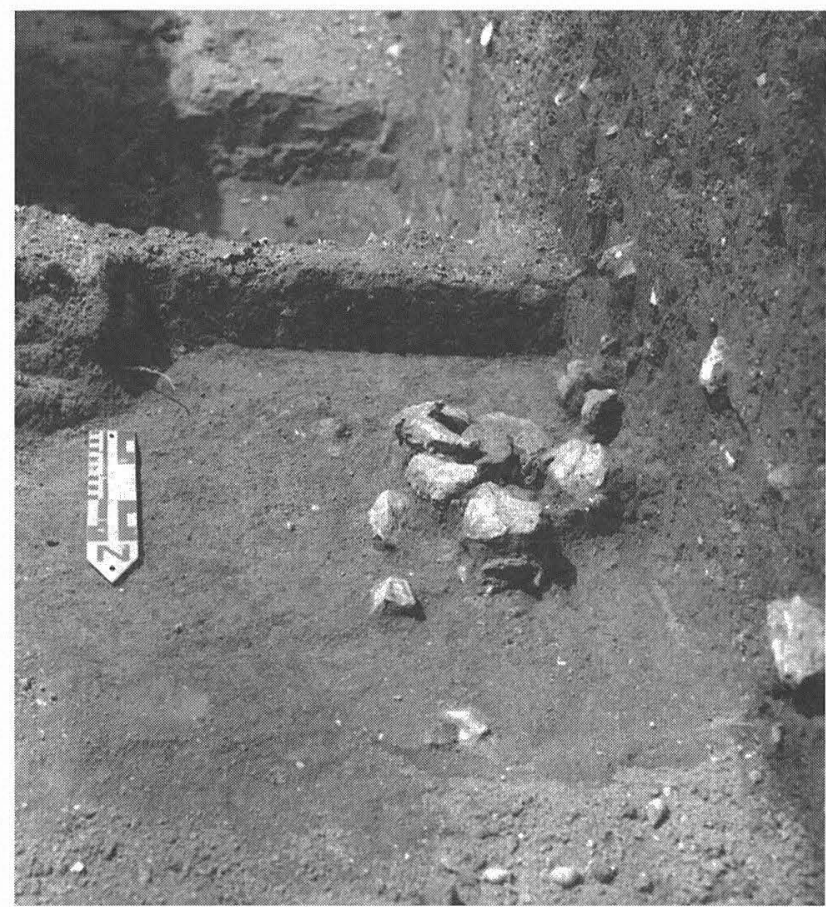

FIGURE 26-12. Feature 22 in Square E20/S86, Level 15, looking south.

burned rocks (5-10-cm size). The cluster measured $35-\mathrm{x}-40 \mathrm{~cm}$ in diameter and no more than $5-10 \mathrm{~cm}$ thick. The rocks were closely spaced and appeared to be resting on a relatively flat surface. Some of the rocks were reddened from burning, but no burned sediment or charcoal was found in the feature area. A complete mussel shell valve (Lampsilis teres, see Chapter 33) was found directly beneath one of the rocks but it exhibited no clear evidence of burning. No other materials were provenienced to this feature.

\section{Feature 28}

Feature Type: burned rock cluster (possibly in a pit?) Provenience: Square E20/S84 (SE quad), Levels 17-18; elevations recorded for 2 rocks are 96.21 and $96.14 \mathrm{~m}$

Stratigraphic Context: the Unit II/IIIa transition Archeological Chronology: Early Archaic

Description: Feature 28 was a cluster of burned rocks that rested in some sort of depression (possibly a pit or a burrow). This feature was difficult to evaluate because it was only partially exposed (it extended into the east wall) and was poorly documented (no field description; only plan drawings and photographs). The exposed portion measured ca. $55-\mathrm{x}-65 \mathrm{~cm}$ with an estimated vertical extent of $20-25 \mathrm{~cm}$. The depression contained at least 35 rocks (2-10-cm size) and a mussel shell valve fragment (Lampsilis teres; see Chapter 37). There is no additional information on the presence/absence of burned sediment, charcoal, or other associated materials.

\section{Feature 29}

Feature Type: burned rock cluster

Provenience: Square E20/S86 (SE quad), Level 17; elevations recorded for 2 rocks are 96.30 and $96.24 \mathrm{~m}$

Stratigraphic Context: the Unit X/II/IIIa transition Archeological Chronology: Early Archaic

Description: Feature 29 was a poorly documented feature and, like Feature 28 (found in the adjacent square at approximately the same depth), there is no field description (only photographs and a plan drawing). These indicate Feature 29 was a cluster of ca. 55 rocks found within a larger, dispersed scatter of rocks. The cluster measured ca. $75-\mathrm{x}-130 \mathrm{~cm}$ with an estimated vertical extent of ca. $5-10 \mathrm{~cm}$. It is not known if any burned sediment or charcoal were observed in the feature area and an Angostura base (10Q-8) is the only artifact provenienced to this feature.

\section{Feature 34}

Feature Type: burned rock cluster

Provenience: Squares E20/S74 (SE and SW quads) and E20/ S76 (NE quad), Level 3; elevations recorded for 7 rocks range from 97.22 to $97.17 \mathrm{~m}$

Stratigraphic Context: Unit IIIC

Archeological Chronology: Late Archaic

Figure: 26-13

Description: Feature 34 was a somewhat crescent-shaped cluster of 38 burned rocks. The cluster, which measured roughly $45-\mathrm{x}-85 \mathrm{~cm}$, was apparently composed of a single

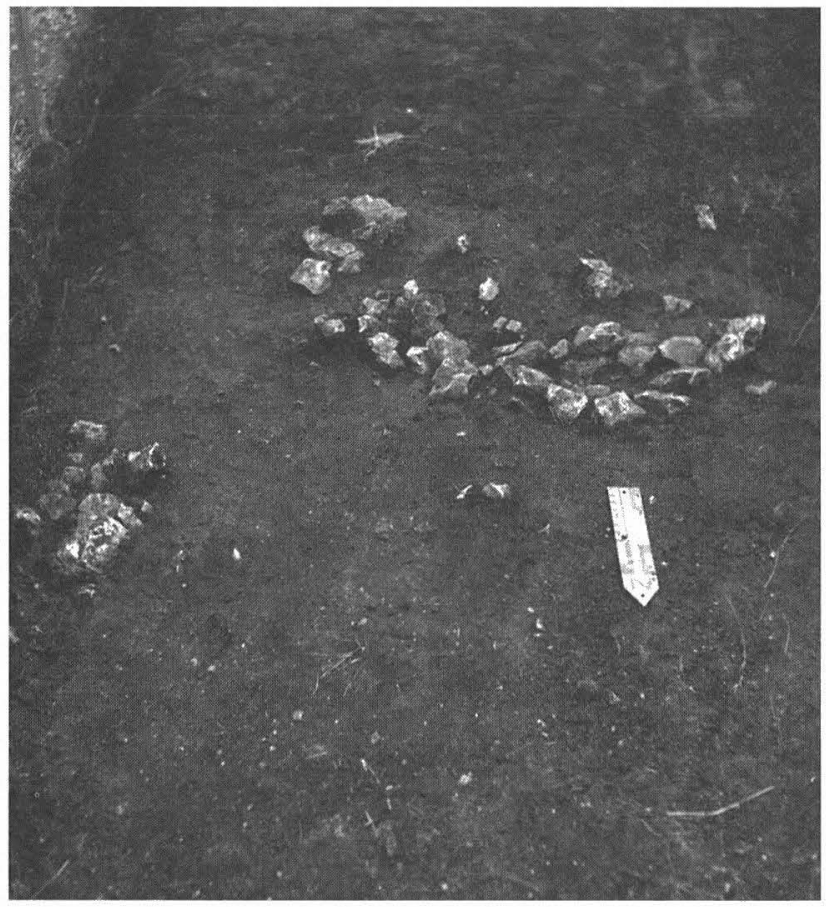

Figure 26-13. Features 34 (right) and 38 (left) in Square E20/S74, Level 3, looking south. 
layer of rocks with a thickness of no more than $5-10 \mathrm{~cm}$. Most of the rocks were quite small $(2-6 \mathrm{~cm}$ size $)$ although a few were slightly larger (up to $12 \mathrm{~cm}$ ). Some of the rocks exhibited heat discoloration and/or thermal fractures, but no burned sediment or charcoal was reported from the feature area. No artifacts or other materials were provenienced to Feature 34.

Comments: Another burned rock cluster (Feature 38) was found about $50 \mathrm{~cm}$ east/northeast of Feature 34 at approximately the same elevation (E20/S74, Levels 3 and 4). Although no artifacts were provenienced to either feature, the general recovery for this level included an Ensor point (16C1) and a tubular stone pipe fragment (16C-2). The latter specimen was submitted for organic residue analysis (see section by Hurst in Chapter 23).

\section{Feature 35}

Feature Type: burned rock ring

Provenience: Square E20/S78 (SE and SW quads), Levels 34; elevations recorded for 5 rocks range from 97.16 to $97.08 \mathrm{~m}$ Stratigraphic Context: Unit IIIc

Archeological Chronology: Late Archaic

Figure: 26-14

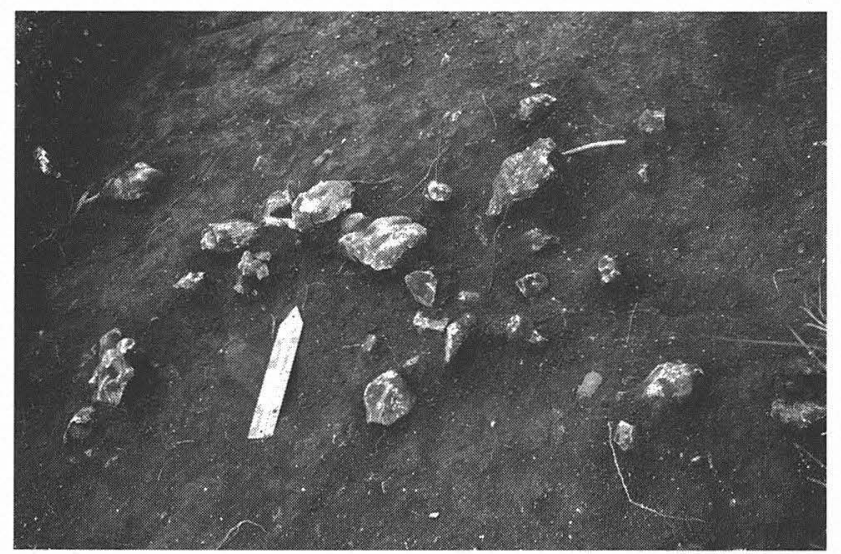

FiguRE 26-14. Feature 35 in Square E20/S78, Level 4, looking north.

Description: Feature 35 consisted of a semicircle of ca. 20 burned rocks arranged in a single layer around a rock-free center. Approximately 8 to 10 additional rocks were loosely scattered around the semicircle, and it looked as if some of the scattered rocks were probably displaced from the more closely spaced arc of rocks. Most of the rocks were angular fragments in the 5-10-cm size range, but the feature included about 7 larger rocks (15-20-cm size). The semicircle measured ca. $50-\mathrm{x}-100 \mathrm{~cm}$, and though the vertical extent was not fully recorded it appears to have been no more than 10 to 15 $\mathrm{cm}$ thick. No charcoal was reported from the feature area, but several of the larger rocks were fractured in situ, and some burned sediment was observed "directly over" Feature 35. No artifacts were provenienced to this feature, but the plan drawing shows a "biface" among the scattered rocks on the east side of the semicircle.

\section{Feature 36}

Feature Type: burned rock cluster

Provenience: Square E20/S72 (SE quad), Level 3; elevations recorded for 4 rocks range from 97.05 to $96.97 \mathrm{~m}$

Stratigraphic Context: Unit IIIC

Archeological Chronology: Late Archaic

Figure: 26-15

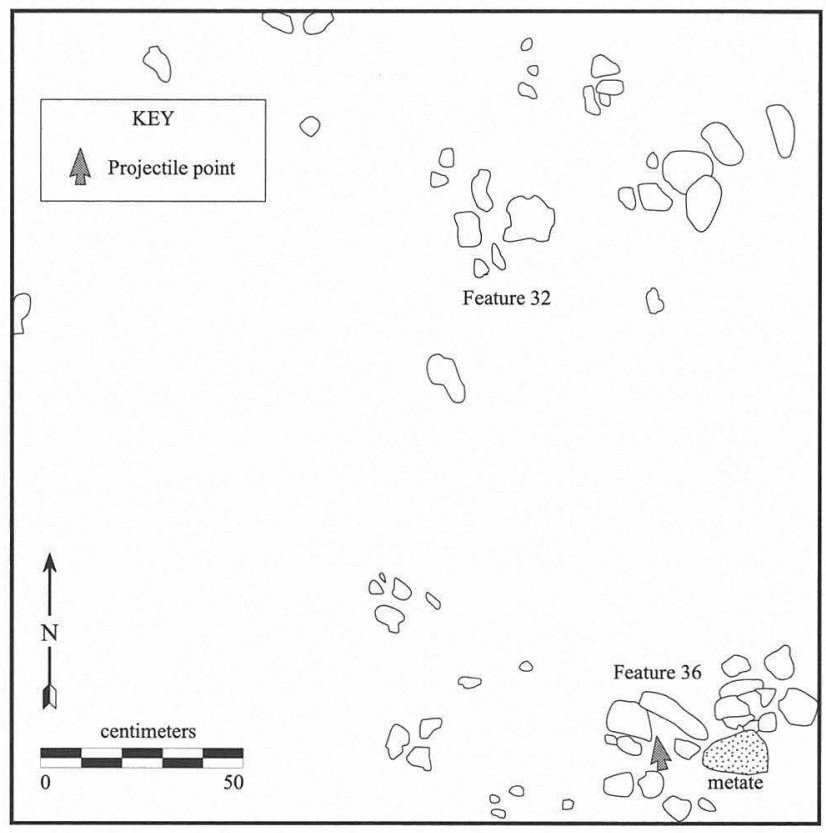

FIGURE 26-15. Features 32 and 36 in Square E20/S72, Level 3.

Description: Feature 36 was a small, roughly oval-shaped cluster of ca. 16 burned rocks. The $40-\mathrm{x}-60$-cm cluster was composed of a single layer of closely spaced rocks with an overall thickness of ca. $10 \mathrm{~cm}$. Most of the rocks were relatively small (2-8 $\mathrm{cm}$ size) though a few were slightly larger $(10-15-\mathrm{cm}$ size). A large fragment of a sandstone metate (17C-5) lay within the cluster along with an Ensor point. Two additional Ensor points were found in general level recovery (the three points from this level are $17 \mathrm{C}-1,17 \mathrm{C}-2$, and $17 \mathrm{C}-3$, but it is unknown which of the three was found in Feature 36). No burned sediment or charcoal was reported, and no additional materials were provenienced to this feature.

Comments: Another small, burned rock cluster, Feature 32, was found about $50 \mathrm{~cm}$ north of Feature 36 in the same level.

\section{Features 37A and 37B}

Feature Type: burned rock clusters

Provenience: Square E20/S78 (37A in NE quad; 37B in SW quad), Level 6; elevations recorded for 6 rocks in 37A range from 97.03 to $96.91 \mathrm{~m}$; elevations for 3 rocks in $37 \mathrm{~B}$ range from 97.09 to $97.04 \mathrm{~m}$ 
Stratigraphic Context: Unit IIIc Archeological Chronology: Middle or Late Archaic Figure: 26-16

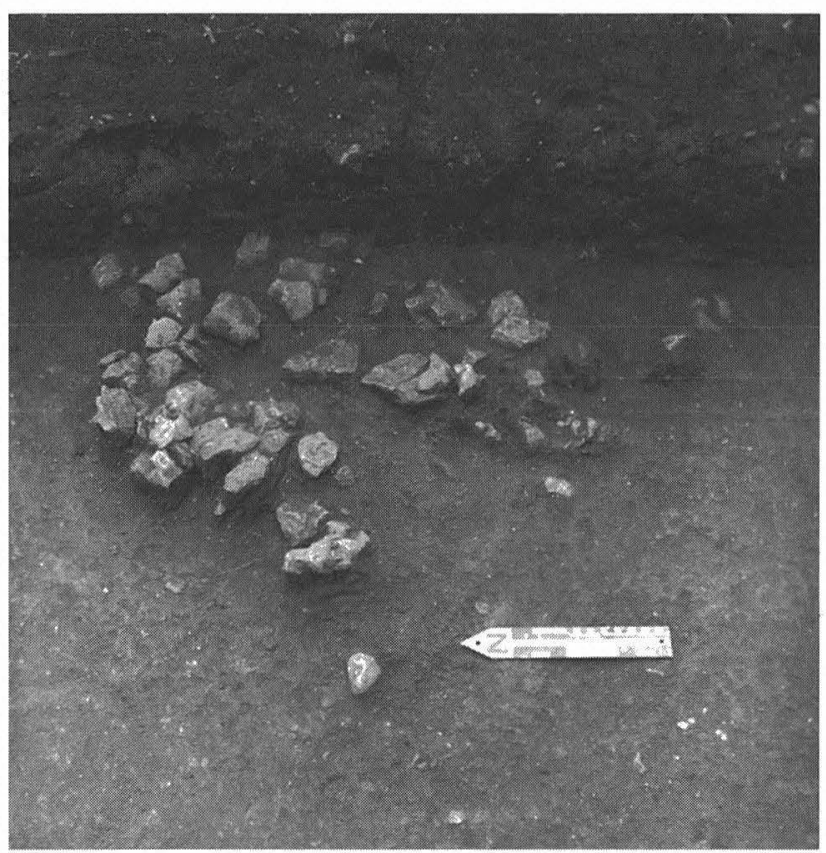

FigURE 26-16. Feature 37A in Square E20/S78, Level 6, looking east.

Description: Feature 37A was a roughly circular, singlelayer cluster of 40 burned rocks (2-15-cm size). Although the eastern edge of the feature extended into the wall, it looked as if most of the cluster was exposed. The exposed portion measured ca. $75-\mathrm{x}-80 \mathrm{~cm}$ with a maximum thickness of ca. $10-15 \mathrm{~cm}$.

Feature 37B was another burned rock cluster that was partially exposed along the west wall in the same level (ca. $120 \mathrm{~cm} \mathrm{SW}$ of 37A). The exposed portion consisted of 11 rocks (2-10-cm size) clustered in a $15-\mathrm{x}-65-\mathrm{cm}$ area with a maximum thickness of ca. $5-10 \mathrm{~cm}$. No burned sediment or charcoal was reported for either cluster, and no artifacts or other cultural material was provenienced to these features. A concentration of bone found at the northern edge of Feature 37B (shown in field sketch) was apparently combined with general level recovery. Most of the bones in this lot (N $=56$ ) were Vertebrata indeterminate fragments, but the sample also included a burned Canis sp. tarsal, four deer elements (unburned), and three large or medium/large mammal elements (unburned).

\section{Feature 38}

Feature Type: burned rock cluster

Provenience: Square E20/S74 (SE quad), Levels 3 and 4; elevations recorded for 2 rocks are 97.19 and $97.17 \mathrm{~m}$

Stratigraphic Context : Unit IIIc

Archeological Chronology: Late Archaic
Figure: see 26-13

Description: Feature 38 was a small cluster of 18 burned rocks exposed along the east wall of Square E20/S74. The eastern edge of the feature appears to have extended into the wall, but the exposed portion measured $30-x-55 \mathrm{~cm}$. The cluster consisted primarily of a single layer of rocks with only a few small rocks found beneath others in the center of the feature. Though the full vertical extent was not recorded, Feature 38 appears to have been no more than $10-15 \mathrm{~cm}$ thick. Most of the rocks were small angular fragments (2-8$\mathrm{cm}$ size) with only one larger slab (ca. 20-cm diameter). No burned sediment or charcoal were reported, and no artifacts were provenienced to this feature.

Comments: Another burned rock cluster was found about $50 \mathrm{~cm}$ west/southwest of Feature 38 in the same level (see Feature 34 description).

\section{Feature 39}

Feature Type: burned rock cluster (small burned rock basin?) Provenience: Square E20/S74 (NW quad), Level 6; elevations recorded for 6 rocks range from $96.92-96.85 \mathrm{~m}$

Stratigraphic Context: Unit IIIc

Archeological Chronology: Middle or Late Archaic Figure: 26-17

Description: Feature 39 was a single-layer, circular cluster

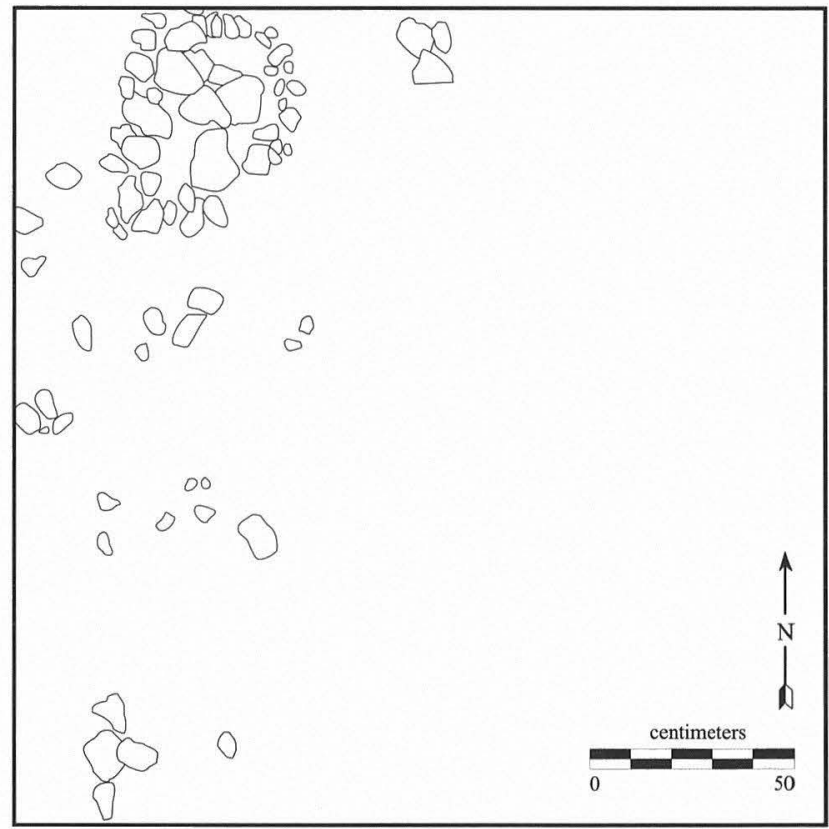

FIGURE 26-17. Feature 39 in Square E20/S74, Level 6.

of approximately 45 burned rocks (2-15-cm size). The cluster measured about $60 \mathrm{~cm}$ in diameter with a maximum vertical extent of no more than $10 \mathrm{~cm}$. The rocks were very closely spaced, and in photographs some appear to be sloping as if they rested in a shallow basin. Unfortunately, this was not described in the field notes, and it is difficult to assess on 
the basis of the photographs alone. No burned sediment or charcoal were reported, and no artifacts or other materials were provenienced to this feature.

\section{Features 40, 41, and 42}

Feature Type: burned rock clusters

Provenience: Squares E20/S74, E20/S76, E20/S78, Level 8; elevations were recorded for 2 rocks in Feature 40, 3 in Feature 41, and 3 in Feature 42, and these range from 96.81 to $96.75 \mathrm{~m}$ (see Table 26-1 for additional provenience data)

Stratigraphic Context: the Unit IIIb/IIIc transition

Archeological Chronology: Middle Archaic?

Figure: $26-18$

Description: These three, similar features were found at approximately the same depth in the southern half of Block 4 , and the available data suggest they were probably constructed on the same occupational surface. Features 41 and 42 were spaced about $50 \mathrm{~cm}$ apart and Feature 40 was located about $150 \mathrm{~cm}$ north of this pair (see Figure 26-18). Vertical extents were not fully documented for any of the three, but elevations recorded for several rocks in each feature are within a few centimeters of one another. All three features were roughly circular, single-layer clusters of ca. $15-25$ burned rocks (2-15-cm size). The cluster ranged from ca. $40-70 \mathrm{~cm}$ in diameter, and all are estimated to have been no more than $5-10 \mathrm{~cm}$ thick. Rocks were closely spaced in all three clusters, and some of the larger rocks were fractured in place.

There was very little description of these features in the field notes (they were documented primarily with plan drawings and photographs), so it is not known if burned sediment or charcoal were found in any of the clusters. No artifacts or other materials were provenienced to any of the three, and no associations are mentioned in the notes.

Comments: The stratigraphic position of Features 40-42 (in the upper portion of the Unit IIIb/IIIc transition) indicates they date to either the Middle or Late Archaic periods. They have been tentatively assigned a Middle Archaic age primarily on the basis of diagnostic artifacts found in the levels encompassing them (i.e., Nolan, Travis, Early Triangular, and Bell-Andice points found in Level 8 of Squares E20/S78-74). The estimate is also based on a radiocarbon date of $5520 \pm$ 80 в.P. (Beta-79700) obtained on a burned tree found about $30 \mathrm{~cm}$ below Features 41 and 42 in the same square (see Feature 50 description).

\section{Feature 43}

Feature Type: burned rock cluster

Provenience: Square E20/S72 (NW quad), Level 9A; detection elevation was not recorded but base elevations were recorded for 7 rocks and they range from 96.63 to $96.57 \mathrm{~m}$ Stratigraphic Context: the Unit IIIb/IIIc transition

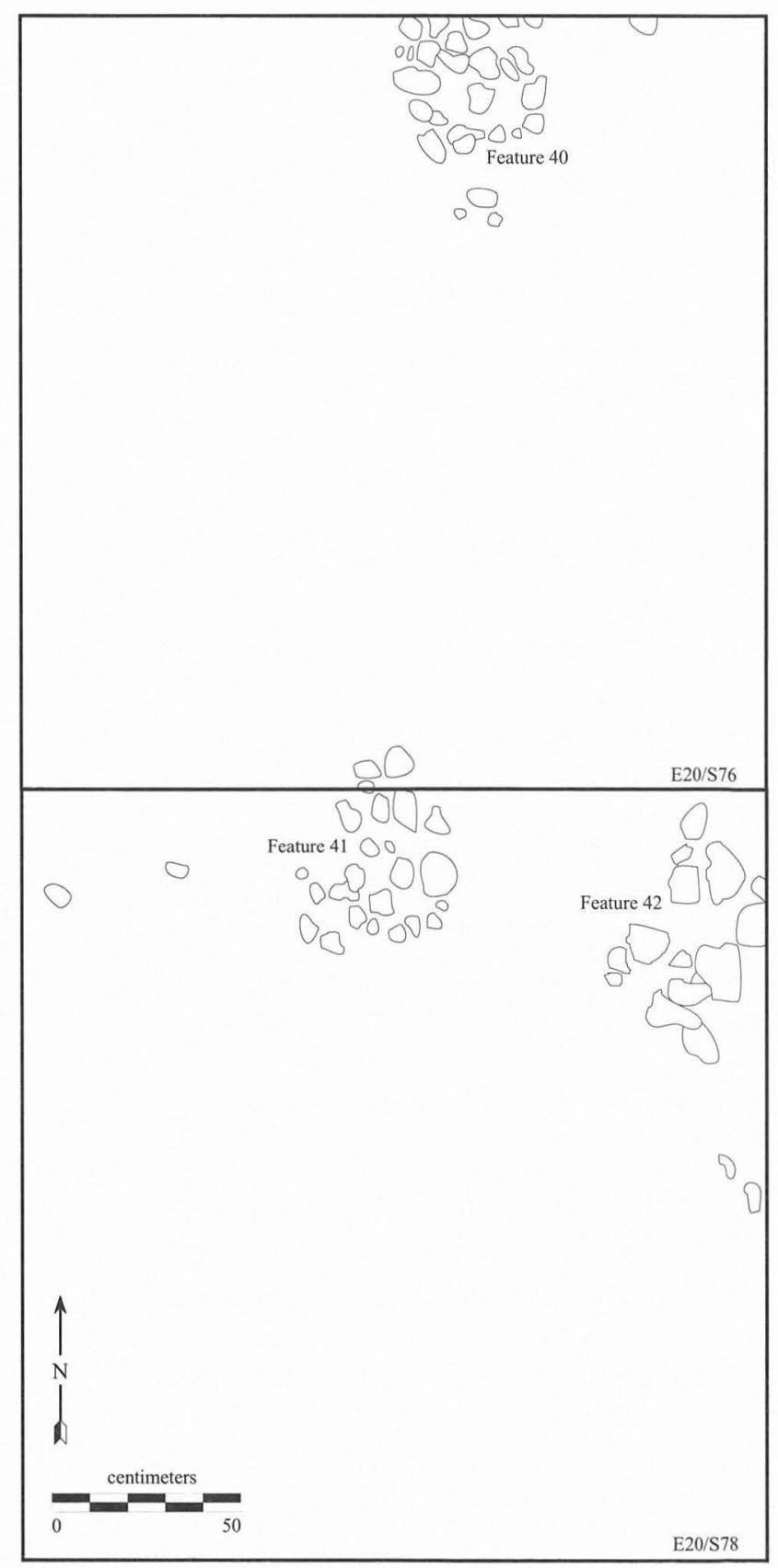

FIGURE 26-18. Features 40-42 in Level 8 of Squares E20/S78 and E20/S76 (though not depicted here, northern edge of Feature 40 extends into Square E20/S76).

Archeological Chronology: Middle Archaic?

Figure: 26-19

Description: Feature 43 was a compact, circular, ca. $75-\mathrm{cm}-$ diameter cluster of ca. 60 burned rocks. It was composed of a single layer of closely spaced stones $(2-15-\mathrm{cm}$ size $)$ with an estimated vertical extent of ca. $5-10 \mathrm{~cm}$. There was no evidence of a basin shape, and the rocks apparently rested on a relatively flat surface. Some of the rocks were fractured in place, but no evidence of burned sediment or charcoal was reported. There were a few voids in the interior of the feature, and it looked like some of the stray rocks scattered 


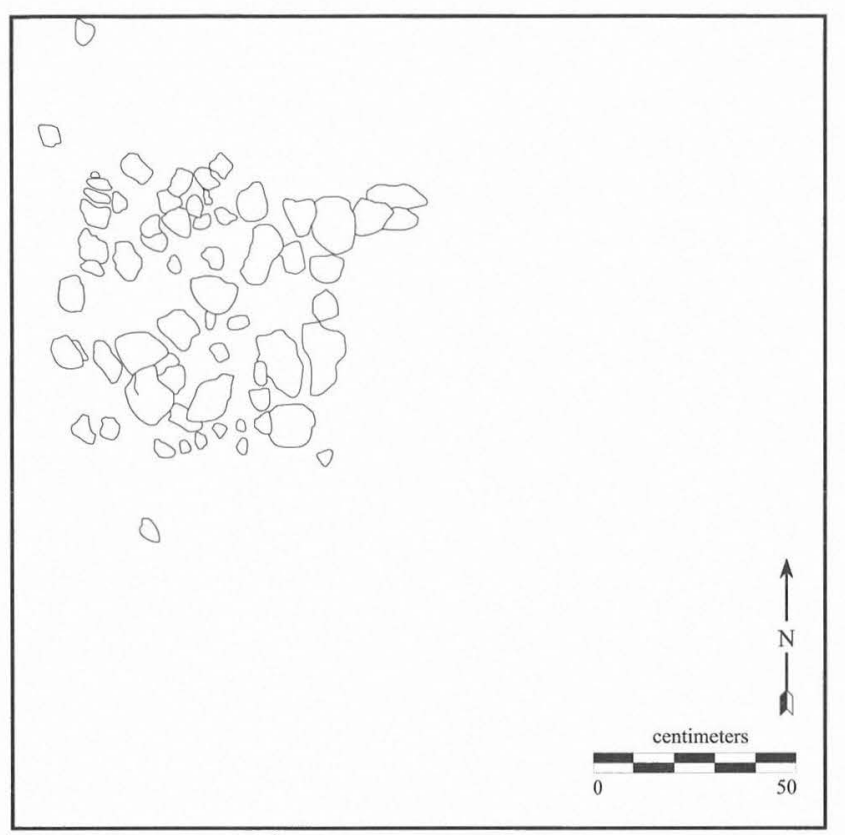

Figure 26-19. Feature 43 in Square E20/S72, Level 9A.

around the margins of the cluster may have been displaced from these voids. No artifacts or other materials were provenienced to Feature 43.

Comments: Like Features 40 through 42 (discussed above), Feature 43 has been assigned a tentative Middle Archaic age estimate. It was located about $2.5 \mathrm{~m}$ north of Feature 40 (and slightly below it) in the upper portion of the Unit IIIb/ IIIc transition zone. No diagnostic artifacts were found in the same level as Feature 43, but a Nolan point was found in the level above it (Level 8 in Square E20/S72). The age estimate is also based on a radiocarbon date of $5560 \pm 60$ в.P. (Beta-79699) obtained on a burned tree found about $2 \mathrm{~m}$ south of and 15-20 cm below Feature 43 (see Feature 199 description).

\section{Feature 50}

Feature Type: burned tree

Provenience: Square E20/S78 (NE quad), Levels 12A-16A; detection elevation ca. $96.44 \mathrm{~m}$; base elevation ca. $96.04 \mathrm{~m}$ Stratigraphic Context: Feature 50 probably originated from surface in Unit IIIb but the roots intrude Unit IIIa

Archeological Chronology: Middle Archaic

\section{Special Studies:}

Radiocarbon: 1 wood charcoal sample was conventionally dated to $5520 \pm 80$ B.P. (Beta-79700; see Chapter 25)

Macrobotanical: 4 macroplant samples analyzed (see Chapter 40)

Figure: 26-20

Description: Feature 50 consisted of irregular-shaped patches of heavily burned sediment and charcoal found within an area measuring roughly $70-90 \mathrm{~cm}$ in diameter. The feature had a vertical extent of at least $40 \mathrm{~cm}$, but its full

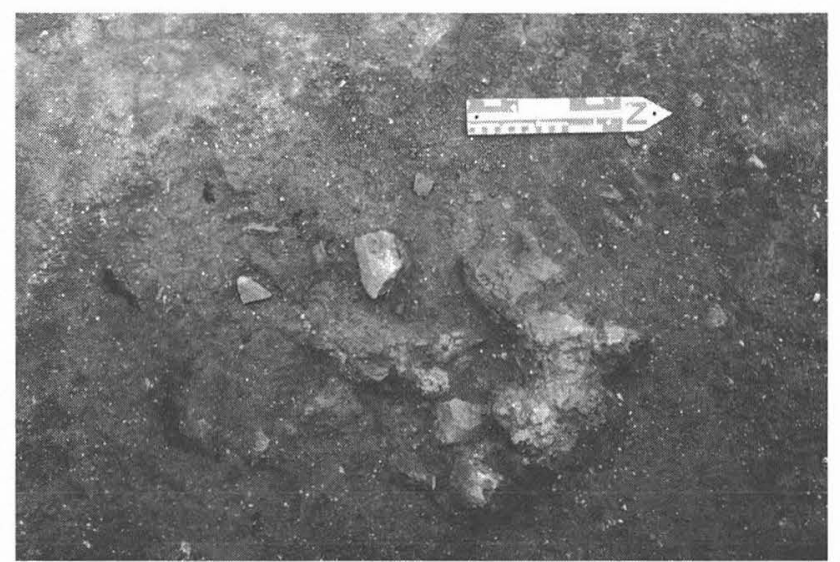

Figure 26-20. Feature 50 in Square E20/S78, Level 12A, looking west. Raised areas of lighter-colored sediment (right of center) are burned/oxidized.

extent may not have been completely documented. Although Feature 50 was initially interpreted as a hearth, the configuration of the burned material suggests it probably represents burned tree roots. Of the four charcoal samples collected, two were identified as live oak wood (CH-1053 and $\mathrm{CH}-1054)$ and two as indeterminate wood (CH-1055 and $\mathrm{CH}-1056)$. A conventional radiocarbon date was obtained on sample $\mathrm{CH}-1054$ (see date above). In addition to the charcoal samples, 88 pieces of debitage, 7 bone fragments, and a mussel shell fragment were provenienced to Feature 50.

Comments: Feature 50 probably represents a burned live oak tree that originated from a surface in mid to upper Unit IIIb. It may have grown on roughly the same surface as Feature 199, a burned red mulberry tree recorded about $4 \mathrm{~m}$ north of Feature 50 in the west wall of Squares E20/S72 and E20/S74. Feature 199 yielded a radiocarbon date of $5560 \pm$ 60 в.P. (see Feature 199 description).

\section{Feature 71}

Feature Type: burned rock ring?

Provenience: Square E20/S78 (NW and SW quads), Level 27A; elevations recorded for 4 rocks range from 94.80 to $94.75 \mathrm{~m}$

Stratigraphic Context: Unit Isi-c

Archeological Chronology: Late Paleoindian

Figure: 26-21

Description: Feature 71 consisted of a somewhat semicircular grouping of six burned rocks encircling a rock-free area. The feature measured ca. $35-\mathrm{x}-70 \mathrm{~cm}$ with an estimated thickness of no more than $5-10 \mathrm{~cm}$. The rocks were angular limestone fragments ranging from $5-15 \mathrm{~cm}$ in length, and they exhibited no obvious discoloration from burning. Small flecks of charcoal were scattered throughout the feature, but no burned sediment was observed. The excavator noted that two additional rocks found in this level were probably 


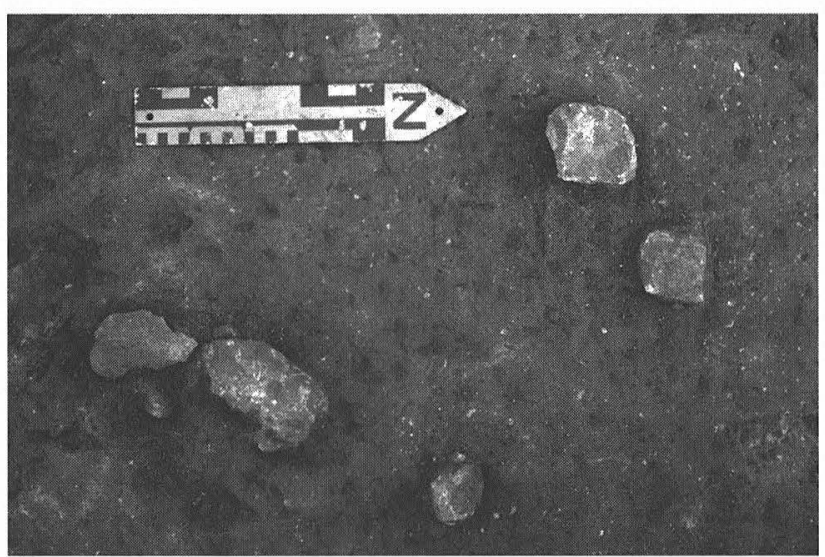

FIGURE 26-21. Feature 71 in Square E20/S78, Level 27A.

displaced from the feature area. No artifacts or other cultural materials were provenienced to Feature 71.

\section{Features 72 and 73}

Feature Type: burned tree roots (associated with the same tree)

Provenience: Square E20/S74 (all quads); Feature 72 was in Levels 27A-27B; Feature 73 was in Levels 28B-30A; detection elevation was $94.73 \mathrm{~m}$ (Feature 72); base elevation was not recorded but the burning extended to at least $94.57 \mathrm{~m}$ (Feature 73)

Stratigraphic Context: Features 72 and 73 were probably associated with a burned tree (Feature 167) that grew from a surface in Unit Isi-c. The extensive root system of this tree intruded both Units Isi and Icl. Feature 72 was recorded in Unit Isi-c, and Feature 73 was recorded in levels provenienced to the Unit Isi/Icl/Isi-c transition.

Archeological Chronology: Late Paleoindian

Special Studies:

Radiocarbon: 1 wood charcoal sample from Feature 72 was AMS-dated to $9430 \pm 60$ в.P. (CAMS-14807; see Chapter 25) Macrobotanical: 3 macroplant samples analyzed (see Chapter 40)

Description: Features 72 and 73 were burned tree roots believed to be part of the same burned tree as Feature 167, a large burned root mass recorded in the western half of Block 6 (see Feature 167 description). Portions of this large feature were found in six squares at approximately the same stratigraphic position as Features 72 and 73 . The radiocarbon date for Feature 167 (9410 \pm 60 B.P.; CAMS-14805) is very close to the Feature 72 date cited above. Feature 72 consisted of irregular-shaped patches of burned (oxidized) sediment and charcoal found within a ca. 110-cm diameter area. The burned sediment and carbonized wood extended downward into Levels 28B-30A in the same square where it was recorded as Feature 73 (initially misinterpreted as a hearth feature).

Two charcoal samples were collected from Feature 72 (CH-1071 and CH-1072) and two from Feature 73 (CH-1073 and $\mathrm{CH}-1076$ ). Sample CH-1071 was dated (see above), and the others were analyzed as macroplant samples. All three were classified as indeterminate wood charcoal. In addition to the charcoal samples, some burned sediment was collected from Feature 73 as a thermoluminescence sample (unanalyzed).

Comments: Feature 72 was first detected in Level 27A, and there is no evidence that a higher portion of this burned area was excavated before it was recognized. There is no mention of burned sediment in the levels above 27A, and no charcoal was collected from Levels 20B through 26B. This suggests that Features 72 and 73 probably relate to a tree that grew from a surface in the upper portion of the Leanne soil (Unit Isi-c).

\section{Feature 74}

Feature Type: gravel pocket

Provenience: Square E20/S76 (NE quad), Levels 29A-29B; no elevations were recorded for this feature but level elevations bracket the feature between ca. 94.53 and $94.44 \mathrm{~m}$ Stratigraphic Context: Unit Isi/Ic1/Isi-c transition zone Archeological Chronology: Early or Late Paleoindian? Description: Feature 74 consisted of an irregular-shaped pocket of gravel measuring roughly $35-\mathrm{x}-40 \mathrm{~cm}$ (and no more than $10 \mathrm{~cm}$ thick?). The gravels were very poorly sorted and included rounded and angular clasts ranging from less than $1 \mathrm{~cm}$ up to ca. $8 \mathrm{~cm}$ in diameter. No evidence of burning was observed, and no artifacts were found in the pocket.

Comments: The TxDOT field and lab notes indicate Feature 74 was initially recorded as a cultural feature, because at that time they did not realize how many natural gravel pockets were present in the site deposits (especially common in Units Isi and II; see Chapter 6). The irregular shape of Feature 74 suggests it most likely represents a natural feature, probably a burrow or other natural depression that filled with gravel during a flood. On the other hand, the relatively large size of some of the clasts (up to $8 \mathrm{~cm}$ ) is a little unusual for a natural gravel pocket in this stratigraphic position.

\section{Features 75 and 76}

Feature Type: small burned rock basin; burned rock cluster Provenience: Square E22/S82 (Feature 75 in SW quad, Feature 76 in SE quad), Level 6; elevations recorded for 3 rocks in Feature 75 range from 97.20 to 97.19 m; elevations for 4 rocks in Feature 76 range from 97.18 to $97.14 \mathrm{~m}$

Stratigraphic Context: Unit IIIb/IIIc transition Archeological Chronology: Late Archaic?

Figure: 26-22

Description: These small burned rock features were 1ocated about $40 \mathrm{~cm}$ apart at approximately the same elevation, and the available data suggest they were probably constructed on the same occupational surface. Feature 75 was a shallow, basin-shaped depression containing three 


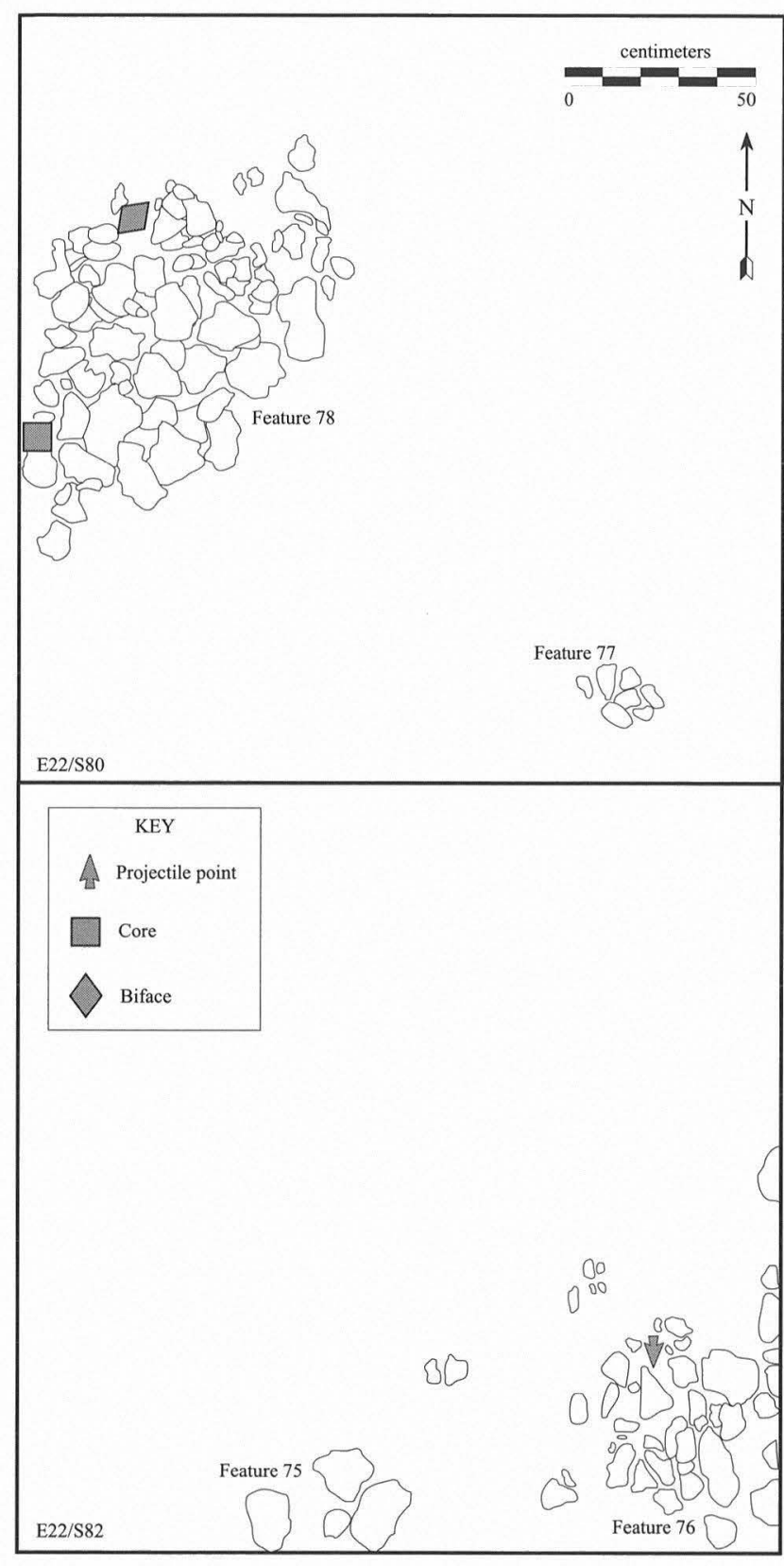

FIGURE 26-22. Features 75-78 in Squares E22/S82 and E22/S80, Level 6.

large limestone slabs (ca. 15-20-cm size) and a smaller (5$\mathrm{cm}$ size) rock. It measured about $40 \mathrm{~cm}$ in diameter with an estimated vertical extent of ca. $5-10 \mathrm{~cm}$. The slabs inclined downward toward the center of the feature, and all were fractured in situ. No burned sediment or charcoal was reported, and no cultural materials were provenienced to this feature.

Feature 76 was a roughly circular cluster of ca. 40 closely spaced rocks. The cluster measured about $60 \mathrm{~cm}$ in diameter with an estimated vertical extent of ca. $5-10 \mathrm{~cm}$. Most of the rocks were small, angular fragments in the $5-10-\mathrm{cm}$ size range, but the cluster included a few larger slabs (15$20-\mathrm{cm}$ size) as well. Some of the rocks were reddened from burning, but no burned sediment or charcoal was reported. A Montell point (22F-2) and a possibly modified flake were point plotted within the cluster, but feature provenience was not maintained for the flake. No other materials were provenienced to Feature 76.

Comments: These features were located about a meter north of the northern edge of Burned Rock Midden 1, and they may be contemporaneous with a portion of this larger feature's use. They most likely date to the Late Archaic period, but they were located in a transitional stratigraphic context where a mixture of Middle and Late Archaic diagnostics were recovered. In addition to the Montell point found in Feature 76, the recovery for this level included two Montell points and a Bell-Andice point.

\section{Features 77 and 78}

Feature Type: burned rock clusters (Feature 78 may have been a small burned rock basin)

Provenience: Square E22/S80 (Feature 77 in SE quad; Feature 78 in NW and SW quads), Level 6; elevations recorded for 3 rocks in Feature 77 range from 97.12 to 97.08 ; elevations for 15 rocks in Feature 78 range from 97.07 to $97.00 \mathrm{~m}$

Stratigraphic Context: Unit IIIc

Archeological Chronology: Late Archaic?

Figure: see 26-22

Description: Features 77 and 78 were found in the same level (ca. $1 \mathrm{~m}$ apart), and they may relate to the same occupational surface as Features 75 and 76 (found a few meters to the south at approximately the same depth). Feature 77 was a very small, circular cluster of 7 angular limestone fragments (5-10-cm size). It measured about $20-25 \mathrm{~cm}$ in diameter with an estimated vertical extent of no more than $5-10 \mathrm{~cm}$. No burned sediment or charcoal was reported, and no materials were provenienced to this feature. Feature 78 was a much larger, circular cluster of ca. 60 rocks. It measured about $80-90 \mathrm{~cm}$ in diameter with an estimated vertical extent of ca. $10-15 \mathrm{~cm}$. The cluster included two layers of closely spaced rocks (5-20-cm size range), and, though no basin shape was documented in the field notes, in the photographs the Feature 78 rocks look like they may have rested in a shallow basin. Many of the rocks were fractured in place, but no burned sediment or charcoal was found. A Stage 3 biface (23F-3) and a "core" were point plotted within Feature 78, but feature provenience was not maintained for the latter artifact (and no "core" was identified in the level recovery). The biface may have been a preform for a stemmed projectile point.

Comments: These features were located a few meters north of Burned Rock Midden 1, and they may be contemporaneous with a portion of the midden's use. Although the stratigraphic positions of Features 77 and 78 (in lower Unit IIIc) suggest they probably date to the Late Archaic period, they were located in an area where there was considerable mixing of Middle and Late Archaic-age artifacts. 


\section{Feature 79}

Feature Type: depression filled with ash and charcoal-stained sediment

Provenience: Square E22/S88 (SW quad) and E22/S90 (NW and NE quads), Level 9; no elevations were recorded for Feature 79, but level elevations bracket it somewhere between ca. 97.34 and $97.18 \mathrm{~m}$

Stratigraphic Context: Unit Y/IIIc transition Archeological Chronology: Early or Middle Archaic?

Figure: 26-23

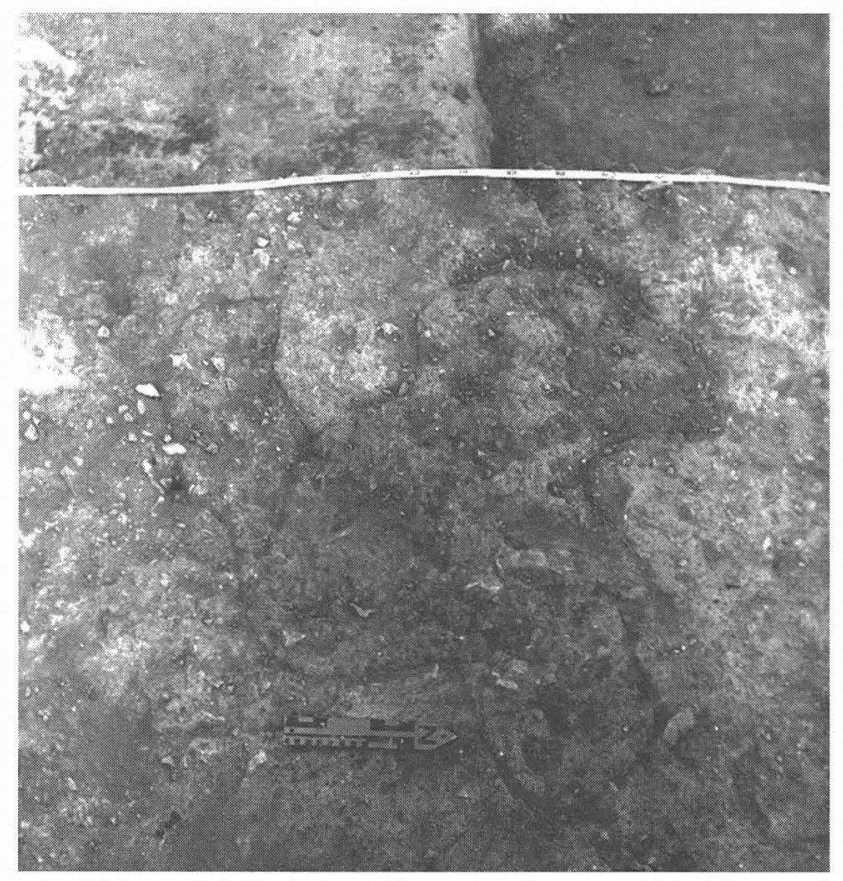

FiguRE 26-23. Feature 79 in Squares E22/S90 and E22/S88, Level 9 , looking west.

Description: Feature 79 was a large, irregular-shaped area of charcoal-stained sediment and ash found beneath the lowest layers of Burned Rock Midden 1. The area measured about $105-\mathrm{x}-130 \mathrm{~cm}$, and though the vertical extent was not documented it was probably no more than 10-20 $\mathrm{cm}$ thick. No burned sediment was found in this area, and no artifacts or other materials were provenienced to Feature 79. The excavators initially thought Feature 79 might represent a cultural pit, but after carefully tracing the outline they concluded that it probably represented a natural topographic depression that was filled with ash and charcoal from the overlying midden deposits.

Comments: Feature 79 was found in a transitional stratigraphic context that contained a mixture of Early and Middle Archaic diagnostics. The charcoal and ash found in this feature may relate to Early Archaic use of this surface, or it may relate to the younger midden deposits that accumulated on top of it.

\section{Feature 90}

Feature Type: isolated human skull (from a disturbed burial?) Provenience: Square E22/S90 (SW quad), Level 12; detection elevation $97.15 \mathrm{~m}$; base elevation $97.07 \mathrm{~m}$

Stratigraphic Context: Feature 90 was found in a level provenienced to the Unit $\mathrm{X} / \mathrm{Y}$ transition but it may have been displaced downward from younger deposits (possibly from Unit IIIc?)

Archeological Chronology: Archaic?

Figure: 26-24

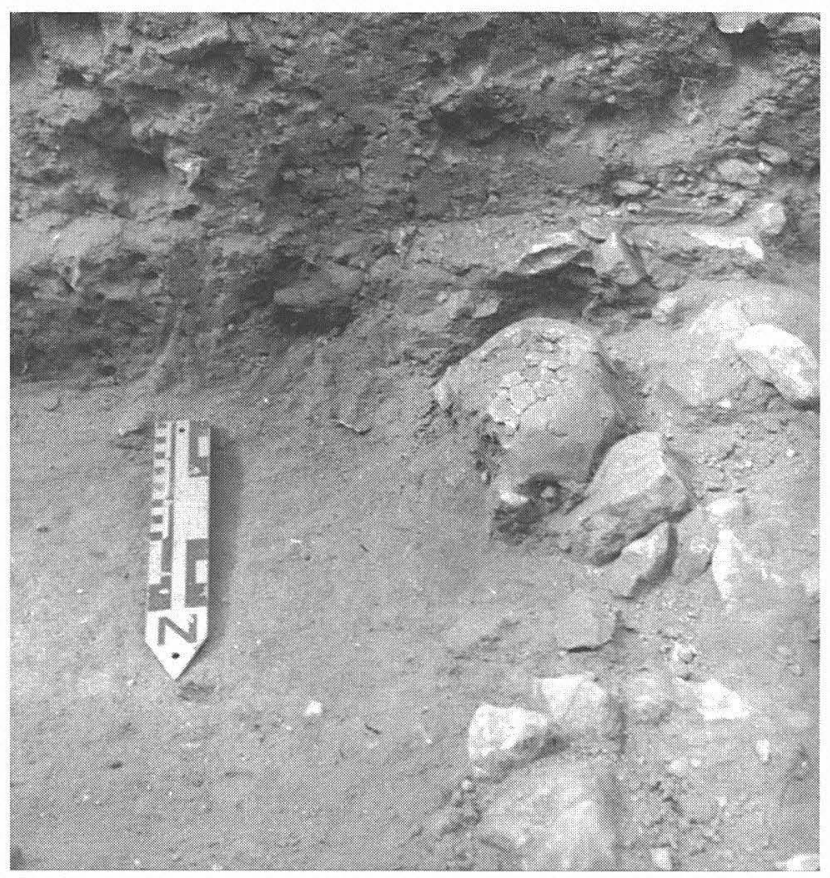

Figure 26-24. Feature 90 in Square E22/S90, Level 12, looking south.

Description: Feature 90 was an isolated, fragmentary skull (cranial vault) found about $20-30 \mathrm{~cm}$ below the base of Burned Rock Midden 1, in what the field notes describe as a small, stone-lined depression or pit (dimensions were not recorded). The excavators believed this skull was probably displaced from nearby Burial 1, which was missing the skull and upper body (see Burial 1 description). The skull was found about 1 $m$ northeast of Burial 1 (which was found in Square E20/S92, Level 6) and ca. $60 \mathrm{~cm}$ below it. The excavators thought the upper portion of Burial 1 was probably disturbed by a pit dug into Burned Rock Midden 1 by prehistoric inhabitants who subsequently reburied the skull in a "stone-lined pit."

Feature 90 was poorly documented, and a stone-lined depression or pit is not clearly visible in either the plan drawing or the photographs (see Figure 26-24). The photographs suggest the skull may have been randomly displaced into a rocky deposit rather than intentionally placed in a stonelined pit. Given the amount of disturbance to Burned Rock 
Midden 1 from prehistoric inhabitants, modern relic collectors, and burrowing animals, the skull could have been displaced by any of these agents.

Steele performed an analysis of both the Feature 90 skull and the Burial 1 postcranial remains and explored their possible association (see Chapter 31). He determined that the skull probably represents an adolescent or young adult female, but the Burial 1 remains are too incomplete and poorly preserved for an accurate gender or age identification (although he tentatively identified the individual as either an adolescent or adult). There was insufficient evidence to determine if these remains represented one or two individuals. Steele also analyzed six isolated human bones and a human molar found in various contexts in Unit III. These specimens were too fragmentary and isolated to be very informative, but several were found near Burial 1 and Feature 90 and were potentially associated with the same individual(s).

Comments: The Feature 90 skull was found in Early to Middle Archaic-age deposits, but it was clearly not in situ and may have been displaced downward from younger deposits. The skull cannot be attributed to Burial 1 with any confidence, and it is difficult to accept the field interpretation of intentional reburial in a stone-lined pit (given the available data). It seems far more likely that the Feature 90 skull was randomly displaced through either human activity or burrowing animals.

\section{Feature 107}

Feature Type: burned rock cluster

Provenience: Square E20/S82 (NE and SE quads), Level 17 and Square E22/S82 (NW and SW quads), Level 16; elevations recorded for 13 rocks range from 96.13 to $95.96 \mathrm{~m}$

Stratigraphic Context: Unit IIIa

Archeological Chronology: Early Archaic

Figure: 26-25

Description: Feature 107 was a large, roughly circular burned rock cluster measuring ca. $130-160 \mathrm{~cm}$ in diameter and ca. 10$20 \mathrm{~cm}$ thick (estimated extent). The single-layer cluster included at least 45 rocks (5-20-cm size), and many were fractured in place. The interior of the feature included a number of rock-free spaces between clumps of closely spaced rocks, and it appeared as though some rocks might have been removed/displaced from the interior. There is very little description of this feature in the field notes, so it is not known if there was any indication that the rocks rested in a basinshaped pit (as the size and circular configuration might suggest) or if any burned sediment or charcoal was found in the feature area. A complete limestone pestle (Specimen 22P-5) was point plotted within the cluster, but no other cultural materials were provenienced to Feature 107.

\section{Feature 109}

Feature Type: burned rock cluster

Provenience: Square E22/S82 (NE quad), Level 17; eleva-

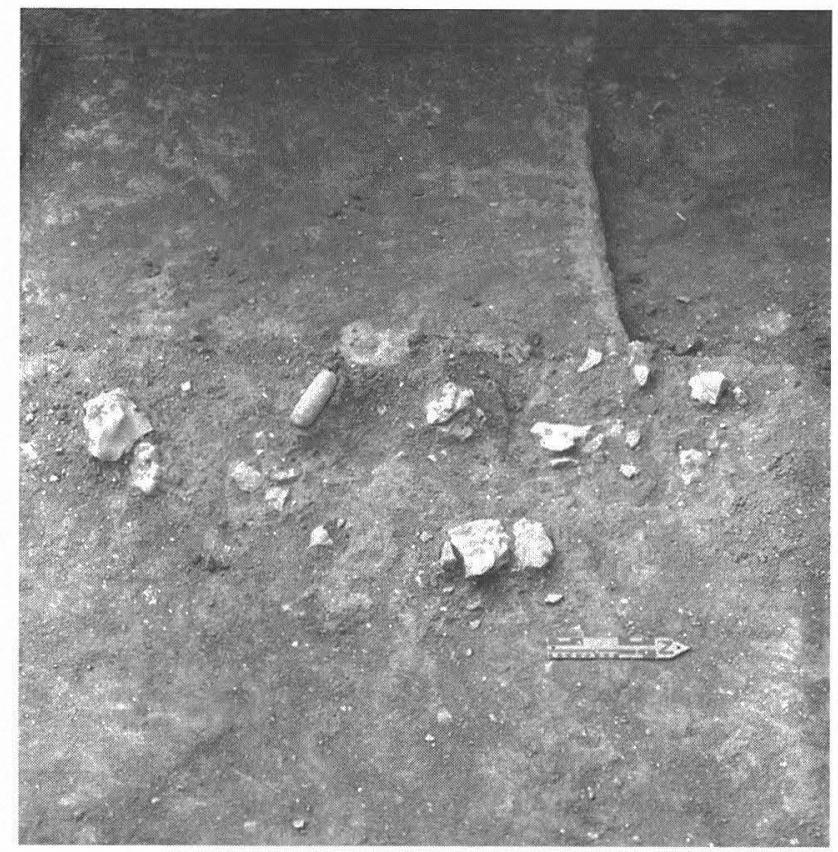

Figure 26-25. Eastern half of Feature 107 in Square E22/S82 (western half removed in earlier excavation in Square E20/S82), looking west. Note limestone pestle (Specimen 22P-5) found within the cluster.

tions recorded for 5 rocks range from 96.00 to $95.96 \mathrm{~m}$

Stratigraphic Context: Unit II

Archeological Chronology: Late Paleoindian

Figure: 26-26

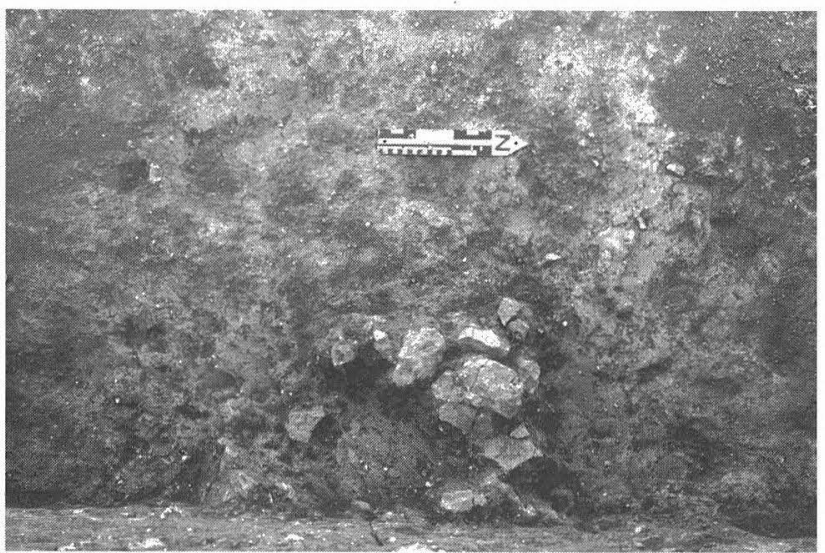

Figure 26-26. Feature 109 in Square E22/S82, Level 17, looking west.

Description: Feature 109 consisted of a relatively small, tight cluster of at least 15 burned limestone fragments (ca. 5$15-\mathrm{cm}$ size). This single-layer cluster was exposed along the east wall of the square, and part of the feature extended into the wall. The exposed portion measured ca. $40-\mathrm{x}-50 \mathrm{~cm}$ with an estimated thickness of ca. $5-10 \mathrm{~cm}$. No burned sediment or charcoal was reported, and no artifacts were provenienced to this feature. 
Comments: Although no artifacts were provenienced to Feature 109, the general recovery for this level included an unusual concentration of stone tools and a relatively high debitage count. The tools included 2 Waco Sinkers, 2 Clear Fork Tools, a Hoxie point, 2 projectile point fragments, and 8 miscellaneous bifacial tools and fragments.

\section{Feature 111}

Feature Type: burned rock cluster

Provenience: Square E22/S82 (SW quad), Level 18; elevations recorded for 5 rocks range from 95.90 to $95.87 \mathrm{~m}$

Stratigraphic Context: Unit II

Archeological Chronology: Late Paleoindian

Figure: 26-27

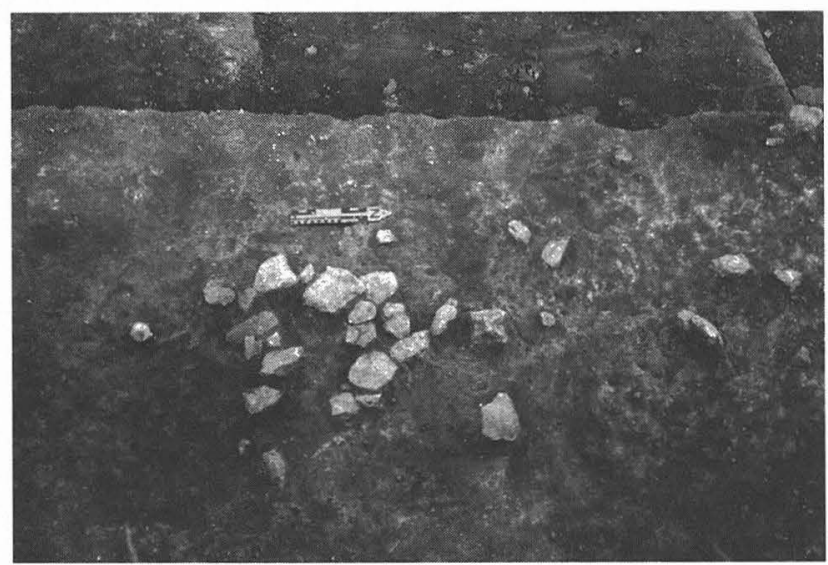

FIGURE 26-27. Feature 111 in Square E22/S82, Level 18, looking west.

Description: Feature 111 was a relatively tight, single-layer cluster of 26 burned rocks ( $4-15 \mathrm{~cm}$ size). It measured ca. 65 $\mathrm{x}-90 \mathrm{~cm}$ with an estimated thickness of about $5-10 \mathrm{~cm}$. The most tightly clustered rocks encircled a small rock-free area (ca. 10-x-20 cm) in the central portion of the feature. No burned sediment or charcoal was reported, and no artifacts or other materials were provenienced to this feature.

\section{Feature 112}

Feature Type: burned rock cluster

Provenience: Square E22/S88 (NE quad), Level 20; elevations recorded for 4 rocks range from 96.13 to $96.01 \mathrm{~m}$

Stratigraphic Context: Unit X

Archeological Chronology: Late Paleoindian

Description: Feature 112 was a burned rock cluster that was partially exposed along the east wall of Square E22/S88. The exposed portion consisted of six small rocks (3-9-cm size) within a $10-\mathrm{x}-45 \mathrm{~cm}$ area. Vertical extent is estimated to have been about $10-15 \mathrm{~cm}$. No burned sediment or charcoal was reported, and no artifacts or other materials were provenienced to this feature.

\section{Feature 113}

Feature Type: burned rock cluster

Provenience: Square E22/S84 (SE quad), Level 20; elevations recorded for 2 rocks are 95.90 and $95.84 \mathrm{~m}$

Stratigraphic Context: Unit X/II transition Archeological Chronology: Late Paleoindian Figure: 26-28

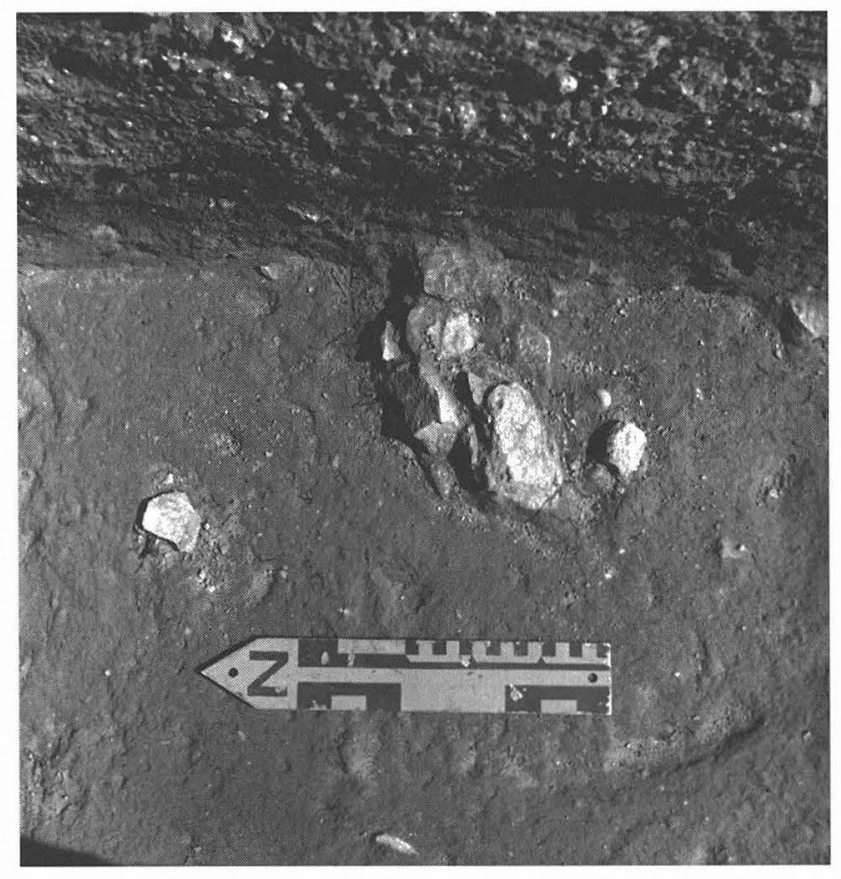

FIGURE 26-28. Feature 113 in Square E22/S84, Level 20, looking east.

Description: Feature 113 consisted of a small, tight cluster of three burned limestone cobbles (5-8-cm size) and at least five smaller burned limestone fragments (2-4-cm size). This single-layer cluster was exposed along the east wall of E22/ S84 and may have extended into the east wall. The exposed portion measured approximately $15-\mathrm{x}-18 \mathrm{~cm}$. The stones exhibited a reddish discoloration from burning; however, no burned sediment or charcoal was observed. No artifacts were provenienced to this feature, but a core (21T-3) was point plotted about $45 \mathrm{~cm}$ west of the cluster (between Features 113 and 114 , another burned rock feature found in this level).

\section{Feature 114}

Feature Type: burned rock cluster

Provenience: Square E22/S84 (all quads ), Level 20; elevations recorded for 2 rocks are 95.79 and $95.76 \mathrm{~m}$

Stratigraphic Context: Unit X/II transition

Archeological Chronology: Late Paleoindian

Figure: 26-29

Description: Feature 114 consisted of somewhat loose cluster of six limestone cobbles. It was surrounded by a scatter 


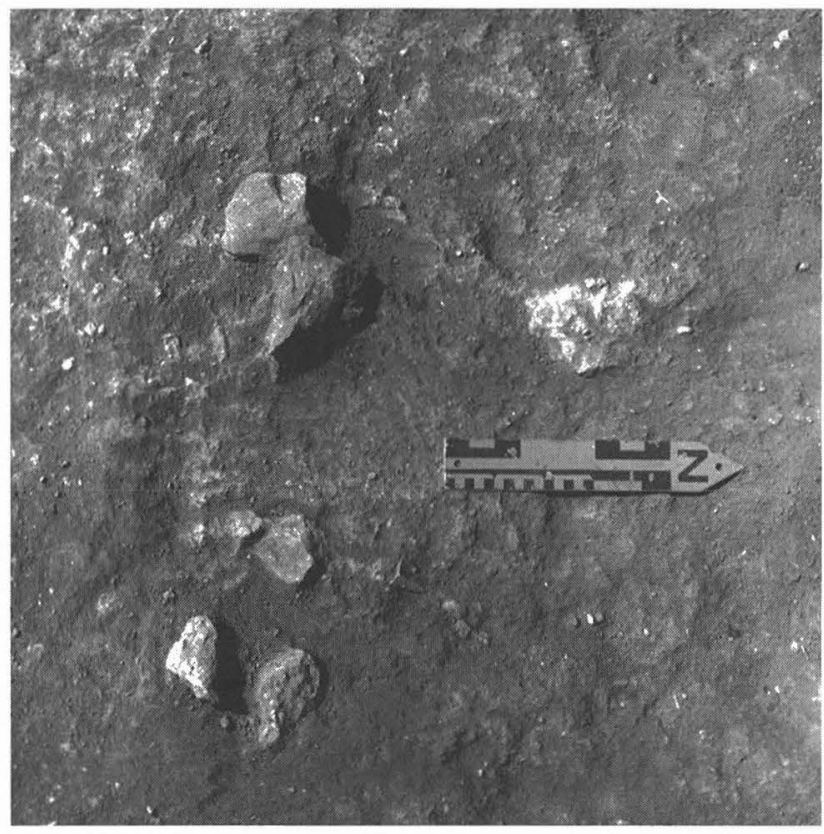

FIGURE 26-29. Feature 114 in Square E22/S84, Level 20, looking west.

of at least four more widely separated cobbles that were not recorded as part of the feature. The cobbles ranged from ca. $5-15 \mathrm{~cm}$ in diameter, and none appeared thermally fractured or discolored. The Feature 114 cluster measured approximately $15-\mathrm{x}-40 \mathrm{~cm}$ with the surrounding scatter encompassing a ca. $90-x-130-\mathrm{cm}$ area. The feature had an estimated vertical extent of ca. $5-10 \mathrm{~cm}$. No burned sediment or charcoal was observed in the feature area, and no artifacts were provenienced to Feature 114.

\section{Feature 115}

Feature Type: burned rock cluster

Provenience: Square E22/S88 (NE quad), Levels 22-23; elevations recorded for 2 rocks are 95.99 and $95.98 \mathrm{~m}$

\section{Stratigraphic Context: Unit X}

Archeological Chronology: Late Paleoindian

Description: Feature 115 was a burned rock cluster that was partially exposed along the east wall of Square E22/S88. The exposed portion consisted of about 15 rocks ( $2-12 \mathrm{~cm}$ size) within a 30-x-95 cm area. Vertical extent is estimated at ca. 5$10 \mathrm{~cm}$. No burned sediment or charcoal was reported, but a quartz mano fragment (Specimen 19W-1) and two pieces of debitage were recovered from the feature area. The mano refits to a fragment from Square E20/S88, Level 14 (Specimen $9 \mathrm{~N}-3$ ). The latter specimen was analyzed for organic residue, but no significant residues were found (see section by Hurst in Chapter 23).

\section{Feature 116}

Feature Type: burned rock cluster
Provenience: Square E22/S86 (NE quad), Level 22; elevations were recorded for 2 rocks and both were $95.80 \mathrm{~m}$ Stratigraphic Context: Unit X Archeological Chronology: Late Paleoindian Description: Feature 116 consisted of a loose cluster of about six burned rocks (2-10-cm size) exposed along the east wall of Square E22/S86. The cluster probably extended into the wall, but the exposed portion measured ca. $40-\mathrm{x}-40 \mathrm{~cm}$ (with an estimated thickness of ca. 5-10 cm). No burned sediment or charcoal was observed, and no artifacts were provenienced to this feature.

\section{Feature 117}

Feature Type: burned rock cluster

Provenience: Square E22/S82 (SW quad), Level 23; elevations recorded for 5 rocks range from 95.64 to $95.53 \mathrm{~m}$ Stratigraphic Context: Unit Id/II transition Archeological Chronology: Late Paleoindian Figure: 26-30

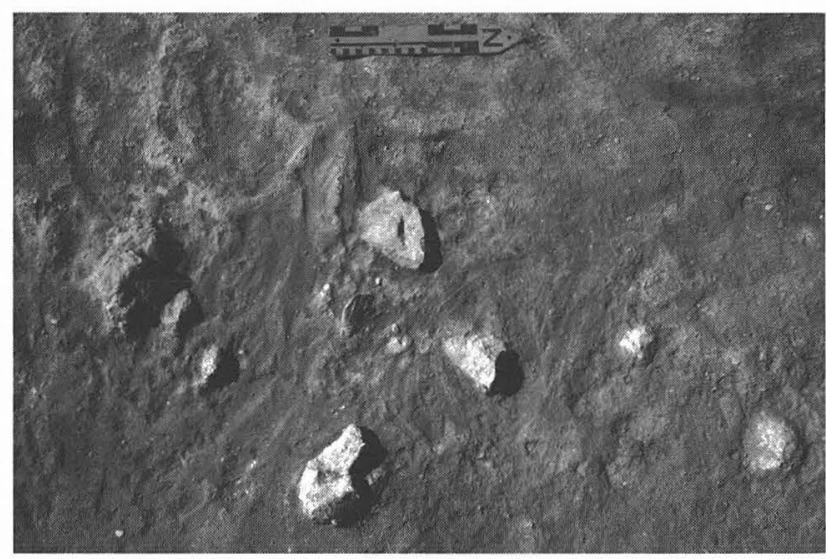

FIGURE 26-30. Feature 117 in Square E22/S82, Level 23, looking west.

Description: Feature 117 consisted of a loose cluster of 11 burned rocks (2-11-cm size). The cluster measured approximately $53-\mathrm{x}-120 \mathrm{~cm}$ with an estimated vertical extent of ca. $10-15 \mathrm{~cm}$. No burned sediment or charcoal was reported, and no artifacts were provenienced to this feature.

\section{Feature 118}

Feature Type: burned rock cluster

Provenience: Square E22/S86 (NE quad), Level 23; elevations recorded for 4 rocks range from 95.81 to $95.77 \mathrm{~m}$

Stratigraphic Context: Unit X

Archeological Chronology: Late Paleoindian

Special Studies:

Use-Wear: 1 artifact analyzed (see section by Kay in Chapter 22)

Figure: 26-31

Description: Feature 118 consisted of about 10 burned rocks 


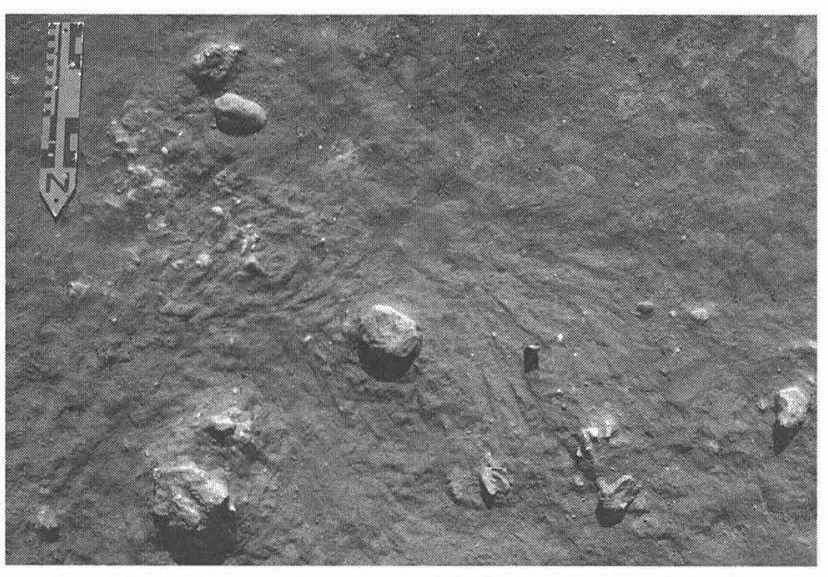

Figure 26-31. Feature 118 in Square E22/S86, Level 23, looking south.

(2-10-cm size) loosely clustered within an area measuring approximately $50-\mathrm{x}-110 \mathrm{~cm}$ (estimated vertical extent of ca. 5$10 \mathrm{~cm}$ ). No burned sediment or charcoal was observed in the feature area but a St. Mary's Hall point (Specimen 20W-1) was found in the approximate center of the cluster, and a few bone fragments were found among the rocks (feature provenience was not maintained for the bone). Kay performed a microwear analysis of the St. Mary's Hall point and concluded it was probably used as a both a projectile and a knife (see Chapter 22).

\section{Feature 119}

Feature Type: burned rock cluster

Provenience: Square E22/S82 (SE quad), Level 24; elevations recorded for 5 rocks range from 95.48 to $95.42 \mathrm{~m}$

Stratigraphic Context: Unit Isi-c/Id transition

Archeological Chronology: Late Paleoindian

Figure: 26-32

Description: Feature 119 was documented with only a plan drawing so there is very little information on this feature. It apparently consisted of 12 burned rocks (2-10-cm size) loosely clustered within a ca. $60-\mathrm{x}-65 \mathrm{~cm}$ area. No burned sediment or charcoal was reported, and no artifacts or other materials were provenienced to this feature.

\section{Feature 123}

Feature Type: small burned rock basin

Provenience: Square E22/S78 (NE quad), Levels 16A-16B; elevations recorded for 6 rocks ranged from $96.02 \mathrm{~m}$ to $95.94 \mathrm{~m}$

\section{Stratigraphic Context: Unit IIIa}

Archeological Chronology: Early Archaic

Figure: 26-33

Description: Feature 123 was a shallow basin-shaped pit containing ca. 100 burned rocks (5-20-cm size). It measured ca. $70-x-100$ with an estimated vertical extent of ca. $10-15 \mathrm{~cm}$.

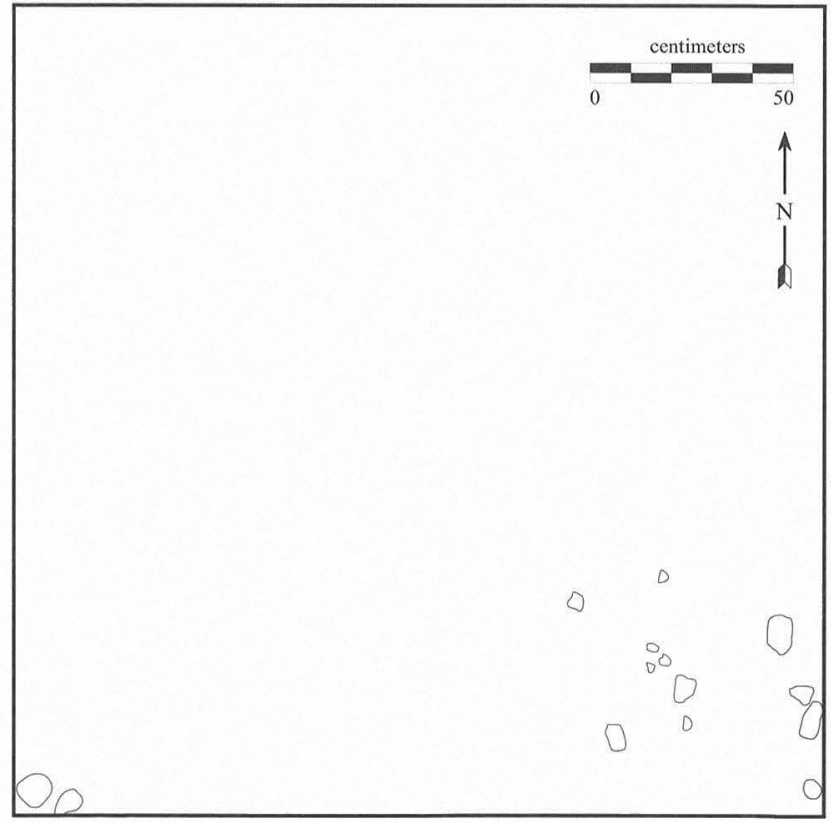

Figure 26-32. Feature 119 in Square E22/S82, Level 24.

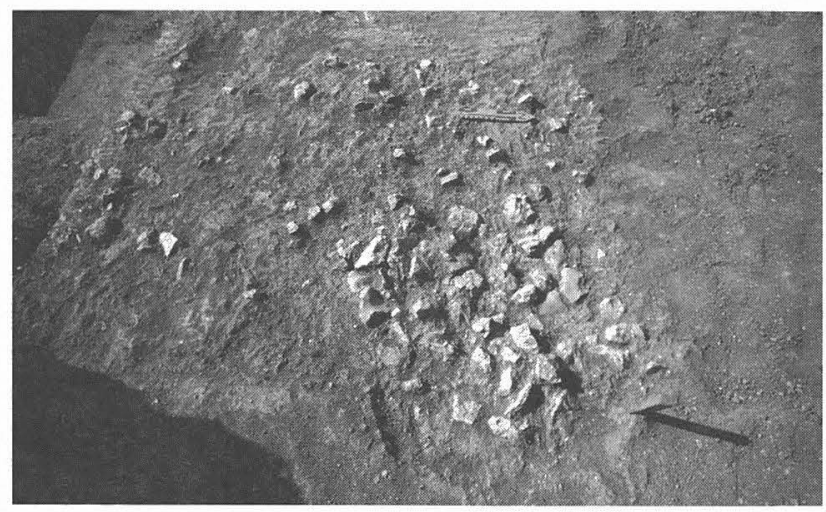

Figure 26-33. Feature 123 as exposed in Square E22/S78, Level $16 \mathrm{~A}$, looking west.

There is very little discussion of this feature in the field notes and no indication of whether burned sediment or charcoal were found in the pit. Associated materials include a Gower point (24P2-3), a Stage 2 biface (24P1-1), 129 pieces of debitage (lot 24P1), and a long-bone fragment from a medium/large mammal (not burned).

\section{Feature 124}

Feature Type: burned rock accumulation

Provenience: Squares E26/S78, E26/S76, E26/S74 (portions of all quads), Levels 15-17B; elevations were recorded for about 100 rocks within Feature 124 and these range from 96.02 to $95.73 \mathrm{~m}$

Stratigraphic Context: Unit IIIa Archeological Chronology: Early Archaic

Figure: 26-34 


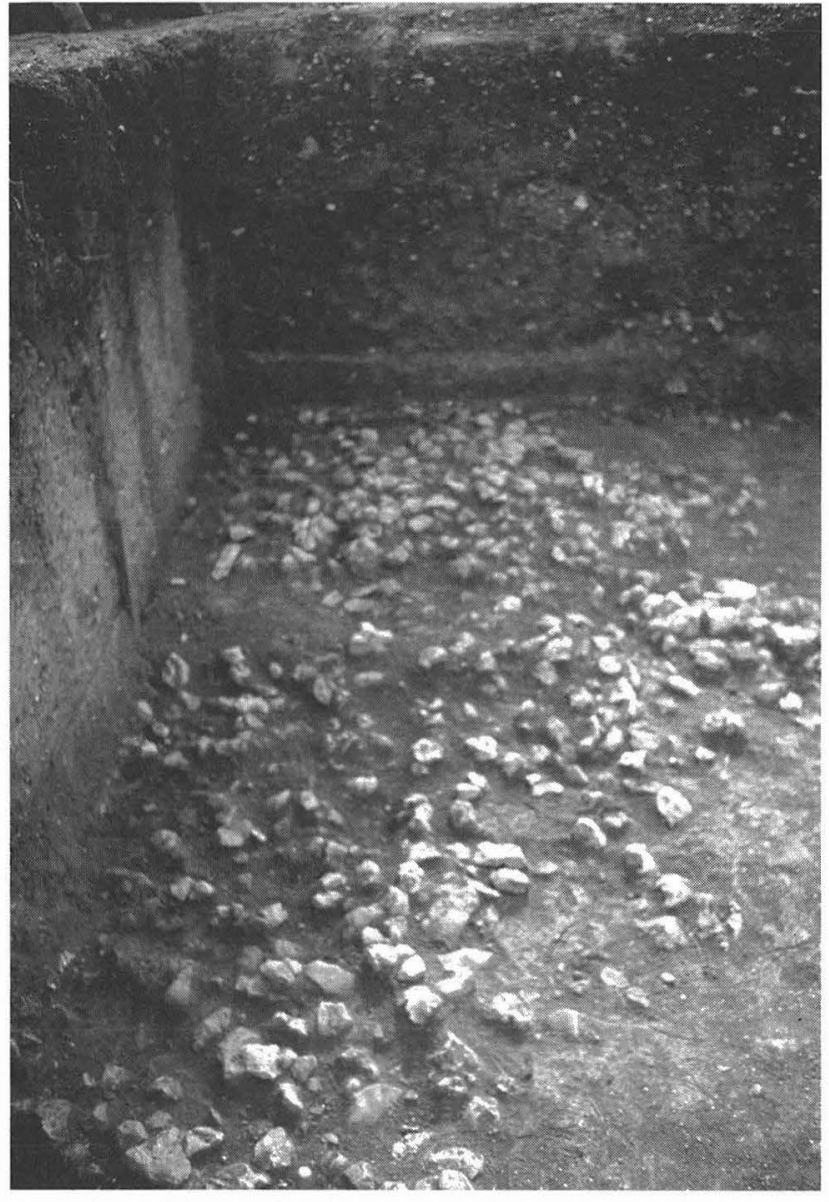

FIGURE 26-34. Feature 124 as exposed at the base of Level 16B in the southeast corner of Block 6 , looking south.

Description: Feature 124 represents the western edge of a large burned rock accumulation that was partially exposed in the southeast corner of TxDOT Block 6 . This accumulation, which extended into the south and east walls of Block 6, was further exposed in TxDOT Square E28/S78 (where it was recorded as the upper portion of Feature 181) and in the East and South Blocks of the TARL excavations where it was recorded as Feature 231 (see Feature 181 and 231 descriptions). The total exposure indicates an areal extent of at least $6-x-8 \mathrm{~m}$, with the Feature 124 portion measuring ca. 2 -x$6 \mathrm{~m}$. The accumulation was about $20-30 \mathrm{~cm}$ thick in the Feature 124 area, but it was a little thicker (up to $40 \mathrm{~cm}$ ) in the Feature 181/231 portion to the east.

There is relatively little description of Feature 124 in the TxDOT field notes (it was documented primarily with plan drawings and photographs), and feature provenience was not maintained for many of the materials found among the burned rocks. The available data indicate Feature 124 consisted of several layers of closely spaced, burned limestone fragments intermingled with an assortment of other cultural debris. No burned sediment was reported, but small quantities of charcoal were found throughout the feature area. Artifacts provenienced to Feature 124 include 2 manos (29R1-
7 and 32P2-11), a Hoxie C point (32P2-12), a perforator (32P13), 7 bifaces/biface fragments, 4 unifaces, a denticulated flake, 2 burin spalls, a thermal core, and 753 pieces of debitage. Twenty-five pieces of bone and 5 mussel shell fragments were also provenienced to this feature (see Chapters 33 and 37). Most of the bone was classified as Vertebrata indeterminate fragments but also included were a turtle shell fragment and 7 medium large mammal fragments. Over half the bone was burned.

Several subfeatures were also recorded within Feature 124. Feature 132 was a poorly defined cluster of about 45 burned rocks (ca. $60-\mathrm{x}-60-\mathrm{x}-10 \mathrm{~cm}$ ) recorded in Level 17B of Square E26/S76. A possible pit (or burrow) was mapped in Level 16B of Square E26/S76, but it was not formally recorded as a feature and there is very little documentation. It was partially exposed along the east wall and measured about $30-35 \mathrm{~cm}$ in diameter and $15 \mathrm{~cm}$ deep. It is depicted as a rockfree area, but there is no description of the "pit" fill.

Six large burned rock basins were also found within the combined Feature 124/231 area, but most of these pits were first detected at (or slightly below) the base of the accumulation where the rock density had decreased significantly. These pits probably originated from surfaces slightly above their detection levels since pit outlines were difficult to discern in the overlying dense concentrations of burned rocks. Features 130 and 131 were found at the western edge of Feature 124; Features 146 and 150 were found at the northern edge of Feature 124; and Features 181 and 245 were found immediately east of Feature 124.

\section{Feature 130}

Feature Type: large burned rock basin

Provenience: Squares E24/S74 (SE quad), E24/S76 (NE quad), E26/S74 (SW quad), E26/S76 (NW quad); Levels 17B-18B; elevations recorded for ca. 30 rocks range from 95.75 to $95.66 \mathrm{~m}$

Stratigraphic Context: Unit IIIa

Archeological Chronology: Early Archaic

Special Studies:

Macrobotanical: 2 macroplant samples analyzed (see Chapter 40)

Figures: $26-35$ and 26-36

Description: Feature 130 was a roughly circular, basinshaped pit measuring ca. $150 \mathrm{~cm}$ in diameter and at least 10$15 \mathrm{~cm}$ deep (vertical extent was not fully documented). The pit contained ca. 500 densely packed burned limestone fragments ranging from ca. $2-15 \mathrm{~cm}$ in length. The largest rocks were concentrated primarily along the outer margins and base of the pit with the interior containing more of the smaller (intensely burned?) fragments. No burned sediment was reported, but small quantities of charcoal were found scattered throughout the feature. Two small charcoal samples were collected, and both were identified as indeterminate wood. The field notes indicate some mussel shell and bone 


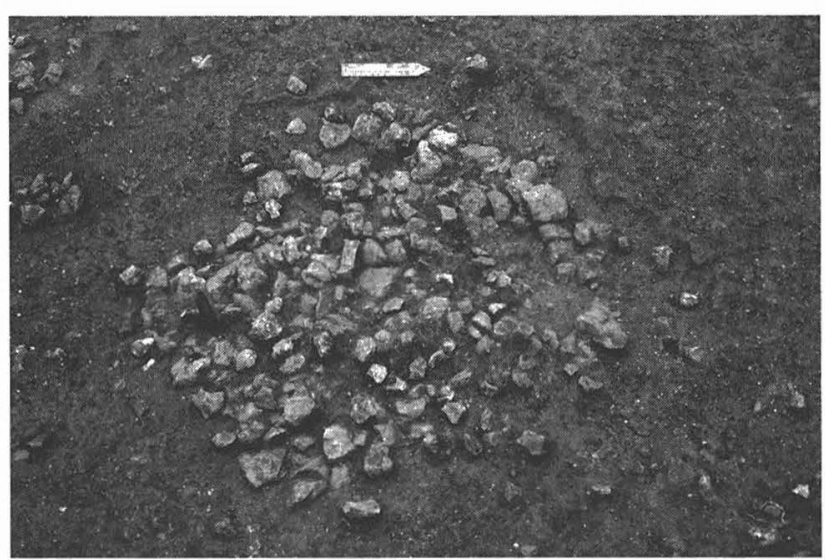

Figure 26-35. Feature 130 as exposed in Squares E24/S74, E24/ S76, E26/S74, and E26/S76 at the base of Level 17B, looking west.

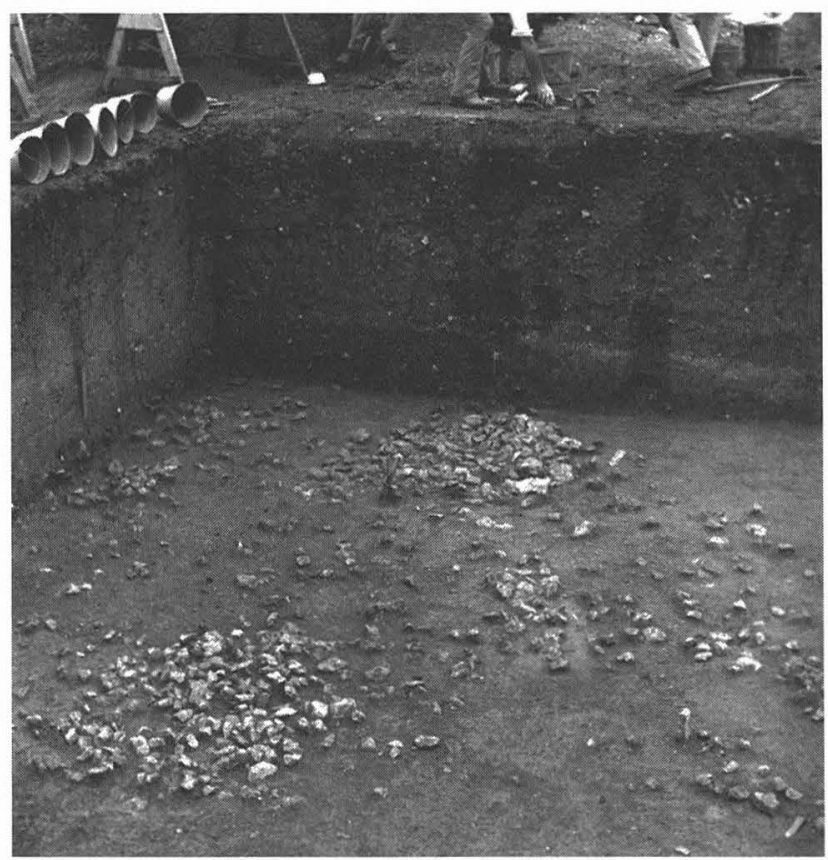

FIGURE 26-36. Features 130 and 131 as exposed in the southeast corner of Block 6 at the base of Level 18A.

fragments were also found within Feature 130 fill, but feature provenience was not maintained for this material (it was apparently combined with general level recovery). Feature provenience may have been lost for some of the artifacts found in the fill as only two artifacts, a modified flake (30R1-5) and a tested chert cobble (30Q2-6) are provenienced to Feature 130 .

\section{Feature 131}

Feature Type: large burned rock basin

Provenience: Squares E24/S76 (SE quad), E24/S78 (NE and SE quads), E26/S76 (SW quad), and E26/S78 (NW and SW quads); Levels 17B-18B; elevations recorded for ca. 45 rocks range from 95.84 to $96.66 \mathrm{~m}$
Stratigraphic Context: Unit IIIa

Archeological Chronology: Early Archaic

Special Studies:

Macrobotanical: 1 macroplant sample analyzed (see Chapter

40)

Figures: 26-36 and 26-37

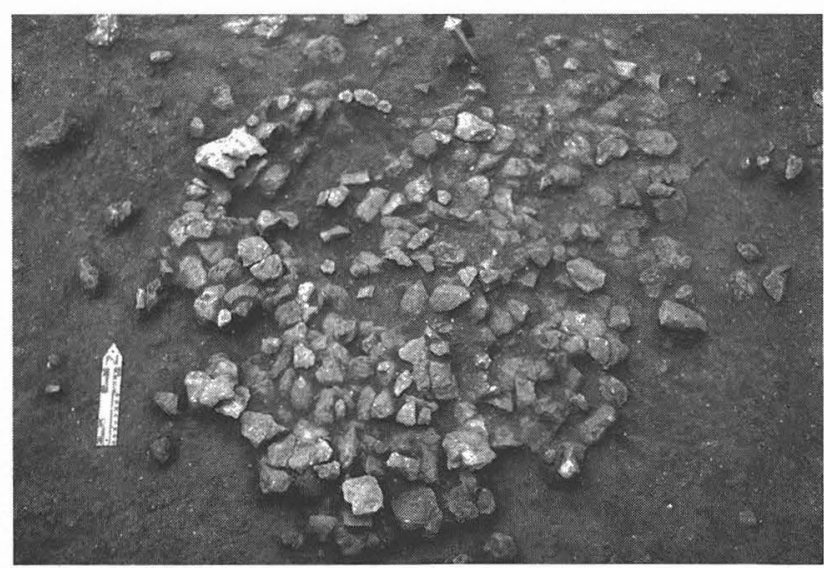

FIGURE 26-37. Feature 131 as exposed in Squares E24/S76, E24/ S78, E26/S76, and E26/S78 at the base of Level 18A, looking north.

Description: Feature 131 was a roughly circular, basinshaped pit measuring about $150-160 \mathrm{~cm}$ in diameter and at least $20 \mathrm{~cm}$ deep (vertical extent was not fully documented). It contained ca. 700 closely spaced burned rocks ranging from ca. $2-25 \mathrm{~cm}$ in length. Large slabs (15-25-cm size) were found throughout the pit, but the majority were concentrated along the outer margins and base. Smaller fragments (5-10-cm size) dominated the interior fill. Many of the rocks were fractured in situ, and some of the larger rocks at the base were reddened from burning. Small quantities of charcoal were found throughout the pit fill, but only one sample was collected (identified as indeterminate wood). Some burned sediment was also observed, but the location was not documented. The field notes mention some burned bone found in the pit fill, but this was apparently combined with general level recovery. Feature provenience was apparently lost for some of the artifacts found in the fill as well. Feature 131 provenience was maintained for 2 modified flakes (28R19,28R1-10), 22 pieces of debitage, and a large hematite pebble. Comments: This large burned rock basin was located less than $2 \mathrm{~m}$ south of Feature 130, and these features resembled one another in many regards. They were about the same diameter, but Feature 131 was probably a little deeper and contained a greater number of rocks (as well as more of the large slabs).

\section{Feature 137}

Feature Type: burned rock ring

Provenience: Square E22/S76 (NE and SE quads), Levels 18B-19A; elevations recorded for 5 rocks range from 95.71 to $95.69 \mathrm{~m}$ 
Stratigraphic Context: Unit IIIa Archeological Chronology: Early Archaic Figure: 26-38

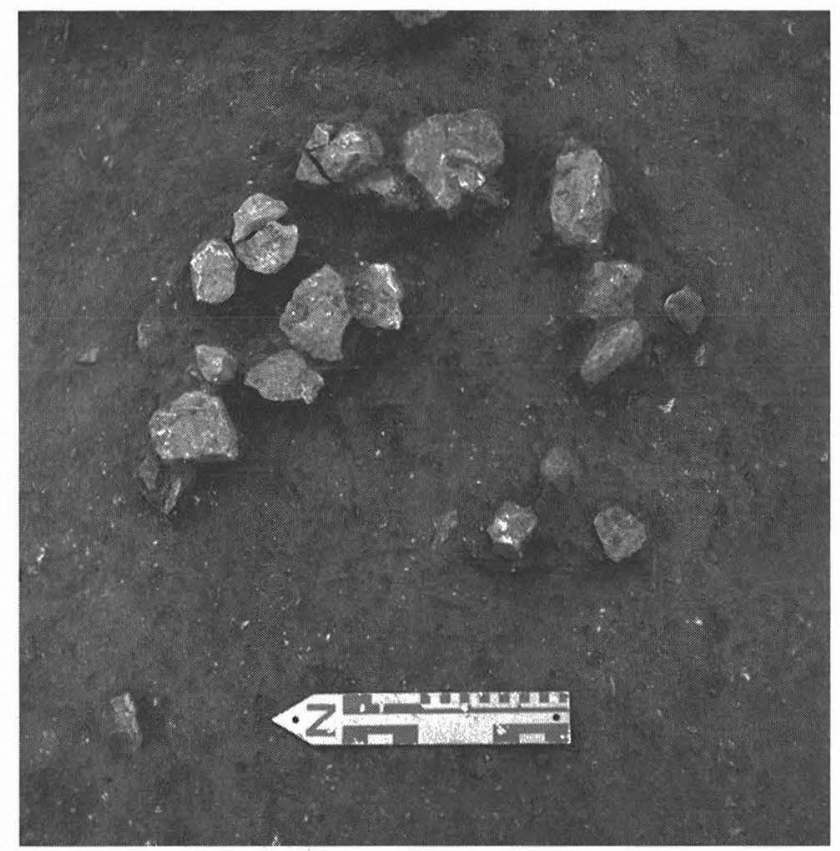

FIGURE 26-38. Feature 137 in Square E22/S76, Level 19A, looking east.

Description: Feature 137 consisted of ca. 20 burned rocks $(5-15 \mathrm{~cm}$ size $)$ arrayed in a ringlike configuration around a rock-free central space. It measured about $60 \mathrm{~cm}$ in diameter and was probably no more than $5-10 \mathrm{~cm}$ thick. There was a $25 \mathrm{~cm}$ gap on the west side of the ring, and it looked like several rocks found on the north side of the feature may have been displaced from this area. No burned sediment or charcoal was found in the feature area, and no artifacts or other materials were provenienced to Feature 137.

\section{Feature 139}

Feature Type: small burned rock basin

Provenience: Squares E24/S74 (NW quad) and E22/S74 (NE quad); Levels 19A-19B; elevations recorded for 10 rocks range from 95.60 to $95.48 \mathrm{~m}$

Stratigraphic Context: Unit IIIIa

Archeological Chronology: Early Archaic

Figure: 26-39

Description: Feature 139 was a shallow, basin-shaped pit containing about 50 burned rocks (5-15-cm size). The roughly circular pit measured about $70 \mathrm{~cm}$ in diameter and ca. 10-15 $\mathrm{cm}$ deep (vertical extent was not fully documented). Some of the rocks along the outer margins were on edge, slanting down toward the center of the pit. Many of the rocks were fractured from burning, and though small quantities of charcoal were found no burned sediment was observed. A rounded sandstone cobble (30S1-7; possible mano) was

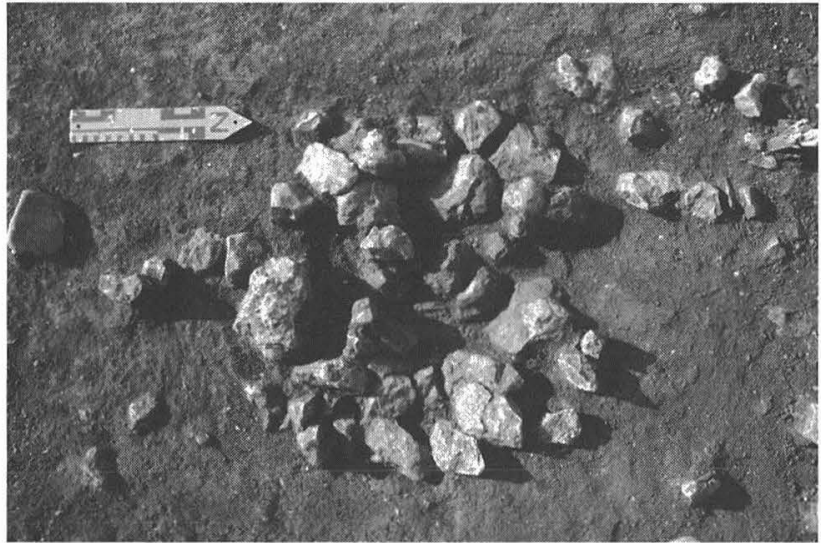

FIGURE 26-39. Feature 139 as exposed in Squares E24/S74 and E22/ S74, Level 19A, looking west.

found immediately south of Feature 139 and 2 biface fragments (27S1-7, 26S2-1) were found near its northern edge. No other materials were provenienced to Feature 139.

\section{Feature 146}

Feature Type: large burned rock basin

Provenience: Squares E26/S74 (NE and NW quads) and E26/ S72 (SE quad), Levels 19B-21A; elevations recorded for 35 rocks range from 95.51 to $95.41 \mathrm{~m}$

Stratigraphic Context: Feature 146 apparently originated from a surface in the lower portion of Unit IIIa and intruded Unit II

Archeological Chronology: Early Archaic

\section{Special Studies:}

Macrobotanical: 2 macroplant samples analyzed (see Chapter 40)

Figure: $26-40$ and 26-41

Description: Feature 146 was a roughly circular, basinshaped pit measuring about $120-130 \mathrm{~cm}$ in diameter and at least 10-20 cm deep (vertical extent was not fully documented). The pit contained about 500 densely packed burned limestone fragments, ranging from ca. $2-20 \mathrm{~cm}$ in length. The larger $(15-20 \mathrm{~cm})$ rocks were found throughout the pit, but they were especially concentrated in the base and along the outer margins. Many of the rocks were fractured and/or discolored from burning but no burned sediment was reported. Small quantities of charcoal were found among the rocks, and 2 samples were collected (both identified as indeterminate wood). Other materials provenienced to Feature 146 include 2 unifaces (34T1A-1 and 34T1A-2), 154 pieces of debitage, and 5 bone fragments ( 4 burned). Three of the bones were classified as medium/large mammal, and the others were Vertebrata indeterminate (see Chapter 33).

\section{Feature 150}

Feature Type: large burned rock basin

Provenience: Squares E24/S74 (NE and SE quads), E26/S74 


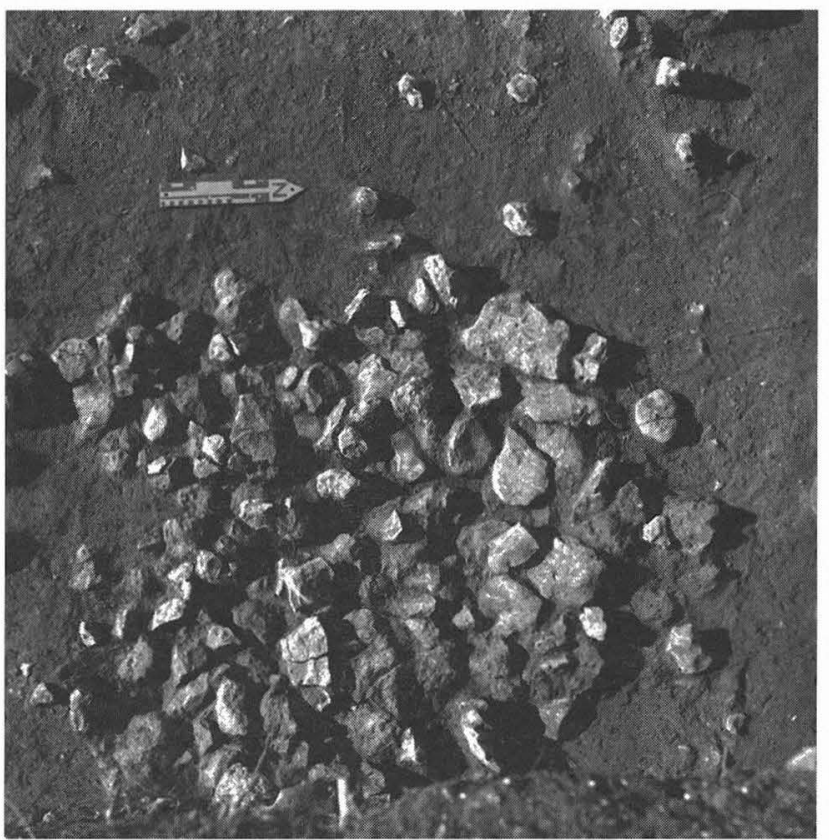

Figure 26-40. Feature 146 as exposed in Squares E26/S74 and E26/ S72, Level 20A, looking west.

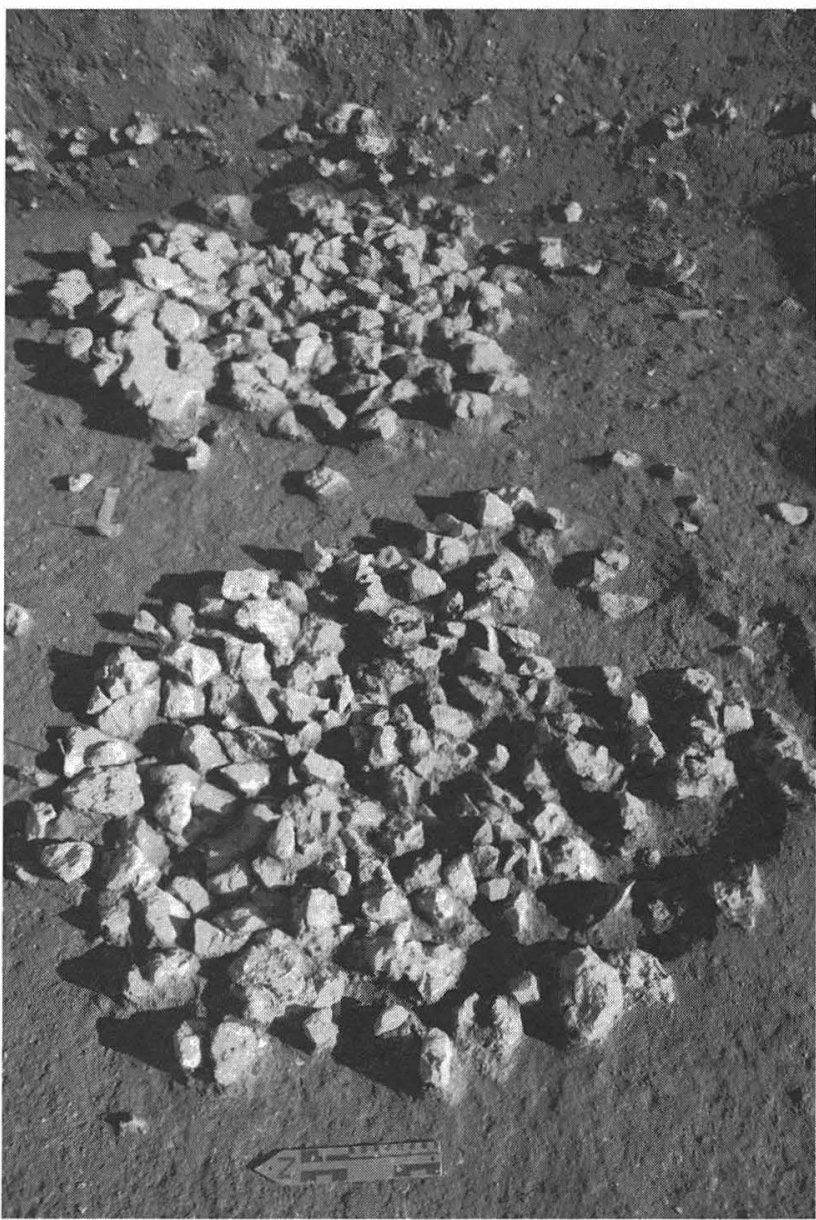

FIGURE 26-41. Feature 146 (background) and Feature 150 (foreground) as exposed in Squares E26/S74, E26/S72, E24/S74, and E24/S72, Level 21A, looking east.
(NW and SW quads), E24/S72 (SE quad), E26/S72 (SW quad); Levels 20B-21B; elevations recorded for 26 rocks range from 95.43 to $95.35 \mathrm{~m}$

Stratigraphic Context: Feature 150 apparently originated from a surface in the lower portion of Unit IIIa and intruded Unit II

Archeological Chronology: Early Archaic

Special Studies:

Macrobotanical: 1 macroplant sample analyzed (see Chapter 40)

\section{Figure: $26-41$}

Description: Feature 150 was a roughly circular, basinshaped pit measuring ca. $120-130 \mathrm{~cm}$ in diameter and at least $10-15 \mathrm{~cm}$ deep (vertical extent was not fully documented). It closely resembled Feature 146, which was found about $40 \mathrm{~cm}$ east of Feature 150 at about the same elevation (top of Feature 146 was detected about $5-10 \mathrm{~cm}$ higher). Like Feature 146, this pit was filled with a dense concentration of burned limestone fragments (ca. 400 rocks in the $2-20$-cm size range) with the largest rocks concentrated primarily along the outer margins and base of the pit. Many of the rocks were fractured and/or discolored from burning, but no burned sediment was observed. A small amount of charcoal was found in the pit fill, and one sample was collected (identified as indeterminate wood). Other materials provenienced to Feature 150 include 45 pieces of debitage, a mussel shell fragment (see Chapter 37), and a burned bone fragment (Vertebrata indeterminate).

\section{Feature 152}

Feature Type: burned rock ring

Provenience: Square E26/S76 (SE quad), Level 20B; elevations recorded for 5 rocks range from 95.48 to $95.43 \mathrm{~m}$

Stratigraphic Context: Unit II/IIIa transition

Archeological Chronology: Late Paleoindian or Early Archaic

Figure: $26-42$

Description: This feature consisted of a ringlike configuration of nine burned stones (5-15-cm size) encircling a rock-free center. The ring measured approximately $45-\mathrm{x}-$ $60 \mathrm{~cm}$ and the rock-free interior measured ca. $25-\mathrm{x}-45 \mathrm{~cm}$. The feature had an estimated vertical extent of ca. 5-10 $\mathrm{cm}$, and the rocks appeared to rest on a relatively level surface. Most of the rocks in the ring were very closely spaced, but there were several 10-20-cm gaps where rocks may have been displaced. A few rocks were found scattered around Feature 152, and some of these may have been displaced from either the ring arrangement or the rock-free interior. There is no description of Feature 152 in the field notes (it was documented with only a plan drawing and photographs), and it is not known if any burned sediment or charcoal was found in the feature area. No materials other than rocks were provenienced to Feature 152. 


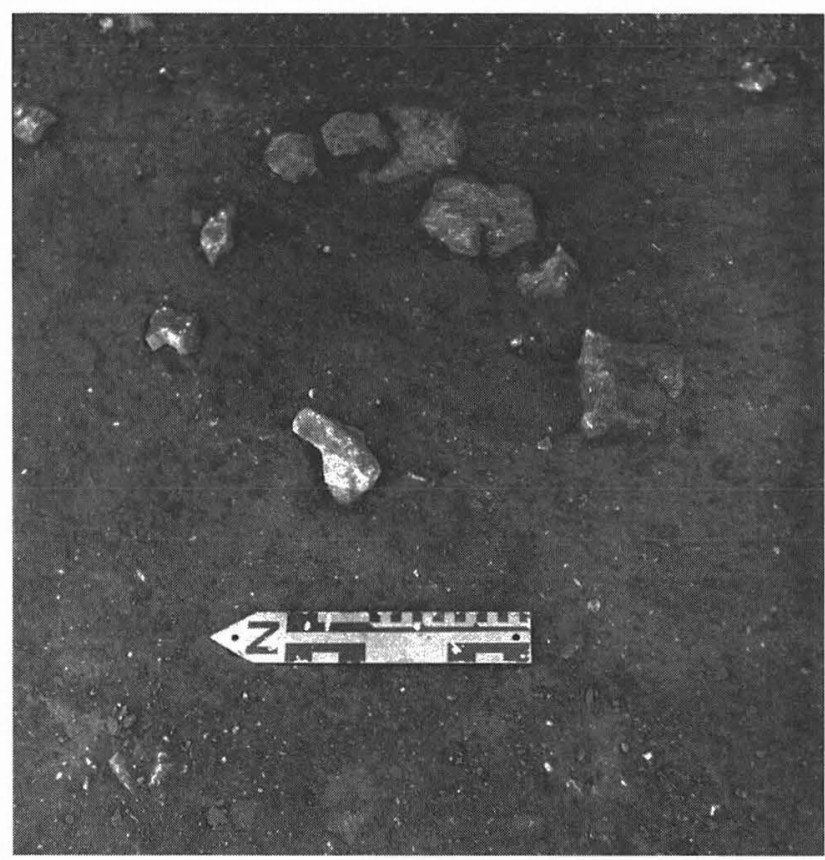

FIGURE 26-42. Feature 152 in Square E26/S76, Level 20B, looking east.

\section{Feature 153}

Feature Type: burned rock ring

Provenience: Square E22/S72 (all quads), Level 21A; the elevations recorded for four rocks range from 95.45 to $95.41 \mathrm{~m}$

Stratigraphic Context: Unit II

Archeological Chronology: Late Paleoindian

Figure: 26-43

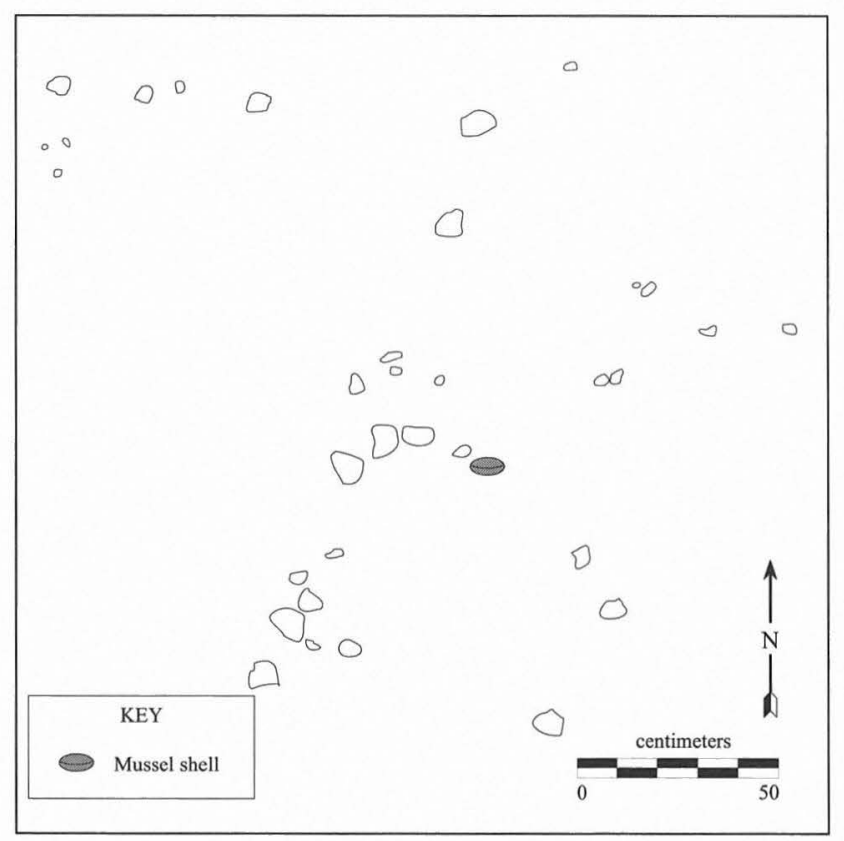

FIGURE 26-43. Feature 153 in Square E22/S72, Level 21A.
Description: Feature 153 consisted of approximately 18 burned rocks loosely arrayed in a somewhat ringlike configuration around a central area devoid of rocks. At least 15 additional rocks were randomly scattered just north of the ring. The ring measured about $90 \mathrm{~cm}$ in diameter with the rocks ranging from $2-10 \mathrm{~cm}$ in diameter. No burned sediment or charcoal was reported from the feature area, but the plan drawing shows a mussel shell within the ring of rocks and an unidentified item labeled "mod." The latter item is probably a granite mano fragment (27U1-1) that was provenienced to Feature 153. Feature provenience was not retained for the mussel shell, but the general level recovery includes 2 mussel shell fragments that are possibly associated with Feature 153 (see Chapter 37). No other materials were provenienced to this feature.

\section{Feature 154}

Feature Type: burned tree (juniper?)

Provenience: Square E40/S70 (SE and SW quads), Levels 23-26; detection elevation $94.71 \mathrm{~m}$; base elevation $94.32 \mathrm{~m}$ Stratigraphic Context: upper portion of Unit I Archeological Chronology: Late Paleoindian?

Description: Feature 154 was an irregular-shaped area of burned sediment, ash, and charcoal that was partially exposed along the south wall of Square E40/S70. The burned area had a maximum east-west extent of ca. $180 \mathrm{~cm}$, and it extended northward from the south wall about $80 \mathrm{~cm}$. Although the full vertical extent was not recorded, Feature 154 had a depth of at least $39 \mathrm{~cm}$. The burned area included scattered patches of orange, oxidized sediment as well as dark brown organically stained sediment. It clearly represented an area of in situ burning, and the irregular form suggests that it probably represents a burned tree. Three (unanalyzed) sediment samples, 45 pieces of debitage, and 2 bone fragments were provenienced to the Feature 154. A charcoal sample (CH-774) that was possibly associated with Feature 154 (found in same level but not provenienced to the feature) was identified as juniper wood charcoal (see Chapter 40).

Comments: The stratigraphy was not clearly established for this isolated square (E40/S70), but Feature 154 was apparently found in the upper portion of Unit I, immediately below the II/I transition. Feature 154 probably represents a burned tree, and it may have originated from the same surface as one or more of the other burned trees found in upper lower Unit II and upper Unit I (Features 164, 165, 167, 198, and 253).

\section{Feature 155}

Feature Type: burned rock cluster (small burned rock ba$\sin$ ?)

Provenience: Square E24/S76 (NW and NE quads), Levels 21B-22B; elevations recorded for ca. 25 rocks range from 95.43 to $95.29 \mathrm{~m}$

Stratigraphic Context: Unit II 


\section{Archeological Chronology: Late Paleoindian}

\section{Special Studies:}

Magnetic Susceptibility: 2 samples analyzed (see Chapter 28)

Micromorphology: 1 sample analyzed (see Chapter 29 and Appendix 7)

Gastropod: 1 sample analyzed (see section by Theler in Chapter 37)

Macrobotanical: 1 flotation sample processed (see Chapter

40)

Figure: $26-44$

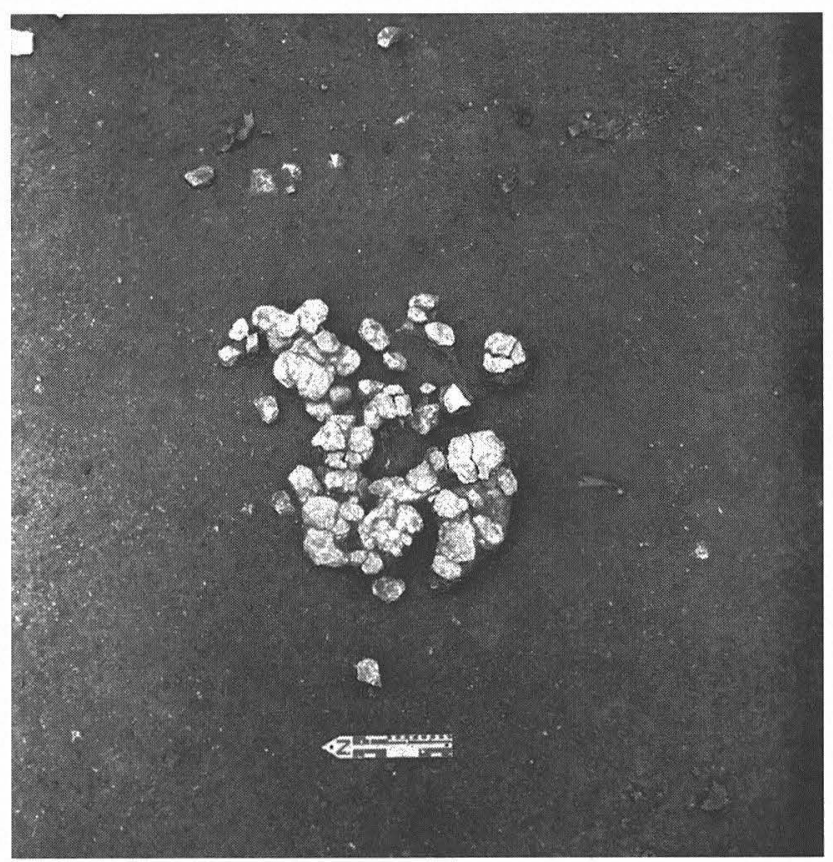

FIGURE 26-44. Feature 155 in Square E24/S76, Level 22B, looking east.

Description: Feature 155 was an oval-shaped cluster of approximately 80 burned limestone fragments. The cluster measured about $80-\mathrm{x}-100 \mathrm{~cm}$ with a vertical extent of ca. $14 \mathrm{~cm}$. It was composed primarily of a single layer of small- to medium-sized rocks (2-15-cm size) with just a few rocks found on top of others. Most of the rocks exhibited angular fractures, and some were fractured in situ. The central core of Feature 155 consisted of a very tight, circular cluster of rocks (ca. 60-cm diameter) that looked like they probably rested in a shallow basin. The feature was not cross-sectioned, but rock elevations recorded on three plan drawings (Levels 21B-22B) provide some support for this interpretation. These data suggest the basin had a depth of ca. $5-10 \mathrm{~cm}$. Some burned sediment was collected from the feature area, but the sample location was not recorded in the field notes. No charcoal was found within the rock cluster, but small quantities were found "around" (outside) the feature. A large mammal jaw fragment with 8 teeth was found in a rock-free space in the approximate center of the central cluster. Although the field notes say this specimen was "larger than deer," the faunal analyst did not classify it further than "large mammal" (see Chapter 33). The field notes also say that "scattered other bone fragments" were found within the feature, but this bone was apparently combined with general level recovery. Feature 155 artifact recovery included a projectile point tip (29V2A-4) and a core fragment (29V1B-3) found along the margins of the central cluster and 2 pieces of debitage found in a sediment sample.

In addition to the burned sediment sample mentioned above (collected as a thermoluminescence sample), a large bulk matrix sample (over 20 liters) and a bag of burned rocks were collected from Feature 155. Portions of both sediment samples were used for various special studies during the TARL analysis, and the remainder was curated. Although the thermoluminescence sample was not used for that purpose, a portion of it was used for a micromorphology thinsection (Sample WL95-24). An ashed vegetal fragment and some scattered ash crystals were identified in this sample, but no clear evidence of burned sediment was observed.

The larger sediment sample was used for magnetic susceptibility, gastropod, flotation, and fine-screen faunal samples. The magnetic susceptibility results were comparable to nonfeature samples from similar stratigraphic contexts (no significant deviation detected). The gastropod sample yielded 163 terrestrial and 4 aquatic snails. Although most of the identifiable terrestrial snails were taxa commonly found throughout the site deposits, several specimens of less-common species were identified as well. The latter group include Punctum vitreum, Glyphyalinia roemeri, and Glyphyalinia umbilicata. These taxa are generally indicative of relatively mesic, woodland habitats. The aquatic snails were identified as Physella sp. and Fossaria dalli. These species are typically found in moist vegetation growing in shallow pools. Although they may have been deposited in the feature area during a flood, they may also represent human collection of water and/or aquatic biota. The flotation sample was not productive, but 42 bone fragments were recovered from the ca. 5.5-liter fine-screen sample (see Appendix 8). Over half were classified as Vertebrata indeterminate fragments, but the sample also included a few specimens classified as mammal $(n=7)$, rodent $(n=8)$, and reptile $(n=1)$. About $45 \%$ of these specimens were burned.

Comments: The overall appearance of this feature and the evidence of in situ burning (ash, charcoal, and burned sediment) suggest it probably represents a relatively intact basin-shaped hearth or cooking feature.

\section{Feature 156}

Feature Type: burned rock ring

Provenience: Square E26/S76 (NE quad), Levels 22A-22B; elevations recorded for 10 rocks ranged from 95.35 to $95.29 \mathrm{~m}$

Stratigraphic Context: Unit II

Archeological Chronology: Late Paleoindian

Figure: 26-45 


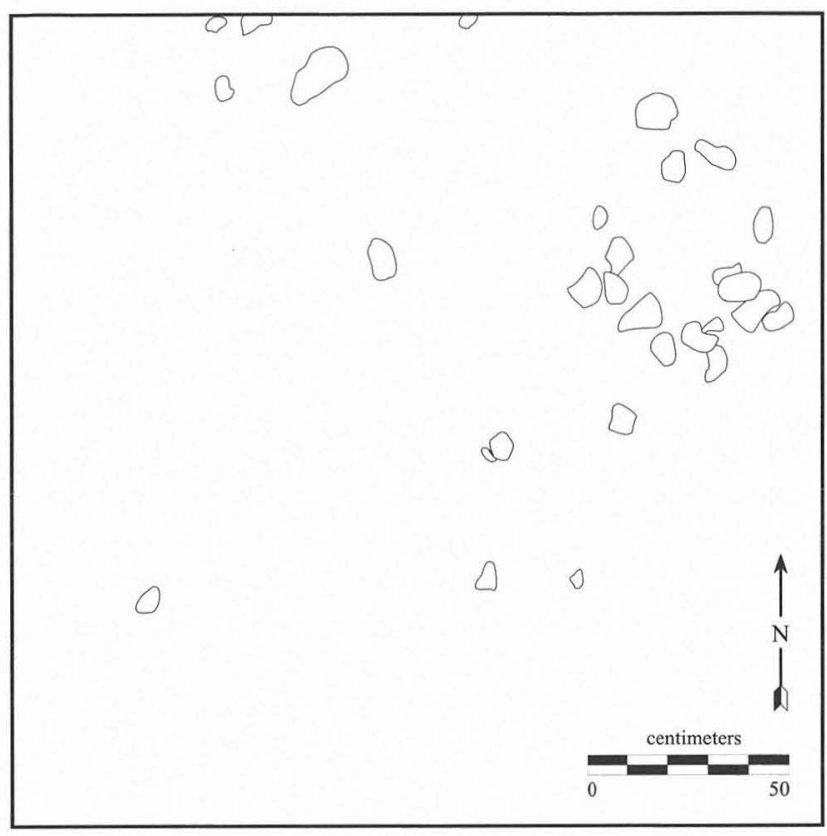

FIGURE 26-45. Feature 156 in Square E26/S76, Levels 22A and 22B.

Description: Feature 156 consisted of approximately 16 burned rocks (5-12-cm size) arranged in a circular, $50-\mathrm{x}-70-\mathrm{cm}$ ringlike configuration with an estimated vertical extent of 6$10 \mathrm{~cm}$. Although no charcoal or ash was observed within the feature area, numerous burned gravels were found in the rock-free center. No artifacts or other materials were provenienced to this feature.

\section{Feature 157}

Feature Type: burned rock cluster

Provenience: Square E26/S72 (all quads), Levels 21B-22B; detection elevation 95.32; base elevation $95.15 \mathrm{~m}$

Stratigraphic Context: Unit II

Archeological Chronology: Late Paleoindian

Special Studies:

Radiocarbon: 1 wood charcoal sample was AMS dated to $9340 \pm 60$ в.P. (CAMS-18640; see Chapter 25)

Magnetic Susceptibility: 2 samples analyzed (see Chapter 28)

Micromorphology: 1 sample analyzed (see Chapter 29)

Macrobotanical: 3 macroplant samples analyzed; 1 flotation sample processed (see Chapter 40)

Figure: $26-46$

Description: Feature 157 was a large, roughly circular burned rock cluster measuring approximately $140-\mathrm{x}-160 \mathrm{~cm}$ and 17 $\mathrm{cm}$ thick. The single-layer cluster included over 100 burned rocks ranging from $5-20 \mathrm{~cm}$ in diameter. The interior of the feature included a number of rock-free spaces between groups of 4 to 10 tightly clustered rocks, and it looked as if some rocks might have been removed/displaced from the interior. Although the feature was not cross-sectioned, the excavator noted that the rocks did not appear to be placed in

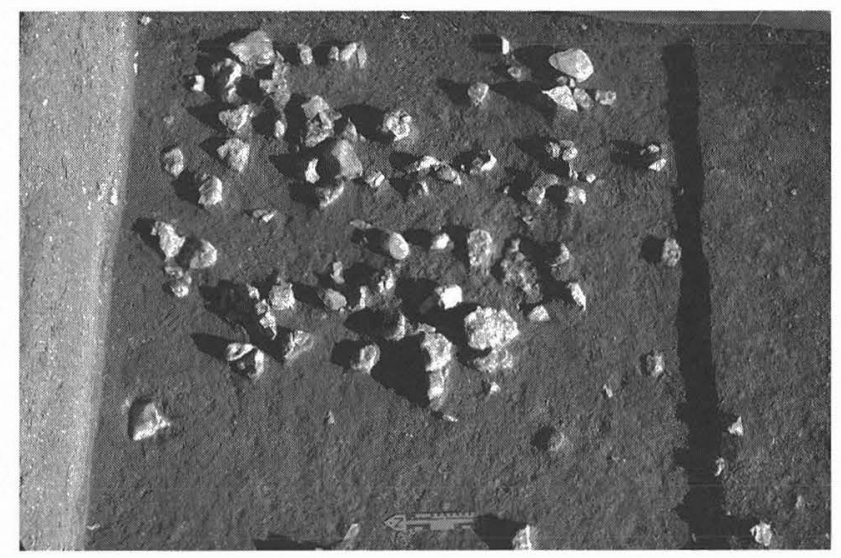

Figure 26-46. Feature 157 as exposed in Square E26/S72, Level 22B, looking east.

a basin. Some of the rocks exhibited evidence of intense burning (thermal fractures and discoloration), but no evidence of burned sediment was reported. Several good concentrations of charcoal were found and three samples were collected (CH-740, CH-742, and CH-743). All three were identified as indeterminate wood charcoal. Sample $\mathrm{CH}-740$ was subsequently AMS-dated (see date above).

Other material found within Feature 157 included a multidirectional core (35V1\&2-1), a uniface (35V1\&2-3), a "rounded limestone rock (possible tool)," 142 pieces of debitage, a Lampsilis teres mussel shell valve (see Chapter 37 ), and 12 bones. The bone included 1 carnivore phalanx, 4 medium/large mammal fragments, 2 small/medium Vertebrata fragments, and 5 Vertebrata indeterminate fragments (see Chapter 33). Nine of the bones were burned, and 5 of these were calcined.

A bulk matrix sample (ca. 3.5 liters) was also collected from Feature 157, and much of this sediment was processed as special samples during the TARL analysis (remainder was curated). These included magnetic susceptibility, micromorphology, flotation, and fine-screen faunal samples. The magnetic susceptibility samples were comparable to nonfeature samples from similar stratigraphic contexts (no significant deviation detected). The flotation sample was not productive, and the micromorphology sample (WL95-20) did not impregnate well so a thin-section was not made. When the polished block was examined under a binocular microscope, a burned limestone fragment and some charcoal dust were observed but no burned sediment was noted. The 0.85 -liter fine-screen sample yielded 2 eggshell fragments and 63 bones (see Chapter 36 and Appendix 8). Most of the bone was classified as Vertebrata indeterminate fragments, but the sample also included a few specimens identified as mammal, rabbit, rodent, and turtle.

Comments: Feature 157 is the largest feature found in Unit II, and though it apparently lacked evidence of a basin shape, it bears some resemblance to the circular concentrations of burned rocks found in the large burned rock basins at this site. Perhaps Feature 157 represents the lower portion of a 
large burned rock basin, or alternatively, it may represent another type of large-capacity cooking feature.

\section{Feature 158}

Feature Type: burned rock ring?

Provenience: Square E22/S72 (NE and SE quads), Level 22B; elevations recorded for 4 rocks range from 95.28 to $95.25 \mathrm{~m}$ Stratigraphic Context: Unit II

Archeological Chronology: Late Paleoindian

Figure: $26-47$

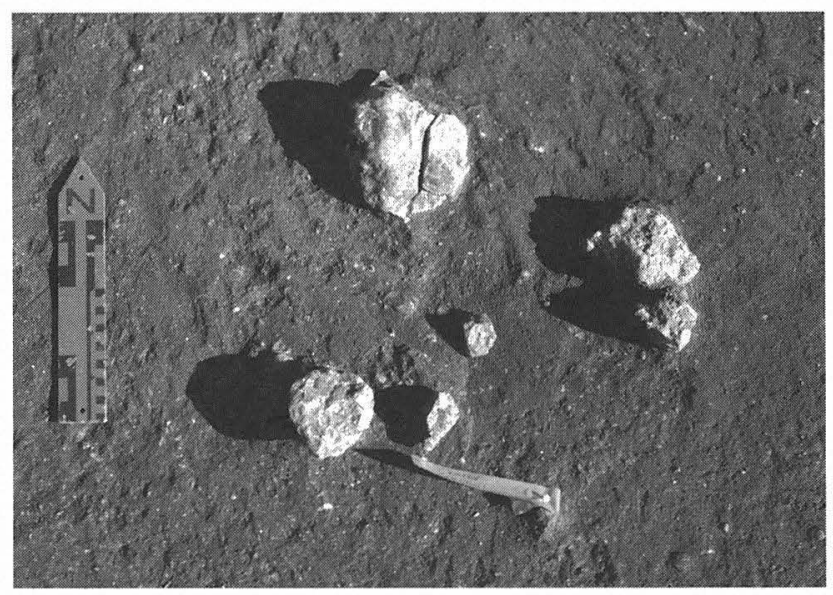

FIGURE 26-47. Feature 158 in Square E22/S72, Level 22B, looking north.

Description: Feature 158 consisted of a small, ringlike configuration of about seven burned rocks. The ring measured about $40-\mathrm{x}-50 \mathrm{~cm}$, and the individual rocks ranged from 4-12 $\mathrm{cm}$ in diameter. At least one of the rocks exhibited thermal fractures. No burned sediment or charcoal was reported within the immediate feature area; however, some charcoal was recovered in the surrounding area. A thin uniface $(27 \mathrm{~V} 2 \mathrm{C}-2)$ was found at the edge of the cluster, but no other materials were provenienced to Feature 158 .

\section{Feature 160}

Feature Type: burned sediment and charcoal (probably a burned plant)

Provenience: Square E24/S72 (NE and NW quads), Levels 23B-24A; detection elevation $95.11 \mathrm{~m}$; base elevation $95.02 \mathrm{~m}$ Stratigraphic Context: Unit II

Archeological Chronology: Late Paleoindian

Description: Feature 160 consisted of a concentration of burned sediment and charcoal found within an area measuring roughly $40-\mathrm{x}-70 \mathrm{~cm}$. The concentration included a circular pocket of burned gravel (ca. $25-\mathrm{cm}$ diameter) with two dendritic stringers of burned gravel extending from one edge. Three bags of burned sediment were collected from the feature area (unanalyzed).
Comments: The size and shape of Feature 160 suggest this concentration of burned sediment probably represents some sort of burned plant.

\section{Feature 161}

Feature Type: artifact cluster (debitage concentration) Provenience: Square E24/S78 (all quads), Level 24A; elevation $95.24 \mathrm{~m}$

Stratigraphic Context: Unit Id/II

Archeological Chronology: Late Paleoindian

Figure: $26-48$

Description: Feature 161 consisted of 37 pieces of debitage concentrated in a ca. 30-x-30-cm area. This group apparently includes at least 3 raw materials (cherts ranging from light to dark gray in color), and several specimens retain some cortex. Flake length ranges from $\mathrm{ca} .1-6 \mathrm{~cm}$, and 7 specimens are at least $4 \mathrm{~cm}$ long. Debitage densities are relatively high for the level as a whole (and in preceding Level 23B), and the excavators felt Feature 161 was probably associated with a chipped stone activity area. The recovery for this level also included 282 pieces of debitage (excluding the Feature 161 group), a distal fragment of a lanceolate dart point (Specimen 28X1C-4), a core tool (Specimen 28X1A-1), and an edgemodified flake (Specimen 28X1C-3).

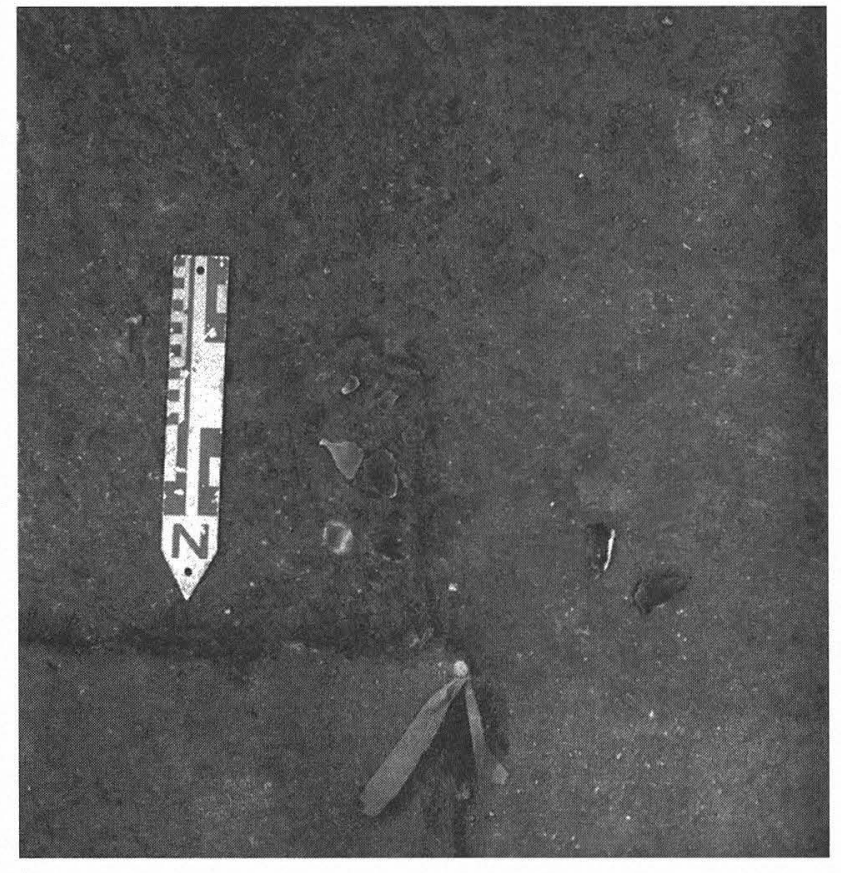

FiguRE 26-48. Feature 161 (debitage concentration) in Square E24/ S78, Level 24A.

\section{Feature 162}

Feature Type: burned sediment with a few burned rocks Provenience: Square E26/S76 (NE quad), Level 24B; elevations recorded for 3 rocks range from 95.09 to $95.04 \mathrm{~m}$ 
Stratigraphic Context: Unit II

Archeological Chronology: Late Paleoindian

\section{Special Studies:}

Macrobotanical: 3 macroplant samples analyzed (see Chapter 40)

Figure: 26-49

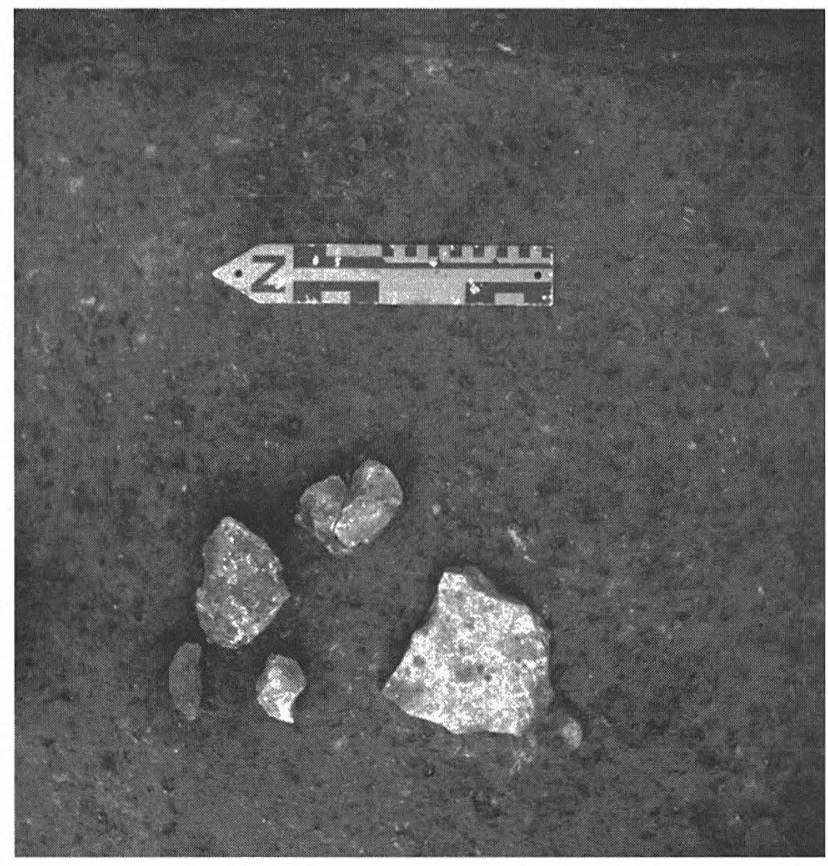

FIGURE 26-49. Feature 162 in Square E26/S76, Level 24B.

Description: Feature 162 was a relatively tight cluster of five burned rocks (5-15-cm size) surrounded by a dispersed scatter of burned rocks. The cluster measured $30-\mathrm{x}-40 \mathrm{~cm}$ with an estimated thickness of ca. $5-10 \mathrm{~cm}$. All of the rocks were discolored from burning, and two exhibited thermal fractures. Three of the smaller rocks rested on a $10-\mathrm{x}-20-\mathrm{cm}$ patch of burned sediment, and some burned gravels were also observed in the feature area. Three small charcoal samples were collected from Feature 162 (CH-600, CH-601, and $\mathrm{CH}-602$ ), and all were classified as indeterminate wood. No artifacts were provenienced to this feature, but a Golondrina-Barber base (33X2C-1) was found about $90 \mathrm{~cm}$ south of the cluster at approximately the same elevation $(95.10 \mathrm{~m})$.

\section{Feature 163}

Feature Type: burned rock cluster

Provenience: Square E22/S78 (all quads), Levels 25A-26A; elevations recorded for 18 rocks range from 95.01 to $95.13 \mathrm{~m}$ (with the majority clustering at 95.07 to 95.12 )

Stratigraphic Context: Unit Isi-c/Unit Id transition

Archeological Chronology: Late Paleoindian Special Studies:

Use-Wear: 1 artifact analyzed by Driskell (see Chapter 22)
Macrobotanical: 1 macroplant sample analyzed (see Chapter 40)

Figure: $26-50$

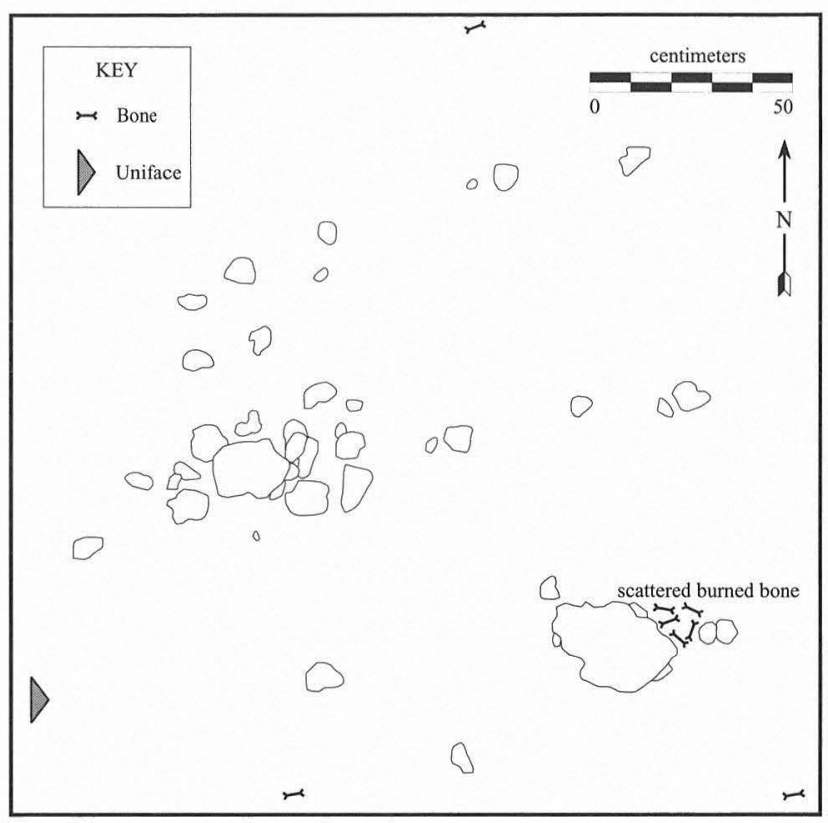

Figure 26-50. Feature 163 in Square E22/S78, Level 26A.

Description: Feature 163 consisted of a relatively tight burned rock cluster surrounded by a dispersed scatter of rocks and other cultural debris. The central cluster measured ca. 30-x$60 \mathrm{~cm}$ with a thickness of ca. $5-10 \mathrm{~cm}$. It included about 17 closely spaced rocks ranging from $3-15 \mathrm{~cm}$ in diameter. About 20 additional rocks were found scattered within a 1.5 -m-diameter area surrounding the cluster. The scatter had a vertical extent of ca. $10-15 \mathrm{~cm}$. Although most of these rocks were rather small (3-7-cm size), the scatter included 1 larger slab (ca. 20-x-30 cm) that had a small concentration of burned bone fragments immediately adjacent to it. Additional bone fragments were scattered throughout the feature area, and the excavator noted an apparent increase in the amount of burned bone and identifiable articulated bone fragments in this level. The excavator also noted a significant increase in the relative density of charcoal, lithic artifacts (both tools and unmodified debitage), and aquatic snails within the feature area. The charcoal primarily consisted of small flecks scattered throughout the feature. Only one charcoal sample was collected (CH-1164), and it was identified as indeterminate wood. Associated lithic artifacts include a Stage 2 biface (24Z1C-1), a thin uniface (24Z1D-3), and 34 pieces of debitage. Driskell performed a use-wear analysis on the thin uniface and concluded it was probably used for hide-working.

A mussel shell umbo fragment (Lampsilis teres; see Chapter 37) and 53 bone fragments were also provenienced to Feature 163 , and much of the bone $(n=43)$ was clearly burned (see Chapter 33). Most of the bone was identified as medium/large mammal or Vertebrata indeterminate fragments, 
but the sample also included 2 burned turtle shell fragments, a burned rabbit calcaneus, an antelope or deer phalanx, a medium-size mammal humerus (proximal end; burned), and 9 mammal long-bone fragments (all burned).

Comments: Feature 163 probably represents a small hearth or cooking feature associated with the Wilson component.

\section{Feature 164}

Feature Type: burned tree (or other large plant)

Provenience: Square E26/S76 (NE and SE quads), Levels 26B-28B; detection elevation $94.90 \mathrm{~m}$; base elevation ca. $94.67 \mathrm{~m}$

Stratigraphic Context: The upper portion of this feature (as recorded) was in the Unit Id/II transition zone but the lower portion extended into the Unit Isi-c/Id/II transition.

Archeological Chronology: Late Paleoindian

\section{Special Studies:}

Radiocarbon: 1 wood charcoal sample was AMS-dated to $9520 \pm 60$ B.P. (CAMS-14806; see Chapter 25)

Macrobotanical: 1 macroplant sample analyzed (see Chapter 40)

Figure: 26-51

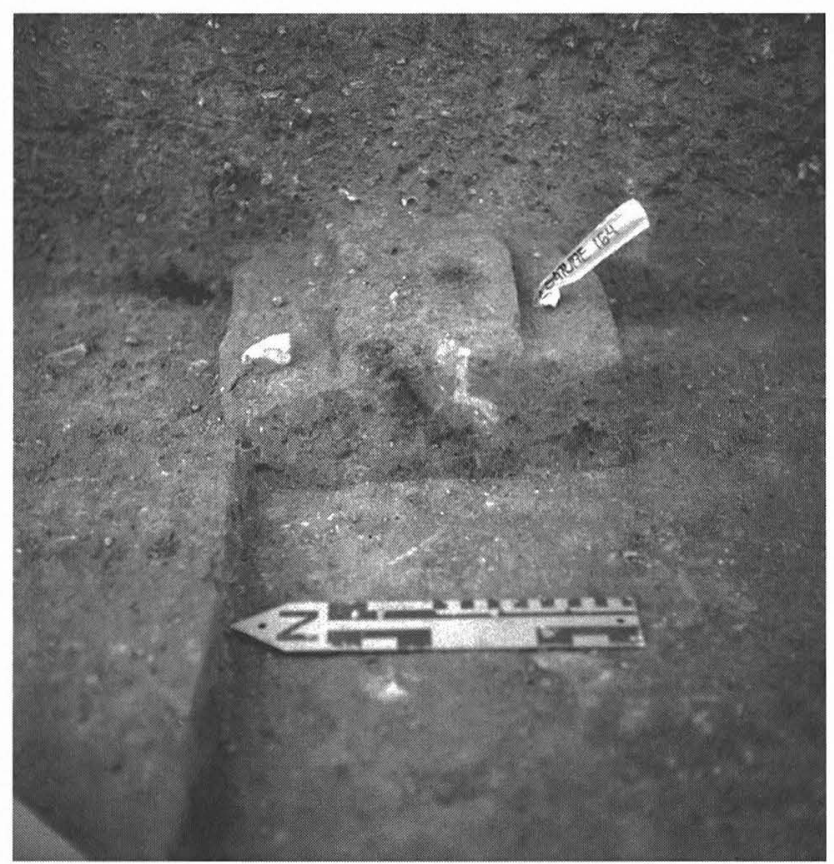

FigURE 26-51. Feature 164 in Square E26/S76, Levels 26B-28B, looking east.

Description: Feature 164 was a burned tree (or other large plant) that apparently grew on a surface in either Unit Id or lower Unit II. The feature extended into the east wall, but the exposed portion measured ca. $40-50 \mathrm{~cm}$ in diameter with a vertical extent of at least $23 \mathrm{~cm}$. Feature 164 had a very irregular outline in plan view with the central core consisting of several dense pockets of charcoal surrounded by intensely burned, oxidized sediment (shades of yellow, orange, and red). Cross-sectioning revealed rootlike stringers of charcoal surrounded by burned sediment. The oxidized sediment was concentrated primarily in the upper portion of the feature (Levels 26B-27A), and the most significant concentrations of charcoal were found in Levels 26B and 28B (at detection level and base).

Associated materials include some burned sediment collected as a thermoluminescence sample (unanalyzed) and two charcoal samples. One of the charcoal samples (CH-558) was radiocarbon dated (see date above), and the other $(\mathrm{CH}-$ 609 ) was analyzed as a macroplant sample (indeterminate wood). Seven pieces of debitage were also provenienced to Feature 164 (presumably before it was recognized as a natural feature).

\section{Feature 165}

Feature Type: burned live oak tree

Provenience: Square E26/S72 (NE and SE quads), Levels 24A-30B; detection elevation $94.98 \mathrm{~m}$; base elevation $94.53 \mathrm{~m}$ Stratigraphic Context: Units Isi-c, Isi-c/II, and II

Archeological Chronology: Late Paleoindian Special Studies:

Radiocarbon: 1 wood charcoal sample was conventionally dated to $9530 \pm 88$ B.P. (Tx-4828; see Chapter 25)

Macrobotanical: 19 macroplant samples analyzed (see Chapter 40)

Figure: 26-52

Description: Feature 165 was a burned live oak tree that grew on a surface in either lower Unit II or upper Unit I. It

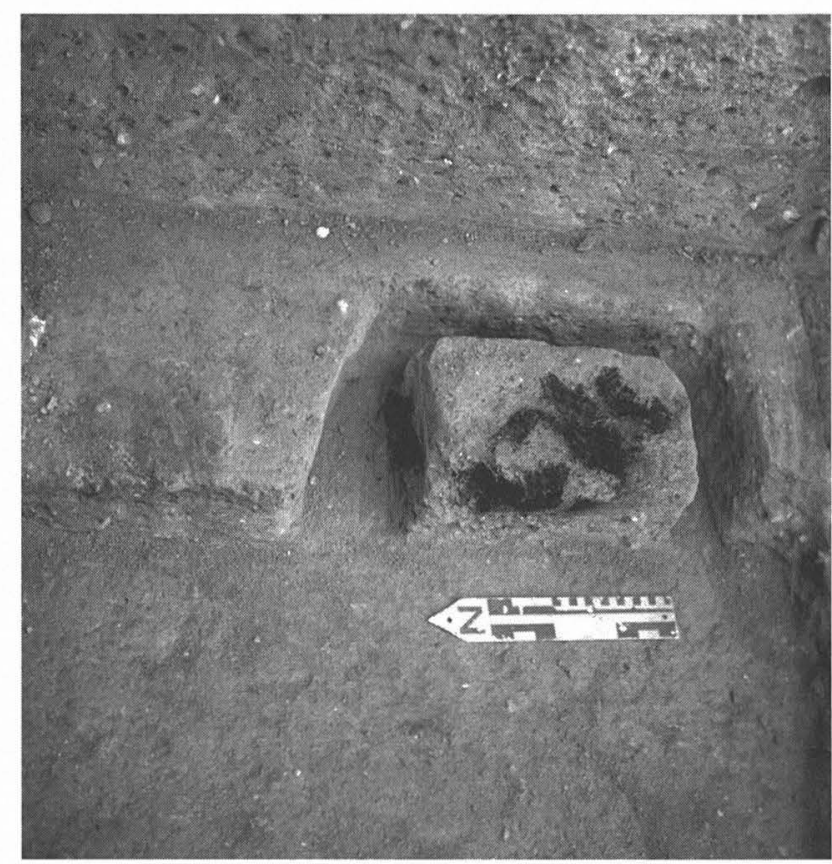

FiguRE 26-52. Feature 165 in Square E26/S72, Levels 24A-30B, looking east. 
was located in the northeast corner of Block 6, and it extended into both the north and east walls (it is clearly visible in the final Block 6 profile drawings and photographs of both walls). The exposed portion of Feature 165 included several large concentrations of charcoal surrounded by intensely burned, oxidized sediment. The largest charcoal concentration (found in Level 26B) measured ca. $25 \mathrm{~cm}$ in diameter, and the burned sediment encompassed an area measuring at least $130 \mathrm{~cm}$ in diameter (maximum extent documented in Level 26A). Cross-sectioning of Feature 165 revealed several tapering cones of charcoal (surrounded by burned sediment) that clearly represented burned roots. The feature had a documented vertical extent of ca. $45 \mathrm{~cm}$.

At least 25 charcoal samples were collected from different areas of Feature 165. One of these samples was conventionally dated (see above), and 19 others were analyzed as macroplant samples (11 were identified as live oak wood; 8 were indeterminate wood). Nine bags of sediment were also collected from the feature area, including 5 bags of burned sediment collected as thermoluminescence samples (unanalyzed). About 39 pieces of debitage were provenienced to Feature 165 as well (presumably before it was recognized as a burned tree).

Comments: The radiocarbon date on Feature 165 is very similar to dates obtained on four other burned trees (Features $164,167,198$, and 253) found in similar stratigraphic positions (at or near the Unit I/II contact). Since these dates were used to estimate the age of the Unit I/II contact (see Chapter 25), the stratigraphic position of Feature 165 warrants further commentary.

The upper portion of Feature 165 (documented in Levels 24A-27A) was located in Unit II, but it extended downward through the Unit Isi-c/II transition (Levels 27B-29A), into Unit Isi-c (Levels 29B-30A). Unit Id is missing (presumably eroded) in this area of the site. The north wall profile for Block 6 shows Feature 165 immediately below a very disturbed looking, tilted wedge of Unit II gravelly matrix. The appearance of this profile suggests Feature 165 may represent a tree heave. The depth of the oxidized, burned sediment and the presence of burned clods fairly deep in the feature (Level 27B) suggest the tree may have burned after it was uprooted or was uprooted as it burned. Although it is still not clear what surface the tree originated from, clearly it burned after the lower portion of Unit II was deposited. Although this suggests it most likely grew from a surface in lower Unit II, the tree may also relate to a surface at the top of Unit I with the base and trunk buried by the deposition of the lower Unit II gravels (presumably after the deposition and subsequent erosion of Id). It is possible that deposition of either Unit Id or Unit II sediments could have killed a live oak tree growing in the upper portion of Isi-c and this could have led to a subsequent tree heave/burning sequence.

\section{Feature 166}

Feature Type: large burned rock basin

Provenience: Area B, Square W0/N8 (NE and SE quads), E2/ N8 (NW, SW, and SE quads), Levels 25A-27A; detection elevation $95.05 \mathrm{~m}$; base elevation $94.83 \mathrm{~m}$

Stratigraphic Context: Unit I/II transition?

Archeological Chronology: Late Paleoindian

Special Studies:

Use-Wear: 4 artifacts analyzed by Driskell, Kay, and Hudler (see Chapter 22)

Magnetic Susceptibility: 4 samples analyzed (see Chapter 28)

Micromorphology: 2 samples analyzed (see Chapter 29 and Appendix 7)

Gastropods: 1 sample analyzed (see section by Theler in Chapter 37)

Macrobotanical: 4 macroplant samples analyzed and 2 flotation samples processed (see Chapter 40)

Figure: 26-53

Description: Feature 166 was a roughly circular, shallow basin containing at least 75 burned rocks. The basin measured $160 \mathrm{~cm}$ east-west by at least $120 \mathrm{~cm}$ north-south (southern edge extended into the wall), and it had a documented depth of about $22 \mathrm{~cm}$. At least 15 large limestone slabs (20$30-\mathrm{cm}$ size) were found in the basin along with a number of smaller fragments. The rocks were clustered primarily along the western and eastern walls of the basin with relatively few rocks found in the center. Most of the larger slabs sloped downward toward the rock-free center. The north side of the feature had a somewhat scattered, disturbed appearance as if some of the rocks had been displaced.

The sediment within the basin was described as being "clearly darker" than sediment outside the feature area, and small charcoal flecks were scattered throughout. A few larger pieces of charcoal were also found, but these were very poorly preserved. Of the six charcoal samples collected from this feature, four were analyzed as macroplant samples $(\mathrm{CH}-$ 953, CH-954, CH-977, and CH-989), and all were classified as indeterminate wood. Although no ash or burned sediment was observed in the field, both were observed in two thinsection slides made from Feature 166 sediment samples (WL94-F1 and WL94-F2). Some calcined limestone fragments were also observed in these slides.

Two Golondrina-Barber points were found in association with Feature 166. The first specimen (51Y1B-1) was found at the northern edge of the feature at approximately the same elevation as the highest rocks. A distal section of a backed knife (51Y1B-3) was also found at the north edge of the feature just a few centimeters below the point. The second Golondrina-Barber point (50YA-1) was found among the rocks clustered on the west side of the basin. A Clear Fork biface (51AA1D-3) and 2 Stage 2 bifaces (51AA1D- 1 and 51AA1D-2) were found in the rock-free central portion of 


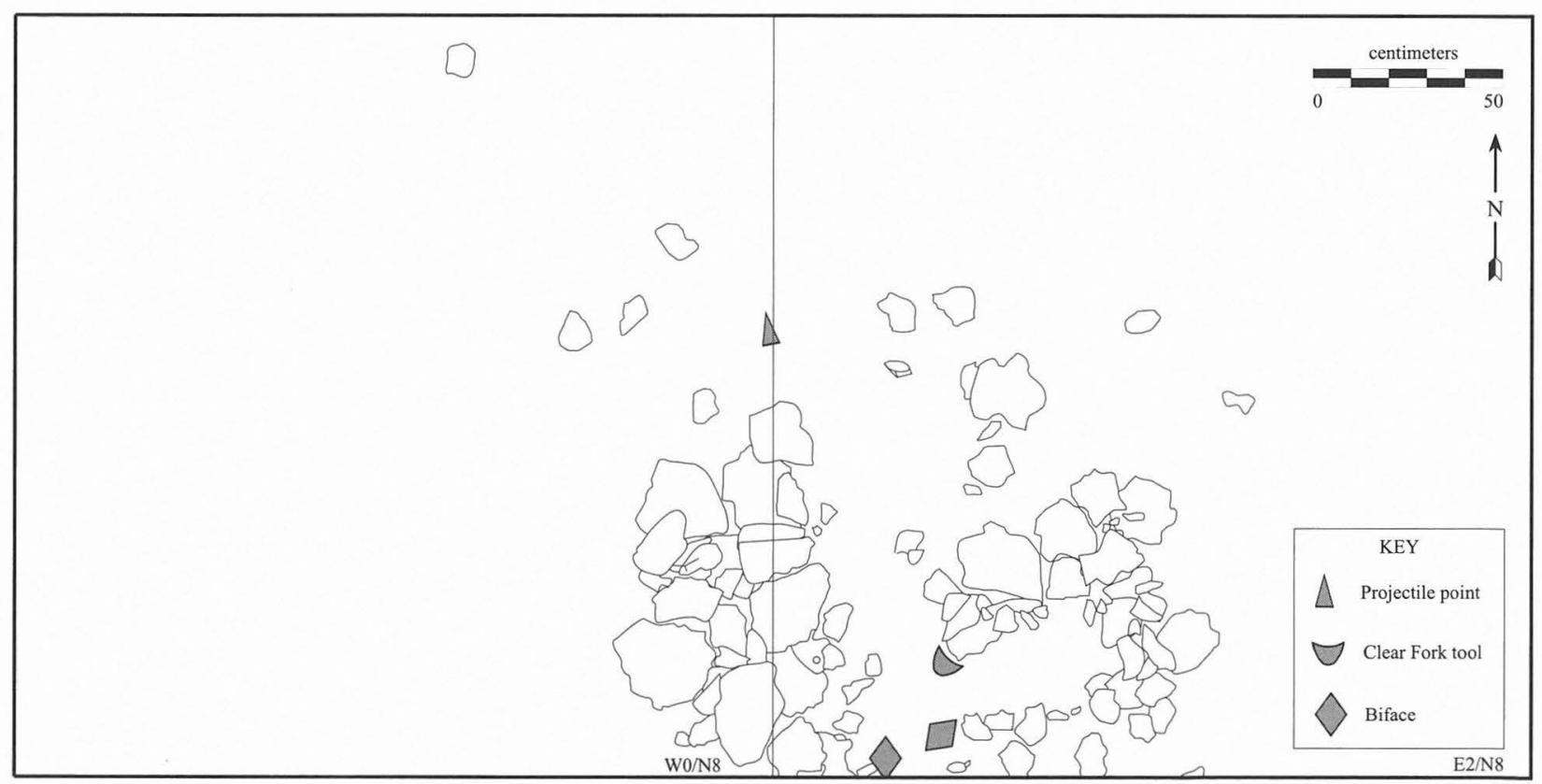

FIGURE 26-53. Feature 166 in Squares W0/N8 and E2/N8.

the feature (near the base). The 1/4-inch screen recovery from Feature 166 also included 77 pieces of debitage and 21 bone fragments. The bone included 19 Vertebrata indeterminate fragments (all burned; 6 calcined), a medium/large Vertebrata long-bone fragment (unburned), and a small/medium Vertebrata long-bone fragment (burned). An additional 24 bone fragments ( 9 mammal, 15 Vertebrata) were recovered from a fine-screened sediment sample (ca. 1.25 liters), and 20 of these specimens were burned.

Use-wear studies were conducted on four of the chipped stone tools provenienced to Feature 166: Kay examined the two Golondrina-Barber points; Driskell examined one of the Stage 2 bifaces (51AA1D-2); and both Driskell and Hudler examined the Clear Fork biface. Kay found evidence to suggest both of the Golondrina-Barber points were initially used as knives rather than projectile points. Specimen 50YA-1 was subsequently broken and then recycled as a radial break tool (gouging/scraping burin), and specimen 51AA1D-3 was last used as a projectile point. Driskell found no definitive use-wear evidence on either of the specimens he examined, but Hudler identified a "domed polish" on the Clear Fork biface which may be indicative of use as a woodworking tool.

Six bulk matrix samples were also collected from Feature 166 , and most of this sediment was used for magnetic susceptibility, micromorphology, gastropod, flotation, and finescreen faunal samples with the remainder curated. The magnetic susceptibility results were difficult to evaluate given the uncertainties of the feature's stratigraphic context, but the values generally fell within the range observed for nonfeature samples in lower Unit II and upper Unit I.

The flotation samples were not productive (no identifiable plant remains), but the gastropod sample was fruitful.
This sample yielded a total of 180 terrestrial (representing at least 12 taxa) and 8 aquatic snails (representing 4 taxa). Most of the identifiable terrestrial snails were taxa commonly found throughout the site deposits, but some lowerfrequency taxa were represented as well. The latter group include Punctum vitreum, Glyphyalinia roemeri, and G. umbilicata, and Vertigo cf. V. rugosula. These species are generally indicative of relatively mesic, woodland habitats. The aquatic snails include 2 Phreatodrobia nugax nugax, 4 Fossaria dalli, 1 Physella sp., and 1 Gyraulus sp. The latter 3 taxa are typically found in moist vegetation growing in shallow pools and $P$. n. nugax is typically found in the deep artesian waters of the Edwards Aquifer (though it can also be expelled through spring vents). Although the aquatic snails may have been deposited in the feature during a flood, they may also reflect human collection of water and/or aquatic biota.

Comments: The stratigraphic position of Feature 166 is somewhat problematical. Since Area B was not sampled in the TARL excavations, we do not have a confident correlation between all of the Area B levels and the stratigraphic units defined in the TARL excavations. The available data suggest Feature 166 was probably located in the lower portion of Unit II, slightly above the Unit I/II transition.

Feature 166 represents the earliest of the large burned rock basin features identified in the Wilson-Leonard excavations. Although the stratigraphic context is somewhat problematical, the feature was clearly located within Late Paleoindian-age deposits (possibly associated with a Golondrina-Barber occupation). Feature 166 is a little smaller than the large burned basins found in Early Archaic contexts at this site, but it may have functioned in a similar fashion. 


\section{Feature 167}

Feature Type: burned live oak tree

Provenience: Squares E22/S72-76, E24/S72-76, E26/S74; Levels 28B-33B; documented elevation range was 94.69-94.11 m Stratigraphic Context: Feature 167 apparently grew on a surface in Unit Isi-c with the root system intruding both Units Isi and Icl

Archeological Chronology: Late Paleoindian

Special Studies:

Radiocarbon: 1 wood charcoal sample was AMS-dated to $9410 \pm 60$ B.P. (CAMS-14805; see Chapter 25); see also the date for Feature 72 (which is probably part of the same tree) Macrobotanical: 2 macroplant samples analyzed (see Chapter 40)

Figure: $26-54$

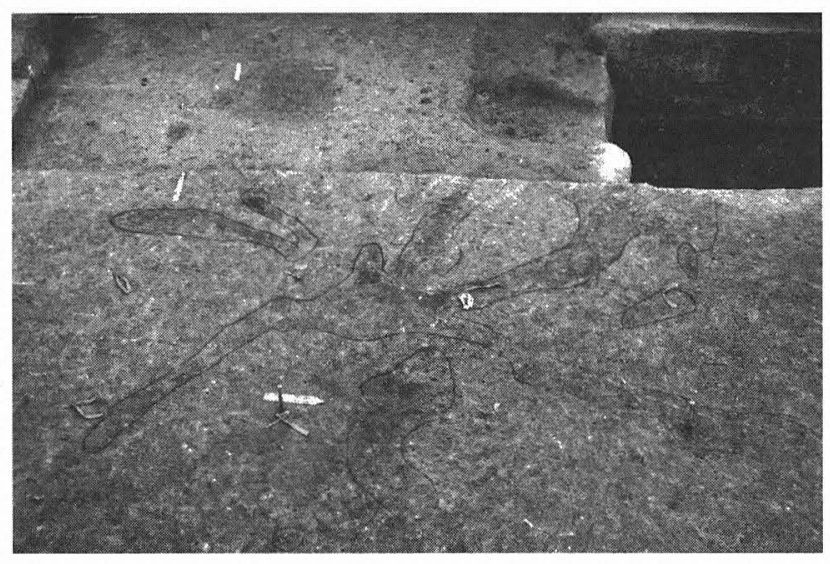

Figure 26-54. Feature 167 as exposed at the base of Level 31A in Block 6 , looking west. Block 4 is visible at top of photo.

Description: Feature 167 was a burned live oak that probably grew from a surface in the upper portion of the Leanne soil (Unit Isi-c). The central core of the tree's root mass was found in Square E22/S74, but the roots extended into at least six other Block 6 squares. Some burned roots recorded as Features 72 and 73 in Block 4 are probably associated with Feature 167 as well (see Feature 72 and 73 description).

The shape of Feature 167 changed considerably as it was excavated, gradually increasing in size in the upper levels and decreasing in the lower levels. At the higher elevations (Levels 28B-29B) it consisted of scattered circular patches of charcoal and oxidized sediment measuring ca. 15$30 \mathrm{~cm}$ in diameter. With depth, these circular patches became more elongated, and they eventually merged into a multilobed shape that clearly represented a connected root mass (see Figure 26-54). At the point of maximum horizontal extent (Levels 30B-31A), Feature 167 measured approximately 3-x-4 $\mathrm{m}$. Much of the sediment within the lobes was organically stained (very dark brown, grayish brown, and grayish black) but there were occasional areas of burned, oxidized sediment (reddish brown, reddish orange, and yellow). Small quantities of charcoal were found scattered throughout the feature, but there were no large concentrations. In the lower levels (31B-33B) the feature contracted into scattered circular patches of burned sediment and charcoal (similar to the upper levels). Feature 167 had a documented vertical extent of ca. $58 \mathrm{~cm}$.

Two of the five charcoal samples provenienced to Feature 167 were analyzed as macroplant samples. One was identified as live oak wood (CH-1217) and the other as indeterminate wood (CH-1214). An AMS radiocarbon date was obtained on the live oak sample (see date above).

Comments: Feature 167 was first detected in the upper portion of the Leanne soil (Isi-c). The level notes for the overlying Unit Id and/or Unit II levels in these squares (Unit Id is missing in some areas) included no references to burned soil or charcoal concentrations. These data suggest Feature 167 burned before Units Id and/or II were deposited in this area of the site.

\section{Feature 168}

Feature Type: pit

Provenience: Square E20/S76 (NE and NW quads), Levels 31A-35B; detection elevation $94.30 \mathrm{~m}$; base elevation $93.90 \mathrm{~m}$ Stratigraphic Context: Unit Isi/Icl/Isi-c transition (Feature 168 intruded Units Isi and Icl, but it appears to have been excavated from a surface in the lower portion of Isi-c )

Archeological Chronology: Late Paleoindian Special Studies:

Magnetic Susceptibility: 12 samples analyzed (see Chapter 28) Micromorphology: 4 samples analyzed (see Chapter 29 and Appendix 7)

Gastropod: 1 sample processed (no recovery; not reported) Macrobotanical: 1 macroplant sample analyzed; 3 flotation samples processed (see Chapter 40)

Phytolith: 1 sample analyzed (see Chapter 41)

Figures: 26-55, 26-56, 26-57, 26-58, 26-59, and 26-60

Description: Feature 168 was an oval-shaped pit with relatively straight sides and a flat to slightly rounded base. It measured approximately $70-x-85 \mathrm{~cm}$ and was at least $40 \mathrm{~cm}$ deep. Although the pit was first recognized and recorded about 10-20 cm below the base of the Leanne soil (Unit Isi-c), it was probably excavated from an occupational surface in the lower portion of this soil. The pit fill resembled the Leanne soil (in both color and texture), and its outline was not clearly visible until the excavation reached the underlying Isi deposits. At this level, the dark fill contrasted sharply with the surrounding pale yellowish brown matrix, and the pit outline was easily delineated (see Figures 26-55 and 26-56).

Feature 168 was located $100 \mathrm{~cm}$ north of a very similar pit (Feature 169) and $85 \mathrm{~cm}$ south of Burial 2 (see Figures 2655 and 26-57). These three features were located in approximately the same stratigraphic position (first detected slightly below the base of the Leanne soil), and all are probably associated with the Wilson component (see Chapter 8). 


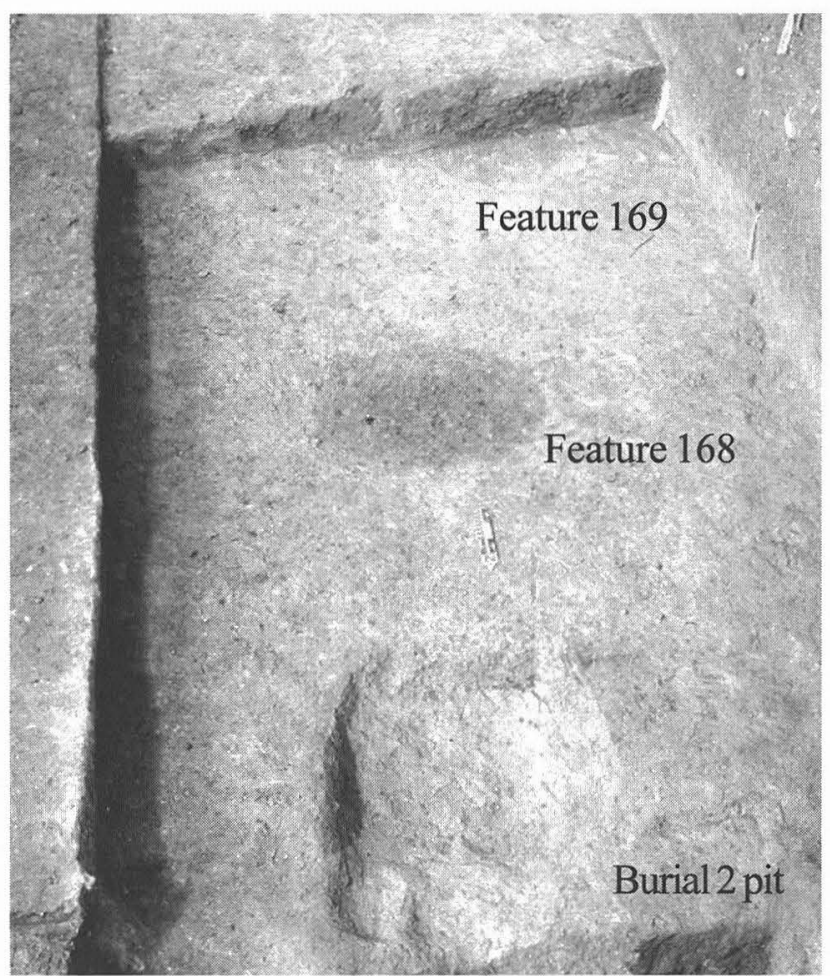

FIGURE 26-55. Features 168 and 169 at detection level in Squares E20/S78, looking south. The base of the Burial 2 pit (after burial removel) is visible in the foreground.

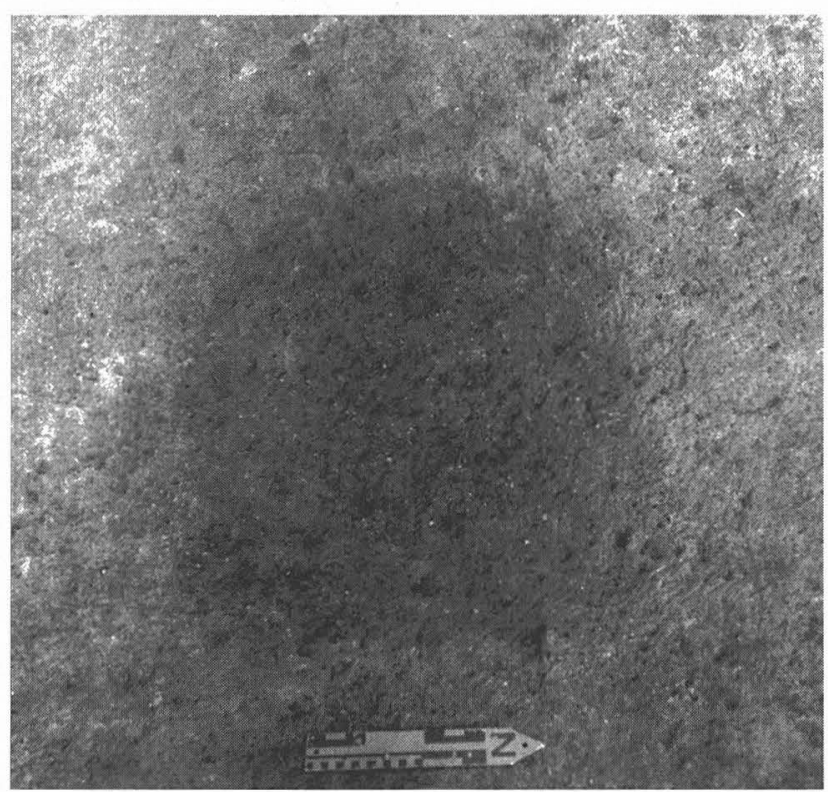

FIGURE 26-56. Feature 168 as it appeared at detection level (base of Level 31A) in Square E20/S76, looking west.

Features 168 and 169 were found several months after Burial 2 was excavated and when they were first identified there was considerable conjecture that they might represent additional human burials. This notion was abandoned when no human remains were found in either pit.

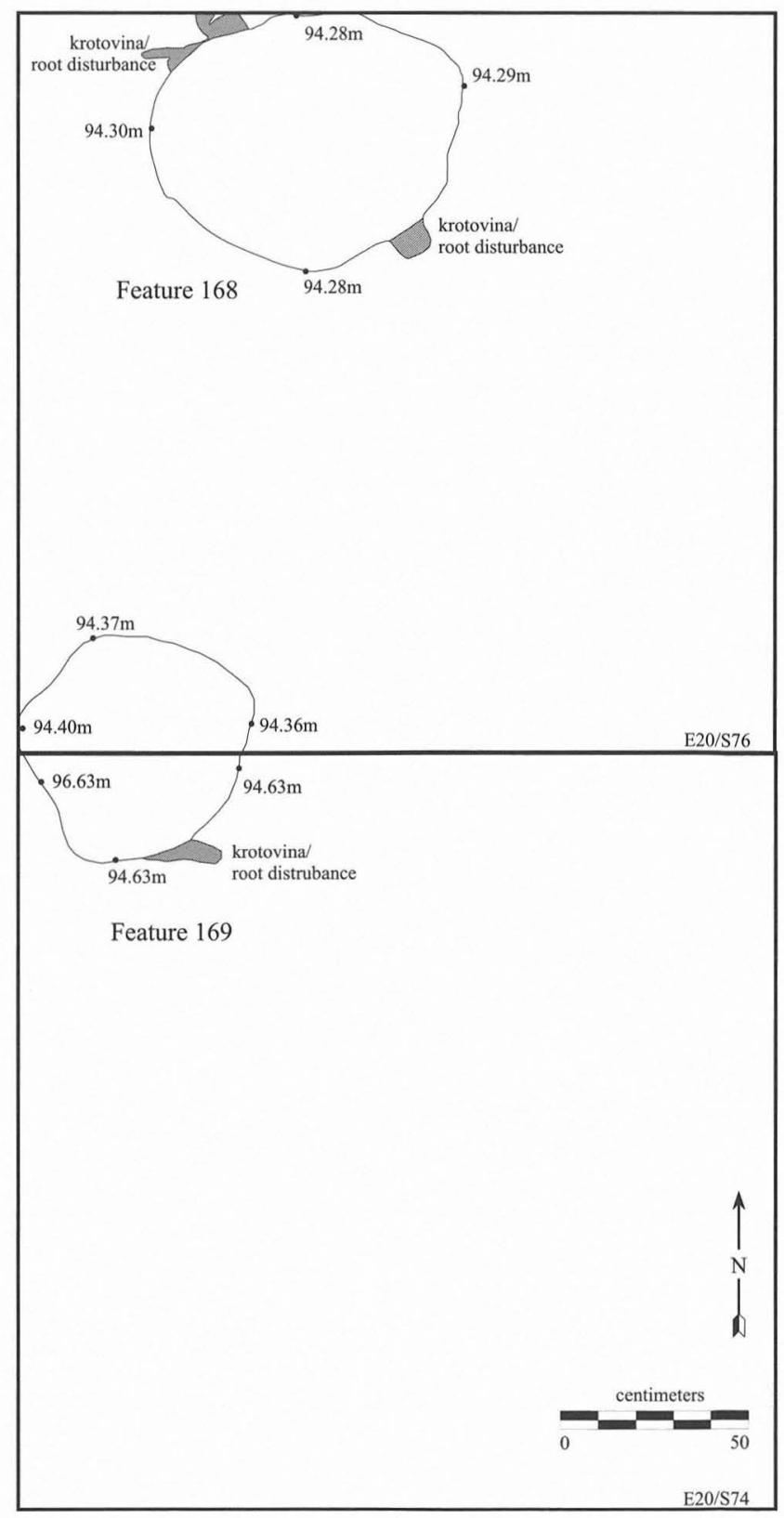

FIGURE 26-57. Features 168 and 169 at their detection levels (base of Level 31A in Square E20/S76 and top of Level 30A in Square E20/S74).

Fill was removed from the south half of Feature 168 first, and the resulting profile was recorded (see Figure 26-58). Two "zones" are depicted on this profile: the upper layer (ca. $8-20 \mathrm{~cm}$ thick) was described as a medium brown silty clay with yellow mottles and a moderate gravel content; the lower layer (ca. $12-27 \mathrm{~cm}$ thick) was described as a dark brown silty clay with a high gravel content. The profile also shows a slightly darker, gravel-filled disturbance (ca. 30-cm diameter) in the approximate center of the pit which probably represents an intrusive burrow. When all the fill was removed (see Figure 26-59), some small indentations and crevices were observed in the walls and floor of the pit, and these 


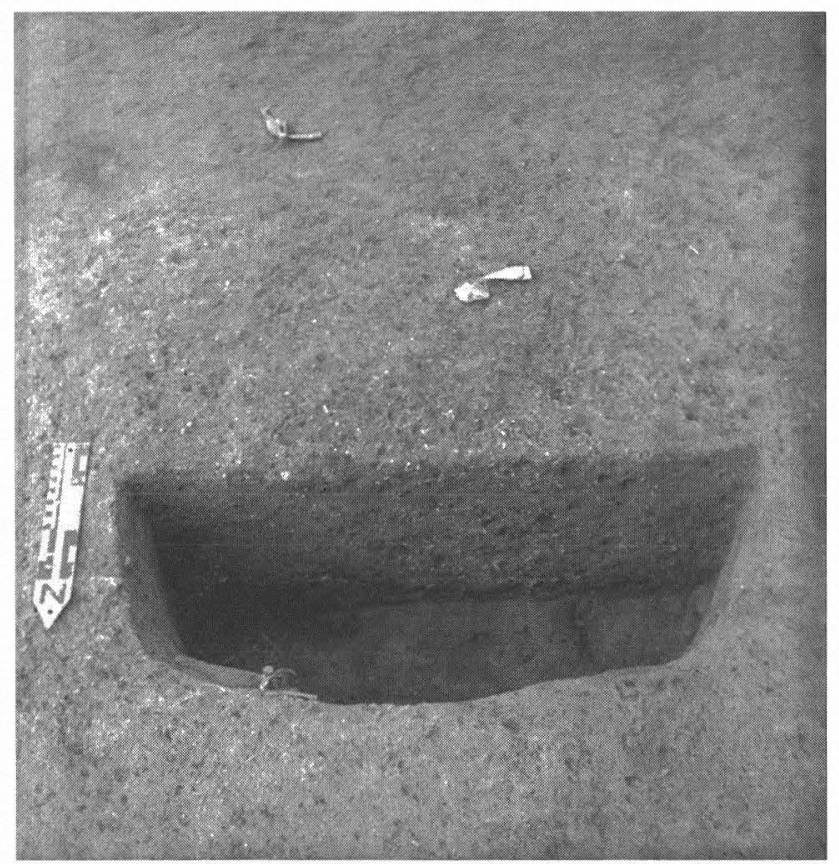

FigURE 26-58. Feature 168 after fill was removed from south half of pit, looking south.

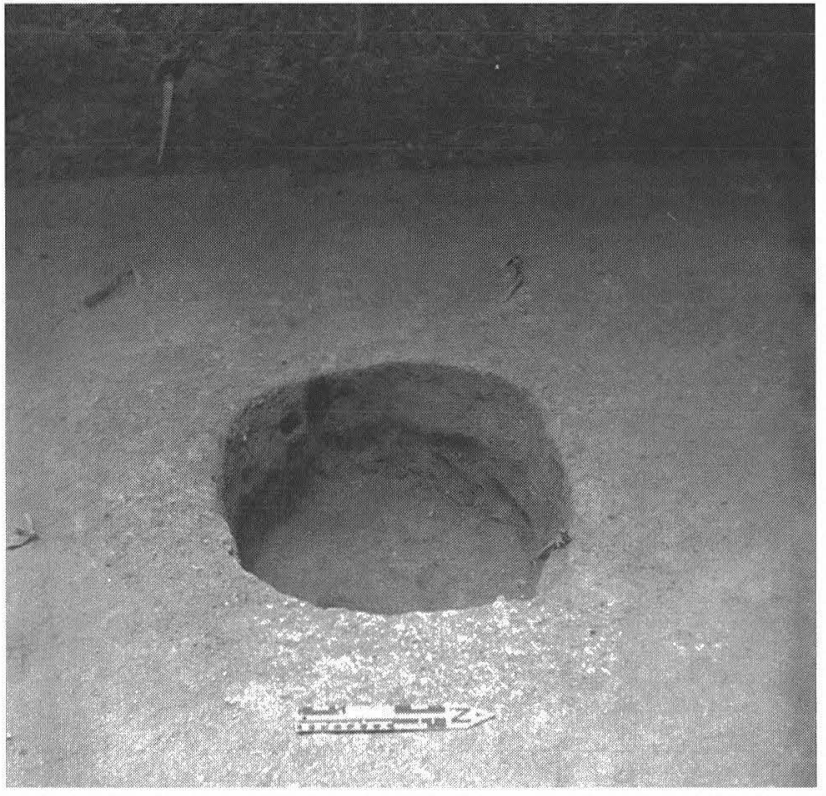

FIGURE 26-59. Feature 168 after fill was removed, looking west.

were interpreted as possible digging stick marks from the initial pit excavation (see Figure 26-60). No evidence of burning was visible in the pit walls and floor, and no burned sediment was observed in the fill.

A small amount of poorly preserved charcoal was collected during fill removal (CH-1060; identified as indeterminate wood) along with a bone fragment (Vertebrata indeterminate; see Chapter 33), a small hematite pebble, and six pieces of debitage. The hematite and at least two debitage pieces were found within the intrusive burrow.

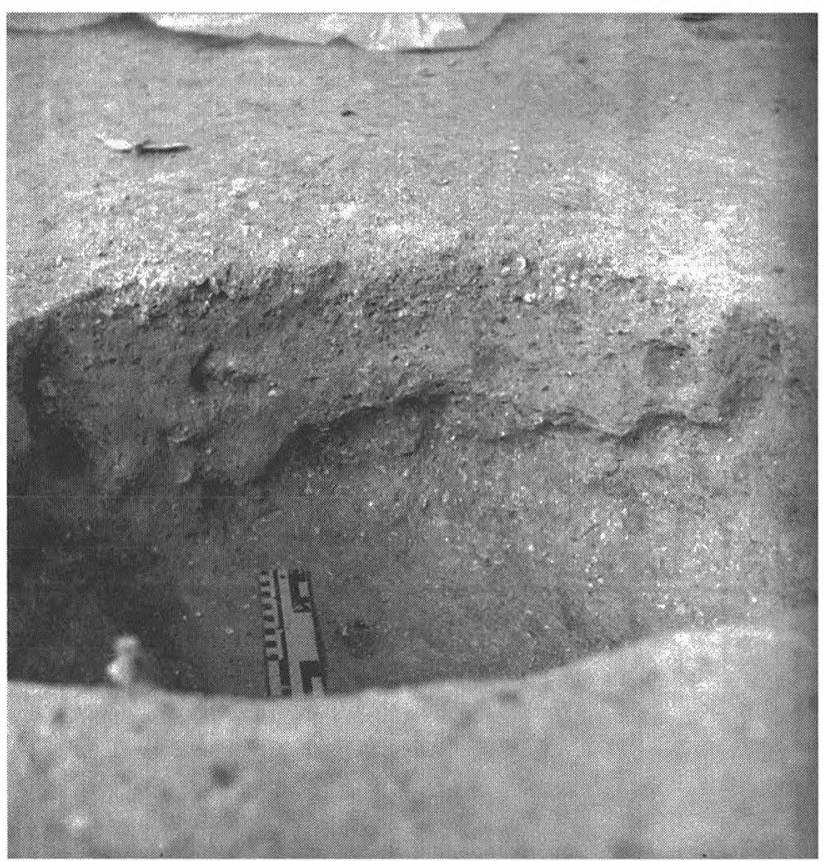

FIGURE 26-60. South wall of Feature 168 after fill removal, looking south. Note indentations thought to represent possible digging stick marks from initial pit excavation.

All of the Feature 168 fill was bagged in the field for processing in the lab. When the TARL analysis began, there were 42 bags of Feature 168 fill that had been screened in the TxDOT lab (dry-screened sediment that was rebagged) and 5 bags of unscreened fill. Since no documentation of the TxDOT screening process was found (the bags were simply labeled as "screened"), it is unknown what mesh size was used or if any materials were recovered. In the TARL analysis 4 magnetic susceptibility samples were pulled from 4 of the previously screened bags; 5 liters of sediment were processed as flotation samples, and the remainder was finescreened using the method described in Chapter 34 (to see if significant materials were missed in the previous screening). Although the flotation samples were not productive, the fine-screening effort was very informative. Numerous small fragments of diverse materials (micro-debitage, small rock and mineral fragments, small pieces of bone and snail shell, etc.) were recovered on both the $1 / 8$-inch and $1 / 16$-inch screens. These results suggest that the previous screening probably used coarser than $1 / 8$-inch (most likely $1 / 4$-inch) mesh.

Both the coarse and fine fractions retrieved in this finescreening effort were examined for general content, unusual inclusions, and evidence of burning (see notes on file at TARL). Both fractions were compared to nonfeature samples from other Unit I contexts (fine-screen samples from Units Isi-c, Isi, and Icl) in an attempt to learn more about the stratigraphic context of Feature 168 and potential sources of its fill (e.g., was the pit actually filled with Leanne soil sediments, as it appeared, or did the pit and its fill predate the 
accumulation of the Leanne soil). No unusual items and relatively little burned material were found in the Feature 168 samples. In the stratigraphic comparison, these samples most closely resembled Isi-c samples, although the bone density seemed to be a little higher (though this was not established statistically). The Feature 168 samples also appeared to have a higher bone density than similar samples from Feature 169 and Burial 2. A total of 356 faunal specimens was retrieved, and though the majority were classified as Vertebrata indeterminate, the sample also included 27 rodent, 3 turtle, 3 fish, 3 amphibian, 1 reptile, and 1 snake specimen (see Appendix 8). Approximately $35 \%$ of this bone appeared burned.

Most of the previously unscreened pit fill was used for magnetic susceptibility, micromorphology, gastropod, flotation, and phytolith samples (remainder was curated). No identifiable remains were retrieved from the gastropod, flotation, and phytolith samples. Most of the magnetic susceptibility samples exhibited values that were comparable to nonfeature samples from Units Isi and Icl. One of the samples, however, exhibited a significantly higher value that more closely resembled samples from Unit Isi-c.

Four micromorphology thin-sections were made from three bags of Feature 168 fill (WL93-Pi1, WL93-Pi2, WL93Pi3[1], WL93-Pi3[2]), and none of the four samples exhibited any evidence of burned sediment or other burned materials. The thin-sections also suggested that the pit may have been filled with a mixture of Isi, Isi-c, and Icl sediments. Relatively little organic material was observed in any of the samples, but the sample from the upper portion of the fill (WL93-Pi1) seemed to have a slightly higher organic content.

Comments: Feature 168 clearly represents a deliberately excavated pit which may have originated from the same occupational surface as Burial 2. Although there was initially some speculation that Feature 168 might represent another human burial, no evidence of human remains was found in the pit fill. Analysis of the pit fill yielded little data to support alternative explanations, and the fill may, in fact, have little to do with the pit's use. It is not unlikely that the pit was left empty after its final use and gradually filled with secondary deposits that were unrelated to its original function. Furthermore, the pit fill was probably disturbed by intrusive burrowing (and possibly other forms of bioturbation) that may have introduced material into the fill.

Nonetheless, the size and shape of the pit suggest at least two possible interpretations: it may represent either a cooking facility or a storage pit. If it was used for cooking, then it probably does not represent a baking or roasting pit since no evidence of in situ burning or baking was observed on the walls or base, there were no burned rocks, and only a small amount of charcoal was found in the fill. Alternatively, it might have been a hide-lined stone boiling pit (with the hide and boiling stones removed after use so they could be used again elsewhere). The lack of evidence of burning might also lend support to the storage pit hypothesis.

\section{Feature 169}

Feature Type: pit

Provenience: Square E20/S78 (NW quad), Levels 30A-34A; Square E20/S76 (SW quad), Levels 31A-34A; detection elevation $94.63 \mathrm{~m}$; base elevation $94.08 \mathrm{~m}$

Stratigraphic Unit: Isi/Isi-c (this feature intruded Unit Isi, but it was apparently excavated from a surface in the lower portion of Unit Isi-c)

Archeological Chronology: Late Paleoindian

Special Studies:

Magnetic Susceptibility: 10 samples analyzed (see Chapter 28)

Micromorphology: 3 samples analyzed (see Chapter 29 and Appendix 7)

Gastropod: 1 sample processed (no recovery; not reported) Macrobotanical: 1 macroplant sample analyzed; 5 flotation samples processed (see Chapter 40)

Phytolith: 1 sample analyzed (see Chapter 41)

Figures: 26-55, 26-57, 26-61, 26-62, 26-63, 26-64, 26-65

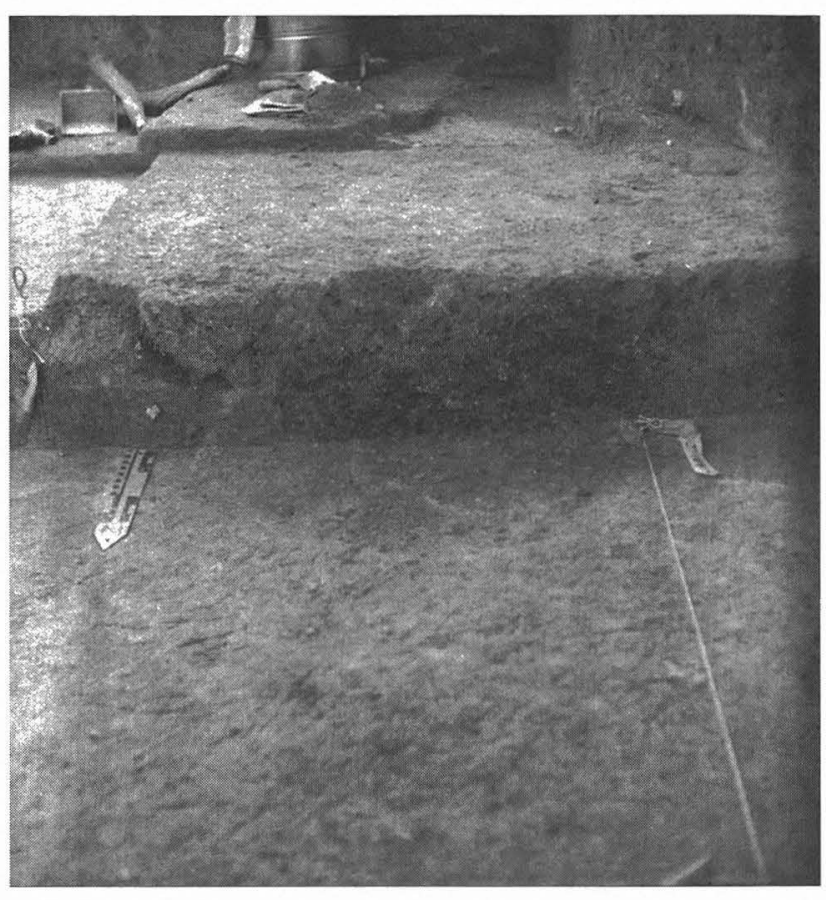

FIGURE 26-61. Feature 169 as it appeared at detection level, looking south. South half of the pit is at the top of Level 30A in Square E20/S78; north half is at the base of Level 31A in Square E20/S76.

Description: Feature 169 was an oval-shaped pit with relatively straight sides and slightly rounded to flat base. It measured approximately $60-\mathrm{x}-65 \mathrm{~cm}$ with a depth of at least $55 \mathrm{~cm}$. Like Feature 168 (located ca. $100 \mathrm{~cm}$ north of Feature 169 ), this pit was probably excavated from a surface slightly above its detection level. It probably originated in the lower portion of the Leanne soil (Unit Isi-c), but it was first recognized slightly below the base of the soil. At this depth there was a stronger contrast between the dark pit fill (which 


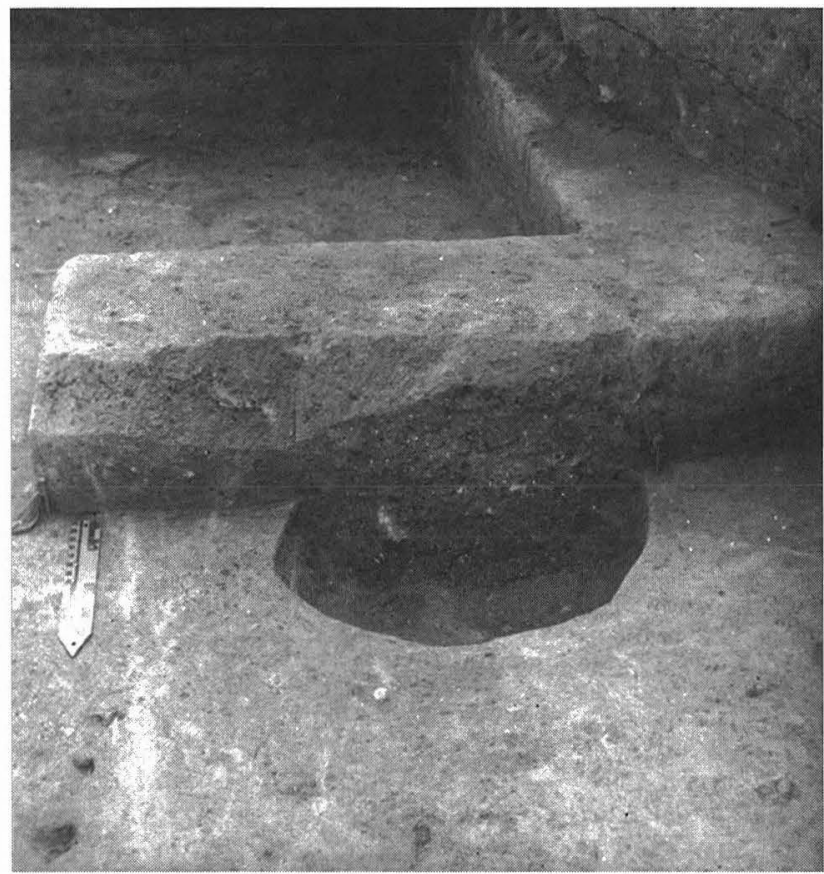

FIGURE 26-62. Feature 169 after fill was removed from the northern half in July 1983, looking south.

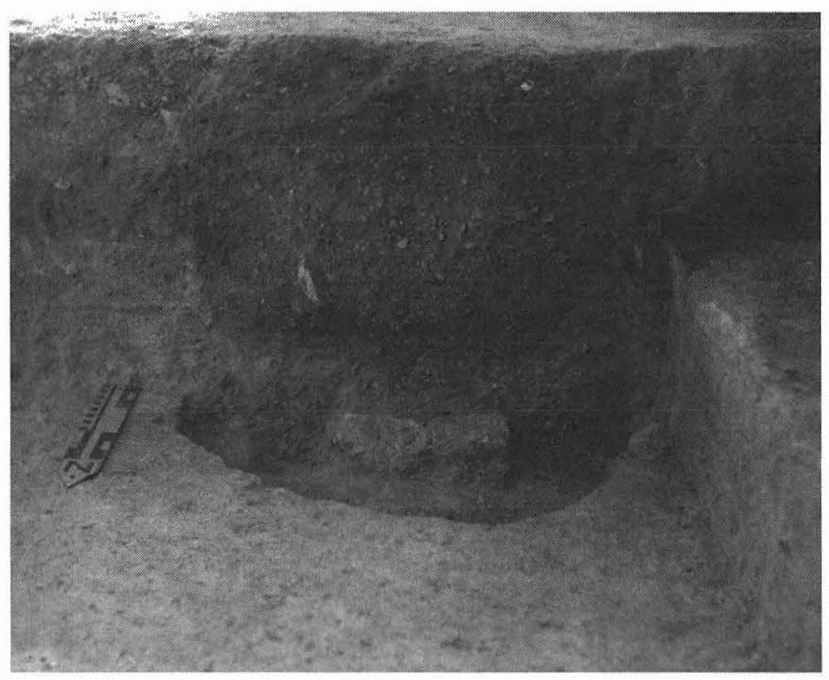

FIGURE 26-63. Feature 169 after additional fill was removed from northern half in December 1983, looking south. Note the limestone cobbles found at the base of the pit.

closely resembled the Leanne soil) and the surrounding Unit Isi matrix.

Feature 169 was investigated in a complicated fashion over a period of seven months. The pit was roughly bisected by the S76 gridline; thus the north half lay within Square E20/S76, and the south half lay within Square E20/ S78. When the pit was first discovered in June 1983, part of the north half had been removed (without recognition) in the excavation of Levels 29-31 in E20/S76. Since E20/S78 was still at the base of Level 29 at that time, the pit had been inadvertently cross-sectioned in the south wall of E20/S78

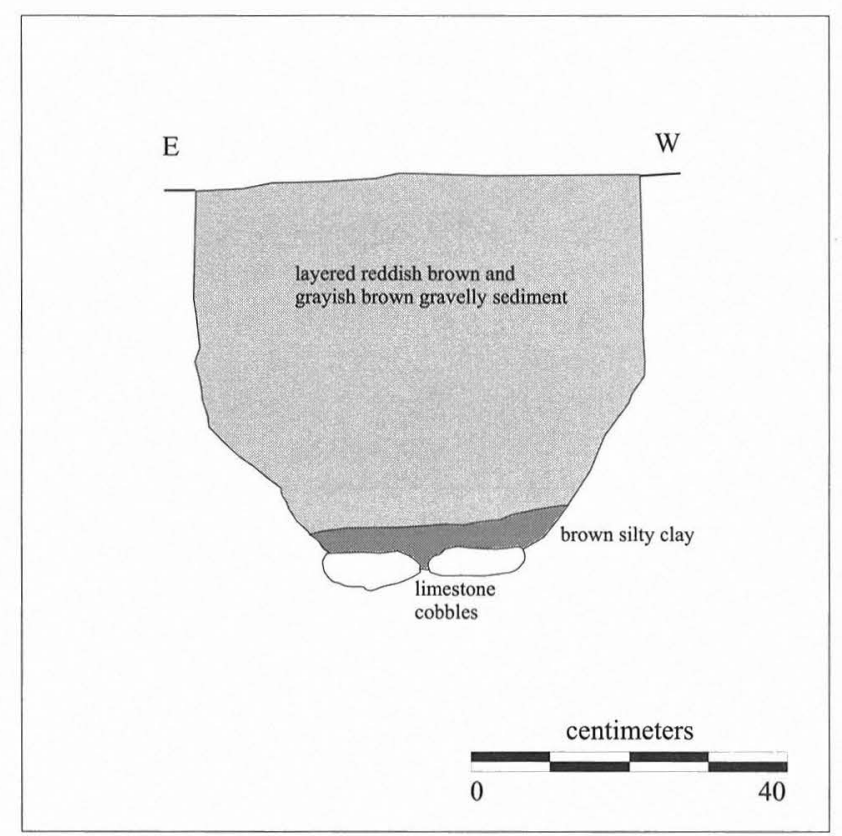

FIGURE 26-64. Profile of the south half of Feature 169 showing the limestone cobbles found in the "brown silty clay" layer at the base of the pit.

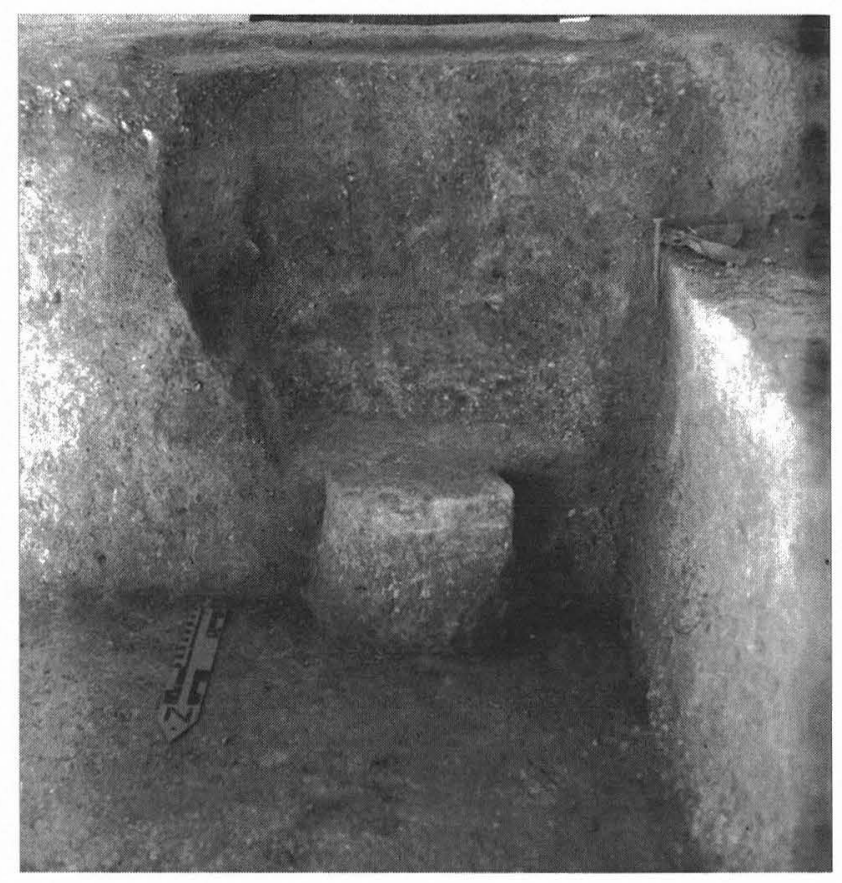

FIGURE 26-65. Feature 169 after fill was removed from the south half of the pit, looking south.

(see Figure 26-61). After the pit outline was recorded, the south half of Feature 169 was pedestaled in E20/S78, and level excavations were resumed in that square. Fill was removed from the surviving portion of the north half in July 1983 (see Figure 26-62), but when level excavations resumed in this square five months later, the excavators discovered that the base of Feature 169 extended below the earlier fill 
removal. Fill was removed from this basal remnant in December 1983 (see Figure 26-63) and about a month later, fill was removed from the south half of the pit (see Figure 26-64).

The records documenting this investigation are quite complex and of variable quality (with the latter stages documented in greater detail). The following description of the pit fill was pieced together from several key sources, but it relies very heavily upon the field notes from the last two months of the investigation. The pit was apparently filled with several distinct layers of sediment. The basal remnant excavated in December 1983 contained a "brown silty clay" that apparently included small carbonate nodules but relatively little gravel. The field notes indicate this layer was very different from the gravelly fill found above it. This layer also contained two tabular limestone cobbles measuring ca. $10-15 \mathrm{~cm}$ in diameter that appear to have been intentionally placed (side by side) in the bottom of the pit (see Figure 2663 and 26-65). The notes do not indicate if the rocks exhibited any evidence of burning, and they were not collected. A small amount of charcoal and some debitage was also found in this layer.

The fill above this (documented primarily during removal of south half of pit fill) was described as having a somewhat layered appearance with poorly defined lenses of darker ("reddish brown") and lighter ("grayish brown") gravelly sediment. This gravelly layered fill had an overall reddish cast that was somewhat anomalous (this reddish color is clearly visible in some of the color photographs of Feature 169). The excavators observed relatively few cultural inclusions in this fill, but they did collect six pieces of debitage, three burned bone fragments, and three charcoal samples (CH-1043, CH-1044, and CH-1066). The bone fragments were identified as a medium-sized mammal metapodial fragment and two Vertebrata indeterminate fragments (see Chapter 33). One of the charcoal samples ( $\mathrm{CH}-1043)$ was classified as indeterminate wood, but the others were too poorly preserved for macrobotanical analysis. The notes also mention some possibly burned gravels and one or two small limestone cobbles in the gravelly fill.

All of the Feature 169 fill was bagged in the field for processing in the lab. When the TARL analysis began, there were 7 bags of fill that had been screened in the TxDOT lab (dry-screened sediment that was rebagged) and 13 bags of unscreened fill. Since there was no documentation of the screening process used in the TxDOT lab (as with Feature 168 fill; see discussion above) these bags were rescreened at TARL using the fine-screen method described in Chapter 34. The results suggest these bags were probably dryscreened through $1 / 4$-inch mesh at TxDOT since quite a bit of material was retrieved on both the $1 / 8$-inch and 1/16-inch TARL screens (microdebitage, rock and mineral fragments, small pieces of bone and snail shell, etc.).

A portion of the unscreened fill was curated, and the remainder was used for magnetic susceptibility, micromorphology, gastropod, flotation, phytolith, and fine-screen fau- nal samples. Although the gastropod, flotation, and phytolith samples were not productive, the other studies were more informative. The magnetic susceptibility samples were drawn from bags representing three locations within the pit fill: the inner core of the south half, the outer margins of the south half, and the base of the north half. The susceptibility results varied slightly for each of these locations with the highest values obtained on samples from the inner core of the south half and the lowest values on the samples from the base of the north half. The values obtained on the south half samples (both inner core and outer margins) fell within the range seen for nonfeature samples from the lower portion of the Leanne soil. The north half results resembled samples from the upper portion of Unit Isi.

The micromorphology samples (WL93-Pi4, WL93Pi5, and WL93-Pi7) were drawn from the same three bags as the susceptibility samples. All three samples resemble Leanne soil thin-sections but two of the samples (WL93-Pi4 and WL93Pi-5) also exhibit localized areas of red-stained matrix that probably represent iron oxide staining (this may account for the reddish color of the fill). These two samples (representing the inner core of the south half and the base of the north half) also contained a few burned limestone fragments that were reddened from heat alteration. Small quantities of ash and/or charcoal were also observed in all three samples.

Faunal remains retrieved from the fine-screening of both the previously screened sediment and the unscreened sediment (ca. 61.4 liters) were combined in the faunal analysis summarized in Appendix 8. The samples included an eggshell fragment (see Chapter 36) and 722 bones/bone fragments (see Appendix 8). Much of the bone was classified as Vertebrata indeterminate fragments, but the sample also included specimens classified as mammal $(\mathrm{n}=58)$, rodent $(\mathrm{n}=$ $48)$, rabbit $(n=2)$, reptile $(n=2)$, snake $(n=2)$, turtle $(n=4)$, fish $(n=12)$, and bird $(n=1)$. Approximately $33 \%$ of this bone appeared burned.

While the faunal remains were being picked from both the 1/8-inch and 1/16-inch fractions of the fine-screen sample, these samples were also examined for general content (e.g., rocks, minerals, microdebitage, snail shell fragments, etc.), unusual inclusions, and evidence of burning (notes on file at TARL). One of the more interesting finds was a Cretaceous shark tooth similar to the one found in nearby Burial 2. Shark teeth were also found in several dozen fine-screen samples from TARL Squares 12 and 20 (primarily from Unit I contexts).

Although the Feature 169 fine-screen samples generally contained little evidence of burning, they did include some small, burned limestone fragments, some burned bone, and some possibly burned calcium carbonate nodules. In comparison to the Feature 168 samples, the Feature 169 samples contained relatively more burned limestone fragments but less bone (and a slightly lower percentage of burned bone). Many of the limestone fragments 
were reddened from heat alteration, and there were also a number of hematite fragments (some may have been ochregrade). As with the Feature 168 samples (see above), a stratigraphic comparison was conducted, and found the Feature 169 samples most closely resembled Leanne soil samples.

Comments: Feature 169 probably represents some sort of domestic feature associated with the Wilson component, and it may have originated from the same occupational surface as Feature 168 and/or Burial 2.

The two limestone cobbles found in the base of the pit may be important functional clues. They may represent heated stones that were used in a food preparation (e.g., baking, roasting, stone-boiling, or leaching), or they may represent basal supports for a hide or basketry container that rested inside the pit. Although no definitive evidence of in situ burning was observed in the walls or base of this pit, some evidence of burning (burned limestone, charcoal, and ash) was observed in the micromorphology and finescreen samples. If this burned material represents secondary fill, it may reflect activities conducted in the pit vicinity that were functionally related to its use (e.g., heating stones for stone boiling). The reddish color of the fill probably represents iron oxide staining, but the source and significance is unknown.

\section{Feature 170}

Feature Type: bone cluster

Provenience: Square E24/S78 (SW quad), Levels 31A-32A; detection elevation ca. $94.51 \mathrm{~m}$; base elevation ca. $94.40 \mathrm{~m}$

Stratigraphic Context: Unit Isi Archeological Chronology: Early Paleoindian

Figure: 26-66

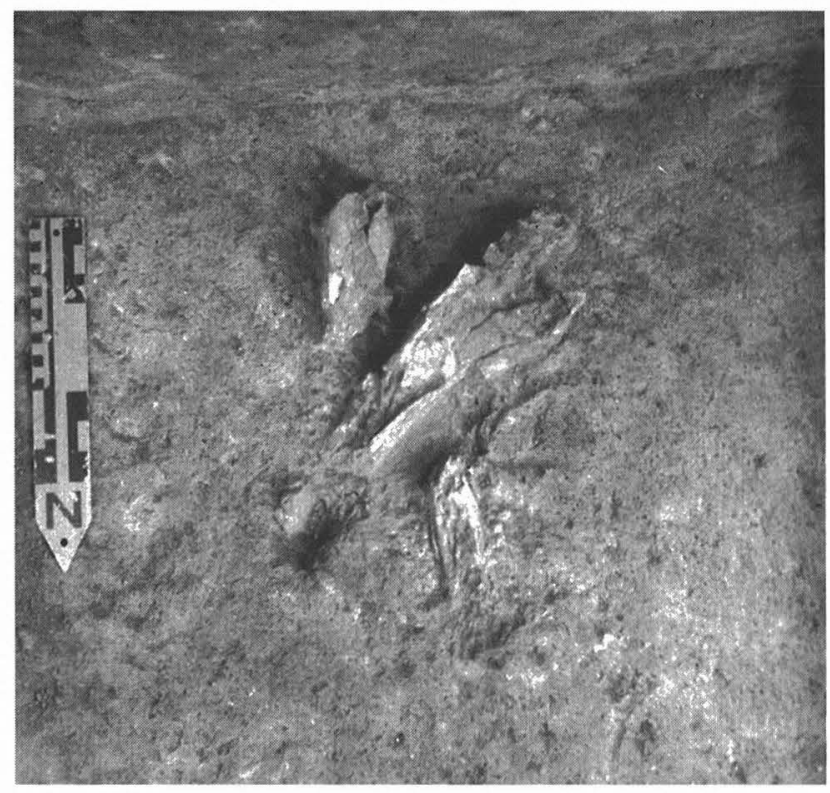

FIGURE 26-66. Feature 170 as exposed in Square E24/S78, Level $31 \mathrm{~B}$, looking south.
Description: Feature 170 consisted of a cluster of at least 63 bone fragments found within a ca. 40 -cm-diameter area. Scattered flecks of charcoal and some debitage were found in the area surrounding the bone (same quad/levels), but the excavators did not associate this material with Feature 170. The bone cluster included 3 large fragments that were tentatively identified in the field as humerus, tibia, and unidentified longbone fragments of a large mammal (possibly a bison). Baker analyzed 63 bone fragments provenienced to Feature 170 and 15 bone fragments from the same quad (SW quad, Level 31B; Lot 28EE2D) that may be associated with this feature as well (see Chapter 33 and Appendix 10). The Feature 170 fragments included 2 fragments classified as very large mammal (long bone), 2 as large Vertebrata (indeterminate), 30 as medium/large mammal (long bone and indeterminate), and 29 as Vertebrata (indeterminate) fragments. All 63 fragments had angular (dry bone) breaks, and none was burned. The possibly associated bone included 1 classified as a bison tibia (distal end), 1 as a medium/large Vertebrata (long bone), 5 as medium large mammal (indeterminate), and 8 as Vertebrata (indeterminate). All of these fragments exhibited angular breaks, and only 8 were burned (the bison tibia and 7 of the Vertebrata indeterminate fragments).

Comments: Although Feature 170 was exposed in transitional levels that cross-cut the Isi-c/Isi stratigraphic boundary, the level notes and point-plot data clearly place this cluster of bone in the upper portion of Isi (just below the base of Isi-c).

\section{Feature 171}

Feature Type: burned rock cluster

Provenience: Squares E24/S78 (NE quad) and E26/S78 (NW quad), Level 32B; detection elevation ca. $94.38 \mathrm{~m}$; base elevation ca. $94.30 \mathrm{~m}$

Stratigraphic Context: Unit Isi-c

Archeological Chronology: Late Paleoindian

Figure: 26-67

Description: Feature 171 consisted of nine burned rocks that were loosely grouped within an area measuring ca. 85 -x$135 \mathrm{~cm}$. Rock elevations indicate a vertical extent of ca. $8 \mathrm{~cm}$. Although most of the rocks were spaced at least $10-20 \mathrm{~cm}$ apart, the group was recorded as a feature "cluster" primarily because relatively few burned rocks were found in the surrounding area. Most of the rocks were relatively small angular fragments (3-8-cm size), but three were slightly larger (10-25-cm size). One of the larger rocks was fractured in situ, and another was reddened from heat exposure. No burned sediment or charcoal was reported from the feature area, but small quantities of charcoal were found in general level recovery. A Stage 2 biface fragment (28FF2A-2) and a thin uniface (32FF2B-1) were found immediately north of the cluster, but no other artifacts were provenienced to Feature 171. Comments: Feature 171 may represent the remains of a small hearth associated with the Wilson component. 


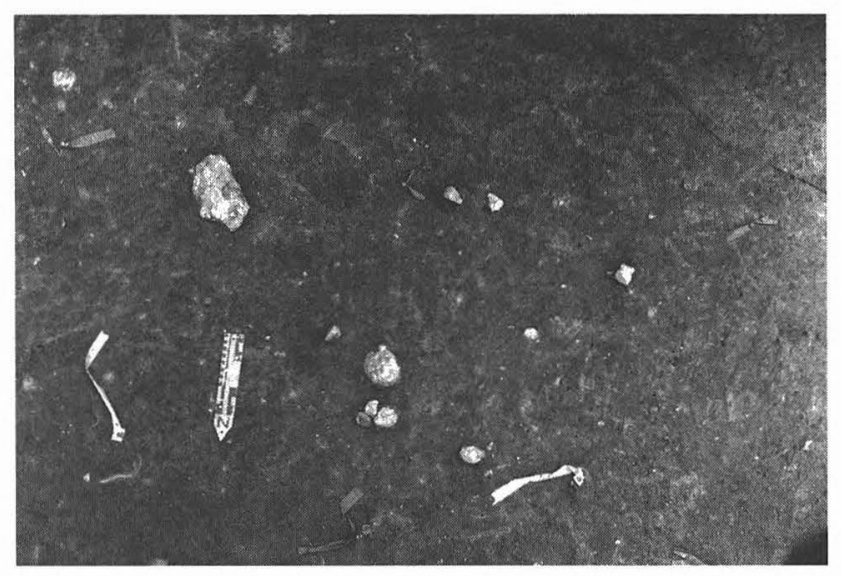

FigURE 26-67. Feature 171 in Squares E24/S78 and E26/S78, Level 32B, looking south.

\section{Feature 175}

Feature Type: probable burrow

Provenience: Squares E26/S76 (SW quad) and E26/S78 (NW quad), Levels 36A-37B; detection elevation $93.93 \mathrm{~m}$; base elevation $93.68 \mathrm{~m}$

Stratigraphic Context: Feature 175 intruded both Unit Icl and Unit Isi deposits, but it may have originated in the lower portion of Unit Isi-c

Archeological Chronology: Early or Late Paleoindian

Special Studies:

Magnetic Susceptibility: 4 samples analyzed (see Chapter 28)

Macrobotanical: 2 macroplant samples analyzed; 2 flotation samples processed (see Chapter 40 )

Figure: 26-68

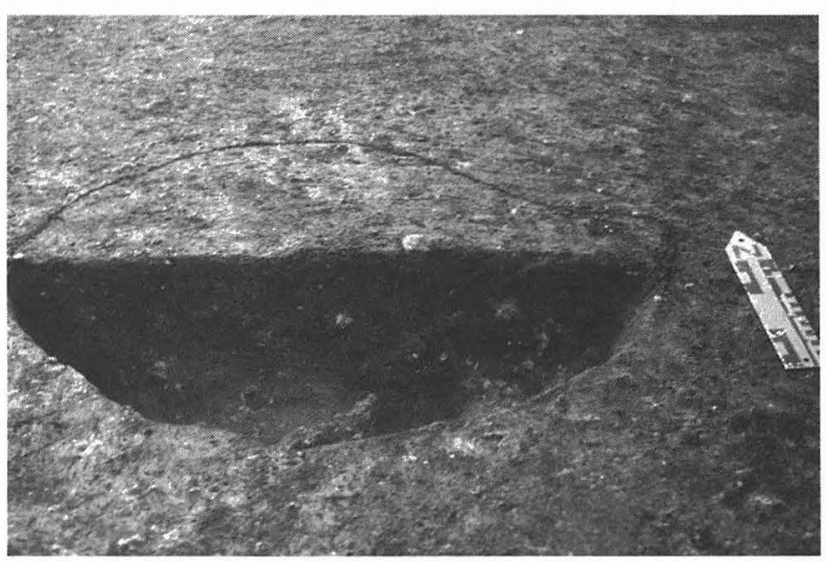

FIGURE 26-68. Feature 175 in Squares E26/S76 and E26/S78, Levels 36A-37B, looking north. Photograph was taken after the fill was removed from the south half of the feature.

Description: Feature 175 was interpreted in the field as a possible cultural pit; however, further analysis of this roughly oval-shaped soil anomaly has indicated it probably represented some sort of animal burrow. It measured approxi- mately $70-\mathrm{x}-80 \mathrm{~cm}$ and had a documented vertical extent of ca. $25 \mathrm{~cm}$. The base of the feature was somewhat irregular with the south half being about $8 \mathrm{~cm}$ deeper than the north half. Feature fill was described as dark grayish brown to medium brown, and it was easily distinguished from the surrounding yellowish brown matrix. During the removal of feature fill the excavators collected 5 pieces of debitage, 14 bone fragments (all Vertebrata indeterminate; see Chapter 33 ), and 2 charcoal samples (CH-510 and CH-578; both classified as indeterminate wood). In addition to these materials, 2 bags of feature fill were collected as bulk matrix samples. During the TARL analysis much of this sediment was processed as special samples in an effort to ascertain the cultural or natural origin of this feature. These samples included magnetic susceptibility, flotation, and fine-screen faunal samples. The magnetic susceptibility results were comparable to nonfeature samples from similar stratigraphic contexts (no significant deviation detected). The flotation samples were not productive but 50 additional bone fragments were recovered from the ca. 1-liter fine-screen sample (see Appendix 8). Almost half were classified as Vertebrata indeterminate fragments, but the sample also included a few specimens classified as mammal, rodent, turtle, and snake.

Comments: Feature 175 was found in approximately the same stratigraphic position as Feature 178, another sediment anomaly that has been interpreted as a probable burrow (see Feature 178 description below).

\section{Feature 176}

Feature Type: burned sediment with a few burned rocks Provenience: Square E28/S78 (NE quad), Levels 9-10; detection elevation $96.50 \mathrm{~m}$; base elevation $96.40 \mathrm{~m}$

Stratigraphic Context: the Unit IIIb/IIIc transition

Archeological Chronology: Middle or Late Archaic Special Studies:

Magnetic Susceptibility: 2 samples analyzed (see Chapter 28)

Micromorphology: 1 sample analyzed (see Chapter 29)

Macrobotanical: 1 flotation sample processed (see Chapter 40)

Figure: 26-69

Description: Feature 176 consisted of two patches of intensely burned (oxidized) sediment found among scattered rocks at the northeast edge of the burned rock cluster recorded as Feature 177 (see description below). The two burned patches were spaced about $10 \mathrm{~cm}$ apart with the larger measuring about $15-\mathrm{x}-30 \mathrm{~cm}$ and the smaller measuring about $5-\mathrm{x}-10 \mathrm{~cm}$. The larger patch was no more than $10 \mathrm{~cm}$ thick. The burned sediment was described as "brick red" to "orange-brown" in color with a fire-hardened, compact texture. Though no charcoal was observed in the immediate feature area, a small amount was retrieved in the general level recovery for this quad. About eight small rocks (5-8 cm size) and a burned core fragment (37JA-3) 


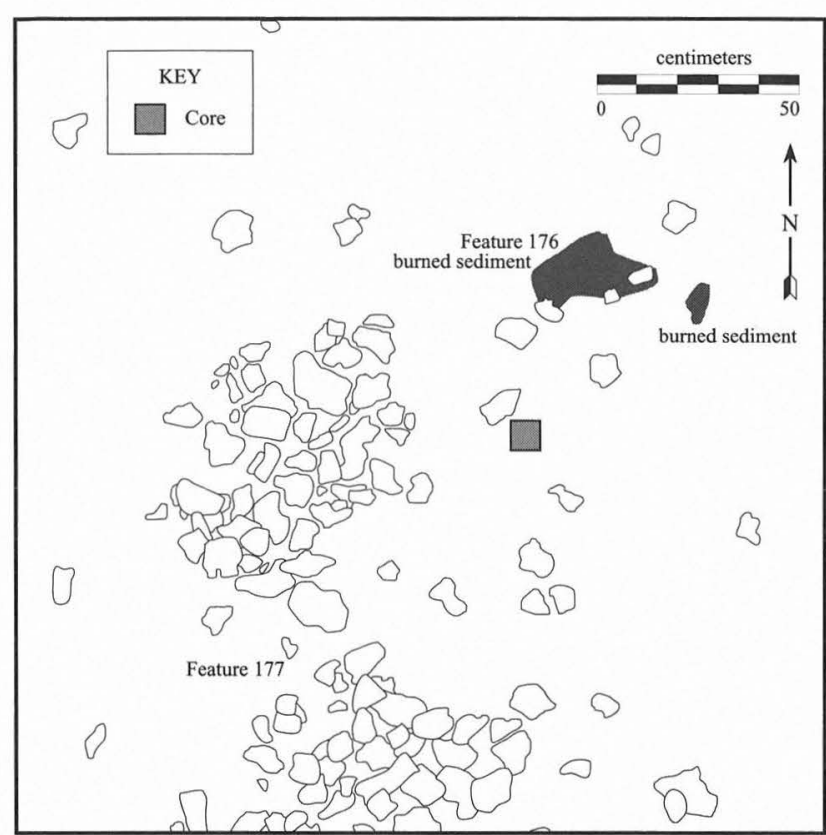

FigURE 26-69. Features 176 and 177 in Square E28/S78, Levels 9 and 10.

were loosely scattered within a $60-x-80 \mathrm{~cm}$ area surrounding the burned sediment. Two additional artifacts were provenienced to Feature 176: a unifacial multiple tool (37JA11) and a flake.

The larger patch of burned sediment was collected as an intact block with the intention of using it as a thermoluminescence sample. Although the block was not used for this purpose, a portion of it was used during the TARL analysis for a micromorphology sample (WL95-4). Traces of rubified sediment were observed in this sample along with dispersed ash crystals, some ashed vegetal fragments, burned snail shell, and burned (partially calcined) limestone fragments. A bulk matrix sample was also collected from the Feature 176 area, and portions of this sample were used for magnetic susceptibility and flotation samples (the remainder was curated). The magnetic susceptibility samples were comparable to nonfeature samples from similar stratigraphic contexts (no significant deviation detected), and the flotation sample yielded no identifiable plant remains.

\section{Feature 177}

Feature Type: burned rock cluster

Provenience: Square E28/S78 (NW, SW, and SE quads), Level 10; detection elevation $96.52 \mathrm{~m}$; base elevation $96.39 \mathrm{~m}$

Stratigraphic Context: the Unit IIIJ/IIIc

Archeological Chronology: Middle or Late Archaic Figure: 26-69

Description: Feature 177 was a roughly crescent-shaped concentration of ca. 100 burned rocks surrounded by a more dispersed scatter of ca. 30 additional rocks. This feature was closely associated with Feature 176, an area of intensely burned (oxidized) sediment found about $35 \mathrm{~cm}$ northeast of the main cluster in the same level (see Feature 176 description above). The main concentration measured approximately $90-\mathrm{x}-130 \mathrm{~cm}$ with a vertical extent of ca. $13 \mathrm{~cm}$. Most of the rocks appeared to be stacked in two piles ( 2 to 3 rocks deep) spaced about $20 \mathrm{~cm}$ apart at either end of the "crescent." Rocks were scattered in a single layer between these two piles (thus giving the feature a crescent-shaped appearance). The rocks ranged from ca. $3-20 \mathrm{~cm}$ in size, but the majority were in the $5-10-\mathrm{cm}$ size range. Although most of the rocks were angular fragments with distinct evidence of burning (discoloration and/or thermal fractures), several of the large cobbles (ca. 15-20-cm size) exhibited little or no evidence of burning. No evidence of in situ burning was observed within the main cluster, and, apart from the burned area recorded as Feature 176, the sediment within and around Feature 177 appeared to be the same color as the rest of the level (although burned gravels were observed throughout the level). Two burned bone fragments (medium/large mammal; see Chapter 33) and 24 pieces of debitage were provenienced to this feature.

\section{Feature 178}

Feature Type: probable burrow

Provenience: Square E24/S72 (NE quad), Levels 37A-37B; detection elevation ca. $93.82 \mathrm{~m}$; base elevation ca. $93.60 \mathrm{~m}$

Stratigraphic Context: Icl (possibly originating from a surface in Isi-c)

Archeological Chronology: Early or Late Paleoindian Figure: $26-70$

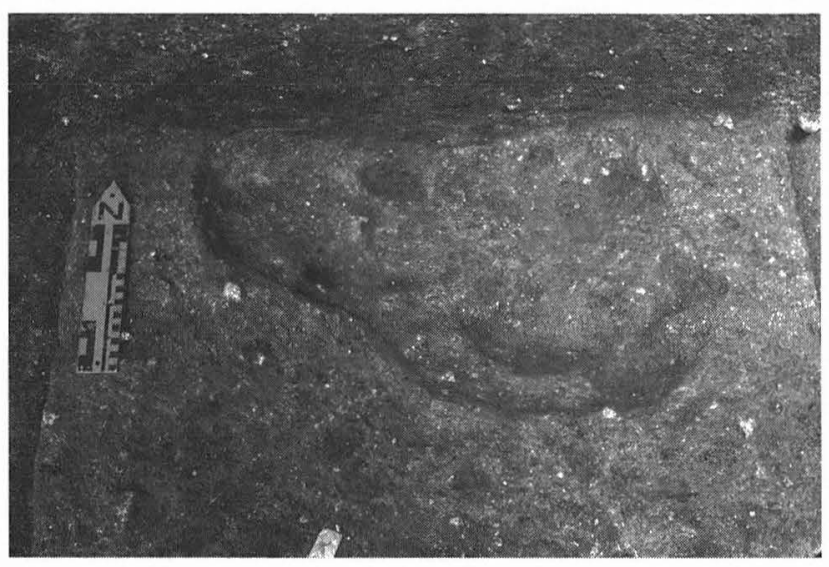

FIGURE 26-70. Feature 178 in Square E24/S72, Level 37B, looking north.

Description: Feature 178 was an irregular-shaped sediment anomaly that probably represented an animal burrow (or other natural feature). The anomaly extended into the north wall of Square E24/S72, but the exposed portion exhibited a somewhat oblong shape in plan view measuring ca. $50-\mathrm{x}-75 \mathrm{~cm}$. The investigated portion had a vertical extent of at least $22 \mathrm{~cm}$ with a very irregular, undulating base 
and a somewhat slanting profile (the profile in the north wall appeared to be extending upward at an oblique angle). Feature fill was described as a "dark gray-brown silty clay" with very pale gray "wash lenses." A small amount of charcoal and at least one piece of debitage were found in the feature fill.

Comments: Feature 178 was detected in the upper portion of stratigraphic Unit Icl (about $25 \mathrm{~cm}$ below the base of the Leanne soil). The dark color of the feature fill suggested it may have originated in the Leanne soil and intruded underlying Icl. This feature was found in approximately the same stratigraphic position as Feature 175, another sediment anomaly that has been interpreted as a probable burrow (see Feature 175 description above).

\section{Feature 180}

Feature Type: burned rock ring

Provenience: Square E28/S78 (NW, NE quads); Levels 1314; detection elevation $96.16 \mathrm{~m}$; base elevation $96.06 \mathrm{~m}$

Stratigraphic Context: Unit IIIa/IIIb transition

Archeological Chronology: Early Archaic

Figure: 26-71

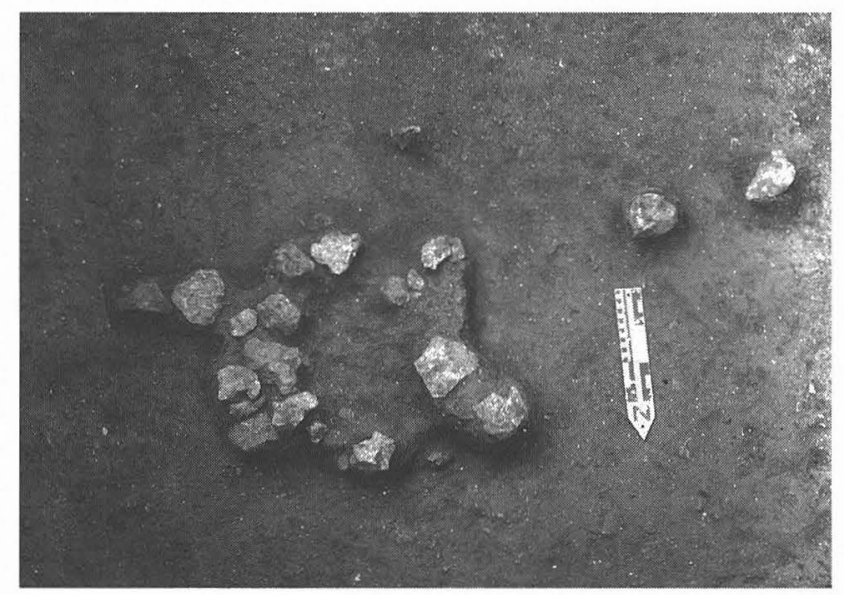

Figure 26-71. Feature 180 in Square E28/S78, Level 13, looking south.

Description: Feature 180 consisted of a roughly circular, ringlike arrangement of ca. 15 burned rocks (5-15 cm size) surrounding a rock-free interior. The ring measured ca. 50-60 $\mathrm{cm}$ in diameter with the rock-free space measuring ca. 25-x$35 \mathrm{~cm}$. The feature had a vertical extent of ca. $10 \mathrm{~cm}$, and it appeared to be resting on a relatively level surface. Most of the rocks in the ring were closely spaced, but there were a few 5-10-cm gaps where it looked like a rock may have been displaced. About 10 rocks were scattered around Feature 180 , and some of these may have been displaced from either the ring configuration or the rock-free interior. No burned sediment or charcoal was found in the feature area, but the field notes indicate the rocks were "fire-fractured" in situ. The notes also indicate at least 20 pieces of debitage and an unburned mussel shell fragment were found in the feature area, but feature provenience was not maintained for this material (it was apparently combined with the general level recovery). No materials were provenienced to Feature 180.

\section{Feature 181}

Feature Type: large burned rock basin

Provenience: TxDOT Square E28/S78 (all quads), Levels 15A20A; TARL Squares 37-39, 50-53; Levels 19-27; detection elevation ca. $95.95 \mathrm{~m}$; base elevation $95.45 \mathrm{~m}$

Stratigraphic Context: Feature 181 was excavated from a surface in Unit IIIa but the lower portion of the pit intruded Unit II

Archeological Chronology: Early Archaic

Special Studies:

Radiocarbon: AMS dates obtained on 9 wild hyacinth bulbs are $7870 \pm 60$ в.P. (CAMS-13840); $7890 \pm 60$ в.P. (CAMS$13841) ; 7890 \pm 80$ в.P. (CAMS-13844); $7990 \pm 60$ в.P. (CAMS$08355) ; 8010 \pm 60$ в.P. (CAMS-13512); $8030 \pm 60$ в.P. (CAMS13513); $8080 \pm 70$ в.P. (CAMS-13514); $8080 \pm 60$ в.P. (CAMS10201); $8130 \pm 70$ в.P. (CAMS-13509) (see Chapter 25)

Archeomagnetic: ca. 144 of 222 samples analyzed (see Chapter 27 and Appendix 6)

Magnetic Susceptibility: 28 samples analyzed (see Chapter 28)

Micromorphology: 5 samples analyzed (see Chapter 29 and Appendix 7)

Macrobotanical: 16 macroplant samples analyzed and 10 flotation samples processed (see Chapter 40)

Phytolith: 1 phytolith sample analyzed (see Chapter 41)

Figures: 26-72, 26-73, 26-74, 26-75, 26-76 (see also Figures 27$61,27-64,27-67,27-68,27-72,27-75,27-76,27-81,27-84,27-85$, 27-88, 27-89, 27-94, 27-97, 27-98, and 27-103 in Chapter 27).

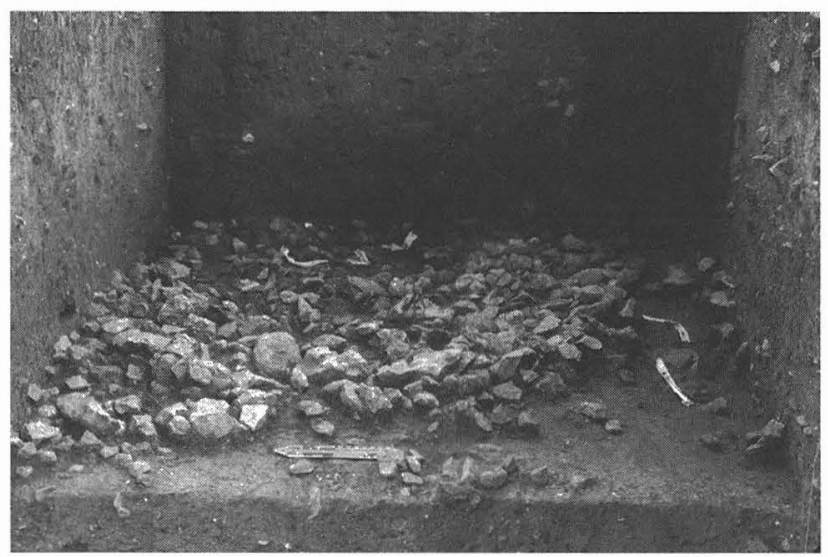

FIGURE 26-72. Feature 181 as exposed in Levels 16B/17A of Square E28/S78, looking east.

Description: Feature 181 was a roughly circular, basinshaped pit filled with a dense concentration of burned limestone fragments and other cultural debris. The pit measured approximately $2.6 \mathrm{~m}$ in diameter with a depth of ca. $50 \mathrm{~cm}$. 


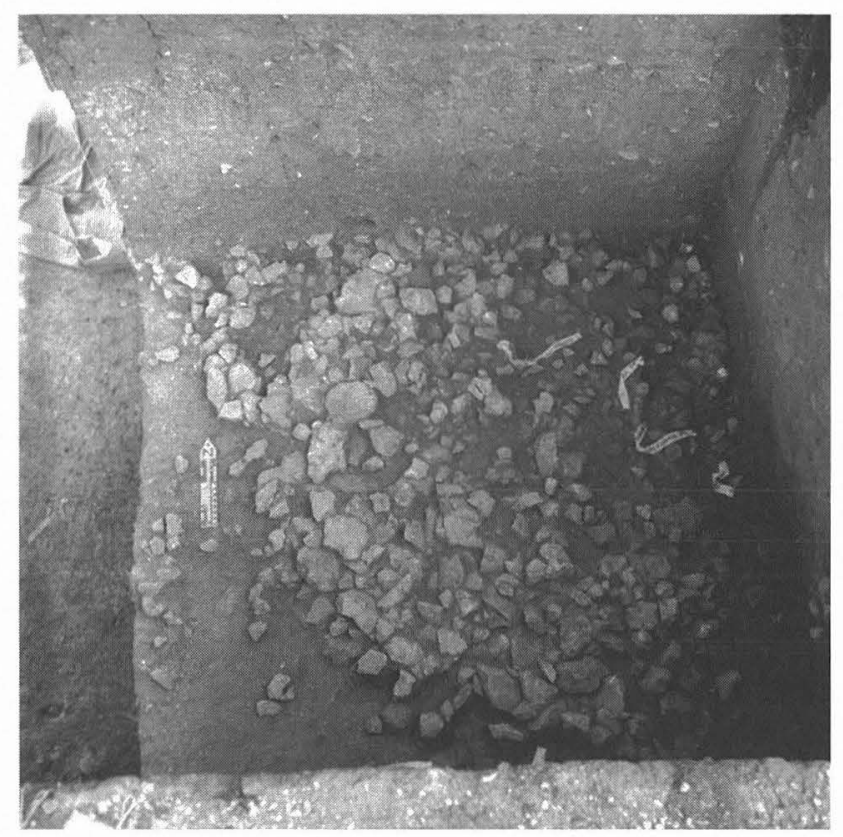

FIGURE 26-73. Feature 181 as exposed in Levels 16B/17A of Square E28/S78, looking north.

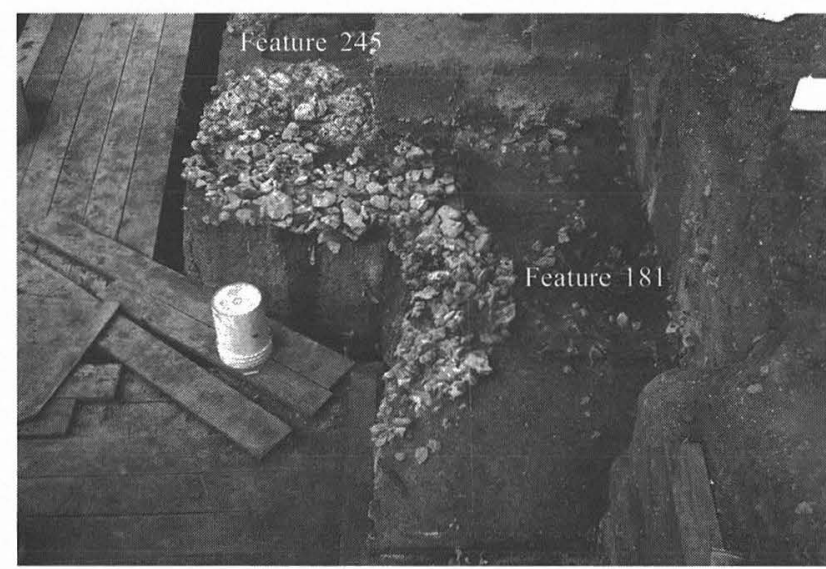

Figure 26-74. Features 181 and 245 exposed at about $95.70 \mathrm{~m}$ (base of Levels 22/23) in the TARL East Block, looking north.

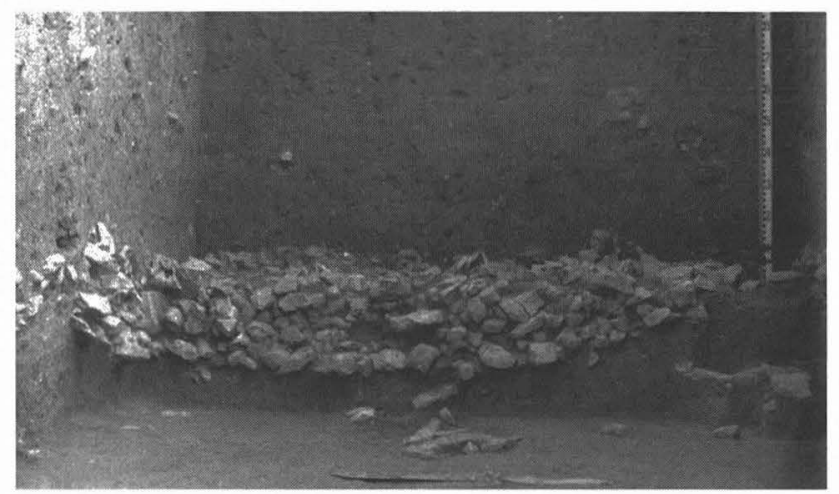

FIGURE 26-75. Feature 181 cross-sectioned in Square E28/S78, looking east. Feature 184 is pedestaled in Level 19A at the right edge of the photo and Feature 185 is exposed in Level 20A at the center (below the base of Feature 181).

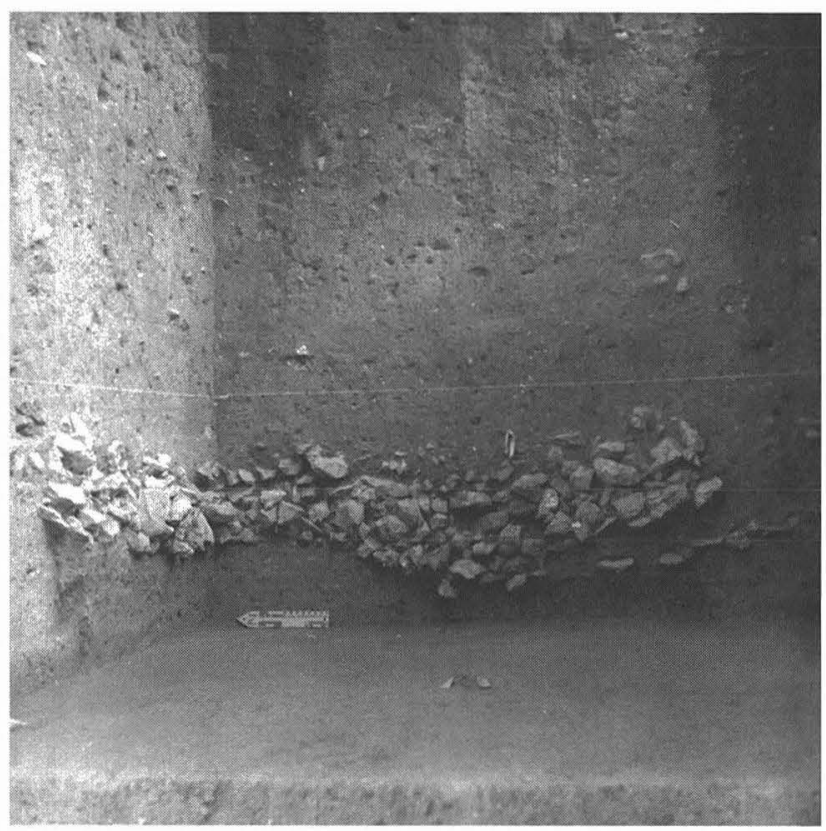

FIGURE 26-76. Feature 181 in the east and north walls of Square E28/S78, looking northeast. The floor of the square is at the base of Level 21B and the stringline is at $96.01 \mathrm{~m}$. The lowest layer of rocks at the right edge of Feature 181 is a remnant of Feature 184.

Most of the rocks were angular fragments in the 5-10-cm size range; however, some larger slabs (ca. 20-30-cm size) were also found, primarily along the outer margins and base of the pit. Although the total amount was not recorded, partial documentation indicates the pit contained several thousand pounds of rocks. Limited evidence of in situ burning (oxidized sediment) was observed during excavation, but it was confined primarily to the base and outer margins of the pit (below the lowest layer of rocks). Poorly preserved charcoal was dispersed throughout the fill, with a slight increase noted in the lowest layers. At least six wood charcoal samples (CH-865, CH-870, CH-877, CH-878, CH-880, and C14-64) were collected, and all were classified as indeterminate wood. Ten carbonized bulbs (CH-1478, CH-1479, CH-1480, CH-1482, CH1483-1, CH-1483-2, CH-1484, C14-158, C14-219, and C14-354) collected from various locations within the pit were all identified as wild hyacinth (Camassia scilloides). Although some materials found in the fill are undoubtedly in secondary context, these bulbs were probably cooked (and inadvertently charred) in this feature. Radiocarbon dates obtained on 9 of the bulbs (all but C14-158) provide an average age of $7997 \pm$ 60 в.P. (see discussion in Chapter 25).

Feature 181 was located within an extensive burned rock accumulation that was partially exposed in the eastern portion of TxDOT Block 6 (where it was recorded as Feature 124 ) and the East and South Blocks of the TARL excavations (where it was recorded as Feature 231). Feature 124/ 231 encompassed at least five other large burned rock basins (Features 130,131, 146, 150, and 245), and most of the burned rocks in the accumulation were probably displaced 
from these basins. With all six of these basins, it was difficult to discern the pit outlines until most of the overlying and surrounding burned rocks were removed. For this reason, it was impossible to determine with any accuracy the surface (or surfaces) from which the pits were excavated.

Feature 181 was first recorded in Level 15A of TxDOT Square E28/S78, but the pit outline was not clearly visible until the base of Level 16B, or ca. $95.80 \mathrm{~m}$ (see Figures 26-72 and 26-73). A little over half of Feature 181 (ca. 55\%) was exposed in this square with the remainder extending into the north and east walls. After mapping the feature in Levels 16B/17A, the TxDOT excavators cross-sectioned the pit on a north-south axis through the approximate center (see Figure 26-75). In addition to revealing the distinct, basin shape of the pit, the cross-sectioning effort also identified three features that appeared to predate Feature 181. Feature 183 was a relatively flat cluster of burned rocks found immediately west of Feature 181, about $20 \mathrm{~cm}$ below its detection level (see Feature 183 description). The Feature 181 pit appeared to cut through the western side of this cluster. Feature 184 was found about $10-20 \mathrm{~cm}$ below the southern end of Feature 181 in the southeast quad of Square E28/S78 (see Figure 26-75). It appears to have been an earlier burned rock basin that was truncated by the excavation of the Feature 181 pit (see Feature 184 description). Feature 185 was a small cluster of burned rocks found about $5-10 \mathrm{~cm}$ below the base of Feature 181 in the center of the square (see Figure 26-75). It may have been a remnant of the same burned rock basin as Feature 184 (see Feature 185 description). Feature 183 was located in the lower portion of stratigraphic Unit IIIa, but Features 184 and 185 were both buried in Unit II sediments (clearly predating Feature 181). After the cross-section pedestal was removed, the Feature 181 pit was still clearly visible in the east and north walls (see Figure 26-76) and Feature 184 was visible in the east wall as a line of rocks extending south from the base of Feature 181.

The rest of Feature 181 (ca. 35\% of the pit) was exposed during the TARL investigations (see Figure 26-74), with a small portion (ca. 10\%) lost in the gap between the TxDOT and TARL excavations. Since the Feature 231 accumulation masked the upper portion of the feature, the pit outline was not clearly visible until Levels 22/23, or ca. $95.80-95.70 \mathrm{~m}$. The outline of another large burned rock basin, Feature 245, emerged immediately north of Feature 181 at approximately this same depth. Feature 245 was significantly smaller than Feature 181 , measuring ca. $1.5 \mathrm{~m}$ in diameter. It was first detected about $17 \mathrm{~cm}$ below the Feature 181 detection level and may predate the larger basin (see Feature 245 description).

The TARL investigation of Feature 181 included intensive archeomagnetic sampling. Approximately 222 archeomagnetic samples were collected from rocks within Feature 181 and 144 of these were analyzed. The total number is uncertain because the pit margins were not clearly delineated in the upper levels. Of the 144 analyzed samples,
98 were definitely provenienced to Feature 181 and 46 were provenienced to Feature 181/231 (though the results suggest most of these are probably associated with Feature 181). Approximately $83 \%$ of the samples definitely provenienced to Feature 181 cooled in or near their find positions. The remainder were either displaced after final cooling or their cooling histories could not be determined. More than half of the samples exhibited single components of magnetization, indicating they probably cooled from temperatures greater than $580^{\circ} \mathrm{C}$ with little or no movement. The others were apparently moved one or more times while cooling. The Feature 181/231 samples exhibited similar results with approximately $65 \%$ cooling in or near their find positions and ca. $46 \%$ exhibiting single components of magnetization.

Five micromorphology samples (intact blocks of sediment) were also collected from Feature 181 during the TARL investigations. Three (WL92-F2, WL92-F5, and WL92-F6) were collected from the eastern portion of the feature in Squares 50 and 51. Two (WL92-F4 and WL92-F7) were collected from the northern portion in Square 52. All five samples exhibited ash and burned limestone fragments, but charcoal was observed in only three (WL92-F2, WL92-F6, and WL92F7). The charcoal was very poorly preserved, and it appeared to have been shredded by earthworms. Only one of the samples (WL92-F7) exhibited burned/oxidized sediment. This sample was collected beneath one of the larger rocks found near the base of the feature. An archeomagnetic sample collected from this rock (AM-543) was not analyzed, but analyzed samples from some of the adjacent rocks indicate they cooled in place (see Figure 27-76 in Chapter 27).

A much larger block (ca. $20-\mathrm{x}-35 \mathrm{~cm}$ ) of Feature 181 fill (sediment, burned rocks, and all other inclusions) was plastered and lifted from the north end of TARL Square 51 (see Figure 27-85 in Chapter 27). This sample was originally intended for micromorphological analysis, but it has been curated (unanalyzed) as an intact block of pit fill.

Feature 181 provenience was not maintained for all materials found within Feature 181 during the TxDOT excavations (some materials were inadvertently mixed with nonfeature recovery from the same level/quad). Material found in Feature 181 during the TARL investigations was field provenienced to Feature 231, with Feature 181 provenience reassigned to some of the more securely located items during the analysis phase. Of the materials that are definitely provenienced to Feature 181, the macroplant, archeomagnetic, and micromorphology samples discussed above are clearly the most significant. Other associated materials include an assortment of artifacts and faunal remains. The TxDOT artifacts include 2 Hoxie points $(37 \mathrm{O} 2 \mathrm{~B}-7$, 37O2C-8), a Jetta point (37O1A-D-1), a projectile point fragment (37O2C-9), a perforator (37P1A-2), 8 bifaces/biface fragments, 16 unifacial tools, 6 burin spalls, and at least 1,832 pieces of debitage. The TARL artifacts include a bifacial tool (OR712), a biface fragment (1671-2), a core/hammerstone 
(OR690), 3 unifacial tools, and 422 pieces of debitage.

The faunal recovery from Feature 181 includes bone recovered on several different screen sizes. Square E28/S78 was the TxDOT fine-screened square, and apart from some bulk matrix samples reserved for special studies, the matrix removed from Feature 181 was water-screened in the field through nested 1/4-inch and 1/16-inch screens (see Chapter 3). Feature provenience was apparently maintained for some of the Feature 181 recovery, but some of it was clearly combined with nonfeature recovery from the same quads/levels. Most of the Feature 181 matrix was water-screened in the field through 1/8-inch screen during the TARL investigations with some bulk matrix samples reserved for special studies. Some of the bulk matrix collected in both investigations was fine-screened through nested 1/8-inch and 1/16inch screens during the TARL analysis phase (using the method described in Chapter 34).

Baker analyzed both the TxDOT $1 / 4$-inch screen recovery and the TARL 1/8-inch screen recovery (see Chapter 33 and Appendix 10). His 1/4-inch screen sample included 22 specimens provenienced to Feature 181 (including some jackrabbit, medium/large mammal, and small/medium Vertebrata bone). His $1 / 8$-inch screen sample included 66 specimens provenienced to Feature 181 (including some large mammal, medium/large mammal, small/medium mammal, small mammal, and rabbit bone).

Winkler (1990) analyzed the recovery from the northwest quad of the TxDOT fine-screened square (entire column). Her samples from Levels $15 \mathrm{~A}$ through $18 \mathrm{~B}$ probably include some Feature 181 bone mixed with nonfeature bone. She analyzed over 9,500 specimens from these levels but most (ca. 89\%) were unidentifiable fragments. The identifiable taxa included relatively high percentages of rodent, rabbit, small mammal, fish, and turtle bone as well as smaller quantities of deer, medium/large mammal, frog/toad, and snake/lizard (see Appendix 11).

Becker analyzed some of the 1/16-inch screen recovery from the northeast quad of this square (entirely within Feature 181) along with bone recovered from TARL fine-screening of TxDOT bulk matrix samples (see Appendix 8). She analyzed a total of 13,377 specimens from Feature 181 with approximately $88 \%$ of the sample consisting of unidentifiable fragments. The 1,538 identifiable specimens were classified as rodent (ca. $43 \%$ of the identifiable taxa), turtle (18\%), mammal (23\%), fish (11\%), rabbit (2\%), snake (2\%), amphibian $(<1 \%)$, and reptile $(<1 \%)$. Becker reports that approximately $23 \%$ of this bone was burned. The 105 eggshell fragments found in these samples were analyzed by Decker (see Chapter 36). Thickness measurements suggest at least 5 species may be represented.

The faunal recovery from Feature 181 also includes eight mussel shell fragments (six TxDOT, two TARL). The identifiable specimens include a Potamilus purpuratus valve fragment and a Toxolasma texasensis hinge fragment (see Chapter 37). The T. texasensis specimen is notable because it has a very restricted habitat range. It is confined to shallow water (ca. 1-2 feet) with little or no current.

Some of the bulk matrix samples collected from Feature 181 were also used for magnetic susceptibility, flotation, and phytolith samples. No significant deviation was detected in the susceptibility samples, and the flotation samples (totaling 19 liters) yielded no identifiable plant remains. The phytolith sample did not exhibit a very high degree of preservation, but the recovery was adequate for stratigraphic comparisons (see Chapter 41). The woodland-grassland ratio was consistent with nonfeature phytolith samples from similar stratigraphic contexts (lower half of Unit IIIa), exhibiting a slight dominance of arboreal phytoliths. The grass short-cell assemblage in the Feature 181 sample was anomalous, however, exhibiting a higher than expected percentage of conical forms and a lower than expected percentage of saddle forms. Since the conical form is not particularly diagnostic, Fredlund could not determine which grasses were represented by this high percentage. He does suggest that these differences could reflect human selection of conical form grasses (which may relate to feature use/function in some way).

Comments: Feature 181 represents the largest burned rock basin found at the Wilson-Leonard site. Although the evidence of in situ burning is not as well preserved in Feature 181 as in adjacent Feature 245 (see Feature 245 description), the combined archeomagnetic and micromorphological evidence indicate it is a relatively well-preserved (undisturbed) feature. The evidence also suggests that it probably represents a large capacity baking/cooking pit (or oven) that saw repeated use. In at least one use event, wild hyacinth bulbs were baked.

\section{Feature 183}

Feature Type: burned rock cluster

Provenience: Square E28/S78 (all quads), Levels 17A-18B; detection elevation $95.74 \mathrm{~m}$; base elevation $95.66 \mathrm{~m}$

Stratigraphic Context: Feature 183 apparently rested on a surface in the lower portion of Unit IIIa, but it was located in an area that had been disturbed by Feature 181 (large burned rock basin that was excavated from a surface in Unit IIIIa and intruded Unit II). Some mixing of Unit IIIIa and Unit II cultural materials probably occurred in the Feature 183 vicinity.

Archeological Chronology: Early Archaic Special Studies:

Macrobotanical: 1 macroplant sample analyzed (see Chapter 40)

Figure: 26-77

Description: Feature 183 was a large cluster of ca. 200 burned rocks ( $3-10 \mathrm{~cm}$ size) found immediately adjacent to the lower portion of Feature 181. The Feature 181 pit cut through the western side of Feature 183, and it clearly postdates this smaller feature. Feature 183 postdates two other burned rock clusters found slightly below Feature 181 in 


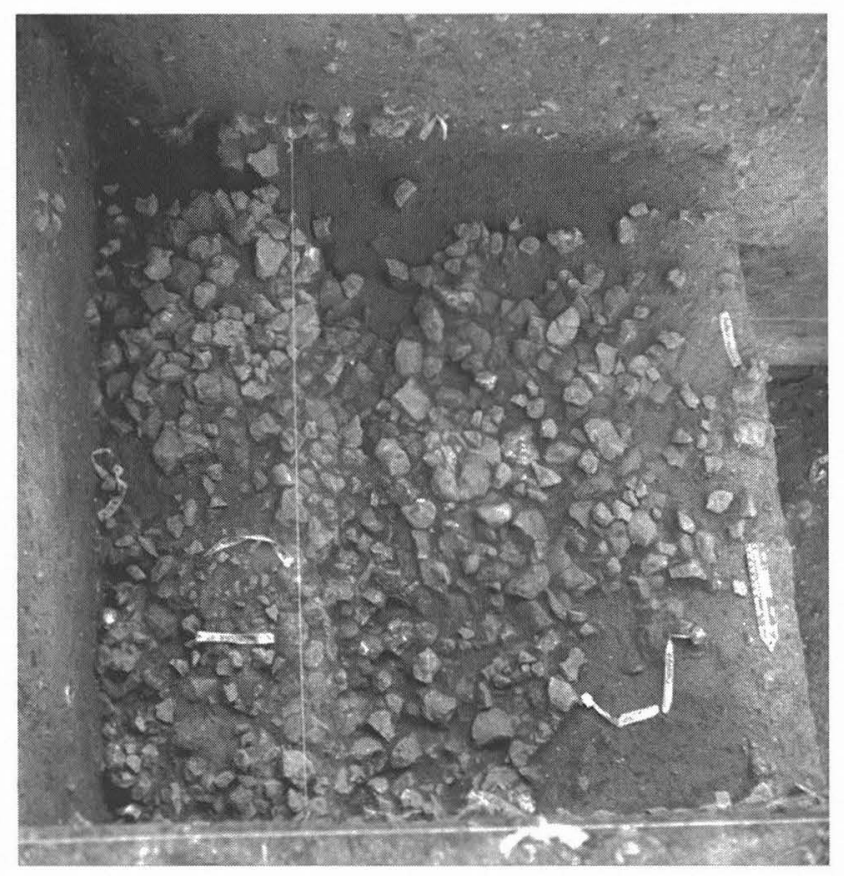

Figure 26-77. Features 181 and 183 in Square E28/S78, looking south. Cross-sectioning of Feature 181 is in progress with the eastern portion of the square pedestaled at the base of Level 17A and the rest of the square at the base of Level 18A. Feature 183 is the smaller cluster at the right.

Levels 18B-20B of Square E28/S78 (see Feature 184, 185 descriptions below).

Feature 183, which measured ca. $75-\mathrm{x}-140 \mathrm{~cm}$, was composed primarily of a single layer of rocks with a vertical extent of ca. $8 \mathrm{~cm}$. There was no evidence to suggest the rocks were in a pit, and they appeared to be a resting on a relatively flat surface. No burned sediment was observed within the feature area, but a small amount of charcoal was found. Feature provenience was maintained for only some of the materials found among the Feature 183 rocks (other materials were combined with general level recovery). The only charcoal sample provenienced to Feature 183 (CH-876) was identified as indeterminate wood. Other associated materials include a perforator (37Q1D-7), a Stage 2 biface (37R1D-6), a core tool (37R1B-1), a piece of debitage, and two mussel shell fragments (one identified as Lampsilis teres; see Chapter 37). The field notes indicate some burned bone was also found in Feature 183, but feature provenience was not maintained for this bone.

\section{Feature 184}

Feature Type: burned rock cluster (large burned rock ba$\sin ?)$

Provenience: TxDOT Square E28/S78 (SE quad), Levels 18B20B; TARL Square 50, Levels 26-27; detection elevation 95.60 $\mathrm{m}$; base elevation $95.45 \mathrm{~m}$

Stratigraphic Context: Feature 184 was located in upper
Unit II, but it was found in an area that had been disturbed by Feature 181 (a large burned rock basin that was excavated from a surface in Unit IIIa and intruded Unit II). Some mixing of Unit IIIa and Unit II cultural materials probably occurred in the Feature 184 vicinity.

Archeological Chronology: Late Paleoindian

Special Studies:

Archeomagnetic: 2 of 2 samples analyzed (see Chapter 27 and Appendix 6)

Magnetic Susceptibility: 2 samples analyzed (see Chapter 28)

Macrobotanical: 1 flotation sample processed (see Chapter 40)

Figures: 26-75, 26-76, 26-78, and 26-79 (see also Figure 27-16 in Chapter 27)

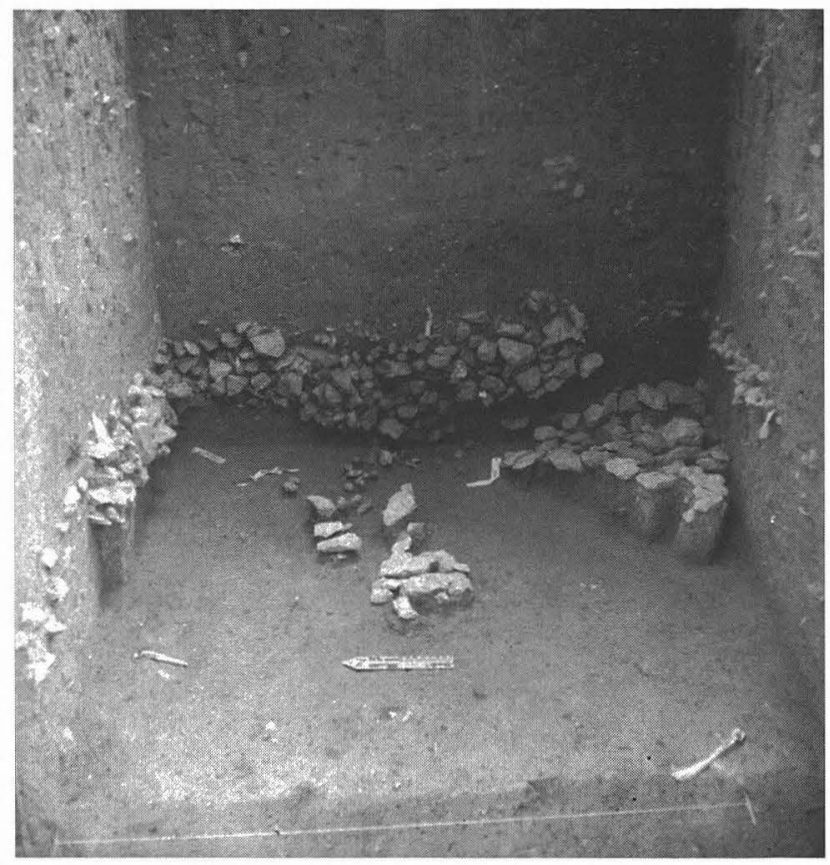

FIGURE 26-78. Feature 181 in the south, east, and north walls of Square E28/S78, looking east. Feature 184 is on the Level 20A pedestal at the right; Feature 185 is exposed in Level 20B in the center of the square.

Description: Feature 184 was partially exposed in the southeast corner of TxDOT Square E28/S78 with portions of the feature extending into both the south and east walls. The eastern margin was further exposed in TARL Square 50. Feature 184 was also located about $10-20 \mathrm{~cm}$ below the southern end of Feature 181 (see description above), and it appears that the base of this large pit probably disrupted the northern portion of Feature 184 (see Figures 26-75 and 26-78).

The investigated portion of Feature 184 consisted of a tight cluster of ca. 60 burned limestone fragments $(5-15 \mathrm{~cm}$ size). The cluster had a diameter of at least $135 \mathrm{~cm}$ (based on its east-west combined measurement) and a vertical extent 


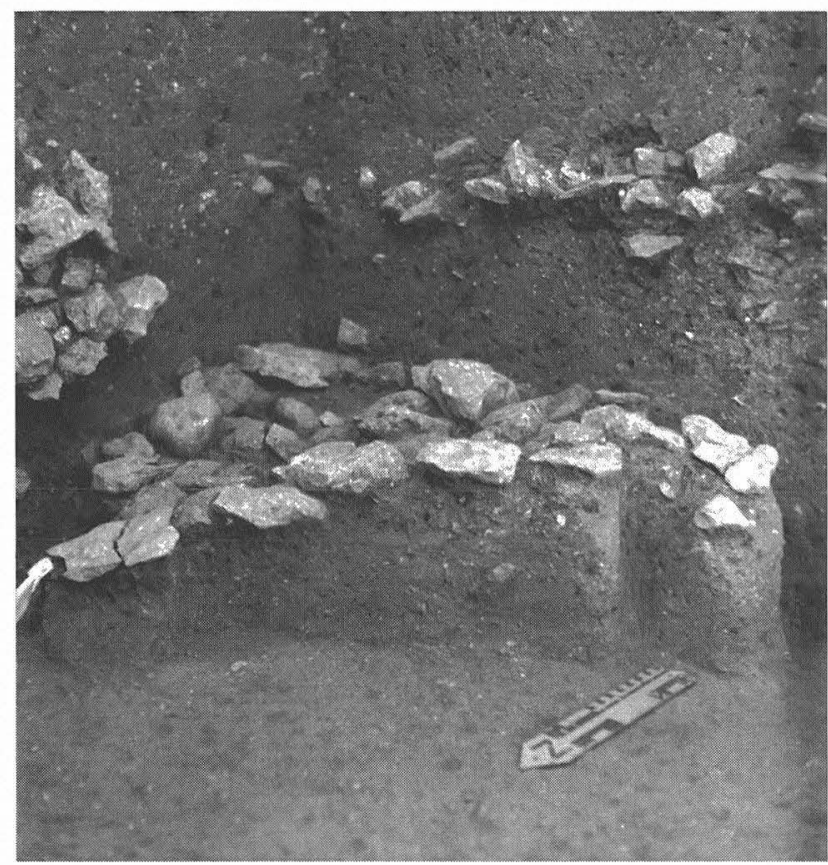

FIGURE 26-79. Feature 184 on the Level 20A pedestal in Square E28/S78, looking southeast. Feature 181 is visible in the south and east walls above Feature 184.

of at least $15 \mathrm{~cm}$. It was composed primarily of a single layer of rocks with only a few rocks found on top of others. Rocks in the northern portion of the cluster sloped downward to the north, and they looked like they were probably resting on the sloping sides and base of a basin-shaped pit (see Figures 26-76, 26-78, and 26-79). If this hypothesis is correct, then Feature 184 may represent the remains of a large burned rock basin that was constructed in the upper portion of Unit II and subsequently truncated by the excavation of the Feature 181 pit (from a surface in Unit IIIa). Feature 185 (found at approximately the same elevation, ca. $50 \mathrm{~cm}$ to the north/ northwest of Feature 184) may represent another remnant of the same feature (see description below).

No burned sediment was found in Feature 184, but small quantities of poorly preserved charcoal were observed (but not collected). Associated artifacts include a notched flake (37R2C-1), a burin (37S1C-4), and ca. 32 pieces of debitage. Feature provenience was not maintained for faunal remains found in this cluster in the TxDOT excavations, but the 1/8 inch-screen recovery from the TARL excavations included 6 small/medium Vertebrata long-bone fragments and 12 Vertebrata indeterminate fragments (see Chapter 33). All but one of these fragments were burned.

Two archeomagnetic samples were collected from rocks exposed in the TARL investigations (eastern edge of the cluster). The results indicate both rocks were probably heated to very high temperatures (at least $580^{\circ} \mathrm{C}$ ). The larger of the two subsequently cooled in place with little or no movement, while the other moved a short distance before cooling in place from a lower temperature.
Two bulk matrix samples were also collected from the Feature 184 area (one during each of the investigations), and most of this sediment was used for magnetic susceptibility, flotation, and faunal fine-screen samples (remainder was curated). No identifiable plant remains were found in the flotation sample but a small amount of bone (unanalyzed) and two eggshell fragments (see Chapter 36) were recovered from the ca. 1-liter fine-screen sample. The susceptibility results were difficult to interpret. The average value of the Feature 184 samples was a little higher than nonfeature samples from comparable Unit II contexts, but it fell within the range seen for Unit II/IIIa contexts. This probably reflects the mixing of Unit II/IIIa deposits caused by intrusive Features 181 and 183.

\section{Feature 185}

Feature Type: burned rock cluster

Provenience: Square E28/S78 (all quads), Levels 20A-20B; detection elevation $95.51 \mathrm{~m}$; base elevation $95.39 \mathrm{~m}$

Stratigraphic Context: Unit II

Archeological Chronology: Late Paleoindian

Special Studies:

Magnetic Susceptibility: 2 samples analyzed (see Chapter 28)

Micromorphology: 1 sample analyzed (see Chapter 29 and Appendix 7)

Macrobotanical: 1 flotation sample processed (see Chapter 40)

Figures: 26-75, 26-78, and 26-80

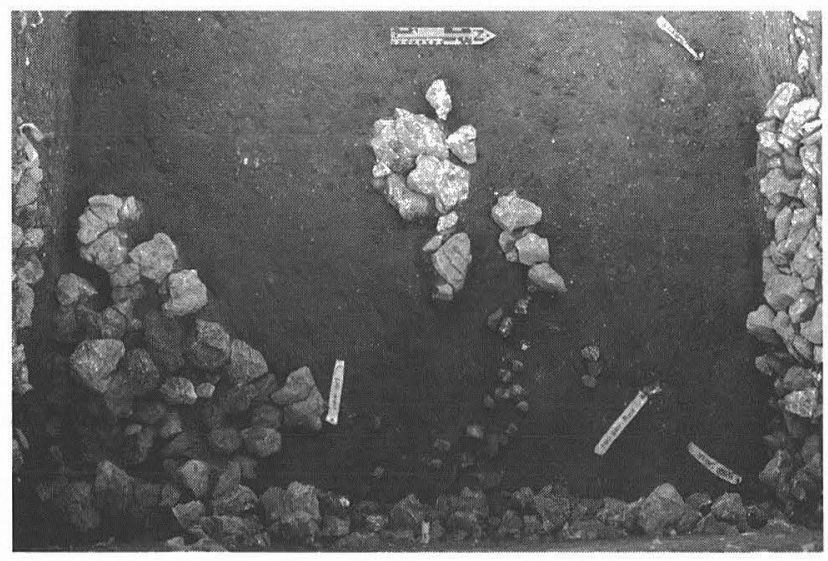

FIGURE 26-80. Features 184, 185, and 186 in Square E28/S78, looking west. Feature 184 is pedestaled in Level $20 \mathrm{~A}$ at left. Feature 185 (in Level 20B) is the cluster of larger rocks in the center of the photo. The string of smaller rocks to the east of Feature 185 (also in Level 20B) lies within the Feature 186 burrow.

Description: Feature 185 was a small cluster of about 21 burned limestone fragments found about $5-10 \mathrm{~cm}$ below the base of Feature 181 (near the center of this large pit feature). Feature 185 was buried in Unit II sediments and clearly predated Feature 181 (see Figure 26-75); however, it was found 
at approximately the same elevation as Feature 184 (located ca. $50 \mathrm{~cm}$ to the south/southeast), and it may represent an associated remnant of this truncated feature (see Feature 184 description and Figures 26-78 and 26-80). Feature 185 was also located immediately adjacent to (west/southwest of) Feature 186, a large burrow that tunneled through Feature 181 into underlying Unit II deposits (see Feature 186 description below and Figure 26-80). This burrow may have disturbed a portion of Feature 185 as well.

Feature 185 measured about $35-\mathrm{x}-70 \mathrm{~cm}$ and was about $12 \mathrm{~cm}$ thick. It was composed of a single layer of 8 tabular cobbles (10-20 cm size) and 13 smaller angular fragments. The rocks appeared very burned, and many were fractured in situ. Sediment within the feature area was no darker than the surrounding matrix, and no burned sediment or charcoal was found within the cluster. Associated artifacts include a Clear Fork biface (37T1D-3), a biface fragment (37T1B-1), and 14 pieces of debitage.

A bulk matrix sample was also collected from the Feature 185 area, and most of this sediment was used for magnetic susceptibility, micromorphology, flotation, and faunal fine-screen samples (remainder was curated). The magnetic susceptibility results were comparable to nonfeature samples from the same stratigraphic contexts (no significant deviation detected). A thin-section slide was not made from the micromorphology sample, but the polished block was examined under the binocular microscope. A possible piece of charcoal but no other evidence of burning was observed in this sample. The flotation sample was not productive (no identifiable plant remains found), but a few bone fragments (unanalyzed) and an eggshell fragment (see Chapter 36) were recovered from the ca. 1.25-liter fine-screen sample.

\section{Feature 186}

Feature Type: burrow

Provenience: Square E28/S78 (NE and SE quads), Levels 20A-23A; detection elevation $95.46 \mathrm{~m}$; base elevation $95.16 \mathrm{~m}$ Stratigraphic Context: Feature 186 probably originated from a surface in Unit IIIa and intruded Unit II deposits

Archeological Chronology: Early Archaic

Figure: 26-80

Description: Feature 186 apparently represents some sort of animal burrow that tunneled through and beneath Feature 181 (see Feature 181 description). The burrow clearly originated from a surface in Unit IIIa and intruded Unit II deposits immediately below Feature 181. It was also located immediately adjacent to Feature 185 (see description above) and it may have disrupted a portion of this feature as well.

The burrow had a very irregular shape in plan view and a tapering profile. It measured ca. $45-\mathrm{x}-95 \mathrm{~cm}$ with a documented vertical extent of ca. $30 \mathrm{~cm}$. It was filled with the dark soil and burned rocks found in Feature 181 as well as charcoal, mussel shell, bone, and assorted lithic artifacts. Feature provenience was not maintained for most of the materi- als found in the burrow fill, but two charcoal samples $(\mathrm{CH}-$ 897 and $\mathrm{CH}-898$, not analyzed) and a bone fragment (the proximal end of a medium-size mammal phalanx, see Chapter 33) were provenienced to Feature 186.

Comments: Feature 249, which was recorded in TARL Squares 50 and 51, probably represents part of the same burrow as Feature 186.

\section{Feature 187}

Feature Type: burned rock cluster (small burned rock ba$\sin$ ?)

Provenience: Square E28/S78 (NE quad), Levels 32A-32B; detection elevation ca. $94.26 \mathrm{~m}$; base elevation ca. $94.17 \mathrm{~m}$

Stratigraphic Context: Unit Isi-c

Archeological Chronology: Late Paleoindian (Wilson component)

\section{Special Studies:}

Magnetic Susceptibility: 2 samples analyzed

Macrobotanical: 1 macroplant sample analyzed; 1 flotation sample processed (see Chapter 40)

Micromorphology: 1 sample analyzed (see Chapter 29 and Appendix 7)

Figure: 26-81

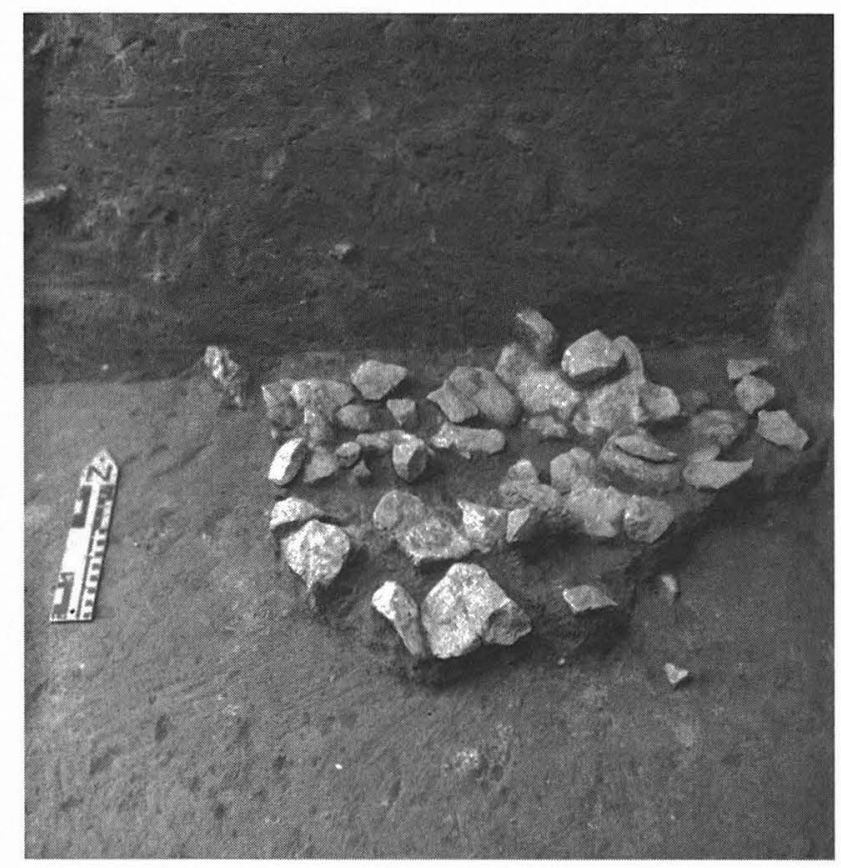

FIGURE 26-81. Feature 187 in Level 33A of Square E28/S78, looking north.

Description: Feature 187 consisted of about 45 burned limestone fragments tightly clustered within a subrectangular area measuring ca. $55-\mathrm{x}-70 \mathrm{~cm}$. The majority of the rocks rested in a single layer, although a few smaller fragments lay on top of larger rocks. The cluster had an estimated vertical extent of about $9 \mathrm{~cm}$, and though no evidence of a basin 
shape was reported, in some of the photographs of this feature the rocks look like they may have rested in a shallow basin. Some of the perimeter stones appear to be sloping down toward the center of the cluster, and rocks in the center seem to be a little lower. Rock elevations recorded on the plan drawing provide some support for this interpretation, but few elevations were recorded in the center of the cluster.

Most of the rocks were no more than $5-10 \mathrm{~cm}$ in diameter with a few in the $15-25-\mathrm{cm}$ range. The rocks were described as having a heavily burned appearance, and many were fractured in situ. No evidence of burned sediment was reported in the feature notes, but some charcoal was found both within and outside the cluster. A small charcoal sample collected from the feature (CH-820) was classified as indeterminate wood.

Four pieces of debitage and a bone fragment (Vertebrata indeterminate; see Chapter 33) were also collected from Feature 187 along with a bulk matrix sample. Much of this sediment was processed for various special studies during the TARL analysis, and the remainder was curated. The special studies included magnetic susceptibility, micromorphology, flotation, and faunal fine-screen. The magnetic susceptibility results were comparable to nonfeature samples from similar stratigraphic contexts (no significant deviation detected). A few ash rhombs were observed in the micromorphology thin-section (WL95-23), but no other evidence of burning was detected. A possible ostracode was also noted along with some unusual calcite grains (Goldberg notes that these are reminiscent of spring-like deposition; see Appendix 7). The flotation sample was not productive, but 84 bones were recovered in the fine-screen sample. Most were classified as Vertebrata indeterminate, but the sample also included 6 mammal, 3 rodent, 2 rabbit, 3 turtle, and 1 fish specimen (see Appendix 8). Approximately half of these appeared burned. The field notes report that the general recovery for Level 33A included a relative increase in the amount of small burned bone fragments, and this was thought to possibly be associated with Feature 187.

Comments: Feature 187 was located about $10 \mathrm{~cm}$ above the base of the Leanne soil (Isi-c). This stratigraphic position is very similar to three nearby burned rock features (Features 171,255 , and 260) that may have rested on the same occupational surface. Feature 187 probably represents a relatively intact (basin-shaped?) hearth or cooking feature relating to the Wilson component. It may be roughly contemporaneous with Feature 255 which has an AMS radiocarbon determination of $9990 \pm 70$ в.P. (CAMS-10195).

\section{Feature 188}

Feature Type: artifact cluster

Provenience: Square E28/S78 (NE quad), Levels 43B-44A; tested cobble found at $93.04 \mathrm{~m}$ and battered cobble found at $93.09 \mathrm{~m}$

Stratigraphic Context: Unit Isi
Archeological Chronology: Early Paleoindian Figure: 26-82

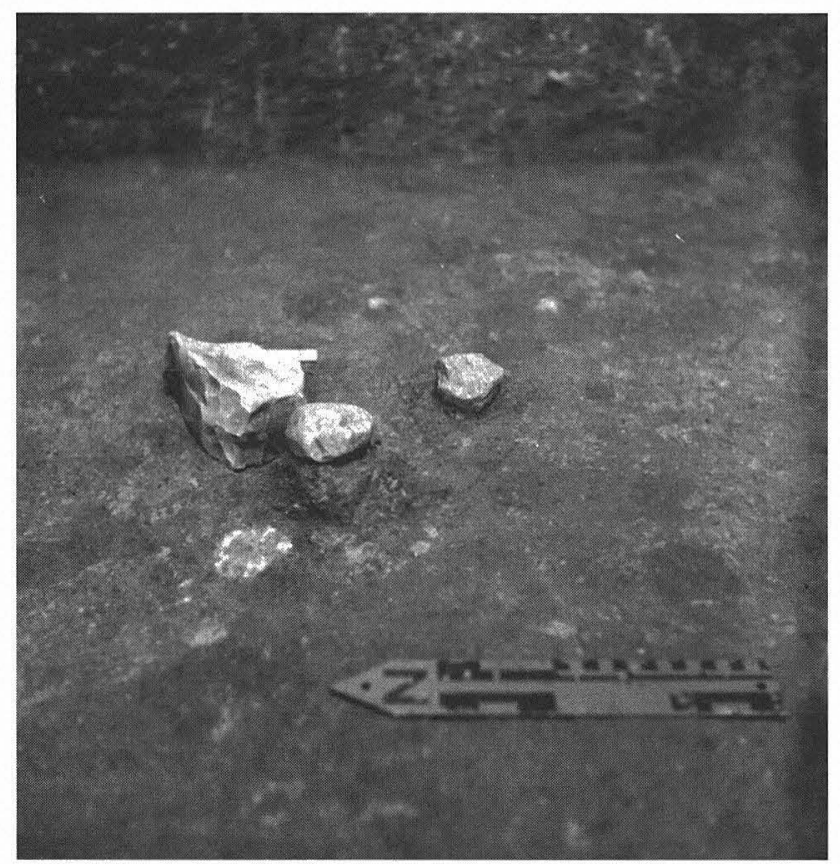

FIGURE 26-82. Feature 188 in Square E28/S78, Level 44A, looking east.

Description: Feature 188 consisted of a tested chert cobble and a battered limestone cobble (possible hammerstone?) found about 5-7 cm apart. The tested cobble (Specimen 37RR1A-1) is of fine-grained Edwards chert, measuring $142 \mathrm{~mm}$ long, $104 \mathrm{~mm}$ wide, and $65 \mathrm{~mm}$ thick. It was described in the field notes as "one of the largest pieces of chert found in this area of the site." The battered cobble (Specimen 37RR1A-2) is of nodular chert and measures 99-x71-x-37 mm with a weight of $358 \mathrm{~g}$. No debitage from the tested cobble or other artifacts were found in the area immediately surrounding these two specimens, but a few pieces of debitage (different raw material) were found in the same quad. An unmodified limestone pebble (ca. $5 \mathrm{~cm}$ diameter) was found about $7 \mathrm{~cm}$ from the hammerstone, but this specimen was apparently not collected. A small amount of bone was also recovered from the feature area, but there were no significant concentrations. The $1 / 4$-inch-screen recovery for Levels 43B and 44A (all quads) included a large mammal (bison?) indeterminate fragment (unburned), four Vertebrata indeterminate fragments (three burned), an unburned fish tooth, and an unburned rodent tooth (see Chapter 33 and Appendix 10). The large mammal fragment and one of the Vertebrata indeterminate fragments exhibited spiral fractures.

\section{Feature 190}

Feature Type: possible pit or burrow?

Provenience: Square E26/S74 (east wall); no level provenience or elevations were recorded 
Stratigraphic Context: lower Unit Icl? (possibly the Unit Isi/Icl transition)

Archeological Chronology: Early Paleoindian

Figure: 26-83

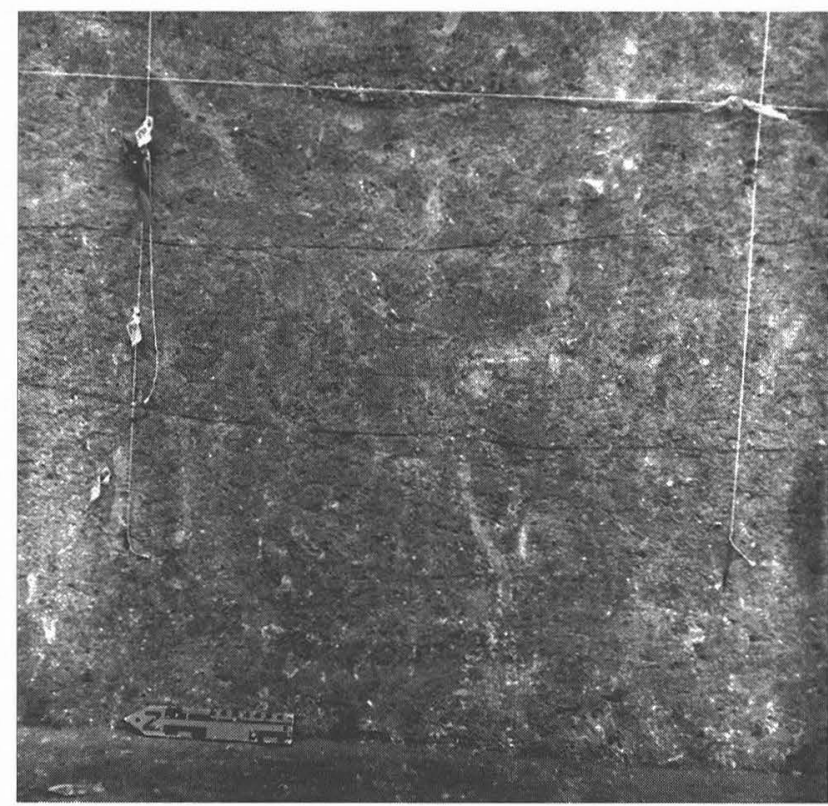

FIGURE 26-83. Feature 190 in the east wall of Square E26/S74, looking east. The floor of the square is at the base of Level 41B.

Description: Feature 190 was documented with only a brief daily journal entry $(3 / 27 / 84)$ and a few photographs so it is very difficult to assess. It was apparently some sort of matrix anomaly (possible pit or burrow?) that was found in the east wall of Square E26/S74 about a month after level excavations unknowingly bisected the feature. Although the journal entry describes it as a basin shaped-pit (measuring ca. $60 \mathrm{~cm}$ in diameter and $20 \mathrm{~cm}$ deep), a pit outline is not clearly visible in the photographs, and there are no drawings to support this description.

Comments: The journal entry describes the stratigraphic position of Feature 190 as "on contact of [TxDOT] strata 16 and 17." This position can be roughly correlated to the lower portion of TARL Unit Icl, at or near the contact with underlying Unit Isi sediments, and it suggests Feature 190 may have been located in the heavily bioturbated transition zone at the base of the Unit Icl cienega (numerous burrows and root disturbances were documented in this transition zone during the TARL investigations; see Chapter 6). Given this stratigraphic position, it seems very likely that Feature 190 represents a natural disturbance (possibly a large burrow).

\section{Feature 193}

Feature Type: burned rock cluster

Provenience: Square E28/S78 (NW and SW quads), Levels 29B-30B; no elevations were recorded for this feature but level elevations bracket the feature between ca. 94.56 and $94.41 \mathrm{~m}$

Stratigraphic Context: Unit Isi-c

Archeological Chronology: Late Paleoindian Special Studies:

Macrobotanical: 1 macroplant sample analyzed (see Chapter 40)

Description: Feature 193 was not recorded as a feature by the TxDOT excavators (number assigned during TARL analysis). It consisted of a relatively tight cluster of about 14 burned rocks that were apparently resting in a single layer on a surface that sloped gently downward to the north. The cluster measured approximately $30-\mathrm{x}-35 \mathrm{~cm}$ with an estimated thickness of ca. $15 \mathrm{~cm}$. Most of the rocks were in the $5-10-\mathrm{cm}$ size range, though a few were smaller. The rocks were exposed, mapped, and removed during the excavation of three 5 -cm levels without the excavators recognizing that the rocks probably related to a single feature. The southern end of the feature (ca. 6-7 rocks) was exposed in Level 29B, the central portion (4 rocks) was exposed in Level 30A, and the northern margin (4 rocks) was exposed in Level 30B. Some charcoal was collected in the central portion of the feature $(\mathrm{CH}-$ 801; indeterminate), and the level notes indicate additional charcoal, burned bone, debitage, and a few aquatic snails were recovered in the quads containing the feature rocks. Possibly associated materials found in general level recovery included a core (37DD2D-1), 50 pieces of debitage, and at least 15 pieces of bone (see Chapter 33). The latter included 2 turtle shell fragments and 9 medium/large mammal bones.

Comments: Level notes and profiles indicate Feature 193 was located about midway through the Leanne soil (Unit Isic). Feature 193 clearly relates to the Wilson component, and it very likely represents a small hearth feature (similar to Features 187 and 255).

\section{Feature 194}

Feature Type: pit with burned rocks

Provenience: Area B, Square W0/N8 (SE quad), Levels 9-12; detection elevation $96.58 \mathrm{~m}$; base elevation $96.31 \mathrm{~m}$

Stratigraphic Context: Feature 194 probably originated from a surface in lower Unit IIIc and intruded underlying Unit III (undifferentiated) deposits

Archeological Chronology: Middle or Late Archaic Special Studies:

Macrobotanical: 1 macroplant sample analyzed (see Chapter 40)

Figure: 26-84, 26-85, and 26-86

Description: Feature 194 was a pit found in the lower portion of Burned Rock Midden 2. It was partially exposed in the southeast corner of Square W0/N8 and extended into both the south and east walls. The exposed portion measured ca. $70-x-70 \mathrm{~cm}$ with a depth of $27 \mathrm{~cm}$. Feature 194 should have been further exposed when adjacent Square E2/N8 was excavated, but it is not mentioned in the level notes for this 


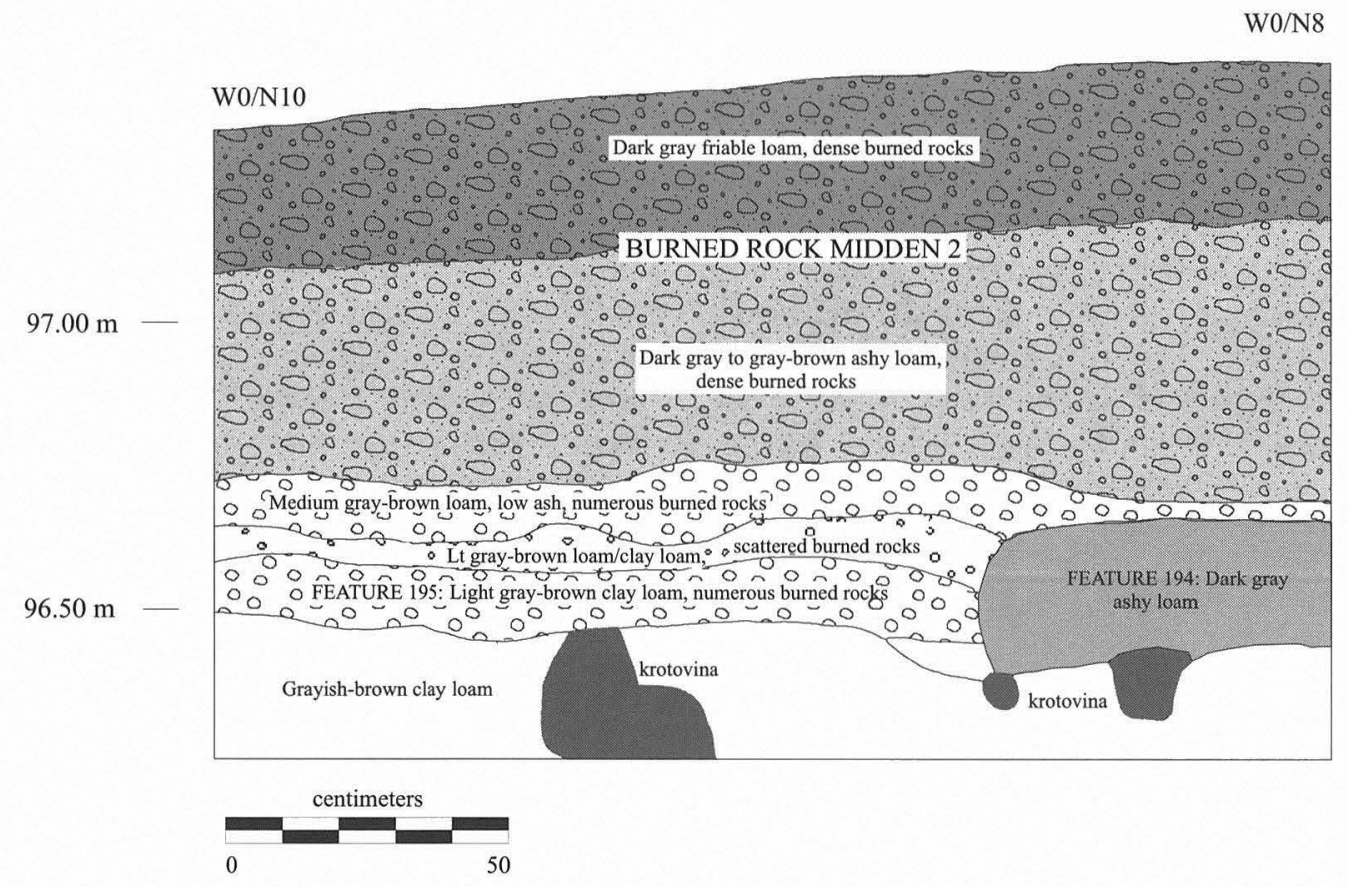

FIGURE 26-84. East wall profile of Square W0/N8 showing Burned Rock Midden 2, Feature 194, and Feature 195.

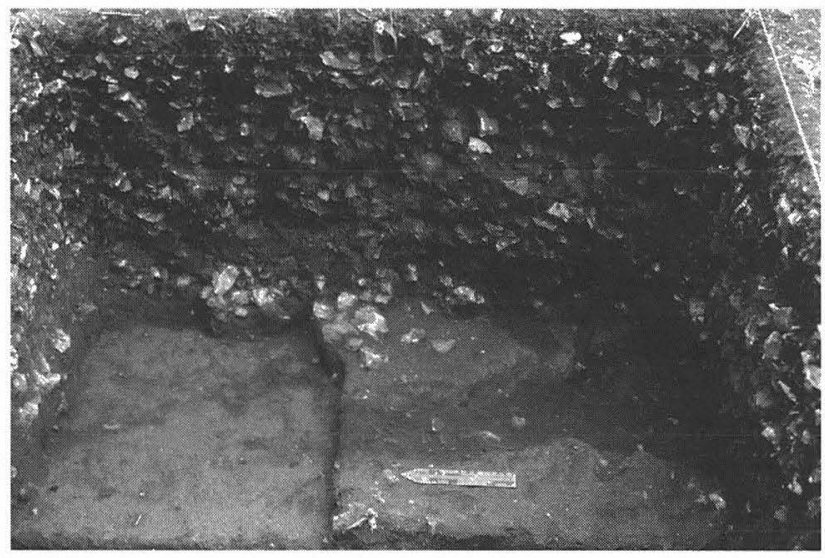

FIGURE 26-85. Eastern half of Square W0/N8, with the southeast quad (right) at the base of Level 10 and the northeast quad (left) at the base of Level 11, looking east. Feature 194 (pit) is partially exposed in the southeast quad. A small portion of Feature 195 is also visible as the layer of rocks exposed at the base of the east wall. Burned Rock Midden 2 is visible in the north, east, and south walls.

square. There was considerable evidence of burrowing at this depth in E2/N8, and the Feature 194 outline may have been obscured by intrusive burrows.

Feature 194 was detected in a thin, 5-10-cm-thick zone that separated the lowest layer of Burned Rock Midden 2 (recorded as Feature 195) from the overlying mounded, midden accumulation. This thin zone (encountered in lower Level 9 and upper Level 10 of W0/N8) was much lighter in color (being brown to grayish brown) than the overlying dark gray sediments, and it contained much less ash and burned rock. Since Feature 194 was filled with dark gray,

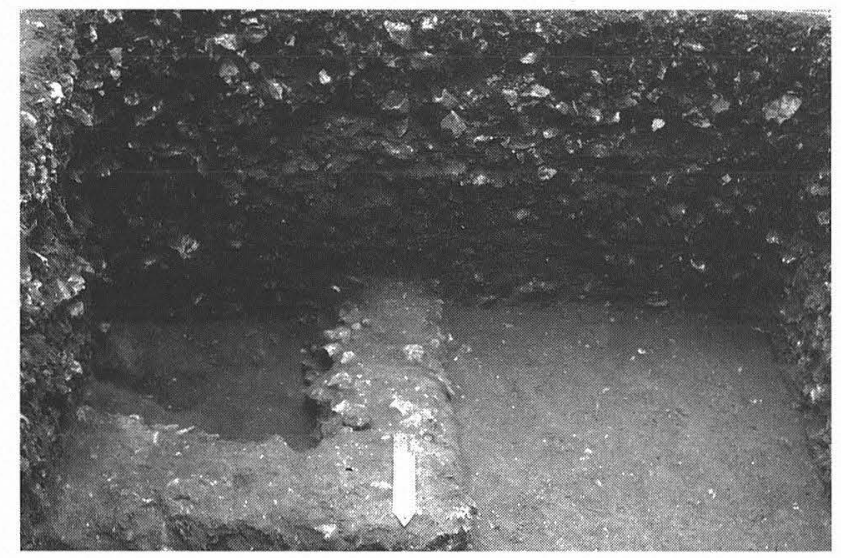

FIGURE 26-86. Feature 194 in Square W0/N8 after fill was removed, looking south. The top of the feature pedestal is at the base of Level 10, and the rest of the square is at the base of Level 11. Burned Rock Midden 2 is visible in the south wall.

ashy sediments, it contrasted distinctly with the surrounding lighter colored matrix. The fill resembled the overlying midden deposits, and it was probably excavated from a surface above its detection level. It had a semicircular outline when it was first detected, but after the fill was removed, it exhibited a somewhat rectilinear outline (see Figure 26-86). Several burrow tunnels intruded the pit margins, and they may have obscured the original shape.

Numerous small ("pebble size") burned rock fragments were scattered throughout the pit fill with several larger rocks ("small to medium cobble size") found at the base. Small quantities of charcoal were scattered around and beneath the rocks found at the base of the pit, and a few small patches 
of burned sediment were also observed at the base. Charcoal flecks were dispersed throughout the fill, but there was a notable increase near the base. The only charcoal sample provenienced to Feature 194 (CH-930) was identified as indeterminate wood. Feature 194 fill also contained at least 3 unifacial tools (50KC-17, 18, and 19) and 35 pieces of debitage. The field notes indicate several bone fragments were also found in the fill, but they were apparently combined with general level recovery.

Comments: Feature 194 clearly postdates Feature 195, an Early or Middle Archaic burned rock accumulation that represents the lowest layer of Burned Rock Midden 2 (see Feature 195 description). Although Feature 194 was detected in the thin zone that separates Feature 195 from the overlying mounded midden deposits, this pit was probably excavated from a surface above its detection level. It was probably associated with the lower portion of the mounded midden deposits (roughly Levels 6-9). A mixture of Middle and Late Archaic projectile points was found in these levels (Nolan, Travis, Bulverde, and Lange; see Appendix 5) and a carbonized Camassia scilloides bulb (CH-925) found in Level 8 of W0/N8 (SW quad) yielded an AMS date of $3780 \pm 70$ в.P. (ETH-14115; see Chapter 25). This bulb was found slightly above (within ca. 10-20 cm) and west of Feature 194. These data suggest Feature 194 probably dates to either the latter portion of the Middle Archaic period or the early portion of the Late Archaic period.

\section{Feature 195}

Feature Type: burned rock accumulation (lowest layer of Burned Rock Midden 2)

Provenience: Squares W0/N8 (NE and SE quads) and E2/ N8 (NW and NE quads), Levels 10-11; detection elevation $96.57 \mathrm{~m}$; base elevation $96.47 \mathrm{~m}$

Stratigraphic Context: undifferentiated Unit III

Archeological Chronology: Middle Archaic?

Figure: 26-84

Description: Feature 195 was a burned rock accumulation that apparently constituted the lowest layer of Burned Rock Midden 2. This layer was buried in the light gray-brown sediments found beneath the dark gray, ashy sediments of the mounded midden accumulation (see Burned Rock Midden 2 description). Feature 195 was separated from the dark gray deposits by a ca. 5-10-cm-thick layer of light gray-brown sediment containing a significantly lower burned rock density than either the overlying deposits or the Feature 195 layer. This zone probably represents a hiatus in the formation of Burned Rock Midden 2.

In contrast to the overlying mounded midden deposits (which were ca. $80-90 \mathrm{~cm}$ thick), Feature 195 was a relatively flat accumulation of burned rocks with a vertical extent of only $10 \mathrm{~cm}$. It was partially exposed in the eastern half of Square W0/N8 and the northern half of E2/N8 with the ex- posed portion measuring ca. $2.7 \mathrm{~m}$ east-west by $1.4 \mathrm{~m}$ northsouth. Rocks were scattered throughout both squares in these levels, but they were more densely packed in the area recorded as Feature 195. The field notes indicate the average rock size was a little larger in Feature 195 than in the overlying midden deposits, with an apparent increase in the number of "small and medium cobble" size rocks. Charcoal was scattered among and under the Feature 195 rocks, and some small, scattered patches of burned sediment were observed as well. This layer contained far less ash than the mounded deposits but significantly more charcoal.

All materials recovered from the levels encompassing Feature 195 (Levels 10-11) were provenienced to Burned Rock Midden 2. At least 19 charcoal samples were recovered from these levels, and 12 were analyzed as macroplant samples. Six were identified as live oak type wood, 1 as walnut wood, 1 as elm wood, and 4 as indeterminate wood. The artifact recovery for these levels includes 13 projectile points (3 Nolan, 2 Travis, 1 Bulverde, 1 Early Triangular, 1 Expanding Concave D, 1 Expanding Stem D, 1 Rectangular Stem B, and 3 fragments), 17 bifaces/biface fragments, 28 unifaces, 1 burin, 2,483 pieces of debitage, 1 piece of worked hematite, 1 mano, and 1 metate fragment (see Appendix 5). Since the projectile point recovery was dominated by Middle Archaic types Feature 195 was assigned a tentative Middle Archaic age estimate.

Faunal recovery for these levels includes 6 mussel shell fragments (see Chapter 37) and 117 bones/bone fragments (see Appendix 10). The latter include 4 turtle shell fragments, 3 specimens classified as deer, 2 as deer/antelope, 8 as rabbit, and 13 as large or medium mammal (the remainder were Vertebrata indeterminate). Approximately 33\% of the bone was burned.

Comments: The stratigraphic context of Feature 195 is somewhat problematical. Since Area B was not sampled in the TARL excavations, we do not have a confident correlation between all of the Area B levels and the stratigraphic units defined in the TARL excavations. The available data suggest the base of the dark gray, ashy midden deposits (upper portion of Level 9 in both Area B squares) probably corresponds to the base of Unit IIIc in the Area A excavations. The lighter-colored sediment found below this may correspond to the upper portion of Unit IIIb, but there was insufficient evidence for a confident correlation. When stratigraphic assignments were given to TxDOT excavation proveniences during the TARL analysis, all of the levels encompassing Burned Rock Midden 2 (including the Feature 195 levels) were assigned to Unit IIIc, and the levels below this (down to the Unit II contact) were assigned to Unit III (undifferentiated). After further study of the Burned Rock Midden 2 data, we now suspect the Unit III/IIIc boundary should have been placed at the base of the dark gray deposits in mid Level 9. 


\section{Feature 198}

Feature Type: burned live oak tree

Provenience: Area B, Square W0/N8 (NE and NW quads), Levels 26B-30; detection elevation ca. $94.86 \mathrm{~m}$; base elevation $94.47 \mathrm{~m}$

Stratigraphic Context: Unit I/II? transition

Archeological Chronology: Late Paleoindian

Special Studies:

Radiocarbon: 1 wood charcoal sample was AMS-dated to $9240 \pm 70$ B.P. (CAMS-19080; see Chapter 25)

Macrobotanical: 4 macroplant samples analyzed (see Chapter 40)

Figure: $26-87$

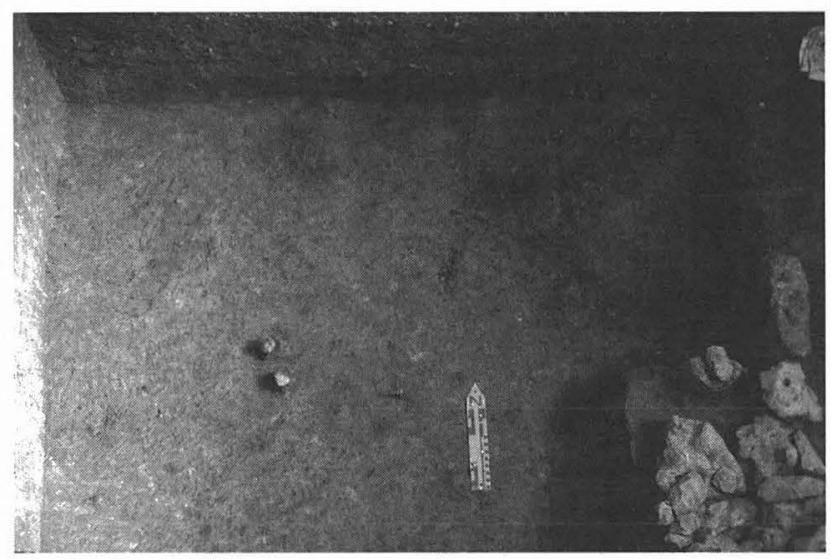

FIGURE 26-87. Feature 198 in Square W0/N8, Level 28B, looking north. Feature 198 is the dark, burned area in the upper right. Burned rocks on pedestal at lower right represent the western edge of Feature 166.

Description: Feature 198 was a burned live oak tree that probably grew on a surface in either lower Unit II or upper Unit I. The feature extended into the north and west walls, but the exposed portion encompassed an area measuring ca. $170 \mathrm{~cm}$ east-west by $80 \mathrm{~cm}$ north-south. Circular and amorphous patches of burned sediment, charcoal, and ash were scattered throughout this area with the largest and best defined concentration encountered in Level 27B. At this depth, there was a semicircular area of dark red sediment (ca. $100 \mathrm{~cm}$ in diameter) that appeared to be the central core of the burned area. Burned, oxidized sediment was found primarily in the upper portion of the feature with the largest charcoal concentrations found in the lower portion of the feature. Feature 198 had a documented vertical extent of ca. $39 \mathrm{~cm}$.

Four of the five charcoal samples provenienced to Feature 198 were analyzed as macroplant samples (CH-914, CH-919, CH-921, and CH-922), and all four were identified as live oak wood. An AMS radiocarbon date was obtained on one of these samples (see date above). Some burned sediment was also collected as a thermoluminescence sample (unanalyzed).
Comments: The stratigraphic position of Feature 198 is somewhat problematical. Since Area B was not sampled in the TARL excavations, we do not have a confident correlation between all of the Area B levels and the stratigraphic units defined in the TARL excavations. The available data suggest Feature 198 probably grew on a surface at or near the Unit I/II contact.

\section{Feature 199}

Feature Type: burned mulberry tree

Provenience: Squares E20/S74 and E20/S72; recorded in west wall profile of Block 4 (not found in level excavations); top elevation $96.40 \mathrm{~m}$; base elevation $96.30 \mathrm{~m}$

Stratigraphic Context: Unit IIIb

Archeological Chronology: Middle Archaic

Special Studies:

Radiocarbon: 1 wood charcoal sample was conventionally dated to $5560 \pm 60$ B.P. (Beta-79699; see Chapter 25)

Macrobotanical: 1 macroplant sample analyzed (see Chapter 40)

Figure: 26-88

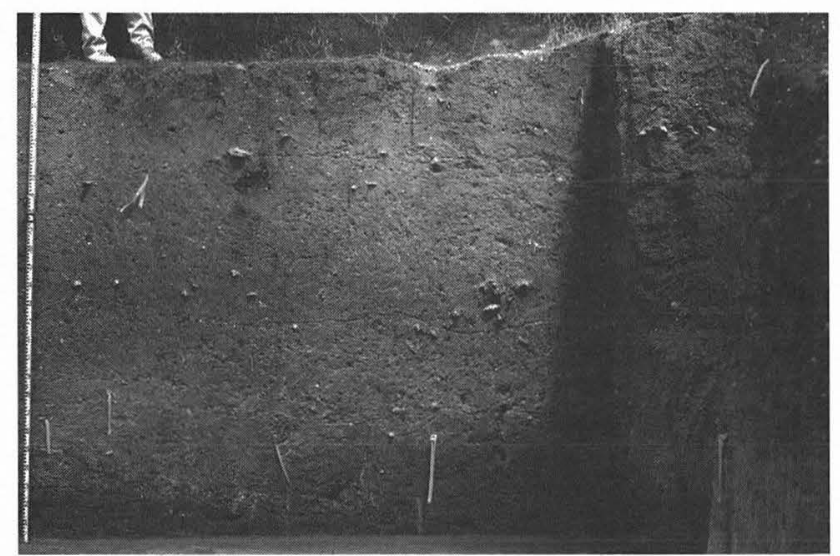

FiguRE 26-88. Feature 199 (burned tree) in the west wall of Block 4 (Squares E20/S74 and E20/S72), looking west.

Description: Feature 199 was a burned tree exposed in the west wall of Block 4 after rain eroded this face. Although it was not recorded as a feature by the TxDOT excavators, there was sufficient documentation for a feature number to be assigned during the TARL analysis. The exposed portion of Feature 199 consisted of a dense concentration of charcoal with a horizontal extent of ca. $20 \mathrm{~cm}$ and a vertical extent of ca. $10 \mathrm{~cm}$. This concentration was mapped in the final profile drawing of the west wall, but it is not mentioned in the level notes for the squares within which it falls (it was apparently not exposed until after the corresponding levels were excavated). A large charcoal sample collected from the feature (CH-1085) was identified as red mulberry (Morus rubra). This same sample yielded the radiocarbon date cited above. 
Comments: Feature 199 probably represents a burned red mulberry tree that grew on a surface in the mid to upper portion of Unit IIIb. It may have grown on roughly the same surface as Feature 50, a probable burned live oak tree recorded about 4 m south of Feature 199 in Square E20/S78 (see Feature 50 description). Feature 50 yielded a radiocarbon date of $5520 \pm 80$ B.P.

\section{Feature 201 (with Subfeatures 203, 205-208, and 211)}

Feature Type: burned rock accumulation

Provenience: South Block, Squares 14-15 (Levels 5-6) and Squares 16-17 (Levels 5-8); East Block, Square 18 (Levels 89), Squares 19-20 (Levels 7-9), and Squares 21-22 (Levels 68); elevation range in South Block was ca. 97.20-96.80 m; elevation range in East Block was ca. 97.10-96.70 m

Stratigraphic Context: the lower portion of Unit IIIc and the Unit IIIb/IIIc transition

Archeological Chronology: Late Archaic

\section{Special Studies:}

Archeomagnetic: 22 of 50 samples analyzed from Features 201, 203, 205-207, 211 (see Chapter 27 and Appendix 6)

Magnetic Susceptibility: 8 samples analyzed from Features 203, 205-208, 211 (see Chapter 28)

Micromorphology: 1 sample analyzed from Feature 206 (see Chapter 29 and Appendix 7)

Gastropod: 1 sample analyzed from Feature 206 (see section by Theler in Chapter 37)

Macrobotanical: 15 macroplant samples analyzed from Features 201, 205, 206, 208 and 9 flotation samples processed from Features 203, 205-208, 211 (see Chapter 40)

Figures: 26-89, 26-90, 26-91, 26-92, 26-93 (see also Figures 27-18 and 27-19 in Chapter 27)

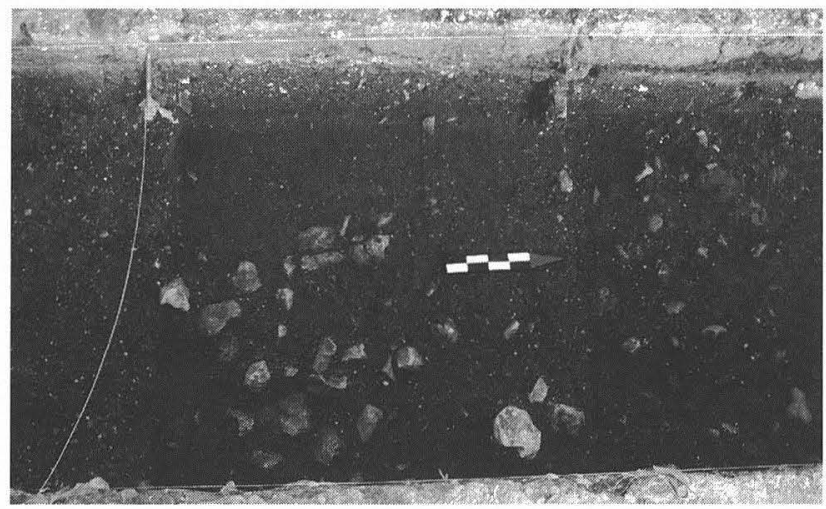

FIGURE 26-89. Portion of Feature 201 exposed in Square 21, Level 6 , looking west.

Description: The Feature 201 designation was initially assigned to a concentration of burned rocks exposed in Level 6 of Square 21 (see Figure 26-89). As the excavations progressed, it became apparent that this concentration was part of a larger burned rock accumulation that extended throughout the East Block (Squares 18-22) and the eastern end of

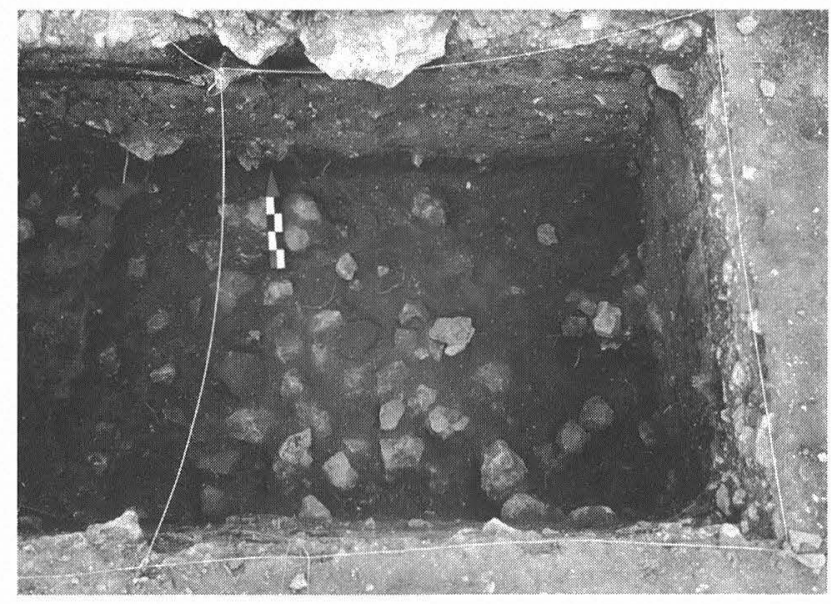

FIGURE 26-90. Portion of Feature 201 exposed in Square 17, Level 7 , looking north.

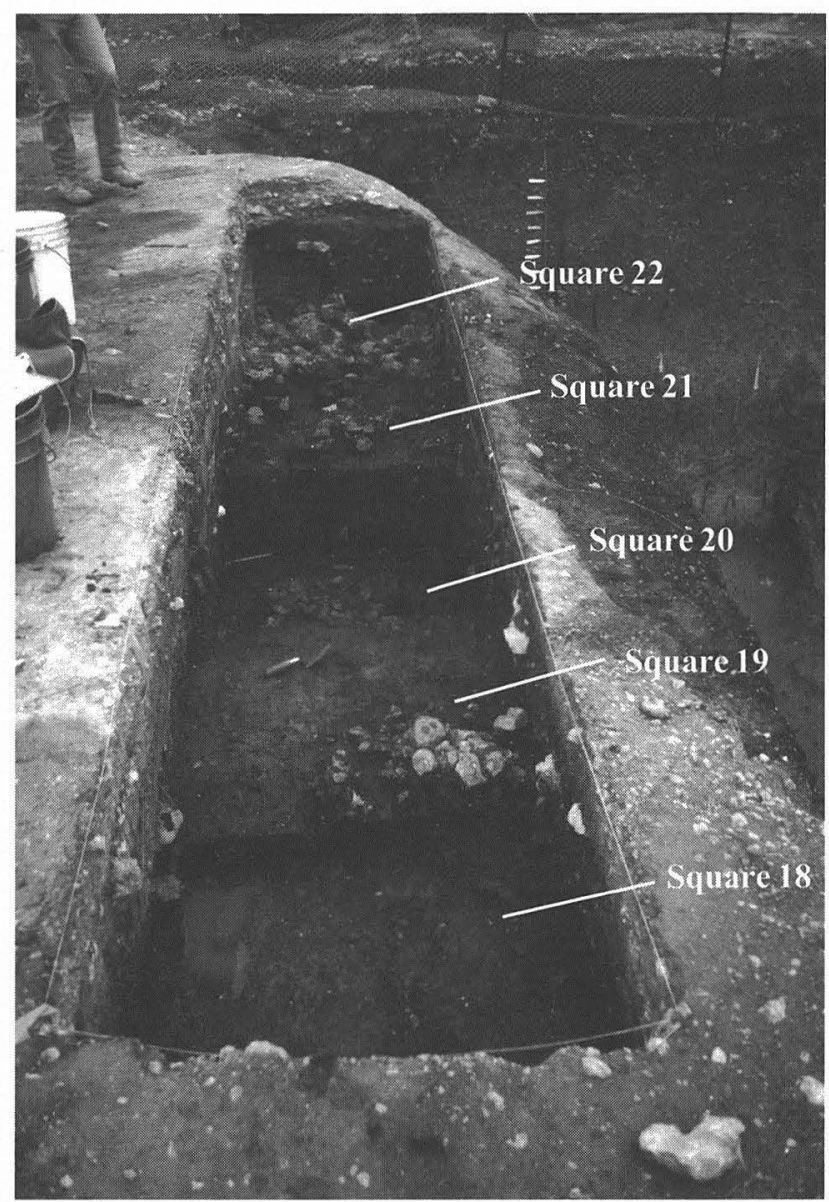

FIGURE 26-91. Portions of Feature 201 exposed in the TARL East Block, looking south. Subfeatures 203 and 205 are visible in Squares 19 and 22. Feature 204 is visible in Square 20, Level 20 (below Feature 201).

the South Block (Squares 14-17). The accumulation extended beyond the limits of the TARL excavations but the investigated portion indicates a horizontal extent of at least $10 \mathrm{~m}$ north-south by $4 \mathrm{~m}$ east-west. It may have extended west 


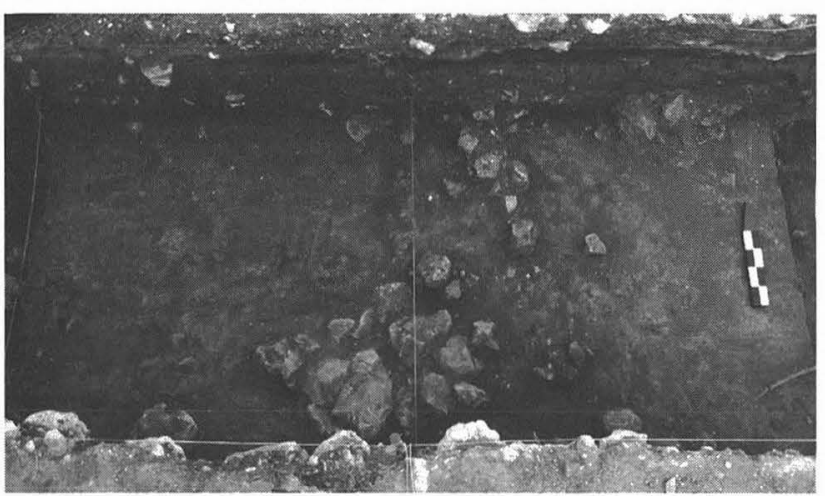

Figure 26-92. Feature 206 in Level 5 of Squares 15 (left) and 16 (right), looking north.

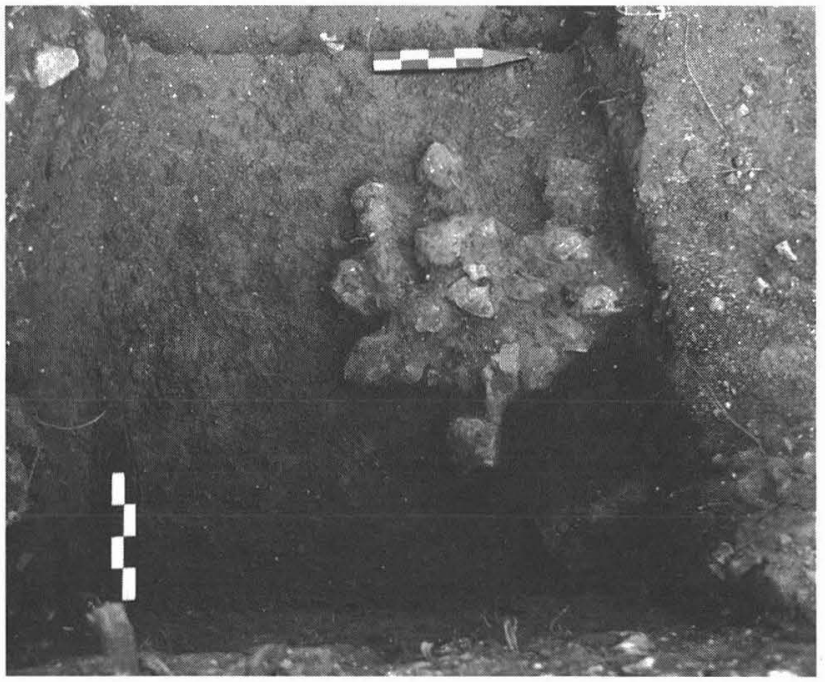

FigURE 26-93. Feature 211 in Level 8 of Square 17, looking west.

into TxDOT Block 6, but this portion of Unit III was removed in the machine excavation of upper Block 6. Feature 173, a burned rock scatter recorded in Levels 4 and 5 of the TxDOT Fine-Screened Square (E28/S78), was located at about the same elevation as the Feature 201 deposits, and it very likely represents part of the same accumulation.

Feature 201 had a maximum vertical extent of ca. 20$40 \mathrm{~cm}$ with its thickness varying considerably from square to square. Within the investigated portion of this feature, the deposits were apparently thickest in the areas sampled by Squares 16, 17, 20, 21, and 22. The lowest layers of Feature 201 lay with the Unit IIIb/IIIc transition zone, but most of the accumulation was buried in the lower portion of the dark grayish brown Unit IIIc sediments. The top of Feature 201 was exposed immediately below the disturbed road construction fill zone (fill/IIIc) in the East Block and ca. $20-30 \mathrm{~cm}$ below the base of this zone in the South Block. Charcoal recovered from the upper portion of Feature 201 in both areas (and especially from the East Block) was potentially introduced from these disturbed deposits (which contained abundant charcoal).
Feature 201 was composed of several layers of mostly small, burned limestone fragments (ca. 2-10-cm size) mixed with assorted other cultural debris (primarily chipped stone artifacts, faunal remains, and carbonized plant remains). No burned sediment was reported from the feature, and though small quantities of charcoal were dispersed throughout the deposits, no significant concentrations were found. The density of the burned rocks varied considerably within Feature 201 (both horizontally and vertically), and it was not documented in a consistent fashion for all squares and levels encompassing this feature. Photographs and plan maps indicate dense concentrations of burned rocks were encountered in some levels (see Figure 26-90) with more dispersed scatters found in others (see Figure 26-91). Total burned rock weight was recorded for some of the levels encompassing Feature 201, and these ranged from ca. 5 to $29 \mathrm{~kg}$ (for ca. 100-x-100-x-10-cm levels).

Additional feature designations were assigned to six concentrations of burned rocks found within this accumulation, and these are considered subfeatures of Feature 201. Features 203 and 205 were poorly defined burned rock scatters recorded in the East Block portion (see Figure 27-18 in Chapter 27) and Features 206 (see Figure 26-92), 207, 208, and 211 (see Figure 26-93) were somewhat better defined clusters of burned rocks found in the South Block portion (see Figure 27-19 in Chapter 27). Feature 210, a burned rock scatter found in the East Block, was considered possibly associated with Feature 201. Feature 210 may represent the lower portion of the Feature 205 scatter, but the association could not be clearly determined.

Archeomagnetic samples were collected from 50 rocks within Feature 201 (and subfeatures). Twenty-two of these samples were analyzed and the results indicate that all of the analyzed rocks were definitely heated; 4 cooled in place (with little or no postcooling displacement); 14 cooled near their find positions; and 4 were either out of place or undetermined (see Figures 27-18 and 27-19 in Chapter 27). Five of the rocks appear to have cooled from temperatures greater than ca. $600^{\circ} \mathrm{C}$ with little or no movement, but most of the others appear to have moved one or more times while cooling from variable temperatures. Ten of the 22 analyzed archeomagnetic samples were collected from the subfeatures (1 from Feature 203, 2 from Feature 205, 2 from Feature 206, 3 from Feature 207, and 2 from Feature 211). The sampling intensity was too low to determine significant patterns, but most of the samples from the subfeatures appear to have moved 1 or more times while cooling, then finished cooling in or near their find positions.

The lithic artifacts from all levels encompassing Feature 201 are reported by square and level in Appendix 5. The combined recovery includes 34 projectile points ( 2 Scallorn, 2 Ensor, 1 Marcos, 1 Marcos/Marshall, 2 Marshall, 2 Castroville, 2 Montell, 2 Williams, 2 Pedernales, 1 Uvalde, 3 miscellaneous side-notched, 1 rectangular-stem $\mathrm{B}, 1$ rectangular-stem $\mathrm{C}, 1$ expanding concave $\mathrm{B}$, and 11 unclassified 
fragments), 45 bifaces/biface fragments, 80 unifaces/flake tools, 2 perforators, 3 cores, 11 burins/burin spalls, and 23,613 pieces of debitage. No ground stone artifacts were identified from these proveniences, and only one bone tool is reported (Specimen 203-9, a "pointed bone" described in Chapter 21). Chipped stone tool and debitage densities are generally a little higher in the East Block portion of Feature 201 with a significant spike noted in the Square 21 and 22 samples for Levels 7 and 8.

A relatively large quantity of faunal remains were recovered from the Feature 201 area, and these data are reported in several chapters and appendixes. The 1/8-inchscreen (general recovery) bone was analyzed by Baker (see Chapter 33 and Appendix 10). He analyzed over 5,400 bones from the levels encompassing Feature 201, with approximately $78 \%$ of this sample consisting of unidentifiable fragments. The identifiable bone is dominated by medium/large mammal (ca. $66 \%$ of identifiable taxa) with smaller quantities of large mammal (ca. 9\%), deer and/or antelope (ca. $8 \%$ ), small and/or medium mammal (ca. 6\%), rabbit (ca. 4\%), turtle (ca. $3 \%$ ), rodent (ca. $2 \%$ ), snake (ca. $1.6 \%$ ), very large mammal (ca. $0.4 \%$ ), Canis sp. (ca. 0.4\%), fish (ca. 0.2\%), carnivore (ca. $0.08 \%$ ), and large bird (ca. $0.08 \%$ ).

The microvertebrate fine-screen column analyzed by Balinsky (see Chapter 35) included 10,136 specimens from levels provenienced to Feature 201 (Levels 7-9 in Square 20). Approximately $91 \%$ of this sample was unidentifiable bone fragments. The identifiable sample included miscellaneous rodents (ca. $24 \%$ of the identifiable taxa), turtle (ca. 19\%), eggshell (ca. 14\%), snakes and/or lizards (ca. 12\%), fish (ca. $6 \%$ ), rabbit (ca. 6\%), small and/or medium mammal (ca. 6\%), large mammal (ca. 5\%), medium/large mammal (ca. 5\%), deer/ artiodactyl (ca. 2.7\%), amphibian (ca. 0.9\%), carnivore (ca. $0.2 \%$ ), Canis sp. (ca. $0.1 \%$ ), and bird (ca. $0.1 \%$ ).

Additional fine-screen faunal recovery was obtained from a ca. 9.75-liter sediment sample collected from Feature 206. A total of 792 bone fragments (see Appendix 8) and 9 eggshell fragments (see Chapter 36 ) were retrieved from this sample. Approximately $86 \%$ of the bone was unidentifiable fragments, with the relatively small sample of identifiable bone ( $\mathrm{N}=112$ specimens) including mammal (ca. $56 \%$ ), rodent (ca. 28\%), fish (ca. 8\%), snake (ca. 4.5\%), rabbit (ca. $2 \%$ ), turtle (ca. $0.9 \%$ ), and bird (ca. $0.9 \%$ ).

The 12 mussel shell specimens found in the Feature 201 area were analyzed by Shaw (see Chapter 37). This group includes a Lampsilis teres valve, an Arcidens confragosus hinge fragment, and 10 fragments ranging in shell thickness from thin to thick.

Only two radiocarbon samples were collected from Feature 201 (C14-3 and C14-4), but due to potential contamination from the overlying fill zone, these were not considered reliable for dating. Seventeen additional charcoal samples were collected as macroplant samples from Feature 201 (and subfeatures) and all were analyzed. Seven were identified as juniper wood (Lots 129, 371, 387, 391, 399, 431, and 576), four as live oak type wood (Lots 267, 396, 454, and 2877), five as indeterminate wood (Lots 218, 226, 250, 480, and 660), and one as carbonized walnut shell (Lot 390). Although most of these appear to be from reliable contexts, it is possible that a few were displaced from the fill zone.

Eleven bulk matrix samples were collected from the Feature 201 subfeatures (one each from Features 203, 205, 207, and 211; three from Feature 206; and four from Feature 208). Most of this sediment was used for various special studies and the remainder was curated. A good portion was used for nine flotation samples (three from Feature 206, two from Feature 208, and one each from Features 203, 205, 207, and 211), but no identifiable plant remains were recovered. A relatively small quantity was used for magnetic susceptibility samples (two each from Feature 203, 205, 207, and four from Feature 208). These results were comparable to nonfeature samples from similar stratigraphic contexts (no significant deviation detected). In addition to the fine-screen faunal sample discussed above, some of the Feature 206 sediment was used for a micromorphology sample and a gastropod sample. The micromorphology sample (WL95-6) exhibited some areas of burned, rubified sediment as well as some ash and a possibly burned eggshell fragment.

Theler identified a total of 668 terrestrial snails (representing at least 11 taxa) in the Feature 206 gastropod sample. Some of these species have wide habitat tolerances and are commonly found throughout the site deposits. Of greater interest are several species considered indicative of relatively mesic, woodland habitats (e.g., Glyphyalinia roemeri, G. umbilicata, Gastrocopta contracta, Strobilops texasiana).

Comments: Feature 201 may represent an occupational midden containing a relatively large quantity of burned rocks. It may encompass the remains of several discrete burned rock features surrounded by a scatter of displaced rocks and other cultural refuse. On the other hand, Feature 201 may represent the margins of a larger burned rock accumulation (possibly a mounded burned rock midden) that lies outside the excavated areas (perhaps to the east of the East Block).

\section{Feature 202}

Feature Type: burned rock cluster

Provenience: Square 14, Level 4; detection elevation 97.33 $\mathrm{m}$; base elevation $97.23 \mathrm{~m}$

Stratigraphic Context: Unit IIIc

Archeological Chronology: Late Archaic or Late Prehistoric Description: Feature 202 consisted of a cluster of seven burned limestone fragments and a deer maxilla (Odocoileus sp.). The cluster measured ca. $35-\mathrm{x}-40 \mathrm{~cm}$ with a maximum vertical extent of ca. $10 \mathrm{~cm}$. The rocks were angular fragments in the 5-20-cm size range. At least 13 additional burned rocks were loosely scattered outside the cluster, and at least some of these may have been associated with Feature 202 
(displaced from the cluster?). No evidence of in situ burning was observed in the feature area, although a few lumps of burned sediment were found in general level recovery. No charcoal was recovered from the entire level. The maxilla was from an adult deer (left side), and it retained six permanent teeth with moderate wear (see Chapter 33). The maxilla and teeth exhibited no evidence of burning. A large flake found immediately adjacent to the maxilla was collected as an organic residue sample (OR98; unanalyzed).

Additional faunal remains and some lithic artifacts were found in the feature area, but they were inadvertently combined with general level recovery. The combined recovery includes a projectile point tip fragment (306-2), a bifurcate stem point base (306-3), a Stage 2 biface (OR91), a biface fragment (OR88), a core tool (306-1), 753 pieces of debitage, and 137 bones/bone fragments. Much of the bone was classified as either medium/large mammal or Vertebrata indeterminate fragments, but the sample also included 3 deer tooth fragments, 2 deer or antelope elements (sesamoid and metapodial), a small mammal femur, a snake vertebra, and a turtle shell fragment (see Appendix 10). About half of these specimens were burned, and 42 exhibited spiral fractures (the deer/antelope metapodial and some of the medium/large mammal and Vertebrata fragments).

Comments: The excavators did not think Feature 202 represented an intact hearth. They felt the deer maxilla and burned rock cluster probably represented a fortuitous (rather than intentional) grouping.

\section{Feature 204}

Feature Type: burned rock cluster

Provenience: Square 20, Levels 11-12; detection elevation $96.59 \mathrm{~m}$; base elevation $96.47 \mathrm{~m}$

Stratigraphic Context: Unit IIIb

Archeological Chronology: Middle Archaic

Special Studies:

Radiocarbon: 1 wood charcoal sample was AMS-dated to $4440 \pm 60$ в.P. (CAMS-10196; see Chapter 25)

Archeomagnetic: 4 of 5 samples analyzed (see Chapter 27 and Appendix 6)

Magnetic Susceptibility: 10 samples analyzed (see Chapter 28)

Micromorphology: 1 sample analyzed (see Chapter 29 and Appendix 7)

Gastropods: 1 sample analyzed (see section by Theler in Chapter 37)

Macrobotanical: 4 flotation samples processed (see Chapter 40)

Phytolith: 1 sample analyzed (see Chapter 41)

Figure: 26-91 (see also Figure 27-21 in Chapter 27)

Description: Feature 204 was a relatively compact, ovalshaped cluster of ca. 50 burned rocks $(2-10-\mathrm{cm}$ size). The cluster measured roughly $50-x-70 \mathrm{~cm}$ with vertical extent of ca. $12 \mathrm{~cm}$. It was composed of a single layer of rocks that appeared to be resting on a relatively flat surface. There were several 10-20-cm rock-free spaces in the interior of the cluster, and it looked as though some rocks may have been displaced from these areas (see Figure 27-21). A few scattered rocks found outside the cluster during level excavations may have been displaced from Feature 204.

Small amounts of ash and charcoal were found in the cluster, but no burned sediment was observed. An AMS radiocarbon date was obtained on the only charcoal sample (C14-5) collected from Feature 204. This sample was collected between two rocks at the southern edge of the cluster. Artifact recovery consisted of 23 pieces of debitage.

Five archeomagnetic samples were collected from rocks within Feature 204, and four of these samples were analyzed. The results indicate three of the rocks were cooled in place from at least $400^{\circ} \mathrm{C}$ with little or no movement. The fourth rock appears to have moved several times while cooling and then finished cooling (near its find position) from ca. $250^{\circ} \mathrm{C}$ or less.

Feature 204 was located in one of the TARL fine-screen squares, and apart from some sediment reserved for special studies, the matrix in the two levels encompassing this feature was fine-screened, primarily to recover microvertebrate fauna (see Chapters 34 and 35). As in other TARL levels encompassing features, each of these levels was horizontally divided into " $\mathrm{A}$ " and " $\mathrm{B}$ " subsets with the " $\mathrm{B}$ " portion encompassing the Feature 204 area as defined by the excavator.

The analyzed bone from Feature 204 fine-screen samples is reported by Balinsky in Chapter 35, and the eggshell is reported by Decker in Chapter 36. Balinsky analyzed a total of 420 specimens from this feature (all from Level 12B). Approximately $87 \%$ were unidentifiable fragments, but the sample also included relatively small quantities of Artiodactyl, rabbit, rodent, large/medium/small mammal, turtle, snake, and fish bones. Seven eggshell fragments were also recovered, and thickness measurements suggest at least 3 species may be represented.

Several bags of sediment were reserved from the "B" portion of both levels, and most was used for magnetic susceptibility, micromorphology, gastropod, flotation, and phytolith samples (with a small portion curated). The magnetic susceptibility results were comparable to nonfeature samples from similar stratigraphic contexts (no significant deviation detected). Although no burned sediment was found in the micromorphology sample (WL95-5), several ash rhombs were observed along with some pieces of calcareous, "ashy" vegetal material.

No identifiable plant remains were found in the flotation samples (totaling 17.25 liters), but the phytolith sample was very productive. It exhibited excellent preservation with a relatively high percent weight extracted. The assemblage was comparable to other Unit IIIb samples (from nonfeature contexts), with a strong dominance of grass (rather than arboreal) phytoliths, a relatively low percentage of conical 
forms (indicative of $\mathrm{C}_{3}$ grasses), and relatively high percentages of saddle and lobate forms (indicative of short and tall $\mathrm{C}_{4}$ grasses). These results suggest more-xeric conditions may have prevailed when Feature 204 was constructed.

A total of 325 terrestrial snails (representing at least 10 taxa) were identified in the gastropod sample. The sample is dominated by species that tolerate a wide range of habitats, but it also includes a significant number of snails that may reflect more-xeric conditions. These species include Pupoides albilabris, Polygyra mooreana, Gastrocopta pellucida, and G. procera.

Comments: Feature 204 probably represents a relatively intact Middle Archaic hearth. It represents one of only a few features in the present sample that can be confidently attributed to the Middle Archaic period. The Feature 204 phytolith and gastropod results suggest this feature may have been utilized during one of the more-xeric intervals in the site's history. These results are consistent with other paleoenvironmental evidence obtained from Unit IIIb deposits.

\section{Feature 209}

Feature Type: burned (?) sediment with a few burned rocks Provenience: Square 20, Level 13; detection elevation 96.38 $\mathrm{m}$; base elevation $96.30 \mathrm{~m}$

Stratigraphic Context: Unit IIIb

Archeological Chronology: Middle Archaic

Special Studies:

Magnetic Susceptibility: 2 samples analyzed (see Chapter 28)

Micromorphology: 1 sample analyzed (see Chapter 29 and Appendix 7)

Gastropods: 1 sample analyzed (see section by Theler in Chapter 37)

Macrobotanical: 1 macroplant samples analyzed and 1 flotation sample processed (see Chapter 40)

Figure: $26-94$

Description: Feature 209 consisted of a ca. $40-\mathrm{x}-40-\mathrm{cm}$ area containing some dark, organically stained sediment, three small burned rocks (ca. $5-\mathrm{cm}$ size), and three small pockets of wood charcoal (ca. 1-2-cm diameter). Although the size and shape of the dark sediment was not explicitly documented, it appears to have encompassed much of the 40-x-40-cm area. The sediment appeared to be charcoal stained, and though it may have been burned, no definitive evidence of burning (other than the charcoal) was reported in the field notes. Several small burrow or root disturbances (1-5-cm size) were also found within the feature area, but these appeared to be intrusive.

The three pockets of charcoal were collected and inadvertently combined into a single sample (C14-11; identified as elm family wood). Associated artifacts include a Stage 1 biface fragment (OR217), an edge-modified flake (Lot 523), and 22 pieces of debitage.

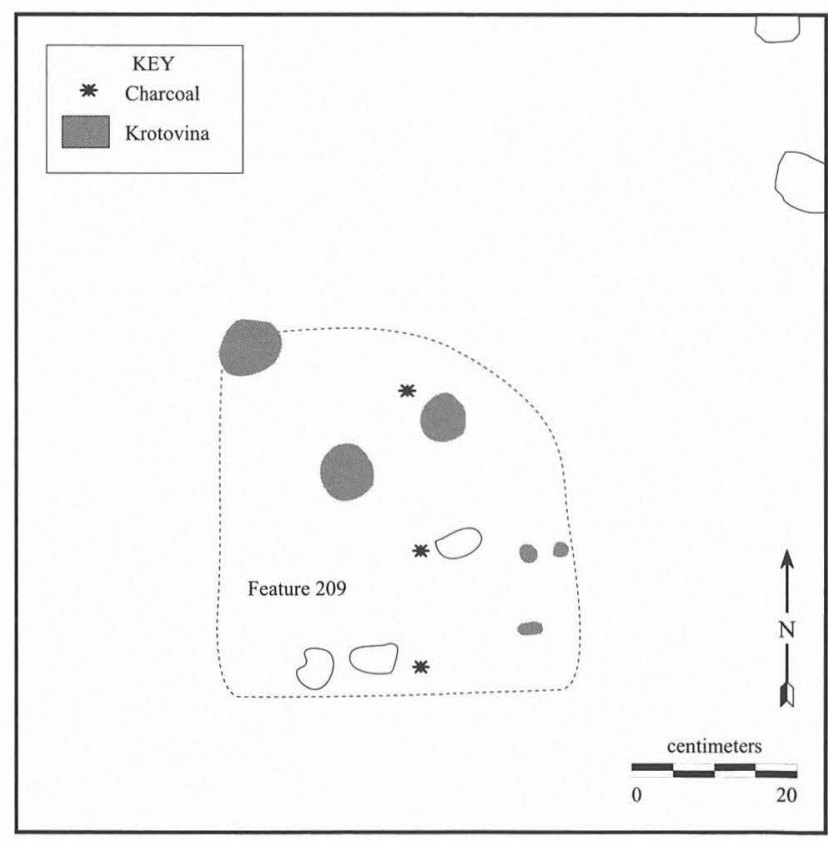

FIGURE 26-94. Feature 209 in Square 20, Level 13.

Feature 209 was located in one of the TARL fine-screen squares, and with the exception of two bags reserved for special studies, the sediment from the feature area was finescreened for a microvertebrate faunal column (see Chapters 34 and 35 ). The feature portion of the level (13B) was screened and analyzed separately from the rest of the level (13A). The analyzed bone from Level 13B includes 191 specimens, but most of these (ca. 91\%) are unidentifiable fragments (see Chapter 35). The 16 identifiable specimens include 6 rodent, 1 rabbit, 4 turtle, 3 snake, 1 frog/toad, and 1 fish. A single eggshell fragment was also found in the fine-screen recovery from Feature 209 (see Chapter 36).

Most of the special studies sediment was used for magnetic susceptibility, micromorphology, gastropod, and flotation samples (remainder was curated). No significant results were obtained from the magnetic susceptibility samples, but the micromorphology sample (WL95-25) exhibited an abundance of what appeared to be very finely divided charcoal. Some ash rhombs and an unburned bone fragment were noted in this sample as well.

The ca. 5 -liter flotation sample from Feature 209 was the most productive flotation sample processed from the site (one of only three to yield identifiable plant remains). Seven carbonized seeds of three genera of grasses (four Panicum, two Setaria, one Paspalum) were identified in this sample, along with some juniper and Rosaceae wood charcoal.

A total of 314 terrestrial snails (representing at least 10 taxa) was recovered from the gastropod sample. The sample is dominated by species that tolerate a wide range of habitats, but it also includes a significant number of snails that may indicate more-xeric conditions prevailed at this time (e.g., Pupoides albilabris, Polygyra mooreana, Gastrocopta pellucida, and G. procera). 
Comments: Although no burned sediment was reported from the Feature 209 area, the carbonized plant remains and the ash observed in the micromorphology sample suggest some sort of burning event is represented by this feature. Since at least six species are represented by the carbonized plant remains, it does not seem likely that the feature represents a single burned plant. Feature 209 may represent the poorly preserved remains of small hearth, however, the evidence is inconclusive.

\section{Feature 212}

Feature Type: burned rock cluster

Proveninece: Squares 37 and 38, Levels 12-13; detection elevation $96.48 \mathrm{~m}$; base elevation $96.32 \mathrm{~m}$

Stratigraphic Context: Unit IIIb

Archeological Chronology: Middle Archaic

Special Studies:

Archeomagnetic: 2 of 4 samples analyzed (see Chapter 27 and Appendix 6)

Magnetic Susceptibility: 4 samples analyzed (see Chapter 28)

Macrobotanical: 1 flotation sample processed (see Chapter 40)

Figure: 26-95 (see also Figure 27-22)

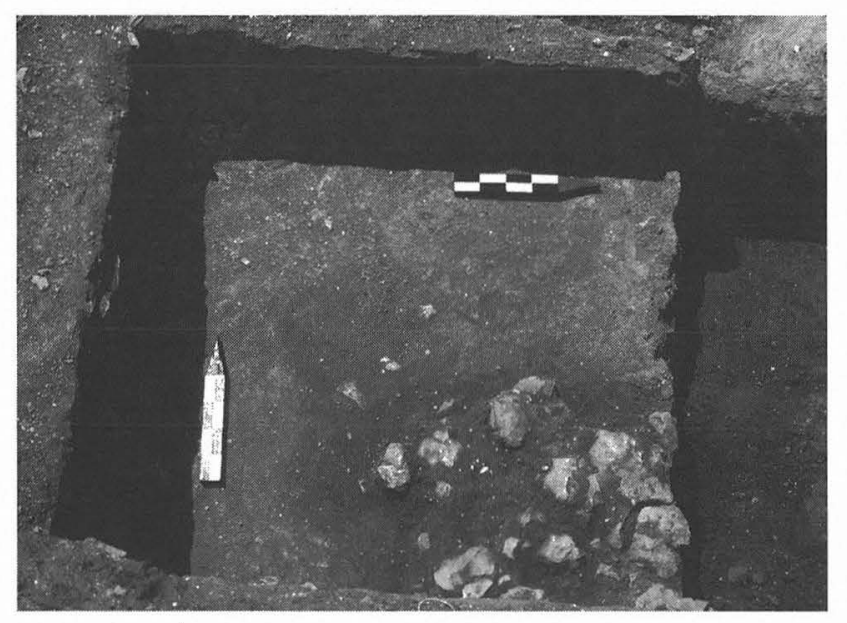

FIGURE 26-95. Feature 212 in Square 37, Level 13.

Description: Feature 212 was a roughly oval-shaped cluster of at least 30 burned rocks. The eastern margin of the feature extended beyond the square walls, but the exposed portion measured ca. $55-\mathrm{x}-75 \mathrm{~cm}$. The cluster was composed of a single layer of rocks with a maximum thickness of ca. $16 \mathrm{~cm}$. The rocks ranged from ca. 5 to $15 \mathrm{~cm}$ in length, and most were spaced no more than a few centimeters apart. Additional burned rocks were scattered outside the main cluster, and a somewhat linear concentration of about 25 small fragments extended about $40 \mathrm{~cm}$ northward from the north edge of the cluster. These fragments looked as if they may have been displaced from the circular cluster. No burned sediment or charcoal was observed in the feature area.

Associated materials include a Stage 2 biface (OR257), a biface fragment (634-1), 173 pieces of debitage (including a flake collected as OR259), 2 mussel shell fragments (thin shell thickness; see Chapter 37), and 51 bones/teeth (see Chapter 33). Most of the bones were Vertebrata indeterminate fragments, but the sample also included 4 Artiodactyl teeth fagments, several medium/large mammal long-bone fragments, a small mammal tooth, and a Neotoma tooth. None of the bone was burned.

Four archeomagnetic samples were collected from three rocks in this feature, and two of these were analyzed. Both rocks were apparently heated to temperatures greater than $500^{\circ} \mathrm{C}$ and then moved one or more times while cooling. They appear to have experienced only minor displacement after final cooling.

Two bulk matrix samples were collected from Feature 212 , and most of this sediment was used for magnetic susceptibility and flotation samples (with a small amount curated). The magnetic susceptibility results were comparable to nonfeature samples from similar stratigraphic contexts (no significant deviation detected). No identifiable plant remains were recovered from the flotation sample.

\section{Feature 214}

Feature Type: burned rock cluster

Provenience: Square 16, Level 10; detection elevation 96.70 $\mathrm{m}$; base elevation $96.64 \mathrm{~m}$

Stratigraphic Context: Unit IIIlb

Archeological Chronology: Middle Archaic

Special Studies:

Radiocarbon: a wood charcoal sample that was conventionally dated to $4880 \pm 70$ B.P. (Beta-79803; see Chapter 25) was possibly associated with Feature 214

Archeomagnetic: 3 of 5 samples analyzed (see Chapter 27 and Appendix 6)

Magnetic Susceptibility: 2 samples analyzed (see Chapter 28)

Macrobotanical: 2 macroplant samples analyzed and 1 flotation sample processed (see Chapter 40)

Figure: 26-96 (see also Figure 27-23 in Chapter 27)

Description: Feature 214 consisted of a tight cluster of 9 relatively large burned rocks (ca. 15-20-cm size). The cluster measured approximately $35-\mathrm{x}-75 \mathrm{~cm}$ with a vertical extent of ca. $6 \mathrm{~cm}$. A dispersed scatter of at least 10 smaller rocks (510 - $\mathrm{cm}$ size) surrounded Feature 214, and some of these fragments may have been displaced from the cluster. Many of the Feature 214 rocks exhibited clear evidence of burning (angular fractures and/or reddish discoloration). Although no burned sediment was observed, a small amount of juniper wood charcoal (Lot 609) was collected. Five archeomagnetic samples were collected from Feature 214 rocks, and three of these were analyzed. All three samples 


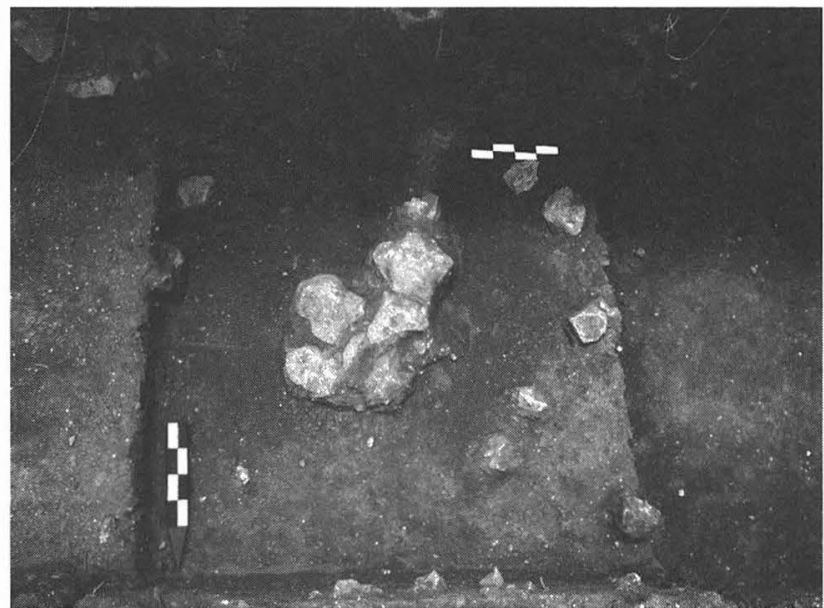

FIGURE 26-96. Feature 214 in Level 10 of Square 16, looking south.

exhibited low remanence intensities, but all were definitely heated, and they all appear to have cooled in or near their find positions.

Although the Feature 214 cluster was confined to Level 10 , scattered rocks found in Levels 11 and 12 were considered possibly associated with this feature. A large pocket of juniper wood charcoal found among these scattered rocks in Level 12 (about $10 \mathrm{~cm}$ below the base of the Level 10 cluster) was judged in the field to be possibly associated with Feature 214. A radiocarbon sample collected from this concentration (C14-15) yielded the conventional date cited above.

Associated artifacts include a Stage 2 biface (OR239), a biface fragment (609-1), an edge modified flake (609-2), and 516 pieces of debitage (including a flake collected as OR237). Associated faunal remains include 77 bones/bone fragments (see Chapter 33). Much of the bone (ca. 70\%) was unidentifiable fragments, but the identifiable taxa included 5 jackrabbit, 1 cottontail, 2 rodent, 2 small mammal, 1 small/medium mammal, 2 medium mammal, 2 medium/large mammal, 3 turtle, and 2 snake specimens. Approximately $17 \%$ of this bone was burned.

A bulk matrix sample was also collected from the Feature 214 area, and this sediment was used for magnetic susceptibility and flotation samples. No identifiable plant remains were recovered from the flotation sample, and no significant deviation was detected in the magnetic susceptibility results.

\section{Feature 215}

Feature Type: burned rock cluster

Provenience: Square 20, Levels 15-16; detection elevation $96.09 \mathrm{~m}$; base elevation $96.01 \mathrm{~m}$

Stratigraphic Context: Unit IIIa/IIIb transition

Archeological Chronology: Early or Middle Archaic Special Studies:

Magnetic Susceptibility: 3 samples analyzed (see Chapter 28)
Macrobotanical: 2 flotation samples processed (see Chapter 40)

Description: Feature 215 was a roughly circular, single-layer cluster of ca. 26 burned rocks (5-10-cm size). The cluster measured ca. $40-x-55 \mathrm{~cm}$ with a vertical extent of ca. $8 \mathrm{~cm}$. The rocks appeared to be resting on a relatively flat surface (no evidence of a basin), and most were closely spaced. No burned sediment or charcoal was found in the feature area, but many of the rocks were clearly discolored or fractured from burning. Associated materials include 51 pieces of debitage and some faunal remains recovered from fine-screen samples.

Feature 215 was located in one of the TARL fine-screen squares, and apart from some sediment reserved for special studies, the matrix in the two levels encompassing this feature was fine-screened for a microvertebrate faunal column (see Chapters 34 and 35). This cluster was not recorded as a feature until Level 15 was completed, therefore feature and nonfeature matrices were not separated in this level. In the next level, sediment from the Feature 215 area was collected and screened separately (as Level 16B) from the nonfeature portion (Level 16A). The analyzed bone from Level 16B is reported by Balinsky in Chapter 35 . She analyzed a total of 532 specimens from Level 16B, but approximately $78 \%$ were unidentifiable fragments. The 117 identifiable specimens include a relatively high percentage of turtle (ca. $48 \%$ of the identifiable taxa) as well as smaller quantities of rodent (ca. $21 \%$ ), fish (ca. 9\%), small mammal (ca. $8 \%$ ), rabbit (ca. $5 \%$ ), snake (ca. $5 \%$ ), large mammal (ca. $2 \%$ ), medium mammal (ca. $2 \%$ ), and lizard $(<1 \%)$. Nine eggshell fragments were also found in the Feature 215 fine-screen recovery (see Chapter 36). Thickness measurements suggest at least 2 species are represented.

Three unscreened bags of sediment were reserved from the Feature 215 area (Level 16B) for special studies. Some of this sediment was used for magnetic susceptibility and flotation samples, and the remainder was curated. No identifiable plant remains were found in the flotation samples, and no significant deviation was detected in the magnetic susceptibility samples.

\section{Feature 220}

Feature Type: burned rock cluster

Provenience: Square 52, Levels 15-16; detection elevation $96.20 \mathrm{~m}$; base elevation $96.09 \mathrm{~m}$

Stratigraphic Context: Unit IIIa/IIIb transition

Archeological Chronology: Early Archaic

Special Studies:

Magnetic Susceptibility: 2 samples analyzed (see Chapter 28)

Micromorphology: 1 sample analyzed (see Chapter 29 and Appendix 7)

Macrobotanical: 2 macroplant samples analyzed and 1 flotation sample processed (see Chapter 40) 
Description: Feature 220 was a roughly oval-shaped cluster of ca. 20 burned rocks (2-10-cm size). The cluster, which measured ca. $50-x-65 \mathrm{~cm}$, was composed of a single layer of rocks with a maximum thickness of ca. $11 \mathrm{~cm}$. The rocks were apparently resting on a relatively flat surface. Two charcoal samples collected in the cluster were identifed as juniper wood (Lot 774) and willow family wood (C14-23). Other associated materials include a Stage 1 biface (OR315), a spurred flake (139-1), 283 pieces of debitage, and 6 bone fragments (1 rabbit, 1 small/medium Vertebrata, 4 Vertebrata).

A bulk matrix sample was also collected from the Feature 220 area, and some of this sediment was used for magnetic susceptibility, micromorphology, and flotation samples (remainder was curated). No identifiable plant remains were recovered from the flotation sample, and the magnetic susceptibility results were comparable to nonfeature samples from Unit IIIb/Unit IIIa contexts (no significant deviation detected). The micromorphology sample exhibited a few ash rhombs, some reddish brown sediment that was probably burned, some coarse organic matter that probably represented burned plant material, and a burned snail shell.

\section{Feature 221}

Feature Type: burned sediment with a few burned rocks Provenience: Square 39, Level 15; detection elevation 96.15 $\mathrm{m}$; base elevation $96.10 \mathrm{~m}$

Stratigraphic Context: the Unit IIIa/IIIb transition

Archeological Chronology: Early Archaic

\section{Special Studies:}

Magnetic Susceptibility: 2 samples analyzed (see Chapter 28) Macrobotanical: 2 macroplant samples analyzed (see Chapter 40)

Figure: 26-97

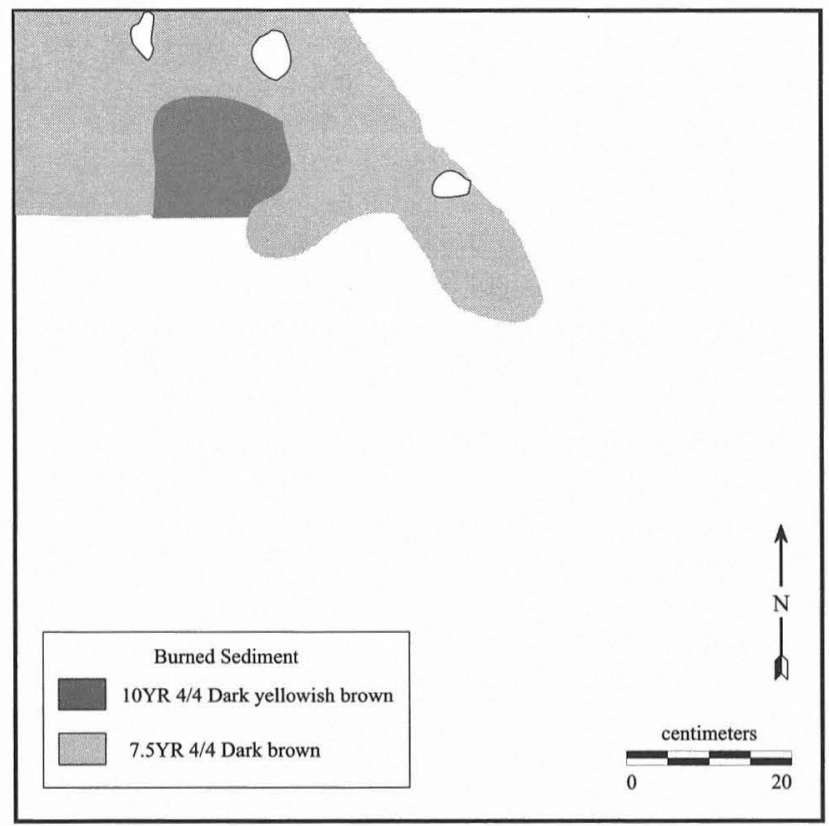

Figure 26-97. Feature 221 in Square 39, Level 15.
Description: This feature number was assigned to a patch of burned; oxidized sediment that was partially exposed along the north wall of Square 39. The exposed portion had an irregular, lobate shape with a horizontal extent of ca. 30-x-60 $\mathrm{cm}$ and a maximum vertical extent of ca. $5 \mathrm{~cm}$. Three small burned limestone fragments (ca. 5-cm size) were also found in this area along with two small charcoal samples. One of the charcoal samples was identified as juniper wood (C1419) and the other as indeterminate wood (Lot 757).

Other associated materials include 39 pieces of debitage, an unburned bone fragment (small/medium Vertebrata), a small block of sediment collected from the burned area as a thermoluminescence sample (TL-1; unanalyzed), and another bag of sediment collected as a bulk matrix sample. Some of the bulk matrix was used for magnetic susceptibility and micromorphology samples, and the remainder was curated. The magnetic susceptibility results were comparable to nonfeature samples from the Unit IIIa/ IIIb transition (no significant deviation detected). The micromorphology sample was aborted when the hardening process failed.

Comments: There is insufficient evidence to determine if the burned area recorded as Feature 221 represents a cultural feature or a natural burning event.

\section{Feature 222}

Feature Type: burned rock cluster

Provenience: Square 37, Level 16; detection elevation 96.10 $\mathrm{m}$; base elevation $96.04 \mathrm{~m}$

Stratigraphic Context: Unit IIIa Archeological Chronology: Early Archaic Special Studies:

Archeomagnetic: 3 of 5 samples analyzed (see Chapter 27 and Appendix 6)

Magnetic Susceptibility: 2 samples analyzed (see Chapter 28)

Micromorphology: 1 sample analyzed (see Chapter 29 and Appendix 7)

Macrobotanical: 1 flotation sample processed (see Chapter 40)

Figure: 26-98 (see also Figure 27-26 in Chapter 27)

Description: Feature 222 consisted of a relatively tight cluster of 7 burned rocks and 3 rocks that may have been displaced from this cluster. The tight cluster measured ca. 35-x$45 \mathrm{~cm}$ with a vertical extent of ca. $6 \mathrm{~cm}$. The possibly displaced rocks were found ca. $15-50 \mathrm{~cm}$ east of the cluster at approximately the same elevation. One or more of these rocks may have been displaced from a ca. $15-\mathrm{x}-15-\mathrm{cm}$ gap in the center of the cluster. All the rocks were angular limestone fragments in the 5-10-cm size range. Although no burned sediment or charcoal was found in the feature area, the rocks were clearly discolored and fractured from burning. The 1/8inch screen recovery from the feature area included 15 pieces of debitage and a burned bone fragment. 


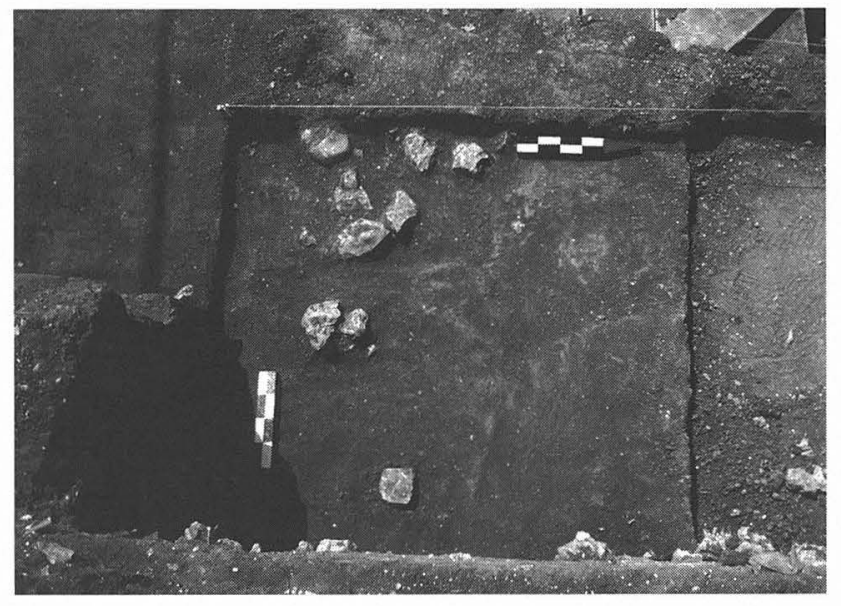

FIGURE 26-98. Feature 222 in Level 16 of Square 37, looking west.

Five archeomagnetic samples were collected from rocks in the cluster, and three of these samples were analyzed (see Figure 27-26 in Chapter 27). The results indicate all three rocks were definitely heated, and all cooled in or near their find positions. One of the rocks was apparently heated to a very high temperature (greater than $580^{\circ} \mathrm{C}$ ) and then cooled in place with no discernible movement. The other rocks moved one or more times while cooling and then finished cooling from lower temperatures $\left(250^{\circ} \mathrm{C}\right.$ or less). One of these remained undisturbed after final cooling, and the other apparently experienced only minor postcooling displacement.

Two bulk matrix samples were also collected from the feature area. Most of this sediment was used for magnetic susceptibility, micromorphology, and flotation samples (remainder was curated). The magnetic susceptibility results were similar to nonfeature samples from Unit IIIa contexts (no significant deviation detected). A thin-section was not made from the micromorphology sample (WL95-29), but the polished block was examined under a binocular microscope. A burned (possibly calcined?) limestone fragment was observed in the block along with some finely divided organic matter that may represent poorly preserved charcoal. No identifiable plant remains were recovered from the flotation sample.

\section{Feature 224}

Feature Type: small burned rock basin

Provenience: Square 12, Levels 18-21; detection elevation $95.98 \mathrm{~m}$; base elevation $95.81 \mathrm{~m}$

Stratigraphic Context: The upper portion of this feature was in lower Unit IIIa, but the base extended into the Unit II/ IIIa transition.

Archeological Chronology: Early Archaic

Special Studies:

Archeomagnetic: 6 of 9 samples analyzed (see Chapter 27 and Appendix 6)

Magnetic Susceptibility: 2 samples analyzed (see Chapter 28)
Micromorphology: 1 sample analyzed (see Chapter 29 and Appendix 7)

Gastropods: 1 sample analyzed (see section by Theler in Chapter 37)

Macrobotanical: 2 flotation samples processed (see Chapter 40)

Figure: Figure 26-99 (see also Figure 27-27 in Chapter 27)

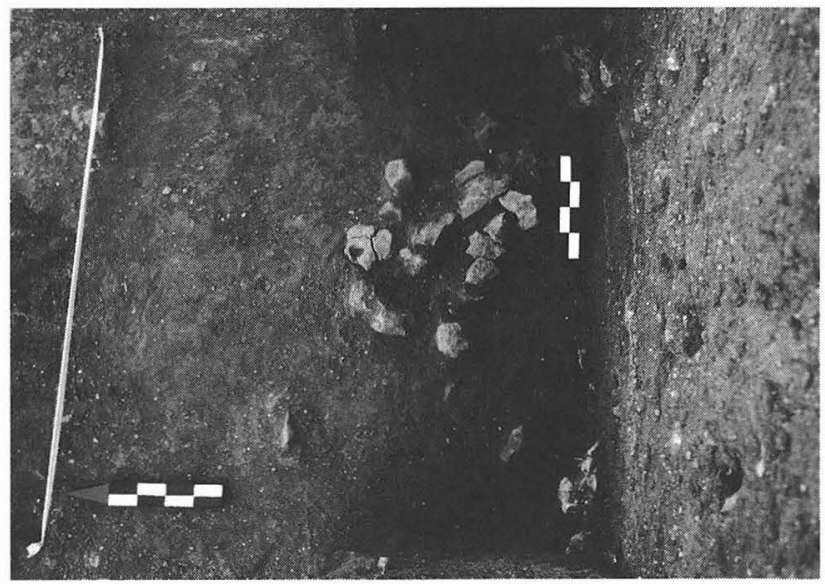

FIGURE 26-99. Feature 224 as exposed at the base of Level 19 in Square 12, looking east.

Description: Feature 224 consisted of an oval-shaped cluster of ca. 25 burned rocks apparently resting in a small, basin-shaped pit. Although the pit outline was not visible in the encompassing matrix, the configuration of the stones suggested they were probably contained within a small pit. The cluster measured ca. $45-\mathrm{x}-50 \mathrm{~cm}$ with a documented vertical extent of ca. $17 \mathrm{~cm}$. The rocks were angular limestone fragments in the 5-15-cm size range, and they appeared to be randomly heaped in ca. 2-3 layers. No burned sediment or charcoal was found in the feature area, but the rocks were clearly discolored and fractured from burning. Associated artifacts include 25 pieces of debitage from the 1/8-inch screen recovery and a flake that was collected from the base of the feature as an organic residue sample (OR355, unanalyzed).

Nine archeomagnetic samples were collected from Feature 224 rocks, and six of these were analyzed (see Figure 2727 in Chapter 27). The results indicate all six rocks were definitely heated (probably in excess of $450^{\circ} \mathrm{C}$ ), and all were found in or near their final cooling positions. The results also indicate each of the rocks was moved one or more times during the cooling process.

Two bulk matrix samples were also collected from Feature 224, and most of this sediment was used for magnetic susceptibility, micromorphology, gastropod, flotation, and faunal fine-screen samples (remainder was curated). The magnetic susceptibility results resembled nonfeature samples from Unit II/IIIa contexts (no significant deviation detected). Although the micromorphology sample (WL959) lacked distinct evidence of in situ burning, the sample contained quite a bit of burned material. This included a 
small clump of reddened sediment, a few ash rhombs, some calcareous, ashy vegetal material, some burned limestone fragments, a burned bone fragment, and a burned snail shell.

The gastropod sample yielded 268 terrestrial and 3 aquatic snails. The terrestrial snails represented at least 6 taxa and most were species commonly found throughout the site deposits (i.e., species that tolerate a relatively wide range of environmental conditions). One of the lower-frequency species found in this sample, Glyphyalinia roemeri, is typically found in very mesic flood plain or cave habitats. The 3 aquatic specimens were all Fossaria dalli, which are typically found in shallow-water pools with aquatic vegetation (see Chapter 37).

No identifiable plant remains were recovered from the flotation samples (totaling 10 liters). The fine-screen faunal sample (ca. 3.75 liters) was a little more productive with 155 bones and an eggshell fragment recovered (see Appendix 8 and Chapter 36). Approximately $74 \%$ of the bones were unidentifiable fragments, but the sample also include 41 identifiable specimens. These were classified as mammal (ca. 44\% of the identifiable taxa), turtle (ca. 39\%), fish (ca. $5 \%$ ), rodent (ca. $2 \%$ ), and amphibian (ca. $2 \%$ ). A relatively low percentage (ca. $19 \%$ ) of the bone appeared burned.

\section{Feature 226}

Feature Type: burned rock cluster

Provenience: Square 46, Levels 20-21; detection elevation $95.87 \mathrm{~m}$; base elevation $95.80 \mathrm{~m}$

Stratigraphic Context: Unit II/IIIa transition

Archeological Chronology: Late Paleoindian or Early Archaic

Special Studies:

Archeomagnetic: 1 of 3 samples analyzed (see Chapter 27 and Appendix 6)

Magnetic Susceptibility: 4 samples analyzed (see Chapter 28)

Micromorphology: 1 sample analyzed (see Chapter 29 and Appendix 7)

Macrobotanical: 2 flotation samples processed (see Chapter 40)

Figure: 26-100 (see also Figure 27-28 in Chapter 27)

Description: Feature 226 was a somewhat linear cluster of 10 burned rocks exposed at the northern margin of Square 46. About 8 additional rocks were scattered to the westsouthwest of this main cluster. Feature 226 lay at the southern edge of the TARL Gradall cut (re-excavation of Block 6), and it looked as if it probably represented the southern margin of a larger burned rock feature that extended into the Gradall cut (and possibly into TxDOT Square E26/S78). The surviving portion measured about $20 \mathrm{~cm}$ north-south by 60 $\mathrm{cm}$ east-west. It was composed of a single layer of rocks with a maximum vertical extent of ca. $7 \mathrm{~cm}$. All the rocks were angular limestone fragments ranging from ca. $5-13 \mathrm{~cm}$ in length. No burned sediment or charcoal was found in the

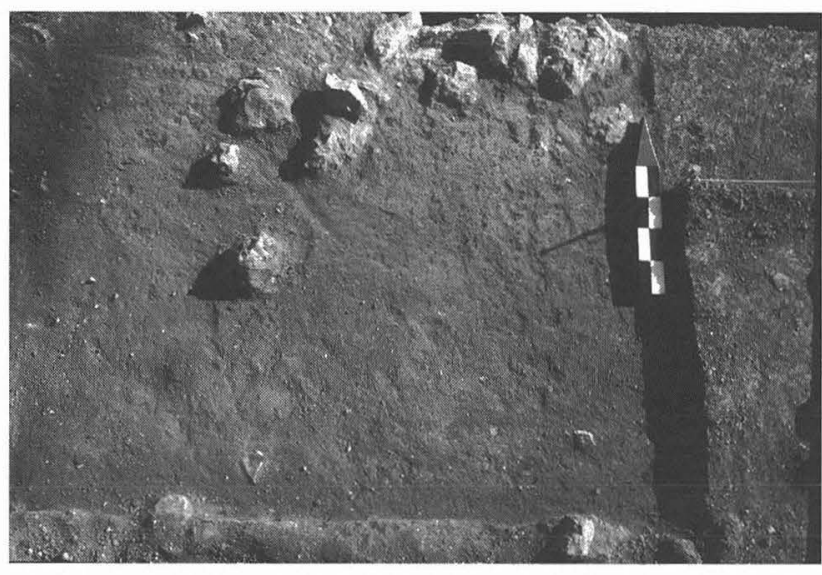

FIGURE 26-100. Feature 226 as exposed at the base of Level 20 in Square 46, looking north.

feature area. The $1 / 8$-inch screen recovery from the feature area included 33 pieces of debitage and 2 bones (a rabbit scapula and an unidentified fragment; see Chapter 33).

Three archeomagnetic samples were collected from Feature 226 rocks, but only one of these samples was analyzed (see Figure 27-28 in Chapter 27). The results indicate the rock was definitely heated, it moved at least once while cooling, and then cooled in place from low to moderate temperatures (ca. $250-450^{\circ} \mathrm{C}$ ) with little or no postcooling displacement.

Two bulk matrix samples were also collected from Feature 226. Most of this sediment was used for magnetic susceptibility, micromorphology, flotation, and faunal fine-screen samples (remainder was curated). Unfortunately, none of these samples was very informative. The magnetic susceptibility results were comparable to nonfeature samples from Unit II/IIIa contexts (no significant deviation detected). No evidence of in situ burning was observed in the micromorphology sample, although some calcareous/ashy vegetal matter was noted. The flotation sample was not productive (no identifiable plant remains), and the small amount of bone recovered from the ca. 0.75 -liter fine-screen sample was not analyzed.

\section{Feature 227}

Feature Type: small burned rock basin

Provenience: Square 30, Levels 20-22; detection elevation $95.90 \mathrm{~m}$; base elevation $95.75 \mathrm{~m}$

Stratigraphic Context: the upper portion of this feature was located in the Unit II/IIIa transition, but the base extended into upper Unit II.

Archeological Chronology: Late Paleoindian or Early Archaic

Special Studies:

Organic Residue: 1 sample analyzed (see section by Beck in Chapter 23)

Archeomagnetic: 4 of 6 samples analyzed (see Chapter 27 
and Appendix 6)

Magnetic Susceptibility: 4 samples analyzed (see Chapter 28)

Micromorphology: 1 sample analyzed (see Chapter 29 and Appendix 7)

Macrobotanical: 2 flotation samples processed (see Chapter 40)

Figures: 26-101 and 26-102 (see also Figure 27-29 in Chapter 27)

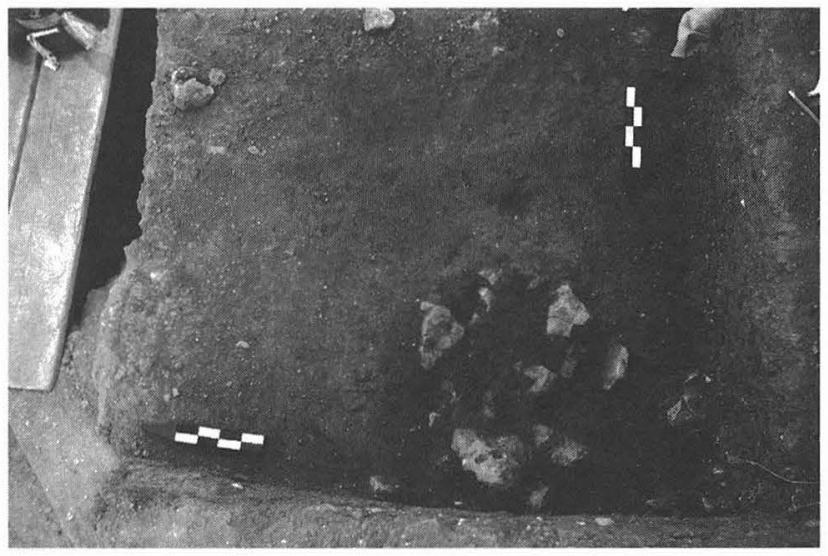

FigURE 26-101. Feature 227 in Level 20 of Square 30, looking east.

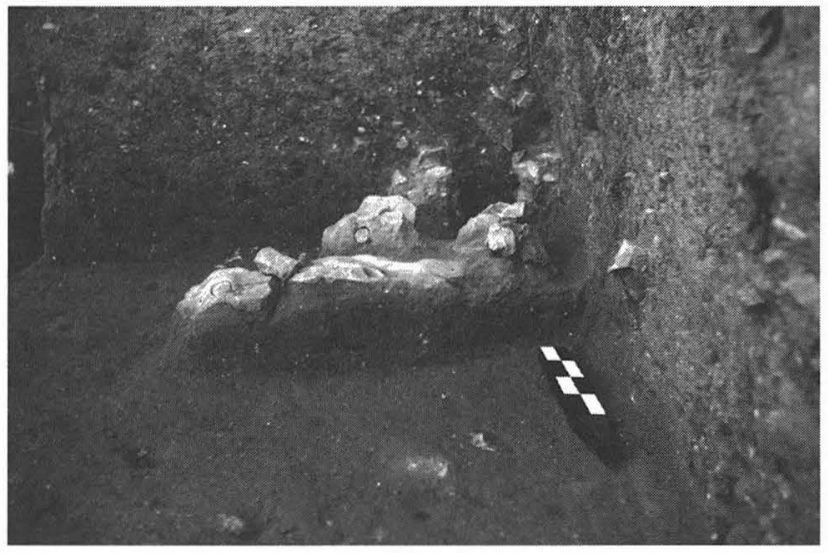

FiguRE 26-102. Feature 227 on Level 22A pedestal in Square 30, looking south.

Description: Feature 227 consisted of a roughly circular cluster of burned rocks resting in a small, basin-shaped pit. The cluster measured approximately $65 \mathrm{~cm}$ in diameter with a vertical extent of ca. $15 \mathrm{~cm}$. A large slab (ca. $20-x-30 \mathrm{~cm}$ ) lay flat in the center of the basin surrounded by ca. 10 angular fragments in the 5-15-cm size range. About 15 smaller fragments (1-4-cm size) were scattered between and on top of the larger rocks. Although no pit outline was visible in the matrix surrounding the rocks, several of the rocks were clearly inclined along the sloping walls of a shallow pit. Charcoal flecks were dispersed throughout the basin, but they were especially concentrated at the base, beneath the larger rocks. Unfortunately, none of the charcoal was large enough to collect. No burned sediment was observed in the basin.

The 1/8-inch screen recovery from Feature 227 included a Stage 2 biface (OR353), a thin uniface fragment (941-2), a possible ground stone fragment (Lot 948), a core fragment (988-1), 189 pieces of debitage, and 69 bone fragments. Approximately $91 \%$ of the bones were unidentified Vertebrata fragments, but the sample also included a jackrabbit tooth, a cottontail rabbit calcaneus, a rabbit/hare tooth, 2 micromammal elements, and a snake vertebra (see Chapter 33). Approximately $62 \%$ of this bone was burned.

Six archeomagnetic samples were collected from five rocks within Feature 227, and four of these samples were analyzed (see Figure 27-29 in Chapter 27). One of the analyzed samples was collected from the large slab at the base of the pit. This rock apparently cooled in place, with no discernible movement, after being heated to at least $580^{\circ} \mathrm{C}$. The other analyzed rocks evidently moved one or more times while cooling and then cooled in or near their find positions from low to moderate temperatures (ca. $250-400^{\circ} \mathrm{C}$ ).

Two burned rocks were collected from Feature 227 as organic residue samples (OR378 and OR379), but only one (OR379) was analyzed. A small quantity of fatty acid residues was found on this sample, but the residues were poorly preserved, and the source(s) could not be identified.

Two bulk matrix samples were also collected from the Feature 227 area, and most of this sediment was used for magnetic susceptibility, micromorphology, flotation, and faunal fine-screen samples (with a small amount curated). The magnetic susceptibility results were comparable to nonfeature samples from similar stratigraphic contexts (no significant deviation detected). A thin-section slide was not made from the micromorphology sample (WL95-11), but the polished block was examined under a binocular microscope. Some pink and gray areas observed in this block may represent burned sediment and ash. No identifiable plant remains were retrieved from the flotation sample, and the bone recovered from the ca. 1-liter fine-sceen sample was not analyzed.

\section{Feature 228}

Feature Type: pit or burrow?

Provenience: Square 38, Levels 20-21; detection elevation $95.85 \mathrm{~m}$; base elevation $95.80 \mathrm{~m}$

Stratigraphic Context: Unit IIIIa

Archeological Chronology: Early Archaic

Special Studies:

Archeomagnetic: 2 of 2 samples analyzed (see Chapter 27 and Appendix 6)

Magnetic Susceptibility: 2 samples analyzed (see Chapter 28)

Micromorphology: 1 sample analyzed (see Chapter 29 and Appendix 7)

Macrobotanical: 1 flotation sample processed (see Chapter 40) 
Figures: see Figures 27-55, 27-59, 27-64, and 27-67 in Chapter 27

Description: Feature 228 was one of the subfeatures recorded within the Feature 231 burned rock accumulation (see Feature 231 description). This designation was assigned to a possible pit identified in the upper layers of Feature 231 (central portion, immediately east of Feature 181). When it was first recorded at the base of Level 20, Feature 228 consisted of a roughly oval-shaped, rock-free area measuring ca. 40-x-75 cm (see Figures 27-55 and 27-59 in Chapter 27). It was surrounded by a relatively dense concentration of small burned rocks (ca. 5-10-cm size) that represented the upper layer of Feature 231 in this square. No burned sediment, ash, or charcoal was found in the rock-free space, and no obvious differences were observed in the sediment found inside and outside this area. The feature was recorded as a possible pit, primarily on the basis of the symmetrical, oval configuration of the stones which suggested the possibility that the rock-free area might represent either a pit that intruded the upper portion of the burned rock accumulation or a pit surrounded by burned rocks.

The burned rock density increased in this square in Level 21 and the rock-free space diminished to approximately $35-x-40 \mathrm{~cm}$ (see Figures 27-64 and 27-67 in Chapter 27). Again, no obvious differences were observed in the sediment in the Feature 228 area, and no clear evidence of in situ burning was identified. One small charcoal sample was collected from Level 21 (C14-46; not analyzed), but small quantities of charcoal were also found among the surrounding rocks. Burned rocks were exposed in this area in the upper $\mathrm{cm}$ of Level 22 (see Figures 27-72 and 27-75 in Chapter 27).

Measuring from the detection level at the base of Level 20 (ca. $95.85 \mathrm{~m}$ ) to the tops of the rocks exposed in Level 22 (ca. $95.80 \mathrm{~m}$ ), Feature 228 had a documented vertical extent of only $5 \mathrm{~cm}$. If it represented an intrusive pit (or burrow?) it probably originated from a surface above its detection level. Pit and burrow outlines were difficult to discern in Unit IIIa sediments, unless the fill contrasted strongly with the surrounding matrix. If the feature was filled with Unit IIIIa sediments the outline would not have been readily visible in the levels above the burned rock accumulation.

In addition to the charcoal sample, 69 pieces of debitage and 11 bone fragments were recovered from the Feature 228 area. The bone included 10 unidentifiable fragments and a jackrabbit tooth (see Chapter 33). A bulk matrix sample was collected from the feature area as well, and some of this sediment was used for magnetic susceptibility, micromorphology, and flotation samples.

No identifiable plant remains were recovered from the flotation sample, and the magnetic susceptibility results were comparable to Unit IIIa samples from nonfeature contexts. The micromorphology sample (WL95-30) exhibited several limestone fragments that were reddened from burning and an intensively burned/calcined fragment with a mass of re- crystallized ash adhered to one surface. No charcoal or burned sediment was observed in this sample.

Two archeomagnetic samples were also provenienced to Feature 228, but these were actually collected from rocks found outside the feature. These rocks were found immediately south of Feature 228 in Level 21. These samples were analyzed along with 14 others collected from rocks surrounding Feature 228 in Levels 20 and 21 (see Figures 27-59 and 27-67). The results indicate all of these rocks were definitely heated, and most cooled in or very near their find positions. The rocks closest to Feature 228 included two that experienced no postcooling displacement, five that experienced relatively minor displacement, and two that were significantly displaced. The significance of these results for the interpretation of Feature 228 are not readily apparent. If Feature 228 represents the base of a pit or burrow that intruded the accumulation, then the surrounding rocks appear to have experienced relatively little displacement. If the feature does not represent a filled pit or burrow, then perhaps some of the displaced rocks were moved from this area.

Comments: There is insufficient evidence for a confident interpretation of Feature 228. Although the outline is suggestive of a filled pit or burrow, no differences were observed between the presumed fill area and the surrounding matrix. The feature is also very shallow and, if it does in fact represent either a pit or a burrow, then it probably originated from a surface above its detection level. Given the available evidence, it seems equally plausible that this rock-free area represents something else (e.g., a random gap in the accumulation or an area where rocks were removed or displaced).

\section{Feature 230}

Feature Type: small burned rock basin

Provenience: Square 39, Levels 21-23; detection elevation $95.84 \mathrm{~m}$; base elevation $95.70 \mathrm{~m}$

Stratigraphic Context: Unit IIIa

Archeological Chronology: Early Archaic

Special Studies:

Archeomagnetic: 16 of 23 samples analyzed (see Chapter 27 and Appendix 6)

Magnetic Susceptibility: 2 samples analyzed (see Chapter 28)

Micromorphology: 1 sample analyzed (see Chapter 29 and Appendix 7)

Macrobotanical: 1 flotation sample processed (see Chapter 40)

Figure: 26-103 (see also Figures 27-60, 27-69, and 27-77 in Chapter 27).

Description: Feature 230 was one of the more discrete subfeatures found within the Feature 231 burned rock accumulation (see Feature 231 description). It was an ovalshaped cluster of ca. 100 burned rocks apparently resting in a small, basin-shaped pit. Although the pit outline was not visible in the surrounding matrix, the configuration of 


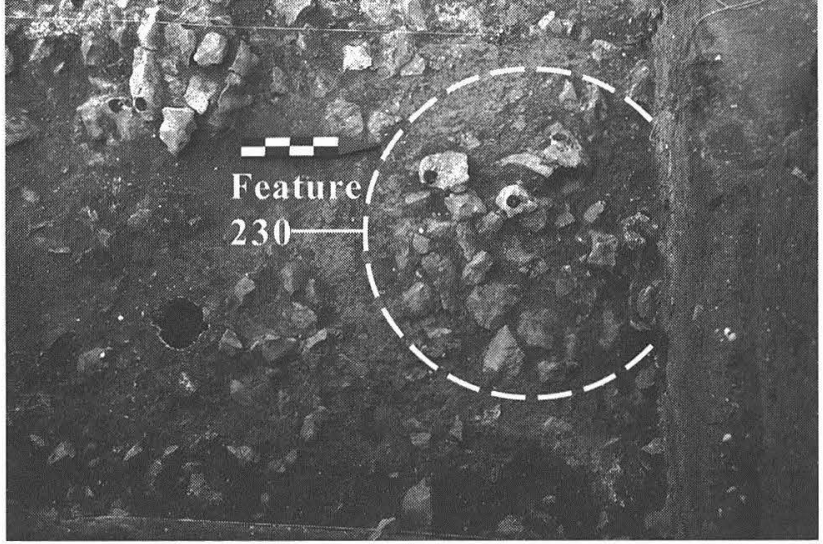

FiguRE 26-103. Feature 230 as exposed in Level 22 of Square 39. Scattered rocks surrounding Feature 230 are part of the Feature 231 burned rock accumulation.

stones suggests they were probably contained within a small pit. The cluster measured ca. $70-\mathrm{x}-75 \mathrm{~cm}$ with a documented vertical extent of ca. $14 \mathrm{~cm}$. The rocks were angular limestone fragments in the 3-15-cm size range, and they appeared to be randomly heaped in ca. 2-3 layers. Although no burned sediment or charcoal was found in the feature area, the rocks were clearly discolored and/or fractured from burning.

The point-plotted and 1/8-inch screen recovery from Feature 230 includes a Stage 1 biface (OR-444), 67 pieces of debitage, a burned piece of chert collected as a thermoluminescence sample (TL-26, unanalyzed), 4 hematite pebbles, 4 mussel shell fragments, and 6 bone fragments. The mussel shell fragments were classified as thin to medium shell thickness (see Chapter 37), and the bone fragments included 1 medium/large mammal and 5 Vertebrata fragments (see Chapter 33).

Of the 23 archeomagnetic samples collected from Feature 230 rocks, 16 were analyzed (see Figures 27-60, 27-69, and 27-77 in Chapter 27). The results indicate all 16 rocks were definitely heated, most moved one or more times while cooling, and most cooled in or very near their find positions. Three of the rocks exhibited single components of magnetization, indicating they cooled without moving from temperatures in excess of $580^{\circ} \mathrm{C}$. Two of these experienced relatively minor postcooling displacement, and the third experienced significant displacement after it was completely cooled. The remaining rocks cooled in or very near their find positions after being moved at temperatures ranging from ca. $250-450^{\circ} \mathrm{C}$.

A single bulk matrix sample was collected from Feature 230 , and most of this sediment was used for magnetic susceptibility, micromorphology, and flotation samples (with a small portion curated). No significant results were obtained from the magnetic susceptibility samples, and the flotation sample yielded no identifiable plant remains. Although a thin-section slide was not made from the micromorphology sample (WL95-16), the polished block was examined under a binocular microscope. Some small areas of orange (possibly burned/oxidized) sediment were observed in this sample along with some gray, ashy areas.

\section{Feature 231 (with Subfeatures 181, 217, 223, $225,228,230,237,245$ )}

Feature Type: burned rock accumulation

\section{Provenience:}

South Block: Square 33, Levels 16-20; Square 48, Levels 1820; Square 34, Levels 18-24; Square 49, Levels 19-24; Square 35, Levels 19-22; the elevation range in the South Block portion of Feature 231 was ca. $96.05 \mathrm{~m}$ to $95.65 \mathrm{~m}$

East Block: Square 27, Levels 19-26; Square 43, Levels 19-25; Square 28, Levels 19-27; Square 44, Levels 19-26; Squares 52 and 53, Levels 20-26; Square 39, Levels 20-25; Squares 38 and 51, Levels 20-27; Square 37, Levels 19-24; Square 50, Levels 19-26; the elevation range in the East Block portion of Feature 231 was ca. $95.95 \mathrm{~m}$ to $95.50 \mathrm{~m}$

Stratigraphic Context: Unit IIIa and Unit II/IIIa transition zone

Archeological Chronology: Early Archaic

Special Studies: (samples from subfeatures 217, 223, and 225 are included below; samples from subfeatures 181, 228, 230,237 , and 245 are summarized in those descriptions)

Organic Residue: 5 samples analyzed from Feature 231 and 1 from Feature 225 (see sections by Beck and Hurst in Chapter 23)

Radiocarbon: 1 wood charcoal sample was AMS dated to $3440 \pm 80$ B.P. (CAMS-13025; see Chapter 25)

Archeomagnetic: $260+$ samples analyzed from Features 217, 223, 225, and 231 (see Chapter 27 and Appendix 6)

Magnetic Susceptibility: 2 samples analyzed from Feature 225 and 28 from Feature 231 (see Chapter 28)

Gastropod: 3 samples analyzed from Feature 231 (see section by Neck and Shaw in Chapter 37)

Macrobotanical: 1 macroplant sample analyzed from Feature 217 and 21 from Feature 231; 15 flotation samples processed from Feature 231 (see Chapter 40)

Figures: 26-104, 26-105, 26-106 (see also numerous figures illustrating this feature in Chapter 27)

Description: Feature 231 represents part of a large burned rock accumulation that was partially exposed in both the TxDOT and TARL investigations. It was first encountered in the eastern third of TxDOT Block 6 , where it was recorded as Feature 124 (see Feature 124 description). It was further exposed in the TxDOT Fine-Screened Square E28/S78 (where it was recorded as the upper portion of Feature 181) and in the TARL excavations, where it was recorded as Feature 231. This deposit probably extended into unexcavated areas to the east and south of the TARL squares as well.

The combined exposure indicates the accumulation had an areal extent of at least $5.5-\mathrm{x}-7.5 \mathrm{~m}$. The portion recorded as Feature 231 encompassed most of the TARL East Block and the eastern half of the South Block, an area measuring ca. 3.5-x-6.5 m (see Figures 26-104 and 26-105). Although it was not excavated/recorded as part of Feature 231, a burned rock 


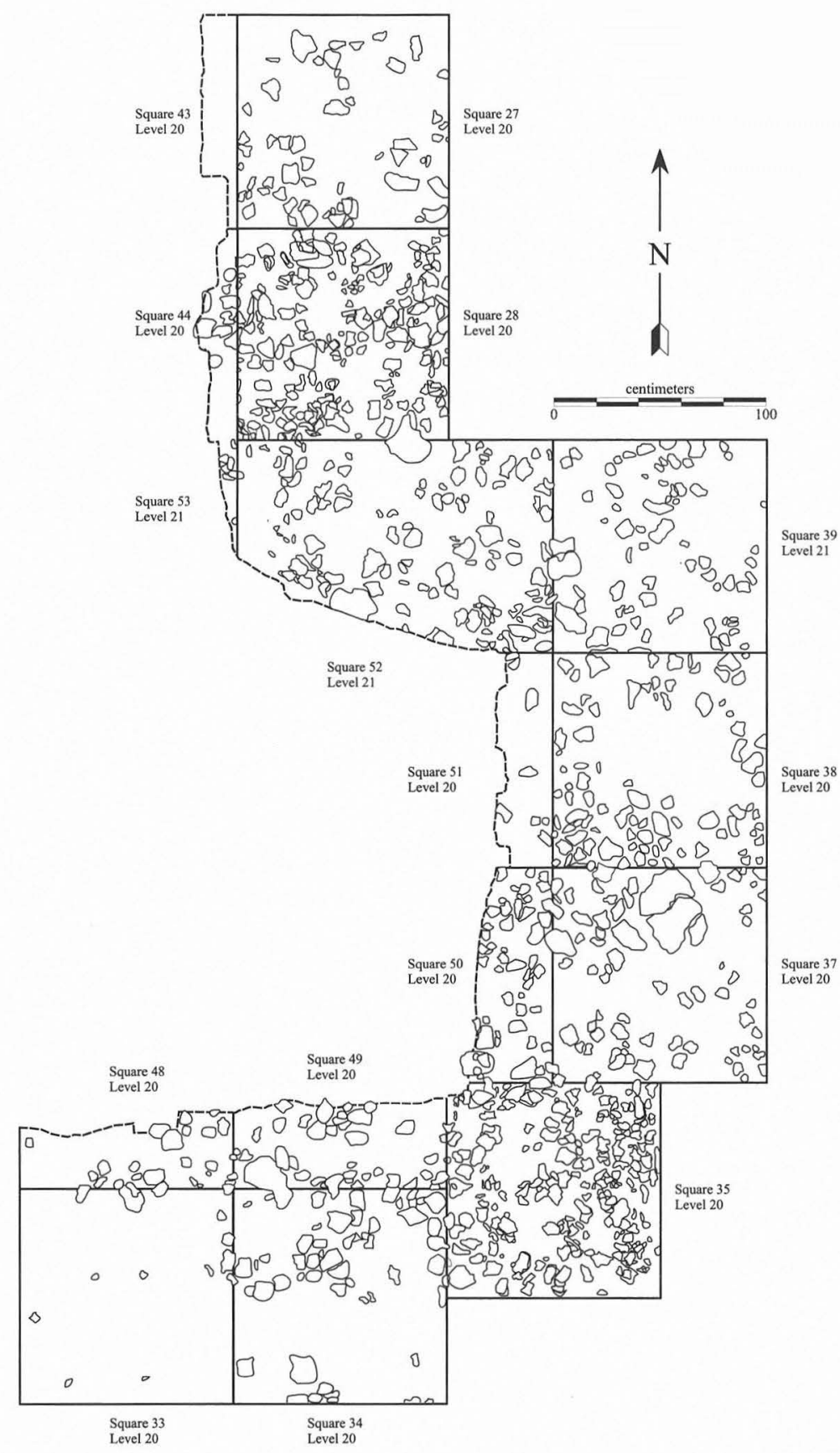

FIGURE 26-104. Composite plan map illustrating recorded extent of the Feature 124/231 burned rock accumulation as exposed in the TARL and TxDOT excavations. Also shown are six large burned rock basins recorded within this accumulation: Features 130, 131, 146, 150, 181 , and 245.

scatter exposed at the north end of the East Block (Squares $20,25,26,41$, and 42 ) probably represents the dispersed margins of the accumulation. Rocks found in some of these squares were included as part of Feature 231 in the archeomagnetic analysis presented in Chapter 27.

The accumulation was composed of several layers of burned rocks mixed with an assortment of other cultural debris (primarily lithic artifacts, faunal remains, and macrobotanical remains). These deposits surrounded and covered at least six large burned rock basins (see Figure 26104), and most of the burned rocks comprising the accumu- lation were probably derived from repeated use of these cooking pits. The largest of these, Feature 181, measured about $2.6 \mathrm{~m}$ in diameter and $50 \mathrm{~cm}$ deep (see Feature 181 description). About half of Feature 181 was excavated in TxDOT Square E28/S78, but a portion extended into the TARL East Block where it was investigated as part of Feature 231 (see Figure 26-106). Another pit, Feature 245, was found immediately north of Feature 181 in the TARL East Block (see Figure 26-106). This pit was significantly smaller than Feature 181, measuring ca. $1.5 \mathrm{~m}$ in diameter and ca. $25 \mathrm{~cm}$ deep (see Feature 245 description). The other four (Features 


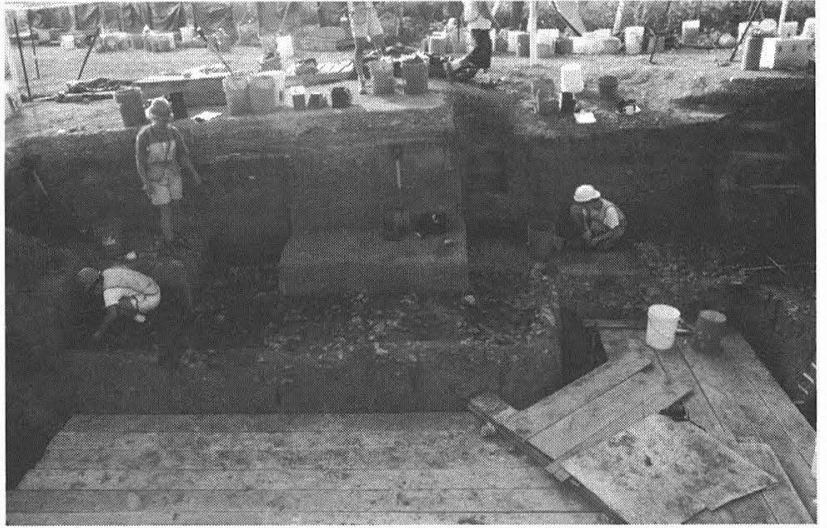

FIGURE 26-105. Excavation of upper layers of Feature 231 in the TARL East Block, looking east.

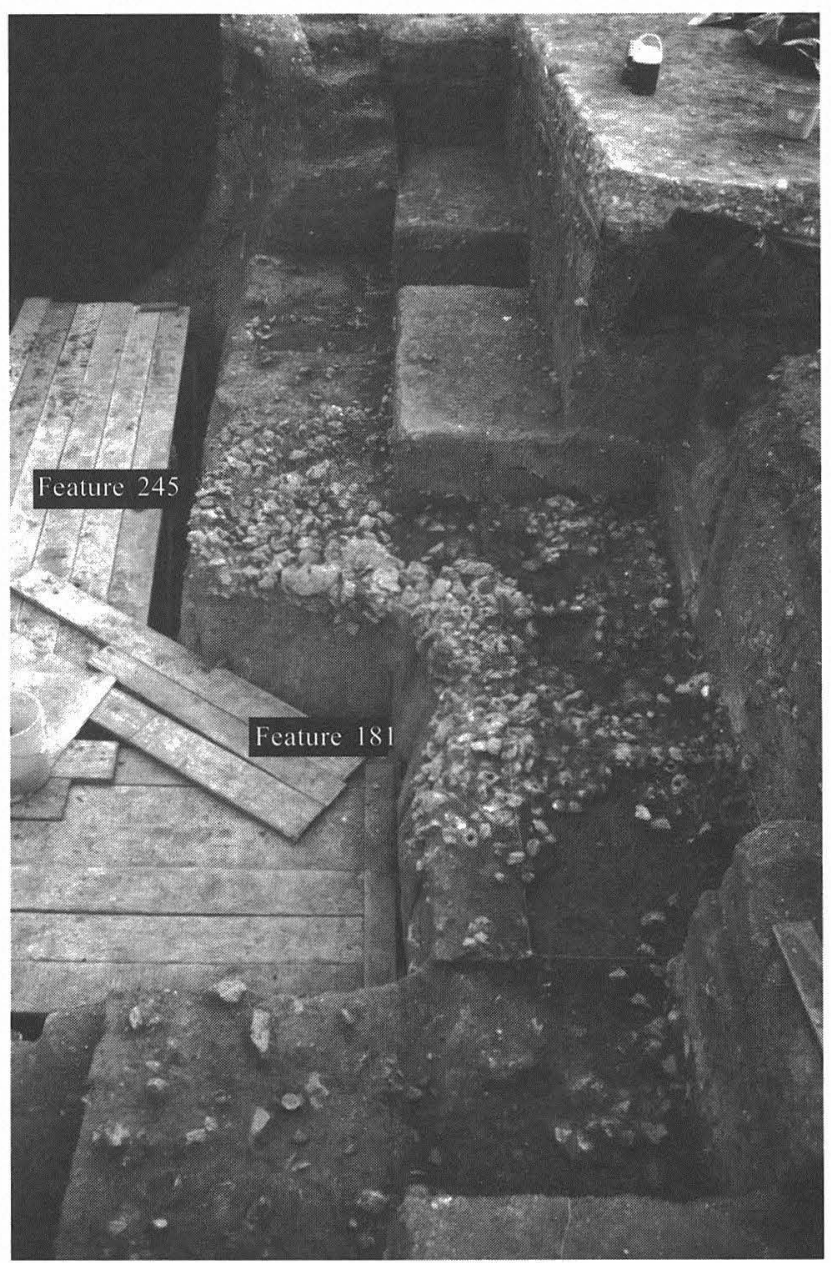

FIGURE 26-106. Feature 231 as exposed in Levels 22/23 (ca. 95.80$95.75 \mathrm{~m}$ ) in the TARL East Block.

$130,131,146$, and 150) were found in the Feature 124 area in the eastern portion of Block 6 . These four were about the same size as Feature 245 , measuring ca. 1.3 to $1.6 \mathrm{~m}$ in diameter (see Feature 130, 131, 146, and 150 descriptions). With all six of these features, it was difficult to discern the pit outlines until most of the overlying and surrounding burned rocks were removed. This made it very difficult to determine the surface or surfaces from which the pits were excavated.

The thickness of the Feature 231 deposits varied considerably from square to square, but in most areas the accumulation was no more than $20-30 \mathrm{~cm}$ thick. The deposits had a greater vertical extent $(\mathrm{ca} .35-40 \mathrm{~cm}$ ) in the squares encompassing the Feature 181 and 245 pits, but this included pit fill that extended below the base of the surrounding accumulation. Burned rock density also varied, both horizontally and vertically. Horizontally, the densities were highest in the squares encompassing and immediately adjacent to Features 181 and 245. The lowest densities generally occurred in the squares at the southern and northern margins of Feature 231. Vertically, the overall density was much higher in the upper half of the accumulation, with rocks concentrated primarily in the bases of Features 181 and 245 in the lower levels. The upper layers of Feature 231 were dominated by small rocks (ca. 5-15-cm size) that, for the most part, appeared to be randomly distributed. The lower layers contained more of the larger rocks (15-30-cm size), and they were concentrated primarily in the area of Feature 181 and 245 (both within the pits and immediately adjacent to the pits).

Charcoal was dispersed throughout the accumulation, but most of it was too small and poorly preserved to collect. Micromorphology thin-sections suggest that much of the charcoal in Unit IIIa was probably ingested and shredded by earthworms (see Chapter 29). The best charcoal samples were collected from Features 181 and 245. These include 10 carbonized Camassia scilloides (wild hyacinth) bulbs collected from various locations within Feature 181 and some wood charcoal concentrations found at the base of Feature 245 (see Feature 181 and 245 descriptions). Burned sediment was also found in both of these pits, but very little was found in the surrounding accumulation.

The stratigraphic position and vertical extent of the accumulation was more thoroughly documented in the Feature 231 portion than in the Feature 124 portion. Although the lowest layers of Feature 231 were provenienced to the culturally mixed Unit II/IIIa transition zone, it appears that the burned rock deposits first began to accumulate on a relatively stable surface that lay at or slightly above the Unit II/IIIa contact. This surface sloped gently downward to the north/northeast and the accumulation followed this slope. At the southwest end (Square 33), the top of Feature 231 was exposed at ca. $96.05 \mathrm{~m}$ and the base lay at ca. $95.85 \mathrm{~m}$. At the north end (Square 27), the top was about $15 \mathrm{~cm}$ lower (ca. $95.90 \mathrm{~m}$ ) and the base was about $20 \mathrm{~cm}$ lower (ca. $95.65 \mathrm{~cm}$ ). The top of Feature 231 lay about $20-25 \mathrm{~cm}$ below the Unit IIIa/IIIb transition at the southwest end. Unit IIIa became thinner to the north/northeast and at the north end of Feature 231, the top of the accumulation lay immediately below the Unit IIIa/IIIb transition.

The Feature 181 and Feature 245 pits were clearly excavated from a surface (or surfaces) in Unit IIIa, but their bases 
intruded the upper portion of Unit II. This undoubtedly led to some mixing of Unit II and Unit III a cultural deposits in these areas. Feature 181 also appears to have cut through at least two earlier features-Feature 183, a large burned rock cluster that apparently rested on a surface in lower Unit IIIIa; and Feature 184, a large burned rock cluster (or large burned rock basin?) that was buried in the upper portion of Unit II (see Feature 181, 183, and 184 descriptions). It also appears that Feature 245 may predate Feature 181. The Feature 181 pit outline was clearly visible in the upper layers of Feature 231 (at an elevation of ca. $95.80 \mathrm{~m}$ ), but the Feature 245 outline was not clearly visible until most of the surrounding accumulation had been removed (at an elevation of ca. $95.70 \mathrm{~m}$ ). Feature 245 was detected at approximately the same elevation as Feature 183 (top was exposed at ca. $95.74 \mathrm{~m}$ ), and it is possible these features relate to the same occupational surface. The northern margin of Feature 181 may have cut through the southern margin of Feature 245 (in the Square 52 area), but this could not be determined with any confidence. The radiocarbon dates for Feature 245 are generally a little earlier than the dates for Feature 181, but this may reflect the different materials dated. Three wood charcoal samples from Feature 245 yielded AMS dates of $8110 \pm 70$ в.Р. (CAMS-10194); $8130 \pm 60$ в.P. (CAMS-10197); and $8420 \pm 200$ в.P. (CAMS-10206). The average of nine AMS dates obtained on the wild hyacinth bulbs from Feature 181 was $7997 \pm 21$ в.P.

In addition to Features 181 and 245, six other features were recorded within Feature 231 (these are considered subfeatures of Feature 231). Three of these (Features 217, 223 , and 225) were representative 1-x-1-m "samples" of the accumulation rather than discrete entities. Feature 228 was a roughly circular, rock-free area found in the middle of a dense burned rock concentration in Square 38, Levels 20-21. The rock-free area measured ca. $35-\mathrm{x}-40 \mathrm{~cm}$ with a documented vertical extent of only $5 \mathrm{~cm}$ (full vertical extent was not accurately determined). It probably represented either an intrusive pit or burrow (see Feature 228 description). Feature 237 was a ca. $15-\mathrm{x}-15-\mathrm{cm}$ patch of burned sediment recorded near the base of Feature 231 in Square 34, Level 23 (see Feature 237 description). Feature 230 was a small burned rock basin (70-x-75-x-14 cm) recorded in Levels 21-23 in Square 39 (see Feature 230 description).

The following sections summarize the special samples and other associated materials provenienced to Feature 231 and subfeatures 217,223 , and 225. Comparable data from subfeatures $181,228,230,237$, and 245 are summarized in the descriptions of those features.

Over 800 archeomagnetic samples were collected from burned rocks found in Feature 231 and its subfeatures. Of the ca. 500 analyzed samples, 260 were provenienced to Features $217,223,225$, and 231 . This group of samples primarily represents the rocks that covered and surrounded Features 181 and 245 and the other discrete subfeatures. The archeomagnetic results indicate this group generally includes a higher percentage of rocks that were displaced after final cooling than seen in the Feature 181, 230, and 245 samples. Approximately $42 \%$ of the rocks in this group were significantly displaced after final cooling in contrast to only $16 \%$ of the analyzed rocks from Feature 181 and $7 \%$ from Feature 245. Many of the displaced rocks found around the perimeters of Features 181 and 245 probably represent rocks removed during clean-out episodes prior to reuse of the pits. Others may represent rocks that were displaced when cooked food was removed from the pit.

The archeomagnetic results for this group of samples also indicates a relatively high percentage (ca. $72 \%$ ) were moved one or more times while cooling from various temperatures. Only $33 \%$ cooled from high temperatures with little or no movement. These data suggest that many of these stones were used in cooking activities that involved movement of heated stones (e.g., opening a partially cooled oven to remove cooked food).

Approximately 50 charcoal samples were collected within Feature 231 and 21 of these were analyzed as macroplant samples. Three were identified as juniper wood (Lots 887, 893, and 1115), two as live oak type wood (C14-59 and C14-85), one as unknown hardwood wood (Lot 173), and the remainder as indeterminate wood. Two charcoal samples were collected from Feature 217, but only one (C1416) was analyzed as a macroplant sample. This sample was identified as live oak type wood.

Two of the Feature 231 charcoal samples were submitted for AMS radiocarbon dating. One was so poorly preserved that it dissolved in pretreatment and the other (C14199) yielded the problematical date (CAMS-13025) cited above. This date is clearly too young for a Unit IIIa context, and it has been disregarded as a stratigraphically displaced sample (see Chapter 25).

The artifact recovery from Feature 231 includes 2 Hoxie/Gower points (OR403 and OR424), 1 Hoxie A point (OR675), 1 contracting stem/concave base point (OR396), 1 Angostura point (1345-1), 1 Golondrina-Barber point (OR439), 1 miscellaneous lanceolate point (1017-3), 2 projectile point fragments, 1 Clear Fork biface (OR372), 5 perforators (OR374, OR385, OR419, OR423, and OR473), 2 Stage 1 bifaces, 11 Stage 2 bifaces, 2 Stage 3 bifaces, 3 bifacial tools, 16 biface fragments, 55 unifacial tools, 7 cores/core fragments (including 3 microcores), 1 core/hammerstone (OR690), 1 piece of worked hematite (1017-5), and 24,827 pieces of debitage (including 45 flakes collected as OR samples). The Golondrina-Barber and Angostura points were recovered from the lower levels of Feature 231, and the Hoxie and Hoxie/Gower points were recovered from mid to upper levels. The subfeature recovery includes 536 pieces of debitage from Feature 217; 3 unifacial tools and 370 pieces of debitage from Feature 223; and 314 pieces of debitage from Feature 225.

The 1/8-inch screen faunal recovery from Feature 231 includes 2,573 bones/bone fragments (see Chapter 33) and 
72 mussel shell fragments (see Chapter 37). The mussel shell fragments include 4 specimens identified as Lampsilis teres, 3 identified as Toxolasma texasensis, and 2 identified as Potamilus purpuratus. Approximately $89 \%$ of the bone is unidentifiable fragments. The identifiable bone (291 specimens) includes medium/large mammal (ca. $42 \%$ of the identifiable bone), rabbit (ca. 13.7\%), small mammal (ca. 9.3\%), turtle (ca. 8.6\%), rodent (ca. 6.9\%), medium mammal (ca. 6.5\%), large mammal (ca. 4\%), snake (ca. 3\%), micromammal (ca. $2.4 \%$ ), fish (ca. $1.7 \%$ ) as well as very small quantities of carnivore, deer, deer/antelope, medium/small mammal, and frog/toad (each represents less than $1 \%$ of the identifiable bone).

The 1/8-inch screen faunal recovery from the subfeatures includes 41 bones from Feature 217, 34 bones from Feature 223, 11 bones from Feature 225, and a Lampsilis teres mussel shell hinge from Feature 225 (see Chapters 33 and 37). Most of the bones in these small samples were unidentifiable fragments. The identifiable specimens included deer, rabbit, turtle, and snake.

Twenty bulk matrix samples were collected from various locations within Feature 231, and 1 small sample was collected from Feature 225. Most of the Feature 231 sediment was used for magnetic susceptibility, macrobotanical, gastropod, and faunal fine-screen samples (remainder was curated). A small amount of the Feature 225 sediment was used for magnetic susceptibility samples, and the rest was curated. No identifiable plant remains were found in the 15 flotation samples (totaling ca. 43 liters), and the magnetic susceptibility and gastropod samples yielded results that were comparable to nonfeature samples from similar stratigraphic contexts (no significant differences identified). The ca. 2.7-liter fine-screen sample yielded a total of 101 bones/ bone fragments (see Appendix 8). Much of the bone (ca. $66 \%$ ) was unidentifiable fragments, but the sample also included a few specimens identified as turtle, fish, rodent, and mammal. Approximately $43 \%$ was burned.

The special studies data also include results obtained on six organic residue samples: four analyzed by Beck and two by Hurst (see Chapter 23). Beck's samples (all from Feature 231) include a contracting stem point (OR396), a Stage 2 biface (OR408), a perforator (OR419), and a flake (OR398). The residues extracted from these specimens were subjected to gas chromatography-mass spectrometry analysis. Beck identified fatty acid residues on all four specimens, but most of the acids he identified are found in a wide variety of plant and animal fats. The exception was a component he identified on OR419, the perforator (and on five other artifacts from this site). He identified this component as Pentadecanoic acid, a very rare substance that has been reported from only three North American genera: the genus Zanthoxylum (which includes the pricklyash or "toothache tree" which grows in the site area); the genus Lonicera (honeysuckle); and unspecified lichens. Beck favors the prickly-ash as the source of the acid on
OR419, primarily because the bark and leaves of this tree are known to have been used medicinally by many Native American groups. He does not, however, rule out other potential sources.

Hurst's samples included a Clear Fork biface from Feature 231 (OR629) and a burned rock from Feature 225 (OR376). Residues extracted from these specimens were subjected to capillary ion analysis and amino acid analysis. With the capillary ion analysis, he identified chloride, nitrate, and carbonate anions on the Clear Fork biface. Chloride and sulfate anions were identified on the burned rock. Although the chloride and carbonate anions were interpreted as natural residues with no cultural significance, the nitrate and phosphate were considered more likely residues from cultural activities. The potential source of the sulfate is unknown. Twelve amino acids were also identified in the residues extracted from this rock, but the source (or sources) was not determined. No amino acid residues were detected on either specimen.

\section{Feature 232}

Feature Type: burned sediment with a few burned rocks Provenience: Square 46, Levels 26-28 (feature was not recorded until Level 27 but the largest burned rock was exposed in Level 26); detection elevation $95.54 \mathrm{~m}$; base elevation $95.45 \mathrm{~m}$

Stratigraphic Context: Unit II

Archeological Chronology: Late Paleoindian

\section{Special Studies:}

Micromorphology: 1 sample analyzed (see Chapter 29 and Appendix 7)

Figure: $26-107$

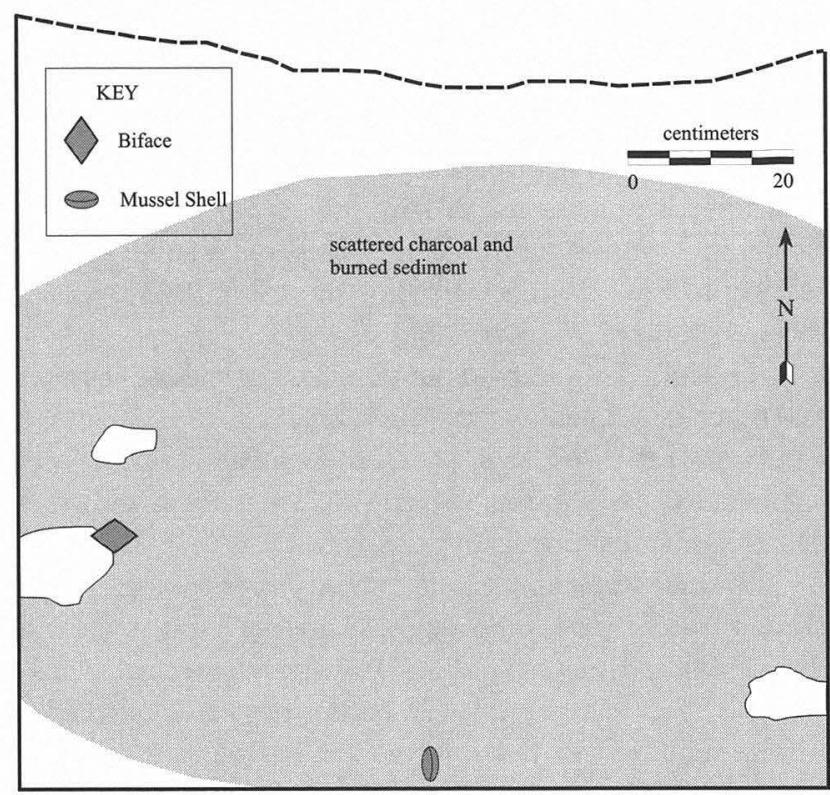

FIGURE 26-107. Feature 232 in Square 46, Levels 26-28. 
Description: Feature 232 consisted of a diffuse area of scattered charcoal flecks, small patches of burned (oxidized) sediment, and a few burned limestone fragments. The excavator believed this burned area probably extended beyond the square into unexcavated areas to the south, east, and west. Although the full horizontal extent is unknown, the documented portion of Feature 232 measured ca. $75-x-100 \mathrm{~cm}$. Three burned limestone fragments were found along the margins of the burned area, and the largest of these (ca. 15$\mathrm{cm}$ diameter) appeared heavily burned. It was first exposed along the west wall in Level 26 before the rest of the feature area was recognized. This rock extended into Level 28 where it was collected as a thermoluminescence sample (TL-22; unanalyzed). A biface fragment found in Level 26 immediately adjacent to this rock was collected as OR435 (this specimen was not provenienced to Feature 232, but it may be associated). A second rock (ca. 10-cm diameter) was exposed in Level 27 along the east wall, and a mussel shell was also found in this level along the south wall. A third limestone fragment (ca. 9-cm diameter) was exposed in Level 28 about $9 \mathrm{~cm}$ northeast of the TL-22 rock. In addition to the burned rocks and mussel shell, 13 pieces of debitage were recovered from the feature area in Levels 27 and 28. Although Level 26 materials were not provenienced to Feature 232 , the level notes mention a relative increase in the amount of bone recovered ("mostly burned").

A block of sediment was collected in situ from the Feature 232 area as a micromorphology sample (WL92-F32). The thin-section made from this block exhibited no evidence of burning.

Comments: There is insufficient evidence to determine if the burned area recorded as Feature 232 represents a cultural feature or a natural burning event.

\section{Feature 233}

Feature Type: burned rock cluster and scatter

Provenience: Square 20, Levels 25-26; detection elevation $95.67 \mathrm{~m}$; base elevation $95.56 \mathrm{~m}$

Stratigraphic Context: Unit II/IIIa transition (upper portion)

Archeological Chronology: Early Archaic

Special Studies:

Archeomagnetic: 5 of 9 of samples analyzed (see Chapter 27 and Appendix 6)

Magnetic Susceptibility: 4 samples analyzed (see Chapter 28)

Micromorphology: 1 sample analyzed (see Chapter 29 and Appendix 7)

Gastropods: 1 sample analyzed (see section by Theler in Chapter 37)

Macrobotanical: 2 macroplant samples analyzed and 3 flotation samples processed (see Chapter 40)

Figure: 26-108 (see also Figure 27-101 in Chapter 27)

Description: Feature 233 was a poorly defined feature found

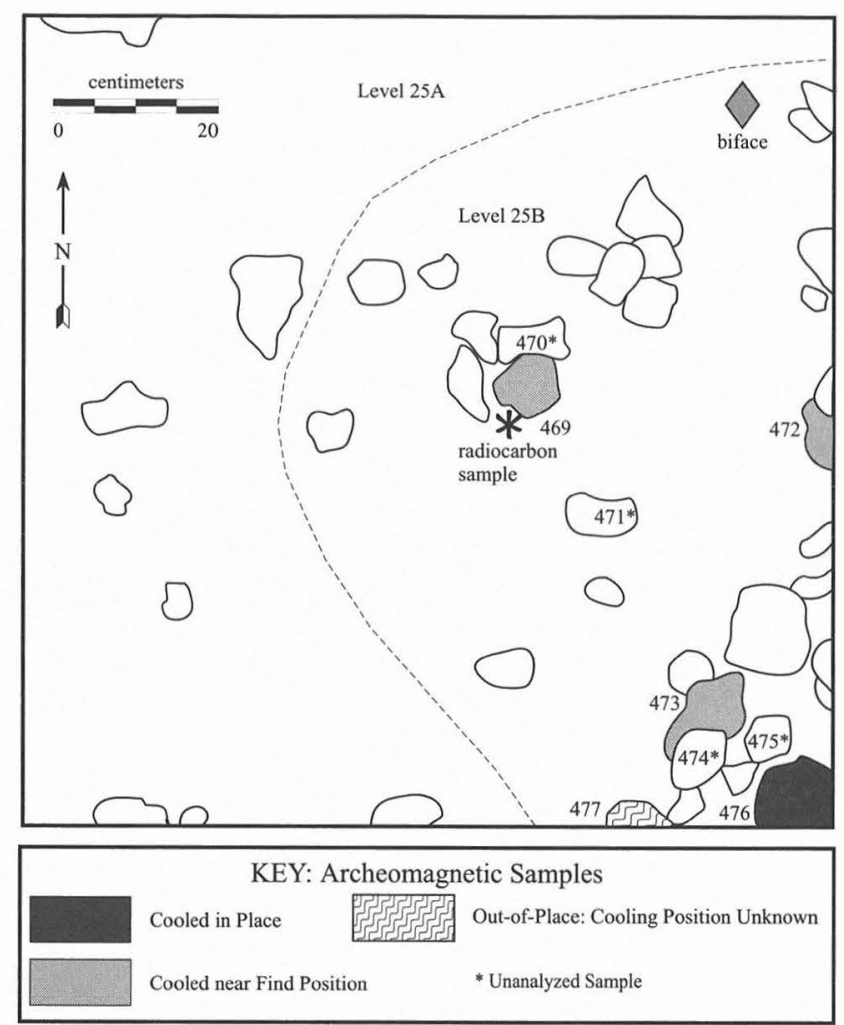

FIGURE 26-108. Feature 233 in Square 20, Level 25.

at the northern edge of the Feature 231 burned rock accumulation. It encompassed a dense cluster of burned rocks that was partially exposed in the southeast corner of Square 20 and a more dispersed scatter of burned rocks in the center of the square. About 15 rocks were exposed in the southeast corner with the dense cluster clearly extending into the east and south walls. About 30 additional rocks were scattered to the north and west of the main cluster. Overall, Feature 233 covered an area measuring $\mathrm{ca}$. $90-\mathrm{x}-90 \mathrm{~cm}$ with a vertical extent of ca. $9 \mathrm{~cm}$. No burned sediment was observed in the feature area during excavation, but some of the rocks were clearly discolored from burning (red and/or blue-gray). Small quantities of charcoal were found throughout the feature area, and two radiocarbon samples were collected (C14-65 and C14-68; both were identified as indeterminate wood). The point-plotted and 1/8-inch screen artifact recovery from the Feature 233 area included two Stage 1 bifaces (OR-437 and OR-457), an edge-modified flake (1185-1), and 203 pieces of debitage (with 1 flake collected as OR-446). Microdebitage recovered from the fine-screen samples discussed below (1/ 16-inch fraction) was not analyzed.

Nine archeomagnetic samples were collected from Feature 233 rocks and five of these samples were analyzed. The results indicate all the analyzed rocks were heated (several in excess of at least $450^{\circ} \mathrm{C}$ ), four probably cooled in or near their find positions, and one was dislocated after final cooling.

Feature 233 was located in one of the TARL fine-screen squares and, apart from some sediment reserved for special 
studies, the matrix in the two levels encompassing this feature was fine-screened, primarily to recover microvertebrate fauna (see Chapters 34 and 35). As in other TARL levels encompassing features, each of these levels was horizontally divided into " $A$ " and " $\mathrm{B}$ " subsets with the " $\mathrm{B}$ " portion encompassing the Feature 233 area as defined by the excavator (see Figure 26-108). Sediment from the A and B sublevels was fine-screened separately, with the exception of two bags from Level 25B that were inadvertently combined with the Level 25A recovery (consequently, the combined $25 \mathrm{~A} / \mathrm{B}$ recovery primarily represents $25 \mathrm{~B}$ ).

The analyzed bone from the Feature 233 fine-screen samples is reported by Balinsky in Chapter 35, and the analyzed eggshell is reported by Decker in Chapter 36. It is important to note that the analyzed fine-screen samples do not represent $100 \%$ of the recovery for either the A or B portions of these levels (see Chapters 35 and 36 for further discussion of sampling strategies). Sixteen eggshell fragments were found in Feature 233 fine-screen samples (from Levels 25B and 26B). On the basis of thickness measurements, Decker suggests at least 4 species may be represented by these eggshells. Balinsky analyzed a total of 858 specimens from Level 25B, 641 specimens from combined Level 25A/B, and 166 specimens from Level 26B. The identifiable specimens from the feature samples include relatively high percentages of fish, turtle, and rodent bones as well as smaller quantities of rabbit, small mammal, medium mammal, snake, and frog. When percentages of identifiable taxa are compared, the Feature 233 samples contain unusually high percentages of fish bone (ca. $40-50 \%$ of the identifiable bone). Most of this bone was classified as unidentified fish, but the samples also include specimens identified to the catfish and sunfish families. Balinsky reports that fish bones are particularly abundant in fine-screen samples from the lower portion of Unit IIII and the Unit II/III a transition, but she notes a definite spike in the Feature 233 samples. She also notes that a high percentage of this bone is burned and suggests it very likely represents cultural refuse.

Approximately 19.5 liters of sediment collected from the "B" portion of both levels was reserved for special studies (not fine-screened). Much of this sediment was used for magnetic susceptibility, micromorphology, gastropod, and flotation samples, and the remainder was curated. No significant results were obtained from the magnetic susceptibility samples, but some evidence of burning was observed in the micromorphology sample (WL-95-12). This sample included some reddened and calcined limestone fragments, quite a few ash rhombs, and several calcareous/ashy vegetal fragments. Two of the flotation samples were nonproductive, but some juniper wood charcoal was identified in the third sample (Flotation Sample 164).

The gastropod sample yielded 166 terrestrial and 6 aquatic snails. Although most of the identifiable terrestrial snails were taxa commonly found throughout the site deposits, several lower-frequency specimens were found as well (i.e., 3 Punctum vitreum and 1 Glyphyalinia roemeri). These 2 taxa are generally indicative of relatively mesic, woodland habitats. The aquatic snails include 2 Phreatodrobia nugax nugax, 2 Fossaria dalli, 1 Gyraulus sp., and 1 Planorbella sp. The latter 3 taxa are typically found in moist vegetation growing in shallow pools, and $P$. n. nugax is typically found in the deep artesian waters of the Edward's Aquifer (though it can also be expelled through spring vents). Although the aquatic snails may have been deposited in the feature during a flood, they may also reflect human collection of water and/or aquatic biota. Given the amount of fish bone recovered from the Feature 233 area, it is also possible that the aquatic snails were introduced via fish entrails.

The Feature 233 sample analyzed by Theler can also be compared to two samples analyzed by Neck from Levels $25 \mathrm{~A}$ and 26A (see section by Neck and Shaw in Chapter 37). These samples, collected as part of the Square 20 gastropod column, were from the southwest quad and were definitely outside the Feature 233 area. They were approximately the same volume as Theler's sample (1.5 liter), and though slightly different processing techniques were employed in the two studies, both analysts used the same size mesh for their finest screen recovery $(.425 \mathrm{~mm})$. Neck reports a much lower gastropod recovery with only 18 terrestrial snails from Level $25 \mathrm{~A}$ and 20 terrestrial snails from Level 26A. He found no aquatic snails in either sample. Although analyst and methodological biases may be reflected in these disparate results, it is also possible that the higher gastropod density in the Feature 233 area may reflect a higher concentration of cultural refuse/organic remains.

Comments: Feature 233 probably represents some type of Early Archaic hearth or cooking feature that extended beyond the east and south walls of Square 20.

\section{Feature 234}

Feature Type: burned sediment and charcoal (probable burned plant?)

Provenience: Square 30, Levels 28-31; detection elevation $95.46 \mathrm{~m}$; base elevation $95.30 \mathrm{~m}$

Stratigraphic Context: Unit Isi-c/II transition

Archeological Chronology: Late Paleoindian Special Studies:

Radiocarbon: see date for Feature 238 (possibly associated with Feature 234; see discussion below)

Archeomagnetic: 1 of 3 samples analyzed (see Chapter 27 and Appendix 6)

Magnetic Susceptibility: 2 samples analyzed (see Chapter 28)

Macrobotanical: 1 macroplant sample analyzed and 1 flotation sample processed (see Chapter 40)

Figure: 26-109 (see also Figure 27-30 in Chapter 27)

Description: This feature number was assigned to some small patches of burned sediment, scattered bits of charcoal, 


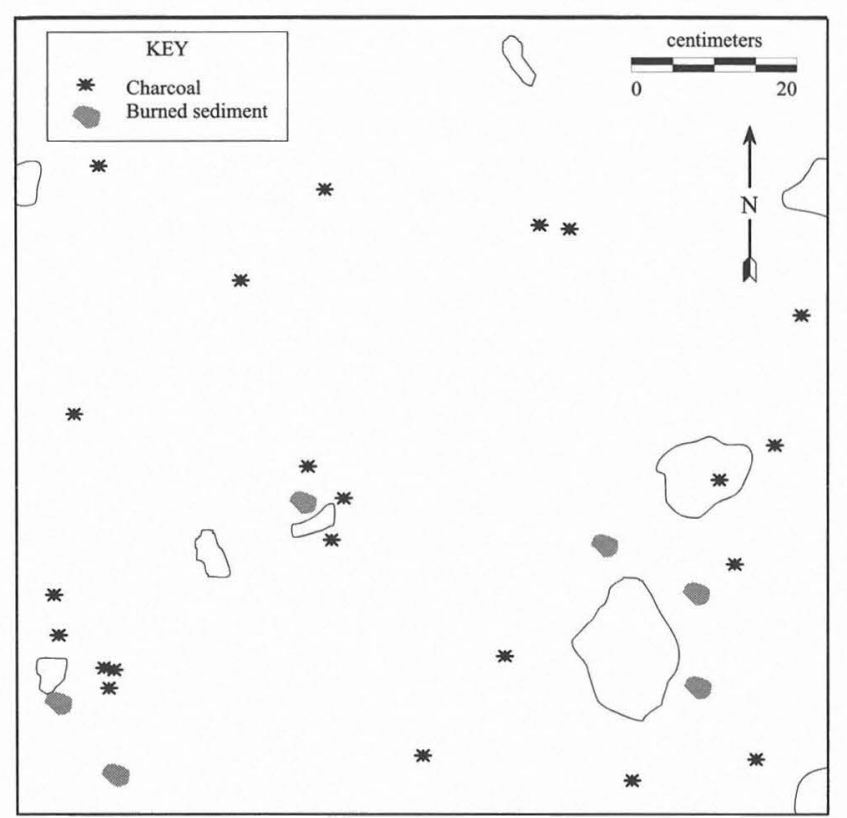

FIgURE 26-109. Feature 234 in Square 30, Levels 28-31.

and a few burned rocks found dispersed throughout a 1-x1 -m square in four levels (ca. 16-cm vertical extent). Although the excavators thought this feature might represent the remnants of a disturbed hearth, the patches of burned sediment and charcoal extended below the recorded base of the feature for at least three more levels, and it appears that they may represent burned plant roots. Feature 238, recorded in Levels 33 and 34 of the same square, is quite similar to Feature 234, and it seems quite likely they represent the same natural burning episode.

Feature 234 recovery included two flakes collected as organic residue samples (OR442 and OR445, both unanalyzed), 298 pieces of debitage, 6 pieces of hematite, 2 small quartz pebbles, and 87 bones/bone fragments (see Chapter 33). Approximately $76 \%$ of the bones was burned. Special samples included 3 archeomagnetic samples, 1 charcoal sample, some burned sediment collected as a thermoluminescence sample (TL-25; unanalyzed), and a bulk matrix sample. Flotation and magnetic susceptibility samples were extracted from the bulk matrix sample, and the remainder was curated.

Only one of the AM samples was analyzed, and the results indicate this rock was probably heated to a relatively high temperature and then cooled in place with relatively little postcooling disturbance. The charcoal sample (C1467) was identified as indeterminate wood, and the flotation sample yielded no identifiable plant remains. The magnetic susceptibility samples exhibited slightly higher values than nonfeature samples from comparable stratigraphic contexts. This slight enhancement may reflect the presence of ash or burned sediment.

Comments: Features 234 and 238 probably represent some sort of burned plant. Although the archeomagnetic results from Feature 234 might support a hearth interpretation, it also seems plausible that the rock was burned during a natural burning episode.

\section{Feature 235}

Feature Type: burned rock cluster

Provenience: Square 32, Levels 28-29; detection elevation $95.49 \mathrm{~m}$; base elevation $95.43 \mathrm{~m}$

Stratigraphic Context: Unit Isi-c/II transition

Archeological Chronology: Late Paleoindian

Special Studies:

Archeomagnetic: 8 of 9 samples analyzed (see Chapter 27 and Appendix 6)

Magnetic Susceptibility: 2 samples analyzed (see Chapter 28)

Macrobotanical: 3 macroplant samples analyzed; 1 flotation sample processed (see Chapter 40)

Figure: $26-110$ (see also Figure 27-31 in Chapter 27)

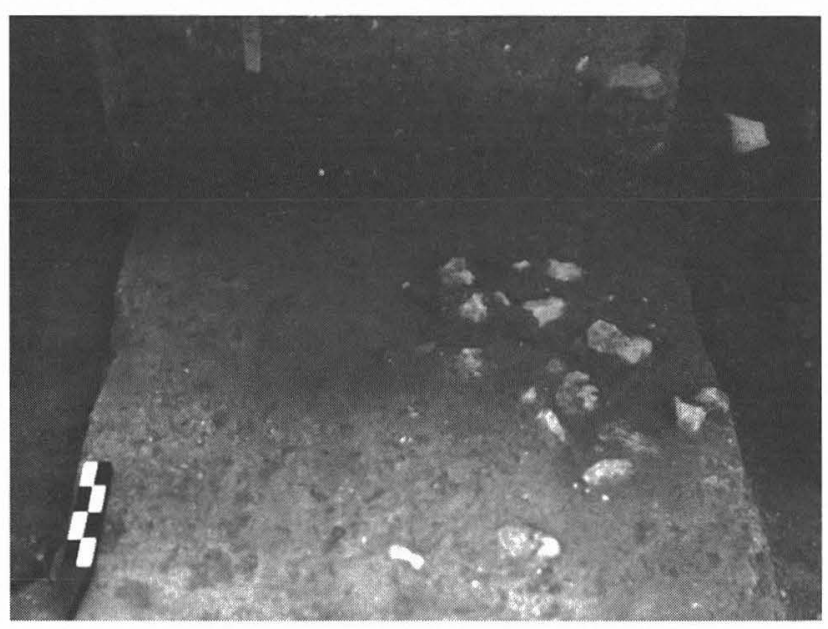

FIGURE 26-110. Feature 235 in Square 32, Level 28, looking south.

Description: Feature 235 consisted of a cluster of about 26 small burned rocks. The single-layer cluster measured about $60-\mathrm{x}-65 \mathrm{~cm}$, and the rocks ranged from $2-10 \mathrm{~cm}$ in diameter. The cluster had a vertical extent of approximately $6 \mathrm{~cm}$. Most of the rocks were spaced less than $5 \mathrm{~cm}$ apart, but a few were spaced a little farther apart $(5-10 \mathrm{~cm})$. Many of the rocks exhibited angular fractures, and some exhibited a reddish color (presumably from heat alteration). One of the rocks (TL29) had an unusual, dark reddish purple tint and a relatively fine-grained texture (somewhat "cherty"). No burned sediment was observed within Feature 235, but small quantities of charcoal were scattered throughout the cluster. Three charcoal samples were collected (C14-74, CH-75, and CH79), and all were identified as indeterminate wood charcoal.

Nine archeomagnetic samples were collected from Feature 235 rocks, and 8 of these were analyzed. The results indicate five of the rocks cooled in or very near their find positions, and 3 others moved after cooling. Feature 235 
recovery also included a flake collected as an organic residue sample (OR468, unanalyzed), 97 pieces of debitage, 8 bone fragments ( $1 / 8$-inch screen recovery, see Chapter 33$), 2$ burned rocks collected as thermoluminescence samples (TL29 and TL30, unanalyzed), 2 bags of burned rocks, and a bulk matrix sample.

Several special samples were pulled from the bulk matrix sample. These include 2 magnetic susceptibility samples, a flotation sample, and a fine-screen faunal sample. The magnetic susceptibility results were comparable to nonfeature samples from similar stratigraphic contexts (no significant deviation detected). The flotation sample was not productive (no identifiable plant remains), but 27 bones were found in the fine-screen sample. Most were classified as Vertebrata indeterminate fragments, but the sample also included 2 specimens classified as mammal and rodent (see Appendix 8).

Comments: The archeomagnetic results indicate that Feature 235 probably represents an in situ hearth with at least some rocks remaining in or near their final cooling positions.

\section{Feature 236}

Feature Type: small burned rock basin

Provenience: Squares 33 and 48, Levels 29-31; detection elevation $95.46 \mathrm{~m}$; base elevation $95.30 \mathrm{~m}$

Stratigraphic Context: Unit Id/II transition

Archeological Chronology: Late Paleoindian

Special Studies:

Organic Residue: 1 sample analyzed by Hurst (see Chapter 23)

Radiocarbon: 2 samples AMS-dated; a wood charcoal sample was dated to $9650 \pm 80$ B.P. (CAMS-07560), and some carbonized bone was dated to $10,400 \pm 280$ B.P. (CAMS07561)

Archeomagnetic: 13 of 17 samples analyzed (see Chapter 27 and Appendix 6)

Magnetic Susceptibility: 15 samples analyzed (see Chapter 28)

Micromorphology: 2 samples analyzed (see Chapter 29 and Appendix 7)

Gastropod: 1 sample analyzed (see section by Theler in Chapter 37)

Macrobotanical: 1 macroplant sample analyzed; 9 flotation samples processed (see Chapter 40)

Phytolith: 1 sample analyzed (see Chapter 41)

Figure: 26-111, 26-112

Description: Feature 236 was a tight, circular cluster of about 20 burned rocks apparently resting in a shallow basin. This feature did not exhibit an obvious basin shape in plan view, but when it was cross-sectioned some of the lower rocks were sloping as though they were lining the sides and base of a shallow depression. The cluster measured about $60 \mathrm{~cm}$ in diameter with a depth of approximately $16 \mathrm{~cm}$. It was composed primarily of a single layer of rocks with a few

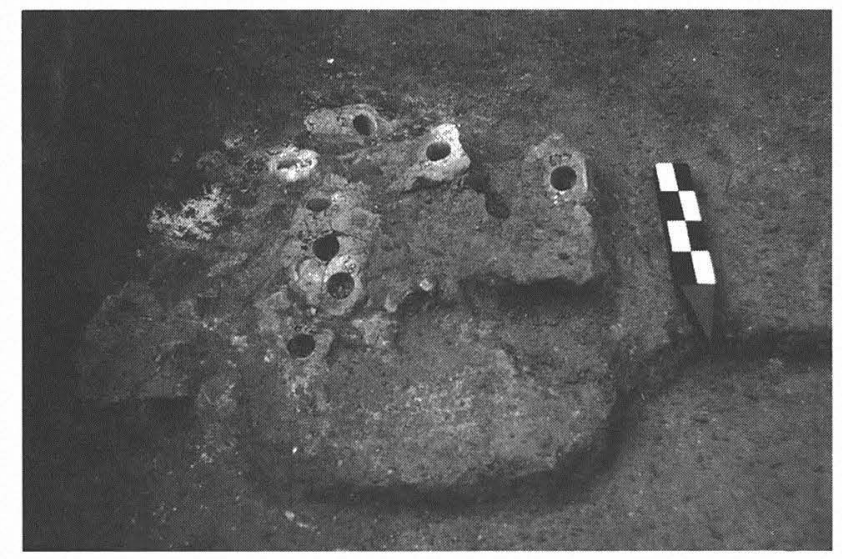

Figure 26-111. Feature 236 as exposed in Level 29 of Square 33 and Level 30 of Square 48, looking south.

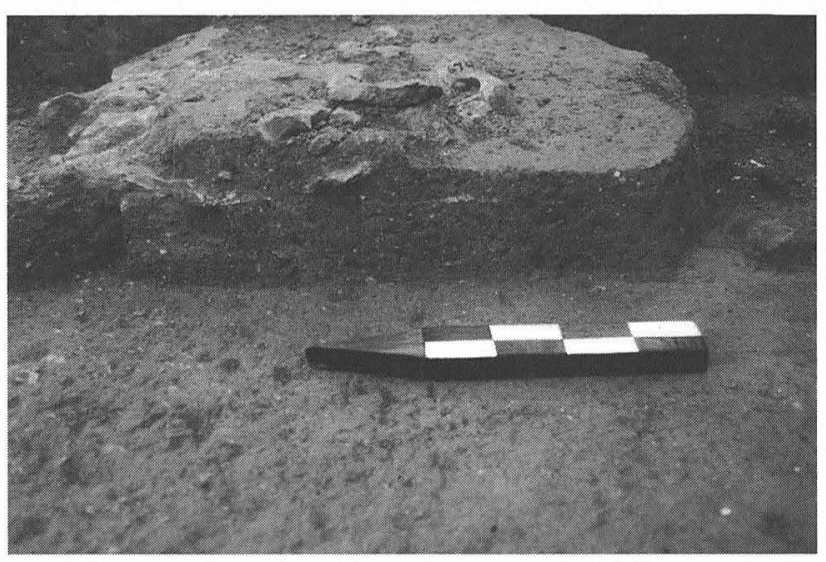

FiguRE 26-112. Feature 236 after cross sectioning in Square 33, Levels 29-31, looking east.

rocks stacked on top of others (primarily in the central portion of the cluster). The feature included about 10 large rocks (10-20-cm size) and 10 smaller fragments (3-5-cm size).

Most of the rocks exhibited angular fractures, and some were clearly reddened from heat alteration. Small quantities of poorly preserved charcoal were found among the burned rocks, and two samples were collected (C14-123 and C14156). One of these (C14-123) was identified as indeterminate wood charcoal. The other sample was submitted for AMS dating (without macrobotanical analysis), and it was found to contain both carbonized wood and bone. It was divided into two subsamples (the wood was C14-156a; the bone was C14-156b) and then both were dated (see dates listed above). The wood charcoal date is judged to be the more accurate age approximation for Feature 236.

Although no evidence of burned sediment was reported in the field notes, clear evidence of in situ burning was observed in two micromorphology thin-sections made from intact blocks of sediment collected from the central portion of the feature (WL92-F3 and WL92-F11). These samples exhibited isolated areas of reddened soil, ash crystals, charcoal, and some calcined limestone. Sample WL92-F11 also 
exhibited some ashy vegetal residue, some eggshell fragments, and a grain of nonlocal plagioclase.

Seventeen archeomagnetic samples were collected from Feature 236 rocks, and 13 of these (representing 11 rocks) were analyzed. The results are complex but generally indicate that Feature 236 is a relatively intact feature. At least four stones were heated above the Curie point and then cooled in place with little or no subsequent movement. Three other rocks apparently cooled from high temperatures with relatively little movement and then tilted slightly downward to the northeast after cooling. The remaining four rocks appear to have rolled downward (probably into a shallow basin) during and/or after cooling.

Nine Feature 236 rocks were collected as organic residue samples, but only one was analyzed. Residues extracted from the analyzed specimen (OR540) were subjected to both capillary ion and amino acid analyses. The capillary ion analysis identified chloride, nitrate, sulfate, phosphate, and carbonate anions. Although the chloride and carbonate anions were interpreted as natural residues with no cultural significance, the nitrate and phosphate were considered more likely residues from cultural activities. The potential source of the sulfate is unknown. Twelve amino acids were also identified in the residues extracted from this rock, but the source (or sources) was not determined.

Feature 236 recovery also included 11 pieces of debitage, 12 Vertebrata bone fragments (all burned; see Chapter 33), and 31 bags of sediment (various volumes; collected from different areas of the feature). Most of the sediment was used for magnetic susceptibility, phytolith, flotation, gastropod, and fine-screen faunal samples (remainder was curated). The magnetic susceptibility samples were generally consistent with nonfeature samples from similar stratigraphic contexts (no significant deviation detected). The phytolith and flotation samples were not productive, but this is consistent with the overall poor preservation of plant remains in Unit II deposits. Fortunately, the gastropod and fine-screen samples were more fruitful and informative. The latter sample included 542 bones and 3 eggshell fragments (see Appendix 8 and Chapter 36). Much of the bone was classified as Vertebrata indeterminate fragments, but the sample also included elements classified as mammal, rodent, rabbit, fish, reptile, and turtle. At least half of this bone (most taxa) appeared to be burned.

A total of 191 terrestrial and 6 aquatic mollusks were recovered from the gastropod sample. Although the vast majority (ca. 91\%) of the identifiable terrestrial mollusks were taxa commonly found throughout the site deposits, a significant number of less common species were identified as well. The latter group include Carychium mexicanum, Punctum vitreum, Helicodiscus parallelus, Glyphyalinia roemeri, G. umbilicata, and Deroceras laeve. These species are generally indicative of a relatively mesic, woodland habitat, and this evidence is consistent with other paleoenvironmental indicators for lower Unit III. The aquatic snails consisted of 4 Fossaria dalli and 2 Phreatodrobia nugax nugax snails. $F$. dalli is found in moist vegetation growing in shallow pools and $P$. n. nugax typically inhabits the deep artesian waters of the Edwards Aquifer but is sometimes expelled through spring vents (see Chapter 37). Although the aquatic snails may have been deposited through overbank flooding of either Brushy or Spanish Oak creeks, they may also reflect human collection of water or aquatic biota. Since fish bones were found in the fine-screen sample, it is also possible that the aquatic snails were introduced in fish entrails.

Comments: The archeomagnetic and micromophology evidence indicate Feature 236 is a relatively undisturbed feature with clear evidence of in situ burning. It probably represents a small basin-shaped hearth/cooking feature, and its stratigraphic position (lower Unit II) and radiocarbon date indicate a Late Paleoindian affiliation (perhaps relating to either the Wilson or Golondrina-Barber occupations).

\section{Feature 237}

Feature Type: burned sediment (within Feature 231)

Provenience: Square 34, Level 23; detection elevation 95.74 $\mathrm{m}$; base elevation $95.72 \mathrm{~m}$

Stratigraphic Context: Unit II/IIIa transition

Archeological Chronology: Early Archaic

Special Studies:

Archeomagnetic: 2 of 3 samples analyzed (see Chapter 27 and Appendix 6)

Magnetic Susceptibility: 2 samples analyzed (see Chapter 28) Micromorphology: 1 sample analyzed (see Chapter 29 and Appendix 7)

Figure: $26-113$ (see also Figure 27-81 in Chapter 27)

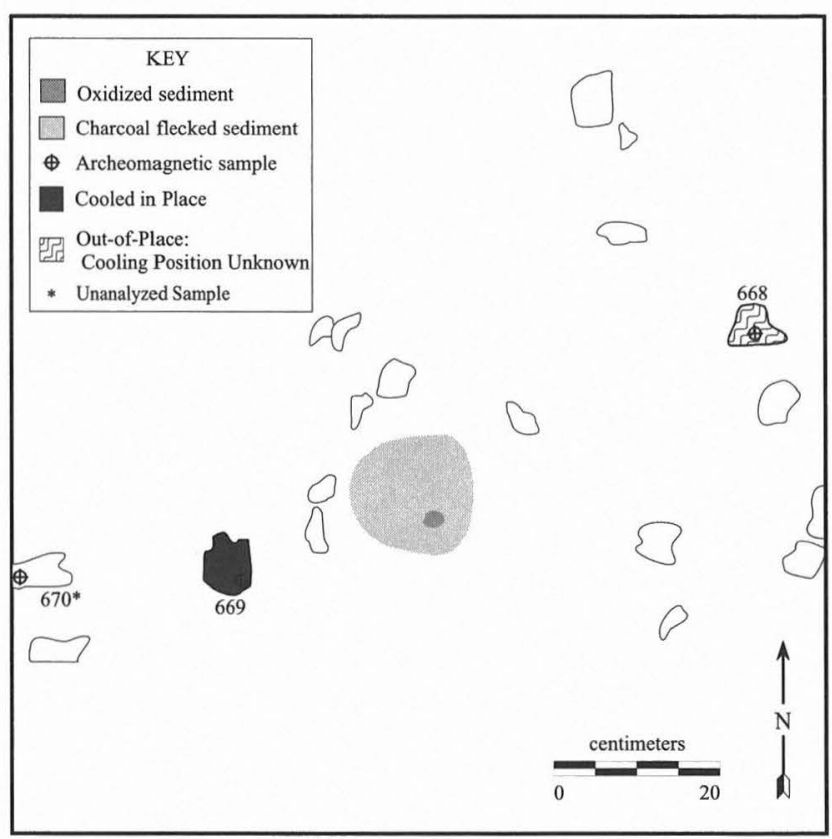

FIGURE 26-113. Feature 237 in Square 34, Level 23. 
Description: This feature number was assigned to a small patch of burned, oxidized sediment found within the larger Feature 231 burned rock accumulation. The oxidized (reddened) patch measured ca. $2-3 \mathrm{~cm}$ in diameter and $2 \mathrm{~cm}$ thick. It was surrounded by an area of charcoal-flecked sediment measuring ca. $15 \mathrm{~cm}$ in diameter. This burned sediment was found in the lowest layer of rocks provenienced to Feature 231 (in this square), and at this depth, the rock density was relatively low (see Figure 27-81 in Chapter 27). When Feature 237 was mapped at the base of Level 23, a dispersed scatter of about 19 small, burned rocks (ca. $2-7-\mathrm{cm}$ size) surrounded the burned sediment. These rocks were treated as part of Feature 237 in the archeomagnetic analysis presented in Chapter 27, and they may very well have been associated with this small patch of burned sediment.

No artifacts were found in the burned area, and none of the charcoal was adequate for a radiocarbon sample. The oxidized and charcoal-flecked sediment was collected as a bulk matrix sample, and some of this sediment was used for magnetic susceptibility and micromorphology samples. No significant results were obtained from the magnetic susceptibility samples, but oxidized sediment, charcoal, and possible ash were observed in the micromorphology sample.

Three archeomagnetic samples were collected from rocks surrounding the burned sediment, and two of these were analyzed (see Figure 26-113). The results indicate both rocks moved at least once while cooling, but one of the rocks cooled in place (from relatively low temperatures), while the other was displaced after final cooling. The undisturbed rock was located about $15 \mathrm{~cm}$ west of the burned/charcoalflecked sediment.

Comments: The burned sediment recorded as Feature 237 probably represents a cultural rather than a natural burning event. Since the archeomagnetic results indicate one of the nearby rocks cooled in place, Feature 237 may represent the remnant of an Early Archaic hearth or other type of heated stone feature.

\section{Feature 238}

Feature Type: burned sediment and charcoal (burned plant?) Provenience: Square 30, Levels 33-34; detection elevation $95.13 \mathrm{~m}$; base elevation $95.00 \mathrm{~m}$

Stratigraphic Context: Feature 238 was recorded in Unit Isi-c but it probably represents a burned plant that originated in Unit II

Archeological Chronology: Late Paleoindian

\section{Special Studies:}

Radiocarbon: 1 wood charcoal sample was AMS-dated to $8830 \pm 90$ B.P. (CAMS-10207; see Chapter 25)

Magnetic Susceptibility: 2 samples analyzed (see Chapter 28)

Macrobotanical: 3 macroplant samples analyzed (see Chapter 40)

Figure: 26-114

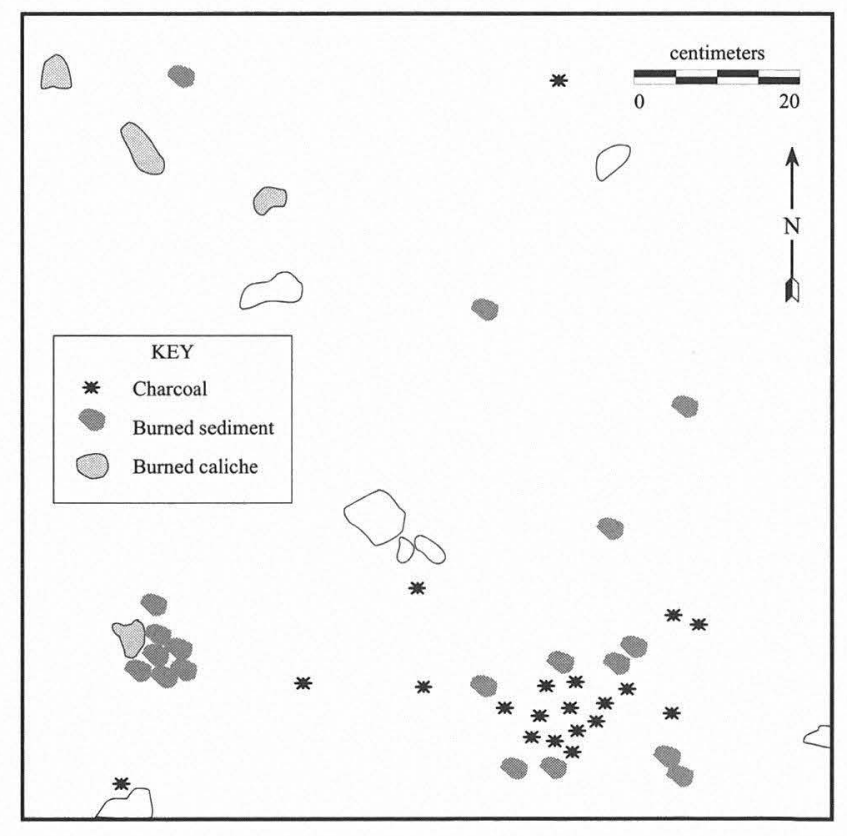

FIGURE 26-114. Feature 238 in Square 30, Levels 33-34.

Description: Feature 238 was a rather diffuse concentration of charcoal and burned sediment that was initially recorded as a possible hearth. The feature encompassed an area measuring ca. $40-\mathrm{x}-90 \mathrm{~cm}$ with the charcoal concentrated primarily in a 15-cm-diameter area. Five or six patches of burned sediment (1-3-cm diameter) were scattered around the charcoal along with a few angular limestone fragments. Although Feature 238 had a documented vertical extent of ca. $13 \mathrm{~cm}$, the burned sediment and charcoal were probably associated with similar concentrations found in the previous five levels (28-32). Feature 234 (recorded in Levels 28-31 of this square) was very similar to Feature 238, and they were probably related to the same burning event (see Feature 234 description).

Three of the four charcoal samples collected from Feature 238 were analyzed as macroplant samples. One was identified as live oak wood (C14-83) and the others as indeterminate wood $(\mathrm{C} 14-86,111)$. The fourth sample was submitted for radiocarbon dating (before the feature was recognized as a burned plant).

Seventeen pieces of debitage, 35 bone fragments (see Chapter 33), and a bulk matrix sample were also collected from the Feature 238 area. Some of the sediment was used for magnetic susceptibility samples and the remainder was curated. The susceptibility results were comparable to nonfeature samples from similar stratigraphic contexts (no significant deviation detected).

Comments: Feature 238 was located in the mid to lower portion of Unit Isi-c but the radiocarbon date of $8830 \pm 90$ B.P. (CAMS-10207) obtained on charcoal from this feature is a little young for this stratigraphic context. The dated sample probably relates to a burned tree (or other large plant) that grew from a surface in Unit II with its roots intruding Unit 
Isi-c. Feature 234 (which probably represents the same burned plant) was located in the Isi-c/II transition zone.

Feature 239

Feature Type: burned rock cluster

Provenience: Square 34, Levels 25-27; detection elevation $95.63 \mathrm{~m}$; base elevation $95.50 \mathrm{~m}$

Stratigraphic Context: Unit II

Archeological Chronology: Late Paleoindian

Special Studies:

Archeomagnetic: 3 of 5 samples analyzed (see Chapter 27 and Appendix 6)

Magnetic Susceptibility: 6 samples analyzed (see Chapter 28)

Micromorphology: 1 sample analyzed (see Chapter 29 and Appendix 7)

Macrobotanical: 1 macroplant sample analyzed and 2 flotation samples processed (see Chapter 40)

Figure: see Figure 27-33 in Chapter 27

Description: Feature 239 was a poorly defined burned rock feature that may have extended beyond the south and east walls of the square. The exposed portion included 15 rocks that were loosely grouped within a $60-\mathrm{x}-65-\mathrm{cm}$ area (ca. 13$\mathrm{cm}$ vertical extent). The rocks included two large, tabular cobbles (13-16-cm size) spaced about $7 \mathrm{~cm}$ apart and two clusters of smaller, angular fragments (2-9-cm size) which appeared to be larger rocks that were fractured in place, then slightly displaced. Small patches of burned sediment and charcoal flecks were found throughout the feature area, but only one piece of charcoal was large enough to collect (C1497; identified as indeterminate wood). Another radiocarbon sample (C14-151) was later identified as carbonized bone.

Five archeomagnetic samples were collected from one of the fragment clusters, and three of these were analyzed. The results indicate all three fragments were displaced after final cooling, but they experienced such similar thermal/movement histories they were probably fragments of a single larger rock (as suspected).

Associated artifacts include a Golondrina-Barber base (1473-1), an edge-modified flake (1382-1), and 128 pieces of debitage. The $1 / 8$-inch screen recovery also included 45 bone fragments: 2 rabbit elements (tooth and tibia), 11 Vertebrata long-bone fragments ( 7 small/medium and 4 medium/ large), and 32 Vertebrata indeterminate fragments (see Chapter 33). The rabbit elements and 37 of the Vertebrata fragments were burned.

Three bulk matrix samples were also collected from the feature area, and most of this sediment was used for magnetic susceptibility, micromorphology, and flotation samples (remainder was curated). Unfortunately none of these samples was very informative-the susceptibility results were similar to nonfeature samples from comparable stratigraphic contexts (no significant deviation detected); no definitive evidence of burning (or other notable attributes) were observed in the micromorphology sample; and no identifiable plant remains were found in the flotation samples.

\section{Feature 241}

Feature Type: burned rock cluster

Provenience: Square 35, Levels 25-26 (not recorded as Feature 241 until Level 26, but some of the rocks were first exposed in Level 25); detection elevation $95.65 \mathrm{~m}$; base elevation $95.52 \mathrm{~m}$

Stratigraphic Context: Unit II

Archeological Chronology: Late Paleoindian

Special Studies:

Archeomagnetic: 5 of 6 samples analyzed (see Chapter 27 and Appendix 6)

Magnetic Susceptibility: 2 samples analyzed (see Chapter 28)

Micromorphology: (see Chapter 29 and Appendix 7)

Macrobotanical: 1 flotation sample processed (see Chapter 40)

Figure: see Figure 27-34 in Chapter 27

Description: Feature 241 consisted of ca. 13 burned rocks (2-15 cm size) loosely clustered within a 45- $\mathrm{x}-55-\mathrm{cm}$ area (maximum vertical extent of ca. $13 \mathrm{~cm}$ ). Two of the larger rocks exhibited reddened/oxidized surfaces (one on the top and the other on the bottom), but no burned sediment or charcoal was found in the feature area. Five pieces of debitage are the only artifacts provenienced to this feature.

Seven archeomagnetic samples were collected from six of the larger rocks, and five of these were analyzed. The results indicate one of the rocks cooled in place from about $300^{\circ} \mathrm{C}$, but the others were all displaced after final cooling.

A bulk matrix sample was also collected from Feature 241 , and most of this sediment was used for magnetic susceptibility, micromorphology, and flotation samples (with a small portion curated). The susceptibility samples exhibited a slightly higher average value than nonfeature samples from similar stratigraphic contexts. This may reflect the presence of ash or sediments altered by heating. No burned sediment was observed in the micromorphology sample (WL95-18), but some gray areas were noted that may represent ash. The flotation sample was not productive (no identifiable plant remains were recovered).

\section{Feature 242}

Feature Type: burned rock cluster

Provenience: Square 20, Levels 28-29; detection elevation $95.49 \mathrm{~m}$; base elevation $95.41 \mathrm{~m}$

Stratigraphic Context: Unit II/IIIa transition

Archeological Chronology: Late Paleoindian or Early Archaic

Special Studies:

Archeomagnetic: 2 of 4 samples analyzed (see Chapter 27 and Appendix 6) 
Magnetic Susceptibility: 2 samples analyzed (see Chapter 28)

Macrobotanical: 2 flotation samples processed (see Chapter 40)

Figure: see Figure 27-109 in Chapter 27

Description: Feature 242 consisted of 16 burned limestone fragments loosely clustered within a $30-x-60-x-8-\mathrm{cm}$ area. Most of the fragments were relatively small (2-5-cm size), but a few were slightly larger (6-10-cm size). Many of the rocks exhibited thermal fractures and discoloration from burning (red and/or blue-gray). No burned sediment or charcoal was found in the feature area, and no artifacts were provenienced to Feature 242.

Archeomagnetic samples were collected from four rocks on the perimeter of the cluster, and two of these were analyzed. The results indicate these rocks were heated (temperatures not specified), but both were displaced after final cooling.

Two bulk matrix samples were also collected from Feature 242 , and most of this sediment was used for magnetic susceptibility, flotation, and faunal fine-screen samples (remainder was curated). Unfortunately none of these samples was very informative: the susceptibility results were comparable to nonfeature samples from similar stratigraphic contexts (no significant deviation detected); no identifiable plant remains were recovered from the flotation sample; and though some bone was recovered from the fine-screen sample, this material has not been analyzed. Comments: Feature 242 may be associated with the Early Archaic burned rock accumulation recorded as Feature 231 (see Feature 231 description), or it may predate this feature. It was located at or slightly below the base of Feature 231 (northern margin) in the stratigraphically mixed Unit II/IIIa transition zone. There is considerable mixing of Late Paleoindian and Early Archaic materials in this zone, and it was difficult to assess the age of some of the features found in these mixed deposits.

\section{Feature 243}

Feature Type: burned sediment with a few burned rocks Provenience: Square 25, Level 33; detection elevation 95.22 $\mathrm{m}$; base elevation $95.12 \mathrm{~m}$

Stratigraphic Context: Unit II

Archeological Chronology: Late Paleoindian Special Studies:

Magnetic Susceptibility: 2 samples analyzed (see Chapter 28)

Micromorphology: 1 micromorphology sample analyzed (see Chapter 29 and Appendix 7)

Figure: 26-115

Description: Feature 243 consisted of a $25-\mathrm{x}-50-\mathrm{cm}$ area containing five angular, burned limestone fragments (5-8$\mathrm{cm}$ size) and a patch of burned, oxidized sediment (10-x-28 $\mathrm{cm})$. The entire feature had a vertical extent of approxi-

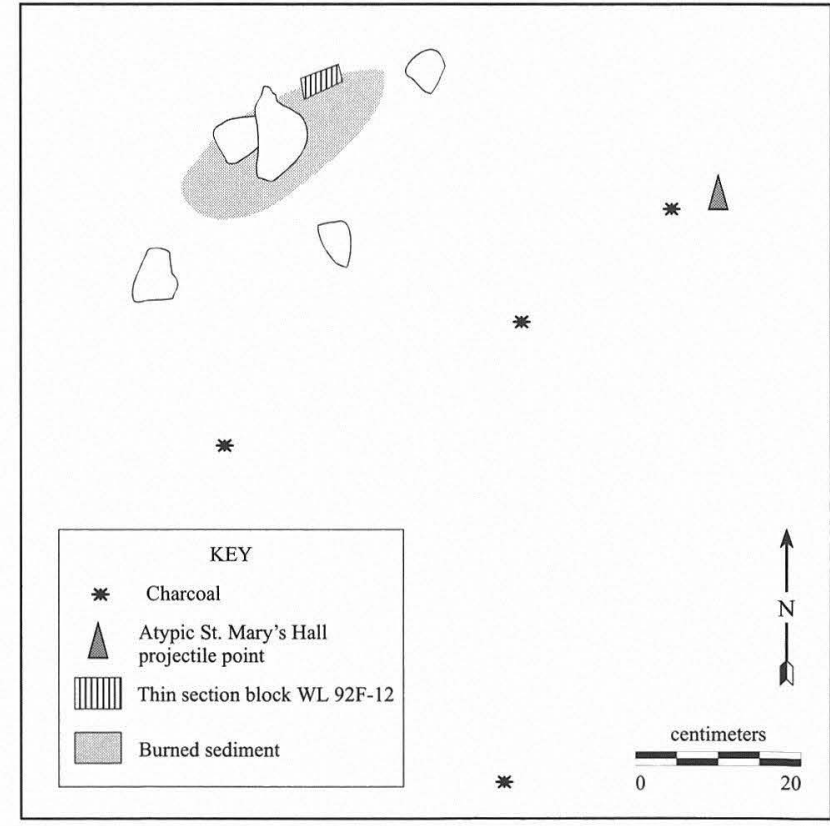

FIGURE 26-115. Feature 243 in Square 25, Level 33.

mately $10 \mathrm{~cm}$, and the area of reddened sediment was several centimeters thick. Two of the rocks were tightly clustered in the approximate center of the burned sediment area, and the remainder encircled the southeast side of it (spaced about $20 \mathrm{~cm}$ apart). All of the rocks exhibited reddish discoloration from burning. No charcoal was found within the immediate feature area, but four small samples collected within $5-30 \mathrm{~cm}$ of Feature 243 at roughly the same elevation were possibly associated. One of these samples was identified as live oak wood (C14-98) and another as unidentified hardwood (C14-121). Three flakes were found beneath one of the perimeter stones, but no other artifacts were recovered from the feature area. An atypical St. Mary's Hall point (OR543) was found about $40 \mathrm{~cm}$ east of Feature 243 (same square/level) at about the same elevation.

No archeomagnetic samples were collected from this feature (rocks were too small to drill), but an intact block of sediment was collected from the burned area for a micromorphology sample (WL92-F12). The thin-section made from this sample exhibited considerable evidence of in situ burning, i.e., rubified sediment, numerous ash crystals, numerous charcoal fragments, some intensely burned, calcined limestone fragments, and some burned bone.

A small bulk matrix sample was also collected from the feature area, but the field notes do not indicate if this sample encompassed or excluded the patch of burned sediment. A small portion of this sediment was used for two magnetic susceptibility samples, and the remainder was curated. The susceptibility results fell within the observed range for nonfeature samples in similar stratigraphic contexts (no significant deviation detected). 
Feature 245

Feature Type: large burned rock basin

Provenience: Squares 27, 28, 39, 44, 52, and 53; Levels 22, 24-27 (Level 23 designation was skipped in these squares); detection elevation ca. $95.78 \mathrm{~m}$; base elevation ca. $95.53 \mathrm{~m}$ Stratigraphic Context: originated in Unit IIIa but lower portion intrudes Unit II

Archeological Chronology: Early Archaic

Special Studies:

Organic Residue: 1 sample analyzed (see section by Hurst in Chapter 23)

Radiocarbon: 3 charcoal samples were AMS-dated to 8110 \pm 70 в.P. (CAMS-10194); $8130 \pm 60$ в.P. (CAMS-10197); and $8420 \pm 200$ B.P. (CAMS-10206) (see Chapter 25)

Archeomagnetic: ca. 101 of 142 samples analyzed (see Chapter 27 and Appendix 6)

Magnetic Susceptibility: 12 samples analyzed (see Chapter 28)

Micromorphology: 8 samples analyzed (see Chapter 29 and Appendix 7)

Gastropod: 3 samples analyzed (see section by Neck and Shaw in Chapter 37)

Macrobotanical: 2 macroplant samples analyzed and 3 flotation samples processed (see Chapter 40)

Phytolith: 1 sample analyzed (see Chapter 41)

Figures: 26-116 and 26-117 (see also Figures 27-72, 27-76, 27-78, 27-85, 27-89, 27-91, 27-94, 27-99, and 27-103 in Chapter 27)

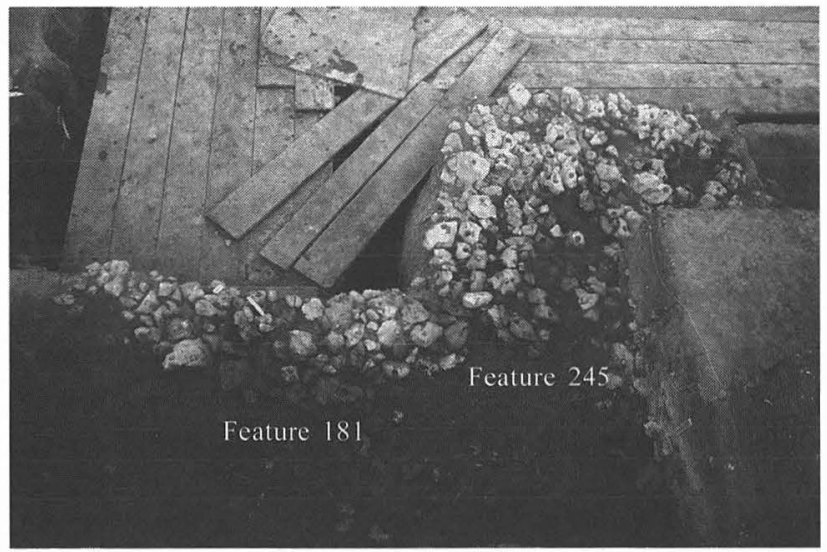

FIGURE 26-116. Feature 245 (right) and Feature 181 (left) as exposed at an elevation of approximately $95.70 \mathrm{~m}$ in the TARL East Block, looking west.

Description: Feature 245 was a large basin-shaped pit that was filled with a dense concentration of burned rocks and other cultural debris. It measured about $1.5 \mathrm{~m}$ in diameter with a depth of at least $25 \mathrm{~cm}$ (it probably originated from a surface slightly above its detection level). Feature 245 was located within the larger Feature 231 burned rock accumulation, and the overlying/surrounding sheet midden of scat-

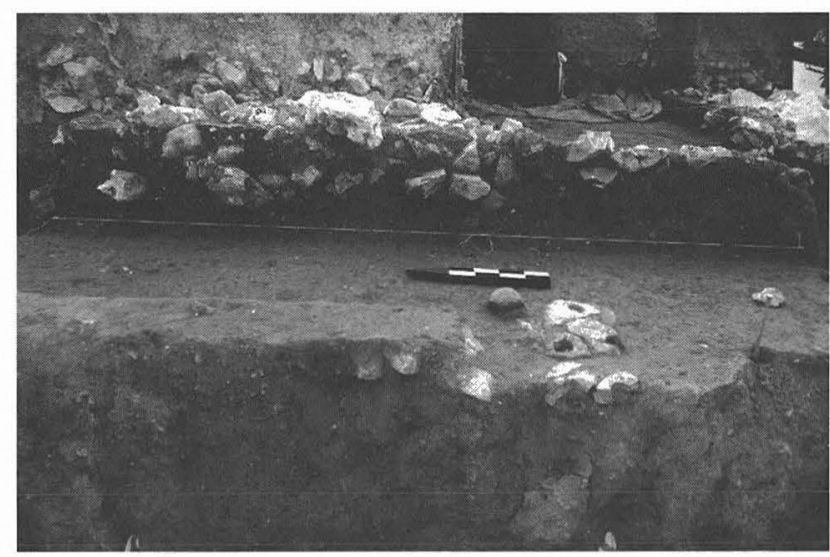

FIGURE 26-117. Feature 245 cross-sectioned in Squares 52 and 28 , looking east. Profile stringline is set at $95.50 \mathrm{~m}$. Feature 248 is partially exposed in the floor of Squares 52 and 53 (right) which are at the base of Level 28 .

tered rocks obscured the upper portion of this pit. Although the pit outline was not clearly visible until Level 24 (at which point the feature number was assigned), the results of the archeomagnetic analysis indicate at least some of the rocks exposed in Level 22 of these squares (originally provenienced to Feature 231) actually lie within Feature 245 pit fill.

Feature 245 contained over 500 burned rocks ranging from ca. $2-20 \mathrm{~cm}$ in length. Although many of these were small, angular fragments, the pit also contained a relatively large number of tabular slabs in the $10-20-\mathrm{cm}$ size range. These larger rocks were found throughout the pit, but they were especially concentrated along the outer margins and base. The smaller rocks (2-10-cm size) were more numerous in the upper portion of the pit (especially in Level 22).

Scattered patches of burned, oxidized sediment and charcoal concentrations were found beneath the lowest layer of rocks at the base of the pit. It looked like a fire had burned in the pit before the lowest layer of rocks was deposited. Charcoal was dispersed throughout Feature 245, and at least 28 samples were collected. Most of these were quite small and poorly preserved but 3 were large enough for AMS radiocarbon determinations (C14-113, C14-143, and C14-152; see dates above). All 3 of these samples were collected from charcoal concentrations found beneath burned rocks in the lower portion of the pit. Two additional charcoal samples were analyzed as macroplant samples with one (C14-132) identified as unknown hardwood wood and the other (Lot 1957) as juniper wood.

Approximately 142 archeomagnetic samples were collected from burned rocks within Feature 245. The total number is uncertain because the pit margins were not clearly delineated in the upper levels. Of the analyzed archeomagnetic samples, 42 were definitely provenienced to Feature 245, and another 50 were provenienced to Feature $231 / 245$ (though the archeomagnetic results suggest most of these are probably associated with Feature 245). Almost 
all (39 of 42) of the samples definitely provenienced to Feature 245 appear to have cooled in or near their find positions. Many of these exhibited single components of magnetization, indicating they probably cooled from temperatures greater than $580^{\circ} \mathrm{C}$ with little or no movement. The Feature 231/245 samples exhibited similar results with 39 of 50 cooling in or near their find positions and many exhibiting single components of magnetization. In general, the archeomagnetic results indicate most of the analyzed rocks were heated to very high temperatures and then cooled in place with little or no postcooling disturbance.

Seven burned rocks were collected as organic residue samples, but only one (OR558) was analyzed. This was one of the large slabs found near the base of the pit and archeomagnetic results for similar rocks found on either side of it indicate they cooled in place. No residues were identified on this rock. Another burned rock was collected as a thermoluminescence sample (TL38), but this sample was not analyzed.

Eleven blocks of sediment were collected in situ within Feature 245 as micromorphology samples. Eight were analyzed (WL92-F8, WL92-F14, WL92-F17, WL92-F18, WL92F19, WL92-F20, WL92-F21, and WL92-F25), and most of these were collected from burned areas found beneath the lowest layer of rocks. Rubified sediment and intensely burned (calcined) limestone fragments were observed in all samples, and most exhibited charcoal and ash as well. Evidence of in situ burning was best preserved in Samples WL92-F17 and WL92-F25.

The point-plotted and 1/8-inch-screen artifact recovery from Feature 245 includes a projectile point fragment (18301), a Stage 2 biface (OR566), 2 unifacial perforators (1830-2, 2008-1), 5 flake tools (1488-1, 1590-1, 1599-1, 1978-1, 2091-1), ca. 1,560 pieces of debitage (including 6 specimens collected as OR samples), and a small hematite pebble.

The 1/8-inch-screen faunal recovery includes 5 mussel shell fragments (see Chapter 37) and 233 bones/bone fragments (see Chapter 33). Much of the bone was classified as Vertebrata indeterminate, but the sample also included specimens identified as deer or antelope, rabbit (both Lepus californicus and Sylvilagus sp.), tree squirrel, gopher (Geomys sp.), small mammal, medium mammal, medium/large mammal, turtle, and fish. Approximately $58 \%$ of this bone was burned.

Twelve bulk matrix samples were also collected from Feature 245 pit fill, and much of this sediment was used for magnetic susceptibility, gastropod, flotation, phytolith, and faunal fine-screen samples (remainder was curated). No identifiable plant remains were found in the 3 flotation samples (totaling 6.5 liters) and the magnetic susceptibility, gastropod, and phytolith samples yielded results that were comparable to nonfeature samples from similar stratigraphic contexts (no significant differences identified). A total of 76 bones/bone fragments was recovered from the ca. 2.7-liter fine-screen sample (see Appendix 8). Most was Vertebrata indeterminate, but the sample also included a few specimens identified as turtle, fish, rodent, and mammal. Approximately $43 \%$ of this bone was burned.

Comments: Feature 245 was located immediately north of Feature 181, a slightly larger burned rock basin found in approximately the same stratigraphic position. The detection level for Feature 245 was about $20 \mathrm{~cm}$ below the detection level for Feature 181, and the latter pit may postdate Feature 245 (as the radiocarbon dates suggest).

\section{Feature 246}

Feature Type: burned rock cluster

Provenience: Square 34, Level 31-32; Square 49, Level 32; detection elevation $95.36 \mathrm{~m}$; base elevation $95.20 \mathrm{~m}$

Stratigraphic Context: Unit II

Archeological Chronology: Late Paleoindian Special Studies:

Archeomagnetic: 10 of 16 samples analyzed (see Chapter 27 and Appendix 6)

Magnetic Susceptibility: 10 samples analyzed (see Chapter 28)

Micromorphology: 1 sample analyzed (see Chapter 29 and Appendix 7)

Macrobotanical: 5 macroplant samples analyzed; 6 flotation samples processed (see Chapter 40)

Figure: 26-118 (see also Figure 27-35 in Chapter 27)

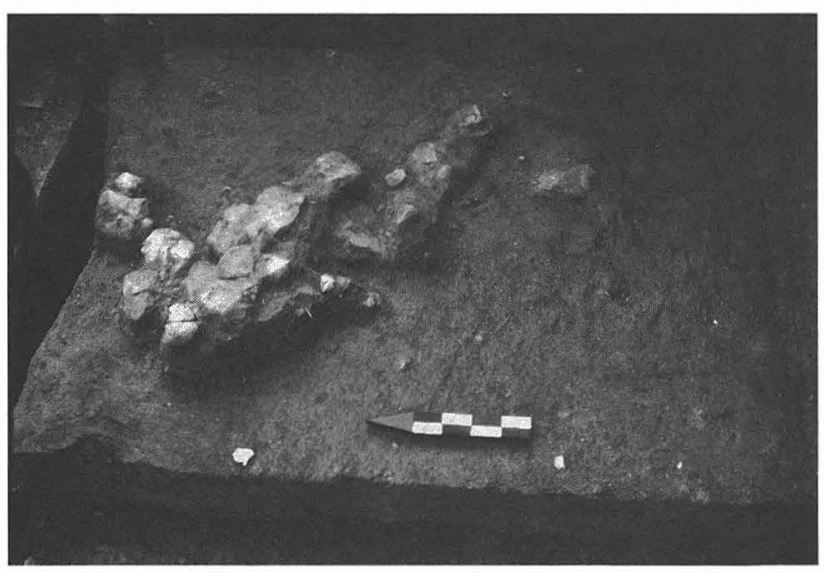

Figure 26-118. Feature 246 in Level 32 of Squares 34 and 49, looking east.

Description: Feature 246 was a roughly circular burned rock cluster measuring about $55-\mathrm{x}-60-\mathrm{x}-16 \mathrm{~cm}$. The central core was composed of 10 closely spaced, large rocks (tabular fragments in the 10-20-cm size range) with ca. 10 smaller fragments (3-9-cm size) clustered on the south side of the cluster. A dispersed scatter of ca. 10 additional rocks extended south/southeast of the cluster for a distance of about $50 \mathrm{~cm}$ (Feature 247 was probably associated with this scatter; see description below). Most of the rocks exhibited angular fractures, and some were discolored from burning. 
Small quantities of charcoal and burned sediment were observed both within and outside the feature area, and 5 small charcoal samples were collected within the cluster (all were identified as indeterminate wood). Thirteen pieces of debitage were the only artifacts provenienced to Feature 246.

Sixteen archeomagnetic samples were collected from Feature 246, and 10 of these were analyzed. The results were quite complex but generally suggest that 4 of the larger rocks in the central core were displaced after final cooling, while 6 of the more peripheral rocks remained in place (or very nearly in place). The latter group includes 3 rocks that appear to have experienced little or no movement while cooling and 3 others that moved short distances and then cooled in place from lower temperatures. Unusual results on the 4 displaced rocks from the central core suggest these may have experienced a great deal of movement while cooling through lower temperature ranges. This pattern might reflect stone boiling, parching, or some other process in which heated stones are kept in movement.

Six bulk matrix samples were also collected from the Feature 246 area. Much of this sediment was used for magnetic susceptibility, micromorphology, flotation, and faunal fine-screen samples with the remaining sediment curated. The susceptibility results were comparable to nonfeature samples from similar stratigraphic contexts (no significant deviation detected). A thin-section slide was not made from the micromorphology sample, but small areas of reddened soil and some possibly calcined limestone fragments were observed in the polished block. A relatively large volume of sediment was floated (ca. 28.5 liters), but no identifiable plant remains were recovered. Fine-screening of another 19.5 liters of sediment retrieved an eggshell fragment (see Chapter 36) and some bone (unanalyzed).

\section{Feature 247}

Feature Type: burned sediment with a few burned rocks Provenience: Square 34, Level 31; Square 35, Levels 30-31; detection elevation $95.35 \mathrm{~m}$; base elevation $95.30 \mathrm{~m}$

Stratigraphic Context: Unit II

Archeological Chronology: Late Paleoindian Special Studies:

Radiocarbon: 1 wood charcoal sample was AMS-dated to $8090 \pm 70$ в.P. (CAMS-07207; see Chapter 25)

Macrobotanical: 3 macroplant samples analyzed (see Chapter 40)

Figure: see Figure 27-35 in Chapter 27

Description: Feature 247 was a poorly defined feature composed of 4 small burned rocks (3-6-cm size) loosely grouped within a $20-\mathrm{x}-25-\mathrm{cm}$ area. Two of the rocks were tightly clustered, but the others were spaced about $15 \mathrm{~cm}$ apart. Scattered charcoal and small patches of burned sediment were observed both within and outside the feature area. Three of the four charcoal samples provenienced to Feature 247 were analyzed as macroplant samples (C14-168, C14-172, C14-14; all were indeterminate wood), and the fourth was dated. The date obtained on this sample ( $8090 \pm 70$ в.P.; CAMS-07207) appears to be a little young for a feature in the lower portion of Unit II. If the date is accurate, than the dated charcoal may have been displaced downward from overlying Unit IIIa.

An archeomagnetic sample was collected from the largest rock (approximate center of feature), but it was not analyzed. Four burned bone fragments (Vertebrata long bone and indeterminate) and 57 pieces of debitage were also recovered from the Feature 247 area.

Comments: Feature 247 was probably a dispersed scatter of burned rocks that extended south/southeast of Feature 246, a larger (and better defined) cluster of burned rocks located about $20 \mathrm{~cm}$ to the northwest in Square 34 (see Feature 246 description above).

\section{Feature 248}

Feature Type: burned rock cluster

Provenience: Squares 28, 44, 52, and 53; Levels 28-29; detection elevation $95.48 \mathrm{~m}$; base elevation $95.40 \mathrm{~m}$

Stratigraphic Context: Unit II

Archeological Chronology: Late Paleoindian

Special Studies:

Archeomagnetic: 11 of 13 samples analyzed (see Chapter 27 and Appendix 6)

Magnetic Susceptibility: 6 samples analyzed (see Chapter 28) Micromorphology: 1 sample analyzed (see Chapter 29 and Appendix 7)

Gastropods: 1 sample analyzed (see section by Theler in Chapter 37)

Macrobotanical: 4 macroplant samples analyzed and 2 flotation samples processed (see Chapter 40)

Figure: 26-117 and 26-119 (see also Figure 27-37 in Chapter

\section{7)}

Description: Feature 248 was a roughly oval-shaped cluster of about 37 burned rocks (ca. $3-10-\mathrm{cm}$ size). It was found

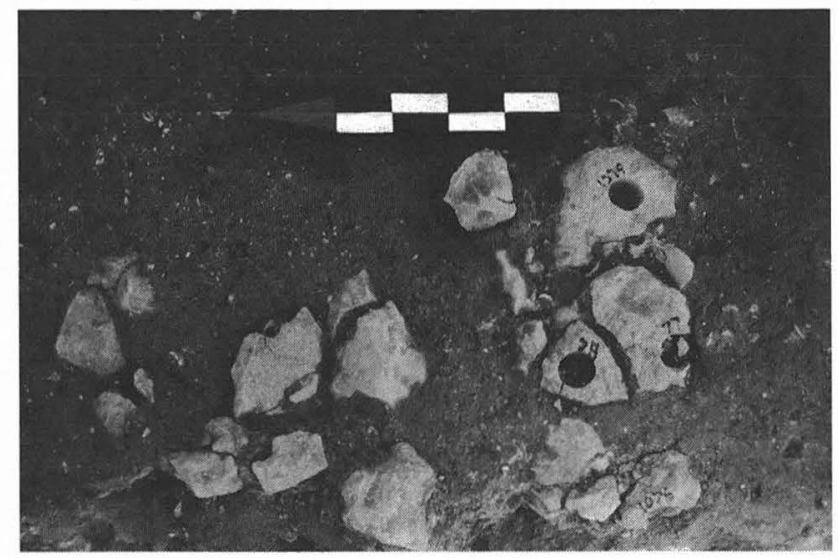

FIGURE 26-119. Feature 248 as exposed at the base of Level 28 in Squares $28,44,52$, and 53 , looking east. 
at the eastern edge of the TARL Gradall cut (re-excavation of Block 6), and it looked as if the western margin of the feature may have been clipped in this effort. The surviving portion measured about $40 \mathrm{~cm}$ east-west by $55 \mathrm{~cm}$ north-south with a vertical extent of approximately $8 \mathrm{~cm}$. Feature 248 lacked an obvious basin configuration, but there was some evidence to suggest that at least some of the rocks rested in a slight depression (see discussion of archeomagnetic samples below). The cluster consisted primarily of a single layer of rocks, although 5 or 6 were found directly beneath others. There was a small (ca. $10-x-20 \mathrm{~cm}$ ) rock-free space in the approximate center of the feature, but elsewhere the rocks were very closely spaced (many were touching). Most were fractured, but it looked like the feature was originally constructed from subangular to rounded cobbles in the $6-15-\mathrm{cm}$ size range. Many of the rocks were reddened from burning. Sediment within the feature area was slightly darker (and a little grayer) than the surrounding matrix. Small flecks of burned, oxidized sediment and some burned gravels were also observed.

Scattered charcoal flecks were found throughout the feature, and four charcoal samples were collected. All were analyzed as macroplant samples with one identified as live oak type wood (C14-237), another as unidentified hardwood (C14-238), and two as indeterminate wood (C14-177, C14236). Feature 248 recovery also included 80 pieces of debitage, a small quartz pebble, a mussel shell hinge fragment (Lampsilis sp., see Chapter 37), and 15 bone fragments (see Chapter 33). Most of the bones were classified as Vertebrata indeterminate fragments, but the sample also included a micromammal phalanx, a small mammal metapodial, a medium/large mammal long bone, and a small/medium Vetebrata long bone. Ten of these specimens were burned.

Thirteen archeomagnetic samples were collected from Feature 248, and 11 of these were analyzed. The results were complex but generally indicate this is a relatively undisturbed feature. One rock cooled in situ from a relatively high temperature (in excess of $500^{\circ} \mathrm{C}$ ) with little or no movement. Most of the others have complex cooling histories but generally appear to have moved relatively short distances and then cooled in place from low to moderate temperatures. Only, 2 or perhaps 3, of the sampled rocks were displaced after cooling. Reconstructed vector rotations for some of these rocks suggest they may have rolled into a shallow depression (located in the central portion of the feature) while they were cooling.

Three bulk matrix samples were also collected from Feature 248. Much of this sediment was used for magnetic susceptibility, micromorphology, gastropod, and flotation samples (remainder was curated). The magnetic susceptibility results were comparable to nonfeature samples from similar stratigraphic contexts (no significant deviation detected). The micromorphology sample exhibited significant evidence of burning: oxidized sediment, charcoal, burned snail shells, and possible traces of ash rhombs. No identifiable plant remains were found in the flotation samples, but the gastropod sample was more productive. The latter recovery included 183 terrestrial snails (representing at least 7 taxa) and 8 aquatic snails ( 3 taxa). Most of the terrestrial snails were taxa commonly found throughout the site deposits, but the sample also included a few specimens of less common taxa as well. The latter group include Punctum vitreum, Glyphyalinia roemeri, G. umbilicata, and Zonitoides arboreus. These species are generally indicative of relatively mesic, woodland habitats (see Chapter 37 ). The aquatic snails include 2 Phreatodrobia nugax nugax, 5 Fossaria dalli, and 1 Gyraulus sp. The latter 2 taxa are typically found in moist vegetation growing in shallow pools and P. $n$. nugax is typically found in the deep artesian waters of the Edwards Aquifer (though it can also be expelled through spring vents). Although the aquatic snails may have been deposited in the feature during a flood, they may also reflect human collection of water and/or aquatic biota.

\section{Feature 249}

Feature Type: probable burrow

Provenience: Square 50, Levels 27-32; Square 51, Levels 2631; detection elevation $95.55 \mathrm{~m}$; base elevation $95.30 \mathrm{~m}$

Stratigraphic Context: originated in Unit IIIa and intruded Unit II

Archeological Chronology: Early Archaic

Special Studies:

Archeomagnetic: 2 of 2 samples analyzed (see Chapter 27 and Appendix 6)

Magnetic Susceptibility: 10 samples analyzed (see Chapter 28) Micromorphology: 2 samples analyzed (see Chapter 29 and Appendix 7)

Macrobotanical: 2 flotation samples processed (see Chapter 40)

Figure: $26-120$

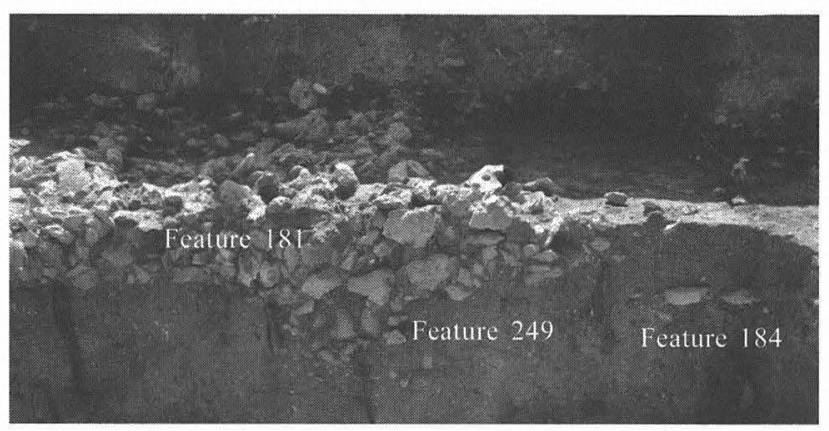

FIGURE 26-120. Features 181, 184, and 249 exposed in the east wall of TxDOT Square E28/S78 after backfill was removed during the TARL investigations, looking east.

Description: Feature 249 was first identified in the east wall of TxDOT Square E28/S78 after backfill was removed during the TARL investigations. At that point, it appeared to be a small U-shaped depression (40-cm diameter, 23-cm depth) 
that extended down from the base of Feature 181 (large burned rock basin that was cross-sectioned in this wall). The depression intruded Unit II, but it was filled with much darker sediment (probably from Unit IIIa) and numerous burned rocks. The fill of Feature 249 closely resembled the fill of overlying Feature 181, and at that time, the investigators thought it might represent the remnant of a pit that predated Feature 181.

When this area was further exposed during the excavation of TARL Squares 50 and 51, it became apparent that Feature 249 probably represented a burrow that tunneled through and beneath Feature 181. It exhibited a very irregular shape in plan view and a tapering profile. The investigated portion had a horizontal extent of ca. $35-\mathrm{x}-80 \mathrm{~cm}$ and a vertical extent of at least $25 \mathrm{~cm}$. The burrow probably extended west into TxDOT Square E28/S78, and the burrow recorded as Feature 186 in this square (see Feature 186) may be part of the same burrow as Feature 249.

Feature 249 clearly intruded Feature 181, and it may have intruded Feature 184 as well. The latter feature was a burned rock cluster (or large burned rock basin) found beneath the southern half of Feature 181 in Unit II. The Feature 181 pit apparently disrupted a portion of Feature 184, and the Feature 186/249 burrow may have further disturbed this feature.

A number of special samples were collected from Feature 249 before it was recognized as a probable burrow. Two small blocks of sediment were collected in situ as micromorphology samples. Both were from the upper portion of Feature 249 , at or near its intersection with the lower margins of Feature 181. Sample WL92-F23 exhibited considerable evidence of in situ burning (rubified sediment, charcoal, ash, burned limestone) that probably reflects burning observed at the base of the Feature 181 pit. The other sample (WL92F30) was collected about $5 \mathrm{~cm}$ lower, and though some burned limestone fragments were noted, no burned sediment, ash, or charcoal was observed.

Two archeomagnetic samples were collected from burned rocks found in the portion of Feature 249 that was exposed in the east wall of Square E28/S78. The results indicate both rocks cooled in or near their find positions with little or no postcooling displacement. These rocks were found at elevations of ca. $95.45 \mathrm{~m}$, and they were probably associated with either the lower portion of Feature 181 or a remnant of Feature 184. They may have been large enough (ca. 10-15-cm size) to escape displacement by the burrowing animal(s).

Feature 249 fill contained an assortment of cultural material that was probably redeposited from both Unit IIIIa and Unit II contexts. The 1/8-inch screen and point-plotted artifact recovery includes a quartzite mano fragment (2449), an apparently unmodified quartzite cobble fragment (OR717), and 117 pieces of debitage. The faunal recovery includes 2 mussel shell fragments (see Chapter 33) and 35 bones (see Chapter 33). Most of the bone was Vertebrata indetermi- nate, but the sample also includes a carnivore phalanx, a rabbit tooth, an artiodactyl tooth fragment, a turtle humerus, and a fish vertebra. Approximately $80 \%$ of these specimens were burned (including the carnivore, rabbit, and turtle elements).

Five bulk matrix samples were also collected from Feature 249. Some of this sediment was used for magnetic susceptibility and flotation samples, and the remainder was curated. No significant results were obtained from the magnetic susceptibility samples, and no identifiable plant remains were found in the flotation samples.

\section{Feature 250}

Feature Type: burned rock cluster (possibly in a small ba$\sin$ ?)

Provenience: Squares 37 and 50, Levels 29-31; Square 38, Level 30; detection elevation $95.43 \mathrm{~m}$; base elevation $95.29 \mathrm{~m}$ Stratigraphic Context: Unit II

Archeological Chronology: Late Paleoindian

Special Studies:

Archeomagnetic: 6 of 10 samples analyzed (see Chapter 27 and Appendix 6)

Figure: see Figure 27-39 in Chapter 27

Description: Feature 250 was a poorly documented cluster of about 20 burned rocks. All of the rocks in this feature were not exposed at the same time (they were found in three levels of three adjacent squares), and the cluster was not recognized as such in the field. The cluster appears to have measured about $50-\mathrm{x}-55 \mathrm{~cm}$ with a vertical extent of approximately $14 \mathrm{~cm}$. Although the feature did not exhibit an obvious basin configuration, several rocks in the central portion of the cluster were found several centimeters below others suggesting they were resting in the lower portion of a basin. Most of the rocks were very closely spaced (touching or less than $5 \mathrm{~cm}$ apart), but some were spaced farther apart. About 15 to 20 additional rocks were scattered outside the cluster. Rocks within the cluster measured 5 to $15 \mathrm{~cm}$ in length, and most exhibited angular fractures (a few were fractured in situ). A few rocks also exhibited an oxidized reddish color, presumably from burning. No burned sediment or charcoal was reported, and no artifacts or bone were provenienced to this feature (some feature-associated materials may have been combined with general level recovery).

Ten archeomagnetic samples were collected from Feature 250 rocks, and 6 of these samples were analyzed. The results indicate they were heated to high temperatures (at least $500^{\circ} \mathrm{C}$ ) and then cooled in place with little or no postcooling displacement.

\section{Feature 251}

Feature Type: burned sediment (burned plant?)

Provenience: Square 58, Levels 40-41; detection elevation $94.40 \mathrm{~m}$; base elevation $94.39 \mathrm{~m}$ 
Stratigraphic Context: Unit Isi-c

Archeological Chronology: Late Paleoindian

Description: Feature 251 consisted of a small, oval-shaped patch of burned (oxidized) sediment and gravel measuring ca. $9-x-13 \mathrm{~cm}$ in diameter and approximately $1 \mathrm{~cm}$ in thickness. The burned sediment was notably reddish in color, and though no charcoal or other burned materials were found in direct association with the feature, burned bone and charcoal were found in general level recovery. Although it was not recorded as part of Feature 251, another small patch of burned, oxidized sediment (ca. 4-cm diameter) was found about $60 \mathrm{~cm}$ east of Feature 251 in the same square/level.

Comments: Although it is possible that Feature 251 represents a cultural feature (e.g., an unprepared hearth) it seems more likely that it represents a natural burning event. It may be related to Feature 165, a burned live oak tree located $1 \mathrm{~m}$ west/northwest of Feature 251 in lower Unit II and upper Unit Isi-c (see Feature 165 description). Since Feature 251 was located in the upper portion of Unit Isi-c (ca. $8 \mathrm{~cm}$ below the Unit Isi-c/II transition) it could represent part of the burned root system of that tree.

\section{Feature 252}

Feature Type: pit or burrow?

Provenience: Square 46, Levels 41-43; Square 55, Levels 4243; detection elevation ca. $94.33 \mathrm{~m}$; base elevation $94.14 \mathrm{~m}$

Stratigraphic Context: Unit Isi/Isi-c transition (probably originated from surface in lower Isi-c and intruded Isi)

Archeological Chronology: Late Paleoindian

Special Studies:

Magnetic Susceptibility: 8 samples analyzed (see Chapter 28)

Micromorphology: 1 sample analyzed (see Chapter 28 and Appendix 7)

Macrobotanical: 3 flotation samples processed (see Chapter 40)

Phytolith: 1 sample analyzed (see Chapter 41)

Figure: 26-121 and 26-122

Description: Feature 252 was probably either a cultural pit or a large burrow. It was first detected slightly below the base of the Leanne soil (Unit Isi-c), but it probably originated from a slightly higher surface (in lower Unit Isi-c). Since the feature fill strongly resembled the Leanne soil in both color and texture, the feature outline was difficult to discern in the Unit Isi/Isi-c transition zone. At detection level it was a roughly oval-shaped area of dark brown sediment measuring ca. $45-x-50 \mathrm{~cm}$. The feature fill contrasted strongly with the surrounding pale yellowish brown matrix although the edges were obscured somewhat by bioturbation. Extensive bioturbation also made it difficult to delineate boundaries when Feature 252 was cross-sectioned, but it appears to have been somewhat U-shaped with a rather irregular base. It had a documented depth of at least $19 \mathrm{~cm}$, but it may have been deeper (at least $40 \mathrm{~cm}$ ?) if it actually originated from a surface above its detection level.

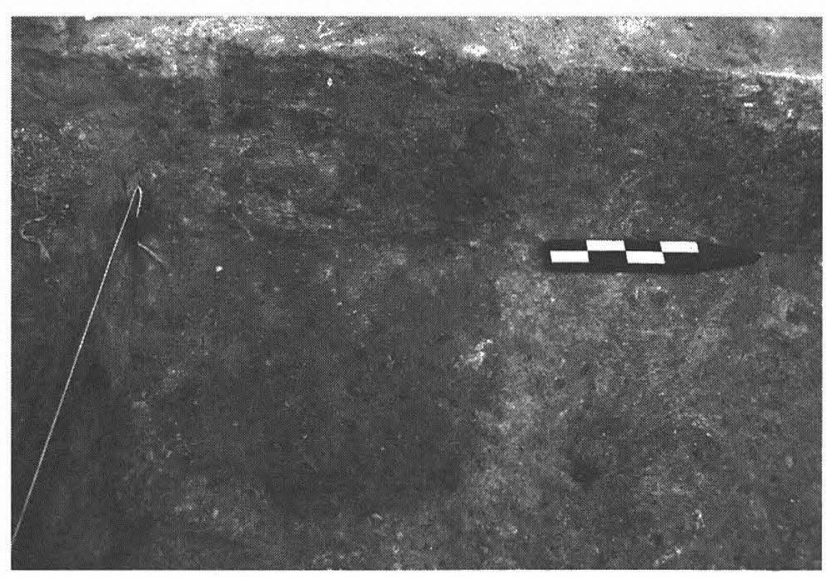

Figure 26-121. Feature 252 in the floor and west wall of Square 55 , looking west. The floor of Square 55 is at the base of Level 42, and the floor of adjacent Square 46 is at the base of Level 39. The outline of Feature 252 was not visible in the floor of Square 46 until the base of Level 41.

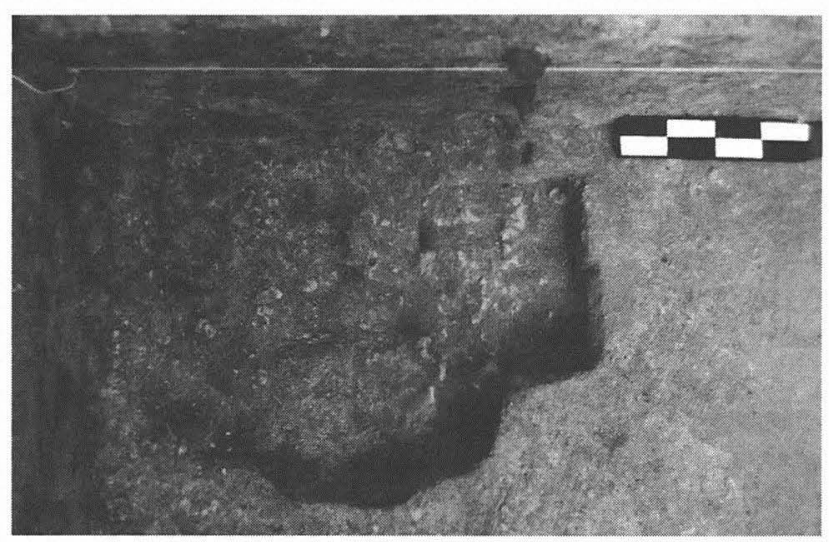

FigURE 26-122. Feature 252 in the floor of Square 55 after the fill was removed from the lower portion of the feature. The square floor is at the base of Level 42, but fill removal was from Level 43. The rectangular area at the right edge of the feature represents the location where micromorphology sample WL92-F22 was collected.

No artifacts were found during the excavation of Feature 252 (cross-sectioning and fill removal), but three pieces of debitage were retrieved from bags of fill processed in the lab. With the exception of a small block of sediment collected as a micromorphology sample (WL92-F22), all of the excavated feature fill was collected as bulk matrix samples (nine bags). The micromorphology thin-section exhibited no evidence of burning, but the sample bore a strong resemblance to thin-sections made from Unit Isi-c sediments (lending support to the field observation that Feature 252 was probably filled with Leanne soil).

Most of the bulk matrix was used for magnetic susceptibility, flotation, phytolith and fine-screen faunal samples (with a small portion curated). The magnetic susceptibility samples were comparable to nonfeature samples from similar stratigraphic contexts (no significant deviation detected). The flotation and phytolith samples were not productive, 
but a small amount of bone ( 33 specimens) was retrieved from the fine-screen sample. Most of the bone was identified as Vertebrata indeterminate fragments, but the sample also included a few specimens classified as bird, turtle, mammal, and rodent (see Appendix 8).

Comments: Feature 252 was interpreted as a probable burrow during the field investigation, primarily because of the irregularities in its contours and the numerous krotovinae observed in and around the feature. Although this may be an accurate interpretation, it also seems plausible that Feature 252 represents a cultural pit that was disturbed by intrusive burrowing. Apart from the irregularities in the base (which could reflect bioturbation), Feature 252 bears a strong resemblance in shape and size to Features 168 and 169, the two cultural pits found immediately south of Burial 2 (see Feature 168 and 169 descriptions). The stratigraphic position of Feature 252 also suggests it originated from approximately the same occupational surface as Features 168, 169, and Burial 2. Feature 252 was apparently filled with Leanne soil matrix after abandonment, but no other clues to its origin/function (cultural or natural) were identified in the fill. Given the equivocal nature of the evidence, a definitive interpretation cannot be offered.

\section{Feature 253}

Feature Type: burned live oak tree

Provenience: Square 57, Levels 37-39; detection elevation $94.72 \mathrm{~m}$; base elevation $94.50 \mathrm{~m}$

Stratigraphic Context: Unit Isi-c

Archeological Chronology: Late Paleoindian

Special Studies:

Radiocarbon: AMS dates obtained on 6 wood charcoal samples are $9480 \pm 100$ в.P. (CAMS-06374); $9500 \pm 80$ в.P. (CAMS-06349); $9540 \pm 70$ в.P. (CAMS-06348); $9540 \pm 80$ в.P. (CAMS-06373); $9590 \pm 80$ B.P. (CAMS-06382); $9610 \pm 70$ B.P. (CAMS-06350). One gastropod was dated to $10,520 \pm 80$ в.P. (CAMS-06377; see Chapter 25)

Macrobotanical: 3 macroplant samples analyzed (see Chapter 40)

Figure: 26-123

Description: Feature 253 was a burned live oak tree that apparently grew on a surface in the upper portion of Unit Isic. The charred stump was partially exposed along the south wall of Square 57 where it appeared as a very dense concentration of wood charcoal surrounded by burned, oxidized sediment. The charcoal concentration was roughly semicircular in plan view with a diameter of ca. $31 \mathrm{~cm}$. The densest concentration of charcoal exhibited a cone-shaped, tapered profile with a vertical extent of ca. $22 \mathrm{~cm}$. Stringers of burned soil and charcoal extended outward and downward from this core area.

Nine charcoal samples (C14-286 through C14-291, C14294, C14-296, and C14-309) and a snail shell (C14-295) were collected from the central core of Feature 253, and all but

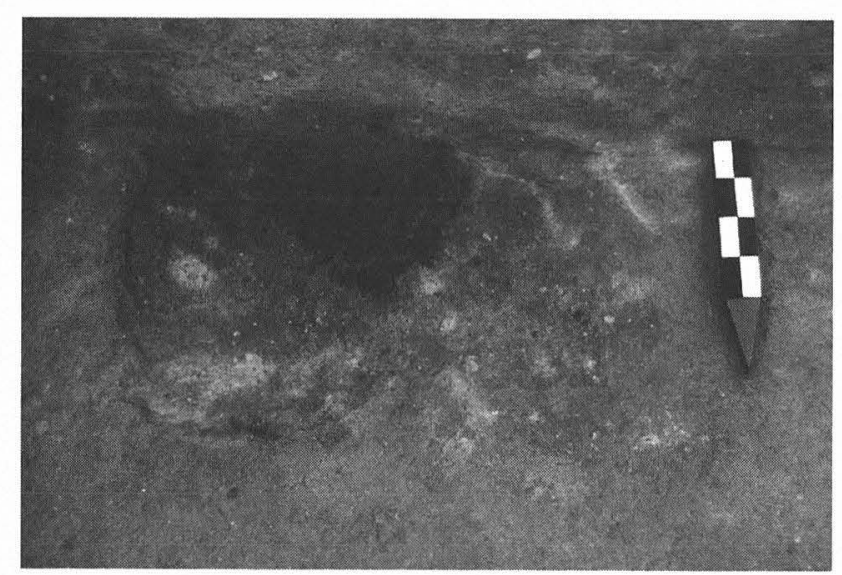

FIGURE 26-123. Feature 253 in Square 57, Levels 37/38, looking south.

three of these samples were AMS-dated (see list above). The six charcoal dates (which were very similar) were judged to be more accurate than the gastropod date (see Chapter 25). After the radiocarbon samples were collected, the portion of the stump remaining in the floor was lifted as a block sample (wrapped in gauze and plaster bandage). This block and one of the undated charcoal samples were identified as live oak wood (another undated sample was classified as indeterminate wood).

\section{Feature 255}

Feature Type: burned rock cluster

Provenience: Squares 35 and 59, Level 42; detection elevation $94.26 \mathrm{~m}$; base elevation $94.19 \mathrm{~m}$

Stratigraphic Context: Unit Isi-c

Archeological Chronology: Late Paleoindian

Special Studies:

Radiocarbon: 1 wood charcoal sample was AMS-dated to $9990 \pm 70$ B.P. (CAMS-10195)

Archeomagnetic: 5 of 7 samples analyzed (see Chapter 27 and Appendix 6)

Magnetic Susceptibility: 2 samples analyzed (see Chapter 28)

Micromorphology: 1 sample analyzed (see Chapter 29 and Appendix 7)

Gastropod: 1 sample analyzed (see Chapter 37)

Macrobotanical: 3 macroplant samples analyzed; 2 flotation samples processed (see Chapter 40)

Phytolith: 1 sample analyzed (see Chapter 41)

Figure: 26-124 (see also Figure 27-40 in Chapter 27)

Description: Feature 255 consisted of a relatively tight cluster of burned rocks within an area measuring approximately $30-\mathrm{x}-50 \mathrm{~cm}$. The single-layer cluster included about 15 limestone fragments (2-10-cm size) and 2 unmodified chert fragments (3-6-cm size; possibly burned). Most of the limestone fragments exhibited angular fracturing, and many appeared heavily burned (dark gray color). Two additional burned 


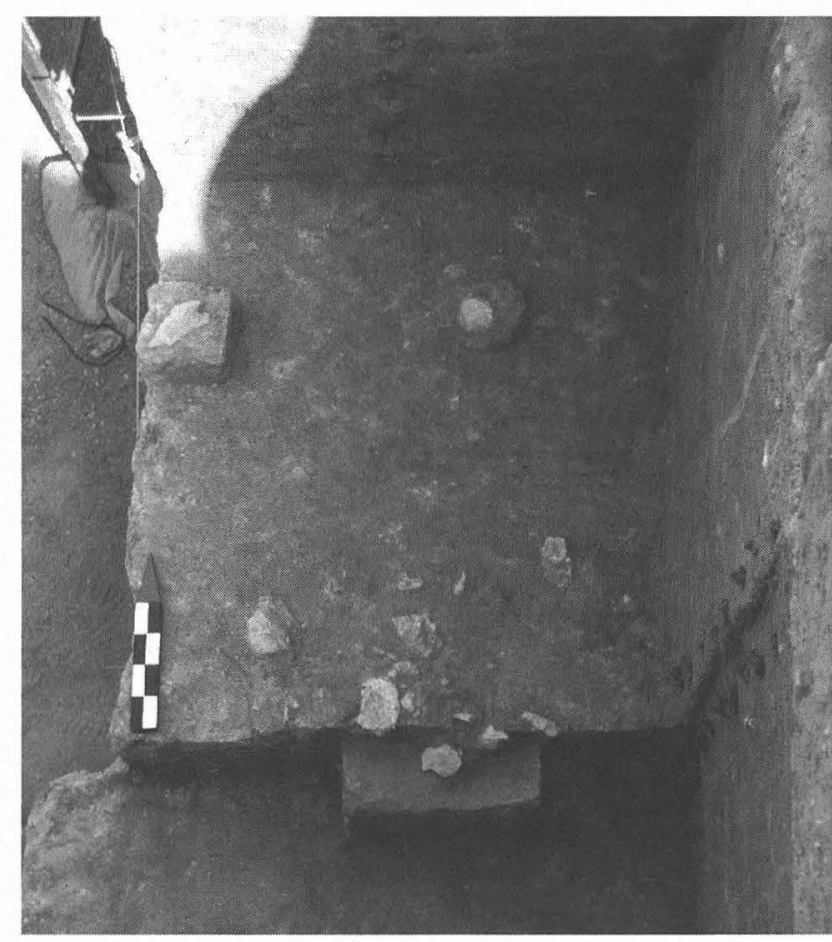

Figure 26-124. Feature 255 in Level 42 of Squares 35 and 59, looking north.

rocks (7-10-cm size) found about $50 \mathrm{~cm}$ north of the cluster may have been displaced from the main concentration. Small charcoal fragments were found scattered between and underneath the burned rocks, and burned soil was also observed beneath several rocks. Artifact recovery was limited to a single flake that was point-plotted in the center of the cluster.

Four charcoal samples were collected within this feature and three $(\mathrm{C} 14-339,340,341)$ were identified as indeterminate wood. The fourth sample (C14-321) was AMS-dated without macrobotanical analysis (see date above).

Seven archeomagnetic samples were collected from Feature 255 rocks and five of these samples were analyzed (see Figure 27-40 in Chapter 27). Three of the rocks in the center of the cluster appear to have cooled in place from high to moderate temperatures with little or no movement after final cooling. Two of the more peripheral rocks were apparently moved at about $200^{\circ} \mathrm{C}$ and then cooled near their find positions.

Some of the sediment from the bulk matrix samples was curated, and the remainder was used for magnetic susceptibility, micromorphology, gastropod, flotation, phytolith, and fine-screen faunal samples. The magnetic susceptibility results were comparable to nonfeature samples from the same stratigraphic context (lower portion of Unit Isi-c). The micromorphology sample (WL95-15) exhibited limited evidence of burning in the form of some possible ash rhombs and an aggregate with a reddish hue that may have been heated.

No identifiable remains were found in either the flotation or phytolith samples, but the gastropod and fine-screen samples were more productive. The gastropod sample included 34 terrestrial snails (representing at least 3 taxa) and 2 aquatic juvenile snails (taxa not specified). The terrestrial taxa included 2 Carychium mexicanum, 3 Helicodiscus singleyanus, 20 Hawaii minuscula, and 9 juveniles (taxa not specified). The C. mexicanum specimens and the aquatic snails are interesting finds given their low frequencies in the site deposits. C. mexicanum, which is indicative of very moist habitats (e.g., mesic flood plains and marshes), has been found in only 2 other gastropod samples from this site- a sample collected from Feature 236 at the base of Unit II and a column sample collected from the Unit Isi-c/Id transition in Square E20/S78 (see Chapter 37).

The fine-screen recovery included an eggshell fragment (see Chapter 36) and 47 bone fragments (see Appendix 8). Over half the bone was classified as Vertebrata indeterminate, but the sample also included a few specimens classified as rabbit, rodent, turtle, and mammal. Approximately $45 \%$ of the bone appeared burned.

Comments: The archeomagnetic data and the burned sediment found beneath several of the burned rocks suggest that Feature 255 probably represents a relatively intact rock hearth that has remained in situ since the final heating event. Features 187 and 260 are burned rock features occurring at approximately the same elevation as Feature 255. It seems very likely that all three of these features were constructed on the same occupational surface.

\section{Feature 256}

Feature Type: burned sediment with a few burned rocks Provenience: Square 28, Levels 41-42; detection elevation $94.32 \mathrm{~m}$; base elevation $94.20 \mathrm{~m}$

Stratigraphic Context: Unit Isi-c

Archeological Chronology: Late Paleoindian Special Studies:

Magnetic Susceptibility: 2 samples analyzed (see Chapter 28)

Micromorphology: 1 sample analyzed (see Chapter 29 and Appendix 7)

Macrobotanical: 1 flotation sample processed (see Chapter 40)

\section{Figure: $26-125$}

Description: Feature 256 consisted of a small, oval-shaped area of burned, oxidized sediment surrounded by six small burned limestone fragments (3-6-cm size). The orange to dark red burned area measured ca. $7-\mathrm{x}-8 \mathrm{~cm}$, and the surrounding rocks were loosely clustered within a ca. $50-\mathrm{cm}$ diameter area. The burned sediment was detected at 94.32 $\mathrm{m}$, and the burned rocks were found at elevations ranging from 94.32 to $94.22 \mathrm{~m}$. There was no visible evidence to indicate the lower rocks were in a depression, but they may have been displaced downward through bioturbation. No charcoal or ash was observed in the feature area, but a carbonized bone fragment was collected as a radiocarbon sample 


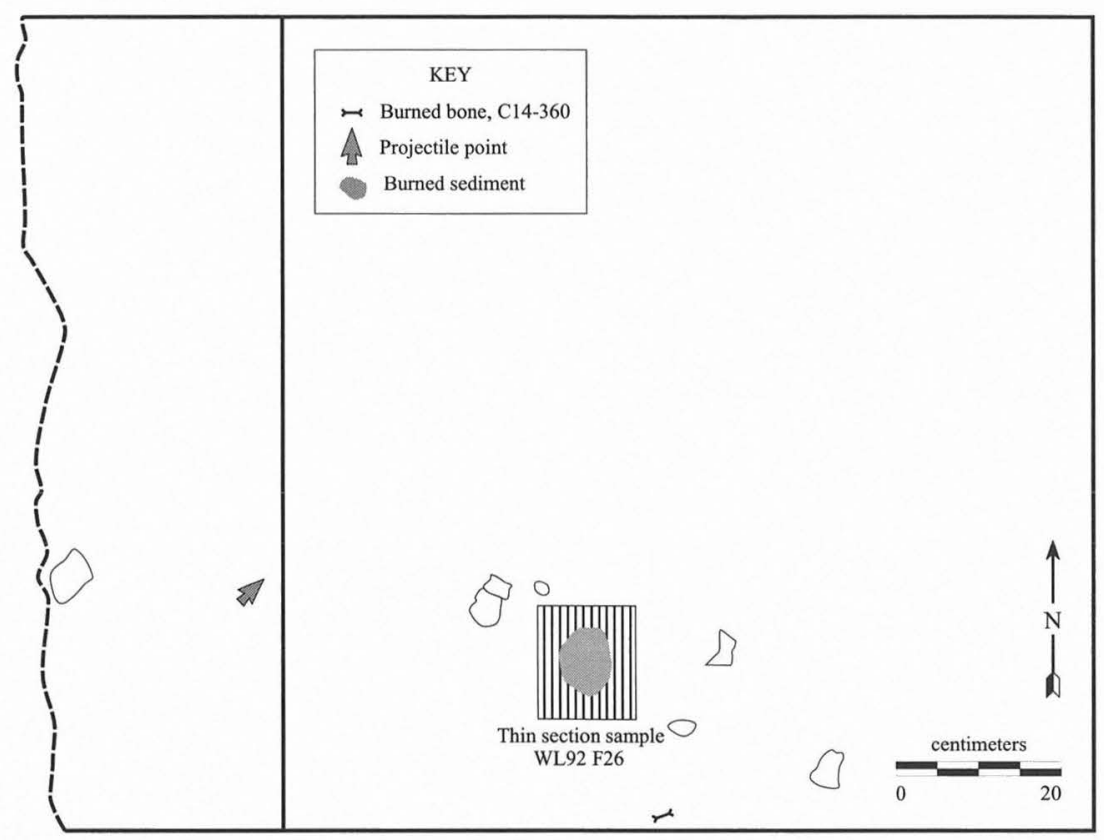

Figure 26-125. Feature 256 in Square 28, Levels 41-42.

(C14-360). Feature recovery also included an archeomagnetic sample collected from one of the rocks (not analyzed), an intact block of burned sediment collected as a micromorphology sample (WL92-F26), and a bulk matrix sample. Although the micromorphology thin-section slide was not informative, a thin layer of burned sediment was visible in the polished block. Some of the bulk sediment was used for magnetic susceptibility and flotation samples and the remainder was curated. The flotation sample was not productive (no identifiable plant remains), and the magnetic susceptibility results were comparable to nonfeature samples from similar stratigraphic contexts (no significant deviation).

Although no artifacts were provenienced to Feature 256 , a stemmed biface (OR680) with extensive heat damage was found about $30 \mathrm{~cm}$ west of the feature at approximately the same elevation. The results of a use-wear analysis (by Kay; see Chapter 22) suggest this specimen was probably used as a knife (possibly for butchering).

\section{Feature 257}

Feature Type: burned rock cluster

Provenience: Square 53, Levels 38-39; detection elevation $94.69 \mathrm{~m}$; base elevation $94.50 \mathrm{~m}$

Stratigraphic Context: Unit Isi-c

Archeological Chronology: Late Paleoindian Special Studies:

Archeomagnetic Analysis: 2 of 2 samples analyzed (see Chapter 27 and Appendix 6)

Magnetic Susceptibility: 4 samples analyzed (see Chapter 28)

Macrobotanical: 6 macroplant samples analyzed and 1 flotation sample processed (see Chapter 40)
Figure: see Figure 27-41 in Chapter 27

Description: Feature 257 consisted of two closely spaced burned rocks ( $8-12-\mathrm{cm}$ size) surrounded by a dispersed scatter of poorly preserved charcoal. The rocks may represent the northern edge of a small burned rock cluster that extended into adjacent TxDOT Square E28/S78. Level records for E28/S78 indicate three or four burned rocks were found about $10-20 \mathrm{~cm}$ south of Feature 257 at approximately the same depth (though no feature number was assigned to these rocks).

Feature 257 recovery included one piece of debitage, seven charcoal samples, two archeomagnetic samples, and two bulk matrix samples. Six of the charcoal samples were analyzed as macroplant samples, and all were classified as indeterminate wood. Both of the archeomagnetic samples were analyzed, and the results indicate one of the rocks cooled in place (with only minor movement) after being heated to at least $600^{\circ} \mathrm{C}$. The other sample had a very weak remanence intensity, and its thermal history could not be confidently reconstructed.

Most of the bulk sediment was used for magnetic susceptibility, flotation, and faunal fine-screen samples (remainder was curated). The magnetic susceptibility samples exhibited slightly higher values than nonfeature samples from similar stratigraphic contexts. This may reflect the presence of ash or sediments altered by heating. The flotation sample yielded no identifiable plant remains, but the fine-screen sample was more productive. Three eggshell fragments (see Chapter 36) and 65 bones were recovered from this sample (see Appendix 8). Most of the bone was classified as Vertebrata indeterminate, but the sample also included some specimens identified as mammal, rodent, reptile, and fish. Approximately $46 \%$ appeared burned. 


\section{Feature 259}

Feature Type: rock cluster (possibly burned)

Provenience: Square 35, Levels 46-47; detection elevation $93.89 \mathrm{~m}$; base elevation $93.69 \mathrm{~m}$

Stratigraphic Context: Feature 259 was found in upper portion of Unit Icl, but it may have been displaced (through burrowing?) from the lower portion of Unit Isi-c

Archeological Chronology: Early or Late Paleoindian?

Special Studies:

Archeomagnetic: 2 of 7 samples analyzed (see Chapter 27 and Appendix 6)

Figure: see Figure 27-42 in Chapter 27

Description: Feature 259 was a problematical feature consisting of nine apparently unburned limestone rocks loosely clustered within a $55-\mathrm{x}-80-\mathrm{cm}$ area. The rocks included five tabular cobbles (10-20-cm size) and four smaller fragments (4-6-cm size). The feature had a maximum vertical extent of ca. $20 \mathrm{~cm}$, but several of the rocks looked as if they may have been displaced downward through bioturbation (which was extensive in this area). The rocks exhibited no clear evidence of burning, and no burned sediment was observed. Two charcoal samples (C14-373 and C14-374) were collected in the feature area, but both were apparently found in small krotovinae. A thin uniface (OR693), a flake (OR684), and eight unburned bone fragments (Vertebrata indeterminate) were also collected from the feature area, but there was such extensive evidence of bioturbation that the feature association is somewhat tenuous.

Seven archeomagnetic samples were collected from four of the larger rocks, and two of these samples were analyzed. Both samples exhibited such weak remanence that vector reconstructions were not attempted. The weak remanence of these rocks resembled results obtained from unburned bedrock and gravel bar samples.

Comments: Feature 259 was located in the upper portion of Unit Icl about $20 \mathrm{~cm}$ below the base of the Leanne soil. Bioturbation (krotovinae and/or root disturbance) was quite extensive in this area, and at least some of the Feature 259 materials may have been displaced downward from the Wilson occupation zone in the Leanne soil (where the density of cultural material is much higher than in Unit Icl).

\section{Feature 260}

Feature Type: burned rock cluster (or ring?)

Provenience: Squares 52 and 39, Levels 42-43; detection elevation $94.30 \mathrm{~m}$; base elevation $94.18 \mathrm{~m}$

Stratigraphic Context: Unit Isi-c

Archeological Chronology: Late Paleoindian

Special Studies:

Archeomagnetic: 6 of 12 samples analyzed (see Chapter 27 and Appendix 6)

Magnetic Susceptibility: 4 samples analyzed (see Chapter 28)
Micromorphology: 1 sample analyzed (see Chapter 29 and Appendix 7)

Gastropod: 1 sample analyzed (see section by Neck and Shaw in Chapter 37)

Macrobotanical: 1 macroplant sample analyzed; 2 flotation samples processed (see Chapter 40)

Figure: 26-126 (see also Figure 27-43 in Chapter 27)

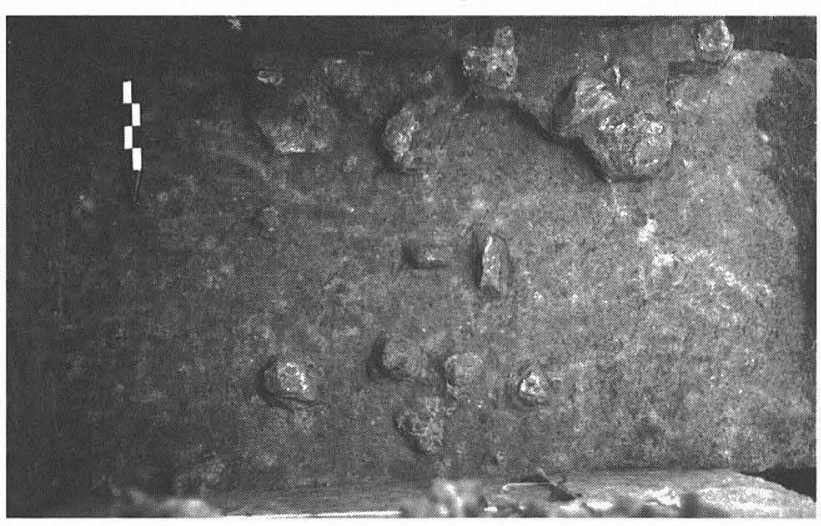

Figure 26-126. Feature 260 in Level 42 of Squares 39 and 52, looking south.

Description: Feature 260 consisted of ca. 22 rocks that appeared to be arranged in a somewhat ring-like configuration around a relatively rockfree center. The feature also looked as if it might extend into unexcavated areas to the north and south, and it may have had a very different configuration/ appearance if it had been more fully exposed. The exposed portion included 12 relatively large cobbles (10-25-cm size) and about 10 smaller rocks ( $2-8 \mathrm{~cm}$ size). Most of the rocks had rounded edges, and none exhibited obvious signs of burning (discoloration or fracturing). Some were heavily encrusted with calcium carbonate. No burned sediment was observed in the feature area, and only a small amount of poorly preserved charcoal was found. Only one charcoal sample (C14-388; indeterminate wood) was collected from the feature area, and this was found directly beneath one of the larger rocks (rock sampled with AM-1246; see Figure 2743). No artifacts were found in the feature area, but a longbone fragment from a large mammal (unburned) was pointplotted in the rockfree center (additional bone was also retrieved from a fine-screen sample; see below).

Twelve archeomagnetic samples were collected from Feature 260 rocks and 6 of these samples were analyzed. All exhibited weak magnetic remanence, but the results from 3 samples (AM-1246, AM-1248, and AM-1251) indicate they probably cooled in place after being heated to at least $250^{\circ} \mathrm{C}$. The latter samples were collected from 3 rocks in the apparent ring configuration, and as noted above, some charcoal was found beneath the AM-1246 rock. The results were more ambiguous for the other analyzed samples, and these rocks may have been unheated or minimally heated. One of these rocks (AM-1242) was in the ring configuration, 
another (AM-1244) was in the center of the ring, and the third (AM-1240) was outside the ring.

A micromorphology sample (WL92-F29) was collected in situ from the western edge of the feature (outside the ring). The sample exhibited no evidence of burning, but it was probably collected from a poor location.

Several bulk matrix samples were collected from the Feature 260 area, and most of this sediment was used for various special studies (with a small portion curated). These included magnetic susceptibility, gastropod, flotation, and fine-screen faunal samples. The magnetic susceptibility results resembled nonfeature samples from similar stratigraphic contexts (no significant deviation detected). Only a few terrestrial snails were recovered from the gastropod sample, and the flotation samples were not productive (no identifiable plant remains). The fine-screen sample was slightly more productive than the other samples, but only 14 bones were retrieved from a ca. 6.5-liter sediment sample. Most of the bones were Vertebrata indeterminate fragments, but the sample also included a few fish, rabbit, and mammal specimens (see Appendix 8). Approximately $43 \%$ of these specimens were burned.

\section{Feature 262}

Feature Type: bone scatter (with possible burned rocks) Provenience: Square 27, Levels 51-52; detection elevation $93.35 \mathrm{~m}$; base elevation $93.20 \mathrm{~m}$

Stratigraphic Context: the Unit Isi/Icl transition Archeological Chronology: Early Paleoindian Special Studies:

Magnetic Susceptibility: 4 samples analyzed (see Chapter 28)

Micromorphology: 1 sample analyzed (see Chapter 29 and Appendix 7)

Macrobotanical: 1 macroplant sample analyzed; 2 flotation samples processed (see Chapter 40)

Description: Feature 262 was a dispersed scatter of bone fragments and possibly burned rocks associated with the Early Paleoindian "bone bed" (initially recorded during the TxDOT investigations). The Feature 262 scatter was located about $1 \mathrm{~m}$ east of the main concentration of bison bone recorded in the TxDOT excavations, but the bison bone density was much lower in the Feature 262 area (as it was in all areas sampled during the TARL investigations).

Although Feature 262 was initially recorded as a possible hearth, there is little definitive evidence to support this hypothesis. The scatter (which measured ca. $80-\mathrm{x}-100 \mathrm{~cm}$ ) included nine point-plotted bone fragments and six limestone fragments (ca. 2-10-cm size). Two of the bone fragments were burned, and they were collected as potential radiocarbon samples (C14-397 and C14-399). Some of the rocks had angular fractures, but there were no obvious signs of burning (discoloration or thermal fractures). An archeomagnetic sample (AM-1263) was collected from one of these, but it was not analyzed. No burned sediment was observed in the field, and none was found in two micromophology samples made from sediment collected in the feature area (WL95-1 and WL95-2). The field notes report scattered charcoal flecks, but there were no sizable concentrations. The only charcoal sample provenienced to Feature 262 (Lot 2538; indeterminate wood) was found in the lab in a bulk matrix sample. Some vegetal matter was observed in the micromorphology samples, but it did not appear to be carbonized. The only artifact found within Feature 262 was a distal fragment of an ultrathin biface (OR722).

In addition to the 2 burned bone fragments collected as radiocarbon samples, the point-plotted and 1/8-inch screen faunal recovery included 50 bone fragments (see Chapter 33). Most of these specimens were classified as either medium/large mammal or Vertebrata indeterminate fragments, but the sample also included 2 large mammal fragments (long bone and indeterminate), $1 \mathrm{small} /$ medium Vertebrata longbone fragment, and 3 rabbit teeth. Only angular (dry bone) fractures were observed, and only the rabbit teeth were burned.

Ten bulk matrix samples were collected from the Feature 262 area, and much of this sediment was used for magnetic susceptibility, micromorphology, flotation, and faunal finescreen samples (remainder was curated). The magnetic susceptibility samples were comparable to nonfeature samples from the same stratigraphic contexts (no significant deviation), and the flotation samples were not productive (no identifiable plant remains).

A large quantity of sediment (ca. 98 liters) was finescreened to increase the faunal sample, and this effort recovered an additional 455 bones (see Appendix 8). Most of these specimens were classified as mammal or Vertebrata indeterminate fragments, but the sample also included $3 \mathrm{rab}$ bit teeth, 1 rabbit metapodial, 1 fish tooth, 1 snake vertebra, and 4 turtle shell fragments. About $20 \%$ appeared burned (burned specimens reported for all taxa except fish and snake). Comments: Feature 262 clearly relates to the Early Paleoindian "bone bed" component, but it does not seem to have much integrity as a feature. It might represent the remains of an extremely disturbed hearth, but it seems more likely that this sort of material was generally scattered throughout this occupation zone. The limestone rocks may have been used to fracture bones (see Chapter 7).

\section{Burned Rock Midden 1}

Provenience: Block 1 Squares: E20/S100, Levels 3-5; E22/ S100, Levels 3-4; E20/S98 and E22/S98, Levels 3-5; although no elevations were recorded for any levels in Block 1, the estimated range was ca. $98.96-98.27 \mathrm{~m}$

Block 2 Squares: E20/S96, Levels 2-5; E20/S94, Levels 2-6; E20/S92, Levels 2-8; although no elevations were recorded for any levels in Block 2, the estimated range was 98.67$97.46 \mathrm{~m}$ 
Block 3 Squares: E20/S90 and E20/S88, Levels 2-10; E20/ S86, Levels 4-9; E20/S84, Level 7; although no elevations were recorded for any levels in Block 3, the estimated range was $98.16-97.06 \mathrm{~m}$

Block 5 Squares: E22/S90, E22/S88, and E22/S86, Levels 610; E22/S84, Levels 6-9; the upper five levels of Block 5 were machine-stripped; the elevation range for the portion of the midden sampled in Block 5 was $97.79-96.82 \mathrm{~m}$

TARL Square 100, Levels 2-11; elevation range was 98.25$97.30 \mathrm{~m}$

Stratigraphic Context: Most of Burned Rock Midden 1 lies in Unit IIIc but the lowest levels extend into Units IIIb/IIIc, $\mathrm{Y} / \mathrm{III} / \mathrm{IIII}$, Y/IIIc, and $\mathrm{Y}$

Archeological Chronology: Early through Late Archaic (possibly including a minor Late Prehistoric contribution)

Special Studies:

Organic Residue: 1 sample analyzed (see section by Beck in Chapter 23)

Radiocarbon: A carbonized wild hyacinth bulb that was AMS-dated to $8250 \pm 80$ B.P. (CAMS-18375; see Chapter 25) may be associated with the lower portion of this midden Archeomagnetic: 62 of 100 samples analyzed (see Chapter 27 and Appendix 6)

Magnetic Susceptibility: 24 samples analyzed (see Chapter 28)

Micromorphology: 5 samples analyzed (see Chapter 29 and Appendix 7)

Gastropod: 13 samples analyzed (see Chapter 37)

Macrobotanical: 15 macroplant samples analyzed and 5 flotation samples processed (see Chapter 40)

Figures: 26-127, 26-128, and 26-129 (see also Figures 27-44 and 27-45 in Chapter 27)

Description: Burned Rock Midden 1 (BRM 1) is located near the southwest edge of the site, at the juncture of the southern edge of the terrace and the valley wall. The midden was damaged during the construction of RR 1431 but it was not completely obliterated. The surviving portion lies between the eastern edge of the road bed and the fenceline that marks the eastern boundary of the right-of-way. The midden may lie entirely within the right-of-way, but it appears that the buried eastern edge may extend into the Archeological Conservancy Tract (see Figure 3-15 in Chapter 3).

Before the road was constructed, BRM 1 was situated a few meters east of a deep erosional gully (ca. $10 \mathrm{~m}$ wide) that ran roughly southeast to northwest toward Spanish Oak Creek (see Figure 2-12 in Chapter 2). Burned Rock Midden 2 was located on the east side of this gully about 25-30 m northwest of Burned Rock Midden 1. A dense stand of trees and other vegetation bordered the gully and a former cultivated field lay east of this treeline (see Figure 26-127). When the TxDOT excavations began, this field was covered in dense grass and scattered juniper. The northern end of the midden lay within the old field, but the southern end lay within a wooded area at the base of the sloping valley wall.
Burned Rock Midden 1 was completely buried in the sloping, valley margin deposits, with the top of the mound forming only a slight protrusion on the modern surface. Since the upper surface was buried under $10-20 \mathrm{~cm}$ of sediment, the full horizontal extent could not be determined from surface indications alone. Excavation results indicate a northsouth extent of ca. $16 \mathrm{~m}$, and the surface evidence suggests it may have been a roughly circular mound. The excavation data also indicate the midden deposits had a maximum vertical extent of ca. $1 \mathrm{~m}$ in the central portion of the mound, with the deposits thinning toward the outer margins.

At the beginning of the TxDOT investigations, there were no obvious indications of damage to this midden, and it appeared to be very well preserved. This was in strong contrast to several of the other middens in the site area, which had been heavily damaged by relic collectors. Unfortunately, the subsequent excavations revealed a number of old, filled potholes which biased the recovery from a number of squares and hindered efforts to sort out the midden's structure.

The TxDOT investigation of BRM 1 began with a single $1-\mathrm{x}-1-\mathrm{m}$ test pit during the $1981 \mathrm{TxDOT}$ testing phase (see Chapter 3). The location of this test pit was not recorded, and the testing notes are not very informative. The level notes indicate the midden deposits were about $85 \mathrm{~cm}$ thick in this area, and the top of the midden was covered by $15 \mathrm{~cm}$ of sediment.

The first several months of the subsequent TxDOT excavations (1982) focused on the hand-excavation of a 2-4-mwide trench through the western half of BRM 1 (see Chapter 3 and Figure 26-128). The north-south baseline of the excavation grid was laid out on an axis designed to cut through the western half of Burned Rock Midden 1 and the center of Burned Rock Midden 2 (see Figure 2-12 in Chapter 2). The original research design called for the sampling of both middens with this trench and the exploration of activity areas between the two middens. This plan was subsequently modified, and Burned Rock Midden 2 was ultimately sampled in a more-limited, and somewhat disconnected, manner (see Chapter 3 and the Burned Rock Midden 2 description).

The Block 1-3 squares were excavated through BRM 1 in the winter and spring of 1982, and the Block 5 squares were excavated the following summer and fall (see Figure 26128). Within these blocks, a total of fifteen $2-x-2-m$ squares sampled the midden deposits. All the Block 1-3 squares were hand-excavated (in 10-cm levels) from the surface down through, and well below, the midden deposits. The Block 5 squares, however, targeted Early Archaic deposits so the upper $50 \mathrm{~cm}$ of each square was machine stripped, and those deposits were discarded without screening. Below this, the squares were excavated in $10-\mathrm{cm}$ levels through the lower portion of the midden deposits and well below them.

Although the vertical extent of the midden deposits can be estimated from the TxDOT field records, it was not thoroughly and accurately documented in either the level records 


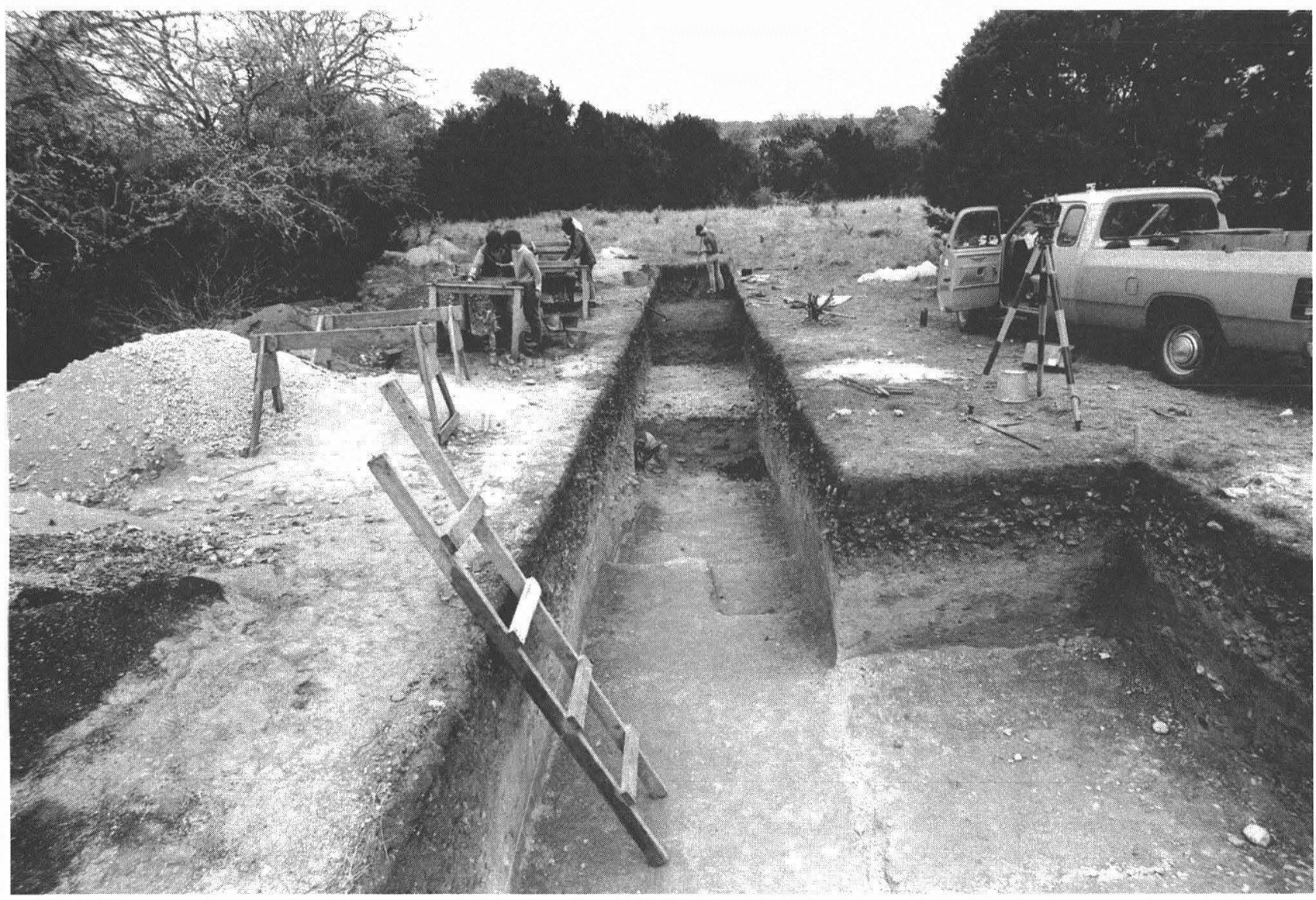

FIGURE 26-127. Burned Rock Midden 1 during the excavation of the Block 3 squares, looking north. Blocks 1 and 2 have been completed and Block 5 has not been started. The treeline at left borders the gully that runs north into Spanish Oak Creek. The old cultivated field lies at the north end of Block 3.

or profile drawings. No elevations were recorded for any levels in Blocks 1-3, and the profile drawings are highly problematical. These problems were compounded by the slope of the midden deposits and the sloping excavation levels that cross-cut the deposits in a complex fashion (see Chapter 3). The field records also lack thorough, consistent documentation of the midden stratigraphy, structure, and internal subfeatures.

Despite these limitations, enough evidence was extracted from the best sources to reconstruct a fairly reliable (albeit general) picture of the midden deposits in the area sampled by the TxDOT squares. A $1.5-\mathrm{x}-1-\mathrm{m}$ test pit (Square 100) was also excavated in the surviving portion of BRM 1 during the TARL investigations (see Figure 26-128). By comparing the most reliable stratigraphic data recorded in the TxDOT field notes to the data collected from Square 100, the midden's stratigraphic context could be correlated to the sequence defined during the TARL investigations.

These sources tell us that Burned Rock Midden 1 accumulated on a slowly aggrading surface that sloped gently down to the north. Most of the midden is buried in Unit IIIc deposits, but the earliest levels in the central part extend into upper Unit Y. At the southern (upslope) end, the base of the midden lies slightly above the Unit Y/IIIc contact. At the northern (downslope) end, the base lies at the Unit IIIb/ IIIc contact. The stratigraphic evidence suggests the midden probably began to accumulate on a surface in the upper portion of Unit $Y$ during the Early Archaic period and gradually accreted both horizontally and vertically during subsequent Middle and Late Archaic occupations. There may have been a minor Late Prehistoric contribution to the midden as well. Unlike some burned rock middens that accumulate rapidly during a relatively short period of time, Burned Rock Midden 1 accreted very slowly, in a complex manner over an estimated period of ca. 7,000 years.

The deposits were thickest (ca. $90-100 \mathrm{~cm}$ ) in the area sampled by Squares E20/S90, E22/S90, E20/S88, and E22/ S88. To the north of this area, the deposits thinned down to $60 \mathrm{~cm}$ in $\mathrm{E} 22 / \mathrm{S} 86,40 \mathrm{~cm}$ in E22/S84, $40 \mathrm{~cm}$ in E20/S86, and 10 $\mathrm{cm}$ in E20/S84. To the south, the deposits ranged from ca. 40-70 cm thick in the Block 2 squares and ca. $20-30 \mathrm{~cm}$ thick in the Block 1 squares.

The Unit IIIc portion of the midden (the upper $60-80 \mathrm{~cm}$ ) consisted of a largely undifferentiated mass of densely packed burned limestone fragments buried in a black, organically enriched clay (described as "greasy" in some level 


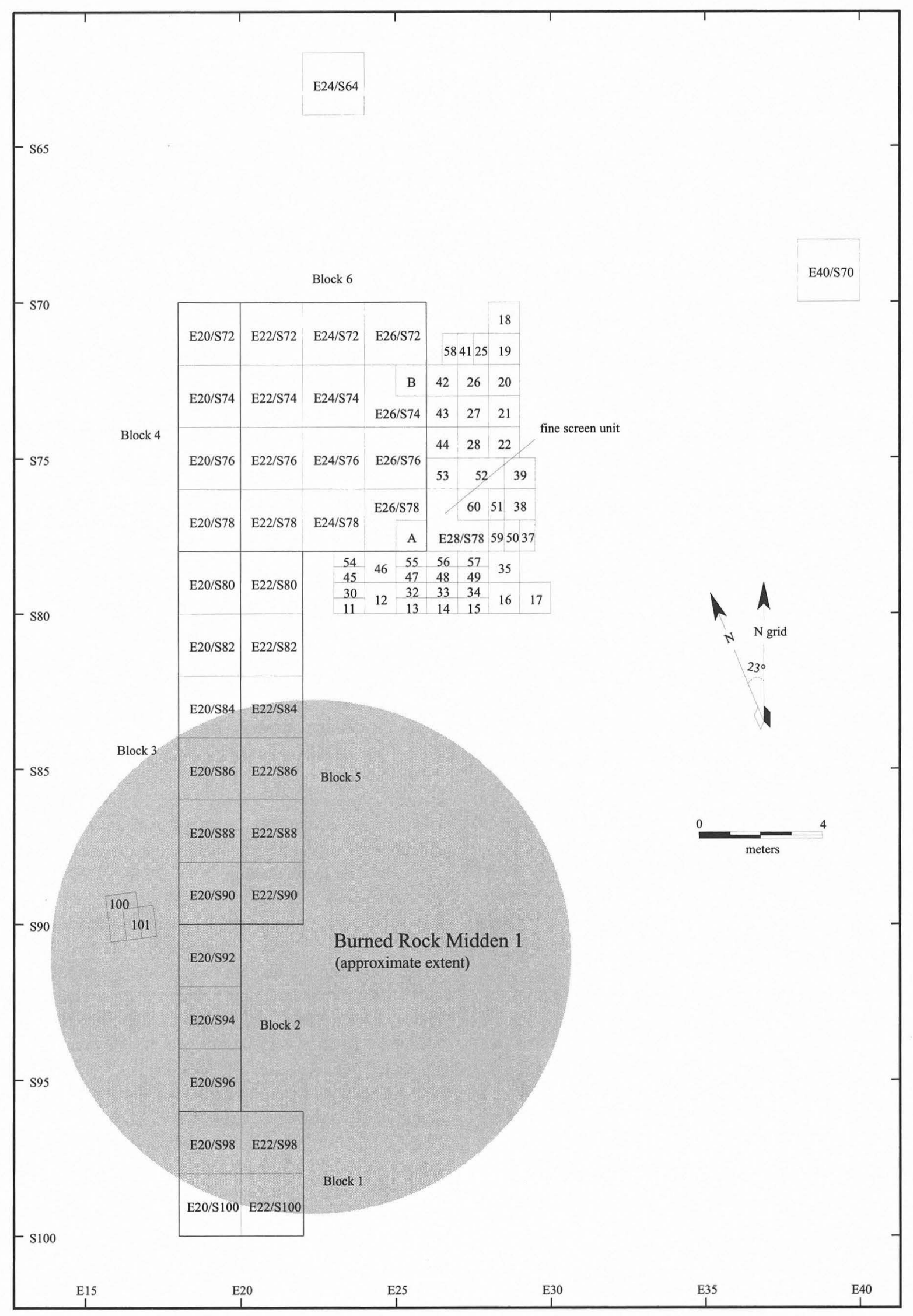

FIGURE 26-128. Plan map illustrating the approximate extent of Burned Rock Midden 1 and the excavation squares that sampled the midden. 


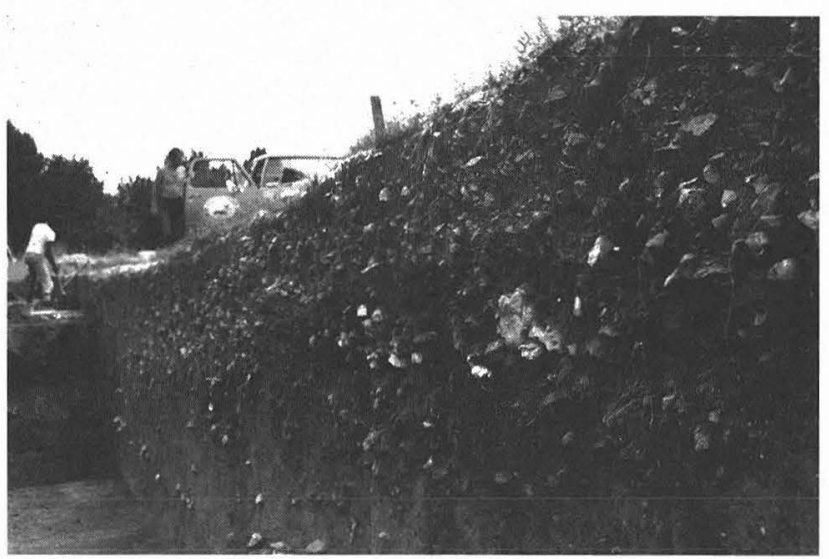

FIGURE 26-129. Burned Rock Midden 1 deposits as exposed in the east walls of the Block 2 and Block 3 squares, looking northeast. Note the larger rocks in the lower portion of the midden deposits and the undulating base of the deposits.

records). Although the burned rocks included a few largeslabs in the 20-30-cm size range, the vast majority were small fragments no more than $5-10 \mathrm{~cm}$ in length (see Figures 26-127 and 26-129). The burned rocks apparently comprised at least $50-60 \%$ of the matrix. The only internal features identified in the Unit IIIc portion of BRM 1 appear to be intrusive features that either postdate the midden or have no functional relationship to the midden deposits. These include Feature 11, a possible Late Archaic biface cache found in Level 5 of E20/S86 (see Feature 11 description); Burial 1, a very disturbed human burial found in Level 6 of E20/S92 (see Burial 1 description); and several large modern potholes (filled) that were documented in the east and west wall profile drawings of Blocks 2 and 3 (the Block 2 area had the worst damage). Numerous intrusive animal burrows are also visible in the photographs, and a few of these are depicted in the profile drawings as well.

Very little ash was observed in the Unit IIIc portion of the midden, but small quantities of charcoal were dispersed throughout the deposits. Charcoal samples collected from these deposits include wood of juniper, live oak, arboreal legume, elm family, and indeterminate forms, as well as black walnut nutshell (see Chapter 40).

A great variety of faunal remains was found in these deposits. The identifiable bone includes deer, antelope, carnivore, jackrabbit, cottontail rabbit, rodent, snake, turtle, and toad/frog (see Chapter 33). The identifiable mussel shell includes Amblema plicata and Potamilus purpuratus (see Chapter 37).

The Unit IIIc portion of the midden also yielded a large variety of lithic artifacts (see Appendix 5). Arrow points were primarily found in the levels encompassing the upper surface of the midden, and they may well postdate the midden. All of the identifiable points $(\mathrm{N}=7)$ were classified as Scallorn points. Thirteen of the fifteen arrow points provenienced to BRM 1 were found in Level 2 of Squares $\mathrm{E} 20 / \mathrm{S} 90$ and E20/S88. This was the first level provenienced to BRM 1 in both squares, and it appears that these levels represent the highest surface of the mound exposed in the TxDOT excavations. The arrow points may reflect Late Prehistoric use of a small portion of the midden (most of it appears to have been buried by that time) or the points may postdate the midden.

The dart point recovery from the Unit IIIc portion of BRM 1 is dominated by Late and Middle Archaic types (see Appendix 5). Darl and Ensor types dominate the upper 40 $\mathrm{cm}$, and a mixture of Marcos, Marshall, Bulverde, Nolan, and Travis points were recovered from the lower $40 \mathrm{~cm}$. A few Early Archaic varieties (e.g., Uvalde, Martindale, Hoxie, and Jetta) were recovered from these deposits as well, but they appear to be stratigraphically displaced.

Other chipped stone artifacts from these deposits include Clear Fork unifaces, perforators, miscellaneous bifaces/ biface fragments (including Stages 1-3), core tools, cores, battered/tested cobbles, miscellaneous unifacial tools, and large quantities of debitage. Only a few ground stone artifacts were recovered, and they had a very limited distribution. Two metate fragments (19F-1 and 19G-2) and a complete mano (19G-1) were found in Levels 6 and 7 of Square E22/S88. Another complete mano (9C-4) was found in Level 3 of adjacent Square E20/S88. Immediately south of this complete specimen, a mano fragment (8B-2) was found in Level 2 of E20/S90, and a metate fragment was found in Level 3 of E20/S90.

Two bone tools were also recovered from the Unit IIIc portion of BRM 1 (see Chapter 21). Specimen 5B-10 is an artiodactyl (probable deer) ulna with a polished and beveled distal point. Specimen 1C-8 is an artiodactyl (probable deer) long-bone fragment with an end that may be slightly rounded from use as an expedient tool.

The lower portion of Burned Rock Midden 1 extends from the upper portion of Unit $Y$ up into the stratigraphically mixed Unit IIIlb/IIIc, IIIb/Y/IIIc, Y/IIIc transition zones. This portion was found in only the north half of the sampled area, and since these deposits appear to be older (for the most part) than the overlying Unit IIIc deposits, the midden appears to have accreted to the south (upslope) over time. The earlier portion of BRM 1 was exposed in TARL Square 100 (Levels 9-11) and TxDOT Squares E20/S90 (Levels 9-10), E20/S88 (Levels 9-10), E20/S86 (Level 9), E22/S90 (Levels 810), E22/S88 (Levels 9-10), E22/S86 (Levels 8-10), and E22/ S84 (Levels 7-8).

Although the documentation for some of these levels is rather limited, the available data indicate there were some significant differences between these earlier midden deposits and the overlying Unit IIIc material. The earlier burned rock deposits were found immediately below the Unit IIIc burned rocks, but they were buried in the lighter-colored sediments below Unit IIIc (Unit Y and possibly some Unit IIIlb sediments). The average size of the burned rocks was significantly larger in this earlier portion of the midden, with a notable increase in the number of large slabs in the $15-30-\mathrm{cm}$ 
size range. More ash was found in these deposits and several sizable areas of burned sediment were also reported. Feature 20 was a large (ca. $85-\mathrm{x}-160-\mathrm{cm}$ ) area of intensely burned sediment found beneath the lowest layer of midden rocks in Squares E20/S86 (Levels 10-12) and E22/S86 (Levels 9-13). Although the documented evidence suggests that this feature represents a burned tree (or other large plant), it is also possible that the burned sediment is associated with the midden deposits (see Feature 20 description). In Level 9 of nearby Squares E22/S88 and E22/S90, a large (ca. 105-x$130-\mathrm{cm})$, irregular-shaped area of ash and charcoal-stained sediment was recorded as Feature 79 (see Feature 79 description). The excavators initially thought Feature 79 might represent a large pit feature, but after further investigation, they concluded it more likely represented a natural topographic depression that filled with ash and charcoal from the overlying midden deposits.

Although they were not provenienced to Burned Rock Midden 1, several features recorded in Levels 11-14 of Squares E20/S88, E22/S88, E20/S90, and E22/S90 may be associated with the midden as well. Feature 8 was a partially exposed (and partially documented) layer of burned rocks exposed roughly $10-20 \mathrm{~cm}$ below the recorded base of BRM 1 (see Feature 8 description). The Feature 8 burned rock accumulation measured over $2-\mathrm{x}-4 \mathrm{~m}$ and ca. $30-40 \mathrm{~cm}$ thick. It was apparently separated from the overlying midden deposits by a thin layer (no more than 10-20 cm thick?) of sediment containing few or no burned rocks. Although the level records place the base of the midden in upper Level 10, Feature 8 may actually represent the lowest layer of the midden, with the intervening sediment representing a depositional episode that interrupted the burned rock accumulation.

The Feature 8 burned rock layer covered and surrounded at least two burned rock basins: Feature 12 was a large basin (ca. $105-\mathrm{x}-150-\mathrm{x}-30 \mathrm{~cm}$ ) found in Squares E20/S88 and E22/ S88 (see Feature 12 description); and Feature 13 was a slightly smaller basin $(70-\mathrm{x}-90-\mathrm{x}-20 \mathrm{~cm})$ found in Squares E20/ $\mathrm{S} 90$ and E22/S90 (see Feature 13 description). A third basin may have been encountered at the southern end of Square $\mathrm{E} 20 / \mathrm{S} 90$, but no feature number was assigned, and it was incompletely documented (see Feature 8 description). A carbonized Camassia scilloides (or wild hyacinth) bulb was recovered from Level 10 of Square E20/S88. This bulb yielded an AMS radiocarbon date of $8250 \pm 80$ B.P. (CAMS-18375). Since it was not documented in the level notes, it is not known if this bulb was found in the upper portion of Level 10 (which was provenienced to BRM 1) or the lower portion (which overlies Feature 8 ). It is quite possible that the bulb was baked in one of the burned rock basins found in Feature 8.

The recovery from Features $8,12,13,20$, and 79 is discussed in the descriptions presented for those features. The recovery from the lower portion of BRM 1 (excluding these features) includes carbonized plant remains, faunal remains, and assorted lithic artifacts. In addition to the wild hyacinth bulb discussed above, the carbonized plant remains include Juglans sp. nutshell, juniper wood, and indeterminate wood (see Chapter 40). The identifiable bone includes deer, antelope/deer, Canis sp., jackrabbit, cottontail rabbit, rodent, snake, bird, and turtle (see Chapter 33). The recovered mussel shell was identified as Uniomerus tetralasmus and medium shell thickness (see Chapter 37).

The projectile point recovery for the lower portion of BRM 1 is dominated by Early Archaic types (Uvalde, Martindale, Baker, and Gower/Uvalde), but it also includes a few Middle and Late Archaic types (Bell-Andice, Bulverde, Marshall, and Marcos). Most (if not all) of the latter specimens are probably stratigraphically displaced from overlying Unit IIIc deposits. Other lithic artifacts found in these deposits include a Clear Fork biface, Clear Fork unifaces, miscellaneous bifaces/biface fragments (including Stages 13 ), perforators, miscellaneous unifacial tools, cores, a core/ hammerstone, and debitage.

During the TARL analysis, a number of special studies were conducted on samples collected from both the upper and lower portions of Burned Rock Midden 1. In addition to the macroplant identifications and radiocarbon results discussed above, these studies include organic residue, archeomagnetic, magnetic susceptibility, micromorphology, flotation, and faunal fine-screen analyses.

The organic residue analysis was performed on a Stage 2 biface (OR408) that was collected from the Unit IIIc portion of the midden during the TARL excavations. Residues extracted from this biface were subjected to gas chromatography-mass spectrometry analysis (see section by Beck in Chapter 23). Although some fatty acid residues were identified in this sample, the source(s) could not be identified.

Archeomagnetic samples were collected from 100 burned limestone rocks found within BRM 1 during the TARL excavations. These samples were collected from Levels 2-11 (all 10 -cm-thick levels) of Square 100, and they span the full extent of the midden. In this square, Levels 2-8 sampled the Unit IIIc portion of the midden; Level 9 (provenienced to Unit Y/IIIc) encompassed a thin layer of less rocky sediment that separated the upper and lower deposits; and Levels 1011 sampled the Unit $Y$ layer of the midden. Sixty-two of the archeomagnetic samples (some from each level) were analyzed, and the results were rather surprising (see Chapter 27). Given the unpatterned appearance of these densely packed rocks, it was expected that the majority were displaced after they were completely cooled. Instead, the results indicate $66 \%$ of the analyzed rocks (from all levels) cooled in place or very near their find positions. Slightly less than a third were significantly displaced after they cooled completely. It was also thought that the Unit Y portion of the midden might have a relatively lower percentage of displaced rocks than the Unit IIIc portion, because it appeared to represent a more discrete episode of accumulation. This was not the case, for a level by level comparison indicates the highest percentage of significantly displaced rocks (ca. 
$67 \%$ ) occurred in Level 10 (which encompassed most of the Unit Y midden layer). The lowest percentages of significantly displaced rocks (ranging from $0-28 \%$ ) occurred in Levels 5-9 of the Unit IIIc portion.

A vertical series of intact blocks of sediment was collected from Square 100 as a micromorphology column (see Chapter 29 and Appendix 7). Three samples (WL-92-300, WL-92-301, and WL-92-302) were collected from the lower levels of the Unit IIIc portion of BRM 1 (roughly Levels 7-9), and two were collected from the Unit Y portion (roughly Levels 10-11). The sediment in all of these samples had been heavily reworked by earthworms. Charcoal and other organic matter was abundant, but it had been finely divided by the earthworm activity. The Unit IIIc samples contained more bone and more intensively burned limestone fragments than the Unit Y samples, but ash was only observed in the Unit Y sample from Level 10. No burned sediment was observed in any of the samples.

Bulk matrix samples were collected from all the midden levels in Square 100, and a series was also collected from one of the walls of TxDOT Square E22/S88 (ca. Levels 2-10). Some of this sediment was used for magnetic susceptibility, gastropod, flotation, and faunal fine-screen samples (remainder was curated).

Twenty-four magnetic susceptibility samples (representing Levels 2-10) were analyzed, and the results generally follow the pattern observed for Unit IIIc in the other susceptibility columns (see Chapter 28 ). The values were highest in the upper levels and gradually decreased with depth. A very slight reversal (an increased rather than decreased value) occurred in Level 10. Since this level contained the Unit Y layer of midden, the slightly increased value may reflect a higher ash content.

Gastropod samples were analyzed from seven levels in Square E22/S88 and six levels in Square 100. Neck analyzed six of the E22/S88 samples (Levels 3-5, 7, and 9) in the mid1980s (see section by Neck and Shaw in Chapter 37) and the seventh (from Level 2, added to complete the column) was analyzed by Theler almost 10 years later (see section by Theler in Chapter 37). Neck also analyzed all of the samples from Square 100 (in 1992-1993; see section by Neck and Shaw in Chapter 37).

Although their samples were collected from the same column, Neck's and Theler's results are not entirely comparable. Apart from the obvious differences generated by analyst bias and a ca. 10-year time difference, there may be significant differences in both sample size and recovery methods (both were incompletely documented for the earlier Neck study; see Chapter 37). With that cautionary note, the results of these studies can be briefly summarized.

Most of the analyzed samples were from the Unit IIIc portion of the midden. Only two samples represented the Unit $Y$ portion, and both were analyzed by Neck (one is from Level 9 in Square E22/S88 and the other is from Level 10 of Square 100). These samples do not appear to differ in any significant way from the suite of Unit IIIc samples. All were dominated by the same three terrestrial taxa: Oligyra orbiculata; Rabdotus mooreanus; and Polygyra mooreana. Although these species have wide environmental tolerances and are commonly found throughout the site deposits, they also favor the rocky habitats afforded by the midden deposits. They were probably attracted by the relatively high organic content of the midden deposits as well.

Other terrestrial snails (found in much lower numbers) have more-restricted habitat tolerances and are noteworthy as possible indicators of environmental conditions. Several species are considered indicative of more-mesic wooded habitats. These include Strobilops texasiana, Gastrocopta contracta, Glyphyalinia roemeri, and Polygyra texasiana. S. texasiana and G. contracta were identified by both Neck and Theler in the E22/S88 samples from the upper portion of Unit IIIc (Levels 2-5). Neck also found G. contracta in samples from Levels 5 and 6 in Square 100. G. roemeri and $P$. texasiana were identified in only the Square 100 samples (Levels 5-10). Species that may reflect more-xeric conditions include Pupoides albilabris and Gastrocopta procera. Theler did not identify either of these species in his sample. Neck identified $P$. albilabris in samples from both squares (Levels 4, 5, and 7 in Square E22/S88 and Levels 5 and 10 in Square 100) and G. procera in only his Square E22/S88 samples (Levels 3-5, and 7).

Seven aquatic snails were also found in three of the samples Neck analyzed from Square E22/S88 (Levels 4, 5 , and 7). These represent four species: Biomphalaria havanensis $(\mathrm{n}=1)$, Helisoma anceps $(\mathrm{n}=2)$, Planorbella tenuis $(\mathrm{n}=3)$, and Fossaria dalli $(\mathrm{n}=1)$. Several different aquatic habitats may be represented by this small sample. According to Neck, B. havanensis is found in slow-moving or still waters, often of a temporary nature; $P$. tenuis is also found in slow-moving waters, and occasionally in temporary waters; $F$. dalli is typically found in moist vegetation growing around or in shallow ponds and streams; and $H$. anceps is usually found in clear, spring-fed waters flowing on limestone bedrock or gravel substrates (see Chapter 37).

Although it is possible that these aquatic snails were deposited during overbank floods (as Theler suggests for other aquatic snails found in the site deposits, see Chapter 37), Burned Rock Midden 1 appears to be buried in primarily colluvial deposits (see Chapters 2 and 6). It seems equally likely, or perhaps more likely, that these snails may reflect anthropogenic deposition. They may reflect human collection of water, aquatic plants, and/or aquatic animals. Given this hypothesis, it is important to note that two fish bones were recovered from a small fine-screen faunal sample from this midden (discussed below).

The five flotation samples from BRM 1 were collected from Levels 4, 6, 8, and 10 of Square 100. A total of ca. 5.5 liters of sediment was processed, but no identifiable plant remains were recovered. Three additional sediment samples from 
Square 100 (Levels 5, 7, and 9; 1 liter each) were processed as fine-screen faunal samples. A total of 54 bones/bone fragments and 2 eggshell fragments were recovered from these samples (see Appendix 8 and Chapter 36). The identifiable bone includes mammal, rodent, amphibian, reptile, and fish.

Comments: Burned Rock Midden 1 probably began to accumulate on a surface in Unit $Y$ sometime during the Early Archaic period. If the Feature 8 accumulation represents the earliest layer of the midden (and the dated bulb was baked in one of Feature 8 burned rock basins), then the midden may have begun to accumulate as early as ca. 8250 B.P. If this is the case, then the earliest portion of BRM 1 compares well to the Early Archaic burned rock accumulation Feature 124/231 (recorded in Unit IIIa in TxDOT Block 6 and adjacent TARL squares; see Feature 124 and 231 descriptions). The Feature 124/231 accumulation surrounded at least 6 large burned rock basins, the largest of which (Feature 181) contained 10 carbonized wild hyacinth bulbs. The AMS radiocarbon determinations on 9 of these bulbs yielded an average age of ca. $7997 \pm 21$ B.P. (see Chapter 25).

A large burned rock basin that was very similar to Feature 181, Feature 19/104, was found about $40 \mathrm{~cm}$ below the recorded base of BRM 1 and about $10-20 \mathrm{~cm}$ below the base of Feature 8. Feature 19/104 was exposed in Levels 15-18 of Squares E20/S90 and E22/S90. It measured over $2 \mathrm{~m}$ in diameter with a recorded depth of ca. $40 \mathrm{~cm}$. If the top of this large pit actually originated above its detection level, then it may have originated from a surface somewhere within the Feature 8 layer. A wood charcoal sample collected from the fill of Feature 19/104 yielded a conventional radiocarbon date of $7470 \pm 230$ B.P. (Tx-4798). The location of this large pit (near the center of the estimated extent of BRM 1) is very reminiscent of the "central pit features" commonly found in Central Texas burned rock middens.

Although no definite pit features (or large burned rock basins) were recorded in the BRM 1 layers above Feature 8 , the photographs suggest the apparently undifferentiated mass of burned rocks found in the Unit IIIc portion of the midden may have encompassed any number of pits that were subsequently filled with burned rocks, thus making their outlines difficult to discern (see for example Figure 26-129). The archeomagnetic data also suggest in situ heating events occurred in this apparently undifferentiated mass.

Burned Rock Midden 1 appears to have accumulated more rapidly during the latter portion of the Late Archaic period as evidenced by the Ensor and Darl points that dominate the upper $40 \mathrm{~cm}$ of the deposits. The midden also appears to have accreted laterally to the south (upslope) during the Late Archaic period. Most of the midden appears to have been buried by the Late Prehistoric period, but a cluster of arrow points found near the upper surface of the highest point of the mound suggests there may have been a minor Late Prehistoric contribution as well.

\section{Burned Rock Midden 2 (with Subfeatures 194 and 195)}

Provenience: Squares W0/N8 and E2/N8; Levels 1-11; highest documented elevation $97.47 \mathrm{~m}$; base elevation ca. $96.47 \mathrm{~m}$ Stratigraphic Context: Unit III (undifferentiated), the Unit III/IIIc transition, Unit IIIc

Archeological Chronology: Middle through Late Archaic Special Studies:

Radiocarbon: a carbonized Camassia scilloides bulb was AMS dated to $3780 \pm 70$ B.P. (ETH-14115; see Chapter 25)

Macrobotanical: 17 macroplant samples analyzed from Burned Rock Midden 2, 1 from Subfeature 194, (see Chapter 40)

Figures: 26-84, 26-85, 26-86, 26-130, 26-131, and 26-132

Description: Burned Rock Midden 2 was apparently located about 25-30 m northwest of Burned Rock Midden 1, near the terrace edge above Spanish Oak Creek. The location of this midden was never accurately mapped during the TxDOT excavations, and since it was obliterated during the construction of RR 1431, it could not be relocated during the TARL investigations. Fortunately, the approximate locations of the midden and the two squares excavated to test it were documented with a sketch map that includes a number of useful reference points (see Figure 26-130). The area depicted in this sketch map was designated "Area B" when testing of BRM 2 began in the spring of 1983 (see Chapter 3). Area B was bounded to the north by a steep, ca. 6-m bluff overlooking Spanish Oak Creek, to the south by a chain-link fence constructed around the main excavation area (or "Area A"), and to the west by a ca. 10-15-m-wide erosional gully. A barbed wire fence ran roughly northeast to southwest across the top of the midden and another bordered the creek bluff. The entire area (including the midden) was covered with a fairly dense stand of cedar, elm, and hackberry trees (see Figure 26-131).

Burned Rock Midden 2 was visible on the surface as a roughly oval-shaped, mounded protrusion measuring approximately $18 \mathrm{~m}$ north-south by $20 \mathrm{~m}$ east-west. The height of this mound (above the surrounding level surface) was not documented. Athough no evidence of a central pit/ depression was reported, BRM 2 had been so heavily damaged by relic collectors that the original contours may have been distorted. The upper portion of the midden was riddled with recent potholes when the TxDOT investigations began (see Figures 26-130, 26-131, and 26-132).

The Area B excavations consisted of two 2-x-2-m squares (W0/N8 and E2/N8) placed in an undisturbed area near the center of the midden. These squares were not laid out using the main (Area A) grid, and since they were never tied into the main grid, their exact location is unknown (see Chapter 3). Both squares were excavated well below the base of BRM 2, revealing midden deposits with a vertical extent of ca. $1 \mathrm{~m}$ (see Figures 26-84, 26-85, 26-86).

The upper $60 \mathrm{~cm}$ of the midden deposits (ca. Levels 1-6) consisted of a largely undifferentiated mass of densely 


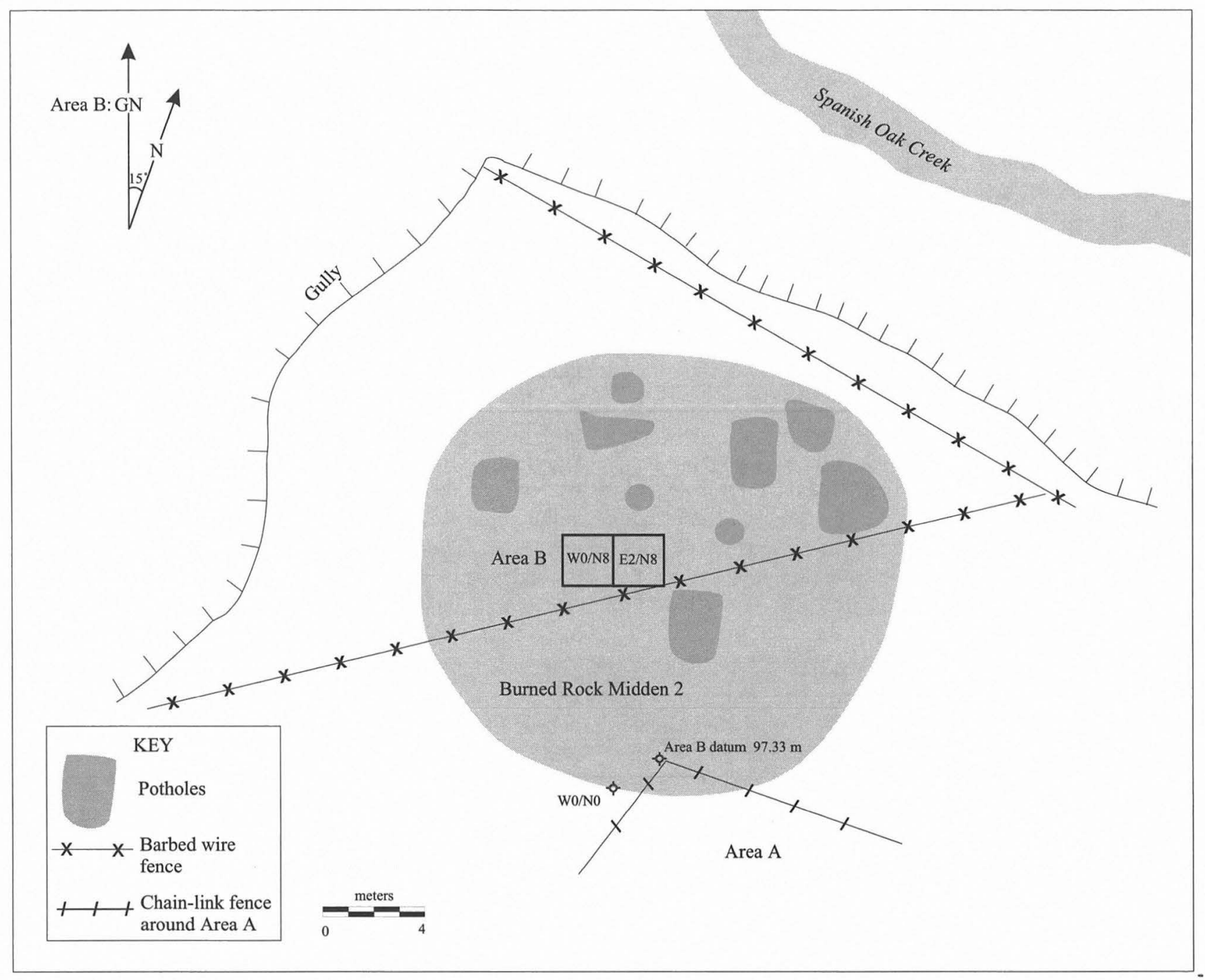

FIGURE 26-130. Burned Rock Midden 2 and the Area B excavations.

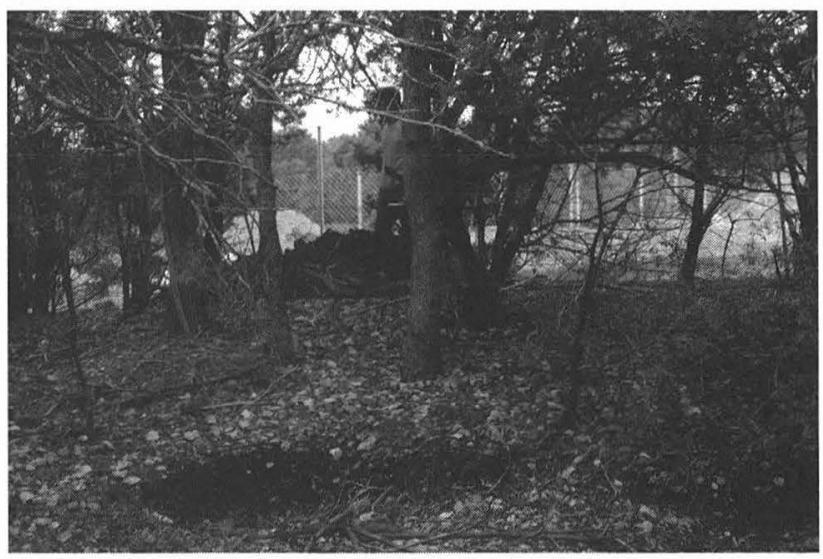

FIGURE 26-131. Looking southeast across Burned Rock Midden 2. Crewmember is standing in the area being cleared for the Area B excavations. The fence around Area $\mathrm{A}$ is visible in the background. Potholes excavated by relic collectors are visible in the foreground.

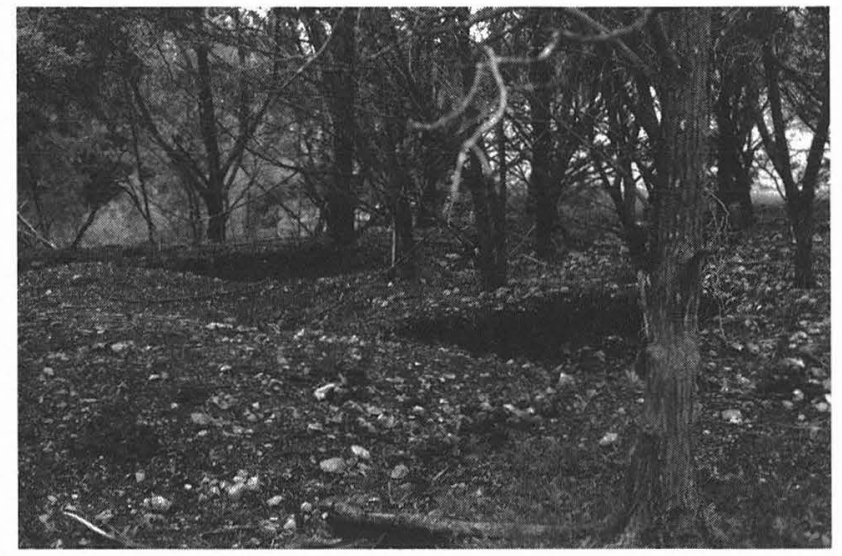

FIGURE 26-132. Looking east across the area with potholes excavated by relic collectors in the northern end of Burned Rock Midden 2. 
packed burned limestone fragments buried in a "dark gray to gray-brown loam" with a variable, but generally high ash content (see Figure 26-84). Most of the rocks were relatively small angular fragments described as "large pebble to small cobble" size in the level notes. No charcoal or faunal remains were recovered from Levels 1-6, and the debitage counts are relatively low (ranging from $54-168$ specimens per 10-cm level). The projectile point recovery includes Bulverde, Bulverde-like, Nolan, Lange, Travis, and miscellaneous rectangular stem points. Other chipped stone tools include a perforator, various bifaces/biface fragments (including Stages 1-3), and an assortment of unifacial tools (see Appendix 5).

A stratigraphic transition occurred in the midden deposits between ca. 65 to $85 \mathrm{~cm}$ below surface (ca. Levels 79). Within these levels, the sediment gradually changed to a lighter-colored "medium gray-brown loam," the ash content dropped, and the burned rock density decreased somewhat (see Figure 26-84). Small quantities of charcoal, bone, and mussel shell were also recovered from these levels. A carbonized Camassia scilloides (wild hyacinth) bulb (CH-925) collected in Level 8 yielded the AMS date cited above. Four other charcoal samples from these levels (CH-923, CH-924, Lot 50HB, and Lot 50IA) were all identified as indeterminate wood. The faunal recovery from Levels 7-9 included 2 mussel shell fragments (see Chapter 37) and 10 bone fragments (see Appendix 10). The identifiable bone included 2 large mammal and 2 medium/large mammal fragments. The chipped stone tool recovery included several Nolan points, a Bulverde-like point, a square-stem point, and an assortment of bifaces and unifaces. Debitage counts increased (overall) in these levels (ranging from 103-460 pieces per level).

From approximately 85 to $95 \mathrm{~cm}$ below surface (ca. lower Level 9 and upper Level 10) there was a thin, 5-10-cm-thick layer of "light gray-brown" sediment containing a significantly lower density of burned rocks (described as "scattered burned rocks"), little or no ash, and very little charcoal (see Figure 26-84). A pit detected in this layer was recorded as Feature 194 (see Figure 26-85). This pit was found in the southeast corner of Square W0/N8 at the base of Level 9. It extended into both the south and east walls with the exposed portion measuring ca. $70-x-70 \mathrm{~cm}$. Since the pit fill resembled the overlying dark gray ashy midden deposits, it was probably excavated from a surface above its detection level, intruding this light gray-brown layer. When the pit fill was removed, Feature 194 extended down into Level 12 for a depth of $27 \mathrm{~cm}$ below detection level; see (see Figure 26-85). Small concentrations of burned sediment and charcoal were found beneath some burned rocks at the base of the pit. The only charcoal sample collected from Feature 194 (CH-930) was identified as indeterminate wood (see Feature 194 description for additional details).

The thin layer with relatively few burned rocks may represent a brief hiatus in the midden accumulation, for immediately below this (in lower Level 10 and Level 11), there was another dense layer of burned rocks (see Figure 26-84). This layer was about $10 \mathrm{~cm}$ thick, and it was apparently buried in the same light gray-brown (low ash) sediment found in the overlying layer. The average rock size was a little larger in this layer than in the overlying midden deposits with an apparent increase in the number of "medium cobble" size rocks. When this layer of rocks was initially exposed in Square W0/N8 (Levels 10-11), it was interpreted as a possible hearth and assigned a separate feature designation (Feature 195). When it was further exposed in Square E2/N8 (Levels 10-11) it was reinterpreted as the lowest layer of Burned Rock Midden 2 (the dense burned rock deposits ended with the Feature 195 layer in both squares).

The recovery from this layer is summarized in the Feature 195 description. Notably, this lowest layer included significantly more charcoal, bone, and mussel shell than the overlying midden deposits. The charcoal included live oak, walnut, and elm wood, and the bone included deer, rabbit, and turtle. The Feature 195 layer also contained the only ground stone artifacts found within BRM 2 (a mano and a metate fragment). The projectile point recovery was dominated by Middle Archaic types (Nolan, Travis, and Early Triangular points).

Comments: The stratigraphic context assigned to the lower portion of Burned Rock Midden 2 is somewhat problematical. Since Area B was not sampled in the TARL excavations, it was difficult to correlate the stratigraphic data recorded for these squares to the stratigraphic units defined in the TARL excavations. Initially the base of Unit IIIc was thought to correspond to the base of BRM 2 in Area B, and Levels 111 in both squares were provenienced to Unit IIIc (this is the stratigraphic assignment listed for the materials recovered from these levels in other chapters and appendixes of this report). Because boundaries were indistinguishable for subunits IIIb and IIIc below the base of BRM 2, levels below the midden were provenienced to Unit III (undifferentiated).

After careful reconsideration of the Area B data (late in the analysis), it appears that the Unit IIIc boundary was actually a little higher, probably at/or near the base of the dark, ashy midden deposits (somewhere between ca. 65-85 $\mathrm{cm}$ below surface, or between Level 7 and upper Level 9). The lighter-colored sediment encountered in the lower levels of Burned Rock Midden 2 (lower Level 9 through Level 11) probably corresponds to Unit IIIb (as defined in Area A) or Unit III (undifferentiated) as it was designated in Area B. Since this reassessment of BRM 2 stratigraphy occurred late in the analysis phase of work (after many of the other studies were completed), no attempt was made to revise the Unit IIIc assignments listed for Levels 7-11 in other chapters and appendixes.

\section{Burial 1 (Wilson-Leonard I)}

Provenience: Square E20/S92 (NE quad), Level 6; although no elevation data were recorded for either the feature or the 
level, the detection level of Burial 1 is estimated to have been between ca. 97.92 and $97.66 \mathrm{~m}$

Stratigraphic Context: Burial 1 was found in the lower portion of Unit IIIc, but the stratigraphic assignment for this level is Unit IIIc (pot). Levels 1-6 were given this assignment in Square E20/S92 because a large "pothole" (dug by modern relic collectors) was documented in the west wall profile drawing.

Archeological Chronology: Late Archaic?

Special Studies:

Organic Residue: 1 sample analyzed (see section by Hurst in Chapter 23)

Figure: 26-133

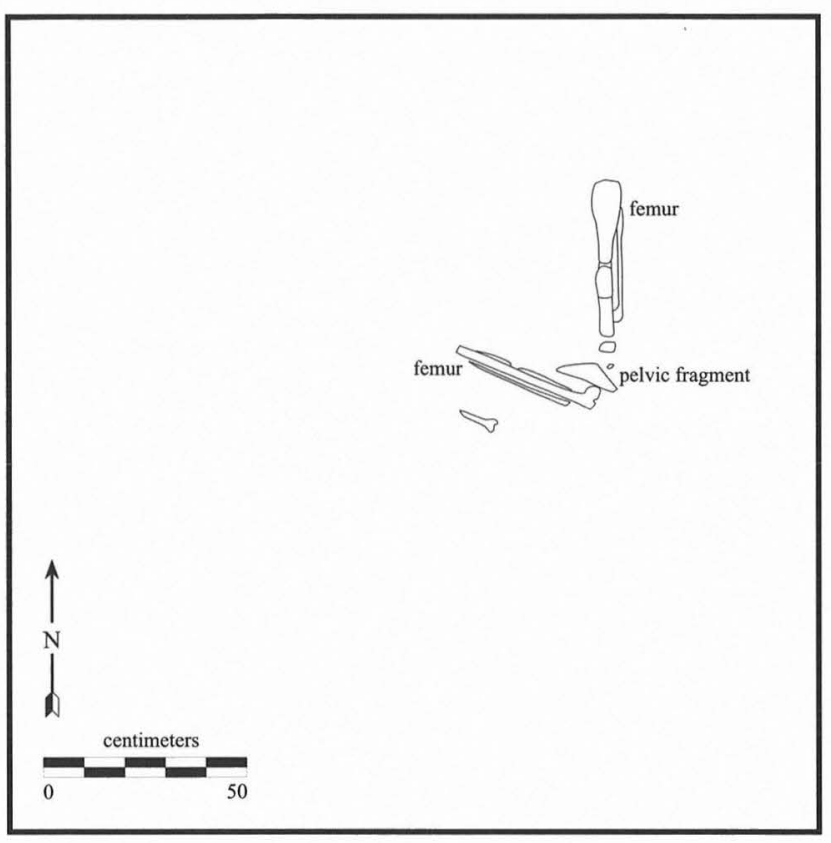

FIGURE 26-133. Burial 1 in Square E20/S92, Level 6.

Description: Burial 1 was a disturbed human burial found in the lower portion of Burned Rock Midden 1. It contained the incomplete and poorly preserved postcranial remains of a single individual. Burial 1 was found in the very early stages of the TxDOT excavations (within the first two weeks), and it is very poorly documented. The field notes include only brief descriptions of the burial and a poor plan drawing of some (most?) of the skeletal remains found in situ (see Figure 26-133). Many critical details are omitted in both the descriptions and the drawing, no elevations were recorded, and there are no photographs of the burial.

The available data indicate the individual was interred in a flexed position (possibly face up) with the lower legs folded under the upper legs. A small portion of the pelvis, both femora, and fragments of the lower leg bones appeared to be in situ, but the feet and all the upper body bones were missing. The plan drawing indicates the legs were spread, with the femora spaced approximately $60 \mathrm{~cm}$ apart at the knees. The right femur was oriented roughly north-south, and the left femur was oriented roughly northwest/southeast. Fragments of the lower leg bones were found directly below the femora.

Although no evidence of a burial pit was detected, the notes indicate a pit outline would have been difficult to discern in the encompassing midden deposits. The skeletal remains were apparently "lying on burned rocks" and "covered with burned limestone slabs." The notes do not indicate how many slabs were found, their locations, or if they appeared to be intentionally placed over the burial.

The field notes do not mention any evidence of an intrusive disturbance that displaced the upper portion of Burial 1. The notes speculate that the burial may have been disturbed by a pit dug into the midden by prehistoric inhabitants. Other possibilities include disturbance from either burrowing animals or modern relic collectors (a large "pothole" was documented in a profile drawing of the west wall of this square).

Two unmodified limestone slabs and a limestone metate fragment were provenienced to Burial 1 in the TxDOT specimen inventory. The slabs, which measure $15-\mathrm{x}-17-\mathrm{x}-6 \mathrm{~cm}$ (7F-3) and 20-x-20-x-6 cm (7F-4), appear to be burned (with dark gray and black discoloration), but neither exhibits obvious thermal fractures (edges are weathered). The metate fragment (7F-5) measures $12-\mathrm{x}-25-\mathrm{x}-6 \mathrm{~cm}$, and it is bifacially ground (see Chapter 20). The slabs are not specifically documented in the field notes, but the metate fragment is briefly mentioned. It was apparently found "near the legs" and the association with the burial was considered tenuous because of the midden context. The notes also mention a mud dauber nest found near the pelvis, but this was apparently not collected.

The skeletal remains recovered from Burial 1 were analyzed by Steele (see Chapter 31), who has designated this individual as Wilson-Leonard I. Steele reports that the Wilson-Leonard I remains include 2 fragments of an ilium (side indeterminate), a portion of a right femur shaft, a portion of a left tibia shaft, fragments of a fibula shaft (side indeterminate), and ca. 130 small postcranial fragments that could not be identified. The identifiable elements were too fragmentary and poorly preserved to determine the sex of this individual, and the age could only be estimated as adolescent or adult.

Steele also analyzed an isolated fragmentary skull found about $1 \mathrm{~m}$ northeast of Burial 1 and ca. $60 \mathrm{~cm}$ below it (see Feature 90 description). The TxDOT archeologists thought this skull was probably displaced from Burial 1 . Steele identified the skull as an adolescent or young adult female. He explored the possible association between the Feature 90 skull and the Burial 1 postcranial remains and found there was insufficient evidence to determine if these remains represented one or two individuals. Steele's analysis also included six isolated human bones and a human molar found in various contexts in Unit III. Several of these specimens were found close enough to Burial 1 and/or Feature 90 to be 
considered potentially associated. Unfortunately, the specimens were too fragmentary and isolated to be very informative or to determine any associations.

In a related study, Wilson performed a stable carbon isotope analysis on a sample of cortical bone from WilsonLeonard I in an effort to gain insights into the individual's diet (see Chapter 32). Specifically, she sought to explore the types of plant foods consumed (i.e., $\mathrm{C}_{3}, \mathrm{C}_{4}$, or CAM plants), the amount of protein in the diet, and possible protein sources by examining relative values of $\delta^{13} \mathrm{C}$ apatite, $\delta^{13} \mathrm{C}$ gelatin, and $\delta^{15} \mathrm{~N}$ gelatin. Unfortunately, the collagen was too poorly preserved in this sample to obtain reliable gelatin values, hence the protein questions could not be addressed. However, a reliable $\delta^{13} \mathrm{C}$ apatite determination was obtained for this sample. Wilson interprets this value $(-9.2 \%)$ as an indication that the Wilson-Leonard I individual's diet was probably based primarily on $\mathrm{C}_{3}$ plants and animals that consumed $\mathrm{C}_{3}$ plants, with a less significant reliance on the $\mathrm{C}_{4}$ and/or CAMS plants (and consumers of these plants).

The metate fragment was submitted to Hurst as an organic residue sample (see Chapter 23). The residues he extracted were subjected to both capillary ion analysis (for the determination of inorganic ions) and high performance liquid chromatography (to identify amino acid residues). With the capillary ion analysis, he identified chloride, phosphate, and carbonate anions on this specimen. Although he interprets the chloride and carbonate as pedogenic residues (with no cultural significance), the phosphate could be derived from cultural sources. No amino acids were identified in the residues from this specimen.

Comments: Burial 1 was given a very tentative Late Archaic age estimate based primarily on its stratigraphic position within Unit IIIc and its position within the Burned Rock Midden 1 deposits. Although no elevations were recorded for this feature, the Level 6 position places it ca. $20 \mathrm{~cm}$ above the base of the midden deposits, indicating that it postdates the earliest stages of Burned Rock Midden 1 accumulation and most likely dates to the Late Archaic period.

\section{Burial 2 (Wilson-Leonard II)}

Provenience: Squares E20/S74 (NE and NW quads) and E20/S72 (SE and SW quads), Levels 31A-34B; the detection elevation for the pit outline was ca. $94.33 \mathrm{~m}$ but the highest point on the limestone slab found in this burial was $94.37 \mathrm{~m}$; base of pit was ca. $94.11 \mathrm{~m}$

Stratigraphic Context: The burial pit intruded both Unit Isi and Unit Icl deposits, but it was apparently excavated from a surface in the lower portion of the Leanne soil (Isi-c).

Archeological Chronology: Late Paleoindian Special Studies:

Organic Residue: 1 sample analyzed (see section by Hurst in Chapter 23)

Radiocarbon: 2 sediment samples from the pit fill were conventionally dated to $9470 \pm 170$ B.P. (Tx-4787) and 9650 \pm 124 B.P. (Tx-4793); problematic assays are: 1 charcoal sample from the pit fill was AMS-dated to $13,000 \pm 3,000$ B.P. (AA$171)$ and 6 human bone samples were AMS-dated to $1270 \pm$ 280 в.P. (AA-753), $4650 \pm 310$ в.P. (AA-747), $5440 \pm 420$ в.P. (AA-752), $5860 \pm 270$ B.P. (AA-751), $5940 \pm 520$ в.P. (AA-748), and $6700 \pm 460$ B.P. (AA-749) (see Chapter 25)

Magnetic Susceptibility: 66 samples analyzed (see Chapter 28)

Micromorphology: 10 samples analyzed (see Chapter 29 and Appendix 7)

Macrobotanical: 1 macroplant sample analyzed and 34 flotation samples processed (see Chapter 40)

Phytolith: 5 samples analyzed (see Chapter 41)

Figure: $26-134$

Description: Burial 2 was a relatively undisturbed, primary inhumation of a young adult female (also referred to as Wilson-Leonard II). In contrast to Burial 1, this burial was very well documented. The Wilson-Leonard II individual was interred in a roughly oval-shaped pit that was oriented with its long axis running generally northeast to southwest (see Figure 26-134). The pit measured ca. $52-\mathrm{x}-104 \mathrm{~cm}$ with a depth of at least $22-26 \mathrm{~cm}$.

The burial pit outline was detected at an elevation of ca. $94.33 \mathrm{~m}$, ca. 10-15 $\mathrm{cm}$ below the base of the Leanne soil (Unit Isi-c). The pit intruded both Unit Isi and Icl sediments, but the field observations suggested it probably originated from a surface within the overlying Leanne soil. The dark color of the pit fill closely resembled the Leanne soil, and it appears that the pit outline could not be discerned until the base of the soil was reached and contrast between the pit fill and the surrounding matrix was more distinct. This same problem was encountered with Features 168 and 169, two pits located ca. 1-2 m south of Burial 2 in approximately the same stratigraphic context (see Feature 168 and 169 descriptions). All three of these features probably relate to a Wilson component occupational surface (or surfaces) in the lower portion of the Leanne soil.

Wilson-Leonard II was placed on her right side, in a semiflexed position, with her head to the northeast and her face to the west. Her lower arms were folded in toward her head, with her head resting on her right hand and her left hand lying on (or near) her right wrist (near the face). Her legs were flexed, with the knees drawn up toward the chest. The left leg was flexed a little more tightly than the right with the left knee also pulled a little closer to the chest. Elevations recorded for various elements of the skeleton range from 94.31 to $94.11 \mathrm{~m}$. The burial pit was apparently excavated just large enough to contain the flexed body, because the skeletal remains were quite close to the pit walls on all sides. The base of the pit was at the same elevation as the lowest elements of the skeleton (ca. $94.11 \mathrm{~m}$ ).

With the exception of some slight displacement of small hand and foot bones, the preserved elements of the skeleton appeared to be largely undisturbed. Unfortunately, the preserved bones were quite fragile. Almost all the pre- 

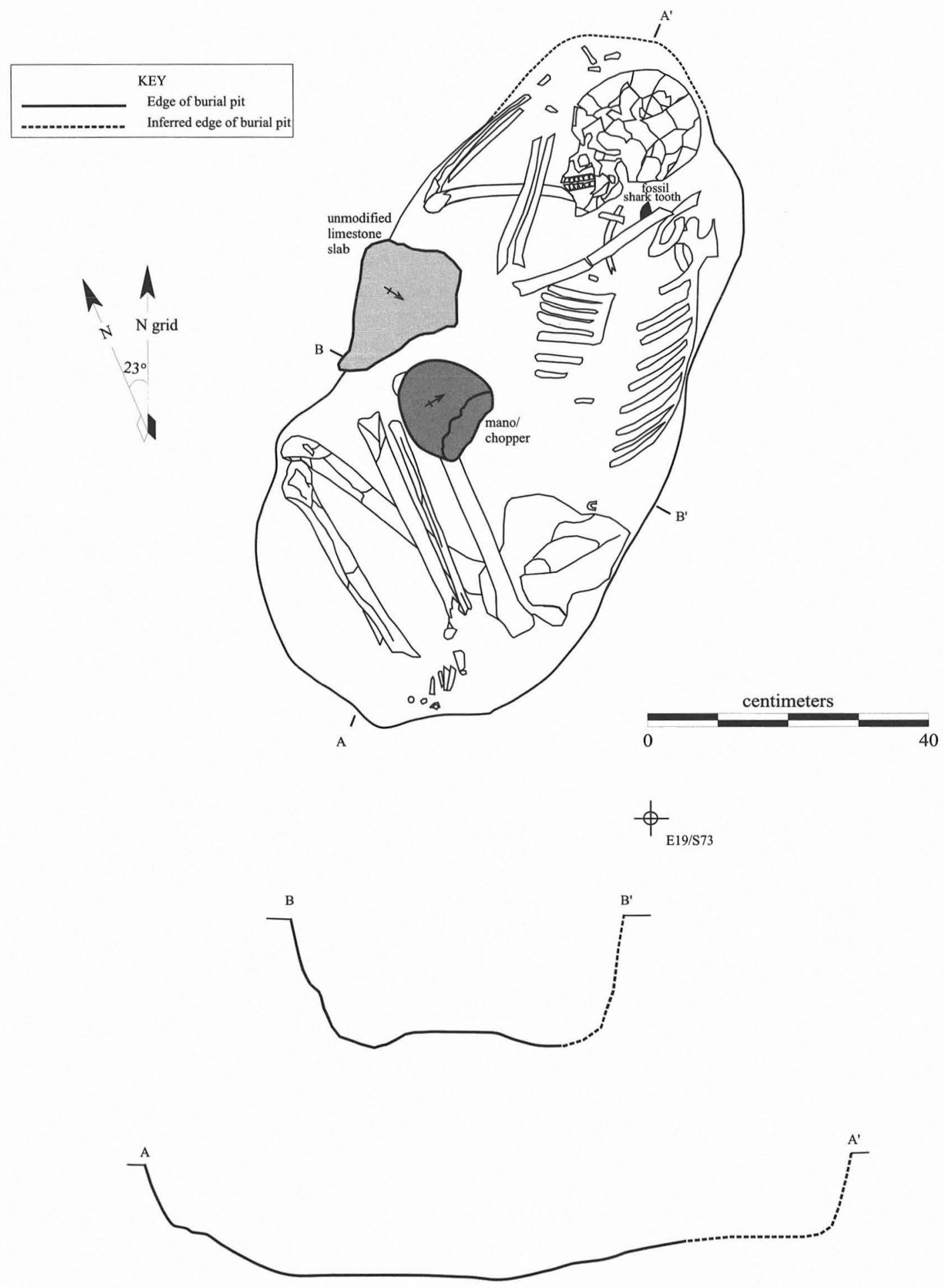

FIGURE 26-134. Plan of Burial 2 and outline profiles of the burial pit.

served bones had been extensively fractured postmortem, and all experienced chemical dissolution to varying degrees (see discussions by Stafford in Chapter 25 and Steele in Chapter 31).
Burial 2 contained at least two (and possibly three) intentional inclusions. One of the unquestionable inclusions is a complete ground stone tool (Specimen FBU2-1), found immediately above the distal end of the left femur 
(see Figure 26-134). The field notes indicate this specimen was either in direct contact with or very close to the body, resting on or just above the left knee. This specimen has been classified as a mano/chopper (see Chapter 20). It is a round, pink sandstone cobble (ca. 14-cm diameter) that is ground/striated on both faces and bifacially flaked along one edge. The flaked edge exhibits crushing, battering, and microflaking that presumably represents wear from heavy use. This tool was resting at a slight angle, with one end sloping down to the east. The highest point on the top of this artifact was ca. $94.27 \mathrm{~m}$, and the base rested at ca. $94.22 \mathrm{~m}$.

The other unquestionable inclusion is a large, apparently unmodified slab of fossiliferous limestone (Specimen FBU2-2), found in the space between the elbows and the knees on the west side of the burial pit (see Figure 26-134). It was located slightly above and ca. $3 \mathrm{~cm}$ north of the mano/chopper. This slab has a very irregular shape (measuring ca. $17-\mathrm{x}-22-\mathrm{x}-10 \mathrm{~cm}$ ) with uneven, naturally pitted surfaces. It tapers to a wedge-like point at one end. Although this limestone has a very high fossil content, it falls within the range of variation found in the local Comanche Peak Formation. No evidence of cultural modification has been detected on this specimen. It was found in the upper portion of the burial pit, resting at a slight angle, with one end sloping down to the south. It did not appear to have been in direct contact with the body. The highest point on this rock (at ca. $94.37 \mathrm{~m}$ ) was higher than all the skeletal remains and the mano/chopper. The lowest point (at ca. $94.26 \mathrm{~m}$ ) was at approximately the same level as the mano/chopper and the higher points on the skeleton. The highest point on the slab was exposed before the pit outline was detected, and the excavators thought a portion of the rock may have protruded above the surface of the grave after it was filled. They speculated that it might have served as a marker for the grave. Certainly, the rock was intentionally placed in the pit (there are no clasts of this size in the surrounding deposits), but it likely represents something other than a marker.

The third inclusion of possible note is a small (ca. 1.5$\mathrm{cm}$-long) fossil shark tooth (cf. Cretoxyrhina sp.) found below the left humerus and above the poorly preserved remains of the cervical vertebrae. The elevation of this specimen (FBU2-3) was $94.19 \mathrm{~m}$. Although this specimen exhibited no evidence of modification, the excavators concluded that it probably represented an ornament of some kind since it was found in the neck area. Although this is certainly possible, it should also be noted that fossil shark teeth occur naturally in the Quaternary deposits of the site where they and other Cretaceous fossils are reworked from the local bedrock. Shark teeth were recovered during the TARL investigations from several dozen fine-screen samples (primarily Unit I contexts). One of these specimens was found in a fine-screen sample from Feature 169, a pit found less than $2 \mathrm{~m}$ south of Burial 2 in approximately the same stratigraphic position (see Feature 169 description).
Apart from the fine-screen recovery (discussed below), other inclusions recovered from the burial pit include at least 2 small charcoal samples, 14 pieces of debitage, ca. 4-5 pieces of unidentified burned animal bone, a small rodent mandible, and 2 small rodent incisors. The mandible and incisors were found in the thoracic region, and the excavators thought they might represent food remains from the individual's digestive tract. Unfortunately, these rodent elements were either lost of misplaced before the TxDOT collections were transferred to TARL.

One of the charcoal samples (CH-1079) was analyzed as a macroplant sample and was identified as indeterminate wood (see Chapter 40). An AMS radiocarbon date was obtained on the other sample (no field number) in 1983. This sample was apparently too small for an accurate date, and the resulting age determination $(13,000 \pm 3000$ B.P., AA-171) had too large a standard deviation to be very informative (see discussion on the dating of Burial 2 in Chapter 25). Additional AMS dates were obtained on six bone samples (listed above) in 1983, but the bone was too poorly preserved, and clearly all of the determinations were too young (see Chapter 25). Two conventional radiocarbon dates were also obtained in ca. 1982-1983 on sediment samples from the pit fill. These determinations ( $9470 \pm 170$ B.P., Tx-4787 and $9650 \pm 124$ в.P., $T x-4793$ ), are thought to be a little young, and they may reflect the presence of stratigraphically displaced (younger) charcoal in the pit fill (see Chapter 25). Charcoal from the roots of an overlying burned live oak tree (see descriptions for Feature 72/73 and 167) was dispersed throughout the upper portion of Unit I deposits in this area of the site. The tree apparently relates to a surface at or near the Unit I/II contact (ca. $70 \mathrm{~cm}$ above Burial 2), and AMS dates obtained on charcoal collected from the burned roots ( $9410 \pm 60$ B.P., CAMS-14805; $9430 \pm 60$ B.P., CAMS-14807) are quite close to the Burial 2 sediment dates.

In refining the age estimate for Burial 2, an AMS date obtained on some charcoal collected from a feature located in approximately the same stratigraphic position as the estimated top of the Burial 2 pit was also considered. Feature 255 was a small hearth constructed on an occupational surface in the lower portion of the Leanne soil (see Feature 255 description). Archeomagnetic results indicate this hearth is in primary context (relatively undisturbed) and its stratigraphic position (slightly above the base of the Leanne soil) is comparable to our stratigraphic reconstruction for the top of the burial pit. An AMS date of $9990 \pm 70$ B.P. (CAMS10195) was obtained on wood charcoal collected from this hearth. After comparing the radiocarbon determinations obtained on the Burial 2 bone and pit fill to the other dates derived from Unit I deposits, Stafford has assigned an age estimate of ca. 10,000-10,500 B.P. to the Wilson-Leonard II burial (see Chapter 25).

The exposure and removal of the Wilson-Leonard II skeletal remains are summarized by Steele in Chapter 31, along with the results of his analysis of the recovered remains. 
The identifiable elements include portions of the cranium, vertebral column, thorax, pectoral girdle/upper limbs, and pelvic girdle/lower limbs. Many of the small bones of the hands and feet are missing, and the bone is rather poorly preserved. Nonetheless, Steele was able to determine that Wilson-Leonard II was a young adult female, probably between ca. 18-25 years old at time of death. He believes she probably had a slight build with relatively short stature (estimated height of ca. $158 \mathrm{~cm}$ ). The braincase and face appear to have been relatively narrow, and her face may have exhibited a moderate degree of alveolar prognathism.

The only evidence of medical disorders was found in her teeth. This includes antemortem loss of an upper first molar, a cracked maxillary molar, an abscessed premolar, several caries on the upper molars, and alveolar resorption along the complete dental arcade. Steele also observed heavier wear on the incisal surfaces of her anterior teeth (incisors and canines) than on the occlusal surfaces of the molars and premolars. He notes that this pattern has been observed in other Paleoindian-age individuals and may reflect use of the anterior teeth as tools (see Chapter 31). In other regards, her tooth wear (which included frequent pits and some moderate-to-large striations) was not dissimilar to that typically observed in later hunters and gatherers. Although this sort of damage might be caused by the consumption of hard and/or gritty plant foods, the damage could be caused by bone consumption as well (see Chapter 31).

In a related study, Wilson performed a stable carbon isotope analysis on a sample of cortical bone from WilsonLeonard II (see Chapter 32). Wilson sought to examine the relative values of $\delta^{13} \mathrm{C}$ apatite, $\delta^{13} \mathrm{C}$ gelatin, and $\delta^{15} \mathrm{~N}$ gelatin, hoping to learn what types of plant foods Wilson-Leonard II consumed (i.e., $\mathrm{C}_{3}, \mathrm{C}_{4}$, or CAM plants), the amount of protein in her diet, and possible protein sources. The protein questions could not be addressed because the collagen was too poorly preserved in this sample to obtain reliable gelatin values. A reliable $\delta^{13} \mathrm{C}$ apatite determination was obtained, however, and this value (-11.2\%) suggests Wilson-Leonard II's diet was based primarily on $\mathrm{C}_{3}$ plants and animals that consumed $\mathrm{C}_{3}$ plants (this value was compared to a range of $-14 \%$ for a completely $\mathrm{C}_{3}$-based diet and $-1 \%$ for a completely $\mathrm{C}_{4}$-based diet).

Several other special studies have been conducted on samples from Burial 2. An organic residue analysis was performed on the mano/chopper by Hurst (see Chapter 23). The residues extracted from this specimen were subjected to both capillary ion analysis (for the determination of inorganic ions) and high performance liquid chromatography (to identify amino acid residues). In the capillary ion analysis, Hurst identified chloride, nitrate, and phosphate anions on this specimen. Although he interprets the chloride as a pedogenic residue (with no cultural significance), he feels the phosphate and nitrate could be derived from cultural sources. This specimen also had residues representing at least 11 amino acids; however, the specific source(s) could not be identified.

The other special studies were all performed on sediment samples from the burial pit fill. With the exception of some blocks of sediment that were lifted along with the skull, rib cage, and pelvis, all of the burial pit fill was bagged in the field and sent to the lab for fine-screening. Most (if not all) of these bags remained unprocessed at the beginning of the TARL analysis, and they were available for a variety of special studies. The blocks of sediment that had supported the skull, ribs, and pelvis had also been bagged after the skeletal remains were conserved and removed, and these were available for further study as well. After various special samples were extracted from these bags during the TARL analysis, approximately 25 liters of pit fill (from various locations within the burial) were reserved for future research.

The sediment samples were especially valuable in efforts to clarify the burial's stratigraphic position. Since the field observations suggested the pit was probably filled with Leanne soil matrix, additional laboratory observations were used to explore this hypothesis further. A series of micromorphology and magnetic susceptibility samples was pulled from the various bags of pit fill, and these samples were then compared to other Unit I samples from known contexts.

The micromorphology samples included two made from sediment collected immediately outside the pit and eight samples made from sediment collected from various locations within the pit (see Chapter 29 and Appendix 7). A thinsection made from matrix outside the west side of the pit (WL93-B5) most closely resembled Unit Isi thin-sections. A sample from outside the east side of the pit (WL93-B6) most closely resembled Unit Icl samples (although it may have been transitional Unit Icl/Isi-c). The eight samples representing the pit fill varied considerably, and on the basis of the features he observed in these thin-sections, Goldberg concluded that the Burial 2 pit was probably filled with a mixture of Unit Isi, Unit Icl, and Unit Isi-c sediments.

Similar results were obtained from the 66 magnetic susceptibility samples (see Chapter 28). The variation in the susceptibility values obtained on samples from different locations within the pit suggest it was filled with a heterogeneous mixture of sediments with different initial magnetic susceptibility values. These values fell within the observed ranges for Unit Isi, Icl, and Isi-c samples and generally support the results of the micromorphological analysis.

Other pit fill studies include 34 flotation samples (see Chapter 40) and 5 phytolith samples (see Chapter 41). Although a relatively large volume of sediment was floated (ca. 95 liters), no identifiable plant remains were recovered. The phytolith samples were also nonproductive, with no phytoliths recovered.

The "sludge" resulting from the flotation samples was subsequently fine-screened through nested $1 / 8$ - and 1/16inch mesh (to examine the heavier inclusions that settled at the bottom of the flotation bucket). A small (ca. 6-liter) sample 
of previously unprocessed sediment was also fine-screened during this process. The recovered coarse and fine fractions were examined for inclusions of interest, but they were not completely sorted/picked (although they have been curated). In addition to very small fragments of probable human bone (unidentifiable), the fine-screen recovery included numerous small fragments of animal bone (about half were burned), an eggshell fragment (see Chapter 36), microdebitage (relatively small amounts), small burned limestone fragments/chips, a few small pieces of hematite, and very eroded snail shells. The recovery (including the noncultural, natural inclusions in both the coarse and fine fractions) generally resembled the recovery from other Leanne soil fine-screen samples.

Comments: The results obtained from the micromorphology, magnetic susceptibility, and fine-screen analyses lend additional support to the field assessment that the top of the Burial 2 pit originated within the Leanne soil (Unit Isi-c). Although the burial pit was probably filled with some of the Unit Isi and Unit Icl sediments that were removed when the pit was excavated, the fill apparently also included some of the overlying Leanne soil sediments. Some of the occupational debris contained in these sediments was apparently incorporated into the pit fill as well. The pit most likely originated from a surface within the lower portion of Unit Isic, because the pit appears to have been excavated just large enough to encompass the flexed body (the top of the pit was probably no more than $20 \mathrm{~cm}$ above the detection level).

The mano/chopper and the limestone slab were clearly intentional inclusions that were carefully placed within the pit. Their ritual or functional significance is unknown. It seems unlikely that the slab served as a marker. Both stones may have been used to dig the grave, or they may have served as weights holding a wrapping around the body in place. The slab may also be functionally related to the mano/ chopper in some way (e.g., an anvil stone). The shark tooth may be a natural inclusion in the pit fill, or it may represent an ornament. The lack of phytoliths could suggest that no plants rich in biosilicates were used as a pit lining.

The reconstructed stratigraphic position of Burial 2 indicates it is very likely associated with the Late Paleoindian Wilson component. The chronostratigraphic evidence suggests the Wilson-Leonard II individual was probably interred ca. 10,000 years B.P.

No cause of death is known, although the age at death is within the childbearing years. Anatomically, WilsonLeonard II compares favorably with the few other North American skeletal remains of this general age. 


\section{Chapter 27}

\section{ARCHEOMAGNETIC ANALYSIS OF BURNED LIMESTONE ROCKS}

by Paul R. Takac

\section{INTRODUCTION}

Archeomagnetic analysis of burned rocks was a principal focus of the 1992-1993 TARL investigations at the Wilson-Leonard site. This analysis was undertaken to evaluate the formation, structure, and preservation of burned rock features by assessing the cooling positions and thermal histories of individual rocks. Archeomagnetic data were used to determine if a rock cooled in place, if it was moved as it cooled, and, if it was moved, the frequency, magnitude, and temperatures of those displacements. In some cases, it was also possible to determine the most likely directions of movement, information that was then used to infer the prior morphology of a feature. In other instances, magnetic analysis was used to simply test whether certain rocks were heated at all.

Application of archeomagnetism to the study of burned rocks has been developed by researchers at The University of Texas at Austin over the past several years (Collins 1991; Collins et al. 1990; Gose 1990, 1994; Gose, Collins, and Takac 1994; Gose, Collins, and Collins 1994; Mueggenborg 1991; Smith 1990; Takac 1997, 1998, n.d.; Takac et al. 1993; Takac and Collins 1995; Takac and Gose 1994, 1997). Similar studies have been conducted on sites of Archaic age in Oklahoma, precontact Australia, Upper Paleolithic France, and Iron Age Switzerland (Barbetti, Taborin et al. 1980; Barbetti, Clark et al. 1980; Clark and Barbetti 1982; Ramseyer 1991; Schmidt 1980). However, these investigations apparently never developed into a sustained research program as have those in Central Texas. The archeomagnetic database resulting from the TARL investigations at the Wilson-Leonard site is the largest of its kind in the number of samples collected and analyzed. This study contributed substantially to the development of this ongoing research program. It resulted not only in more-detailed interpretations at WilsonLeonard but also a greater understanding of the potential of burned rock archeomagnetic research generally.

A total of 1,269 archeomagnetic samples was collected. Of these, 7 were from natural bedrock or gravel bar contexts for comparative purposes. The remainder include 11 whole rocks, 4 plastic cubes of burned sediment, and 1,247 rock core samples drilled from 1,207 individual burned rocks. A total of 725 core samples were analyzed. Six were subsequently discarded due to provenience problems, and the remainder (including the whole rocks, sediment, and unanalyzed specimens) have been curated. A complete list of all analyzed and curated samples is given in Appendix 6 .

\section{OVERVIEW}

Paleomagnetic evaluation of burned rocks is based on the same principles used to date clay-lined fireplaces and burned sediments (e.g., Eighmy and Sternberg 1990; Tarling 1983, Wolfman 1984). Limestone rocks recovered at archeological sites in Central Texas typically contain minute quantities of small iron-oxide grains, such as magnetite and hematite, which carry small internal magnetic charges (or "moments"). The direction of these magnetic moments can be realigned-parallel to the Earth's magnetic or geomagnetic field-by heating. After cooling, some grains retain these new magnetic moment directions as a thermoremanent magnetization (TRM). The specific temperature at which this occurs in an individual grain varies according to its chemical composition, size, and atomic arrangement and is termed its blocking temperature. TRM acquisition typically occurs throughout a wide range of temperatures below the Curie point, which can be considered the maximum blocking temperature of a particular iron-oxide type. If a rock cools through some temperature range without moving, then all grains with blocking temperatures in that range will share a common magnetic moment direction. This combined or net magnetization within a specific range is termed a partial thermoremanent magnetization (pTRM) or, more commonly, a "component." While it can be used interchangeably with component, the term "vector" may also refer to the total magnetization in a rock (which may be composed of many components). Each vector is three-dimensional: it is 
defined by both direction (declination and inclination) and intensity (which may be thought of as its length). The processes by which thermoremanent magnetizations are acquired, and later recovered in the laboratory, are discussed in greater detail in the sections that follow.

Archeomagnetic data provide archeologists with a new tool for investigating the context and thermal histories of burned or heat-modified rocks. For example, if all of the rocks in a particular feature were heated in excess of the Curie point and then allowed to cool without moving, they will share identical, single-component magnetizations (parallel to the ambient geomagnetic field) as shown in Figure 27-1a. If, on the other hand, they were displaced after completely cooling they will have chaotic (and perhaps random) magnetic directions as shown in Figure 27-1b. Finally, if they moved after only partially cooling or were heated only to some maximum temperature below the Curie point, then two or more components (pTRM's) might be recognized. The lower temperature components would have a common alignment while the higher temperature ones would be scattered. An idealized two-component situation is shown in Figure 27-1c. If a rock moved during or after cooling, the deviation of its measured components from the Earth's magnetic field can, in some cases, be used to infer the rock's prior location(s) and how it may have come to be in its final position.
The circular diagrams (or stereonets) that accompany each feature in Figure 27-1 are graphical representations of measured magnetic vector directions. Stereonets are discussed in greater detail in the Data Presentation Section below. At this point, however, it is sufficient to note that common directions will cluster tightly while scattered ones will also scatter on the stereonet.

The following sections briefly outline the physical basis of magnetic remanence, the acquisition of thermoremanence in burned rocks, and the specific techniques and analytical procedures used in this study. These introductory sections provide the foundation necessary for a greater understanding of the results and interpretations presented herein. This chapter is one of the first attempts to fully describe the archeomagnetic study of burned rocks to an archeological audience. Thus, the explanations of complex magnetic phenomena have perhaps been oversimplified, but they are a necessary prerequisite for appreciating the dimensionality and interpretive potential of this technique. In other cases, concepts are presented in more than one way in order to reiterate and clarify important, though probably unfamiliar, aspects of archeomagnetism. The following section draws heavily from the introductory chapters of numerous texts on paleomagnetism and rock magnetism (Collinson et al. 1983; Merrill and McElhinny 1983; Tarling

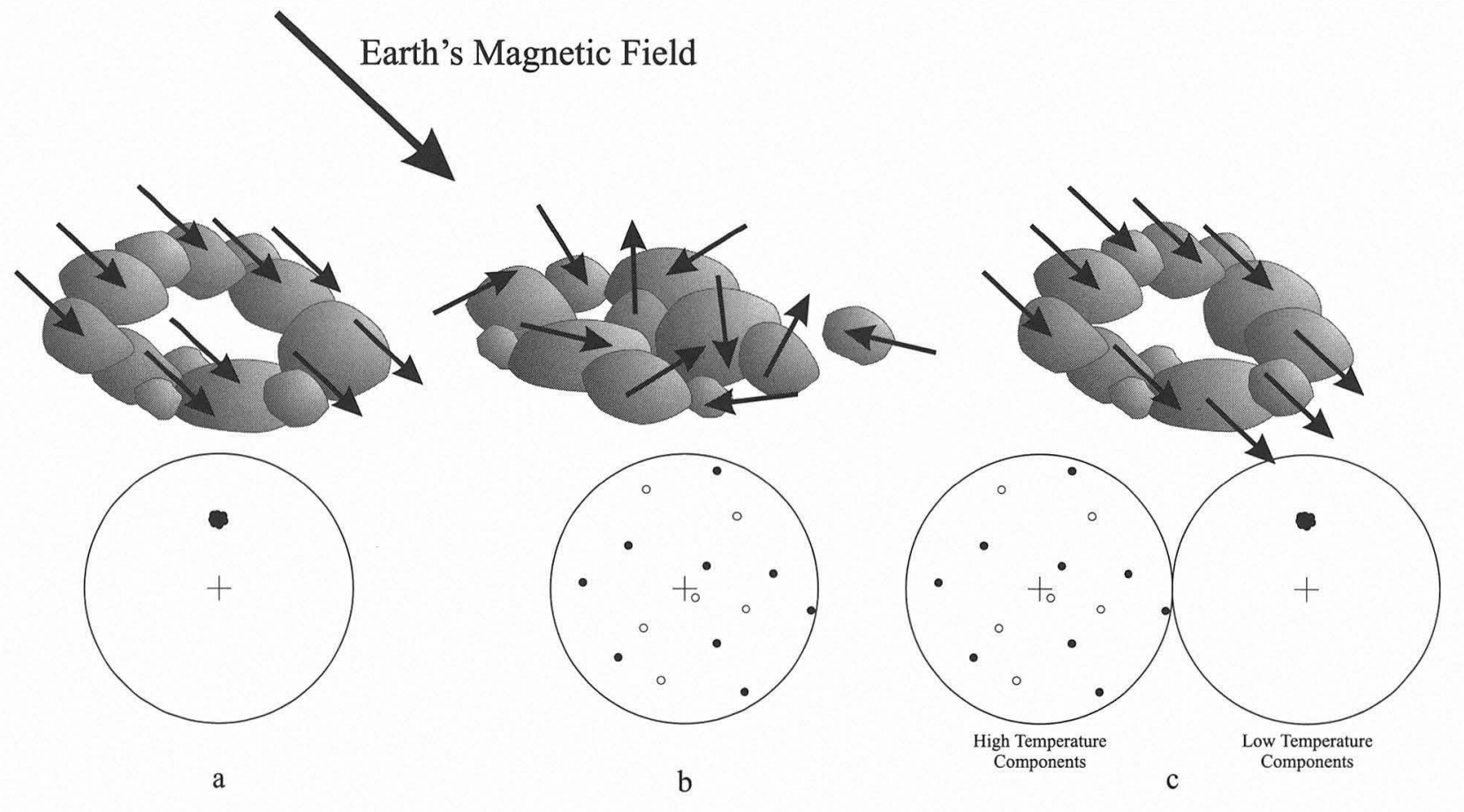

FiguRE 27-1. Figure showing three idealized burned rock features (after Kappelman 1993). In (a), a cluster of rocks with a single component of magnetization have remained in their final cooling locations (as indicated by the close clustering of solid dots on the accompanying stereonet). The feature in (b) is composed of single component rocks that have been displaced from their final cooling positions (as evidenced by the widely scattered remanence directions on the stereonet). (C) shows a two-component situation. The rocks are shown in their final cooling locations (as indicated on the right-hand stereonet on which the low temperature components are plotted) but the scattered directions of higher temperature components on the left-hand stereonet indicate that these rocks did not cool in these positions from the Curie point. Given only this information, one cannot determine whether the two components result from movement while cooling or only partial reheating. 
1983; Thompson and Oldfield 1986) and especially from Paleomagnetism by Butler (1992), which is an excellent starting point for those wishing to further pursue these topics.

\section{The Physical Basis of Rock Magnetization}

All materials react when placed in a magnetic field. The intensity of this "induced" magnetization is a function of both the field strength and the magnetic susceptibility of the material, which may be regarded as its "magnetizability." However, induced magnetization in the great majority of materials is transitory: the effect disappears when the surrounding magnetic field is removed. Matter composed of these effectively (for our purposes) "nonmagnetic" materials will therefore react to whatever magnetic field is currently acting on them, independent of any previously applied magnetic fields.

Certain minerals, on the other hand, can record magnetizations acquired in prior magnetic fields. Materials capable of retaining such remanent magnetizations are termed ferromagnetic (sensu Butler 1992:26) and are composed primarily of iron oxides $\left(\mathrm{Fe}_{x} \mathrm{O}\right)$ and iron sulfides $\left(\mathrm{Fe}_{x} \mathrm{~S}\right)$. Two of the most common ferromagnetic minerals are magnetite $\left(\mathrm{Fe}_{3} \mathrm{O}_{4}\right)$ and hematite $\left(\mathrm{Fe}_{2} \mathrm{O}_{3}\right)$. Ferrromagnetism results from particular crystallographic ordering in these grains and is characterized by higher susceptibilities and stronger magnetizations than are found in nonmagnetic minerals.

The limestone rocks of Central Texas, such as those recovered at Wilson-Leonard, contain a heterogeneous mix of ferromagnetic grains dispersed in a matrix of essentially nonmagnetic material. There are many types of magnetic remanence, but the present study deals solely with the thermoremanent overprinting of original depositional remanence, with some consideration of the possible effects of viscous (postdepositional) and/or chemical magnetizations. That is, the focus is on the alteration of the original depositional remanence (acquired by the limestone formation as it was deposited and lithified) by heating, resulting in a thermoremanence (acquired in an individual stone as it cooled in prehistory).

\section{Acquisition of Thermoremanence (TRM)}

TRM acquisition is possible because remanent magnetizations are not permanent and can be altered by increases in either temperature or magnetic field strength, as well as by chemical or physical alteration of the grain itself. The stabil- ity of magnetization can be defined in terms of "relaxation time." At low temperatures, some ferromagnetic grains have relaxation times on the order of millions or even billions of years while others can rapidly develop a modern or viscous magnetization (cf., Borradaile and Brann 1997). As the temperature of a ferromagnetic grain rises, its relaxation time decreases until a point (the blocking temperature) at which the magnetic moment of that grain realigns with the ambient magnetic field. ${ }^{1}$ The maximum blocking temperature for any ferromagnetic mineral is its Curie point $\left(580^{\circ} \mathrm{C}\right.$ for magnetite and $680^{\circ} \mathrm{C}$ for hematite). However, due to variations in grain size, structure, and composition, a wide range of blocking temperatures is typically encountered for most ferromagnetic minerals. Depositional rocks (such as those analyzed at WilsonLeonard) typically contain a heterogeneous magnetic mineralogy and, consequently, a wide range of blocking temperatures over which thermal data can be recorded (Butler 1992:192193; Lowrie and Heller 1982; Tarling 1983:27, 56-62).

The magnetic moment of a ferromagnetic grain can also be realigned at constant temperature by increasing the strength of the ambient magnetic field. This is primarily important in the laboratory where it is used as a demagnetization technique. The energetic equivalent of blocking temperature is "coercivity" (or the threshold magnetic field strength at which a grain's existing remanence is removed). Coercivity, as used here, is defined by the energetic strength of that applied magnetic field and is measured in Oersteds (Oe). ${ }^{2}$ For purposes of comparison, the geomagnetic field varies from 0.24 to $0.66 \mathrm{Oe}$ across the Earth's surface and is strongest at the poles and weakest at the equator (Butler 1992:Table 1.1; Tarling 1983:163-171).

As either the coercivities or blocking temperatures of more and more grains are exceeded, the magnetic moments of each are realigned as shown in Figure 27-2. In this idealized depiction, each grain is represented by a circle and its magnetic moment direction by an arrow. In Figure 27-2a, the magnetic moment of each grain points in a different direction. However, as either the temperature or the magnetic field strength is progressively increased, more and more grains are realigned (the darkened circles in Figures $2 \mathrm{~b}$ and 2c). Finally, when the Curie point or the maximum coercivity is reached, all of the magnetic moments are realigned as shown in Figure 27-2d. If the magnetic field strength or temperature then decreases, these newly acquired directions will remain unless or until, of course, either one increases again. $^{3}$

\footnotetext{
${ }^{1}$ The interrelationship of temperature, grain characteristics, and relaxation time is fully described in Neel's equation (see Butler 1992:5255) but involves a level of complexity far beyond the scope of this discussion.

${ }^{2}$ Note that the unit system employed in this report is the Gauss or "cgs" (centimeter/gram/second) system rather than the Système Internationale (SI) to avoid the pitfalls commonly encountered as the result of such conversions (discussed in Butler 1992:15-17). Units of magnetic field strength are commonly (but not precisely) related by 1 Oersted (cgs) $=10^{-4} \mathrm{Tesla}$ (or $0.1 \mathrm{milliTesla}$ in SI).

${ }^{3}$ The actual remanence direction in any individual grain may not exactly parallel the ambient geomagnetic field due to preferred planes and impurities within the crystal lattice. However, in a group of grains, these effects are generally averaged out and accurately reflect the magnetic field direction.
} 


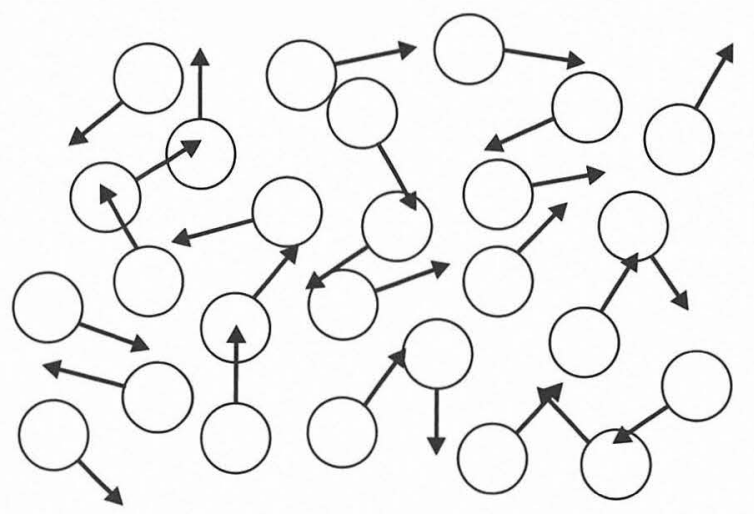

a

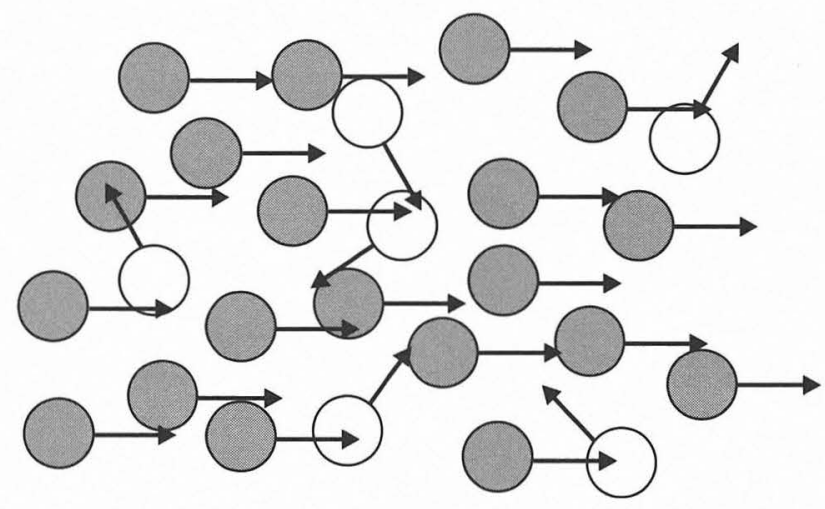

C

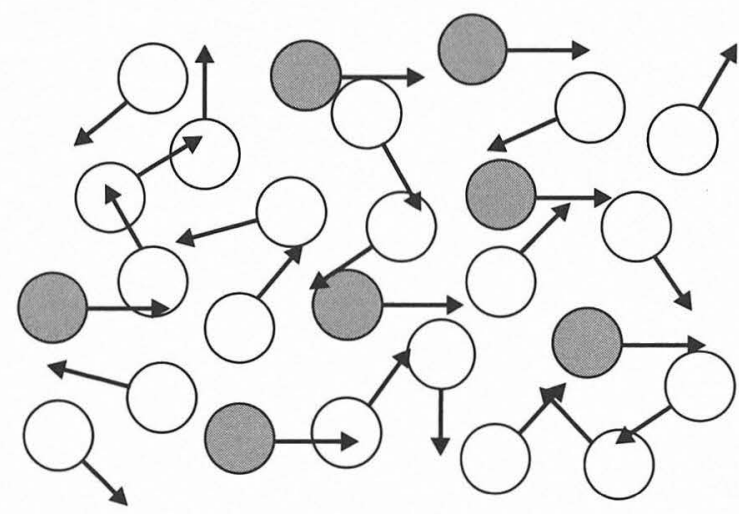

b

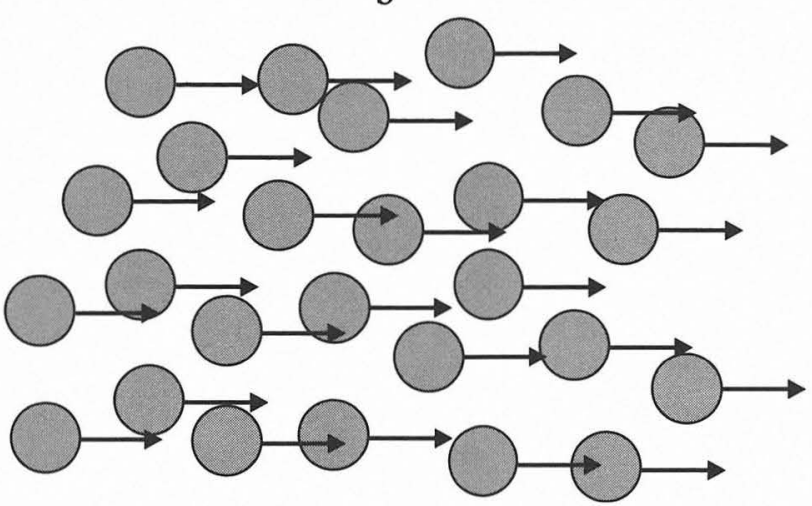

d

FIGURE 27-2. Schematic figure showing the progression of remanence acquisition in a hypothetical group of ferromagnetic grains as either the ambient temperature or electromagnetic field strength is increased. The grains in (a) are randomized, before the temperature or magnetic field strength is raised. As the coercivities or blocking temperatures of more and more individual grains are exceeded, the magnetic moments of those grains are realigned, as shown in (b) and (c). Finally, in (d) the Curie point or maximum coercivity has been reached and all of the grains have acquired a common direction of magnetization. If the temperature or magnetic field strength then decreases, these new component directions may be retained as a remanence.

A common alignment of magnetic moments within a particular range of blocking temperatures or coercivities is termed a component of magnetization. If all of the ferromagnetic grains in a burned rock have the same direction (i.e., they are uniformly aligned below the Curie point), the rock is said to be single component. If, however, two or more directions are noted, the rock is multicomponent. In archeological settings, multiple components could result from either movement while cooling or from only partial heating or reheating.

Returning to the relevance of this for archeomagnetic studies, a rock containing ferromagnetic grains with a wide range of blocking temperatures can record its orientation relative to the Earth's magnetic field at various temperatures. The burned limestone rocks recovered from the WilsonLeonard site are almost all of a mineralogy sufficient to record TRM's as they cooled. It was therefore possible to decipher their thermal histories and to test hypotheses about the context of individual burned rocks, as well as the formation and preservation of the features from which they were recovered.

\section{Demagnetization and Component Separation}

The topics of TRM directionality in heated rocks and the laboratory demagnetization processes by which these components may be reconstructed are closely related. One of the challenges involved with separating individual components (pTRMs) is that the measured remanence of the sample is the sum of the direction and intensity of all vectors contained within it. For example, if a rock is heated above the Curie point and then cools (without moving) to $200^{\circ} \mathrm{C}$ but is then flipped over and finishes cooling in a different position, it will contain two pTRMs (components). The first component will result from the aligned magnetic moments of those grains with blocking temperatures greater than $200^{\circ} \mathrm{C}$, and the second pTRM from those grains with blocking temperatures below $200^{\circ} \mathrm{C}$. The total initial vector (before demagnetization) is termed the "natural" remanent magnetization (or NRM) and will point somewhere between these two components. In order to separate the pTRM's, it is necessary to isolate the direction, 
intensity, and temperature (or coercivity) range of each.

Short of changing the chemical structure of a grain, there are two primary ways to realign magnetic moments: increasing either the temperature or the strength of the surrounding magnetic field. Both methods are in fact the basis of laboratory techniques used for measuring and reconstructing component magnetizations. Thermal demagnetization (TD) is essentially the controlled, incremental reversal of TRM acquired in antiquity while Alternating-field demagnetization (AF) exposes the sample to increasingly stronger electromagnetic fields that affect progressively more stable, higher coercivity ferromagnetic grains (which usually, though not always, also have higher blocking temperatures).

As a rock sample cools in the laboratory it can easily acquire a new thermoremanence which complicates the task of reconstructing ancient TRM component(s). However, if that sample is allowed to cool in a virtually zero-strength magnetic field, then the directions in which the ferromagnetic grains "lock in" will be randomized and thereby impart no net bias in TRM direction (effectively the reverse of the progression seen in Figure 27-2). This is the essence of thermal demagnetization. The Wilson-Leonard rock samples were heated to progressively higher threshold temperatures and then allowed to cool in a chamber wrapped with three layers of magnetically impenetrable metal (" $\mu$-metal"). The cooling chamber is itself contained within a small room made of the same magnetic field-resistant material. Following each heating step, the samples were measured in a magnetometer also housed within this shielded room. Each heating/cooling interval isolates only those grains with blocking temperatures greater than the last laboratory heating. As heating temperatures increase, fewer and fewer grains with an ancient remanence are being measured, until the Curie point is reached and all grains have been randomized. By tracking the remaining direction and intensity of the magnetic vector at each interval, the individual components contributing to the total, pretreatment (NRM) magnetization can be separated and identified.

Alternating-field demagnetization, on the other hand, exposes the sample to electromagnetic fields of progressively greater strength. However, the applied magnetic field does not decrease instantaneously; instead, as it decreases in intensity, its polar direction flips back and forth (hence the term alternating field). Since anti-parallel magnetizations of equivalent strength cancel each other out (resulting in a zero net magnetization), alternating-field demagnetization effectively "erases" those grains with coercivities below the maximum applied field. As with thermal demagnetization, the remaining initial magnetization is measured after each exposure. Once again, all samples are treated and measured in the $\mu$-metal-shielded room to avoid contaminating laboratory magnetization(s). The maximum electromagnetic field applied is limited by the equipment used. The ceiling for alternating-field demagnetization of the Wilson-Leonard samples was 1,000 Oe (or approximately
2,000 times the average strength of the Earth's surficial magnetic field in Central Texas). Such maximum intensities are sufficient to demagnetize almost any magnetite grain but are typically too weak to affect more-stable hematite grains which can have much higher coercivities. Nevertheless, for the purposes of determining primary TRM direction(s), this afforded adequate, if not complete, separation of individual magnetic components.

The archeomagnetic samples from the Wilson-Leonard site were demagnetized by either TD or AF demagnetization. In all cases, NRM was reduced by at least $50 \%$ and typically much more in order to determine the primary components of magnetization. The advantages and disadvantages of each demagnetization technique are discussed in the Laboratory Procedures section below.

Recording changes in initial NRM magnetizations as they are progressively reduced under controlled laboratory conditions provides the data necessary for statistical analyses (discussed in the next section) by which these components are identified, separated, and oriented in three-dimensional space. In the following sections, bear in mind the aggregate nature of remanence. The original, pretreatment NRM of any rock is the sum of all components; just as each component is the sum of the individual magnetic moments contributing to it.

\section{THE PRESENTATIONANDANALYSIS OFTHREE-DIMENSIONALDATA}

The goal of laboratory demagnetization is the isolation of individual magnetic components (pTRMs) by tracking changes in overall remanence as demagnetization proceeds. This can be demonstrated on a three-dimensional coordinate system (Figure 27-3). The intensity of the initial, pretreatment vector (NRM) is depicted by an arrow emanating from the origin (or the point of view of the observer measuring the sample) in Figure 27-3a. After the sample has been demagnetized to $200^{\circ} \mathrm{C}$, the measured remanence has moved (see Figure 27-3b). Continued demagnetization to $400^{\circ} \mathrm{C}$ results in more movement (see Figure 27-3c). However, from this point on, further heating results only in the loss of remanence intensity; the direction remains more or less constant. Eventually, when all of the grains with higher blocking temperatures are demagnetized, the remanence intensity will be reduced to zero. This unidirectional loss of intensity indicates that the highest temperature or coercivity component has been isolated.

It is inherently difficult to depict such three-dimensional data in two dimensions. Diagrams like Figure 27-3 are impractical to construct and difficult to interpret when dealing with real data. Therefore, the graphical techniques outlined next are those commonly employed in paleomagnetic studies and each has strengths and weaknesses. They are complementary and used for different purposes in successive stages of archeomagnetic analysis. 


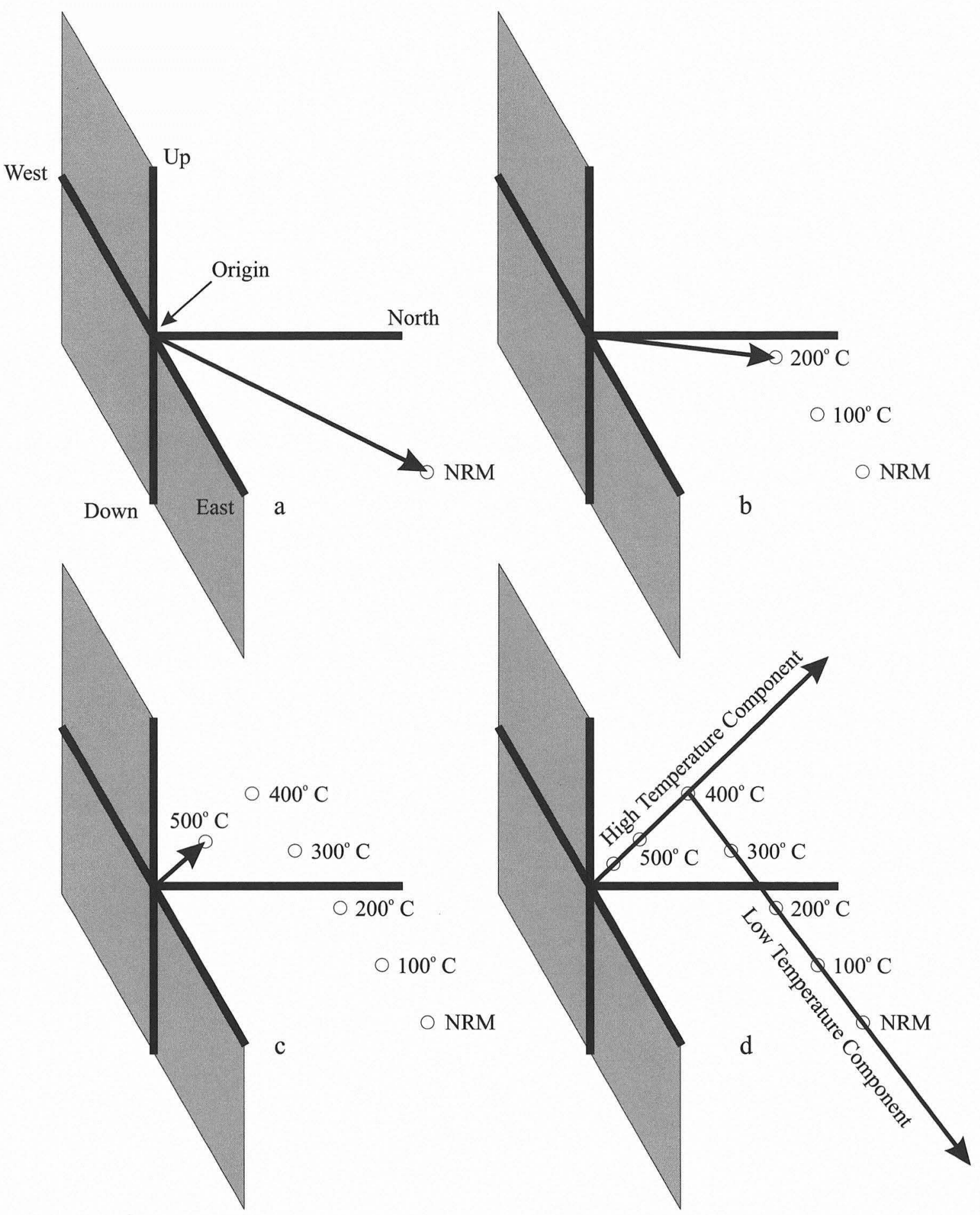

FIGURE 27-3. This figure shows the changes in direction and intensity of remanence as demagnetization proceeds. In this case, the initial pretreatment vector (NRM, or "natural" remanent magnetization) of the sample is measured as shown in (a). Following thermal demagnetization to first $100^{\circ} \mathrm{C}$ and then $200^{\circ} \mathrm{C}$, as shown in (b), the endpoints of the measured remanence (shown as open circles) have changed both in terms of direction and intensity. As demagnetization proceeds to $500^{\circ} \mathrm{C}$, as shown in (c), measured remanence continues to change. However, note that between $400^{\circ}$ and $500^{\circ} \mathrm{C}$ only the intensity changes, the direction does not. This is the highest temperature component. Further demagnetization will result only in continued weakening of the remanence intensity (the direction will remain constant). After the Curie point has been reached and demagnetization is completed as shown in (d), the two components which contributed to the original NRM measurement can be reconstructed by passing a line through the measured endpoints at each demagnetization step (see Principal Component Analysis below). 


\section{As-Zijderveld Diagrams}

As-Zijderveld (AZ) or vector component diagrams (Butler 1992:110-117; Dunlop 1979) are vitally important to the analysis of the multicomponent samples commonly encountered in archeological contexts. AZ diagrams were constructed for each analyzed sample at Wilson-Leonard and a complete set is on file at TARL.

AZ diagrams depict a three-dimensional vector by projecting it into two planes and combining them on a single Cartesian projection. An example is given in Figure 27-4. Unlike stereonets, which depict only direction, AZ plots include information on remanence intensity but at the cost of splitting the vector into separate planes. As in Figure 273 , the measured vector endpoints at each demagnetization step are plotted (as solid dots). Distance from the origin is normalized to the highest remanence intensity (typically NRM or the initial measurement). As the component(s) comprising NRM are progressively removed during demagnetization, the trend (or slope) of the data reveal the directions and ranges of those components.

In Figure 27-4a the component is shown in the horizontal plane, as if looking down on the vector, like reading a compass. Note the axes correspond to the cardinal directions.
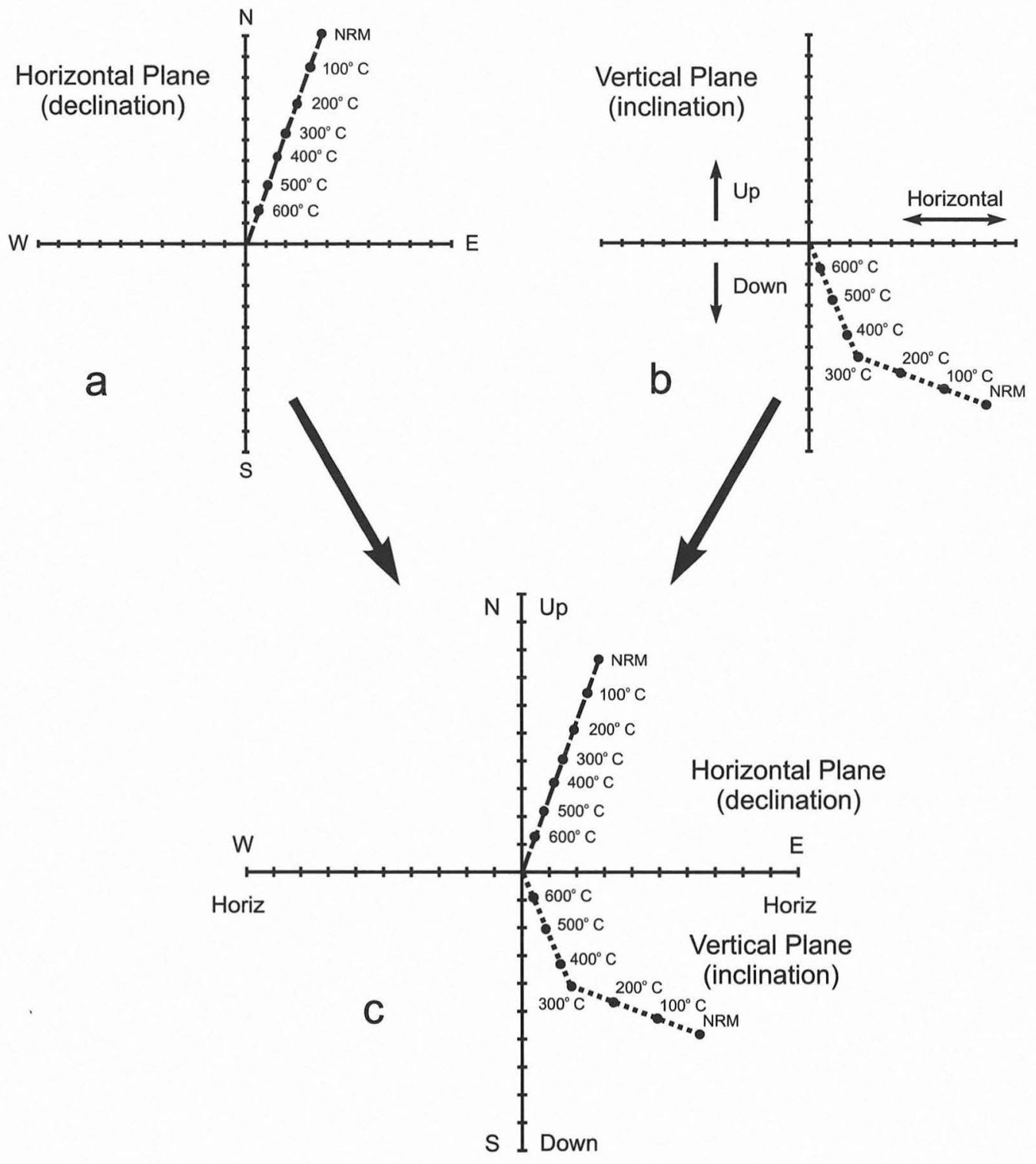

FigURE 27-4. Figure showing the construction of an As-Zijderveld (AZ) or vector component diagram for a hypothetical burned rock sample. In (a) vector endpoint measurements at each demagnetization step are plotted in the horizontal (azimuth) plane. Only a single, north-northeasterly trend is apparent in the data. The slope is on a path to intersect the origin. In (b) the same vector endpoints are plotted relative to the horizontal plane (i.e. in vertical aspect). Here, a break in slope at $300^{\circ} \mathrm{C}$ indicates a pTRM component change (cf. $400^{\circ} \mathrm{C}$ in Figure 27-3d). The rock was either moved or partially reheated to this temperature threshold. Both planes are then combined on a single $\mathrm{AZ}$ plot in (c). 
A "break" in the slope of the azimuthal direction would mark the endpoints of individual magnetic components but no change in slope is apparent in Figure 27-4a. Therefore, only a single vector (roughly north-northeast) is indicated. However, one must also consider the vertical plane plotted on Figure 27-4b. Note that in this plane, the axes depict the relationship of the measured endpoints to horizontal. Positive inclinations (slopes) trend toward the horizontal axes from below while negative ones slope down to the horizontal from above. Two distinct slopes are evident: a shallow, positive low-temperature component $\left(<300^{\circ} \mathrm{C}\right)$ and a steeper, higher temperature one $\left(>300^{\circ} \mathrm{C}\right)$. Therefore, two pTRM's are clearly indicated. The complete AZ diagram combines both the declination and inclination planes as shown in Figure $27-4 \mathrm{c}$. Note that the axes represent both azimuthal and horizontal planes, depending on which aspect of the vector is being considered. This example illustrates the importance of considering both two-dimensional planes to adequately describe a three-dimensional vector.

AZ diagrams are particularly useful for the recognition of individual components and deciphering complex magnetizations (Dunlop 1979) and are the basis of Principal Component Analysis (discussed below). Once these constituent components have been defined for individual samples, however, it is often more informative to plot them on a stereonet, as is done in the bulk of this report.

\section{Schmidt Equal-Area Stereonets}

Schmidt Equal-Area stereonets are also used to represent three-dimensional directional data on a two-dimensional plane (Figure 27-5). Imagine a stereonet as a transparent ball with one hemisphere extending into the page and the other projecting out of the page. The drawn circle is where the plane of the paper bisects the sphere. The cross in the middle is the center of this transparent ball: the "origin" or point of view of the observer. The azimuthal (declination) directions are indicated around the outside edge like a compass face. North $\left(0^{\circ}\right.$ or $\left.360^{\circ}\right)$ is at the top and all directions are measured east of north so that the cardinal directions are $90^{\circ}(\mathrm{E})$, $180^{\circ}(\mathrm{S})$, and $270^{\circ}(\mathrm{W})$. The inclination is measured from horizontal (around the outside edge of the sphere) to $90^{\circ}$ straight up (or down) at the origin. The dots represent the points at which magnetic vectors or components, emanating from the origin, intersect the surface of the sphere (of unit radius). By convention, positive inclinations are below the horizontal and are represented by solid symbols (where the components intersect the hemisphere extending into the page) while open symbols indicate negative inclination values (which intersect the hemisphere coming out of the page).

Although the pole of the Earth's magnetic field is known to vary (or wander) through time - a phenomenon known as geomagnetic secular variation, the foundation of most archeomagnetic dating techniques - its time-averaged direction has been found to be indistinguishable from the Geo-

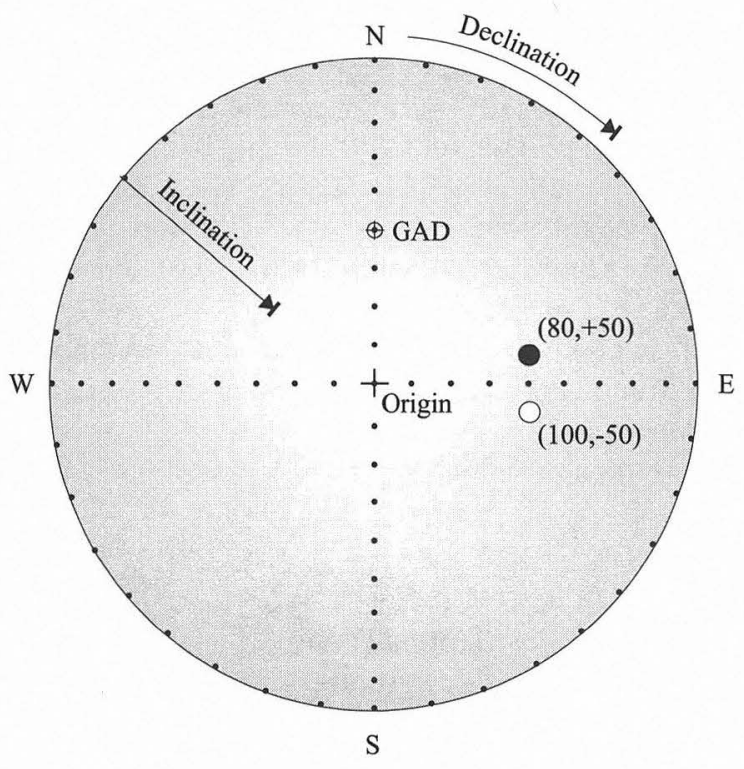

FIGURE 27-5. Figure showing how to read a Schmidt Equal-area stereonet. The declination is read around the outside of the circle. The inclination is indicated by the distance of the dots from the outer ring $\left(0^{\circ}\right.$, or horizontal) to the center cross $\left( \pm 90^{\circ}\right.$, or straight down or up, respectively). This center cross is the origin, or point of view of the observer. The small circled cross marked GAD is the approximate direction of the Geocentric Axial Dipole as viewed from Central Texas. The remanence components of rocks that cooled in place should cluster as solid dots around the GAD. Note that the dots are either open (negative inclinations, or those above the horizon) or closed (positive inclinations, or those below horizontal).

centric Axial Dipole (GAD), a mathematical model which places a magnetic dipole at the center of the Earth, aligned with its rotational axis (Butler 1992:12). This GAD direction, as viewed from Central Texas (approximately $360^{\circ}$ North and $50^{\circ}$ down), is the direction near which the measured components of all rocks that cooled in place should cluster (e.g., Figure 27-1a). Bear in mind, however, that the degree of clustering depends on factors such as (1) past secular variation, (2) depositional and postdepositional disturbances (such as compaction, settling, and shrink/swell cycles of the soil matrix), and (3) intentional and unintentional disturbances caused by human and animal inhabitants of the site. The actual GAD direction in Central Texas has a slightly greater inclination, but the direction indicated here served as a convenient baseline for all stereonets and vector rotation reconstructions (see next section). The observed deviation of the modern geomagnetic field from the GAD is taken into account during the initial computation of individual magnetic components.

When interpreting stereonets, it is important to remember the differences in direction represented by solid and open dots. For example, although the two dots shown on the stereonet in Figure 27-5 appear close, they actually indicate very different directions. The solid dot (declination $80^{\circ}$, inclination $+50^{\circ}$ ) represents a vector pointing away from the 
viewer while the open $\operatorname{dot}\left(\right.$ declination $100^{\circ}$, inclination $-50^{\circ}$ ) represents one that is coming out of the page toward the viewer. The angular difference between them is more than $100^{\circ}$.

The disadvantage of stereonets is that they depict only direction: all intensity (or vector length) measurements are normalized to the radius of the sphere. However, the advantage is that once individual magnetic components are defined they can be easily grouped on a single stereonet whereas $\mathrm{AZ}$ diagrams quickly become cluttered and indecipherable when depicting more than one or two samples.

\section{Statistics and Component Identification}

Because the direction and intensity of the remanence of each sample is tracked during demagnetization, the direction and range of the individual magnetic components can be reconstructed and identified statistically using either Principal Component Analysis (Kirschvink 1980) or Fisher (1953) statistics, both of which are standard in paleomagnetic research (e.g., Butler 1992).

\section{Principal Component Analysis}

Principal Component Analysis (PCA) can be used to assess the collinearity of three or more points in three-dimensional space (Kirschvink 1980). Maximum angular deviation (MAD) is a quantitative measure of the precision with which a component has been defined by PCA. The smaller the MAD value, the more collinear the points and, consequently, the better defined the vector. Those components defined by PCA are identified in Tables A6-1 and A62 in Appendix 6 by a B (for Best-fitting vector) preceding the parameters of the range. The accuracy of their corresponding MAD values are given to the first decimal place.

\section{Fisher Distribution Statistics}

The Fisher statistic is a measurement of the dispersion of directions on the stereonet (see Butler 1992:136-145). In component identification, it is used mainly when the primary change during demagnetization is decreasing intensity while the declination and inclination remain relatively constant (as was the case above $400^{\circ} \mathrm{C}$ in Figure $27-3$ above). The dispersion of a Fisher distribution is given by $\kappa$ (kappa, or the precision parameter). Mathematically, this is always an unknown value but can be reasonably estimated. This estimation takes into account many factors, including the number of data points (in this case, magnetometer readings). The larger the $\kappa$ value, the more well-defined the vector. The ranges of those components identified using Fisher statistics are preceded by an $\mathrm{F}$ in Appendix 6 and $\kappa$ is given in whole numbers.

For both PCA and Fisher statistics, individual magnetometer measurements that were clearly aberrant were ex- cluded. These are listed following the range of the identified components in Appendix 6. In rare instances, the difference between only two measurements was used. In such cases, the component was defined as a straight-line and the statistical uncertainty was zero (i.e., a straight line between two points cannot vary). Nevertheless, they are the most poorly defined vectors. Straight-line vectors were used only where the trend in the demagnetization data on the $\mathrm{AZ}$ diagram clearly indicated the likelihood of a vector in that range. Straight-line derived components are preceded by an $\mathrm{S}$ in Appendix 6.

\section{Vector Rotation Reconstructions}

Vector rotation reconstructions are an attempt to quantify the likely directions of rock movement in order to reconstruct, insofar as possible, the prior configuration or morphology of a feature, not just its final structure. Stated another way, measured component directions can, in some cases, be used to infer the likely motion of a burned rock during and after cooling. Basically, this analytical step seeks to find the minimum rotation necessary for a TRM component - which, when acquired, must have roughly paralleled the GAD— to arrive at its measured archeological direction.

Unfortunately, there are an infinite number of ways to get from one fixed point to another. In order to arrive at a unique solution, it is necessary to place three artificial constraints on these rotation reversals. First, all rocks are considered to be spheres like that shown in Figure 27-6. The second is that all rotations must occur along a horizontal axis. This can be imagined by turning a desktop globe on its side so that the axis through the North and South Poles is horizontal. The direction of this rotation axis can change (i.e., it can turn clockwise or counterclockwise), but it cannot tilt. The third constraint is that the rotation necessary to get from the GAD to the measured vector direction be of the smallest possible magnitude (i.e., less than $180^{\circ}$ ). This, of course, determines which direction the rock is thought to have moved. If some rotation less than $180^{\circ}$ is chosen (call this $\mathrm{X}$ ), then the rock will go one way, if the complementary rotation $\left(360^{\circ}\right.$ minus $\left.\mathrm{X}\right)$ is selected, the rotation will be in the opposite direction.

Vector rotations can be uniquely described by the direction of the horizontal axis and the magnitude of rotation. The convention used in this report for defining horizontal axes is the "left-hand rule." That is, the orientation of the rotation axis can be envisioned by turning your left hand (palm up) so that your extended thumb points in the axis strike direction. Imagining then that you have a rock in your palm, cup your fingers around the rock and rotate it toward your inner forearm (cf. Figure 27-6). This is the direction of the inferred movement of the rock (the minimum necessary to get from the GAD to the measured component direction). 


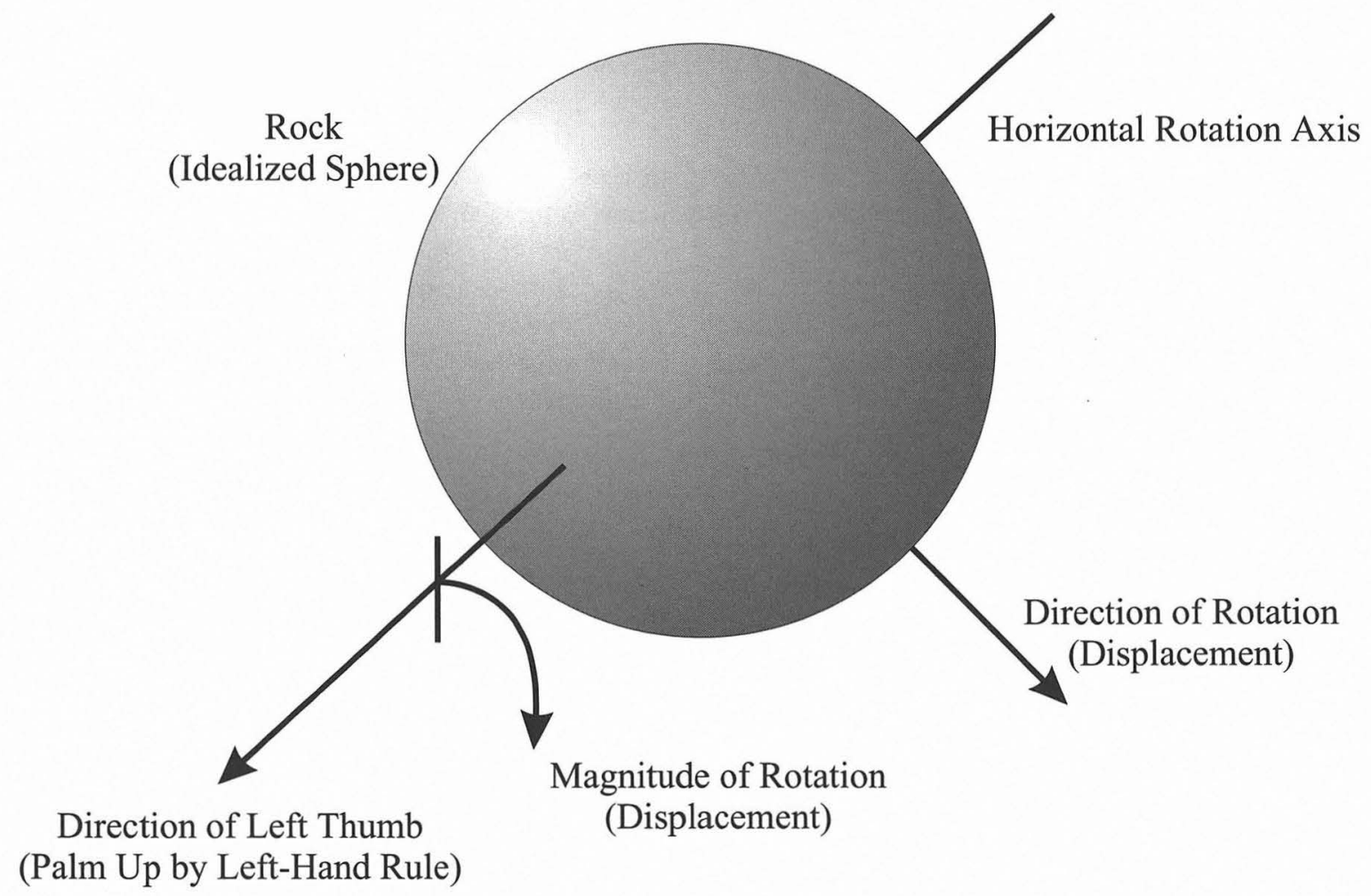

FIGURE 27-6. Figure showing the major conventions of Vector Rotation Reconstructions. The rock is assumed to be a perfect sphere which may only rotate around a horizontal axis. By the left-hand rule, the rock's rotation is equivalent to being placed in the palm of your left hand (the direction of the thumb is indicated). The direction of apparent displacement is then equivalent to a curling motion of the palm back toward the forearm (or to the lower right on this figure). The opposite of this rotation is the minimum necessary to return the measured out-of-place vector back to the time-averaged geomagnetic field direction (the Geocentric Axial Dipole or GAD). Rotation reconstructions are used for inferring the prior cooling locations of burned rocks as well as for discerning between movement while cooling versus partial reheating.

These constraints, though necessary, are obviously artificial. Vector rotation reconstructions probably do not, in most cases, reflect the actual prehistoric movements of these rocks. However, in order to discern overall patterning, the method often works rather well. By itself, one reconstructed direction rotation usually cannot be considered significant, but when that rotation makes sense based on the final location of a rock or when it contributes to an overall pattern evident in several rocks, it may permit the reconstruction of the prior morphology or arrangement of the rocks in a feature. These rotations can also aid in understanding the immediate surroundings or shape of a feature, such as the plane of a paleoslope or the existence of a central depression. In other cases, rotations along the same or similar planes within a single rock at different temperatures may be used to infer movement while cooling rather than reheating. The utility of vector rotation reconstructions lies in the patterning of multiple rotations within a single rock or between many rocks.

The complexity of the actual movements of a rock are admittedly only approximated by this technique. For example, a rotation reconstruction will "split the difference" of complex, multidirectional displacements. Moreover, the accuracy of any rotation is dependent on any prior rotation recon- structions. Stated another way, each displacement of a rock affects any and all components acquired at higher temperatures that are already "locked in." When attempting to reverse this process by "unfolding" sequential components back to the GAD, an erroneous rotation calculation at a lower temperature will affect the interpretation of those in higher temperature or coercivity ranges.

Of course, one must also consider the relationship of the actual geomagnetic field direction at any point in the past to the GAD. Because the actual paleopole position varied relative to the GAD due to secular variation, the reconstructed vector rotations may either exaggerate or obscure the effects of actual rock displacement(s). Since the true geomagnetic field position cannot be known a priori and in light of the difficulties and inherent uncertainties involved calculating a paleopole position in burned rock features (where each of the rocks/data points can and usually do move independently; cf. Takac 1998), the GAD was used as the baseline for all vector rotation calculations in this report. Generally speaking, larger calculated displacements are probably more accurate than are smaller rotations. That is, what appear to be small rotations may be due to secular variation rather than rock movement. 
Vector rotation calculations were performed on all identified components for each rock analyzed. The results of these reconstructions are listed after each component in Appendix 6. For convenience, in addition to the strike axis, the direction of each rotation is also given in reference to the cardinal directions (e.g., north, east-southeast, west, etc.). The complementary rotation (i.e., in the opposite direction) is also listed where it seems plausible or where the rotations are nearly the same magnitude (i.e., rotations greater than about $150^{\circ}$ ). Refining the technique and interpretive potential of vector rotation reconstructions, which emerged directly from research on the Wilson-Leonard burned rock samples, is the subject of ongoing field and laboratory investigations (Takac n.d.).

\section{SUMMARY: MODELINGTRM IN BURNED ROCKS}

Having discussed how thermoremanence is acquired, how demagnetization works, and how three-dimensional data can be plotted and manipulated, we may now tie these threads together in a single hypothetical example. Understanding the application of, and relationships between, the concepts and procedures outlined thus far are crucial for appreciating the dimensionality of archeomagnetic data and how those data can be employed in archeological inference. A simple self-demonstration will serve to illustrate TRM acquisition, component recognition, and the stereographic presentation of results.

First, make a fist with your left hand and hold it in front of you about chest-high. Imagine this is a rock containing ferromagnetic grains that have blocking temperatures uniformly distributed below $580^{\circ} \mathrm{C}$ (the Curie point of magnetite). Furthermore, envision an ambient magnetic field aligned at a $50^{\circ}$ angle; to a spot on the floor a few feet in front of you (i.e. to the "north"). Now imagine that this rock is heated to $600^{\circ} \mathrm{C}$. All magnetic moments will be aligned with the ambient magnetic field, regardless of the orientation of the rock. Stated another way, if the rock turns at this temperature, the magnetic moments of all grains (though not the grains themselves) will remain parallel to the magnetic field because the ambient temperature exceeds their blocking temperatures.

Now suppose your rock cools to $300^{\circ} \mathrm{C}$ without moving. The magnetic moments of all ferromagnetic grains with blocking temperatures greater than $300^{\circ} \mathrm{C}$ will have been "relocked" and preserved as a thermoremanence. You can represent this component by placing a pencil between the fingers of your left hand, pointing at the "magnetic north" spot on the floor in front of you. As the rock has cooled, the intensity of this remanence component increased as more and more magnetic moments contributed to it.

At $300^{\circ} \mathrm{C}$, however, imagine the rock rolls backward and slightly eastward so that the pencil now points just above your right shoulder. The direction of the magnetic field remains the same. Nevertheless, only those grains with blocking temperatures below $300^{\circ} \mathrm{C}$ will realign with it: those with higher blocking temperatures have a stable TRM component (the pencil) that will move along with the rock. If the rock then finishes cooling without further movement, a second remanence component will be acquired, this time by grains with blocking temperatures lower than $300^{\circ} \mathrm{C}$. The magnetic field has not changed, only the orientation of the rock (relative to that field) at different temperatures as it cooled. So long as the rock is not subsequently reheated and/or moved, these two TRM components will remain in these newly acquired directions. Now imagine the rock is buried and later excavated. The excavator might then be faced with the common archeological situation where much of the context and cooling history of that rock is unknown. Addressing such questions has, until now, often been limited to the subjective assessment of indirect evidence: for example, the apparent relationship of that rock to other nearby rocks or the presence/absence of in-situ cracking, burned sediment, or charcoal. However, the data necessary to definitively address these questions has been recorded in the ferromagnetic grains present in the rock itself.

The demagnetization of this sample is shown on the AZ diagram in Figure 27-7a. Both magnetic components are apparent in the slopes of the data on the $\mathrm{AZ}$ diagram (see change at $300^{\circ} \mathrm{C}$ ). The low temperature component (NRM to $300^{\circ} \mathrm{C}$ ) is equivalent to the Geocentric Axial Dipole position used in this study: $0^{\circ}$ or $360^{\circ}$ declination and $50^{\circ}$ inclination. The higher temperature component $\left(>300^{\circ} \mathrm{C}\right)$, which ended up pointing just over your right shoulder has a declination of $100^{\circ}$ and a slightly inverted $-20^{\circ}$ inclination. Once defined, these components may be plotted on a stereonet (Figure 27-7a lower). Such basic data provide the foundation for assessing whether a burned rock cooled in place; if or how many times it was displaced as it cooled; and estimating the magnitude of those dislocations, either before or after heating.

Vector rotation reconstructions take this line of inquiry a step further by attempting to quantify the direction and magnitude of rock displacements. The AZ diagram shown in Figure $27-7 \mathrm{~b}$ demonstrates the rotation of the higher temperature TRM component to its final, measured direction. The goal of rotation reconstruction is the "unfolding" of this out-of-place vector (and therefore the rock) back to its original, in-situ orientation. If this component is, in fact, thermoremanent then it must have been acquired parallel to the ambient magnetic field (which is unknown but may be approximated by the Geocentric Axial Dipole (GAD), or $360^{\circ}$ declination and $50^{\circ}$ inclination). Rotation back to this assumed initial position is shown on the stereonet in (b). The horizontal rotation axis is defined by the line intersecting the stereonet approximately northeast to southwest. The rotation reconstruction may be used either to describe rock movement (e.g., rotation of your fist and the pencil toward your right shoulder) or to reposition the rock in its original orientation (i.e., the opposite rotation). Of course, the validity of such reconstructions needs to be evaluated on a case-by- 

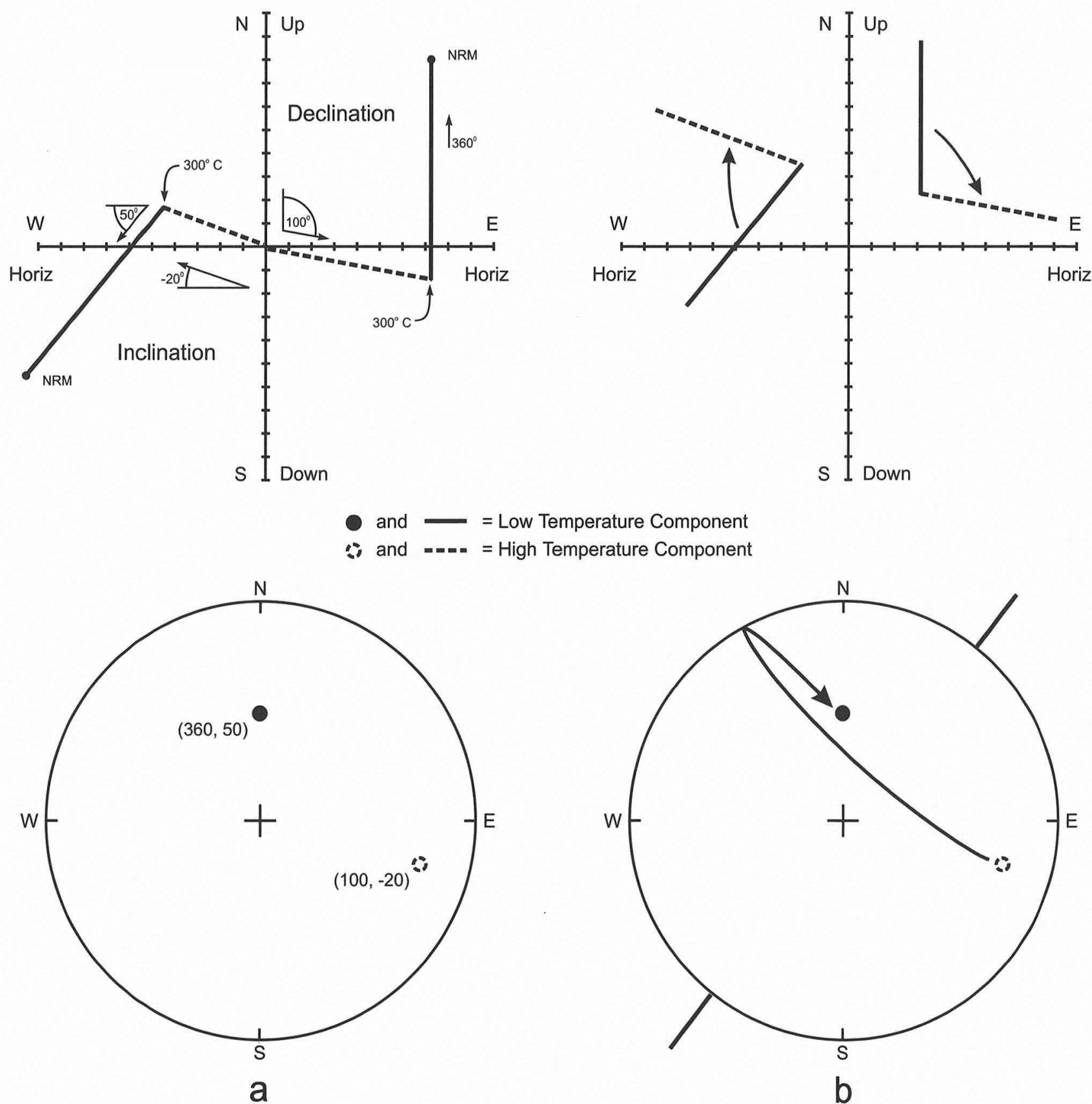

Figure 27-7. As-Zijderveld and stereonet plots to accompany the self-demonstration described in the text. The AZ diagram in (a) shows two identified components in both azimuthal (declination) and vertical (inclination) planes. The slope angles for each component are given relative to North and Horizontal, respectively. Note that individual magnetometer measurements have been omitted - only the two components have been plotted. These components are shown on the Equal-Area stereonet in (a). The AZ plot in (b) illustrates the rotation of the higher temperature component (acquired at temperatures $>300^{\circ} \mathrm{C}$ ) from its acquisition orientation (equivalent to the GAD) to its final position (slightly above your right shoulder). The accompanying stereonet shows the axis, direction, and magnitude of the rotation necessary to return this component (and therefore the "rock") back to its original position.

case basis, as discussed in the previous section. The example provided merely illustrates the procedure.

The analytical and inferential progression outlined for this hypothetical burned rock was conducted on all analyzed samples from Wilson-Leonard. However, due to space restrictions it is not possible to provide the $\mathrm{AZ}$ diagrams of each analyzed sample. Rather, results from the first feature reported (Feature 236) will be the most thoroughly described, including $\mathrm{AZ}$ diagrams, numbering individual components on the stereonets, and discussing vector rotation reconstructions in specific terms. Thereafter, only unlabeled stereonets will be provided and discussions will be limited 
to a summary of results and interpretations. Nonetheless, complete directional and statistical data on each identified component are presented in Appendix 6. Again, the raw data and plots used in the analysis are on file at TARL.

\section{SAMPLE COLLECTIONAND ANALYSIS}

The final consideration before proceeding to the results is how the samples were collected and processed. Archeomagnetic investigations on the scale of those conducted at Wilson-Leonard had not been attempted before, so several unanticipated shortcomings in methodology became apparent as the research progressed. Through these efforts much was learned that can be, and has already been, applied in other investigations.

\section{Field Collection}

The contextual determination of whether a rock cooled in place requires samples accurately oriented in three-dimensions so that their remanence components can be compared to the GAD direction. There are a number of ways to collect oriented rock samples and each has advantages and disadvantages.

The first seven samples at Wilson-Leonard were collected using a variation of the plaster cap procedure outlined in Collins et al. (1990). It soon became clear, however, that this technique was too slow and labor intensive to adequately collect samples on the scale required for the archeomagnetic investigations planned at Wilson-Leonard. Therefore, the sampling method shifted almost exclusively to the drilling of cylindrical core samples from "parent rocks" soon after they were exposed and before being moved (see Butler 1992:Figure 4.2). Drilling is common in paleomagnetic research and is accomplished using a hollow, diamond-tipped drill bit powered by a modified chainsaw motor (Figure 278a). The drill bit is water-cooled; the flow of water also serving to flush away rock dust as the core is being drilled. Before being extracted from the parent rocks, the cores were marked and oriented using a Brunton compass mounted on an inclinometer (Figure 27-8b). After extraction, the samples were numbered and complete provenience information was obtained, including feature number (where appropriate), square, level, northing and easting, elevation, and date collected. A complete copy of this provenience information is on file at TARL.

Sample drilling has a distinct advantage over plastering in terms of the rapidity with which cores can be drilled, oriented, and removed. Furthermore, the samples require only minimal laboratory preparation before being magnetometerready. Bulk volume and weight of the burned rock collected is also greatly reduced. A total of 1,254 samples was collected in this way.

Exclusive use of the drill also presented some difficulties and hindered data collection in several ways, most of

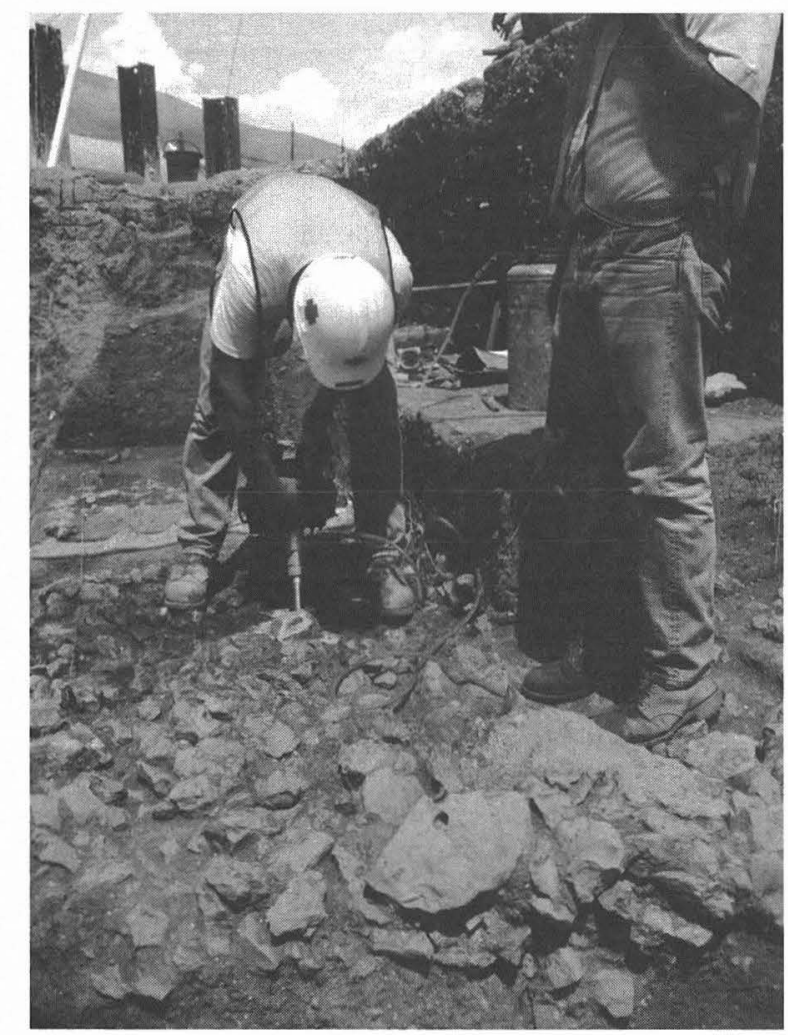

a

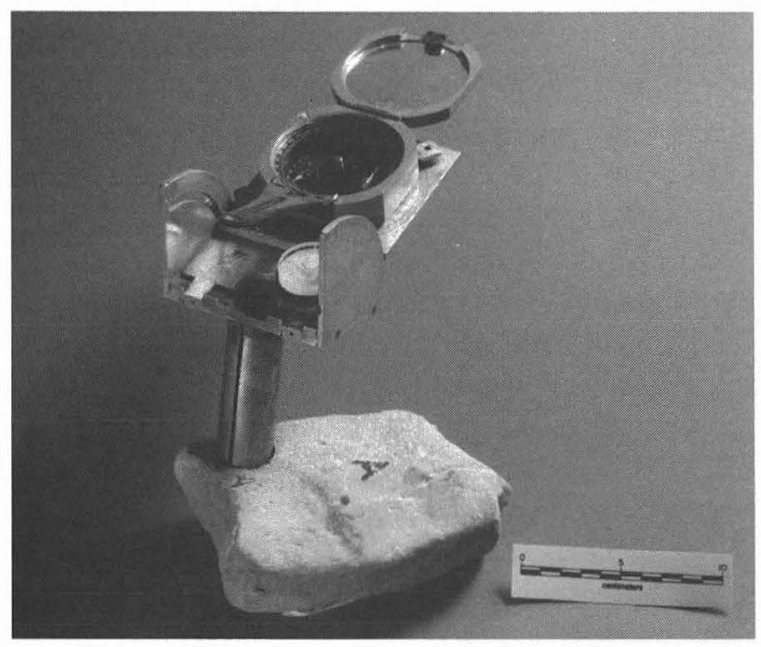

b

FIGURE 27-8. Collecting and orienting archeomagnetic samples. (a) core sample being drilled using a water-cooled diamond-tip drill bit mounted on a modified chainsaw; (b) combination Brunton compass and inclinometer device used to orient the individual cores prior to their removal from the parent rock.

which became apparent only later in the investigations. The first disadvantage was that the water to cool the spinning drill bit typically sprayed and soaked the feature, covering nearby rocks and sediment with a thin coating of wet limestone dust. Soaking also presented the possibility of contamination (e.g., radiometric or sediment samples) although 
this does not appear to have adversely affected such studies at Wilson-Leonard. The noise of the drill in close quarters and the disruption caused by spraying water in adjacent units were additional disadvantages. Excavation techniques, such as pedestaling feature rocks, also had to be modified because of the need for the rocks to remain sufficiently stable to resist the torque caused by drilling.

Perhaps the most serious problem with drilling was the bias toward larger and more-intact (less-friable) rocks. Smaller and thinner rocks are undoubtedly underrepresented in the Wilson-Leonard dataset. However, this became less pronounced as the proficiency of sample collection and drilling increased. Toward the end of the investigations many more small rocks were successfully drilled than was the case in upper levels. Nearly all of the samples were drilled, oriented, and extracted by the author. This consistency reduced potential biases caused by "operator error."

A final disadvantage of drilling was the loss of orientation for the parent rock once the sample was removed. Initially, many of the parent rocks were discarded. As the investigations progressed, however, it became increasingly clear that secondary samples (preferably, but not necessarily, oriented) for additional analyses might be desirable. Therefore, an attempt was made later in the excavations to collect as many of the parent rocks as possible. Previously discarded rocks on which sample numbers could be read (originally marked for mapping purposes) were also collected from the backdirt piles.

Following the excavations and before the laboratory preparation of samples, an effort was made to refit the extracted cores to the parent rocks and remark them so that supplemental samples could be extracted in the future. The success of this effort varied due to the positioning of the core sample on the parent rock and the size of the parent rock fragment. In some cases it was necessary to turn the remarked line $90^{\circ}$ or even $180^{\circ}$ from the original orientation line. A complete list of refitted rock/core pairs is on file at TARL and is accompanied by a subjective assessment of the quality and precision of each refit.

Deficiencies in sample collection noted at WilsonLeonard have implications for developing collection strategies for future archeomagnetic investigations. It is clear that sample collection must be individually tailored to research objectives and should be carefully selected from among the many available choices. Perhaps the best approach for situations similar to those at Wilson-Leonard would be to glue a wooden or plastic cylinder to the rock which could then be oriented with the Brunton/inclinometer rather than drilling into the rock (Tarling 1983:Figure 5.2). Multiple samples could then be extracted in the laboratory and the parent rock curated for future analyses. This has the additional advantages of decreased time and effort in the field, eliminating water spray and, most importantly, allowing for the recovery of smaller rocks. These advantages are of course offset by greater preparation time in the laboratory and by potentially enormous increases in the mass of rock collected and transported. Final selection of the sample collection strategy to be used will depend on the questions posed and the practicalities of the fieldwork situation (e.g., proximity to the laboratory and access to a drill).

During field collection, some degree of reddening was noted for approximately two dozen samples. This "reddening" ranged from pink to dark red and from a homogeneous discoloration throughout the specimen to one or more bands of varying thickness extending from the cortex (or just beneath it) into the interior of the rock. In other cases, the samples were distinctly mottled. The reddened samples were not concentrated in one area or stratigraphic unit or in one type of feature. Similarly, archeomagnetic analysis of these samples yielded no consistent patterning in terms of cooling context, remanence intensity, or number of identified magnetic components. While rock color is almost certainly related to a combination of factors, including original petrology and the type or degree of thermal alteration (e.g., oxygen conditions, rate and/or duration of heating, etc.), these factors are not yet well understood. Furthermore, color descriptions are difficult to accurately quantify without sophisticated spectrographic equipment. Exploring the relationships between burned rock use, color, and physical, chemical, or magnetic properties will be a key element of future investigations. However, given our present understanding of such phenomena, the color of individual samples is not emphasized in this report.

\section{Sampling Strategy}

The intensity of sample collection increased as the excavations progressed. As a result, the features in Unit IIIc (including Feature 201 and its subfeatures) were less intensively sampled than were those excavated later. Although the focus was typically on more well-defined feature clusters or contexts, an attempt was made to obtain an adequate sample from more-scattered, undifferentiated deposits. This effort was relatively successful in retrospect and has, in some cases, yielded unanticipated and enlightening results.

Our primary sampling objective was to obtain a representative sample in terms of spatial coverage (the lateral and vertical distribution of the rocks) and rock size. As previously mentioned, there was an unintentional (and to some degree unavoidable) bias in favor of larger, more-intact rocks. Many samples were broken during drilling or extraction. Regardless, if they could be accurately oriented, most of them were glued back together with Duco cement ${ }^{4}$ and collected. The range of variation in terms of core size and integ-

\footnotetext{
${ }^{4}$ Duco cement is magnetically inert and does not affect the measurement of thermoremanence.
} 
rity is great in archeological contexts. Unlike geological situations, it is not always possible to try again; each rock is a unique datapoint and if the drilling or orientation is unsuccessful, the information from it is lost. Although a great many samples were collected, it became apparent after leaving the field that several gaps in the data existed. However, with few exceptions, these gaps are in the more-scattered, undifferentiated burned rocks peripheral to the main features and accumulations. The information loss resulting from these gaps is partially offset by representative samples from similar contexts elsewhere.

In some cases, two or more "sister" samples were drilled from the same rock so that their results could be compared or so that one could be curated. A total of 1,247 cores were drilled from 1,207 burned rocks.

\section{Laboratory Procedures}

All samples were analyzed in the Paleomagnetic Laboratory in the Department of Geological Sciences (UTDOGS) at The University of Texas at Austin (Dr. Wulf A. Gose, Director). Sample selection in the laboratory was similar to that used in the field. The goal was to obtain a representative sample from within each feature or level. Whenever possible, preference was given to those cores for which parent or sister rock samples were available. In some cases, samples were rejected for analysis because they were too fragmentary or small relative to other available samples. However, many small or fragmentary cores were analyzed and, with few exceptions, yielded more than adequate results.

Following its selection and after attempting to refit it to its parent rock (if available), the base of each 2.5 -cm-diameter cylindrical core sample was trimmed to no more than 2.3 $\mathrm{cm}$ in length, leaving the cortex intact. It was then marked, weighed, and its bulk susceptibility measured.

After these preparations were completed, the demagnetization process began. All demagnetization treatments and measurements were performed in a magnetically shielded $(\mu-$ metal) room. The magnetometer used was a SQUID (Superconducting QUantum Interference Device) magnetometer with two sensors. This magnetometer is termed a "cryogenic" magnetometer because it is cooled with liquid Helium (to $4^{\circ} \mathrm{K}$ ) to enable the superconducting electronics. This greatly increases its sensitivity, which is necessary for measuring the relatively weak remanences often found in limestones. Nevertheless, some of the samples from Wilson-
Leonard did approach the measuring limits of the magnetometer. These samples are discussed where appropriate in the Results section below.

Remanence intensities of the Wilson-Leonard samples varied over four orders of magnitude (cgs units). Although such variation has previously been used in archeomagnetic studies of burned rocks (e.g., Gose 1994), remanence intensities are not presented in this report because the factors controlling it are not yet well understood. Moreover, preliminary assessment revealed little patterning in the distribution of remanence intensities. Complete intensity information for each sample is contained in the data on file at TARL.

Thermal demagnetization was done in a digitally controlled furnace and cooling chamber, both housed in the shielded room and wrapped with additional layers of $\mu$-metal. The samples were demagnetized in $50^{\circ} \mathrm{C}$ intervals to at least $550^{\circ} \mathrm{C}$ (and in most cases to 600 or $650^{\circ} \mathrm{C}$ ). If, during the course of thermal demagnetization, the sample broke, it was reglued with Duco cement.

The remaining samples were treated in an electromagnetic specimen demagnetization unit, which is also $\mu$-metal wrapped. A typical Alternating-field exposure series proceeded in alinear increments: $10 \mathrm{Oe}, 25 \mathrm{Oe}, 50 \mathrm{Oe}, 100 \mathrm{Oe}, 150$ $\mathrm{Oe}, 200 \mathrm{Oe}, 300 \mathrm{Oe}$, and $400 \mathrm{Oe}$. If required, additional fields were applied (to a maximum of $1,000 \mathrm{Oe}$ ).

Of the 725 samples processed, 399 were thermally demagnetized and 326 were exposed to alternating electromagnetic fields. Raw magnetometer measurements were downloaded automatically to a Macintosh computer. The plotting and statistical calculations of these data were done using both commercial spreadsheet applications and in-house programs (written by W. A. Gose) for analyzing three-dimensional paleomagnetic data. All of the raw data and first-order analytical diagrams (As-Zijderveld plots and stereonets for individual samples) are curated at TARL in both electronic and hardcopy forms.

Each method of demagnetization has inherent advantages and disadvantages. The primary advantage of thermal demagnetization is that it provides information on temperature. ${ }^{5}$ The disadvantages, however, are that it requires a much greater amount of time and effort (both in terms of the number of measurement intervals and how long each takes to complete). In addition, heating may cause physical and/or chemical alteration of the sample and can result in thermal expansion and fracturing. Most importantly, new minerals can be created that were not present in the original sample. Once this

\footnotetext{
${ }^{5}$ It should be noted that these temperatures are only estimates - they are laboratory equivalent temperatures. As discussed in preceding sections, blocking temperatures are a function of both time and temperature. The relationship of heating time and unblocking temperatures is discussed in Pullaiah et al. (1975) and is currently being investigated for burned limestones in particular (W. A. Gose, personal communication 1997). The laboratory samples were thoroughly heated for a specified amount of time (20 minutes), but the precise equivalent or, more accurately, equivalents of that are not known. This is probably more of a problem for maximum temperature of heating than for the temperatures at which rocks moved because movement probably took place in a relatively short period of time (approximated by the laboratory heating time), whereas the rocks may have been at more-elevated temperatures for extended periods of time.
} 
potential was recognized (after the first 100 or so samples were demagnetized), the susceptibility of all subsequent specimens was monitored after each heating interval. When the susceptibility changed (usually increased) more than $50 \%$, subsequent measurements were usually excluded from the final analysis. This occurred in only a few samples, and almost exclusively at very high temperatures (near the Curie point).

Alternating-field demagnetization takes less time but offers only indirect temperature information. For example, single AF components imply heating in excess of the Curie point and no movement while cooling. AF is further complicated by the very high coercivity of many hematite grains. While the maximum fields attained in the laboratory $(1000$ Oe) were sufficiently strong to demagnetize nearly all of the magnetite grains, the coercivity of some hematite grains can be more than five times greater. Therefore, alternating-field demagnetization did not always result in the identification of all remanence components in a sample but with few exceptions did yield sufficient component information to assess the cooling context of the sample. On the other hand, alternating-field demagnetization cannot induce physical or chemical alteration of a sample.

In the case of both alternating-field and thermal demagnetization, the prehistoric remanence components are permanently removed (which was one reason for obtaining sister samples as discussed in the Sampling Strategy section). All of the analyzed and unanalyzed archeomagnetic samples are curated at TARL for future analyses.

\section{Tables and Stereonets}

This section provides an explanation of the coding system used in the alphanumeric tables contained in this chapter. Individual magnetic components and vector rotation reconstructions for each sample are tabulated in Appendix 6, and the content and structure of those tables is discussed there. The tables in this chapter are a higher-level interpretation or distillation of the data in the appendix. Together the chapter and appendix tables present the complete analytical and interpretive results of the archeomagnetic investigations.

It must be stressed that although many analytical and interpretive steps precede the identification of the individual components given in Appendix 6, a complete tabulation of the archeomagnetic data from Wilson-Leonard is beyond the scope of this report. The results clearly require some distillation given both the number of samples and the complexity of three-dimensional data. Without an abbreviated tabulation, the quantity of available information would quickly become unmanageable. For example, there are well over 7,000 individual magnetometer readings for the 725 samples analyzed. The potential iterations of these data to define individual magnetic components are overwhelming. Instead, the entire dataset has been archived at TARL and is available (in both electronic and paper formats) to any researcher who wishes to access it. The data include, but are not limited to, (1) complete provenience data for each sample; (2) specimen groupings and magnetometer-run information; (3) laboratory sheets; (4) a complete set of magnetometer readings; (5) As-Zijderveld diagrams for each sample; and (6) printouts of the many vectoral and statistical calculations considered for each sample.

Provenience information and ordering in the chapter tables differs somewhat from those in Appendix 6. For example, entries in the Chapter 27 tables are grouped by the subfeature assignment of specimens from within the Feature 231 deposit (i.e., Features 181, 231, or 245) whereas in Appendix 6 the samples are listed only by the square and level (or individual feature) from which they were collected. Where it is uncertain to which subfeature a sample belongs (e.g., if it falls between two subfeatures), the numbers are separated by a slash. For example, a rock labeled $181 / 231$, is associated with either Feature 181 or Feature 231, but which one is ambiguous. In those cases where a sample is not clearly associated with a particular subfeature, it was labeled simply Feature 231, the default or catch-all category for the palimpsest deposit as a whole.

There are three parts to the coding system used in the Chapter 27 tables. The column headed Cooling Context denotes whether the rock remains in the location and position in which it last cooled. Each rock was assigned a letter corresponding to the degree to which it was judged to be cooled in place or disturbed after cooling. The "A" category rocks are those considered to be cooled in or very near the locations and orientations in which they were found. The " $\mathrm{B}$ " samples are those remaining near, but not exactly in, their final cooling locations, while "C $\mathrm{C}$ " category rocks are out of place but their probable cooling locations can be inferred. The " $\mathrm{D}$ " samples are also out of place, but their last cooling locations are unknown. Finally, "E" category samples are those for which the final cooling context is uncertain or unknown.

The second part of the coding system indicates either the lowest temperature of the rock when it was last significantly moved or the maximum temperature to which it was partially reheated. This is independent of cooling context and represents only the temperature range of last significant movement while the rock was still heated. Those samples for which only one component of magnetization was identified are starred $(*)$ because the rock did not evidence any discernible movement while cooling from maximum temperatures in excess of the Curie point. The " $\mathrm{L}$ " category stands for low temperatures (less than or equal to $250^{\circ} \mathrm{C}$ ); the " $\mathrm{M}$ " for moderate temperature ranges (between $250^{\circ}$ and $450^{\circ} \mathrm{C}$ ); and " $\mathrm{H}$ " for high temperatures (greater than $450^{\circ} \mathrm{C}$ ). Where a component change crosscuts these boundaries, the ranges are hyphenated. Alternating-field demagnetized samples having at least two components (and consequently no available temperature data) are marked by an " $\mathrm{X}$ ".

The next column represents the maximum number of discernible movements of the rock while it cooled. The number in this column equals the number of identified 
components minus one (i.e., the number of component changes, not the number of individual components). In some cases, these observed component changes can be more appropriately attributed to partial reheating rather than to movement while cooling. Such instances are discussed where they apply in the Results section. A "plus" (+) sign following this number means that there appears to be one or more additional movements or displacements but that these were minor and did not produce distinct, identifiable components. Where there is some question as to the number of actual (as opposed to apparent or well-defined) movements, this uncertainty is reflected by a hyphen (e.g., "2-3" means " 2 or 3").

Although this tripartite coding system may at first seem overly cumbersome and complex, it merely reflects the complexity and abundance of information available from archeomagnetic analyses. At the most basic level, for those interested in whether rocks cooled where they were found, one needs only to consider the $\mathrm{A}$ through $\mathrm{E}$ coding of the results. In other instances, it may be instructive to note that although all of the rocks within a particular feature cooled in place, they did so only from low temperatures following two or more displacements (e.g., A/L/2+). Another example might be one in which all of the rocks were displaced after they cooled but, prior to that, cooled without moving from temperatures in excess of the Curie point (e.g., D/*/0). Finally, one might want to know if the rocks were subjected to a great deal of movement while they cooled (and therefore represented by large numbers in the third column). The goal of this coding system is to make such assessments easier by making the data in Appendix 6 more accessible.

The stereonet pairs in the following section are all arranged in the same way. Higher temperature and coercivity components are always plotted on the left stereonet while the lowest temperature and coercivity range vectors are displayed on the right. The stereonet pairs for any given feature or level will often have a different number of data points. This is because a single sample may yield two or more hightemperature or coercivity components but can have only one lowest temperature or coercivity vector. If a specimen has only a single component, the same data point is plotted on both stereonets (unless that vector is defined only in a very restricted temperature or coercivity range). In the extreme case of a feature in which all of the rocks have a single component of magnetization, both stereonets would be identical. Except where indicated, the identified components of E-category samples (i.e., those with unknown or uncertain cooling contexts) have been excluded from the stereonets. Finally, note that on all plan maps the "north" arrow is aligned to Grid-North or roughly $23^{\circ}$ East of True- (or Geographic-) North (see Chapter 3 in Volume I).

\section{RESULTS OF THE WILSON-LEONARD ANALYSES}

Archeomagnetic results from individual features are presented first, followed by those from Burned Rock Midden 1 (TARL Square 100) and from Feature 231 and its associ- ated subfeatures. Individual features are discussed in numeric order while the Feature 231 palimpsest is presented in stratigraphic order. The only exception is Feature 236. It is presented first as a representative example of the overall analysis and interpretation of burned rock features at WilsonLeonard. Therefore, selected As-Zijderveld diagrams, as well as labels for the individual components plotted on the stereonets, are included in this introductory section but have been omitted from the remainder of the chapter. Comprehensive descriptions of these features (including Feature 231) are available in Chapter 26 and are not repeated here.

\section{Individual Features}

Feature 236

Feature 236 was a small cluster of burned rocks found in the lower portion of Unit II (Figure 27-9). Archeomagnetic results from 13 samples (representing 11 individual rocks)

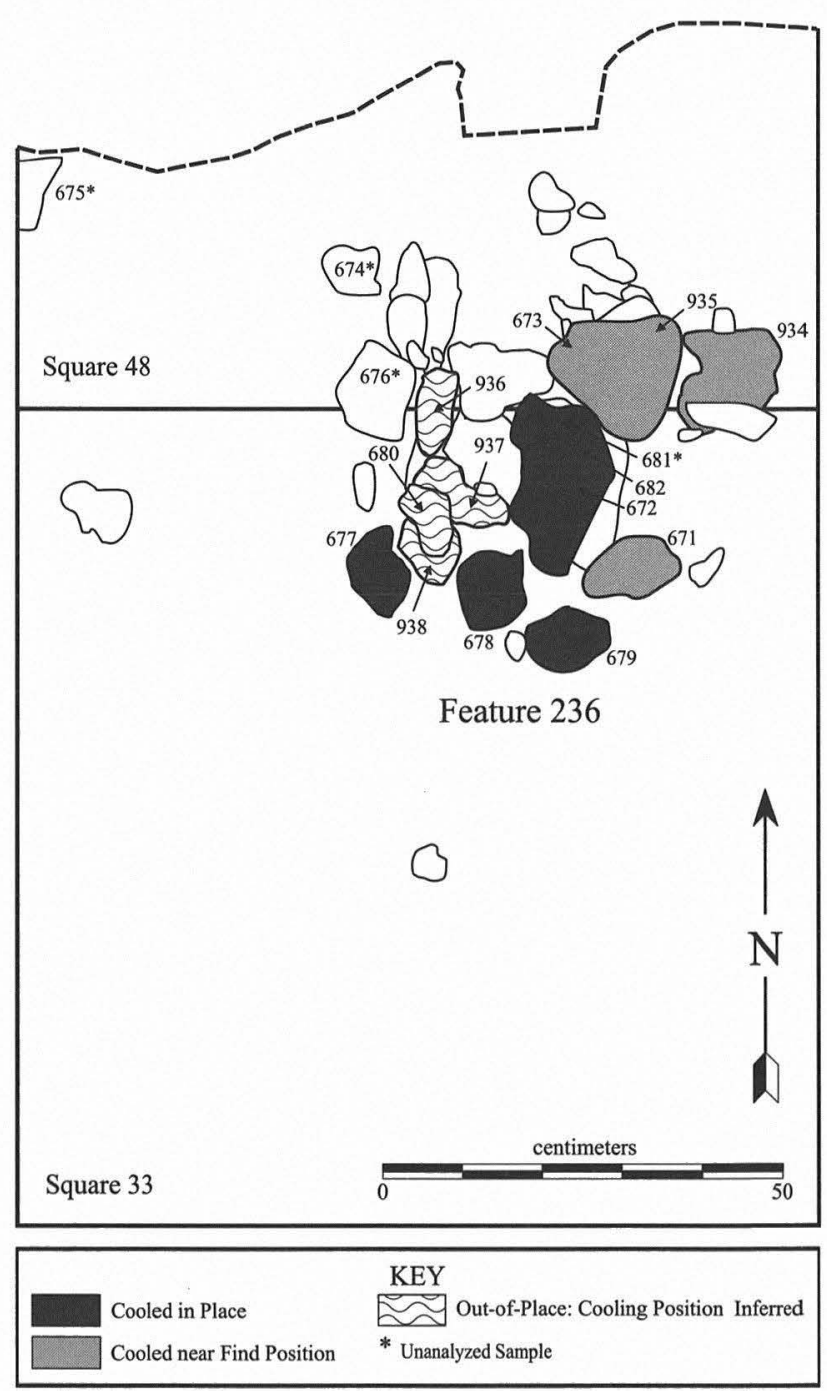

Figure 27-9. Plan map of Feature 236 in Squares 33 and 48, Levels 29 and 30. 


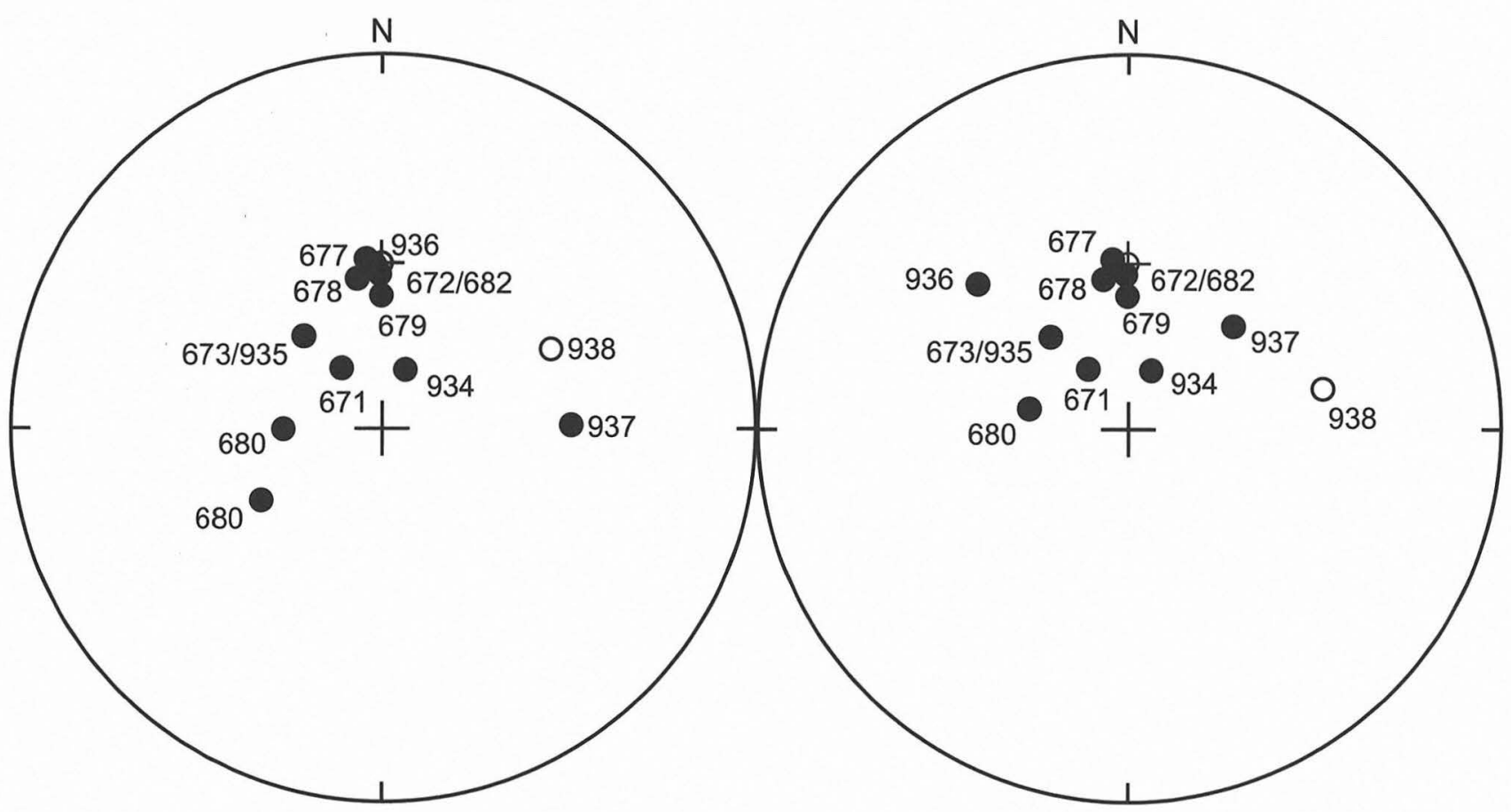

FIGURE 27-10. Stereonets of results from Feature 236. Labels correspond to rocks shown on Figure 27-9. Following the convention employed throughout this chapter, the lowest temperature and coercivity components are presented in the stereonet at right while those vectors defined in higher temperature or coercivity ranges are shown on the stereonet at left. Note that seven rocks have a single component and therefore plot in the same place on both stereonets. Because AM-680 yielded three components it is represented twice on the left stereonet. Note in particular the close clustering of several remanence directions about the GAD and the relatively modest scatter of the others (especially AM-938 which is inverted).

are presented in Figure 27-10 and in Table 27-1. These data illustrate the potential of archeomagnetic analysis for understanding the context, formation, and even prior morphology of burned rock features. Furthermore, Feature 236 typifies the analytical relationships between data, inference, and interpretation that characterize the Wilson-Leonard study as a whole. In particular, the results indicate that (1) the rocks in Feature 236 were clearly heated to temperatures approaching or exceeding $580^{\circ} \mathrm{C}$; (2) most rocks then cooled without noticeable movement; (3) those rocks that did move while cooling seem to have done so in patterned ways; (4) patterns in apparent rock movement suggest that Feature 236 had a shallow central depression and was constructed on a paleosurface inclined slightly to the northeast; and finally, (5) the results from "sister" samples support the reliability of the analysis in general and the demagnetization procedures in particular. The remainder of this section outlines the data on which these inferences are based and these various lines of evidence are then woven back together into a comprehensive picture of this ca. 9,500 year old burned rock feature (see Table 25-5).

Rocks in Feature 236 were last heated to very high temperatures and many remained in the same positions throughout their final cooling period. Moreover, several remained in those positions until excavated. Seven analyzed rocks had a single component of magnetization (Table 27-1) and plot in the same locations on both stereonets in Figure 27-10. A single component indicates that a rock was last heated to some maximum temperature in excess of the Curie point (or to a somewhat lower temperature for a longer period of time) and was then allowed to cool without moving. An example, Rock AM-678, is given in Figure 27-11. Although the sample from this rock was demagnetized in an alternating field, the unilinearity of its remanence indicates that all ferromagnetic grains within it have essentially the same magnetic moment orientation. Assuming the sample contains grains with blocking temperatures at or near the Curie point, it must have been heated to roughly equivalent temperatures. The measured remanence of AM-678, as indicated on the vector component diagram in Figure 27-11, is very near the GAD position. At least three other single-component rocks (AM-672/ 682, AM-677, and AM-679) also remained in or very near their final cooling locations as indicated by the tight clustering near the GAD position in Figure 27-10. All four of these rocks are coded " $\mathrm{A} / * / 0$ " on Table $27-1$. Based on these findings, it must be concluded that at least a portion of Feature 236 remains in situ.

Results from two of the seven single component rocks are given in Figure 27-12. A pair of sister samples were analyzed from each of these rocks: Samples AM-672 and AM682 from one and Samples AM-673 and AM-935 from the other. One sample from each was demagnetized thermally, and the other was treated in an alternating field. In both cases, the results were essentially identical and they were 
TABLE 27-1

Individual Features and Burned Rock Midden 1 (Square 100) Archeomagnetic Interpretation of Vectoral Data

Cooling Context
A cooled in place
B cooled near find position
C out-of-place: cooling location inferred
D out-of-place: unknown cooling orientation
E uncertain / unknown

Lowest Temperature of Movement

* no discernible movement

$\mathrm{X}$ unknown (AF demagnetized)

$\mathrm{V}$ possible viscous magnetization

$\mathrm{L}$ less or equal to $250^{\circ} \mathrm{C}$

$\mathrm{M}$ between $250^{\circ}$ and $450^{\circ} \mathrm{C}$

$\mathrm{H}$ greater than $450^{\circ} \mathrm{C}$

\begin{tabular}{|c|c|c|c|c|c|c|}
\hline Feature No. & Square & Level & $\begin{array}{l}\text { Sample No. } \\
\text { (AM-) }\end{array}$ & $\begin{array}{l}\text { Cooling } \\
\text { Context } \\
\end{array}$ & $\begin{array}{c}\text { Lowest Temperature of } \\
\text { Movement }\end{array}$ & $\begin{array}{c}\text { No. of Discernible Movements } \\
\text { while Cooling }\end{array}$ \\
\hline 181 & \multicolumn{6}{|c|}{ see Tables $27-6,27-8,27-10,27-12,27-14,27-16,27-18$} \\
\hline 184 & 50 & 26 & 1028 & B & * & 0 \\
\hline 184 & 50 & 25 & 1029 & A & $\mathrm{X}$ & $1+$ \\
\hline 201 South Block & 14 & 5 & 0039 & B & * & $0+$ \\
\hline 201 South Block & 14 & 5 & 0040 & $\mathrm{E}$ & $\mathrm{H}$ & $1-2$ \\
\hline 201 East Block & 18 & 8 & 0008 & B & $\mathrm{L}$ & $1+$ \\
\hline 201 East Block & 20 & 8 & 0011 & B & M & 1 \\
\hline 201 East Block & 20 & 8 & 0012 & B & * & $0+$ \\
\hline 201 East Block & 20 & 8 & 0013 & E & $\mathrm{L}$ & $1+$ \\
\hline 201 East Block & 20 & 8 & 0014 & E & L-H & $1+$ \\
\hline 201 East Block & 21 & 6 & 0018 & B & $\mathrm{L}$ & 2 \\
\hline 201 East Block & 21 & 6 & 0019 & B & L-M & $2-3$ \\
\hline 201 East Block & 21 & 7 & 0032 & A & M & 2 \\
\hline 201 East Block & 21 & 7 & 0035 & B & * & 0 \\
\hline 201 East Block & 22 & 7 & 0038 & B & * & $0+$ \\
\hline 203 (201 East) & 19 & 8 & 0030 & B & $\mathrm{L}$ & 2 \\
\hline 204 & 20 & $11-\mathrm{B}$ & 0060 & A & * & $0+$ \\
\hline 204 & 20 & $11-\mathrm{B}$ & 0061 & A & M & 1 \\
\hline 204 & 20 & 11-B & 0063 & B & $\mathrm{L}$ & $2-3$ \\
\hline 204 & 20 & $11-\mathrm{B}$ & 0064 & A & $\mathrm{M}-\mathrm{H}$ & 1 \\
\hline 205 (201 East) & 22 & 8 & 0047 & A & M & 2 \\
\hline 205 (201 East) & 22 & 8 & 0048 & B & $\mathrm{L}$ & 2 \\
\hline 206 (201 South) & 15 & 5 & 0051 & B & M & 1 \\
\hline 206 (201 South) & 15 & 5 & 0053 & B & M & $1-2$ \\
\hline 207 (201 South) & 14 & $6 \mathrm{~A}$ & 0054 & B & $\mathrm{L}$ & $1+$ \\
\hline 207 (201 South) & 14 & $6 \mathrm{~A}$ & 0056 & $\mathrm{D}$ & * & 0 \\
\hline 207 (201 South) & 14 & $6 \mathrm{~B}$ & 0058 & A & $\mathrm{L}$ & 2 \\
\hline 211 (201 South) & 17 & $8-B$ & 0077 & A & $\mathrm{L}$ & 2 \\
\hline 211 (201 South) & 17 & $8-B$ & 0078 & B & M & 1 \\
\hline 212 & 37 & $13-\mathrm{B}$ & 0093 & B & M & $1-2$ \\
\hline 212 & 37 & $13-\mathrm{B}$ & 0094 & B & $\mathrm{L}$ & 1 \\
\hline 214 & 16 & 10 & 0083 & A & $\mathrm{L}$ & 2 \\
\hline 214 & 16 & 10 & 0084 & B & $\mathrm{L}$ & 1 \\
\hline 214 & 16 & 10 & 0085 & B & $* ?$ & $0 ?$ \\
\hline 217 & see Table 27-3 & & & & & \\
\hline 218 & 19 & 14-A & 0098 & B & $\mathrm{L}$ & 2 \\
\hline 222 & 37 & 16 & 0101 & A & $\mathrm{L}$ & 3 \\
\hline 222 & 37 & 16 & 0102 & B & $\mathrm{L}$ & $1+$ \\
\hline 222 & 37 & 16 & 0104 & A & * & 0 \\
\hline 223 & see Table $27-4$ & & & & & \\
\hline 224 & 12 & 18 & 0112 & A & M-H & 1 \\
\hline 224 & 12 & 18 & 0115 & A & L-M & 2 \\
\hline 224 & 12 & 18 & 0116 & B & $\mathrm{L}$ & 2 \\
\hline 224 & 12 & 19 & 0138 & B & $\mathrm{X}$ & 1 \\
\hline 224 & 12 & 19 & 0139 & B & M & 1 \\
\hline
\end{tabular}




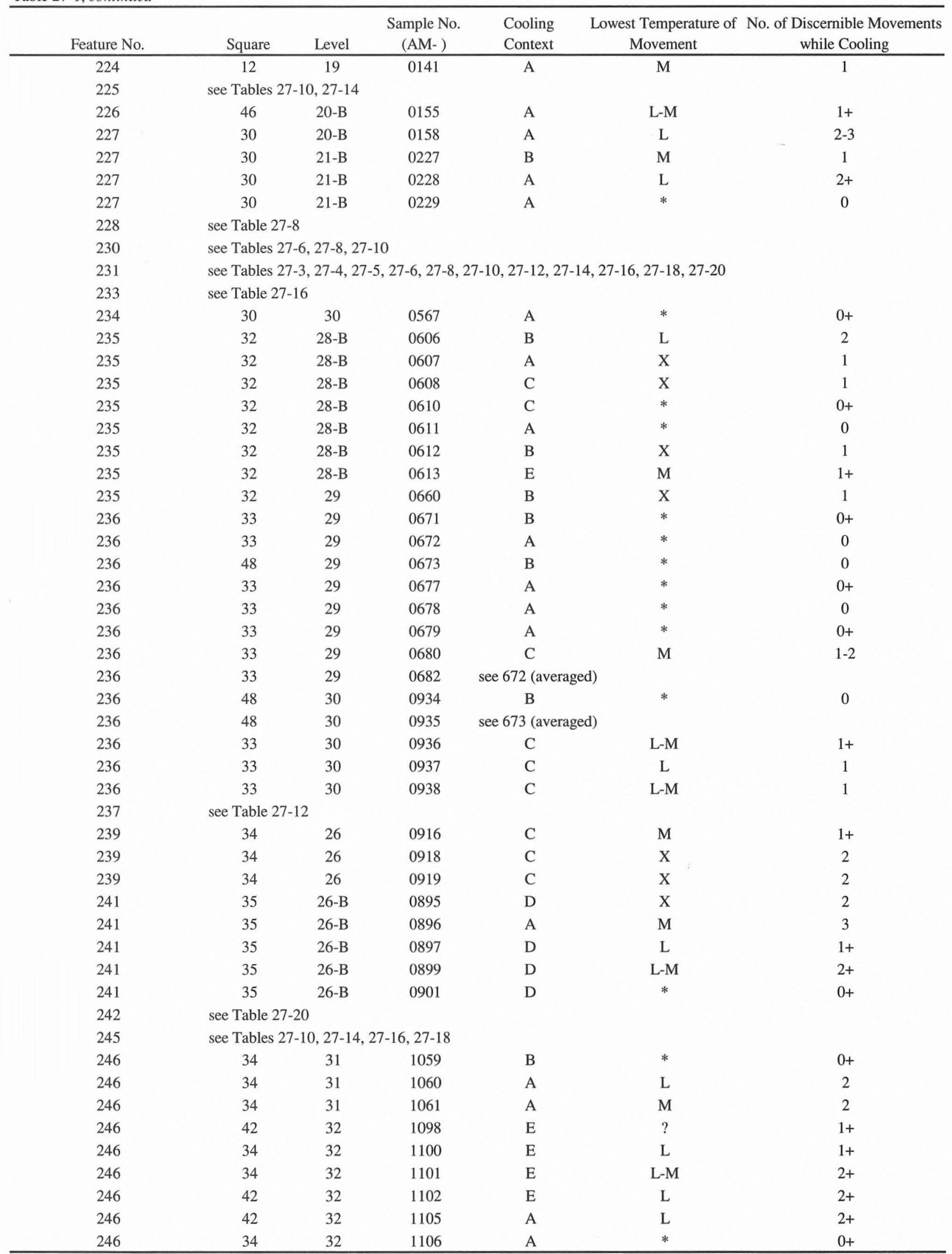


Table 27-1, continued

\begin{tabular}{|c|c|c|c|c|c|c|}
\hline Feature No. & Square & Level & $\begin{array}{l}\text { Sample No. } \\
\text { (AM-) }\end{array}$ & $\begin{array}{l}\text { Cooling } \\
\text { Context } \\
\end{array}$ & $\begin{array}{c}\text { Lowest Temperature of } \\
\text { Movement }\end{array}$ & $\begin{array}{c}\text { No. of Discernible Movements } \\
\text { while Cooling } \\
\end{array}$ \\
\hline 246 & 34 & 32 & 1107 & A & $*$ & $0+$ \\
\hline 248 & 53 & 28 & 1077 & $\mathrm{E}$ & $\mathrm{L}$ & $1+$ \\
\hline 248 & 53 & 28 & 1078 & A & $\mathrm{L}$ & 3 \\
\hline 248 & 52 & 28 & 1079 & A & $\mathrm{L}$ & 2 \\
\hline 248 & 44 & 28 & 1122 & B & $\mathrm{L}$ & $1-2$ \\
\hline 248 & 44 & 28 & 1124 & B & M & 1 \\
\hline 248 & 52 & 29 & 1130 & $\mathrm{E}$ & $\mathrm{X}$ & 1 \\
\hline 248 & 52 & 29 & 1131 & A & M & $2+$ \\
\hline 248 & 52 & 29 & 1132 & A & $*$ & $0+$ \\
\hline 248 & 52 & 29 & 1133 & $\mathrm{C}$ & $\mathrm{X}$ & 1 \\
\hline 248 & 44 & 29 & 1134 & B & $\mathrm{X}$ & 1 \\
\hline 248 & 28 & 29 & 1135 & B & M & $2-3$ \\
\hline $248 ?$ & 52 & 29 & 1141 & A & $\mathrm{L}$ & 1 \\
\hline 249 & \multicolumn{2}{|c|}{ see Table $27-20$} & & & & \\
\hline 250 & 50 & 30 & 1113 & B & $*$ & $0+$ \\
\hline 250 & 50 & 29 & 1114 & A & $\mathrm{X}$ & 1 \\
\hline 250 & 37 & 29 & 1116 & A & M-H & 1 \\
\hline 250 & 37 & 29 & 1118 & A & $\mathrm{H}$ & 1 \\
\hline 250 & 37 & 30 & 1126 & A & $\mathrm{H}$ & 1 \\
\hline 250 & 50 & 31 & 1128 & A & $*$ & $0+$ \\
\hline 250 & 38 & 30 & 1189 & A & M-H & $1+$ \\
\hline 255 & 59 & 42 & 1181 & B & $\mathrm{L}$ & $1+$ \\
\hline 255 & 59 & 42 & 1182 & B & $\mathrm{L}$ & $1+$ \\
\hline 255 & 59 & 42 & 1184 & A & $\mathrm{H}$ & 1 \\
\hline 255 & 59 & 42 & 1186 & A & * & $0+$ \\
\hline 255 & 59 & 42 & 1187 & A & M & 1 \\
\hline 257 & 53 & $39-\mathrm{B}$ & 1194 & A & * & 0 \\
\hline 257 & 53 & $39-B$ & 1195 & $\mathrm{E}$ & $?$ & $?$ \\
\hline 258 & \multicolumn{2}{|c|}{ see Table 27-16 } & & & & \\
\hline 259 & 35 & 46 & 1226 & $\mathrm{E}$ & $?$ & $?$ \\
\hline 259 & 35 & 47 & 1228 & $\mathrm{E}$ & $?$ & $?$ \\
\hline 260 & 52 & $42-B$ & 1240 & $\mathrm{E}$ & $?$ & $?$ \\
\hline 260 & 52 & $42-B$ & 1242 & $\mathrm{E}$ & $?$ & $?$ \\
\hline 260 & $39 / 52$ & $42-B$ & 1244 & $\mathrm{E}$ & $?$ & $?$ \\
\hline 260 & 52 & 42-B & 1246 & A & M & $1+$ \\
\hline 260 & 52 & $42-B$ & 1248 & A & M & $1+$ \\
\hline 260 & 52 & 42-B & 1251 & A & $\mathrm{L}$ & $0+$ \\
\hline 261 & 20 & 54 & 1256 & NA & & \\
\hline 261 & 20 & 54 & 1259 & NA & & \\
\hline \multicolumn{7}{|c|}{ Burned Rock Midden 1} \\
\hline \multirow[t]{7}{*}{ (Square 100) } & 100 & 2 & 0591 & $\mathrm{D}$ & M & 2 \\
\hline & 100 & 2 & 0592 & $\mathrm{C}$ & $*$ & $0+$ \\
\hline & 100 & 2 & 0593 & $\mathrm{D}$ & $\mathrm{X}$ & 1 \\
\hline & 100 & 2 & 0596 & A & $\mathrm{L}$ & 1 \\
\hline & 100 & 2 & 0598 & $\mathrm{D}$ & $*$ & $0+$ \\
\hline & 100 & 2 & 0601 & B & $\mathrm{L}$ & 2 \\
\hline & 100 & 2 & 0602 & B & $\mathrm{X}$ & 1 \\
\hline \multicolumn{7}{|c|}{ Burned Rock Midden 1} \\
\hline \multirow[t]{5}{*}{ (Square 100) } & 100 & 3 & 0647 & $\mathrm{D}$ & $\mathrm{X}$ & 1 \\
\hline & 100 & 3 & 0648 & $\mathrm{D}$ & L-M & $1-2$ \\
\hline & 100 & 3 & 0649 & D & L-M & $2+$ \\
\hline & 100 & 3 & 0653 & B & $*$ & $0+$ \\
\hline & 100 & 3 & 0654 & $\mathrm{~B}$ & $\mathrm{~L}$ & 1 \\
\hline
\end{tabular}


Table 27-1, continued

\begin{tabular}{|c|c|c|c|c|c|c|}
\hline Feature No. & Square & Level & $\begin{array}{l}\text { Sample No. } \\
\text { (AM-) }\end{array}$ & $\begin{array}{l}\text { Cooling } \\
\text { Context }\end{array}$ & $\begin{array}{c}\text { Lowest Temperature of } \\
\text { Movement }\end{array}$ & $\begin{array}{l}\text { No. of Discernible Movements } \\
\text { while Cooling }\end{array}$ \\
\hline & 100 & 3 & 0655 & B & L-M & $1+$ \\
\hline & 100 & 3 & 0656 & B & $\mathrm{X}$ & 1 \\
\hline & 100 & 3 & 0659 & B & $\mathrm{X}$ & 1 \\
\hline \multicolumn{7}{|c|}{ Burned Rock Midden 1} \\
\hline \multirow[t]{9}{*}{ (Square 100) } & 100 & 4 & 0684 & A & $\mathrm{L}$ & $1+$ \\
\hline & 100 & 4 & 0685 & A & $\mathrm{X}$ & 1 \\
\hline & 100 & 4 & 0687 & $\mathrm{~B}$ & $\mathrm{X}$ & $1-2$ \\
\hline & 100 & 4 & 0688 & $\mathrm{D}$ & $\mathrm{L}$ & 1 \\
\hline & 100 & 4 & 0690 & $\mathrm{D}$ & $\mathrm{L}$ & $1+$ \\
\hline & 100 & 4 & 0692 & $\mathrm{D}$ & L-M & $1+$ \\
\hline & 100 & 4 & 0694 & $\mathrm{D}$ & $*$ & $0+$ \\
\hline & 100 & 4 & 0696 & A & $\mathrm{L}$ & 1 \\
\hline & 100 & 4 & 0697 & $\mathrm{~B}$ & $\mathrm{x}$ & 1 \\
\hline \multicolumn{7}{|c|}{ Burned Rock Midden 1} \\
\hline \multirow[t]{9}{*}{ (Square 100) } & 100 & 5 & 0737 & $\mathrm{C}$ & * & $0+$ \\
\hline & 100 & 5 & 0738 & A & $\mathrm{L}-\mathrm{H}$ & $2+$ \\
\hline & 100 & 5 & 0739 & $\mathrm{D}$ & $\mathrm{X}$ & 1 \\
\hline & 100 & 5 & 0740 & B & * & 0 \\
\hline & 100 & 5 & 0742 & A & $\mathrm{X}$ & 1 \\
\hline & 100 & 5 & 0743 & A & $\mathrm{L}$ & 1 \\
\hline & 100 & 5 & 0744 & B & $\mathrm{X}$ & 1 \\
\hline & 100 & 5 & 0745 & A & L-M & 1 \\
\hline & 100 & 5 & 0747 & A & $\mathrm{X}$ & $1-2$ \\
\hline \multicolumn{7}{|c|}{ Burned Rock Midden 1} \\
\hline \multirow[t]{7}{*}{ (Square 100) } & 100 & 6 & 0806 & B & $\mathrm{L}$ & 1 \\
\hline & 100 & 6 & 0807 & B & $\mathrm{X}$ & $1+$ \\
\hline & 100 & 6 & 0809 & A & $*$ & 0 \\
\hline & 100 & 6 & 0810 & B & $*$ & $\mathrm{O}+$ \\
\hline & 100 & 6 & 0811 & A & * & $0+$ \\
\hline & 100 & 6 & 0812 & $\mathrm{D}$ & $*$ & 0 \\
\hline & 100 & 6 & 0815 & $\mathrm{D}$ & $\mathrm{H}$ & 1 \\
\hline \multicolumn{7}{|c|}{ Burned Rock Midden 1} \\
\hline \multirow[t]{6}{*}{ (Square 100) } & 100 & 7 & 0849 & A & * & 0 \\
\hline & 100 & 7 & 0850 & B & $*$ & 0 \\
\hline & 100 & 7 & 0852 & A & M & 2 \\
\hline & 100 & 7 & 0853 & A & $\mathrm{X}$ & $1+$ \\
\hline & 100 & 7 & 0855 & $\mathrm{~A}$ & $*$ & 0 \\
\hline & 100 & 7 & 0857 & B & $\mathrm{H}$ & 1 \\
\hline \multicolumn{7}{|c|}{ Burned Rock Midden 1} \\
\hline \multirow[t]{6}{*}{ (Square 100) } & 100 & 8 & 0947 & B & $\mathrm{L}$ & 2 \\
\hline & 100 & 8 & 0948 & B & $*$ & $0+$ \\
\hline & 100 & 8 & 0949 & A & $*$ & $0+$ \\
\hline & 100 & 8 & 0953 & $\mathrm{D}$ & $\mathrm{X}$ & 1 \\
\hline & 100 & 8 & 0955 & $\mathrm{~A}$ & $\mathrm{~L}$ & 2 \\
\hline & 100 & 8 & 0956 & A & $\mathrm{X}$ & 1 \\
\hline \multicolumn{7}{|c|}{ Burned Rock Midden 1} \\
\hline \multirow[t]{2}{*}{ (Square 100) } & 100 & 9 & 0985 & A & $\mathrm{L}$ & $1+$ \\
\hline & 100 & 9 & 0987 & $\mathrm{~A}$ & L-M & 1 \\
\hline \multicolumn{7}{|c|}{ Burned Rock Midden 1} \\
\hline \multirow[t]{3}{*}{ (Square 100) } & 100 & 10 & 1001 & $\mathrm{D}$ & $*$ & 0 \\
\hline & 100 & 10 & 1004 & $\mathrm{D}$ & * & $0+$ \\
\hline & 100 & 10 & 1005 & $\mathrm{E}$ & L-M & $2+$ \\
\hline
\end{tabular}


Table 27-1, continued

\begin{tabular}{|c|c|c|c|c|c|c|}
\hline Feature No. & Square & Level & $\begin{array}{l}\text { Sample No. } \\
\text { (AM-) }\end{array}$ & $\begin{array}{l}\text { Cooling } \\
\text { Context } \\
\end{array}$ & $\begin{array}{c}\text { Lowest Temperature of } \\
\text { Movement }\end{array}$ & $\begin{array}{c}\text { No. of Discernible Movements } \\
\text { while Cooling }\end{array}$ \\
\hline & 100 & 10 & 1007 & B & $\mathrm{L}$ & 2 \\
\hline & 100 & 10 & 1008 & $\mathrm{C}$ & $\mathrm{x}$ & 1 \\
\hline & 100 & 10 & 1009 & A & L & 1 \\
\hline \multicolumn{7}{|c|}{ Burned Rock Midden 1} \\
\hline (Square 100) & 100 & 11 & 1170 & B & * & $0+$ \\
\hline & 100 & 11 & 1171 & $\mathrm{D}$ & * & 0 \\
\hline nonfeature & 27 & 35 & 1168 & B & $\mathrm{x}$ & $0+$ \\
\hline nonfeature & 27 & 35 & 1169 & B & $\mathrm{x}$ & 2 \\
\hline nonfeature & 28 & 35 & 1179 & $\mathrm{E}$ & $\mathrm{x}$ & $1+$ \\
\hline nonfeature & 28 & 35 & 1180 & $\mathrm{D}$ & $\mathrm{x}$ & $1+$ \\
\hline nonfeature & 50 & $32-\mathrm{A}$ & 1136 & A & * & $0+$ \\
\hline bedrock & & & 1264 & no results & & \\
\hline bedrock & & & 1265 & no results & & \\
\hline
\end{tabular}
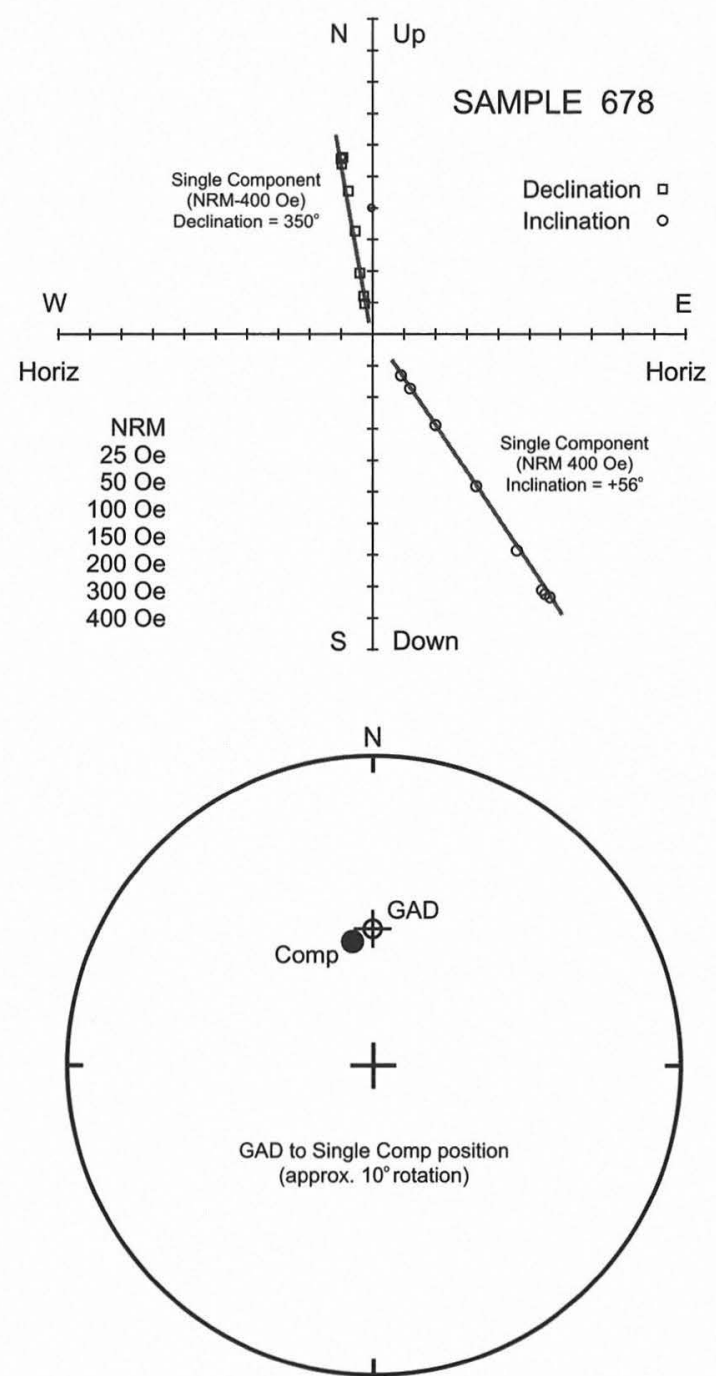

FiguRE 27-11. Archeomagnetic results from Rock AM-678. The $\mathrm{AZ}$ diagram shows the remaining remanence at each demagnetization step. The slope of the data are consistent and a single component was defined for this sample. This component is plotted on the stereonet below. Note that the calculated vector lies within about $10^{\circ}$ of the GAD position and AM-678 is therefore considered to be cooled in place. therefore combined into a single component for each rock as given in (c) and (f) in Figure 27-12. Slight differences between the individual samples are probably due to small variations introduced while orienting them in the field, placing them in the magnetometer, and/or trimming their bases. In addition, all four samples were analyzed early in the investigations which may have contributed somewhat to the observed (but still very subtle) angular differences. These results inspire confidence in the reproducibility of results, at least for single component rocks.

The single remanence component of Sample AM-673/ 935 (Figure 27-12f) is clearly separated from the GAD position (see Figure 27-10) which implies movement of the rock after, but not during, cooling. The stereonet in Figure 27-13 isolates this component and shows the direction and magnitude of postcooling disturbance as determined using the assumptions and constraints described in the Vector Rotation Reconstruction section. The AM-673/935 rock seems to have "tilted" or settled about $28^{\circ}$ toward the northeast after complete cooling. However, as shown in Figure 27-12, no discernible movement of the rock is apparent during cooling.

Two other single component rocks, AM-671 and AM934, also appear to have been displaced by roughly the same magnitude but in slightly more northward and northwestward directions, respectively (see final positions on Figures 27-9 and 27-10). These minor postcooling displacements are consistent with settling or tilting downward along the recognized plane of the reconstructed paleoslope (see Chapters 6 and 29). A similar situation, supported by results from many more samples, is discussed in Square 38, Level 22 (Composite F) below. The base elevations of larger rocks in Feature 236 also suggest a surface gently sloping to the north-northeast (see Chapter 26). Note that the AM-673/935 rock partially overlays AM-934 and may have deflected its rotation slightly. All three of these rocks (AM-671, AM-673/935, and AM-934) are coded "B/*/0" on Table $27-1$. In conclusion, archeomagnetic data from along the eastern edge of Feature 236 suggest that postcooling rock movement, though subtle, was not toward the center but away from it. 


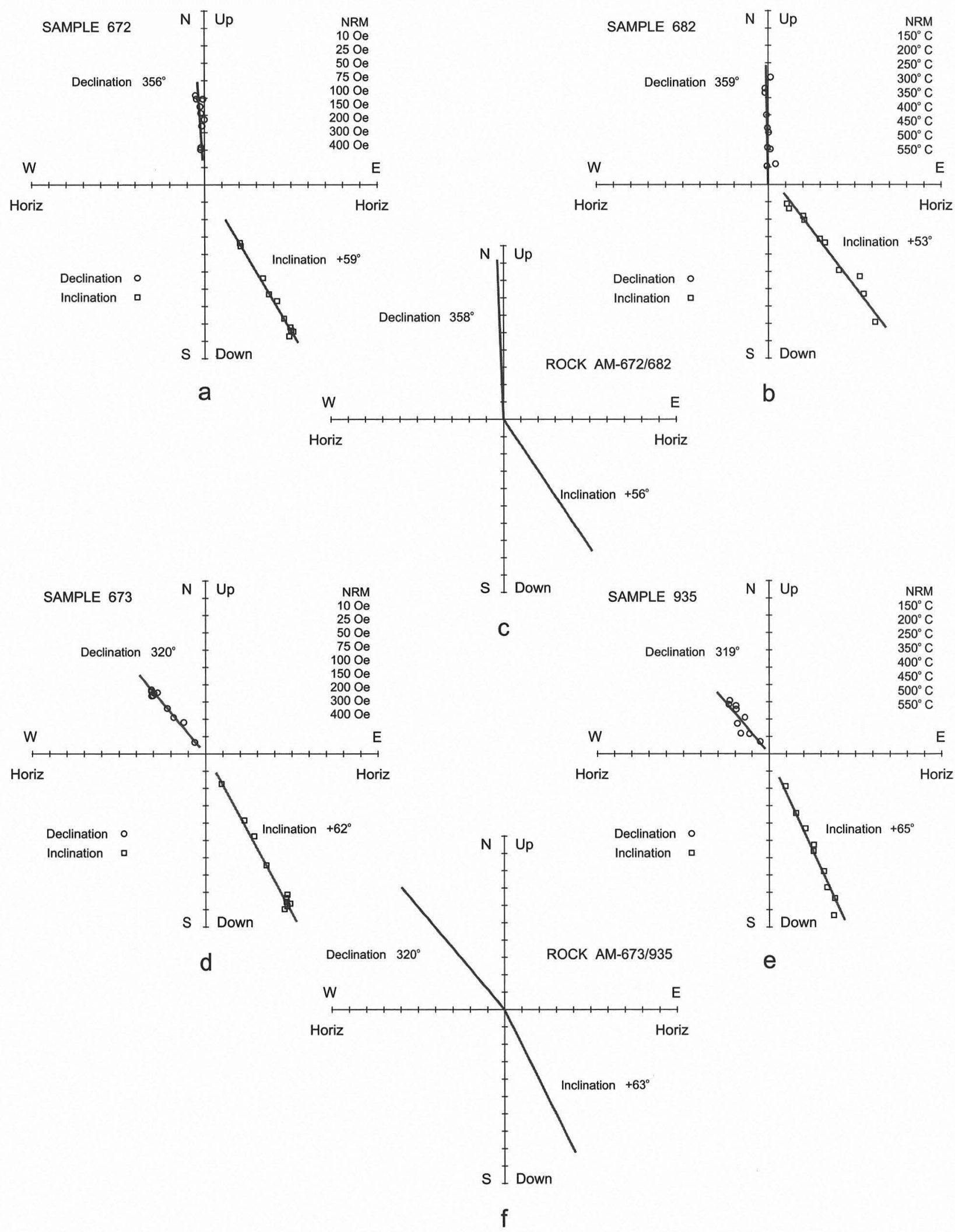

FIGURE 27-12. Sister sample results from Feature 236. Samples AM-672 (a) and AM-682 (b) are from one parent rock while Samples AM673 (d) and AM-935 (e) are from another. Note that in both cases one sister sample was demagnetized thermally and the other in an alternating magnetic field. The close agreement for these sister samples in terms of directions and number of components (all singlecomponent) allowed for the averaging of these results for each parent rock, as shown in (c) and (f). 


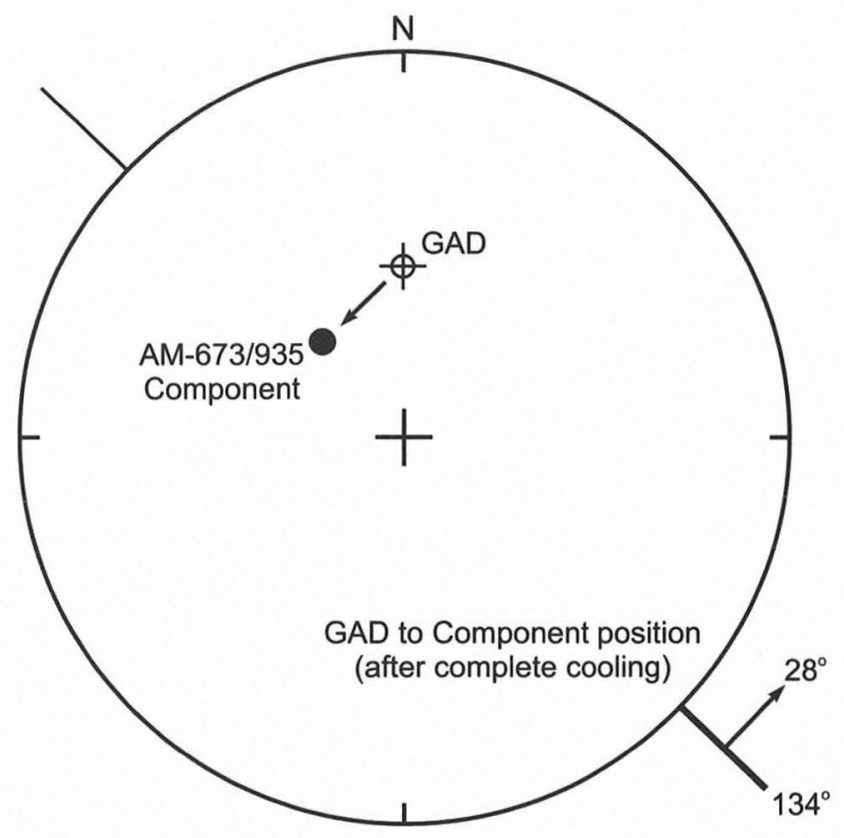

FIGURE 27-13. Stereonet plot of the single remanence component calculated for AM-673/935 (see Figure 27-12f) and its likely post cooling rotation. The thicker end of the axis (on the lower right at $\left.134^{\circ}\right)$ is the position of the thumb by the left-hand rule. The arrow perpendicular to this axis indicates the direction of inferred rock movement, in this case northeastward. The corresponding angular value $\left(28^{\circ}\right)$ is the magnitude of this reconstructed rotation.

Whether a central depression or shallow basin existed within Feature 236 was the subject of some debate in the field and during subsequent analysis. The feature was observed to be a single rock layer except in the center where minimal stacking was noted. Although no conclusive evidence of either a basin or pit could be seen in profile, some of the lower rocks did appear to slope as if lining a shallow basin or central depression. An alternative possibility was that an animal burrow penetrated the center of Feature 236 at some later date. Data from three of the remaining rocks (AM680, AM-937, and AM-938), all of which were moved both during and after cooling, indicate postcooling rotations toward the center and thus the existence of either a depression or a post depositional burrow. Furthermore, patterning in the directions, magnitudes, and temperature ranges of reconstructed vector rotations favor the depression rather than the burrow hypothesis. All three rocks were coded as " $\mathrm{C}$," or "out-of-place, cooling location inferred," on Table 27-1. They were moved at low to moderate temperatures (and thus "L," "L-M," or "M") and each experienced at least one displacement while cooling.

For example, analysis of AM-937 yielded two remanence components, one below and one above $200-250^{\circ} \mathrm{C}$ (Figure 27-14). Based in part on the observation that the lowest temperature component (A in Figure 27-14) is more than $30^{\circ}$ from both the GAD and the modern magnetic North polar position, modern viscous overprinting can be ruled out. Moreover, the apparent postcooling displacement, $33^{\circ}$ to

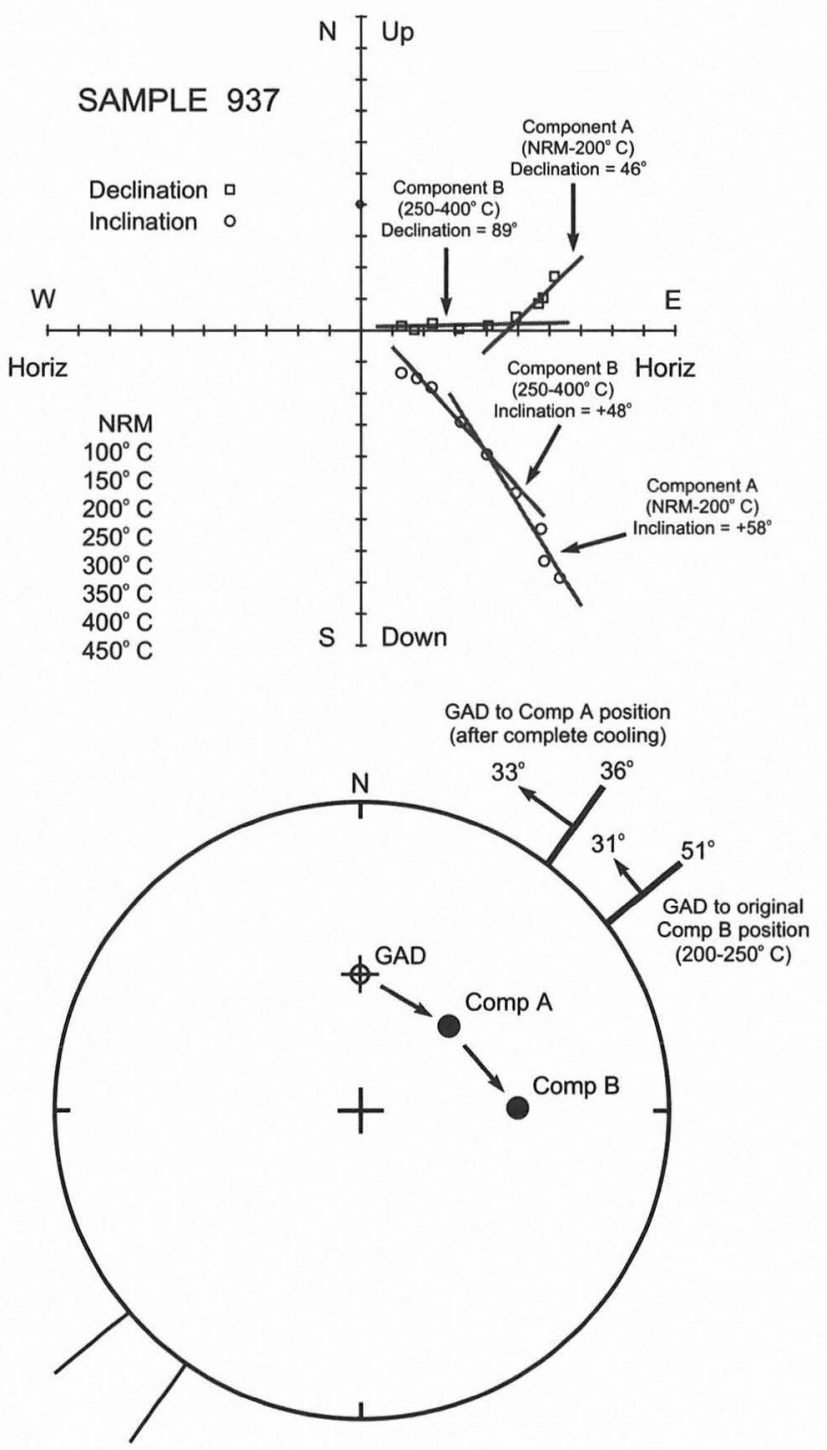

FiguRE 27-14. Archeomagnetic results from Sample AM-937. Two separate components can be defined as indicated on the AZ diagram. Their corresponding directions are shown in the lower stereonet. Vector rotation results for this sample are given on the outside edge of the stereonet. Because the lowest temperature component deviates from the GAD by $33^{\circ}$, this rock is considered out-ofplace (Table 27-1). However, the similarity in calculated displacements, as well as AM-937's final location (see Figure 279), suggest that these components resulted from movement while cooling rather than partial reheating and that its final cooling location can be confidently inferred.

the northwest $\left(36^{\circ}\right.$ axial position, or toward the center of Feature 236$)$, is very similar to the magnitude $\left(31^{\circ}\right)$ and direction $\left(51^{\circ}\right.$ axis) of the rotation between $200-250^{\circ} \mathrm{C}$. Such correspondence in sequential rotation values not only supports the contention that the lower temperature component is not a viscous remagnetization (VRM) but also that these two components resulted from movement while cooling rather than partial reheating. The latter is, of course, also likely given the proximity of seven rocks unequivocally heated to 
at least Curie point-equivalent temperatures during the final use of this feature. Available evidence suggests that postcooling movement of AM-937 toward the center of Feature 236 was essentially the continuation of displacements initiated before cooling was complete.

Perhaps the most compelling evidence for rotation toward the center comes from AM-680 and AM-938 (Figure 27-15). Furthermore, the planes along which these rocks apparently were displaced suggest a likely final cooling morphology for Feature 236 quite different from that observed during excavation.

Both rocks were clearly displaced from their final cooling positions. The sample AM-680 rock appears to have been displaced twice while cooling and once afterwards. The first displacement was a minor southward movement of about $17^{\circ}$ (not pictured in Figure $27-15$ ) at ca. $450^{\circ} \mathrm{C}$. Then

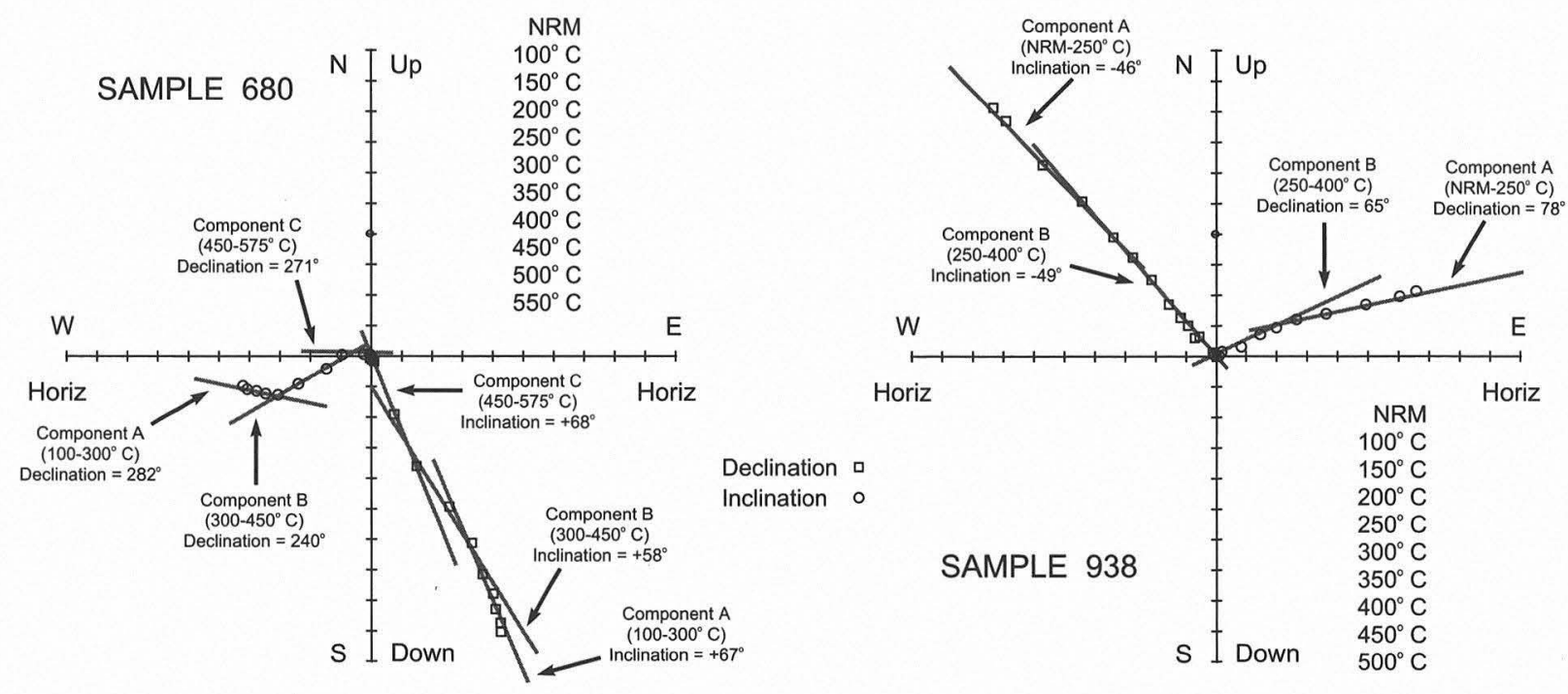

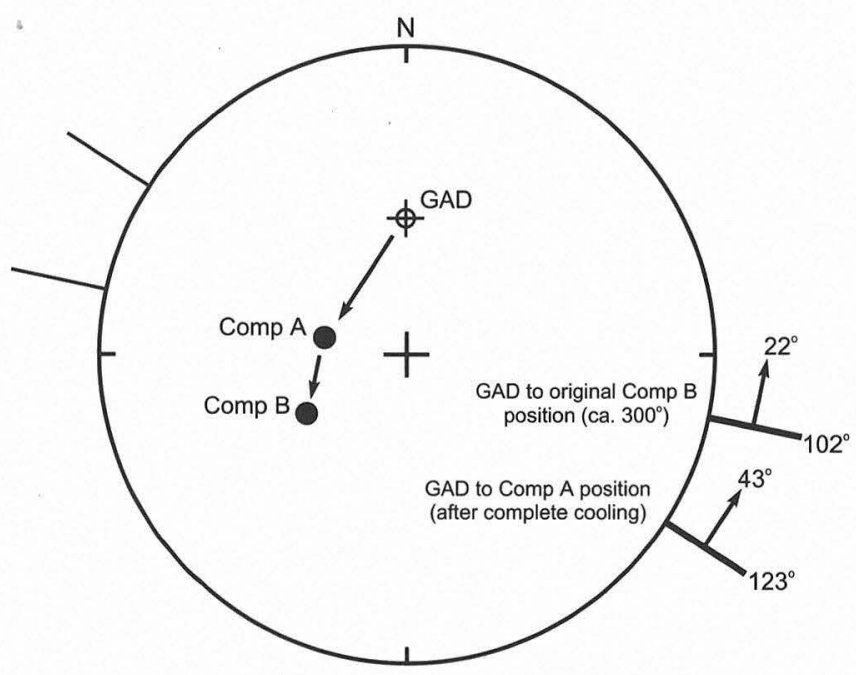

a

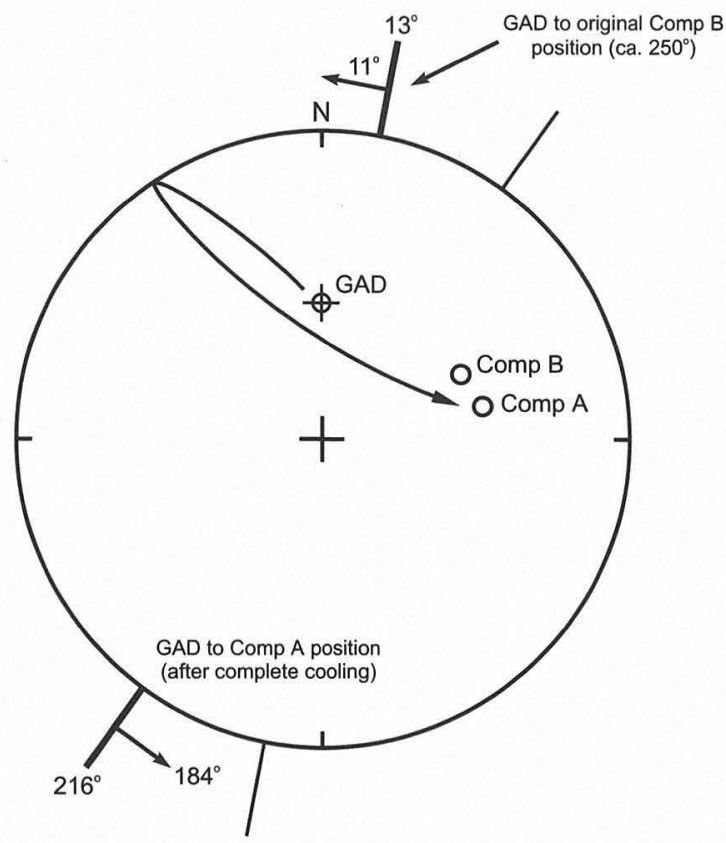

b

FIGURE 27-15. Identified components and vector rotation reconstructions for AM-680 and AM-938. Although both rocks are clearly outof-place, their most likely final cooling locations can be inferred. The AM-680 rock was probably displaced roughly north-northeast on two separate occasions-once at ca. $300^{\circ} \mathrm{C}$ and again after cooling. (Note that the displacement at around $450^{\circ} \mathrm{C}$, which is not shown, is approximately opposite the $300^{\circ} \mathrm{C}$ rotation.) These displacements suggest that $\mathrm{AM}-680$ began cooling (from at least $450^{\circ} \mathrm{C}$ ) roughly between the AM-677 and AM-678 rocks (see Figure 27-9). On the other hand, postcooling rotation of AM-938 appears to have been about a half-turn $\left(184^{\circ}\right)$ to the east-southeast, indicating that it probably cooled somewhere between AM-676 and AM-677 (see Figure 27 9). It previously experienced only a very minor displacement (ca. $\left.11^{\circ}\right)$ at around $250^{\circ} \mathrm{C}$. 
at around $300^{\circ} \mathrm{C}$, it appears to have moved back to the north about $22^{\circ}$. Finally, after cooling the rock was displaced northeastward by about $43^{\circ}$, toward the center of Feature 236. This postcooling movement would put the final cooling location of AM- 680 roughly between AM-677 and AM-678 along the southern edge of Feature 236 (see Figure 27-9). Again, given the close proximity of single component rocks and directional consistency in at least two sequential rotations, these components surely resulted from movement while cooling rather than incomplete reheating. Similarly, AM-938 may also have experienced a minor (ca. $11^{\circ}$ ) rotation at about $250^{\circ} \mathrm{C}$. However, after it cooled it was moved dramatically (Figure 27-15). The most likely scenario is that it flipped over (about $184^{\circ}$ rotation) toward the southeast ( $216^{\circ}$ axis). If so, its previous final-cooling location would be roughly between AM-677 and AM-676 (see Figure 27-9). Interestingly, AM-680 and AM-938 both appear to have experienced small magnitude displacements $\left(\right.$ at $450^{\circ} \mathrm{C}$ and $250^{\circ} \mathrm{C}$, respectively) roughly antiparallel to their postcooling rotations. One might speculate that these represent prehistoric attempts to counteract some tendency of the rocks to rotate inward and thereby maintain the original structure of Feature 236. If so, this effort was eventually abandoned after the rocks cooled and they were allowed to continue settling into the positions in which they were recovered.

Thus, vector rotation reconstructions for all three outof-place rocks discussed thus far (AM-680, AM-937, and AM-938) suggest that when it cooled, Feature 236 was probably a roughly circular arrangement of stones surrounding a relatively rock-free central area and that it was only afterward that the rocks were displaced toward the center. Nevertheless, such disturbances could result from either a burrow or an existing depression. It is critical, therefore, that the postcooling rotations of both AM-680 and AM-937 appear to be the continuation of previous displacements during cooling. This clearly favors a shallow depression although the effects of animal disturbances exacerbating or mimicking these patterns cannot be ruled out.

Finally, AM-936 is enigmatic, due at least in part to its weak remanence intensity. The lowest temperature component $\left(<150^{\circ} \mathrm{C}\right)$ deviates from the GAD by nearly $45^{\circ}$ (see Figure 27-10). Vector rotation reconstructions therefore suggest an eastward displacement from a final cooling location along the western edge of Feature 236. However, the higher temperature component (defined between $150^{\circ} \mathrm{C}$ and $300^{\circ} \mathrm{C}$ ) is nearly identical to the GAD and the four in-situ rocks. This would mean that AM-936 rotated first to the west (at ca. $150^{\circ} \mathrm{C}$ ) and then back to the east (after cooling) by quite similar magnitudes. Alternatively, the NRM $-150^{\circ} \mathrm{C}$ component could be a postcollection, viscous overprint. If so, then the $150^{\circ}-300^{\circ} \mathrm{C}$ component is the sole prehistoric remanence and AM-936 remains in its final cooling location. Nevertheless, because the $<150^{\circ} \mathrm{C}$ component cannot be ruled out as a VRM and because the rotation reconstructions calculated using it are reasonable based on the location of AM-936 vis- à-vis the other rocks in Feature 236, it is provisionally retained as a valid component. Consequently, this rock is coded on Table 27-1 as "out-of-place, cooling location inferred," but bear in mind the caveat that it may actually be in rather than near its final cooling location. Either interpretation is consistent with the overall archeomagnetic interpretation of Feature 236 based on the other 10 rocks.

To summarize, of the 11 rocks analyzed from Feature 236, 7 (and perhaps 8) cooled without moving from initial temperatures in excess of the Curie point, and the majority of these remained in their final cooling locations. Furthermore, patterning in the cooling and postcooling movement of the analyzed rocks supports the interpretation that Feature 236 was originally a roughly circular arrangement of stones, some enclosing a shallow central depression, on a gently sloping occupation surface. It may also have been disturbed to some degree by an animal burrow.

The archeomagnetic analysis of Feature 236 serves as an exemplary illustration not only of the potential of archeomagnetism for understanding the dynamic history and context of burned rock features but also of the complexity of the archeological record (and our expectations of it). Although many rocks cooled in place, not all did, and consequently the original configuration of Feature 236 was subtly but significantly different from that observed during excavation. Regardless of the veracity of the specific interpretations offered here, it is obvious that while Feature 236 is clearly "intact," its history is much more complex than is implied by this simple generalization.

\section{Feature 184}

Feature 184 was a burned rock cluster excavated by TxDOT in the southeastern quadrant of Square E28/S78. The cluster extended into the southern and eastern walls of the TxDOT square and its eastern margin was exposed in Levels 25 and 26 of TARL Square 50 (Figure 27-16). One rock in each level was collected and analyzed (see Table 27-1). Both were found to have cooled in or nearly in place (Figure 27-17). However, whereas the larger of the two rocks (AM1028) did not move significantly while cooling (i.e., it has a single remanence component), the smaller rock was displaced about one-quarter turn to the north (toward the main body of Feature 184) at some unknown temperature. This suggests that the AM-1029 rock was probably also heated in excess of the Curie point and that its two magnetic components resulted from movement during cooling. The archeomagnetic data demonstrate that the rocks in at least this small portion of Feature 184 remained in place after final cooling.

\section{Feature 201}

Feature 201 was originally assigned to a small somewhat dispersed cluster of burned rocks excavated in Square 


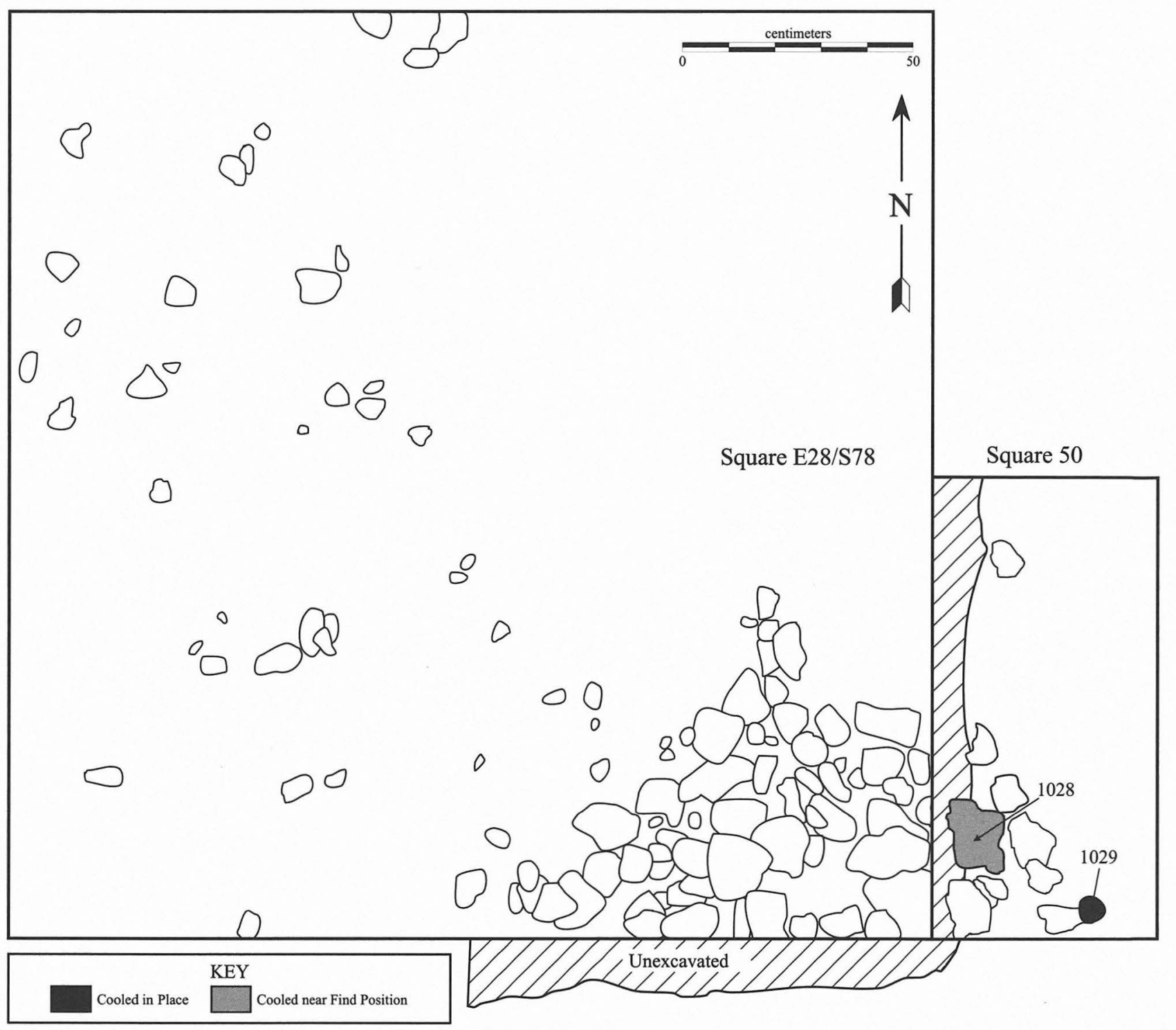

FIGURE 27-16. Plan map of Feature 184 in TARL Square 50 and TxDOT Square E28/S78.

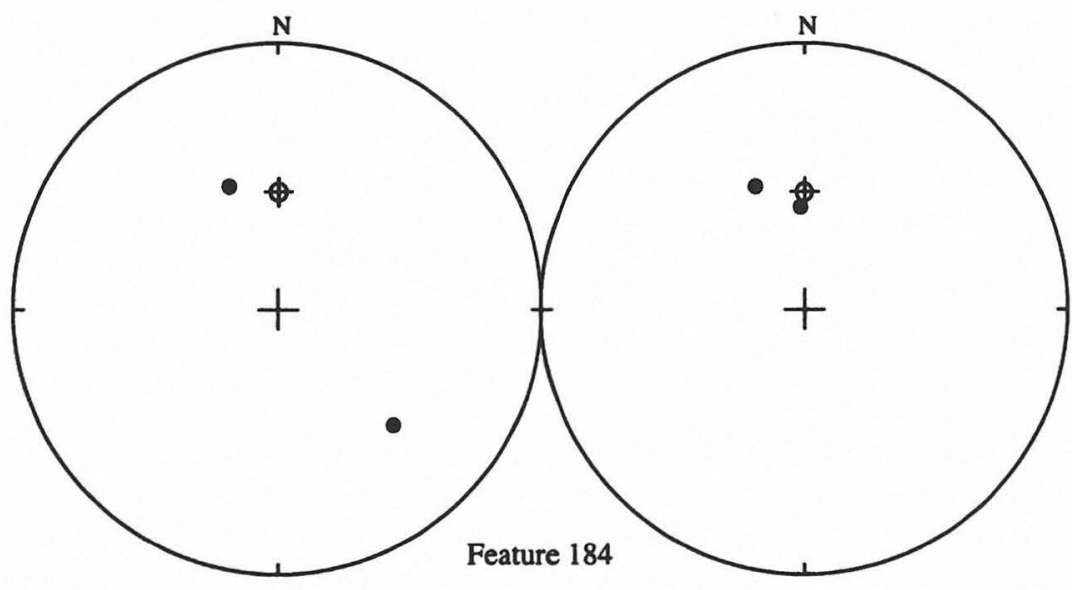

FIGURE 27-17. Stereoplots of results for Feature 184. 
21, Level 6 (in lower Unit IIIc). It soon became clear, however, that this was only a small portion of a much larger burned rock accumulation composed of numerous small clusters and more scattered deposits, which thinly covered much of the TARL excavation area. Therefore, the Feature 201 designation was eventually extended to include burned rocks from several levels and excavation squares (see Chapter 26). Within this palimpsest accumulation, additional feature numbers were assigned to seven clusters of rocks considered subfeatures of Feature 201. In Table 27-1 the five subfeatures with archeomagnetic results (Features 203, 205, 206, 207, and 211) are listed first by their primary feature number followed by Feature 201 in parentheses. The results from all rocks depicted on the same plan map (Figures 27-18 and 2719) have been combined on the same stereonet pair (shown in Figure 27-20) and are discussed along with the subfeature results.

\section{FEATURE 201,EASTBLOCK(INCLUDING FEATURES 203 AND 205)}

The burned rock distribution data from the East Block of the TARL excavations have been combined on a single plan map showing Feature 201 and the two subfeatures in this block, Features 203 and 205 (see Figure 27-18). In some cases, rocks from two successive levels in the same excavation square have been overlaid onto a single projection. The levels included are listed beside the square number on the map. Sampling intensity was quite low during the early stages of TARL investigations. Therefore limited information is available and many rock clusters are represented by only one or two analyzed samples. Only 13 of the 29 samples collected from the East Block of Feature 201 were analyzed (see Table 27-1).

Overall, archeomagnetic analysis of East Block samples yielded mixed results; while many of the rocks surely cooled in place, most of them cooled where they were found from only low temperatures (see Table 27-1). A few were displaced somewhat after they last cooled (see Figure 27-20) but not sufficiently to be considered out-of-place. A few of the rocks cooled from high temperatures with little or no discernible movement, but nearly half were moved two or more times while cooling. While no clear patterns in the direction of rock movement can be seen, the reconstructed vector rotations do indicate that several rocks (most notably AM-11, AM-19, and AM-48, among others) were probably displaced in the same or similar directions during successive rotations. These observations support the inference that their magnetic component differences resulted from movement while cooling from high temperatures rather than from partial reheating. The overall conclusion is that although the analyzed rocks in the East Block of Feature 201 probably cooled in place, their cooling histories are complex. The available data suggest that most or all of these rocks were heated to maximum temperatures approaching or exceeding the Curie point.

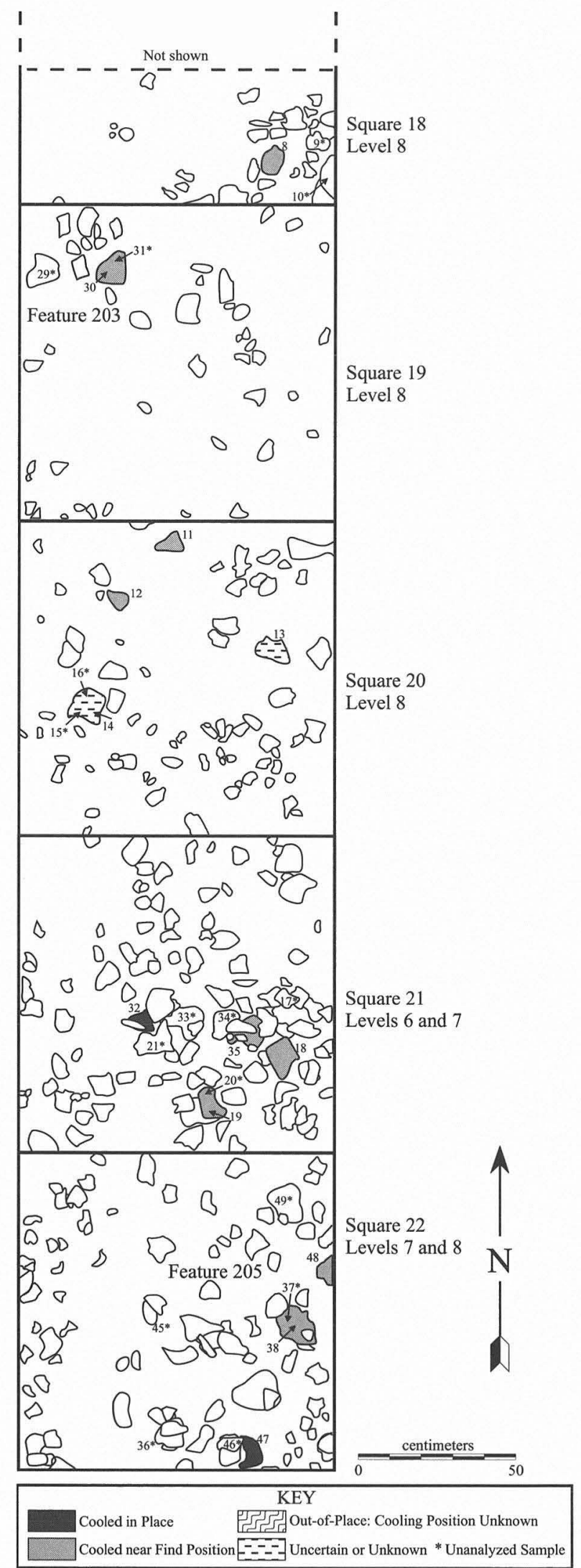

Figure 27-18. Composite plan map of Feature 201 and associated features in East Block, Levels 6-8 (including Features 203 and 205). 


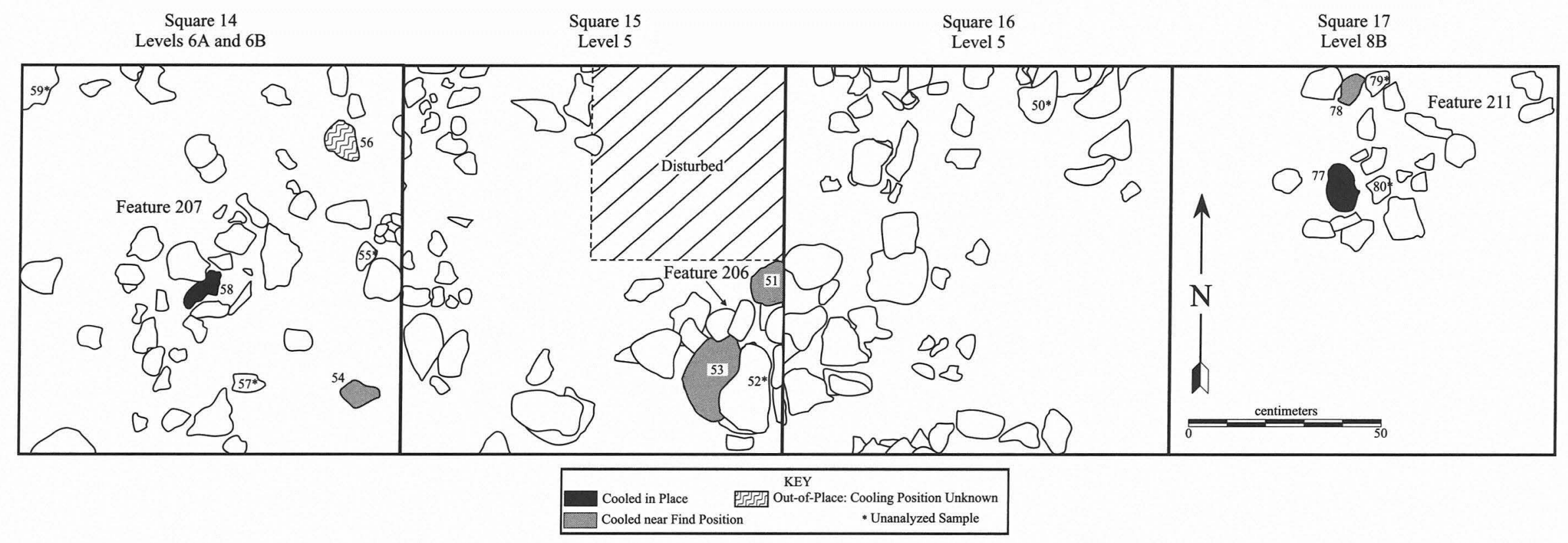

FIGURE 27-19. Composite plan map of Feature 201 and associated features in South Block, Levels 5-8 (including Features 206, 207, and 211). 


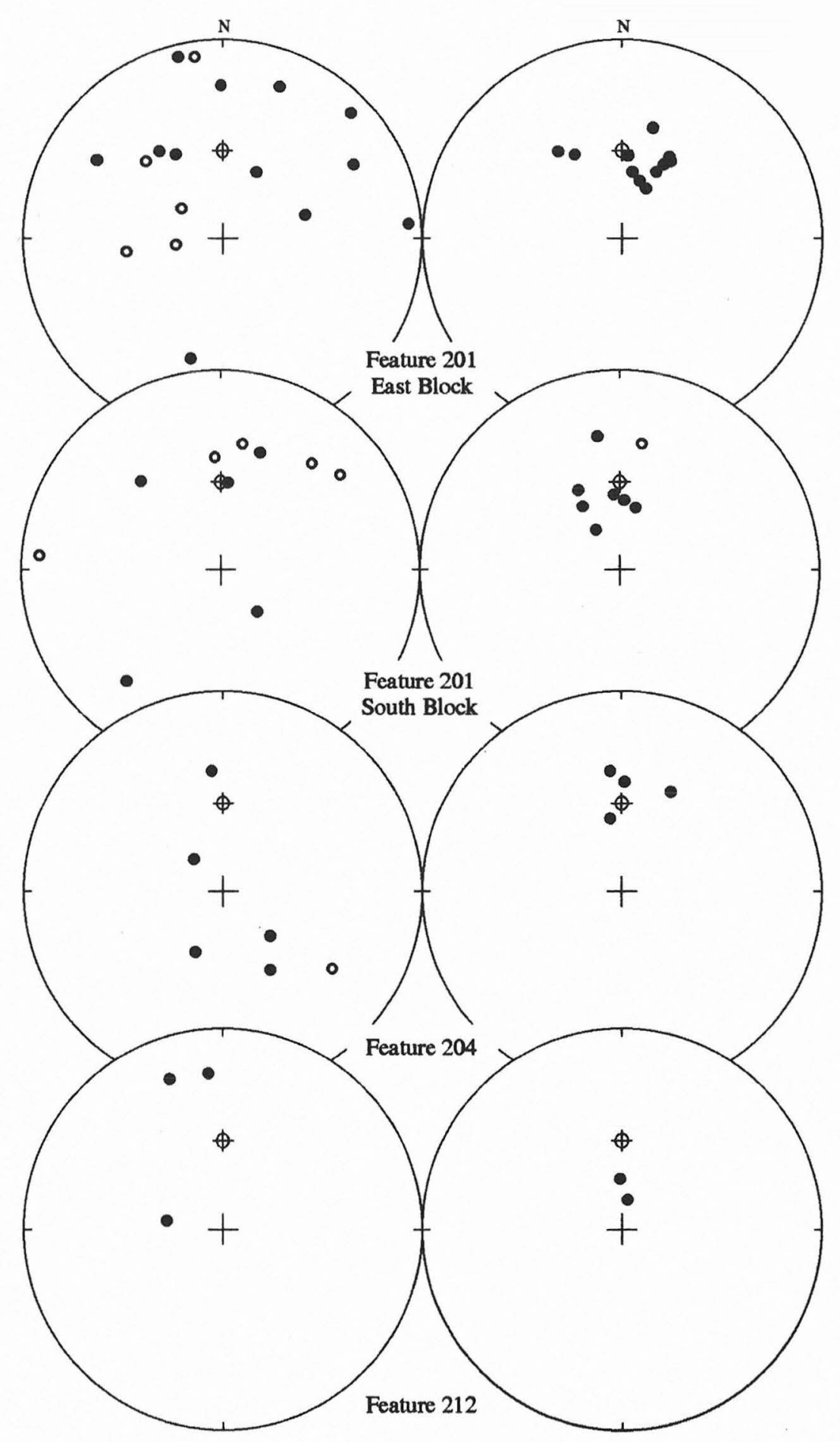

FIGURE 27-20. Stereoplots of results for Feature 201, East and South Block, as well as for Features 204 and 212.

\section{FEATURE201, SOUTHBLOCK (INCLUDING}

FEATURES 206, 207,AND 211)

The distribution of burned rocks and the locations of the analyzed archeomagnetic samples from Feature 201, South Block are shown in Figure 27-19 and the stereonet projections of their combined directional data are given in
Figure 27-20. The burned rock clusters in the South Block generally appear to be more circumscribed than in the East Block, but again sampling intensity was low and the results are limited. Only 21 samples were collected from the South Block portion of Feature 201 and only 9 of these were analyzed (see Table 27-1). Note that due to the sloping of deposits at the site (gently downward to the north), the levels 
in the South and East blocks are nearly equivalent stratigraphically.

The archeomagnetic results from the South Block of Feature 201 demonstrate that, while many of the rocks cooled in or near where they were found, all but one did so from only low to moderate temperatures (see Table 27-1). Only two rocks remained relatively still while cooling from high temperatures and one of these (AM-56) was clearly displaced thereafter. Again, no patterning is evident in the vector rotation reconstructions for these samples, but unlike the East Block, there is little consistency in direction even within the samples. This complicates the assessment of whether the observed component differences resulted from movement while cooling or partial reheating. However, given that at least two of the sampled rocks did reach temperatures nearing or exceeding the Curie point, it seems likely that the rocks were heated to relatively high temperatures.

\section{Feature 204}

Feature 204 was a small, nearly circular cluster of stones stratigraphically within or just below the lower levels of Feature 201 (Figure 27-21). Results from four of the five samples collected (AM-60, AM-61, AM-63, and AM-64) confirm that each remained in or very near the position where it cooled (see Figure 27-20, Table 27-1). Sample AM-63, the smallest rock analyzed, moved more frequently while cooling, and a greater distance afterward, than did the others which cooled in place with little or no disturbance from temperatures of at least $400^{\circ} \mathrm{C}$. Vector rotation reconstructions are generally

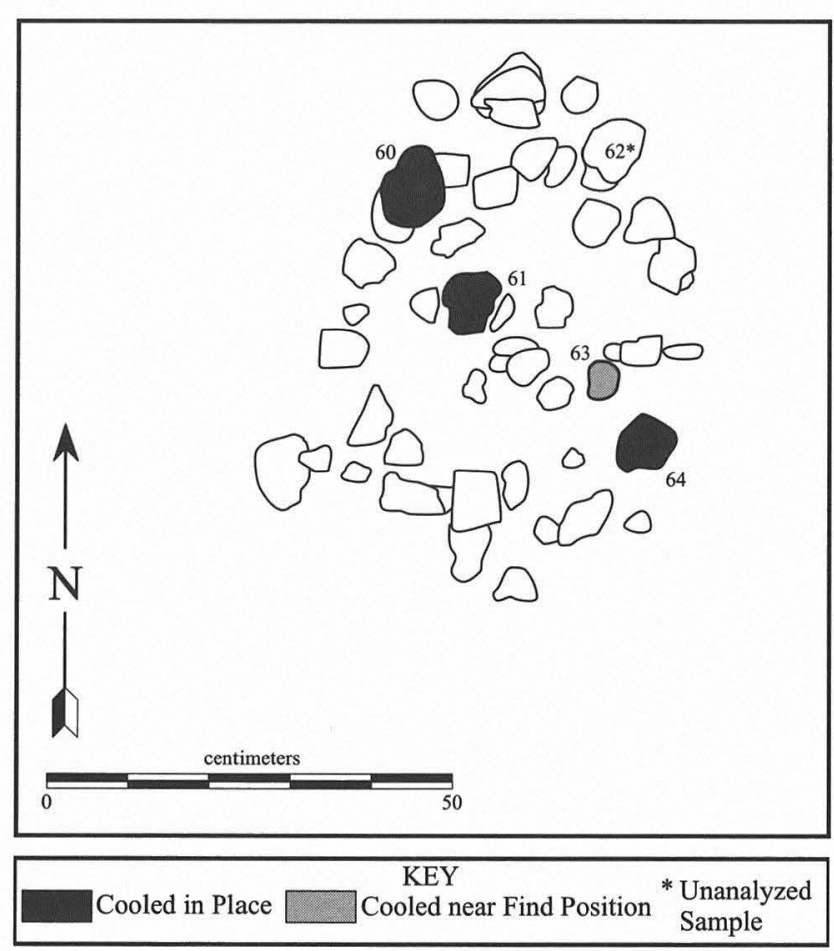

FIGURE 27-21. Plan map of Feature 204 in Square 20, Level 11B. consistent with cooling rotations toward the feature center, possibly into a shallow depression. In sum, the archeomagnetic evidence clearly indicates that at least some of the rocks in Feature 204 remained in their final cooling arrangement after being heated to initial temperatures in excess of $550^{\circ} \mathrm{C}$. There is little evidence for intentional movement of the rocks while they cooled. Instead, rotation data suggest the likelihood of a small central depression.

\section{Feature 212}

Only limited archeomagnetic data are available from Feature 212 (Figure 27-22). Results from the two rocks sampled (AM-93 and AM-94) reveal that they cooled largely in place from low to moderate temperatures (see Figure 2720). Each rock experienced at least one significant disturbance while cooling (see Table 27-1). If they moved after cooling, they did so in very similar ways as evidenced by the similarity of their measured low temperature remanence directions (see Appendix 6). The larger rock (AM-93) appears to have been displaced at a somewhat higher temperature than the smaller one. This suggests the possibility that, although they may have been displaced simultaneously, the larger rock (because of its lower surface-to-volume ratio) might have retained more heat energy and therefore registered the dislocation at a slightly higher temperature. The experimental testing and replication of such inferences using control samples are one aspect of the ongoing archeomagnetic research on burned rocks. Nevertheless, the magnetic vector changes in both rocks from Feature 212 are seen primarily in either declination or inclination (but not both). It therefore seems more likely that these components were acquired while cooling rather than from partial reheating. Matching directions (in any plane) of two separate rocks purely by chance is improbable. The conclusion is that the sampled portion of Feature 212 remains in primary cultural context and is fairly well preserved.

\section{Feature 214}

Although somewhat ambiguous due to low remanence intensities, the archeomagnetic results from Feature 214 (Figure 27-23) are consistent with the interpretation that the three rocks analyzed (AM-83, AM-84, and AM-85) cooled in place from at least low temperatures (Figure 27-24; see Table 27-1). Sample AM-84, which yielded the strongest (albeit still rather weak) remanence, probably experienced two successive southeastward rotations, suggesting that it moved while cooling from higher initial temperatures.

\section{Feature 218}

Only one sample (AM-98) was analyzed from Feature 218 (Figure 27-25). It probably cooled near its find position from low temperatures, but it remains unclear whether this 


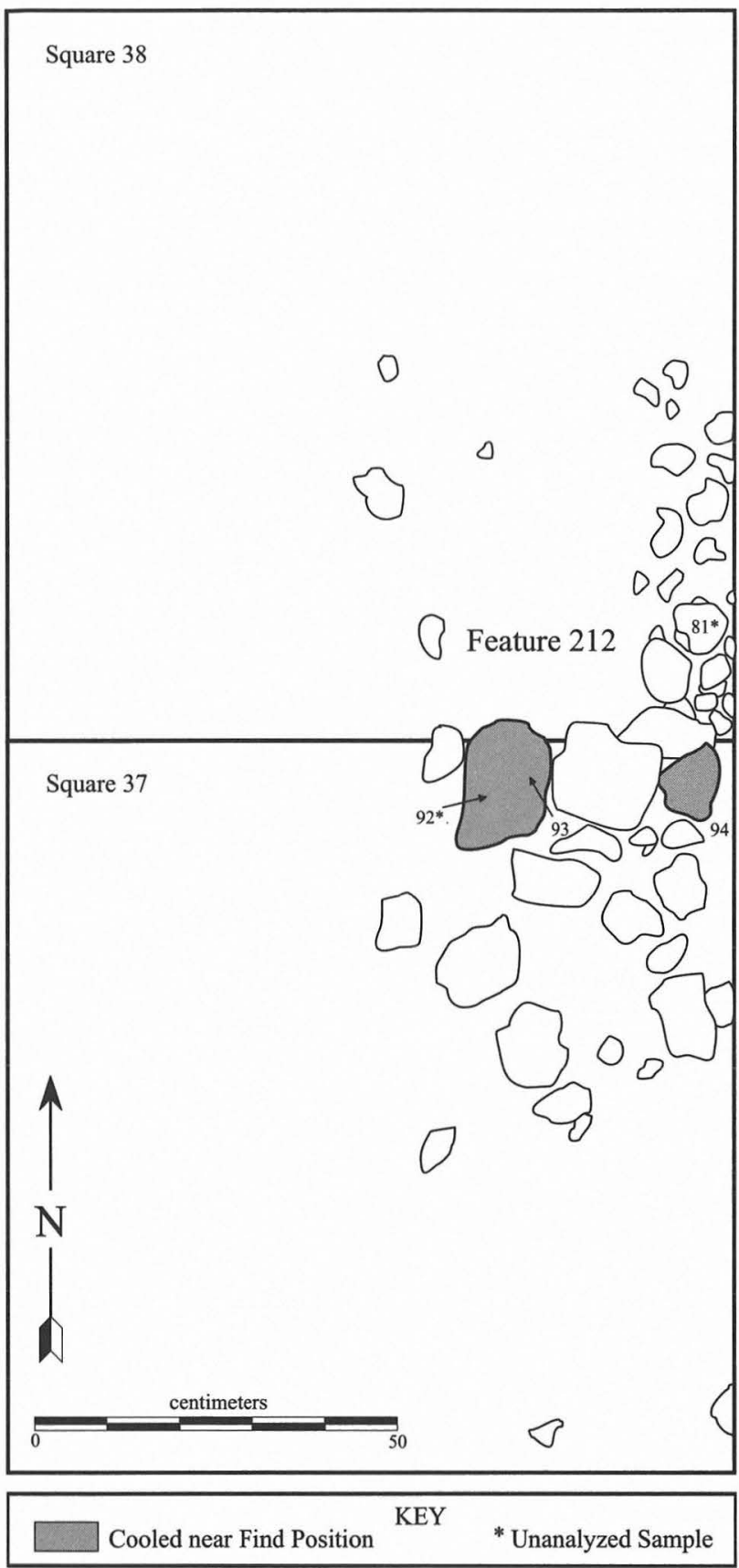

Figure 27-22. Plan map of Feature 212 in Squares 37 and 38, Level 13.

resulted from low temperature reheating or displacement while cooling. If acquired while cooling, the widely dispersed directions of the three components identified below $500^{\circ} \mathrm{C}$ evidence significant movement during final cooling (see Figure 27-24).

\section{Feature 222}

All three of the analyzed rocks from Feature 222 (AM101, AM-102, and AM-104) on Figure 27-26 were recovered in or very near their final cooling locations (see Figure 27-

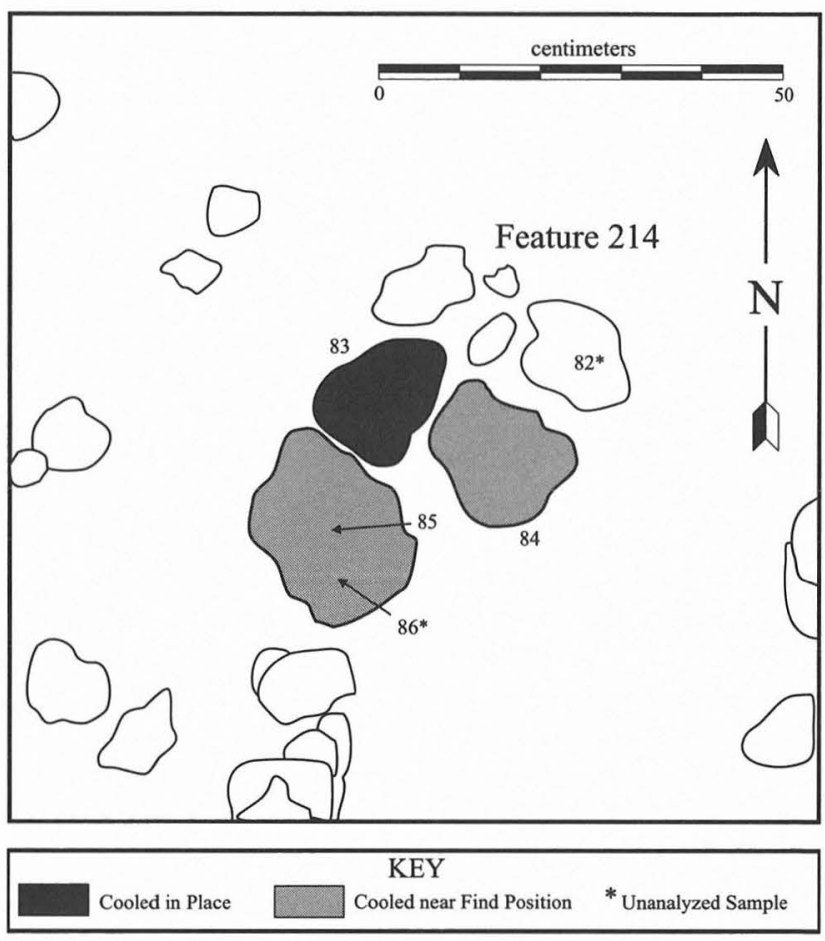

Figure 27-23. Plan map of Feature 214 in Square 16, Level 10.

24). Vector rotation reconstructions argue for primarily northward displacements during and after cooling. This is consistent with the field interpretation that this feature was probably constructed on an unmodified paleosurface with a slight downward slope to the north-northeast. The rock that appears to have experienced the most numerous and significant displacements (AM-101) had its long axis perpendicular to this plane (see Figure 27-26). The other two analyzed rocks moved much less while cooling from initial temperatures near the Curie point. The archeomagnetic data support the excavator's opinion that Feature 222 rested on a slightly sloping surface and was a relatively well-preserved hearth remnant.

\section{Feature 224}

Feature 224 was a circumscribed, elliptical cluster of burned rocks (Figure 27-27) underlying a more diffuse, amorphous rock scatter that may have been an extension of the Feature 231 palimpsest deposit (see below). Feature 224 was at least $10 \mathrm{~cm}$ deep, but there was minimal overlap and stacking of the rocks. The six archeomagnetic samples analyzed from in or near the feature (AM-112, AM-115, AM-116, AM138, AM-139, and AM-141) all cooled in place and remained in or near these positions until excavated (see Figure 27-24; Table 27-1).

Within the main cluster, the lowermost rocks (AM-138, AM-139, and AM-141) moved less while cooling than did the slightly more elevated rock (AM-112) on the northwestern edge. All four, however, cooled in or near where they 


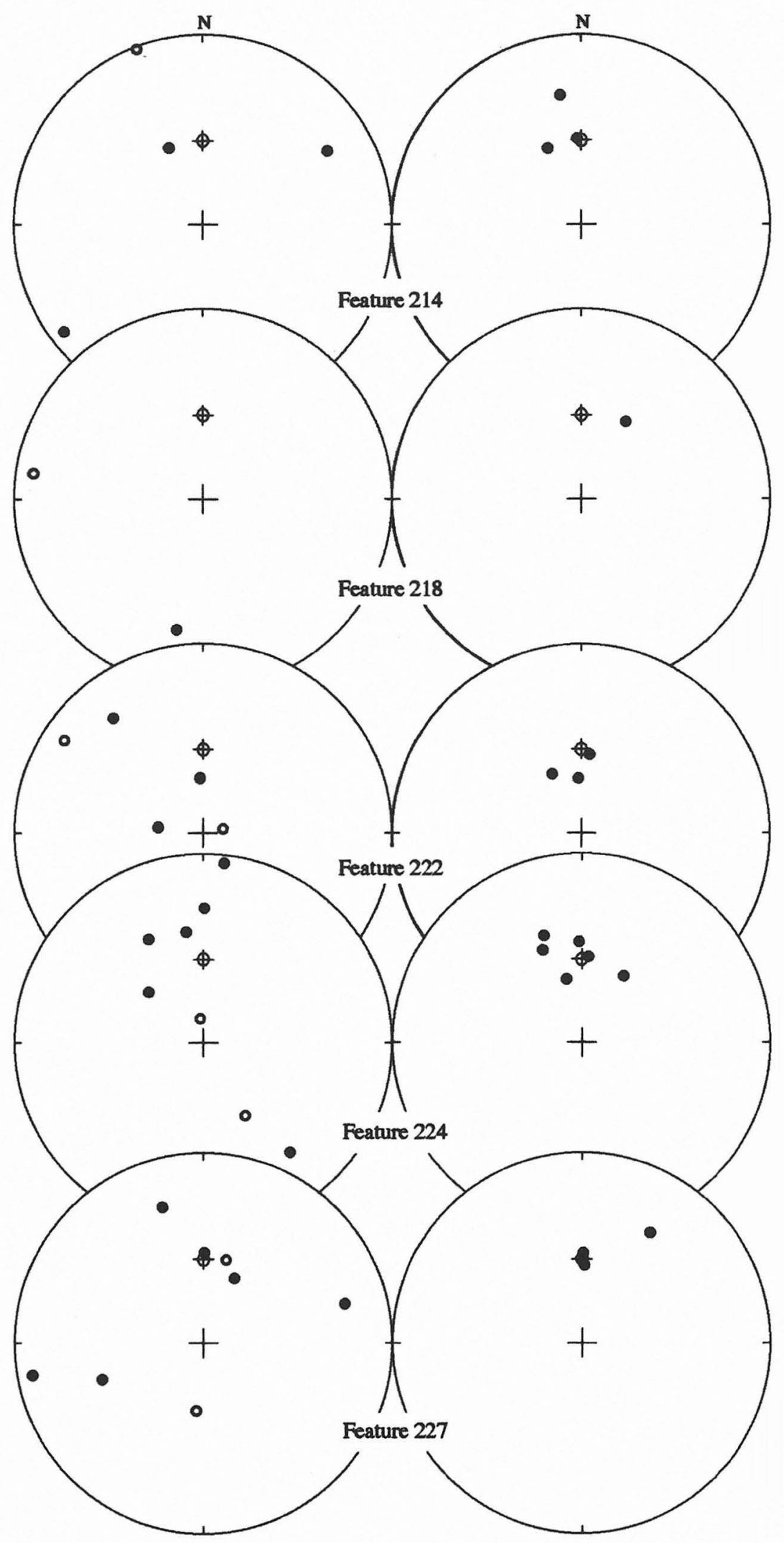

FIGURE 27-24. Stereoplots of results for Features 214, 218, 222, 224, and 227. 


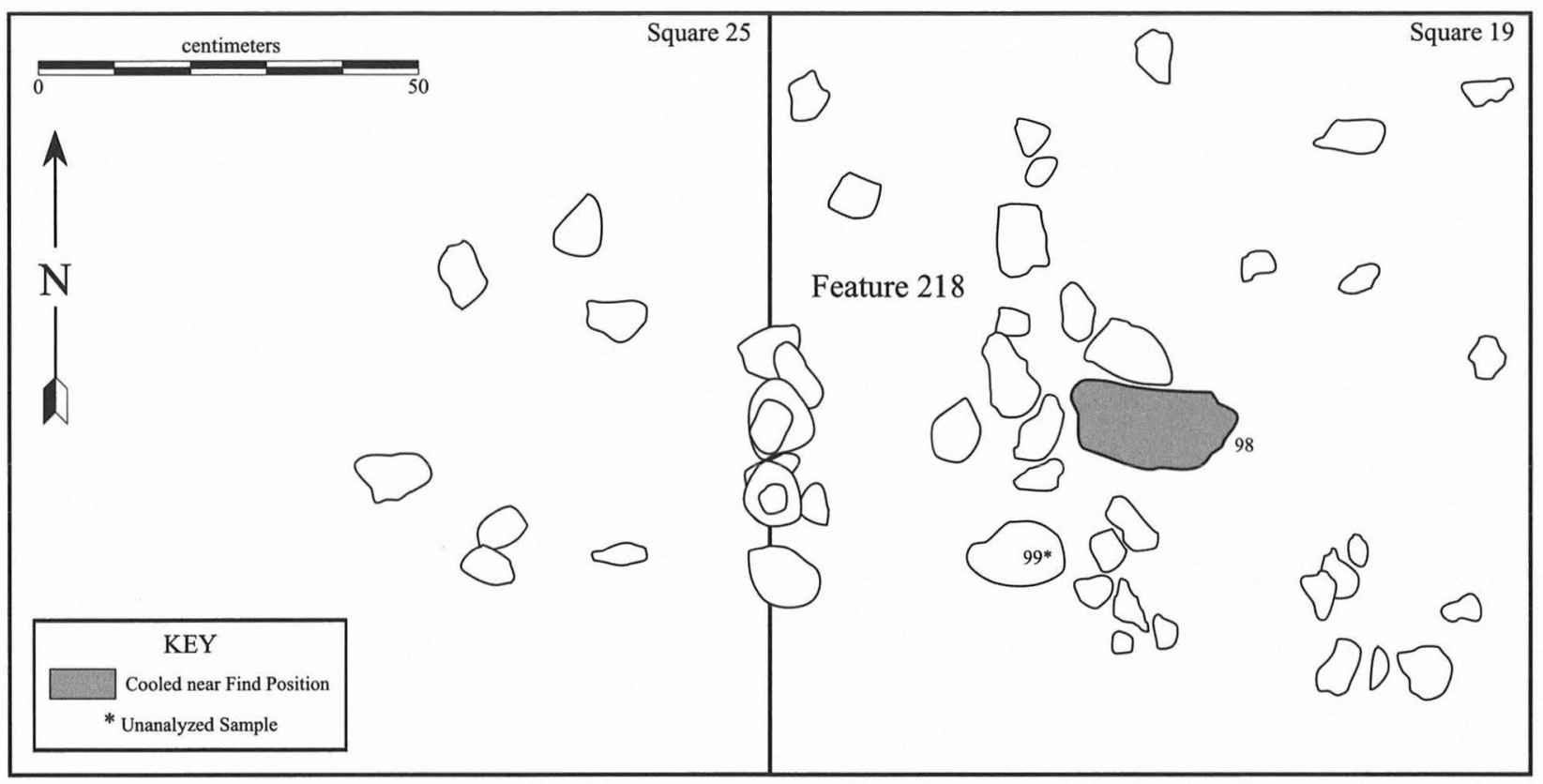

FIGURE 27-25. Plan map of Feature 218 in Squares 19 and 25, Level 14.

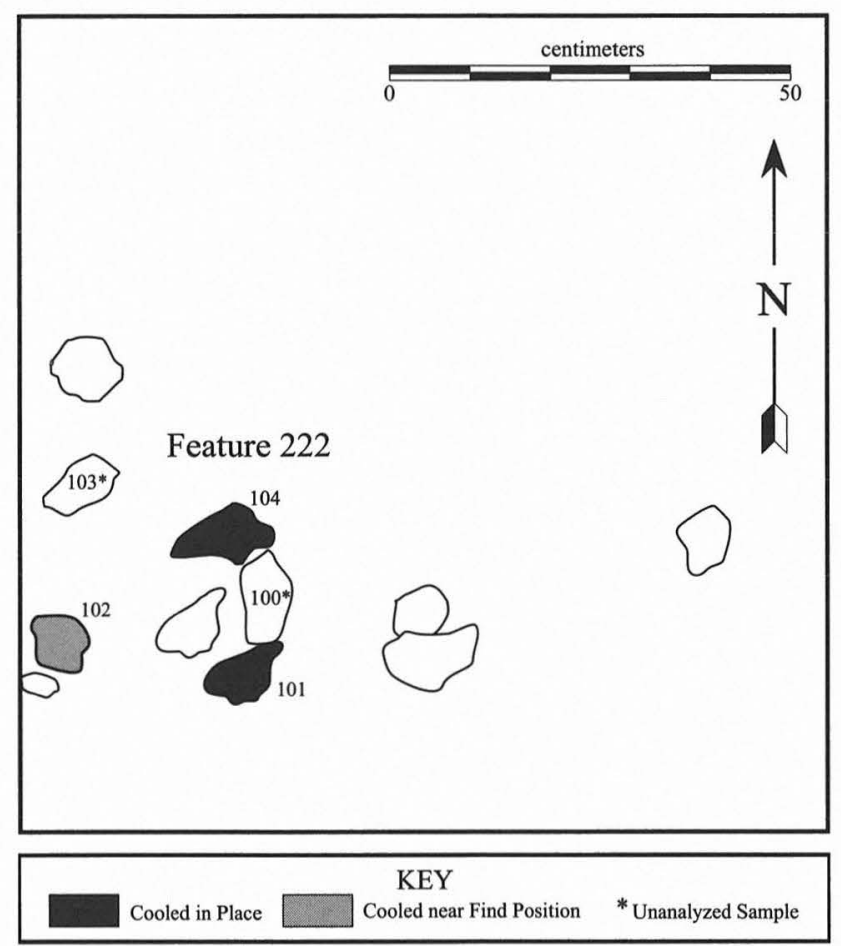

FIGURE 27-26. Plan map of Feature 222 in Square 37, Level 16.

were found from between $300^{\circ}$ and $450^{\circ} \mathrm{C}$ (see Table 27-1). The apparent southward rotation of $\mathrm{AM}-112$ at $450^{\circ} \mathrm{C}$ suggests that these four rocks may have been part of a singlelayer heating element lining a small shallow basin. The two more peripheral rocks (AM-115 on the southern edge and AM-116 about $30 \mathrm{~cm}$ to the west) also cooled in place but only from lower temperatures and following more displace-

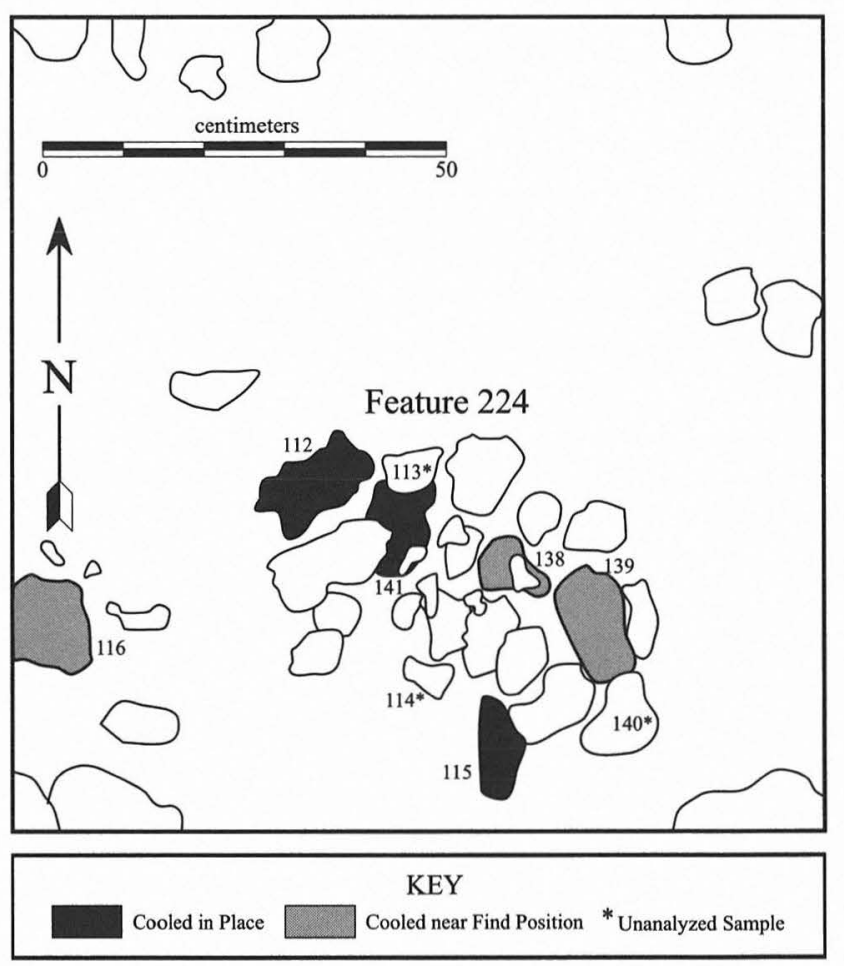

FIGURE 27-27. Plan map of Feature 224 in Square 12, Levels 18 and 19.

ments (see Table 27-1). Alternatively, these two rocks may only have been heated to maximum temperatures of $450^{\circ} \mathrm{C}$. However, similarities in their apparent rotations at about $450^{\circ} \mathrm{C}$, as well as the observation that the other Feature 224 rocks were also moved (albeit less dramatically) around this temperature supports the conclusion that AM-115 and AM- 
116 probably acquired their individual components while cooling rather than from partial reheating. While the relationship of AM-116 to the main cluster remains unclear, it evidently cooled in-situ, as did the others. Since at least six of the rocks remained in or near their final cooling position, Feature 224 probably experienced relatively little disturbance after its final use (see Figure 27-24).

Feature 226

Feature 226 was encountered at the northern edge of TARL Square 46 and may be the remnant of a larger burned rock feature that extended northward into the TxDOT excavation area (Figure 27-28). Only one sample (AM-155) was analyzed from this feature (see Table 27-1). Although not conclusive (due in part to a weak remanence intensity), the results suggest that the rock cooled in place from low to moderate temperatures and was excavated in or very near this position.

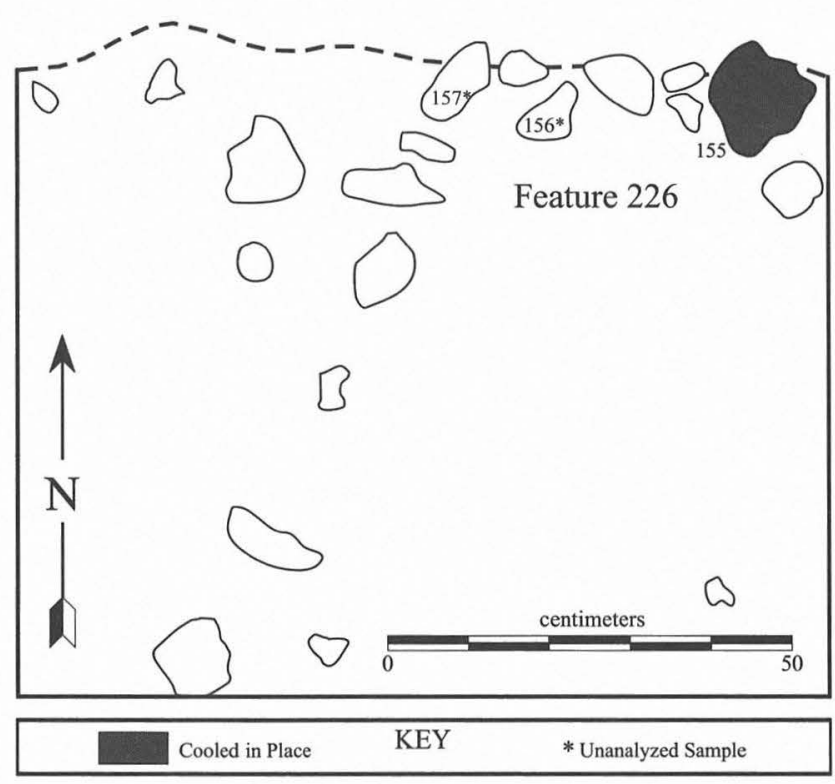

Figure 27-28. Plan map of Feature 226 in Square 46, Level 20B.

Feature 227

Feature 227 consisted of one large ( $>25-\mathrm{cm}$ diameter) rock with several smaller rocks clustered around it (Figure 27-29). Four samples (AM-158, AM-227, AM-228, and AM229) were analyzed from this cluster (see Figure 27-24; Table 27-1). Archeomagnetic analysis of the largest rock (AM229) indicated that, although it had a rather weak remanence, it probably cooled in its find location from temperatures nearing the Curie point. With the possible exception of AM-227, which had a very weak remanence, the smaller rocks were moved at least twice while cooling from high temperatures before coming to rest where they were found at temperatures between $200^{\circ}$ and $250^{\circ} \mathrm{C}$. The very tight clustering of

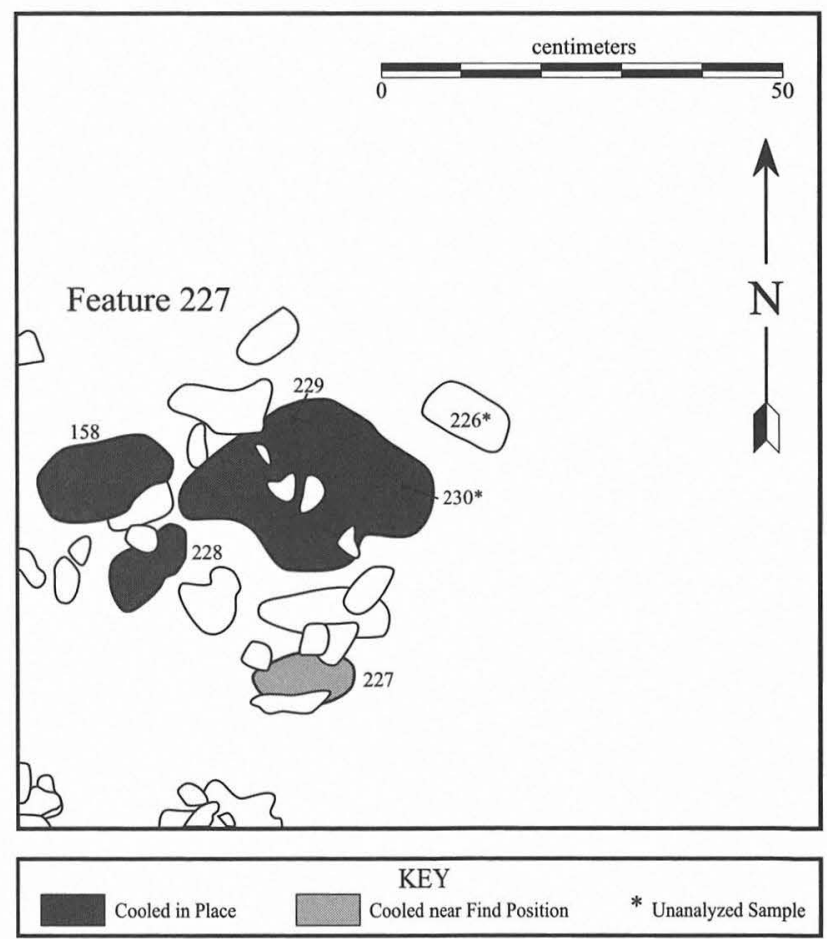

FIGURE 27-29. Plan map of Feature 227 in Square 30, Levels 20B and 21B.

low temperature remanence directions of the samples near the GAD (see Figure 27-24) supports the inference that Feature 227 is largely intact and accurately reflects the final cooling arrangement of these rocks. Only AM-227 appears to have been noticeably displaced after cooling.

\section{Feature 234}

Feature 234 was an area of patchy, burned sediment, scattered charcoal flecks, and dispersed burned rocks that extended through several levels (Figure 27-30). It may represent burned plant roots (see Chapter 26). The one sample analyzed (AM-567) yielded a single component of magnetization indicating that the rock was heated to very high temperatures (approaching or exceeding the Curie point), cooled without significant movement, and then remained in this position (see Table 27-1). Nevertheless, it remains unclear whether this resulted from cultural or natural heating.

\section{Feature 235}

Feature 235 consisted of about two dozen small burned rocks, many of which appeared angular and discolored, presumably from heating (Figure 27-31). Archeomagnetic analyses on eight of them revealed that while over half (AM-606, AM-607, AM-611, AM-612, and AM-660) cooled in place or nearly in place, the others (AM-608, AM-610, and AM-613) were no longer in their cooling locations or yielded ambiguous results (Figure 27-32; see Table 27-1). Only two rocks 


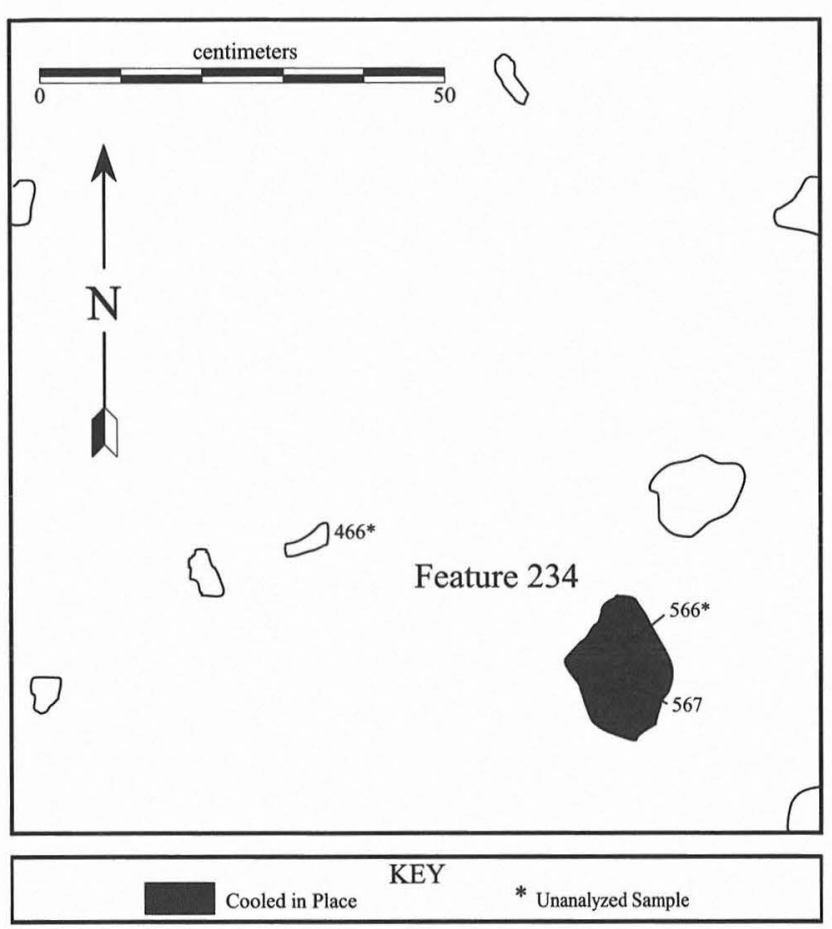

FIGURE 27-30. Plan map of Feature 234 in Square 30, Level 30.

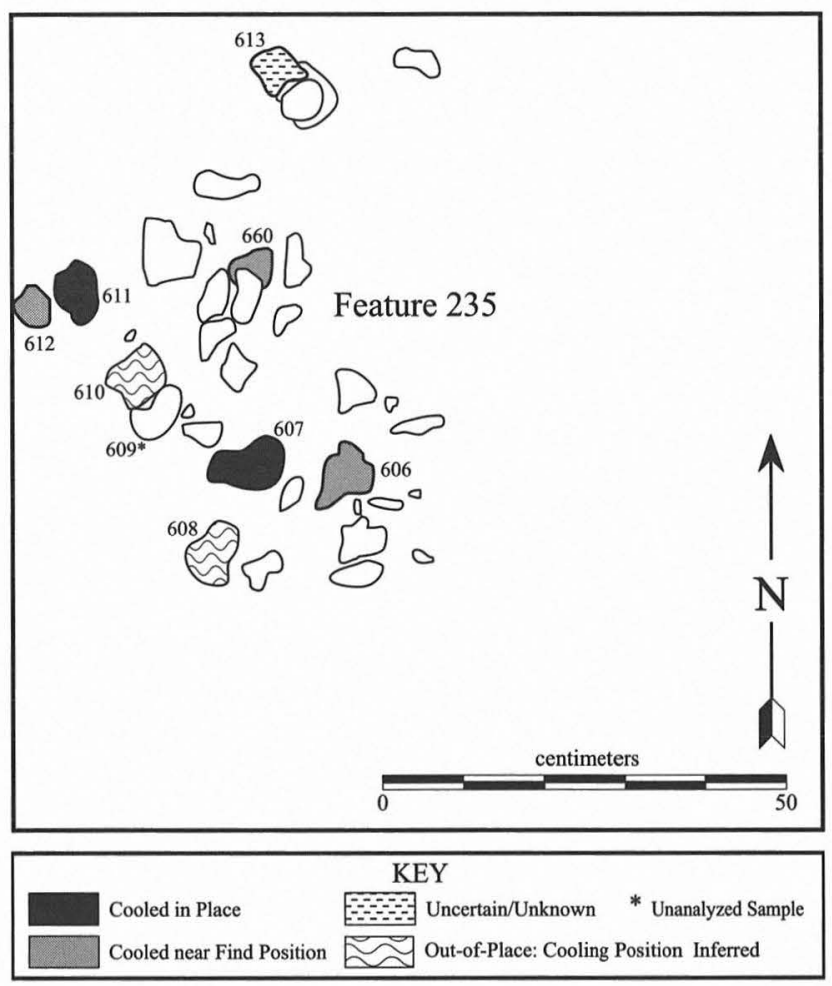

FiguRE 27-31. Plan map of Feature 235 in Square 32, Levels 28B and 29.

(AM-610 and AM-611) exhibited a single magnetization indicative of unmolested cooling from very high temperatures (see Table 27-1). Both were found near the northwest edge of Feature 235 and one (AM-610) had clearly been displaced after it finished cooling. The other rock in this area, AM-612, had two components, but they were only subtly different suggesting only minor movement while cooling from initially high temperatures. This area may have been the locus of heating. It was, in any case, the least disturbed portion of Feature 235 during cooling. The high temperature vector directions of AM-606 and AM-660 are very tightly grouped in the upper southeastern quadrant of the left stereonet in Figure 27-32. This implies similar disturbances which, in turn, supports cooling movement rather than incomplete heating as the origin for their in place components (see Table 27-1).

\section{Feature 239}

Feature 239 was a loose grouping of burned rocks that contained within it two clusters of small rocks or rock fragments (each less than $10 \mathrm{~cm}$ in size) which may represent larger rocks that fractured in place (Figure 27-33). Three archeomagnetic samples (AM-916, AM-918, and AM-919) were analyzed from one of these clusters, and the results are shown on the stereonet in Figure 27-32. Each of the samples was clearly moved after cooling and has approximately the same number of magnetic components (see Table 27-1). The grouping of these components on the stereonets in Figure 27-32 implies that the rocks experienced very similar dislocations while cooling. However, the concurrent movement of three individual rocks along nearly identical planes, by about the same magnitude, during and after cooling appears highly improbable. It seems much more likely that these are the fractured remnants of a larger rock that (while still whole) experienced these dislocations. After breaking apart, the fragments probably dispersed somewhat resulting in the loose grouping of magnetic components noted on both stereonets in Figure 27-32. The cracking of the larger rock may have occurred while it was still warm or after it completely cooled. In either case, a common origin is the most parsimonious explanation of the remarkable similarities between the three analyzed rock fragments.

\section{Feature 241}

Feature 241 was a rather loosely grouped scatter of burned rocks exposed in Square 35, Levels 25 and 26 (Figure 27-34). Four of the five analyzed rocks (AM-895, AM-897, AM-899, and AM-901) were displaced after cooling (see Figure 27-32). Only one rock (AM-896) cooled where it was found but did so only from about $300^{\circ} \mathrm{C}$. Three rocks (AM895, AM-896, and AM-899) yielded three or more components of magnetization, indicating a great deal of movement while cooling (see Table 27-1). Each appears to have been displaced in the same or similar directions during cooling. Along with the single component of magnetization in a small, centrally located rock (AM-897), these intrasample results are consistent with movement while cooling rather than partial reheating. Otherwise there is no evidence of patterning in rock movement. 


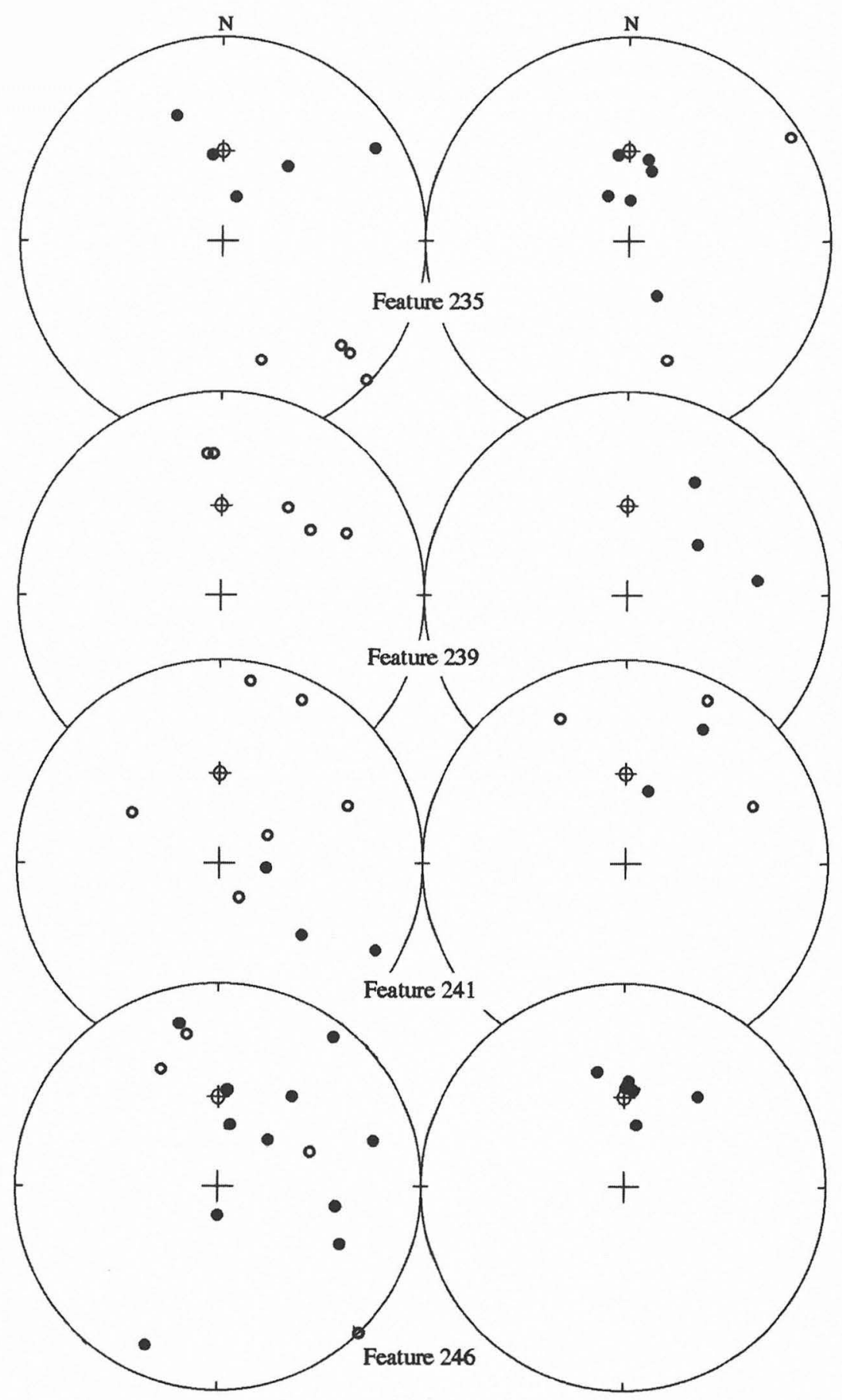

FIGURE 27-32. Stereoplots of results for Features 235, 239, 241, and 246. E-category rock AM-613 is included on the Feature 235 stereonets while the four E-category samples from Feature 246 are excluded.

\section{Feature 246}

The results from Feature 246 are intriguing and run contrary to what might be expected given its morphology (Figure 27-35). While 6 of the 10 analyzed rocks cooled in (or nearly in) place (see Figure 27-32), these were among the smallest rocks; the cooling context of the 4 largest rocks analyzed is uncertain, but they are probably out-of-place.

Three of the smaller, in-place rocks (AM-1059, AM1106, and AM-1107) moved little if at all while cooling (see Table 27-1). Three others (AM-1060, AM-1061, and AM1105 ) cooled in situ from lower temperatures. Two of them (AM-1060 and AM-1061) in fact evidence a remarkable correspondence in measured vector directions. Both apparently 


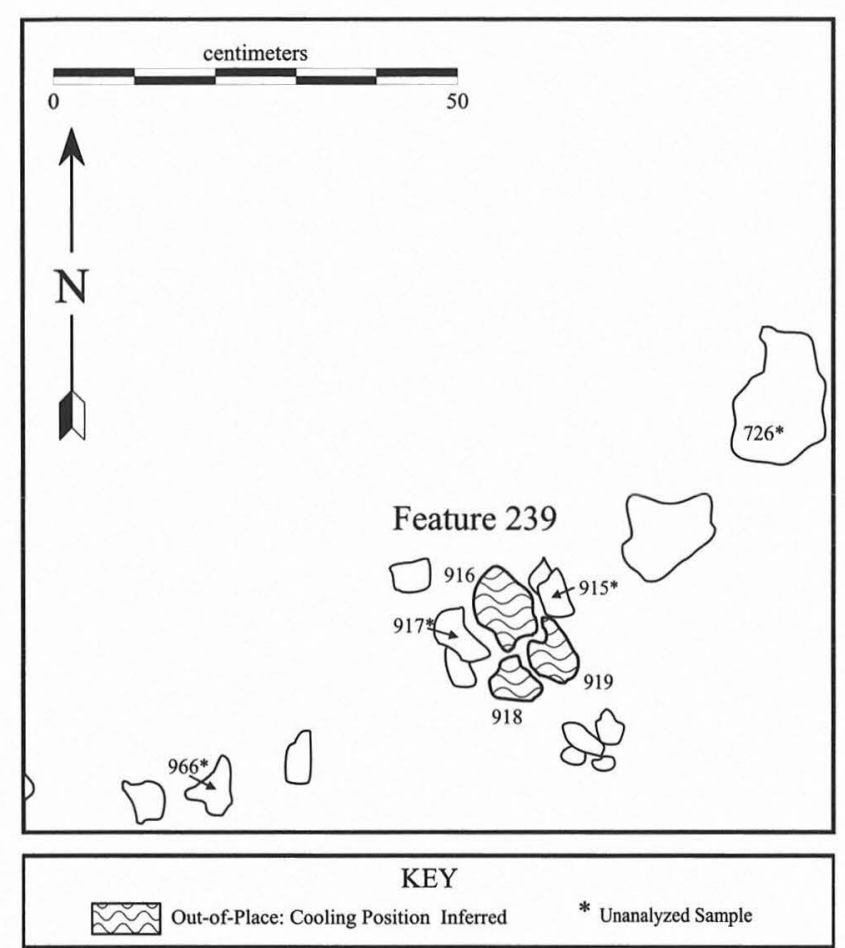

FIGURE 27-33. Plan map of Feature 239 in Square 34, Level 26.

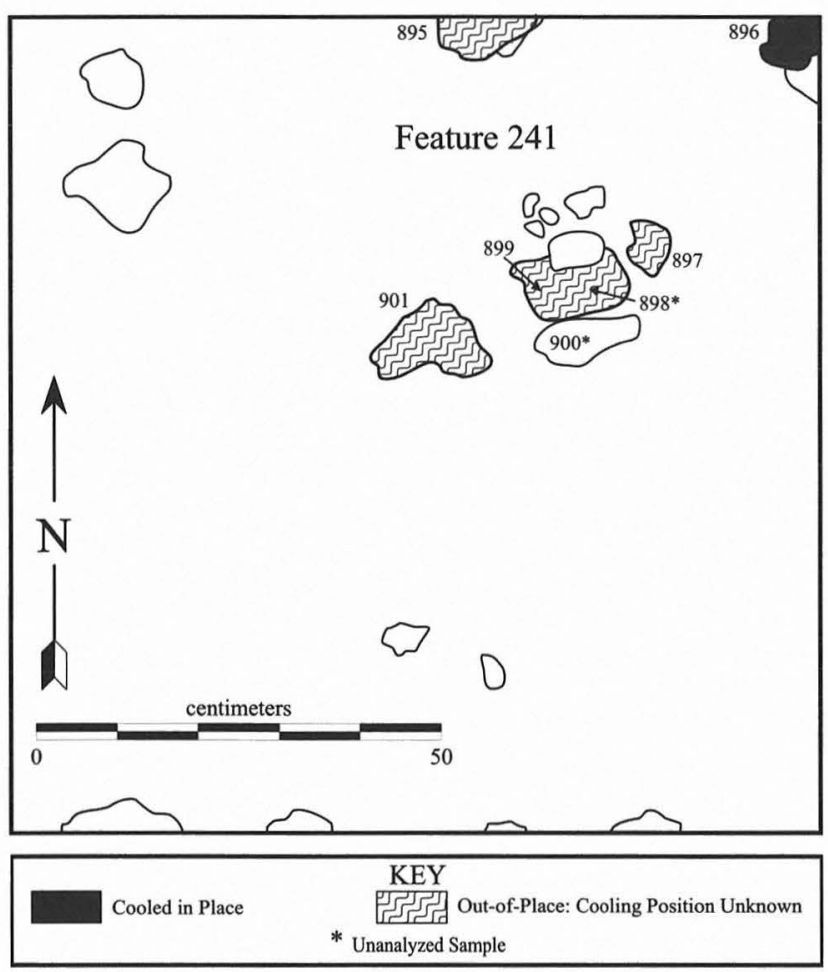

Figure 27-34. Plan map of Feature 241 in Square 35, Level 26B.

experienced two separate but virtually identical northwestward rotations while cooling. The only significant difference in these displacements is that the larger rock (AM1061) was moved at temperatures up to $100^{\circ} \mathrm{C}$ higher than

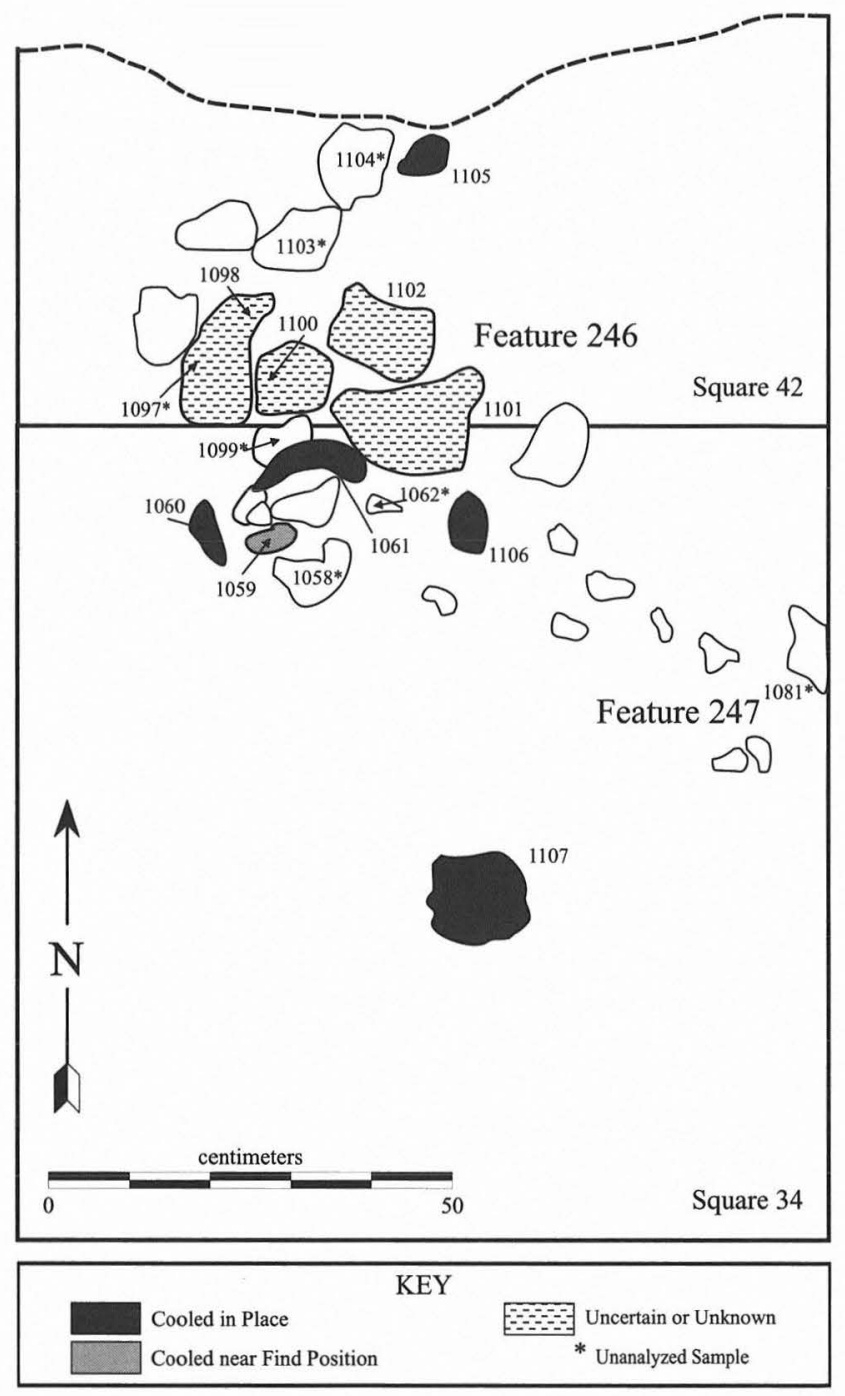

Figure 27-35. Plan map of Feature 246 in Squares 34 and 42, Levels 31 and 32.

was the smaller rock. Such remarkable similarities are almost certainly a consequence of movement while cooling and, furthermore, probably resulted from a single coincident disturbance. If so, it seems reasonable to conclude that the observed temperature differences (i.e., where the magnetic components change) can be attributed to different cooling rates. The larger rock, with a lower surface to volume ratio, probably lost heat more slowly than did the smaller rock.

The possibility of identifying magnetic "signatures" corresponding to specific uses of burned rocks was recognized while examining the remanence of the four large rocks in the center of Feature 246 (AM-1098, AM-1100, AM-1101, and AM-1102; see Figure 27-35). The cooling context of these rocks is unknown due primarily to the stability of their remanence intensities to laboratory demagnetization temperatures of $300^{\circ} \mathrm{C}$ or more. Stasis in remanence intensity complicates interpretation, because it is unclear what orientation the lower temperature grains recorded. The measured 
remanence simply does not move in three-dimensional space (see again Figure 27-3a). One possible reason for this might to be rapid or constant movement while a rock is cooling. As the rock cools, each grain records its orientation relative to the geomagnetic field, but the position of the rock relative to that field is constantly changing, in effect randomizing the remanence. The effect would be similar to that achieved during alternating-field demagnetization in the laboratory: grains with similar blocking temperatures are effectively canceled out by randomization (in this case caused by rapid movement rather than by a sinusoidal electromagnetic field). Another possibility, however, is that a rock does not contain a sufficient magnetic mineralogy. That is, there might not be any grains within the rock with blocking temperatures capable of recording a remanence in that range. In either case, the result might be a demagnetization-resistant remanence similar to those observed in these four Feature 246 samples.

In order to test which of these alternatives most likely affected the Feature 246 results, a second sample drilled from the AM-1100 parent rock was intentionally given an isothermal remanent magnetization (IRM) in the laboratory. Subsequent thermal demagnetization of this second sample unequivocally demonstrated that the AM-1100 rock did in fact contain grains with blocking temperatures below $300^{\circ} \mathrm{C}$ (Figure 27-36). This suggests that the lack of response in the archeological samples from Feature 246 is not due to mineralogical insufficiency but instead to a great deal of movement while cooling. What the specific reasons might be for moving rocks so much is unclear but stone boiling or some other similar activity seems most likely. The effects of rapid movement on thermoremanence, stimulated by evaluation of the Feature 246 rocks, is a major aspect of ongoing archeomagnetic research (Takac n.d.).

Nevertheless, the final cooling context of these four larger rocks is unknown. Data from the other Feature 246 samples, however, clearly endorse the interpretation that it is a relatively intact feature. The distribution of single-component, in-place rocks suggests that the locus of heating may have been to the south of the cluster of large rocks; somewhere between AM-1106 and AM-1107.

\section{Feature 248}

The archeomagnetic results from 11 rocks recovered in Feature 248 provide unambiguous evidence that most of these rocks cooled in or near the positions shown in Figure 27-37. However, with a single exception, they cooled in place from only low to moderate temperatures (see Table 27-1), and many experienced two or even three disturbances as they cooled (Figure 27-38). The only rock that cooled in place from high temperatures without moving was AM-1132. Results from AM-1077 and AM-1130 were insufficient to adequately determine their cooling context but the higher temperature vector rotation reconstructions for one (AM1077) generally agree with those of the other rocks in the

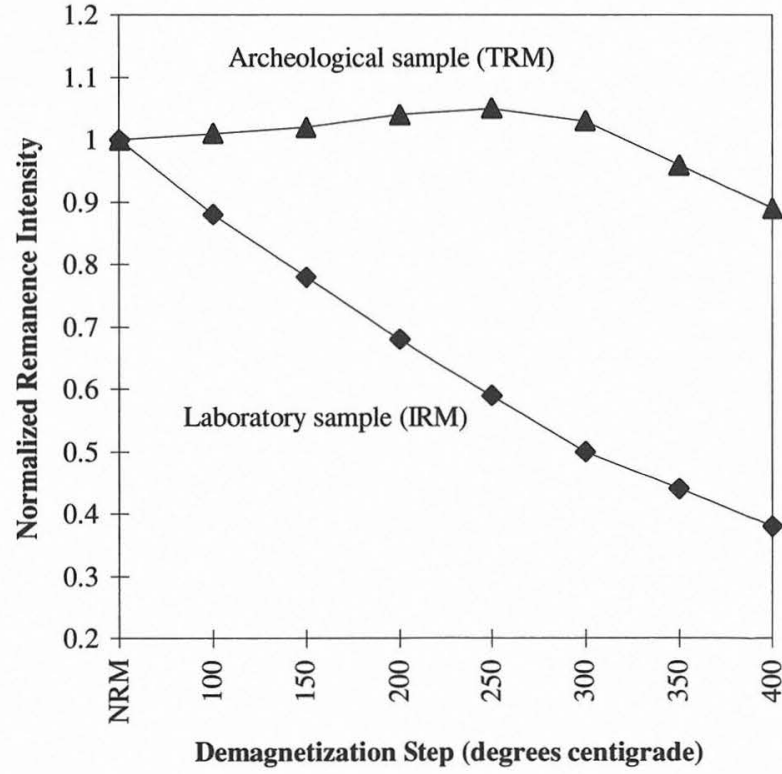

Figure 27-36. Figure showing the loss of remanent magnetization during demagnetization in two samples from AM-1100. In the original archeological sample, the intensity of TRM remained relatively stable until demagnetization temperatures of ca. $350^{\circ} \mathrm{C}$ were reached. Conversely, the second sample, which was given a strong isothermal remanence (IRM) in the laboratory, showed an immediate, consistent loss of remanence intensity during demagnetization. Therefore, AM-1100 does contain grains with blocking temperatures less than $350^{\circ} \mathrm{C}$, and the remanence stability noted for the original sample must be due to some factor(s) other than mineralogical insufficiency.

feature. Therefore, this rock is probably near its final cooling location.

Patterning in reconstructed vector rotations indicate that these rocks were probably heated to temperatures approaching or exceeding the Curie point. The higher temperature and coercivity components of those rocks displaced two or more times while cooling are found almost exclusively in the lower half of the stereonet in Figure 27-38, suggesting primarily northward rotations. Such consistency (both within and between samples) argues for cooling movement rather than partial reheating. Furthermore, the magnitude of many of these displacements and the ultimate locations of the rocks suggest multiple, progressive (northward and perhaps slightly downward) rotations into a shallow depression which may have originally extended to the west and north, beyond the TARL excavation area. The central depression hypothesis is further supported by AM-1133, which seems to have rotated almost a full half turn to the west after it cooled. This presumably occurred from an initial cooling position along the eastern edge of the depression. Finally, it should be noted that although AM-1141 cooled in place and was also probably displaced northward while cooling, its relationship to the main cluster of rocks in Feature 248 remains unclear. The archeomagnetic evidence from Feature 248 suggests that although largely cooled in place, the 


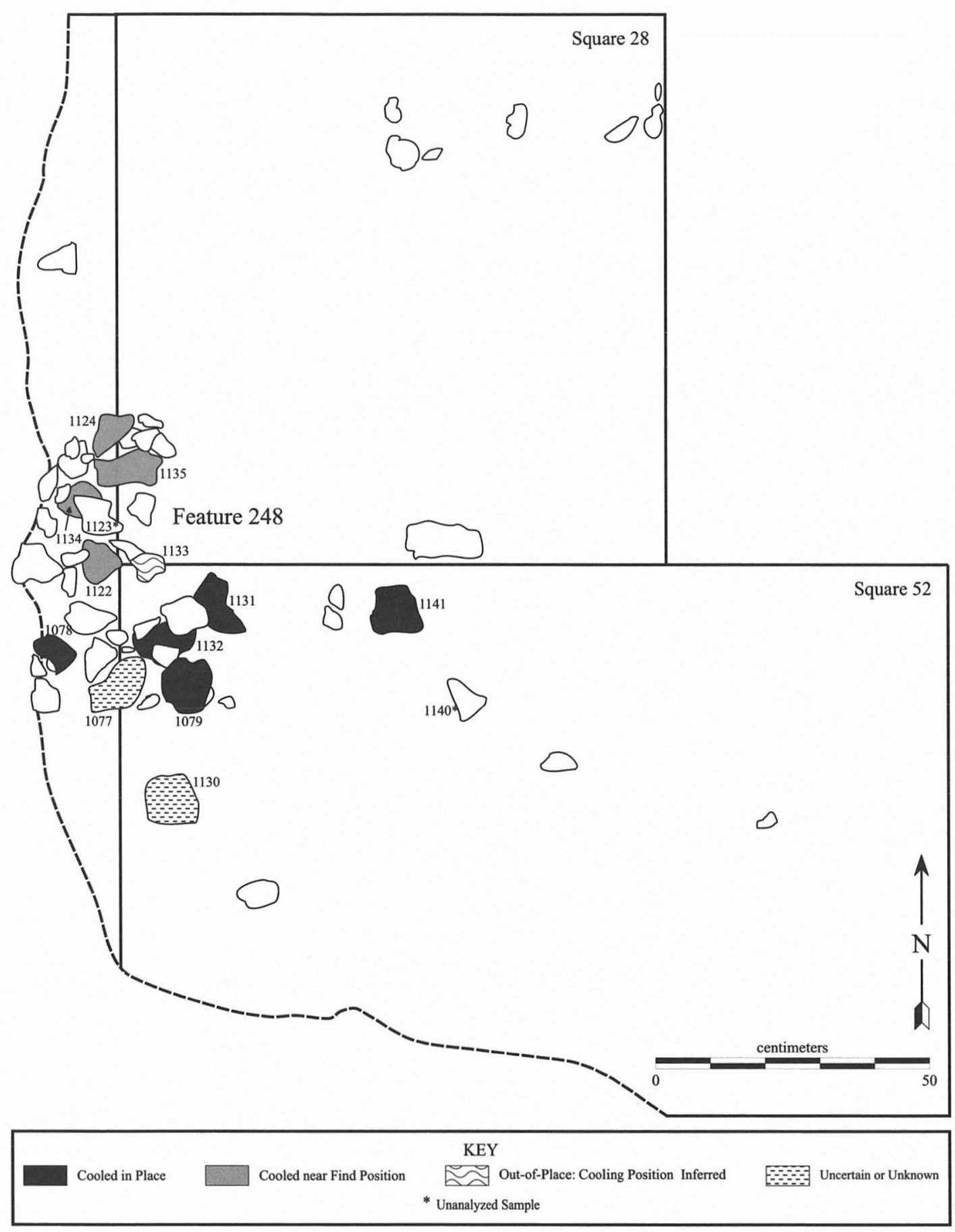

Figure 27-37. Plan map of Feature 248 in Squares 28, 44, 52, and 53, Levels 28 and 29.

original high temperature arrangement of the rocks was somewhat different than that seen in Figure 27-37.

\section{Feature 250}

The burned rocks in Feature 250 were encountered in three successive levels of TARL Squares 37, 38, and 50. These rocks may have been distributed within a small basin (Figure 27-39). Archeomagnetic analyses of six rocks (AM-
1113, AM-1114, AM-1116, AM-1126, AM-1128, and AM1189) from within this feature cluster as well as from one rock (AM-1118) about $50 \mathrm{~cm}$ to the east, revealed that all of them cooled in place with little or no noticeable movement from temperatures averaging $500^{\circ} \mathrm{C}$ or more (see Figure 27-38, Table 27-1). Due to a lack of directional patterning in the vector rotation reconstructions at these high temperatures, these component changes conceivably represent maximum heating temperatures rather than movements of the rocks as 


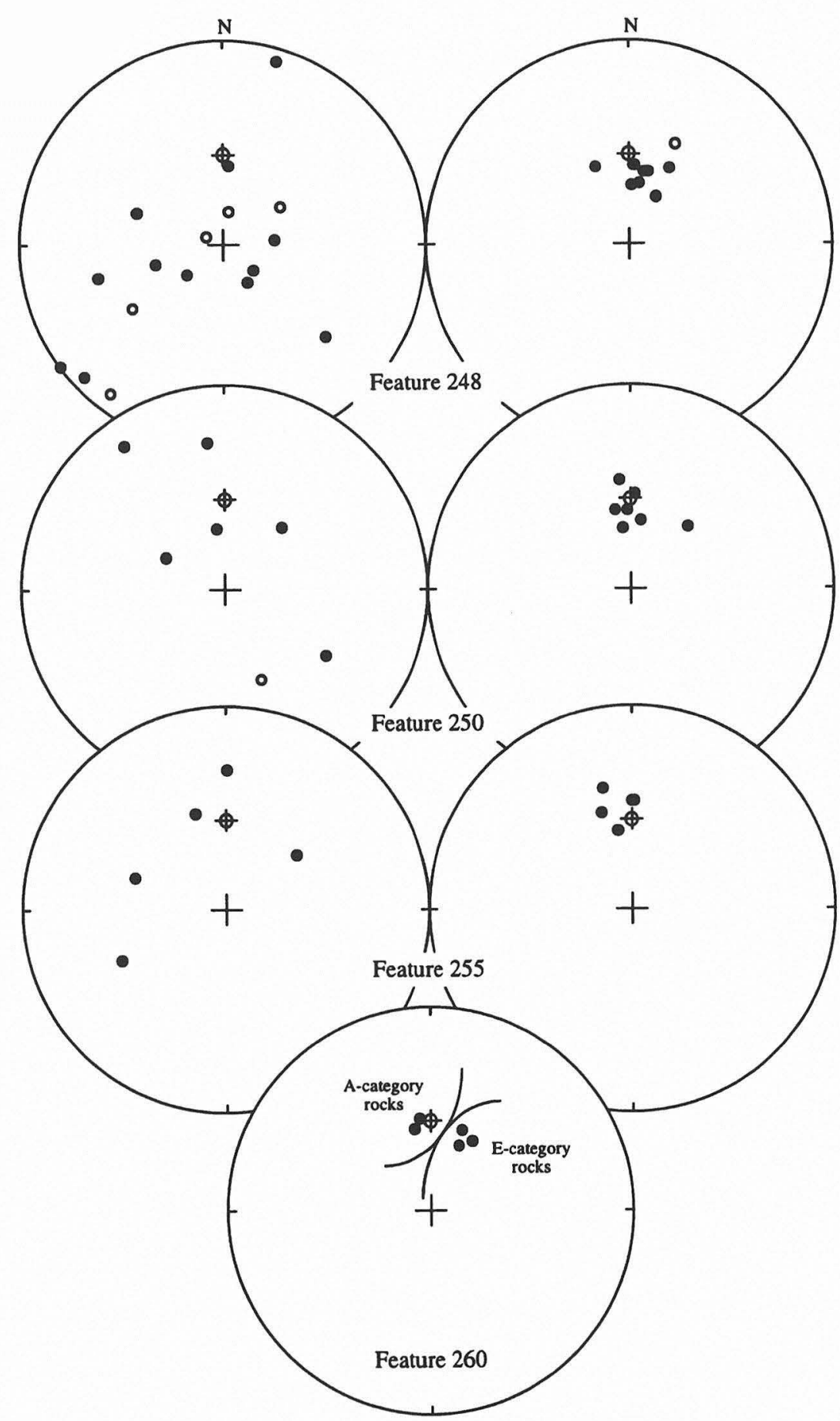

FIGURE 27-38. Stereoplots of results for Features 248, 250, 255, and 260. Note that only a single component of magnetization could be defined for each of the Feature 260 samples and therefore only a single stereoplot is necessary.

they cooled. However, this could vary stratigraphically within the feature. These temperature thresholds may represent the maximum heating temperatures of the lower rocks, but for the upper rocks (which were probably more effectively heated due to rising heat energy) some movement while cooling may have occurred. Regardless, the rocks were clearly heated to significant temperatures and allowed to cool in or very near the same positions documented during excavation, with little or no disturbance. The relationship of AM-1118 to the main cluster of Feature 250 is uncertain, but it also clearly cooled in place from about $550^{\circ} \mathrm{C}$ without moving.

\section{Feature 255}

Results of archeomagnetic analyses on five rocks sampled in Feature 255 (Figure 27-40) indicate that all of 


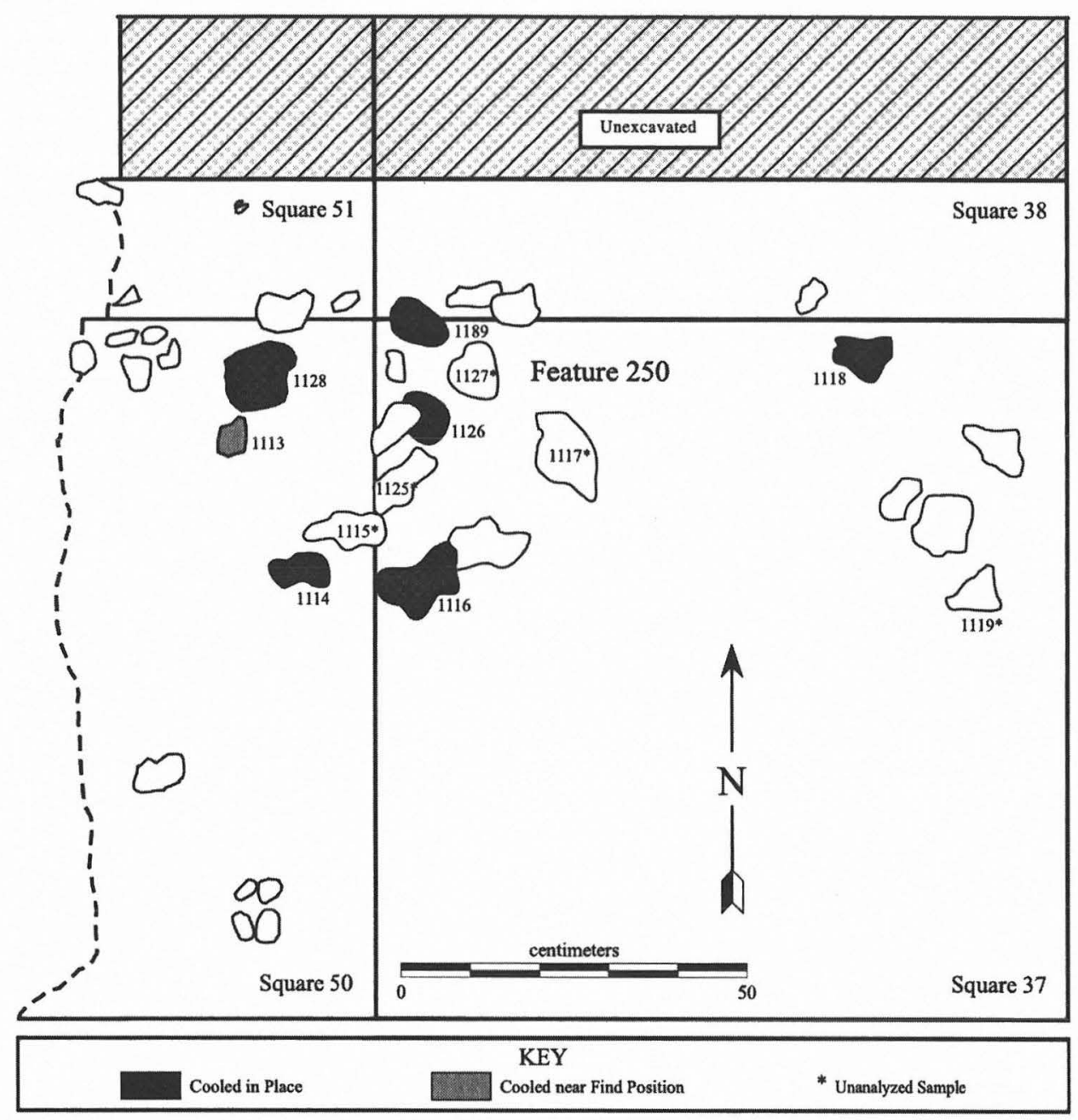

FIGURE 27-39. Plan map of Feature 250 in Squares 37, 38, 50, and 51, Levels 29 and 30.

them cooled in or near the locations in which they were found (see Figure 27-38). Burned sediment, dispersed charcoal, and the angular fracturing of the rocks observed during excavation further support this interpretation.

The tightly clustered rocks nearest the southern edge of Square 59 definitely cooled in place from at least $500^{\circ} \mathrm{C}$ and have moved little, if at all, since then (see Table 27-1). The AM-1184 stone evidently rolled toward the center of the cluster at $500^{\circ} \mathrm{C}$, implying an even higher maximum heating temperature. The more peripheral rocks (AM-1181 and AM-1182) were moved at around $200^{\circ} \mathrm{C}$ (perhaps away from the main cluster) before cooling very near where they were found. Feature 255 is undoubtedly the preserved remnant of in-situ burning.

\section{Feature 257}

Feature 257 consisted of two closely spaced limestone rocks at the edge of TARL Square 53 that are probably the remnant of a larger feature that once extended into the northwest quadrant of TxDOT Square E28/S78 (Figure 27-41). Both of the Feature 257 rocks were thought in the field to have been burned due to angular fracturing and discoloration. The AM-1194 rock in particular was found to be very red during AM sample drilling. In-situ burning was suggested by the presence of numerous charcoal flecks (see Chapter 26).

The AM-1194 stone moved very little while cooling from temperatures of at least $600^{\circ} \mathrm{C}$ (see Table 27-1). A single, very well-defined component was identified, although what appears to be a viscous, postcollection magnetic overprint was noted below $200^{\circ} \mathrm{C}$. There may have been minor movement in the horizontal (declination) plane but the rock otherwise remained very stable while cooling. Sample AM-1195, on the other hand, had a very weak remanence intensity which prevented the identification of unquestionably cultural magnetic components. The general direction of its low temperature measurements suggest that it is in or near its final cooling location although viscous remagnetization prior to excavation cannot be ruled out.

Based almost entirely on the evidence provided by AM1194, the archeomagnetic data from Feature 257 encourage 


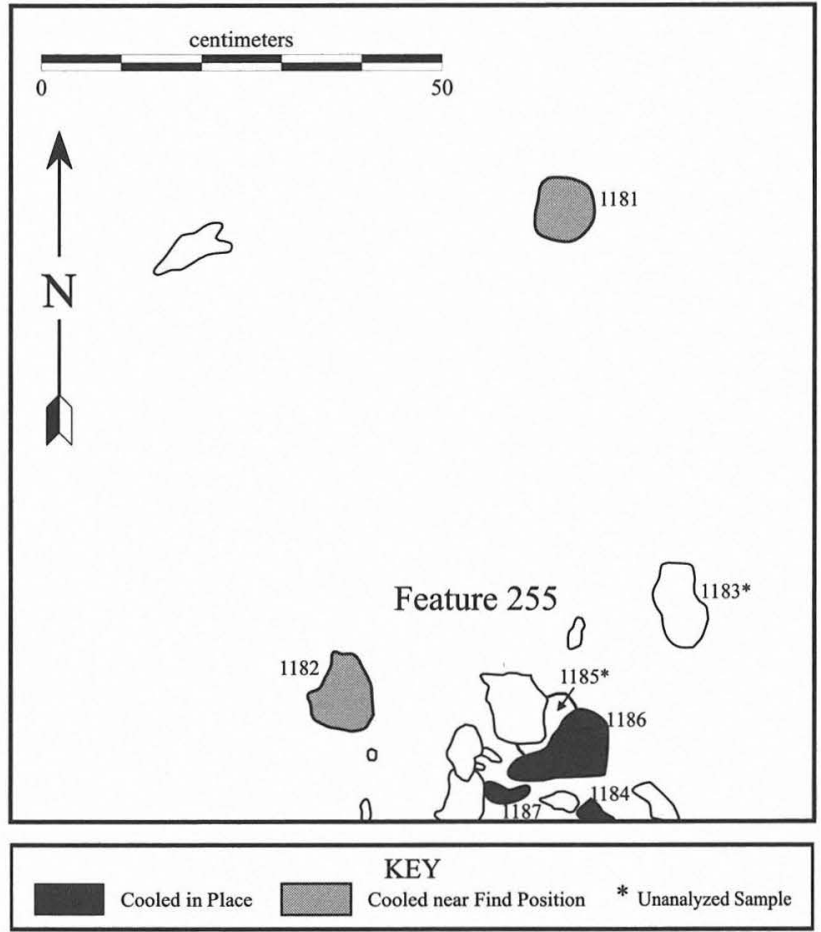

FIGURE 27-40. Plan map of Feature 255 in Square 59, Level 42.

the conclusion that it is the intact remnant of a cultural feature; an interpretation supported by nearby artifacts and charcoal flecks as well as by the absence of evidence for natural burning such as roots.

\section{Feature 259}

Feature 259 was a small cluster of rocks in an area of very low artifact density (Figure 27-42). Archeomagnetic samples were collected primarily to determine if these rocks had been heated. However, both samples analyzed from this feature were too weak to permit reliable vector determinations (see Table 27-1). They resemble in many ways the analyzed samples from natural bedrock and Feature 261, the buried gravel bar (discussed below). Furthermore, marked magnetic susceptibility increases noted for one of the rocks during laboratory demagnetization suggests that the rock was not previously heated.

\section{Feature 260}

Feature 260 consisted of a rather loose arrangement of ca. two dozen rocks found in lower Unit Isi-c (Figure 2743). No burned sediment was observed, and with the exception of a small charcoal sample collected from beneath one of the rocks, only scattered charcoal was noted. The primary question was if these rocks had been heated. Adequate resolution of this question, however, was complicated by the very weak remanence intensities of the samples.

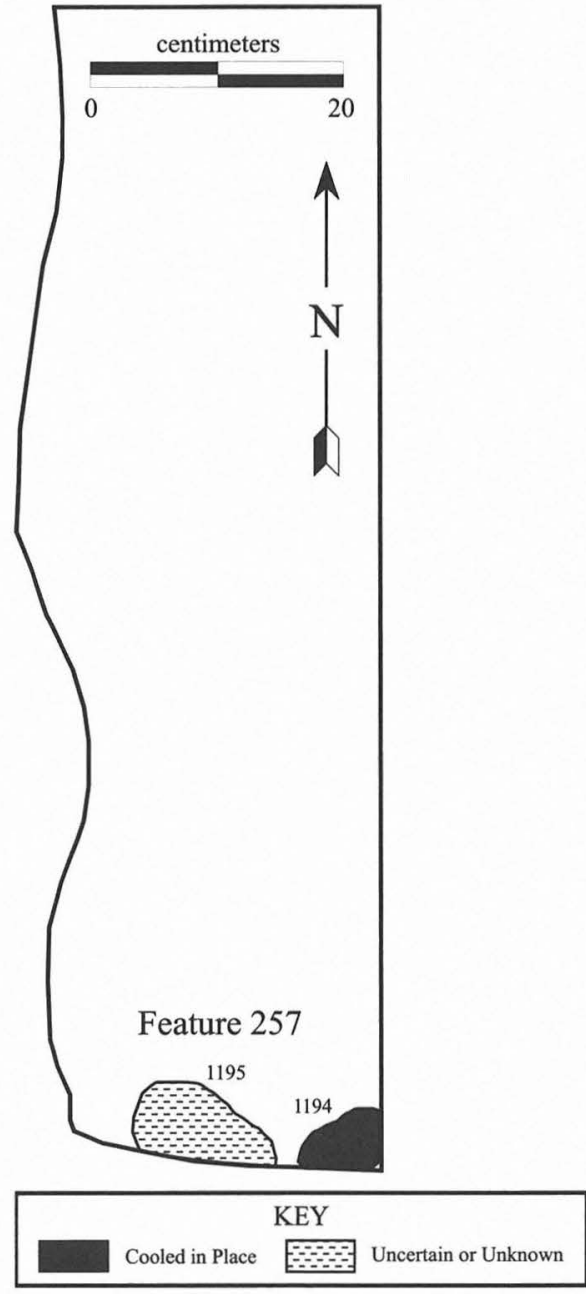

FIGURE 27-41. Plan map of Feature 257 in Square 53, Level 39B.

Of the six specimens analyzed, only three (AM-1246, AM-1248, and AM-1251) yielded reliably identified components (see Table 27-1), although even these are ambiguous because their component directions cluster near the modern magnetic pole and could result from viscous overprinting (see Figure 27-38). On the other hand, the measured directions of the other three samples (which did not yield statistically well-defined vectors) also cluster but approximately $30^{\circ}$ east of the first three (see Figure 27-38). That is, both sets are grouped rather well internally but are separated. This seems unlikely if both resulted from viscous overprinting: either there should be a single common cluster or they should all scatter similarly. Such bimodal clustering, along with their better-defined remanence components, led to the conclusion that the three A-category rocks were probably heated rather than overprinted, an inference that is further supported by charcoal beneath one of them (AM-1246).

One must conclude, however, that the results for Feature 260 are ambiguous. While there is some evidence that a few of the rocks in Feature 260 were heated and then cooled 


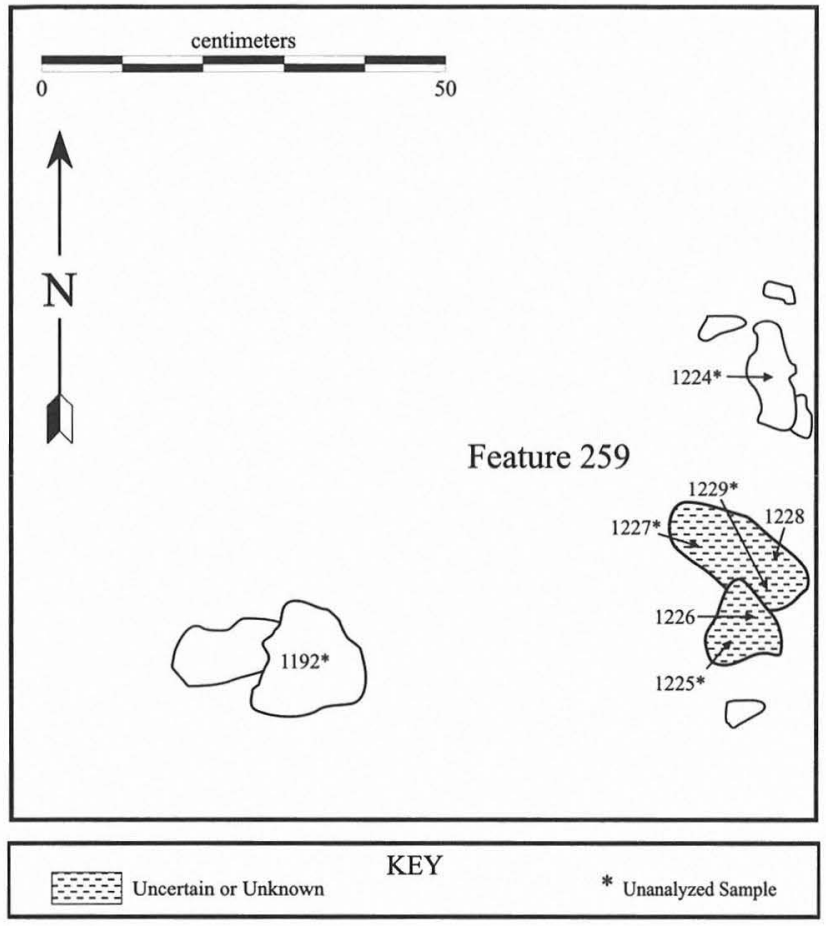

FiguRE 27-42. Plan map of Feature 259 in Square 35, Levels 46 and 47.

in place, weak remanence intensities preclude a definitive resolution. In many ways, the Feature 260 rocks (especially the three with unknown cooling contexts) resemble those from nearby natural bedrock samples in terms of a weak pretreatment remanence (NRM) and its rapid loss during demagnetization.

\section{Isolates/Nonfeature Contexts}

Several rocks with questionable cultural affiliations and/ or evidence of heating were sampled in lower Unit II deposits. These typically occurred as single or loosely associated rocks and were not assigned feature numbers in the field. Most were collected to determine if they were in fact burned and, if so, whether they might have cooled in place. Surprisingly, several did yield relatively good evidence for both heating and in situ cooling.

Sample AM-1136 was the only sample collected in Square 50, Level 32-A. Nevertheless, archeomagnetic analysis demonstrated that it had a single, well-defined magnetic component suggesting the rock was heated and cooled in place from a significant temperature, probably near the Curie point (see Table 27-1). The remanence intensity of the sample decreased gradually during demagnetization despite its low intensity and, furthermore, did not exhibit any of the erratic direction and intensity changes noted in the bedrock and gravel bar control samples. This component probably represents prehistoric thermoremanence rather than magnetic overprinting.

The two rocks drilled in Square 27, Level 35 (AM-1168 and AM-1169) were also found to have weak remanence intensities and more-or-less in situ magnetizations. The larger rock (AM-1168) yielded a single, poorly defined vector while the smaller one had three rather distinct components. Components in both rocks, however, clearly differ from each other as well as from the modern geomagnetic pole. This variability suggests that these remanences were probably acquired while cooling and that the rocks were

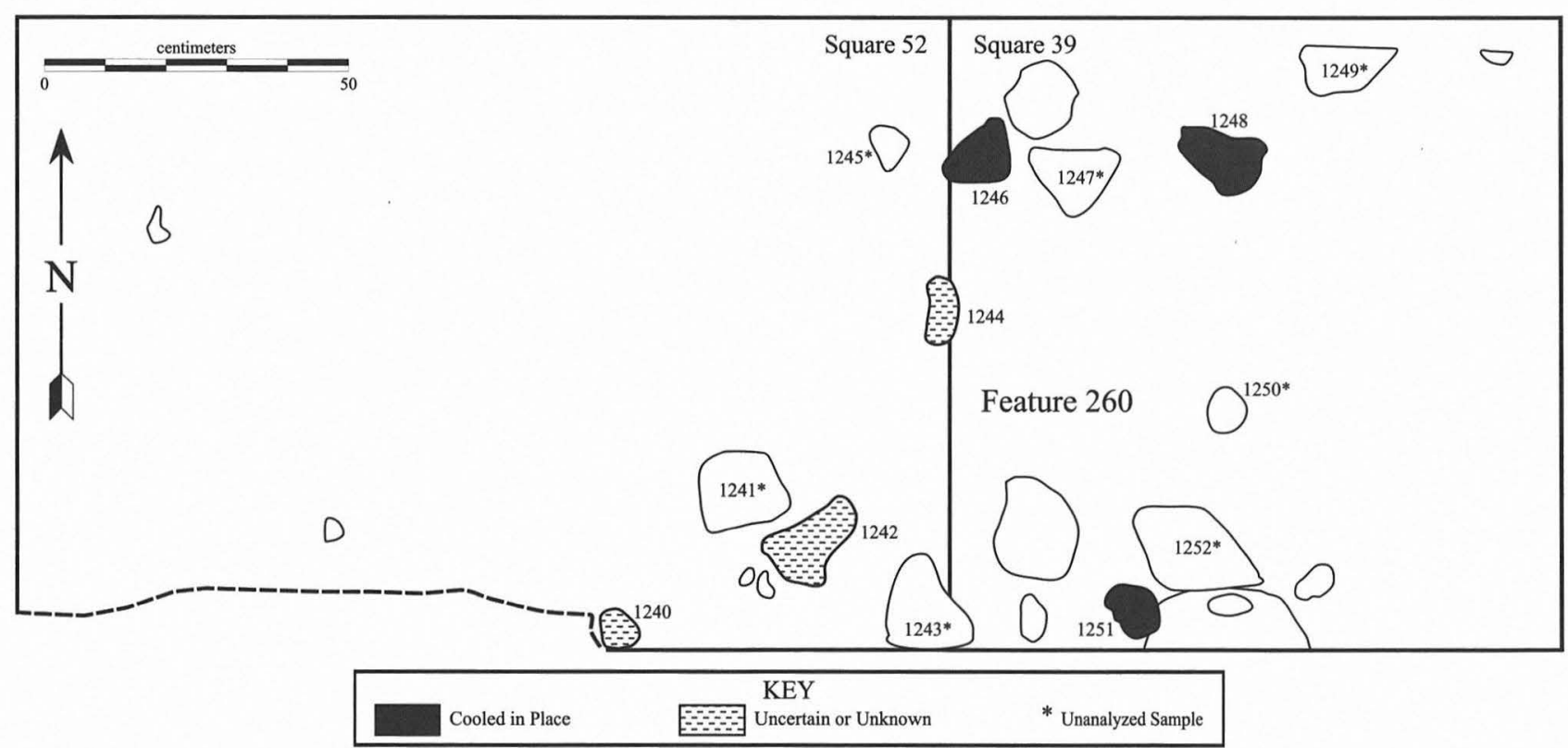

FIGURE 27-43. Plan map of Feature 260 in Squares 39 and 52, Level 42B. 
heated and probably cooled nearby, but probably not from high temperatures.

Samples AM-1179 and AM-1180, on the other hand, definitely did not cool where they were found in Square 28, Level 35 , although they may have been previously heated and cooled elsewhere. Like the other nonfeature rocks, these had very weak remanence intensities. The component data from AM-1179 are contradictory, and its cooling context is unknown. Sample AM-1180 yielded a stable, well-defined component that differs significantly from the geomagnetic pole. The behavior of its remanence during demagnetization did not resemble that of either the bedrock or the gravel bar control samples. This supports the interpretation that while its remanence is probably thermoremanent, AM-1180 did not cool where it was found (although how far away it might be from that location is unknown).

Future attempts to differentiate between viscous and thermal magnetizations will hopefully resolve the interpretive ambiguity caused by these isolated, weakly remanent rocks for which contextual or complementary evidence is inadequate or lacking entirely. However, while these results are provocative, they are not yet definitive and, therefore, the question of what such isolates might mean in terms of human occupation or behavior remains open.

\section{Square 100 (Burned Rock Midden 1)}

TARL Square 100 sampled the central portion of Burned Rock Midden 1, immediately northwest of TxDOT Block 2 (see Figure 3-1 in Volume 1). Burned Rock Midden 1 was characterized by a dense accumulation of small, angular rock fragments, interspersed with very dark, organically enriched sediments. The burned rock deposits appeared undifferentiated, and the objective of archeomagnetic sampling was to obtain a representative sample of all the rocks exposed in each level; specific rock clusters were not targeted. Sample selection in the laboratory was also based on analyzing a representative sample of this apparently amorphous mass of rocks. There did, however, appear to be a stratigraphic separation of deposits. The density of burned rocks fell dramatically in Level 9 and then rose again near the base of Level 10 before finally declining in Level 11. Burned Rock Midden 1, therefore, apparently accumulated in two phases: an initial, brief accretion separated from a later, more substantial accumulation by a thin layer of sediment. Initial expectations were that the majority of rocks in both lenses would be found to have been displaced after cooling or to have cooled in place only from low temperatures.

Contrary to these expectations, the archeomagnetic results clearly indicate that a large number of the Burned Rock Midden 1 rocks cooled in place and that many did so from high temperatures (see Table 27-1). Photographs of four representative levels (Levels 3, 4, 7, and 8) within the upper Burned Rock Midden 1 deposits, along with schematic plan maps of cooling context results for analyzed samples in those levels, are presented in Figures 27-44 and 27-45. The photos clearly show the undifferentiated appearance of the burned rock while the plan maps illustrate the unexpected results (i.e., that many of these rocks cooled in place). The stereonets of results, arrayed in stratigraphic order, are shown in Figures 27-46, 27-47, and 27-48.

Due to the sloping of deposits northward toward Brushy Creek, the upper Burned Rock Midden 1 deposit was encountered first in the southern half of Level 2. By the time the base of Level 3 was exposed, rocks were spread fairly evenly across nearly the entire $1.5 \times 1.0-\mathrm{m}$ unit (see Figure 27-44). The rocks in these first two levels were the most disturbed in the upper Burned Rock Midden 1 lens (Table 27-2). By Level 4, a substantial number of rocks were found to have cooled in place, although still nearly half had been displaced after cooling (see Figure 27-46).

The results from the remainder of the upper Burned Rock Midden 1 deposit were dramatically different. When the results from Levels 5 through 9 are combined, well over three-quarters of the rocks cooled in or near the locations in which they were found (see Table 27-2). This is especially evident in Levels 7 and 9 (see Figures 27-45, 27-47, and 2748), although some of the rocks in Level 8 did experience more substantial postcooling movement. Several rocks from Levels 10 and 11 in the earlier lens were also found near where they last cooled, but a higher percentage were displaced in these lower levels than in the upper Burned Rock Midden 1 (see Table 27-1). The majority of postcooling displacements in all levels seem to have been northward, perhaps along the plane of the paleoslope. These results (especially those from Levels 5 through 9) are remarkable given the apparently undifferentiated distribution of rocks in the Burned Rock Midden 1 deposits.

Another significant finding, again contrary to initial expectations, was that many of the rocks moved little while cooling (see Table 27-1). In fact, of the 62 samples analyzed from all levels, almost one-third (31\%) had a single component of magnetization. Half had two identified components; meaning that these rocks were moved only once while cooling. In total, less than $20 \%$ of the 62 rocks analyzed from Square 100 were displaced two or more times. Admittedly, many of these latter displacements were of large magnitude and occurred at relatively low temperatures. However, when the results from Levels 6 and 7 are considered separately, nearly $70 \%$ (9 of 13) of the analyzed rocks were found to have cooled without any noticeable movement from temperatures of at least $450^{\circ} \mathrm{C}$ and only two (AM-812 and AM-815) were later displaced from those cooling positions. This means that the accumulation of these ostensibly undifferentiated "midden" deposits almost certainly resulted (at least in these levels) from the in-situ use of these rocks.

The data from Square 100 provide important evidence not only for the interpretation of this specific midden feature, 

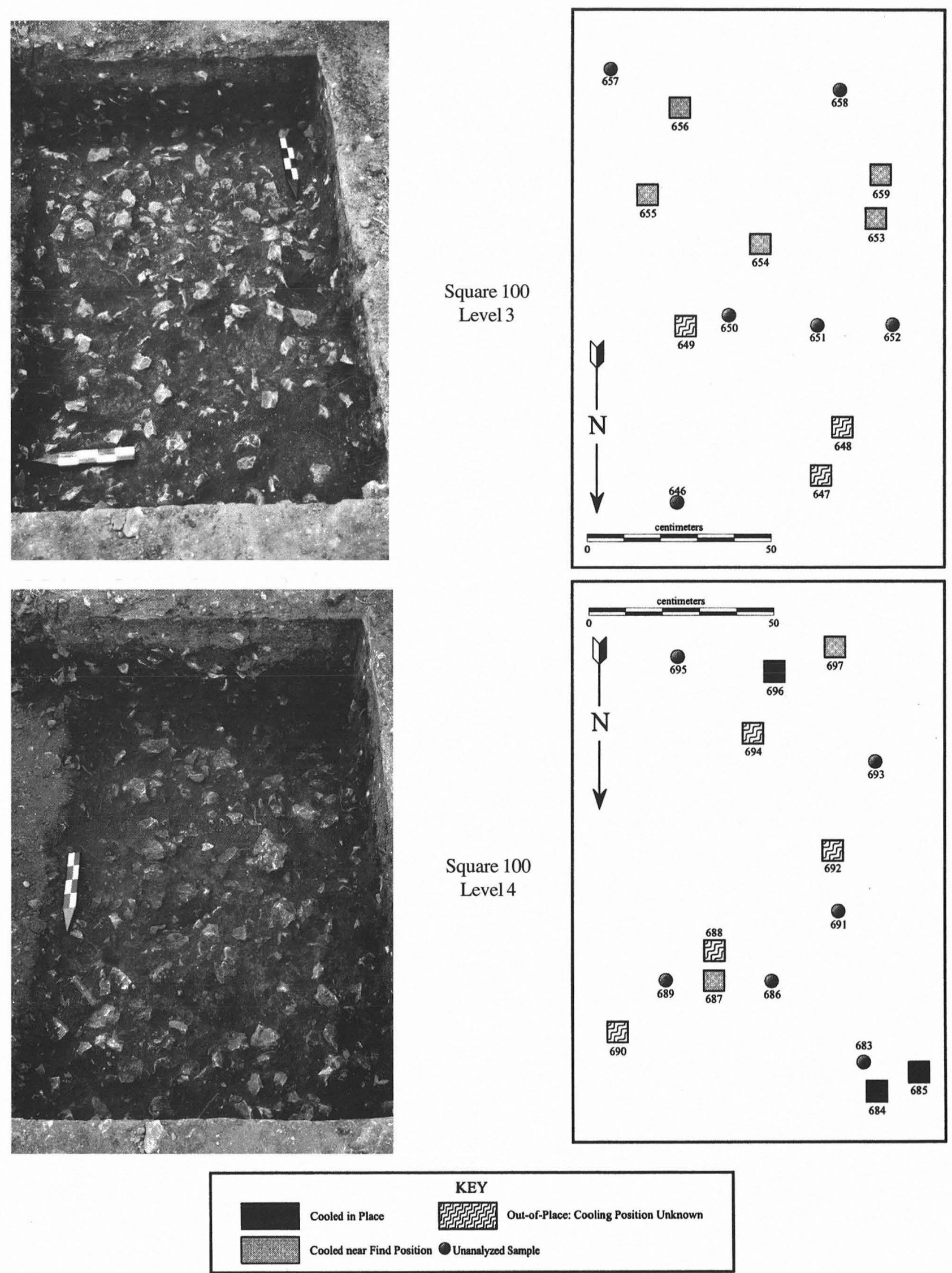

FIGURE 27-44. Photographs and schematic plan maps of sample locations and results for Levels 3 and 4 in Burned Rock Midden 1 (Square 100). 

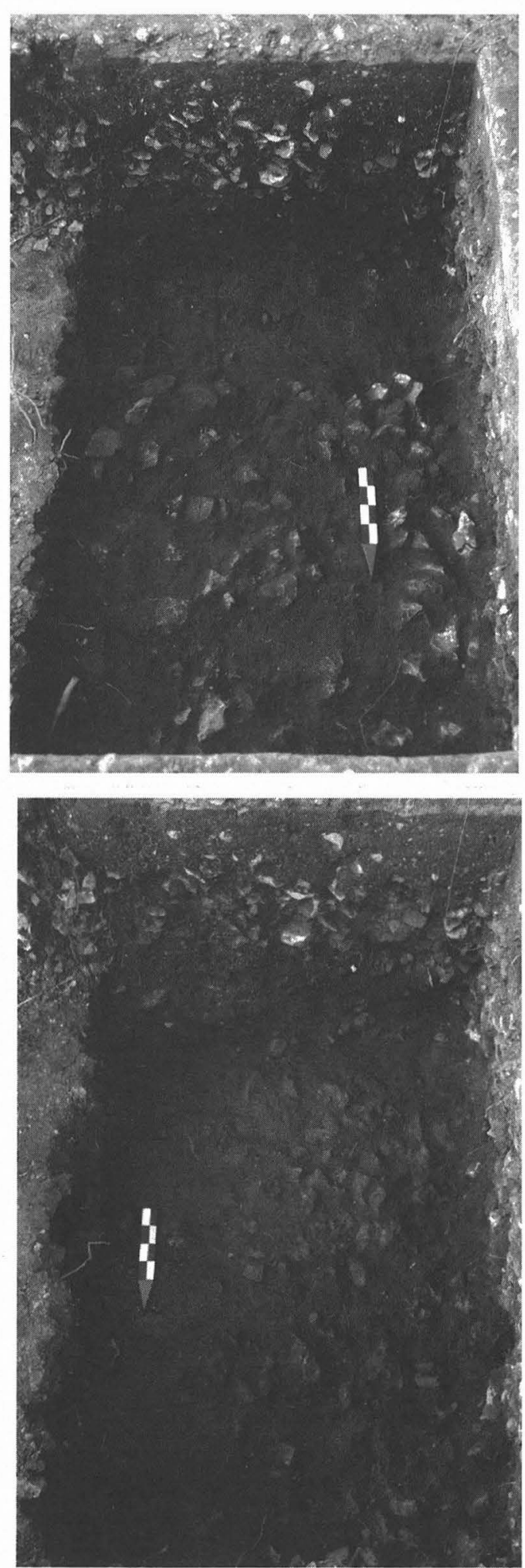
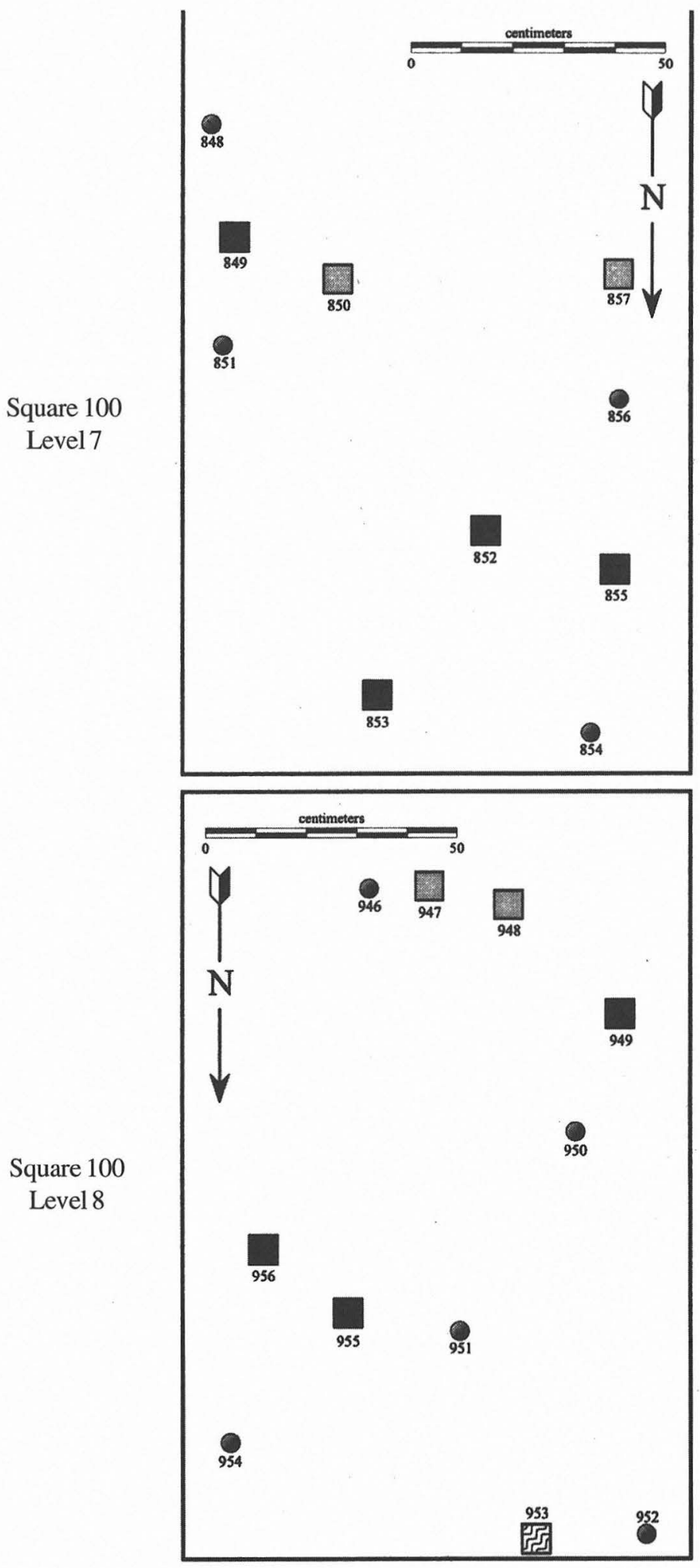

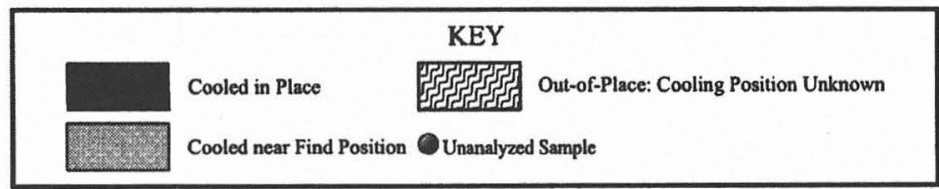

FIGURE 27-45. Photographs and schematic plan maps of sample locations and results for Levels 7 and 8 in Burned Rock Midden 1 (Square $100)$. 


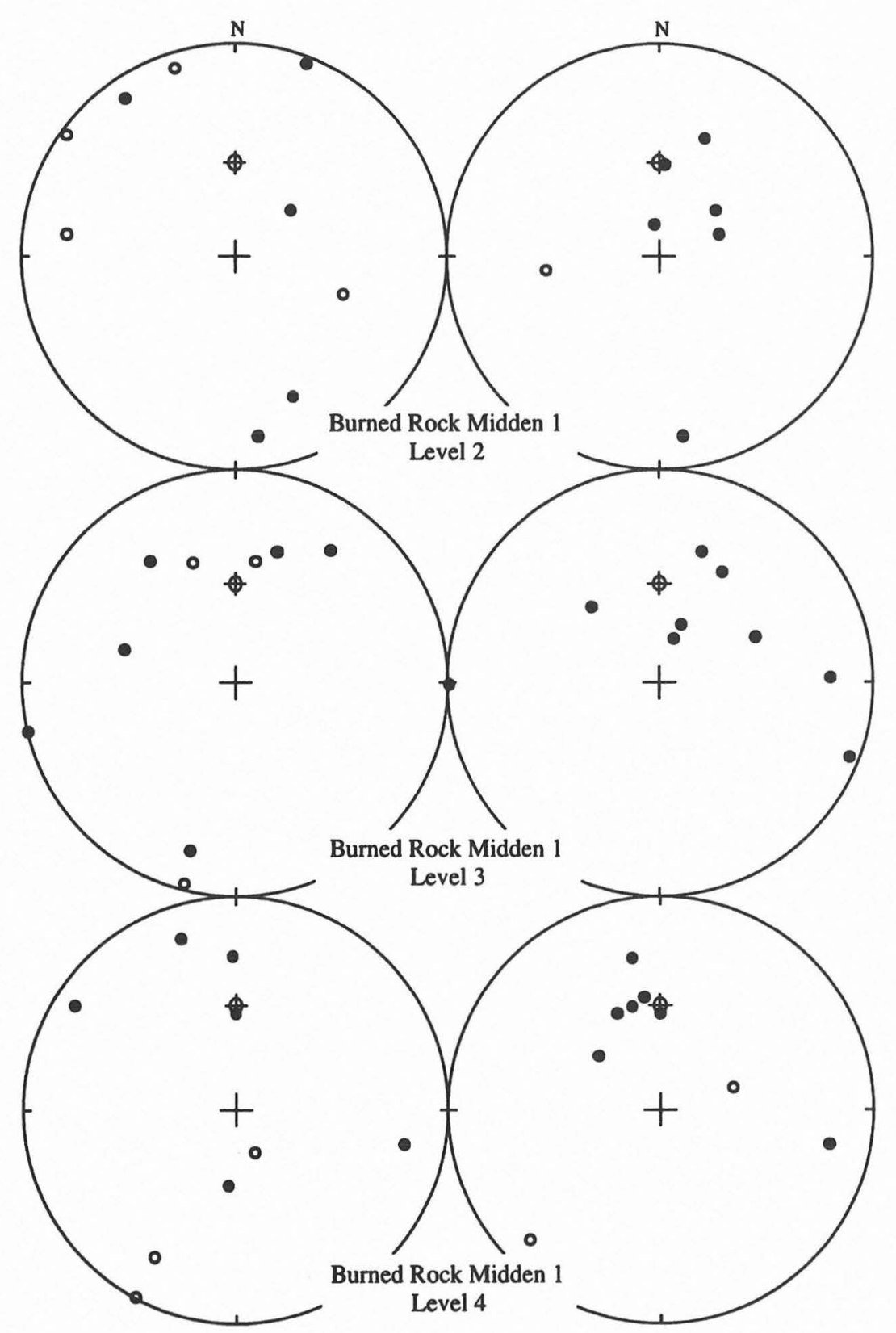

FIGURE 27-46. Stereoplots of results for Levels 2, 3, and 4 in Burned Rock Midden 1 (Square 100).

but also for guiding future archeomagnetic investigations. These data suggest that at least a portion of Burned Rock Midden 1 accumulated not through the random, secondary discard of previously used rocks (as suggested by the lack of internal patterning) but rather the final use of these rocks in or very near the locations in which they were found. Greater sampling intensity and more fine-grained analysis of similar features may provide crucial evidence needed to eventually resolve long-standing questions about the formation of burned rock "middens" (e.g., Black and Creel 1997; Collins 1991, 1994; Creel 1986; Hester 1991 passim; Kelly and Campbell 1942; Prewitt 1991; Sorrow 1969).

\section{Natural/Control Samples}

Feature 261

Feature Number 261 was assigned to a gravel bar encountered at the base of TARL excavations in Square 20 before it was fully exposed and recognized as a natural feature. There were no indications that these rocks had been heated or were associated with cultural material. The samples were collected mainly for comparative purposes. Two (AM1256 and AM-1259) were eventually analyzed. Their measured remanences were very weak and chaotic, and, there- 


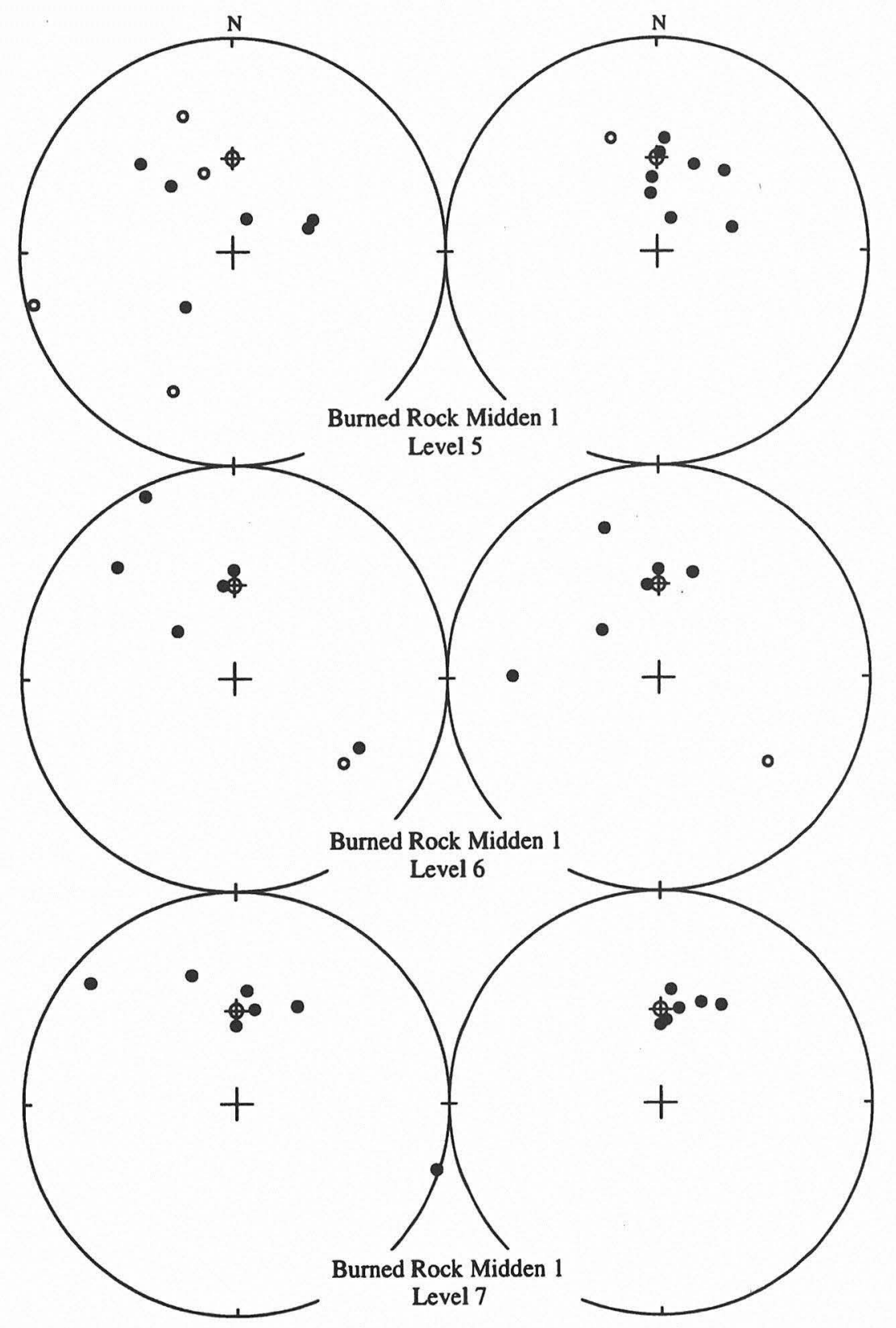

FIGURE 27-47. Stereoplots of results for Levels 5, 6, and 7 in Burned Rock Midden 1 (Square 100).

fore, individual components could not be isolated (see Table 27-1). The weak intensities were rapidly diminished by demagnetization: one sample lost more than $75 \%$ of its original remanence when heated to only $150^{\circ} \mathrm{C}$.

\section{Bedrock Samples}

Two samples from exposed bedrock at the site were also analyzed (AM-1264 and AM-1265). Both were found to have a very weak initial remanence (NRM) which, nevertheless, rapidly decreased as the samples were demagnetized. The direction of their remanence components in low temperatures range generally approximated the present geomagnetic field, presumably due to viscous overprinting or prolonged exposure to the environment (i.e., weathering, solar heating, etc.). The directional data, however, became quite chaotic at temperatures around $200^{\circ} \mathrm{C}$.

\section{Feature 231 and Associated Features}

We now turn to Feature 231, the large burned rock accumulation encountered in Unit IIIa (see Chapter 26). As was the case with Feature 201, Feature 231 was a large entity with several other features subsumed within it. An analogy for the three-dimensional distribution of burned rocks within Feature 231 is an "egg carton," an apparently undifferentiated 


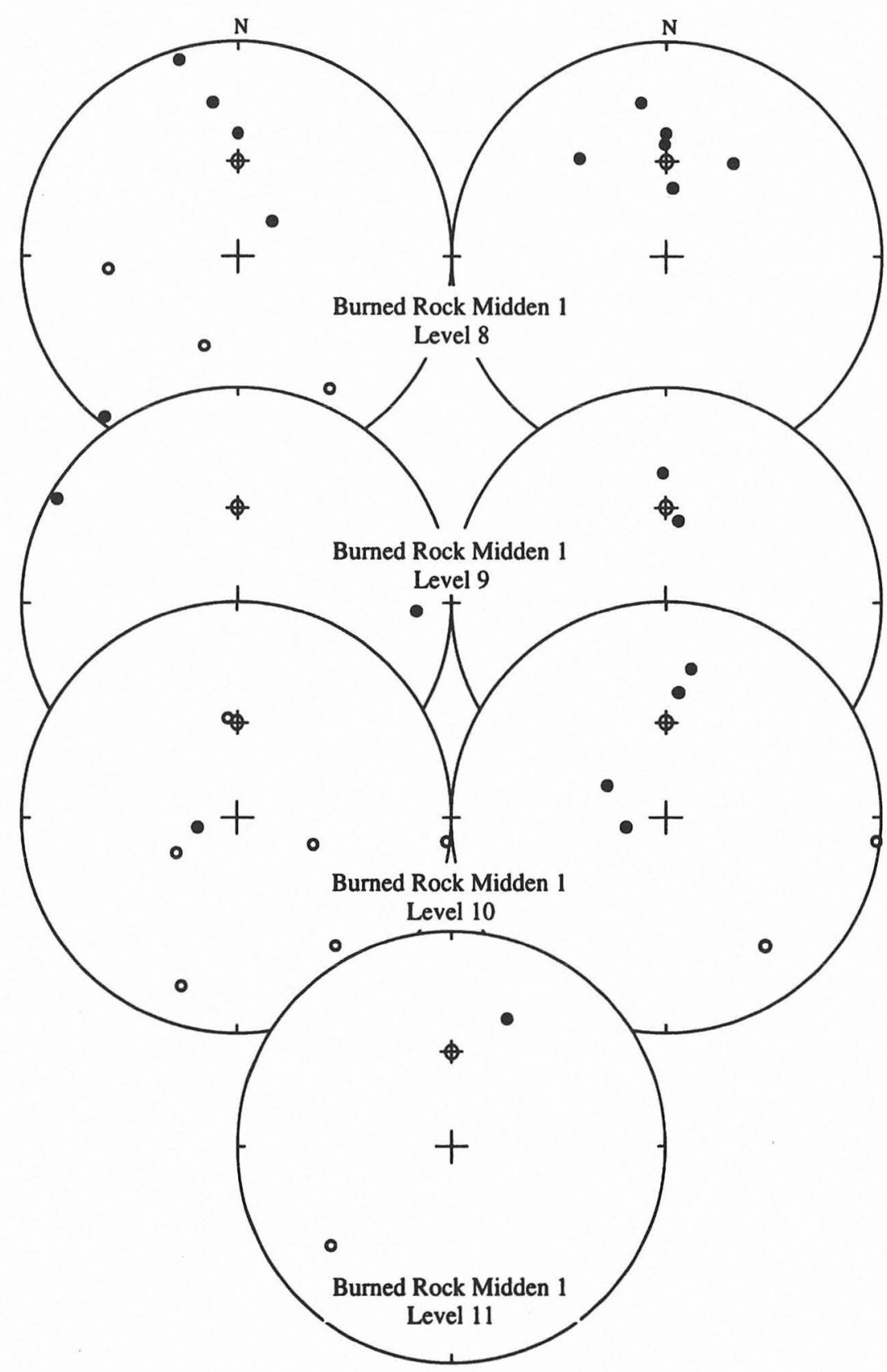

FIGURE 27-48. Stereoplots of results for Levels 8, 9, 10, and 11 in Burned Rock Midden 1 (Square 100). Results for E-category rock AM1005 are included on the Level 10 stereonets.

mass of burned rocks in upper levels which eventually coalesced into more discrete basin-shaped features protruding (or extending) beneath it. This section discusses several of these "subfeatures" within Feature 231. Some are merely representative levels within the undifferentiated mass of Feature 231 , while others are discrete features which, when recognized during excavation, were assigned feature numbers of their own. Unlike previous sections where features were organized numerically, the presentation order here is stratigraphic.

Given the sheer number of analyzed samples within Feature 231 and its associated subfeatures (almost 500 analyzed samples), a detailed sample-by-sample discussion of the results and their individual implications is beyond the scope of the present report. Instead, broad outlines and patterns are emphasized in order to see the development of (and discern subdivisions within) this composite feature. However, where individual results significantly affect the interpretations offered, the discussion is more detailed.

The data are presented in much the same way as were those from the individual features in the previous section, with a few important differences. First, each sample was assigned in the field or laboratory to either a subfeature (e.g., 
TABLE 27-2

Summary of TARL Square 100 (Burned Rock Midden) Results by Level

\begin{tabular}{ccccccc}
\hline Level & A & B & C & D & E & $\begin{array}{c}\text { No. of } \\
\text { Analyzed } \\
\text { Samples }\end{array}$ \\
\hline 2 & 1 & 2 & 1 & 3 & 0 & 7 \\
3 & 0 & 5 & 0 & 3 & 0 & 8 \\
4 & 3 & 2 & 0 & 4 & 0 & 9 \\
5 & 5 & 2 & 1 & 1 & 0 & 9 \\
6 & 2 & 3 & 0 & 2 & 0 & 7 \\
7 & 4 & 2 & 0 & 0 & 0 & 6 \\
8 & 3 & 2 & 0 & 1 & 0 & 6 \\
9 & 2 & 0 & 0 & 0 & 0 & 2 \\
10 & 1 & 1 & 1 & 2 & 1 & 6 \\
11 & 0 & 1 & 0 & 1 & 0 & 2 \\
\hline Totals: & 21 & 20 & 3 & 17 & 1 & 62 \\
\hline
\end{tabular}

Levels 5-9 combined ( $\mathrm{N}=30)$

$\begin{array}{ccccc}\mathrm{A} & \mathrm{B} & \mathrm{C} & \mathrm{D} & \mathrm{E} \\ 53 \% & 30 \% & 4 \% & 13 \% & 0 \%\end{array}$

Feature 181, 230, or 245) or the more general Feature 231 deposit. If a sample was recovered near a subfeature, a composite number (e.g., 231/245) was used. Given the palimpsest nature of Feature 231, it was sometimes difficult to accurately assess the relationships of any particular rock or group of rocks. Even after archeomagnetic analyses were completed, such determinations were occasionally uncertain. Due to these difficulties, in most cases subfeature boundaries are not delineated on the plan maps. Instead, only the immediate subfeature loci are identified. Results are grouped separately on tables and stereonets according to subfeature designation.

Another difference results from the fact that adjacent squares were excavated at varying rates and in different level increments. Consequently, the burned rocks within Feature 231 were never exposed simultaneously across the entire excavation area at any given elevation. This was primarily a function of burned rock density. Those squares where burned rocks were most dense required greater documentation including, of course, the drafting of multiple plan maps. It was often necessary to make two (or even three) plan maps per level, as each layer of rocks was exposed, sampled, mapped, and removed. Archeomagnetic samples from these sublevels ("Middle" or "Base") are indicated on the tables where appropriate. Also, in some cases, level depths were decreased from $10 \mathrm{~cm}$ to $5 \mathrm{~cm}$, resulting in variation of level numbering across squares. Due to these difficulties, in the laboratory it was necessary to construct composite maps from excavation plan drawings and photographs in order to plot the contiguous distribution of burned rocks in adjacent squares.
A total of 11 such composite maps are presented here in stratigraphic order (each given a letter designation A through $\mathrm{K})$. The elevation parameters for each composite are given in the text and figure captions. Note that there is some overlap of elevations. This is because the composites were assembled to reflect the patterned distribution of burned rocks exposed within a stated elevation range. They were not intended to be simple compilations of exposed rocks at some uniform elevation slice through Feature 231, a situation precluded in any case by the high density of rocks within each excavation level. Each composite is followed by selected plan maps detailing the archeomagnetic results for single or adjacent excavation squares. On two of the larger maps (Composites $\mathrm{F}$ and $\mathrm{H}$ ), cooling contexts are shown in color. Patterns of in-situ cooling and disturbance are readily apparent on the colored maps.

Each composite map is also accompanied by a table on which the tripartite cooling context of all archeomagnetic samples depicted on that map is given. Note that on each of these tables the samples are first grouped according to subfeature designation and are then further subdivided by square and level. Those samples discussed in the text but not illustrated on the composite maps are listed, where appropriate, at the bottom of each table. The results from samples neither illustrated nor discussed in the text are tabulated in Appendix 6.

The stereonet pairs for each composite are also arrayed according to assigned subfeature designation. The first pair (at the top of each composite grouping) includes results from all rocks shown on the composite map. The stereonets stacked beneath them and/or included on the following figure further subdivide these overall results. In all cases, the stereonet on the left depicts higher temperature and coercivity components while the one on the right includes only the lowest range vectors. Archeomagnetic results from rocks recovered in excavation squares at the same elevation (but not included on the composite maps) have been omitted from the stereonets.

In addition, it is important to point out that the upper portions of some larger rocks were exposed and sampled in one level but their bases were not reached (and they were not removed) until deeper levels had been excavated. Therefore, several rocks appear on successive composite maps. Moreover, some of these larger rocks yielded two or more "sister" samples from different portions of the same rock, corresponding to different excavation levels. In only rare instances did these "sister" samples yield different cooling context interpretations (most notably the rock in Square 52 that yielded AM-216, AM-217, and AM-546). In such cases, the results given on the plan maps correspond to the sample extracted from that level. The justification for this is that the upper portion of a rock may have been incorporated into a later feature and independently reheated, although the rock as a whole may not have been moved at that time. Although these anomalous cases have not been explored in detail for 
this report, data on thermal gradients across large rocks may eventually become an important source of information about the construction and internal thermodynamics of burned rock features as well as the reuse of individual rocks comprising them.

Finally, eight of the composites are accompanied by a summary table that lists, by subfeature, the number of samples in each of the "Cooling Context" categories. That is, these tables summarize the tripartite data by totaling, for example, the number of A-category versus D-category samples. It is important to remember the independence of each of part of the coding system: the question of whether a rock cooled in place is independent of the number of times (or at what temperatures) that rock may have been moved. The "Lowest Temperature of Movement" and "Maximum Number of Movements While Cooling" data for E-category (Unknown or Uncertain) samples are only included where they could be reasonably ascertained. Lastly, it should be emphasized again that the tripartite coding system in these tables (and the vector identifications and rotation reconstructions on which they are based, given in Appendix 6) is preceded by several analytical and interpretive steps. A complete copy of the data upon which these interpretations are based is on file at TARL.

\section{Feature 231, Composite A: South Block, Levels $17 / 18$ (including Subfeature 217)}

Due to the north-northwest slope of the deposits, the initial exposure of Feature 231 was in the South Block of the TARL excavation units, immediately south of TxDOT Block 6. It was first encountered as a moderately dense but largely unpatterned deposit of burned rocks at ca. $95.95 \mathrm{~m}$. Level 17 in TARL Square 33 was sampled as a representative level of these upper Feature 231 deposits and given a separate feature designation (Feature 217). This "feature" (shown in Composite A; Figure 27-49) was a loosely patterned accumulation of burned rocks extending northward into Level 18 of Square 48. Most of the rocks were relatively small, but a single large rock (AM-117) was found which projected northward into the previous TxDOT excavation area.

Archeomagnetic analyses of 10 rocks (Table 27-3) revealed that while most of these cooled near where they were recovered, they did so only from low temperatures (Figure 27-50). Although only 3 (AM-119, AM-121, and AM-124), are considered out-of-place relative to their final cooling location, most appear to have settled to some degree after cooling. Furthermore, half of the 10 sampled rocks (including AM-117, the largest rock, and AM-120, AM-122, AM-123, and AM-125) seem to have been displaced at least twice during cooling. Four of the remaining rocks (AM-97, AM-118, AM-119, and AM-124) did not move substantially while cooling from initial temperatures in excess of the Curie point, but only 2 of them (AM-97 and AM-118) remained near their final cooling locations. The latter were separated by nearly $1 \mathrm{~m}$ and

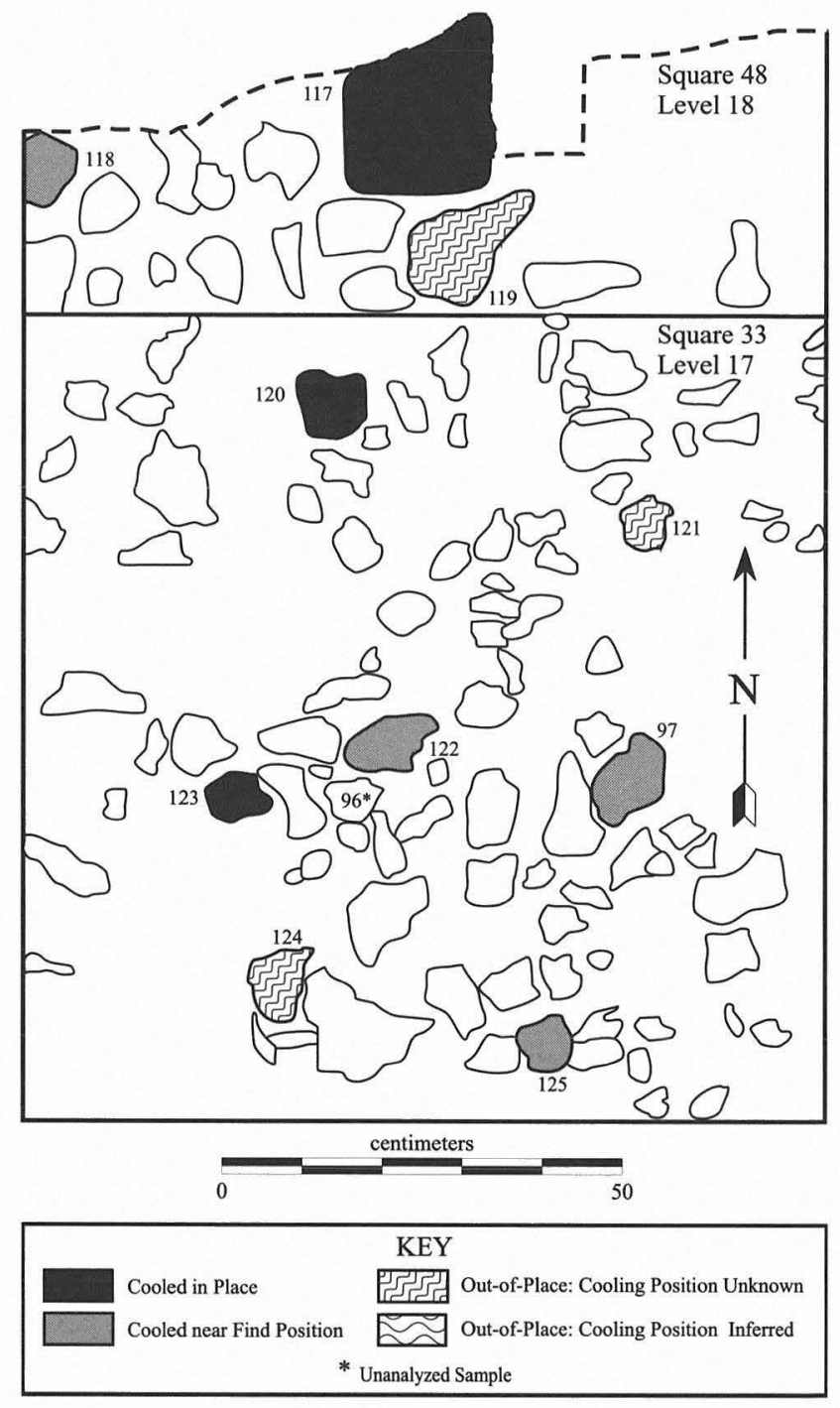

Figure 27-49. Feature 231, Composite A: Subfeature 217 in Squares 33 and 48, Levels 17/18 (ca. $95.95 \mathrm{~m}$ ).

no locus or concentration of heating can be inferred. However, most of the higher temperature and coercivity vector directions of the displaced rocks are in the southern hemisphere of the stereonet in Figure 27-50, probably as a result of northward (perhaps downslope) rotation while cooling.

Four samples from Level 18 in Square 32, adjacent to Feature 217, were also analyzed (see Table 27-3). All were found to have cooled near where they were recovered but only from low temperatures and following up to two displacements (although it is unclear whether they were only partially reheated).

\section{Feature 231, Composite B: South Block, Level 19 (including Subfeature 223)}

As mentioned, the upper strata of burned rocks in Feature 231 sloped slightly downward to the north-northeast. Composite B (Figure 27-51) illustrates the Feature 231 burned 
TABLE $27-3$

Archeomagnetic Interpretation of Vectoral Data, Composite A

\begin{tabular}{|c|c|c|c|c|c|c|}
\hline \multicolumn{4}{|c|}{ Cooling Context } & \multicolumn{3}{|c|}{ Lowest Temperature of Movement } \\
\hline \multicolumn{4}{|c|}{ A cooled in place } & \multicolumn{3}{|c|}{ * no discernible movement } \\
\hline \multicolumn{4}{|c|}{ B cooled near find position } & \multicolumn{3}{|c|}{$\mathrm{X}$ unknown (AF demagnetized) } \\
\hline \multicolumn{4}{|c|}{ C out-of-place: cooling location inferred } & \multicolumn{3}{|c|}{$\mathrm{V}$ possible viscous magnetization } \\
\hline \multicolumn{4}{|c|}{ D out-of-place: unknown cooling } & \multicolumn{3}{|c|}{$\mathrm{L}$ less or equal to $250^{\circ} \mathrm{C}$} \\
\hline \multicolumn{4}{|l|}{ orientation } & \multicolumn{3}{|c|}{$\mathrm{M}$ between $250^{\circ}$ and $450^{\circ} \mathrm{C}$} \\
\hline \multicolumn{4}{|c|}{ E uncertain / unknown } & \multicolumn{3}{|c|}{$\mathrm{H}$ greater than $450^{\circ} \mathrm{C}$} \\
\hline Feature No. & Square & Level & $\begin{array}{l}\text { Sample No. } \\
\text { (AM- ) }\end{array}$ & $\begin{array}{l}\text { Cooling } \\
\text { Context }\end{array}$ & $\begin{array}{c}\text { Lowest Temperature } \\
\text { of Movement }\end{array}$ & $\begin{array}{c}\text { No. of Discernible } \\
\text { Movements while Cooling }\end{array}$ \\
\hline 217 & 33 & 17 & 0097 & B & * & $0+$ \\
\hline 217 & 48 & 18 & 0117 & A & $\mathrm{L}$ & 2 \\
\hline 217 & 48 & 18 & 0118 & B & $*$ & 0 \\
\hline 217 & 48 & 18 & 0119 & $\mathrm{D}$ & * & $0+$ \\
\hline 217 & 33 & $17 \mathrm{~B}$ & 0120 & A & $\mathrm{L}$ & 2 \\
\hline 217 & 33 & $17 \mathrm{~B}$ & 0121 & D & $\mathrm{L}$ & 1 \\
\hline 217 & 33 & 17B & 0122 & B & L & 2 \\
\hline 217 & 33 & 17B & 0123 & A & $\mathrm{L}$ & 2 \\
\hline 217 & 33 & 17B & 0124 & D & $*$ & 0 \\
\hline 217 & 33 & 17B & 0125 & B & $\mathrm{L}$ & 2 \\
\hline \multicolumn{7}{|c|}{ Not Illustrated: } \\
\hline & 32 & 18 & 0105 & B & L & 2 \\
\hline & 32 & 18 & 0107 & B & $\mathrm{L}$ & 2 \\
\hline & 32 & 18 & 0108 & B & $\mathrm{L}$ & 2 \\
\hline & 32 & 18 & 0111 & B & $\mathrm{L}$ & $2+$ \\
\hline
\end{tabular}

rocks exposed at approximately $95.90 \mathrm{~m}$. This composite includes Feature 223 (Figure 27-52) in Level 19 of Square 34 (immediately adjacent to and slightly deeper than Feature 217, see again Figure 27-49). Most of the rocks in Feature 223 were small, and no patterning in their distribution was evident. The decreasing density of burned rocks in Square 33 following the excavation of Feature 217 (Figure 27-53) indicates that this southern extension of the Feature 231 palimpsest was relatively thin (less than $20 \mathrm{~cm}$ thick) in marked contrast to squares excavated farther north (discussed below).

The archeomagnetic data from 16 rocks sampled in Composite B (Table 27-4) demonstrate that nearly all of them were displaced after they last cooled (see stereonet in Figure 27-50). Only three rocks (AM-168, AM-222, and AM250) remained in or near their final cooling locations: the rest were displaced, in various directions, after they completely cooled. All three of these in-place rocks were recovered within or just south of Squares 48 and 49, suggesting that they may have been slightly deeper stratigraphically within Feature 231 and/or that a less-disturbed subfeature may have extended northward into the TxDOT excavation area.

These data differ from the Composite A results in that none of the Composite B rocks was moved more than once while cooling (compare Tables 27-3 and 27-4). In fact, 10 of the 16 analyzed rocks moved very little, if at all, while cooling from temperatures exceeding the Curie point (i.e., those with a 0 or $0+$ in the last column of Table 27-4). In sum, the Composite $\mathrm{B}$ rocks remained more stable than those from Composite A during cooling but were more profoundly displaced thereafter. Archeomagnetic analyses clearly indicate that over $80 \%$ of the Composite B rocks did not cool where they were recovered.

\section{Feature 231, Composite C: East Block, Levels 19/20}

The first exposure of Feature 231 in the East Block was a low-density scatter of burned rocks of varying sizes. Composite C (Figure 27-54) illustrates Feature 231 burned rocks exposed at ca. $95.85 \mathrm{~m}$ in Level 19 of Squares 28 and 44 and Level 20 of Squares 39, 52, and 53. Archeomagnetic data are available for three samples from Level 19 in Square 28 (Table 27-5). The two smaller rocks (AM-133 and AM-135) each had two magnetic components and both were displaced after cooling. The larger rock (AM-136), on the other hand, yielded three (and possibly four) vectors and cooled nearer where it was found (see Figure 27-50). It is unclear whether the final component change in these rocks resulted from 


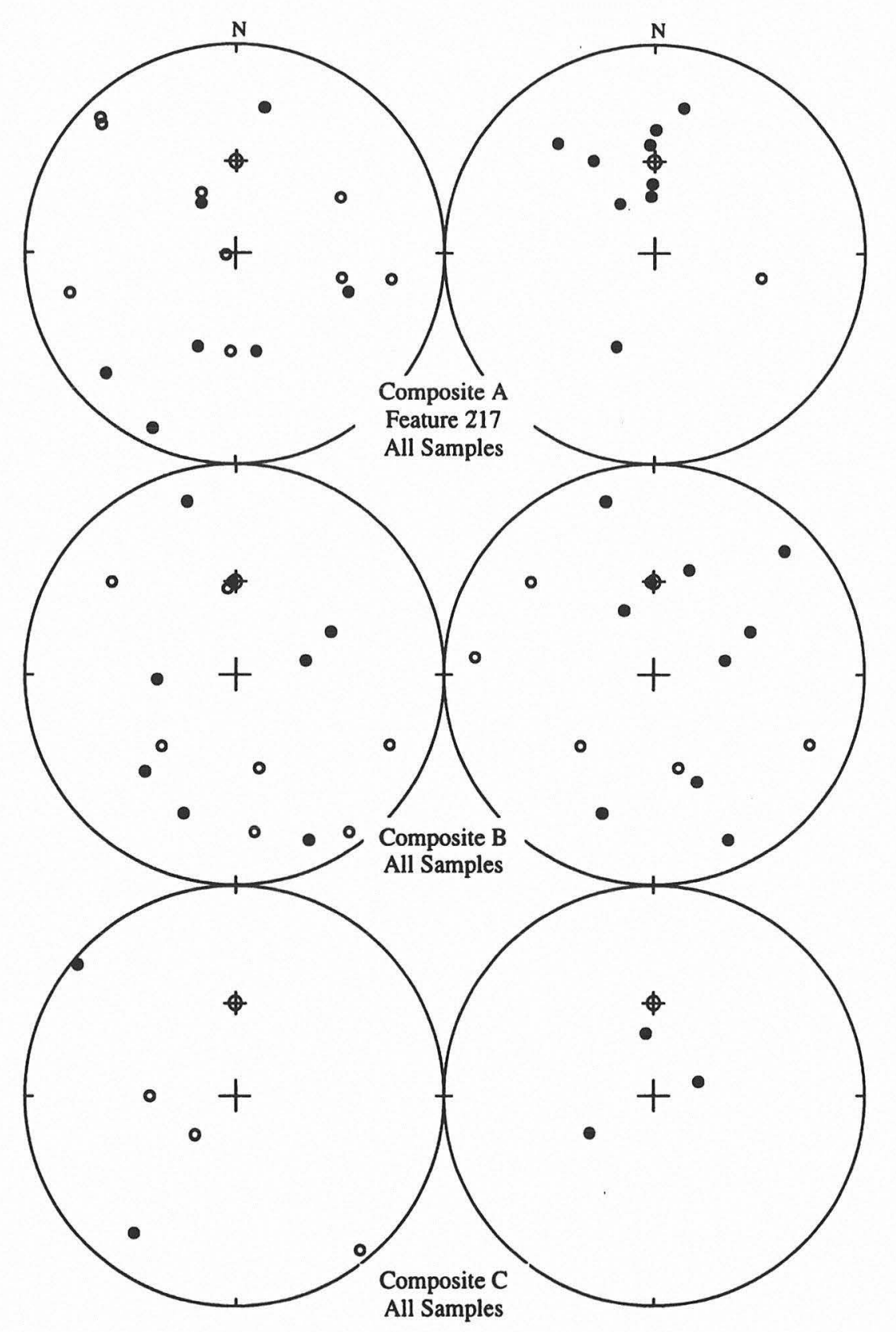

FIGURE 27-50. Stereoplots of results for Feature 231, Composites A, B, and C.

movement while cooling or from partial reheating. However, the reconstructed vector rotations suggest generally northward displacements for all three rocks which implies a similar mode of dislocation while cooling. The temperature at which this final vector change occurs is also somewhat greater for the larger rock (AM-136). Given that AM-136 is the only one cooled in place, it is possible that these differences in temperature (and cooling context) could be due to greater heat retention in the larger rock, with its smaller surface-to-volume ratio. That is, all of the rocks might have moved at nearly the same time, but the smaller ones (which presumably cooled more quickly) had already finished cooling while the larger one had not. Notwithstanding this particular inference, there is no evidence of in-situ cooling from high temperatures in any of these three samples.

\section{Feature 231, Composite D: East and}

South Blocks, Levels 20/21

Composite D (Figure 27-55) depicts the Feature 231 burned rocks exposed at ca. $95.85-95.80 \mathrm{~m}$ in Levels 20 and 21 (East Block and eastern end of South Block). At this depth, Feature 231 consisted of a generalized scatter with some indistinct, localized concentrations of greater rock size 


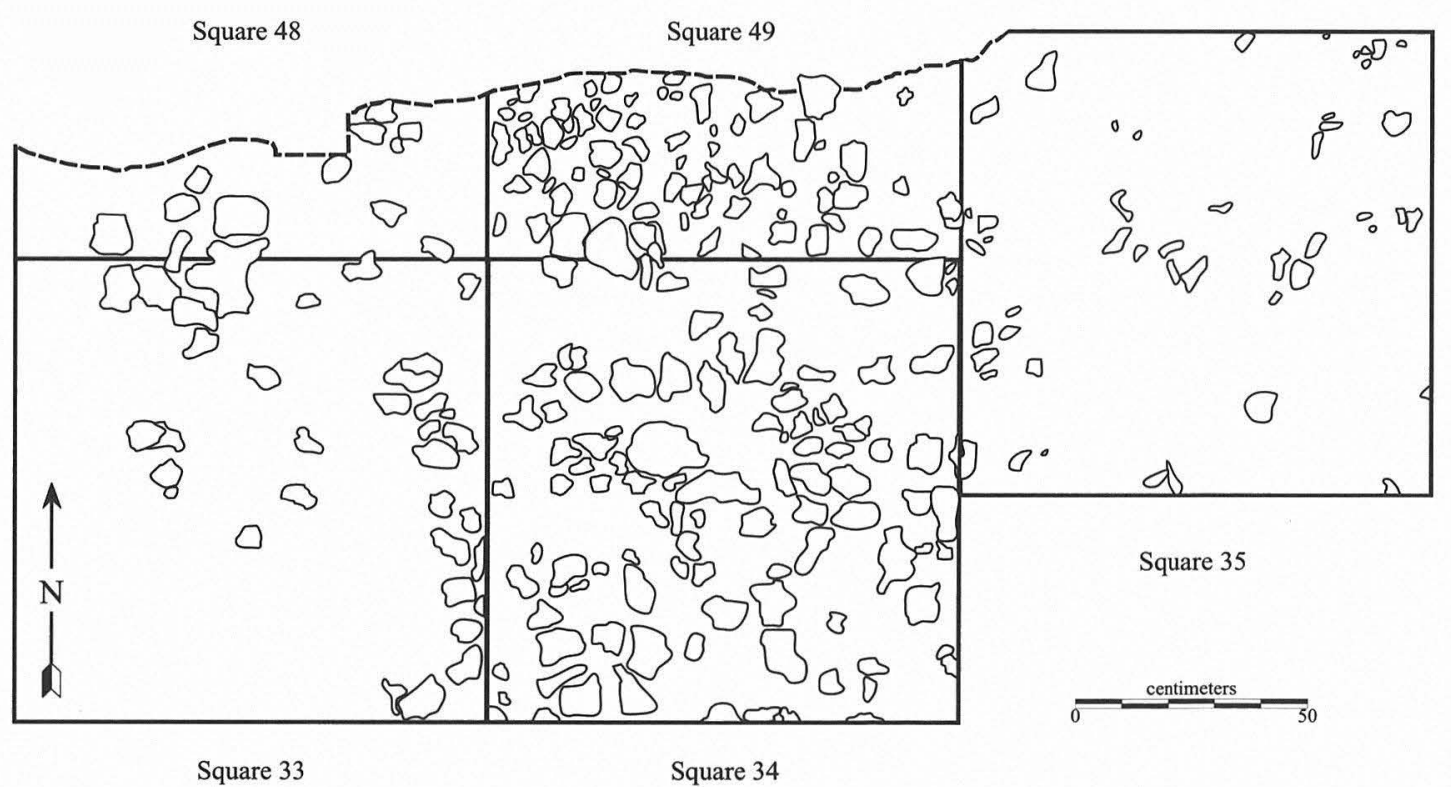

FIGURE 27-51. Feature 231 and associated subfeatures, Composite B: South Block, Level 19 (ca. 95.90 m).

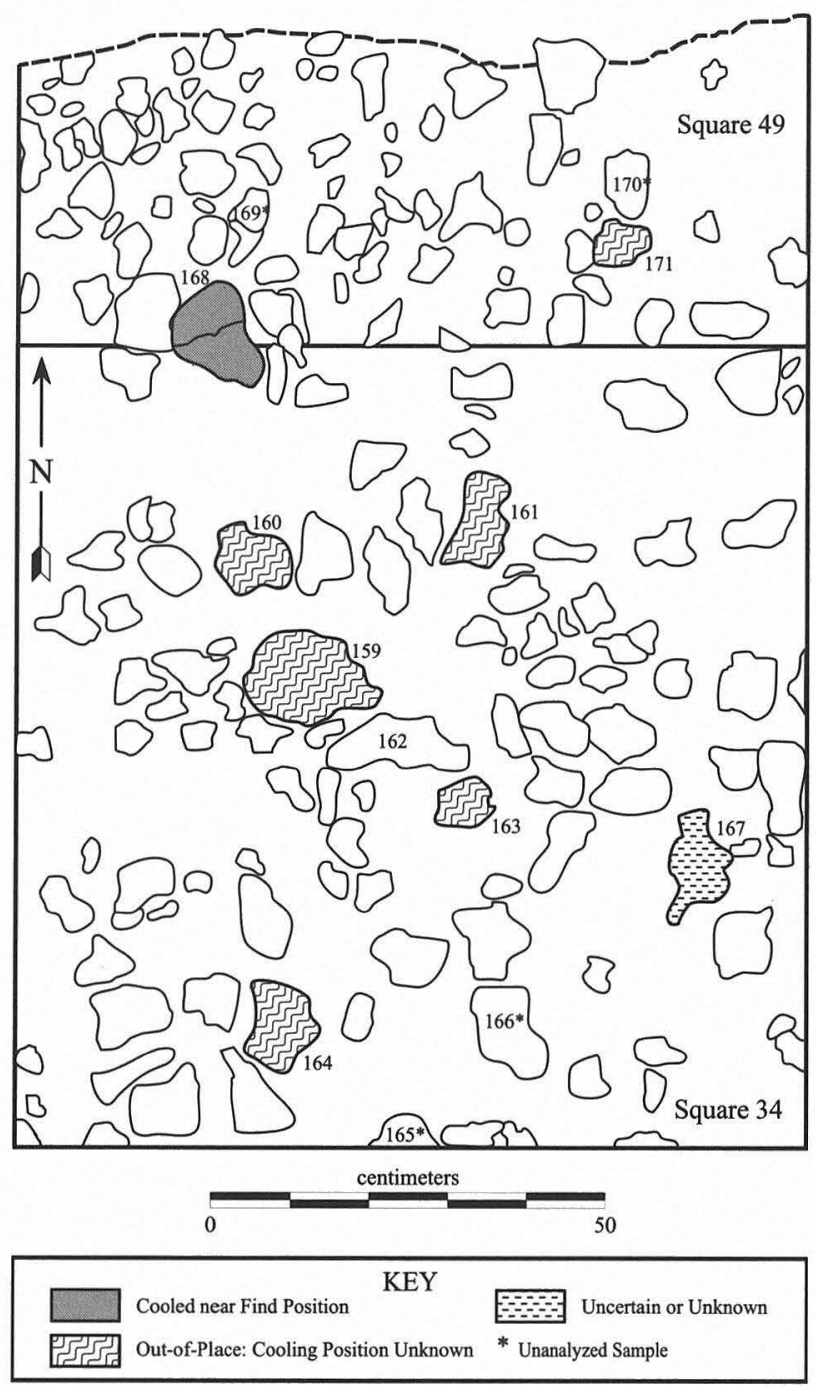

FIGURE 27-52. Detail from Composite B: Feature 223 in Squares 34 and 49, Level 19 (ca. $95.90 \mathrm{~m}$ ).

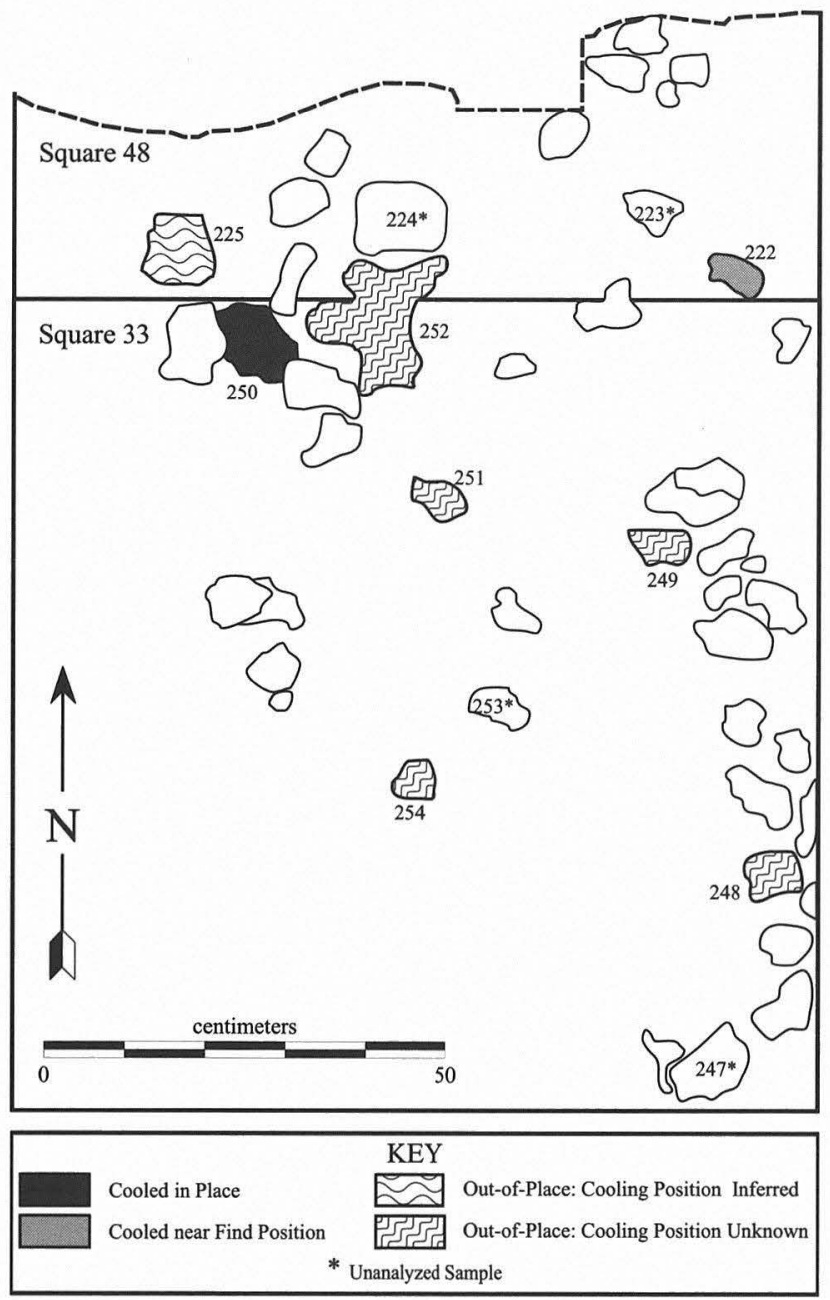

FIGURE 27-53. Detail from Composite B: Squares 33 and 48, Level 19 (ca. $95.90 \mathrm{~m})$. 
TABLE $27-4$

Archeomagnetic Interpretation of Vectoral Data, Composite B

\begin{tabular}{|c|c|c|c|c|c|c|}
\hline \multicolumn{4}{|l|}{ Cooling Context } & \multicolumn{3}{|c|}{ Lowest Temperature of Movement } \\
\hline \multicolumn{4}{|l|}{ A cooled in place } & \multicolumn{3}{|c|}{ * no discernible movement } \\
\hline \multicolumn{4}{|c|}{ B cooled near find position } & \multicolumn{3}{|c|}{$\mathrm{X}$ unknown (AF demagnetized) } \\
\hline \multicolumn{4}{|c|}{ C out-of-place: cooling location inferred } & \multicolumn{3}{|c|}{$\mathrm{V}$ possible viscous magnetization } \\
\hline \multicolumn{4}{|c|}{ D out-of-place: unknown cooling orientation } & \multicolumn{3}{|c|}{$\mathrm{L}$ less or equal to $250^{\circ} \mathrm{C}$} \\
\hline \multirow{2}{*}{\multicolumn{4}{|c|}{ E uncertain / unknown }} & \multicolumn{3}{|c|}{$\mathrm{M}$ between $250^{\circ}$ and $450^{\circ} \mathrm{C}$} \\
\hline & & & & \multicolumn{3}{|c|}{$\mathrm{H}$ greater than $450^{\circ} \mathrm{C}$} \\
\hline Feature No. & Square & Level & $\begin{array}{c}\text { Sample No. } \\
\text { (AM-) }\end{array}$ & $\begin{array}{l}\text { Cooling } \\
\text { Context }\end{array}$ & $\begin{array}{c}\text { Lowest Temperature } \\
\text { of Movement }\end{array}$ & $\begin{array}{c}\text { No. of Discernible } \\
\text { Movements while Cooling }\end{array}$ \\
\hline 223 & 34 & 19 & 0159 & $\mathrm{D}$ & $\mathrm{X}$ & 1 \\
\hline 223 & 34 & 19 & 0160 & $\mathrm{D}$ & $*$ & 0 \\
\hline 223 & 34 & 19 & 0161 & $\mathrm{D}$ & $\mathrm{X}$ & $1+$ \\
\hline 223 & 34 & 19 & 0163 & $\mathrm{D}$ & * & 0 \\
\hline 223 & 34 & 19 & 0164 & D & * & $0+$ \\
\hline 223 & 34 & 19 & 0167 & $\mathrm{E}$ & $\mathrm{L}$ & $1+$ \\
\hline 223 & 49 & 19 & 0168 & B & L-M & 1 \\
\hline 223 & 49 & 19 & 0171 & $\mathrm{D}$ & $*$ & 0 \\
\hline 231 & 33 & 19 & 0248 & D & * & $0+$ \\
\hline 231 & 33 & 19 & 0249 & D & * & 0 \\
\hline 231 & 33 & 19 & 0250 & A & * & $0+$ \\
\hline 231 & 33 & 19 & 0251 & $\mathrm{D}$ & * & 0 \\
\hline 231 & 33 & 19 & 0252 & $\mathrm{D}$ & $*$ & 0 \\
\hline 231 & 33 & 19 & 0254 & $\mathrm{D}$ & $X$ & $1+$ \\
\hline 231 & 48 & 19 & 0222 & B & L-M & 1 \\
\hline 231 & 48 & 19 & 0225 & $\mathrm{C}$ & * & 0 \\
\hline
\end{tabular}

and/or density. Composite D represents the first broad-scale exposure of Feature 231, but its subfeatures and the patterning at this level remain unclear.

The archeomagnetic results (Table 27-6; Figure 27-56), however, can be used to meaningfully subdivide the composite rocks and identify emerging subfeatures (even in these upper levels). While there are a mix of intact and displaced rocks in Composite D, most cooled in or near their find positions. Nevertheless, only about one-quarter of them did so from temperatures in excess of the Curie point (Table 27-7), and most appear to have moved at least once while cooling (see differences between the stereonet pairs in Figure 2756).

Beginning at the southern end of Composite D (in and around Squares 33, 34, 48, and 49), only three (AM-296, AM-406, and AM-408) of the eight analyzed rocks shown in Figure 27-57 cooled near where they were recovered. Of these, only two (AM-296 and AM-406) had a single component of magnetization, indicating no movement while cooling from high temperatures. The remaining 5 samples (AM-295, AM400, AM-401, AM-404, and AM-407) were moved at least once while cooling (or were only partially reheated) and were further dislocated after cooling. Of the 10 samples in adja- cent Square 35 to the east (Figure 27-58), only 4 (AM-237, AM-240, AM-241, and AM-243) cooled in or near where they were found. Two of these (AM-237 and AM-240) did not move noticeably while cooling from high temperatures. Most of the rocks that cooled in-situ are well separated, and no loci or concentrations of in-place rocks are apparent. The remaining 6 rocks analyzed in Square 35 (AM-219, AM-221, AM-239, AM-245, AM-291, and AM-292) have been displaced from their final cooling locations. Of these, only AM239 and AM-291 were moved while cooling.

This pattern of primarily displaced rocks continues into the southern half of excavation Square 37 (Figure 27-59), but in the northern half of this square and in adjacent squares to the west and north, most of the rocks were found to have cooled in or nearly in place. The larger rock (AM-281) in Square 37 cooled very close to where it was recovered, apparently from slightly higher temperatures than did its three nearest neighbors (AM-280, AM-332, and AM-333) to the north, which also remain in or near their final cooling positions. This slightly elevated temperature may be due to its lower surface-to-volume ratio.

Two (AM-335 and AM-337) of the analyzed rocks which encircle Feature 228 (defined in the field as the rock-free 


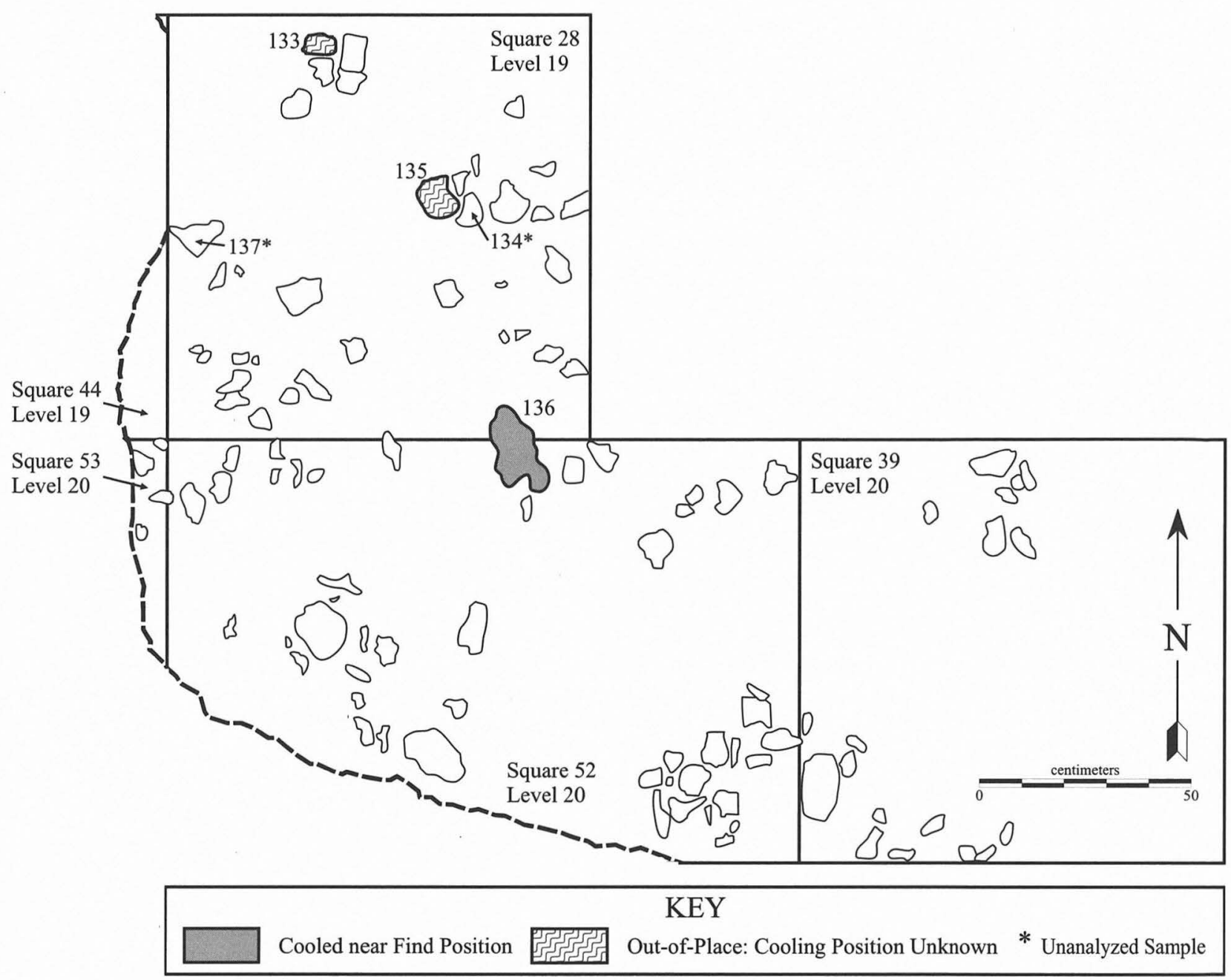

Figure 27-54. Feature 231, Composite C: East Block, Levels 19 and 20 (ca. 95.85 m).

TABLE 27-5

Archeomagnetic Interpretation of Vectoral Data, Composite C

Cooling Context

A cooled in place

B cooled near find position

C out-of-place: cooling location inferred

D out-of-place: unknown cooling orientation

E uncertain/ unknown
Lowest Temperature of Movement

* no discernible movement

$\mathrm{X}$ unknown (AF demagnetized)

$\mathrm{V}$ possible viscous magnetization

L less or equal to $250^{\circ} \mathrm{C}$

$\mathrm{M}$ between $250^{\circ}$ and $450^{\circ} \mathrm{C}$

$\mathrm{H}$ greater than $450^{\circ} \mathrm{C}$

\begin{tabular}{ccccccc}
\hline Feature No. & Square & Level & $\begin{array}{c}\text { Sample No. } \\
\text { (AM- })\end{array}$ & $\begin{array}{c}\text { Cooling } \\
\text { Context }\end{array}$ & $\begin{array}{c}\text { Lowest Temperature } \\
\text { of Movement }\end{array}$ & $\begin{array}{c}\text { No. of Discernible } \\
\text { Movements while Cooling }\end{array}$ \\
\hline 231 & 28 & 19 & 0133 & D & X & 1 \\
231 & 28 & 19 & 0135 & D & L & 1 \\
231 & 28 & 19 & 0136 & B & L-M & $2-3$ \\
\hline \hline
\end{tabular}




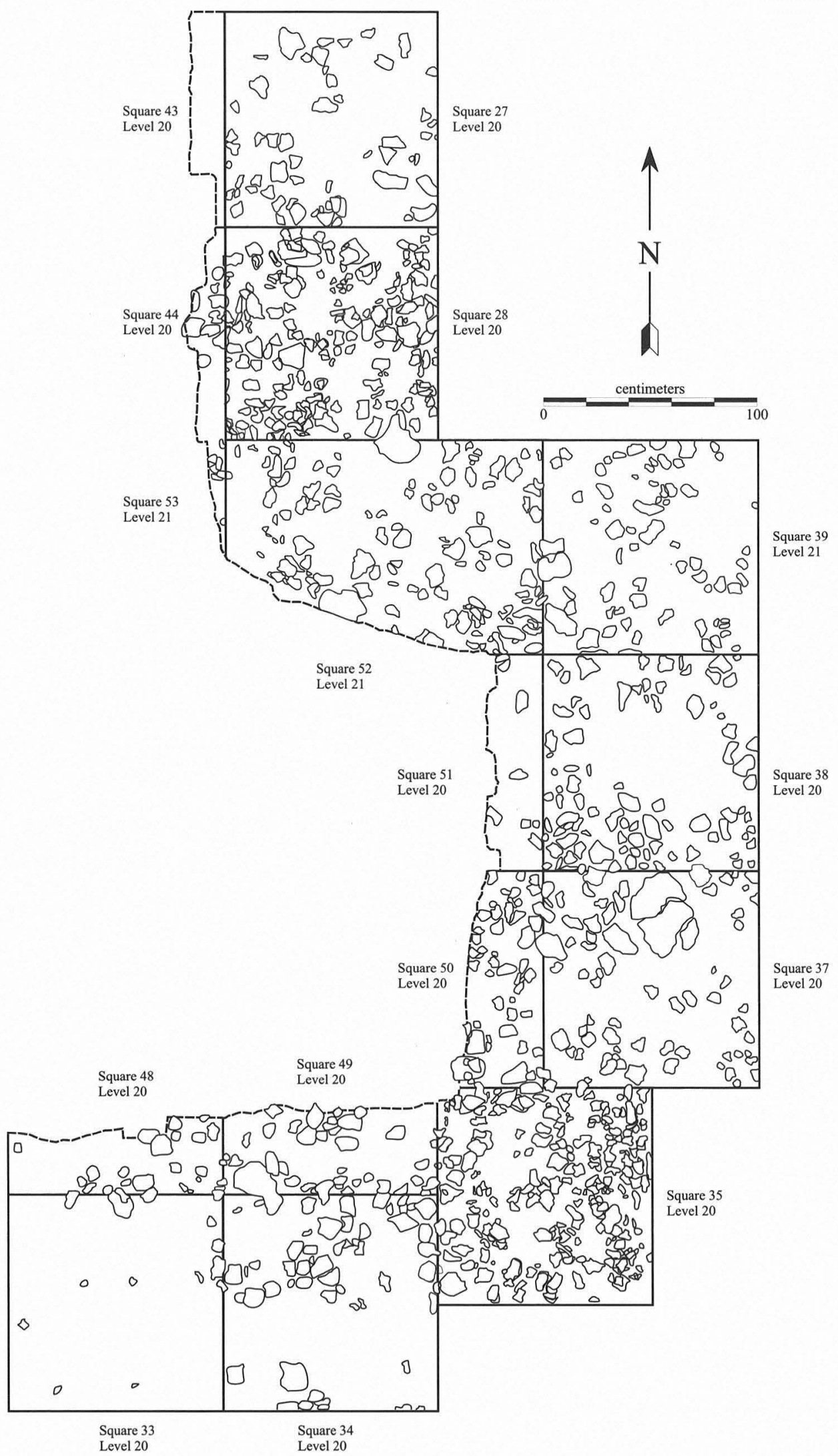

FIGURE 27-55. Feature 231 and associated subfeatures, Composite D: East and South Blocks, Levels 20 and 21 (ca. 95.85 - 95.80 m). 
TABLE 27-6

Archeomagnetic Interpretation of Vectoral Data, Composite D

Cooling Context
A cooled in place
B cooled near find position
C out-of-place: cooling location inferred
D out-of-place: unknown cooling orientation
E uncertain / unknown

Lowest Temperature of Movement

* no discernible movement

$\mathrm{X}$ unknown (AF demagnetized)

$\mathrm{V}$ possible viscous magnetization

$\mathrm{L}$ less or equal to $250^{\circ} \mathrm{C}$

$\mathrm{M}$ between $250^{\circ}$ and $450^{\circ} \mathrm{C}$

$\mathrm{H}$ greater than $450^{\circ} \mathrm{C}$

\begin{tabular}{|c|c|c|c|c|c|c|}
\hline Feature No. & Square & Level & $\begin{array}{c}\text { Sample No. } \\
\text { (AM-) }\end{array}$ & $\begin{array}{l}\text { Cooling } \\
\text { Context } \\
\end{array}$ & $\begin{array}{c}\text { Lowest Temperature } \\
\text { of Movement }\end{array}$ & $\begin{array}{c}\text { No. of Discernible } \\
\text { Movements while Cooling }\end{array}$ \\
\hline 181 & 52 & 21 & 0213 & A & $\mathrm{L}$ & 2 \\
\hline $181 / 231$ & 52 & 21 & 0216 & B & L-M & 2 \\
\hline $181 / 231$ & 52 & 21 & 0217 & B & M & $1+$ \\
\hline 230 & 39 & 21B & 0393 & $\mathrm{C}$ & $\mathrm{X}$ & 1 \\
\hline 230 & 39 & $21 B$ & 0394 & B & $\mathrm{X}$ & 1 \\
\hline 230 & 39 & $21 B$ & 0397 & B & $\mathrm{L}$ & 2 \\
\hline 230 & 39 & $21 \mathrm{~A}$ & 0398 & A & M & 1 \\
\hline 231 & 27 & 20 & 0127 & B & $*$ & 0 \\
\hline 231 & 27 & 20 & 0128 & B & $\mathrm{X}$ & $1+$ \\
\hline 231 & 27 & 20 & 0130 & B & $\mathrm{L}$ & 2 \\
\hline 231 & 27 & 20 & 0131 & B & $\mathrm{X}$ & $1+$ \\
\hline 231 & 27 & 20 & 0132 & C & $\mathrm{X}$ & 1 \\
\hline 231 & 28 & 20-Base & 0193 & B & $\mathrm{L}$ & $2-3$ \\
\hline 231 & 28 & 20-Base & 0194 & $\mathrm{E}$ & $\mathrm{X}$ & $1+$ \\
\hline 231 & 28 & 20-Base & 0196 & A & $\mathrm{L}$ & 1 \\
\hline 231 & 28 & 20-Base & 0199 & B & $\mathrm{L}$ & 2 \\
\hline 231 & 28 & 20-Base & 0202 & B & $*$ & $0+$ \\
\hline 231 & 28 & 20-Base & 0203 & A & L-M & 3 \\
\hline 231 & 28 & 20-Base & 0204 & D & $\mathrm{X}$ & 1 \\
\hline 231 & 28 & 20-Base & 0258 & A & $\mathrm{L}$ & 1 \\
\hline 231 & 28 & 20-Base & 0260 & $\mathrm{C}$ & $*$ & $0+$ \\
\hline 231 & 28 & 20-Base & 0262 & E & $* ?$ & $0+$ \\
\hline 231 & 34 & 20 & 0400 & C & $\mathrm{L}$ & 1 \\
\hline 231 & 34 & 20 & 0401 & $\mathrm{C}$ & $\mathrm{X}$ & 1 \\
\hline 231 & 35 & 20 & 0219 & D & $*$ & $0+$ \\
\hline 231 & 35 & 20 & 0221 & D & $*$ & $0+$ \\
\hline 231 & 35 & 20 & 0237 & B & $\mathrm{H}$ & $1+$ \\
\hline 231 & 35 & 20 & 0239 & D & $\mathrm{X}$ & 1 \\
\hline 231 & 35 & 20 & 0240 & A & $*$ & $0+$ \\
\hline 231 & 35 & 20 & 0241 & A & L-M & $2+$ \\
\hline 231 & 35 & 20 & 0243 & B & $\mathrm{X}$ & 1 \\
\hline 231 & 35 & 20 & 0245 & D & * & 0 \\
\hline 231 & 35 & 20 & 0291 & D & $\mathrm{X}$ & $1+$ \\
\hline 231 & 35 & 20 & 0292 & D & $*$ & $0+$ \\
\hline 231 & 37 & 20 & 0277 & C & $\mathrm{H}$ & 1 \\
\hline 231 & 37 & 20 & 0279 & E & $?$ & $?$ \\
\hline 231 & 37 & 20 & 0280 & A & $\mathrm{L}$ & 1 \\
\hline 231 & 37 & 20 & 0281 & B & M & 2 \\
\hline 231 & 37 & 20 & 0284 & D & * & $0+$ \\
\hline
\end{tabular}


Table 27-6, continued

\begin{tabular}{|c|c|c|c|c|c|c|}
\hline Feature No. & Square & Level & $\begin{array}{l}\text { Sample No. } \\
\text { (AM- ) }\end{array}$ & $\begin{array}{l}\text { Cooling } \\
\text { Context }\end{array}$ & $\begin{array}{c}\text { Lowest Temperature } \\
\text { of Movement }\end{array}$ & $\begin{array}{c}\text { No. of Discernible } \\
\text { Movements while Cooling }\end{array}$ \\
\hline 231 & 37 & 20 & 0286 & $\mathrm{D}$ & $*$ & $0+$ \\
\hline 231 & 37 & 20 & 0287 & A & L-M & 1 \\
\hline 231 & 37 & 20 & 0288 & $\mathrm{D}$ & $\mathrm{X}$ & 1 \\
\hline 231 & 38 & 20 & 0330 & B & M & $1+$ \\
\hline 231 & 38 & 20 & 0332 & B & $\mathrm{X}$ & 1 \\
\hline 231 & 38 & 20 & 0333 & B & $\mathrm{L}$ & $1+$ \\
\hline 231 & 38 & 20 & 0335 & A & * & 0 \\
\hline 231 & 38 & 20 & 0336 & B & $*$ & 0 \\
\hline 231 & 38 & 20 & 0337 & $\mathrm{~A}$ & L-M & 2 \\
\hline 231 & 39 & $21 \mathrm{~A}$ & 0386 & B & $\mathrm{L}$ & 2 \\
\hline 231 & 39 & $21 \mathrm{~A}$ & 0387 & D & $*$ & $0+$ \\
\hline 231 & 39 & $21 \mathrm{~A}$ & 0389 & A & $\mathrm{L}$ & $2-3$ \\
\hline 231 & 39 & $21 \mathrm{~A}$ & 0391 & A & $X$ & 1 \\
\hline 231 & 48 & 20 & 0295 & D & M & 2 \\
\hline 231 & 48 & 20 & 0296 & B & $*$ & $0+$ \\
\hline 231 & 49 & 20 & 0404 & C & $\mathrm{X}$ & 1 \\
\hline 231 & 49 & 20 & 0406 & B & $*$ & 0 \\
\hline 231 & 49 & 20 & 0407 & $\mathrm{E}$ & $X$ & $1+$ \\
\hline 231 & 49 & 20 & 0408 & A & $\mathrm{L}$ & 1 \\
\hline 231 & 50 & 20 & 0276 & B & $*$ & 0 \\
\hline 231 & 50 & 20 & 0289 & C & $\mathrm{H}$ & $1+\cdot$ \\
\hline 231 & 52 & 21 & 0207 & B & $\mathrm{L}$ & $1+$ \\
\hline 231 & 52 & 21 & 0209 & B & L-M & $1+$ \\
\hline 231 & 52 & 21 & 0211 & A & $\mathrm{L}$ & 1 \\
\hline 231 & 52 & 21 & 0214 & B & $X$ & $2+$ \\
\hline 231 & 52 & 21 & 0246 & D & $\mathrm{X}$ & 1 \\
\hline
\end{tabular}

area in Square 38; see Figure 27-59) cooled in-situ, and four others (AM-330, AM-332, AM-333, and AM-336) cooled near their find positions. Two (AM-335 and AM-336) of these six rocks cooled without noticeable movement from maximum temperatures above the Curie point, while the others were moved at least once while cooling. These two single-component rocks are also closer to Feature 228 than the others suggesting that the latter may have originally been nearer to or within the rock-free area, a supposition finding additional support in vector rotation reconstructions which indicate a subtle west-southwestward settling of AM-330 and a northwestward tilting of AM-333 after cooling.

The three rocks (AM-386, AM-389, and AM-391) from the southern half of Square 39 (Figure 27-60) that cooled in place or nearly in place were all moved last at low temperatures (see Table 27-6). Two of these samples (AM-386 and AM-389) yielded three or more components suggesting complex cooling histories, probably involving two or more displacements while cooling. The AM-387 rock did not move while cooling from high temperatures but was displaced after final cooling.
The upper portion of Feature 230 can be seen in the northern half of Square 39 (see Figure 27-60). This pit-shaped feature continued into the next two levels. Despite the loose patterning of burned rocks in this uppermost level, three (AM-394, AM-397, and AM-398) of the four Feature 230 rocks analyzed were found to have cooled in (or nearly in) place. The other rock (AM-393) was slightly more displaced after cooling but nonetheless remains near its final cooling location (see Figure 27-56). Internal consistency in rotation reconstructions suggests that the two easternmost rocks were moved toward the center of the feature during, and again somewhat after, cooling. Thus they were probably displaced while cooling from temperatures in excess of the Curie point. The other two rocks (AM-397 and AM-398) may have been heated to some lower maximum temperature.

The two analyzed rocks along the southern edge of Square 52 (AM-213, AM-216, and AM-217; Figure 27-61) are probably associated with Feature 181 (a feature previously encountered in TxDOT Square E28/S78). Both cooled in or near where they were found, the larger one from slightly higher temperatures (again perhaps due to its decreased surface area relative to volume). Although the two samples 


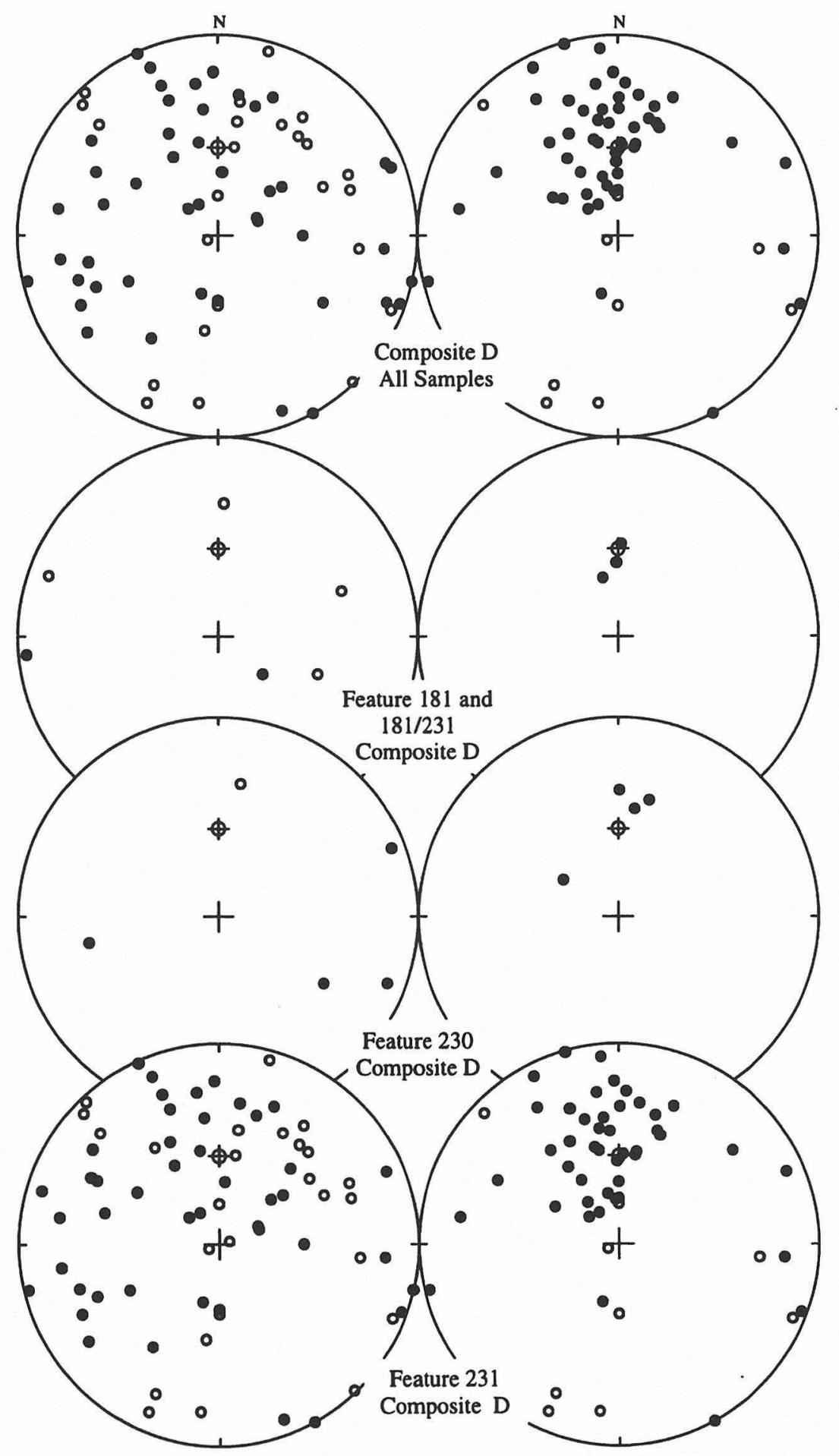

FIGURE 27-56. Stereoplots of results for Composite D, including subfeatures.

(AM-216 and AM-217) analyzed from this larger rock agreed well in lower temperature ranges, they had significantly different higher temperature vector directions. Even greater differences are noted for another sample taken from about $20 \mathrm{~cm}$ lower on the same rock (AM-546, from Level 23). These findings suggest caution when interpreting results from large rocks. They may have been exposed to multiple heat sources. For example, a large rock may be heated on one side (or from above) while the opposite side remains cool and, consequently, does not register that heating event. In any case, the common thermoremanence directions of AM-216 and AM-217 in low temperature ranges 
TABLE 27-7

Summary of Archeomagnetic Results for Composite D

\begin{tabular}{|c|c|c|c|c|c|c|c|c|c|c|c|c|c|c|}
\hline \multirow[b]{2}{*}{ Feature } & \multicolumn{5}{|c|}{ Cooling Context } & \multicolumn{5}{|c|}{ Lowest Temperature of Movement } & \multicolumn{4}{|c|}{ Maximum Number of Movements } \\
\hline & A & B & $\mathrm{C}$ & $\mathrm{D}$ & E & $*$ & $\begin{array}{c}\text { L or L- } \\
\text { M }\end{array}$ & $\begin{array}{l}\mathrm{M} \text { or } \\
\mathrm{M}-\mathrm{H}\end{array}$ & $\mathrm{H}$ & $\mathrm{X}$ & 0 & $\begin{array}{l}1,1+\text {, } \\
\text { or } 1-2\end{array}$ & $\begin{array}{l}2,2+, \\
\text { or } 2-3\end{array}$ & $\begin{array}{l}3 \text { or } \\
\text { more }\end{array}$ \\
\hline $181 / 231$ & & 2 & & & & & 1 & 1 & & & & 1 & 1 & \\
\hline 231 & 13 & 21 & 7 & 13 & 4 & 16 & 18 & 3 & 3 & 16 & 17 & 29 & 10 & 1 \\
\hline 230 & 1 & 2 & 1 & & & & 1 & 1 & & 2 & & 3 & 1 & \\
\hline
\end{tabular}

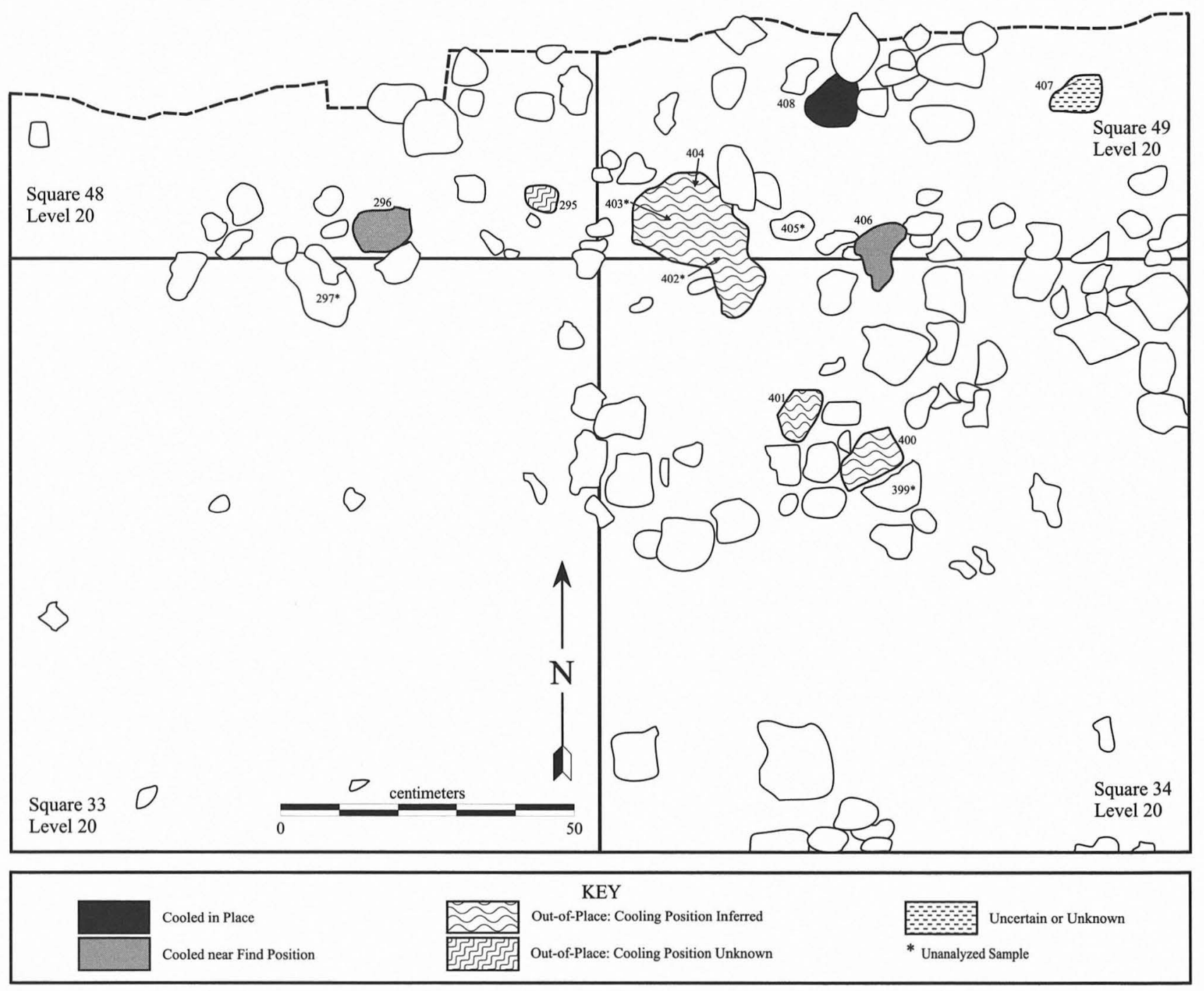

Figure 27-57. Detail from Composite D: Squares 33, 34, 48, and 49, Level 20 (ca. 95.85 m). 


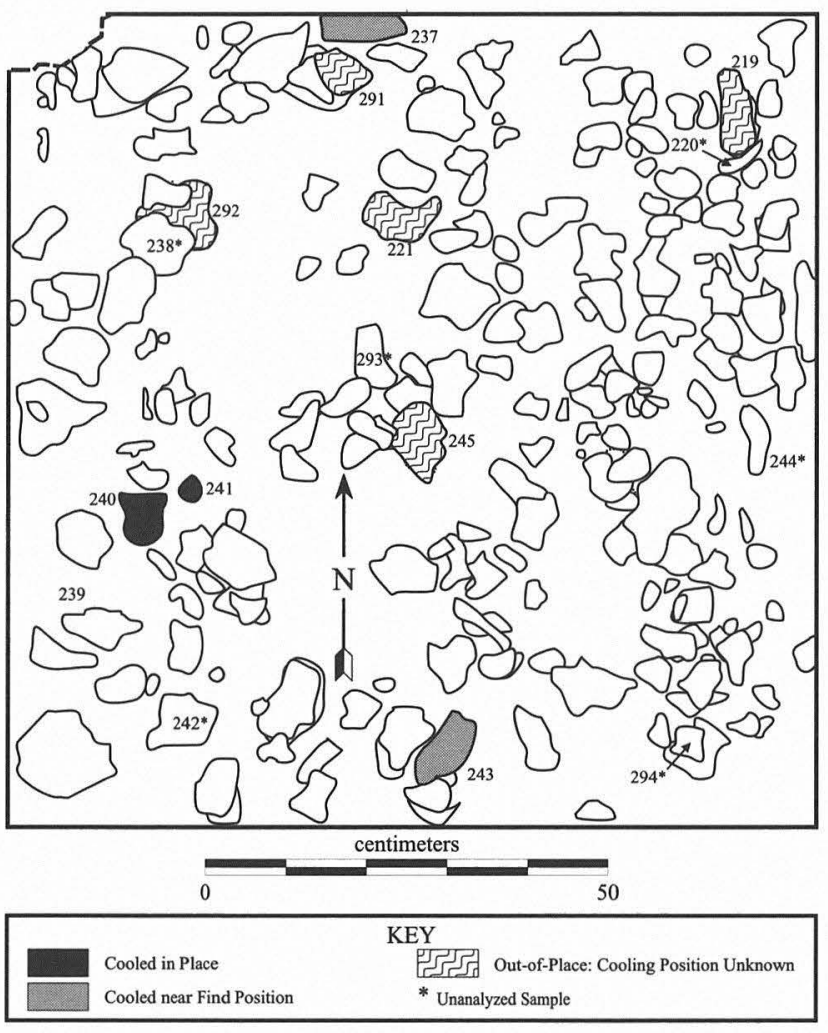

Figure 27-58. Detail from Composite D: Square 35, Level 20 (ca. $95.85 \mathrm{~m})$.

imply at least a final partial reheating. However, the heat source may have been northwest of where the rock was recovered (discussed below) and therefore not associated with the use of Feature 181.

All but one (AM-246) of the remaining rocks in Square 52 (AM-207, AM-209, AM-211, and AM-214) also cooled in or near their final archeological positions. All cooled in these locations only from $250^{\circ} \mathrm{C}$ or less, with the probable exception of the larger rock along the northern edge (AM-209) which apparently cooled in place from slightly higher temperatures (see Table 27-6).

Of the 10 rocks analyzed in Square 28 (Figure 27-62), 6 (AM-193, AM-196, AM-199, AM-202, AM-203, and AM258 ) cooled in (or nearly in) place. Only one (AM-202) did so from high temperatures, while the rest were moved last at low temperatures (see Table 27-6). Similarities in vector rotation reconstructions imply that at least some of these rocks began cooling from temperatures near or in excess of the Curie point and that the large number of components represents a great deal of displacement while cooling (rather than multiple reheating events).

Four (AM-127, AM-128, AM-130, and AM-131; Figure 27-63) of the five rocks analyzed in Square 27 remain near where they cooled, but only one (AM-127) had a single remanence component (see Table 27-6). Vector rotation reconstructions for these samples are consistent with movement while cooling. Furthermore, two or more

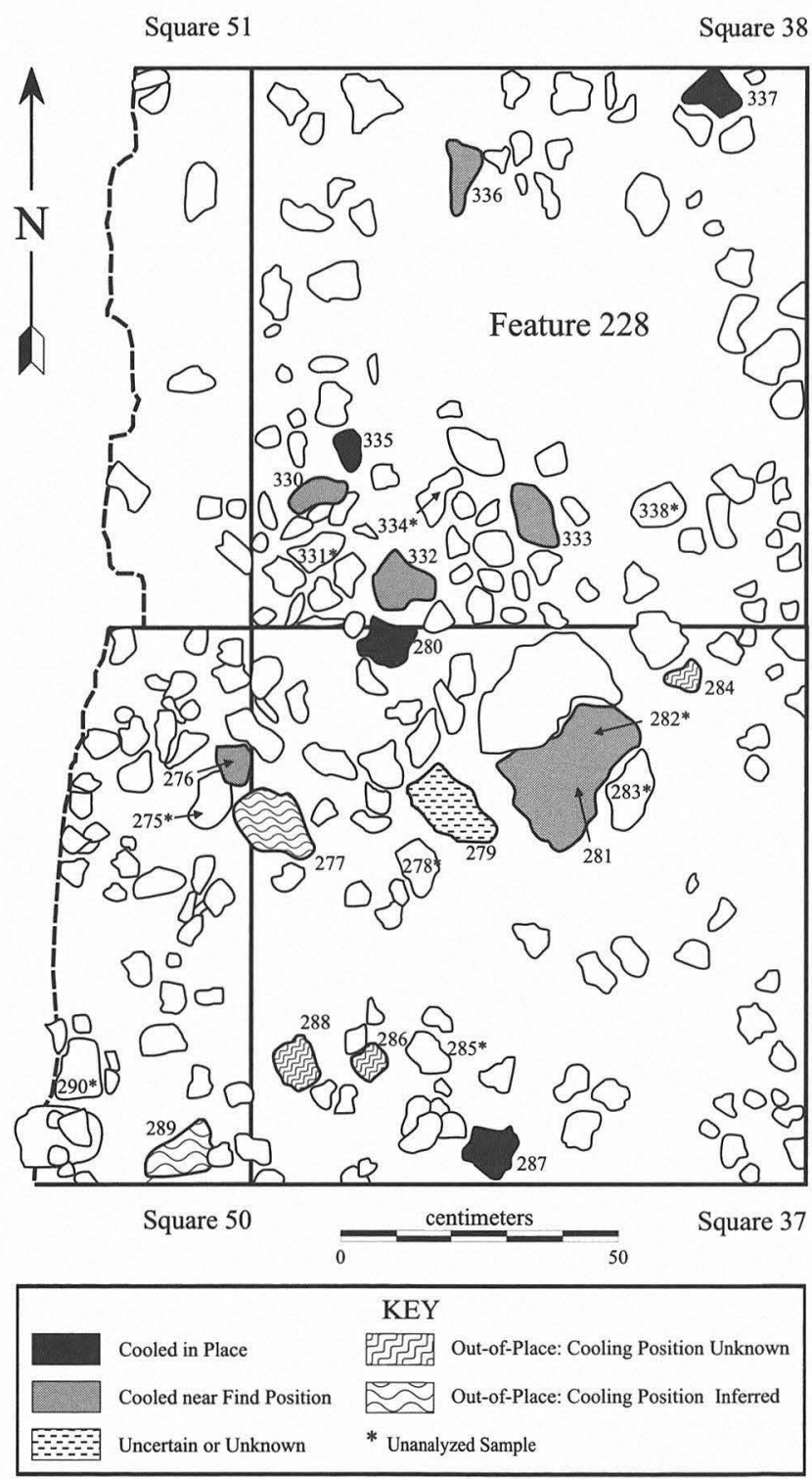

Figure 27-59. Detail from Composite D: Squares 37, 38, 50 and 51, Level 20 (ca. $95.85 \mathrm{~m}$ ), including Feature 228.

loci or depressions may have existed toward which the rocks may have settled. Both AM-130 and AM-131 seem to have settled to the northeast after cooling (following similar magnitude, but different direction rotations, while cooling). Meanwhile, AM-127 and AM-128 apparently settled slightly to the southwest and north, respectively, after cooling. Rock AM-132 probably experienced two displacements of similar magnitude (to the east and southeast) during and after cooling. These results suggest complex cooling histories and good preservation of the Square 27 burned rocks.

The archeomagnetic data from Composite D as a whole indicate that while there are no clear concentrations of rocks cooled in-situ from high temperatures, many of the rocks remain in or near the locations in which they 


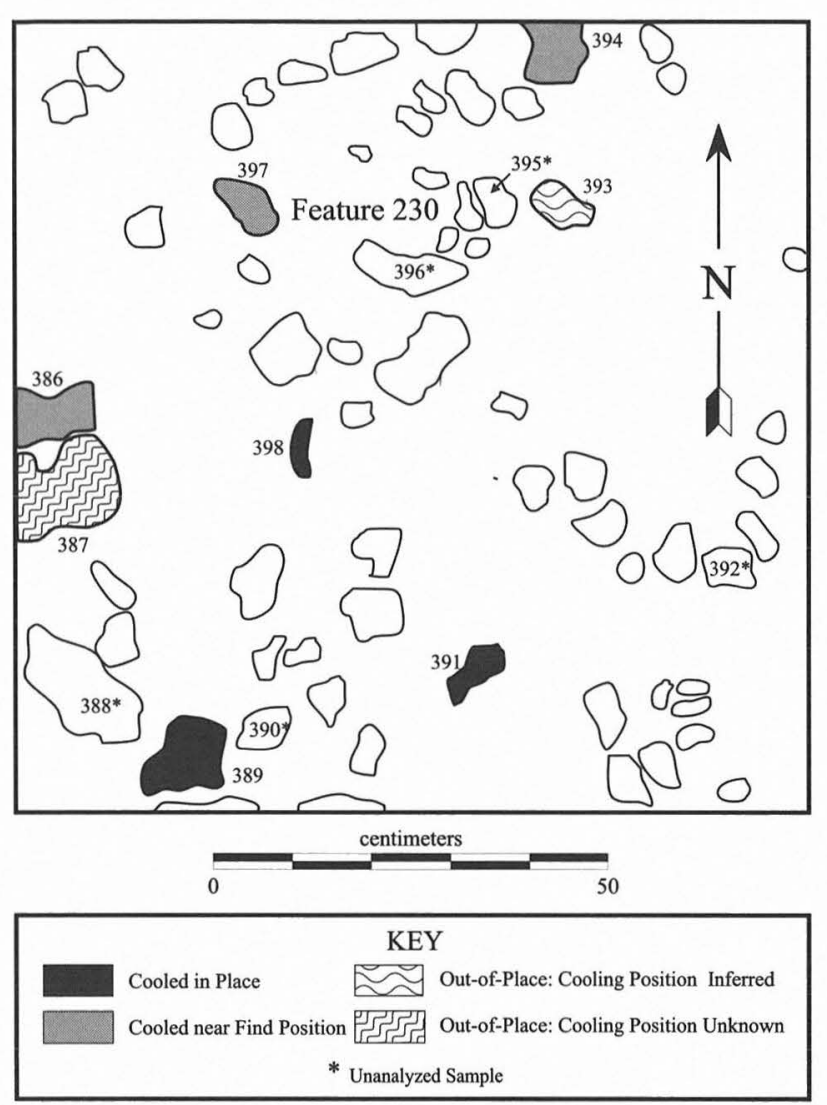

FIGURE 27-60. Detail from Composite D: Feature 230 in Square 39, Level 21 (ca. $95.80 \mathrm{~m}$ ). cooled (see Table 27-7). Most did so, however, only from low to moderate temperatures. The majority of the displaced rocks were found in the South Block (e.g., Square 35) although several were found scattered throughout the level. The archeomagnetic results (and the vector rotation reconstructions derived from them) do indicate that, even in this upper portion, Feature 231 is largely intact and that some of its component subfeatures can be discerned. With greater depth, definition of these constituent subfeatures improved, as seen in Composites $\mathrm{E}$ and $\mathrm{F}$.

\section{Feature 231, Composite E: East and South Blocks, Levels 21/22}

Composite E (Figure 27-64) depicts Feature 231 burned rocks exposed at ca. $95.80-95.75 \mathrm{~m}$ in Levels 21 and 22 (East Block and eastern end of South Block). An increased density of burned rocks can be clearly seen in this composite. In addition, Features 181 and 230 are better defined as are other potential subfeatures that were not recorded in the field, most noticeably along the boundary between Squares 27 and 28 as well as the semiarc of larger rocks in Square 26. Feature 228 (the rock-free void in Square 38) continues in this level as well. Archeomagnetic analyses were conducted on 76 samples from Composite $E$ and the results are plotted on Figures 27-65 and 27-66. Cooling context interpretations are given in Table 27-8 and summarized in Table 27-9.

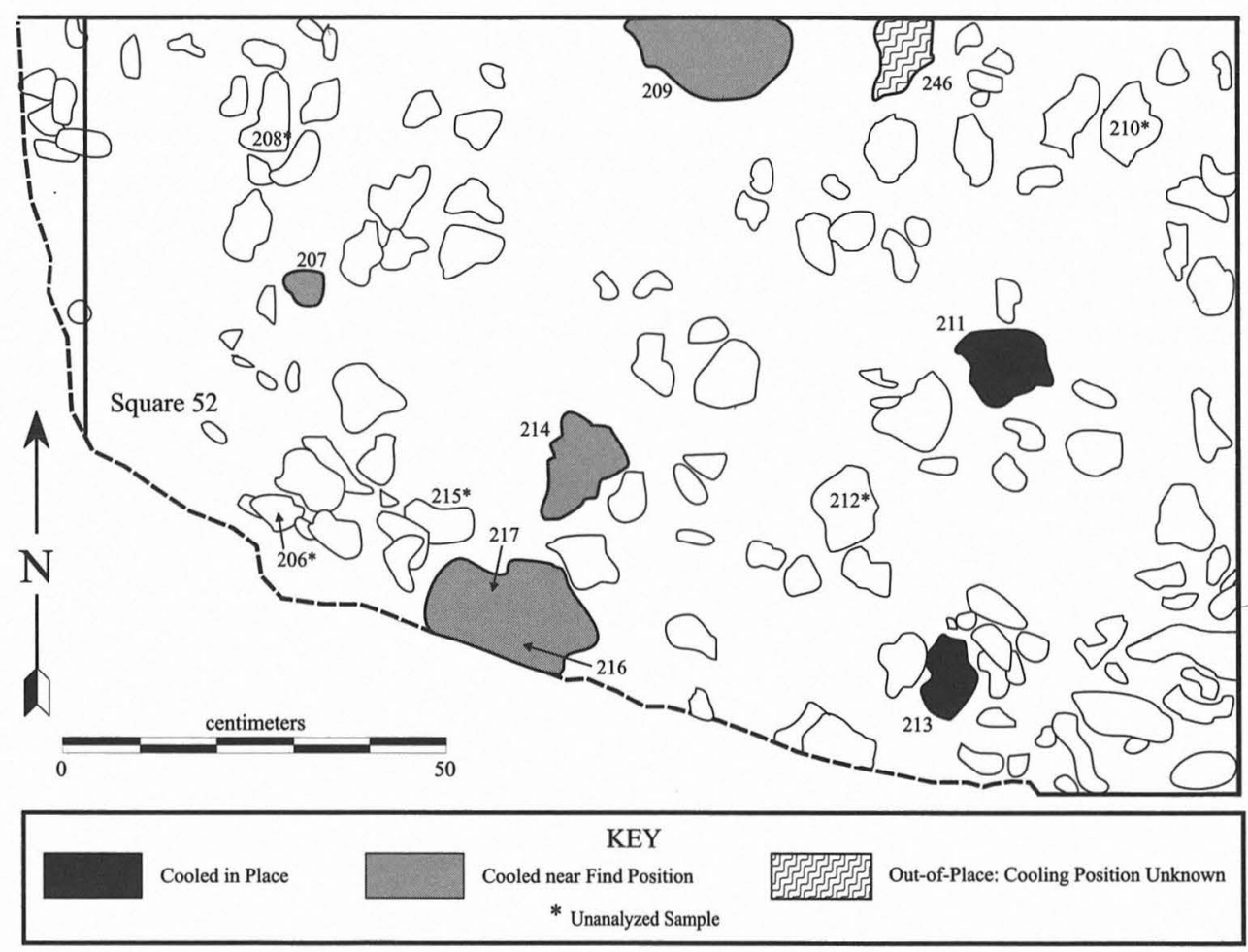

FIGURE 27-61. Detail from Composite D: Squares 52 and 53, Level 21 (ca. 95.80 m). 


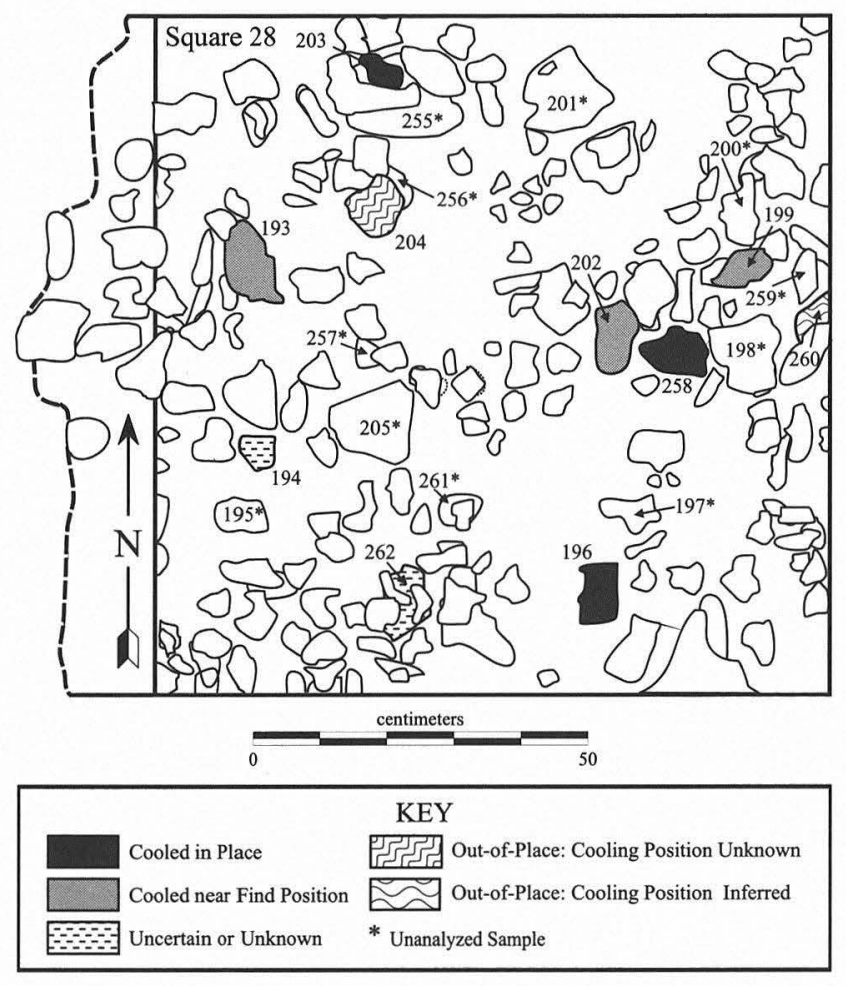

FIGURE 27-62. Detail from Composite D: Squares 28 and 44, Level 20 (ca. $95.80 \mathrm{~m}$ ).

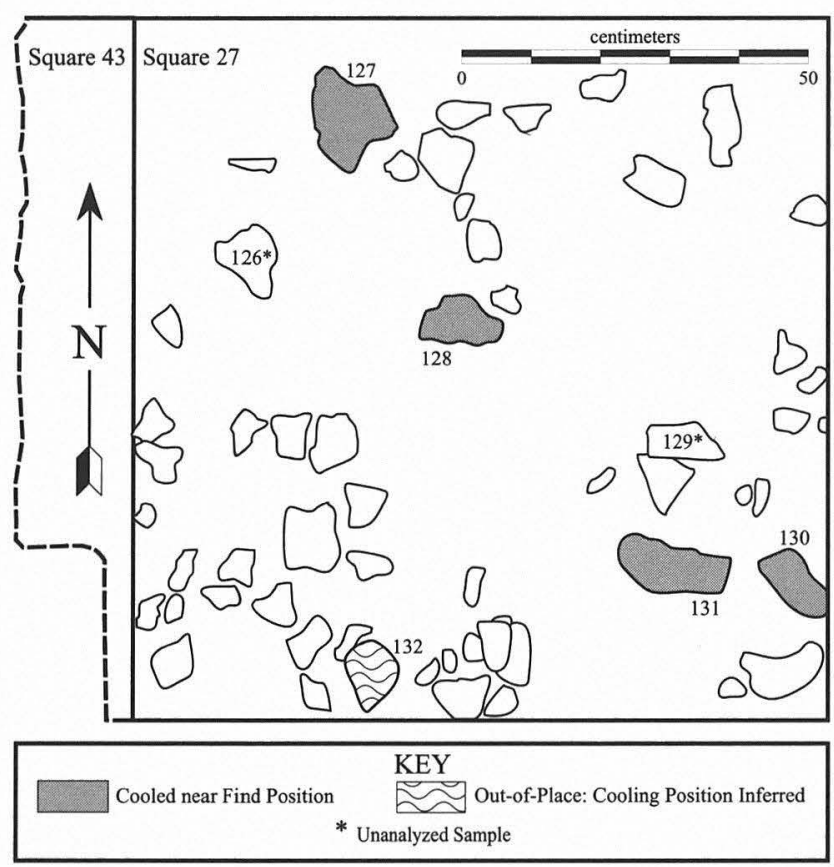

FIGURE 27-63. Detail from Composite D: Squares 27 and 43, Level 20 (ca. $95.80 \mathrm{~m}$ ).

All six analyzed samples (AM-437, AM-439, and AM442 in Square 51, Level 21 [Figure 27-67]; AM-351, AM353, and AM-354 in Square 52, Level 22 [Figure 27-68]) associated with Feature 181 cooled more-or-less in place (see Figure 27-65) and only one (AM-353) did so from temperatures less than about $300^{\circ} \mathrm{C}$. Rock AM-354 is the only one that was not moved at least once while cooling but was displaced slightly more than the others after cooling. The conjecture that the other five rocks moved while cooling (rather than partially heated) is supported by consistencies in the vector rotation reconstructions both within and between adjacent samples.

Of the 11 analyzed rocks potentially associated with Feature 181 (and therefore designated 181/231; see Table 278 ), 8 cooled in or near where they were found (see Figure 2765). Two of these (AM-342 and AM-348) were located in Square 52, Level 22 (see Figure 27-68); three (AM-614, AM708, and AM-709) were in the southwestern corner of Square 39, Level 22 (Figure 27-69); one (AM-435) was at the western edge of Square 38, Level 21 (see Figure 27-67); two (AM-444 and AM-445) were at the north end of Square 50, Level 21 (see Figure 27-67); and one (AM-371) was in the northwestern corner of Square 37, Level 21 (see Figure 27-67). Six of the 181/231 rocks (AM-348, AM-436, AM-445, AM-708, AM709, and AM-710) had a single component of magnetization (indicating little or no movement while cooling), but three of these (AM-436, AM-445, and AM-710) were displaced after they had completely cooled (see Table 27-8). The directions of the single TRM component rocks are the same in both stereonets shown in Figure 27-65. None of these rocks moved more than once while cooling (see Table 27-9).

Two other numbered subfeatures of Feature 231-Features 230 and 228-also continued into this level (see Figures 27-67 and 27-69). Two rocks (AM-340 and AM-339 [see AM-635 results]) from the edge of the Feature 228 rock-free area in Square 38, Level 21 both cooled in place and had two TRM components (see Figure 27-66). Similar reconstructed vector rotations during and after cooling within each sample supports the inference that these rocks began cooling for the last time from temperatures in excess of the Curie point.

Feature 230 was very well defined in Square 39 where the main body of the rock-filled pit was bisected, resulting in a dense cluster of burned rocks from which 10 archeomagnetic samples were eventually analyzed (see Figure 27-69). Eight of these samples are in or near the positions in which they finished cooling (see Table 27-8). The other two (AM-623 and AM-699), although more dislocated than the others, also probably remain near, but certainly not in, their final cooling locations (see Figure 27-66). None of these samples moved more than once while cooling. Seven of the 10 (all except AM-620, AM-699, and AM-701), however, did move while cooling (see Table 27-9). Those (AM-618, AM619, and AM-622) for which temperature data are available moved last at approximately $400^{\circ} \mathrm{C}$. The reconstructed vector rotations of several of these rocks suggest movement toward the main portion of the feature while cooling. Feature 230 is clearly the intact remnant of the final heating and cooling of these rocks within the confines of a small pit. 


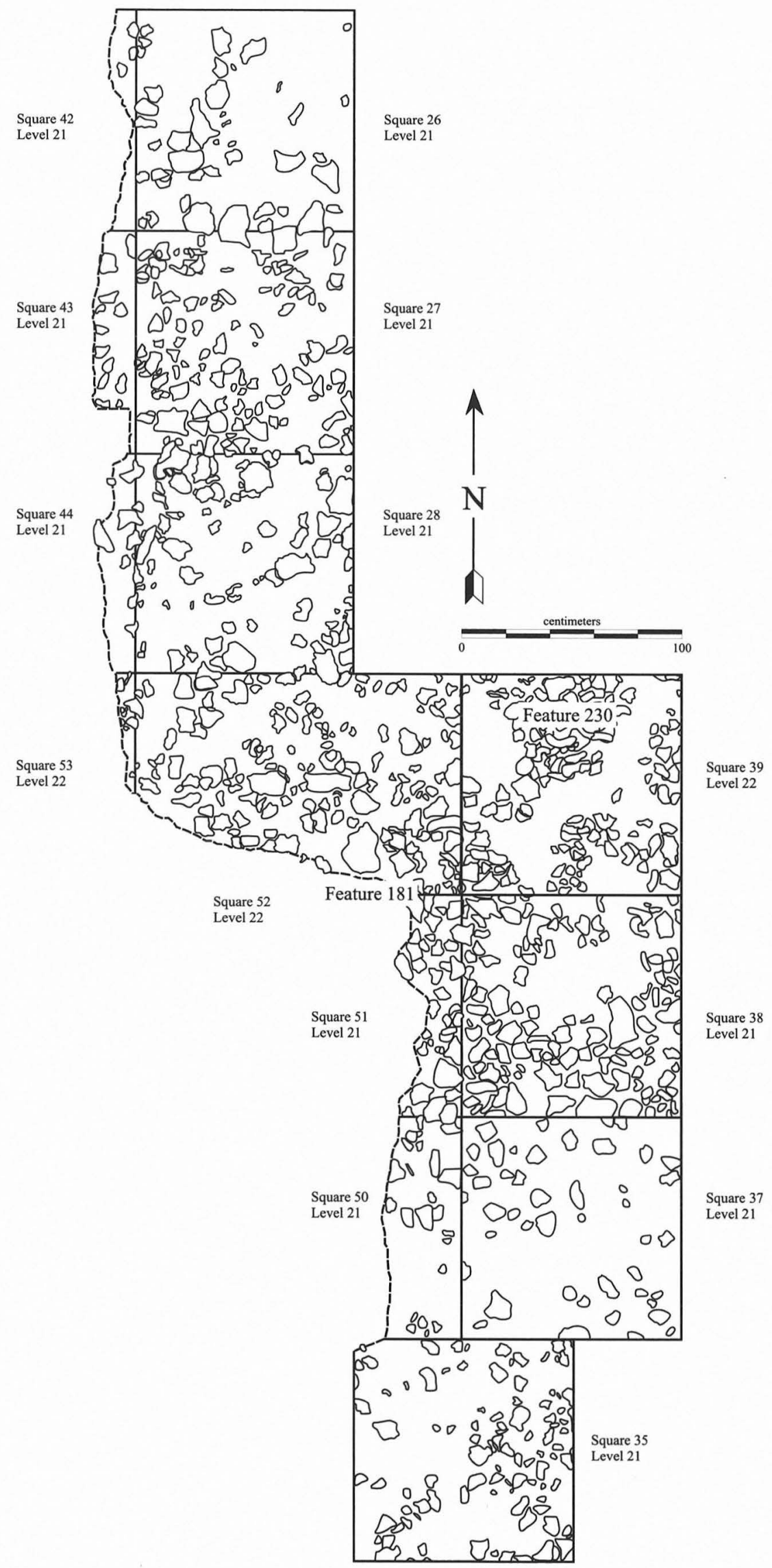

FIGURE 27-64. Feature 231 and associated subfeatures, Composite E: East and South Blocks, Levels 21 and 22 (ca. 95.80 - 95.75 m). 


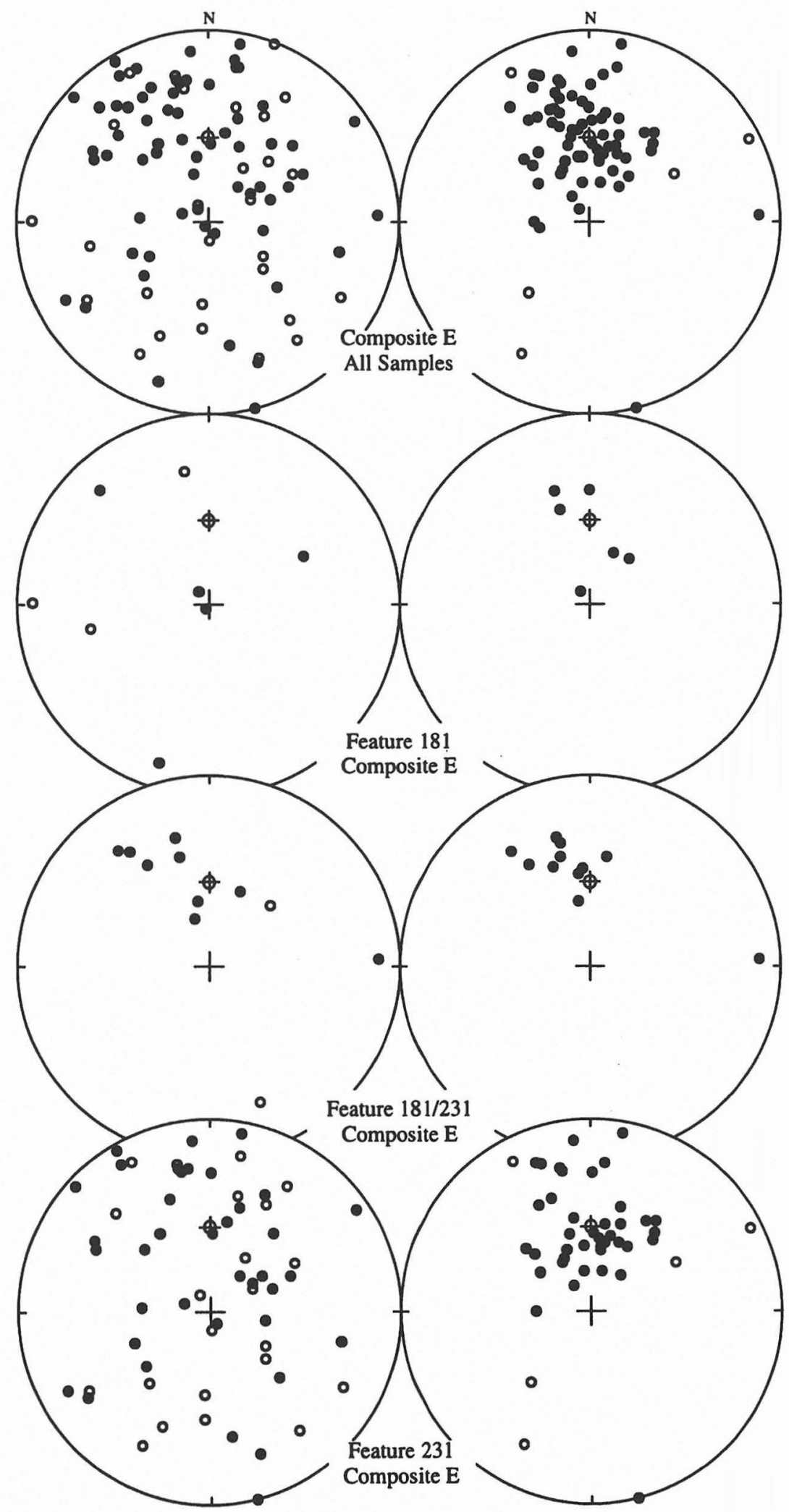

FIGURE 27-65. Stereoplots of results for Composite E, including :subfeatures. 


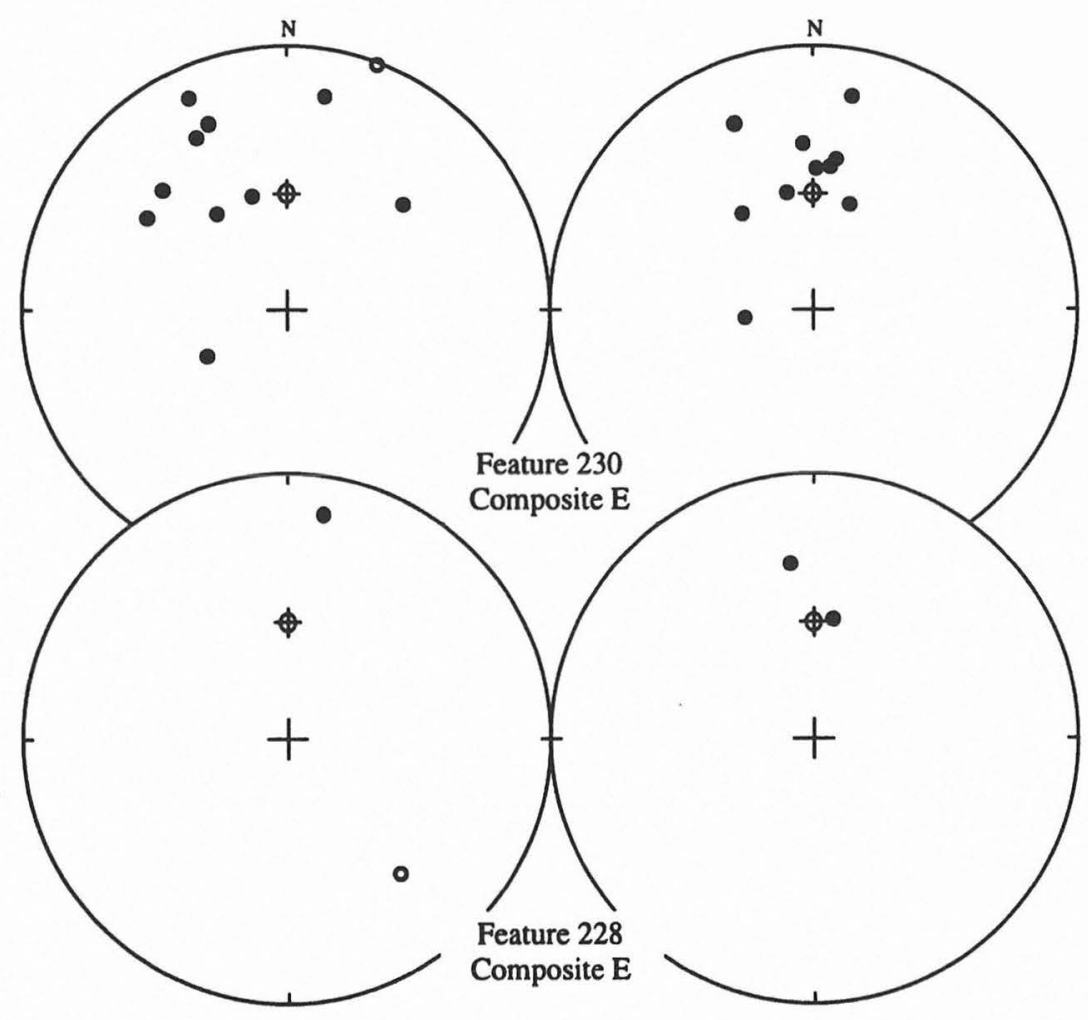

FIGURE 27-66. Stereoplots of results for Composite E subfeatures.

The remainder of the Feature 231 rocks in Composite E are also instructive. Roughly $60 \%$ of the 47 samples analyzed came from rocks that remained in or near their final cooling locations (see Table 27-9). Almost all of these either did not move while cooling from high temperatures or moved only at low temperatures. Only about $25 \%$ moved more than once while cooling. These results indicate that if the Feature 231 rocks were moved, they were most likely moved only after they had cooled considerably.

Some degree of patterning is evident in the distribution of the Feature 231 results in Composite E (see Figure 27-64). Most of the samples in the southern excavation Squares (35, 37 , and 50) were either displaced after cooling or cooled in place from only low temperatures (see Table 27-8). The same is true of those samples from the northern half of Square 52 (see Figure 27-68) and the southern half of Square 28 (Figure 27-70). These latter rocks fall roughly between the potential limits of Feature 181 and the cluster of burned rocks seen in the northwestern quadrant of Square 28, extending somewhat into Square 27 (Figure 27-71). This potential subfeature (not defined or numbered during excavation) includes AM318 and AM-329 (see Figure 27-70), both of which cooled without noticeable movement from temperatures above the Curie point and remained in approximately these positions until excavated. Two of the three samples from the southwestern corner of Square 27 (AM-173 and AM-174; see Figure 27-71) also did not move while cooling but were then displaced after completely cooling. These dislocations were apparently in similar directions and the rocks probably remain somewhat near their final cooling locations.

The other subfeature of note (which also was not defined or numbered in the field) is the arc of larger rocks around the southern and western edges of a mostly rockfree area in Square 26 (see Figure 27-71). All of the six rocks analyzed from this perimeter (including AM-180, which was collected in Square 27) cooled in their find positions only from $300^{\circ} \mathrm{C}$ or less. Five of these (all except AM-142) also yielded three or more components. Along with internal consistency within the samples in terms of vector rotation reconstructions, these results indicate a great deal of movement while cooling from high temperatures. The directions of reconstructed rotations suggests that the rocks may have rotated away from a common point within the void area. This would mean that the rocks began cooling closer together than they were when they finished cooling. Finally, apparent continuity in displacement direction, both during and after cooling, for several samples supports the inference that their low temperature components are valid prehistoric pTRM's rather than modern magnetic overprints.

In summary, the archeomagnetic data from Composite $\mathrm{E}$ confirmed the validity of the Feature 231 subfeatures defined during excavation. Furthermore, the results helped to define additional subareas not identified in the field. The data established that the majority of the rocks either cooled 
TABLE $27-8$

Archeomagnetic Interpretation of Vectoral Data, Composite E

Cooling Context
A cooled in place
B cooled near find position
C out-of-place: cooling location inferred
D out-of-place: unknown cooling orientation
E uncertain / unknown

Lowest Temperature of Movement

* no discernible movement

$\mathrm{X}$ unknown (AF demagnetized)

$\mathrm{V}$ possible viscous magnetization

$\mathrm{L}$ less or equal to $250^{\circ} \mathrm{C}$

$\mathrm{M}$ between $250^{\circ}$ and $450^{\circ} \mathrm{C}$

$\mathrm{H}$ greater than $450^{\circ} \mathrm{C}$

\begin{tabular}{|c|c|c|c|c|c|c|}
\hline Feature No. & Square & Level & $\begin{array}{l}\text { Sample No. } \\
\text { (AM-) }\end{array}$ & $\begin{array}{l}\text { Cooling } \\
\text { Context }\end{array}$ & $\begin{array}{c}\text { Lowest Temperature } \\
\text { of Movement }\end{array}$ & $\begin{array}{c}\text { No. of Discernible } \\
\text { Movements while Cooling }\end{array}$ \\
\hline 228 & 38 & $21 \mathrm{~B}$ & 0339 & see 635 (Tabl & 7-10) & \\
\hline 228 & 38 & 21B & 0340 & A & M & 1 \\
\hline 230 & 39 & 22 & 0617 & A & $\mathrm{X}$ & 1 \\
\hline 230 & 39 & 22 & 0618 & A & $\mathrm{M}-\mathrm{H}$ & 1 \\
\hline 230 & 39 & 22 & 0619 & A & M-H & 1 \\
\hline 230 & 39 & 22 & 0620 & B & * & 0 \\
\hline 230 & 39 & 22 & 0622 & A & $\mathrm{H}$ & 1 \\
\hline 230 & 39 & 22 & 0623 & $\mathrm{C}$ & $\mathrm{X}$ & 1 \\
\hline 230 & 39 & 22-Base & 0699 & $\mathrm{C}$ & * & $0+$ \\
\hline 230 & 39 & 22-Base & 0701 & B & * & $0+$ \\
\hline 230 & 39 & 22-Base & 0703 & A & $\mathrm{X}$ & 1 \\
\hline 230 & 39 & 22-Base & 0704 & A & $\mathrm{X}$ & 1 \\
\hline 181 & 51 & 21 & 0437 & B & M & 2 \\
\hline 181 & 51 & 21 & 0439 & B & M-H & 1 \\
\hline 181 & 51 & 21 & 0442 & A & M-H & 1 \\
\hline 181 & 52 & 22 & 0351 & B & M-H & $1+$ \\
\hline 181 & 52 & 22 & 0353 & B & $\mathrm{L}$ & $2+$ \\
\hline 181 & 52 & 22 & 0354 & $\mathrm{C}$ & * & $0+$ \\
\hline $181 / 231$ & 37 & 21 & 0371 & B & $\mathrm{M}-\mathrm{H}$ & 1 \\
\hline $181 / 231$ & 38 & $21 \mathrm{~A}$ & 0435 & A & $\mathrm{X}$ & 1 \\
\hline $181 / 231$ & 38 & $21 \mathrm{~A}$ & 0436 & D & * & $0+$ \\
\hline $181 / 231$ & 39 & 22 & 0614 & A & $\mathrm{X}$ & 1 \\
\hline $181 / 231$ & 39 & 22-Base & 0708 & B & $*$ & 0 \\
\hline $181 / 231$ & 39 & 22-Base & 0709 & B & * & 0 \\
\hline $181 / 231$ & 39 & 22-Base & 0710 & C & * & 0 \\
\hline $181 / 231$ & 50 & 21 & 0444 & A & $\mathrm{X}$ & 1 \\
\hline $181 / 231$ & 50 & 21 & 0445 & $\mathrm{C}$ & * & 0 \\
\hline $181 / 231$ & 52 & 22 & 0342 & A & M & 1 \\
\hline $181 / 231$ & 52 & 22 & 0348 & A & $*$ & $0+$ \\
\hline 231 & 26 & 21 & 0142 & B & $\mathrm{L}$ & 1 \\
\hline 231 & 26 & 21 & 0144 & A & $\mathrm{L}$ & 2 \\
\hline 231 & 26 & 21 & 0146 & B & L-M & 2 \\
\hline 231 & 26 & 21 & 0147 & A & $\mathrm{L}$ & 2 \\
\hline 231 & 26 & 21 & 0148 & B & L-M & 2 \\
\hline 231 & 27 & 21 & 0172 & A & L & $1+$ \\
\hline 231 & 27 & 21 & 0173 & D & * & $0+$ \\
\hline 231 & 27 & 21 & 0174 & D & * & 0 \\
\hline 231 & 27 & 21 & 0176 & D & L-M & $1+$ \\
\hline 231 & 27 & 21 & 0177 & B & $\mathrm{X}$ & 1 \\
\hline 231 & 27 & 21 & 0179 & E & $\mathrm{L}$ & $1+$ \\
\hline 231 & 27 & 21 & 0180 & A & L-M & 2 \\
\hline 231 & 27 & 21 & 0181 & A & L & 1 \\
\hline 231 & 28 & 21 & 0316 & D & $\mathrm{L}$ & 1 \\
\hline 231 & 28 & 21 & 0318 & B & * & $0+$ \\
\hline 231 & 28 & 21 & 0320 & B & $\mathrm{L}$ & 1 \\
\hline 231 & 28 & 21 & 0321 & B & $\mathrm{X}$ & 1 \\
\hline 231 & 28 & 21 & 0323 & B & $\mathrm{L}$ & 3 \\
\hline 231 & 28 & 21 & 0325 & A & $\mathrm{L}$ & 3 \\
\hline 231 & 28 & 21 & 0326 & D & X & $1+$ \\
\hline 231 & 28 & 21 & 0329 & B & $*$ & $0+$ \\
\hline
\end{tabular}


Table 27-8, continued

\begin{tabular}{|c|c|c|c|c|c|c|}
\hline Feature No. & Square & Level & $\begin{array}{l}\text { Sample No. } \\
\text { (AM- ) }\end{array}$ & $\begin{array}{l}\text { Cooling } \\
\text { Context }\end{array}$ & $\begin{array}{c}\text { Lowest Temperature } \\
\text { of Movement }\end{array}$ & $\begin{array}{c}\text { No. of Discernible } \\
\text { Movements while Cooling }\end{array}$ \\
\hline 231 & 35 & 21 & 0355 & B & L-M & $2+$ \\
\hline 231 & 35 & 21 & 0357 & $\mathrm{~A}$ & L-M & 1 \\
\hline 231 & 35 & 21 & 0360 & B & L-M & 1 \\
\hline 231 & 35 & 21 & 0361 & $\mathrm{D}$ & $*$ & $0+$ \\
\hline 231 & 35 & 21 & 0362 & B & * & $0+$ \\
\hline 231 & 37 & 21 & 0368 & B & L-M & $1+$ \\
\hline 231 & 37 & 21 & 0369 & $\mathrm{C}$ & $X$ & $2+$ \\
\hline 231 & 37 & 21 & 0372 & D & $*$ & 0 \\
\hline 231 & 37 & 21 & 0375 & $\mathrm{C}$ & $\mathrm{X}$ & 1 \\
\hline 231 & 37 & 21 & 0376 & B & $\mathrm{L}$ & 2 \\
\hline 231 & 38 & $21 \mathrm{~A}$ & 0425 & $\mathrm{D}$ & $*$ & $0+$ \\
\hline 231 & 38 & $21 \mathrm{~A}$ & 0427 & B & M & $1+$ \\
\hline 231 & 38 & $21 \mathrm{~A}$ & 0428 & A & $\mathrm{X}$ & 1 \\
\hline 231 & 38 & $21 \mathrm{~A}$ & 0430 & $\mathrm{C}$ & M & 1 \\
\hline 231 & 38 & $21 \mathrm{~A}$ & 0432 & B & $*$ & 0 \\
\hline 231 & 38 & $21 \mathrm{~A}$ & 0434 & B & $*$ & $0+$ \\
\hline 231 & 39 & 22 & 0624 & $\mathrm{~B}$ & $\mathrm{~L}$ & $2-3$ \\
\hline 231 & 39 & 22 & 0625 & $\mathrm{~A}$ & $X$ & $1+$ \\
\hline 231 & 39 & 22 & 0626 & $\mathrm{C}$ & $*$ & 0 \\
\hline 231 & 39 & 22 & 0628 & $\mathrm{D}$ & $*$ & $0+$ \\
\hline 231 & 39 & 22-Base & 0706 & $\mathrm{C}$ & $*$ & 0 \\
\hline 231 & 39 & 22-Base & 0707 & D & $*$ & $0+$ \\
\hline 231 & 52 & 22 & 0343 & B & * & 0 \\
\hline 231 & 52 & 22 & 0344 & A & $\mathrm{L}$ & 2 \\
\hline 231 & 52 & 22 & 0347 & $\mathrm{C}$ & $*$ & 0 \\
\hline 231 & 52 & 22 & 0349 & $\mathrm{E}$ & $?$ & $?$ \\
\hline
\end{tabular}

TABLE 27-9

Summary of Archeomagnetic Results for Composite E

\begin{tabular}{|c|c|c|c|c|c|c|c|c|c|c|c|c|c|c|}
\hline \multirow[b]{2}{*}{ Feature } & \multicolumn{5}{|c|}{ Cooling Context } & \multicolumn{5}{|c|}{ Lowest Temperature of Movement } & \multicolumn{4}{|c|}{ Maximum Number of Movements } \\
\hline & $\mathrm{A}$ & $\mathrm{B}$ & $\mathrm{C}$ & $\mathrm{D}$ & $\mathrm{E}$ & $*$ & $\begin{array}{c}\text { L or L- } \\
M\end{array}$ & $\begin{array}{l}\mathrm{M} \text { or } \\
\mathrm{M}-\mathrm{H}\end{array}$ & $\mathrm{H}$ & $\mathrm{X}$ & 0 & $\begin{array}{c}1,1+, \text { or } \\
1-2\end{array}$ & $\begin{array}{l}2,2+, \\
\text { or } 2-3\end{array}$ & $\begin{array}{l}3 \text { or } \\
\text { more }\end{array}$ \\
\hline 181 & 1 & 4 & 1 & & & 1 & 1 & 4 & & & 1 & 3 & 2 & \\
\hline $181 / 231$ & 5 & 3 & 2 & 1 & & 6 & & 2 & & 3 & 6 & 5 & & \\
\hline 231 & 10 & 19 & 6 & 10 & 2 & 16 & 20 & 2 & & 7 & 16 & 17 & 10 & 2 \\
\hline 230 & 6 & 2 & 2 & & & 3 & & 2 & 1 & 4 & 3 & 7 & & \\
\hline 228 & 1 & 1 & & & & & & 1 & & 1 & & 2 & & \\
\hline
\end{tabular}

without any movement from very high temperatures or were moved only after cooling to about $250^{\circ} \mathrm{C}$. Furthermore, with the exception of those in Square 26, few of the rocks in Composite $\mathrm{E}$ evidence more than one displacement while cooling. What behaviors or uses such patterns represent is unclear but whatever the rocks were being used for prehistorically, it does not seem to have required moving them much while they were hot.

\section{Feature 231, Composite F: East and South Blocks, Levels 22/23}

Composite F (Figure 27-72) depicts Feature 231 burned rocks exposed at elevations of ca. 95.75 - 95.70 $\mathrm{m}$ in Levels 22 and 23 (East Block and eastern end of South Block). Inspection of this composite demonstrates that, while discrete, individual subfeatures continued to coalesce in the southern end of Feature 231, in the northern area (especially Square 28 and the western half of Square 52), the distribution of burned rocks remained largely undifferentiated. Table 27-10 lists the archeomagnetic determinations of the analyzed rocks shown on Composite F while Table 27-11 summarizes these findings by subfeature designation. The stereonet plots of the Composite F, results are given in Figures 27-73 and 27-74.

Much of Feature 181 was previously excavated in TxDOT Square E28/S78, but its northern and eastern margins extended into the area excavated by TARL (see Chapter 26). 


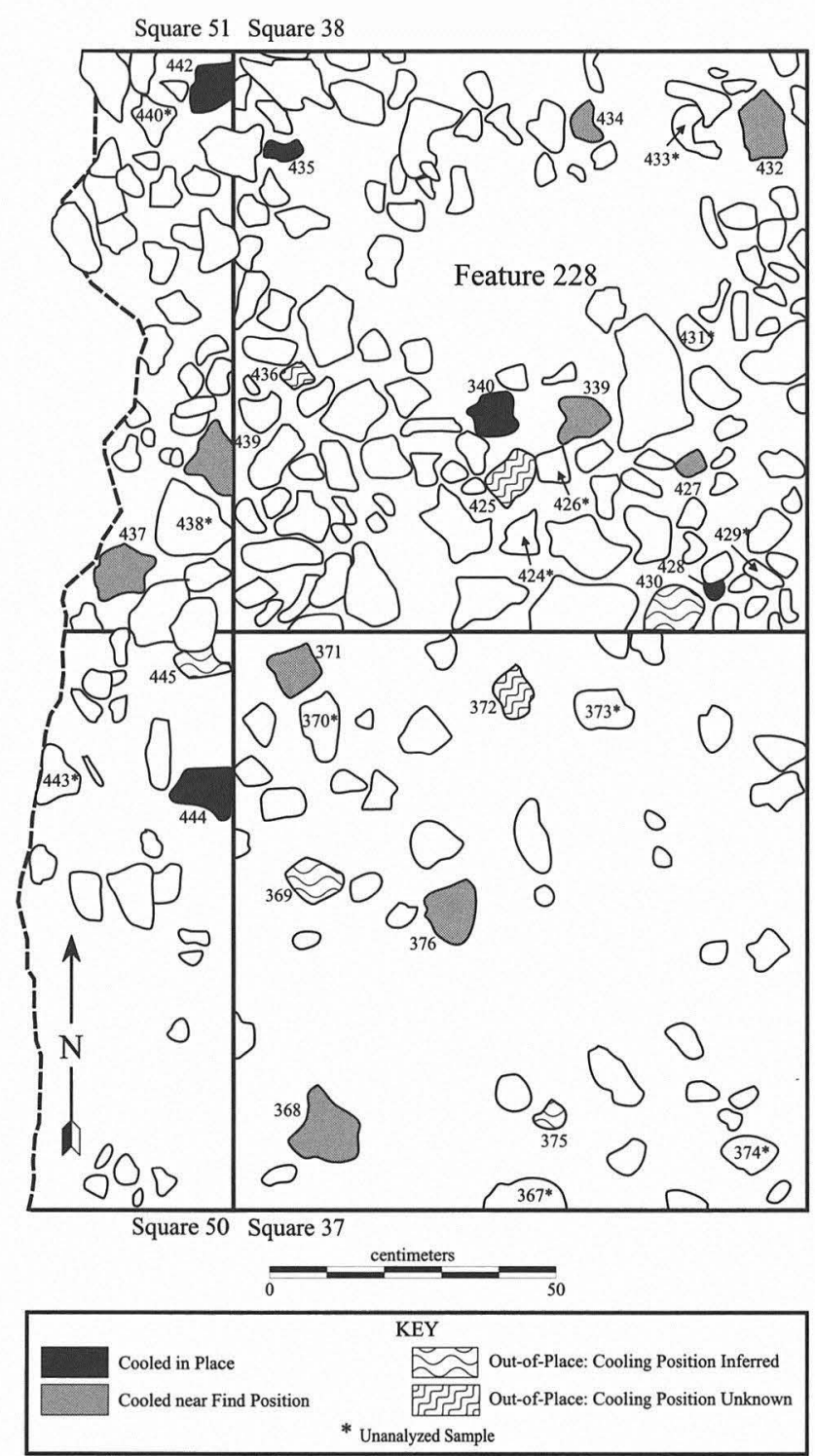

FIGURE 27-67. Detail of Composite E: Squares 37, 38, 50, and 51, Level 21 (ca. $95.80 \mathrm{~m}$ ), including Feature 228.

The eastern edge of Feature 181 (the curving arc of rocks in the western half of Square 38 and adjacent squares) can be clearly seen in Figure 27-72; as can a moderately dense scatter of rocks spread across much of Square 38. Feature 181 entirely covered Square 51, and it extended into the north end of Square 50, the northeast corner of Square 37, the west edge of Square 38, the southwest corner of Square 39, and the south half of Square 52. The curving northeastern perimeter of Feature 181 (seen in the southeast corner of Square 52 ) blends into a more undifferentiated, higher-density zone of burned rocks in the west half of Square 52 .

More than half of the analyzed rocks within the limits of Feature 181 had a single component of magnetization (see Tables 27-10 and 27-11). Again, this means that they were heated to temperatures in excess of the Curie point and allowed to cool completely with little or no disturbance. Less

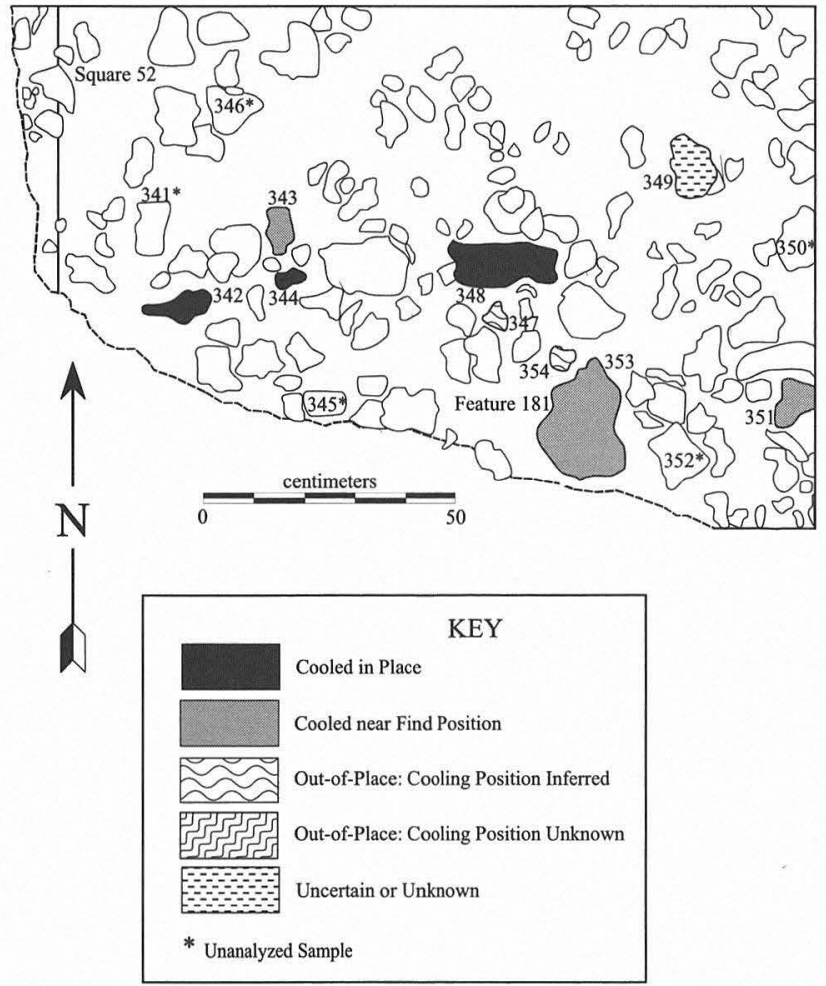

FIGURE 27-68. Detail of Composite E: Squares 52 and 53, Level 22 (ca. $95.75 \mathrm{~m}$ ).

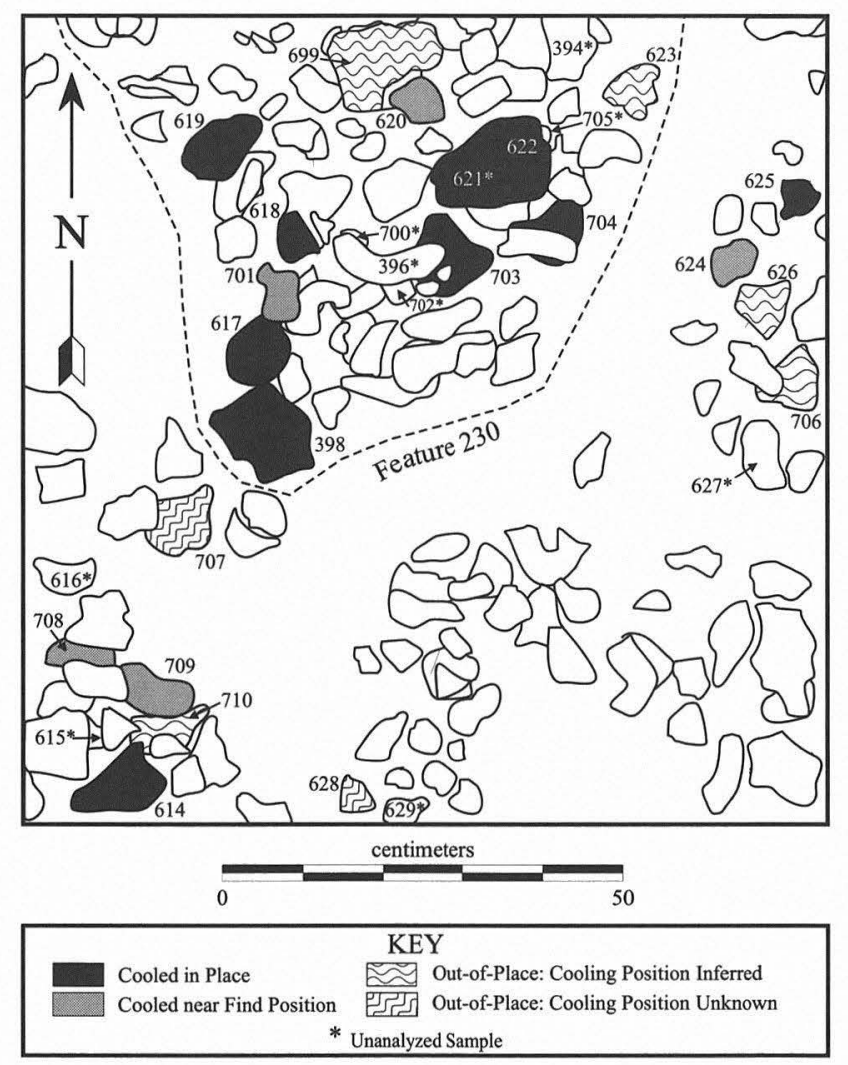

FIGURE 27-69. Detail of Composite E: Feature 230 in Square 39, Level 22 (ca. $95.75 \mathrm{~m}$ ). 


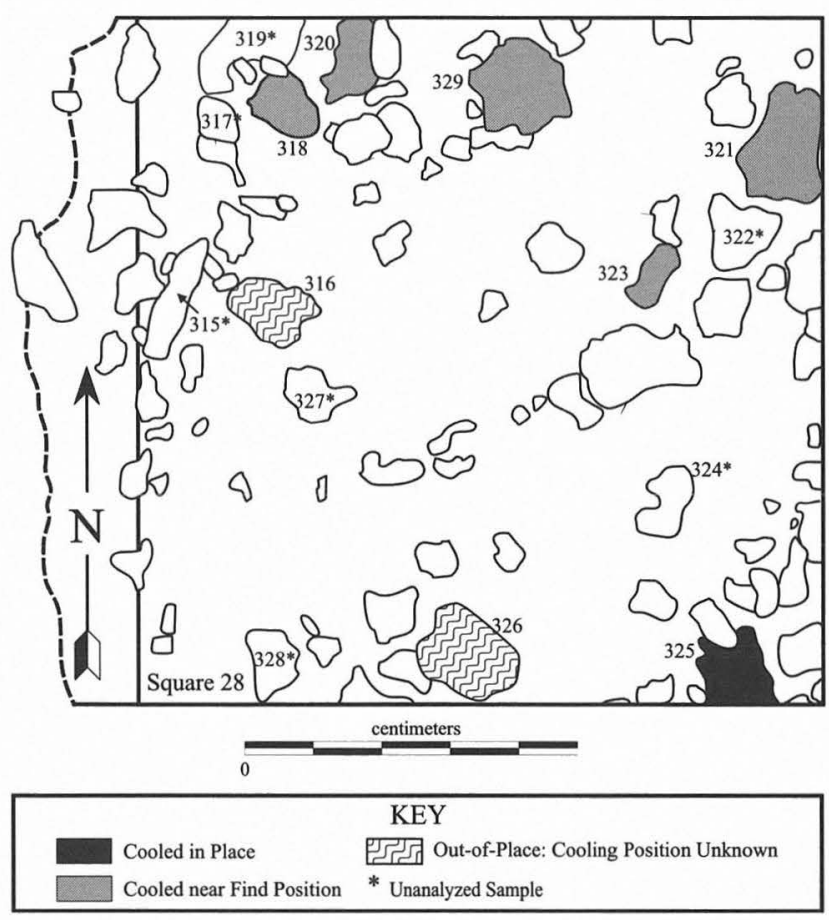

FIGURE 27-70. Detail of Composite E: Squares 28 and 44, Level 21 (ca. $95.75 \mathrm{~m}$ ).

than $10 \%$ ( 3 of 35 ) of the analyzed rocks were moved more than once while cooling (see Table 27-11). Moreover, almost $80 \%$ of the rocks examined were found to be in or near the positions in which they last cooled (A- or B-category samples, see Table 27-11; see also Figure 27-73). Most of the analyzed rocks along the outer edge of Feature 181 moved slightly after they finished cooling but nevertheless remained quite near their final cooling locations (see ring of blue rocks in Figure 27-72). Many of the smaller rocks just inside this outer edge moved little, if at all, after they were completely cooled (see those shown in red in Figure 27-72). Several rocks from the interior of Feature 181 were displaced after cooling, but their prior locations can be inferred with some confidence (i.e., the green rocks in Figure 27-72).

Results from rocks surrounding, but less certainly associated with, Feature 181 (listed as 181/231 on Tables 27-10 and 27-11) are nearly identical to those from within it with the exception that a somewhat greater number were dislocated after cooling (Figures 27-75 and 27-76). Nevertheless, two-thirds of the analyzed rocks cooled in or near the positions in which they were recovered (see Figure 27-73 and Table 27-11). Again, about one-half had a single TRM vector and only 1 of 26 had three or more components. Interestingly, adjacent, single-component rocks AM-718 and AM719 (see Figure 27-75) seem to have experienced nearly the same postcooling displacement: their final measured remanence directions were nearly identical.

The base of Feature 230 was encountered in Square 39 at this elevation (Figure 27-77). Both of the rocks analyzed

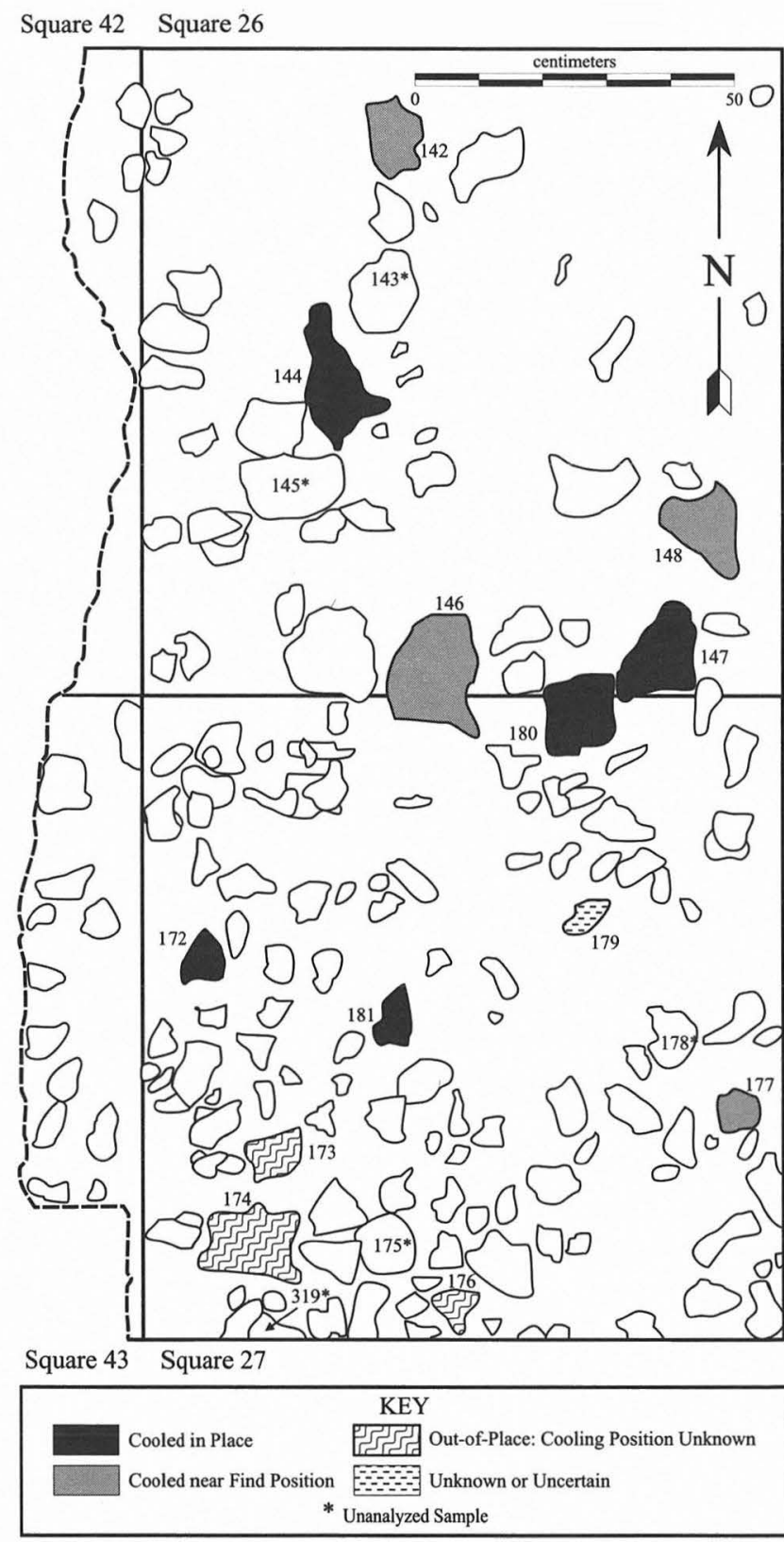

FiguRE 27-71. Detail of Composite E: Squares 26, 27, 42, and 43, Level 21 (ca. $95.75 \mathrm{~m}$ ).

from the bottom of this basin-shaped feature (AM-906 and AM-907) moved at least twice while cooling before finally coming to rest at low to moderate temperatures (see Figure 27-74). There is inconclusive evidence from vector rotation reconstruction that AM-906 was displaced toward the center of Feature 230 while cooling.

The rocks that could not be definitively associated with a particular subfeature were clearly the most disturbed relative to their final cooling positions (listed simply as " 231 " on Tables 27-10 and 27-11). In fact, only 8 of the 29 analyzed rocks were found to be in or near their final cooling positions (see Figure 27-73). However, as with many of the other 


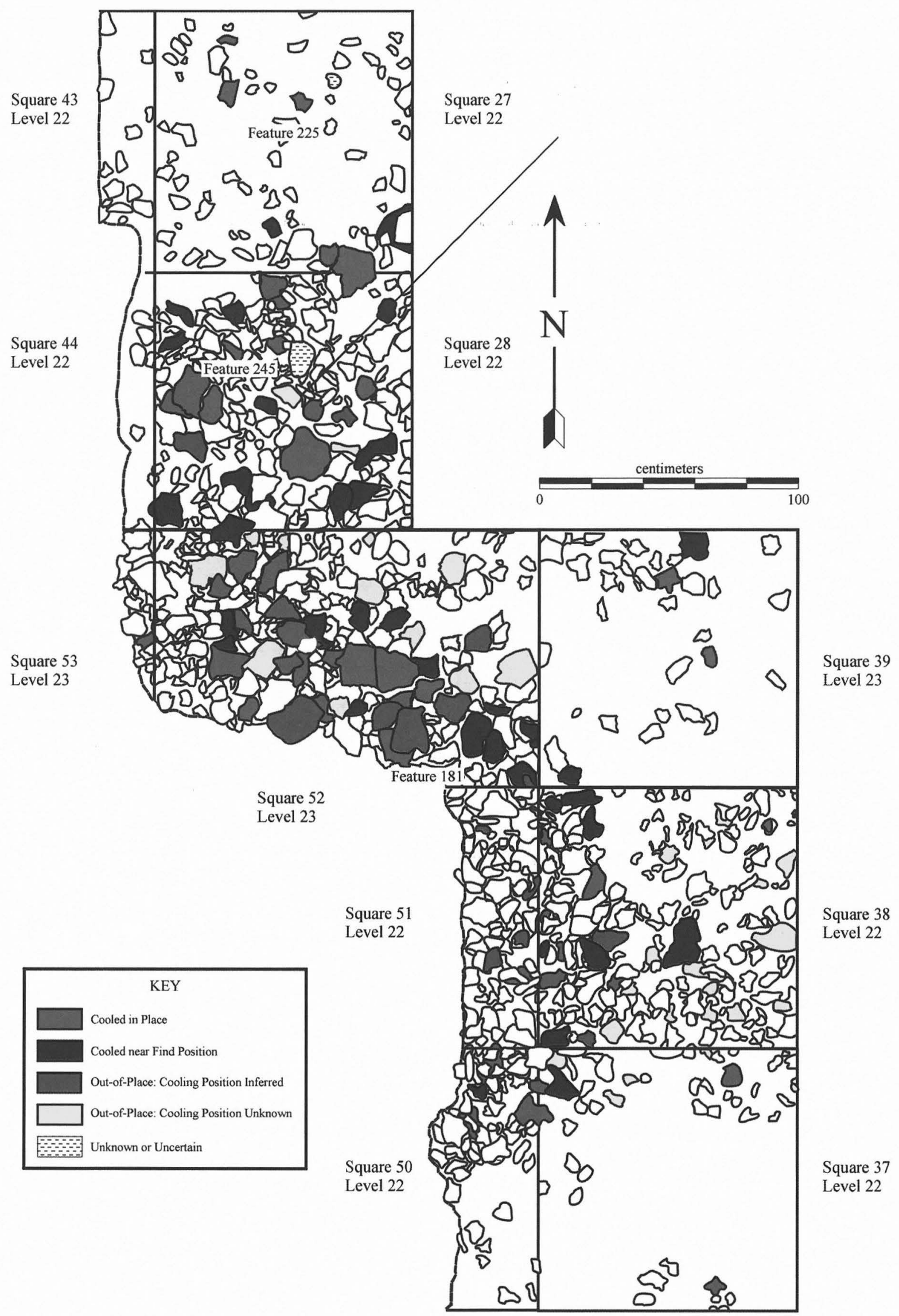

FIGURE 27-72. Feature 231 and associated subfeatures, Composite F: East and South Blocks, Levels 22 and 23 (ca. 95.75 - 95.70 m). 
TABLE $27-10$

Archeomagnetic Interpretation of Vectoral Data, Composite F

Cooling Context

A cooled in place

B cooled near find position

C out-of-place: cooling location inferred

D out-of-place: unknown cooling orientation

E uncertain / unknown
Lowest Temperature of Movement

* no discernible movement

$\mathrm{X}$ unknown (AF demagnetized)

$\mathrm{V}$ possible viscous magnetization

$\mathrm{L}$ less or equal to $250^{\circ} \mathrm{C}$

$\mathrm{M}$ between $250^{\circ}$ and $450^{\circ} \mathrm{C}$

$\mathrm{H}$ greater than $450^{\circ} \mathrm{C}$

\begin{tabular}{|c|c|c|c|c|c|c|}
\hline Feature No. & Square & Level & $\begin{array}{l}\text { Sample No. } \\
\text { (AM-) }\end{array}$ & $\begin{array}{l}\text { Cooling } \\
\text { Context }\end{array}$ & $\begin{array}{c}\text { Lowest Temperature } \\
\text { of Movement }\end{array}$ & $\begin{array}{c}\text { No. of Discernible } \\
\text { Movements while Cooling }\end{array}$ \\
\hline 225 & 27 & 22 & 0264 & $\mathrm{~A}$ & $\mathrm{~L}$ & 3 \\
\hline 225 & 27 & 22 & 0266 & A & L-M & 2 \\
\hline 225 & 27 & 22 & 0267 & E & $\mathrm{L}$ & $0+$ \\
\hline 225 & 27 & 22 & 0270 & B & M & $1+$ \\
\hline $231 / 225$ & 27 & 24 & 0499 & A & $*$ & $0+$ \\
\hline 230 & 39 & 23 & 0906 & B & M & 2 \\
\hline 230 & 39 & 23 & 0907 & A & $\mathrm{L}$ & 2 \\
\hline 181 & 38 & 22 & 0603 & $\mathrm{C}$ & $\mathrm{X}$ & 1 \\
\hline 181 & 38 & 22 & 0604 & B & * & $0+$ \\
\hline 181 & 38 & 22 & 0637 & $\mathrm{C}$ & $\mathrm{X}$ & 1 \\
\hline 181 & 38 & 22 & 0638 & B & M & 2 \\
\hline 181 & 38 & 22 & 0640 & A & * & 0 \\
\hline 181 & 38 & 22 & 0643 & B & * & 0 \\
\hline 181 & 38 & 22 & 0644 & B & $*$ & 0 \\
\hline 181 & 38 & 22-Base & 0711 & $\mathrm{~B}$ & $*$ & 0 \\
\hline $\begin{array}{l}101 \\
181\end{array}$ & $\begin{array}{l}30 \\
38\end{array}$ & 22-Base & 0712 & A & * & 0 \\
\hline $\begin{array}{l}101 \\
181\end{array}$ & $\begin{array}{l}30 \\
38\end{array}$ & 22-Base & 0714 & A & * & $0+$ \\
\hline 181 & 38 & 22-Base & 0715 & A & $*$ & 0 \\
\hline 181 & 38 & 22-Base & 0716 & B & $\mathrm{X}$ & 1 \\
\hline 181 & $\begin{array}{l}30 \\
38\end{array}$ & 22-Base & 0720 & A & * & 0 \\
\hline 181 & 39 & 23 & 0871 & B & M & 2 \\
\hline 181 & 50 & 22 & 0755 & A & $\mathrm{X}$ & 1 \\
\hline 181 & 50 & 22 & 0756 & A & L-M & 2 \\
\hline 181 & 50 & 22 & 0757 & A & $*$ & $0+$ \\
\hline 181 & 50 & 22 & 0758 & $\mathrm{D}$ & * & $0+$ \\
\hline 181 & 51 & 22-Base & 0751 & $\mathrm{C}$ & * & 0 \\
\hline 181 & 51 & 22-Base & 0753 & A & $\mathrm{H}$ & 1 \\
\hline 181 & 52 & 22 & 0351 & $\mathrm{~B}$ & M-H & $1+$ \\
\hline 181 & 52 & 22 & 0354 & $\mathrm{C}$ & $*$ & $0+$ \\
\hline 181 & 52 & 23-Middle & 0549 & $\mathrm{C}$ & $\mathrm{X}$ & 1 \\
\hline 181 & 52 & 23-Middle & 0550 & B & * & $0+$ \\
\hline 181 & 52 & 23-Middle & 0556 & A & $\mathrm{X}$ & 1 \\
\hline 181 & 52 & 23 & 0588 & $\mathrm{C}$ & * & 0 \\
\hline 181 & 52 & 23 & 0698 & B & $\mathrm{L}$ & $1-2$ \\
\hline 181 & 52 & 23 & 0836 & A & * & 0 \\
\hline 181 & 52 & 23 & 0843 & $\begin{array}{l}\mathrm{A} \\
\mathrm{B}\end{array}$ & * & 0 \\
\hline 181 & 52 & 23 & 0844 & A & $\mathrm{X}$ & 1 \\
\hline 181 & 52 & 23 & 0846 & B & $\mathrm{M}$ & 1 \\
\hline $\begin{array}{l}101 \\
181\end{array}$ & 52 & 23-Base & $\begin{array}{l}0909 \\
0909\end{array}$ & A & 然 & 0 \\
\hline 181 & 52 & 23-Base & 0910 & $\mathrm{C}$ & * & 0 \\
\hline 181 & 52 & 23-Base & 0912 & B & M & $1+$ \\
\hline 181 & 52 & 23-Base & 0914 & $\mathrm{~B}$ & $*$ & 0 \\
\hline $\begin{array}{c}181 \\
181 / 231\end{array}$ & 37 & 22 & 0457 & $\begin{array}{l}\mathrm{B} \\
\mathrm{B}\end{array}$ & $\mathrm{H}$ & 1 \\
\hline $181 / 231$ & 37 & 22-Base & 0760 & $\mathrm{E}$ & $\mathrm{X}$ & $1+$ \\
\hline $181 / 231$ & 38 & 22-Base & 0717 & A & $\mathrm{X}$ & 1 \\
\hline $181 / 231$ & 38 & 22-Base & 0718 & D & $\hat{*}$ & $0+$ \\
\hline $181 / 231$ & 38 & 22-Base & 0719 & $\begin{array}{l}\mathrm{D} \\
\mathrm{D}\end{array}$ & * & 0 \\
\hline $181 / 231$ & 50 & 21 & 0444 & A & $\mathrm{X}$ & 1 \\
\hline $181 / 231$ & 51 & 22 & 0582 & C & $*$ & $0+$ \\
\hline $181 / 231$ & 51 & 22 & 0584 & $\mathrm{C}$ & * & $0+$ \\
\hline $181 / 231$ & 51 & 22 & 0586 & $\mathrm{C}$ & * & $0+$ \\
\hline $181 / 231$ & 52 & 21 & 0216 & B & L-M & 2 \\
\hline $181 / 231$ & 52 & 21 & 0217 & B & M & $1+$ \\
\hline $181 / 231$ & 52 & 22 & 0342 & A & M & 1 \\
\hline $181 / 231$ & 52 & 22 & 0348 & A & $*$ & $0+$ \\
\hline $181 / 231$ & 52 & 23-Middle & 0539 & B & * & $0+$ \\
\hline $181 / 231$ & 52 & 23-Middle & 0540 & $\mathrm{C}$ & $\mathrm{X}$ & 1 \\
\hline $181 / 231$ & 52 & 23-Middle & 0541 & A & M & 1 \\
\hline
\end{tabular}


Table 27-10, continued

\begin{tabular}{|c|c|c|c|c|c|c|}
\hline Feature No. & Square & Level & $\begin{array}{l}\text { Sample No. } \\
\text { (AM-) }\end{array}$ & $\begin{array}{l}\text { Cooling } \\
\text { Context }\end{array}$ & $\begin{array}{c}\text { Lowest Temperature } \\
\text { of Movement }\end{array}$ & $\begin{array}{c}\text { No. of Discernible } \\
\text { Movements while Cooling }\end{array}$ \\
\hline $181 / 231$ & 52 & 23-Middle & 0544 & $\mathrm{~A}$ & $\mathrm{X}$ & 1 \\
\hline $181 / 231$ & 52 & 23-Middle & 0546 & $\mathrm{C}$ & $\mathrm{X}$ & 1 \\
\hline $181 / 231$ & 52 & 23-Middle & 0557 & B & $\mathrm{X}$ & $1+$ \\
\hline $181 / 231$ & 52 & 23-Middle & 0559 & D & X & 1 \\
\hline $181 / 231$ & 52 & 23 & 0822 & B & $\mathrm{X}$ & 1 \\
\hline $181 / 231$ & 52 & 23 & 0823 & A & L-M & 1 \\
\hline $181 / 231$ & 52 & 23 & 0835 & A & $*$ & 0 \\
\hline $181 / 231$ & 52 & 23 & 0838 & A & $*$ & $0+$ \\
\hline $181 / 231$ & 52 & 23 & 0839 & B & * & $0+$ \\
\hline $181 / 231$ & 52 & 23 & 0840 & B & $*$ & $0+$ \\
\hline $181 / 231$ & 52 & 23 & 0841 & D & $*$ & 0 \\
\hline 231 & 37 & 22 & 0459 & D & M & $1+$ \\
\hline 231 & 37 & 22 & 0461 & A & $\mathrm{L}$ & $2+$ \\
\hline 231 & 37 & 22 & 0463 & D & * & $0+$ \\
\hline 231 & 37 & 22 & 0464 & $\mathrm{~A}$ & $\mathrm{~L}$ & 2 \\
\hline 231 & 37 & 22-Base & 0761 & D & * & 0 \\
\hline 231 & 37 & 22-Base & 0762 & D & $\mathrm{X}$ & 1 \\
\hline 231 & 38 & 22 & 0632 & $\mathrm{D}$ & $*$ & 0 \\
\hline 231 & 38 & 22 & 0633 & D & * & 0 \\
\hline 231 & 38 & 22 & 0635 & B & $\mathrm{X}$ & 1 \\
\hline 231 & 38 & 22 & 0636 & D & * & $0+$ \\
\hline 231 & 38 & 22 & 0645 & D & $*$ & $0+$ \\
\hline 231 & 38 & 22-Base & 0721 & D & $*$ & 0 \\
\hline 231 & 38 & 22-Base & 0722 & D & $*$ & $0+$ \\
\hline 231 & 38 & 22-Base & 0723 & $\mathrm{D}$ & $\mathrm{X}$ & 1 \\
\hline 231 & 38 & 22-Base & 0730 & $\mathrm{D}$ & $*$ & $0+$ \\
\hline 231 & 38 & 22-Base & 0731 & $\mathrm{D}$ & $*$ & $0+$ \\
\hline 231 & 38 & 22-Base & 0732 & A & * & $0+$ \\
\hline 231 & 38 & 22-Base & 0733 & D & * & 0 \\
\hline 231 & 38 & 22-Base & 0734 & $\mathrm{D}$ & $*$ & $0+$ \\
\hline 231 & 38 & 22-Base & 0735 & $\mathrm{D}$ & $X$ & 1 \\
\hline 231 & 39 & 23 & 0904 & $\mathrm{~A}$ & $*$ & 0 \\
\hline 231 & 50 & 22 & 0569 & B & $X$ & 1 \\
\hline 231 & 52 & 23-Middle & 0553 & D & * & $0+$ \\
\hline 231 & 52 & 23-Middle & 0554 & $\mathrm{C}$ & M & 2 \\
\hline 231 & 52 & 23-Middle & 0555 & D & $\mathrm{X}$ & 1 \\
\hline 231 & 52 & 23-Middle & 0562 & $\mathrm{D}$ & $\mathrm{X}$ & 1 \\
\hline 231 & 52 & 23-Middle & 0563 & D & $X$ & 2 \\
\hline 231 & 52 & 23 & 0842 & $\mathrm{D}$ & $*$ & 0 \\
\hline 231 & 53 & 23-Middle & 0532 & A & $*$ & 0 \\
\hline $231 / 245$ & 27 & 22 & 0308 & A & $\mathbf{H}$ & 1 \\
\hline $231 / 245$ & 27 & 24 & 0500 & B & $*$ & 0 \\
\hline $231 / 245$ & 27 & 24 & 0501 & A & * & 0 \\
\hline $231 / 245$ & 28 & 22-Middle & 0508 & $\mathrm{E}$ & L & 1 \\
\hline $231 / 245$ & 28 & 22-Middle & 0509 & $\mathrm{~B}$ & $\mathrm{M}$ & 2 \\
\hline $231 / 245$ & 28 & 22-Middle & 0510 & D & $\mathrm{X}$ & $1+$ \\
\hline $231 / 245$ & 28 & 22-Middle & 0512 & $\mathrm{C}$ & $*$ & $0+$ \\
\hline $231 / 245$ & 28 & 22-Middle & 0513 & A & L-M & 2 \\
\hline $231 / 245$ & 28 & 22-Middle & 0515 & B & L-M & 2 \\
\hline $231 / 245$ & 28 & 22-Middle & 0518 & $\mathrm{~B}$ & $*$ & 0 \\
\hline $231 / 245$ & 28 & 22-Middle & 0519 & B & L-M & 2 \\
\hline $231 / 245$ & 28 & 22-Middle & 0521 & B & $\mathrm{L}$ & $1+$ \\
\hline $231 / 245$ & 28 & 22-Middle & 0522 & $\mathrm{C}$ & $X$ & 1 \\
\hline $231 / 245$ & 28 & 22 & 0791 & A & $*$ & 0 \\
\hline $231 / 245$ & 28 & 22 & 0793 & B & $X$ & 1 \\
\hline $231 / 245$ & 28 & 22 & 0794 & $\mathrm{D}$ & L-M & $2-3$ \\
\hline $231 / 245$ & 28 & 22 & 0795 & A & M & 2 \\
\hline $231 / 245$ & 28 & 22 & 0801 & $\mathrm{~B}$ & $*$ & 0 \\
\hline $231 / 245$ & 28 & 22 & 0803 & B & M & 1 \\
\hline $231 / 245$ & 28 & 22 & 0805 & $\mathrm{~B}$ & L-M & 2 \\
\hline $231 / 245$ & 52 & 23-Middle & 0537 & A & $\mathrm{X}$ & 2 \\
\hline $231 / 245$ & 52 & 23 & 0826 & D & * & 0 \\
\hline $231 / 245$ & 52 & 23 & 0829 & $\mathrm{~A}$ & L-M & 2 \\
\hline $231 / 245$ & 52 & 23 & 0830 & $\mathrm{D}$ & $\mathrm{M}$ & 1 \\
\hline $231 / 245$ & 52 & 23 & 0832 & $\mathrm{~A}$ & $\mathrm{M}-\mathrm{H}$ & 1 \\
\hline $231 / 245$ & 52 & 23 & 0833 & $\mathrm{~A}$ & $*$ & 0 \\
\hline $231 / 245$ & 52 & 23 & 0834 & B & $\mathrm{H}$ & $1+$ \\
\hline
\end{tabular}


Table 27-10, continued

\begin{tabular}{|c|c|c|c|c|c|c|}
\hline Feature No. & Square & Level & $\begin{array}{l}\text { Sample No. } \\
\text { (AM- ) }\end{array}$ & $\begin{array}{l}\text { Cooling } \\
\text { Context }\end{array}$ & $\begin{array}{c}\text { Lowest Temperature } \\
\text { of Movement }\end{array}$ & $\begin{array}{c}\text { No. of Discernible } \\
\text { Movements while Cooling }\end{array}$ \\
\hline 245 & 28 & 22-Middle & 0502 & $\mathrm{~A}$ & * & 0 \\
\hline 245 & 28 & 22-Middle & 0503 & B & * & $0+$ \\
\hline 245 & 28 & 22-Middle & 0504 & B & * & 0 \\
\hline 245 & 28 & 22-Middle & 0505 & A & * & $0+$ \\
\hline 245 & 28 & 22-Middle & 0506 & A & M-H & 1 \\
\hline 245 & 28 & 22-Middle & 0524 & A & $\mathrm{H}$ & 1 \\
\hline 245 & 28 & 22-Middle & 0525 & B & $*$ & $0+$ \\
\hline 245 & 28 & 22 & 0787 & A & $\mathrm{L}$ & 1 \\
\hline 245 & 28 & 22 & 0788 & A & * & 0 \\
\hline 245 & 28 & 22 & 0789 & $\mathrm{~A}$ & * & 0 \\
\hline 245 & 28 & 22 & 0797 & B & * & $0+$ \\
\hline \multicolumn{7}{|c|}{ Illustrated but not included on Composite F (see Figure 27-72): } \\
\hline 231 & 33 & 22 & 0364 & B & L-M & $2-3$ \\
\hline 231 & 33 & 22 & 0365 & $\mathrm{C}$ & $*$ & 0 \\
\hline 231 & 33 & 22 & 0366 & B & M & 2 \\
\hline \multicolumn{7}{|l|}{ Not Illustrated: } \\
\hline 231 & 25 & 22 & 0231 & A & $\mathrm{X}$ & $1+$ \\
\hline 231 & 25 & 22 & 0232 & B & L-M & 1 \\
\hline 231 & 25 & 22 & 0233 & C & L & 1 \\
\hline 231 & 25 & 22 & 0235 & D & $\mathrm{X}$ & 1 \\
\hline 231 & 26 & 22 & 0182 & $\mathrm{E}$ & $\mathrm{X}$ & $1+$ \\
\hline 231 & 26 & 22 & 0184 & $\mathrm{D}$ & $\mathrm{H}$ & 1 \\
\hline 231 & 26 & 22 & 0185 & $\mathrm{D}$ & L & $2+$ \\
\hline 231 & 26 & 22 & 0186 & $\mathrm{C}$ & * & 0 \\
\hline 231 & 26 & 22 & 0187 & $\mathrm{D}$ & $*$ & $0+$ \\
\hline 231 & 26 & 22 & 0189 & $\mathrm{D}$ & $\mathrm{L}$ & 1 \\
\hline 231 & 26 & 22 & 0191 & D & $\mathrm{X}$ & 1 \\
\hline & 34 & 22 & 0480 & D & $\mathrm{X}$ & $1+$ \\
\hline & 34 & 22 & 0481 & $\mathrm{E}$ & $?$ & ? \\
\hline & 34 & 22 & 0482 & A & $\dot{\mathrm{X}}$ & $i$ \\
\hline & 35 & 22 & 0483 & D & $*$ & $0+$ \\
\hline & 35 & 22 & 0484 & A & M & 2 \\
\hline & 35 & 22 & 0486 & B & L-M & 2 \\
\hline & 35 & 22 & 0488 & $\mathrm{E}$ & $*$ & $0+$ \\
\hline & 35 & 22 & 0489 & $\mathrm{~A}$ & $x$ & 1 \\
\hline
\end{tabular}

TABLE 27-11

Summary of Archeomagnetic Results for Composite F

\begin{tabular}{|c|c|c|c|c|c|c|c|c|c|c|c|c|c|c|}
\hline \multirow[b]{2}{*}{ Feature } & \multicolumn{5}{|c|}{ Cooling Context } & \multicolumn{5}{|c|}{ Lowest Temperature of Movement } & \multicolumn{4}{|c|}{ Maximum Number of Movements } \\
\hline & A & B & $\mathrm{C}$ & D & $\mathrm{E}$ & * & $\begin{array}{c}\mathrm{L} \text { or } \mathrm{L}- \\
\mathrm{M}\end{array}$ & $\begin{array}{l}\text { M or } \\
\text { M-H }\end{array}$ & $\mathrm{H}$ & $\mathrm{X}$ & 0 & $\begin{array}{l}1,1+\text {, } \\
\text { or } 1-2\end{array}$ & $\begin{array}{l}2,2+, \\
\text { or } 2-3\end{array}$ & $\begin{array}{l}3 \text { or } \\
\text { more }\end{array}$ \\
\hline 181 & 13 & 14 & 7 & 1 & & 20 & 2 & 5 & 1 & 7 & 20 & 12 & 3 & \\
\hline $181 / 231^{*}$ & 9 & 8 & 5 & 4 & 1 & 12 & 2 & 3 & 1 & 9 & 12 & 14 & 1 & \\
\hline 231 & 5 & 2 & 1 & 21 & & 17 & 2 & 2 & & 8 & 17 & 8 & 4 & \\
\hline $231 / 245$ & 10 & 11 & 2 & 5 & 1 & 8 & 9 & 5 & 2 & 5 & 8 & 12 & 9 & \\
\hline 245 & 7 & 4 & & & & 8 & 1 & 1 & 1 & & 8 & 3 & & \\
\hline 230 & 1 & 1 & & & & & 1 & 1 & & & & & 2 & \\
\hline 225 & 3 & 1 & & & 1 & 1 & 3 & 1 & & & 2 & 1 & 1 & 1 \\
\hline
\end{tabular}

* note that two B-category specimens from Feature 181/231 are sister samples from the same rock.

Composite F rocks, over half ( 17 of 29 ) had a single component of magnetization (see Table 27-11), meaning that they were only moved after completely cooling. Only four had three or more components. By far, the greatest number of displaced rocks were found in Squares 38 and 52 (east and north of Feature 181, see Figure 27-72). Almost all of the rocks recovered in the eastern two-thirds of Square 38 (see Figure 27-75) were displaced but only after cooling without discernible movement from initial temperatures in excess of the Curie point. Rocks AM-730 and AM-731 (as well as AM-721, AM-722, and AM-636) were dislocated in nearly identical fashion after they cooled. In nearly all cases, the reconstructed rotation directions for the displaced rocks in Square 38 were to the north and east, perhaps following the plane of the paleoslope (i.e., downward to the northeast). This can be seen in the 


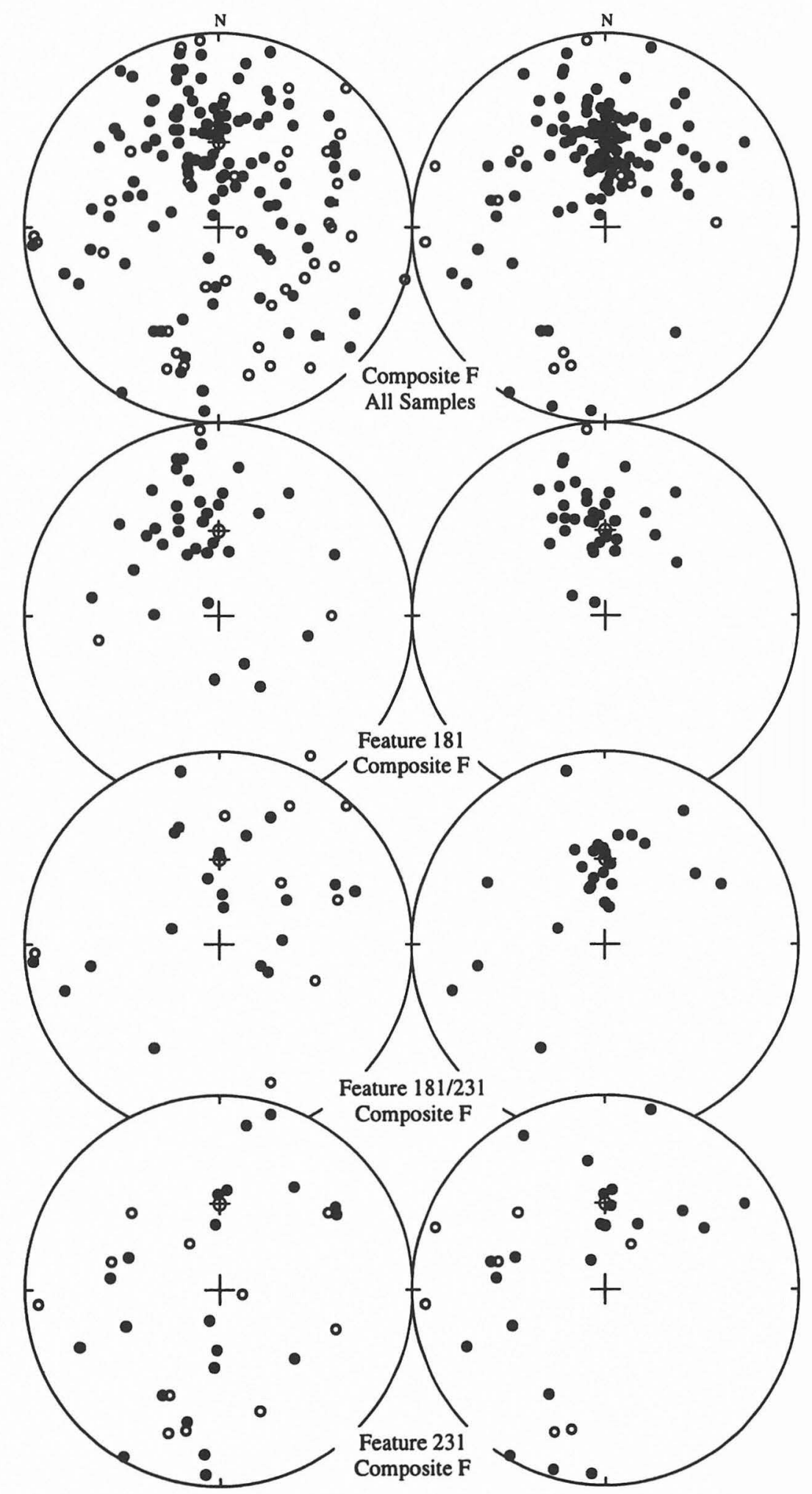

FIGURE 27-73. Stereoplots of results for Composite F, including subfeatures. 


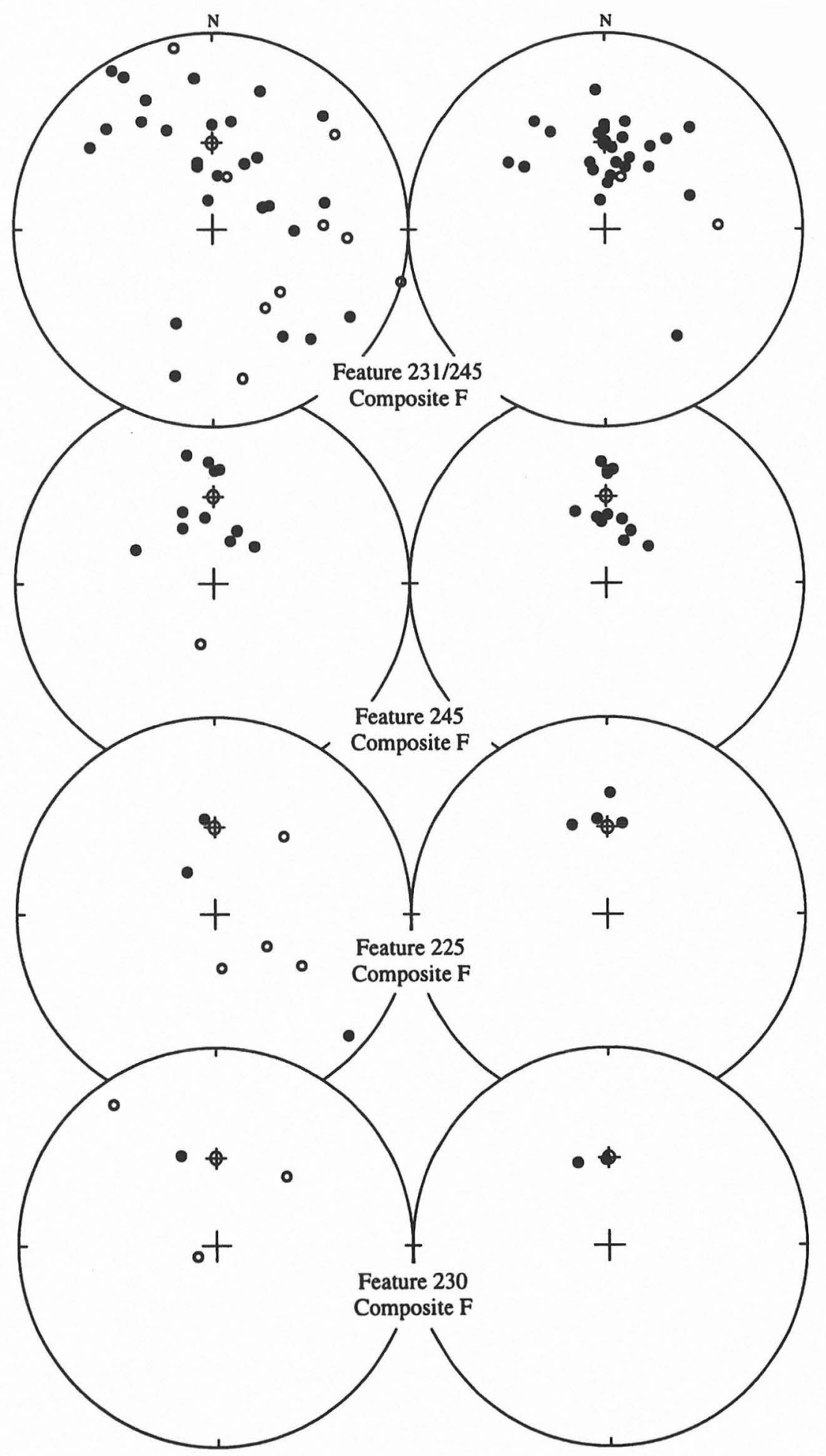

FIGURE 27-74. Stereoplots of results for Composite F subfeatures.

lowest temperature and coercivity component stereonet on the right in Figure 27-73 where almost all of the displaced components are in the western hemisphere. This pattern is expected for small- to moderate-magnitude displacements generally to the north and east (see again Figure 27-7 and accompanying text). With the single exception of AM-732, all Square 38 rocks that were both single component and cooled in place came from along the western edge and are probably associated with Feature 181.

Note the distribution of yellow rocks in Figure 27-72 (i.e., those that were displaced and have an unknown cooling location or for which the remanence data are unclear). 


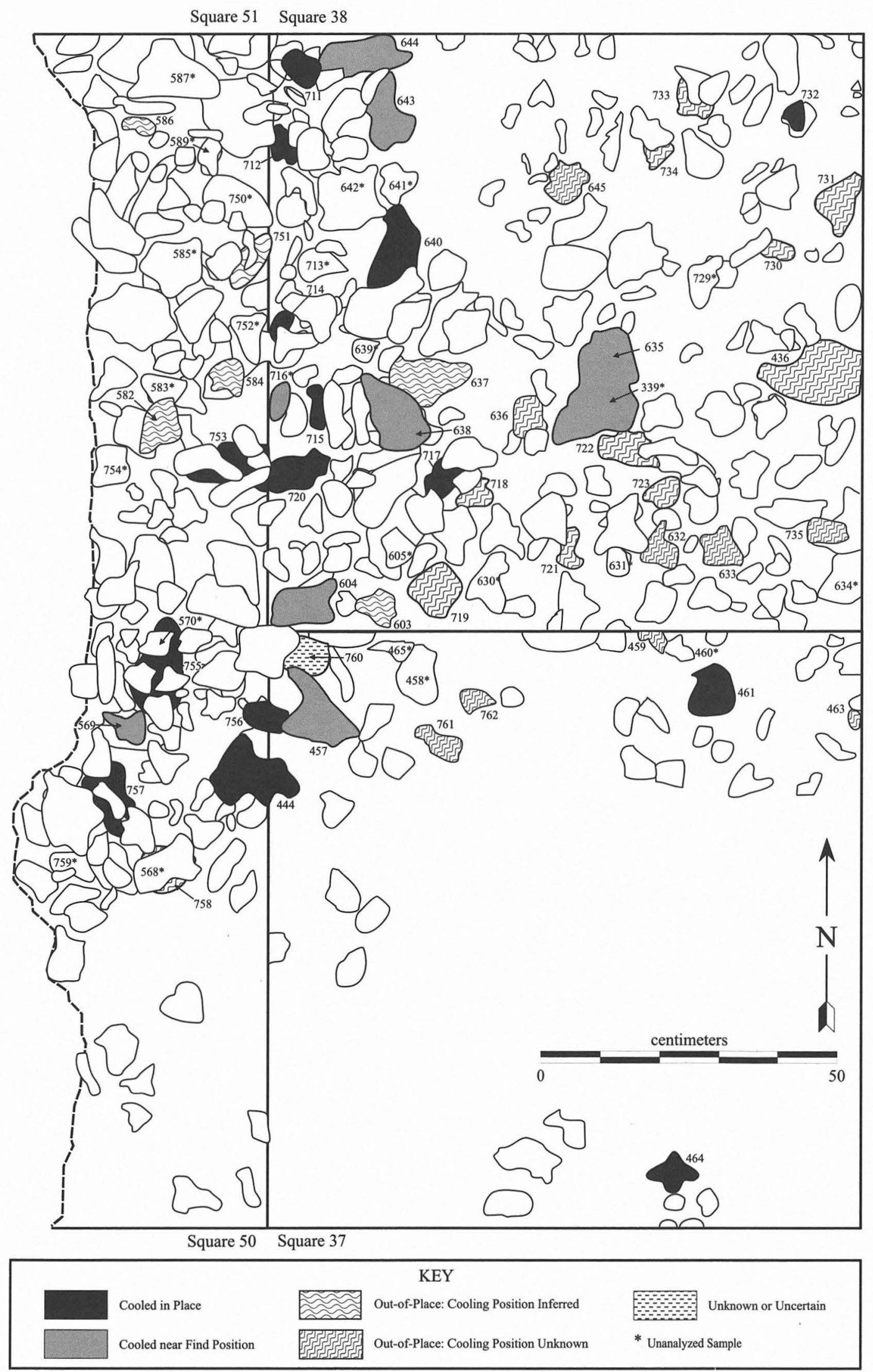

Figure 27-75. Detail of Composite F: Squares 37, 38, 50, and 51, Level 22 (ca. 95.75 m). 


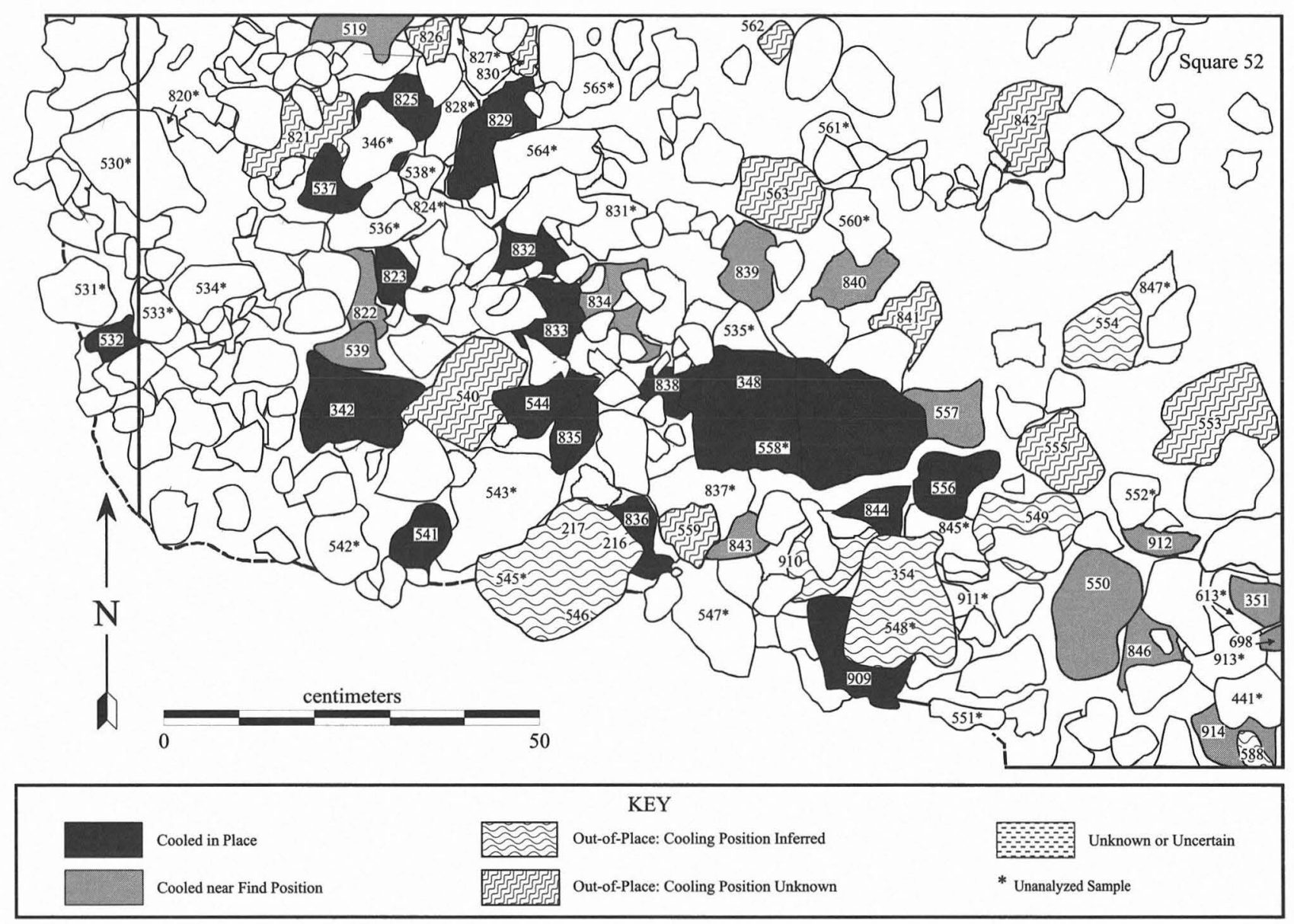

Figure 27-76. Detail of Composite F: Squares 52 and 53, Level 23 (ca. 95.70 m).

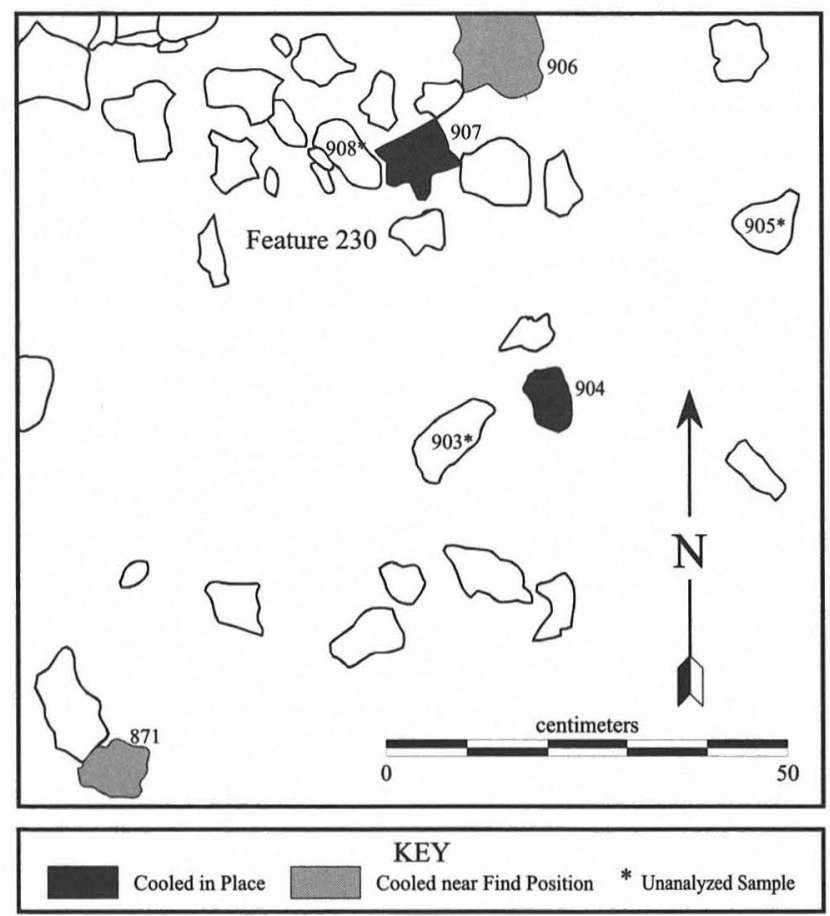

FIGURE 27-77. Detail of Composite F: Feature 230 in Square 39, Level 23 (ca. $95.70 \mathrm{~m}$ ).
They are concentrated primarily in Square 38 and around the perimeter of Feature 181 in Square 52 as well as in the center of a group of intact rocks (Feature 245) in Square 28 (discussed below).

Over $70 \%$ ( 21 of 29) of the rocks in Squares 28 and 52 potentially associated with Feature 245 (listed as " $231 / 245$ " on Tables 27-10 and 27-11) cooled in or near the positions in which they were found (see Figure 27-74), but a somewhat lower percentage (only 8 of 29) had a single component of magnetization. About the same number ( 9 of 29) may have been dislocated two or more times during cooling, the majority in low to medium temperature ranges (see Table 27-11). Most of the 231/245 rocks were recovered in the western half of Square 52 (see Figure 27-76) and in the south and east halves of Square 28 (Figure 27-78). Only rocks recovered in the northwest quadrant of Square 28 were designated "Feature 245" in Tables 27-10 and 27-11.

The cluster of intact rocks in the northwest quadrant of Square 52 (e.g., AM-519, AM-537, AM-825, and AM-829) may be a small separate feature not recognized as such in the field. The vector rotation reconstructions of several of these rocks suggest the likelihood of cooling and postcooling rotations toward the northwestern corner of Square 52 . This feature would probably be stratigraphically 


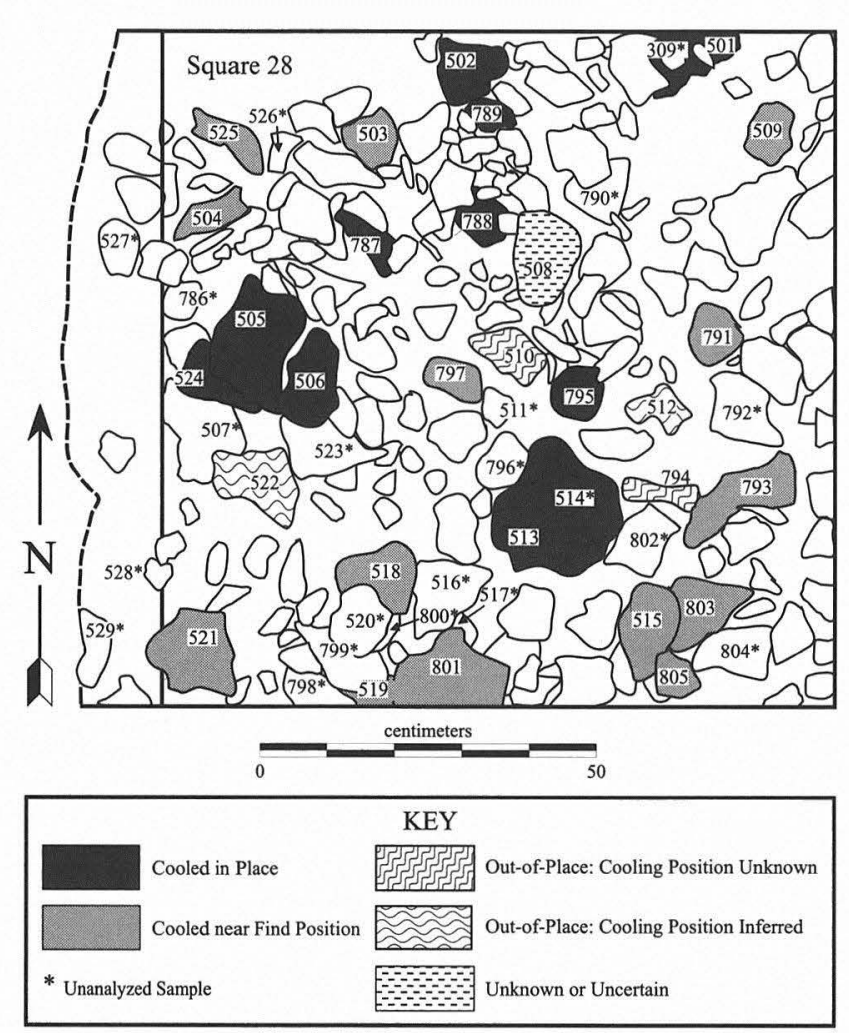

FIGURE 27-78. Detail of Composite F: Squares 28 and 44, Level 22 (ca. $95.70 \mathrm{~m}$ ).

above Features 181 and 245 (or at least did not extend as deep as the others).

The emergence of Feature 245 in Square 28 could not be easily recognized in the field but can be seen in Figure 27-72 as a concentration of red and blue rocks in the northwest corner of Square 28 (see Figure 27-78). All 11 of the analyzed rocks from Feature 245 cooled in or very near the positions in which they were recovered (see Figure 27-74). Furthermore, seven had a single component of magnetization. Of the three rocks that did move while cooling, only one (AM787) came to rest at low temperatures. The proximity of other rocks that also cooled in place (AM-513 and AM-795 in Square 28 and AM-500 and AM-309/501 in Square 27) suggests that the upper portion of Feature 245 may have extended beyond the northwest corner of Square 28, an inference largely corroborated in subsequent levels (see below). The significance of a displaced rock (AM-510) and an unknown context rock (AM-508) near the center of Square 28 is unclear. They may be related to either a later occupation or to a localized disturbance of Feature 245.

Feature 225 was defined in the field as a loose scatter of burned rocks covering the base of Square 27 at the northern edge of Feature 231 (see Figure 27-72; Figure 27-79). Four of the five rocks analyzed cooled in place (see Figure 27-74). Archeomagnetic data from one rock (AM-267) were inconclusive. With the exception of three rocks in the southeast corner (AM-308, AM-500, and AM-309/501, that may be more closely related to the Feature 245 rocks in Square 28)

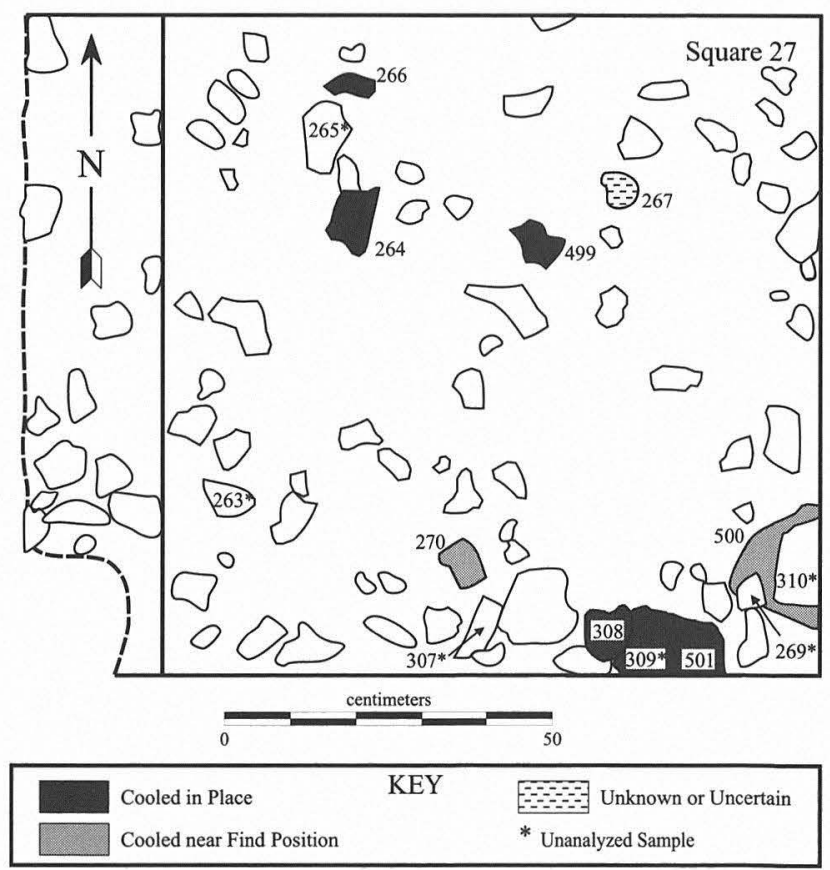

Figure 27-79. Detail of Composite F: Feature 225 in Squares 27 and 43, Level 22 (ca. $95.70 \mathrm{~m})$.

and AM-267, the analyzed rocks shown on Figure 27-79 seem to have moved a great deal while cooling and come to rest in the locations in which they were found from temperatures probably no greater than about $300^{\circ} \mathrm{C}$ (see Tables 27 10 and 27-11).

Several archeomagnetic samples were also analyzed from South Block squares just west of the area shown in Composite F. Three samples were analyzed from a small, somewhat isolated cluster of rocks excavated in Level 22 of Square 33 (Figure 27-80). Two of the rocks cooled nearly in place from low to moderate temperatures, but they apparently experienced multiple displacements as they cooled (see Table 27-10). The small rock cluster in Figure 27-80 may be an intact feature but was not designated as such during the fieldwork phase of investigations. Vector rotation reconstructions suggest that rocks AM-365 and AM-366 were displaced toward each other, perhaps into a central depression or low area. The larger, more northerly rock (AM-364) seems to have been subjected to at least three episodes of movement (see Table 27-10).

A total of nineteen rocks from Level 22 in Squares 25, 26,34 , and 35 was also analyzed (see Table 27-10). These rocks were recovered from low density, largely unpatterned deposits representing the margins of the Feature 231 deposits at this depth. In nearly all instances, they were displaced and/or were cooled in place only from low temperatures following one or more dislocations while cooling.

In summary, the archeomagnetic data from Composite $\mathrm{F}$ help to further subdivide and define the limits of subfeatures within the Feature 231 palimpsest. The probable postcooling 


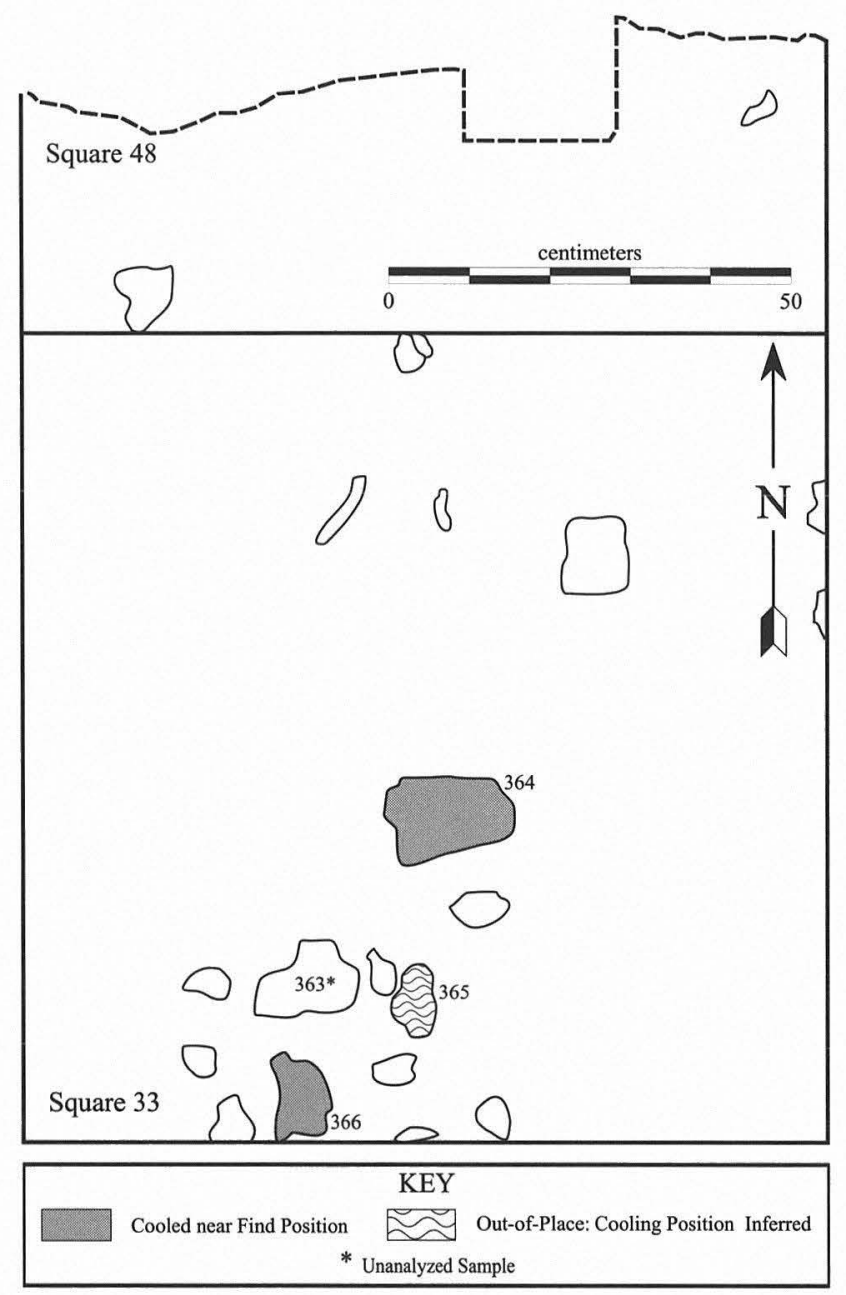

Figure 27-80. Plan map of Squares 33 and 48, Level 22 (ca. $95.75 \mathrm{~m})$.

displacements of the Square 38 rocks suggest some period of subaerial exposure during which they rolled downslope to the northeast. The remanence data also confirm that, although Feature 245 was not immediately recognizable in the field at this depth, Level 22 clearly penetrated the upper portion of this subfeature. The data also help to establish that Feature 181 (originally sampled during TxDOT investigations) is an intact feature. Additionally, the data verify that, despite the relatively amorphous patterning of burned rocks in Feature 225, many of the individual rocks within it were cooled where they were found, although only one did so from high temperatures. Finally, the great majority of rocks assigned to the general Feature 231 deposit were displaced from their final cooling locations. Significantly, the Feature 231 rocks included on Composite $\mathrm{F}$ (and therefore nearer the individual subfeatures) were more likely to have cooled without moving than were the more peripheral rocks not included on the composite plan map (see Table 27-10) although both groups were mostly outof-place relative to final cooling location. An explanation to account for this is not immediately evident, but it seems reasonable to infer that some of these rocks must indeed be associated with one or more subfeatures.

\section{Feature 231, Composite G: East end of South Block, Level 23}

Composite G (Figure 27-81) depicts Feature 231 at the base of Level 23 (ca. $95.70 \mathrm{~m}$ ) at the east end of the South Block (Squares 34/49, 35, 37/50, and 38/51). In addition, Feature 237, encountered in Square 34, is shown on Composite $\mathrm{G}$ and is discussed in this section. This composite bridges the offset level numbers and elevations of the East and South blocks. Hereafter, all composites will be composed of squares at the same level and elevation. Results of the archeomagnetic analysis are listed individually on Table 27-12 and are summarized in Table 27-13. Stereonets are presented in Figure 27-82.

Burned rocks in Squares 37/50 and 38/51 (see Figure 2781) correspond to the eastern edge of TxDOT Feature 181. Of the 35 rocks analyzed in Composite $\mathrm{G}$ (excluding those from Feature 237), 21 (60\%) were single component and 25 (over $70 \%$ ) were recovered in or near the locations in which they last cooled (see Table 27-13), all from temperatures of at least $300^{\circ} \mathrm{C}$.

Seventeen samples (from 15 individual rocks) were assigned to Feature 181. All but 2 of the 15 rocks cooled in or nearly in place and, of these, 10 did so without noticeably moving from initial temperatures greater than at least $580^{\circ} \mathrm{C}$. The only rock that was dramatically displaced after cooling (see right stereonet in Figure 27-82) was from the extreme southern end of Feature 181 in Square 50 (AM-928; Figure 27-83). Just one rock (AM-870/871, from the northern perimeter of Feature 181 in Square 38) may have moved more than once while cooling (Figure 27-84). The large number of singlecomponent rocks can be seen in the similarity of the two stereonets for the Feature 181 samples in Figure 27-82. Single component samples have the same direction in both stereonets.

Six rocks from along the southern end of Feature 181 are thought to be associated with it (coded "181/231" in Table 27-12). Of the five that yielded meaningful archeomagnetic results, all but one (AM-939) cooled in or near the same positions in which they were excavated. Two of these in-situ rocks (AM-877 and AM-941) appear to have been dislocated once while cooling. The consistency in the apparent direction of displacement for AM-941 (both during and after cooling) supports the contention that it was originally heated above the Curie point and that it moved while cooling from this higher temperature. Note the linearity of Feature 181/ 231 remanence components on the high temperature and coercivity stereonet shown in Figure 27-82. This result suggests that whatever (or whomever) moved these rocks probably displaced them along a roughly east-west plane. Indeed, six samples from the Feature 181 and 181/231 categories (AM-715, AM-753, AM-875, AM-876, AM-879, and 


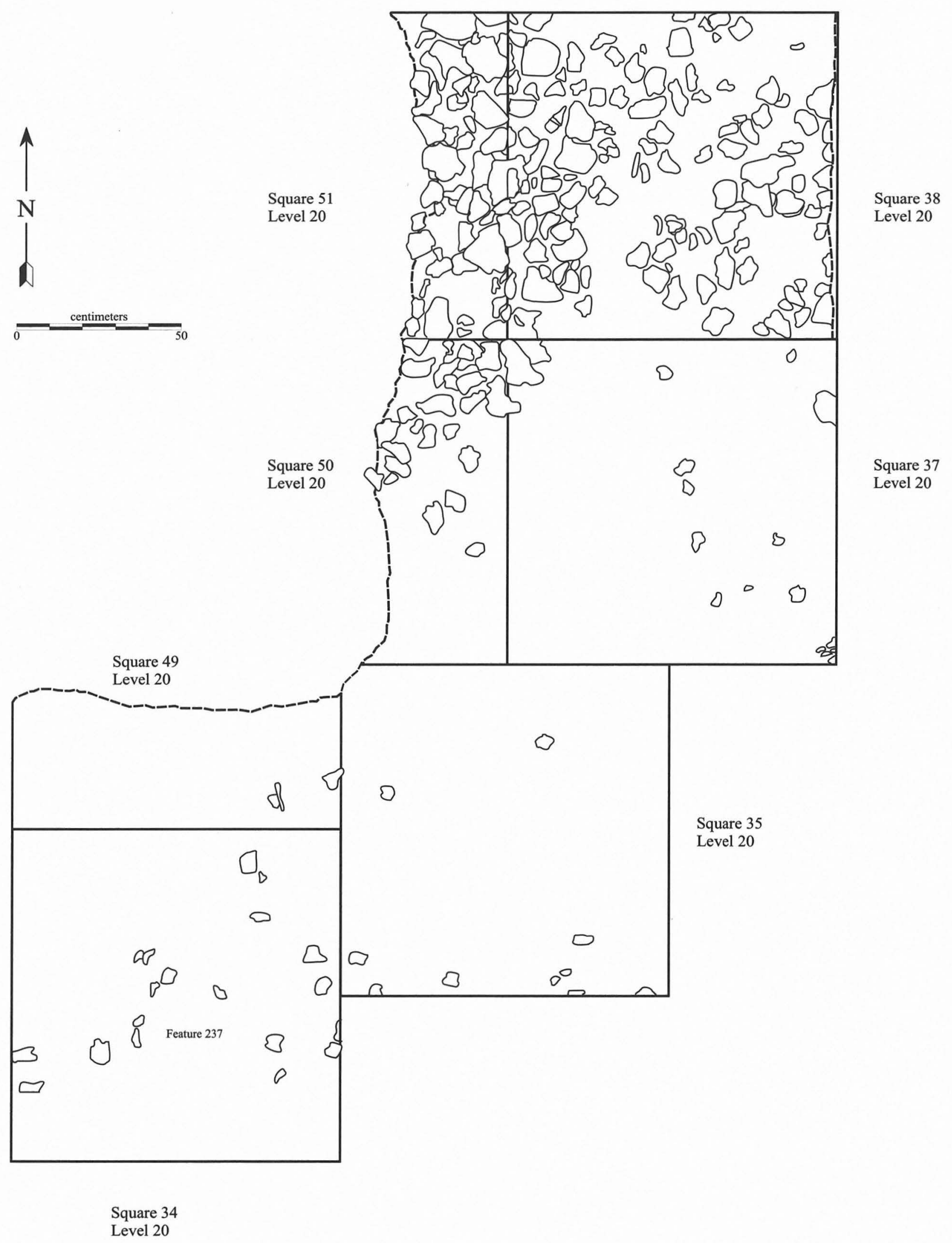

FiguRE 27-81. Feature 231 and associated subfeatures, Composite G: South Block, Level 23 (ca. 95.70 m). 
TABLE 27-12

Archeomagnetic Interpretation of Vectoral Data, Composite G

Cooling Context
A cooled in place
B cooled near find position
C out-of-place: cooling location inferred
D out-of-place: unknown cooling orientation
E uncertain / unknown

Lowest Temperature of Movement

* no discernible movement

$\mathrm{X}$ unknown (AF demagnetized)

$\mathrm{V}$ possible viscous magnetization

$\mathrm{L}$ less or equal to $250^{\circ} \mathrm{C}$

$\mathrm{M}$ between $250^{\circ}$ and $450^{\circ} \mathrm{C}$

$\mathrm{H}$ greater than $450^{\circ} \mathrm{C}$

\begin{tabular}{|c|c|c|c|c|c|c|c|}
\hline Feature No. & Square & Level & $\begin{array}{l}\text { Sample No. } \\
\text { (AM-) }\end{array}$ & $\begin{array}{l}\text { Cooling } \\
\text { Context } \\
\end{array}$ & $\begin{array}{c}\text { Lowest Temperature } \\
\text { of Movement }\end{array}$ & $\begin{array}{l}\text { Number of Discernible } \\
\text { Movements while Cooling }\end{array}$ & \\
\hline 181 & 38 & 22 & 0640 & A & $*$ & 0 & \\
\hline 181 & 38 & 22-Base & 0715 & A & * & 0 & \\
\hline 181 & 38 & 23 & 0869 & B & $*$ & 0 & \\
\hline 181 & 38 & 23 & 0870 & B & M & $1-2$ & (see 871) \\
\hline 181 & 38 & 23 & 0873 & A & $*$ & 0 & (see 640) \\
\hline 181 & 38 & 23 & 0874 & A & M-H & 1 & \\
\hline 181 & 38 & 23 & 0878 & A & $*$ & 0 & \\
\hline 181 & 38 & 23 & 0879 & B & $*$ & $0+$ & \\
\hline 181 & 38 & 23-Base & 0940 & A & $*$ & 0 & \\
\hline 181 & 39 & 23 & 0871 & B & M & 2 & $($ see 870$)$ \\
\hline 181 & 50 & 23 & 0928 & D & $X$ & 1 & \\
\hline 181 & 51 & 22-Base & 0751 & $\mathrm{C}$ & $*$ & 0 & \\
\hline 181 & 51 & 22-Base & 0753 & A & $\mathrm{H}$ & 1 & \\
\hline 181 & 51 & 23 & 0920 & A & $*$ & 0 & \\
\hline 181 & 51 & 23 & 0921 & A & $*$ & $0+$ & \\
\hline 181 & 51 & 23 & 0924 & A & $*$ & $0+$ & \\
\hline 181 & 51 & 23 & 0925 & $\mathrm{~A}$ & $*$ & $0+$ & \\
\hline $181 / 231$ & 37 & 22-Base & 0760 & $\mathrm{E}$ & $\mathrm{X}$ & $1+$ & \\
\hline $181 / 231$ & 38 & 23 & 0875 & B & $*$ & $0+$ & \\
\hline $181 / 231$ & 38 & 23 & 0876 & $\mathrm{~A}$ & $*$ & $0+$ & \\
\hline $181 / 231$ & 38 & 23 & 0877 & A & $\mathrm{X}$ & 1 & \\
\hline $181 / 231$ & 38 & 23-Base & 0939 & $\mathrm{C}$ & $*$ & $0+$ & \\
\hline $181 / 231$ & 38 & 23-Base & 0941 & A & $\mathrm{X}$ & 1 & \\
\hline 231 & 38 & 22-Base & 0721 & D & $*$ & 0 & \\
\hline 231 & 38 & 22-Base & 0723 & $\mathrm{D}$ & $X$ & 1 & \\
\hline 231 & 38 & 22-Base & 0731 & D & $*$ & $0+$ & \\
\hline 231 & 38 & 23 & 0859 & $\mathrm{D}$ & $*$ & 0 & \\
\hline 231 & 38 & 23 & 0861 & D & $\mathrm{H}$ & $1+$ & \\
\hline 231 & 38 & 23 & 0862 & $\mathrm{~A}$ & $\mathrm{~L}$ & 2 & \\
\hline 231 & 38 & 23 & 0863 & A & $*$ & $0+$ & \\
\hline 231 & 38 & 23 & 0864 & B & $X$ & 1 & \\
\hline 231 & 38 & 23 & 0865 & B & $\mathrm{X}$ & 1 & \\
\hline 231 & 38 & 23 & 0867 & A & $X$ & $1+$ & \\
\hline 231 & 38 & 23 & 0868 & A & $*$ & 0 & \\
\hline 231 & 38 & 23-Base & 0943 & B & $\mathrm{X}$ & 1 & \\
\hline 231 & 38 & 23-Base & 0944 & D & $*$ & $0+$ & \\
\hline 231 & 39 & 23 & 0904 & D & $*$ & 0 & \\
\hline 237 & 34 & 23 & 0668 & D & $\mathrm{X}$ & 1 & \\
\hline 237 & 34 & 23 & 0669 & $\mathrm{~A}$ & $\mathrm{~L}$ & 1 & \\
\hline
\end{tabular}

TABLE 27-13

Summary of Archeomagnetic Results for Composite G

\begin{tabular}{|c|c|c|c|c|c|c|c|c|c|c|c|c|c|c|}
\hline \multirow[b]{2}{*}{ Feature } & \multicolumn{5}{|c|}{ Cooling Context } & \multicolumn{5}{|c|}{ Lowest Temperature of Movement } & \multicolumn{4}{|c|}{ Maximum Number of Movements } \\
\hline & A & $\mathrm{B}$ & $\mathrm{C}$ & $\mathrm{D}$ & $\mathrm{E}$ & * & $\begin{array}{c}\text { L or L- } \\
\text { M }\end{array}$ & $\begin{array}{l}\mathrm{M} \text { or } \\
\mathrm{M}-\mathrm{H}\end{array}$ & $\mathrm{H}$ & $\mathrm{X}$ & 0 & $\begin{array}{l}1,1+, \\
\text { or } 1-2\end{array}$ & $\begin{array}{l}2,2+ \\
\text { or } 2-3\end{array}$ & $\begin{array}{l}3 \text { or } \\
\text { more }\end{array}$ \\
\hline 181 & 11 & 4 & 1 & 1 & & 12 & & 3 & 1 & 1 & 12 & 4 & 1 & \\
\hline $181 / 231$ & 3 & 1 & 1 & & 1 & 3 & & & & 3 & 3 & 3 & & \\
\hline 231 & 5 & 3 & & 6 & & 7 & 1 & & 1 & 5 & 7 & 6 & 1 & \\
\hline 237 & 1 & & & 1 & & & 1 & & & 1 & & 2 & & \\
\hline
\end{tabular}

*note that two A-category and two B-category specimens from Feature 181 are sister samples from the same rock. 


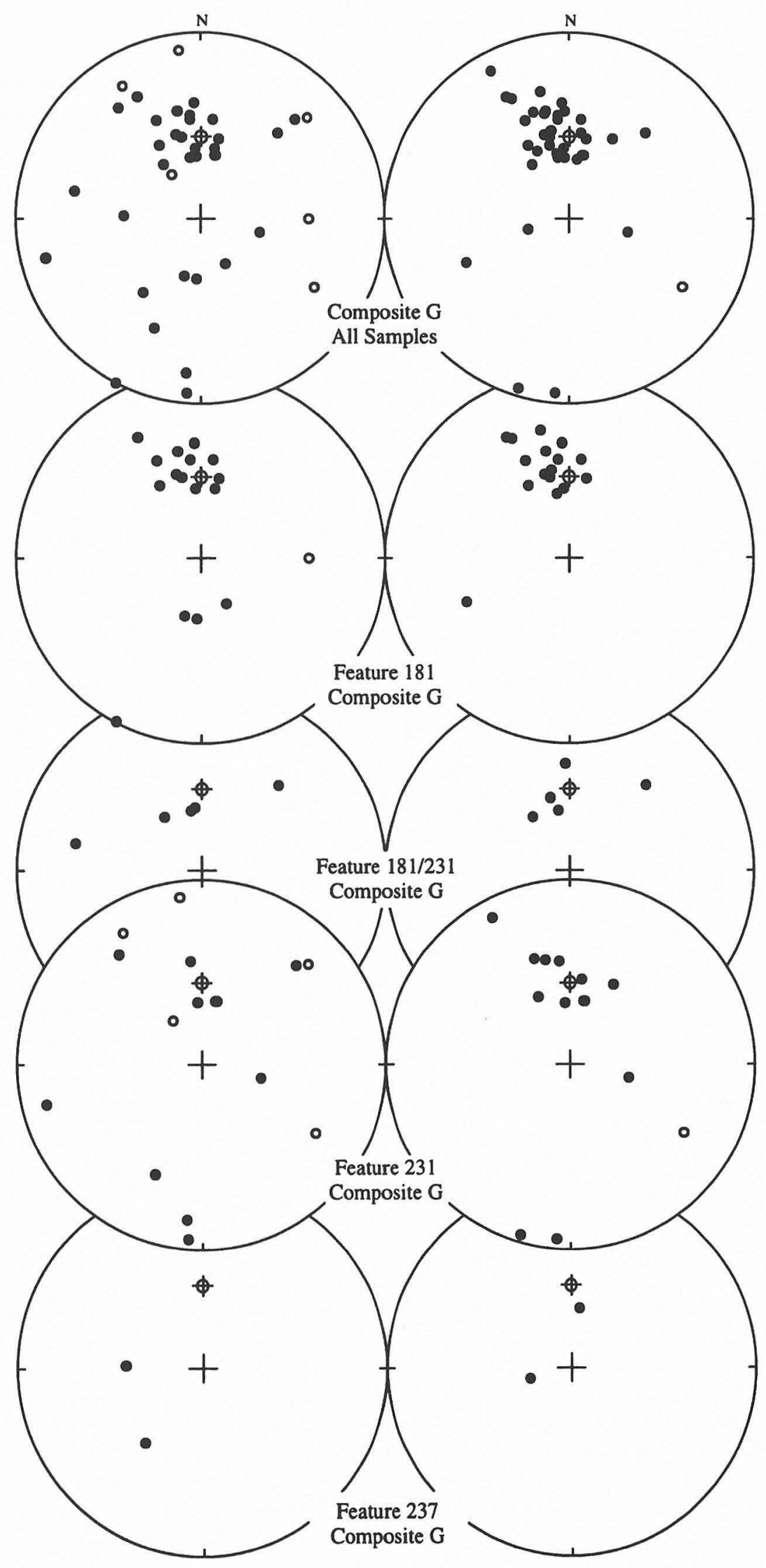

FIGURE 27-82. Stereoplots of results for Composite G, including subfeatures. 


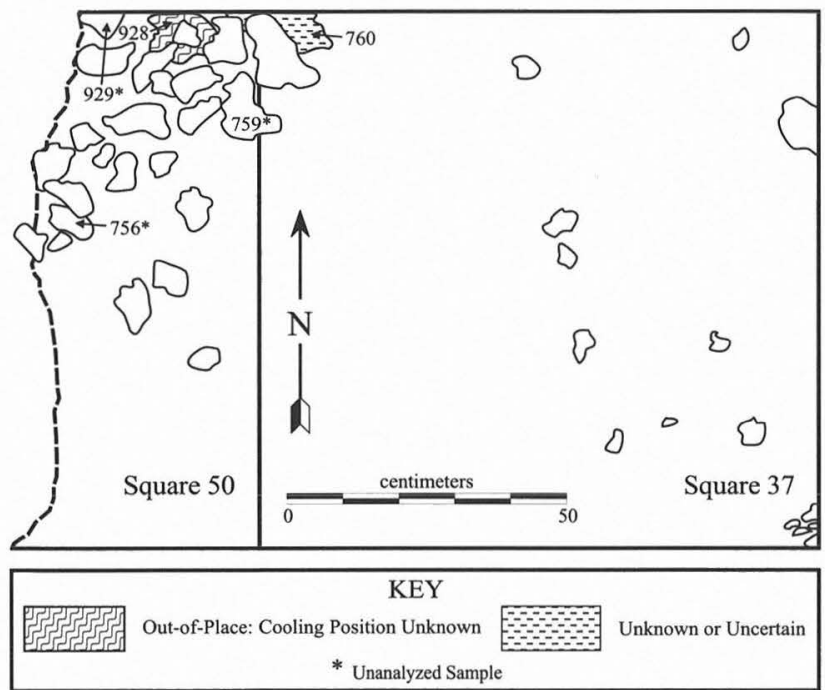

Figure 27-83. Detail of Composite G: Feature 181 in Squares 37 and 50, Level 23 (ca. $95.70 \mathrm{~m}$ ).
AM-941) —all clustered near the southern end of Feature 181-share northeastward vector rotation reconstructions; some during, and some after, cooling. Such correspondence could be due to either a natural process (such as rotation along the paleoslope) or, perhaps, intentional displacements related to feature use or maintenance. Regardless of the specific cause, however, such patterning clearly suggests a common mechanism of movement. Nonetheless, archeomagnetic results demonstrate that, for the most part, Feature 181 was undisturbed both during and after cooling.

Fourteen rocks analyzed from the eastern two/thirds of Square 38 (and a single sample from Square 39) were assigned to Feature 231 (see Figure 27-84 and Table 27-12). Results from these rocks were quite different. Six of the 14 were found to have been displaced from their final cooling locations (see Figure 27-82), although 4 had not previously been moved while cooling from temperatures of $500^{\circ} \mathrm{C}$ or more (see Table 27-12). Furthermore, despite the lack of

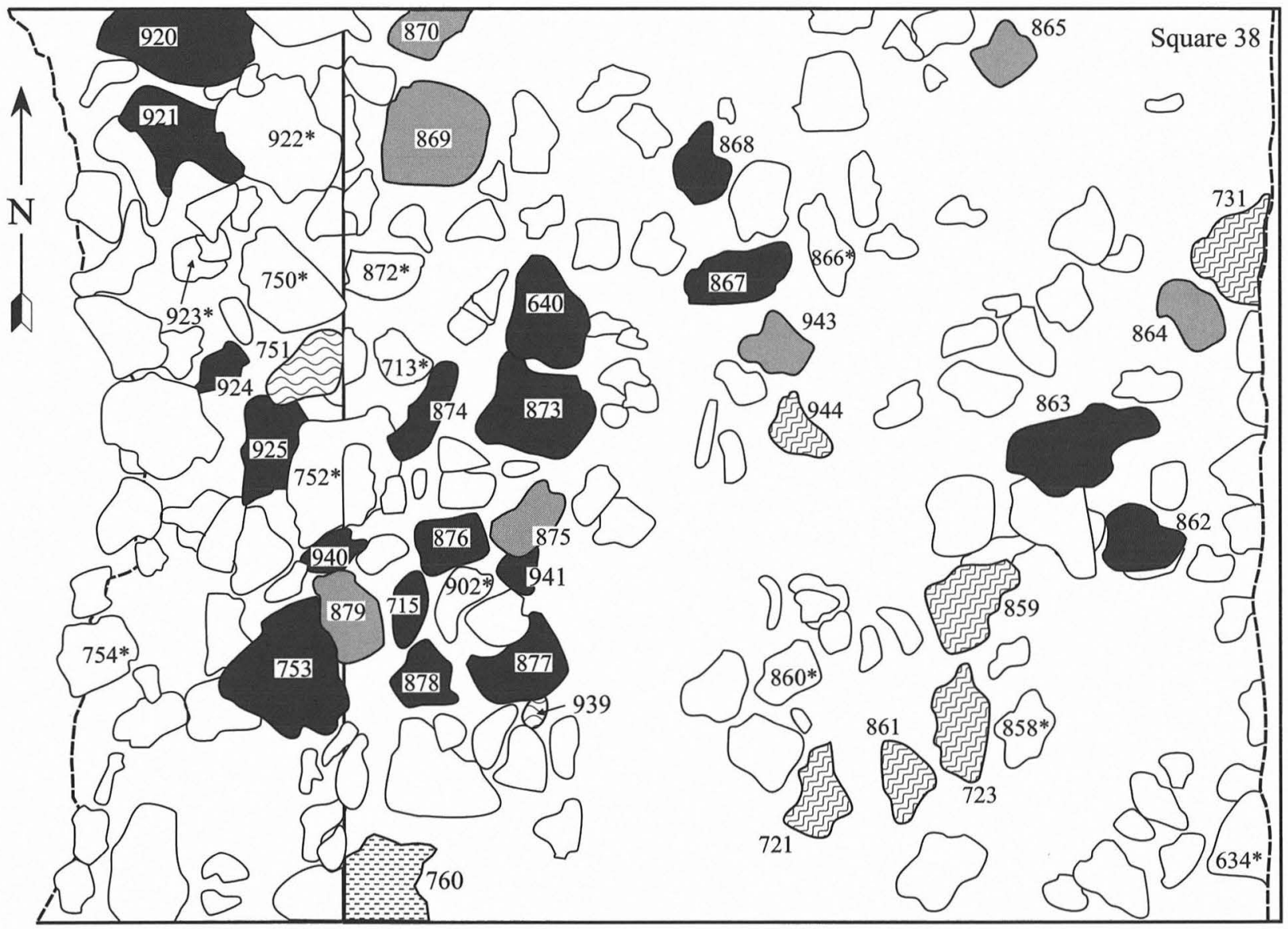

centimeters

0

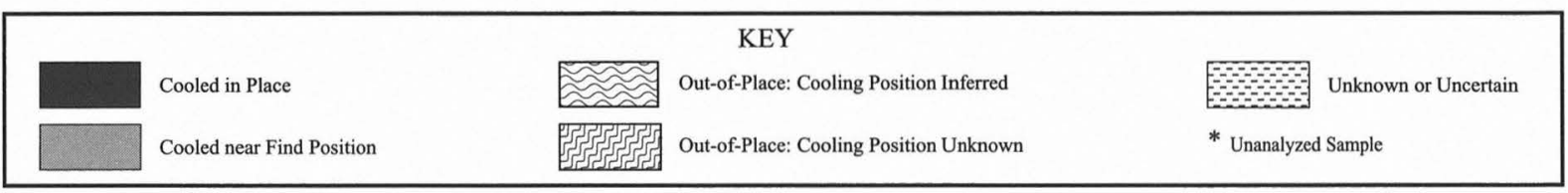

FIGURE 27-84. Detail of Composite G: Feature 181 in Squares 38 and 51, Level 23 (ca. 95.70 m). 
thermal data for 4 of the 8 in-situ samples, it is clear that only 3 cooled where they were found from temperatures approaching or exceeding the Curie point: 2 (AM-863 and AM-868) from Square 38 and the 1 (AM-904) from Square 39. The other 5 rocks were moved at least once while cooling. The distribution of these cooled-in-place rocks suggests the possibility of another feature locus, perhaps centered in the northeastern quadrant of Square 38 (see Figure 27-84). There is little patterning evident in the vector rotation reconstructions except for the internally consistent results from AM-943 which support movement while cooling rather than incomplete heating as the origin of its two remanence components.

Feature 237 was defined as a small patch of burned clay and sediment loosely associated with about 15 small, dispersed burned rocks in Square 34, Level 23. It probably corresponds to the lower levels of Feature 231. Archeomagnetic results from 2 of these rocks (AM-668 and AM-669, which are not illustrated but are listed in Table 27-12) indicate that both moved at least once while cooling but that AM-669 remained more or less in its final cooling position while AM-668 was displaced after it completely cooled (see Figure 27-82).

\section{Feature 231, Composite H: East and South Blocks, Level 24}

Composite H (Figure 27-85) depicts Feature 231 at the base of Level 24 (ca. $95.65 \mathrm{~m}$ ) in the East Block and the east end of the South Block. The colors shown in this composite correspond to cooling context and are the same as those used for Composite F. The stereonet plots for Composite $\mathrm{H}$ are given in Figures 27-86 and 27-87. The archeomagnetic results for individual samples are listed in Table 27-14 and are summarized in Table 27-15.

The distribution of burned rocks in Composite $\mathrm{H}$ continued the trend noted in earlier levels: contraction into more-discrete areas corresponding to individual subfeatures (especially Feature 181 in Squares 38 and 51). Rock density continued to decrease in Square 52 and, to a lesser degree, in Square 28 where the mass of burned rocks nevertheless remained somewhat amorphous.

Of the 36 rocks belonging to Feature 181 (recovered primarily in Square 51 but also in adjacent excavation Squares 38, 50, and 52), 29 (over 80\%) cooled in or near the locations shown in Figures 27-85, 27-88, and 27-89 (see also Table 27-15). Final cooling positions could not be determined for 2 of the displaced rocks (AM-1210 in Square 38 and AM-928 in Square 50). Results from a third sample (AM-1206) were inconclusive. The archeomagnetic results indicate that not only were most of the Feature 181 rocks cooled in place (see Figure 27-86), they also remained quite stable while cooling. Half of the 36 rocks had a single remanence component and only 2 experienced 2 or more dislo- cations while cooling (see Table 27-15). There is no evidence for movement at low temperatures; all of the rocks for which thermal data are available last moved at temperatures of at least $300^{\circ} \mathrm{C}$ or more. Nearly all of the postcooling displacements of the Feature 181 rocks were rather subtle, unlike those noted during cooling which were typically of greater magnitude. Two peripheral rocks (AM-1196 and AM-1197) did not move while cooling (see Figure 27-88). However, only the rock (AM-1197) nearer Feature 181 remained in its final cooling location.

All of the Feature 181 rocks recovered in the southeastern quadrant of Square 52 (see Figure 27-89) cooled in or near those same positions (most from temperatures approaching or exceeding the Curie point; see Table 27-14). The two C-category rocks (AM-1037 and AM-1040) in Square 52 were displaced only slightly more than the evaluative criteria allow and therefore can be considered near, but not in, their final cooling positions.

The remainder of the rocks in Square 52 were also cooled in or nearly in place, but many did so only from low temperatures. As a group, these rocks were moved a greater number of times while cooling; almost all yielded two or more components of magnetization. Most of these rocks were assigned to Feature 231/245 in Table 27-14 (see also Figure 27-87). Vector rotation reconstructions indicate that several of these rocks moved in roughly the same directions both during and after cooling, supporting the contention that their remanence components resulted from movement while cooling rather than from partial or incomplete heating. Rocks in the western half of Square 52 seem (on the whole) to have been moved less profoundly than were those in the central and eastern areas. In a few cases, rocks found next to each other clearly moved in similar ways but (with the exception of the intrarock consistency already noted) there is no overall patterning evident in the vector rotation reconstructions.

Rock AM-1057 in Square 52 was assigned to Feature 231 and cooled in place (see Table 27-14). Two analyzed rocks from Level 24 in Square 39 (Figure 27-90) were also assigned to Feature 231. The larger rock (AM-993) cooled in place after experiencing one or possibly two dislocations while cooling from temperatures in excess of $600^{\circ} \mathrm{C}$. The other rock (AM-990) did not move perceptibly while cooling but was then displaced about one-quarter turn to the south after it had completely cooled.

The burned rocks shown in Figure 27-91 (Square 28) are believed to be associated with Feature 245 (with the exception of displaced rocks AM-1142 and AM-1143 from the southeastern corner which were coded as " $231 / 245$ "). In addition, 2 rocks from the southeastern corner of Square 27 (AM-500 and AM-501) were also included with Feature 245. All but 2 (AM-973 and AM-977) of these 11 rocks cooled in place (see Tables 27-14 and 27-15). A reasonable cooling location could not be determined for only 1 (AM- 


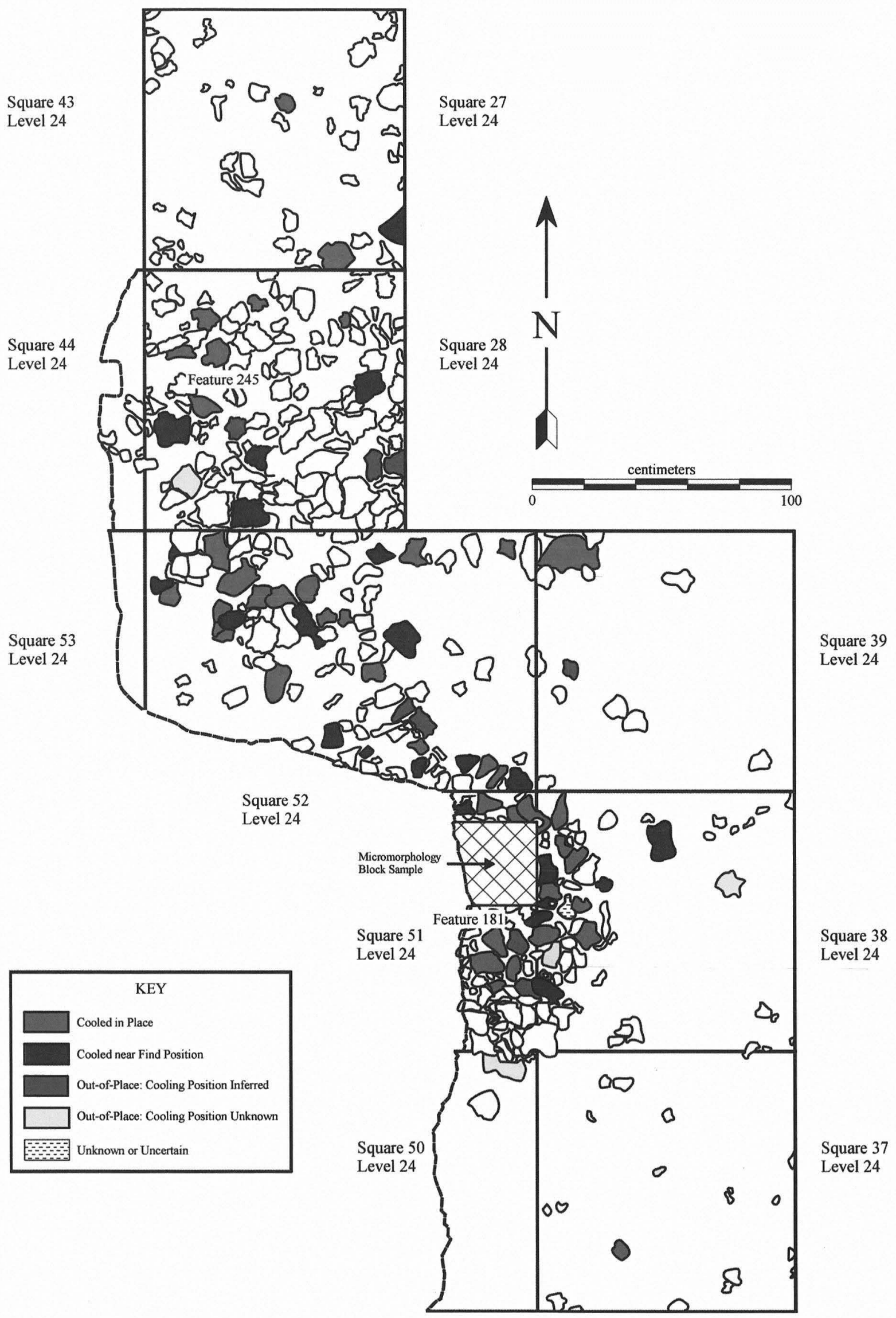

FIGURE 27-85. Feature 231 and associated subfeatures, Composite H: East and South Blocks, Level 24 (ca. 95.65 m). 


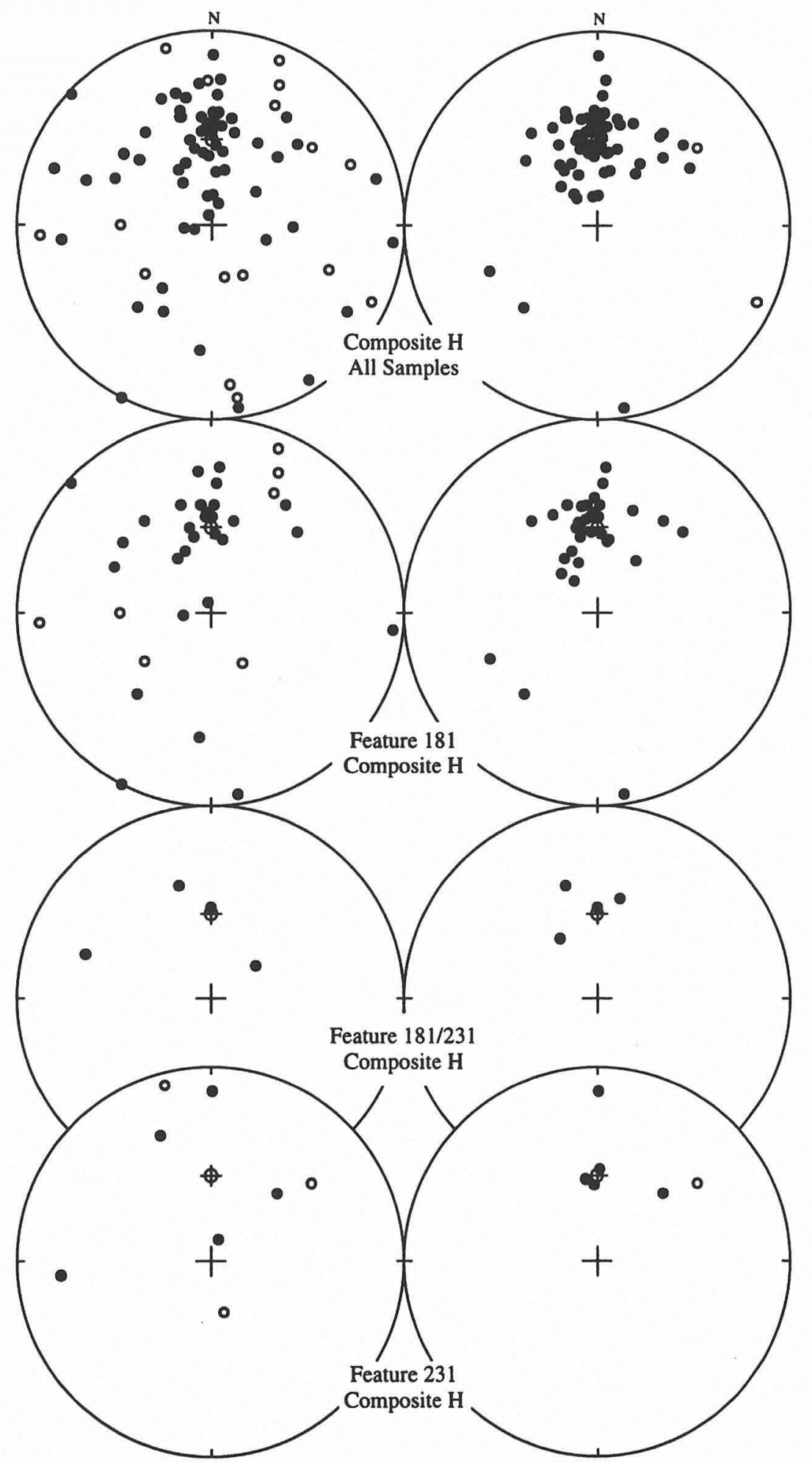

FIGURE 27-86. Stereoplots of results for Composite H, including subfeatures.

973) of these displaced rocks. Only 3 rocks (all of which cooled in place) moved while cooling: the rest had only a single component of magnetization (see Table 27-15; Figure 27-87). The rocks in the western half of Square 28 were, with three exceptions (AM-982, AM-973, and perhaps AM-
977), moved less during and after cooling than were those in the eastern half. This observation, along with similar findings in Square 52, suggests that the westernmost rocks in these excavation units probably remained closer to their initial, higher temperature locations than did the more easterly 


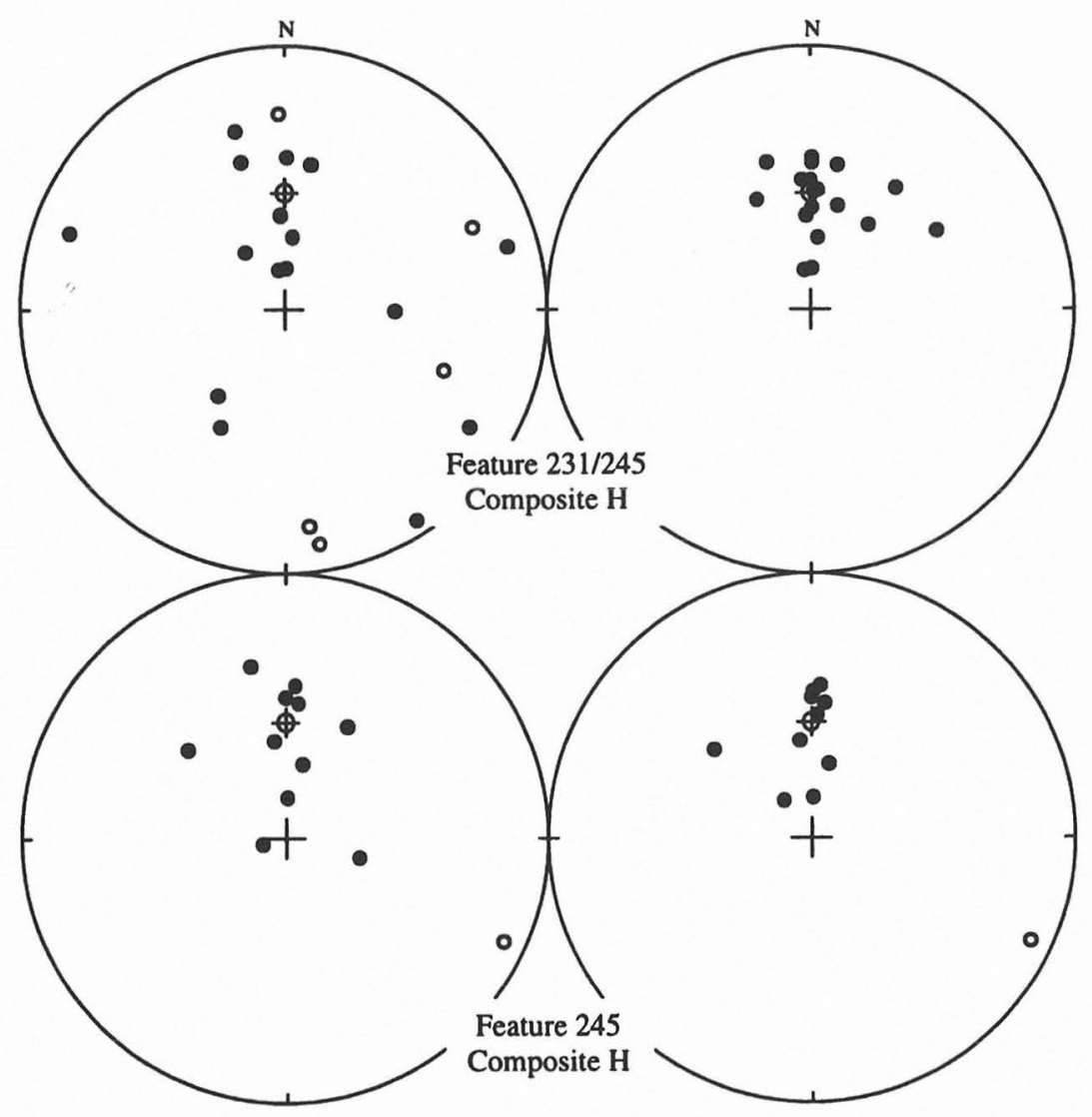

FIGURE 27-87. Stereoplots of results for Composite H subfeatures.

ones. Regardless, the archeomagnetic data clearly demonstrate that nearly all of the Feature 245 rocks remained in or very near the positions in which they last cooled.

In addition to the rocks depicted on Composite $\mathrm{H}$, several Feature 231 samples were analyzed from Level 24 in squares to the north and west of the main concentration shown on this map. Three of the four rocks (AM-381, AM382, AM-383, and AM-384 on Figure 27-92) clustered in the northeast quadrant of Square 20 cooled in or nearly in place (see Table 27-14). Furthermore, all moved in nearly identical directions two or more times (during and again after cooling) implying that they were originally heated to initial temperatures in excess of the Curie point. Moreover, the directions of these displacements suggest that the rocks settled toward each other as they cooled, perhaps into a shallow depression. The other two Square 27 rocks (AM-377 and AM380) analyzed were both displaced after cooling (see Table 27-14).

Three rocks (AM-725, AM-727, and AM-728) analyzed from Square 34 in the South Block also cooled in place (Figure 27-93). Again, two (AM-725 and AM-728) of these had internally consistent reconstructed vector rotations and, consequently, were probably last heated to temperatures in excess of the Curie point. The third (AM-727) had a single remanence component.
The four rocks analyzed from other squares in Level 24 came from more-scattered, amorphous burned rock deposits and, although three were found to have cooled in place, none appears to have done so from high temperatures (see bottom Table 27-14).

In summary, the archeomagnetic data from Composite $\mathrm{H}$ demonstrate that the lower portions of Features 181 and 245 are almost wholly intact with the rocks remaining in or very near their final cooling locations. Furthermore, few of the rocks in these features moved a great deal while cooling from very high temperatures. Distinct similarities in terms of frequency and/or magnitude of rock disturbance were also noted. Finally, the results from both Squares 20 and 34 suggest the possible existence of two small, intact features (or heating loci) not recognized or recorded as such during the TARL fieldwork at Wilson-Leonard.

\section{Feature 231, Composite I: East and South Blocks, Level 25}

Composite I (Figure 27-94) depicts Feature 231 burned rocks at the base of Level 25 (ca. $95.60 \mathrm{~m}$ ) in the East Block and eastern end of the South Block. Isolation of subfeatures continued in this level as the distribution of burned rocks contracted into more-discrete, circumscribed areas. This is 
TABLE $27-14$

Archeomagnetic Interpretation of Vectoral Data, Composite $\mathrm{H}$

Cooling Context
A cooled in place
B cooled near find position
C out-of-place: cooling location inferred
D out-of-place: unknown cooling orientation
E uncertain / unknown

Lowest Temperature of Movement

* no discernible movement

$\mathrm{X}$ unknown (AF demagnetized)

$\mathrm{V}$ possible viscous magnetization

$\mathrm{L}$ less or equal to $250^{\circ} \mathrm{C}$

$\mathrm{M}$ between $250^{\circ}$ and $450^{\circ} \mathrm{C}$

$\mathrm{H}$ greater than $450^{\circ} \mathrm{C}$

\begin{tabular}{|c|c|c|c|c|c|c|}
\hline Feature No. & Square & Level & $\begin{array}{l}\text { Sample No. } \\
\text { (AM-) }\end{array}$ & $\begin{array}{l}\text { Cooling } \\
\text { Context }\end{array}$ & $\begin{array}{c}\text { Lowest Temperature } \\
\text { of Movement }\end{array}$ & $\begin{array}{c}\text { No. of Discernible } \\
\text { Movements while Cooling }\end{array}$ \\
\hline $231 / 225$ & 27 & 24 & 0499 & $\mathrm{~A}$ & * & $0+$ \\
\hline 181 & 38 & 24 & 1198 & A & $X$ & 1 \\
\hline 181 & 38 & 24 & 1199 & B & $\mathrm{X}$ & 1 \\
\hline 181 & 38 & 24 & 1200 & A & $\mathrm{X}$ & 1 \\
\hline 181 & 38 & 24 & 1201 & A & $*$ & $0+$ \\
\hline 181 & 38 & 24 & 1202 & B & $X$ & 1 \\
\hline 181 & 38 & 24 & 1203 & A & $*$ & 0 \\
\hline 181 & 38 & 24 & 1204 & B & $*$ & $0+$ \\
\hline 181 & 38 & 24 & 1205 & B & X & 1 \\
\hline 181 & 38 & 24 & 1206 & E & $X$ & $0-2$ \\
\hline 181 & 38 & 24 & 1207 & $\mathrm{~A}$ & M & $2+$ \\
\hline 181 & 38 & 24 & 1208 & A & M & 1 \\
\hline 181 & 38 & 24 & 1209 & A & $*$ & 0 \\
\hline 181 & 38 & 24 & 1210 & D & $*$ & 0 \\
\hline 181 & 38 & 24 & 1211 & B & $\mathrm{X}$ & 1 \\
\hline 181 & 38 & 24 & 1212 & A & $X$ & 1 \\
\hline 181 & 50 & 23 & 0928 & D & X & 1 \\
\hline 181 & 51 & 24 & 1213 & $\mathrm{C}$ & $*$ & 0 \\
\hline 181 & 51 & 24 & 1214 & A & M & $2+$ \\
\hline 181 & 51 & 24 & 1215 & A & $*$ & $0+$ \\
\hline 181 & 51 & 24 & 1216 & $\mathrm{C}$ & $*$ & $0+$ \\
\hline 181 & 51 & 24 & 1217 & A & $\mathrm{X}$ & 1 \\
\hline 181 & 51 & 24 & 1218 & A & $*$ & 0 \\
\hline 181 & 51 & 24 & 1219 & A & $*$ & $0+$ \\
\hline 181 & 51 & 24 & 1220 & A & $*$ & 0 \\
\hline 181 & 51 & 24 & 1221 & A & $*$ & $0+$ \\
\hline 181 & 51 & 24 & 1222 & B & $*$ & 0 \\
\hline 181 & 52 & 24 & 1030 & B & $*$ & 0 \\
\hline 181 & 52 & 24 & 1031 & A & $*$ & 0 \\
\hline 181 & 52 & 24 & 1032 & A & $X$ & 1 \\
\hline 181 & 52 & 24 & 1033 & B & $\mathrm{X}$ & 1 \\
\hline 181 & 52 & 24 & 1035 & B & $*$ & 0 \\
\hline 181 & 52 & 24 & 1036 & A & $\mathrm{H}$ & $1+$ \\
\hline 181 & 52 & 24 & 1037 & $\mathrm{C}$ & $*$ & 0 \\
\hline 181 & 52 & 24 & 1040 & $\mathrm{C}$ & $\mathrm{X}$ & 1 \\
\hline 181 & 52 & 24 & 1042 & B & $*$ & 0 \\
\hline 181 & 52 & 24 & 1043 & B & $\mathrm{X}$ & 1 \\
\hline $181 / 231$ & 38 & 24 & 1197 & B & $*$ & $0+$ \\
\hline $181 / 231$ & 52 & 23 & 0835 & A & $*$ & 0 \\
\hline $181 / 231$ & 52 & 24 & 1047 & A & $\mathrm{H}$ & $1+$ \\
\hline $181 / 231$ & 52 & 24 & 1048 & B & $\mathrm{X}$ & $1+$ \\
\hline 231 & 37 & 24 & 0963 & D & $X$ & 1 \\
\hline 231 & 37 & 24 & 0964 & A & $\mathrm{L}$ & 2 \\
\hline 231 & 38 & 24 & 1196 & D & * & $0+$ \\
\hline 231 & 39 & 24 & 0990 & $\mathrm{C}$ & $*$ & $0+$ \\
\hline 231 & 39 & 24 & 0993 & A & M & $1-2$ \\
\hline 231 & 52 & 24 & 1057 & A & $\mathrm{X}$ & 1 \\
\hline $231 / 245$ & 27 & 24 & 0500 & B & $*$ & 0 \\
\hline $231 / 245$ & 27 & 24 & 0501 & A & $*$ & 0 \\
\hline $231 / 245$ & 28 & 22 & 0801 & B & $*$ & 0 \\
\hline $231 / 245$ & 28 & 24-Base & 1142 & $\mathrm{C}$ & L-M & 2 \\
\hline $231 / 245$ & 28 & 24-Base & 1143 & $\mathrm{C}$ & $\mathrm{X}$ & 1 \\
\hline
\end{tabular}


Table 27-14, continued

\begin{tabular}{|c|c|c|c|c|c|c|}
\hline Feature No. & Square & Level & $\begin{array}{l}\text { Sample No. } \\
\text { (AM-) }\end{array}$ & $\begin{array}{l}\text { Cooling } \\
\text { Context }\end{array}$ & $\begin{array}{c}\text { Lowest Temperature } \\
\text { of Movement }\end{array}$ & $\begin{array}{c}\text { No. of Discernible } \\
\text { Movements while Cooling }\end{array}$ \\
\hline $231 / 245$ & 52 & 23 & 0832 & A & M-H & 1 \\
\hline $231 / 245$ & 52 & 23 & 0834 & B & $\mathrm{H}$ & $1+$ \\
\hline $231 / 245$ & 52 & 24-Middle & 0958 & B & * & $0+$ \\
\hline $231 / 245$ & 52 & 24-Middle & 0959 & A & L-M & 2 \\
\hline $231 / 245$ & 52 & 24-Middle & 0962 & B & M & $1+$ \\
\hline $231 / 245$ & 52 & 24-Middle & 0968 & B & * & 0 \\
\hline $231 / 245$ & 52 & 24-Middle & 0970 & A & $\mathrm{X}$ & 1 \\
\hline $231 / 245$ & 52 & 24-Middle & 0971 & A & L-M & 2 \\
\hline $231 / 245$ & 52 & 24 & 1050 & A & $\mathrm{M}-\mathrm{H}$ & 1 \\
\hline $231 / 245$ & 52 & 24 & 1051 & A & $\mathrm{X}$ & 1 \\
\hline $231 / 245$ & 52 & 24 & 1052 & A & $\mathrm{X}$ & $1+$ \\
\hline $231 / 245$ & 52 & 24 & 1054 & B & $\mathrm{X}$ & 1 \\
\hline $231 / 245$ & 52 & 24 & 1055 & A & * & 0 \\
\hline 245 & 28 & 22 & 0787 & A & $\mathrm{L}$ & 1 \\
\hline 245 & 28 & 22 & 0788 & A & * & 0 \\
\hline 245 & 28 & 24 & 0973 & D & * & $0+$ \\
\hline 245 & 28 & 24 & 0974 & B & * & $0+$ \\
\hline 245 & 28 & 24 & 0976 & A & * & 0 \\
\hline 245 & 28 & 24 & 0977 & $\mathrm{C}$ & * & 0 \\
\hline 245 & 28 & 24 & 0978 & B & * & 0 \\
\hline 245 & 28 & 24 & 0980 & A & * & 0 \\
\hline 245 & 28 & 24 & 0982 & A & M & 2 \\
\hline 245 & 28 & 24-Base & 1145 & B & L-M & 1 \\
\hline 245 & 28 & 24-Base & 1147 & A & * & 0 \\
\hline \multicolumn{7}{|c|}{ Illustrated (but not included on Composite $\mathrm{H}$ ): } \\
\hline 231 & 20 & 24 & 0377 & $\mathrm{D}$ & * & $0+$ \\
\hline 231 & 20 & 24 & 0380 & $\mathrm{D}$ & $\mathrm{X}$ & $1+$ \\
\hline 231 & 20 & 24 & 0381 & B & L-M & $2-3$ \\
\hline 231 & 20 & 24 & 0382 & B & $\mathrm{X}$ & 1 \\
\hline 231 & 20 & 24 & 0383 & D & * & $0+$ \\
\hline 231 & 20 & 24 & 0384 & B & L-M & 2 \\
\hline 231 & 34 & 24 & 0725 & A & L & $2+$ \\
\hline 231 & 34 & 24 & 0727 & A & * & $0+$ \\
\hline 231 & 34 & 24 & 0728 & B & $\mathrm{L}$ & 2 \\
\hline \multicolumn{7}{|l|}{ Not Illustrated: } \\
\hline 231 & 25 & 24 & 0312 & B & $\mathrm{X}$ & 2 \\
\hline 231 & 25 & 24 & 0313 & B & $\mathrm{L}$ & 2 \\
\hline 231 & 35 & 24 & 0817 & B & $\mathrm{X}$ & 1 \\
\hline 231 & 35 & 24 & 0819 & D & $X$ & $1+$ \\
\hline
\end{tabular}

TABLE 27-15

Summary of Archeomagnetic Results for Composite $\mathrm{H}$

\begin{tabular}{|c|c|c|c|c|c|c|c|c|c|c|c|c|c|c|}
\hline \multirow[b]{2}{*}{ Feature } & \multicolumn{5}{|c|}{ Cooling Context } & \multicolumn{5}{|c|}{ Lowest Temperature of Movement } & \multicolumn{4}{|c|}{ Maximum Number of Movements } \\
\hline & A & B & C & D & E & $*$ & $\begin{array}{l}\text { L or } \\
\text { L-M }\end{array}$ & $\begin{array}{l}\mathrm{M} \text { or } \\
\mathrm{M}-\mathrm{H}\end{array}$ & $\mathrm{H}$ & $\mathrm{X}$ & 0 & $\begin{array}{l}1,1+\text {, } \\
\text { or } 1-2\end{array}$ & $\begin{array}{l}2,2+, \\
\text { or } 2-3\end{array}$ & $\begin{array}{l}3 \text { or } \\
\text { more }\end{array}$ \\
\hline 181 & 18 & 11 & 4 & 2 & 1 & 18 & & 3 & 1 & 14 & 18 & 15 & 2 & \\
\hline $181 / 231$ & 2 & 2 & & & & 2 & & & 1 & 1 & 2 & 2 & & \\
\hline 231 & 3 & & 1 & 2 & & 2 & 1 & 1 & & 2 & 2 & 3 & 1 & \\
\hline $231 / 245$ & 9 & 7 & 2 & & & 6 & 3 & 3 & 1 & 5 & 6 & 9 & 3 & \\
\hline 245 & 6 & 3 & 1 & 1 & & 8 & 2 & 1 & & & 8 & 2 & 1 & \\
\hline
\end{tabular}




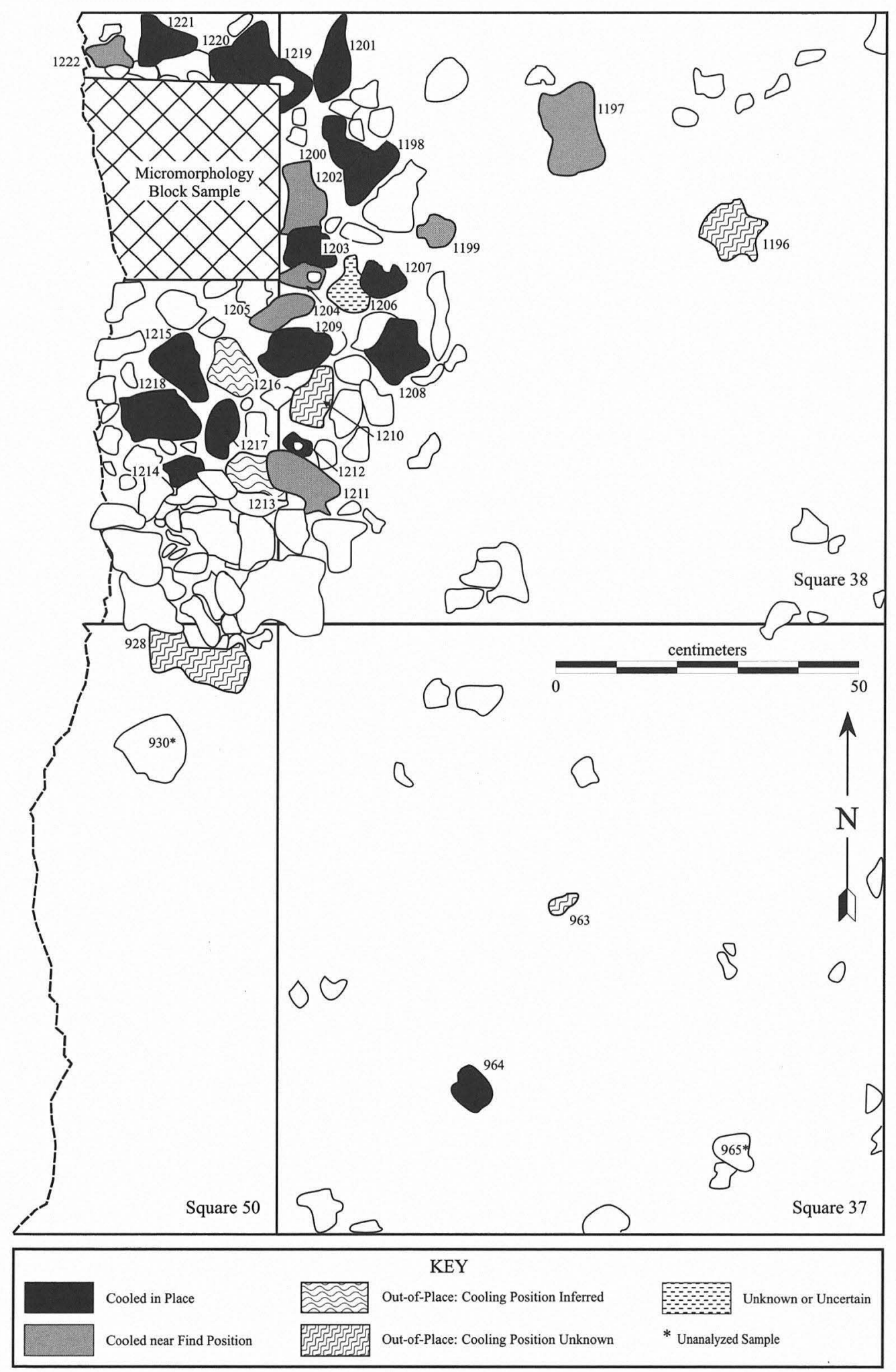

FIGURE 27-88. Detail of Composite H: Feature 181 in Squares 37, 38, 50, and 51, Level 24 (ca. 95.65 m). 


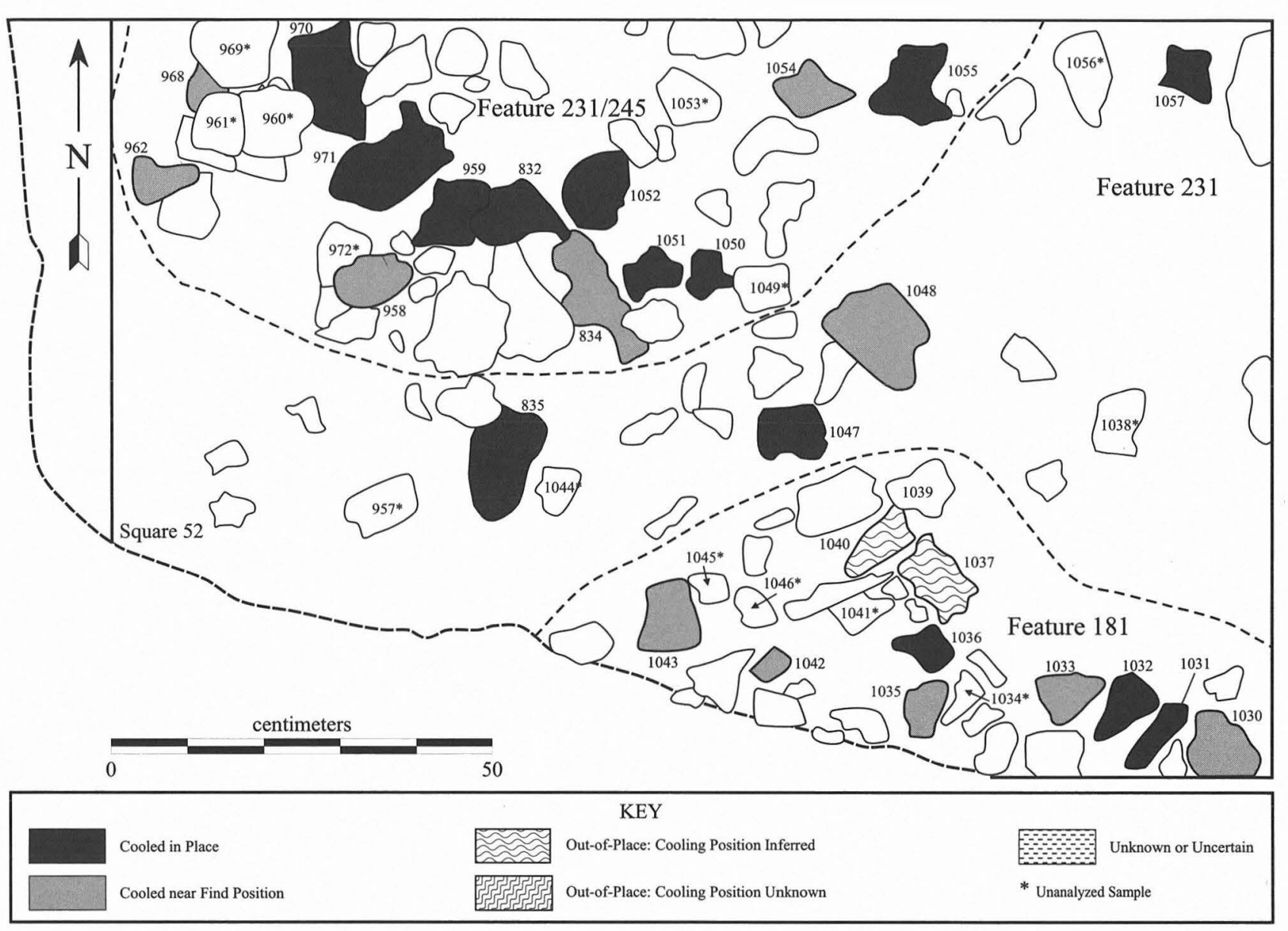

FIGURE 27-89. Detail of Composite H: Features 181 and 231/245 in Squares 52 and 53, Level 24 (ca. 95.65 m).
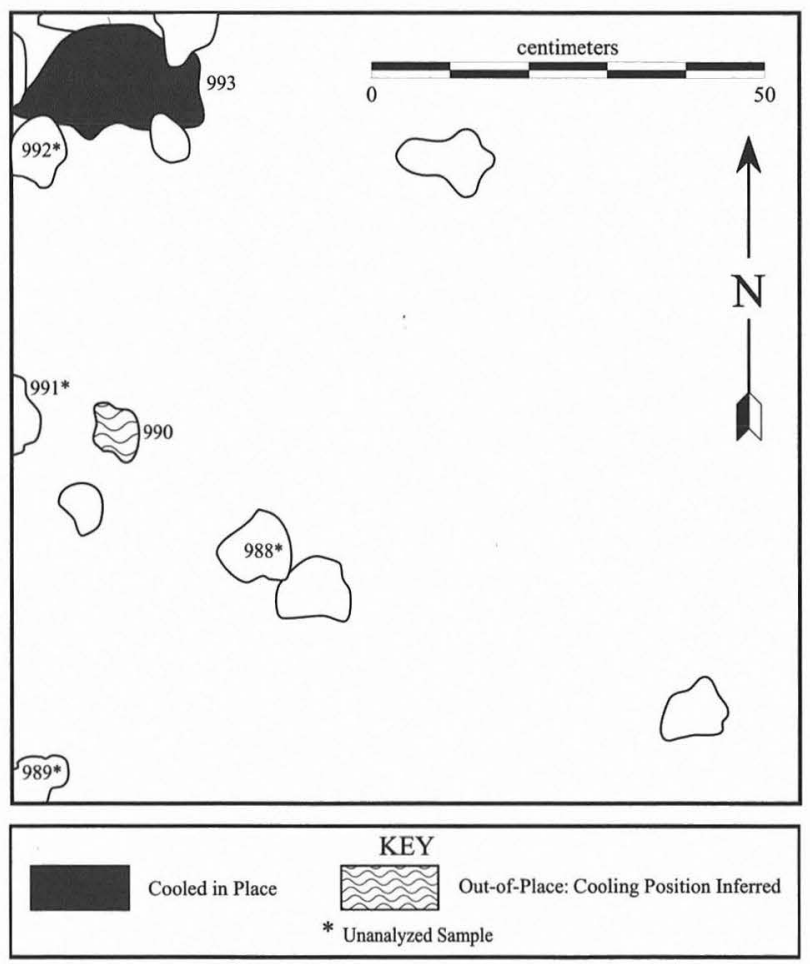

Figure 27-90. Detail of Composite H: Square 39, Level 24 (ca. $95.65 \mathrm{~m})$. especially true for Features 181 and 245 which are seen, respectively, as an arc of small burned rocks centered on Square 51 and a cluster of larger burned rocks in Square 28. Archeomagnetic results for the Composite I are listed by sample number on Table 27-16 and are summarized by subfeature designation in Table 27-17. Stereonets are shown in Figures 27-95 and 27-96.

Feature 258 was defined as an area of scattered rocks in the eastern half in Square 38 (Figure 27-97). Three archeomagnetic samples from this feature were analyzed, and all were found to have cooled from very high temperatures without moving during their last use (see Table 27-16). However, two (AM-1254 and AM-1255) were displaced after cooling (see also Table 27-17). The similarity in the final direction of their remanence components (see Figure 27-96) suggests that they were moved in roughly the same general direction (north-northeast) by about the same magnitude (ca. $120^{\circ}$ ). Thus they may have last cooled near each other (just south of where they were found) before being displaced in the same manner, although how or why they were moved is unknown. The third sample (AM-1253), from a larger rock along the northern perimeter of Feature 258, remained in or very near its final cooling location until excavated (see Table 27-16). 


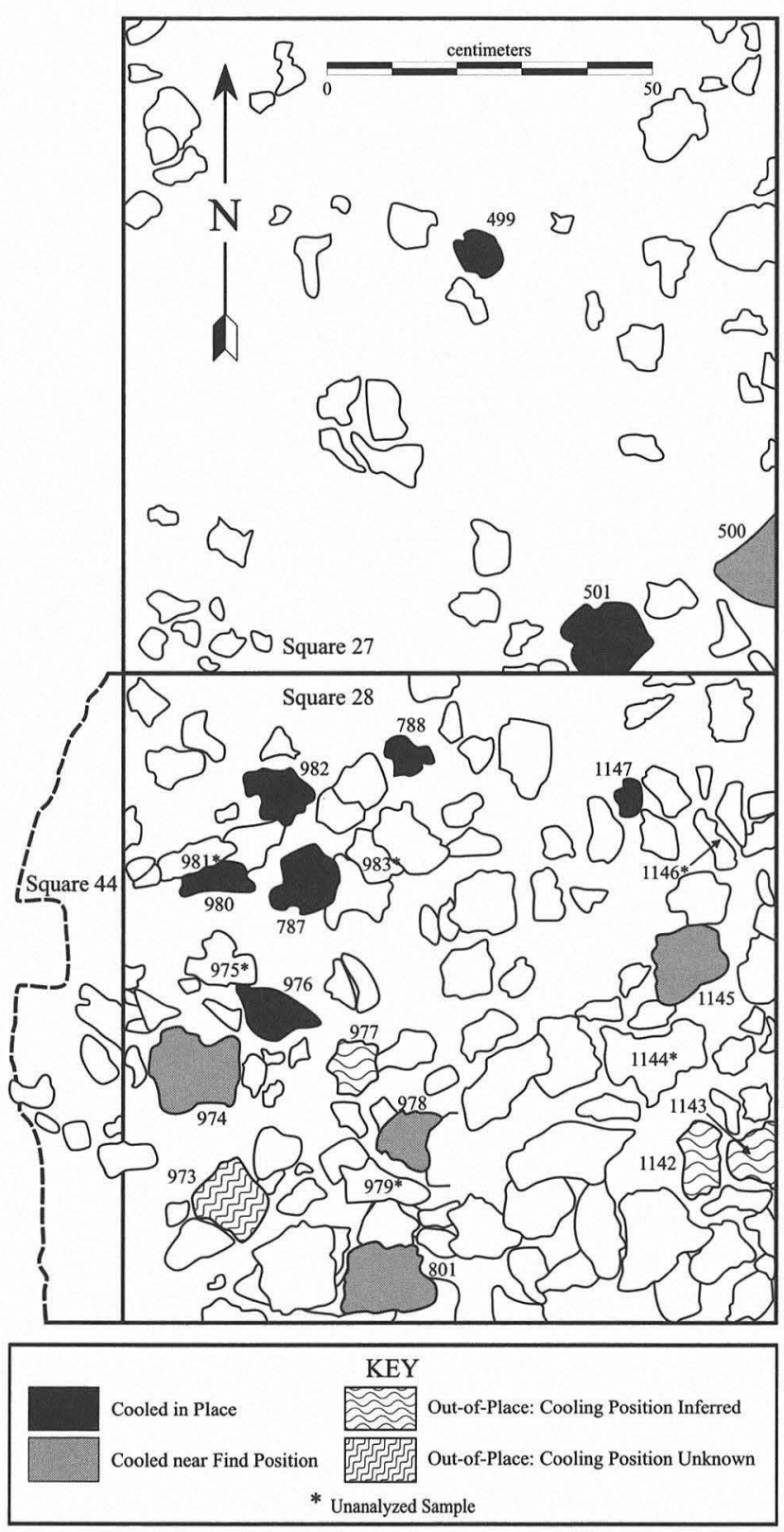

FIGURE 27-91. Detail of Composite H: Feature 245 in Squares 27, 28, and 44, Level 24 (ca. $95.65 \mathrm{~m}$ ).

Feature 181 continued into Level 25 . Its original basin shape is reflected by the continuing contraction of rocks in Squares 50,51, and the southern half of 52, toward TxDOT Square E28/S78 (Figures 27-97 and 27-98). Nine of the 10 samples analyzed from this feature in Level 25 were in or near their final cooling positions (see Tables 27-16 and 2717; Figure 27-95). Internal consistency in rotation direction of several rocks (including AM-1235 and AM-1239), combined with the observation that 5 of the rocks cooled with little or no movement from temperatures in excess of $500^{\circ} \mathrm{C}$, indicates that their magnetic component changes are most likely the result of movement while cooling rather than partial heating. However, with the exception of AM-1085 in

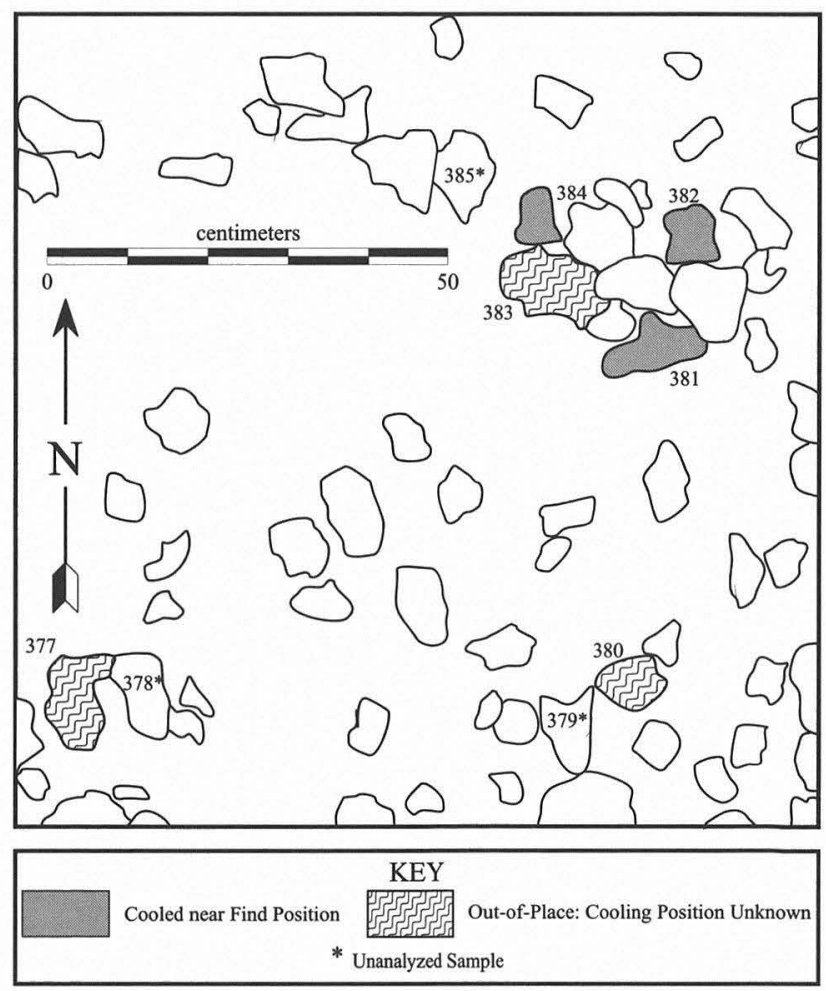

FIGURE 27-92. Feature 231 in Square 20, Level 24 (ca. 95.65 m).

Square 52, none of the Feature 181 rocks experienced more than one movement while cooling. Reconstruction of the likely rotations of these rocks suggest settling toward the center of Feature 181, probably as the fuel load supporting the rocks disintegrated. The final cooling location of the one significantly displaced Feature 181 rock (AM-1236) was probably just south of where it was found. Two other rocks (AM1018 and AM-1024, both coded as "231/245" in Table 27-16) recovered at the extreme southern edge of Feature 181 were also displaced after they were completely cooled. Vector rotation reconstructions suggest that they began rotating toward the east and northeast, respectively, while still warm and continued to settle in the same directions after they were completely cooled. The archeomagnetic data in the lower portion of Feature 181 clearly indicate that most rocks were heated to temperatures approaching or exceeding the Curie point and cooled in or near the positions in which they were found.

The small lobe of burned rocks along the southern edge of Square 52 was assigned to Feature 181. As seen in Figure 27-98, these rocks were well separated from another cluster along the northern edge that continued into Square 28. Rocks from the western half of this northern cluster seem to be associated with Feature 245. Six of these more northerly Square 52 rocks are designated " $231 / 245$ " on Table 27-16 while AM-1092 is assigned to Feature 245 and one of the smaller rocks (AM-1083), farther east, is considered a Feature 231 sample. All rocks sampled in Square 28 are assigned 


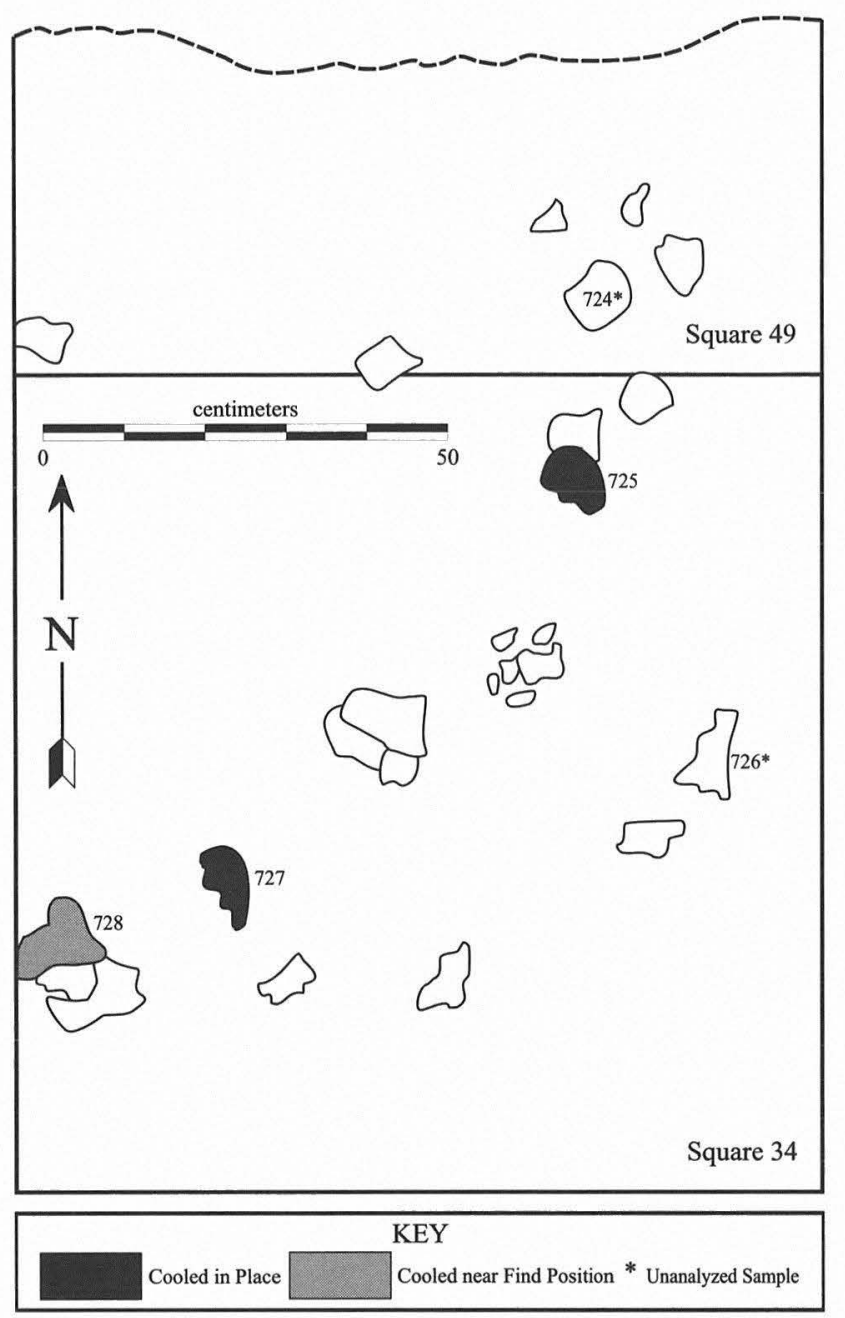

Figure 27-93. Feature 231 in Squares 34 and 49, Level 24 (ca. $95.65 \mathrm{~m})$.

to Feature 245 (Figure 27-99) as are two small rocks (AM-665 and AM-666 in Figure 27-100) from along the southern edge of Square 27. The two more northerly rocks from Square 27 are included in Feature 231 (see Table 27-16).

Of the six rocks classified as " $231 / 245$ " in Square 52, only one (AM-1090) was displaced from its final cooling location (see Table 27-16), although the prior position of this rock was probably only slightly south of where it was recovered (see Figure 27-96). The remaining rocks were cooled in or near the locations shown in Figure 27-98. These six rocks can be divided into two groups based on their archeomagnetic results. Three (AM-1055, AM-1091, and AM-1108) evidenced very little if any movement while cooling from temperatures in excess of the Curie point. Conversely, the others (AM-1090, AM-1093, and AM-1111) apparently experienced a single large magnitude disturbance between $300^{\circ}$ and $500^{\circ} \mathrm{C}$. The significance of these two groups, however, is unclear.

All nine of the Feature 245 rocks were cooled in or very near the locations in which they were found, as were two small Feature 231/245 rocks along the boundary between Squares 27 and 28 (AM-665 and AM-666; see Figure 27100). More than half ( 5 of 9 [or 7 of 11 if the Square 27 rocks are included]) had a single component of magnetization (see Table 27-17). Note the tight clustering of the measured TRM directions on the Feature 245 stereonet in Figure 2796. The four Feature 245 rocks (AM-1010, AM-1012, AM1154, and AM-1092) that were moved came to rest in their final positions at temperatures less than about $350^{\circ} \mathrm{C}$ following one or two dislocations while cooling (see Table 27-16). Between $200^{\circ}$ and $350^{\circ} \mathrm{C}$ rocks AM- 1010 and AM1012 were moved somewhat northward while AM-1092 and AM-1154 experienced more pronounced northwesterly displacements in this same temperature range. Nearly identical postcooling rotations are inferred for AM-665 and AM666 , which both may have rotated to the southwest about $20^{\circ}$ (toward the larger group of rocks in Square 28). Taken together, these rotation reconstructions are consistent with field observations that the Feature 245 rocks lay in a shallow basin.

Two Feature 231 samples from Square 27 were also analyzed (Figure 27-100). Rock AM-663 was clearly displaced after cooling while AM-662, though cooled near its find location, was last moved at some temperature less than $250^{\circ} \mathrm{C}$.

Just to the north of the area shown in Composite I, Feature 233 consisted of a dense cluster of burned rocks partially exposed in the southeastern corner of TARL Square 20 along with a more dispersed scatter nearby (Figure 27101). Archeomagnetic analysis was conducted on four samples from the cluster and one from the scatter. The results reveal that three of the rocks (AM-472, AM-473, and AM-476) from the main cluster moved significantly while cooling but at quite different temperatures (see Table 27-16). Furthermore, they did settle somewhat after cooling (see Table 27-16 and stereonets in Figure 27-96). The other rock (AM-477) from this main group did not move appreciably while cooling but was dislocated thereafter. The rock (AM469) analyzed from the scatter, despite a weak remanence, seems to have cooled near where it was found from temperatures of perhaps $300^{\circ} \mathrm{C}$.

Finally, two small rocks (not shown on Composite I or included on the stereonets) were analyzed from Level 25 in Squares 25 and 26 (Figure 27-102). The diffuse scatter of rocks exposed in these squares lay north of the main Feature 231 concentration but may be related to the same occupation(s). Although both AM-409 and AM-418 cooled in or near where they were found (see Table 27-16), neither did so from significant temperatures, and both probably experienced at least two dislocations while cooling from higher temperatures.

In summary, the archeomagnetic results clearly indicate that the rocks in Features 181 and 245 largely cooled in place, many from high temperatures. However, in both 


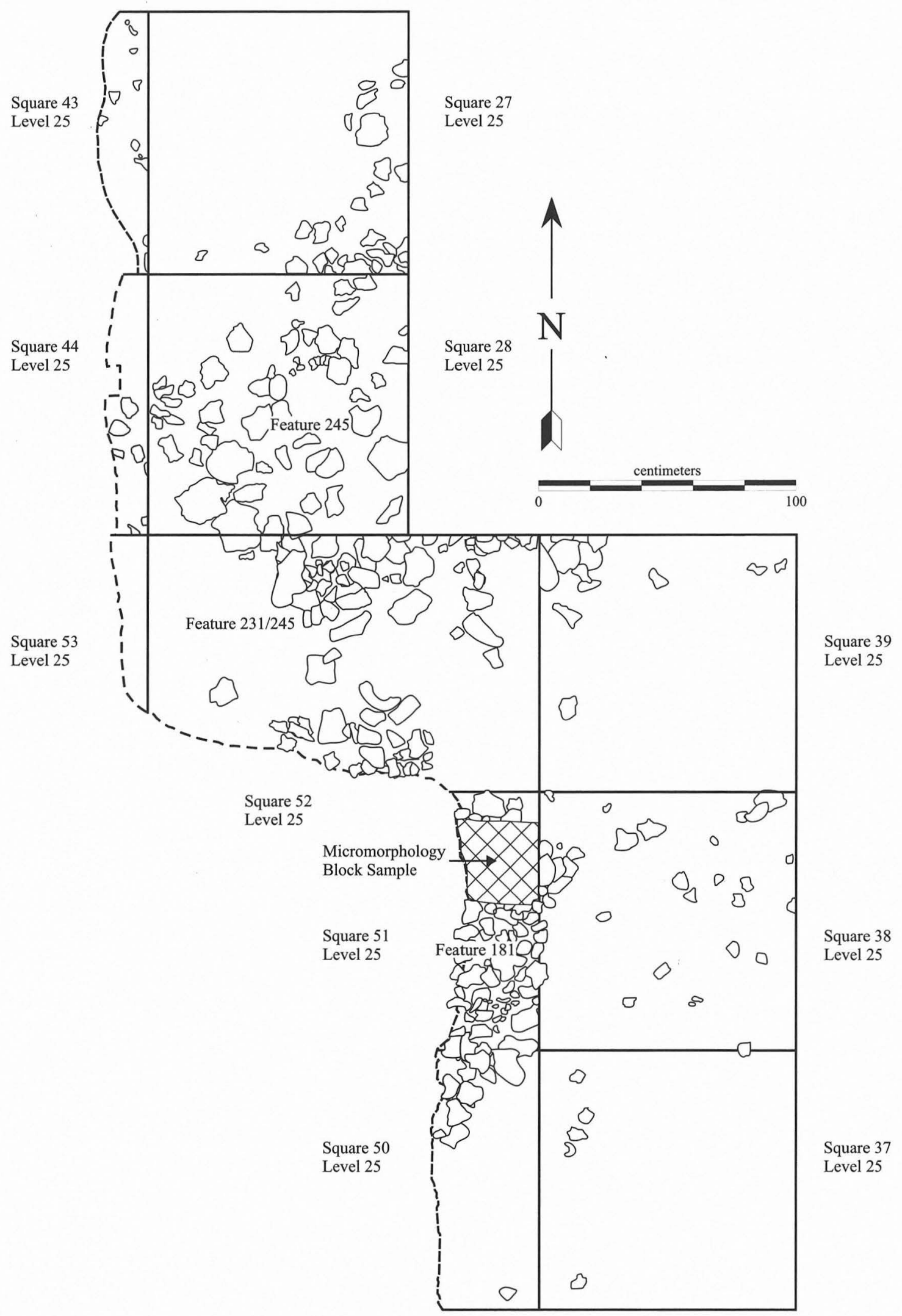

FIGURE 27-94. Feature 231 and associated subfeatures, Composite I: East and South Blocks, Level 25 (ca. 95.60 m). 
TABLE 27-16

Archeomagnetic Interpretation of Vectoral Data, Composite I

Cooling Context
A cooled in place
B cooled near find position
C out-of-place: cooling location inferred
D out-of-place: unknown cooling orientation
E uncertain / unknown

Lowest Temperature of Movement

* no discernible movement

$\mathrm{X}$ unknown (AF demagnetized)

$\mathrm{V}$ possible viscous magnetization

$\mathrm{L}$ less or equal to $250^{\circ} \mathrm{C}$

$\mathrm{M}$ between $250^{\circ}$ and $450^{\circ} \mathrm{C}$

$\mathrm{H}$ greater than $450^{\circ} \mathrm{C}$

\begin{tabular}{|c|c|c|c|c|c|c|}
\hline Feature No. & Square & Level & $\begin{array}{l}\text { Sample No. } \\
\text { (AM- ) }\end{array}$ & $\begin{array}{l}\text { Cooling } \\
\text { Context }\end{array}$ & $\begin{array}{c}\text { Lowest Temperature } \\
\text { of Movement }\end{array}$ & $\begin{array}{c}\text { No. of Discernible } \\
\text { Movements while Cooling }\end{array}$ \\
\hline 258 & 38 & $25 \mathrm{~A}$ & 1253 & $\mathrm{~A}$ & $*$ & $0+$ \\
\hline 258 & 38 & $25 \mathrm{C}$ & 1254 & $\mathrm{D}$ & $*$ & $0+$ \\
\hline 258 & 38 & $25 \mathrm{C}$ & 1255 & $\mathrm{D}$ & $*$ & $0+$ \\
\hline 181 & 38 & $25 B$ & 1235 & B & $*$ & $0+$ \\
\hline 181 & 50 & $25 B$ & 1020 & A & $\mathrm{H}$ & 1 \\
\hline 181 & 50 & $25 B$ & 1025 & A & $\mathrm{X}$ & 1 \\
\hline 181 & 51 & 25 & 1233 & A & * & $0+$ \\
\hline 181 & 51 & 25 & 1236 & $\mathrm{C}$ & $\mathrm{X}$ & 1 \\
\hline 181 & 51 & 25 & 1238 & A & $*$ & 0 \\
\hline 181 & 51 & 25 & 1239 & B & $\mathrm{L}$ & 1 \\
\hline 181 & 52 & 24 & 1043 & B & $\mathrm{X}$ & 1 \\
\hline 181 & 52 & 25 & 1085 & A & M & 2 \\
\hline 181 & 52 & 25 & 1086 & A & $*$ & 0 \\
\hline $181 / 231$ & 50 & $25 B$ & 1018 & $\mathrm{C}$ & L-M & 2 \\
\hline $181 / 231$ & 50 & $25 \mathrm{~B}$ & 1024 & $\mathrm{D}$ & $\mathrm{X}$ & $1+$ \\
\hline 231 & 27 & 25 & 0662 & B & $\mathrm{L}$ & 2 \\
\hline 231 & 27 & 25 & 0663 & $\mathrm{D}$ & $\mathrm{X}$ & 1 \\
\hline 231 & 39 & 24 & 0993 & A & M & 2 \\
\hline 231 & 52 & 25 & 1083 & A & $\mathrm{X}$ & 2 \\
\hline $231 / 245$ & 27 & 25 & 0665 & A & $*$ & 0 \\
\hline $231 / 245$ & 27 & 25 & 0666 & A & $*$ & 0 \\
\hline $231 / 245$ & 52 & 24 & 1055 & A & $*$ & 0 \\
\hline $231 / 245$ & 52 & 25 & 1090 & $\mathrm{C}$ & $\mathrm{X}$ & 1 \\
\hline $231 / 245$ & 52 & 25 & 1091 & A & $*$ & 0 \\
\hline $231 / 245$ & 52 & 25 & 1093 & A & M & $1+$ \\
\hline $231 / 245$ & 52 & 25 & 1108 & A & $*$ & 0 \\
\hline $231 / 245$ & 52 & 25 & 1111 & B & M-H & $1+$ \\
\hline 245 & 28 & 25 & 1010 & A & L-M & 1 \\
\hline 245 & 28 & 25 & 1012 & A & L-M & 1 \\
\hline 245 & 28 & 25 & 1013 & B & * & 0 \\
\hline 245 & 28 & 25 & 1015 & A & $*$ & 0 \\
\hline 245 & 28-East & 25 & 1154 & A & L-M & 2 \\
\hline 245 & 28-East & 25 & 1156 & A & $*$ & 0 \\
\hline 245 & 28-East & 25 & 1157 & $\mathrm{~A}$ & $*$ & $0+$ \\
\hline 245 & 28-East & 25 & 1158 & A & $*$ & $0+$ \\
\hline 245 & 52 & 25 & 1092 & B & M & $2+$ \\
\hline \multicolumn{7}{|c|}{ Illustrated (but not included on Composite I): } \\
\hline 233 & 20 & $25 \mathrm{~B}$ & 0469 & B & M & $0+$ \\
\hline 233 & 20 & East Wall Profile & 0472 & B & $\mathrm{L}$ & $2+$ \\
\hline 233 & 20 & $25 \mathrm{~B}$ & 0473 & B & $\mathrm{H}$ & $1+$ \\
\hline 233 & 20 & $25 B$ & 0476 & A & M & 2 \\
\hline 233 & 20 & South Wall Profile & 0477 & $\mathrm{D}$ & $*$ & $0+$ \\
\hline 231 & 25 & 25 & 0409 & A & $\mathrm{L}$ & 2 \\
\hline 231 & 26 & 25 & 0418 & B & M & 2 \\
\hline
\end{tabular}


TABLE 27-17

Summary of Archeomagnetic Results for Composite I

\begin{tabular}{|c|c|c|c|c|c|c|c|c|c|c|c|c|c|c|}
\hline \multirow[b]{2}{*}{ Feature } & \multicolumn{5}{|c|}{ Cooling Context } & \multicolumn{5}{|c|}{ Lowest Temperature of Movement } & \multicolumn{4}{|c|}{ Maximum Number of Movements } \\
\hline & A & B & $\mathrm{C}$ & $\mathrm{D}$ & $\mathrm{E}$ & $*$ & $\begin{array}{c}\text { L or L- } \\
M\end{array}$ & $\begin{array}{l}\mathrm{M} \text { or } \\
\mathrm{M}-\mathrm{H}\end{array}$ & $\mathrm{H}$ & $\mathrm{X}$ & 0 & $\begin{array}{l}1,1+, \\
\text { or } 1-2\end{array}$ & $\begin{array}{l}2,2+, \\
\text { or } 2-3\end{array}$ & $\begin{array}{l}3 \text { or } \\
\text { more }\end{array}$ \\
\hline $\begin{array}{c}181 \\
181 / 231\end{array}$ & 6 & 3 & $\begin{array}{l}1 \\
1\end{array}$ & 1 & & 4 & $\begin{array}{l}1 \\
1\end{array}$ & 1 & 1 & $\begin{array}{l}3 \\
1\end{array}$ & 4 & $\begin{array}{l}5 \\
1\end{array}$ & $\begin{array}{l}1 \\
1\end{array}$ & \\
\hline 231 & 2 & 1 & & 1 & & & 1 & 1 & & 2 & & 1 & 3 & \\
\hline $231 / 245$ & 6 & 1 & 1 & & & 5 & & 2 & & 1 & 5 & 3 & & \\
\hline 245 & 7 & 2 & & & & 5 & 3 & 1 & & & 5 & 2 & 2 & \\
\hline 258 & 1 & & & 2 & & 3 & & & & & 3 & & & \\
\hline
\end{tabular}

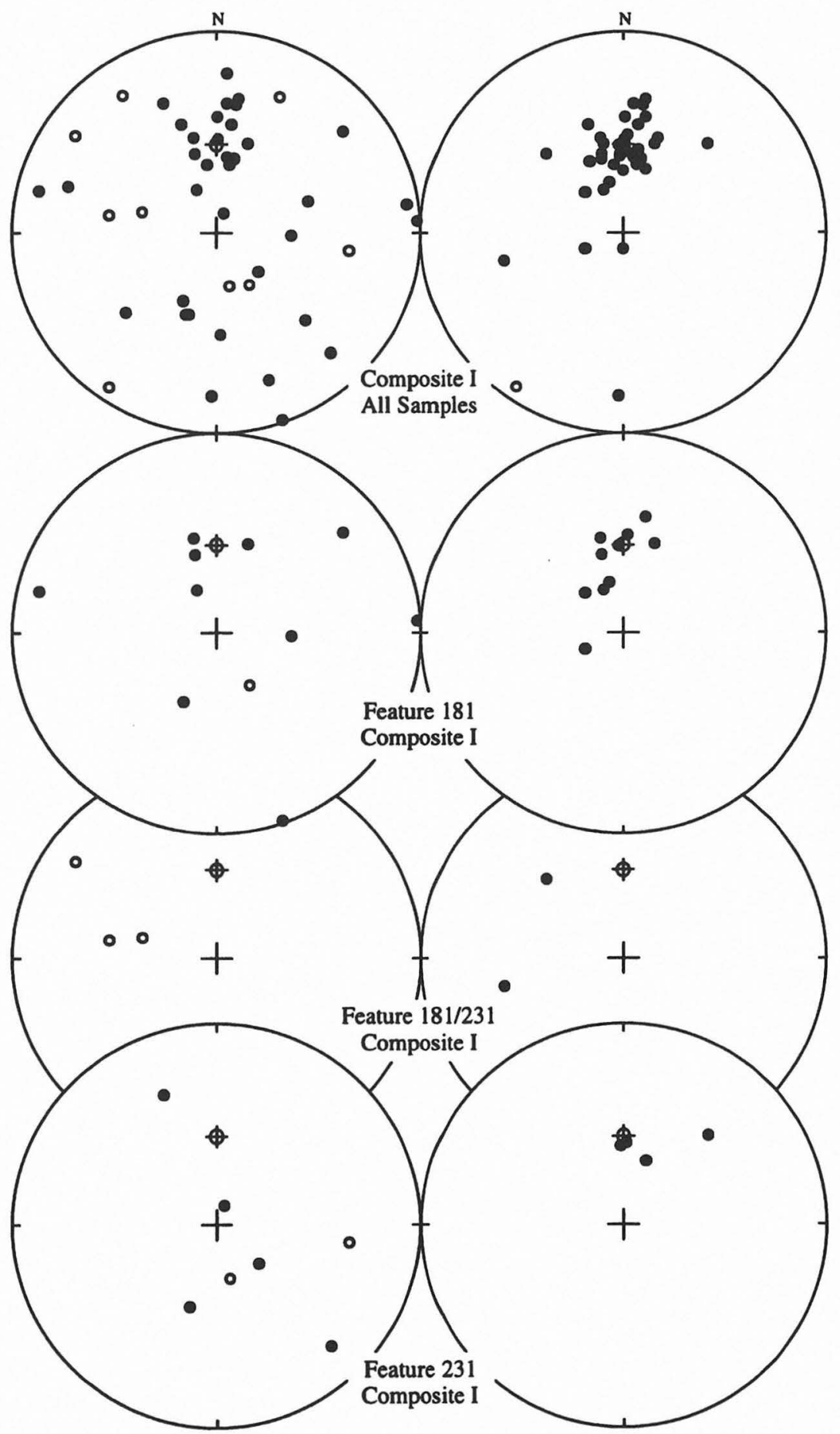

FIGURE 27-95. Stereoplots of results for Composite I, including subfeatures. 


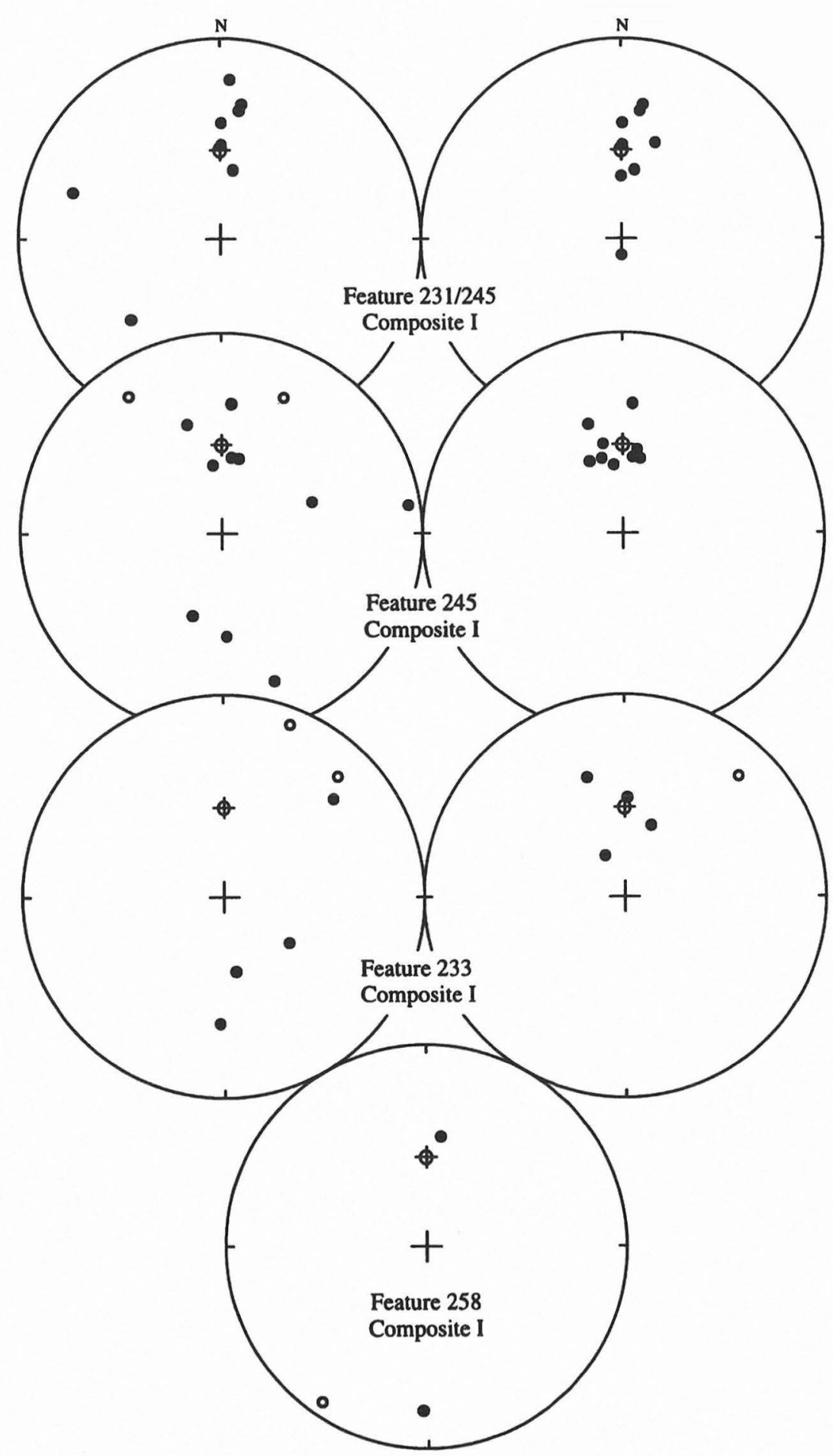

FIGURE 27-96. Stereoplots of results for Composite I subfeatures.

features one or more rocks were moved quite significantly after cooling to between $200^{\circ}$ and $350^{\circ} \mathrm{C}$. On the other hand, those rocks not clearly associated with a particular subfeature and therefore assigned (at least in part) to Feature 231 were more likely to have experienced a greater overall degree of movement both during and after cooling.
Feature 231, Composite J: East and South Blocks, Level 26

Composite J (Figure 27-103) illustrates Feature 231 at the base of Level 26 (ca. $95.55 \mathrm{~m}$ ) in the East Block and the east end of the South Block. With the exception of a diffuse 


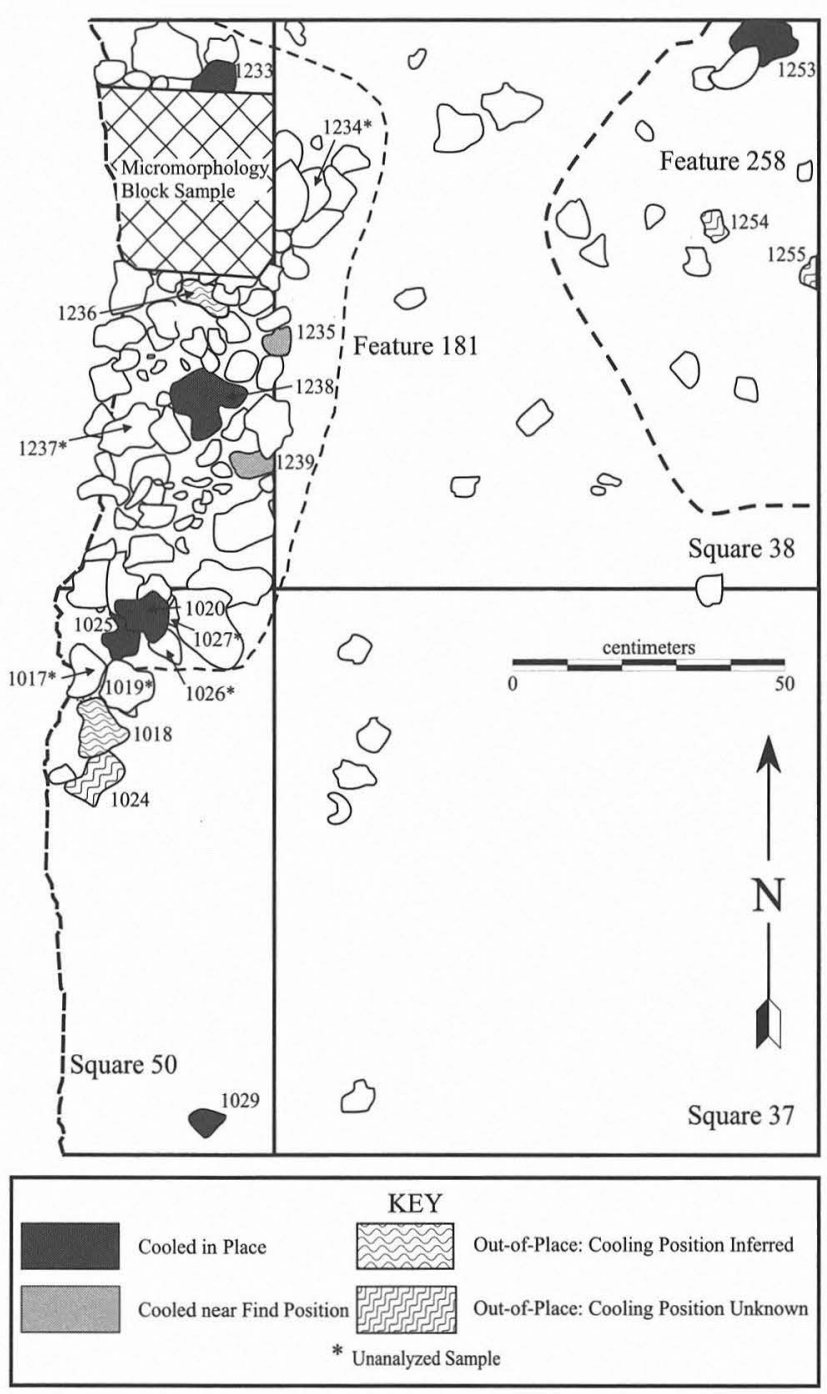

Figure 27-97. Detail of Composite I: Features 181 and 258 in Squares 37, 38, 50, and 51, Level 25 (ca. $95.60 \mathrm{~m}$ ).

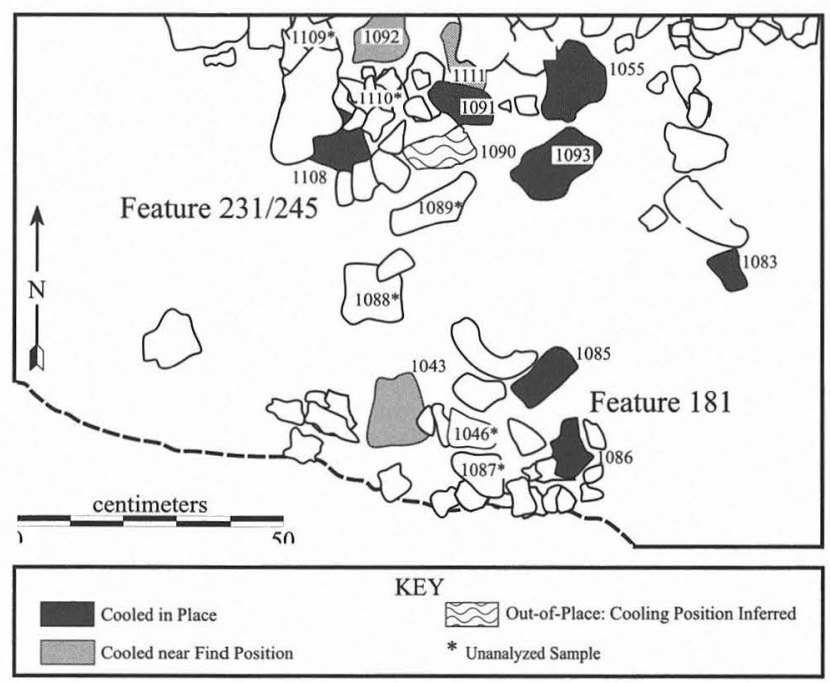

Figure 27-98. Detail of Composite I: Features 181 and 231/245 in Square 52, Level 25 (95.60 m).

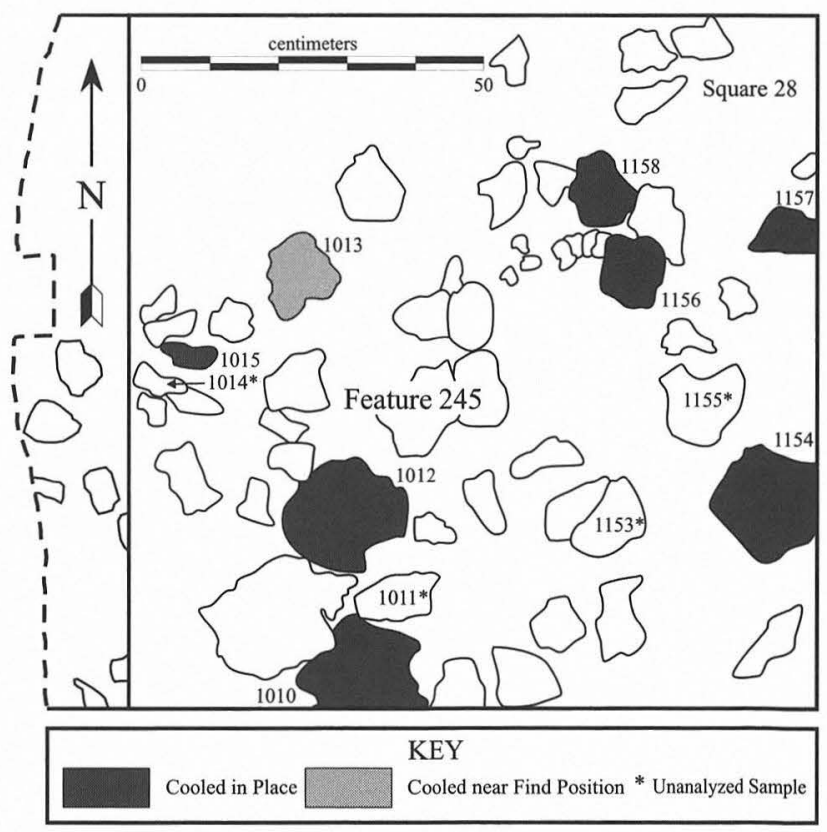

FIGURE 27-99. Detail of Composite I: Feature 245 in Squares 28 and 44, Level 25 (ca. $95.60 \mathrm{~m}$ ).

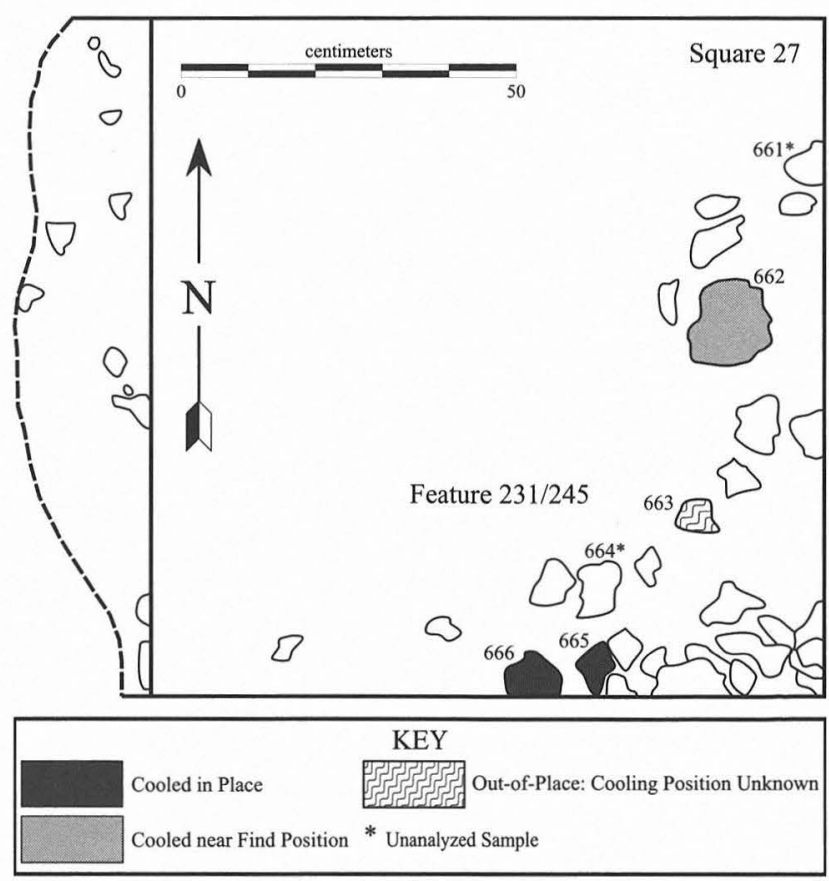

Figure 27-100. Detail of Composite I: Feature 231/245 in Squares 27 and 43, Level 25 (ca. $95.60 \mathrm{~m}$ ).

burned rock scatter at the north end of the East Block (Squares 25 through 27), the Feature 231 palimpsest deposit had been almost entirely removed at this this level (see also Figure 27-108 below). In the south half of Composite J, all that remained (other than the lower portions of Features 181 and 184) was a low-density scatter of burned rocks (within Unit II) that predated the accumulation of Feature 231 and its component subfeatures. Unlike the upper levels, nearly 


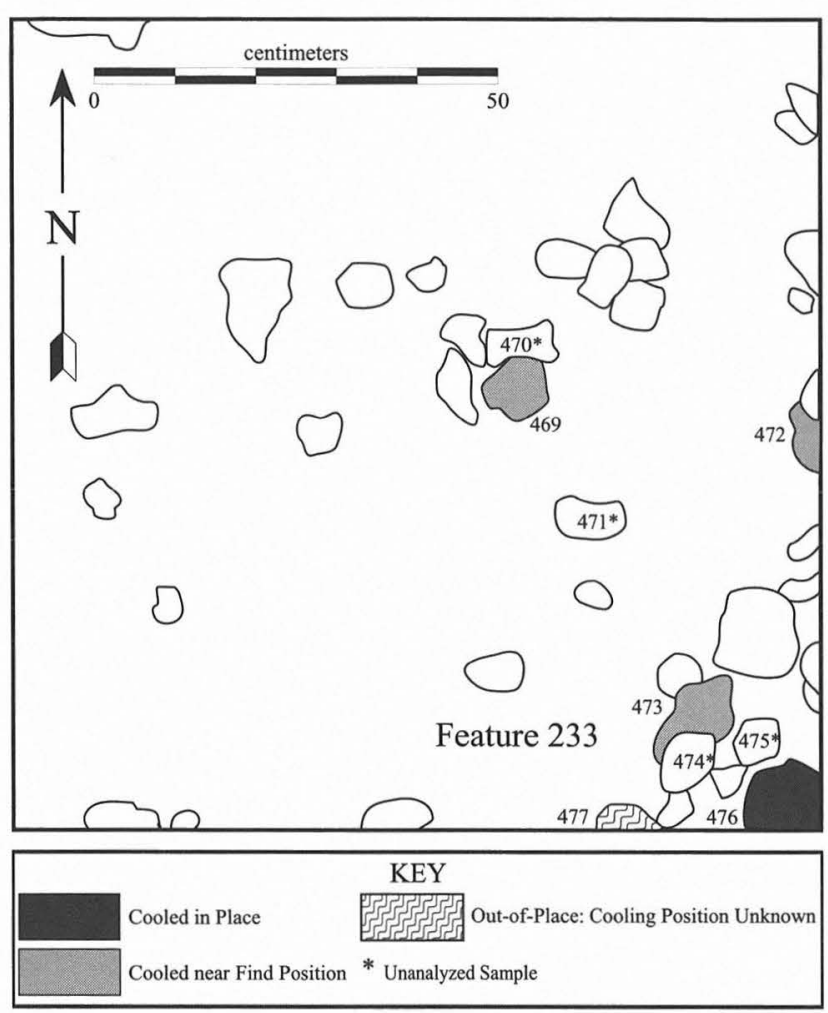

FigURE 27-101. Feature 233 in Square 20, Level 25 (ca. 95.60 m).

all of the rocks in Composite $\mathrm{J}$ can be linked with individual subfeatures. For the most part, these rocks cooled in place. However, aside from those clearly associated with Feature 245 , the majority moved while cooling (or were only partially reheated). These component changes were noted at a wide range of temperatures. Stereonets for Composite J samples are shown in Figures 27-104 and 27-105. Cooling context determinations are given in Table 27-18 and are summarized by subfeature in Table 27-19.

The base of Feature 181 was excavated in Square 51 (Figure 27-106). Two of the three analyzed rocks cooled in place, but both moved at least once while cooling (see Table 27-18). AM-1260 appears to have experienced at least two north-northwesterly displacements before cooling where it was found from about $200^{\circ}$ to $300^{\circ} \mathrm{C}$. AM- 1152 seems to have undergone a southward dislocation while cooling but then remained in its find position. AM-1151, meanwhile, does not appear to have moved at all while cooling from temperatures in excess of the Curie point but, after completely cooled, it was apparently displaced about one-quarter turn to the northeast, toward AM-1152 (see Figure 27-104). These results indicate that although the base of Feature 181 is intact, the rocks appear to have been moved more while cooling than were those rocks recovered in higher levels. Alternatively, AM-1152 and AM1260 may have been only partially reheated by some later use of Feature 181. However, consistent reconstructed rotations in the latter sample, as well as the single out-of-

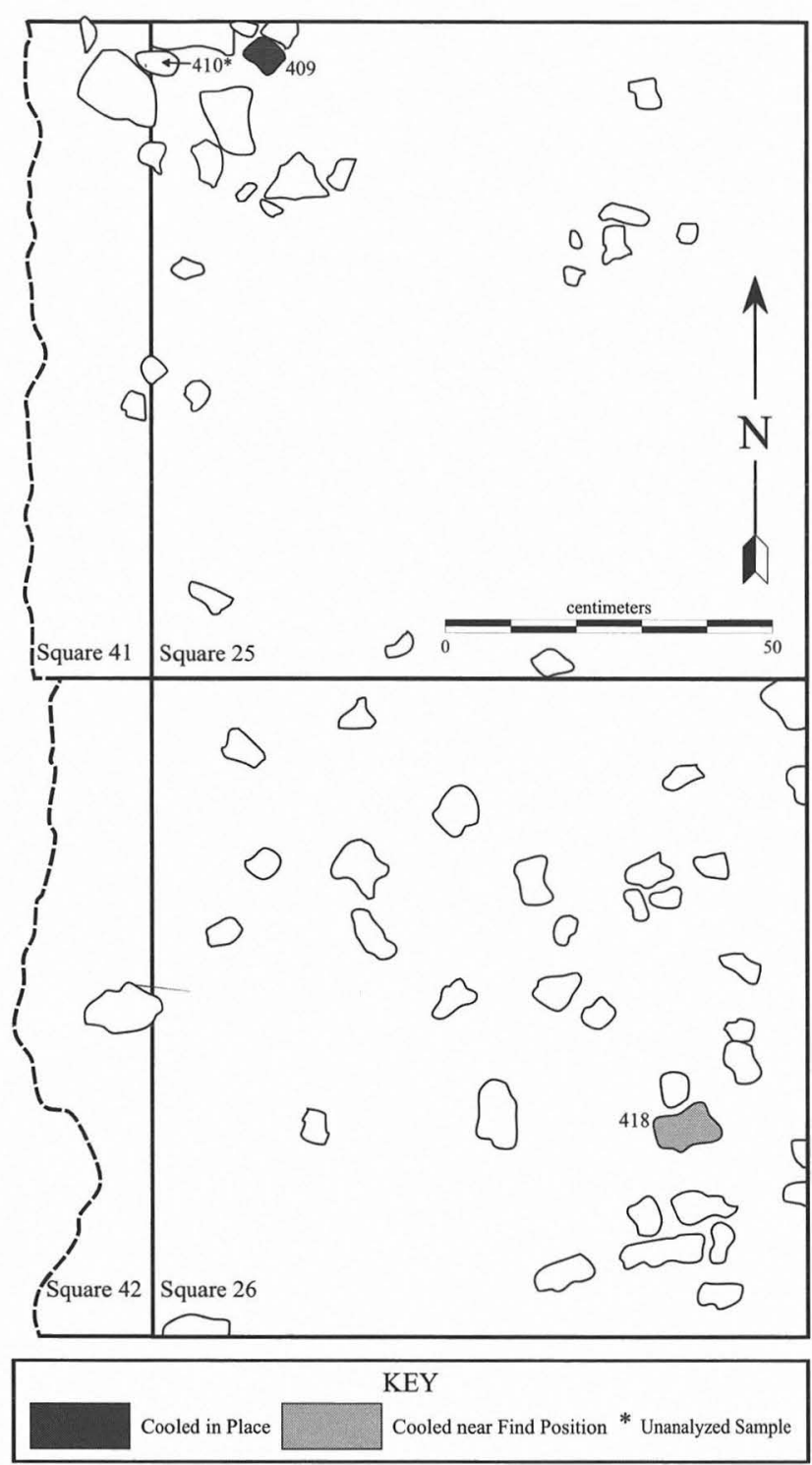

FIGURE 27-102. Feature 231 in Squares 25, 26, 41, and 42, Level 25 (ca. $95.60 \mathrm{~m}$ ).

place component for the former, argues against such an interpretation.

The base of Feature 184 also appears in Composite $\mathrm{J}$ (see Figures 27-103 and 27-106), but this feature was well within Unit II and clearly predates Feature 231. The archeomagnetic results from Feature 184 are discussed in the Individual Feature section of this report.

Virtually no burned rock was encountered in Squares 39 and 52 with the exception of a concentration of larger rocks along the southern edge of Square 28. Although the single sample analyzed from Square 52 (AM-1111; Figure 27-107) and the two smaller rocks recovered in the southeastern corner of Square 27 (AM-775 and AM-776; Figure 27-108) are almost certainly associated with Feature 245 , they are, nevertheless, coded as " $231 / 245$ " on Table 27-18. Archeomagnetic data support the contention that 


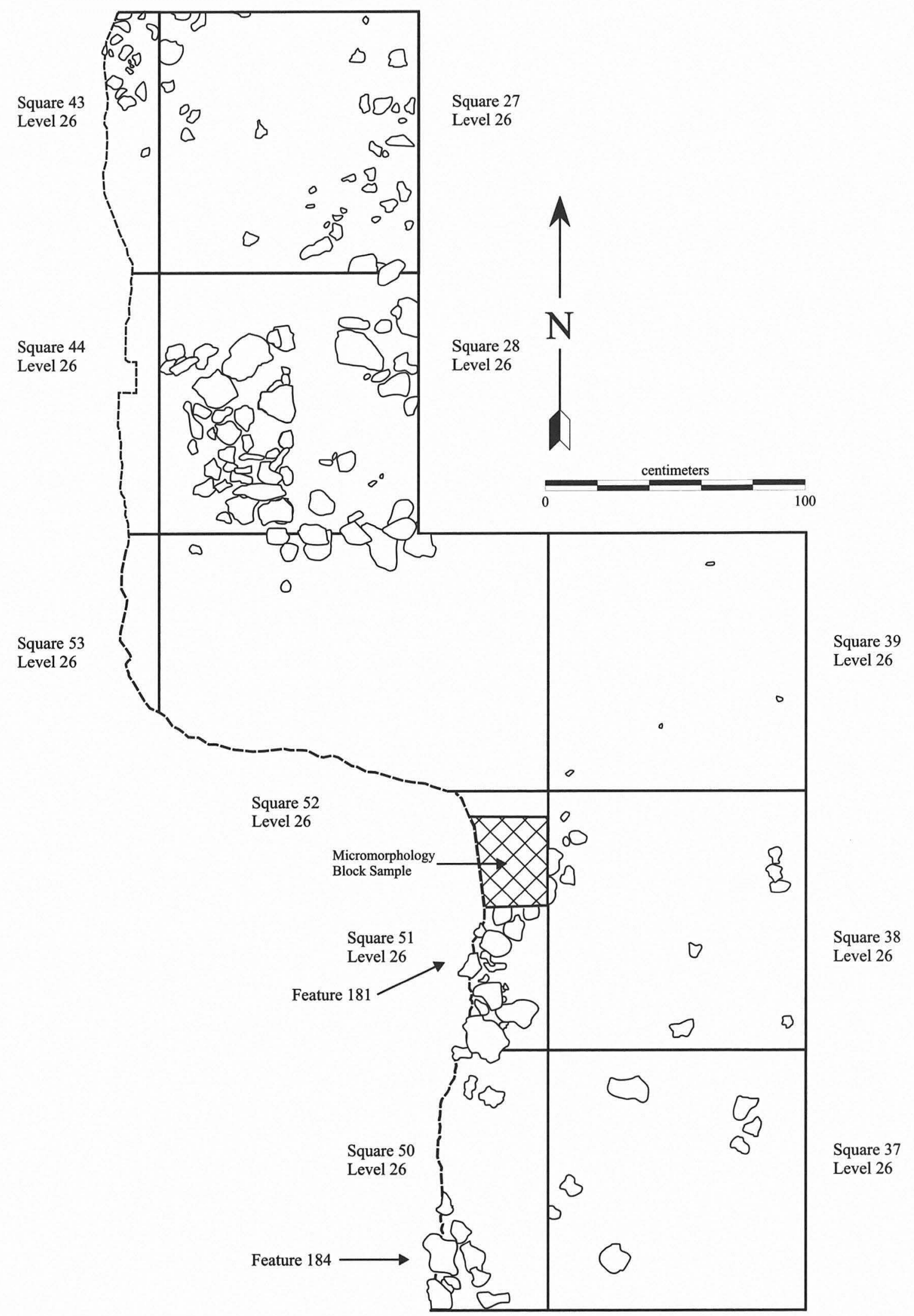

Figure 27-103. Feature 231 and associated subfeatures, Composite J: East and South Blocks, Level 26 (ca. 95.55 m). 


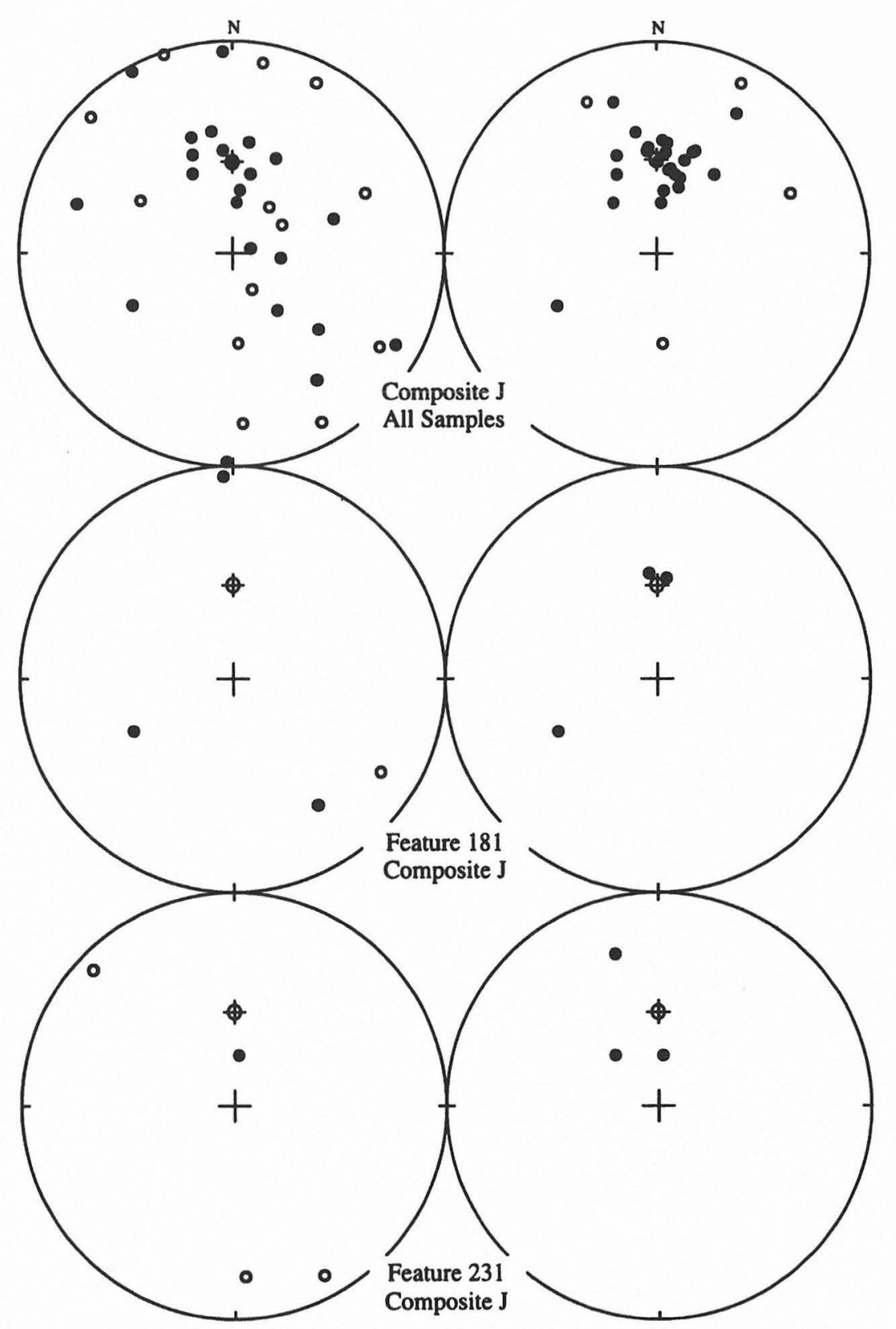

FIGURE 27-104. Stereoplots of results for Composite J, including subfeatures.

these rocks are related to Feature 245 (discussed below).

The base of Feature 245 was encountered in Level 26 in Square 28. All of the rocks in this square were assigned to Feature 245. However, the three samples most peripheral to the main cluster (AM-1165, AM-1167, and perhaps AM1164) could arguably be related to a separate, unrecognized feature cluster (see Figure 27-107).

Twelve of the 13 rocks analyzed were recovered in or near the positions in which they finished cooling (see Figure 27-105; Table 27-19). Only AM-1063 (from the northern edge of the main rock cluster) appears to have been significantly displaced after cooling. All of the Feature 245 rocks had a single component of magnetization except for those recovered along the southern and eastern edges of Square 28 (see Figure 27-107 and Table 27-18). The rocks in the southern area appear to have been moved more (in terms of magnitude) than were those in the northeastern quadrant of Square 28, which were moved more subtly (but in similar directions) during and after cooling. Only two rocks (AM1074 and AM-1165) may have been moved more than once while cooling (see Table 27-18) although in both cases the existence of the second displacement is ambiguous. This is due, in part, to the possibility that AM-1074 may have only been heated to $600^{\circ} \mathrm{C}$. Both AM-1111 and AM-1074 seem to have rotated toward what may have been a shallow depression centered on or near AM-1164. Likewise, 


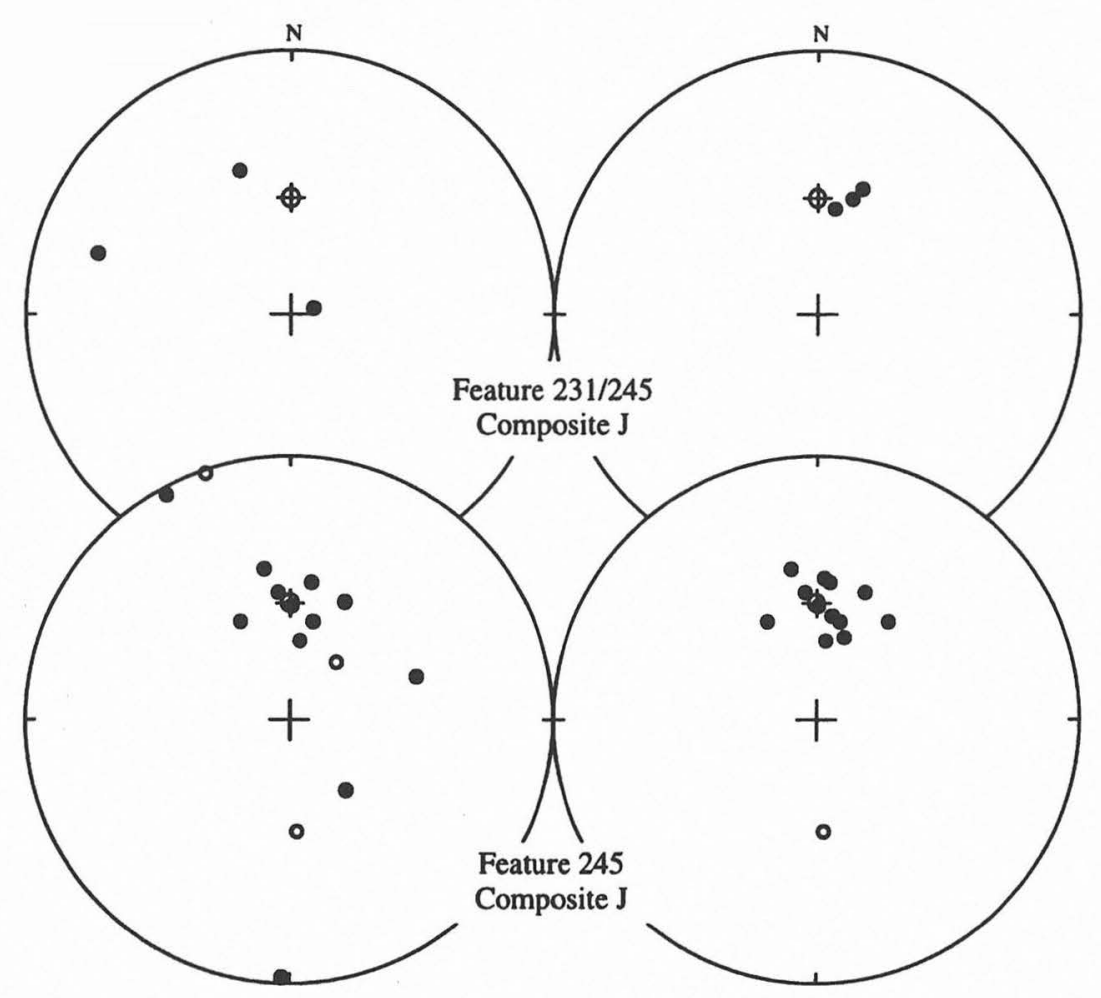

FIGURE 27-105. Stereoplots of results for Composite J subfeatures.

the postcooling displacement of AM-1063 was probably southward, toward the main burned rock cluster. In conclusion, the base of Feature 245 is composed of rocks that cooled in place (most from high temperatures; see Table 27-19), but those along its southern margin were moved more both during and after cooling. The apparent movement of rocks toward the center of the feature during and after cooling is consistent with a shallow central basin (see also Chapter 26).

Despite the fact that nearly all of the Feature 231 rocks were found to have cooled in place, most did so from only low temperatures (see Table 27-18). Three small rocks (AM773, AM-778, and AM-779) sampled in the northern half of Square 27 (see Figure 27-108) are considered to be the base of Feature 231. All three were found near their final cooling locations (see Figure 27-104), but they differed in both the number and temperature of displacements (see Table 27-19). For example, AM-779 had a single component of magnetization, while AM-778 was probably displaced at least twice while cooling. Vector rotation reconstructions are consistent with movement while cooling.

In addition to those included on Composite I, three rocks in Square 26 and one in Square 25, at the northern end of Feature 231, were analyzed (see Figure 27-108, Table 27-18). The Square 26 rocks (AM-446, AM-449, and AM-451) cooled in or near the positions in which they were recovered but only from about $250^{\circ} \mathrm{C}$. The single Square 25 rock (AM-455) was displaced after complete cooling.
In summation, Composite $\mathrm{J}$ is dominated by the bases of Features 181 and 245. Nearly all rocks associated with these two subfeatures cooled in or nearly in place. Likewise, 6 of the 7 Feature 231 rocks analyzed in Level 26 also cooled in situ but typically did so only from lower temperatures. Surprisingly, the basal Feature 181 rocks experienced more displacement than did those in upper levels. This seems counterintuitive: if a rock beneath another rock moved, then both should move. However, it is also possible that the higher rocks were more effectively heated (due to heat energy rising) than were those lower down and stayed hotter longer. Another possibility is that the basal rocks represent an earlier use of the same feature facility and that they were partially reheated through reuse. Data recovery was not sufficient to adequately evaluate the implications of reuse (e.g., thermal gradients and direction of heating). However, archeomagnetic data should provide a means of addressing such concerns in the future.

\section{Feature 231, Composite K: East Block, Levels 27/28/29}

In addition to the levels presented thus far, archeomagnetic samples were also collected from the Feature 231 area in Levels 27, 28, and 29. These include samples from three features: Feature 240, exposed in Square 27, Levels 27 and 28; Feature 242, in Square 20, Level 28 (at the northern end of the East Block); and Feature 249 (in the eastern end of the South Block). Composite K (Figure 27- 
TABLE 27-18

Archeomagnetic Interpretation of Vectoral Data, Composite J

\begin{tabular}{|c|c|c|c|c|c|c|}
\hline \multicolumn{4}{|c|}{ Cooling Context } & \multicolumn{3}{|c|}{ Lowest Temperature of Movement } \\
\hline \multicolumn{4}{|c|}{ A cooled in place } & \multicolumn{3}{|c|}{ * no discernible movement } \\
\hline \multicolumn{4}{|c|}{ B cooled near find position } & \multicolumn{3}{|c|}{$\mathrm{X}$ unknown (AF demagnetized) } \\
\hline \multicolumn{4}{|c|}{ C out-of-place: cooling location inferred } & \multicolumn{3}{|c|}{$\mathrm{V}$ possible viscous magnetization } \\
\hline \multicolumn{4}{|c|}{ D out-of-place: unknown cooling } & \multicolumn{3}{|c|}{$\mathrm{L}$ less or equal to $250^{\circ} \mathrm{C}$} \\
\hline \multirow{2}{*}{\multicolumn{4}{|c|}{ E uncertain / unknown }} & \multicolumn{3}{|c|}{$\mathrm{M}$ between $250^{\circ}$ and $450^{\circ} \mathrm{C}$} \\
\hline & & & & \multicolumn{3}{|c|}{$\mathrm{H}$ greater than $450^{\circ} \mathrm{C}$} \\
\hline Feature No. & Square & Level & $\begin{array}{l}\text { Sample No. } \\
\text { (AM- ) }\end{array}$ & $\begin{array}{l}\text { Cooling } \\
\text { Context }\end{array}$ & $\begin{array}{c}\text { Lowest Temperature } \\
\text { of Movement }\end{array}$ & $\begin{array}{c}\text { No. of Discernible Movements } \\
\text { while Cooling }\end{array}$ \\
\hline 181 & 51 & 26 & 1151 & $\mathrm{D}$ & * & $\mathrm{O}$ \\
\hline 181 & 51 & 26 & 1152 & A & $\mathrm{X}$ & $1+$ \\
\hline 181 & 51 & 26 & 1260 & A & $\mathrm{L}$ & 2 \\
\hline 231 & 27 & 26 & 0773 & B & $\mathrm{X}$ & 1 \\
\hline 231 & 27 & 26 & 0778 & B & $\mathrm{L}$ & 2 \\
\hline 231 & 27 & 26 & 0779 & B & * & $0+$ \\
\hline $231 / 245$ & 27 & 26 & 0775 & A & $\mathrm{H}$ & $1+$ \\
\hline $231 / 245$ & 27 & 26 & 0776 & A & $\mathrm{X}$ & 1 \\
\hline $231 / 245$ & 52 & 25 & 1111 & B & M-H & $1+$ \\
\hline 245 & 28 & 26 & 1063 & $\mathrm{C}$ & $*$ & 0 \\
\hline 245 & 28 & 26 & 1064 & A & $*$ & $0+$ \\
\hline 245 & 28 & 26 & 1066 & B & * & 0 \\
\hline 245 & 28 & 26 & 1068 & A & $*$ & 0 \\
\hline 245 & 28 & 26 & 1069 & A & * & 0 \\
\hline 245 & 28 & 26 & 1071 & A & * & 0 \\
\hline 245 & 28 & 26 & 1072 & A & * & $0+$ \\
\hline 245 & 28 & 26 & 1073 & B & $\mathrm{X}$ & 1 \\
\hline 245 & 28 & 26 & 1074 & A & $\mathrm{H}$ & $1+$ \\
\hline 245 & 28 & 26 & 1075 & A & M & 1 \\
\hline 245 & 28-East & 26 & 1164 & B & $\mathrm{H}$ & 1 \\
\hline 245 & 28-East & 26 & 1165 & B & $X$ & $1+$ \\
\hline 245 & 28-East & 26 & 1167 & B & $\mathrm{L}$ & 1 \\
\hline \multicolumn{7}{|c|}{ Illustrated (but not included on Composite J): } \\
\hline 231 & 25 & 26 & 0455 & $\mathrm{D}$ & $\mathrm{X}$ & $1+$ \\
\hline 231 & 26 & 26 & 0446 & B & L-M & $1+$ \\
\hline 231 & 26 & 26 & 0449 & B & L-M & 1 \\
\hline 231 & 26 & 26 & 0451 & A & $\mathrm{L}$ & 2 \\
\hline
\end{tabular}

TABLE 27-19

Summary of Archeomagnetic Results for Composite J

\begin{tabular}{|c|c|c|c|c|c|c|c|c|c|c|c|c|c|c|}
\hline \multirow[b]{2}{*}{ Feature } & \multicolumn{5}{|c|}{ Cooling Context } & \multicolumn{5}{|c|}{ Lowest Temperature of Movement } & \multicolumn{4}{|c|}{ Maximum Number of Movements } \\
\hline & A & B & $\mathrm{C}$ & D & $\mathrm{E}$ & $*$ & $\begin{array}{c}\mathrm{L} \text { or } \mathrm{L}- \\
\mathrm{M}\end{array}$ & $\begin{array}{l}\mathrm{M} \text { or } \\
\mathrm{M}-\mathrm{H}\end{array}$ & $\mathrm{H}$ & $\mathrm{X}$ & 0 & $\begin{array}{l}1,1+, \\
\text { or } 1-2\end{array}$ & $\begin{array}{l}2,2+, \\
\text { or } 2-3\end{array}$ & $\begin{array}{l}3 \text { or } \\
\text { more }\end{array}$ \\
\hline 181 & 2 & & & 1 & & 1 & 1 & & & 1 & 1 & 1 & 1 & \\
\hline 231 & & 3 & & & & 1 & 1 & & & 1 & 1 & 1 & 1 & \\
\hline $231 / 245$ & 2 & 1 & & & & & & 1 & 1 & 1 & & 3 & & \\
\hline 245 & 7 & 5 & 1 & & & 7 & 1 & 1 & 2 & 2 & 7 & 6 & & \\
\hline
\end{tabular}




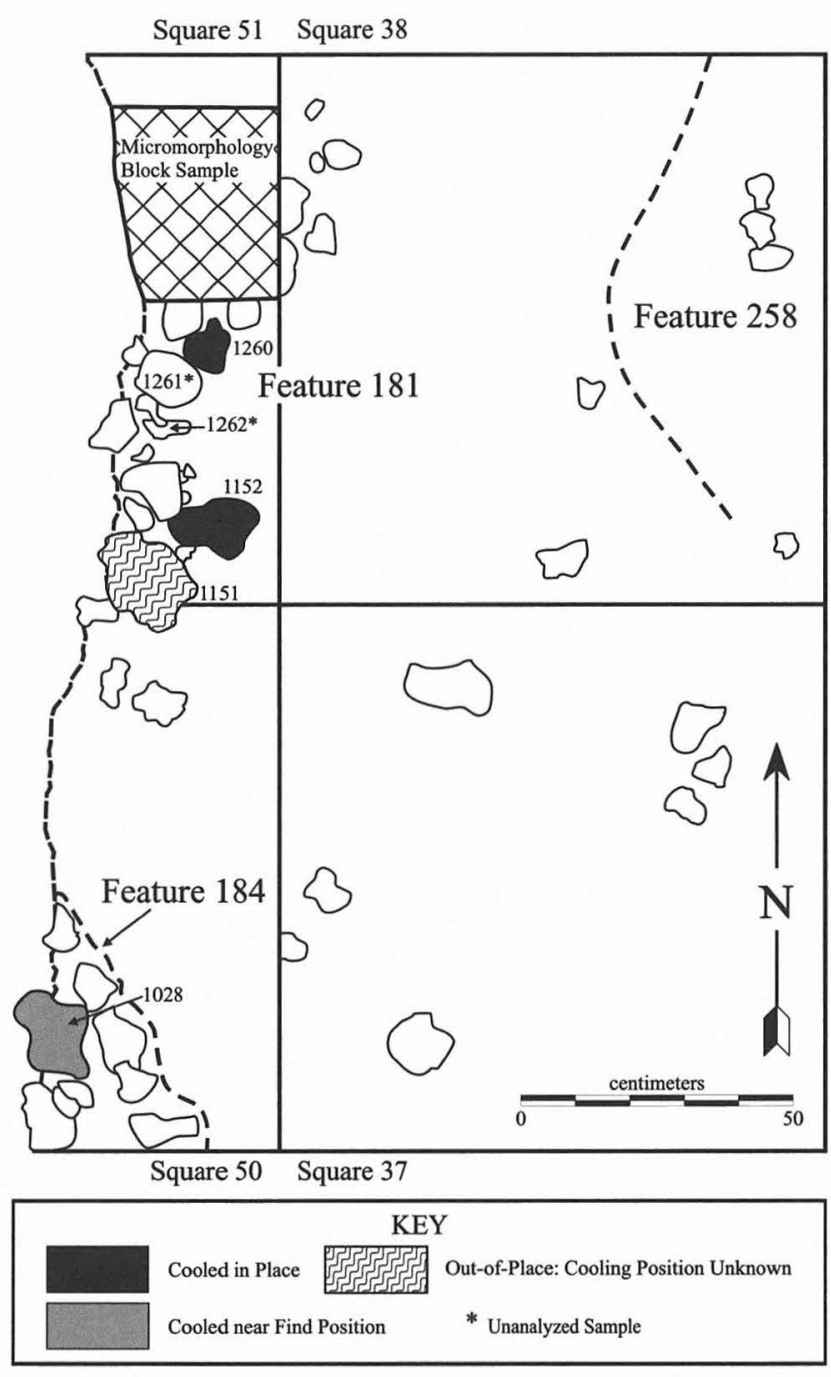

FIGURE 27-106. Detail of Composite J: Features 181, 258, and 184 in Squares 37, 38, 50, and 51, Level 26 (ca. $95.55 \mathrm{~m}$ ).

109) depicts the burned rocks exposed in Levels 27 through 29 (ca. $95.55-95.40 \mathrm{~m}$ ) in the northernmost squares of the East Block (including Feature 242). The rocks shown on Composite $\mathrm{K}$ were in an ambiguous Unit IIIa/II transition zone, stratigraphically equivalent to (or just below) Feature 231 , and may represent a northern extension of this palimpsest deposit. Features 240 and 249 are not included on Composite $\mathrm{K}$ and are discussed separately below. Archeomagnetic results from all samples discussed in this section are given in Table 27-20. A summary of the cooling context determinations by square and level for nonfeature rocks is provided as Table 27-21. Selected stereonets are presented in Figure 27-110.

Feature 242 (see Figure 27-109) was encountered in Square 20, Levels 28 and 29. The two rocks (AM-893 and AM-894) analyzed in this feature did not cool in place (see Figure 27-110, Table 27-20).

However, immediately west of Feature 242 was a group of rocks encircling a rock-free central area in Square 26 (see
Figure 27-109). Note that these rocks were recovered in three successive 5-cm levels and that these have been collapsed onto a single composite plan map in Figure 27-109. Although it was not considered a separate feature in the field, 25 archeomagnetic samples were collected from it. Nearly $80 \%$ (19 of 25) were found to have cooled in place (see Tables 2720 and 27-21; Figure 27-110) but most did so from only low to medium temperatures (i.e., less than $450^{\circ} \mathrm{C}$ ). Just 3 samples (AM-574, AM-578, and AM-771) cooled without moving from higher temperatures, and, of these, only AM-574 remained in place while the other 2 were dislocated after completely cooled. Of the remaining 22 rocks, half (11 of 22) experienced two or more dislocations during cooling. Patterning in reconstructed rotations for most of the rocks is consistent with movement while cooling rather than partial reheating. There is, however, no rotational consistency relative to the central void area, although a few rocks do appear to have been displaced toward it. Archeomagnetic analysis of the Composite $\mathrm{K}$ rocks clearly suggest the existence of one or more intact features in or near Square 26 but do not provide much information regarding its structure or even precise location. Finally, it remains unclear whether these rocks predate Feature 231, although this seems unlikely given the sloping deposits noted previously.

Feature 240 was identified as an ill-defined area of very diffuse rocks and gravels in Levels 27 and 28 in Square 27 (not illustrated). The rocks exhibited no obvious patterning and probably do not represent a specific activity or feature area but rather the lowest levels of Feature 231. Nevertheless, three rocks were analyzed, two of which yielded meaningful results. Rock AM-998 had a remarkably strong singlecomponent remanence but clearly was displaced from its final cooling position (see Table 27-20). Rock AM-886, on the other hand, seems to have cooled in place from moderate to low temperatures, perhaps following one or two dislocations while cooling. It was, however, found just south of Square 27 and, based on its proximity and magnetization, probably should be grouped with those rocks rather than with Feature 240.

Feature 249 was identified in the profile of Feature 181 (eastern face of TxDOT Square E28/S78). It appeared to be either a burrow or the remnant of an earlier pit feature originating just below the southern edge of Feature 181 (see Chapter 26). In either case, Feature 249 probably once extended into the TxDOT excavation area. Only a few rocks were exposed in this profile, and two archeomagnetic samples (AM-1095 and AM-1096) were taken (see Table 27-20). Rock AM-1096 cooled in place from temperatures in excess of the Curie point with little noticeable movement, while AM-1095 moved several times during, and again somewhat after, cooling (see also Figure 27-110). The direction of this rock's final two displacements suggest that it cooled east of where it was found. Based on the archeomagnetic evidence, Feature 249 is probably the intact remnant of a cultural feature; albeit one was almost 


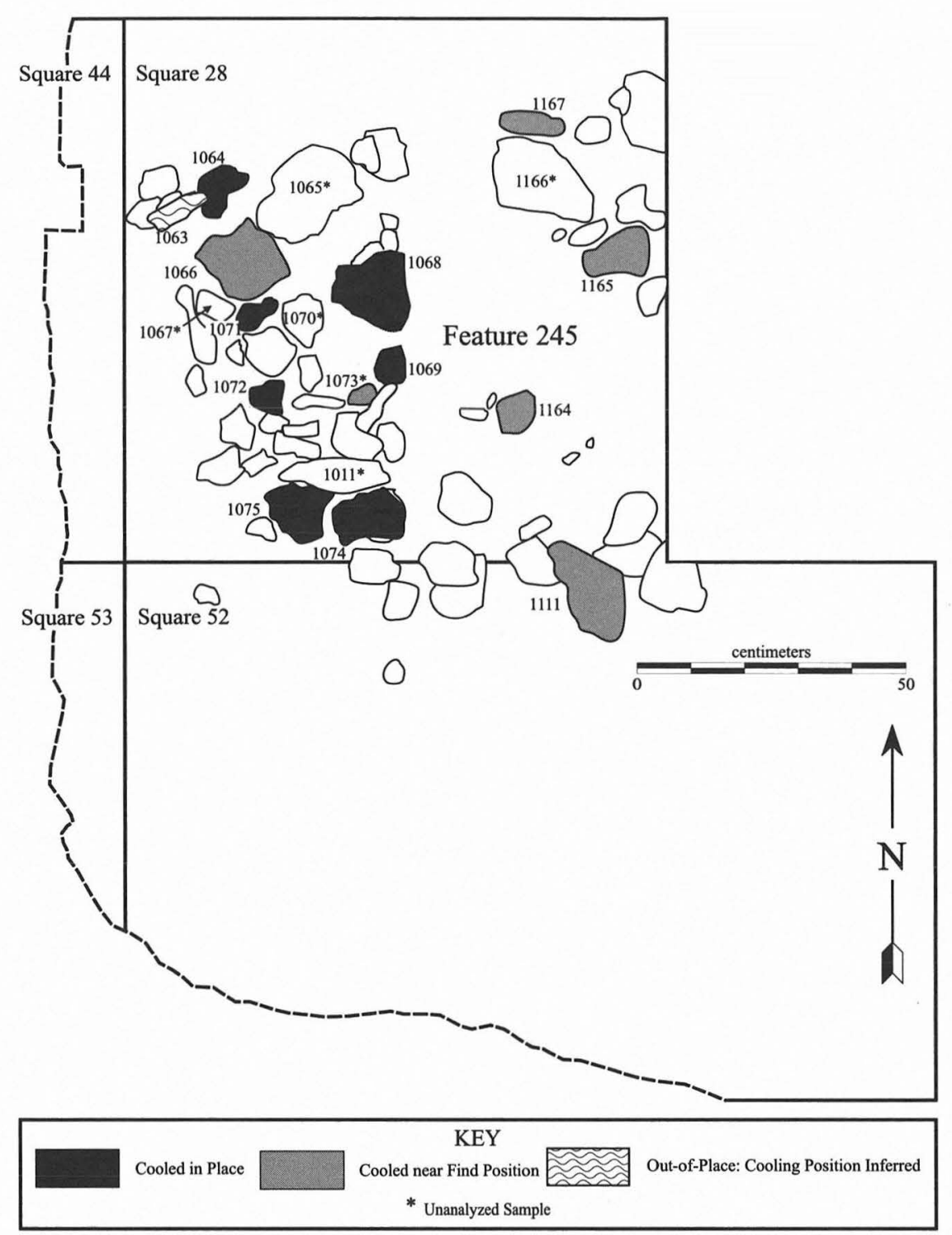

FIGURE 27-107. Detail of Composite J: Feature 245 in Squares 28, 44, 52, and 53, Level 26 (ca. 95.55 m).

completely obliterated by the later construction of Feature 181 and/or an animal burrow through it.

\section{CONCLUSIONS}

At the most basic level, the application of paleomagnetic techniques to the study of burned rocks provides a way of determining the position of a rock relative to the Earth's magnetic field at different temperatures as it cooled. Archeomagnetic investigations contributed substantively to our understanding of the formation, structure, and preservation of burned rock features at Wilson-Leonard. Archeomagnetic analysis was effective in linking the preserved, static archeological record with dynamic cultural and natural processes by allowing a determination of whether individual rocks cooled in place and, if so, from approximately what temperatures. In addition, the relative stability of the rocks as they cooled as well as unobserved structural attributes of features and their immediate surroundings could be appraised. The development of such analysis reflects an increasing awareness by archeologists of the information potential of burned rocks. The analytical and interpretive advancements that grew out of this study strengthen not only this report but will undoubtedly serve as a baseline for future studies and for the continued development of archeomagnetic applications in burned rock research.

\section{Paleomagnetism of Burned Rocks at Wilson-Leonard}

Burned rock features at Wilson-Leonard are the endproduct of a complex interplay of cultural, depositional, and physical forces. A significant finding of the TARL investigations was that small burned rock features (less than $1 \mathrm{~m}$ in diameter) were clearly being used by ca. 10,000 в.P. (e.g., 


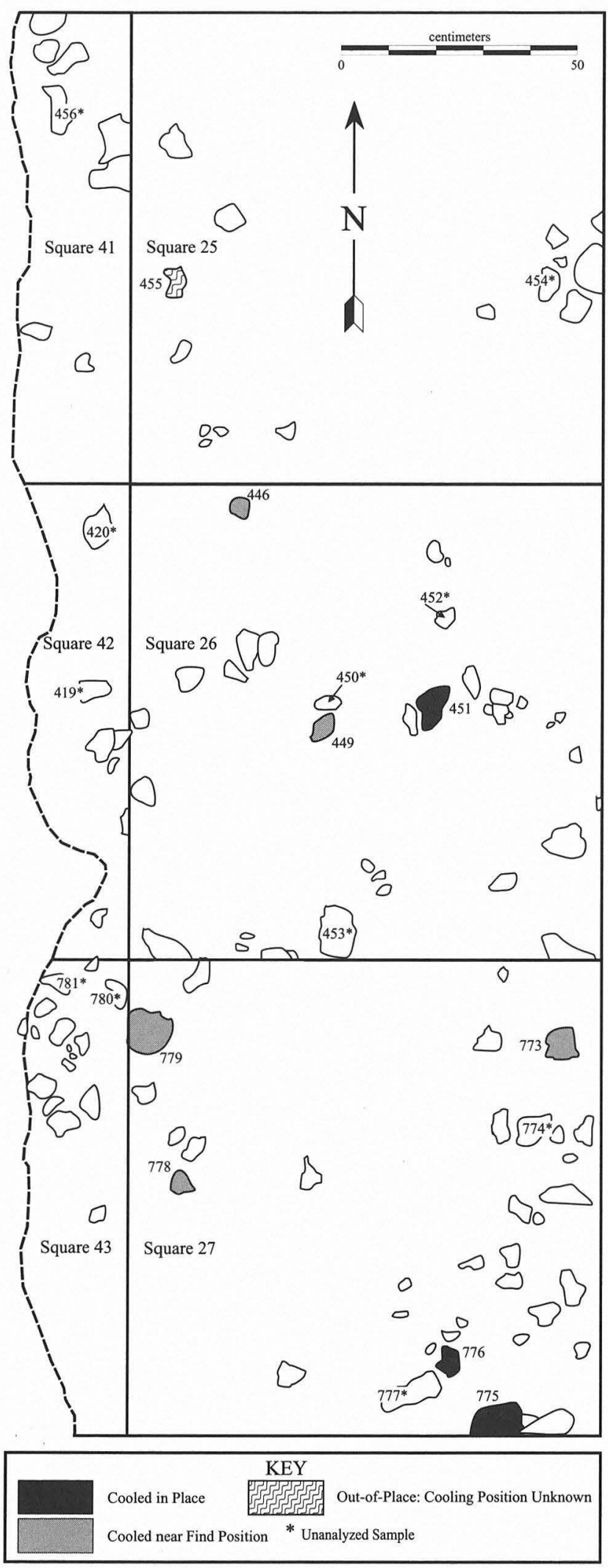

FIGURE 27-108. Detail and extension of Composite J: Squares 25, 26, 27, 41, 42, and 43, Level 26 (ca. $95.55 \mathrm{~m}$ ).
Feature 255, see Chapter 26). While these features varied in size and density thereafter, their construction and use continued. Although many of the analyzed rocks in individual burned rock features cooled where they were found (many from high temperatures), often one or more was moved after cooling, resulting in an archeological morphology that was different (to some degree) from that during its use. Archeomagnetic data was used to assess the integrity of these features and, in certain cases, to reconstruct details of their prior structure or morphology. For example, certain features (e.g., Features 236 and 248) seem to have been constructed in or around central depressions into which rocks rolled or settled during and after cooling. The archeomagnetic data indicate that rocks in many of these smaller features (even some recorded as only "dispersed" clusters) cooled in place. Despite the fact that smaller, more-dispersed features might be underemphasized by some archeologists (due to their ubiquity and less than impressive appearance), they are probably an important component of prehistoric human adaptations in Central Texas. However, it is important to note the existence of "negative cases" as well (e.g., Feature 241 ) in which the rocks were found to be out-of-place. These are important because, without such evidence, it would be difficult to rule out noncultural mechanisms of magnetic realignment such as modern viscous overprinting or contaminating chemical remanences.

The construction of larger burned rock features $(1 \mathrm{~m}$ or more in diameter) at Wilson-Leonard commenced by ca. 9500 в.P. and by ca. 8000 в.P., numerous large "oven" features were in use (see Chapter 26). In Unit IIIIa some of the larger features coalesced into a palimpsest (Feature 231) that encompassed (and later obscured) several of these distinct "subfeatures" (e.g., Features 181, 230, and 245). This deposit was analogous to an egg-carton-an apparently undifferentiated mass of rocks in upper levels underlain by several basin-shaped, rock-filled subfeatures. Intensive sampling and archeomagnetic analysis demonstrated not only that many of the rocks in these subfeatures cooled where they were found (typically from high temperatures) but also that the upper portions of these subfeatures extended or began much higher up in the palimpsest than could be seen or recognized during excavation. These results suggest that the intervening areas (between subfeatures) were filled in mostly with disturbed rocks derived from elsewhere or from the partial truncation of the upper levels of these subfeatures.

In rare instances, rocks from features previously excavated by TxDOT (e.g., Features 181 and 184) were recovered and analyzed. Nearly all of these were found to have cooled in place.

One of the most startling archeomagnetic findings was the remarkable integrity of the Burned Rock Midden 1 deposits. Although visibly undifferentiated, this "midden" deposit yielded a large number of rocks (especially from lower levels) that cooled in place-with little or no move- 


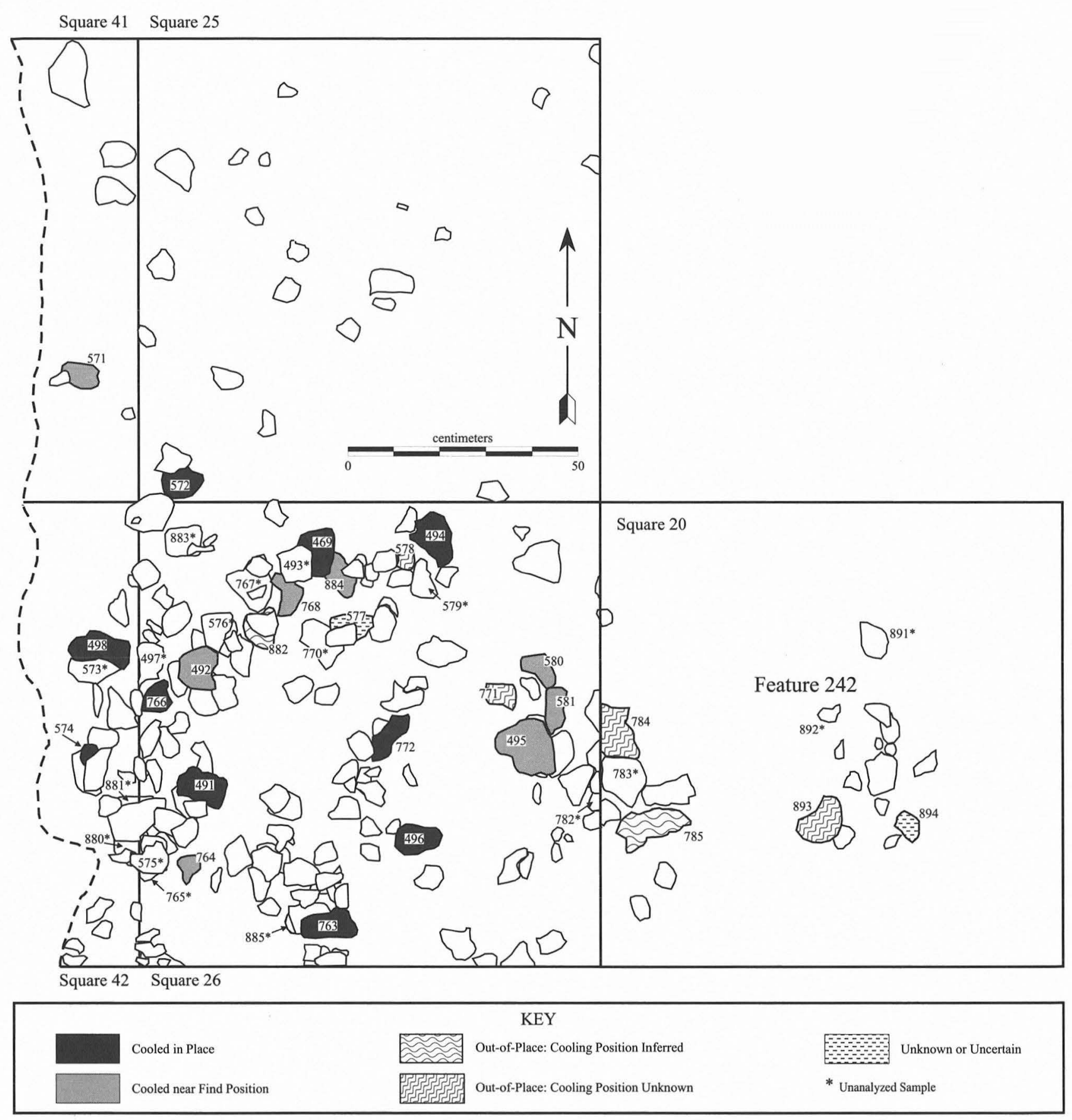

Figure 27-109. Feature 231 and associated Subfeature 242, Composite K: East Block, Squares 20, 25, 26, 41, and 42, Levels 27 - 29 (ca. $95.55-95.40 \mathrm{~m})$.

ment while cooling - from temperatures in excess of $500^{\circ} \mathrm{C}$. These results clearly do not support the hypothesis that this midden formed exclusively as a secondary, detrital deposit of rocks cooled elsewhere. Instead, the only reasonable conclusion is that at least part of the midden is composed of rocks probably heated (and certainly cooled) where they were found.

Another significant finding was that the traditional criteria by which rocks are judged to have been heated are in fact supported by archeomagnetic analysis. In nearly all cases where rocks were thought in the field to have been burned, archeomagnetic evidence of heating was found. Alternatively, where there was some uncertainty regarding whether they were heated or not, the archeomagnetic results were typically ambiguous.

Archeomagnetic data were also useful for discerning aspects of the prehistoric landscape. For example, many of the rocks appear to have been tilted or settled (after 
TABLE 27-20

Archeomagnetic Interpretation of Vectoral Data, Composite K

\begin{tabular}{|c|c|c|c|c|c|c|}
\hline \multicolumn{4}{|l|}{ Cooling Context } & \multicolumn{3}{|c|}{ Lowest Temperature of Movement } \\
\hline \multicolumn{4}{|c|}{ A cooled in place } & \multicolumn{3}{|c|}{ * no discernible movement } \\
\hline \multicolumn{4}{|c|}{ B cooled near find position } & \multicolumn{3}{|c|}{$\mathrm{X}$ unknown (AF demagnetized) } \\
\hline \multicolumn{4}{|c|}{ C out-of-place: cooling location inferred } & \multicolumn{3}{|c|}{$\mathrm{V}$ possible viscous magnetization } \\
\hline \multicolumn{4}{|c|}{ D out-of-place: unknown cooling orientation } & \multicolumn{3}{|c|}{$\mathrm{L}$ less or equal to $250^{\circ} \mathrm{C}$} \\
\hline \multirow{2}{*}{\multicolumn{4}{|c|}{ E uncertain / unknown }} & \multicolumn{3}{|c|}{$\mathrm{M}$ between 250 and $450^{\circ} \mathrm{C}$} \\
\hline & & & & \multicolumn{3}{|c|}{$\mathrm{H}$ greater than $450^{\circ} \mathrm{C}$} \\
\hline Feature No. & Square & Level & $\begin{array}{l}\text { Sample No. } \\
\text { (AM- ) }\end{array}$ & $\begin{array}{l}\text { Cooling } \\
\text { Context }\end{array}$ & $\begin{array}{c}\text { Lowest Temperature } \\
\text { of Movement }\end{array}$ & $\begin{array}{c}\text { No. of Discernible } \\
\text { Movements while Cooling }\end{array}$ \\
\hline 242 & 20 & 28 & 0893 & $\mathrm{D}$ & $\mathrm{X}$ & 1 \\
\hline 242 & 20 & 28 & 0894 & $\mathrm{E}$ & L-H & $1-2$ \\
\hline 231 & 20 & 27 & 0784 & D & $\mathrm{L}$ & $2-3$ \\
\hline 231 & 20 & 27 & 0785 & $\mathrm{C}$ & $\mathrm{X}$ & $1+$ \\
\hline 231 & 25 & 28 & 0572 & A & $\mathrm{L}$ & 2 \\
\hline 231 & 26 & 27 & 0491 & A & M & 2 \\
\hline 231 & 26 & 27 & 0492 & B & L-M & $2+$ \\
\hline 231 & 26 & 27 & 0494 & A & $\mathrm{L}$ & $2+$ \\
\hline 231 & 26 & 27 & 0495 & B & $\mathrm{L}$ & 2 \\
\hline 231 & 26 & 27 & 0496 & A & M & 1 \\
\hline 231 & 26 & 27 & 0577 & E & M & $1+$ \\
\hline 231 & 26 & 27 & 0578 & D & $*$ & $0+$ \\
\hline 231 & 26 & 27 & 0580 & B & $\mathrm{x}$ & 1 \\
\hline 231 & 26 & 27 & 0581 & B & $\mathrm{L}$ & 2 \\
\hline 231 & 26 & 28 & 0763 & A & M-H & $1+$ \\
\hline 231 & 26 & 28 & 0764 & B & $\mathrm{X}$ & 1 \\
\hline 231 & 26 & 28 & 0766 & A & M & 1 \\
\hline 231 & 26 & 28 & 0768 & B & L-M & 2 \\
\hline 231 & 26 & 28 & 0769 & A & $\mathrm{X}$ & 1 \\
\hline 231 & 26 & 28 & 0771 & D & * & $0+$ \\
\hline 231 & 26 & 28 & 0772 & A & M & 1 \\
\hline 231 & 26 & 29 & 0882 & $\mathrm{C}$ & L-M & $1+$ \\
\hline 231 & 26 & 29 & 0884 & B & L-M & 2 \\
\hline 231 & 41 & 28 & 0571 & B & $\mathrm{L}$ & 4 \\
\hline 231 & 42 & 27 & 0498 & A & $\mathrm{L}$ & 1 \\
\hline 231 & 42 & 27 & 0574 & A & * & 0 \\
\hline 231 & 42 & 29 & 0881 & B & $\mathrm{L}$ & 2 \\
\hline Not Illustrated: & & & & & & \\
\hline 240 & 27 & 27 & 0886 & B & $\mathrm{X}$ & \\
\hline 249 & 51 & & 1095 & B & L & 3 \\
\hline 249 & 51 & & 1096 & A & * & $0+$ \\
\hline
\end{tabular}

cooling) parallel to the plane of the paleoslope, indicating that they probably came to rest on that surface rather than in a depression or low area such as a basin.

Numerous data were generated as a result of archeomagnetic analysis. More than 500 core samples are curated and well over 100 parent rocks (from which analyzed samples were drilled) are also available. In addition, the voluminous data upon which this report is based undoubtedly represent a wealth of information not presented (or even realized) here. These data, as well as the curated specimens, are available for future research.

Archeomagnetic data complement other lines of evidence.
For certain questions, patterning in the magnetic data alone is sufficient. In others, additional information is needed to support, or even suggest, specific interpretations. Nonetheless, in most cases, archeomagnetic studies limit the number of competing hypotheses so that the best explanation can be reached.

The Wilson-Leonard archeomagnetic investigations have contributed both to our understanding of burned rock use in Central Texas and to the continued development of archeomagnetic research. Perhaps more importantly, they also suggest several avenues for continued research. 
TABLE 27-21

Summary of Archeomagnetic Results for Composite K (excluding Feature 242)

\begin{tabular}{|c|c|c|c|c|c|c|c|c|c|c|c|c|c|}
\hline & \multicolumn{5}{|c|}{ Cooling Context } & \multicolumn{4}{|c|}{ Lowest Temperature of Movement } & \multicolumn{4}{|c|}{$\begin{array}{l}\text { Maximum Number of } \\
\text { Movements }\end{array}$} \\
\hline & A & $\mathrm{B}$ & $\bar{C}$ & $\mathrm{D}$ & $\mathrm{E}$ & * & $\begin{array}{l}\mathrm{L} \text { or } \\
\mathrm{L}-\mathrm{M}\end{array}$ & $\begin{array}{ll}\text { M or } & \mathrm{H} \\
\mathrm{M}-\mathrm{H} & \\
\end{array}$ & $\mathrm{X}$ & 0 & $\begin{array}{l}1,1+, \\
\text { or } 1-2\end{array}$ & $\begin{array}{l}2,2+, \\
\text { or } 2-3\end{array}$ & $\begin{array}{l}3 \text { or } \\
\text { more }\end{array}$ \\
\hline Square 20, Level 27 & & & 1 & 1 & & & 1 & & 1 & & 1 & 1 & \\
\hline Square 25 , Level 28 & 1 & & & & & & 1 & & & & & 1 & \\
\hline Square 26, Level 27 & 3 & 4 & & 1 & 1 & 1 & 4 & 3 & 1 & 1 & 3 & 5 & \\
\hline Square 26, Level 28 & 4 & 2 & & 1 & & 1 & 1 & 3 & 2 & 1 & 5 & 1 & \\
\hline Square 26, Level 29 & & 1 & 1 & & & & 2 & & & & 1 & 1 & \\
\hline Square 41, Level 28 & & 1 & & & & & 1 & & & & & & 1 \\
\hline Square 42, Level 27 & 2 & & & & & 1 & 1 & & & 1 & 1 & & \\
\hline Square 42, Level 29 & & 1 & & & & & 1 & & & & & 1 & \\
\hline Totals: & 10 & 9 & 2 & 3 & 1 & 3 & 12 & 6 & 4 & 3 & 11 & 10 & 1 \\
\hline
\end{tabular}

\section{Current and Future Paleomagnetic Research on Burned Rocks}

Burned rock features traditionally have been underutilized as sources of data in archeology although this has recently begun to change as evidenced by recent publications and symposia (Buckley 1990; Hester 1991; Hodder and Barfield 1991; March 1996; Olive and Taborin 1989; Perles 1977; Thoms et al. 1997). This realization may be characterized as a paradigm shift (or at least a shift in disciplinary emphasis) in recognizing the importance and potential of burned rocks; a broadening of scope that seems to parallel earlier developments in archeology such as stable isotope, microwear, and even debitage analysis. While archeomagnetic analyses currently can be used to distinguish between certain natural and cultural attributes of burned rock features, the potential of these methods has been only partially realized. The archeomagnetic investigations at Wilson-Leonard have aided in the understanding of what works and what does not work by adding to our understanding of both the potentials and limitations of the technique. More importantly, they suggest several avenues which, if pursued, may lead to further advancements.

For example, a major obstacle to interpretation in earlier archeomagnetic studies has been the difficulty in distinguishing between remanence components resulting from movement while cooling and those imparted by partial reheating (e.g., Collins et al. 1990; Gose 1990, 1994). The standardization of vector rotation reconstructions as presented in this report offers one potential solution for resolving such ambiguity, at least where patterning in apparent rotations can be discerned within individual rocks or among rocks in the same feature. In many cases, it is unlikely that such patterning could result from prior (probably random) displacement and subsequent reheating. The efficacy of using vector rotation reconstruction for discriminating between movement and reheating, for reconstructing the prior mor- phology of features, and for identifying disturbance processes is the subject of ongoing "blind" tests and experimental replications (Takac n.d.).

Another potential variable that may assist in discerning between movement and reheating is thermal gradients within a rock (cf. Gose 1990). The direction of heat flow, either in toward the center (during heating) or out from it (while cooling), may be one means of obtaining such information. Heat flow data might also eventually be used to pinpoint heat sources (e.g., heating from above, below, or from one side) or to determine the number and duration of individual heating events. Although thermal gradient and heat flow analyses have not been systematically investigated to date, they are also the subject of an ongoing research program (W. A. Gose, personal communication 1997).

A potential signature for certain uses of boiling stones was also identified as the result of analyzing the WilsonLeonard data (see Feature 246 discussion). If a rock is moved rapidly or quasi-continuously while cooling (as might be the case for stone boiling), the observed remanence intensity and direction should remain more or less constant during laboratory demagnetization. An observable magnetic component can only be acquired (and later measured) if a rock remains still long enough for magnetic grains (within a sufficient range of blocking temperatures, e.g., $100^{\circ} \mathrm{C}$ ) to acquire a common direction. If not, no net change in the measured remanence will occur during demagnetization because their directions are effectively randomized. This stone boiling signature has recently been replicated under experimental conditions (Takac n.d.). The recognition of other magnetic signatures corresponding to burned rock usage is anticipated.

Several lessons learned during the Wilson-Leonard analysis concern collection and laboratory procedures. For example, it is now clear that sampling strategy must be explicitly developed, from the many available alternatives, based on the research questions posed, the anticipated level of 


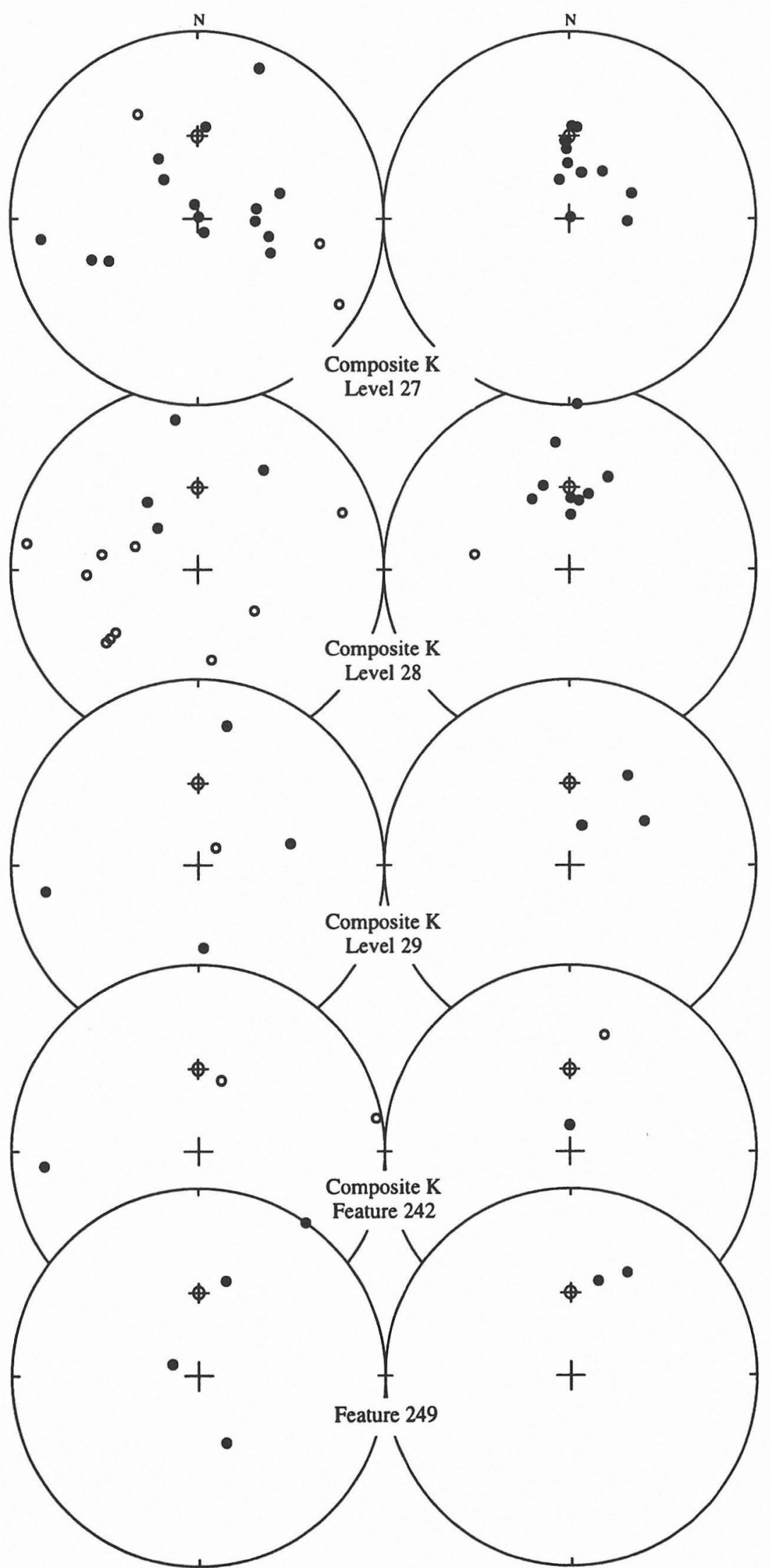

FIGURE 27-110. Stereoplots of results for Composite K, including Feature 242 and Feature 249. 
analytical effort, and the practicalities of a particular fieldwork situation. Sampling intensity was surely an important contributing factor for the success of the archeomagnetic research at Wilson-Leonard (especially in undifferentiated deposits such as Burned Rock Midden 1). More-focused research strategies in future studies will contribute to even greater understandings of both large and small burned rock features. The experience gained while dealing with the large and complex Wilson-Leonard database is similarly invaluable. An important consideration is the cost in time and effort of detailed laboratory analyses. Clearly, however, an investment in data collection is a prerequisite for how far the investigations can ultimately proceed. Archeomagnetic analysis can and should be progressive and hierarchical; that is, the results at each stage should be considered when deciding whether (or in what direction) to proceed. Again, research effort (e.g., sampling strategies, demagnetization intervals, and specialized magnetic tests or treatments) should depend on the questions asked.

The Wilson-Leonard analysis also identified and clarified additional topics to be addressed in future research. These include, but are not limited to, the following:

(1) the relationship of remanence intensity and magnetic mineralogy to heating conditions and initial petrology;

(2) the relationship between heating history and oxidation conditions as well as how these might be expressed in terms of color, brittleness, magnetic mineralogy, etc.;

(3) the structural changes caused by heating;

(4) the relationship between heating and observed laboratory demagnetization temperatures;

(5) the dynamics of heat flow and how thermal gradient analyses might help in determining the direction, intensity, rate, and duration of heating;

(6) the possible effects of existing magnetizations (within nearby rocks and features) on the local magnetic field and how this might complicate the acquisition and interpretation of thermoremanence in heated rocks;

(7) the acquisition of viscous remanence in heated versus unheated rocks;
(8) identification of the carriers of remanent magnetizations (e.g., hematite vs. magnetite) in specific cases and how they are altered under different conditions (which may prove valuable for discerning otherwise unobservable aspects of the structure and use of burned rock features);

(9) the exploration of what might be learned from the study of existing collections of unoriented rocks, beyond what is already apparent (e.g., single-component samples, regardless of whether they subsequently remained in place or not);

(10) the wider application of paleomagnetic techniques to materials other than burned rocks (such as thick ceramic sherds, ground stone bowls, or chert) in order to determine if they were heated and, if so, what the specifics of that heating may have been; and, finally;

(11) the use of burned rock data for chronometric determinations (see discussion in Takac 1997).

The development of paleomagnetic techniques for nonchronometric research on burned rocks is still clearly in its infancy. Nonetheless, analyses such as those outlined in this chapter provide direct and important information on the construction, use, and preservation of burned rock features. Moreover, they can potentially be applied anywhere. They require only mineralogical sufficiency, not a pre-existing database or secular variation curve. Advances in the sensitivity and accuracy of instrumentation will undoubtedly continue to expand the range of rock types and materials that may be studied.

In summary, archeomagnetic analysis of burned rocks at Wilson-Leonard was successful in terms of recognizing and evaluating specific cultural and natural processes. It also contributed substantially to the continued development of paleomagnetic investigations of burned rocks and to the identification of possible future research programs. A large number of curated samples (including parent rocks) as well as the extant data are available for future research. The Wilson-Leonard database will, in all likelihood, continue to be a primary source for furthering archeomagnetic analysis generally and for better understanding prehistoric occupations at Wilson-Leonard in particular. 


\section{Chapter 28}

\section{MAGNETIC SUSCEPTIBILITY OF SEDIMENTS}

by Paul R. Takac and Wulf A. Gose

\section{INTRODUCTION}

When any material is placed in a magnetic field it will acquire an induced magnetization. For small magnetic fields, this magnetization is linearly proportional to the inducing magnetic field. The constant of proportionality is the Magnetic Susceptibility (MS), commonly represented by the Greek letter $\chi$ (chi). MS can roughly be considered the "magnetizability" of a material and is proportional to the concentration and grain size of its ferro- and ferrimagnetic constituents. The MS of sediments can be modified by pedogenic and cultural processes, both of which tend to enhance $\chi$ values. Postdepositional effects such as groundwater leaching can reduce $\chi$.

Magnetic susceptibility analyses at Wilson-Leonard were performed on both sediment column and bulk matrix samples to aid in understanding the depositional and postdepositional history of the site as well as to better understand the use-history and stratigraphic context of individual features. Results of these studies attest to at least three individual periods of soil development as well as to probable groundwater saturation or throughflow of the Unit I deposits. Certain feature samples were useful for clarifying stratigraphic contexts while others suggest that intensive and/or repeated burning may have enhanced $\chi$ values. MS enhancement is also positively correlated with the intensity of human occupation, as determined by other criteria such as artifact and feature density.

Le Borgne $(1955,1960,1964)$ first recognized that MS can be enhanced as the result of pedogenesis and human activities. He suggested that existing iron compounds in the sediment (e.g., hematite $\left[\alpha \mathrm{Fe}_{2} \mathrm{O}_{3}\right]$ and goethite $[\mathrm{FeOOH}]$ ) are chemically reduced to magnetite $\left(\mathrm{Fe}_{3} \mathrm{O}_{4}\right)$, which in turn is reoxidized to slightly less magnetic but still relatively high susceptibility minerals such as maghemite $\left(\gamma \mathrm{Fe}_{2} \mathrm{O}_{3}\right)$. Le Borgne identified two primary mechanisms of authigenic $\chi$ enhancement. The first results from burning in oxygen- reduced conditions, followed by reoxidation as the fire cools and air enters the system (the "heating mechanism," see Tite and Mullins 1971:209). The second process (the "fermentation mechanism," see Tite and Mullins 1971:209) results from the decay of organic matter under anaerobic conditions during wet periods followed by partial reoxidation in dry periods. Subsequent research has corroborated the basic tenets of Le Borgne's hypotheses in terms of mineralogical changes, the reduction/reoxidation process, and conditions controlling maximum MS enhancement (e.g., Longworth and Tite 1977; Mullins 1977; Schwertmann and Taylor 1977, Singer and Fine 1989, Tite and Mullins 1971). In addition, maghemite has been found to be the product of subaerial weathering (Mullins 1977) and hydrothermal alteration at temperatures $<200^{\circ} \mathrm{C}$ (Butler 1992:37). Human occupations are typically characterized by an increased input of organic debris and Fe-rich materials (e.g., ochre) as well as the production of large quantities of high MS material such as wood ash (McClean and Kean 1993). Gleyed or waterlogged sediments, as well as those subjected to active groundwater throughflow, often have unusually low MS due to the dissolution and/or leaching of magnetic minerals (e.g., Gale and Hoare 1991:213-214; Mullins 1977:236).

Enhancement of MS in soils starts at or near the surface where $\chi$ may be up to 10 times higher than that of the parent material. Absolute MS values depend a variety of factors, including parent material, climate, topography, and time (Singer and Fine 1989:1119). Magnetic minerals formed at the surface are moved downward by eluviation and bioturbation. The latter process also maintains aerobic conditions at depth, often reducing postdepositional hydromorphism (Allen and MacPhail 1987:674-675). This typically results in a gradual decrease in $\chi$ values down through the profile of a well-developed soil (i.e., through the A- and into the B-horizon; cf. Singer and Fine 1989). Eluviation occasionally results in a thin zone of low MS at 
the top of the A-horizon (e.g., Figure 4.29 in Gale and Hoare 1991:214).

In archeological contexts, localized areas of high susceptibility ("features"), mixing of burned and unburned sediment, and/or mixing of differentially enhanced pedogenic sediments (e.g., by the excavation and refilling of pits or burials) can result in significant variations in $\chi$ over small vertical and horizontal distances. MS variations associated with intervals of human occupation are sometimes recognized in profile as anomalous "spikes" (e.g., Collins et al. 1994). Susceptibility studies have also been used in an attempt to differentiate between cultural and natural features (Bellomo 1990, 1993).

Magnetic susceptibility studies at Wilson-Leonard were performed as an independent test of geomorphological and cultural reconstructions and to determine what effect depositional, postdepositional, and cultural factors may have had on the vertical and horizontal distribution of $\chi$. In addition, MS analysis was used in an attempt to determine the surface(s) from which several Paleoindian-age pits (i.e., Burial 2 and Features 168 and 169) originated.

\section{METHODS}

Magnetic susceptibility measurements are nondestructive, rapid, and inexpensive. Susceptibility meters generally require only a small quantity of unoriented sediment. All of the analyzed samples were collected in magnetically inert 8-cc plastic cubes. A total of 663 individual samples was analyzed (Table 28-1). Of these, 118 were collected in the field from three sediment profiles in Squares 12, 20, and $33 / 56$. The remainder were obtained in the laboratory using curated bulk matrix samples from both TxDOT and TARL features and other excavation contexts. Most of the bulk sediment samples had only limited provenience information (e.g., "feature fill") which diminished their interpretive value.

\section{TABLE 28-1}

General Provenience of Analyzed Magnetic Susceptibility Samples

\begin{tabular}{l|r}
\hline TxDOT Square S28/E78 (including & 158 \\
Features 181, 184, 185, and 187 & \\
TxDOT features (excluding Burial 2) & 46 \\
TxDOT Burial 2 & 66 \\
TARL column samples (Squares 12, 20, and 33/56) & 118 \\
TARL features and special samples & $\underline{275}$ \\
Total: & 663 \\
\hline \hline
\end{tabular}

All measurements were done in the Paleomagnetic Laboratory in the Department of Geological Sciences at The University of Texas at Austin using a Bartington Model MS2 Susceptibility Meter. Results reported herein are low frequency $(0.465 \mathrm{kHz})$ measurements given in
Gauss or "cgs" ("centimeter/gram/second") rather than SI (Systéme International) units. In either system, magnetic susceptibility - the ratio of induced magnetization to the strength of an applied magnetic field—-is dimensionless.

Additional magnetic tests were also performed on selected samples, as described below. Original laboratory sheets and data are on file at TARL.

\section{RESULTS}

Susceptibility samples were collected in three columns from which micromorphological samples were also taken (Squares 12, 20, and 33/56). Curated bulk sediment from excavated levels and features in TxDOT Square E28/S78 (Fine Screen Unit) was also sampled. When combined, the E28/S78 data yield a quasi-continuous stratigraphic column. In addition, MS samples were available from 48 TARL features as well as from 14 features excavated by TxDOT.

\section{Profiles}

The three sediment columns collected by TARL include 39 samples from the south wall of Square 12, in the South Block of the TARL excavation area, as well as 36 samples from the east wall of Square 20, in the East Block. In addition, 43 samples were collected from the re-exposed south wall of the TxDOT Block 6 excavation area. It was initially believed that these samples corresponded to the northern edge of what would become TARL Square 33. However, it was later discovered that Square 33 was offset slightly from this re-exposed section and that TARL Square 56 linked them. Therefore, these samples are more accurately provenienced to Square 33/56. These field-collected MS samples correspond roughly to soil micromorphology samples taken at the same time (discussed in Chapter 29 and Appendix 7, this volume) as follows: (1) the Column 100 series (WL-92-100 to WL-92-143) in Square 12; (2) the Column 200 series (WL-92-201 through WL-92-236) in Square 20; and (3) WL-92-011 to WL-92-031 in Square 33/ 56.

A series of bulk sediment samples from TxDOT Square E28/S78, at the east end of the South Block of TARL excavations, were not collected as a continuous column. Instead, they were commonly provenienced to levels in one of four quadrants in this $2-\mathrm{m}^{2}$ excavation square and include both feature and nonfeature contexts. In order to obtain a composite stratigraphic column, all results from within each excavation level (including feature contexts) were averaged so that a level MS value could be determined. A total of 154 individual samples, from 41 different levels, was analyzed.

Results for TARL Squares 12, 20, and 33/56 are presented in Tables $28-2,28-3$, and 28-4, respectively. Those 
TABLE 28-2

Magnetic Susceptibility Results from Square 12

\begin{tabular}{|c|c|c|c|}
\hline $\begin{array}{l}\text { Square } 12 \text { Column } \\
\text { Sample Number }\end{array}$ & $\begin{array}{c}\text { TARL } \\
\text { Elevation }\end{array}$ & Unit & $\begin{array}{l}\text { Susceptibility }(\chi) \\
\times 10^{-6} \mathrm{cgs} \text { units }\end{array}$ \\
\hline 1 & 96.79 & IIIb & 39.5 \\
\hline 2 & 96.70 & IIIb & 36.1 \\
\hline 3 & 96.60 & IIIb & 41.2 \\
\hline 4 & 96.52 & IIIb/IIIa & 45.5 \\
\hline 5 & 96.39 & IIIb/IIIa & 35.8 \\
\hline 6 & 96.29 & IIIa & 39.2 \\
\hline 7 & 96.18 & IIIa & 41.0 \\
\hline 8 & 96.09 & IIIa & 43.6 \\
\hline 9 & 95.99 & IIIa & 43.5 \\
\hline 10 & 95.91 & IIIa & 40.4 \\
\hline 11 & 95.77 & IIIa/II & 35.5 \\
\hline 12 & 95.69 & II & 32.4 \\
\hline 13 & 95.57 & II/Isi-c & 25.9 \\
\hline 14 & 95.43 & II/Isi-c & 24.2 \\
\hline 15 & 95.30 & II/Isi-c & 26.2 \\
\hline 16 & 95.18 & Isi-c & 26.6 \\
\hline 17 & 95.08 & Isi-c & 20.5 \\
\hline 18 & 94.95 & Isi-c/Isi & 14.4 \\
\hline 19 & 94.82 & Isi-c/Isi & 5.2 \\
\hline 20 & 94.71 & Isi-c/Isi & 5.8 \\
\hline 21 & 94.58 & Isi-c/Isi & 3.0 \\
\hline 22 & 94.46 & Isi & 2.5 \\
\hline 23 & 94.38 & Isi & 4.1 \\
\hline 24 & 94.29 & Isi & 1.4 \\
\hline 25 & 94.19 & Isi & 1.8 \\
\hline 26 & 94.05 & Isi & 0.7 \\
\hline 27 & 93.95 & Isi & 1.0 \\
\hline 28 & 93.88 & Isi & 0.8 \\
\hline 29 & 93.77 & Isi & 0.8 \\
\hline 30 & 93.72 & Isi & 0.5 \\
\hline 31 & 93.60 & Isi & 1.0 \\
\hline 32 & 93.48 & Isi & 0.7 \\
\hline 33 & 93.41 & Isi & 0.6 \\
\hline 34 & 93.28 & Isi & 1.1 \\
\hline 35 & 93.15 & Isi & 0.8 \\
\hline 36 & 92.98 & Isi & 0.9 \\
\hline 37 & 92.86 & Isi & 0.8 \\
\hline 38 & 92.74 & Isi & 1.3 \\
\hline 39 & 92.64 & Isi & 1.0 \\
\hline
\end{tabular}

from Square E28/S78 are given in Table 28-5. ${ }^{1}$ The MS data for these columns (excluding Square 33/56) are shown in Figure 28-1. The results from Square 33/56 are reproduced separately in Figure 28-2. The face of the latter section was exposed for an extended period during the TxDOT excavations and was subjected to significant subaerial weathering and perhaps some superficial leaching. Consequently, the data from this column are more variable and the patterns less distinct. The columns in Figure 28-1 are arrayed roughly perpendicular to the valley margin so that Square 12 (the farthest upslope) is the far left, Square 20 (the farthest downslope) is on the right, and Square E28/S78 is in the
TABLE 28-3

Magnetic Susceptibility Results from Square 20

\begin{tabular}{|c|c|c|c|}
\hline $\begin{array}{c}\text { Square } 20 \text { Column } \\
\text { Sample Number }\end{array}$ & $\begin{array}{c}\text { TARL } \\
\text { Elevation }\end{array}$ & Unit & $\begin{array}{c}\text { Susceptibility }(\chi) \\
\times 10^{-6} \text { cgs units }\end{array}$ \\
\hline 1 & 97.10 & Fill & 41.6 \\
\hline 2 & 97.00 & Fill/IIIc & 57.8 \\
\hline 3 & 96.90 & IIIc & 54.6 \\
\hline 4 & 96.80 & IIIc/IIIb & 52.0 \\
\hline 5 & 96.70 & IIIc/IIIb & 49.0 \\
\hline 6 & 96.60 & IIIb & 41.9 \\
\hline 7 & 96.50 & IIIb & 43.4 \\
\hline 8 & 96.40 & IIIb & 42.9 \\
\hline 9 & 96.33 & IIIb & 42.8 \\
\hline 10 & 96.17 & IIIb/IIIa & 40.7 \\
\hline 11 & 96.00 & IIIb/IIIa & 38.7 \\
\hline 12 & 95.87 & IIIa & 43.5 \\
\hline 13 & 95.76 & IIIIa & 39.6 \\
\hline 14 & 95.63 & IIIa & 36.6 \\
\hline 15 & 95.53 & IIIa/II & 32.2 \\
\hline 16 & 95.40 & II & 27.4 \\
\hline 17 & 95.31 & II & 28.4 \\
\hline 18 & 95.20 & II & 25.5 \\
\hline 19 & 95.10 & II & 26.7 \\
\hline 20 & 95.00 & II & 14.0 \\
\hline 21 & 94.88 & II & 10.6 \\
\hline 22 & 94.78 & II & 3.5 \\
\hline 23 & 94.69 & II/Isi-c & 7.1 \\
\hline 24 & 94.57 & II/Isi-c & 4.7 \\
\hline 25 & 94.47 & Isi-c & 3.5 \\
\hline 26 & 94.39 & Isi-c & 5.7 \\
\hline 27 & 94.29 & Isi-c & 2.2 \\
\hline 28 & 94.14 & Isi-c & 3.8 \\
\hline 29 & 94.04 & Isi-c/Icl & 3.4 \\
\hline 30 & 93.95 & Isi-c/Icl & 3.5 \\
\hline 31 & 93.84 & Isi-c/Icl & 2.9 \\
\hline 32 & 93.71 & Isi-c/Icl & 3.2 \\
\hline 33 & 93.61 & Icl & 1.8 \\
\hline 34 & 93.48 & Icl & 2.4 \\
\hline 35 & 93.37 & Icl & 2.4 \\
\hline 36 & 93.28 & Icl & 2.4 \\
\hline
\end{tabular}

middle. However, the actual location of Square E28/S78 is offset somewhat (see Figure 3-1 in Volume I). Stratigraphic assignments in the tables correspond to units defined and discussed in detail in Chapters 6 and 29. The approximate stratigraphic positions of the major sedimentary units (i.e., excluding transition zone distinctions) are also given on the figures.

Several clear patterns can be seen in Figure 28-1. Most striking perhaps is the uniformly low $\chi$ values in all three columns below ca. $94.5 \mathrm{~m}$. In contrast, by $95.0 \mathrm{~m}$ all three profiles have MS readings several times greater than in their lowermost strata. Each section has two distinctive, welldefined MS trends typical of developed soil profiles (each soil connected by thick gray lines on Figure 28-1). As mentioned previously, MS values in a well-developed soil are highest at the surface and decrease downward through the

\footnotetext{
${ }^{1}$ Note that although the MS measurements for Features 181, 184, 185, and 187 are included in Table 28-5 they are also presented separately in the discussion of individual TxDOT features below.
} 
TABLE 28-4

Magnetic Susceptibility Results for Square 33/56

\begin{tabular}{|c|c|c|c|}
\hline $\begin{array}{c}\text { Square 33/56 } \\
\text { Column Sample No. }\end{array}$ & $\begin{array}{c}\text { TARL } \\
\text { Elevation }\end{array}$ & Unit & $\begin{array}{c}\text { Susceptibility }(\chi) \\
\times 10^{-6} \text { cgs units }\end{array}$ \\
\hline 1 & 96.76 & IIIc/IIIb & 41.4 \\
\hline 2 & 96.70 & IIIc/IIII & 40.8 \\
\hline 3 & 96.66 & IIIb & 41.6 \\
\hline 4 & 96.60 & IIIb & 38.6 \\
\hline 5 & 96.54 & IIIb & 40.3 \\
\hline 6 & 96.46 & IIIb/IIIa & 41.7 \\
\hline 7 & 96.39 & IIIJ/IIIa & 40.6 \\
\hline 8 & 96.32 & IIIb/IIIa & 39.6 \\
\hline 9 & 96.28 & IIIJ/IIIa & 44.8 \\
\hline 10 & 96.21 & IIIa & 43.9 \\
\hline 11 & 96.15 & IIIIa & 41.7 \\
\hline 12 & 96.06 & IIIa & 42.9 \\
\hline 13 & 96.00 & IIIIa & 48.6 \\
\hline 14 & 95.94 & IIIIa & 44.9 \\
\hline 15 & 95.89 & IIIIa & 62.6 \\
\hline 16 & 95.85 & IIIIa & 39.2 \\
\hline 17 & 95.79 & IIIa/II & 36.3 \\
\hline 18 & 95.75 & IIIa/II & 35.1 \\
\hline 19 & 95.69 & IIIa/II & 34.5 \\
\hline 20 & 95.64 & IIIa/II & 36.5 \\
\hline 21 & 95.56 & IIIa/II & 32.9 \\
\hline 22 & 95.54 & IIIa/II & 26.9 \\
\hline 23 & 95.47 & II & 31.4 \\
\hline 24 & 95.45 & II & 27.4 \\
\hline 25 & 95.39 & II & 23.6 \\
\hline 26 & 95.34 & $\mathrm{II} / \mathrm{Id}$ & 27.5 \\
\hline 27 & 95.28 & $\mathrm{II} / \mathrm{Id}$ & 23.3 \\
\hline 28 & 95.23 & $\mathrm{II} / \mathrm{Id}$ & 21.2 \\
\hline 29 & 95.20 & $\mathrm{II} / \mathrm{Id}$ & 18.2 \\
\hline 30 & 95.15 & Id & 16.7 \\
\hline 31 & 95.10 & Id & 14.0 \\
\hline 32 & 95.03 & $\mathrm{Id} / \mathrm{Isi}-\mathrm{c}$ & 19.0 \\
\hline 33 & 94.98 & $\mathrm{Id} / \mathrm{Isi}-\mathrm{c}$ & 13.3 \\
\hline 34 & 94.93 & $\mathrm{Id} / \mathrm{Isi}-\mathrm{c}$ & 8.6 \\
\hline 35 & 94.87 & $\mathrm{Id} / \mathrm{Isi}-\mathrm{c}$ & 1267 \\
\hline 36 & 94.82 & $\mathrm{Id} / \mathrm{Isi}-\mathrm{c}$ & 9.0 \\
\hline 37 & 94.77 & $\mathrm{Id} / \mathrm{Isi}-\mathrm{c}$ & 9.1 \\
\hline 38 & 94.73 & $\mathrm{Id} / \mathrm{Isi}-\mathrm{c}$ & 9.9 \\
\hline 39 & 94.68 & $\mathrm{Id} / \mathrm{Isi}-\mathrm{c}$ & 3.9 \\
\hline 40 & 94.62 & $\mathrm{Id} / \mathrm{Isi}-\mathrm{c}$ & 4.6 \\
\hline 41 & 94.57 & Isi-c & 7.1 \\
\hline 42 & 94.54 & Isi-c & 12.5 \\
\hline 43 & 94.49 & Isi-c & 5.8 \\
\hline
\end{tabular}

solum. Evidence of two buried paleosols (the Leanne and Stiba, described in Chapters 6 and 29) can be clearly seen in the Square 12 and E28/S78 columns. Likewise, the Stiba soil can be seen in the Square 20 profile although the Leanne soil cannot. The modern, surficial Wilson-Leonard soil is also evident in the Square 20 data (capped by a small amount of construction fill). The uppermost sections of Squares 12 and E28/S78 were truncated due to road construction and, therefore, the Wilson-Leonard soil is missing in these profiles.

Despite an extended period of subaerial exposure, results from the Square 33/56 column are similar to those from the other three columns (see Figure 28-2). Although somewhat more irregular, these MS data also indicate initially low
MS below $95.0 \mathrm{~m}$, increasing values through Unit IIIa (probably associated with development of the Stiba soil), and regular, elevated $\chi$ values in Unit IIIb (cf. Squares E28/S78 and 20 in Figure 28-1). The isolated high $\chi$ value at $95.89 \mathrm{~m}$ may represent an unrecognized cultural feature, perhaps related to the multiple burned rock features found nearby in Unit IIIa (see Chapter 26).

The low MS values below $94.5 \mathrm{~m}$ may be due to rapid alluvial deposition or postdepositional groundwater saturation or throughflow (cf. Chapters 6 and 29) as well as the low density of human occupation prior to Late Paleoindian times (cf. Chapters 7 and 8 in Volume I). Some degree of groundwater influence is indicated by extensive iron-staining and gleying below ca. $95.0 \mathrm{~m}$. As mentioned, the MS of gleyed and highly oxidized sediments is typically quite low (e.g., Gale and Hoare 1991:214; Mullins 1977:236). MS enhancements below $95.0 \mathrm{~m}$ are related to later soil development postdating the iron-staining and gleying noted in Unit I. This probably represents a shift from wetter to drier conditions beginning with the development of the Leanne soil (cf. Chapter 6).

The primary ferromagnetic mineral in the pedogenic intervals is probably maghemite (with some magnetite) related to soil development and an increase in human occupation (and therefore organic input). The gradual changes in the MS of cultural deposits seen in Figure 28-1 are markedly different from those observed in cave or rockshelter settings where cultural occupation zones often have "spiky," irregular $\chi$ values (Collins et al. 1994). This probably reflects the action of earthworms, tree roots, and other bioturbation in alluvial, open-air settings. The localized increases in MS related to individual features and other cultural deposits are probably "smeared" or blurred somewhat, both prior to and after burial.

The absence of evidence for the Leanne soil in Square 20 is curious. However, the lower density of artifacts in an arc around this area suggests that the area around Square 20 may have remained boggy during development of the Leanne soil (see Chapters 6, 8, and 29). The most dramatic MS evidence for the Leanne soil can be seen in Square 12, where it formed on alluvial, overbank silt (Isi) deposits. The evidence is less pronounced in Square E28/S78 where the Leanne soil formed on clayey, cienega (Icl) sediments. These laterally transgressive MS enhancements may reflect progressively drier conditions as the Leanne soil developed. If so, persistent moist conditions in and around Square 20 may have inhibited the creation of pedogenic maghemite which seems to require alternating wet/dry conditions (Le Borgne 1955, 1960; Vodyanitskiy 1982, cited in Singer and Fine 1989).

Additional magnetic studies were performed in order to better understand the magnetic mineralogy associated with these MS changes through time. These studies take advantage of differences in the magnetic properties of individual ferromagnetic minerals and grains. Specifically, their abililty to acquire and retain a remanent magnetization 
TABLE $28-5$

Magnetic Susceptibility Results from Square E28/S78

\begin{tabular}{|c|c|c|c|c|c|}
\hline Unit & TARL Elevation & Associated Features & Level & Number of Samples & Susceptibility $(\chi) \times 10^{-6} \mathrm{cgs}$ units \\
\hline $\mathrm{IIIb} / \mathrm{IIIc}$ & 96.61 & & 8 & 2 & 43.1 \\
\hline $\mathrm{IIIb} / \mathrm{IIIC}$ & 96.40 & & 10 & 2 & 40.6 \\
\hline IIIb/IIIc & 96.31 & & 11 & 2 & 40.8 \\
\hline IIIa/IIIb & 96.01 & & 14 & 2 & 42.8 \\
\hline IIIa/IIIb & 95.96 & & $15 \mathrm{~A}$ & 2 & 45.6 \\
\hline IIIa & 95.86 & & $16 \mathrm{~A}$ & 2 & 44.6 \\
\hline IIIIa & 95.81 & & $16 \mathrm{~B}$ & 2 & 44.1 \\
\hline IIIa & 95.76 & F181 & $17 \mathrm{~A}$ & 4 & 47.2 \\
\hline IIIIa & 95.71 & F181 & $17 \mathrm{~B}$ & 6 & 45.5 \\
\hline II/IIIIa & 95.66 & F181 & $18 \mathrm{~A}$ & 8 & 45.3 \\
\hline II/IIIa & 95.61 & F181, 184 & $18 \mathrm{~B}$ & 6 & 41.6 \\
\hline II/IIIa & 95.56 & F181, 184 & $19 \mathrm{~A}$ & 6 & 38.9 \\
\hline II/IIIa & 95.51 & F181, 184 & $19 B$ & 8 & 36.7 \\
\hline II/IIIIa & 95.46 & F181, 184 & $20 \mathrm{~A}$ & 6 & 38.1 \\
\hline II & 95.41 & F185 & $20 \mathrm{~B}$ & 6 & 29.8 \\
\hline II & 95.36 & & $21 \mathrm{~A}$ & 4 & 28.6 \\
\hline II & 95.31 & & $21 \mathrm{~B}$ & 2 & 26.1 \\
\hline II & 95.26 & & $22 \mathrm{~A}$ & 4 & 26 \\
\hline II & 95.16 & & $23 \mathrm{~A}$ & 4 & 21.4 \\
\hline II & 95.11 & & $23 B$ & 4 & 18.1 \\
\hline Id/II & 95.01 & & $24 \mathrm{~B}$ & 4 & 14.3 \\
\hline Id/II & 94.96 & & $25 \mathrm{~A}$ & 2 & 14.4 \\
\hline $\mathrm{Id} / \mathrm{II}$ & 94.91 & & $25 \mathrm{~B}$ & 4 & 13.9 \\
\hline $\mathrm{Id} / \mathrm{II}$ & 94.86 & & $26 \mathrm{~A}$ & 2 & 14.1 \\
\hline Isi-c/Id & 94.76 & & $27 \mathrm{~A}$ & 4 & 17.2 \\
\hline Isi-c/Id & 94.71 & & 27B & 2 & 14.8 \\
\hline Isi-c/Id & 94.61 & & $28 \mathrm{~B}$ & 4 & 12.7 \\
\hline Isi-c & 94.51 & & $29 \mathrm{~B}$ & 4 & 10.8 \\
\hline Isi-c & 94.41 & & $30 \mathrm{~B}$ & 8 & 7.7 \\
\hline Icl/Isi-c & 94.26 & & $32 \mathrm{~A}$ & 4 & 4.3 \\
\hline Icl/Isi-c & 94.21 & F187 & $32 \mathrm{~B}$ & 2 & 3.3 \\
\hline Icl & 94.01 & & 34B & 4 & 3 \\
\hline Icl & 93.91 & & $35 \mathrm{~B}$ & 4 & 2.8 \\
\hline Icl & 93.86 & & $36 \mathrm{~A}$ & 4 & 2.9 \\
\hline Icl & 93.76 & & $37 \mathrm{~A}$ & 4 & 2.6 \\
\hline $\mathrm{Isi} / \mathrm{Icl}$ & 93.66 & & $38 \mathrm{~A}$ & 2 & 2.8 \\
\hline Isi & 93.56 & & $39 A$ & 2 & 2.7 \\
\hline Isi & 93.51 & & $39 \mathrm{~B}$ & 2 & 2.7 \\
\hline Isi & 93.46 & & $40 \mathrm{~A}$ & 2 & 2.8 \\
\hline Isi & 93.31 & & $41 \mathrm{~B}$ & 4 & 1.3 \\
\hline Isi & 93.16 & & $43 \mathrm{~A}$ & 4 & 2.7 \\
\hline
\end{tabular}

(or remanence): an internal magnetization which remains after an applied magnetic field has been removed. Magnetic minerals capable of retaining a remanence are called ferromagnetic (sensu Butler 1992:26). The stability of existing remanence in any given grain or magnetic mineral type can be described in terms of coercivity $\left(\mathrm{H}_{\mathrm{c}}\right)$, or the energetic resistence to remagnetization, as defined by the strength of an applied electromagnetic field. $\mathrm{H}_{\mathrm{c}}$ is the threshold magnetic field beyond which an isothermal remanent magnetization (IRM) is acquired.

Different ferromagnetic minerals acquire IRM's at varying rates and reach their maximum remanence intensities ("saturation magnetization") at different magnetic field strengths. Magnetite and maghemite rapidly acquire a saturation IRM in magnetic fields of ca. $0.3 \mathrm{~T}$ (Tesla in SI units). In contrast, hematite and goethite grains have higher coercivites and may require magnetic fields exceeding those of magnetite/maghemite by an order of magnitude or more. In IRM acquisition studies, samples are exposed to electromagnetic fields of increasing strength and after each exposure, the remanent magnetization is measured. Differences in the rate of IRM acquisition between magnetite and hematite are shown in Figure 28-3. Note that the remanence of hematite will continue to increase in fields $>1.0 \mathrm{~T}$. When both minerals are present, the observed curve is intermediate between these two curves. Nevertheless, due to their much higher remanence intensities, magnetite and maghemite will normally dominate the distribution, even when present only as a few percent of the total ferromagnetic mineralogy.

Complete IRM acquisition analyses were conducted on eight selected samples from the Square 20 column (Samples $3,11,13,15,18,22,27$, and 33) in order to compare them to the reference curves shown in Figure 28-3. The results of this analysis are shown on Figure 28-4. Sediment from deeper 


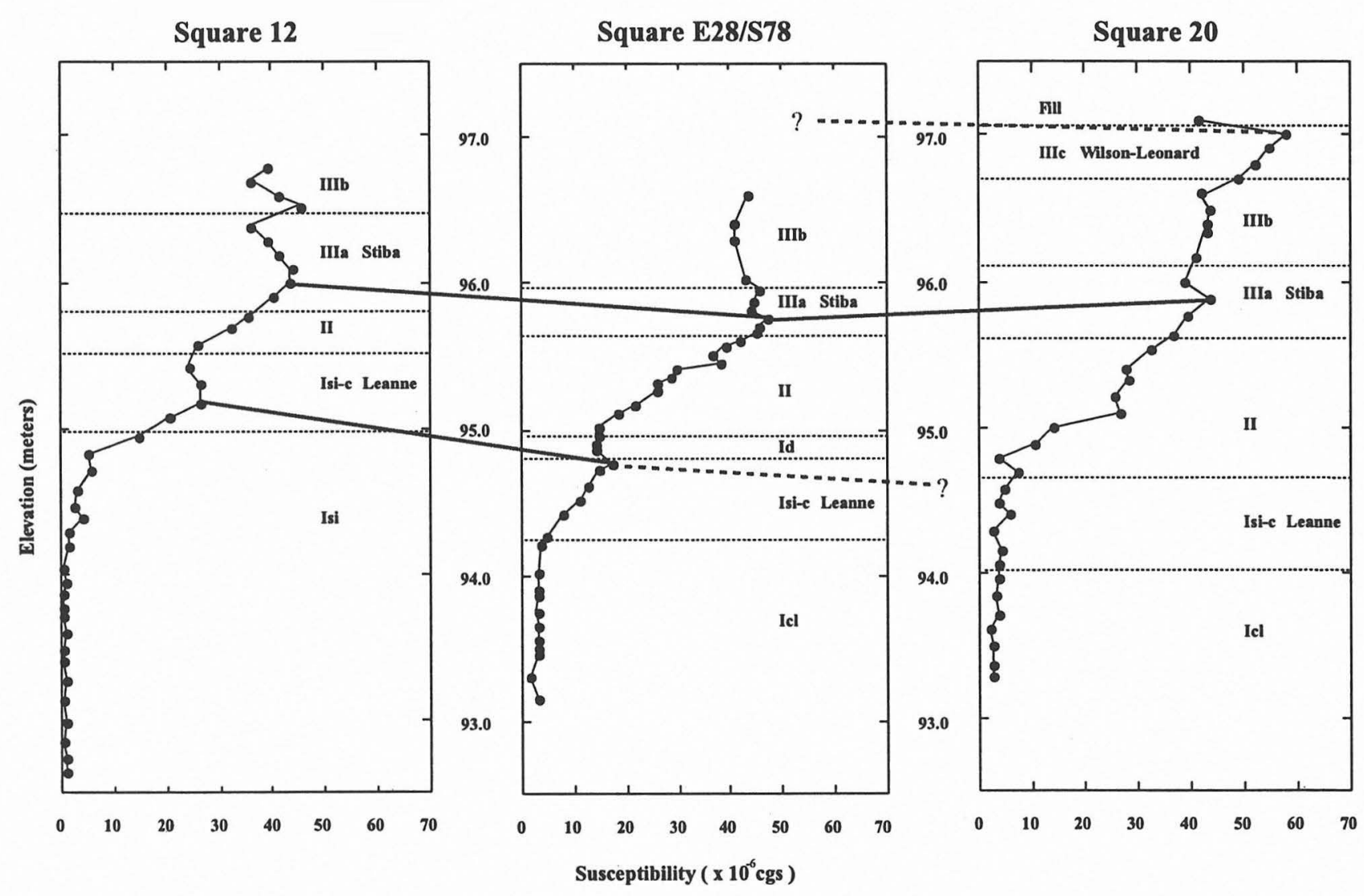

FIGURE 28-1. Magnetic susceptibility results from Squares 12, E28S78, and 20. The solid gray lines connect MS peaks related to the development of three soils (the Leanne, Stiba, and Wilson-Leonard). Approximate locations of stratigraphic units (e.g., Unit II, Unit IIIb) are also included.

strata (i.e., Samples 27 and 33) clearly have more high than low $\mathrm{H}_{\mathrm{c}}$ grains. The upper samples $(3,11,13,15$, and 18) contain a larger fraction of low coercivity minerals. Sample 22 , at the transition to pedogenically altered sediments (see Figure 28-1), has an IRM curve characteristic of a small amount of maghemite (or magnetite) but a predominance of high coercivity (and lower MS) ferromagnetic minerals. Trace amounts of higher MS and lower $\mathrm{H}_{\mathrm{c}}$ minerals in Sample 22 may reflect illuviation and/or earthworm bioturbation associated with soil development in Unit IIIa. Overall, these IRM results are consistent with those already discussed and again clearly support a change in ferromagnetic mineralogy.

In order to characterize the relative proportions of high $\mathrm{H}_{\mathrm{c}}$ and low $\mathrm{H}_{\mathrm{c}}$ magnetic minerals in a much larger number of samples, a similar IRM technique was employed which requires only two magnetic field treatments (King and Channel 1991). A maximum field ${ }^{2}$ (in this case, $1.2 \mathrm{~T}$ ) is first applied to each sample along one axis and the resulting IRM measured (see Chapter 27 for a description of the magnetometer used in this study). Then a second field of only 0.3
$\mathrm{T}$ is applied-in a direction exactly oppposite to the first IRM - and the remanence remeasured. This second IRM affects only grains in the magnetite/magnetite range. The ratio of IRM $_{-0.3 \mathrm{~T}}$ to $\mathrm{IRM}_{1.2 \mathrm{~T}}$ yields the proportion of high and low coercivity minerals (ranging from 0 and 1 ). If the sample contains an abundance of low coercivity minerals, such as magnetite and/or maghemite, then the two remanences will be quite similar and the ratio will approach values of 1.0. If, on the other hand, a sample contains nearly all high $\mathrm{H}_{\mathrm{c}}$ minerals (i.e., hematite or goethite) $I_{R M}{ }_{-0.3 T}$ will be small and its ratio will be low (approaching 0). However, it should be stressed that these values cannot be taken as a direct measure of the relative proportions of different magnetic minerals because of both coercivity variations within individual grains as well as the significant differences in saturation intensities between them. In the latter case, even a small amount of magnetite may overwhelm the remanence contribution of hematite.

All samples from the three TARL sediment columns were analyzed using this IRM ratio. Results are shown in Figure

\footnotetext{
${ }^{2}$ The maximum applied electromagnetic field is limited by the equipment available. The impulse magnetization unit used in this study is capable of ca. 1.2 Tesla fields which is sufficient to magnetize nearly the entire sample (including all low and most high coercivity magnetic mineral grains).
} 


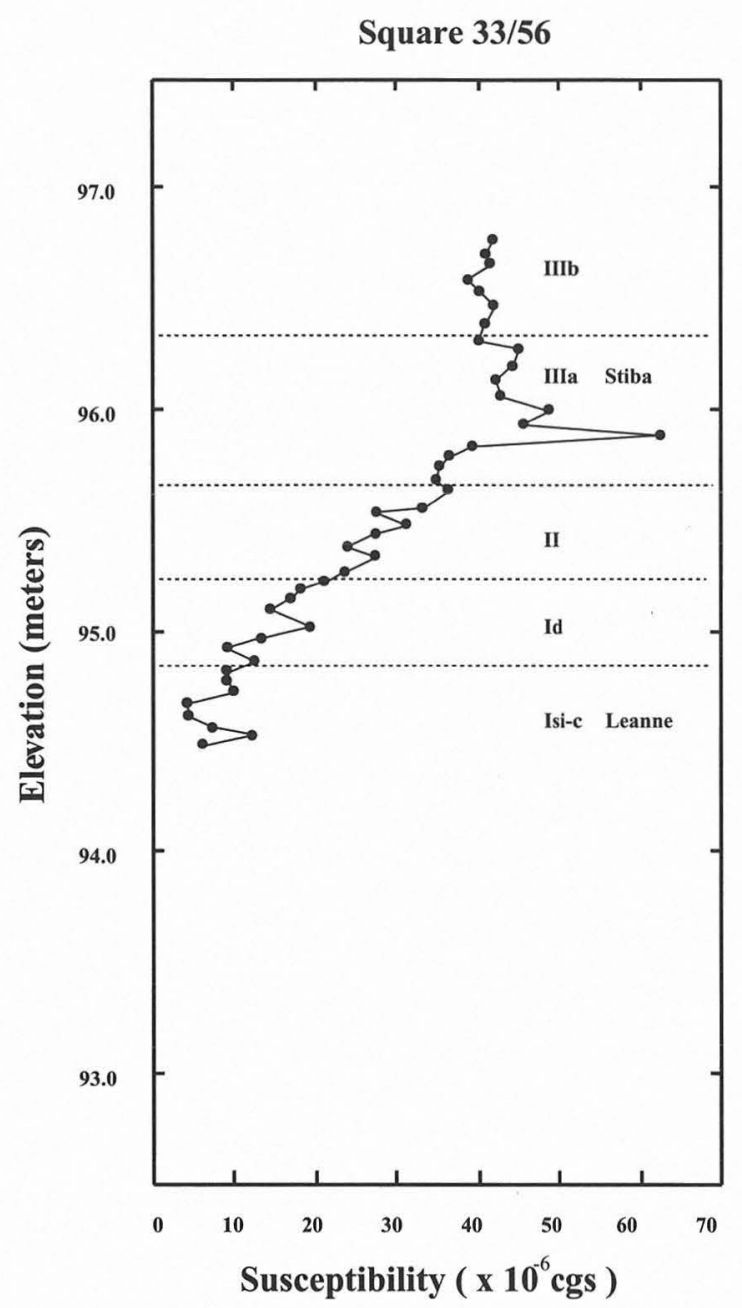

FIGURE 28-2. Magnetic susceptibility results from Square 33/56. The sawtooth pattern in this column is most likely due to significant subaerial weathering during earlier TxDOT investigations. The trend toward increasing MS through time, however, remains evident.

28-5. Clearly, between 94.0 and 95.0 m overall magnetic mineralogy changes from a preponderance of high $\mathrm{H}_{\mathrm{c}}$ minerals (e.g., hematite and/or goethite) to larger amounts of lower $\mathrm{H}_{c}$ minerals (e.g., magnetite and/or maghemite). Note that this pattern is evident even in Square 33/56 despite the effects of weathering and leaching. These data demonstrate that the MS increases seen in Figures 28-1 and 28-2 are not merely due to greater concentrations of the same ferromagnetic mineral(s) but rather to mineralogical change. The fluctuations in the Square 12 column in Figure 28-5 below $95.0 \mathrm{~m}$ may represent isolated enhancements related to intermittent cultural occupations whereas the uniformly high values (ca. 0.9 ) above this elevation in all three columns reflect some combination of pedogenesis and/or human occupation. The shift toward higher values between 94.0 and $95.0 \mathrm{~m}$ is probably associated with the initial period of soil development (i.e., the Leanne soil; see Figure 28-1).

The data in Figure 28-4 and 28-5 support the presence of high coercivity, oxidized ferromagnetic minerals in the

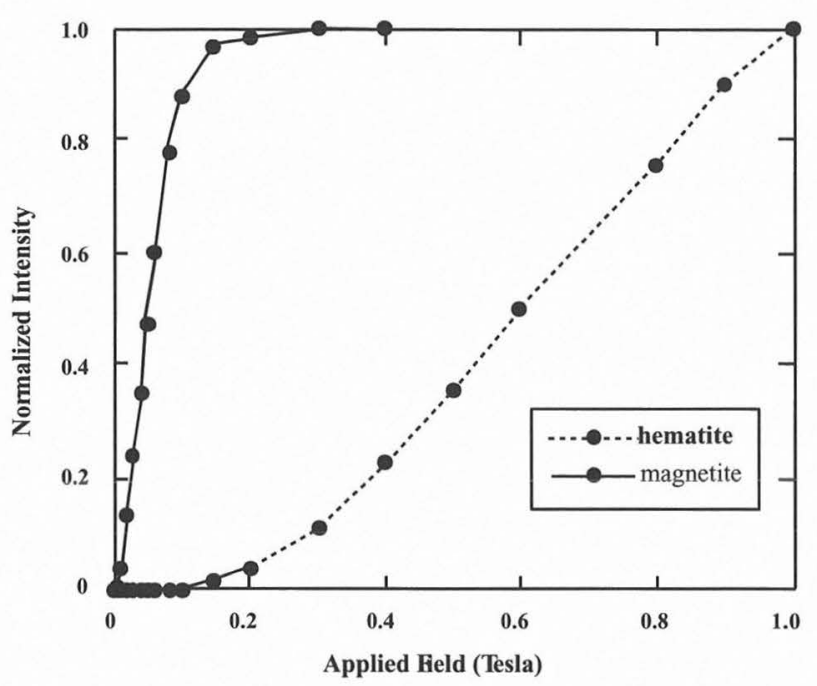

FIGURE 28-3. Isothermal remanence acquisition curves for magnetite and hematite (after Thompson 1986).

basal Unit I sediments (generally $<95.0 \mathrm{~m}$ ), although it remains uncertain whether this is due mainly to rapid alluvial deposition or postdepositional groundwater. However, the extensive gleying noted in these sediments clearly attests to some groundwater effect. Sediments above $95.0 \mathrm{~m}$ include greater amounts of magnetite and/or maghemite associated with pedogenesis and cultural occupations although some high $\mathrm{H}_{\mathrm{c}}$ minerals persist.

The column data clearly support both geological (e.g., Chapters 6 and 29) and archeological evidence relating to individual periods of soil development, probable postdepositional alteration(s), and greater intensity of human occupations through time, as indicated by artifact and feature density.

\section{Feature Analyses}

In feature contexts, the presence of ash or $\chi$-enhanced sediments altered by heating are often recorded as locally elevated $\chi$ values relative to the "background" sediments in which those features are found (e.g., Collins et al. 1994). It appears that MS enhancement is most consistent and of greatest intensity as the result of multiple rather than single burning events (Bellomo 1990, 1993; McClean and Kean 1993). Given sufficient sampling density, it should be possible to trace the boundaries and internal differences between areas of high and low $\chi$ within individual features.

However, unlike the TARL stratigraphic columns, feature samples were not collected in the field as part of a planned research objective. Rather, like those samples obtained from curated TxDOT sediment, the TARL feature samples were collected in the laboratory from bulk matrix. In this sense, MS analysis of features was an experimental, post hoc effort. Although the interpretive results of these 

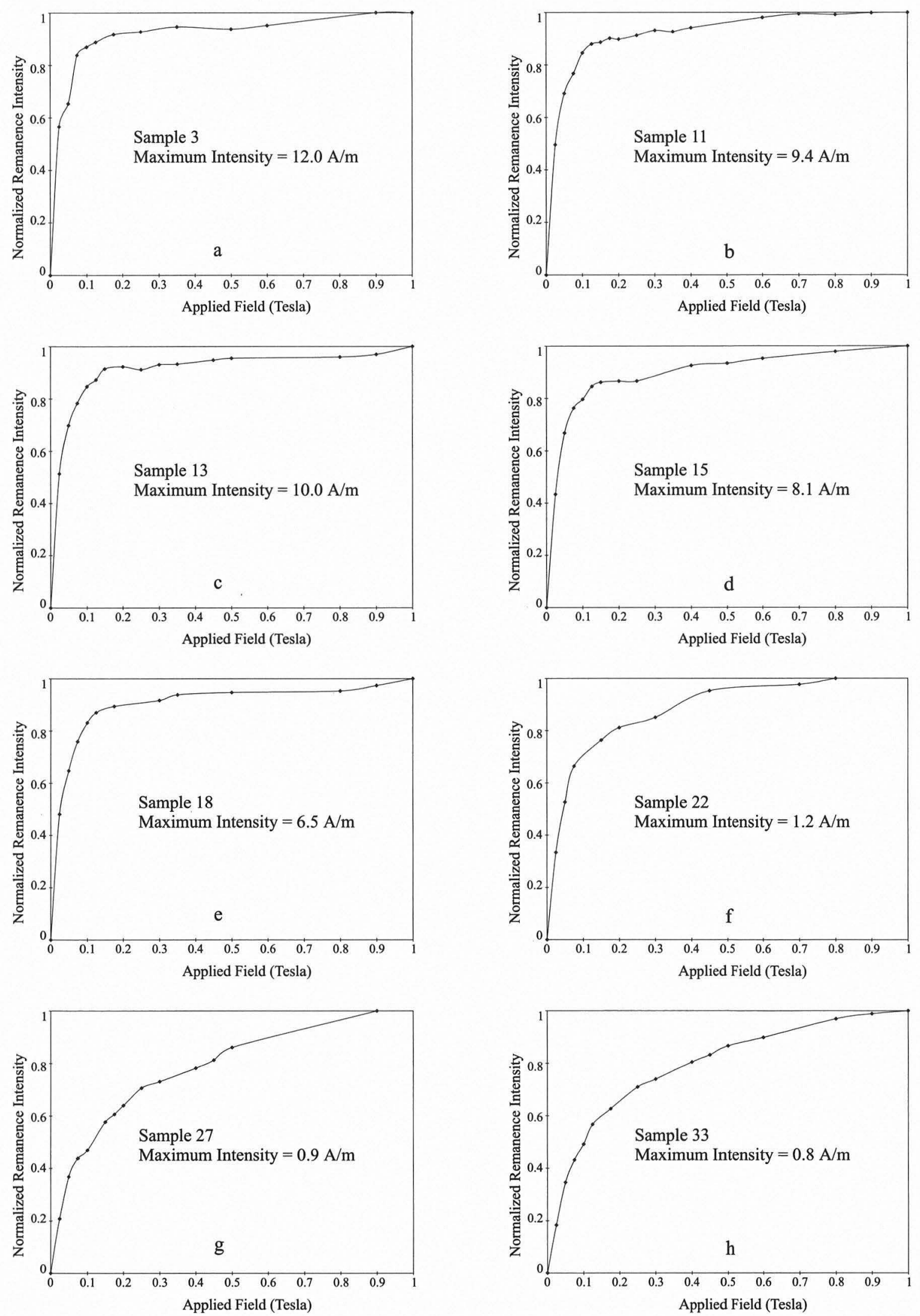

FIGURE 28-4. Results of IRM analyses from eight selected samples from the Square 20 profile (maximum remanence intensities are given in Amperes/meter (A/m). (a) Sample 3; (b) Sample 11; (c) Sample 13; (d) Sample 15; (e) Sample 18; (f) Sample 22; (g) Sample 27; (h) Sample 33. 
Square 12

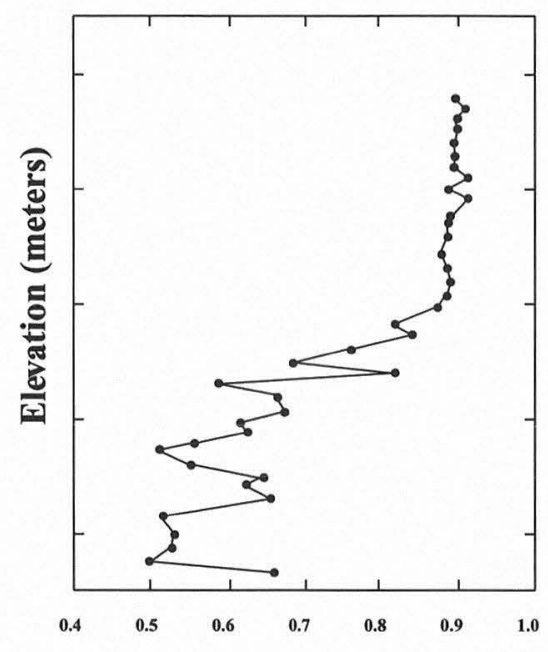

Square 20

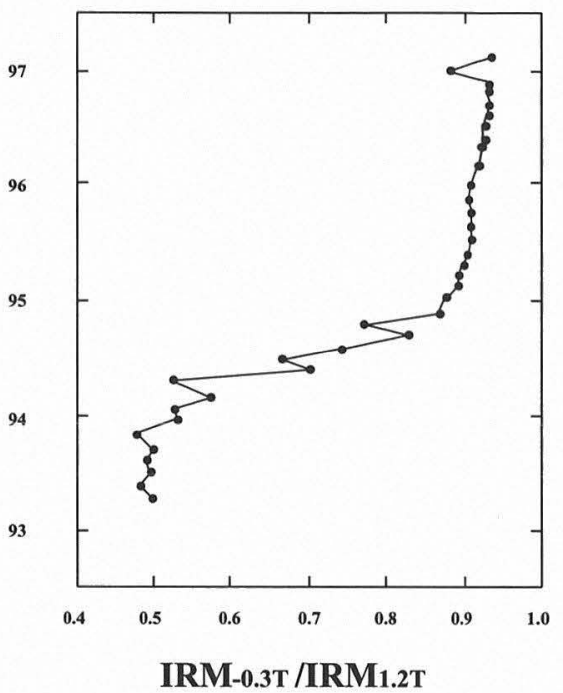

Square 33

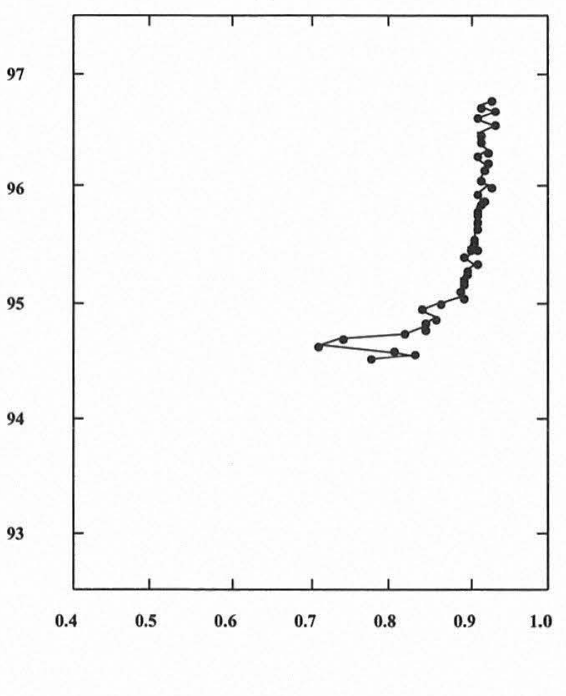

FIGURE 28-5. The ratio of low coercivity ferromagnetic minerals $\left(\operatorname{IRM}_{-0.3 \mathrm{~T}}\right)$ to high coercivity minerals $\left(\mathrm{IRM}_{1.2 \mathrm{~T}}\right)$ in TARL sediment columns from Squares 12, 20, and 33/56.

investigations are somewhat limited, a great deal was learned that may be applied to future research. Primary among these is the recognition that a large number of samples from within and around a feature may be instructive in terms of how it was used and/or its likely stratigraphic position and lateral extent. Information from both TARL and TxDOT features were limited for the most part to small quantities of sediment provenienced only to the feature as a whole. Therefore, positive evidence of increased MS in feature sediments should be considered more significant than the absence of such enhancements because any particular sample may have randomly sampled an area of lower $\chi$. Likewise, a single high MS measurement cannot be used to infer that the entire feature is uniformly enhanced. The limited number of samples from each feature probably obscures significant internal variability. Despite these limitations, MS analyses were found to be useful for comparing features to the stratigraphic units in which they were found. Furthermore, for those features from which multiple samples are available (such as Burial 2), additional inferences could be made about the likely composition or origin of the sediments as well as the lateral and horizontal distribution of $\chi$ enhancement.

In order to determine if the MS of individual features was greater than the sediments in which they were found, a detailed point-by-point comparison was made between the measured $\chi$ value and the nearest stratigraphic column(s). In some cases, the samples were close enough that elevation became the primary determinant of which values to compare, while in other instances it was necessary to interpolate where within a particular sedimentary unit a feature was found in order to compare column values from approximately that same stratigraphic position.

\section{TARL Features}

The results from TARL features and individual excavation levels are presented in Table 28-6. The overall trend in these data show a correlation between MS and elevation: younger features tend to have higher $\chi$ values. This mirrors the pattern seen in the column data and probably reflects increasing intensity of human occupation at Wilson-Leonard through time and/or greater soil development. Greater inputs of organic matter, as well as heating events, seem to have contributed to higher overall MS in these primarily anthropogenic sediments, especially Unit III. Similar trends can also be seen in phosphate and organic matter measurements (see Chapter 6). The lower $\chi$ values of features in Units I and II may reflect either single heating events that did not result in significant enhancement or dilution through the admixture of lower MS (natural, as opposed to anthropogenic) sediments.

Only four TARL features appear to have significantly enhanced MS relative to the sediments in which they were recovered. ${ }^{3}$ These are (1) Feature 213 in transitional Unit IIIb/IIIa, (2)Feature 249 in Unit IIIIa/II, (3) Feature 241 in Unit II, and (4) Feature 257 in Unit Isi-c. In addition, Feature 244 (and an associated sample labeled NF-32-35) from sediments transitional between Isi-c and Isi, also appears to have slightly higher MS, but in this case the differences are less pronounced. Among the former features, the first three have $\chi$ values about 20 to $30 \%$ greater than background values.

\footnotetext{
${ }^{3}$ Complete provenience information for all features, including detection and basal elevations, are given in Chapter 26.
} 
TABLE 28-6

Magnetic Susceptibility Results from TARL Features and Excavation Levels

\begin{tabular}{|c|c|c|c|c|c|c|c|c|c|c|c|}
\hline Unit & Feature & Square & Level & $\begin{array}{l}\text { No. of } \\
\text { Sample }\end{array}$ & $\begin{array}{c}\text { Susceptibility }(\chi) \\
\times 10^{-6} \text { cgs units }\end{array}$ & Unit & Feature & Square & Level & \begin{tabular}{|c|} 
No. of \\
Samples
\end{tabular} & $\begin{array}{l}\text { Susceptibility }(\chi) \\
\times 10^{-6} \text { cgs units }\end{array}$ \\
\hline IIIC & 206 & & & 4 & 61.8 & IIIa/II & 231 & 38 & 24 & 2 & 42.9 \\
\hline IIIC & 207 & & & 2 & 57.5 & $\mathrm{IIIa} / \mathrm{II}$ & 231 & 38 & $25 \mathrm{~B}$ & 2 & 41.7 \\
\hline IIIc & BRM & 100 & 2 & 2 & 60.2 & IIIa/II & 231 & 38 & $26 \mathrm{~B}$ & 2 & 39.0 \\
\hline IIIC & BRM & 100 & 3 & 2 & 65.4 & IIIa/II & 231 & 51 & 26 & 2 & 41.8 \\
\hline IIIc & BRM & 100 & 4 & 2 & 61.3 & IIIa/II & 231 & 52 & 24 & 2 & 46.0 \\
\hline IIIc & BRM & 100 & 5 & 2 & 54.3 & IIIa/II & $231 / 245$ & 52 & $24 B$ & 2 & 45.1 \\
\hline IIIC & BRM & 100 & 6 & 2 & 54.5 & IIIa/II & $231 / 245$ & 52 & $25 \mathrm{~B}$ & 2 & 44.0 \\
\hline IIIC & BRM & 100 & 7 & 4 & 44.8 & IIIa/II & $231 / 245$ & \multicolumn{2}{|c|}{ Average } & 28 & 43.6 \\
\hline IIIIC & BRM & 100 & 8 & 4 & 40.9 & IIIa/II & NF & 33 & 24 & 2 & 34.1 \\
\hline Y/IIIc & BRM & 100 & 9 & 4 & 35.8 & II & 239 & & & 6 & 31.7 \\
\hline $\mathrm{Y}$ & BRM & 100 & 10 & 2 & 42.2 & II & 241 & & & 2 & 39.3 \\
\hline IIIc/IIIb & 203 & & & 2 & 56.3 & II & 243 & & & 2 & 19.0 \\
\hline IIIc/IIIb & 205 & & & 2 & 47.0 & II & $243 ?$ & 25 & $33 \mathrm{~A}$ & 2 & 19.8 \\
\hline IIIc/IIIb & 208 & & & 4 & 52.2 & II & 248 & & & 6 & 27.8 \\
\hline IIIc/IIIb & 210 & & & 2 & 48.4 & II & 184 & 50 & $26 \mathrm{C}$ & 2 & 33.7 \\
\hline IIIc/IIIb & 211 & & & 2 & 48.9 & II & 231 & 38 & $27 \mathrm{~B}$ & 2 & 34.7 \\
\hline IIIb & 204 & & & 10 & 44.4 & II & NF & 38 & $27 \mathrm{~A}$ & 2 & 32.6 \\
\hline IIIb & 209 & & & 2 & 40.0 & II & NF & 46 & $28 \mathrm{~A}$ & 2 & 28.2 \\
\hline IIIb & 212 & & & 4 & 39.8 & II/Isi-c & 234 & & & 2 & 27.2 \\
\hline IIIb & 214 & & & 2 & 41.2 & II/Isi-c & 235 & & & 2 & 24.7 \\
\hline IIIb & $214 ?$ & & & 4 & 43.2 & II/Isi-c & 238 & & & 4 & 22.8 \\
\hline IIIb & 216 & & & 2 & 41.9 & II/Id & 236 & & & 15 & 26.1 \\
\hline IIIb/IIIa & 213 & & & 8 & 56.6 & II/Id & 246 & & & 10 & 22.4 \\
\hline IIIb/IIIa & 215 & & & 3 & 43.2 & $\mathrm{Id} / \mathrm{Isi}-\mathrm{c}$ & NF & 39 & $38 \mathrm{~B}$ & 2 & 11.4 \\
\hline IIIb/IIIa & 220 & & & 2 & 38.5 & Isi-c & 255 & & & 2 & 3.2 \\
\hline IIIb/IIIa & 221 & & & 2 & 46.0 & Isi-c & 257 & & & 4 & 16.7 \\
\hline IIIa & 222 & & & 2 & 39.5 & Isi-c & 256 & & & 2 & 4.3 \\
\hline IIIa & 225 & & & 2 & 48.7 & Isi-c & $256 ?$ & & & 2 & 3.9 \\
\hline IIIa & 228 & & & 2 & 44.2 & Isi-c & 260 & & & 4 & 4.1 \\
\hline IIIa & 230 & & & 2 & 44.1 & Isi-c/Isi & Burrow & 12 & 39 & 2 & 6.5 \\
\hline IIIa & 231 & 28 & 22 & 2 & 47.3 & Isi-c/Isi & NF & 32 & 35 & 2 & 26.2 \\
\hline IIIa & 231 & 51 & 24 & 2 & 46.5 & Isi-c/Isi & 244 & & & 2 & 17.3 \\
\hline IIIa & 231 & 51 & 25 & 2 & 44.2 & Isi-c/Isi & 252 & & & 8 & 2.0 \\
\hline IIIa & 231 & 52 & 23 & 2 & 43.5 & Isi/Icl & 262 & & & 4 & 2.7 \\
\hline IIIa & 231 & 52 & 23 & 2 & 48.3 & Igl & 261 & & & 3 & 2.3 \\
\hline IIIa/II & 224 & & & 2 & 35.7 & Igl & NF & 43 & $55 \mathrm{C}$ & 2 & 3.1 \\
\hline IIIa/II & 226 & & & 4 & 35.1 & Igl & NF & 43 & $56 \mathrm{C}$ & 2 & 2.5 \\
\hline $\mathrm{IIIa} / \mathrm{II}$ & 227 & & & 4 & 35.5 & Igl & NF & 44 & $56 \mathrm{C}$ & 2 & 2.3 \\
\hline IIIa/II & 233 & & & 4 & 35.9 & Igl & NF-7 & TU B & & 2 & 2.6 \\
\hline IIIa/II & 237 & & & 2 & 40.4 & Igl & NF-2 & TU B & & 2 & 0.9 \\
\hline IIIa/II & 242 & & & 2 & 29.1 & Igl & NF-3 & TU B & & 2 & 0.9 \\
\hline IIIa/II & 245 & & & 12 & 46.8 & Igl & NF-4 & TU B & & 2 & 2.9 \\
\hline IIIa/II & 249 & & & 10 & 36.5 & Igl & NF-5 & TU B & & 2 & 2.1 \\
\hline IIIa/II & 258 & & & 4 & 37.9 & Igl & NF-1 & TU B & & 2 & 2.1 \\
\hline IIIa/II & 231 & 38 & 24 & 2 & 45.4 & & & & & & \\
\hline
\end{tabular}

$\mathrm{NF}=$ Nonfeature; $\mathrm{TU}=$ Test Unit.

The last (Feature 257) has a value more than 50\% higher, although its overall MS remains rather low. These enhancements are probably due to one or more cultural heating events resulting in the localized production of higher MS iron oxides such as magnetite or maghemite. On the other hand, the higher value in Feature 249 may instead be attributed to a burrow emanating from a higher stratigraphic level.

The partial column through the Burned Rock Midden 1 deposits-Levels 2 through 10 in Square 100 (see Table 286) - have maximum $\chi$ values similar to those from Unit IIIc in the Square 20 column (see Table 28-3 and Figure 28-1). The higher MS values near the top of the midden gradually decrease through Level 9 (where burned rock density also decreases dramatically) before rising again somewhat in Level 10 , accompanied in turn by an increase in burned rocks. This pattern resembles a pedogenic profile and may, in fact, indicate development of the Wilson-Leonard soil at or near the top of the midden after it accumulated. Alternatively, this may represent translocation or leaching of iron oxides produced during latter-stage use(s) of the midden.

Given the nature of Unit IIIc as a primarily anthropogenic sediment (with some input of colluvial material, see 
Chapter 6), it is not surprising that maximum MS values across the site are similar. The fact that the midden and other features within Unit IIIc do not appear to be enhanced over background sediments may say as much about the origin of the sediments as about the features. Extensive bioturbation in open-air, alluvial settings is not conducive to the preservation of highly localized MS enhancements seen in caves and rockshelters (cf. Collins et al. 1994). Nevertheless, close interval sampling of cultural features at open sites in the future may yield similarly irregular $\chi$ results.

In summary, susceptibility measurements of TARL features were found to be useful for broadly characterizing them relative to background values. In only a few cases were features found to have significantly enhanced MS. This is likely due to some combination of (1) mixing as a consequence of sampling sediment with inexact provenience information; (2) the primarily anthropogenic origin of these sediments (beginning at least in the Unit II/IIIa transition); and (3) the blurring effects of bioturbation or leaching .

\section{TxDOT Features}

Bulk sediment results from TxDOT-excavated features (other than Burial 2) are given in Table 28-7. Overall, these results are consistent with the TARL features discussed above: as elevation increases, so too does average MS. In some cases, the evaluation of whether TxDOT feature samples have enhanced $\chi$ is complicated by the absence of directly comparable sediments as well as by the often increased distance between a feature and its nearest column profile. Another difficulty is that several TxDOT feature samples (i.e., Features 181, 184, 185, and 187) came from within Square E28/S78 and were used in the calculation of the level averages comprising that profile. This raises a potentially tautological situation in which features are compared to column values that were calculated using those same feature values. A partial solution was to evaluate differences between individual samples within these features and then compare them to TARL columns nearby. Despite these problems, some relevant observations can be made regarding the TxDOT features (note that Features 168, 169, and Burial 2 are discussed separately below).

Features 104, 155, 157, 5/166, 175, and 176 do not appear to have enhanced MS. Within Square E28/S78, Features 181, 184 , and 185 share roughly equivalent MS at the same stratigraphic position. The remarkable consistency in c between Levels 17A and 20A suggest that Feature 181 may be internally undifferentiated in terms of MS enhancement. Feature 187 exhibits the very low c values typically associated with Unit Icl sediments suggesting that it probably was encountered at or below the lower limits of the Leanne soil (Isi-c) and may have been subjected to postdepositional groundwater saturation or throughflow.

Like those from TARL Square 100, the TxDOT BRM-1 samples show a decreasing trend from top to bottom but with lower overall MS values than in the TARL profile (Unit IIIc). This implies lateral differences within BRM-1, but what such differences might represent is unknown. Note, too, that Feature 104 is similar to the sample from the base of BRM-1 (Sample 19J), suggesting that its reported stratigraphic position at the transition between IIIc and $\mathrm{Y}$ is probably correct.

Features 168 and 169 were small pits found in upper Unit I in approximately the same stratigraphic position as Burial 2. Their MS results are presented in Table 28-7, while those from the 31 individually provenienced samples collected within Burial 2 are given in Table 28-8. Within all three of these features, there appear to be significant variations between individual sediment samples. For example, the inner core of the south half of Feature 169 has systematically higher $\chi$ values than do other areas within the feature (see Table 28-7). Likewise, the Square 15, Level II2/JJ1 samples in Feature 168 are consistently greater than others from within the same feature. MS values from different areas within Burial 2 (and occasionally between "sister" samples from the same provenience) are also consistently different, although in most cases the absolute differences are not great. However, in the context of very low overall background sediment values (e.g., Isi) such consistency in even slightly enhanced samples are surely significant. Interestingly, there does not appear to be a single area from within Burial 2 where all of the enhanced samples are derived (see Table 28-8). They come from not only around the skull and rib areas but also from other areas within the pit fill.

Taken together, these data suggest a mixing of sediments with higher and lower MS within the Burial 2 pit fill rather than postdepositional alteration or the patterned introduction of some organic material within the burial (e.g., offerings or grave goods). Likewise, the observed variability in MS within Features 168 and 169 is also consistent with the mixing of different sediment sources rather than homogeneous, uniform postdepositional alterations. These inferences are supported by evidence from micromorphological studies (see Chapter 29 and Appendix 7) for the mixing of Leanne soil sediments and those from deeper, lower-susceptibility silt (Isi) and/or cienega (Icl) sediments. However, the relatively low values of even the highest MS subsamples in Burial 2 (e.g., 10.3 for Sample 16-2 and 7.2 for Sample 5-1) and Features 168 and 169 do not suggest the mixing of strongly enhanced sediment. These pits (and their associated fill) probably originated from surfaces no higher than Unit Id or Isi-c. These observations are consistent with a minimum date for excavation of these pits no later than ca. 9500 B.P. (see Chapter 25).

\section{CONCLUSIONS}

The magnetic susceptibility analyses presented here reflect depositional, postdepositional, and cultural factors. All three periods of soil development (the Leanne, Stiba, 
TABLE 28-7

Magnetic Susceptibility Results from TxDOT Features

\begin{tabular}{|c|c|c|c|c|c|c|}
\hline Feature & Unit Equivalent & Square & Level & $\begin{array}{c}\text { Number of } \\
\text { Samples }\end{array}$ & $\begin{array}{c}\text { Susceptibility }(\chi) \\
\times 10^{-6} \text { cgs units }\end{array}$ & Notes \\
\hline 104 & IIIc/Y/X & 18 & & 2 & 21.2 & see BRM-19J below \\
\hline 155 & II(upper) & 29 & & 2 & 22.1 & \\
\hline 157 & II & 35 & $\mathrm{~V} 1+2$ & 2 & 22.9 & \\
\hline 168 & Isi/Icl & & & 2 & 2.1 & outside pit \\
\hline 168 & Isi-c/Isi/Icl & 15 & 16 & 2 & 2.9 & \\
\hline 168 & Isi-c/Isi/Icl & 15 & & 2 & 2.1 & \\
\hline 168 & Isi & 15 & II2 & 4 & 2.2 & \\
\hline 168 & Isi-c/Isi/Icl & 15 & II2/JJ1 & 2 & 4.5 & \\
\hline 168 & Isi-c/Isi/Icl & 15 & JJ2/LL1 & 2 & 2.6 & \\
\hline 168 (average) & & & & & 2.7 & \\
\hline 169 & Isi/Isi-c & 14 & DD1/HH1 & 2 & 2.9 & outer margins of the south half \\
\hline 169 & Isi/Isi-c & $14+15$ & DD1/HH1 & 4 & 3.8 & inner core of south half \\
\hline 169 & Isi & 15 & GG2/HH1 & 4 & 2.0 & lower extension of north half \\
\hline 169 (average) & & & & & 2.9 & \\
\hline 175 & Isi-c/Isi/Icl & 32 & $\mathrm{KK} 1 / \mathrm{LL} 1$ & 2 & 2.7 & \\
\hline 175 & Isi-c/Isi/Icl & 33 & $\mathrm{KK} 1 / \mathrm{LL} 1$ & 2 & 2.5 & \\
\hline 176 & IIIb & & $\mathrm{I} / \mathrm{J}$ & 2 & 39.3 & \\
\hline 181 & IIIIa & E28S78 & $17 \mathrm{~A}$ & 4 & 50.6 & \\
\hline 181 & IIIa & $\mathrm{E} 28 \mathrm{~S} 78$ & $17 \mathrm{~B}$ & 4 & 48.6 & \\
\hline 181 & IIIa/II & E28S78 & $18 \mathrm{~A}$ & 8 & 45.3 & \\
\hline 181 & $\mathrm{IIIa} / \mathrm{II}$ & E28S78 & $18 \mathrm{~B}$ & 2 & 49.9 & \\
\hline 181 & IIIa/II & $\mathrm{E} 28 \mathrm{~S} 78$ & $19 \mathrm{~A}$ & 4 & 45.2 & \\
\hline 181 & IIIa/II & E28S78 & $19 B$ & 2 & 43.7 & \\
\hline 181 & IIIa/II & E28S78 & $20 \mathrm{~A}$ & 4 & 46.4 & \\
\hline 181(average) & $\mathrm{IIIa} / \mathrm{II}$ & & & & 47.1 & average \\
\hline $181 ?$ & $\mathrm{IIIa} / \mathrm{II}$ & E28S78 & $18 \mathrm{~B}$ & 2 & 39.4 & \\
\hline $181 ?$ & IIIa/II & E28S78 & $19 \mathrm{~B}$ & 2 & 33.7 & \\
\hline $181 ?$ & $\mathrm{IIIa} / \mathrm{II}$ & E28S78 & $20 \mathrm{~A}$ & 2 & 29.8 & \\
\hline $181 ?$ (average) & IIIa/II & & & & 34.3 & average \\
\hline 184 & $\mathrm{IIIa} / \mathrm{II}$ & E28S78 & $19 B$ & 2 & 35.8 & \\
\hline 185 & IIIa/II & E28S78 & $20 \mathrm{~B}$ & 2 & 30.7 & \\
\hline 187 & Isi-c/Icl & E28S78 & 32B & 2 & 3.3 & \\
\hline BRM & IIIc & 19B & & 2 & 42.5 & \\
\hline BRM & IIIc & $19 \mathrm{H}$ & & 2 & 39.6 & \\
\hline BRM & $\mathrm{Y} / \mathrm{III} / \mathrm{IIIb}$ & $19 \mathrm{~J}$ & & 2 & 20.2 & \\
\hline $5 / 166$ & II/I & $50 \mathrm{Y}$ & & 2 & 13.0 & \\
\hline $5 / 166$ & $\mathrm{I}$ & 51-AA1 & & 2 & 16.4 & \\
\hline
\end{tabular}

and Wilson-Leonard) are represented in one or more of the $\chi$ column profiles. The anthrosolic character of the Stiba soil is supported by the homgeneity of MS within the sediment and the numerous features sampled within it. In addition, IRM analyses clearly indicate a change in magnetic mineralogy at an elevation of ca. $95.0 \mathrm{~m}$, probably associated with a shift to drier conditions and reduced deposition resulting in soil formation and greater human occupation. Boggy conditions and variability in cultural occupation across the site may account for the low $\chi$ values in Isi-c (Leanne soil) sediments in the Square 20 profile. MS and IRM results are also consistent with iron staining and gleying within the Unit I deposits. Finally, MS variations within the Paleoindian pit features investigated by TxDOT (i.e., Burial 2 and Features 168 and 169) support the contention that they originated from an occupational surface (or surfaces) within Isi-c. Those same variations also indicate that they were not significantly affected by postdepositional alterations. 
TABLE $28-8$

Magnetic Susceptibility Results of Burial 2 Sediment Samples

\begin{tabular}{|c|c|c|c|c|}
\hline $\begin{array}{c}\text { Sediment } \\
\text { Sample Number }\end{array}$ & Unit & $\begin{array}{l}\text { Number of } \\
\text { Samples }\end{array}$ & $\begin{array}{l}\text { Susceptibility }(\chi) \\
\times 10^{-6} \text { cgs units }\end{array}$ & Notes \\
\hline $\begin{array}{c}1 \\
2 \\
3 \\
4 \\
5 \\
5 \\
6 \\
7 \\
8 \\
9 \\
9 \\
10 \\
11 \\
12 \\
13 \\
15 \\
16 \\
17 \\
18 \\
19 \\
20 \\
21 \\
22 \\
23 \\
24 \\
25 \\
26\end{array}$ & $\begin{array}{l}\text { Isi? } \\
\text { Isi? } \\
\text { Isi? } \\
\text { Isi? } \\
\text { Isi? } \\
\text { Isi? } \\
\text { Isi? } \\
\text { Isi? } \\
\text { Isi? } \\
\text { Isi? } \\
\text { Isi? } \\
\text { Isi? } \\
\text { Isi? } \\
\text { Isi? } \\
\text { Isi? } \\
\text { Isi? } \\
\text { Isi? } \\
\text { Isi? } \\
\text { Isi? } \\
\text { Isi? } \\
\text { Isi? } \\
\text { Isi? } \\
\text { Isi? } \\
\text { Isi? } \\
\text { Isi? } \\
\text { Isi? } \\
\text { Isi? } \\
\text { Isi? } \\
\text { Isi? } \\
\text { Isi? } \\
\text { Isi? }\end{array}$ & 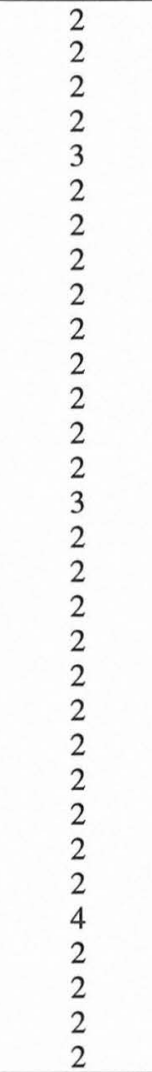 & $\begin{array}{l}2.0 \\
5.1 \\
3.8 \\
3.5 \\
4.4 \\
1.8 \\
5.7 \\
1.5 \\
2.5 \\
3.7 \\
4.5 \\
4.0 \\
4.5 \\
5.1 \\
5.1 \\
4.4 \\
3.9 \\
4.8 \\
5.4 \\
2.7 \\
4.1 \\
3.8 \\
3.5 \\
3.5 \\
2.8 \\
2.9 \\
6.1 \\
2.1 \\
1.8 \\
2.3 \\
4.3\end{array}$ & $\begin{array}{l}\text { Skull, right side } \\
\text { Soil in vial \#2, cf. WL93B9 } \\
\text { Soil in vial \#3, cf. WL93B10 } \\
\text { Soil in vial \#4 } \\
\text { Leanne skull matrix } \\
\text { Leanne rib matrix, cf. WL93B2 } \\
\text { Skull matrix (interior) } \\
\text { Matrix pelvis block, cf. WL93B1 } \\
\text { Leanne matrix right side } \\
\text { cf. W193b3 } \\
\text { cf. W193b4 } \\
\text { Pit fill, cf. WL93B8 } \\
\text { Pit fill, cf. WL93B7 } \\
\text { Pit fill (bag \#8) } \\
\text { Rib block (bone pulled from matrix) } \\
\text { Pit fill (bag \#3) } \\
\text { Pit fill (bag \#4) } \\
\text { Pit fill (bag \#5) } \\
\text { Pit fill (bag \#1) } \\
\text { Matrix west of Burial 2, cf. WL93B5 } \\
\text { East of Burial 2, cf. WL93B6 } \\
\text { Pit fill (bag \#12) } \\
\text { Pit fill (bag \#10) } \\
\text { Pit fill (bag \#11) } \\
\text { Pit fill (bag \#9) } \\
\text { Pit fill (bag \#14) } \\
\text { Mixed around \& beneath skull } \\
\text { Pit fill (bag \#16) } \\
\text { Rib cage area, mixed pit fill } \\
\text { Pit fill (bag \#17) } \\
\text { Pit fill (bag \#6) }\end{array}$ \\
\hline
\end{tabular}




\title{
Chapter 29
}

\section{MICROMORPHOLOGICAL ANALYSIS OF SEDIMENTS}

\author{
by Paul Goldberg
}

\section{INTRODUCTION}

Over the past decade, it has become evident that a number of factors limit the interpretive value of the stratigraphic field and conventional laboratory data from archeological sites. These limitations stem primarily from the typically complex nature of the composition, texture, and fabric of soils and sediments associated with archeological sites. For example, it would seem reasonable to question the significance of grain-size analysis of the "gray ashy" deposits commonly found in the burned rock features of Unit III. The results generated by a grain-size analysis in such cases do not discriminate between the mineral (e.g., quartz sand, silt, clay; calcareous ash crystals; phytoliths; bone) and nonmineral components (charcoal or disseminated organic matter), and one would simply observe a poorly sorted sediment. Moreover, a particle-size analysis of a poorly sorted colluvial deposit would not reveal whether the sediment was transported in aggregated form, since grain-size analyses typically attempt to break down a sediment into its primary components. Finally, many of the analytical techniques typically used to study archeological sediments are limited in their ability to recognize and discern a succession of pedological, geological, or anthropogenic events that have been superimposed on the same material or substrate, and a specific analysis may shed light only on one of these events. At the field scale, for example, a dark layer within a Holocene archeological site context may represent a soil horizon, an occupation layer, or both. Measurement of Munsell color or organic matter in this case, does not really help (Courty et al. 1989:35). Similarly, a calcium carbonate analysis may encompass primary (depositional) or secondary (pedogenic) carbonate.

A technique that is proving increasingly valuable in avoiding many of the above-mentioned limitations is that of micromorphology, the study of undisturbed soils, sediments, and other archeological materials at a microscopic scale
(Courty et al. 1989). Micromorphology employs undisturbed, oriented samples in which the original components and their geometrical relationships are conserved. Micromorphological analysis allows for the observation of composition (mineral and organic), texture (size, sorting), and most important, fabric - the geometric relationships among the constituents. Within an individual thin section, it is therefore possible to observe microstratigraphic sequences that might reflect temporal changes in depositional and postdepositional processes, as for example, sedimentation followed by bioturbation and then clay translocation. Such sequences would be difficult to monitor using more-conventional techniques.

\section{METHODS}

Most of the samples for micromorphological analysis were collected in the field as intact blocks, roughly 15-x-7-x$7 \mathrm{~cm}$ in size. For these intact samples, sediment was removed with a trowel and large knife and securely wrapped with toilet paper and packaging tape; orientation was indicated by an arrow using an indelible pen (Courty et al. 1989). In addition to the intact blocks, 59 samples were made from loose sediment collected as bulk matrix samples. These included 6 "Column Samples" from the TxDOT excavations and 53 from feature contexts.

In the laboratory, samples were dried at about $60^{\circ} \mathrm{C}$ for several days in a drying oven. They were then impregnated under vacuum with unpromoted polyester resin (Dion resin, Reichold Chemicals [Catalog no. 31-022-01]; distributed by FRP Supply, Houston [1-800-950-4377]), diluted with styrene; the latter is mixed with the resin in the approximate ratio of $700 \mathrm{ml}$ resin to $300 \mathrm{ml}$ styrene. The mixture was catalyzed with methyl ethyl ketone peroxide (MEKP), which was added to the diluted polyester/styrene mixture at the ratio of 7-8 $\mathrm{ml}$ MEKP per liter of diluted polyester/styrene mixture (see Murphy [1986:45-64] and Courty et al. [1989:57- 
62] for details). The resin was then allowed to cure three to five days, during which time the liquid is transformed into a gel-like mass and then into a hard, brittle substance. When the blocks were hard, they were placed in the drying oven at about $50-60^{\circ} \mathrm{C}$ for 24 hours. They were then sliced with a rock saw and made into thin sections. Large format (2-x-3 inch) thin sections were manufactured, some at the Geology Department, The University of Texas at Austin and others at Spectrum Petrographics, Inc. (Winston, Oregon).

The large, intact blocks were commonly subdivided into lower and upper parts, and multiple thin sections were made from the same large block in order to cover the entire the area of the block. For thin sections made from loose sediment (bulk samples without recorded orientation), individual centimeter-size clods were placed into a container and then impregnated with resin. The resulting blocks, composed of aggregate, were trimmed to $2-x-3$ inches and processed into standard thin sections. While these cemented aggregates were less desirable than large, intact, oriented blocks, individual clods were large enough to provide valuable information about composition, texture and fabric that allowed inferences of depositional and postdepositional processes to be made.

For many samples, slices of the impregnated blocks were ground on a lap wheel down to 600 mesh. Such polished surfaces were then observed with the binocular microscope under magnifications between $8 \mathrm{X}$ to $50 \mathrm{X}$. The thin sections were examined at magnifications ranging from $20 \mathrm{X}$ to $200 \mathrm{X}$ with a variety of instruments - a microfiche viewer, binocular microscope, and petrographic microscope under plane polarized (PPL), cross-polarized light (XPL), and UV epi-fluorescence. Observations were noted using the descriptive terminology of Bullock et al. (1985) and Courty et al. (1989).

\section{MICROMORPHOLOGICALANALYSIS}

The micromorphological analysis entailed the detailed observation and description of 156 samples of the total of 271 that were collected (Table 29-1 and Table 29-2). The analyzed samples include 104 collected as intact blocks during the TARL excavation and 52 "experimental" samples produced from loose, bulk matrix samples from both the TxDOT and TARL excavations. Although most of the collected samples were examined, not all are described in Appendix 7. In certain cases (e.g., those from Column 400 in Square 35), descriptions are omitted because these samples stratigraphically overlap with those from other sample columns, and they essentially mirrored themes from those other sampling columns. In other cases, the samples did not impregnate properly, and they were not very informative. Finally, in addition to micromorphological analysis, many samples were collected to provide a sedimentary archive where future researchers would have access to these intact materials that are otherwise no longer accessible in the field.
Since many aspects of the thin sections (e.g., composition, texture, postdepositional features) are similar from slide to slide, the essential criteria used to characterize the thin sections are first described followed by summary descriptions of the samples and discussion of the interpretations of the depositional and postdepositional elements of the site as revealed in the thin sections. It is not possible here to provide complete descriptions of the terms and nomenclature used in this report, and the reader is advised to consult works dealing with micromorphology (Brewer 1976; Bullock et al. 1985; Courty et al. 1989; Douglas 1990; Fedoroff et al. 1987; FitzPatrick 1993; Jongerius and Rutherford 1979).

\section{Terms and Elements Used or Identified in the Study of the Thin Sections}

\section{Coarse Fraction}

The coarse fraction constitutes the larger-sized components in the sample, typically sand $(62 \mu \mathrm{m}$ to $2 \mathrm{~mm})$ and silt ( 2 to $62 \mathrm{~mm}$ ) sizes. Due to their size, they are generally not difficult to identify in the thin section, which is normally about 25 to $30: \mu$ thick. At Wilson-Leonard, the coarse fraction includes constituents that are readily identifiable and commonly observed in sediments from archeological sites. These include quartz silt, bone, charcoal, and charred remains of plant tissues, carnivore coprolites, eggshell, hackberry seed coats, phytoliths, granule- and sand-sized clasts of limestone, and snail shell fragments. Other components in the coarse fraction are not typical and merit a brief description.

\section{CALCINEDLIMESTONE CLASTS}

These are grains of limestone that have been subjected to heating. In thin section, heating is expressed as a lowering of the interference colors and obliteration of the original internal constituents of the clast (e.g., fossils) (Figure 29-1a, b).

\section{ASH RHOMBS}

These are rhomb-shaped predominantly calcium carbonate crystals that are pseudomorphs of calcium oxalates (Wattez and Courty 1987). In undisturbed ash accumulations, outlines of the original vegetation structure can be observed. In disturbed ashes, isolated rhombs can be observed dispersed throughout the slide.

\section{RED/AMBER ORGANIC MATTER}

This is comprised of finely divided silt-sized, reddish amber-colored pieces that appear to be residues of vegetal tissues. In light of their general fresh appearance, it seems that these fragments are remains of relatively modern vegetation. 
TABLE 29-1

Micromorphological Samples Analyzed from Wilson-Leonard

\begin{tabular}{|c|c|c|}
\hline Micromorphological Samples & $\begin{array}{l}\text { Total No. } \\
\text { Collected }\end{array}$ & Total No. Described \\
\hline Geological Column Samples Collected as Intact Blocks: ${ }^{1}$ & & \\
\hline Brushy Creek Bank: WL-92-1 through WL-92-9 & 9 & 0 \\
\hline TARL Square 33: WL-92-10 through WL-92-41 & 32 & 0 \\
\hline TARL Square 55: WL-92-42 through WL-92-63 & 22 & 0 \\
\hline Column 100/TARL Square 12: (WL-92-100 through WL-92-143) & 44 & 35 \\
\hline Column 200/TARL Square 20: (WL-92-200 through WL-92-236) & 37 & 31 \\
\hline Column 300/TARL Square 100: (WL-92-300 through WL-92-320) & 21 & 16 \\
\hline Column 400/TARL Square 35: (WL-92-401 through WL-92-415) & 15 & 0 \\
\hline $\begin{array}{l}\text { Geological Column Samples Collected as Bulk Matrix: } \\
\text { TxDOT Square E20/S72: (WL-94-S1 through WL-94-S6) }\end{array}$ & 6 & 6 \\
\hline $\begin{array}{l}\text { Feature Samples Collected as Intact Blocks: }{ }^{3} \\
\text { WL-92-F1 through WL-92-F32 (Features 181, 232, 236, 243, 244, 245, 249, } 252 \text {, } \\
\quad 256,260 \text { ) }\end{array}$ & 32 & 22 \\
\hline $\begin{array}{l}\text { Feature Samples Collected as Bulk Matrix: }{ }^{4} \\
\text { WL-93-B1 through WL-93-B10 (Burial 2) } \\
\text { WL-93-Pi1 through WL-93-Pi7 (Features 168, 169) } \\
\text { WL-94-F1 through WL-94-F4 (Feature 166) } \\
\text { WL-95-1 through WL-95-32 (Features } 104,155,157,166,175,176,185,187,204 \text {, } \\
\quad 206,209,213,215,216,216,220,221,222,224,226,227,228,230,233,235 \text {, } \\
\quad 237,239,241,242,246,248,255,262 \text { ) }\end{array}$ & $\begin{array}{l}10 \\
7 \\
4 \\
32\end{array}$ & $\begin{array}{l}10 \\
7 \\
2 \\
27\end{array}$ \\
\hline Total No. & 271 & 156 \\
\hline \multicolumn{3}{|c|}{$\begin{array}{l}{ }^{1} \text { These are intact blocks collected as column samples either from the TARL excavation squares or from the Brushy Creek bank. } \\
{ }^{2} \text { Samples prepared from bulk matrix samples collected as a geologic column from TxDOT Square E20/S72. } \\
{ }^{3} \text { Intact blocks collected from feature contexts during the TARL excavations. } \\
{ }^{4} \text { Samples prepared from bulk matrix samples collected from feature contexts during the TxDOT and TARL excavations. }\end{array}$} \\
\hline
\end{tabular}

\section{Groundmass/Matrix}

Groundmass or matrix is used in the sense of Bullock et al. $(1985: 88)$ to refer to "the coarse and/or fine material which forms the base material of a thin section." Normally in the Wilson-Leonard thin sections, the groundmass is comprised of clay-sized and fine silt-sized material that is generally calcareous (Figure 29-2; see Figures 29-1c, d, e, f).

\section{Postdepositional Effects}

\section{EARTHWORMCASTS}

Earthworm casts occur as rounded, smooth aggregates of matrix material (Figure 29-3; see Figures 29-1c, d, e, f and 29-2). They appear as individual casts (generally in Units IIIc and IIIb) or ones that have been compacted or welded together. The latter tend to occur and are more common in and below Unit IIIIa.

\section{BAKED MATRIX}

This term refers to clayey material that is brighter and redder than the brown and brownish red clay typically ob- served in thin sections from the area. As visible in hearth sediments both ancient and modern, these brighter colors clearly reflect heating of the original clay material.

\section{NONCALCAREOUS DOMAINS}

This designates small, millimeter-sized, noncalcareous patches intimately mixed within predominantly calcareous matrix (see Figure 29-1e, f). They appear to represent relicts of the original noncalcareous soil material formed on nowdenuded slopes that have not been secondarily calcified by pedogenic processes including earthworm activity. These domains are rare and tend to occur mostly in Unit III.

\section{CALCIUM CARBONATE(VOID) HYPOCOATINGS}

These are secondary accumulations in which the matrix enclosing a void is impregnated with calcium carbonate. This contrasts with calcium carbonate that accumulates within or fills a void, termed carbonate coatings or infillings. Void coatings at Wilson-Leonard usually take the form of fine-sized (i.e., silt) masses of calcite needles, or more rarely, accumulations of microcrystalline calcite (micrite) (Figure 29-4a-c; see Figure 29-1c, d, g, h). 
TABLE $29-2$

Summary of Wilson-Leonard Geological Samples

\begin{tabular}{|c|c|c|c|c|c|c|c|c|c|c|}
\hline Sample No. & Elevation & Thickness & Unit & Level & Feature & Matrix color & Mottle color & Square & Wall & Location \\
\hline WL-92-001 & 91.88 & 12 & $1 \mathrm{a}$ & & & $2.5 \mathrm{Y} 7 / 2$ & & & & Brushy Creek bank \\
\hline WL-92-002 & & 18 & $1 b$ & & & $2.5 \mathrm{Y} 7 / 2$ & & & & Brushy Creek bank \\
\hline WL-92-003 & & 17 & $1 \mathrm{c}$ & & & $2.5 \mathrm{Y} 7 / 2$ & 10YR5/8 & & & Brushy Creek bank \\
\hline WL-92-004 & & 12 & $1 \mathrm{c} / 2$ & & & 10YR6/2 & 10YR5/8 & & & Brushy Creek bank \\
\hline WL-92-005 & & 15 & 2 & & & 10YR6/2 & 10YR5/8 & & & Brushy Creek bank \\
\hline WL-92-006 & & 12 & 2 & & & $10 \mathrm{YR} 6 / 2$ & 10 YR5/8 & & & Brushy Creek bank \\
\hline WL-92-007 & & 20 & 3 & & & 10YR5/4 & & & & Brushy Creek bank \\
\hline WL-92-008 & & 20 & & & & 10YR5/4 & 10YR3/3 & & & Brushy Creek bank \\
\hline WL-92-009 & & 20 & 2 & & & 10YR6/2 & 10YR5/8 & & & Brushy Creek bank \\
\hline WL-92-010 & 97.02 & 18 & IIIc & & & 10YR3/2 & & 33 & $\mathrm{~N}$ & South Profile \\
\hline WL-92-011 & 96.84 & 12 & ШIC & & & 10YR3/2 & & 33 & $\mathrm{~N}$ & South Profile \\
\hline WL-92-012 & 96.72 & 12 & IIIC & & & 10YR3/2 & & 33 & $\mathrm{~N}$ & South Profile \\
\hline WL-92-013 & 96.60 & 13 & шाb & & & 10YR $4 / 3$ & & 33 & $\mathrm{~N}$ & South Profile \\
\hline WL-92-014 & 96.47 & 12 & IIIb & & & $10 \mathrm{YR} 4 / 3$ & & 33 & $\mathrm{~N}$ & South Profile \\
\hline WL-92-015 & 96.35 & 14 & IIIb/ IIIa & & & 10YR4/3 & & 33 & $\mathrm{~N}$ & South Profile \\
\hline WL-92-016 & 96.20 & 12 & IIIa & & & 10YR3/4 & & 33 & $\mathrm{~N}$ & South Profile \\
\hline WL-92-017 & 96.08 & 13 & IIIa & & & 10YR3/4 & & 33 & $\mathrm{~N}$ & South Profile \\
\hline WL-92-018 & 95.95 & 15 & IIIa & & & 10YR3/4 & & 33 & $\mathrm{~N}$ & South Profile \\
\hline WL-92-019 & 95.80 & 10 & ШII/IIb & & & 10YR4/3.5 & & 33 & $\mathrm{~N}$ & South Profile \\
\hline WL-92-020 & 95.70 & 12 & II & & & 10YR4/3.5 & & 33 & $\mathrm{~N}$ & South Profile \\
\hline WL-92-021 & 95.58 & 11 & II & & & 10YR4/4 & & 33 & $\mathrm{~N}$ & South Profile \\
\hline WL-92-022 & 95.47 & 11 & II & & & 10YR5/4 & & 33 & $\mathrm{~N}$ & South Profile \\
\hline WL-92-023 & 95.36 & 11 & II & & & 10YR5/4 & & 33 & $\mathrm{~N}$ & South Profile \\
\hline WL-92-024 & 95.25 & 11 & IIa & & & 10YR5/4 & & 33 & $\mathrm{~N}$ & South Profile \\
\hline WL-92-025 & 95.14 & 11 & II & & & 10YR4/6 & & 33 & $\mathrm{~N}$ & South Profile \\
\hline WL-92-026 & 95.03 & 10 & II/Id & & & -- & & 33 & $\mathrm{~N}$ & South Profile \\
\hline WL-92-027 & 94.93 & 11 & Id & & & 10YR6/3 & 10YR4/4 & 33 & $\mathrm{~N}$ & South Profile \\
\hline WL-92-028 & 94.82 & 10 & Isi & & & 10YR5/4 & & 33 & $\mathrm{~N}$ & South Profile \\
\hline WL-92-029 & 94.72 & 10 & Isi & & & 10YR5/4 & & 33 & $\mathrm{~N}$ & South Profile \\
\hline WL-92-030 & 94.62 & 11 & Isi & & & $2.5 \mathrm{Y} 6 / 3$ & & 33 & $\mathrm{~N}$ & South Profile \\
\hline WL-92-031 & 94.51 & 10 & Isi & & & $2.5 \mathrm{Y} 6 / 3$ & & 33 & $\mathrm{~N}$ & South Profile \\
\hline WL-92-032 & 94.41 & 10 & Isi & & & 10YR6/3 & 10YR5/4 & 33 & $\mathrm{~N}$ & South Profile \\
\hline WL-92-033 & 94.31 & 9 & Isi & & & 10YR6/3 & & 33 & $\mathrm{~N}$ & South Profile \\
\hline WL-92-034 & 94.22 & 11 & Isi & & & 10YR6/3 & & 33 & $\mathrm{~N}$ & South Profile \\
\hline WL-92-035 & 94.11 & 10 & Isi/Icl & & & 10YR6/3 & & 33 & $\mathrm{~N}$ & South Profile \\
\hline WL-92-036 & 94.01 & 8 & Icl & & & 10YR7/2 & & 33 & $\mathrm{~N}$ & South Profile \\
\hline WL-92-037 & 93.93 & 11 & Icl & & & 10YR7/2 & & 33 & $\mathrm{~N}$ & South Profile \\
\hline WL-92-038 & 93.82 & 10 & Icl & & & 10YR7/2 & & 33 & $\mathrm{~N}$ & South Profile \\
\hline WL-92-039 & 93.72 & 11 & Icl & & & 10YR7/2 & & 33 & $\mathrm{~N}$ & South Profile \\
\hline WL-92-040 & 93.61 & 12 & Icl & & & 10YR7/2 & & 33 & $\mathrm{~N}$ & South Profile \\
\hline WL-92-041 & 93.49 & 14 & Icl & & & 10YR7/2 & & 33 & $\mathrm{~N}$ & South Profile \\
\hline WL-92-042 & 94.50 & 11 & Isi & & & $\begin{array}{l}\text { pale brown } \\
\text { to brown }\end{array}$ & & 55 & $\mathrm{~N}$ & South Profile \\
\hline WL-92-043 & 94.39 & $11 *$ & Isi & & & $\begin{array}{l}\text { pale brown } \\
\text { to brown }\end{array}$ & & 55 & $\mathrm{~N}$ & South Profile \\
\hline WL-92-044 & 94.28 & 11 & Isi & & & $\begin{array}{l}\text { pale brown } \\
\text { to brown }\end{array}$ & & 55 & $\mathrm{~N}$ & South Profile \\
\hline WL-92-045 & 94.17 & 11 & Isi & & & 10YR7/2 & & 55 & $\mathrm{~N}$ & South Profile \\
\hline WL-92-046 & 94.06 & 11 & Isi & & & 10YR7/2 & & 55 & $\mathrm{~N}$ & South Profile \\
\hline WL-92-047 & 93.96 & 10 & Isi & & & 10YR7/2 & & 55 & $\mathrm{~N}$ & South Profile \\
\hline WL-92-048 & 93.85 & 11 & Isi & & & 10YR7/2 & & 55 & $\mathrm{~N}$ & South Profile \\
\hline WL-92-049 & 93.75 & 10 & Isi & & & 10YR7/2 & & 55 & $\mathrm{~N}$ & South Profile \\
\hline WL-92-050 & 93.65 & 10 & Isi & & & 10YR7/2 & & 55 & $\mathrm{~N}$ & South Profile \\
\hline WL-92-051 & 93.44 & 11 & Isi & & & 10YR7/2 & & 55 & $\mathrm{~N}$ & South Profile \\
\hline WL-92-052 & 93.34 & 10 & Isi & & & 10YR7/2 & & 55 & $\mathrm{~N}$ & South Profile \\
\hline WL-92-053 & 93.23 & 11 & Isi & & & 10YR7/2 & & 55 & $\mathrm{~N}$ & South Profile \\
\hline WL-92-054 & 93.15 & 8 & Isi & & & 10YR7/2 & & 55 & $\mathrm{~N}$ & South Profile \\
\hline WL-92-055 & 93.04 & 11 & Isi & & & 10YR7/2 & & 55 & $\mathrm{~N}$ & South Profile \\
\hline
\end{tabular}


Table 29-2, continued

\begin{tabular}{|c|c|c|c|c|c|c|c|c|c|c|}
\hline Sample No. & Elevation & Thickness & Unit & Level & Feature & Matrix color & Mottle color & Square & Wall & Location \\
\hline WL-92-056 & 92.94 & 10 & Isi & & & $10 Y R 7 / 2$ & & 55 & $\mathrm{~N}$ & South Profile \\
\hline WL-92-057 & 92.84 & 10 & Isi & & & $2.5 Y 7 / 2$ & $2.5 Y 6 / 6$ & 55 & $\mathrm{~N}$ & South Profile \\
\hline WL-92-058 & 92.75 & 9 & Isi & & & $2.5 \mathrm{Y} 7 / 2$ & $2.5 \mathrm{Y} 6 / 6$ & 55 & $\mathrm{~N}$ & South Profile \\
\hline WL-92-059 & 92.65 & 10 & Isi & & & $2.5 \mathrm{Y} 7 / 2$ & $2.5 Y 6 / 6$ & 55 & $\mathrm{~N}$ & South Profile \\
\hline WL-92-060 & 92.54 & 11 & Isi & & & $2.5 \mathrm{Y} 7 / 2$ & $2.5 \mathrm{Y} 6 / 6$ & 55 & $\mathrm{~N}$ & South Profile \\
\hline WL-92-061 & 92.42 & 12 & Isi & & & $2.5 \mathrm{Y} 7 / 2$ & $2.5 \mathrm{Y} 6 / 6$ & 55 & $\mathrm{~N}$ & South Profile \\
\hline WL-92-062 & 92.33 & 9 & Isi & & & $2.5 \mathrm{Y} 7 / 2$ & $2.5 Y 6 / 6$ & 55 & $\mathrm{~N}$ & South Profile \\
\hline WL-92-063 & 92.31 & 11 & Isi & & & $2.5 \mathrm{Y} 7 / 2$ & $2.5 Y 6 / 6$ & 55 & $\mathrm{~N}$ & South Profile \\
\hline WL-92-100 & 97.46 & 7 & fill & & & & & 12 & $S$ & Column 100 \\
\hline WL-92-101 & 97.40 & 7 & & & & & & 12 & $S$ & Column 100 \\
\hline WL-92-102 & 97.32 & 8 & IIIc & & & 10YR3/6 & & 12 & $S$ & Column 100 \\
\hline WL-92-103 & 97.22 & 13 & IIIc & & & 10YR3/2 & & 12 & $S$ & Column 100 \\
\hline WL-92-104 & 97.11 & 8 & IIIc & & & 10YR4/2 & & 12 & S & Column 100 \\
\hline WL-92-105 & 97.98 & 9 & IIIc & & & 10YR4/2 & & 12 & $S$ & Column 100 \\
\hline WL-92-106 & 96.90 & 8 & IIIb* & & & $\begin{array}{l}\text { 7.5YR- } \\
10 Y R 4 / 2\end{array}$ & & 12 & $S$ & Column 100 \\
\hline WL-92-107 & 96.79 & 14 & IIIb* & & & $\begin{array}{l}\text { 7.5YR- } \\
10 \text { YR } 4 / 2\end{array}$ & & 12 & $S$ & Column 100 \\
\hline WL-92-108 & 96.68 & 8 & IIIb & & & $\begin{array}{l}\text { 7.5YR- } \\
\text { 10YR4/2 }\end{array}$ & & 12 & $S$ & Column 100 \\
\hline WL-92-109 & 96.60 & 8 & IIIb & & & 10YR5/3 & & 12 & $S$ & Column 100 \\
\hline WL-92-110 & 96.50 & 9 & IIIb & & & 10YR5/3 & & 12 & $S$ & Column 100 \\
\hline WL-92-111 & 96.42 & 9 & IIIb & & & $10 \mathrm{YR} 4 / 3$ & & 12 & S & Column 100 \\
\hline WL-92-112 & 96.32 & 11 & IIIa & & & 10YR5/3 & & 12 & $S$ & Column 100 \\
\hline WL-92-113 & 96.22 & 10 & ПIIа & & & 10YR5/3 & & 12 & S & Column 100 \\
\hline WL-92-114 & 96.11 & 12 & IIIa & & & 10YR4/3 & & 12 & S & Column 100 \\
\hline WL-92-115 & 96.00 & 10 & IIIa & & & 7.5YR4/4 & & 12 & S & Column 100 \\
\hline WL-92-116 & 95.91 & 8 & IIIIa & & & 7.5-10YR4/4 & & 12 & $S$ & Column 100 \\
\hline WL-92-117 & 95.83 & 8 & Ша & & & 7.5-10YR5/4 & & 12 & S & Column 100 \\
\hline WL-92-118 & 95.72 & 14 & II/IIIa & & & 7.5YR4/4 & & 12 & $S$ & Column 100 \\
\hline WL-92-119 & 95.61 & 9 & II & & & 7.5YR4/4 & & 12 & S & Column 100 \\
\hline WL-92-120 & 95.50 & 12 & II [bot $] / \mathrm{Id}$ & & & 7.5YR4/4 & & 12 & $S$ & Column 100 \\
\hline WL-92-121 & 95.37 & 14 & Id & & & 7.5 YR5/4 & & 12 & $S$ & Column 100 \\
\hline WL-92-122 & 95.24 & 14 & Id & & & 7.5YR5/4 & & 12 & $S$ & Column 100 \\
\hline WL-92-123 & 95.10 & 12 & Id & & & 7.5YR6/4 & & 12 & S & Column 100 \\
\hline WL-92-124 & 95.11 & 8 & Isi & & & 7.5YR5/4 & & 12 & S & Column 100 \\
\hline WL-92-125 & 95.00 & 13 & Isi & & & $\begin{array}{l}\text { 7.5YR- } \\
\text { 10YR5/4 }\end{array}$ & & 12 & S & Column 100 \\
\hline WL-92-126 & 94.87 & 13 & Isi & & & 10YR7/4 & 10YR6/4 & 12 & $S$ & Column 100 \\
\hline WL-92-127 & 94.76 & 10 & Isi & & & 7.5YR6/6 & & 12 & S & Column 100 \\
\hline WL-92-128 & 94.64 & 13 & Isi & & & 10YR8/3 & 10YR6/8 & 12 & $S$ & Column 100 \\
\hline WL-92-129 & 94.51 & 13 & Isi & & & $10 \mathrm{YR} 8 / 3$ & 10YR6/8 & 12 & S & Column 100 \\
\hline WL-92-130 & 94.41 & 9 & Isi & & & 10YR $8 / 3$ & 10YR6/8 & 12 & $S$ & Column 100 \\
\hline WL-92-131 & 94.32 & 8 & Isi & & & 10YR7/3 & 10YR6/8 & 12 & $S$ & Column 100 \\
\hline WL-92-132 & 94.24 & 8 & Isi & & & $10 \mathrm{YR} 7 / 3$ & 10YR6/8 & 12 & $S$ & Column 100 \\
\hline WL-92-133 & 94.12 & 15 & Isi & & & $10 \mathrm{YR} 7 / 3$ & 10YR6/8 & 12 & S & Column 100 \\
\hline WL-92-134 & 93.94 & 8 & Isi & & & $10 \mathrm{YR} 7 / 2$ & 10YR6/8 & 12 & S & Column 100 \\
\hline WL-92-135 & 93.84 & 12 & Isi & & & $10 \mathrm{YR} 7 / 2$ & 10YR6/8 & 12 & $S$ & Column 100 \\
\hline WL-92-136 & 93.68 & 12 & Isi & & & 10YR7/2 & 10YR6/8 & 12 & $S$ & Column 100 \\
\hline WL-92-137 & 93.56 & 12 & Isi & & & 10YR7/2 & 10YR6/8 & 12 & S & Column 100 \\
\hline WL-92-138 & 93.35 & 14 & Isi & & & 10YR7/4 & 10YR6/8 & 12 & S & Column 100 \\
\hline WL-92-139 & 93.22 & 12 & Isi & & & 10YR7/4 & 10YR6/8 & 12 & $S$ & Column 100 \\
\hline WL-92-140 & 93.03 & 22 & Isi & & & 10YR7/2 & 10YR6/4 & 12 & S & Column 100 \\
\hline WL-92-141 & 92.90 & 12 & Isi & & & 10YR7/2 & 10YR6/4 & 12 & S & Column 100 \\
\hline WL-92-142 & 92.78 & 12 & Isi & & & 10YR7/2 & 10YR6/4 & 12 & S & Column 100 \\
\hline WL-92-143 & 92.68 & 9 & Isi & & & 10YR7/2 & 10YR6/4 & 12 & S & Column 100 \\
\hline WL-92-200 & & 15 & recent & & & & & & & Column 200 \\
\hline WL-92-201 & 97.01 & 9 & IIIc & 1 & & 10YR3/4 & & 20 & E & Column 200 \\
\hline WL-92-202 & 97.12 & 12 & IIIc & 1,8 & & 10YR7/4 & & 20 & $\mathrm{E}$ & Column 200 \\
\hline WL-92-203 & 96.90 & 14 & IIIb & 8 & & $10 \mathrm{YR} 4 / 2$ & & 20 & $\mathrm{E}$ & Column 200 \\
\hline
\end{tabular}


Table 29-2, continued

\begin{tabular}{|c|c|c|c|c|c|c|c|c|c|c|}
\hline Sample No. & Elevation & Thickness & Unit & Level & Feature & Matrix color & Mottle color & Square & Wall & Location \\
\hline WL-92-204 & 96.80 & 7 & IIIb & 9 & & 10YR5/3 & & 20 & $E$ & Column 200 \\
\hline WL-92-205 & 97.71 & 10 & IIIb & 10 & & 10YR5/3 & & 20 & $\mathrm{E}$ & Column 200 \\
\hline WL-92-206 & 96.61 & 9 & IIIb & 11 & & $10 \mathrm{YR} 5 / 2$ & & 20 & $\mathrm{E}$ & Column 200 \\
\hline WL-92-207 & 96.51 & 12 & $\mathrm{IIb}$ & 11,12 & & 10YR5/3 & & 20 & $\mathrm{E}$ & Column 200 \\
\hline WL-92-208 & 96.39 & 11 & IIIb & 12,13 & & 10YR5/3 & & 20 & $\mathrm{E}$ & Column 200 \\
\hline WL-92-209 & 96.23 & 10 & IIIb* & 14,15 & & 10YR5/4 & & 20 & $\mathrm{E}$ & Column 200 \\
\hline WL-92-210 & 96.12 & 12 & IIIa & 15,16 & & 10YR5/4 & & 20 & $\mathrm{E}$ & Column 200 \\
\hline WL-92-211 & 95.97 & 9 & ШІа & 16,17 & & 10YR5/4 & & 20 & $\mathrm{E}$ & Column 200 \\
\hline WL-92-212 & 95.86 & 11 & IIIa & 17,18 & & 10YR3/4 & & 20 & $\mathrm{E}$ & Column 200 \\
\hline WL-92-213 & 95.75 & 11 & IIIa & 18,19 & & $10 \mathrm{YR} 3 / 4$ & & 20 & $\mathrm{E}$ & Column 200 \\
\hline WL-92-214 & 95.61 & 10 & IIIa & 25 & & $10 \mathrm{YR} 4 / 4$ & & 20 & $\mathrm{E}$ & Column 200 \\
\hline WL-92-215 & 95.51 & 10 & II & 26,27 & & $10 \mathrm{YR} 4 / 4$ & & 20 & $\mathrm{E}$ & Column 200 \\
\hline WL-92-216 & 95.40 & 12 & II & 29,30 & & 10YR4/4 & & 20 & $\mathrm{E}$ & Column 200 \\
\hline WL-92-217 & 95.29 & 11 & II & 31,32 & & 10YR4/4 & & 20 & $\mathrm{E}$ & Column 200 \\
\hline WL-92-218 & 95.19 & 9 & II & 32,33 & & 10YR4/4 & & 20 & $\mathrm{E}$ & Column 200 \\
\hline WL-92-219 & 95.09 & 11 & II & 33,34 & & 10YR4/4 & 10YR6/3 & 20 & $\mathrm{E}$ & Column 200 \\
\hline WL-92-220 & 94.99 & 9 & II & 34,35 & & 10YR5.5/4 & & 20 & $\mathrm{E}$ & Column 200 \\
\hline WL-92-221 & 94.86 & 13 & II & 35,36 & & 10YR5.5/4 & & 20 & $\mathrm{E}$ & Column 200 \\
\hline WL-92-222 & 94.77 & 8 & II & 36,37 & & 7.5-10YR5/4 & & 20 & $\mathrm{E}$ & Column 200 \\
\hline WL-92-223 & 94.67 & 12 & II/Id & 37,38 & & 7.5-10YR5/4 & & 20 & $\mathrm{E}$ & Column 200 \\
\hline WL-92-224 & 94.54 & 14 & Isi & 39 & & 7.5YR5/4 & & 20 & $\mathrm{E}$ & Column 200 \\
\hline WL-92-225 & 94.41 & 12 & Isi & 40 & & 7.5YR5/4 & & 20 & $\mathrm{E}$ & Column 200 \\
\hline WL-92-226 & 94.32 & 6 & Isi & 41 & & 7.5YR5/4 & & 20 & $\mathrm{E}$ & Column 200 \\
\hline WL-92-227 & 94.22 & 14 & Isi & 42,43 & & $10 \mathrm{YR} 4 / 3$ & 10YR5/6 & 20 & $\mathrm{E}$ & Column 200 \\
\hline WL-92-228 & 94.10 & 10 & Isi & 42,43 & & 10YR5/4 & & 20 & $\mathrm{E}$ & Column 200 \\
\hline WL-92-229 & 94.00 & 15 & Isi & 43,44 & & 10YR5/4 & 10YR6/8 & 20 & $\mathrm{E}$ & Column 200 \\
\hline WL-92-230 & 93.94 & 10 & Icl & 44 & & 10YR5/3 & & 20 & $\mathrm{E}$ & Column 200 \\
\hline WL-92-231 & 93.84 & 10 & Icl & 46,47 & & 10YR5/3 & & 20 & $\mathrm{E}$ & Column 200 \\
\hline WL-92-232 & 93.70 & 12 & Icl & 47,48 & & 10YR5/3 & & 20 & E & Column 200 \\
\hline WL-92-233 & 93.60 & 14 & Icl & 48,49 & & 10YR5/3 & 10YR5/8 & 20 & $\mathrm{E}$ & Column 200 \\
\hline WL-92-234 & 93.50 & 12 & Icl & 50,51 & & 10YR5/2 & & 20 & $\mathrm{E}$ & Column 200 \\
\hline WL-92-235 & 93.36 & 10 & Icl & 51 & & 10YR5/2 & 10YR5/8 & 20 & E & Column 200 \\
\hline WL-92-236 & 93.30 & 8 & Icl & 51 & & 10YR5/2 & 10YR5/8 & 20 & $\mathrm{E}$ & Column 200 \\
\hline WL-92-300 & 97.66 & 10 & IIIc & & & 10YR5/2 & & 100 & W & Column 300 \\
\hline WL-92-301 & 97.56 & 10 & IIIc & & & 10YR5/2 & & 100 & W & Column 300 \\
\hline WL-92-302 & 97.51 & 10 & IIIc & & & 10YR4/2 & & 100 & W & Column 300 \\
\hline WL-92-303 & 97.46 & 9 & $\mathrm{Y}$ & & & 10YR4/2 & & 100 & W & Column 300 \\
\hline WL-92-304 & 97.37 & 8 & $\mathrm{Y}$ & & & 10YR5/4 & & 100 & W & Column 300 \\
\hline WL-92-305 & 97.29 & 8 & $\mathrm{Y}$ & & & 10YR5/4 & & 100 & W & Column 300 \\
\hline WL-92-306 & 97.20 & 9 & $\mathrm{Y}$ & & & 10YR5/4 & & 100 & W & Column 300 \\
\hline WL-92-307 & 97.11 & 8 & $\mathrm{Y}$ & & & 10YR5/4 & & 100 & W & Column 300 \\
\hline WL-92-308 & 97.03 & 9 & $\mathrm{Y}$ & & & 10YR5/4 & & 100 & W & Column 300 \\
\hline WL-92-309 & 96.94 & 10 & $\mathrm{X}$ & & & 10YR7/4 & & 100 & W & Column 300 \\
\hline WL-92-310 & 96.84 & 10 & $\mathrm{X}$ & & & $2.5 Y 6 / 4$ & & 100 & W & Column 300 \\
\hline WL-92-311 & 96.74 & 11 & $\mathrm{X}$ & & & $2.5 Y 7 / 4$ & & 100 & W & Column 300 \\
\hline WL-92-312 & 96.65 & 12 & $\mathrm{X}$ & & & $2.5 \mathrm{Y} 7 / 4$ & $\begin{array}{l}\text { Increase in } \\
\text { gravel and } \\
\text { carbonate } \\
\text { cementation }\end{array}$ & 100 & W & Column 300 \\
\hline WL-92-313 & 96.53 & 9 & $\mathrm{X}$ & & & $2.5 Y 7 / 4$ & & 100 & W & Column 300 \\
\hline WL-92-314 & 96.44 & 10 & $\mathrm{X}$ & & & $2.5 Y 7 / 4$ & & 100 & W & Column 300 \\
\hline WL-92-315 & 96.34 & 10 & $\mathrm{X}$ & & & $2.5 Y 7 / 4$ & & 100 & W & Column 300 \\
\hline WL-92-316 & 96.24 & 8 & $\mathrm{X}$ & & & $2.5 \mathrm{Y} 7 / 4$ & & 100 & W & Column 300 \\
\hline WL-92-317 & 96.16 & 10 & $\mathrm{X}$ & & & $2.5 \mathrm{Y} 7 / 4$ & & 100 & W & Column 300 \\
\hline WL-92-318 & 96.06 & 10 & $\mathrm{X}$ & & & $2.5 \mathrm{Y} 7 / 4$ & & 100 & W & Column 300 \\
\hline WL-92-319 & 95.96 & 11 & $\mathrm{X}$ & & & $2.5 Y 7 / 4$ & & 100 & W & Column 300 \\
\hline WL-92-320 & 95.85 & 11 & $\mathrm{X}$ & & & $2.5 \mathrm{Y} 7 / 4$ & & 100 & W & Column 300 \\
\hline WL-92-401 & 94.93 & 10 & Id & 36 & & 10YR6/4 & 10YR4/6 & 35 & $\mathrm{E}$ & Column 400 \\
\hline WL-92-402 & 94.90 & 15 & Id & 37 & & 10YR6/4 & & 35 & $\mathrm{E}$ & Column 400 \\
\hline WL-92-403 & 94.66 & 13 & Isi & 38 & & $7.5 \mathrm{YR} 4 / 4$ & & 35 & $\mathrm{E}$ & Column 400 \\
\hline WL-92-404 & 94.55 & 10 & Isi & 39 & & 10YR4/4 & 10YR7/4 & 35 & $\mathrm{E}$ & Column 400 \\
\hline
\end{tabular}


Table 29-2, continued

\begin{tabular}{|c|c|c|c|c|c|c|c|c|c|c|}
\hline Sample No. & Elevation & Thickness & Unit & \begin{tabular}{|l|} 
Level \\
\end{tabular} & \begin{tabular}{|l|} 
Feature \\
\end{tabular} & Matrix color & Mottle color & Square & Wall & Location \\
\hline WL-92-405 & 94.33 & 13 & Isi & 40 & & 10YR4/4 & 10YR7/4 & 35 & $E$ & Column 400 \\
\hline WL-92-406 & 94.32 & 10 & Isi & 41 & & $10 \mathrm{YR} 4 / 4$ & 10YR7/4 & 35 & E & Column 400 \\
\hline WL-92-407 & 94.22 & 9 & Isi & 43 & & 10YR4/4 & & 35 & $\mathrm{E}$ & Column 400 \\
\hline WL-92-408 & 94.07 & 10 & Isi/Icl & 44 & & 10YR4/4 & & 35 & $\mathrm{E}$ & Column 400 \\
\hline WL-92-409 & 93.96 & 12 & Icl & 45 & & 10YR4/3 & & 35 & $\mathrm{E}$ & Column 400 \\
\hline WL-92-410 & 93.83 & 13 & Icl & 46 & & $10 \mathrm{YR} 4 / 3$ & 10YR5/8 & 35 & E & Column 400 \\
\hline WL-92-411 & 93.71 & 12 & Icl & 47 & & $10 \mathrm{YR} 4 / 3$ & 10YR5/8 & 35 & $\mathrm{E}$ & Column 400 \\
\hline WL-92-412 & 93.59 & 12 & Icl/Isi & 48 & & $10 \mathrm{YR} 4 / 3$ & 10YR5/8 & 35 & $\mathrm{E}$ & Column 400 \\
\hline WL-92-413 & 93.46 & 14 & Icl//si & 49 & & 10YR5/3 & & 35 & E & Column 400 \\
\hline WL-92-414 & 93.32 & 14 & Isi & 50 & & 10YR5/4 & & 35 & $\mathrm{E}$ & Column 400 \\
\hline WL-92-415 & 93.18 & 13 & Isi & 51 & & 10YR7/2 & 10YR5/8 & 35 & $\mathrm{E}$ & Column 400 \\
\hline WL-92-F01 & 95.60 & 20 & ш/Шाа & 22 & 245 & & & 44 & & \\
\hline WL-92-F02 & 95.77 & & IIIa & 22 & 181 & & & 50 & & \\
\hline WL-92-F03 & 95.38 & 8 & II & 30 & 236 & & & 33 & & \\
\hline WL-92-F04 & 95.71 & & IIIa & 23 & 181 & & & 52 & & \\
\hline WL-92-F05 & 95.65 & & IIIIa & 24 & 181 & & & 51 & & \\
\hline WL-92-F06 & 95.67 & & IIIIa & 23 & 181 & & & 51 & & \\
\hline WL-92-F07 & 95.68 & & Па & 24 & 181 & 7.5YR4/2 & & 52 & & \\
\hline WL-92-F08 & 95.69 & & IIIa & 24 & 245 & $7.5 \mathrm{YR} 4 / 3$ & & 28 & & \\
\hline WL-92-F09 & 95.29 & & II/Id & 31 & 236 & 10YR5/4 & & 33 & & \\
\hline WL-92-F10 & 94.90 & & Isi & 35 & & 10YR5/4 & & 32 & & \\
\hline WL-92-F11 & 95.29 & & II & $30 ; 31$ & 236 & 10YR5/4 & & 33 & & \\
\hline WL-92-F12 & 95.12 & & II & 33 & 243 & 10YR4/4 & & 25 & & \\
\hline WL-92-F13 & 95.59 & 3 & IIIa/II & & 245 & 10YR3/4 & & 52 & & \\
\hline WL-92-F14 & 95.63 & 6 & IIIa & 25 & 245 & $7.5 \mathrm{YR} 4 / 4$ & & 28 & & \\
\hline WL-92-F15 & 95.59 & 5 & IIIIa & 26 & 245 & $7.5 Y R 4 / 4$ & & 28 & & \\
\hline WL-92-F16 & & & II & $28 ; 29$ & burrow & & & 27 & & \\
\hline WL-92-F17 & 95.58 & 11 & IIlb/ Ша & $26 ; 27$ & 245 & $\begin{array}{l}10 \mathrm{YR} 3 / 2 ; 10 \\
\text { YR5/3 }\end{array}$ & & 52 & & \\
\hline WL-92-F18 & 95.60 & 6 & IIIlb/ IIIa & $25 ; 26$ & 245 & $\begin{array}{l}10 \text { YR3/2;10 } \\
\text { YR5/3 }\end{array}$ & & 52 & & \\
\hline WL-92-F19 & 95.55 & 10 & IIIa/II & $25 ; 27$ & 245 & & & 52 & & \\
\hline WL-92-F20 & 95.55 & 10 & IIIa/II & $25 ; 27$ & 245 & & & 52 & & \\
\hline WL-92-F21 & 95.55 & 10 & IIIa/II & $25 ; 27$ & 245 & & & 52 & & \\
\hline WL-92-F22 & & & Isi & 42 & 252 & & & 55 & & \\
\hline WL-92-F23 & 95.55 & 9 & $\mathrm{III} / \mathrm{IIl}$ & $27 ; 28$ & 249 & & & 51 & & \\
\hline WL-92-F24 & $95 / 45$ & 10 & $\mathrm{III} / \mathrm{Il} \mathrm{b}$ & $27 ; 28$ & $\begin{array}{l}231 ; \\
249\end{array}$ & & & 51 & & \\
\hline WL-92-F25 & 95.58 & & $\mathrm{IIIa} / \mathrm{IIb}$ & 25 & 245 & & & 52 & & \\
\hline WL-92-F26 & 94.29 & 7 & Isi & $41 ; 42$ & 256 & $10 \mathrm{YR} 5 / 3$ & & 28 & & \\
\hline WL-92-F27 & 93.46 & 12 & Icl & 50 & burrow & 10YR6/1 & $\begin{array}{l}\text { 10YR5/2;10 } \\
\text { YR4/1 }\end{array}$ & 35 & & \\
\hline WL-92-F28 & 93.43 & 6 & Icl & 50 & burrow & 10YR7/1 & 10YR8/4 & 35 & & \\
\hline WL-92-F29 & 94.22 & 5 & Isi & $42 b$ & 260 & & & 52 & & \\
\hline WL-92-F30 & 95.50 & 10 & IIIa/II & $27 c ; 28 c$ & 249 & $10 Y R 3 / 4$ & & 51 & & \\
\hline WL-92-F31 & 93.15 & 10 & Isi & 53 & & 10YR7/1 & 10YR6/8 & 59 & & \\
\hline WL-92-F32 & ca. $95.50 ?$ & & II & 27 & 232 & & & 46 & & \\
\hline WL-93-B1 & $\begin{array}{l}\text { TxDOT: pelvis } \\
@ \text { approx. } \\
94.74\end{array}$ & & Isi? & $\begin{array}{l}\text { TxDOT: } \\
\text { 31A-34B }\end{array}$ & Burial 2 & "10YR4/3" & & E20/S74 & & \\
\hline WL-93- B2 & \begin{tabular}{|l|} 
TxDOT: ribs \\
$@$ approx. \\
$94.825-94.78$ \\
\end{tabular} & & Isi? & $\begin{array}{l}\text { TxDOT: } \\
\text { 31A-34B }\end{array}$ & Burial 2 & "10YR4/3" & & E20/S74 & & \\
\hline WL-93-B3 & $\begin{array}{l}\text { TxDOT:base } \\
\text { of rock @ } \\
\text { approx. } \\
94.885\end{array}$ & & Isi? & $\begin{array}{l}\text { TxDOT: } \\
\text { 31A? }\end{array}$ & Burial 2 & "10YR4/3" & & E20/ S74 & & \\
\hline WL-93-B4 & $\begin{array}{l}\text { TxDOT: base } \\
\text { of mano = } \\
94.885\end{array}$ & & Isi? & $\begin{array}{l}\text { TxDOT: } \\
\text { 31A? }\end{array}$ & Burial 2 & "10YR4/3" & & E20/ S74 & & \\
\hline WL-93-B5 & $\begin{array}{l}\text { TxDOT: } \\
\text { 94.92-94.87 }\end{array}$ & & Isi? & $\begin{array}{c}\text { TxDOT: } \\
\text { 31A }\end{array}$ & $\begin{array}{l}\text { west of } \\
\text { Burial } 2\end{array}$ & "10YR5/4" & "10YR5/6" & E20/ S74 & & \\
\hline
\end{tabular}


Table 29-2, continued

\begin{tabular}{|c|c|c|c|c|c|c|c|c|c|c|}
\hline Sample & Elevation & Thicknes & Unit & Level & \begin{tabular}{|l|} 
Feature \\
\end{tabular} & Matrix & Mottle color & Square & Wall & Location \\
\hline LL-93-PI-1 & $\begin{array}{l}\text { TxDOT: } \\
94.888-94.678\end{array}$ & & Isi? & \begin{tabular}{|c|} 
TxDOT: \\
32A-34A
\end{tabular} & 168 & not recorded & & E20/S76 & & \\
\hline VL-93-PI-2 & $\begin{array}{l}\text { TxDOT: } \\
94.788-94.55\end{array}$ & & Isi? & $\begin{array}{r}\text { TxDOT: } \\
\text { 33B-35A }\end{array}$ & 168 & not recorded & & E20/S76 & & \\
\hline VL-93-PI-3 & $\begin{array}{l}\text { TxDOT: } 94.59- \\
94.53\end{array}$ & & Isi? & $\begin{array}{c}\text { TxDOT: } \\
\text { 35B }\end{array}$ & 168 & not recorded & & $\begin{array}{l}\text { E20/ S76; } \\
\text { NW quad }\end{array}$ & & \\
\hline VL-93-PI-4 & $\begin{array}{l}\text { TxDOT: } 94.80- \\
94.74\end{array}$ & & Isi? & \begin{tabular}{|} 
TxDOT: \\
33B-34A
\end{tabular} & 169 & not recorded & & $\begin{array}{l}\text { E20/ S76; } \\
\text { SW quad }\end{array}$ & & \\
\hline VL-93-PI-5 & $\begin{array}{l}\text { TxDOT: } 95.26- \\
94.70\end{array}$ & & Isi? & $\begin{array}{l}\text { TxDOT: } \\
\text { 30-34A }\end{array}$ & 169 & not recorded & & $\begin{array}{l}\text { E20/ S78; } \\
\text { NW quad }\end{array}$ & & \\
\hline VL-93-PI-6 & $\begin{array}{l}\text { TXDOT: ca. } \\
94.89 ?\end{array}$ & & Isi? & $\begin{array}{c}\text { TxDOT: } \\
32 \mathrm{~A}\end{array}$ & $\begin{array}{c}\text { outside } \\
\text { F168 }\end{array}$ & not recorded & & E20/S76 & & \\
\hline VL-93-PI-7 & $\begin{array}{l}\text { TxDOT: } 95.26- \\
94.70\end{array}$ & & Isi? & $\begin{array}{r}\text { TxDOT: } \\
\text { 30A-34A }\end{array}$ & 169 & not recorded & & $\begin{array}{l}\text { E20/ S78; } \\
\text { NW quad }\end{array}$ & & \\
\hline VL-93-B6 & $\begin{array}{l}\text { TxDOT: } 94.92- \\
94.87\end{array}$ & & Isi? & $\begin{array}{c}\text { TxDOT } \\
31 \mathrm{~A}\end{array}$ & $\begin{array}{c}\text { east of } \\
\text { Burial 2 }\end{array}$ & not recorded & & $\begin{array}{l}\text { E20/ S74; } \\
\text { NE quad? }\end{array}$ & & \\
\hline VL-93-B7 & $\begin{array}{l}\text { TxDOT: } \\
\text { approx. 94.96- } \\
94.91\end{array}$ & & Isi? & $\begin{array}{c}\text { TxDOT } \\
31 \mathrm{~A}\end{array}$ & \begin{tabular}{|l} 
Burial 2 \\
"pit fill"
\end{tabular} & $\begin{array}{l}\text { not recorded } \\
\text { but probably } \\
10 \text { YR } 4 / 3\end{array}$ & & $\begin{array}{c}\text { E20/ S74; } \\
\text { NE \& NW } \\
\text { quads }\end{array}$ & & \\
\hline VL-93-B8 & $\begin{array}{l}\text { TxDOT: } \\
\text { approx. 94.97- } \\
94.94\end{array}$ & & Isi? & $\begin{array}{c}\text { TxDOT } \\
31 \mathrm{~A}\end{array}$ & $\mid$\begin{tabular}{|} 
Burial 2 \\
"pit fill"
\end{tabular} & not recorded & & $\begin{array}{l}\text { E20/ S74; } \\
\text { NE \& NW } \\
\text { quads }\end{array}$ & & \\
\hline VL-93-B9 & $\begin{array}{l}\text { TxDOT: } \\
\text { approx. } 94.92\end{array}$ & & Isi? & $\begin{array}{c}\text { TxDOT } \\
31 \mathrm{~A}\end{array}$ & \begin{tabular}{|} 
Burial 2 \\
"pit fill"
\end{tabular} & $\begin{array}{l}\text { "10YR5/4 } \\
\text { (moist)" }\end{array}$ & & $\begin{array}{l}\mathrm{E} 20 / \mathrm{S} 74 \\
\mathrm{NW} \text { quad }\end{array}$ & & $\begin{array}{l}\text { sample location plotted on plan } \\
\text { map 1-B as "Munsell 2" }\end{array}$ \\
\hline VL-93-B10 & $\begin{array}{l}\text { TxDOT: } \\
\text { approx. } 94.92\end{array}$ & & Isi? & $\begin{array}{c}\text { TxDOT } \\
31 \mathrm{~A}\end{array}$ & $\mid \begin{array}{l}\text { Burial 2 } \\
\text { "pit fill" }\end{array}$ & $\begin{array}{l}\text { "10YR4/3 } \\
\text { (moist)" }\end{array}$ & & $\begin{array}{l}\text { E20/ S74; } \\
\text { NW quad }\end{array}$ & & $\begin{array}{l}\text { sample location plotted on plan } \\
\text { map 1-B as "Munsell Sample 3" }\end{array}$ \\
\hline VL-94-S1 & $\begin{array}{l}\text { TxDOT: } \\
\text { approx. } 95.52\end{array}$ & 10 & & $\begin{array}{c}\text { TxDOT\# } \\
12\end{array}$ & & & & E20/S72 & $\mathrm{N}$ & \\
\hline VL-94-S2 & $\begin{array}{l}\text { TxDOT: } \\
\text { approx. } 95.30\end{array}$ & 10 & & $\begin{array}{c}\text { TxDOT\# } \\
13\end{array}$ & & & & E20/S72 & $\mathrm{N}$ & \\
\hline VL-94-S3 & $\begin{array}{l}\text { TxDOT: } \\
\text { approx. } 95.10\end{array}$ & 10 & & $\begin{array}{c}\text { TxDOT\# } \\
14\end{array}$ & & & & E20/S72 & $\mathrm{N}$ & \\
\hline VL-94-S4 & $\begin{array}{l}\text { TxDOT: } \\
\text { approx. } 94.85\end{array}$ & 10 & & $\begin{array}{c}\text { TxDOT\# } \\
15\end{array}$ & & & & E20/S72 & $\mathrm{N}$ & \\
\hline VL-94-S5 & $\begin{array}{l}\text { TxDOT: } \\
\text { approx. } 94.67\end{array}$ & 10 & & $\begin{array}{c}\text { TxDOT\# } \\
16\end{array}$ & & & & E20/S72 & $\mathrm{N}$ & \\
\hline VL-94-S6 & $\begin{array}{l}\text { TxDOT: } \\
\text { approx. } 94.50\end{array}$ & 10 & & $\begin{array}{c}\text { TxDOT2 } \\
8 \mathrm{~A}\end{array}$ & & & & E20/S72 & $\mathrm{N}$ & \\
\hline VL-94-F1 & $\begin{array}{l}\text { TxDOT: } \\
95.60\end{array}$ & & II? & $\begin{array}{c}\text { TxDOT } \\
25\end{array}$ & 166 & $\begin{array}{l}\text { 10YR5/4m } \\
{[\text { VTH] }}\end{array}$ & & N8 W0 & $\begin{array}{l}\text { SE } \\
\text { Quad }\end{array}$ & Area B \\
\hline VL-94-F2 & $\begin{array}{l}\text { TxDOT: } \\
95.60\end{array}$ & & ПI? & $\begin{array}{c}\text { TxDOT } \\
25 \mathrm{~B}\end{array}$ & 166 & $\begin{array}{l}10 Y R 5 / 4 \mathrm{~m} \\
{[\mathrm{VTH}]}\end{array}$ & & N8 E2 & $\begin{array}{l}\text { SW } \\
\text { Quad }\end{array}$ & Area B \\
\hline VL-94-F3 & $\begin{array}{l}\text { TxDOT: } \\
95.40\end{array}$ & & $\begin{array}{c}\text { I [Leanne } \\
\text { or Id?] }\end{array}$ & $\begin{array}{c}\text { TxDOT } \\
27 \mathrm{~B}\end{array}$ & $\begin{array}{c}\text { Below } \\
166 ? \\
\text { (cross- } \\
\text { section } \\
\text { trench) }\end{array}$ & $\begin{array}{l}10 \mathrm{YR} 4 / 4 \\
{[\mathrm{VTH}]}\end{array}$ & & N8 E2 & $\begin{array}{l}\text { SW } \\
\text { Quad }\end{array}$ & Area B \\
\hline VL-94-F4 & TxDOT: 95.35 & & $\begin{array}{c}\text { I [Leanne } \\
\text { or Id?] }\end{array}$ & $\begin{array}{c}\text { TxDOT } \\
28 \mathrm{~A}\end{array}$ & $\begin{array}{c}\text { Below } \\
166 ? \\
\text { (cross- } \\
\text { section } \\
\text { trench) }\end{array}$ & $\begin{array}{l}10 \mathrm{YR} 4 / 4 \\
{[\mathrm{VTH}]}\end{array}$ & & N8 E2 & $\begin{array}{l}\text { SW } \\
\text { Quad }\end{array}$ & Area B \\
\hline NL-95-1 & & & Icl/Isi? & $51 \mathrm{~B}$ & 262 & 10YR4/6 & & 27 & & \\
\hline WL-95-2 & & & Icl/Isi? & $52 \mathrm{~B}$ & 262 & 10YR4/6 & & 27 & & \\
\hline NL-95-3 & & & III//II? & TxDOT & 104 & $?$ & & $\mathrm{E} 22 / \mathrm{S} 90$ & & \\
\hline NL-95-4 & $\begin{array}{l}\text { TxDOT: ca. } \\
97.13--97.025\end{array}$ & & IIIc/b? & $\begin{array}{c}\text { TxDOT } \\
9 \& 10\end{array}$ & 176 & ? & & E28/S78 & & \\
\hline WL-95-5 & & & IIIb & $\begin{array}{c}11 \& \\
12\end{array}$ & 204 & $\begin{array}{l}\text { 10YR4/2 } \\
\& / \text { or } \\
\text { 10YR3/3 }\end{array}$ & & 20 & & \\
\hline NL-95-6 & & & $\mathrm{IIIc} / \mathrm{b}$ & $6 \mathrm{~B}$ & 206 & 10YR2/1 & & 15 & & \\
\hline NL-95-7 & & & IIIb/a & $12 \mathrm{~B}$ & 213 & 10YR3/3 & & 12 & & \\
\hline WL-95-8 & & & IIIb/a & $16 \mathrm{~B}$ & 215 & 10YR4/2 & & 20 & & \\
\hline NL-95-9 & & & ШIIa/II & $20 \mathrm{~B}$ & 224 & $10 \mathrm{YR} 4 / 3$ & & 12 & & \\
\hline NL-95-10 & & & IIIa/II & $21 \mathrm{~B}$ & 226 & 10YR5/3 & & 46 & & \\
\hline
\end{tabular}


Table 29-2, continued

\begin{tabular}{|c|c|c|c|c|c|c|c|c|c|c|}
\hline Sample No. & Elevation & Thickness & Unit & Level & Feature & Matrix & Mottle color & Square & Wall & Location \\
\hline WL-95-11 & & & IIIa/II & $22 \mathrm{~B}$ & 227 & 10YR5/3 & & 30 & & \\
\hline WL-95-12 & & & IIIa/II & $25 \mathrm{~B}$ & 233 & 10YR3/4 & & 20 & & \\
\hline WL-95-13 & & & II/Isi-c & $29 \mathrm{~B}$ & 235 & 10YR5/4 & & 32 & & \\
\hline WL-95-14 & & & II/Id & $31 \mathrm{~B}$ & 246 & 10YR4/4 & & 49 & & \\
\hline WL-95-15 & & & Isi-c & $42 \mathrm{~B}$ & 255 & $10 \mathrm{YR} 4 / 3$ & & 59 & & \\
\hline WL-95-16 & & & IIIIa & 21B & 230 & 10YR4/4 & & 39 & & \\
\hline WL-95-17 & & & II & $25 \mathrm{~B}$ & 239 & 10YR4/4 & & 34 & & \\
\hline WL-95-18 & & & II & 26B & 241 & 10YR5/4 & & 35 & & \\
\hline WL-95-19 & & & II & $28 \mathrm{~B}$ & 248 & $10 \mathrm{YR} 4 / 6$ & & 44 & & \\
\hline WL-95-20 & & & II & $\begin{array}{c}\text { TxDOT } \\
22 \mathrm{~A} \& \mathrm{~B} ?\end{array}$ & 157 & $?$ & & E26/S72 & & \\
\hline WL-95-21 & & & $\begin{array}{c}\text { Isi(c?/Isi } \\
?\end{array}$ & $\begin{array}{c}\text { TxDOT } \\
\text { 37A-38A }\end{array}$ & 175 & $?$ & & E26/S76 & & \\
\hline WL-95-22 & & & II & $\begin{array}{c}\text { TxDOT } \\
\text { 20B }\end{array}$ & 185 & $?$ & & E28/S78 & & \\
\hline WL-95-23 & & & Isi-c & $\begin{array}{c}\text { TxDOT } \\
\text { 32B }\end{array}$ & 187 & ? & & E28/S78 & & \\
\hline WL-95-24 & $\begin{array}{l}\text { TxDOT } \\
95.945\end{array}$ & & II & $\begin{array}{c}\text { TxDOT } \\
22 \mathrm{~A} \& \mathrm{~B} ?\end{array}$ & 155 & $?$ & & E24/S76 & & \\
\hline WL-95-25 & & & IIIb & $13 \mathrm{~B}$ & 209 & 10YR3/1 & & 20 & & \\
\hline WL-95-26 & & & IIIb & $12 \mathrm{~B}$ & 216 & & & 22 & & \\
\hline WL-95-27 & & & $\mathrm{IIIb} / \mathrm{a}$ & 15B & 220 & $10 \mathrm{YR} 4 / 3$ & & 52 & & \\
\hline WL-95-28 & & & IIIb & $15 \mathrm{C}$ & 221 & 7.5YR4/4 & & 39 & & \\
\hline WL-95-29 & & & IIIa & $16 \mathrm{~B}$ & 222 & 10YR5/4 & & 37 & & \\
\hline WL-95-30 & & & IIIIa & $21 \mathrm{~B}$ & 228 & 10YR4/3 & & 38 & & \\
\hline WL-95-31 & & & IIIIa/II & $23 B$ & 237 & $10 Y R 4 / 3$ & & 34 & & \\
\hline WL-95-32 & & & II & $29 \mathrm{~B}$ & 242 & $10 \mathrm{YR} 4 / 4$ & & 20 & & \\
\hline
\end{tabular}

\section{Interpretations of Micromorphological Observations}

Concise, summary descriptions of 156 micromorphological samples (see Table 29-1), highlighting the important aspects of the samples, are presented in Appendix 7 (for sampling locations see Table 29-2). The following section discusses the interpretations of the thin sections in terms of depositional and postdepositional processes operating at the site. The discussion that follows is based on intact blocks collected in two long columns, referred to as Column 100 from the south wall of TARL Square 12 and as Column 200 from the south wall of TARL Square 20. Samples from features are described in Appendix 7, but they are discussed primarily in Chapter 26.

\section{Sampling Column 100 from Square 12}

\section{UNIT ISI}

\section{Composition}

Samples from the lower part of the stratigraphic section (e.g., WL-92-133) show extensive secondary cementation by calcium carbonate, and consequently, it is quite difficult to recognize the original fluvial sediments because of the extensive diagenesis of these deposits. Some limestone clasts and snails are present as is some quartz silt, but there is so much cementation that it is difficult to observe them. It is assumed that these calcareous lithoclasts are from Brushy Creek.

Bones are relatively rare, and ash rhombs, while barely visible at the top of the unit, disappear with depth into a mass of secondary carbonate. Ash rhombs are present but are more difficult to recognize in the abundance of calcite. Likewise, organic matter and charcoal-like material are confined to the upper part of the unit, generally corresponding to the Leanne soil. Snail shells show the same distribution with depth as do bones.

Secondary carbonates take the form of well-developed hypocoatings in the upper part of the unit and are more massive and less differentiated in the lower part. Already in Sample WL-92-124, about $50 \mathrm{~cm}$ below the top of the unit, hypocoatings are widespread and much of the matrix has been embedded with secondary carbonate along vesicle/root systems. The hypocoatings are quite complex (see Figure 29-4a, b); they often seem to coalesce, resulting in a locally spongy fabric. Where hypocoatings and vesicles are fewer, the microstructure is subangular blocky. Sample WL-92-122 (Figure 29-5a, b), for example, exhibits a spongy, porous microstructure formed by the coalescence of numerous vesicles and pelletal carbonate. In this sample, it appears that carbonate hypocoatings have formed, broken off, become rounded (possibly by pedoturbation), and then become integrated into the matrix. 


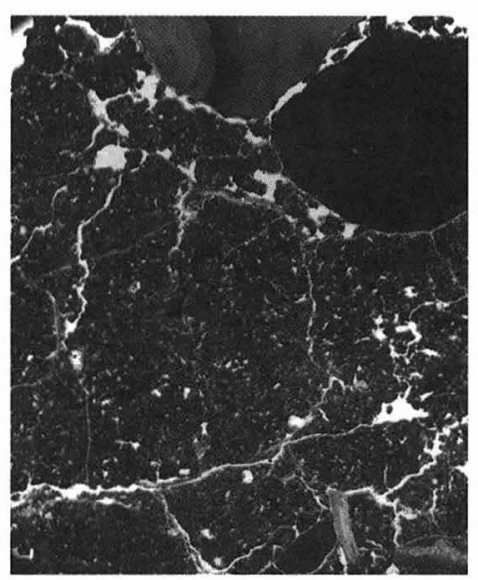

a

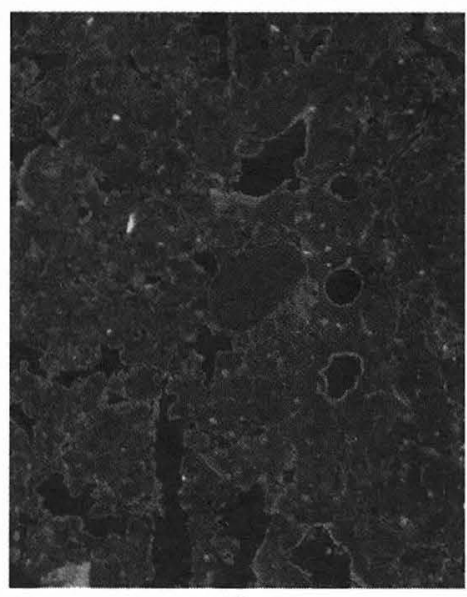

d

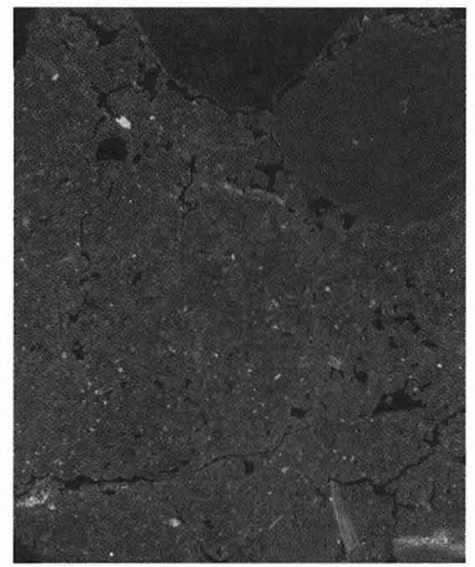

b

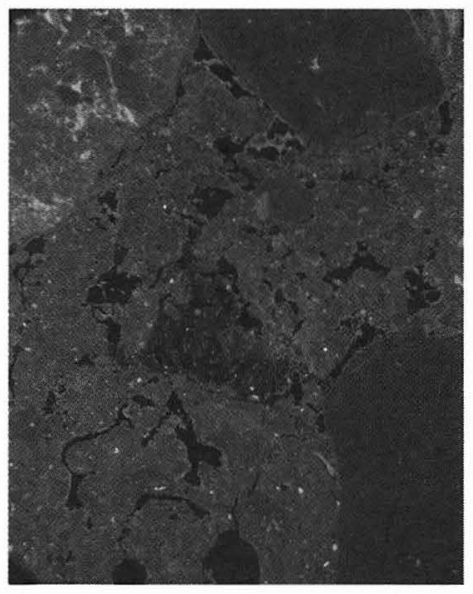

e

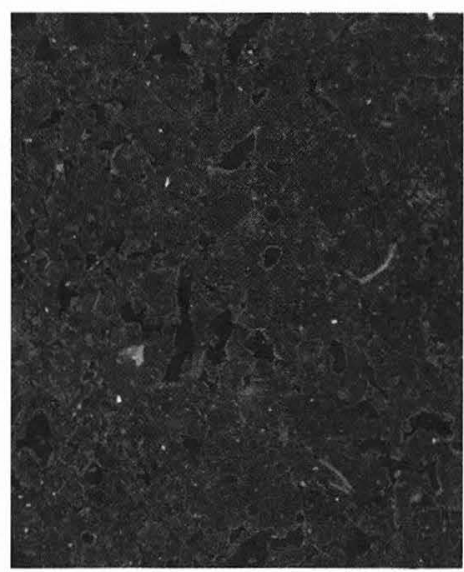

c

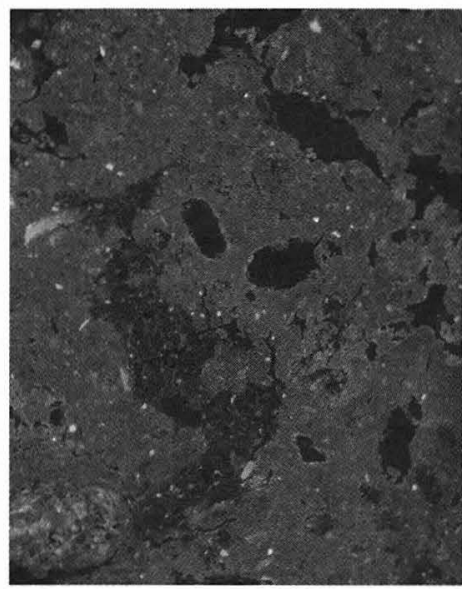

f

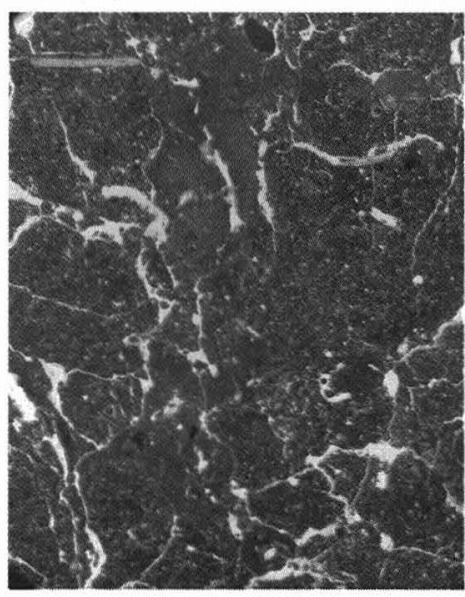

g

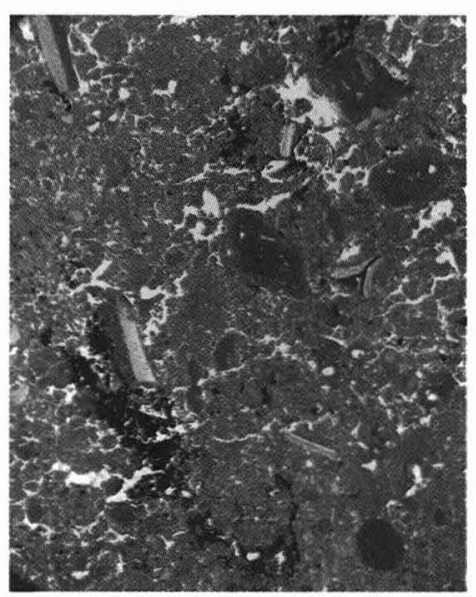

h

FIGURE 29-1. Photomicrographs of micromorphological samples. (a) Sample WL-92-110, lighter rock fragment on the lower left has been subjected to heating; (b) Sample WL-92-110, in XPL; (c) Sample WL-92-118, carbonate hypocoatings in center are developed around circular voids and vesicles, earthworm casts are more compact and welded than in overlying Units IIIb and IIIc, in XPL; (d) Sample WL92-118, detail showing hypocoatings, in XPL; (e) Sample WL-92-120, note darker noncalcified domain in the center which appears to be remains of noncalcareous soil material mixed by earthworms which are also responsible for secretion of some of the secondary calcium carbonate, rounded earthworm casts are also visible, in XPL; (f) Sample WL-92-120, detail showing irregular nature of the noncalcareous domain and adjacent hypocoatings associated with vesicles in center, in XPL; (g) Sample WL-92-227, complex hypocoatings appear to predate the massive carbonate at left center, note the subangular blocky structure punctuated by several vugs and vesicles, in PPL; (h) Sample WL-92-306, note dense hypocoatings and complex voids and the curve-shaped piece of charcoal that has been broken and distorted by the burrowing activity of earthworms, several grains exhibit coatings of calcareous silt that suggest downslope movement of the grains, in PPL. 


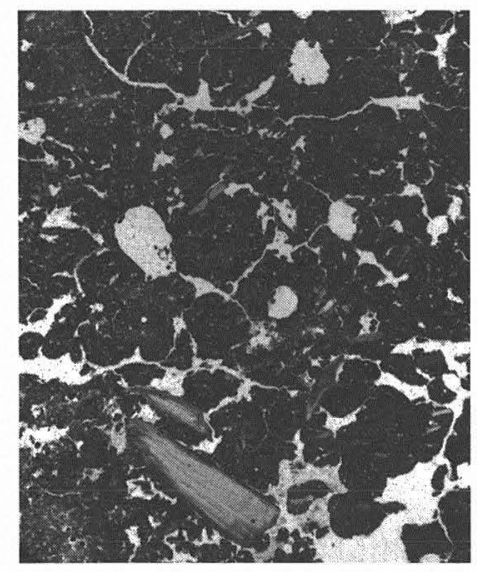

FIGURE 29-2. Photomicrograph of micromorphological Sample WL92-105, shown here by numerous earthworm casts at center is this unit's characteristic abundance of biological reworking, two snail shells are present at left, in PPL.

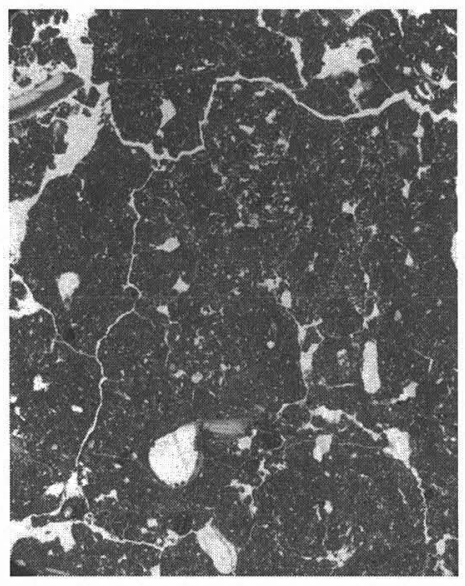

FIGURE 29-3. Photomicrograph of micromorphological Sample WL92-208, note the extensive bioturbation as expressed by earthworm casts, many of which are compressed or welded.

\section{Iron Staining}

Unit Isi exhibits considerable iron staining, which was quite marked in the field. The uppermost occurrence of iron and manganese staining observable in thin section occurs in Sample WL-92-123 (elevation of 95.10 m; see Figure 29$5 c)$. In these uppermost samples, secondary iron formation appears as irregular millimeter-sized flecks that are scattered sparsely throughout the slide.

Somewhat below this level (e.g., Sample WL-92-127), the iron stains are more diffuse and are expressed as broad impregnations of the matrix rather than as localized flecks and splotches. Moreover, in this sample and most others, the iron staining seems to postdate the time of most of the massive carbonate impregnations, or at least part of it. In the lower levels of Unit Isi (e.g., Sample WL-92-133; Figure 29$6 \mathrm{a}, \mathrm{b})$, the latest phase of carbonate accumulation in vesicles and vugs clearly postdates the bulk of iron/manganese precipitation. However, taken as a whole, it would seem that micromorphologically most of the iron and carbonate precipitation in Unit Isi are roughly contemporaneous.

It should also be pointed out that parts of certain thin sections (Samples WL-92-128 and WL-92-130) were partially decalcified in order to observe a "prediagenetic" window into the sediments. Examination of these samples shows, to some extent, that areas most impregnated with iron are initially more clay rich, since some underlying birefringence can be observed in these areas.

\section{Microstructure}

Spongy fabrics (see Figure 29-5a) are prominent in this unit, particularly in the upper part (e.g., Sample 92-121). As mentioned above, they commonly appear to be associated with vesicular hypocoatings. With depth, however, porosity is predominantly expressed in the form of vugs and

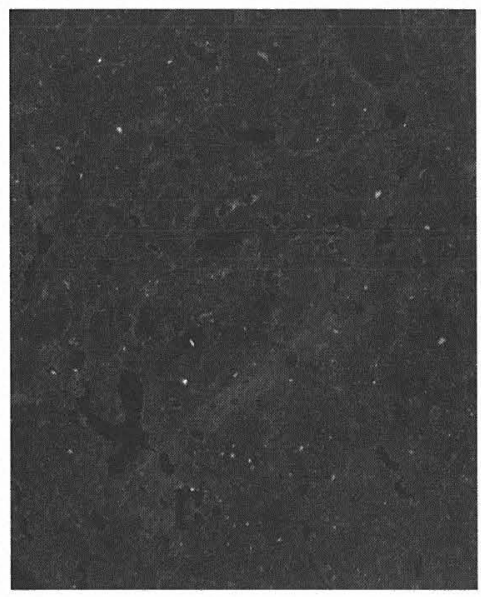

a

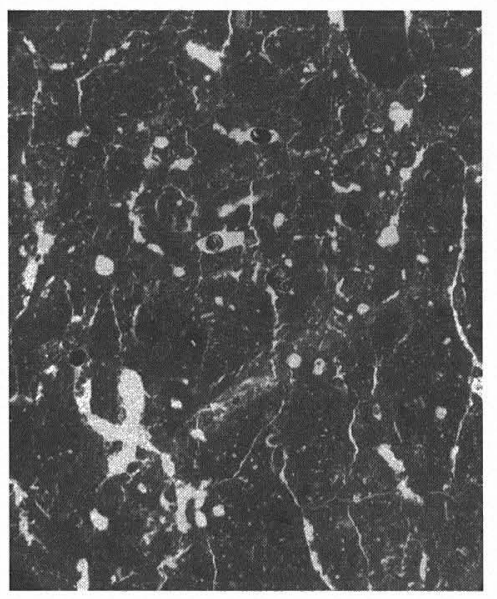

b

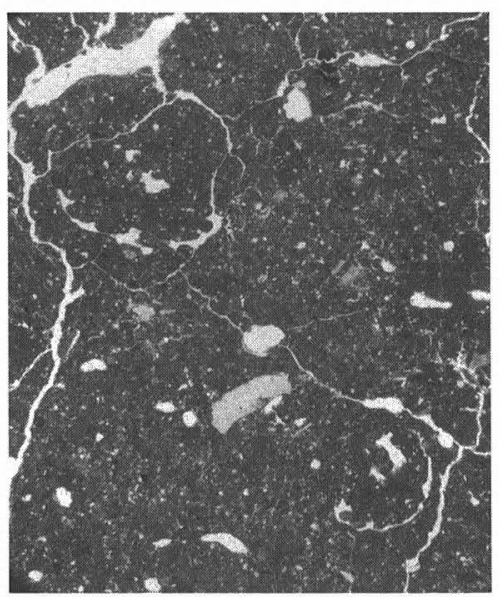

$\mathrm{c}$

FIGURE 29-4. Photomicrographs of micromorphological samples. (a) Sample WL-92-129, note the numerous vugs and complex hypocoatings producing a spongy and fine-crack structure, in PPL; (b) Sample WL-92-129, note that iron seems to pre- and postdate the precipitation of carbonate, in XPL; (c) Sample WL-92-213, note the bone fragment in the center and the subangular blocky microstructure, with intrapedal locations punctuated by vesicles and hypocoatings, in PPL. 


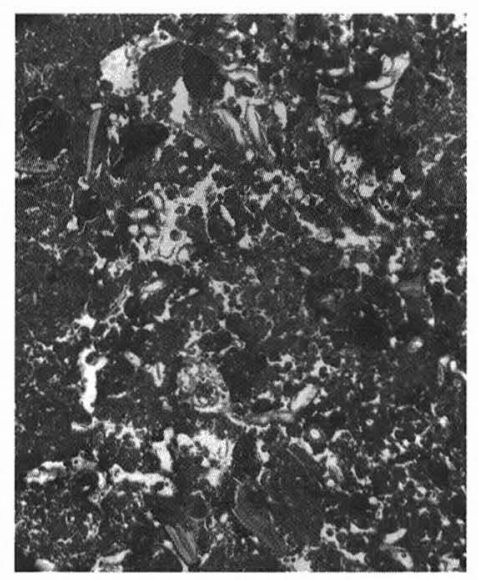

a

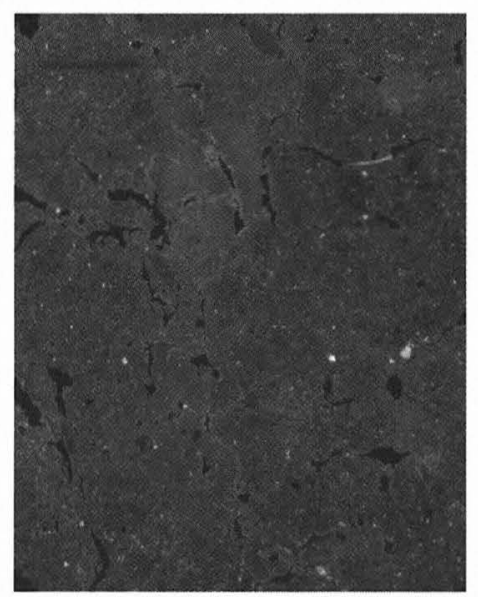

d

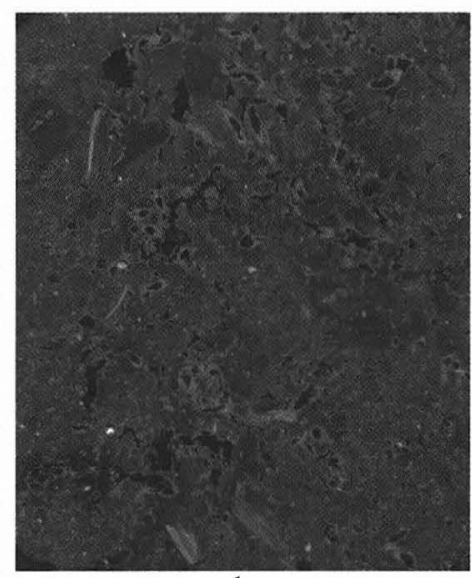

b

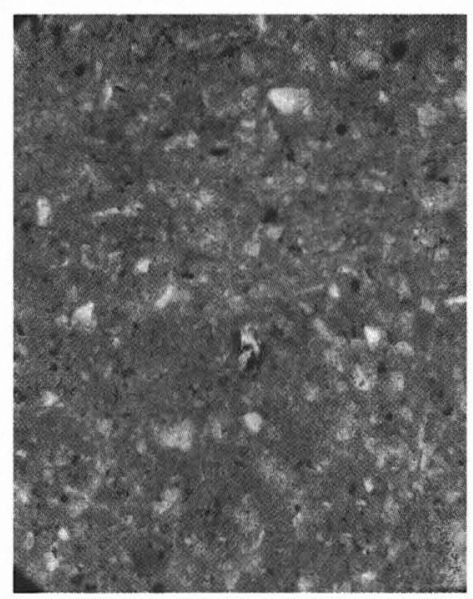

e

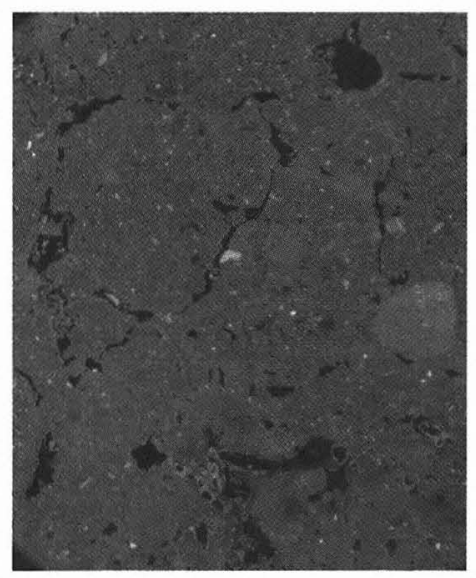

c

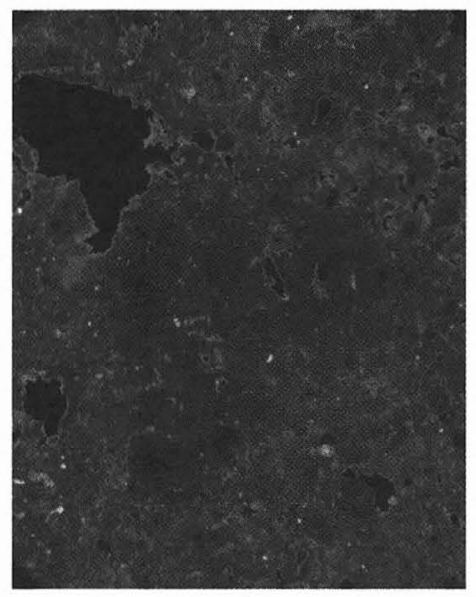

f

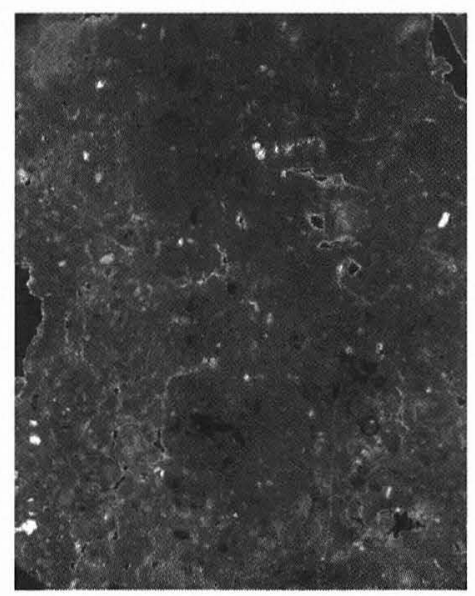

g

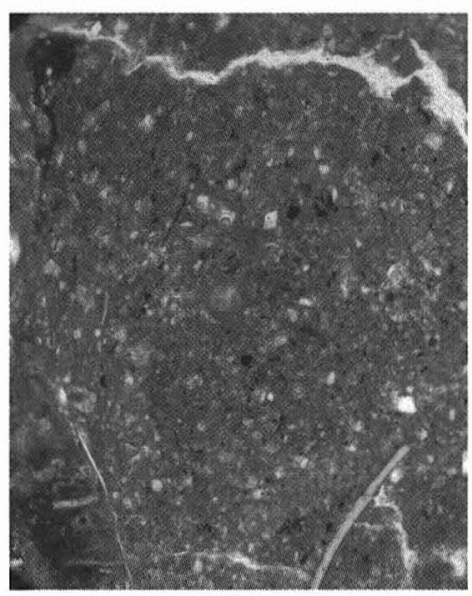

$\mathrm{h}$

FIGURE 29-5. Photomicrographs of micromorphological samples. (a) Sample WL-92-122, note the spongy microstructure, numerous vesicles and pelletal carbonate; this sample is more diagenetic than those from Units III, II, and the upper part of Id, in PPL; (b) Sample WL-92-122, note the more-pelletal nature of the sample in this view, in XPL; (c) Sample WL-92-123, this sample has the uppermost occurrence of iron staining expressed as localized mm-sized irregular impregnations of the matrix, in XPL; (d) Sample WL-92-227 (same sample as Figure 29-1g), note the lack of iron staining of the carbonate nodule at left center, in XPL; (e) Sample WL-92-227, detail showing the fine-grained pieces of yellow brown organic matter that typify the Leanne soil and render its darker color in the field, in XPL; (f) Sample WL-92-126, note the massive impregnation of carbonate at center that resembles incipient carbonate nodules, in XPL; (g) Sample WL-92126, detail showing massive carbonate nodule and iron flecks, note that the iron stains the nodule indicating that the carbonate precipitated first, in XPL; (h) Sample WL-92-232, note the fine-grained yellow brown pieces of organic matter visible as flecks scattered throughout the matrix and the subangular blocky microstructure, typical of Unit Icl sediments. The thin line at right is an ostracode fragment and diffuse iron staining is noticeable throughout, in PPL. 


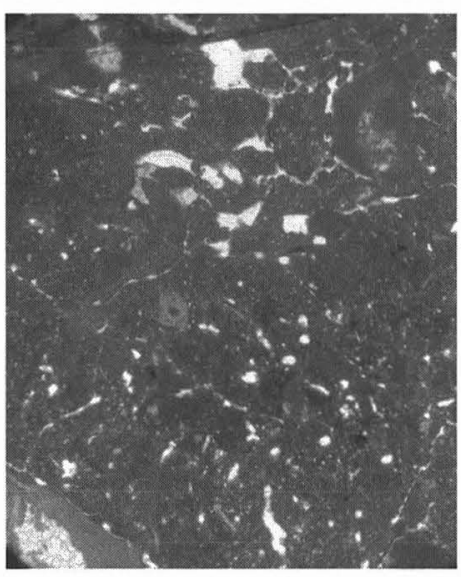

a

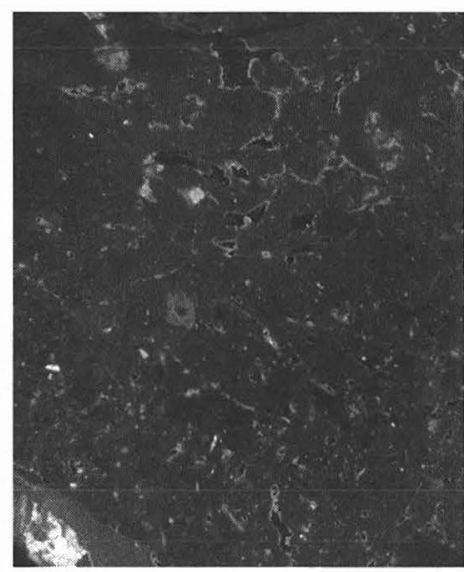

b

FIGURE 29-6. Photomicrographs of micromorphology samples. (a) Sample WL-92-133, note complex voids and hypocoatings that point to repeated phases of carbonate precipitation typical of the sediments from Unit Isi, in PPL; (b) Sample WL-92-133, note that iron staining postdates the massive phase of carbonate precipitation, in XPL.

vesicles that perforate a massive calcareous matrix which has been locally disengaged by fissures and cracks.

In many cases, partial artificial decalcification of certain thin sections (see above) shows that in a precalcified state, the sediments are initially comprised of rounded clayey aggregates with quartz silt inclusions; these aggregates are similar to the worm casts so abundant in Unit III and would appear to be a result of worm bioturbation. In other words, it seems that these former flood plain sediments were bioturbated at the time of deposition by Brushy Creek.

\section{UNIT Id}

Micromorphologically, Unit Id is not unlike Unit Isi. Most earthworm casts have a welded appearance and concomitantly, the voids are complex: packing voids, vugs, and some vesicles are prominent, and a spongy fabric is weakly visible. In addition, hypocoatings are well developed, and calcium carbonate permeates much of the matrix. However, massive carbonates are not as prominent as in Unit Isi, and it is only near the contact with Isi that carbonate nodules are visible, being typically rounded. Some bone is found but is rather rare. Both field and micromorphological evidence show that Unit Id is less pedogenically modified than is Unit Isi, although Sample WL-92-123 (see Figure 29-5c) does exhibit traces of iron staining, and it represents the uppermost occurrence of iron-stained sediment in Column 100.

\section{UNIT II}

The sediments in Unit II are as a whole different from those in Unit I. As observed in the field, they contain a higher proportion of centimeter-sized rock fragments. Cultural contributions, however, in the form of bones and charcoal, become much more prominent, and some of the snail shells and limestone clasts show signs of having been heated. Similarly, individual ash rhombs and calcite vegetal fragments are more clearly visible, although as in Unit III (see below) they are well worked into the matrix by biological activity. Earthworm activity is more visible than below, and casts have an "aged" appearance, tending to be compacted, welded, and slightly richer in calcium carbonate (see Figure 29-1e, f). Casts become much fresher and more prominent in Unit III (see below).

Part of the greater visibility of depositional and postdepositional constituents (e.g., silt and earthworm casts, respectively) is due to a drop-off in the intensity of the degree of development of secondary calcium carbonate. In Unit I, secondary carbonates were pervasive and massive. In Unit II, on the other hand, secondary carbonate is more subtle and less impressive and takes the form of more-individualized and less-coalesced hypocoatings, which are quite pronounced. They are more abundant and thicker in the lower part of the unit and become less so upwards. The hypocoatings are normally associated with rounded to elliptical voids and vesicles that are produced by fine roots and possibly linked to grassy vegetation. The vertical trend in secondary carbonate distribution is probably related to greater relative effective dryness in Unit II in comparison to Unit I. In the latter, greater soil moisture was likely tied to a high local water table associated with greater throughflow and overland flow that resulted in the abundant redoximorphic features observed in Unit I (features related to oxidation-reduction of iron). With the effective drop of the water table during Unit II times (resulting from downcutting or avulsion of Brushy Creek, simple groundwater drop associated with desiccation and less throughflow derived from surface water, or the aggradation of Unit II, placing it farther from the influence of a stable water table level) calcium carbonate precipitation would tend to be more 
localized around pores linked to roots. The subject of secondary carbonates is discussed in greater detail in Chapter 6.

Microstructures in samples from Unit II are also different from those in Unit I. Vugs and vesicles are quite prominent, and some of the samples (e.g., Sample WL-92-120; see Figure 29-1e, f) exhibit subrounded blocky micro-structures. However, toward the top of the unit, the microstructure becomes more granular, reflecting less diagenesis and the better preservation of biological activity in the form of earthworm casts; these tend to be less welded upward.

\section{UNIT III}

\section{Coarse Fraction}

The coarse fraction of Unit III is more varied than that of the other units and is no doubt related to the anthropogenic inputs into the sediments. These components included the following:

Subrounded to rounded clasts of limestone. In some samples (e.g., Samples WL-92-104, WL-92-110; see Figure 29-1a, b), these show signs of having been heated, whereby the outer part of the clast is partially calcined, and the original calcite has been partially recrystallized.

Numerous fragments of terrestrial snail shells. These are uncommonly whole and normally broken. Like the limestone clasts, they are occasionally heated and partially calcined (e.g., Samples WL-92-111, WL-92-113). They are particularly common in Unit IIIlb (upper part) and IIIC and slightly less so in Unit IIIa.

Bioclasts derived from the bedrock. These are commonly mollusks, such as Grypheae, or oyster shells; many of these fragments were also observed in the field, particularly in the lowermost deposits of Unit Isi that are close to bedrock.

Bone fragments are common but occur in varying amounts and are normally represented as sand-sized pieces or splinters; whole bones were not observed. Bones tend to be more common in Units IIIb and IIIc.

Charcoal fragments are never really abundant in any of the Wilson-Leonard sediments but like bone, occur in trace amounts from slide to slide; some samples exhibit a few more fragments, but these differences do not appear to be significant. The general absence of large pieces of charcoal in this strongly cultural unit where it might be expected is due to the great deal of bioturbation by earthworms. This inference is not readily apparent from field observations.

Coprolite pieces were found only sporadically (e.g., Sample WL-92-104) and consist of sand-sized grains of pale yellowish phosphate containing inclusions of fine quartz silt; they are isotropic in cross-polarized light (XPL). These yellowish phosphatic coprolites are typical of those originating from carnivores that ingest considerable amounts of bone. Herbivore coprolites are much less phosphatic but are rich in plant tissues and residues, particularly phytoliths.
Eggshell, characterized microscopically by thin curvate fragments composed of fine prismatic crystals of calcium carbonate $\left(\mathrm{CaCO}_{3}\right)$, was recognized in a few of the samples. Many of these (e.g., Samples WL-92-109, WL-92-112, WL92-113, WL-92-114, WL-92-115, WL-92-118) are situated in Unit IIII and the lower part of Unit IIIb (see Table 29-1 and Chapter 6). It is not possible to make any large-scale inferences about the stratigraphic occurrence of eggshell fragments other than the fact that they are concentrated in Unit III, which has a strong anthropogenic character. Their general scarcity, even in the Unit III samples, precludes comparisons among subunits of Unit III.

Most of the samples from Unit III (and many from Unit II) exhibit the presence of individual rhombs of calcareous ash $\left(\mathrm{CaCO}_{3}\right)$ (Wattez and Courty 1987). These are usually dispersed throughout the matrix and not in their original position, having been disturbed by bioturbation (see above). Rarely, pieces of brownish black vegetal matter or charcoal include rhombs of calcium oxalate, which are replaced by calcite. In any case, the dispersal of individual rhombs throughout the matrix matches field observations noting the general lack of in situ ash or burned layers, except in certain features (see Appendix 7 and Chapter 26).

The microscopic evidence shows that burned limestone clasts and snail fragments, ash crystals, and charred organic matter are not strictly in their original positions. Both calcitic ash rhombs and finely comminuted charcoal, for example, have been locally dispersed throughout the matrix by earthworm activity. Although earthworm activity is slightly visible in the field, it is more clearly apparent in thin section and is likely the primary agent responsible for erasing evidence for reddened or burned substrates and associated ash layers.

Common to Unit III are rounded, sand-sized grains of bright reddish clay with quartz silt inclusions. The origin of these clay/silt aggregates seems to be clayey "terra rosa" soil remnants that are common on the surfaces and in karst features of the limestone plateaus of central and west-central Texas. The red color of the clay aggregates observed in thin section, however, differs from that of the natural karstic clays and are much brighter. This color difference in thin section is more typical of clay that has been heated, which is compatible with other indications of burning such as calcined stone and shell fragments and ash crystals.

Matrix

The matrix of virtually all samples is comprised of predominantly calcareous clay whereby fine calcite crystals are intimately mixed with clay. In addition, finely integrated within the matrix are numerous, finely divided "micro contrasted" particles, which are possibly organic matter and are responsible for providing the overall dark color of Unit III in the field. Recognizable in most samples from Unit III and Unit II are localized domains of noncalcareous, dusty, yellowish 
brown clay that are enriched in silt-sized fragments of finely divided organic matter. These domains are likely the result of bioturbation by earthworms that have mixed calcified and noncalcified material. Calcification by earthworms has been noted for over a century (Darwin 1885; Edwards and Lofty 1972). It shows, however, that noncalcareous soil material did still exist on the hillslopes at the time of accumulation of these units.

Common to Unit III are sand- and silt-sized pieces of fresh-looking, reddish brown vegetal material that appear to be the remains of modern roots. These finely divided fragments are well worked into the matrix by earthworm activity.

\section{Microstructure/Porosity}

As has been discussed above, the matrix displays clear and abundant signs of extensive bioturbation by earthworms (see Figure 29-1c-f, and h, Figure 29-2 and Figure 29-3). This is illustrated by the presence of individual earthworm casts, which result in crumbly to granular and vuggy to spongy microfabrics. At the base of Unit III, many of the individual casts are coalesced or welded, resulting in a more compact sediment and tending to produce less granular and more vugy microstructures; these microstructures were also found in Unit II. At the top of Unit III, the casts are more individualized and the sample looks quite fresh, with the excrements appearing to maintain their original shape.

Within the subunits, however, some subtle but significant changes in microstructure were noted. For example, Samples WL-92-111, WL-92-112, and WL-92-113, situated at the very base of Unit IIIb and at the top Unit IIIa (more or less corresponding to the position of the Stiba soil), display the formation of incipient hypocoatings and the initial development of secondary calcium carbonate impregnations of the matrix. These hypocoatings tend to be localized around circular voids, suggesting association with biologically produced pores, such as roots, as discussed above. In Sample WL-92-113, carbonate hypocoatings are more prominent and thicker than in any of the overlying samples from Units IIIc or upper IIIb. Below Sample WL-92-113, calcareous pedofeatures become prominent only in the lower half of Unit IIIa near the contact with Unit II.

The calcareous features in these samples seem to represent an incipient B-horizon formed beneath either an A-horizon represented by Unit IIIb above it or below an A-horizon in Unit III, which has been subsequently eroded. In the latter case, there should be a slight unconformity between the Unit IIIb base/Unit IIIa top and the overlying sediments within the bulk of Unit IIIb. These calcareous features likely correlate with the Stiba soil, which was recognized in the original TxDOT excavations. It is unlikely that these calcification features are pedogenetically related to the Wilson soil. For one, they are located too far below the Wilson soil to have been affected by it (e.g., Sample WL-92-111 is over $1 \mathrm{~m}$ below the present-day surface, which is itself several centimeters below the level of the Wilson soil when it was exposed during the TxDOT excavation). Moreover, intervening levels (e.g., Sample WL-92-106) within Unit IIIlb situated between the Wilson soil and the calcified sediments of Units IIIa/IIIb, do not show any signs of pedogenic carbonates which should be there if the calcification was derived from the Wilson surface.

\section{Sampling Column 200 from Square 20}

Trends in Square 20 are similar to those discussed for Square 12 above. These are outlined below.

Unit Icl was not present in Square 12 and hence was not discussed there. The matrix is not too dissimilar from that found in the layers containing the Leanne soil (Unit Isi; see below) and is composed of an abundance of finely comminuted organic matter; the matrix also has a pinkish color which is characteristic of Icl. Iron staining is prevalent, but hypocoatings are not stained nor are the nodules. The microstructure is generally represented by fissures with subangular blocky peds that are punctuated by vugs and vesicles. At the base (e.g., Sample WL-92-236), carbonate is quite abundant to the extent that much of the sample is impregnated with carbonate that has diffused from vugs and vesicles. Also, carbonate nodules are present, locally with clotted appearance, and many nodules seem to be produced by repeated phases of carbonate precipitation; hypocoatings are not very well expressed. Different zones within the nodules appear to be more iron stained than others, suggesting that these nodules formed intermittently with the precipitation of the iron. Also characteristic of these cienega deposits are numerous ostracodes (see Chapter 39). Potentially anthropogenic components (charcoal, bone, etc.) are rare (e.g., generally restricted to Sample WL-92-234).

Unit Isi, in Square 20 as in Square 12, is characterized by the extensive development of calcification as represented by dense carbonate nodules, hypocoatings, and clotted carbonate aggregates near complex vugs. Carbonate precipitation is much more extensive toward the base of the unit where it is expressed as dense micritic nodules that are commonly cracked and show dissolution along arcuate cracks, fissures, and voids. Iron precipitation, prevalent as dark massive flecks which are more diffuse in the lower part of the unit, seems to stain most of the carbonate matrix but not the hypocoatings adjacent to voids. Within the Leanne soil (e.g., Samples WL-92-225, WL-92-226, and WL-92-227; see Figures $29-5 \mathrm{~d}$, e and 29-1g) fine-grained organic matter is well distributed throughout the matrix as fine silt-sized pieces.

Unit Id (Sample WL-92-224) exhibits many of the features of Unit Isi. Iron staining takes the form of masses, and well-developed hypocoatings occur that appear as incipient nodules up to $2 \mathrm{~mm}$ across, thus reflecting a reduction in massive carbonate precipitation. Locally, vugs and vesicles coalesce and exhibit carbonate hypocoatings that have a clotted appearance. This mirrors the trend in Square 12 which 
shows more individualized hypocoatings up the profile, from Unit Isi through Unit II. Finally, the microstructure is cracked, with fine subangular blocky peds.

The sediments in the upper part of Unit II (e.g., Samples WL-92-215, WL-92-216, and WL-92-217) begin to show a marked cultural influence as seen by the presence of bone fragments, ash rhombs, numerous burned rocks, and charcoal. Earthworm casts begin to appear although they have an "aged" appearance; they are not fresh looking and are somewhat more compressed and welded. In addition, hypocoatings are better developed and tend to be associated with a spongy and clotted appearance. Iron staining appears in the lower part of the unit (Samples WL-92-219 and WL-92-221), where it takes the form of localized sandsized impregnations and flecks; staining becomes less well developed upward in the unit. No changes in quartz silt content were noted.

Irregular vugs and vesicles and hypocoatings begin to decrease in Unit IIIa but are both more numerous and thicker than in the overlaying sediments. As discussed above, the development of hypocoatings in the upper part of the unit is likely tied to the weak development of the Stiba soil. Worm casts are both individualized and coalesced, with the latter locally resulting in a spongy microfabric. Anthropogenic effects are also quite prominent as shown by the presence of calcined limestone fragments (e.g., Sample WL-92-214). In short, this unit is overall less "fresh looking" than the ones above it, although as a whole, Units IIIa, IIIb, and IIIc are more similar to themselves as a group than they are to the units below.

Voids in Unit IIIb produced by bioturbation ("intercast voids") are abundant, although the appearance of some fissures and vesicles were noted; many of the casts show a slightly "aged" appearance in which they are compressed or slightly coalesced as in Unit IIIa. Most interesting is that the lower part of the unit (e.g., Samples WL-92-209, WL-92-211, and WL-92-212) shows the occurrence of incipient carbonate hypocoatings, particularly affiliated with vesicles which are somewhat more abundant in this lower part of the unit. These hypocoatings appear to be associated with the Stiba soil described above. Some samples (e.g., Sample WL-92208) exhibit the presence of calcined rock fragments, again an anthropogenic manifestation.

Unit IIIc samples exhibit well-developed excremental fabrics produced by earthworms, which are also responsible for the production of numerous noncalcareous domains discussed above. Many snail shell fragments, some bone, and isolated pieces of eggshell were also observed. Evidence of heating is indicated by the occurrence of some pieces of charcoal, isolated ash rhombs, and a few aggregates of bright reddish clay.

\section{Samples from Feature Contexts}

Micromorphological examination of matrix from Burial 2 and other features addressed specific questions related to the individual features, and accordingly, the results are discussed in Chapter 26 (sample descriptions appear in Appendix 7). As an example, thin sections prepared from clods taken from Burial 2 pit fill (archived by the TxDOT excavations) included aggregates of Leanne soil that had been thrown into the pit after interment. This indicated that the burial pit was likely excavated beneath an occupation surface on the silts of Unit Isi and had been modified by Leanne pedogenesis. Thus, even a decade after the original excavation, something of the "paleogeography" of the burial scene was reconstructed.

Micromorphological examination of the burned rock features was similarly fruitful. For example, both field and archeomagnetic evidence associated with Feature 181 indicated that in situ burning did take place, although fire reddening was not marked. Micromorphological analysis of this feature (e.g., Samples WL-92-F2 and WL-92-F6, Appendix 7), showed burned snail and limestone fragments, as well as finely divided pieces of charcoal that had been broken up by earthworms. In addition, dispersed rhomb-shaped crystals of calcareous ash were observed. Similar types of inferences based on thin-section analysis were made for Feature 236 (e.g., Sample WL-92-F3), which contained burned bone, calcined limestone clasts, charcoal, and fire-reddened fine matrix (see Appendix 7). In most cases, thin-section analysis confirmed and in fact strengthened field observations and evidence of burning. In a few cases, thin sections provided stronger evidence of in situ burning than was possible to observe with the naked eye in the field.

\section{DISCUSSION OF MICROMORPHOLOGY RESULTS}

The micromorphological results from Columns 100 and 200 are summarized schematically in condensed form in Figure 29-7. The analyses of these samples revealed a number of morphological features relating to the depositional and postdepositional history of the site that were not evident with other analyses based on bulk samples. These features are discussed here following the order in Figure 29-7. The integration of these results on a broader scale is considered in the section on the geological history of the site in Chapter 6.

\section{Bone and Snail Shells}

Bone and snail shells are most abundant in the upper portion of the column, particularly in Units IIIc, IIIb (upper), and IIIa (upper). Consistently, lower amounts are found below in Unit II and the upper part of Unit I. These distributions are to a large extent a function of the relatively greater anthropogenic activity in Unit III as has been discussed above and in other chapters. Postdepositional factors might also be thought of as playing a role in preservation, although direct evidence for this is not apparent. For example, the paucity of snail shells in Unit I could be ascribed to dissolution, but this does not fit with the calcareous nature of these 


\begin{tabular}{|c|c|c|c|c|c|c|c|c|c|c|c|}
\hline Unit/Microstructure & Bone & Snails & Charcoal & $\begin{array}{l}\text { Fine Organic } \\
\text { Matter }\end{array}$ & $\begin{array}{l}\text { Heated } \\
\text { Limestone }\end{array}$ & Eggshell & \begin{tabular}{|l|} 
Carbonate \\
Void Needles
\end{tabular} & \begin{tabular}{l|} 
Carbonate \\
Hypocoatings
\end{tabular} & $\begin{array}{l}\text { Nodular } \\
\text { Carbonate-clotted }\end{array}$ & $\begin{array}{l}\text { Iron } \\
\text { Staining }\end{array}$ & $\begin{array}{l}\text { Earthworm Casts } \\
\text { (Bioturbation) }\end{array}$ \\
\hline IIIc - packing voids; vugs & $* * * * *$ & $* * * * *$ & $* * * * *$ & $* * *$ & - & * & $* * *$ & - & - & - & ****** Individual \\
\hline $\begin{array}{l}\text { IIIb upper - vugy; spongy; } \\
\text { fissures; vesicles }\end{array}$ & ***** & ***** & ****** & *** & *** & * & - & - & - & - & $\begin{array}{l}* * * * * \text { Individual }(+ \\
\text { welded) }\end{array}$ \\
\hline $\begin{array}{l}\text { IIIlb lower - vugy; spongy; } \\
\text { fissures }\end{array}$ & ** & **** & - & - & $* * * * *$ & ** & - & * & - & - & $\begin{array}{l}* * * * * \text { welded } \\
\text { (+individual) }\end{array}$ \\
\hline $\begin{array}{l}\text { IIIa upper -blocky (fissures), } \\
\text { with vugs and vesicles }\end{array}$ & *** & $* * * * *$ & - & - & $*$ & $* * *$ & - & * & - & - & $\begin{array}{l}* * * * * \text { Individual } \\
\text { (+welded) }\end{array}$ \\
\hline $\begin{array}{l}\text { IIIa lower - blocky, with vugs } \\
\text { and vesicles, locally spongy }\end{array}$ & - & - & $* * *$ & - & $* * *$ & $* * *$ & - & ** & - & - & $* * * * *$ \\
\hline $\begin{array}{l}\text { II upper - granular to blocky with } \\
\text { vesicles }\end{array}$ & $* *$ & - & ** & - & * & - & - & *** & * & - & ***** welded \\
\hline $\begin{array}{l}\text { II lower - vugs, chambers, } \\
\text { fissures, and channels }\end{array}$ & $* * *$ & - & ** & - & - & - & - & $* * *$ & ** & * & $* * * * *$ welded \\
\hline $\begin{array}{l}\text { Id - blocky (fissures), vesicles, } \\
\text { vugs; incipient spongy }\end{array}$ & $*$ & $*$ & * & $*$ & - & - & $*$ & $* * *$ & ** & $* *$ & $* * *$ \\
\hline $\begin{array}{l}\text { Isi-c - blocky (fissures), vesicles, } \\
\text { vugs; spongy; complex }\end{array}$ & * & * & * & * & - & - & - & $* * *$ & **** & $* * *$ & - \\
\hline $\begin{array}{l}\text { Icl - blocky (fissures), vesicles, } \\
\text { vugs; spongy; complex }\end{array}$ & - & - & ** & ****** & - & - & - & $* * * * *$ & $* * * * *$ & $* * * * *$ & - \\
\hline $\begin{array}{l}\text { Isi lower - blocky (fissures), } \\
\text { vesicles, vugs; complex }\end{array}$ & * & - & - & - & - & - & - & $* * * * *$ & $* * * * *$ & $* * * * *$ & - \\
\hline
\end{tabular}

\section{- absent}

* rare

** occasional

*** frequent

$* * * * *$ abundant 
lower sediments where carbonate precipitation is widespread, although local dissolution of shell and reprecipitation of carbonate could have taken place. The presence of ostracodes in the lower layers would also suggest that dissolution of snail shells is not likely; signs of chemical etching of shells is not evident in thin section either. Snail shells, however, are more fragmented below Unit II, which would suggest that they might have suffered from physical breakage either associated with alluvial deposition of these lower units or by compaction of the overlying sediments. Overall density of snail shells is inversely related to rates of deposition, another possible explanation.

Bone distribution at first glance does not seem to be related to postdepositional effects because of the presence of the prominent bison bone bed found in Unit Icl/Isi although the larger, denser bison bones are disregarded, bone quantities and conditions drop off with depth (see Chapters 33 and 35). Also, Stafford (see Chapter 25) documents significant chemical degradation of bone with depth (age).

\section{Charcoal}

Whatever charcoal is present is generally most noticeable in Units IIIc, IIIb, and IIIa, with some amounts in Unit II. Again, this is clearly related to the degree of anthropogenic activity and burned rock features in the upper part of the site, coupled with the lower rates of geogenic sedimentation during the time of accumulation of Unit III, thus enriching the relative proportion of charcoal.

Preservation is another factor. This is shown by the decrease of organic matter with depth in the profile (see Chapter 6), and, as such, is clearly related to age. Moreover, in thin section, there are virtually no pieces of charcoal larger than sand size, although larger pieces of wood stumps and hyacinth bulbs were uncovered. The likely explanation for this comminution of charcoal is continual bioturbation of the sediments, most evident by earthworms. Figure 29-1h clearly shows the effect of bioturbation on "smearing" charred material throughout the slide. Fine charcoal, well worked into the matrix can be observed at higher magnifications, thus showing the homogenizing effect of earthworms on the sediment. Earthworm activity is also responsible for the destruction or modification of in situ burned or ash layers and explains why it is so difficult to find well-preserved evidence of in situ burning, in spite of the overwhelming signs of burned features.

\section{Fine Organic Matter}

These are silt-sized traces of organic vegetal fragments that are well worked into the matrix. Part of this material is charcoal (discussed above), but much of it is vegetal detritus that has been incorporated into the sediment during deposition or soil formation. The highest proportion of this material is found in Unit Icl and attests to organic matter that accumulated within the cienega. It is also found in the Leanne soil in the upper part of Unit I and in this case would represent organic matter that accumulated with the mineral sediment but also during the time of formation of the soil itself, when biological activity would incorporate organic matter into the soil. Units IIIc and IIIb (upper) also contain high amounts of fine organic matter and again reflect the combined effects of human and biological activity, particularly in light of the development of the Wilson soil at the top of the section. What remains unclear is the lack of correspondence between soil chemical data and micromorphological observations. The former (see Chapter 6) show no differences in amounts of organic carbon in layers below Unit II, although microscopically, differences clearly exist. This may be due to the sensitivity of the analytical techniques employed or the type of organic matter analyzed (total carbon vs. oxidizable carbon). It is apparent, however, that micromorphology is qualitatively more effective in picking up subtle and significant differences in organic remains than are the chemical analyses.

\section{Burned Limestone}

Evidence of heated limestone fragments matches fairly closely the occurrence of burned rock features observed in the field, and these are predominantly in Unit III. Again, quantitative inferences from Figure 29-7 should be avoided, although the absence of heated limestone in Unit IIIc is somewhat surprising. This apparent lack could reflect the location of where the sample block was sliced during thin section manufacture. There are some heated fragments in the upper part of Unit II, again reflecting the presence of burned features in the field.

\section{Eggshell}

Eggshell fragments were observed in a number of samples. They are never abundant in absolute terms, although they are relatively more common in Unit IIIa and less so in the overlying units. They do not appear to occur below Unit III. The vertical distribution of eggshells reflects that of macroremains recovered from sieving (see Chapter 36).

\section{Carbonate Features}

Several types of postdepositional accumulations of calcium carbonate were distinguished. The least well-developed form consists of thin, silt-sized needles of calcite occurring as felt-like wads that weakly fill or coat voids. These needles are most common in the uppermost layers of Unit IIIc, in the Wilson soil, and occur in relatively greater amounts in Unit Id. They appear to represent the type and degree of carbonate accumulation acting over the last 4,000 years, corresponding to the duration of pedogenesis associated with the Wilson soil. They indicate that carbonate move- 
ment during this time has been relatively minimal and by comparison, the well-developed rhizoliths and 'popcorn nodules' that occur in Units I and II and produced the Leanne soil point to a markedly different pedogenic regime during the early Holocene than during the later Holocene.

Evidence of more-developed secondary calcite precipitation is exemplified by hypocoatings, nodular carbonate, and clotted fabrics, all of which are genetically related. Hypocoatings and associated voids are quite complex in the lower part of the section (Units Isi and Igl). There, carbonate-impregnated vesicles and voids are more common and coalesce, resulting in a large portion of the matrix being cemented. If cementation is sufficiently intense and localized, such coalesced hypocoatings take the form of nodules.

Hypocoatings become more individualized stratigraphically upward, as do associated vesicles. This is evident in the field as well, where rhizoliths (macroscopic expression of hypocoatings) begin to decline slightly in abundance in Unit Id and continue to diminish in Unit II; they tend to disappear in the upper part of Unit II. Hypocoatings generally follow this same reduction trend as the rhizoliths. However, after disappearing in the middle part of Unit IIIa they reappear stratigraphically at the base of Unit IIIb and the top of Unit IIIa, and their occurrence is clearly associated with the Stiba soil. Interestingly, secondary carbonate was not readily observed below the surface of the Stiba soil, and its appearance is brought to light only by thin section observation. Nevertheless, the development of hypocoatings in this level is unlike the secondary carbonates forming today and in the later Holocene, which as described above, are characterized by the accumulation of only calcite needles within voids of the Wilson soil. In comparison, the greater degree of carbonate mobilization during the formation of the Stiba soil is interesting in light of the time that the soil might have formed, which appears from the micromorphological evidence to have been either just after or at the close of deposition of Unit IIIa. The top of Unit IIIa is dated to between 6000 to 6500 B.P. (see Chapter 25), whereas the middle part of Unit IIIb dates to approximately 5600 в.P. Thus, the formation of the Stiba soil appears to have taken between ca. 500 to 900 years to form at the most. This contrasts with the 4,000 years represented by the formation of the Wilson soil. Thus, the greater degree of hypocoating development and carbonate precipitation associated with the Stiba soil must be tied to different extant environmental conditions. These circumstances are likely affiliated with greater water movement through soil pores, accompanied by strong evaporation to concentrate the carbonates. Since, the abundance of vesicles is broadly comparable in both Unit IIIa top/Unit IIIb base (Stiba) and Unit IIIc (Wilson), differences in permeability can be ruled out, particularly since both stratigraphic units are "open" due to extensive bioturbation. In sum, we might imagine a brief, wet episode of approximately 500 to 1,000 years at the end of the deposition of Unit IIIa and the beginning of the accumulation of Unit IIIb. It is interesting to note that although carbonate precipitation in Units I and II is clearly visible in the field, and secondary carbonate precipitation in Unit III was more subtle, the morphology and significance of the carbonates in the different units were more fully appreciated with micromorphological analysis.

Nodular carbonate (noted as "popcorn carbonate" in the field) is more confined to Units I and II, although less prominent in the latter. Overall, the formation of the nodular carbonate is tied to that of the hypocoatings, since they are commonly observed together in thin section: as mentioned above, thick carbonate hypocoatings tend to coalesce to form nodules. Moreover, nodules appear to have a complex origin, as exhibited by their commonly "clotted" appearance (Esteban and Clappa 1983). It seems that many individual nodules are apparently comprised of several nodule aggregates representing continual yet interrupted periods of precipitation: during formation, the nodules dried, cracked, and became re-cemented. This was seen in Sample WL-92-126 where the following sequence was observed (see Appendix 7). Hypocoatings were produced by impregnation of the matrix inward from the surface of the void or vesicle; this was followed by shrinking and break-up of the carbonate nodule, possibly due to drying and then reincorporation of the broken nodule into the matrix resulting in the formation of a complex aggregated nodule and clotted micritic matrix (see Figure 29-5f, g). Part of this sequence is also visible in the field, as the popcorn carbonates typically have a cracked appearance.

The greater development of nodules and carbonate precipitation in general in Units I and II is not totally clear. Their hardness and well-defined shape originally implied that they were phreatic in origin, being tied to precipitation from ground water. This was compatible with the formation of the extensive iron mottling and staining (redoximorphic features) in Units Igl, Isi, and Icl. However, the stable carbon isotope measurements (see Chapter 6) indicated that they were pedogenic in origin, associated with vadose water. As outlined above, this conclusion is supported by their association with vesicles and hypocoatings (and rhizoliths), which are clearly soil-related features. Their greater development in the lowermost units does not appear to be a function of their greater age or more-protracted period of soil development as with the Leanne soil in Unit Isi, since the radiocarbon dates point to relatively rapid rates of deposition for the deposits of Units I and II, and major nondepositional gaps of several centuries or millennia are not present (see Chapter 25). Moreover, the upper third of the Wilson-Leonard sequence, Unit III, accumulated at a much slower rate, and nodule formation is not present.

A scenario that might explain the distribution and development of the carbonate features discussed above would involve formation of the nodules in relatively moist soil conditions that would permit the growth of vegetation and formation of associated root pores along which carbonate-rich solutions could migrate. Such wet conditions would also be 
necessary for the mobilization of iron (see Chapter 6). Hence, during initial stages, hypocoatings would be formed whereby the carbonate-impregnated matrix would serve as a nucleus for further carbonate precipitation. As the profile builds through the aggradation of the deposits of Units Isi and Icl, hypocoatings would continue to form in the uppermost tens of centimeters below the extant surface. With depth, however, older sediments would have thicker and better developed hypocoatings, which with time, would coalesce eventually to form nodules. However, it is likely that even though soil moisture remained generally high during this period, the soil must have been subjected to complete drying - either seasonally or annually - in order to explain the break-up by desiccation and ultimate re-cementation of the carbonate in these units. As noted during fieldwork, the sediments resting above bedrock in Square 12 are saturated with water from throughflow after heavy rains. A greater frequency of throughflow events in the past would help maintain moisture conditions in the sediment.)

Fluctuations in moisture conditions would help explain the apparent co-precipitation of iron and carbonate, since in thin section there is no systematic microstratigraphic relationship between the carbonate and iron stains; in other words, the precipitation of carbonate does not systematically predate or postdate the mobilization of iron.

\section{Iron Staining}

As viewed in the field, iron staining is most evident and striking both in the field and in thin section in Units Isi (lower) and Unit Icl and, to a lesser extent, in Units Id and II. It is not present in the sediments from Unit III.

The movement of iron is tied to wet conditions without which iron could not have been mobilized. As discussed above, throughflow originating from surface water flowing on slopes just south (upslope) of the site is one water source. During the earlier part of the Wilson-Leonard sequence (Unit I and Unit II), extensive precipitation of carbonate as well as redoximorphic features could point to higher amounts of rainfall and runoff than existed during the later part correlated with Unit III.

\section{Bioturbation}

Bioturbation is quite active at Wilson-Leonard. In the field, the most prominent form is visible in Unit Icl and adjacent Unit Isi, where circular, centimeter-sized root holes can be observed. As discussed in Chapter 6, these features are the result of tree root disturbance, presumably by bank vegetation associated with water relatively close to the surface. The growth of these roots was responsible for the mixing of the sediment at the interface between these two units and commonly made it difficult to recognize the contact between them.
A much subtler form of bioturbation is from earthworm activity. This activity was discernible in the field, particularly for Unit III, only after careful observation with a hand lens. Micromorphological analysis also revealed differences that were not possible to visualize in the field. First, the earthworm casts in Units IIIc and IIIb (upper) tended to be fresh and individualized, resulting in a crumbly microstructure. Second, with greater depth within the Stiba soil and into Unit II, the casts were slightly more calcareous and more compacted/coalesced. As a consequence, the microstructure was less granular and more subangular blocky in nature, with fissures and planes in addition to intergranular porosity.

Furthermore, as discussed above, earthworm activity was responsible for the disruption of intact sediment, such that few in situ burning substrates were observed. The presence of numerous burned rocks in the field and in thin section, as well as calcareous ash rhombs that are dispersed throughout much of the sediments, testifies to the effectiveness of earthworms in moving soil as Darwin pointed out over century ago.

Finally, the mineralogical modifications brought about by these invertebrates must be noted. A certain portion of the Unit III sediments seems to have been originally noncalcified clayey soil material present on the slopes and calcified after passage through worm gut (see Figure 29-1e, f). These noncalcareous domains are particularly evident in Unit III, although some were observed in Unit II as well. The recognition of this aspect of the biological activity is noteworthy, since it is not normally included in processes that are responsible for enriching soils with carbonates. Consequently, it should be taken into account in evaluating certain analyses of soil carbonate, although here it was not possible to appraise quantitatively the effect of bio-calcification.

\section{Porosity/Microstructure}

Porosity and microstructure undergo changes throughout the profile and reflect numerous postdepositional changes, many of which have already been mentioned. Blocky microstructures and associated fissures, for example, are prevalent in diagenetically altered deposits, such as those from Unit I; they also occur but are less marked in the upper part of Unit II and Unit IIIa and are poorly expressed in Unit IIIb. Elsewhere, mostly in Unit IIIc, microstructure is more granular and reflective of active and relatively recent earthworm casting.

An additional aspect of the microstructure are vesicles, which as described above, are affiliated with the development of hypocoatings. Although they are present in virtually all the samples, they are more prominent in Unit I and decrease markedly up into Unit IIIa. They are particularly notable in units that have undergone pedogenesis, such as in the Stiba soil or Leanne soil, where often the vesicles are 
of sufficient density to result in a spongy fabric. Vesicles are produced by fine roots, presumably from grassy vegetation, and it would seem that these soils are affiliated with such vegetation, although trees were obviously growing in the area, as seen by burned stumps as well as the root holes in Unit Icl.

\section{CONCLUSIONS}

The micromorphological analyses of the WilsonLeonard sediments were designed to elucidate the nature of depositional and postdepositional processes of geogenic and anthropogenic origin. Whereas the chemical and physical analyses were somewhat helpful as descriptive aids, they were less successful as interpretive ones, and they furnished a limited number of meaningful insights above those gleaned from careful field observations. Phosphate results reflected the intensity and spatial differentiation of anthropogenic activities, such as burned rock features. Furthermore, although signs of pedogenesis were clearly recognized in the field for the Leanne, Stiba, and Wilson soils, typical laboratory data did little to clarify some of the types of soil forming processes.

It is hoped that the above discussion and observations help illustrate the types of nuances that can be teased from the pedo-sedimentary record. The vertical differentiation of the morphology and genesis of the carbonates, for example, was revealed by the change from massive carbonate nodules at the base (Unit Isi), to more-individualized hypocoatings associated with pores in Units II, IIIa, and IIIb; hypocoatings in the latter two units are expressions of the Stiba soil. Carbonate precipitation in all of these units was shown to differ micromorphologically from the weakly developed needle calcite that occurs in the Late Holocene Wilson soil. These differences in calcite morphology, in turn, suggest markedly distinct soil moisture conditions between those of Units I and II and those of Unit III, particularly IIIc. Such inference was not available without the help of micromorphological analysis and underscores the fact that microscopic observations can yield inferences of large-scale processes and conditions.

Finally, micromorphological analysis proved to be vital in revealing anthropogenic effects, both in relation to clarifying certain issues related to Burial 2 and to understanding better the burned rock features. Overall, micromorphological techniques proved useful at this site and hold promise for valuable results at many open sites in the region where stratigraphy is poorly preserved and features lack visible details. 


\section{REFERENCES CITED IN VOLUME IV}

Abbott, M. B., and T. W. Stafford, Jr.

1996 Radiocarbon Geochemistry of Modern and Ancient Arctic Lake Systems, Baffin Island, Canada. Quaternary Research 45:300-311.

Allen, M. J., and R. I. MacPhail

1987 Micromorphology and Magnetic Susceptibility Studies: Their Combined Role in Interpreting Archaeological Soils and Sediments. In Soil Micromorphology: Proceedings of the VIIth International Working Meeting in Soil Micromorphology, edited by N. Fedoroff L. M. Bresson, and M. A. Courty, pp. 669-676. International Association of Soil Science, Paris.

Barbetti, M., J. D. Clark, F. M. Williams, and M. A. J. Williams

1980 Paleomagnetism and the Search for Very Ancient Fireplaces in Africa. In Homo Erectus and His Time, edited by J. Jelinek, pp. 299-304. Anthropologie 18. Moravian Museum, Brno.

Barbetti, M., Y. Taborin, B. Schmider, and K. Flude

1980 Archaeomagnetic Results from Late Pleistocene Hearths at Etiolles and Marsangy, France. Archaeometry 22(1):2546.

Bellomo, R. V.

1990 The Use of Actualistic Studies of Fire on Contemporary African and North American Landscapes for Assisting in the Identification of Traces of Natural and Humanly Controlled Fire in the Archaeological Record. Unpublished $\mathrm{PhD}$. dissertation. University of Wisconsin, University Microfilms, Ann Arbor.

1993 A Methodological Approach for Identifying Archaeological Evidence of Fire Resulting from Human Activities. Journal of Archaeological Science 20:525553.

Black, S. L.

1997 Oven Cookery at the Honey Creek Site. In Hot Rock Cooking on the Greater Edwards Plateau: Four Burned Rock Midden Sites in West Central Texas, by S. L. Black, L. W. Ellis, D. G. Creel, and G. T. Goode, pp. 255-268. Studies in Archeology 22 and Archeology Studies Program, Report 2. Texas Archeological Research Laboratory, The University of Texas at Austin and Texas Department of Transportation, Austin.

Black, S. L., L. W. Ellis, D. G. Creel, and G. T. Goode

1997 Hot Rock Cooking on the Greater Edwards Plateau: Four Burned Rock Midden Sites in West Central Texas. Studies in Archeology 22 and Archeology Studies Program, Report 2. Texas Archeological Research Laboratory, The University of Texas at Austin and Texas Department of Transportation, Austin.

Black, S. L., and D. G. Creel

1997 The Central Texas Burned Rock Midden Reconsidered. In Hot Rock Cooking on the Greater Edwards Plateau: Four Burned Rock Midden Sites in West Central Texas, by S. L. Black, L. W. Ellis, D. G. Creel, and G. T. Goode, pp. 269-301. Studies in Archeology 22 and Archeology Studies Program, Report 2. Texas Archeological Research Laboratory, The University of Texas at Austin and Texas Department of Transportation, Austin.

Black, S. L., and L. W. Ellis

1997 Introduction: A Study of Four Burned Rock Midden Sites. In Hot Rock Cooking on the Greater Edwards Plateau: Four Burned Rock Midden Sites in West Central Texas, by S. L. Black, L. W. Ellis, D. G. Creel, and G. T. Goode, pp. 1-21. Studies in Archeology 22 and Archeology Studies Program, Report 2. Texas Archeological Research Laboratory, The University of Texas at Austin and Texas Department of Transportation, Austin.

Black, S. L., K. Jolly, and D. R. Potter

1993 The Higgins Experiment, Field Report. Wurzbach Project Working Papers. Texas Archeological Research Laboratory, The University of Texas at Austin.

Borradaile, G. J., and M. Brann

1997 Remagnetization Dating of Roman and Mediaeval Masonry. Journal of Archaeological Science 24:813-824.

Bradley, L.-A., and T. W. Stafford, Jr.

1995 Comparison of Manual and Automated Pretreatment Methods for AMS Radiocarbon Dating of Plant Fossils. Radiocarbon 36:399-405.

Brewer, R.

1976 Fabric and Mineral Analysis of Soils. Robert E. Krieger Publishing Co., Huntington, New York.

Buckley, V. (compiler)

1990 Burnt Offerings: International Contributions to Burnt Mound Archaeology. Wordwell-Academic, Dublin.

Bullock, P. N., A. Jongerius, and T. Tursina

1985 Handbook for Soil Thin Section Description. Waine Research Publishers, Wolverhampton.

Butler R. F.

1992 Paleomagnetism: Magnetic Domains to Geologic Terranes. Blackwell Scientific, Boston.

Clark, P., and M. Barbetti

1982 Fires, Hearths, and Palaeomagnetism. In Archaeometry: An Australasian Perspective, edited by W. Ambrose and P. Duerden, pp. 144-150. Australian National University, Canberra.

Collins, M. B.

1991 Thoughts on Future Investigation of Burned Rock Middens. In The Burned Rock Middens of Texas: An Archeological Symposium, edited by T. R. Hester, pp. 1-24. Studies in Archeology 13. Texas Archeological Research Laboratory, The University of Texas at Austin. 
1994 Late Archaic Evidence in the Project Area. In Archaic and Late Prehistoric Human Ecology in the Middle Onion Creek Valley, Hays County, Texas. Volume 1: Archeological Components, by R. A. Ricklis and M. B. Collins, pp. 101-189. Studies in Archeology 19. Texas Archeological Research Laboratory, The University of Texas at Austin.

1995 Forty Years of Archeology in Central Texas. Bulletin of the Texas Archeological Society 66:361-400.

Collins, M. B., B. Ellis, and C. Dodt-Ellis

1990 Excavations at the Camp Pearl Wheat Site (41KR243), an Early Archaic Campsite on Town Creek, Kerr County, Texas. Studies in Archeology 6. Texas Archeological Research Laboratory, The University of Texas at Austin.

Collins, M. B., W. A. Gose, and S. Shaw

1994 Preliminary Geomorphological Findings at Dust and Nearby Caves. Journal of Alabama Archaeology 40(1):3556.

Collins, M. B., J. Guy, and S. Carpenter

1991 An Evaluation of Documentation from 1981-1984 Investigations at the Wilson-Leonard Site (41WM235), Williamson County, Texas. Technical Series 21. Texas Archeological Research Laboratory, The University of Texas at Austin.

Collinson, D. W., K. M. Creer, and S. K. Runcorn (editors)

1983 Methods in Palaeomagnetism. Elsevier, Amsterdam.

Courty, M. A., P. Goldberg, and R. Macphail

1989 Soils and Micromorphology in Archaeology. Cambridge University Press, Cambridge.

Creel, D. G.

1986 A Study of Prehistoric Burned Rock Middens in West Central Texas. Unpublished Ph.D. dissertation, Department of Anthropology, The University of Arizona, Tucson.

Darwin, C.

1885 The Formation of Vegetable Mould, through the Action of Worms, with Observations on their Habits. The University of Chicago Press, Chicago.

Douglas, L. A. (editor)

1990 Soil Micromorphology. Elsevier, Amsterdam.

Dunlop, D. J.

1979 On the Use of Zijderveld Vector Diagrams in Multicomponent Paleomagnetic Samples. Physics of the Earth and Planetary Sciences Letters 20:12-24.

Edwards, C. A., and J. R. Lofty

1972 Biology of Earthworms. Chapman \& Hall, London.

Eighmy, J. L., and R. S. Sternberg (editors)

1990 Archaeomagnetic Dating. University of Arizona Press, Tucson.

Ellis, L. W.

1997 Hot Rock Technology. In Hot Rock Cooking on the Greater Edwards Plateau: Four Burned Rock Midden Sites in West
Central Texas, by S. L. Black, L. W. Ellis, D. G. Creel, and G. T. Goode, pp. 43-81. Studies in Archeology 22 and Archeology Studies Program, Report 2. Texas Archeological Research Laboratory, The University of Texas at Austin and Texas Department of Transportation, Austin.

Esteban, M., and C. F. Clappa

1983 Subaerial Exposure Environment. In Carbonate Depositional Environments, edited by P. A. Scholle, D. G. Bebout, and C. H. Moore, pp. 1-54. Memoir 33. American Association of Petroleum Geologists, Boulder.

Fedoroff, N., L. M. Bresson, and M. A. Courty (editors)

1987 Micromorphologie des Sols - Soil Micromorphology. Association Francaise pour l'Etude du Sol, France.

Fisher, R. A.

1953 Dispersion on a Sphere. Proceedings of the Royal Society of London A217:295-305.

FitzPatrick, E. A.

1993 Soil Microscopy and Micromorphology. John Wiley \& Sons, Chichester.

Gale, S. J., and P. G. Hoare

1991 Quaternary Sediments: Petrographic Methods for the Study of Unlithified Rocks. John Wiley and Sons, New York.

Goodfriend, G. A., and D. Hood

1983 Carbon Isotope Analysis of Land Snail Shells: Implications for Carbon Sources and Radiocarbon Dating. $\mathrm{Ra}$ diocarbon 25:810-830.

Goodfriend, G. A., and J. J. Stipp

1983 Limestone and the Problem of Radiocarbon Dating of Land-snail Shell Carbonate. Geology 11:575-577.

Gose, W. A.

1990 Data from Archeomagnetic Analysis. In Excavations at the Camp Pearl Wheat Site, 41KR243: An Early Archaic Campsite on Town Creek, Kerr County, Texas, by M. B. Collins, B. Ellis, and C. Dodt-Ellis, pp. 115-124. Studies in Archeology 6. Texas Archeological Research Laboratory, The University of Texas at Austin.

1994 Archeomagnetism. In Archaic and Late Prehistoric Human Ecology in the Middle Onion Creek Valley, Hays County, Texas. Volume II: Topical Studies, by R. A. Ricklis and M. B. Collins, pp. 507-537. Studies in Archeology 19. Texas Archeological Research Laboratory, The University of Texas at Austin.

Gose, W. A., K. S. Collins, and M. B. Collins

1994 Paleomagnetic Studies from the Moore-Hancock Farmstead, Austin, Texas. Journal of Field Archaeology 21(1):125-129.

Gose, W. A., M. B. Collins, P. R. Takac, and J. Guy-Motriuk

1994 Paleomagnetic Studies of Prehistoric Burned Rock Features (abstract). EOS (Transactions, American Geophysical Union) 75(supplement):128. 
Hester, T. R. (editor)

1991 The Burned Rock Middens of Texas: An Archeological Symposium. Studies in Archeology 13. Texas Archeological Research Laboratory, The University of Texas at Austin.

Hodder, M. A., and L. H. Barfield (editors)

1991 Burnt Mounds and Hot Stone Technology: Papers of the Second International Burnt Mound Conference. Sandwell Metropolitan Borough Council, West Midlands, U.K.

Holliday, V. T.

1992 Soil Formation, Time, and Archaeology. In Soils in Archaeology, edited by V. T. Holliday, pp. 101-117. Smithsonian Institution Press, Washington, D.C.

Howard, M. H.

1991 Burned Rock Midden Excavations, Hearths and Botanical Remains. In The Burned Rock Middens of Texas: An Archeological Symposium, edited by T. R. Hester, pp. 45-69. Studies in Archeology 13. Texas Archeological Research Laboratory, The University of Texas at Austin.

Jongerius, A., and G. K. Rutherford

1979 Glossary of Soil Micromorphology. Centre for Agricultural Publishing and Documentation, Wageningen.

Kappelman, J.

1993 The Attraction of Paleomagnetism. Evolutionary Anthropology 2(3):89-99.

Kelley, J. C., and T. N. Campbell

1942 What Are the Burnt Rock Mounds of Texas? American Antiquity 7:319-322.

King, J. W., and J. E. T. Channell

1991 Sedimentary Magnetism, Environmental Magnetism, and Magnetostratigraphy. Reviews of Geophysics Supplement 29:358-370.

Kirschvink, J. L.

1980 The Least-squares Line and Plane and the Analysis of Paleomagnetic Data. Geophysical Journal of the Royal Astronomical Society 62:699-718.

Le Borgne, E.

1955 Susceptibilitié Magnétique Anormale du Sol Superficiel. Annales de Geophysique 11:399-419.

1960 Influence du Feu sur les Propriétés Magnétiques du Sol et sur celles du Schiste et du Granite. Annales de Geophysique 16:159-195.

1964 The Relationship Between the Magnetic Susceptibility and the History of Soils. In Problems in Palaeoclimatology, edited by A. E. M. Nairn, pp. 666669. Interscience, London.

Long, A., and B. Rippeteau

1974 Testing Contemporaneity and Averaging Radiocarbon Dates. American Antiquity 39:205-215.
Longworth, G., and M. S. Tite

1977 Mossbauer and Magnetic Susceptibility Studies of Iron Oxides in Soils from Archaeological Sites. Archaeometry 19(1):3-14.

Lowrie, W., and F. Heller

1982 Magnetic Properties of Marine Limestones. Reviews of Geophysics and Space Physics 20(2):171-192.

Maher, B. A., and R. M. Taylor

1989 Origin of Soil Magnetite. Nature 340:160.

March, R. J. (organizer)

1996 The Study of Human Behavior in Relation to Fire in Archaeology: New Data and Methodologies for Understanding Prehistoric Fire Structures (Colloquium IX). XIII Congress of the International Union of Prehistoric and Protohistoric Sciences, Forli, Italy.

McClean, R. G., and W. F. Kean

1993 Contributions of Wood Ash Magnetism to Archaeomagnetic Properties of Fire Pits and Hearths. Earth and Planetary Science Letters 119:387-394.

Merrill, R. T., and M. W. McElhinny

1983 The Earth's Magnetic Field. Academic Press, London.

Mueggenborg, H. E.

1991 Excavations at the Blue Hole Site, Uvalde County, Texas, 1990. Bulletin of the Texas Archeological Society 62:174.

Mullins, C. E.

1977 Magnetic Susceptibility of the Soil and Its Significance in Soil Science3/4A Review. Journal of Soil Science 28(2):223246.

Murphy, C. P.

1986 Thin Section Preparation of Soils and Sediments. AB Academic Publishers, Berkhamsted.

Neck, R. W.

1988 Analysis of the Paleomolluscan Assemblages of the Wilson-Leonard Site (41WM235). Ms. on file at the Texas Archeological Research Laboratory, The University of Texas at Austin.

Olive, M., and Y. Taborin (editors)

1989 Nature et Fonction des Foyers Prehistoriques: Actes du Colloque de Nemours 1987. Memoires du Musee de Prehistoire d'lle de France 2, Paris.

Perles, C.

1977 Prehistoire du Feu. Masson, New York.

Prewitt, E. R.

1974 Archeological Investigations at the Loeve-Fox Site, Williamson County, Texas. Research Report 49. Texas Archeological Survey, The University of Texas at Austin.

1981 Cultural Chronology in Central Texas. Bulletin of the Texas Archeological Society 52: 65-89. 
1991 Burned Rock Middens: A Summary of Previous Investigations and Interpretations. In The Burned Rock Middens of Texas: An Archeological Symposium, edited by T. R. Hester, pp. 25-32. Studies in Archeology 13. Texas Archeological Research Laboratory, The University of Texas at Austin.

Pullaiah, G. E., E. Irving, K. L. Buchan, and D. J. Dunlop

1975 Magnetization Changes Caused by Burial and Uplift. Earth and Planetary Science Letters 28:122-143.

Ramseyer, D.

1991 Bronze and Iron Age Cooking Ovens in Switzerland. In Burnt Mounds and Hot Stone Technology, edited by M. A. Hodder, and L. H. Barfield, pp. 71-91. Sandwell, West Midlands, United Kingdom.

Ricklis, R. A., and M. B. Collins

1994 Archaic and Late Prehistoric Human Ecology in the Middle Onion Creek Valley, Hays County, Texas, Vol. 1, Archeological Components. Studies in Archeology 19. Texas Archeological Research Laboratory, The University of Texas at Austin.

Schmidt, V. A.

1980 Appendix I: Archaeomagnetic Results. In Archeological Investigations at the Graham Site, 34At-90: 1975,1977 , and 1978, edited by C. D. Cheek, S. Bearden, W. Young, and C. B. Bousman, pp. 379-393. Research Report 23. Archeological Research Associates, Tulsa.

Schwertmann, U., and R. M. Taylor

1977 Iron Oxides. In Minerals in Soil Environments, edited by J. B. D. Weed, and S. B. Weed, pp. 145-180. Soil Science Society of America, Madison.

Singer, M. J., and P. Fine

1989 Pedogenic Factors Affecting Magnetic Susceptibility of Northern California Soils. Journal of the Soil Science Society of America 53:1119-1127.

Slota, P. J., Jr., A. J. T. Jull, T. W. Linick, and L. J. Toolin

1987 Preparation of Small Samples for ${ }^{14} \mathrm{C}$ Accelerator Targets by Catalytic Reduction of CO. Radiocarbon 29:303-306.

Smith, L. L.

1990 Excavations at the Smith Site, Uvalde County, Texas. Paper presented at the Sixty-first Annual Meeting of the Texas Archeological Society, Dallas.

Sorrow, W. M.

1969 Archaeological Investigations at the John Ischy Site: A Burnt Rock Midden in Williamson County, Texas. Papers of the Texas Archeological Salvage Project No. 18. Texas Archeological Salvage Project, The University of Texas at Austin.

Sorrow, W. M., H. J. Shafer, and R. E. Ross

1967. Excavations at Stillhouse Hollow Reservoir. Papers of the Texas Archeological Salvage Project, No. 11. The University of Texas at Austin.
Stafford, T. W., Jr.

1990 Late Pleistocene Megafauna Extinctions and the Clovis Culture: Absolute Ages Based on Accelerator ${ }^{14} \mathrm{C}$ Dating of Skeletal Remains. In Megafauna and Man: Discovery of America's Heartland, Volume 1, edited by L. Agenbroad, J. I. Mead, and L. Nelson, pp. 118-122. Scientific Papers. The Mammoth Site of Hot Springs, South Dakota, Inc., Hot Springs.

Stafford, T. W., P.E. Hare, L. Currie, A. J. T. Jull, and D. Donahue 1991 Accelerator Radiocarbon Dating at the Molecular Level. Journal of Archeological Science 18:35-72.

Stafford, T. W., Jr., A. J. T. Jull, K. Brendel, R. C. Duhamel, and D. Donahue

1987 Study of Bone Radiocarbon Dating Accuracy at the University of Arizona NSF Accelerator Facility for Radio Isotope Analysis. Radiocarbon 29:24-44.

Takac, P. R.

1997 Archaeomagnetic Analysis of the Feature 22 Rocks. In Hot Rock Cooking on the Edwards Plateau: Four Burned Rock Midden Sites in West Central Texas, edited by S. L. Black, L. W. Ellis, D. G. Creel, and G. T. Goode, pp. 755762. Studies in Archeology 22. Texas Archeological Research Laboratory, The University of Texas at Austin.

1998 Archeomagnetic Investigations of Burned Rocks. In Investigation and Experimentation at the Higgins Site (41BX184), Volume 1, by S. L. Black, K. Jolly, C. D. Frederick, J. R. Lucas, J. W. Karbula, P. R. Takac, and D. R. Potter, pp. 119-156. Studies in Archeology 27. Texas Archeological Research Laboratory, The University of Texas at Austin.

n.d. New Directions in Archeomagnetism: The Use and Modification of Paleomagnetism for Interpreting the Context, Formation, and Preservation of Burned Rock Features in Central Texas Archaeological Sites. Manuscript on file, Department of Anthropology, Southern Methodist University, Dallas.

Takac, P. R., and M. B. Collins

1995 New Directions in Archaeomagnetism: Analyzing the Context of Burned Rock Features (abstract). Geological Society of America, Abstracts with Programs 27(6):A-301.

Takac, P. R., M. B. Collins, and W. A. Gose

1993 The Archeomagnetic Investigation of Burned Limestone Rocks: An Interpretive Technique (abstract). Abstracts of the 58th Annual Meeting, Society for American Archaeology, Washington, D.C.

Takac, P. R., and W. A. Gose

1994 Archeomagnetic Results at the Wilson-Leonard Site. Paper presented at the Fifty-second Annual Meeting of the Plains Anthropological Society, Lubbock, Texas.

1997 Paleomagnetism of Archeologically and Experimentally Produced Burned Rock as an Indicator of Feature Function and Integrity. Paper presented at the Sixty-second Annual Meeting of the Society for American Archeology, Nashville. 
Tarling, D. H.

1983 Palaeomagnetism: Principles and Applications in Geology, Geophysics, and Archaeology. Chapman and Hall, New York.

Taylor, R. E., C. V. Haynes, Jr., and M. Stuiver

1996 Clovis and Folsom Age Estimates: Stratigraphic Context and Radiocarbon Calibration. Antiquity 70:515-525.

Thompson, R.

1986 Modeling Magnetization Data Using SIMPLEX. Physics of the Earth and Planetary Interiors 42:113-127.

Thompson, R., and F. Oldfield

1986 Environmental Magnetism. Allen and Unwin, London.

Thoms, A. V.

1989 The Northern Roots of Hunter-Gatherer Intensification: Camas and the Pacific Northwest. Unpublished Ph.D. dissertation, Department of Anthropology, Washington State University, Pullman.

Thoms, A. V., J. Leach, and M. B. Collins (organizers)

1997 Symposium: Learning from Once-Hot Rocks (Parts I \& II): Middle-range Archeological Research Strategies for Burned Rock Studies. Sixty-second Annual Meeting of the Society for American Archeology, Nashville.

Tite, M. S., and C. Mullins

1971 Enhancement of the Magnetic Susceptibility of Soils in Archaeological Sites. Archaeometry 13(2):209-219.

Vodyanitskiy, Yu. N.

1982 Formation of Ferromagnetics in Sodpodzolic Soil. Soviet Soil Science 14:89-100.
Vogel, J. C., A. M. Fuls, E. Visser, and B. Becker

1993 Pretoria Calibration Curve for Short-lived Samples, 19303350 B.C. Radiocarbon 735:73-85.

Wandsnider, L.

1997 The Roasted and the Boiled: Food Composition and Heat Treatment with Special Emphasis on Pit Hearth Cooking. Journal of Anthropological Archaeology 16:148.

Wattez, J., and M. A. Courty

1987 Morphology of Ash of Some Plant Materials. In Micromorphologie des Sols - Soil Micromorphology, edited by N. Fedoroff, L. M. Bresson, and M. A. Courty, pp. 677-683. Ass'n Francaise pour l'Etude du Sol, Plaisir.

Weir, F. A.

1976 The Central Texas Archaic. Unpublished Ph.D. dissertation, Department of Anthropology, Washington State University, Pullman.

1979 Greenhaw: An Archaic Site in Central Texas. Bulletin of the Texas Archeological Society 50:5-67.

Winkler, A. J.

1990 Small Mammals from a Holocene Sequence in Central Texas and Their Paleoenvironmental Implications. The Southwestern Naturalist 35(3):199-205.

Wolfman, D.

1984 Geomagnetic Dating Methods in Archaeology. In Advances in Archaeological Method and Theory, Volume 7, edited by M. B. Schiffer, pp. 363-458. Academic Press, New York. 
APPENDIX 6: ARCHEOMAGNETIC DATA

by Paul R. Takac 
The individual magnetic components and vector rotation reconstructions for each analyzed sample are listed in Tables A6-1 and A6-2. Table Appendix 6-1 includes those samples from Burned Rock Midden 1 (Square 100), from nonfeature contexts, and from all features other than 231, 181, and 245 (which are instead given in Table A6-2, organized by square and level). Feature number assignments are not presented in Table A6-2 but are instead listed in the Feature 231 Composite tables provided in Chapter 27. Tables A6-1 and A6-2 are organized into two halves: the left half labeled "Identified Vectors" and the right half termed "Reconstructed Vector Rotations."

The "Identified Vector" columns list the individual components of magnetization identified for each sample. The first two columns give the declinations and inclinations of the reconstructed vectors while the third gives the corresponding statistical confidence of that reconstruction. The temperature or coercivity range of each vector is then given in the fourth column. Measurements omitted in the calculation of vectors are noted in parentheses. Each range is preceded by a letter (B, F, or S), which serves to identify the demagnetization technique used for that particular sample. The B or "Best-fitting vector" components were defined using Principal Component Analysis; F by Fisher statistics; and $\mathrm{S}$ by Straight-Line calculations.

The letter preceding the range also signals how to interpret the statistic given in the third column. The B components are defined by a mean angular deviation or MAD value (given to the first decimal place) where the smaller the MAD value, the better-defined the vector. Components defined by Fisher statistics are preceded by a $\mathrm{k}$ (or precision parameter) value. For these components, the higher the 6 value, the more well-defined the vector. Those vectors preceded by $\mathrm{S}$ are always preceded by a zero (due to the invariability of straight line calculations). S vectors were defined only after other statistical means failed to identify a vector that nonetheless could be clearly seen on the sample's AsZijderveld projection.

When it was determined that a sample probably contained another component that could not be isolated, a modifier was included. For example, if the listed vector appeared to approximate the true vector, then the prefix " " was used to mean "approximately." If, however, the direction of the vector could not be approximated (although it was clear that another component remained) then signs indicating "greater than" ( $>$ ) or "less than" $(<)$ were used. Finally, where the endpoint of a component is listed as Origin, the interpretation was that further demagnetization would result in only a loss of remanence intensity (rather than a change in direction) and that therefore this component may, with some confidence, be considered the highest temperature or coercivity component.
The second half of Tables A6-1 and A6-2 are grouped under the heading "Vector Rotation Reconstructions." Again, these values are the calculated shortest-distance rotations necessary to move a vector from the Geocentric Axial Dipole (GAD) direction to that measured direction. These are, of course, higher-level abstractions or interpretations of the "Identified Vector" data. Remember also that each rotation depends on any prior rotations. That is, those rotations listed at higher thresholds for any particular sample are dependent on both the identification and rotation of any lower temperature components. All rotation reconstructions follow the left-hand rule and horizontality conventions. For convenience, the directional equivalent of each rotation is also listed. These directions were derived by subdividing the azimuthal directions into eight equivalent $45^{\circ}$ subdivisions (north, northeast, east, etc.). When a calculated strike fell within $2.5^{\circ}$ of a boundary between two such directional subdivisions, the directions were conjoined (for example, "northnorthwest"). The magnitude of rotation is listed in the third column. The Vector Rotation direction and magnitude are always listed first by the smaller magnitude rotation (i.e., less than $180^{\circ}$ ), but where it seems likely that the rotation was in the opposite direction (i.e., antipolar to the direction listed) both rotations are listed (and are separated by "or, opposite"). In such cases, the strikes differ precisely by $180^{\circ}$ (i.e., antipolar strikes equal opposite direction rotations), and the two magnitudes sum to $360^{\circ}$ (one complete rotation). Where the magnetic components are uncertain or approximated, the reconstructed rotations are also approximated.

The last column is the temperature or coercivity "threshold" (range) within which the rotation was recognized. "Postcooling" displacements are those that occurred after the rock was completely cooled. Again, patterning in Vector Rotation Reconstructions were used to evaluate hypotheses regarding the cooling locations of individual rocks and the prior configuration of features as well as to assess the severity of disturbance as a rock cooled. In other words, they were the raw data used to generate the interpretive tripartite codes presented in Chapter 27. Once again, it should be emphasized that all of the data contained in Tables A6-1 and A6-2 are higher-order interpretations of the basic data on file at TARL.

Finally, the other tables in this appendix supplement the data presented in Chapter 27. Table A6-3 lists the cooling context determinations of those analyzed samples that were not illustrated or discussed in Chapter 27, while Tables A6-4 and A6-5 list the provenience (by square and level) of all samples collected but not subsequently analyzed. These unanalyzed samples have been curated for future research. 
TABLE A6-1

Individual Feature, Burned Rock Midden 1 (Square 100) and Nonfeature Samples

\begin{tabular}{|c|c|c|c|c|c|c|c|c|}
\hline & & Ident & fied Vectors & & & Reconstru & acted Vector Ro & tations \\
\hline $\begin{array}{l}\text { Sample } \\
\text { (AM-) }\end{array}$ & Declination & Inclination & MAD or $\kappa$ & Range & Strike & $\begin{array}{l}\text { Direction of } \\
\text { rotation }\end{array}$ & $\begin{array}{l}\text { Magnitude of } \\
\text { rotation }\end{array}$ & Threshold \\
\hline Feature 184 & & & & & & & & \\
\hline 1028 & 338 & 48 & 1230 & F NRM-AF400 & 173 & E & 19 & postcooling \\
\hline 1029 & 357 & 58 & 3.8 & B AF100-AF200 & 104 & $\mathrm{~N}$ & 8 & $<100 \mathrm{Oe}$ \\
\hline & 135 & 39 & 3.9 & B AF300-AF400 & 63 & NW & 82 & $200-300 \mathrm{Oe}$ \\
\hline Feature 201 & & & & & & & & \\
\hline Unit $14, \mathrm{~L}$ & vel 5 & & & & & & & \\
\hline 39 & 332 & 52 & 5.6 & B TD100-TD250 & 161 & $\mathrm{E}$ & 23 & postcooling \\
\hline 40 & 4 & -54 & 0.8 & B TD350-TD550 & 230 & SE & 123 & $<350^{\circ} \mathrm{C}$ \\
\hline & 74 & -10 & 4.1 & B TD550-TD600 & 333 & SW & 87 & $550^{\circ} \mathrm{C}$ \\
\hline Unit $18, \mathrm{~L}$ & evel 8 & & & & & & & \\
\hline 8 & 31 & 52 & 1 & B TD100-TD250 & 20 & W-NW & 25 & postcooling \\
\hline Unit $20, \mathrm{~L}$ & vel 8 & & & & & & & \\
\hline 11 & 28 & 55 & 2.6 & B TD150-TD300 & 26 & NW & 20 & $<150^{\circ} \mathrm{C}$ \\
\hline & 73 & 55 & 2.4 & B TD300-TD550 & 52 & NW & 30 & $300^{\circ} \mathrm{C}$ \\
\hline 12 & 324 & 44 & 895 & F NRM-AF400 & 171 & E & 32 & postcooling \\
\hline 13 & 57 & 21 & 6.3 & B TD100-TD200 & 10 & W & 60 & postcooling \\
\hline 14 & 359 & 12 & 1.4 & B TD450-TD550 & 268 & S & 37 & $<450^{\circ} \mathrm{C}$ \\
\hline Unit $21, \mathrm{~L}$ & vel 6 & & & & & & & \\
\hline 18 & 15 & 65 & 4.4 & B TD100-TD200 & 64 & NW & 18 & postcooling \\
\hline & 359 & 23 & 2.2 & B TD200-TD500 & 262 & $S$ & 45 & $200^{\circ} \mathrm{C}$ \\
\hline & 346 & 6 & 1.1 & B TD550-TD650 & 217 & SE & 23 & $500-550^{\circ} \mathrm{C}$ \\
\hline 19 & 29 & 51 & 5.5 & B TD100-TD200 & 16 & W & 22 & postcooling \\
\hline & 20 & 19 & 1.8 & B TD250-TD350 & 306 & SW & 36 & $200-250^{\circ} \mathrm{C}$ \\
\hline & 45 & 11 & 2.2 & B TD350-TD450 & 32 & NW & 29 & $350^{\circ} \mathrm{C}$ \\
\hline & 302 & 26 & 3.9 & B TD450-TD550 & 162 & E & 143 & $450^{\circ} \mathrm{C}$ \\
\hline & & & & & or, opposite & & & \\
\hline & & & & & 342 & W & 217 & \\
\hline Unit $21, \mathrm{~L}$ & vel 7 & & & & & & & \\
\hline 32 & 8 & 62 & 3.2 & B NRM-TD200 & 73 & $\mathrm{~N}$ & 13 & postcooling \\
\hline & 315 & -44 & 3.6 & B TD400-TD500 & 327 & SW & 168 & $200<\mathrm{t}<400^{\circ} \mathrm{C}$ \\
\hline & 263 & -49 & 1.8 & B TD550-TD600 & or, opposite & & & \\
\hline & & & & & 147 & NE & 192 & \\
\hline & & & & & 10 & $\mathrm{~W}$ & 48 & $500-550^{\circ} \mathrm{C}$ \\
\hline 35 & 25 & 59 & 6342 & F NRM-TD500 & 36 & NW & 19 & postcooling \\
\hline Unit $22, \mathrm{~L}$ & vel 7 & & & & & & & \\
\hline 38 & 330 & 49 & 2.9 & B TD100-TD600 & 167 & $\mathrm{E}$ & 25 & postcooling \\
\hline Feature 203 & & & & & & & & \\
\hline 30 & 15 & 41 & 5.2 & B NRM-TD150 & W-SW & 17 & postcooling & \\
\hline & 196 & 38 & 1.5 & B TD200-TD450 & $\mathrm{N}$ & 103 & $150-200^{\circ} \mathrm{C}$ & \\
\hline & 60 & 26 & 3.1 & B TD550-TD600 & W-NW & 161 & $450-550^{\circ} \mathrm{C}$ & \\
\hline & & & & & E-SE & 199 & & \\
\hline Feature 204 & & & & & & & & \\
\hline 60 & 354 & 39 & 1175 & F NRM-TD550 & 237 & SE & 14 & postcooling \\
\hline 61 & 350 & 59 & 1.2 & B TD150-TD350 & 116 & NE & 12 & $<150^{\circ} \mathrm{C}$ \\
\hline & 125 & -34 & 2.6 & B TD500-TD575 & 54 & NW & 85 & $350<\mathrm{t}<500^{\circ} \mathrm{C}$ \\
\hline 63 & 25 & 44 & 7.3 & B NRM-TD200 & 358 & W & 24 & postcooling \\
\hline & 317 & 71 & 5.9 & B TD200-TD350 & 144 & NE & 50 & $200^{\circ} \mathrm{C}$ \\
\hline & 149 & 53 & 0 & S TD350-TD400 & 62 & NW & 63 & $350^{\circ} \mathrm{C}$ \\
\hline & 206 & 63 & 0.8 & B TD450-TD550 & 190 & E & 40 & $400-450^{\circ} \mathrm{C}$ \\
\hline 64 & 0 & 44 & 2.7 & B TD100-TD400 & & & $<5$ & postcooling \\
\hline
\end{tabular}


Table A6-1, continued

\begin{tabular}{|c|c|c|c|c|c|c|c|c|}
\hline \multicolumn{5}{|c|}{ Identified Vectors } & \multicolumn{4}{|c|}{ Reconstructed Vector Rotations } \\
\hline $\begin{array}{l}\text { Sample } \\
\text { (AM-) }\end{array}$ & Declination & Inclination & MAD or $\kappa$ & Range & Strike & $\begin{array}{l}\text { Direction of } \\
\text { rotation }\end{array}$ & $\begin{array}{l}\text { Magnitude of } \\
\text { rotation }\end{array}$ & Threshold \\
\hline & 133 & 64 & 1.3 & B TD500-TD575 & 74 & $\mathrm{~N}$ & 68 & $400-500^{\circ} \mathrm{C}$ \\
\hline \multicolumn{9}{|l|}{ Feature 205} \\
\hline \multirow[t]{5}{*}{47} & 3 & 55 & 2.2 & B TD150-TD300 & & & $<6$ & $<150^{\circ} \mathrm{C}$ \\
\hline & 264 & -70 & 2.5 & B TD350-TD450 & 302 & SW & 162 & $300-350^{\circ} \mathrm{C}$ \\
\hline & 306 & -68 & 2.1 & B TD450-TD575 & or, opposite & & & \\
\hline & & & & & 122 & NE & 198 & \\
\hline & & & & & 146 & $\mathrm{NE}$ & 18 & $450^{\circ} \mathrm{C}$ \\
\hline \multirow[t]{3}{*}{48} & 24 & 67 & 6.3 & B TD100-TD200 & 62 & NW & 22 & postcooling \\
\hline & 85 & 8 & 4.6 & B TD250-TD350 & 31 & NW & 114 & $200-250^{\circ} \mathrm{C}$ \\
\hline & 351 & -8 & 3 & B TD400-TD500 & 59 & NW & 88 & $350-400^{\circ} \mathrm{C}$ \\
\hline \multicolumn{9}{|l|}{ Feature 206} \\
\hline \multirow[t]{2}{*}{51} & 350 & 32 & 4.9 & B NRM-TD300 (MINUS 200) & 231 & SE & 22 & postcooling \\
\hline & 138 & 68 & 0.9 & B TD500-TD650 & 69 & N-NW & 81 & $300<\mathrm{t}<500^{\circ} \mathrm{C}$ \\
\hline \multirow[t]{5}{*}{53} & 329 & 59 & 2.5 & B TD100-TD350 & 143 & NE & 24 & postcooling \\
\hline & 51 & -25 & 1.6 & B TD450-TD550 & 22 & W-NW & 176 & $350-450^{\circ} \mathrm{C}$ \\
\hline & 40 & -30 & 1 & B TD550-TD650 & or, opposite & & & \\
\hline & & & & & 202 & E-SE & 184 & \\
\hline & & & & & 22 & W-NW & 12 & $550^{\circ} \mathrm{C}$ \\
\hline \multicolumn{9}{|l|}{ Feature 207} \\
\hline \multirow[t]{2}{*}{54} & 13 & 63 & 4.6 & B TD100-TD200 & 63 & NW & 16 & postcooling \\
\hline & 18 & 38 & 1.5 & B TD450-TD650 & 310 & SW & 28 & $200<\mathrm{t}<450^{\circ} \mathrm{C}$ \\
\hline 56 & 9 & -36 & 1746 & F NRM-AF600 & 310 & SW & 97 & postcooling \\
\hline \multirow[t]{3}{*}{58} & 355 & 58 & 4 & B NRM-TD200 & 112 & $\mathrm{~N}-\mathrm{NE}$ & 9 & postcooling \\
\hline & 318 & 39 & 4 & B TD200-TD400 & 183 & $\mathrm{E}$ & 42 & $200^{\circ} \mathrm{C}$ \\
\hline & 4 & 53 & 1.6 & B TD400-TD575 & 355 & W & 48 & $400^{\circ} \mathrm{C}$ \\
\hline \multicolumn{9}{|l|}{ Feature 211} \\
\hline \multirow[t]{3}{*}{77} & 2 & 61 & 2.7 & B NRM-TD150 & 84 & $\mathrm{~N}$ & 11 & postcooling \\
\hline & 275 & -9 & 0.9 & B TD250-TD350 & 148 & NE & 131 & $150-250^{\circ} \mathrm{C}$ \\
\hline & 221 & 28 & 2.9 & B TD450-TD575 & 19 & $\mathrm{~W}$ & 88 & $350-450^{\circ} \mathrm{C}$ \\
\hline \multirow[t]{2}{*}{78} & 329 & 70 & 4.6 & B TD100-TD300 & 116 & NE & 26 & postcooling \\
\hline & 356 & -42 & 4.7 & B TD500-TD575 & 312 & SW & 138 & $300<\mathrm{t}<500^{\circ} \mathrm{C}$ \\
\hline \multicolumn{9}{|l|}{ Feature 212} \\
\hline \multirow[t]{3}{*}{93} & 7 & 77 & 6.9 & B NRM-TD400 & 86 & $\mathrm{~N}$ & 28 & postcooling \\
\hline & 340 & 21 & 2.9 & B TD400-500 & 220 & SE & 70 & $400^{\circ} \mathrm{C}$ \\
\hline & 354 & 22 & 1.7 & B TD550-650 & 322 & SW & 16 & $500-550^{\circ} \mathrm{C}$ \\
\hline \multirow[t]{2}{*}{94} & 356 & 69 & 3.1 & B NRM-TD150 & 94 & $\mathrm{~N}$ & 20 & postcooling \\
\hline & 280 & 66 & 1.8 & B TD200-TD575 & 144 & $\mathrm{NE}$ & 33 & $150-200^{\circ} \mathrm{C}$ \\
\hline \multicolumn{9}{|l|}{$\overline{\text { Feature } 214}$} \\
\hline \multirow[t]{5}{*}{83} & 356 & 52 & 0 & S NRM-TD150 & & & $<5$ & postcooling \\
\hline & 59 & 25 & 3.9 & B TD200-TD500 & 10 & W & 69 & $150-200^{\circ} \mathrm{C}$ \\
\hline & 233 & 8 & 0 & S TD500-TD550 & 110 & N-NE & 162 & $500 \mathrm{C}$ \\
\hline & & & & & or, opposite & & & \\
\hline & & & & & 290 & S-SW & 198 & \\
\hline 84 & 350 & 31 & 2.3 & B NRM-TD200 (MINUS 100) & 231 & SE & 22 & postcooling \\
\hline & 339 & -1 & 0.1 & B TD200-TD300 & 216 & SE & 38 & $200^{\circ} \mathrm{C}$ \\
\hline 85 & 336 & 53 & 81 & F NRM-TD500 & 156 & E-NE & 20 & postcooling \\
\hline Feature 217 & & & & & & & & \\
\hline 97 & 11 & 29 & 87 & F TD150-TD500 & 310 & SW & 25 & $<150^{\circ} \mathrm{C}$ \\
\hline 117 & 0 & 40 & 5.6 & B NRM-TD200 & 270 & $\mathrm{~S}$ & 10 & postcooling \\
\hline & 61 & -43 & 4.3 & B TD250-TD450 & 32 & NW & 175 & $200-250^{\circ} \mathrm{C}$ \\
\hline
\end{tabular}


Table A6-1, continued

\begin{tabular}{|c|c|c|c|c|c|c|c|c|}
\hline \multicolumn{5}{|c|}{ Identified Vectors } & \multicolumn{4}{|c|}{ Reconstructed Vector Rotations } \\
\hline $\begin{array}{l}\text { Sample } \\
\text { (AM-) }\end{array}$ & Declination & Inclination & MAD or $\kappa$ & Range & Strike & $\begin{array}{l}\text { Direction of } \\
\text { rotation }\end{array}$ & $\begin{array}{l}\text { Magnitude of } \\
\text { rotation }\end{array}$ & Threshold \\
\hline & 184 & -52 & 4.5 & B TD450-TD550 & or, opposite & & & \\
\hline & 257 & -20 & 4 & B TD550-TD650 & 212 & SE & 185 & \\
\hline & & & & & 120 & NE & 89 & $450^{\circ} \mathrm{C}$ \\
\hline & & & & & 50 & NW & 69 & $550^{\circ} \mathrm{C}$ \\
\hline 118 & 325 & 66 & 1880 & F NRM-TD600 & 126 & NE & 26 & postcooling \\
\hline \multirow[t]{3}{*}{119} & 102 & -47 & 1 & B AF300-AF600 & 50 & NW & 176 & $<300^{\circ} \mathrm{C}$ \\
\hline & & & & & or, opposite & & & \\
\hline & & & & & 230 & SE & 184 & \\
\hline \multirow[t]{3}{*}{120} & 357 & 62 & 0 & S NRM-TD150 & 96 & $\mathrm{~N}$ & 13 & postcooling \\
\hline & 99 & -26 & 2.2 & B TD250-TD450 & 45 & NW & 150 & $150-250^{\circ} \mathrm{C}$ \\
\hline & 272 & -86 & 0.203 & S TD500-TD550 & 83 & $\mathrm{~N}$ & 68 & $450-500^{\circ} \mathrm{C}$ \\
\hline \multirow[t]{2}{*}{121} & 319 & 30 & 4.7 & B TD100-TD200 & 181 & $\mathrm{E}$ & 49 & postcooling \\
\hline & 315 & -9 & 1.2 & B TD200-TD650 & 185 & E & 52 & $200^{\circ} \mathrm{C}$ \\
\hline \multirow[t]{3}{*}{122} & 355 & 67 & 9.7 & B NRM-TD150 & 98 & $\mathrm{~N}$ & 18 & postcooling \\
\hline & 330 & -62 & 2.1 & B TD300-TD400 & 297 & SW & 144 & $150<\mathrm{t}<300^{\circ} \mathrm{C}$ \\
\hline & 314 & -11 & 2.9 & B TD450-TD550 & 168 & $\mathrm{E}$ & 69 & $400-450^{\circ} \mathrm{C}$ \\
\hline \multirow[t]{3}{*}{123} & 357 & 46 & 4.6 & B NRM-TD200 & & & $<5$ & postcooling \\
\hline & 228 & 17 & 5.2 & B TD250-TD450 & 117 & NE & 112 & $200-250^{\circ} \mathrm{C}$ \\
\hline & 206 & 9 & 0.8 & B TD450-TD550 & 40 & NW & 26 & $450^{\circ} \mathrm{C}$ \\
\hline 124 & 203 & 51 & 653 & F NRM-AF400 & 100 & $\mathrm{~N}$ & 79 & postcooling \\
\hline \multirow[t]{3}{*}{125} & 327 & 45 & 3.2 & B NRM-TD200 & 173 & E & 30 & postcooling \\
\hline & 168 & 51 & 3.9 & B TD350-TD450 & 67 & N-NW & 86 & $200<\mathrm{t}<350^{\circ} \mathrm{C}$ \\
\hline & 108 & 43 & 1.8 & B TD450-TD650 & 327 & SW & 25 & $450^{\circ} \mathrm{C}$ \\
\hline \multicolumn{9}{|l|}{ Feature 218} \\
\hline \multirow[t]{5}{*}{98} & 29 & 51 & 1.7 & B TD100-TD200 & 16 & W & 23 & postcooling \\
\hline & 279 & -9 & 3.4 & B TD300-TD450 & 147 & $\mathrm{NE}$ & 154 & $200-300^{\circ} \mathrm{C}$ \\
\hline & 192 & 31 & 2.7 & B TD500-TD650 & or, opposite & & & \\
\hline & & & & & 327 & SW & 206 & \\
\hline & & & & & 32 & NW & 124 & $450-500^{\circ} \mathrm{C}$ \\
\hline
\end{tabular}

Feature 222

\begin{tabular}{|c|c|c|c|c|c|c|c|c|}
\hline 101 & 5 & 55 & 3.8 & B TD100-TD200 & & & $<5$ & postcooling \\
\hline & 73 & -82 & 2.8 & B TD250-TD350 & 260 & $S$ & 144 & $200-250^{\circ} \mathrm{C}$ \\
\hline & 322 & 23 & 4.7 & B TD400-TD500 & \multicolumn{4}{|l|}{ or, opposite } \\
\hline & 304 & -12 & 4.5 & B TD500-TD575 & 80 & $\mathrm{~N}$ & 216 & \\
\hline & & & & & 99 & $\mathrm{~N}$ & 120 & $350-400^{\circ} \mathrm{C}$ \\
\hline & & & & & 211 & SE & 48 & $500^{\circ} \mathrm{C}$ \\
\hline \multirow[t]{2}{*}{102} & 333 & 61 & 2.4 & B TD150-TD250 & 135 & NE & 21 & $<150^{\circ} \mathrm{C}$ \\
\hline & 278 & 70 & 0.9 & B TD250-TD350 & 103 & $\mathrm{~N}$ & 24 & $250^{\circ} \mathrm{C}$ \\
\hline 104 & 355 & 66 & 1.6 & B NRM-AF400 & 98 & $\mathrm{~N}$ & 16 & postcooling \\
\hline \multicolumn{9}{|l|}{ Feature 223} \\
\hline \multirow[t]{2}{*}{159} & 158 & 45 & 0 & S AF100-AF150 & 78 & $\mathrm{~N}$ & 84 & $<100^{\circ} \mathrm{Oe}$ \\
\hline & 144 & -9 & 1.3 & B AF300-AF600 & 62 & NW & 59 & $150<\mathrm{t}<300^{\circ} \mathrm{Oe}$ \\
\hline 160 & 65 & 49 & 1.1 & B TD100-TD200 & 31 & NW & 50 & postcooling \\
\hline \multirow[t]{2}{*}{161} & 276 & -15 & 4.7 & B AF100-AF200 & 149 & NE & 131 & $<100^{\circ} \mathrm{Oe}$ \\
\hline & 268 & 59 & 1 & B AF300-AF600 & 357 & $\mathrm{~W}$ & 103 & $200-300^{\circ} \mathrm{Oe}$ \\
\hline 163 & 77 & 62 & 3925 & F AF100-AF400 & 49 & NW & 47 & $<100^{\circ} \mathrm{Oe}$ \\
\hline 164 & 307 & -27 & 4176 & F TD200-TD600 & 171 & $\mathrm{E}$ & 134 & $<200^{\circ} \mathrm{C}$ \\
\hline \multirow[t]{2}{*}{167} & 67 & 46 & 4 & B NRM-TD150 & 21 & W-NW & 53 & postcooling \\
\hline & 358 & 41 & 4.2 & B TD250-TD400 (MINUS 300) & 221 & SE & 57 & $150-250^{\circ} \mathrm{C}$ \\
\hline 168 & 335 & 62 & 2.4 & B NRM-TD200 & 132 & NE & 21 & postcooling \\
\hline
\end{tabular}


Table A6-1, continued

\begin{tabular}{|c|c|c|c|c|c|c|c|c|}
\hline \multicolumn{5}{|c|}{ Identified Vectors } & \multicolumn{4}{|c|}{ Reconstructed Vector Rotations } \\
\hline $\begin{array}{l}\text { Sample } \\
(\text { AM- ) }\end{array}$ & Declination & Inclination & MAD or $\kappa$ & Range & Strike & $\begin{array}{c}\text { Direction of } \\
\text { rotation }\end{array}$ & $\begin{array}{l}\text { Magnitude of } \\
\text { rotation }\end{array}$ & Threshold \\
\hline & 224 & 37 & 2.2 & B TD300-TD600 & 108 & $\mathrm{~N}$ & 69 & $200-300^{\circ} \mathrm{C}$ \\
\hline \multirow[t]{3}{*}{171} & 227 & -50 & 2.5 & B AF100-AF600 & 292 & S-SW & 180 & $<100^{\circ} \mathrm{Oe}$ \\
\hline & & & \multicolumn{6}{|c|}{ or, opposite } \\
\hline & & & & & 112 & $\mathrm{~N}-\mathrm{NE}$ & 180 & \\
\hline \multicolumn{9}{|l|}{ Feature 224} \\
\hline \multirow[t]{2}{*}{112} & 4 & 52 & 1.5 & B TD150-TD450 & & & $<5$ & $<150^{\circ} \mathrm{C}$ \\
\hline & 352 & -79 & 3.5 & B TD450-TD600 & 280 & $S$ & 130 & $450^{\circ} \mathrm{C}$ \\
\hline \multirow[t]{3}{*}{115} & 345 & 61 & 3.6 & B TD150-TD250 & 123 & NE & 15 & $<150^{\circ} \mathrm{C}$ \\
\hline & 313 & 57 & 4.7 & B TD250-TD350 & 162 & $\mathrm{E}$ & 22 & $250^{\circ} \mathrm{C}$ \\
\hline & 142 & 28 & 0 & B TD450-TD500 & 56 & NW & 105 & $350-450^{\circ} \mathrm{C}$ \\
\hline \multirow[t]{5}{*}{116} & 340 & 39 & 3 & B TD100-TD200 & 198 & $\mathrm{E}$ & 23 & postcooling \\
\hline & 150 & -54 & 3.6 & B TD300-TD450 & 272 & S & 164 & $200-300^{\circ} \mathrm{C}$ \\
\hline & 6 & 4 & 0.8 & B TD550-TD650 & or, opposite & & & \\
\hline & & & & & 92 & $\mathrm{~N}$ & 196 & \\
\hline & & & & & 86 & $\mathrm{~N}$ & 122 & $450-550^{\circ} \mathrm{C}$ \\
\hline \multirow[t]{2}{*}{138} & 31 & 56 & 4.6 & B NRM-AF200 & 30 & NW & 24 & postcooling \\
\hline & 351 & 40 & 1.9 & B AF200-AF400 & 216 & SE & 36 & $200^{\circ} \mathrm{Oe}$ \\
\hline \multirow[t]{2}{*}{139} & 337 & 45 & 4 & B TD100-TD300 & 181 & $\mathrm{E}$ & 22 & postcooling \\
\hline & 360 & 29 & 3.3 & B TD350-TD500 & 308 & SW & 27 & $300-350^{\circ} \mathrm{C}$ \\
\hline \multirow[t]{2}{*}{141} & 358 & 45 & 5.5 & B NRM-TD400 & & & $<5$ & postcooling \\
\hline & 332 & 37 & 1.9 & B TD400-TD550 & 180 & $\mathrm{E}$ & 30 & $400^{\circ} \mathrm{C}$ \\
\hline \multicolumn{9}{|l|}{ Feature 225} \\
\hline \multirow[t]{8}{*}{264} & 0 & 38 & 3 & B NRM-TD200 (MINUS 150) & 272 & S & 13 & postcooling \\
\hline & 120 & -48 & 2 & B TD300-TD400 & 234 & SE & 177 & $200-300^{\circ} \mathrm{C}$ \\
\hline & 173 & -68 & 4.1 & B TD400-TD500 & or, opposite & & & \\
\hline & 326 & 68 & 0.7 & B TD500-TD600 & 54 & NW & 183 & \\
\hline & & & & & 106 & $\mathrm{~N}$ & 34 & $400^{\circ} \mathrm{C}$ \\
\hline & & & & & 92 & $\mathrm{~N}$ & 171 & $500^{\circ} \mathrm{C}$ \\
\hline & & & & & or, opposite & & & \\
\hline & & & & & 272 & $S$ & 189 & \\
\hline \multirow[t]{5}{*}{266} & 8 & 51 & 2.8 & B NRM-TD250 & & & $<10$ & postcooling \\
\hline & 121 & -65 & 4.9 & B TD400-TD500 & 252 & S & 163 & $250<\mathrm{t}<400^{\circ} \mathrm{C}$ \\
\hline & 41 & -46 & 3 & B TD500-TD600 & or, opposite & & & \\
\hline & & & & & 72 & $\mathrm{~N}$ & 197 & \\
\hline & & & & & 47 & NW & 54 & $500^{\circ} \mathrm{C}$ \\
\hline 267 & 309 & 65 & 3.8 & B TD500-TD600 & 129 & NE & 34 & $<500^{\circ} \mathrm{C}$ \\
\hline \multirow[t]{2}{*}{270} & 338 & 49 & 3.8 & B NRM-TD300 & 172 & $\mathrm{E}$ & 19 & postcooling \\
\hline & 132 & 10 & 3 & B TD500-TD600 & 60 & NW & 128 & $300<\mathrm{t}<500 \mathrm{C}$ \\
\hline \multirow[t]{2}{*}{308} & 18 & 58 & 2.7 & B NRM-TD550 & 42 & NW & 15 & postcooling \\
\hline & 32 & 54 & 0.9 & B TD575-TD650 & 2 & W & 13 & $550-575^{\circ} \mathrm{C}$ \\
\hline \multicolumn{9}{|l|}{ Feature 226} \\
\hline \multirow[t]{4}{*}{155} & 5 & 61 & 3.2 & B NRM-TD200 (MINUS 100) & 77 & $\mathrm{~N}$ & 11 & postcooling \\
\hline & 290 & -59 & 1.1 & B TD300-TD400 & 305 & SW & 160 & $200-300^{\circ} \mathrm{C}$ \\
\hline & & & & & or, opposite & & & \\
\hline & & & & & 125 & $\mathrm{NE}$ & 200 & \\
\hline Feature 227 & & & & & & & & \\
\hline 158 & 1 & 56 & 5.6 & B NRM-TD150 & & & $<5$ & postcooling \\
\hline & 74 & 24 & 4.7 & B TD250-TD350 & 19 & W & 75 & $<250^{\circ} \mathrm{C}$ \\
\hline & 24 & 59 & 3.4 & B TD350-TD450 & 197 & $\mathrm{E}$ & 61 & $350^{\circ} \mathrm{C}$ \\
\hline & 343 & 26 & 2.2 & B TD500-TD575 & 222 & SE & 48 & $450-500^{\circ} \mathrm{C}$ \\
\hline 227 & 31 & 32 & 15.5 & B NRM-TD350 & 349 & W & 38 & postcooling \\
\hline
\end{tabular}


Table A6-1, continued

\begin{tabular}{|c|c|c|c|c|c|c|c|c|}
\hline & & Ident & fied Vectors & & & Reconstru & ucted Vector R & otations \\
\hline $\begin{array}{l}\text { Sample } \\
\text { (AM-) }\end{array}$ & Declination & Inclination & MAD or $\kappa$ & Range & Strike & $\begin{array}{l}\text { Direction of } \\
\text { rotation }\end{array}$ & $\begin{array}{l}\text { Magnitude of } \\
\text { rotation }\end{array}$ & Threshold \\
\hline & 260 & 8 & 8.9 & B TD350-TD550 & 136 & NE & 154 & $350^{\circ} \mathrm{C}$ \\
\hline & & & & & or, oppos & & & \\
\hline & & & & & 316 & SW & 206 & \\
\hline 228 & 359 & 53 & 3.5 & B NRM-TD200 & & & $<5$ & postcooling \\
\hline & 251 & 42 & 6.1 & B TD250-TD350 & 128 & NE & 74 & $200-250^{\circ} \mathrm{C}$ \\
\hline & 187 & -61 & 6.9 & B TD400-TD500 & 104 & $\mathrm{~N}$ & 118 & $350-400^{\circ} \mathrm{C}$ \\
\hline & 14 & -52 & 0.5 & B TD500-TD575 & 120 & NE & 72 & $500^{\circ} \mathrm{C}$ \\
\hline 229 & 0 & 50 & 230 & F TD150-TD550 (MINUS 200) & & & $<1$ & $<150^{\circ} \mathrm{C}$ \\
\hline Feature 228 & & & & & & & & \\
\hline 340 & 8 & 52 & 2.3 & B NRM-TD200 & 23 & W-NW & 8 & postcooling \\
\hline & 140 & -35 & 1.4 & В TD400-TD650 & 65 & N-NW & 157 & $200<\mathrm{t}<400^{\circ} \mathrm{C}$ \\
\hline & & & & & or, oppos & & & \\
\hline & & & & & 245 & S-SE & 203 & \\
\hline see also 6 ? & 5/339 in Squa & e 38 , Level 2 & (Table App & endix 6-2) & & & & \\
\hline Feature 230 & & & & & & & & \\
\hline 393 & 304 & 62 & 3 & B AF050-AF150 & 136 & NE & 36 & $<50^{\circ} \mathrm{Oe}$ \\
\hline & 259 & 34 & 0.3 & B AF300-AF600 & 134 & NE & 46 & $150<\mathrm{t}<300^{\circ} \mathrm{Oe}$ \\
\hline 394 & 8 & 44 & 0 & S AF050-AF100 & 330 & SW & 10 & $<50^{\circ} \mathrm{Oe}$ \\
\hline & 9 & -32 & 4.1 & B AF $150-A F 400$ & 312 & SW & 88 & $100-150^{\circ} \mathrm{Oe}$ \\
\hline 397 & 14 & 39 & 5.9 & B NRM-TD200 (MINUS 100) & 330 & SW & 18 & postcooling \\
\hline & 68 & 8 & 1.7 & B TD200-TD300 & 20 & W-NW & 114 & $200^{\circ} \mathrm{C}$ \\
\hline & 122 & 39 & 0.8 & B TD350-TD650 & 126 & NE & 63 & $300-350^{\circ} \mathrm{C}$ \\
\hline 398 & 0 & 36 & 2.2 & B TD100-TD400 & 270 & S & 14 & postcooling \\
\hline & 111 & 11 & 1.7 & B TD450-TD650 & 48 & NW & 116 & $400-450^{\circ} \mathrm{C}$ \\
\hline 617 & 18 & 55 & 3.6 & B NRM-AF150 & 31 & NW & 15 & postcooling \\
\hline & 342 & 52 & 3.1 & B AF200-AF400 & 187 & $\mathrm{E}$ & 28 & $150-200^{\circ} \mathrm{Oe}$ \\
\hline & $\sim 303.9$ & $\sim 35.6$ & 0 & S 400-ORIGIN & $\sim 162$ & $\sim \mathrm{E}$ & $\sim 43$ & $>400^{\circ} \mathrm{Oe}$ \\
\hline 618 & 347 & 52 & 5.4 & B TD150-TD400 & 147 & NE & 11 & $<150^{\circ} \mathrm{C}$ \\
\hline & 314 & 34 & 1.1 & B TD500-TD600 & 174 & $\mathrm{E}$ & 43 & $400-500^{\circ} \mathrm{C}$ \\
\hline 619 & 1 & 45 & 4.9 & B TD250-TD450 & & & $<5$ & $<250^{\circ} \mathrm{C}$ \\
\hline & 335 & 12 & 3.8 & B TD500-TD600 & 202 & E-SE & 53 & $450-500^{\circ} \mathrm{C}$ \\
\hline 620 & 323 & 52 & 10872 & F NRM-AF400 & 157 & E-NE & 30 & postcooling \\
\hline 622 & 8 & 41 & 6.2 & B NRM-TD500 & 310 & SW & 13 & postcooling \\
\hline & 47 & 40 & 5.2 & B TD500-TD600 & 27 & NW & 36 & $500^{\circ} \mathrm{C}$ \\
\hline 623 & 266 & 68 & 4.3 & B AF100-AF200 & 120 & NE & 49 & $<100^{\circ} \mathrm{Oe}$ \\
\hline & 241 & 61 & 2.2 & B AF200-AF400 & 99 & $\mathrm{~N}$ & 13 & $200 \mathrm{Oe}$ \\
\hline 699 & 337 & 24 & 2.1 & B AF150-AF400 & 209 & SE & 40 & $<150^{\circ} \mathrm{Oe}$ \\
\hline 701 & 10 & 18 & 928 & F NRM-AF600 & 302 & SW & 32 & postcooling \\
\hline 703 & 356 & 36 & 1.7 & B AF050-AF 150 & 246 & S-SE & 15 & $<50^{\circ} \mathrm{Oe}$ \\
\hline & 332 & 26 & 1.1 & B AF200-AF400 & 182 & $\mathrm{E}$ & . 30 & $150-200^{\circ} \mathrm{Oe}$ \\
\hline 704 & 6 & 44 & 4.6 & B AF050-AF150 & 312 & SW & 9 & $<50^{\circ} \mathrm{Oe}$ \\
\hline & 20 & 0 & 1.8 & B AF $200-A F 400$ & 318 & SW & 51 & $100-200^{\circ} \mathrm{Oe}$ \\
\hline 906 & 339 & 53 & 2.3 & B TD150-TD300 & 160 & E-NE & 17 & $<150^{\circ} \mathrm{C}$ \\
\hline & 45 & -48 & 5.3 & B TD350-TD450 & 228 & SE & 140 & $300-350^{\circ} \mathrm{C}$ \\
\hline & 324 & -12 & 2.6 & B TD500-TD600 & 65 & $\mathrm{~N}-\mathrm{NW}$ & 79 & $450-500^{\circ} \mathrm{C}$ \\
\hline 907 & 357 & 54 & 1.5 & B TD100-TD200 & & & $<5$ & postcooling \\
\hline & 338 & 49 & 1.6 & B TD200-TD500 & 187 & E & 16 & $200^{\circ} \mathrm{C}$ \\
\hline & 248 & -81 & 0.6 & В TD575-TD650 & 301 & SW & 164 & $500-575^{\circ} \mathrm{C}$ \\
\hline & & & & & or, oppos & & & \\
\hline & & & & & 121 & NE & 196 & \\
\hline
\end{tabular}


Table A6-1, continued

\begin{tabular}{|c|c|c|c|c|c|c|c|c|}
\hline & & Ident & fied Vectors & & & Reconstru & acted Vector Ro & tations \\
\hline $\begin{array}{l}\text { Sample } \\
\text { (AM-) }\end{array}$ & Declination & Inclination & $\mathrm{MAD}$ or $\kappa$ & Range & Strike & $\begin{array}{l}\text { Direction of } \\
\text { rotation }\end{array}$ & $\begin{array}{l}\text { Magnitude of } \\
\text { rotation }\end{array}$ & Threshold \\
\hline Feature 233 & & & & & & & & \\
\hline 469 & 342 & 38 & 0.4 & B TD150-TD300 (MINUS 250) & 202 & E-SE & 22 & $<150^{\circ} \mathrm{C}$ \\
\hline 472 & 19 & 59 & 2.6 & B NRM-TD200 & 47 & NW & 17 & postcooling \\
\hline & 172 & 60 & 2.9 & B TD400-TD500 & 94 & $\mathrm{~N}$ & 59 & $200<\mathrm{t}<400^{\circ} \mathrm{C}$ \\
\hline & 183 & 38 & 5.6 & B TD500-TD650 & 101 & $\mathrm{~N}$ & 24 & $500^{\circ} \mathrm{C}$ \\
\hline 473 & 334 & 71 & 4.7 & B NRM-TD450 & 112 & N-NE & 26 & postcooling \\
\hline & 21 & -9 & 0 & S TD500-TD550 & 340 & W-SW & 120 & $450-500^{\circ} \mathrm{C}$ \\
\hline 476 & 1 & 49 & 1.4 & B TD150-TD300 & & & $<2$ & $<150^{\circ} \mathrm{C}$ \\
\hline & 125 & 58 & 4.7 & B TD350-TD450 & 343 & W & 81 & $300-350^{\circ} \mathrm{C}$ \\
\hline & 48 & 28 & 5.9 & B TD450-TD575 & 66 & N-NW & 67 & $450^{\circ} \mathrm{C}$ \\
\hline 477 & 43 & -19 & 434 & F NRM-TD500 & 356 & W & 112 & postcooling \\
\hline Feature 234 & & & & & & & & \\
\hline 567 & 9 & 54 & 401 & F NRM-AF400 & 34 & NW & 9 & postcooling \\
\hline Feature 235 & & & & & & & & \\
\hline 606 & 334 & 69 & 2.9 & B NRM-TD150 & 117 & $\mathrm{NE}$ & 24 & postcooling \\
\hline & 131 & -24 & 3.5 & B TD250-TD450 & 66 & N-NW & 144 & $150-250^{\circ} \mathrm{C}$ \\
\hline & 134 & -3 & 2.5 & B TD450-TD550 & or, opposite & & & \\
\hline & & & & & 246 & S-SE & 216 & \\
\hline & & & & & 270 & S & 20 & $450^{\circ} \mathrm{C}$ \\
\hline 607 & 12 & 56 & 2.1 & B AF050-AF150 & 42 & NW & 10 & $<50^{\circ} \mathrm{Oe}$ \\
\hline & 339 & 34 & 7.7 & B AF150-AF300 & 287 & S & 40 & $150^{\circ} \mathrm{Oe}$ \\
\hline 608 & 153 & 66 & 6.8 & B NRM-AF100 & 80 & $\mathrm{~N}$ & 63 & postcooling \\
\hline & 15 & 71 & 1.7 & B AF200-AF400 & or, opposite & & & \\
\hline & & & & & 260 & $S$ & 243 & \\
\hline & & & & & 264 & $S$ & 40 & $100-200^{\circ} \mathrm{Oe}$ \\
\hline & & & & & or, opposite & & & \\
\hline & & & & & 84 & $\mathrm{~N}$ & 320 & $100-200^{\circ} \mathrm{Oe}$ \\
\hline 610 & 162 & -39 & 466 & F NRM-AF400 & 81 & $\mathrm{~N}$ & 169 & postcooling \\
\hline & & & & & or, opposite & & & \\
\hline & & & & & 261 & S & 191 & \\
\hline 611 & 352 & 54 & 1552 & F NRM-AF400 & 143 & $\mathrm{NE}$ & 8 & postcooling \\
\hline 612 & 17 & 60 & 0.4 & B AF100-AF200 & 49 & NW & 16 & $<100^{\circ} \mathrm{Oe}$ \\
\hline & 40 & 50 & 3.1 & B AF200-AF400 & 360 & W & 22 & $200^{\circ} \mathrm{Oe}$ \\
\hline 613 & 57 & -6 & 0.2 & B TD350-TD450 & 7 & W & 105 & $<350^{\circ} \mathrm{C}$ \\
\hline & 58 & 14 & 0.5 & B TD450-TD550 & 183 & E & 29 & $450 \mathrm{C}$ \\
\hline 660 & 359 & 73 & 2.9 & B NRM-AF150 & 91 & $\mathrm{~N}$ & 23 & postcooling \\
\hline & 131 & -19 & 6.1 & B AF300-AF600 & 62 & NW & 130 & $150<\mathrm{t}<300^{\circ} \mathrm{C}$ \\
\hline Feature 236 & & & & & & & & \\
\hline 671 & 325 & 73 & 709 & F NRM-AF300 & 112 & N-NE & 30 & postcooling \\
\hline $672 / 682$ & 358 & 56 & 290 & F (Average of both samples) & 106 & $\mathrm{~N}$ & 6 & postcooling \\
\hline $673 / 935$ & 320 & 63 & 856 & F (Average of both samples) & 134 & NE & 28 & postcooling \\
\hline 677 & 355 & 51 & 130 & F NRM-TD500 & & & $<4$ & postcooling \\
\hline 678 & 350 & 56 & 4741 & F NRM-AF400 & 136 & NE & 10 & postcooling \\
\hline 679 & 359 & 61 & 2.8 & B TD100-TD350 & 94 & $\mathrm{~N}$ & 11 & postcooling \\
\hline 680 & 282 & 67 & 4.1 & B TD100-TD300 & 123 & NE & 43 & postcooling \\
\hline & 240 & 58 & 2.9 & B TD300-TD450 & 102 & $\mathrm{~N}$ & 22 & $300^{\circ} \mathrm{C}$ \\
\hline & 271 & 68 & 0.8 & B TD450-TD575 & or, opposite & & & \\
\hline & & & & & 282 & $S$ & 338 & \\
\hline & & & & & 283 & S & 17 & $450^{\circ} \mathrm{C}$ \\
\hline 934 & 17 & 76 & 5815 & F NRM-AF300 & 81 & $\mathrm{~N}$ & 34 & postcooling \\
\hline 936 & 314 & 42 & 2.2 & B NRM-TD150 & 166 & $\mathrm{E}$ & 42 & postcooling \\
\hline
\end{tabular}


Table A6-1, continued

\begin{tabular}{|c|c|c|c|c|c|c|c|c|}
\hline & & Identi & fied Vectors & & & Reconstru & cted Vector Ro & tations \\
\hline $\begin{array}{l}\text { Sample } \\
\text { (AM-) }\end{array}$ & Declination & Inclination & MAD or $\kappa$ & Range & Strike & $\begin{array}{l}\text { Direction of } \\
\text { rotation }\end{array}$ & $\begin{array}{l}\text { Magnitude of } \\
\text { rotation }\end{array}$ & Threshold \\
\hline & 351 & 50 & 5.7 & B TD150-TD300 (MINUS 200) & 342 & $\bar{W}$ & 35 & $150^{\circ} \mathrm{C}$ \\
\hline 937 & 46 & 58 & 9.3 & B NRM-TD200 & 36 & NW & 33 & postcooling \\
\hline & 89 & 48 & 4.7 & B TD250-TD400 & 51 & NW & 31 & $200-250^{\circ} \mathrm{C}$ \\
\hline 938 & 78 & -46 & 1.4 & B NRM-TD250 & 36 & NW & 176 & postcooling \\
\hline & 65 & -49 & 1.6 & B TD250-TD400 & or, opposite & & & \\
\hline & & & & & 216 & SE & 184 & \\
\hline & & & & & 13 & W & 11 & $250^{\circ} \mathrm{C}$ \\
\hline Feature 237 & & & & & & & & \\
\hline 668 & 258 & 71 & 2.3 & B NRM-AF150 & 114 & $\mathrm{~N}-\mathrm{NE}$ & 50 & postcooling \\
\hline & 273 & 55 & 1.6 & B AF $200-A F 400$ & 183 & $\mathrm{E}$ & 26 & $150-200^{\circ} \mathrm{Oe}$ \\
\hline 669 & 6 & 63 & 4.3 & B NRM-TD200 & 80 & $\mathrm{~N}$ & 14 & postcooling \\
\hline & 219 & 48 & 1 & B TD200-TD575 & 114 & $\mathrm{~N}-\mathrm{NE}$ & 69 & $200^{\circ} \mathrm{C}$ \\
\hline Feature 239 & & & & & & & & \\
\hline 916 & 53 & 55 & 4.1 & B TD100-TD300 & 33 & NW & 38 & postcooling \\
\hline & 356 & -30 & 6.2 & B TD350-TD450 & 3 & W & 164 & $300-350^{\circ} \mathrm{C}$ \\
\hline & & & & & or, opposite & & & \\
\hline & & & & & 183 & E & 196 & \\
\hline 918 & 83 & 36 & 2.1 & B AF025-AF100 & 33 & NW & 72 & postcooling \\
\hline & 36 & -45 & 4.7 & B AF150-AF300 & 24 & W-NW & 120 & $100-150^{\circ} \mathrm{Oe}$ \\
\hline & 354 & -30 & 0 & S AF300-AF400 & 22 & W-NW & 40 & $300^{\circ} \mathrm{Oe}$ \\
\hline 919 & 30 & 35 & 2.7 & B AF025-AF100 & 351 & W & 34 & postcooling \\
\hline & 63 & -32 & 4.8 & B AF100-AF200 & 14 & W & 100 & $100^{\circ} \mathrm{Oe}$ \\
\hline & 53 & -45 & 2.1 & B AF200-AF400 & 7 & W & 22 & $200^{\circ} \mathrm{Oe}$ \\
\hline Feature 240 & & & & & & & & \\
\hline 1000 & 118 & 31 & 0 & S NRM-TD150 & 53 & NW & 90 & postcooling \\
\hline Feature $240 ?$ & & & & & & & & \\
\hline 886 & 18 & 41 & 4.9 & B NRM-AF150 & 343 & W & 19 & postcooling \\
\hline & 158 & 29 & 0.5 & B AF400-AF800 & 84 & $\mathrm{~N}$ & 102 & $150<\mathrm{t}<400^{\circ} \mathrm{Oe}$ \\
\hline 998 & 139 & -26 & 630 & F NRM-AF600 & 67 & N-NW & 155 & postcooling \\
\hline & & & & & or, opposite & & & \\
\hline & & & & & 247 & S-SE & 205 & \\
\hline Feature 241 & & & & & & & & \\
\hline 897 & 26 & -11.3 & 1.6 & B NRM-TD250 (MINUS 200) & 330 & SW & 79 & $<200^{\circ} \mathrm{C}$ \\
\hline 899 & 335 & -22 & 1.5 & B TD200-TD300 & 206 & SE & 96 & postcooling \\
\hline & 300 & -48 & 5.2 & B TD350-TD450 & 159 & E-NE & 56 & $300-350^{\circ} \mathrm{C}$ \\
\hline & 9 & -9 & 0.1 & B TD500-TD575 & 140 & NE & 84 & $450-500^{\circ} \mathrm{C}$ \\
\hline 901 & 65 & -32 & 2244 & F NRM-AF400 & 20 & W-NW & 149 & postcooling \\
\hline & & & & & or, opposite & & & \\
\hline & & & & & 200 & E-SE & 211 & \\
\hline Feature 241? & & & & & & & & \\
\hline 895 & 29 & 25 & 4.5 & B NRM-AF100 & 341 & $\mathrm{~W}$ & 42 & postcooling \\
\hline & 58 & -68 & 2.6 & B AF100-AF200 & 18 & W & 138 & $100^{\circ} \mathrm{Oe}$ \\
\hline & 150 & -75 & 1.1 & B AF300-AF600 & 83 & $\mathrm{~N}$ & 28 & $200-300^{\circ} \mathrm{Oe}$ \\
\hline 896 & 16 & 59 & 3 & B NRM-TD300 & 46 & NW & 14 & postcooling \\
\hline & 119 & 14 & 4.4 & B TD350-TD450 & 54 & NW & 95 & $300-350^{\circ} \mathrm{C}$ \\
\hline & 131 & 46 & 9.3 & B TD450-TD550 & 200 & E-SE & 44 & $450^{\circ} \mathrm{C}$ \\
\hline & 94 & 72 & 2.2 & B TD550-TD650 & 213 & SE & 36 & $550^{\circ}$ \\
\hline Feature 242 & & & & & & & & \\
\hline 893 & 16 & -35 & 3.3 & B AF100-AF200 & 330 & SW & 109 & postcooling \\
\hline & 17 & -57 & 1.5 & B AF200-AF400 & 360 & W & 30 & $200^{\circ} \mathrm{Oe}$ \\
\hline
\end{tabular}


Table A6-1, continued

\begin{tabular}{|c|c|c|c|c|c|c|c|c|}
\hline & & Identi & fied Vectors & & & Reconstru & cted Vector Ro & tations \\
\hline $\begin{array}{l}\text { Sample } \\
\text { (AM-) }\end{array}$ & Declination & Inclination & MAD or $\kappa$ & Range & Strike & $\begin{array}{l}\text { Direction of } \\
\text { rotation }\end{array}$ & $\begin{array}{l}\text { Magnitude of } \\
\text { rotation }\end{array}$ & Threshold \\
\hline 894 & 358 & 78 & 0 & S NRM-TD200 & 90 & $\mathrm{~N}$ & 29 & postcooling \\
\hline & 265 & 18 & 1.2 & В TD300-TD550 & 149 & NE & 92 & $200-300^{\circ} \mathrm{C}$ \\
\hline & 79 & -4 & 1.2 & B TD575-TD650 & 268 & S & 164 & $550-575^{\circ} \mathrm{C}$ \\
\hline & & & & & or, opposite & & & \\
\hline & & & & & 88 & $\mathrm{~N}$ & 196 & \\
\hline Feature 246 & & & & & & & & \\
\hline 1059 & 38 & 42 & 4.3 & B NRM-TD550 & 8 & W & 36 & postcooling \\
\hline 1060 & 2 & 46 & 4.1 & B NRM-TD200 & & & $<5$ & postcooling \\
\hline & 73 & 22 & 3.1 & B TD200-TD350 & 26 & NW & 82 & $200^{\circ} \mathrm{C}$ \\
\hline & 334 & -35 & 7.3 & B TD400-TD550 (MINUS 500) & 32 & NW & 174 & $350-400^{\circ}$ \\
\hline & & & & & or, opposite & & & \\
\hline & & & & & 212 & SE & 186 & \\
\hline 1061 & 360 & 49 & 5.3 & B NRM-TD300 & & & $<5$ & postcooling \\
\hline & 115 & 35 & 0.6 & B TD350-TD450 & 53 & NW & 86 & $300-350^{\circ} \mathrm{C}$ \\
\hline & 348 & -24 & 5.4 & B TD450-TD600 (MINUS 575) & 53 & NW & 193 & $450^{\circ} \mathrm{C}$ \\
\hline & & & & & or, opposite & & & \\
\hline & & & & & 233 & SE & 167 & \\
\hline 1098 & 320 & 9 & 2.1 & B TD350-TD500 & 190 & E & 70 & $<350^{\circ} \mathrm{C}$ \\
\hline & 346 & 18 & 1.8 & В TD500-TD600 & 329 & SW & 33 & $500^{\circ} \mathrm{C}$ \\
\hline 1100 & 68 & 73 & 7.7 & B NRM-TD200 & 62 & NW & 38 & postcooling \\
\hline & 68 & -50 & 2130 & F TD300-TD550 & 45 & NW & 161 & $200-300^{\circ} \mathrm{C}$ \\
\hline & & & & & or, opposite & & & \\
\hline & & & & & 225 & SE & 199 & \\
\hline 1101 & 12 & 43 & 0 & S NRM-TD250 & 337 & W-SW & 13 & postcooling \\
\hline & 136 & -1 & 5.4 & B TD250-TD400 (MINUS 350) & 63 & NW & 125 & $250^{\circ} \mathrm{C}$ \\
\hline & 205 & 16 & 0.2 & B TD500-TD600 & 146 & NE & 85 & $400-500^{\circ} \mathrm{C}$ \\
\hline 1102 & 277 & 31 & 0.3 & B TD200-TD300 & 148 & NE & 77 & $<200^{\circ} \mathrm{C}$ \\
\hline & 183 & 79 & 5.9 & B TD450-TD550 & 18 & W & 80 & $300<\mathrm{t}<450^{\circ} \mathrm{C}$ \\
\hline & 45 & 63 & 1.2 & B TD550-TD650 & 360 & $\mathrm{~W}$ & 50 & $550^{\circ} \mathrm{C}$ \\
\hline 1105 & 346 & 41 & 5.3 & B NRM-TD200 & 204 & E-SE & 16 & postcooling \\
\hline & 37 & 8 & 3.8 & B TD200-TD400 (MINUS 300) & 348 & W & 75 & $200 \mathrm{C}$ \\
\hline & 99 & 42 & 1.3 & B TD450-TD650 & 97 & $\mathrm{~N}$ & 64 & $400-450^{\circ} \mathrm{C}$ \\
\hline 1106 & 9 & 64 & 3.9 & B TD150-TD300 & 72 & $\mathrm{~N}$ & 16 & $<150^{\circ} \mathrm{C}$ \\
\hline 1107 & 4 & 50 & 4.7 & B NRM-TD300 (MINUS 150) & & & $<5$ & postcooling \\
\hline Feature 248 & & & & & & & & \\
\hline 1077 & 55 & 84 & 10.2 & B TD150-TD400 (MINUS 250) & 82 & $\mathrm{~N}$ & 37 & $<150^{\circ} \mathrm{C}$ \\
\hline & 140 & 55 & 2.4 & B TD450-TD550 & 62 & NW & 37 & $400-450^{\circ} \mathrm{C}$ \\
\hline & 115 & 35 & 0 & S TD550-TD600 & 17 & W & 34 & $550^{\circ} \mathrm{C}$ \\
\hline 1078 & 10 & 60 & 1.1 & B TD100-TD200 & 60 & NW & 13 & postcooling \\
\hline & 83 & 70 & 4.2 & B TD200-TD300 & 60 & NW & 31 & $200^{\circ} \mathrm{C}$ \\
\hline & 132 & 34 & 4.8 & B TD350-TD550 & 65 & N-NW & 48 & $300-350^{\circ} \mathrm{C}$ \\
\hline & 218 & -10 & 0.4 & B TD575-TD650 & 120 & $\mathrm{NE}$ & 98 & $550-575^{\circ} \mathrm{C}$ \\
\hline 1079 & 8 & 65 & 1.6 & B TD100-TD200 & 74 & $\mathrm{~N}$ & 16 & postcooling \\
\hline & 233 & 71 & 3.6 & B TD250-TD450 & 118 & $\mathrm{NE}$ & 43 & $200-250^{\circ} \mathrm{C}$ \\
\hline & 236 & -45 & 4.3 & B TD500-TD575 & 113 & $\mathrm{~N}-\mathrm{NE}$ & 123 & $450-500^{\circ} \mathrm{C}$ \\
\hline 1122 & 27 & 55 & 2.3 & B NRM-TD200 (MINUS 150) & 28 & NW & 21 & postcooling \\
\hline & 296 & -82 & 5.6 & В TD350-TD450 & 254 & $\mathrm{~S}$ & 149 & $200<\mathrm{t}<350^{\circ} \mathrm{C}$ \\
\hline & 7 & -76 & 3.4 & B TD450-TD575 & or, opposite & & & \\
\hline & & & & & 74 & $\mathrm{~N}$ & 211 & \\
\hline & & & & & 21 & W-NW & 16 & $450^{\circ} \mathrm{C}$ \\
\hline 1124 & 27 & 68 & 4.1 & B NRM-TD400 & 60 & NW & 24 & postcooling \\
\hline
\end{tabular}


Table A6-1, continued

\begin{tabular}{|c|c|c|c|c|c|c|c|c|}
\hline \multirow{2}{*}{$\begin{array}{l}\text { Sample } \\
(\mathrm{AM}-)\end{array}$} & \multicolumn{4}{|c|}{ Identified Vectors } & \multicolumn{4}{|c|}{ Reconstructed Vector Rotations } \\
\hline & Declination & Inclination & MAD or $\kappa$ & Range & Strike & $\begin{array}{c}\text { Direction of } \\
\text { rotation }\end{array}$ & $\begin{array}{l}\text { Magnitude of } \\
\text { rotation }\end{array}$ & Threshold \\
\hline & 227 & 7 & 3.9 & B TD450-TD600 & 122 & NE & 114 & $400-450^{\circ} \mathrm{C}$ \\
\hline \multirow[t]{2}{*}{1130} & 148 & 74 & 7.8 & B AF025-AF100 & 81 & $\mathrm{~N}$ & 55 & postcooling \\
\hline & 26 & 53 & 1.5 & B AF200-AF400 & 300 & SW & 50 & $100-200^{\circ} \mathrm{Oe}$ \\
\hline \multirow[t]{3}{*}{1131} & 15 & 60 & 5 & B NRM-TD300 & 54 & NW & 15 & postcooling \\
\hline & 16 & 7 & 2.8 & B TD300-TD500 (MINUS 400) & 310 & SW & 58 & $300^{\circ} \mathrm{C}$ \\
\hline & 129 & 75 & 1.7 & B TD500-TD600 & 113 & $\mathrm{~N}-\mathrm{NE}$ & 91 & $500^{\circ} \mathrm{C}$ \\
\hline 1132 & 3 & 58 & 3.5 & B TD100-TD500 (MINUS 250) & 73 & $\mathrm{~N}$ & 8 & postcooling \\
\hline \multirow[t]{2}{*}{1133} & 24 & -45 & 3.1 & B AF100-AF200 & 1 & W & 159 & $<100^{\circ} \mathrm{Oe}$ \\
\hline & 55 & -63 & 0.8 & B AF200-AF400 & 270 & S & 24 & $200^{\circ} \mathrm{Oe}$ \\
\hline \multirow[t]{2}{*}{1134} & 336 & 55 & 2.1 & B AF050-AF150 & 150 & $\mathrm{NE}$ & 20 & $<50^{\circ} \mathrm{Oe}$ \\
\hline & 291 & 52 & 2.6 & B AF200-AF400 & 137 & $\mathrm{NE}$ & 29 & $150-200^{\circ} \mathrm{Oe}$ \\
\hline \multirow[t]{4}{*}{1135} & 2 & 66 & 6.8 & B NRM-TD300 & 92 & $\mathrm{~N}$ & 16 & postcooling \\
\hline & 255 & 61 & 4.7 & B TD300-TD400 & 132 & $\mathrm{NE}$ & 47 & $300^{\circ} \mathrm{C}$ \\
\hline & 234 & 0 & 4.3 & B TD400-TD550 & 120 & $\mathrm{NE}$ & 68 & $400^{\circ} \mathrm{C}$ \\
\hline & 256 & 36 & 0 & S TD550-TD600 & 262 & S & 41 & $550^{\circ} \mathrm{C}$ \\
\hline \multirow[t]{2}{*}{1141} & 2 & 58 & 1.6 & B TD150-TD250 & 81 & $\mathrm{~N}$ & 8 & $<150^{\circ} \mathrm{C}$ \\
\hline & 147 & 73 & 4 & B TD300-TD550 & 80 & $\mathrm{~N}$ & 48 & $250-300^{\circ} \mathrm{C}$ \\
\hline \multicolumn{9}{|l|}{ Feature 249} \\
\hline \multirow[t]{4}{*}{1095} & 28 & 37 & 4.4 & B TD100-TD200 & 350 & W & 31 & postcooling \\
\hline & 35 & 0 & 3.6 & B TD250-TD350 & 341 & W & 47 & $200-250^{\circ} \mathrm{C}$ \\
\hline & 158 & 60 & 4.9 & B TD500-TD575 & 117 & NE & 113 & $350<\mathrm{t}<500^{\circ} \mathrm{C}$ \\
\hline & 295 & 77 & 0.9 & B TD575-TD650 & 176 & $\mathrm{E}$ & 54 & $575^{\circ} \mathrm{C}$ \\
\hline 1096 & 15 & 46 & 2.7 & B TD100-TD600 (MINUS 250) & 352 & W & 14 & postcooling \\
\hline \multicolumn{9}{|l|}{ Feature 250} \\
\hline 1113 & 41 & 57 & 2.2 & B TD200-TD575 & 32 & NW & 31 & $<200^{\circ} \mathrm{C}$ \\
\hline \multirow[t]{2}{*}{1114} & 357 & 58 & 1.6 & B AF050-AF200 & 102 & $\mathrm{~N}$ & 8 & $<50^{\circ} \mathrm{Oe}$ \\
\hline & 299 & 62 & 5.1 & B AF200-AF400 & 141 & NE & 34 & $200^{\circ} \mathrm{Oe}$ \\
\hline 1116 & 354 & 45 & 5.7 & B NRM-TD300 & 220 & SE & 8 & postcooling \\
\hline 1116 & 123 & 41 & 2 & B TD500-TD600 & 60 & NW & 80 & $300<t<500 \mathrm{C}$ \\
\hline \multirow[t]{2}{*}{1118} & 2 & 51 & 2.9 & B NRM-TD550 (MINUS 400) & & & $<2$ & postcooling \\
\hline & 353 & 28 & 2.7 & B TD550-TD600 & 226 & SE & 25 & $550^{\circ} \mathrm{C}$ \\
\hline \multirow[t]{4}{*}{1126} & 348 & 57 & 2.7 & B TD100-TD500 & 134 & $\mathrm{NE}$ & 12 & postcooling \\
\hline & 159 & -51 & 2.9 & B TD500-TD600 & 266 & $S$ & 178 & $500^{\circ} \mathrm{C}$ \\
\hline & & & & & or, opposite & & & \\
\hline & & & & & 86 & $\mathrm{~N}$ & 182 & \\
\hline 1128 & 352 & 65 & 211 & F NRM-TD575 & 102 & $\mathrm{~N}$ & 16 & postcooling \\
\hline \multirow[t]{2}{*}{1189} & 7 & 62 & 3.2 & B TD300-TD450 & 72 & $\mathrm{~N}$ & 13 & $<300^{\circ} \mathrm{C}$ \\
\hline & 325 & 14 & 0.6 & B TD500-TD600 & 197 & E & 74 & $450-500^{\circ} \mathrm{C}$ \\
\hline \multicolumn{9}{|l|}{ Feature 255} \\
\hline \multirow[t]{2}{*}{1181} & 346 & 38 & 3.4 & B NRM-TD200 & 213 & SE & 18 & postcooling \\
\hline & 290 & 50 & 4.1 & B TD200-TD400 & 124 & $\mathrm{NE}$ & 44 & $200^{\circ} \mathrm{C}$ \\
\hline 1182 & 349 & 57 & 3.8 & B TD100-TD200 & 132 & $\mathrm{NE}$ & 10 & postcooling \\
\hline & 51 & 54 & 96 & F TD350-TD550 & 16 & W & 44 & $200<\mathrm{t}<350^{\circ} \mathrm{C}$ \\
\hline 1184 & 1 & 45 & 3.4 & B NRM-TD450 & & & $<5$ & postcooling \\
\hline & 245 & 42 & 5.7 & B TD500-TD600 & 113 & $\mathrm{~N}-\mathrm{NE}$ & 90 & $450-500^{\circ} \mathrm{C}$ \\
\hline 1186 & 342 & 48 & 175 & F TD150-TD550 & 176 & $\mathrm{E}$ & 15 & $<150^{\circ} \mathrm{C}$ \\
\hline 1187 & 359 & 45 & 2.2 & B NRM-TD300 (MINUS 150) & & & $<5$ & postcooling \\
\hline & 0 & 31 & 3.4 & B TD300-TD600 & 270 & S & 15 & $300^{\circ} \mathrm{C}$ \\
\hline Feature 257 & & & & & & & & \\
\hline 1194 & 6 & 56 & 2 & B TD200-TD600 & 49 & NW & 7 & $<200^{\circ} \mathrm{C}$ \\
\hline 1195 & 335 & 68 & 5.3 & B NRM-TD150 & 116 & $\mathrm{NE}$ & 22 & postcooling \\
\hline
\end{tabular}


Table A6-1, continued

\begin{tabular}{|c|c|c|c|c|c|c|c|c|}
\hline \multicolumn{5}{|c|}{ Identified Vectors } & \multicolumn{4}{|c|}{ Reconstructed Vector Rotations } \\
\hline $\begin{array}{l}\text { Sample } \\
\text { (AM- ) }\end{array}$ & Declination & Inclination & MAD or $\kappa$ & Range & Strike & $\begin{array}{l}\text { Direction of } \\
\text { rotation }\end{array}$ & $\begin{array}{l}\text { Magnitude of } \\
\text { rotation }\end{array}$ & Threshold \\
\hline \multicolumn{9}{|l|}{ Feature 258} \\
\hline 1253 & 7 & 44 & 4.6 & B NRM-AF400 & 340 & W-SW & 8 & postcooling \\
\hline 1254 & 215 & -8 & 1.8 & B AF150-AF400 & 111 & $\mathrm{~N}-\mathrm{NE}$ & 137 & $<150^{\circ} \mathrm{Oe}$ \\
\hline 1255 & 182 & 20 & 2.6 & $\mathrm{~B}$ AF $100-\mathrm{AF} 400$ & 91 & $\mathrm{~N}$ & 111 & $<100^{\circ} \mathrm{Oe}$ \\
\hline
\end{tabular}

Feature 259

1226 unable to identify vectors

1228 unable to identify vectors

\begin{tabular}{|c|c|c|c|c|c|c|c|c|}
\hline \multicolumn{9}{|l|}{ Feature 260} \\
\hline \multirow[t]{2}{*}{1240} & 30 & 57 & 0 & S NRM-TD150 & 33 & NW & 22 & postcooling \\
\hline & 62 & 10 & 23 & F TD250-TD550 & 2 & W & 71 & $150-250^{\circ} \mathrm{C}$ \\
\hline 1242 & 22 & 61 & 13 & F NRM-TD450 (MINUS $200 \&$ & 50 & NW & 19 & postcooling \\
\hline 1244 & 20 & 55 & 41 & F NRM-TD500 & 28 & NW & 16 & postcooling \\
\hline \multirow[t]{2}{*}{1246} & 349 & 56 & 4.2 & B TD150-TD300 & 138 & NE & 10 & $<150^{\circ} \mathrm{C}$ \\
\hline & 22 & 24 & 27 & F TD400-TD600 & 331 & SW & 28 & $300-400^{\circ} \mathrm{C}$ \\
\hline \multirow[t]{3}{*}{1248} & 348 & 56 & 3.9 & B NRM-TD400 (MINUS 150 \& & 138 & NE & 10 & postcooling \\
\hline & 24 & 27 & 0 & S TD450-TD500 & & & & \\
\hline & & & & & 346 & $\mathrm{~W}$ & 30 & $400-450^{\circ} \mathrm{C}$ \\
\hline 1251 & 353 & 52 & 564 & F NRM-TD250 & 156 & E-NE & 6 & postcooling \\
\hline
\end{tabular}

\begin{tabular}{|c|c|c|c|c|c|c|c|c|}
\hline \multicolumn{9}{|l|}{ Nonfeature } \\
\hline \multicolumn{9}{|c|}{ Square 27 Level 35} \\
\hline 1168 & 345 & 84 & 8.7 & B NRM-AF4OO & 91 & $\mathrm{~N}$ & 35 & postcooling \\
\hline \multirow[t]{3}{*}{1169} & 333 & 32 & 1.3 & B NRM-AF100 & 196 & $\mathrm{E}$ & 35 & postcooling \\
\hline & 351 & 36 & 3.4 & B AF100-AF200 & 351 & $\mathrm{~W}$ & 20 & $100^{\circ} \mathrm{Oe}$ \\
\hline & 347 & -25 & 0 & S AF300-AF400 & 220 & SE & 71 & $200-300^{\circ} \mathrm{Oe}$ \\
\hline \multicolumn{9}{|l|}{ Nonfeature } \\
\hline \multicolumn{9}{|c|}{ Square 27 Level 35} \\
\hline 1179 & 348 & 52 & 0.7 & B AF200-AF400 & 161 & $\mathrm{E}$ & 10 & postcooling \\
\hline 1180 & 324 & 24 & 2.8 & B AF025-AF300 & 190 & $\mathrm{E}$ & 49 & postcooling \\
\hline \multicolumn{9}{|l|}{ Nonfeature } \\
\hline \multicolumn{9}{|c|}{ Square 50 Level 32-A } \\
\hline 1136 & 352 & 48 & 5.1 & B AF050-AF400 & 191 & $\mathrm{E}$ & 7 & $<50^{\circ} \mathrm{Oe}$ \\
\hline \multicolumn{9}{|c|}{ Burned Rock Midden 1 (Square 100) } \\
\hline \multicolumn{9}{|l|}{ Level 2} \\
\hline \multirow[t]{5}{*}{591} & 264 & -45 & 3.6 & B TD150-TD300 & 134 & NE & 175 & $<150^{\circ} \mathrm{C}$ \\
\hline & 278 & -21 & 3.1 & B TD300-TD450 & or, opposite & & & \\
\hline & 325 & 10 & 1 & B TD450-TD575 & 314 & SW & 185 & \\
\hline & & & & & 231 & SE & 30 & $300^{\circ} \mathrm{C}$ \\
\hline & & & & & 157 & E-NE & 57 & $450^{\circ} \mathrm{C}$ \\
\hline 592 & 49 & 62 & 1531 & F NRM-AF400 & 43 & NW & 34 & postcooling \\
\hline \multirow[t]{2}{*}{593} & 68 & 66 & 6 & B NRM-AF100 & 45 & NW & 44 & postcooling \\
\hline & 109 & -46 & 0.6 & B AF200-AF600 & 51 & NW & 130 & $100-200^{\circ} \mathrm{Oe}$ \\
\hline \multirow[t]{2}{*}{596} & 3 & 54 & 2.8 & B TD100-TD200 & & & $<5$ & postcooling \\
\hline & 158 & 30 & 1491 & F TD250-TD550 & 78 & $\mathrm{~N}$ & 95 & $200-250^{\circ} \mathrm{C}$ \\
\hline 598 & 173 & 17 & 1.2 & B AF100-AF400 & 87 & $\mathrm{~N}$ & 114 & $<100^{\circ} \mathrm{Oe}$ \\
\hline \multirow[t]{3}{*}{601} & 349 & 77 & 2.2 & B TD100-TD200 & 95 & $\mathrm{~N}$ & 27 & postcooling \\
\hline & 306 & -2 & 2.1 & B TD350-TD500 & 170 & $\mathrm{E}$ & 119 & $200<\mathrm{t}<350^{\circ} \mathrm{C}$ \\
\hline & 342 & -7 & 0.6 & В TD500-TD575 & 192 & $\mathrm{E}$ & 48 & $500^{\circ} \mathrm{C}$ \\
\hline \multirow[t]{2}{*}{602} & 20 & 40 & 3.8 & B AF050-AF150 & 344 & W & 22 & $<50^{\circ} \mathrm{Oe}$ \\
\hline & 20 & 3 & 3.6 & B AF200-AF400 & 314 & SW & 41 & $150-200^{\circ} \mathrm{Oe}$ \\
\hline
\end{tabular}


Table A6-1, continued

\begin{tabular}{|c|c|c|c|c|c|c|c|c|}
\hline & & Ident & fied Vectors & & & Reconstru & ucted Vector Ro & otations \\
\hline $\begin{array}{l}\text { Sample } \\
\text { (AM-) }\end{array}$ & Declination & Inclination & MAD or $\kappa$ & Range & Strike & $\begin{array}{l}\text { Direction of } \\
\text { rotation }\end{array}$ & $\begin{array}{l}\text { Magnitude of } \\
\text { rotation }\end{array}$ & Threshold \\
\hline Burned Rock $\mathrm{N}$ & idden 1 (Squar & 100) & & & & . & & \\
\hline Level 3 & & & & & & & & \\
\hline 647 & 88 & 22 & 3.3 & B AF050-AF200 & 33 & NW & 88 & $<50^{\circ} \mathrm{Oe}$ \\
\hline & 90 & 0 & 4.4 & B AF200-AF400 & 33 & NW & 27 & $200^{\circ} \mathrm{Oe}$ \\
\hline 648 & 63 & 49 & 4.8 & B NRM-TD150 & 30 & NW & 49 & postcooling \\
\hline & 9 & -41 & 1.5 & B TD300-TD575 & 17 & W & 157 & $150<\mathrm{t}<200^{\circ} \mathrm{C}$ \\
\hline & 340 & -39 & 0.5 & B TD575-TD650 & or, opposite & & & \\
\hline & & & & & 197 & $\mathrm{E}$ & 203 & \\
\hline & & & & & 39 & NW & 27 & $575^{\circ} \mathrm{C}$ \\
\hline 649 & 111 & 6 & 5.9 & B TD200-TD300 & 47 & NW & 115 & $<200^{\circ} \mathrm{C}$ \\
\hline & 325 & 30 & 1.1 & B TD400-TD550 & 216 & SE & 131 & $300-400^{\circ} \mathrm{C}$ \\
\hline & 257 & 0 & 6.3 & B TD550-TD650 & 134 & $\mathrm{NE}$ & 53 & $550^{\circ} \mathrm{C}$ \\
\hline 653 & 17 & 35 & 914 & F NRM-TD600 & 331 & SW & 24 & postcooling \\
\hline 654 & 16 & 72 & 3 & B NRM-TD200 & 76 & $\mathrm{~N}$ & 23 & postcooling \\
\hline & 196 & 20 & 866 & F TD250-TD550 & 102 & $\mathrm{~N}$ & 90 & $200-250^{\circ} \mathrm{C}$ \\
\hline 655 & 318 & 50 & 3.4 & B TD150-TD250 & 159 & E-NE & 35 & $<150^{\circ} \mathrm{C}$ \\
\hline & 287 & 44 & 2.8 & B TD250-TD550 & 129 & NE & 22 & $250^{\circ} \mathrm{C}$ \\
\hline 656 & 19 & 66 & 4.7 & B NRM-AF100 & 63 & NW & 20 & postcooling \\
\hline & 195 & -4 & 2.2 & B AF200-AF400 & 101 & $\mathrm{~N}$ & 111 & $100-200^{\circ} \mathrm{Oe}$ \\
\hline 659 & 29 & 40 & 1.8 & B NRM-AF150 & 356 & W & 30 & postcooling \\
\hline & 35 & 24 & 1.2 & B AF200-AF400 & 340 & W-SW & 21 & $150-200^{\circ} \mathrm{Oe}$ \\
\hline 1180 & 324 & 24 & 2.8 & B AF025-AF300 & 190 & $\mathrm{E}$ & 49 & postcooling \\
\hline Burned Rock $\mathrm{N}$ & idden 1 (Squar & 100) & & & & & & \\
\hline Level 4 & & & & & & & & \\
\hline 684 & 359 & 52 & 2 & B NRM-TD150 & & & $<3$ & postcooling \\
\hline 685 & 344 & 48 & 3.3 & B NRM-AF100 & 178 & E & 13 & postcooling \\
\hline & 303 & 10 & 0.2 & B AF200-AF400 & 172 & $\mathrm{E}$ & 69 & $100-200^{\circ} \mathrm{Oe}$ \\
\hline 687 & 336 & 48 & 0.4 & B AF050-AF150 & 173 & $\mathrm{E}$ & 21 & $<50^{\circ} \mathrm{Oe}$ \\
\hline & 358 & 28 & 2.9 & B AF $200-A F 400$ & 297 & SW & 28 & $150-200^{\circ} \mathrm{Oe}$ \\
\hline 688 & 311 & 58 & 5.6 & B NRM-TD150 & 142 & NE & 35 & postcooling \\
\hline & 209 & 0 & 1.7 & B TD250-TD650 & 105 & $\mathrm{~N}$ & 99 & $150-250^{\circ} \mathrm{C}$ \\
\hline 690 & 226 & -15 & 2.5 & B TD200-TD400 & 118 & NE & 142 & $<200^{\circ} \mathrm{C}$ \\
\hline & 210 & -22 & 0.9 & B TD400-TD600 & 47 & NW & 20 & $400^{\circ} \mathrm{C}$ \\
\hline 692 & 72 & -61 & 2.9 & B TD200-TD300 & 228 & SE & 161 & $<200^{\circ} \mathrm{C}$ \\
\hline & 156 & -73 & 2.6 & B TD500-TD650 & or, opposite & & & \\
\hline & & & & & 48 & NW & 199 & \\
\hline & & & & & 147 & NE & 37 & $300<\mathrm{t}<500^{\circ} \mathrm{C}$ \\
\hline 694 & 101 & 21 & 1.1 & B AF150-AF400 & 42 & NW & 97 & $<150^{\circ} \mathrm{Oe}$ \\
\hline 696 & 351 & 45 & 0.4 & B TD100-TD200 & 207 & SE & 9 & postcooling \\
\hline & 342 & 16 & 1.2 & B TD250-TD650 & 224 & SE & 34 & $200-250^{\circ} \mathrm{C}$ \\
\hline 697 & 349 & 28 & 1.3 & B NRM-AF150 (MINUS 100) & 232 & SE & 27 & postcooling \\
\hline & 187 & 61 & 0 & S AF300-AF400 & 82 & $\mathrm{~N}$ & 91 & $150-300^{\circ} \mathrm{Oe}$ \\
\hline Burned Rock $\mathrm{N}$ & idden 1 (Squar & $100)$ & & & & & & \\
\hline Level 5 & & & & & & & & \\
\hline 737 & 71 & 60 & 1.4 & B AF200-AF400 & 45 & NW & 45 & $<200^{\circ} \mathrm{Oe}$ \\
\hline 738 & 22 & 53 & 2.5 & B NRM-TD500 & 21 & W-NW & 17 & postcooling \\
\hline & 256 & -3.8 & 0 & S TD550-ORIGIN & 135 & $\mathrm{NE}$ & 141 & $500-550^{\circ} \mathrm{C}$ \\
\hline 739 & 338 & -41 & 3.9 & B AF050-AF150 & 188 & E & 143 & $<50^{\circ} \mathrm{Oe}$ \\
\hline & 340 & -57 & 1.4 & B AF150-AF400 & or, opposite & & & \\
\hline & & & & & 8 & W & 217 & \\
\hline & & & & & 150 & $\mathrm{BE}$ & 19 & $150^{\circ} \mathrm{Oe}$ \\
\hline
\end{tabular}


Table A6-1, continued

\begin{tabular}{|c|c|c|c|c|c|c|c|c|}
\hline \multicolumn{5}{|c|}{ Identified Vectors } & \multicolumn{4}{|c|}{ Reconstructed Vector Rotations } \\
\hline $\begin{array}{l}\text { Sample } \\
\text { (AM-) }\end{array}$ & Declination & Inclination & MAD or $\kappa$ & Range & Strike & $\begin{array}{l}\text { Direction of } \\
\text { rotation }\end{array}$ & $\begin{array}{l}\text { Magnitude of } \\
\text { rotation }\end{array}$ & Threshold \\
\hline 740 & 21 & 76 & 1741 & F NRM-AF400 & 79 & $\mathrm{~N}$ & 28 & postcooling \\
\hline \multirow[t]{2}{*}{742} & 352 & 67 & 1.4 & B AF050-AF150 & 100 & $\mathrm{~N}$ & 13 & $<50^{\circ} \mathrm{Oe}$ \\
\hline & 223 & 62 & 1.4 & B AF200-AF400 & 108 & $\mathrm{~N}$ & 47 & $150-200^{\circ} \mathrm{Oe}$ \\
\hline \multirow[t]{2}{*}{743} & 1 & 51 & 5.3 & B NRM-TD200 & & & $<2$ & postcooling \\
\hline & 340 & -32 & 3 & B TD250-TD575 & 208 & SE & 110 & $200-250^{\circ} \mathrm{C}$ \\
\hline \multirow[t]{2}{*}{744} & 39 & 49 & 3.4 & B AF050-AF150 & 17 & W & 32 & $<50^{\circ} \mathrm{Oe}$ \\
\hline & 67 & 57 & 2.6 & B AF200-AF400 & 88 & $\mathrm{~N}$ & 19 & $150-200^{\circ} \mathrm{Oe}$ \\
\hline \multirow[t]{4}{*}{745} & 3 & 45 & 0 & S TD100-TD150 & & & $\sim 6$ & postcooling \\
\hline & 204 & -30 & 1.2 & B TD300-TD600 & 104 & $\mathrm{~N}$ & 160 & $150<\mathrm{t}<300^{\circ} \mathrm{C}$ \\
\hline & & & & & or, opposite & & & \\
\hline & & & & & 284 & S & 200 & \\
\hline \multirow[t]{3}{*}{747} & 355 & 61 & 3 & B NRM-AF100 & 102 & $\mathrm{~N}$ & 12 & postcooling \\
\hline & 317 & 54 & 2 & B AF100-AF200 & 170 & $\mathrm{E}$ & 29 & $100^{\circ} \mathrm{Oe}$ \\
\hline & 314 & 39 & 2.9 & B AF300-AF600 & 192 & E & 20 & $200-300^{\circ} \mathrm{Oe}$ \\
\hline \multicolumn{9}{|c|}{ Burned Rock Midden 1 (Square 100) } \\
\hline \multicolumn{9}{|l|}{ Level 6} \\
\hline \multirow[t]{2}{*}{806} & 17 & 46 & 2 & B NRM-TD150 & 354 & W & 17 & postcooling \\
\hline & 119 & 34 & 3.7 & B TD250-TD600 & 64 & NW & 77 & $150-250^{\circ} \mathrm{C}$ \\
\hline \multirow[t]{2}{*}{807} & 340 & 25 & 3.7 & B AF100-AF200 & 214 & SE & 35 & $<100^{\circ} \mathrm{Oe}$ \\
\hline & 334 & 4 & 1.2 & B AF200-AF400 & 208 & SE & 27 & $200^{\circ} \mathrm{Oe}$ \\
\hline 809 & 352 & 53 & 3892 & F NRM-AF400 & & & $<5$ & postcooling \\
\hline 810 & 310 & 61 & 2.5 & B NRM-AF600 & 138 & NE & 35 & postcooling \\
\hline 811 & 359 & 47 & 3.1 & B AF200-AF400 & & & $<5$ & $<200^{\circ} \mathrm{Oe}$ \\
\hline \multirow[t]{3}{*}{812} & 128 & -36 & 3370 & F TD200-TD600 & 60 & NW & 165 & $<200^{\circ} \mathrm{C}$ \\
\hline & & & & & or, opposite & & & \\
\hline & & & & & 240 & SE & 195 & \\
\hline \multirow[t]{2}{*}{815} & 271 & 31 & 2.5 & B NRM-TD450 & 144 & NE & 80 & postcooling \\
\hline & 314 & 24 & 1.2 & B TD500-TD575 & 230 & SE & 43 & $450-500^{\circ} \mathrm{C}$ \\
\hline \multicolumn{9}{|c|}{ Burned Rock Midden 1 (Square 100) } \\
\hline \multicolumn{9}{|l|}{ Level 7} \\
\hline 849 & 10 & 52 & 1171 & F NRM-TD575 & 19 & W & 9 & postcooling \\
\hline 850 & 31 & 45 & 0.6 & B AF050-AF400 & 6 & W & 28 & $<50^{\circ} \mathrm{Oe}$ \\
\hline \multirow[t]{3}{*}{852} & 3 & 57 & 1.8 & B TD100-TD400 & 77 & $\mathrm{~N}$ & 8 & postcooling \\
\hline & 310 & 11 & 1.8 & B TD450-TD550 & 180 & $\mathrm{E}$ & 83 & $400-450^{\circ} \mathrm{C}$ \\
\hline & 341 & 35 & 1.9 & B TD575-TD650 & 335 & W-SW & 46 & $550-575^{\circ} \mathrm{C}$ \\
\hline 853 & 359 & 59 & 2 & B AF100-AF400 & 92 & $\mathrm{~N}$ & 10 & $<100^{\circ} \mathrm{Oe}$ \\
\hline 855 & 5 & 45 & 1040 & F NRM-AF400 & & & $\sim 6$ & postcooling \\
\hline \multirow[t]{2}{*}{857} & 21 & 47 & 2.4 & B TD100-TD500 & 2 & W & 19 & postcooling \\
\hline & 108 & 2 & 1.3 & B TD550-TD600 & 47 & NW & 101 & $500-550^{\circ} \mathrm{C}$ \\
\hline \multicolumn{9}{|c|}{ Burned Rock Midden 1 (Square 100) } \\
\hline \multicolumn{9}{|l|}{ Level 8} \\
\hline 947 & 35 & 46 & 1.8 & B NRM-TD200 & 10 & W & 32 & postcooling \\
\hline & 145 & -27 & 5.1 & B TD250-TD400 & 65 & N-NW & 130 & $200-250^{\circ} \mathrm{C}$ \\
\hline & 202 & -54 & 0.6 & B TD450-TD550 & 92 & $\mathrm{~N}$ & 55 & $400-450^{\circ} \mathrm{C}$ \\
\hline 948 & 350 & 28 & 1886 & F NRM-TD400 & 234 & SE & 25 & postcooling \\
\hline 949 & 359 & 42 & 116 & F NRM-TD550 & & & $\sim 8$ & postcooling \\
\hline 953 & 318 & 38 & 5 & B AF050-AF150 & 175 & $\mathrm{E}$ & 42 & $<50^{\circ} \mathrm{Oe}$ \\
\hline & 265 & -39 & 3.1 & B AF $200-A F 400$ & 143 & NE & 113 & $150-200^{\circ} \mathrm{Oe}$ \\
\hline 955 & 4 & 63 & 2.5 & B NRM-TD200 & 81 & $\mathrm{~N}$ & 13 & postcooling \\
\hline & 42 & 71 & 2.1 & B TD200-TD400 & 48 & NW & 18 & $200^{\circ} \mathrm{C}$ \\
\hline
\end{tabular}


Table A6-1, continued

\begin{tabular}{|c|c|c|c|c|c|c|c|c|}
\hline & & Identi & fied Vectors & & & Reconstru & ucted Vector Ro & tations \\
\hline $\begin{array}{l}\text { Sample } \\
\text { (AM-) }\end{array}$ & Declination & Inclination & MAD or $\kappa$ & Range & Strike & $\begin{array}{c}\text { Direction of } \\
\text { rotation }\end{array}$ & $\begin{array}{l}\text { Magnitude of } \\
\text { rotation }\end{array}$ & Threshold \\
\hline & 220 & 4 & 1.5 & B TD575-TD650 & 116 & $\mathrm{NE}$ & 113 & $400<t<575^{\circ} \mathrm{C}$ \\
\hline 956 & 358 & 46 & 5.4 & B NRM-AF150 & & & $\sim 6$ & postcooling \\
\hline & 343 & 4 & 2.7 & B AF $200-A F 400$ & 224 & SE & 50 & $150-200^{\circ} \mathrm{Oe}$ \\
\hline Burned Rock $\mathrm{N}$ & dden 1 (Squa & e 100) & & & & & & \\
\hline Level 9 & & & & & & & & \\
\hline 985 & 358 & 39 & 2.8 & B TD100-TD200 & 264 & S & 11 & postcooling \\
\hline & 92 & 18 & 5.6 & B TD350-TD575 & 39 & NW & 99 & $200<\mathrm{t}<350^{\circ} \mathrm{C}$ \\
\hline 987 & 8 & 58 & 3.2 & B NRM-TD250 & 57 & NW & 10 & postcooling \\
\hline & 300 & 3 & 2.2 & B TD400-TD600 & 170 & $\mathrm{E}$ & 108 & $250<\mathrm{t}<400^{\circ} \mathrm{C}$ \\
\hline Burned Rock $\mathrm{A}$ & dden 1 (Squa & e 100) & & & & & & \\
\hline Level 10 & & & & & & & & \\
\hline 1001 & 96 & -3 & 3152 & F NRM-AF400 & 37 & NW & 120 & postcooling \\
\hline 1004 & 259 & 74 & 2026 & F NRM-AF600 & 110 & $\mathrm{~N}-\mathrm{NE}$ & 47 & postcooling \\
\hline 1005 & 142 & -27 & 1.4 & B TD350-TD650 & 68 & N-NW & 156 & $<350^{\circ} \mathrm{C}$ \\
\hline & & & & & or, oppo & & & \\
\hline & & & & & 248 & S-SE & 204 & \\
\hline 1007 & 9 & 30 & 6 & B TD100-TD200 & 302 & SW & 22 & postcooling \\
\hline & 354 & -51 & 6.2 & B TD250-TD350 & 290 & S-SW & 86 & $200-250^{\circ} \mathrm{C}$ \\
\hline & 242 & -63 & 0.9 & B TD450-TD600 & 292 & S-SW & 56 & $350-450^{\circ} \mathrm{C}$ \\
\hline 1008 & 299 & 64 & 4.9 & B NRM-AF100 (MINUS & 131 & NE & 39 & postcooling \\
\hline & 199 & -20 & 3.6 & $\mathrm{~B}$ AF $200-\mathrm{AF} 400$ & 101 & $\mathrm{~N}$ & 115 & $100-200^{\circ} \mathrm{Oe}$ \\
\hline 1009 & 5 & 41 & 5.5 & B NRM-TD150 & 300 & SW & 10 & postcooling \\
\hline & 109 & -60 & 1.5 & B TD250-TD600 & 230 & SE & 171 & $150-250^{\circ} \mathrm{C}$ \\
\hline & & & & & or, oppo & & & \\
\hline & & & & & 50 & NW & 189 & \\
\hline Burned Rock $\mathrm{I}$ & dden 1 (Squa & e 100) & & & & & & \\
\hline Level 11 & & & & & & & & \\
\hline 1170 & 23 & 35 & 397 & F NRM-TD600 & 341 & W & 29 & postcooling \\
\hline 1171 & 232 & -28 & 1188 & F TD200-TD600 & 116 & NE & 137 & $<200^{\circ} \mathrm{C}$ \\
\hline
\end{tabular}


TABLE A6-2

Feature 231, 181, and 245 Samples

\begin{tabular}{|c|c|c|c|c|c|c|c|c|}
\hline & & & entified Vect & & & Reconstruc & ed Vector Rc & tations \\
\hline $\begin{array}{l}\text { Sample } \\
\text { (AM-) }\end{array}$ & Declination & Inclination & MAD or $\kappa$ & Range & Strike & $\begin{array}{c}\text { Direction } \\
\text { of rotation }\end{array}$ & $\begin{array}{l}\text { Magnitude } \\
\text { of rotation }\end{array}$ & Threshold \\
\hline Square $20, \mathrm{~L}$ & vel 19 & & & & & & & \\
\hline 299 & 327 & 50 & 0 & S NRM-TD250 & 162 & E & 26 & postcooling \\
\hline & 152 & -61 & 2.2 & B TD350-TD650 & 96 & $\mathrm{~N}$ & 172 & $250-350^{\circ} \mathrm{C}$ \\
\hline & & & & & or, opposite & & & \\
\hline & & & & & 276 & $S$ & 188 & \\
\hline 300 & 355 & 56 & 16545 & F NRM-AF400 & 119 & NE & 7 & postcooling \\
\hline 301 & 331 & 43 & 2.5 & B NRM-TD200 (MINUS 150) & 179 & E & 28 & postcooling \\
\hline & 249 & -32 & 0.3 & B TD250-TD350 & 135 & NE & 127 & $200-250^{\circ} \mathrm{C}$ \\
\hline & 158 & -25 & 2.2 & B TD400-TD650 & 71 & $\mathrm{~N}$ & 80 & $350-400^{\circ} \mathrm{C}$ \\
\hline 302 & 306 & 56 & 3.3 & B AF050-AF200 & 145 & $\mathrm{NE}$ & 38 & $<50^{\circ} \mathrm{Oe}$ \\
\hline & $>341$ & $<21$ & 2.2 & B AF300-AF600 & $\sim 240$ & SE & $\sim 45$ & $200-300^{\circ} \mathrm{Oe}$ \\
\hline 304 & 328 & 66 & 4.8 & B NRM-TD150 & 124 & NE & 25 & postcooling \\
\hline & 252 & 57 & 0.7 & B TD350-TD650 & 121 & NE & 37 & $150<\mathrm{t}<350^{\circ} \mathrm{C}$ \\
\hline 306 & 314 & -54 & 4 & B TD200-TD650 & 330 & SW & 168 & $<200^{\circ} \mathrm{C}$ \\
\hline & & & & & or, opposite & & & \\
\hline & & & & & 150 & $\mathrm{NE}$ & 192 & \\
\hline Square $20, \mathrm{~L}$ & vel 24 & & & & & & & \\
\hline 377 & 266 & -24 & 2.2 & B TD200-TD650 & 142 & NE & 146 & $<200^{\circ} \mathrm{C}$ \\
\hline 380 & 170 & 27 & 3.9 & B TD150-TD300 & 84 & $\mathrm{~N}$ & 104 & $<150^{\circ} \mathrm{C}$ \\
\hline & 166 & 12 & 2.9 & B TD350-TD575 & 63 & NW & 15 & $300-350^{\circ} \mathrm{C}$ \\
\hline 381 & 352 & 69 & 3.6 & B TD100-TD200 & 100 & $\mathrm{~N}$ & 20 & postcooling \\
\hline & 168 & 8 & 6.8 & В TD200-TD300 & 82 & $\mathrm{~N}$ & 102 & $200^{\circ} \mathrm{C}$ \\
\hline & 125 & -60 & 5.1 & B TD350-TD450 & 74 & $\mathrm{~N}$ & 79 & $300-350^{\circ} \mathrm{C}$ \\
\hline & 47 & -62 & 1.4 & B TD500-TD575 & 76 & $\mathrm{~N}$ & 36 & $450-500^{\circ} \mathrm{C}$ \\
\hline 382 & 22 & 51 & 1.8 & B NRM-AF150 (MINUS 50) & 12 & W & 18 & postcooling \\
\hline & 37 & 35 & 2.8 & B AF200-AF600 & 350 & W & 26 & $<200^{\circ} \mathrm{Oe}$ \\
\hline 383 & 151 & -9 & 1657 & F TD300-TD575 & 72 & $\mathrm{~N}$ & 137 & $<300^{\circ} \mathrm{C}$ \\
\hline 384 & 17 & 45 & 2.6 & B TD100-TD200 & 351 & W & 15 & postcooling \\
\hline & 57 & -16 & 1 & B TD300-TD400 & 7 & W & 102 & $200-300^{\circ} \mathrm{C}$ \\
\hline & 330 & -7 & 2.8 & B TD500-TD600 & 344 & W & 119 & $400-500^{\circ} \mathrm{C}$ \\
\hline Square $20, \mathrm{~L}$ & vel 27 & & & & & & & \\
\hline 784 & 66 & 61 & 3.9 & B NRM-TD150 & 46 & NW & 42 & postcooling \\
\hline & 101 & -34 & 1.4 & B TD500-TD650 & 45 & NW & 118 & $150<\mathrm{t}<500^{\circ} \mathrm{C}$ \\
\hline 785 & 9 & 89 & 5.1 & B AF050-AF150 & 90 & $\mathrm{~N}$ & 39 & $<50^{\circ} \mathrm{Oe}$ \\
\hline & 159 & 84 & 2.2 & B AF150-AF800 & 65 & $\mathrm{~N}-\mathrm{NW}$ & 7 & $150^{\circ} \mathrm{Oe}$ \\
\hline Square $25, \mathrm{~L}$ & vel 22 & & & & & & & \\
\hline 231 & 7 & 55 & 2.8 & B AF025-AF400 & 47 & NW & 7 & postcooling \\
\hline & $\sim 351$ & $<22$ & 0 & S AF400-ORIGIN & $?$ & $?$ & $?$ & $400^{\circ} \mathrm{Oe}$ \\
\hline 232 & 321 & 66 & 1.9 & B TD100-TD250 (MINUS 200) & 128 & NE & 28 & postcooling \\
\hline & 317 & 50 & 2.2 & B TD250-TD400 & 203 & E-SE & 20 & $250^{\circ} \mathrm{C}$ \\
\hline 233 & 313 & 48 & 4 & B NRM-TD150 & 160 & E-NE & 38 & postcooling \\
\hline & 192 & 32 & 2236 & F TD250-TD600 & 82 & $\mathrm{~N}$ & 85 & $150-250^{\circ} \mathrm{C}$ \\
\hline 235 & 10 & 30 & 0 & S NRM-AF100 & 306 & SW & 23 & postcooling \\
\hline & 275 & -35 & 4.2 & B AF150-AF400 & 150 & NE & 170 & $100-150^{\circ} \mathrm{Oe}$ \\
\hline$\overline{\text { Square } 25, \mathrm{~L}}$ & vel 24 & & & & & & & \\
\hline 312 & 355 & 41 & 0 & S NRM-AF100 & 236 & SE & 10 & postcooling \\
\hline & 93 & -72 & 2.4 & B AF150-AF300 & 248 & S-SE & 141 & $100-150^{\circ} \mathrm{C}$ \\
\hline & 147 & -74 & 5 & B AF300-AF600 & 182 & E & 20 & $300^{\circ} \mathrm{C}$ \\
\hline 313 & 355 & 67 & 4.3 & B NRM-TD150 & 97 & $\mathrm{~N}$ & 17 & postcooling \\
\hline & 181 & 8 & 2.7 & B TD200-TD400 & 90 & $\mathrm{~N}$ & 105 & $150-200^{\circ} \mathrm{C}$ \\
\hline
\end{tabular}


Table A6-2, continued

\begin{tabular}{|c|c|c|c|c|c|c|c|c|}
\hline \multicolumn{5}{|c|}{ Identified Vectors } & \multicolumn{4}{|c|}{ Reconstructed Vector Rotations } \\
\hline $\begin{array}{l}\text { Sample } \\
\text { (AM-) }\end{array}$ & Declination & Inclination & MAD or $\kappa$ & Range & Strike & $\begin{array}{l}\text { Direction } \\
\text { of rotation }\end{array}$ & $\begin{array}{l}\text { Magnitude } \\
\text { of rotation }\end{array}$ & Threshold \\
\hline & 216 & 18 & 4.3 & B TD500-TD600 & 184 & $\mathrm{E}$ & 46 & $400-500^{\circ} \mathrm{C}$ \\
\hline \multicolumn{9}{|c|}{ Square 25, Level 25} \\
\hline \multirow[t]{5}{*}{409} & 354 & 51 & 4 & B NRM-TD250 (MINUS 200) & & & $<5$ & postcooling \\
\hline & 144 & -27 & 5.4 & B TD400-TD500 & 69 & N-NW & 155 & $250<\mathrm{t}<400^{\circ} \mathrm{C}$ \\
\hline & 142 & 19 & 0.4 & B TD500-TD600 & or, opposite & & & \\
\hline & & & & & 249 & S-SE & 205 & \\
\hline & & & & & 258 & $\mathrm{~S}$ & 45 & $500^{\circ} \mathrm{C}$ \\
\hline \multicolumn{9}{|c|}{ Square 25 , Level 26} \\
\hline \multirow[t]{2}{*}{455} & 59 & 31 & 8.8 & B NRM-AF100 & 15 & W & 62 & postcooling \\
\hline & 129 & -68 & 1.8 & B AF200-AF800 & 49 & NW & 133 & $100-200^{\circ} \mathrm{C}$ \\
\hline \multicolumn{9}{|c|}{ Square 25 , Level 28} \\
\hline \multirow[t]{5}{*}{572} & 0 & 58 & 0.1 & B NRM-TD150 & 90 & $\mathrm{~N}$ & 8 & postcooling \\
\hline & 233 & -44 & 1.7 & B TD200-TD400 & 116 & NE & 162 & $150-200^{\circ} \mathrm{C}$ \\
\hline & 68 & -18 & 2.4 & B TD550-TD650 & or, opposite & & & \\
\hline & & & & & 296 & SW & 198 & \\
\hline & & & & & 82 & $\mathrm{~N}$ & 123 & $400<\mathrm{t}<550^{\circ} \mathrm{C}$ \\
\hline \multicolumn{9}{|c|}{ Square 26, Level 21} \\
\hline \multirow[t]{2}{*}{142} & 315 & 55 & 7.8 & B TD100-TD200 & 149 & NE & 33 & postcooling \\
\hline & 236 & 23 & 706 & F TD200-TD600 & 115 & N-NE & 70 & $200^{\circ} \mathrm{C}$ \\
\hline \multirow[t]{3}{*}{144} & 10 & 60 & 2.5 & B NRM-TD150 & 62 & NW & 13 & postcooling \\
\hline & 54 & 68 & 3.4 & B TD150-TD250 & 51 & NW & 22 & $150^{\circ} \mathrm{C}$ \\
\hline & 204 & -36 & 1.2 & B TD400-TD650 & 97 & $\mathrm{~N}$ & 143 & $250<\mathrm{t}<400^{\circ} \mathrm{C}$ \\
\hline \multirow[t]{5}{*}{146} & 5 & 23 & 1.3 & B TD200-TD300 & 286 & $S$ & 28 & $<200^{\circ} \mathrm{C}$ \\
\hline & 299 & 32 & 2.1 & B TD300-TD550 & 149 & $\mathrm{NE}$ & 32 & $300^{\circ} \mathrm{C}$ \\
\hline & 60 & -70 & 0 & S TD550-TD600 & 309 & SW & 169 & $550^{\circ} \mathrm{C}$ \\
\hline & & & & & or, opposite & & & \\
\hline & & & & & 129 & $\mathrm{NE}$ & 191 & \\
\hline \multirow[t]{3}{*}{147} & 349 & 49 & 5.7 & B NRM-TD150 & 180 & $\mathrm{E}$ & 9 & postcooling \\
\hline & 27 & -37 & 0.8 & B TD250-TD350 & 348 & W & 137 & $150-250^{\circ} \mathrm{C}$ \\
\hline & 32 & -62 & 3.2 & B TD500-TD600 & 26 & NW & 32 & $350<\mathrm{t}<500^{\circ} \mathrm{C}$ \\
\hline \multirow[t]{3}{*}{148} & 31 & 44 & 2.9 & B TD100-TD250 & 4 & W & 28 & postcooling \\
\hline & 329 & 11 & 2.4 & B TD350-TD450 & 200 & E-SE & 80 & $250-350^{\circ} \mathrm{C}$ \\
\hline & 316 & -29 & 1.7 & B TD450-TD650 & 186 & E & 56 & $450^{\circ} \mathrm{C}$ \\
\hline \multicolumn{9}{|c|}{ Square 26, Level 22} \\
\hline \multirow[t]{3}{*}{182} & 218 & -46 & 2.7 & B AF200-AF400 & 109 & $\mathrm{~N}$ & 176 & $<200^{\circ} \mathrm{Oe}$ \\
\hline & & & & & or, opposite & & & \\
\hline & & & & & 289 & $S$ & 184 & \\
\hline \multirow[t]{2}{*}{184} & 120 & 48 & 6.6 & B NRM-TD500 & 59 & NW & 75 & postcooling \\
\hline & 156 & 19 & 0.4 & B TD575-TD650 & 100 & $\mathrm{~N}$ & 42 & $500-575 \mathrm{C}$ \\
\hline \multirow[t]{2}{*}{185} & 165 & -9 & 7.2 & B TD200-TD500 (MINUS 350) & 81 & $\mathrm{~N}$ & 139 & $<200^{\circ} \mathrm{C}$ \\
\hline & 113 & 2 & 1.4 & B TD500-TD600 & 5 & W & 71 & $500^{\circ} \mathrm{C}$ \\
\hline \multirow[t]{2}{*}{186} & 295 & 15 & 5.1 & B NRM-TD150 & 165 & E & 83 & postcooling \\
\hline & 151 & -31 & 0.7 & B TD400-TD650 & 98 & $\mathrm{~N}$ & 145 & $150<\mathrm{t}<400^{\circ} \mathrm{C}$ \\
\hline 187 & 43 & -2 & 1230 & F NRM-TD550 & 353 & W & 86 & postcooling \\
\hline 189 & 57 & 64 & 2.1 & B TD100-TD200 & 48 & NW & 36 & postcooling \\
\hline & 156 & 27 & 5.1 & B TD200-TD600 & 85 & $\mathrm{~N}$ & 71 & $200^{\circ} \mathrm{C}$ \\
\hline 191 & 351 & 44 & 0 & S AF050-AF100 & 4 & W & 26 & $<50^{\circ} \mathrm{Oe}$ \\
\hline & 89 & -75 & 4.4 & B AF200-AF400 & 45 & NW & 178 & $100-200^{\circ} \mathrm{Oe}$ \\
\hline & & & & & or, opposite & & & \\
\hline & & & & & 225 & SE & 182 & \\
\hline
\end{tabular}


Table A6-2, continued

\begin{tabular}{|c|c|c|c|c|c|c|c|c|}
\hline \multicolumn{5}{|c|}{ Identified Vectors } & \multicolumn{4}{|c|}{ Reconstructed Vector Rotations } \\
\hline $\begin{array}{l}\text { Sample } \\
\text { (AM-) }\end{array}$ & Declination & Inclination & MAD or $\kappa$ & Range & Strike & $\begin{array}{c}\text { Direction } \\
\text { of rotation }\end{array}$ & $\begin{array}{l}\text { Magnitude } \\
\text { of rotation }\end{array}$ & Threshold \\
\hline \multicolumn{9}{|c|}{ Square 26, Level 25} \\
\hline \multirow[t]{3}{*}{418} & 16 & 64 & 5.5 & B NRM-TD300 & 62 & NW & 18 & postcooling \\
\hline & 74 & 86 & 3.7 & B TD300-TD450 & 101 & $\mathrm{~N}$ & 25 & $300^{\circ} \mathrm{C}$ \\
\hline & 242 & 0 & 0.6 & B TD550-TD600 & 130 & NE & 105 & $450-550^{\circ} \mathrm{C}$ \\
\hline \multicolumn{9}{|c|}{ Square 26, Level 26} \\
\hline \multirow[t]{3}{*}{446} & 355 & 68 & 8.1 & B TD100-TD250 & 96 & $\mathrm{~N}$ & 19 & postcooling \\
\hline & 290 & 84 & 3.6 & B TD250-TD450 & 99 & $\mathrm{~N}$ & 20 & $250^{\circ} \mathrm{C}$ \\
\hline & 241 & 81 & 0.5 & B TD450-TD575 & 135 & $\mathrm{NE}$ & 18 & $450^{\circ} \mathrm{C}$ \\
\hline \multirow[t]{4}{*}{449} & 0 & 46 & 10.5 & B TD150-TD250 & & & $\sim 4$ & $<150^{\circ} \mathrm{C}$ \\
\hline & 310 & -37 & 1.3 & B TD300-TD575 & 164 & $\mathrm{E}$ & 159 & $250-300^{\circ} \mathrm{C}$ \\
\hline & & & & & or, opposite & & & \\
\hline & & & & & 344 & W & 201 & \\
\hline \multirow[t]{5}{*}{451} & 0 & 57 & 4 & B NRM-TD200 & 88 & $\mathrm{~N}$ & 7 & postcooling \\
\hline & 266 & -35 & 2.1 & B TD250-TD350 & 136 & NE & 160 & $200-250^{\circ} \mathrm{C}$ \\
\hline & 257 & -72 & 1.7 & B TD500-TD600 & or, opposite & & & \\
\hline & & & & & 316 & SW & 200 & \\
\hline & & & & & 96 & $\mathrm{~N}$ & 37 & $350<\mathrm{t}<500^{\circ} \mathrm{C}$ \\
\hline \multicolumn{9}{|c|}{ Square 26, Level 27} \\
\hline \multirow[t]{3}{*}{491} & 357 & 55 & 3.6 & B NRM-TD300 & & & $<5$ & postcooling \\
\hline & 347 & 83 & 4 & B TD300-TD600 & 90 & $\mathrm{~N}$ & 28 & $300^{\circ} \mathrm{C}$ \\
\hline & $>118$ & $<54$ & 0 & S TD600-ORIGIN & $<39$ & NW? & $>45$ & $>600^{\circ} \mathrm{C}$ \\
\hline \multirow[t]{3}{*}{492} & 14 & 69 & 3.1 & B NRM-TD200 & 76 & $\mathrm{~N}$ & 20 & postcooling \\
\hline & 72 & 52 & 1.9 & B TD300-TD400 & 22 & W-NW & 42 & $200-300^{\circ} \mathrm{C}$ \\
\hline & 121 & -13 & 4.8 & B TD450-TD550 & 61 & NW & 83 & $400-450^{\circ} \mathrm{C}$ \\
\hline \multirow[t]{3}{*}{494} & 357 & 59 & 3.2 & B NRM-TD200 & & & $<5$ & postcooling \\
\hline & 22 & 14 & 4.3 & B TD250-TD350 & 315 & SW & 53 & $200-250^{\circ} \mathrm{C}$ \\
\hline & 330 & -35 & 4.9 & B TD500-TD600 & 261 & $S$ & 69 & $350<\mathrm{t}<500^{\circ} \mathrm{C}$ \\
\hline \multirow[t]{3}{*}{495} & 344 & 72 & 4.5 & B TD100-TD200 & 100 & $\mathrm{~N}$ & 28 & postcooling \\
\hline & 245 & 46 & 5.6 & B TD250-TD350 & 134 & $\mathrm{NE}$ & 53 & $200-250^{\circ} \mathrm{C}$ \\
\hline & 103 & 58 & 1.7 & В TD450-TD600 & 8 & W & 99 & $350-450^{\circ} \mathrm{C}$ \\
\hline \multirow[t]{2}{*}{496} & 0 & 48 & 6.9 & B NRM-TD300 & & & $<2$ & postcooling \\
\hline & 263 & 16 & 1.5 & B TD500-TD575 & 140 & NE & 103 & $300<\mathrm{t}<500^{\circ} \mathrm{C}$ \\
\hline \multicolumn{9}{|c|}{ Square 26, Level 27-Base } \\
\hline \multirow[t]{2}{*}{577} & 178 & 2 & 4.2 & B TD350-TD450 & 88 & $\mathrm{~N}$ & 138 & $<350^{\circ} \mathrm{C}$ \\
\hline & 249 & 39 & 1.1 & B TD500-TD575 & 178 & $\mathrm{E}$ & 115 & $450-500^{\circ} \mathrm{C}$ \\
\hline 578 & 92 & 65 & 2138 & F NRM-TD600 & 57 & NW & 50 & postcooling \\
\hline \multirow[t]{2}{*}{580} & 33 & 65 & 3.6 & B AF025-AF150 & 52 & NW & 25 & postcooling \\
\hline & 79 & 64 & 1.2 & B AF200-AF400 & 52 & NW & 21 & $150-200^{\circ} \mathrm{Oe}$ \\
\hline \multirow[t]{3}{*}{581} & 357 & 65 & 2.7 & B TD100-TD200 & 96 & $\mathrm{~N}$ & 15 & postcooling \\
\hline & 319 & 67 & 6 & B TD200-TD400 & 153 & NE & 20 & $200^{\circ} \mathrm{C}$ \\
\hline & 115 & 55 & 2.6 & B TD450-TD550 & 110 & $\mathrm{~N}-\mathrm{NE}$ & 35 & $400-450^{\circ} \mathrm{C}$ \\
\hline Square $26, \mathrm{Le}$ & vel 28 & & & & & & & \\
\hline 763 & 7 & 59 & 3577 & F NRM-TD350 & 65 & N-NW & 10 & postcooling \\
\hline & 33 & 36 & 4.2 & B TD550-TD650 & 322 & SW & 35 & $350<\mathrm{t}<550^{\circ} \mathrm{C}$ \\
\hline 764 & 353 & 31 & 2.5 & B AF050-AF150 & 244 & SE & 21 & $<50^{\circ} \mathrm{Oe}$ \\
\hline & 351 & 19 & 1.6 & B AF200-AF400 & 244 & SE & 13 & $150-200^{\circ} \mathrm{Oe}$ \\
\hline 766 & 13 & 55 & 1.3 & B TD100-TD350 & 36 & NW & 11 & postcooling \\
\hline & 126 & -60 & 1.9 & B TD450-TD575 & 63 & NW & 179 & $350-450^{\circ} \mathrm{C}$ \\
\hline & & & & & or, opposite & & & \\
\hline & & & & & 243 & SE & 181 & \\
\hline 768 & 332 & 54 & 5.6 & B TD100-TD250 (MINUS 200) & 155 & E-NE & 22 & postcooling \\
\hline
\end{tabular}


Table A6-2, continued

\begin{tabular}{|c|c|c|c|c|c|c|c|c|}
\hline & & & entified Vect & & & Reconstruc & ed Vector Ro & tations \\
\hline $\begin{array}{l}\text { Sample } \\
\text { (AM-) }\end{array}$ & Declination & Inclination & MAD or $\kappa$ & Range & Strike & $\begin{array}{l}\text { Direction } \\
\text { of rotation }\end{array}$ & $\begin{array}{l}\text { Magnitude } \\
\text { of rotation }\end{array}$ & Threshold \\
\hline & 291 & -60 & 5.1 & B TD300-TD450 & 141 & NE & 169 & $250-300^{\circ} \mathrm{C}$ \\
\hline & 268 & -40 & 2.1 & B TD450-TD600 & or, opposite & & & \\
\hline & & & & & 321 & SW & 191 & \\
\hline & & & & & 321 & SW & 27 & $450^{\circ} \mathrm{C}$ \\
\hline 769 & 342 & 50 & 0.5 & B AF100-AF200 & 171 & $\mathrm{E}$ & 15 & $<100^{\circ} \mathrm{Oe}$ \\
\hline & 324 & 52 & 2.8 & B AF300-AF600 & 143 & $\mathrm{NE}$ & 14 & $200-300^{\circ} \mathrm{Oe}$ \\
\hline 771 & 280 & -46 & 2.8 & B AF150-AF400 & 141 & NE & 175 & $<150^{\circ} \mathrm{C}$ \\
\hline & & & & & or, opposite & & & \\
\hline & & & & & 321 & SW & 185 & \\
\hline 772 & 0 & 65 & 0.6 & B TD150-TD300 (MINUS 250) & 90 & $\mathrm{~N}$ & 15 & $<150^{\circ} \mathrm{C}$ \\
\hline & 316 & 64 & 1.2 & B TD300-TD575 & 160 & E-NE & 24 & $300^{\circ} \mathrm{C}$ \\
\hline Square $26, \mathrm{Le}$ & vel 29 & & & & & & & \\
\hline 882 & 58 & 52 & 3.4 & B TD100-TD200 & 31 & NW & 44 & postcooling \\
\hline & 261 & 18 & 1.6 & B TD450-TD600 & 140 & NE & 137 & $200<\mathrm{t}<450^{\circ} \mathrm{C}$ \\
\hline 884 & 15 & 71 & 3.8 & B NRM-TD150 & 76 & $\mathrm{~N}$ & 22 & postcooling \\
\hline & 177 & 54 & 3.3 & B TD250-TD450 & 92 & $\mathrm{~N}$ & 56 & $150-250^{\circ} \mathrm{C}$ \\
\hline & 40 & -79 & 1.4 & B TD500-TD575 & 84 & $\mathrm{~N}$ & 152 & $450-500^{\circ} \mathrm{C}$ \\
\hline Square 27, Le & vel 20 & & & & & & & \\
\hline 127 & 15 & 33 & 1260 & F TD150-TD575 & 321 & SW & 23 & $<150^{\circ} \mathrm{C}$ \\
\hline 128 & 358 & 64 & 4.3 & B AF025-AF100 & 96 & $\mathrm{~N}$ & 15 & postcooling \\
\hline & 62 & -73 & 1.1 & B AF150-AF400 & 254 & $S$ & 151 & $100-150^{\circ} \mathrm{Oe}$ \\
\hline & $<44$ & $>-63$ & 0 & S 400-ORIGIN & or, opposite & & & \\
\hline & & & & & 74 & $\mathrm{~N}$ & 209 & \\
\hline 130 & 323 & 68 & 5.5 & B NRM-TD200 & 123 & NE & 27 & postcooling \\
\hline & 214 & 39 & 1.5 & B TD300-TD400 & 102 & $\mathrm{~N}$ & 62 & $200-300^{\circ} \mathrm{C}$ \\
\hline & 234 & 20 & 5.2 & B TD550-TD600 & 160 & E-NE & 36 & $400<\mathrm{t}<550^{\circ} \mathrm{C}$ \\
\hline 131 & 330 & 59 & 0 & S NRM-AF050 & 143 & NE & 23 & postcooling \\
\hline & 89 & 56 & 3.1 & B AF $100-A F 200$ & 31 & NW & 69 & $50-100^{\circ} \mathrm{Oe}$ \\
\hline & 47 & 62 & 1.8 & B AF200-AF400 & 256 & S & 22 & $200^{\circ} \mathrm{Oe}$ \\
\hline 132 & 324 & 41 & 5.5 & B NRM-AF100 & 175 & $\mathrm{E}$ & 36 & postcooling \\
\hline & 338 & 10 & 1.4 & B AF200-AF400 & 235 & SE & 36 & $100-200^{\circ} \mathrm{Oe}$ \\
\hline Square 27, Le & vel 21 & & & & & & & \\
\hline 172 & 8 & 63 & 5.8 & B NRM-TD200 & 74 & $\mathrm{~N}$ & 14 & postcooling \\
\hline & 313 & 4 & 2.1 & B TD400-TD550 & 182 & E & 98 & $200<\mathrm{t}<400^{\circ} \mathrm{C}$ \\
\hline 173 & 307 & 62 & 1.3 & B NRM-AF100 & 136 & $\mathrm{NE}$ & 36 & postcooling \\
\hline & 275 & 60 & 0.5 & B AF200-AF400 & 112 & $\mathrm{~N}-\mathrm{NE}$ & 16 & $100-200^{\circ} \mathrm{Oe}$ \\
\hline 174 & 314 & 50 & 1.5 & B NRM-AF400 & 157 & E-NE & 37 & postcooling \\
\hline 176 & 62 & -7 & 0 & S TD150-TD200 & 11 & W & 109 & $<150^{\circ} \mathrm{C}$ \\
\hline & 11 & -18 & 1.2 & В TD450-TD650 & 333 & SW & 62 & $200<\mathrm{t}<450^{\circ} \mathrm{C}$ \\
\hline 177 & 332 & 64 & 2.9 & B NRM-AF100 & 128 & NE & 22 & postcooling \\
\hline & 292 & 78 & 0.9 & B AF $150-A F 400$ & 84 & $\mathrm{~N}$ & 19 & $100-150^{\circ} \mathrm{Oe}$ \\
\hline 179 & 14 & -6 & 0.8 & B TD300-TD400 & 306 & SW & 62 & $<300^{\circ} \mathrm{C}$ \\
\hline & 294 & -19 & 1.6 & B TD400-TD600 & 185 & E & 112 & $400^{\circ} \mathrm{C}$ \\
\hline 180 & 5 & 58 & 4.7 & B NRM-TD250 (MINUS 100) & & & $<10$ & postcooling \\
\hline & 121 & -63 & 2.1 & B TD300-TD450 & 246 & S-SE & 174 & $250-300^{\circ} \mathrm{C}$ \\
\hline & 102 & 31 & 0.2 & B TD500-TD650 & or, opposite & & & \\
\hline & & & & & 66 & N-NW & 186 & \\
\hline & & & & & 338 & W-SW & 104 & $450-500^{\circ} \mathrm{C}$ \\
\hline 181 & 353 & 61 & 0.7 & B NRM-TD200 & 110 & N-NE & 13 & postcooling \\
\hline & 185 & -55 & 1.9 & B TD300-TD550 & 94 & $\mathrm{~N}$ & 173 & $200-300^{\circ} \mathrm{C}$ \\
\hline & & & & & or, opposite & & & \\
\hline & & & & & 274 & S & 187 & \\
\hline
\end{tabular}


Table A6-2, continued

\begin{tabular}{|c|c|c|c|c|c|c|c|c|}
\hline & & & ntified Vectc & & & Reconstruct & ed Vector Ro & tations \\
\hline $\begin{array}{l}\text { Sample } \\
\text { (AM-) }\end{array}$ & Declination & Inclination & MAD or $\kappa$ & Range & Strike & $\begin{array}{l}\text { Direction } \\
\text { of rotation }\end{array}$ & $\begin{array}{l}\text { Magnitude } \\
\text { of rotation }\end{array}$ & Threshold \\
\hline Square $27, \mathrm{Le}$ & vel 24 & & & & & & & \\
\hline 499 & 353 & 49 & 1.5 & B AF150-AF400 & 184 & $\mathrm{E}$ & 6 & $<150^{\circ} \mathrm{Oe}$ \\
\hline 500 & 348 & 77 & 782 & F NRM-TD600 & 96 & $\mathrm{~N}$ & 27 & postcooling \\
\hline 501 & 10 & 43 & 1846 & F NRM-AF600 & 326 & SW & 13 & postcooling \\
\hline Square $27, \mathrm{Le}$ & vel 25 & & & & & & & \\
\hline 662 & 17 & 62 & 6.1 & B NRM-TD200 & 56 & NW & 16 & postcooling \\
\hline & 199 & 55 & 3.7 & B TD300-TD450 (MINUS 400) & 108 & $\mathrm{~N}$ & 65 & $200<\mathrm{t}<300^{\circ} \mathrm{C}$ \\
\hline & 137 & 20 & 1.4 & B TD450-TD650 & 33 & NW & 70 & $450^{\circ} \mathrm{C}$ \\
\hline 663 & 42 & 39 & 5.5 & B AF025-AF 100 & 7 & W & 42 & postcooling \\
\hline & 97 & -35 & 3 & B AF200-AF400 & 38 & NW & 110 & $100-200^{\circ} \mathrm{Oe}$ \\
\hline 665 & 9 & 32 & 3017 & F NRM-AF400 & 305 & SW & 20 & postcooling \\
\hline 666 & 8 & 35 & 1.4 & B NRM-TD650 & 304 & SW & 18 & postcooling \\
\hline Square $27, \mathrm{Le}$ & vel 26 & & & & & & & \\
\hline 773 & 344 & 26 & 7.9 & B AF050-AF150 & 222 & SE & 31 & $<50^{\circ} \mathrm{Oe}$ \\
\hline & 314 & -8 & 1.5 & B AF200-AF400 & 179 & E & 59 & $150-200^{\circ} \mathrm{Oe}$ \\
\hline 775 & 16 & 52 & 5.6 & B NRM-TD500 & 15 & W & 13 & postcooling \\
\hline & 68 & 83 & 1.1 & B TD500-TD575 & 73 & $\mathrm{~N}$ & 36 & $500^{\circ} \mathrm{C}$ \\
\hline 776 & 8 & 56 & 2.5 & B AF100-AF200 & 54 & NW & $<8$ & $<100^{\circ} \mathrm{Oe}$ \\
\hline & 340 & 41 & 1.9 & B AF300-AF600 & 205 & E-SE & 28 & $200-300^{\circ} \mathrm{Oe}$ \\
\hline 778 & 320 & 64 & 5.1 & B NRM-TD150 & 131 & $\mathrm{NE}$ & 28 & postcooling \\
\hline & 152 & -12 & 2.1 & B TD300-TD400 & 75 & $\mathrm{~N}$ & 130 & $150<\mathrm{t}<300^{\circ} \mathrm{C}$ \\
\hline & 177 & -22 & 0.6 & B TD500-TD575 & 162 & E & 33 & $400-500^{\circ} \mathrm{C}$ \\
\hline 779 & 4 & 70 & 1364 & F NRM-AF400 & 86 & $\mathrm{~N}$ & 20 & postcooling \\
\hline Square 28, Le & vel 19 & & & & & & & \\
\hline 133 & 241 & 61 & 4.7 & B AF050-AF150 & 114 & $\mathrm{~N}$ & 61 & $<50^{\circ} \mathrm{Oe}$ \\
\hline & 217 & 20 & 0.9 & B AF200-AF400 & 108 & N-NE & 47 & $150-200^{\circ} \mathrm{Oe}$ \\
\hline 135 & 71 & 72 & 6.1 & B NRM-TD200 (MINUS 100) & 62 & NW & 40 & postcooling \\
\hline & 141 & -7 & 2 & B TD350-TD650 & 66 & N-NW & 95 & $200<\mathrm{t}<350^{\circ} \mathrm{C}$ \\
\hline 136 & 352 & 65 & 4.3 & B TD100-TD250 & 104 & $\mathrm{~N}$ & 16 & postcooling \\
\hline & 229 & -68 & 0.4 & B TD250-TD350 & 286 & $\mathrm{~S}$ & 175 & $250^{\circ} \mathrm{C}$ \\
\hline & 271 & -56 & 3.9 & & or, opposite & & & \\
\hline & 310 & 2 & 1.2 & & 106 & $\mathrm{~N}$ & 185 & \\
\hline & & & & B TD350-TD450 & 170 & $\mathrm{E}$ & 29 & $350^{\circ} \mathrm{C}$ \\
\hline & & & & B TD550-TD650 & 140 & NE & 81 & $450-550^{\circ} \mathrm{C}$ \\
\hline Square $28, \mathrm{Le}$ & vel 20-Middle & & & & & & & \\
\hline 193 & 0 & 31 & 3.2 & B TD100-TD200 & 270 & S & 19 & postcooling \\
\hline & 43 & -36 & 2.8 & B TD250-TD350 & 349 & W & 108 & $200-250^{\circ} \mathrm{C}$ \\
\hline & 64 & -29 & 1.4 & B TD350-TD450 & 109 & $\mathrm{~N}$ & 23 & $350^{\circ} \mathrm{C}$ \\
\hline & 35 & -28 & 0.4 & B TD450-TD650 & 253 & S & 28 & $450^{\circ} \mathrm{C}$ \\
\hline 194 & 2 & -66 & 2.7 & B AF200-AF400 & 268 & $S$ & 116 & $<200^{\circ} \mathrm{Oe}$ \\
\hline 196 & 2 & 52 & 1.7 & B TD100-TD200 & & & $<2$ & postcooling \\
\hline & 286 & 40 & 1981 & F TD200-TD600 & 28 & NW & 61 & $200^{\circ} \mathrm{C}$ \\
\hline 199 & 355 & 71 & 2.1 & B TD100-TD200 & 95 & $\mathrm{~N}$ & 21 & postcooling \\
\hline & 9 & -41 & 0.9 & B TD300-TD500 & 243 & SE & 120 & $200-300^{\circ} \mathrm{C}$ \\
\hline & 51 & 57 & 0.5 & В TD550-TD600 & 46 & NW & 123 & $500-550^{\circ} \mathrm{C}$ \\
\hline 202 & 311 & 73 & 6797 & F NRM-AF400 (MINUS 200) & 115 & N-NE & 32 & postcooling \\
\hline 203 & 358 & 55 & 3.4 & B NRM-TD200 & & & $<5$ & postcooling \\
\hline & 189 & -51 & 2.4 & B TD250-TD350 & 93 & $\mathrm{~N}$ & 176 & $200-250^{\circ} \mathrm{C}$ \\
\hline & 339 & 20 & 6.1 & B TD400-TD500 & or, opposite & & & \\
\hline & 38 & -36 & 1.1 & B TD550-TD650 & 273 & $S$ & 184 & \\
\hline & & & & & 107 & $\mathrm{~N}$ & 146 & $350-400^{\circ} \mathrm{C}$ \\
\hline & & & & & 90 & $\mathrm{~N}$ & 121 & $500-550^{\circ} \mathrm{C}$ \\
\hline
\end{tabular}


Table A6-2, continued

\begin{tabular}{|c|c|c|c|c|c|c|c|c|}
\hline & & & entified Vect & & & Reconstruc & ed Vector Ro & tations \\
\hline $\begin{array}{l}\text { Sample } \\
\text { (AM-) }\end{array}$ & Declination & Inclination & MAD or $\kappa$ & Range & Strike & $\begin{array}{l}\text { Direction } \\
\text { of rotation }\end{array}$ & $\begin{array}{l}\text { Magnitude } \\
\text { of rotation }\end{array}$ & Threshold \\
\hline 204 & 113 & -7 & 503 & F NRM-AF400 & 49 & NW & 130 & postcooling \\
\hline Square $28, \mathrm{~L}$ & vel 20-Base & & & & & & & \\
\hline 258 & 346 & 48 & 2.8 & B NRM-TD150 & & & $<5$ & postcooling \\
\hline & 336 & 0 & 2172 & F TD250-TD575 & 215 & SE & 64 & $150-250^{\circ} \mathrm{C}$ \\
\hline 260 & 21 & 26 & 8378 & F NRM-AF400 & 328 & SW & 36 & postcooling \\
\hline 262 & 244 & 77 & 3224 & F NRM-AF100 & 104 & $\mathrm{~N}$ & 48 & postcooling \\
\hline Square $28, \mathrm{~L}$ & vel 21 & & & & & & & \\
\hline 316 & 341 & 20 & 2.7 & B TD150-TD300 & 219 & SE & 38 & $<150^{\circ} \mathrm{C}$ \\
\hline & 330 & 3 & 1.2 & B TD450-TD600 & 193 & E & 27 & $300<\mathrm{t}<450^{\circ} \mathrm{C}$ \\
\hline 318 & 15 & 43 & 1 & B AF100-AF400 & 343 & W & 16 & $<100^{\circ} \mathrm{Oe}$ \\
\hline 320 & 21 & 58 & 2.4 & B NRM-TD200 & 39 & NW & 18 & postcooling \\
\hline & 54 & 63 & 1.2 & B TD200-TD600 & 53 & NW & 19 & $200^{\circ} \mathrm{C}$ \\
\hline 321 & 14 & 72 & 5.2 & B NRM-AF100 & 78 & $\mathrm{~N}$ & 23 & postcooling \\
\hline & 98 & 67 & 2.5 & B AF100-AF400 & 48 & NW & 28 & $100 \mathrm{Oe}$ \\
\hline 323 & 329 & 65 & 5.7 & B NRM-TD200 (MINUS 100) & 127 & $\mathrm{NE}$ & 24 & postcooling \\
\hline & 68 & 62 & 4.2 & B TD200-TD400 & 19 & W & 50 & $200^{\circ} \mathrm{C}$ \\
\hline & 10 & 50 & 3.1 & B TD400-TD500 & 260 & $S$ & 34 & $400^{\circ} \mathrm{C}$ \\
\hline & 31 & -24 & 4.7 & B TD500-TD575 & 116 & NE & 22 & $500^{\circ} \mathrm{C}$ \\
\hline 325 & 13 & 56 & 4.2 & B NRM-TD150 & 41 & NW & 12 & postcooling \\
\hline & 327 & 49 & 2.7 & B TD200-TD300 & 178 & $\mathrm{E}$ & 38 & $150-200^{\circ} \mathrm{C}$ \\
\hline & 119 & -22 & 4 & B TD350-TD450 & 63 & NW & 170 & $300-350^{\circ} \mathrm{C}$ \\
\hline & 130 & -60 & 3.5 & B TD500-TD650 & or, opposite & & & \\
\hline & & & & & 243 & SE & 190 & \\
\hline & & & & & 119 & NE & 42 & $450-500^{\circ} \mathrm{C}$ \\
\hline 326 & 271 & 66 & 5.5 & B AF075-AF150 & 122 & $\mathrm{NE}$ & 48 & $<75^{\circ} \mathrm{Oe}$ \\
\hline & 249 & 55 & 2.1 & B AF150-AF400 & 122 & NE & 65 & $150^{\circ} \mathrm{Oe}$ \\
\hline 329 & 347 & 24 & 2005 & F NRM-AF400 & 229 & SE & 30 & postcooling \\
\hline Square $28, \mathrm{~L}$ & vel 22-Middle & & & & & & & \\
\hline 502 & 0 & 42 & 3734 & F NRM-TD600 & 270 & $S$ & 8 & postcooling \\
\hline 503 & 20 & 71 & 3.1 & B AF050-AF400 & 69 & N-NW & 23 & $<50^{\circ} \mathrm{Oe}$ \\
\hline 504 & 23 & 66 & 3536 & F NRM-TD600 & 60 & NW & 20 & postcooling \\
\hline 505 & 351 & 62 & 1971 & F NRM-TD550 & 112 & $\mathrm{~N}-\mathrm{NE}$ & 13 & postcooling \\
\hline 506 & 12 & 62 & 3.5 & B NRM-TD400 & 64 & NW & 14 & postcooling \\
\hline & 294 & 54 & 0.7 & B TD500-TD600 & 158 & E-NE & 51 & $400-500^{\circ} \mathrm{Oe}$ \\
\hline 508 & 199 & -33 & 1142 & F NRM-TD600 & 100 & $\mathrm{~N}$ & 163 & postcooling \\
\hline & & & & & or, opposite & & & \\
\hline & & & & & 280 & $S$ & 197 & \\
\hline 509 & 356 & 29 & 1.7 & B TD150-TD250 & 254 & $S$ & 22 & $<150^{\circ} \mathrm{C}$ \\
\hline & 132 & -52 & 2.8 & B TD450-TD550 & 243 & SE & 160 & $250<\mathrm{t}<450^{\circ} \mathrm{C}$ \\
\hline & 52 & -22 & 6.3 & B TD575-TD650 & or, opposite & & & \\
\hline & & & & & 63 & NW & 190 & \\
\hline & & & & & 22 & W-NW & 86 & $550-575^{\circ} \mathrm{C}$ \\
\hline 510 & 87 & -43 & 0.9 & B AF200-AF400 & 39 & NW & 169 & $<200^{\circ} \mathrm{Oe}$ \\
\hline & & & & & or, opposite & & & \\
\hline & & & & & 219 & SE & 191 & \\
\hline 512 & 327 & 34 & 3 & B NRM-AF800 & 185 & $\mathrm{E}$ & 38 & postcooling \\
\hline 513 & 8 & 61 & 2.8 & B TD100-TD200 & 69 & N-NW & 12 & postcooling \\
\hline & 333 & 26 & 5 & B TD250-TD350 & 208 & SE & 52 & $200-250^{\circ} \mathrm{C}$ \\
\hline & 304 & 26 & 2.8 & В TD400-TD600 & 129 & $\mathrm{NE}$ & 28 & $350-400^{\circ} \mathrm{C}$ \\
\hline 515 & 348 & 64 & 4.5 & B NRM-TD200 & 72 & $\mathrm{~N}$ & 17 & postcooling \\
\hline & 346 & -62 & 2.3 & B TD300-TD650 & 296 & S-SW & 139 & $200-300^{\circ} \mathrm{C}$ \\
\hline & & & & & or, opposite & & & \\
\hline & & & & & 116 & N-NE & 221 & \\
\hline
\end{tabular}


Table A6-2, continued

\begin{tabular}{|c|c|c|c|c|c|c|c|c|}
\hline \multicolumn{5}{|c|}{ Identified Vectors } & \multicolumn{4}{|c|}{ Reconstructed Vector Rotations } \\
\hline $\begin{array}{l}\text { Sample } \\
\text { (AM-) }\end{array}$ & Declination & Inclination & MAD or $\kappa$ & Range & Strike & $\begin{array}{c}\text { Direction } \\
\text { of rotation }\end{array}$ & $\begin{array}{l}\text { Magnitude } \\
\text { of rotation }\end{array}$ & Threshold \\
\hline 518 & 47 & 67 & 1.7 & B AF100-AF400 & 53 & NW & 31 & $<100^{\circ} \mathrm{Oe}$ \\
\hline \multirow[t]{3}{*}{519} & 33 & 44 & 8.9 & B NRM-TD250 (MINUS 150) & 6 & W & 30 & postcooling \\
\hline & 314 & 26 & 3.9 & B TD350-TD500 & 179 & $\mathrm{E}$ & 88 & $250-350^{\circ} \mathrm{C}$ \\
\hline & 348 & -5 & 4.4 & B TD500-TD650 & 280 & $S$ & 38 & $500^{\circ} \mathrm{C}$ \\
\hline \multirow[t]{2}{*}{521} & 2 & 70 & 0.7 & B NRM-TD150 & 89 & $\mathrm{~N}$ & 20 & postcooling \\
\hline & 202 & 48 & 1.5 & B TD250-TD600 & 104 & $\mathrm{~N}$ & 62 & $150-250^{\circ} \mathrm{C}$ \\
\hline \multirow[t]{2}{*}{522} & 39 & 33 & 5.4 & B AF150-AF400 & 358 & W & 44 & $<150^{\circ} \mathrm{Oe}$ \\
\hline & $\sim 44$ & $<20$ & 0 & S AF400-ORIGIN & 352 & $\mathrm{~W}$ & 10 & $400^{\circ} \mathrm{Oe}$ \\
\hline \multirow[t]{4}{*}{524} & 0 & 61 & 1.1 & B NRM-TD575 & 90 & $\mathrm{~N}$ & 12 & postcooling \\
\hline & 194 & -65 & 0.9 & B TD575-TD650 & 274 & S & 176 & $575^{\circ} \mathrm{C}$ \\
\hline & & & \multicolumn{6}{|c|}{ or, opposite } \\
\hline & & & & & 94 & $\mathrm{~N}$ & 184 & \\
\hline 525 & 336 & 57 & 792 & F NRM-AF400 & 146 & NE & 19 & postcooling \\
\hline \multicolumn{9}{|c|}{ Square 28, Level 22} \\
\hline \multirow{2}{*}{787} & 0 & 43 & 1.3 & B TD100-TD200 & 270 & $S$ & 7 & postcooling \\
\hline & 348 & 33 & 1.4 & B TD250-TD650 & 207 & SE & 15 & $200-250^{\circ} \mathrm{C}$ \\
\hline 788 & 3 & 41 & 3509 & F NRM-TD600 & 284 & $S$ & 12 & postcooling \\
\hline 789 & 357 & 38 & 1.7 & B NRM-AF600 & 252 & $S$ & 12 & postcooling \\
\hline 791 & 347 & 61 & 2.3 & B NRM-TD600 & 124 & $\mathrm{NE}$ & 14 & postcooling \\
\hline \multirow[t]{2}{*}{793} & 27 & 50 & 0.9 & B AF100-AF200 & 12 & W & 22 & $<100^{\circ} \mathrm{Oe}$ \\
\hline & 19 & 26 & 2.2 & B AF200-AF400 & 300 & SW & 28 & $200^{\circ} \mathrm{Oe}$ \\
\hline \multirow[t]{4}{*}{794} & 305 & 39 & 5.7 & B TD150-TD250 & 162 & $\mathrm{E}$ & 51 & $<150^{\circ} \mathrm{C}$ \\
\hline & 328 & 4 & 2.9 & B TD250-TD350 & 212 & SE & 48 & $250^{\circ} \mathrm{C}$ \\
\hline & 65 & 67 & 3.8 & B TD450-TD550 & 18 & $\mathrm{~W}$ & 123 & $350-450^{\circ} \mathrm{C}$ \\
\hline & 195 & 25 & 0 & S TD600-TD650 & 116 & NE & 88 & $550-600^{\circ} \mathrm{C}$ \\
\hline \multirow[t]{3}{*}{795} & 359 & 47 & 5.2 & B TD100-TD350 & & & $<4$ & postcooling \\
\hline & 335 & 43 & 2.8 & B TD350-TD450 & 176 & E & 24 & $350^{\circ} \mathrm{C}$ \\
\hline & 66 & 64 & 1.5 & B TD550-TD650 & 32 & NW & 66 & $450-550^{\circ} \mathrm{C}$ \\
\hline \multirow[t]{2}{*}{797} & 354 & 64 & 3.1 & B TD100-TD200 & 118 & NE & 18 & postcooling \\
\hline & 330 & 63 & 1.6 & B TD200-TD600 & 176 & $\mathrm{E}$ & 8 & $200^{\circ} \mathrm{C}$ \\
\hline 801 & 5 & 67 & 2.4 & B NRM-TD600 & 82 & $\mathrm{~N}$ & 17 & postcooling \\
\hline \multirow[t]{4}{*}{803} & 16 & 62 & 5.1 & B TD100-TD200 & 58 & NW & 16 & postcooling \\
\hline & 146 & -51 & 1.1 & B TD500-TD600 & 70 & N-NW & 165 & $200<\mathrm{t}<500^{\circ} \mathrm{C}$ \\
\hline & & & & & or, opposite & & & \\
\hline & & & & & 250 & S-SE & 195 & \\
\hline \multirow[t]{3}{*}{805} & 331 & 42 & 1.9 & B TD100-TD250 (MINUS 200) & 181 & $\mathrm{E}$ & 28 & postcooling \\
\hline & 25 & 59 & 1.5 & B TD250-TD350 & 16 & W & 48 & $250^{\circ} \mathrm{C}$ \\
\hline & 105 & 0 & 2 & B TD450-TD550 & 46 & NW & 97 & $350-450^{\circ} \mathrm{C}$ \\
\hline \multicolumn{9}{|c|}{ Square 28, Level 24} \\
\hline 973 & 115 & -10 & 862 & F AF100-AF400 & 50 & NW & 134 & $<100^{\circ} \mathrm{Oe}$ \\
\hline 974 & 11 & 66 & 1125 & F TD100-TD600 & 72 & $\mathrm{~N}$ & 18 & postcooling \\
\hline 976 & 359 & 45 & 2771 & F NRM-AF600 & 260 & $\mathrm{~S}$ & 5 & postcooling \\
\hline 977 & 312 & 48 & 808 & F NRM-TD600 & 158 & E-NE & 40 & postcooling \\
\hline 978 & 1 & 77 & 1559 & F TD100-TD600 & 91 & $\mathrm{~N}$ & 27 & postcooling \\
\hline 980 & 5 & 47 & 3448 & F NRM-AF400 & & & $<5$ & postcooling \\
\hline \multirow[t]{3}{*}{982} & 2 & 51 & 0.2 & B TD150-TD250 & & & $<2$ & $<150^{\circ} \mathrm{C}$ \\
\hline & 28 & 50 & 1.8 & B TD450-TD550 & 12 & W & 21 & $250<\mathrm{t}<450^{\circ} \mathrm{C}$ \\
\hline & 104 & 67 & 2.6 & B TD550-TD600 & 90 & $\mathrm{~N}$ & 40 & $550^{\circ} \mathrm{C}$ \\
\hline \multicolumn{9}{|c|}{ Square 28, Level 24-Base } \\
\hline 1142 & 34 & 43 & 1.3 & B TD150-TD250 & 4 & W & 32 & $<150^{\circ} \mathrm{C}$ \\
\hline & 210 & 48 & 3.4 & B TD300-TD400 & 120 & NE & 96 & $250-300^{\circ} \mathrm{C}$ \\
\hline
\end{tabular}


Table A6-2, continued

\begin{tabular}{|c|c|c|c|c|c|c|c|c|}
\hline & & & entified Vecto & & & Reconstruc & ed Vector Ro & tations \\
\hline $\begin{array}{l}\text { Sample } \\
\text { (AM-) }\end{array}$ & Declination & Inclination & MAD or $\kappa$ & Range & Strike & $\begin{array}{l}\text { Direction } \\
\text { of rotation }\end{array}$ & $\begin{array}{l}\text { Magnitude } \\
\text { of rotation }\end{array}$ & Threshold \\
\hline & 174 & -19 & 5.9 & B TD450-TD550 & 58 & NW & 73 & $400-450 \mathrm{C}$ \\
\hline 1143 & 57 & 43 & 3.6 & B AF050-AF150 & 21 & W-NW & 49 & $<50^{\circ} \mathrm{Oe}$ \\
\hline & 74 & 13 & 0.7 & B AF300-AF800 & 23 & W-NW & 41 & $150<\mathrm{t}<300^{\circ} \mathrm{Oe}$ \\
\hline 1145 & 322 & 75 & 4.8 & B TD100-TD250 & 110 & N-NE & 31 & postcooling \\
\hline & 262 & 82 & 1.1 & B TD250-TD650 & 80 & $\mathrm{~N}$ & 13 & $250^{\circ} \mathrm{C}$ \\
\hline 1147 & 352 & 59 & 1.9 & B NRM-TD650 & 119 & $\mathrm{NE}$ & 10 & postcooling \\
\hline Square $28, \mathrm{Le}$ & vel 25 & & & & & & & \\
\hline 1010 & 9 & 55 & 3.4 & B TD100-TD200 & 41 & NW & 9 & postcooling \\
\hline & 201 & 55 & 3.1 & B TD350-TD600' & 105 & $\mathrm{~N}$ & 70 & $200<\mathrm{t}<350^{\circ} \mathrm{C}$ \\
\hline 1012 & 344 & 58 & 2 & B TD100-TD200 & 138 & $\mathrm{NE}$ & 14 & postcooling \\
\hline & 178 & 48 & 0.9 & B TD350-TD650 & 82 & $\mathrm{~N}$ & 23 & $200<\mathrm{t}<350^{\circ} \mathrm{C}$ \\
\hline 1013 & 342 & 42 & 1214 & F NRM-TD600 & 194 & E & 20 & postcooling \\
\hline 1015 & 12 & 58 & 926 & F NRM-AF400 & 48 & NW & 12 & postcooling \\
\hline Square 28-Ea & t, Level 25 & & & & & & & \\
\hline 1154 & 347 & 52 & 2 & B TD150-TD250 & 161 & E & 11 & $<150^{\circ} \mathrm{C}$ \\
\hline & 81 & 7 & 2.2 & B TD350-TD450 & 25 & W-NW & 115 & $250-350^{\circ} \mathrm{C}$ \\
\hline & 326 & -18 & 0.1 & B TD575-TD650 & 34 & NW & 168 & $450<\mathrm{t}<575^{\circ} \mathrm{C}$ \\
\hline & & & & & or, opposite & & & \\
\hline & & & & & 214 & SE & 192 & \\
\hline 1156 & 4 & 35 & 1673 & F NRM-AF400 & 286 & S & 16 & postcooling \\
\hline 1157 & 7 & 58 & 1732 & F NRM-TD650 & 62 & NW & 10 & postcooling \\
\hline 1158 & 352 & 61 & 1198 & F NRM-AF800 & 112 & $\mathrm{~N}-\mathrm{NE}$ & 10 & postcooling \\
\hline Square $28, \mathrm{Le}$ & vel 26 & & & & & & & \\
\hline 1063 & 177 & -56 & 5004 & F NRM-AF400 & 91 & $\mathrm{~N}$ & 176 & postcooling \\
\hline & & & & & or, opposite & & & \\
\hline & & & & & 271 & $S$ & 184 & \\
\hline 1064 & 12 & 58 & 1319 & F NRM-AF400 & 48 & NW & 12 & postcooling \\
\hline 1066 & 333 & 55 & 3095 & F NRM-TD600 & 152 & NE & 22 & postcooling \\
\hline 1068 & 350 & 41 & 1502 & F NRM-TD650 & 215 & SE & 12 & postcooling \\
\hline 1069 & 0 & 54 & 8068 & F NRM-TD550 & & & $<5$ & postcooling \\
\hline 1071 & 6 & 65 & 6968 & F TD100-TD600 & 80 & $\mathrm{~N}$ & 16 & postcooling \\
\hline 1072 & 354 & 49 & 3120 & F NRM-AF400 & & & $<5$ & postcooling \\
\hline 1073 & 20 & 47 & 3.8 & B AF050-AF200 & 1 & W & 18 & $<50^{\circ} \mathrm{Oe}$ \\
\hline & $\sim 341$ & $\sim-1$ & 0 & S AF600-ORIGIN & 220 & SE & 68 & $>200^{\circ} \mathrm{Oe}$ \\
\hline 1074 & 7 & 57 & 3.8 & B NRM-TD500 & 60 & NW & 9 & postcooling \\
\hline & 331 & 2 & 2 & B TD550-TD600 & 204 & E-SE & 81 & $500-550^{\circ} \mathrm{C}$ \\
\hline & 38 & -67 & 0 & S TD600-TD650 & 178 & E & 121 & $600^{\circ} \mathrm{C}$ \\
\hline 1075 & 2 & 45 & 3.9 & B TD100-TD350 & & & $<5$ & postcooling \\
\hline & 141 & 63 & 2.1 & B TD350-TD600 & 76 & $\mathrm{~N}$ & 70 & $350^{\circ} \mathrm{C}$ \\
\hline Square $28-\mathrm{Ea}$ & t, Level 26 & & & & & & & \\
\hline 1164 & 17 & 63 & 1.4 & B TD100-TD450 & 60 & NW & 17 & postcooling \\
\hline & 182 & 3 & 2 & B TD550-TD650 & 92 & $\mathrm{~N}$ & 113 & $450-550^{\circ} \mathrm{C}$ \\
\hline 1165 & 5 & 46 & 1.5 & B AF050-AF150 & & & $<5$ & $<50^{\circ} \mathrm{Oe}$ \\
\hline & 24 & 49 & 2.2 & B AF150-AF300 & 24 & N-NW & 18 & $150^{\circ} \mathrm{Oe}$ \\
\hline & 8 & 46 & 3.6 & B AF300-AF600 & 208 & SE & 16 & $300^{\circ} \mathrm{Oe}$ \\
\hline 1167 & 35 & 52 & 3.2 & B TD100-TD200 & 24 & N-NW & 28 & postcooling \\
\hline & 70 & 48 & 4392 & F TD200-TD600 & 45 & NW & 26 & $200^{\circ} \mathrm{C}$ \\
\hline Square $28-\mathrm{We}$ & st, Level 27-B & & & & & & & \\
\hline 1174 & 359 & 55 & 1.9 & B AF050-AF200 & & & $<5$ & $<50^{\circ} \mathrm{Oe}$ \\
\hline & 338 & 61 & 0.8 & B AF200-AF400 & 142 & NE & 14 & $200^{\circ} \mathrm{Oe}$ \\
\hline
\end{tabular}


Table A6-2, continued

\begin{tabular}{|c|c|c|c|c|c|c|c|c|}
\hline & & & entified Vecto & & & Reconstruc & ed Vector Ro & tations \\
\hline $\begin{array}{l}\text { Sample } \\
(\mathrm{AM}-)\end{array}$ & Declination & Inclination & MAD or $\kappa$ & Range & Strike & $\begin{array}{l}\text { Direction } \\
\text { of rotation }\end{array}$ & $\begin{array}{l}\text { Magnitude } \\
\text { of rotation }\end{array}$ & Threshold \\
\hline Square $32, \mathrm{Le}$ & vel 18 & & & & & & & \\
\hline 105 & 336 & 44 & 3.1 & B NRM-TD150 & 181 & $\mathrm{E}$ & 23 & postcooling \\
\hline & 221 & -7 & 2.7 & B TD450-TD650 & 114 & N-NE & 121 & $150<\mathrm{t}<450^{\circ} \mathrm{C}$ \\
\hline 107 & 325 & 62 & 4.8 & B NRM-TD150 & 136 & NE & 26 & postcooling \\
\hline & 177 & 13 & 6.6 & B TD200-TD400 & 83 & $\mathrm{~N}$ & 102 & $150-200^{\circ} \mathrm{C}$ \\
\hline & 176 & 87 & 0.1 & B TD500-TD575 & 319 & SW & 87 & $400-500^{\circ} \mathrm{C}$ \\
\hline 108 & 332 & 54 & 0.8 & B NRM-TD150 & 155 & E-NE & 22 & postcooling \\
\hline & 341 & -38 & 1.5 & B TD300-TD450 & 170 & $\mathrm{E}$ & 140 & $150<\mathrm{t}<300^{\circ} \mathrm{C}$ \\
\hline & 176 & 8 & 3.8 & B TD500-TD600 & 77 & $\mathrm{~N}$ & 141 & $450-500^{\circ} \mathrm{C}$ \\
\hline 111 & 39 & 59 & 5.5 & B TD100-TD200 & 37 & NW & 28 & postcooling \\
\hline & 17 & 0 & 2.9 & B TD200-TD300 & 319 & SW & 71 & $200^{\circ} \mathrm{C}$ \\
\hline & 344 & -17 & 3.3 & B TD300-TD450 & 313 & SW & 45 & $300^{\circ} \mathrm{C}$ \\
\hline & 258 & 39 & 1.6 & B TD500-TD600 & 340 & W-SW & 180 & $450-500^{\circ} \mathrm{C}$ \\
\hline & & & & & or, opposite & & & \\
\hline & & & & & 160 & E-NE & 180 & \\
\hline Square $33, \mathrm{Le}$ & vel 19 & & & & & & & \\
\hline 248 & 114 & -21 & 2.5 & B AF200-AF600 & 50 & NW & 146 & $<200^{\circ} \mathrm{Oe}$ \\
\hline 249 & 344 & 15 & 1307 & F NRM-AF600 & 226 & SE & 41 & postcooling \\
\hline 250 & 357 & 53 & 7348 & F NRM-TD450 & & & $<3$ & postcooling \\
\hline 251 & 156 & 16 & 2.7 & B TD200-TD500 & 76 & $\mathrm{~N}$ & 112 & $<200^{\circ} \mathrm{C}$ \\
\hline 252 & 166 & -53 & 1295 & F TD150-TD600 & 82 & $\mathrm{~N}$ & 181 & $150^{\circ} \mathrm{C}$ \\
\hline & & & & & or, opposite & & & \\
\hline & & & & & 262 & $\mathrm{~S}$ & 179 & \\
\hline 254 & 46 & 16 & 8.9 & B NRM-AF150 (MINUS 50) & 357 & W & 64 & postcooling \\
\hline & 354 & -56 & 3.1 & B AF300-AF600 & 3 & W & 124 & $150<\mathrm{t}<300^{\circ} \mathrm{Oe}$ \\
\hline Square $33, \mathrm{Lc}$ & vel 22 & & & & & & & \\
\hline 364 & 360 & 31 & 4.3 & B TD100-TD250 & 270 & S & 19 & postcooling \\
\hline & 196 & 23 & 3.8 & B TD350-TD450 & 98 & $\mathrm{~N}$ & 25 & $250-350^{\circ} \mathrm{C}$ \\
\hline & 175 & 54 & 3.6 & B TD500-TD575 & 321 & SW & 40 & $450-500^{\circ} \mathrm{C}$ \\
\hline & 138 & 43 & 1.8 & B TD575-TD650 & 30 & NW & 32 & $575^{\circ} \mathrm{C}$ \\
\hline 365 & 103 & -59 & 1740 & F NRM-AF400 & 236 & SE & 169 & postcooling \\
\hline & & & & & or, opposite & & & \\
\hline & & & & & 56 & NW & 191 & \\
\hline 366 & 28 & 53 & 4.7 & B TD100-TD400 (MINUS 200) & 22 & W-NW & 22 & postcooling \\
\hline & 5 & 50 & 3 & B TD400-TD500 & 206 & SE & 18 & $400^{\circ} \mathrm{C}$ \\
\hline & 309 & 50 & 2.3 & B TD550-TD650 & 166 & E & 57 & $500-550^{\circ} \mathrm{C}$ \\
\hline Square $34, \mathrm{~L}$ & vel 20 & & & & & & & \\
\hline 400 & 300 & 59 & 5.5 & B AF050-150 & 138 & $\mathrm{NE}$ & 40 & $<50^{\circ} \mathrm{Oe}$ \\
\hline & 253 & 27 & 1.6 & B AF200-AF600 & 129 & $\mathrm{NE}$ & 51 & $150-200^{\circ} \mathrm{Oe}$ \\
\hline 401 & 327 & 51 & 4.8 & B NRM-TD150 & 161 & E & 27 & postcooling \\
\hline & 262 & 21 & 1.4 & B TD250-TD600 & 134 & NE & 67 & $150-250^{\circ} \mathrm{C}$ \\
\hline Square $34, \mathrm{~L}$ & vel 21 & & & & & & & \\
\hline 422 & 82 & 43 & 1.6 & B TD400-TD500 & 36 & NW & 71 & $<400^{\circ} \mathrm{C}$ \\
\hline & 98 & 9 & 0.8 & B TD500-TD575 & 43 & NW & 35 & $500^{\circ} \mathrm{C}$ \\
\hline 423 & 169 & 11 & 3617 & F NRM-AF600 & 83 & $\mathrm{~N}$ & 119 & postcooling \\
\hline Square $34, \mathrm{~L}$ & vel 22 & & & & & & & \\
\hline 480 & 31 & 23 & 1.6 & B AF150-AF300 & 342 & W & 46 & $<150^{\circ} \mathrm{Oe}$ \\
\hline & 44 & 18 & 1.7 & B AF300-AF600 & 32 & NW & 14 & $300^{\circ} \mathrm{Oe}$ \\
\hline 481 & 73 & 47 & 4 & B TD200-TD300 & 35 & NW & 56 & $<200^{\circ} \mathrm{C}$ \\
\hline & 0 & 60 & 6.4 & B TD300-TD400 & 201 & E-SE & 54 & $300^{\circ} \mathrm{C}$ \\
\hline
\end{tabular}


Table A6-2, continued

\begin{tabular}{|c|c|c|c|c|c|c|c|c|}
\hline & & & entified Vect & & & Reconstruc & ed Vector Ro & tations \\
\hline $\begin{array}{l}\text { Sample } \\
\text { (AM-) }\end{array}$ & Declination & Inclination & MAD or $\kappa$ & Range & Strike & $\begin{array}{l}\text { Direction } \\
\text { of rotation }\end{array}$ & $\begin{array}{l}\text { Magnitude } \\
\text { of rotation }\end{array}$ & Threshold \\
\hline & 54 & 54 & 7.8 & B TD450-TD550 & 14 & $\mathrm{~W}$ & 36 & $400-450^{\circ} \mathrm{C}$ \\
\hline & 316 & 32 & 7.5 & B TD550-TD600 & 181 & $\mathrm{E}$ & 109 & $550^{\circ} \mathrm{C}$ \\
\hline 482 & 345 & 56 & 1.7 & B AF025-AF100 & 144 & NE & 13 & postcooling \\
\hline & 26 & 57 & 3.4 & B AF150-AF400 & 7 & W & 29 & $100-150^{\circ} \mathrm{Oe}$ \\
\hline Square $34, \mathrm{Le}$ & vel 24 & & & & & & & \\
\hline 725 & 359 & 56 & 6.1 & B NRM-TD250 (MINUS 100) & & & $<5$ & postcooling \\
\hline & 287 & 65 & 4.6 & B TD250-TD350 & 131 & NE & 38 & $250^{\circ} \mathrm{C}$ \\
\hline & 246 & 3 & 4.4 & B TD400-TD575 & 133 & NE & 76 & $350-400^{\circ} \mathrm{C}$ \\
\hline 727 & 354 & 63 & 4 & B NRM-AF400 (MINUS 150) & 101 & $\mathrm{~N}$ & 14 & postcooling \\
\hline 728 & 340 & 42 & 3.4 & B NRM-TD200 (MINUS 100) & 190 & $\mathrm{E}$ & 21 & postcooling \\
\hline & 157 & -58 & 4.6 & B TD250-TD500 & 274 & $\mathrm{~S}$ & 166 & $200-250^{\circ} \mathrm{C}$ \\
\hline & 106 & -51 & 1.8 & B TD550-TD650 & or, opposite & & & \\
\hline & & & & & 94 & $\mathrm{~N}$ & 194 & \\
\hline & & & & & 250 & S-SE & 55 & $500-550^{\circ} \mathrm{C}$ \\
\hline Square $35, \mathrm{Le}$ & vel 20 & & & & & & & \\
\hline 219 & 181 & -62 & 1.6 & B AF200-AF400 & 270 & $\mathrm{~S}$ & 168 & $<200^{\circ} \mathrm{Oe}$ \\
\hline & & & & & or, opposite & & & \\
\hline & & & & & 90 & $\mathrm{~N}$ & 192 & \\
\hline 221 & 298 & 31 & 5.3 & B AF100-AF400 & 162 & $\mathrm{E}$ & 65 & $<100^{\circ} \mathrm{Oe}$ \\
\hline 237 & 359 & 71 & 646 & F NRM-TD500 & 91 & $\mathrm{~N}$ & 21 & postcooling \\
\hline & 4 & 64 & 0.3 & B TD500-TD650 & 308 & SW & 8 & $500^{\circ} \mathrm{C}$ \\
\hline 239 & 354 & 6 & 2 & B AF010-AF050 & 254 & $S$ & 46 & postcooling \\
\hline & 244 & 48 & 1.2 & B AF $200-A F 400$ & 108 & $\mathrm{~N}$ & 103 & $50<\mathrm{t}<200^{\circ} \mathrm{Oe}$ \\
\hline 240 & 348 & 50 & 5.4 & B TD100-TD200 & & & $<2$ & postcooling \\
\hline 241 & 10 & 51 & 5.7 & B NRM-TD200 & 11 & W & 9 & postcooling \\
\hline & 137 & -2 & 3.4 & B TD350-TD450 & 63 & NW & 122 & $200<\mathrm{t}<350^{\circ} \mathrm{C}$ \\
\hline & 103 & 1 & 1.1 & B TD450-TD650 & 343 & W & 45 & $450^{\circ} \mathrm{C}$ \\
\hline 243 & 344 & 35 & 7.4 & B NRM-AF100 & 212 & SE & 22 & postcooling \\
\hline & 313 & -19 & 0.5 & B AF200-AF400 & 182 & E & 84 & $100-200^{\circ} \mathrm{Oe}$ \\
\hline 245 & 187 & -18 & 1 & B AF150-AF400 & 92 & $\mathrm{~N}$ & 148 & $<150^{\circ} \mathrm{Oe}$ \\
\hline 291 & 344 & 0 & 0 & S AF100-AF150 & 229 & SE & 58 & $<100^{\circ} \mathrm{Oe}$ \\
\hline & 29 & -36 & 0 & S AF200-AF300 & 292 & S-SW & 56 & $150-200^{\circ} \mathrm{Oe}$ \\
\hline & 70 & -31 & 0 & S AF300-AF400 & 342 & W & 45 & $300^{\circ} \mathrm{Oe}$ \\
\hline 292 & 358 & -73 & 4526 & F TD200-TD600 & 272 & $S$ & 122 & $<200^{\circ} \mathrm{Oe}$ \\
\hline Square 35, Le & vel 21 & & & & & & & \\
\hline 355 & 35 & 42 & 4.8 & B TD100-TD200 & 4 & W & 34 & postcooling \\
\hline & 143 & -25 & 5.3 & B TD300-TD400 & 64 & NW & 127 & $200-300^{\circ} \mathrm{C}$ \\
\hline & 184 & -44 & 2.7 & B TD500-TD575 & 89 & $\mathrm{~N}$ & 34 & $400-500^{\circ} \mathrm{C}$ \\
\hline 357 & 344 & 55 & 3.7 & B NRM-TD200 & & & $<10$ & postcooling \\
\hline & 161 & 24 & 1.9 & B TD300-TD650 & 72 & $\mathrm{~N}$ & 102 & $200-300^{\circ} \mathrm{C}$ \\
\hline 360 & 28 & 58 & 1.7 & B TD100-TD250 & 36 & NW & 22 & postcooling \\
\hline & 65 & 52 & 1 & B TD250-TD575 & 72 & $\mathrm{~N}$ & 12 & $250^{\circ} \mathrm{C}$ \\
\hline 361 & 166 & 0 & 1.8 & B AF150-AF600 & 81 & $\mathrm{~N}$ & 130 & $<150^{\circ} \mathrm{Oe}$ \\
\hline 362 & 37 & 70 & 1421 & F NRM-TD500 & 61 & NW & 28 & postcooling \\
\hline Square 35, Le & vel 22 & & & & & & & \\
\hline 483 & 145 & -57 & 1.7 & B AF075-AF400 & 254 & S & 173 & $<75^{\circ} \mathrm{Oe}$ \\
\hline & & & & & or, opposite & & & \\
\hline & & & & & 74 & $\mathrm{~N}$ & 187 & \\
\hline 484 & 352 & 59 & 3 & B NRM-TD250 & 116 & NE & 10 & postcooling \\
\hline & 159 & -60 & 3.5 & B TD300-TD500 & 80 & $\mathrm{~N}$ & 173 & $250-300^{\circ} \mathrm{C}$ \\
\hline & 205 & -51 & 1.5 & B TD500-TD650 & or, opposite & & & \\
\hline
\end{tabular}


Table A6-2, continued

\begin{tabular}{|c|c|c|c|c|c|c|c|c|}
\hline \multicolumn{5}{|c|}{ Identified Vectors } & \multicolumn{4}{|c|}{ Reconstructed Vector Rotations } \\
\hline $\begin{array}{l}\text { Sample } \\
\text { (AM-) }\end{array}$ & Declination & Inclination & MAD or $\kappa$ & Range & Strike & $\begin{array}{l}\text { Direction } \\
\text { of rotation }\end{array}$ & $\begin{array}{l}\text { Magnitude } \\
\text { of rotation }\end{array}$ & Threshold \\
\hline & & & & & 260 & $\mathrm{~S}$ & 187 & \\
\hline & & & & & 192 & $\mathrm{E}$ & 37 & $500^{\circ} \mathrm{C}$ \\
\hline \multirow[t]{3}{*}{486} & 335 & 39 & 8.6 & B TD100-TD200 & 191 & $\mathrm{E}$ & 27 & postcooling \\
\hline & 306 & -12 & 2.4 & B TD300-TD550 & 175 & $\mathrm{E}$ & 111 & $200-300^{\circ} \mathrm{C}$ \\
\hline & 322 & 37 & 0.2 & B TD550-TD600 & 358 & W & 104 & $550^{\circ} \mathrm{C}$ \\
\hline 488 & 0 & 56 & 3.4 & B AF100-AF300 & 81 & $\mathrm{~N}$ & 6 & $<100^{\circ} \mathrm{Oe}$ \\
\hline \multirow[t]{2}{*}{489} & 348 & 62 & 5.3 & B AF050-AF200 & 116 & $\mathrm{NE}$ & 15 & $<50^{\circ} \mathrm{Oe}$ \\
\hline & 236 & 77 & 2.8 & B AF200-AF400 & 95 & $\mathrm{~N}$ & 35 & $200^{\circ} \mathrm{Oe}$ \\
\hline \multicolumn{9}{|c|}{ Square 35, Level 24} \\
\hline \multirow[t]{2}{*}{817} & 339 & 44 & 6 & B AF100-AF200 & 186 & $\mathrm{E}$ & 20 & $<100^{\circ} \mathrm{Oe}$ \\
\hline & $<329$ & -7 & 0 & S AF600-ORIGIN & 202 & E-SE & 66 & $>600^{\circ} \mathrm{Oe}$ \\
\hline \multirow[t]{2}{*}{819} & 68 & 58 & 5.4 & B AF050-AF150 & 42 & NW & 45 & $<50^{\circ} \mathrm{Oe}$ \\
\hline & 80 & -28 & 3.9 & B AF150-AF300 & 31 & NW & 110 & $150^{\circ} \mathrm{Oe}$ \\
\hline \multicolumn{9}{|c|}{ Square 37, Level 20} \\
\hline \multirow[t]{2}{*}{277} & 333 & 6 & 2.1 & B TD150-TD500 & 208 & SE & 61 & $<150^{\circ} \mathrm{C}$ \\
\hline & 244 & 24 & 0.8 & B TD575-TD650 & 101 & $\mathrm{~N}$ & 90 & $500-575^{\circ} \mathrm{C}$ \\
\hline \multirow[t]{2}{*}{279} & 92 & 56 & 6.5 & B AF050-AF 150 & 50 & NW & 58 & $<50^{\circ} \mathrm{Oe}$ \\
\hline & 35 & 49 & 7.3 & B AF150-AF300 & 272 & $\mathrm{~S}$ & 36 & $150^{\circ} \mathrm{Oe}$ \\
\hline \multirow[t]{2}{*}{280} & 350 & 40 & 3.9 & B NRM-TD200 & 220 & SE & 13 & postcooling \\
\hline & 307 & 21 & 2.9 & B TD250-TD600 & 167 & $\mathrm{E}$ & 55 & $200-250^{\circ} \mathrm{C}$ \\
\hline \multirow[t]{3}{*}{281} & 2 & 24 & 6.6 & B TD350-TD450 & 276 & $\mathrm{~S}$ & 27 & $<350^{\circ} \mathrm{C}$ \\
\hline & 303 & 49 & 0.9 & B TD450-TD550 & 132 & $\mathrm{NE}$ & 59 & $450^{\circ} \mathrm{C}$ \\
\hline & 317 & -2 & 0 & B TD550-TD600 & 200 & E-SE & 67 & $550^{\circ} \mathrm{C}$ \\
\hline 284 & 110 & 4 & 2049 & F TD300-TD550 & 46 & NW & 117 & $<300^{\circ} \mathrm{C}$ \\
\hline \multirow[t]{3}{*}{286} & 95 & -31 & 2.9 & B TD250-TD550 & 39 & NW & 156 & $<250^{\circ} \mathrm{C}$ \\
\hline & & & & & or, opposite & & & \\
\hline & & & & & 219 & SE & 204 & \\
\hline \multirow[t]{2}{*}{287} & 358 & 52 & 3.6 & B NRM-TD200 & & & $<2$ & postcooling \\
\hline & 152 & 1 & 4.4 & B TD350-TD550 & 72 & $\mathrm{~N}$ & 126 & $200<\mathrm{t}<350^{\circ} \mathrm{C}$ \\
\hline \multirow[t]{2}{*}{288} & 349 & -69 & 2.9 & B AF050-AF150 & 283 & $\mathrm{~S}$ & 122 & $<50^{\circ} \mathrm{Oe}$ \\
\hline & 253 & -85 & 1.5 & B AF200-AF400 & 292 & S-SW & 42 & $150-200^{\circ} \mathrm{Oe}$ \\
\hline \multicolumn{9}{|c|}{ Square 37, Level 21} \\
\hline \multirow[t]{2}{*}{368} & 338 & 61 & 1.2 & B TD100-TD250 (MINUS 150) & 131 & NE & 19 & postcooling \\
\hline & 242 & 16 & 3.4 & B TD300-TD400 & 128 & NE & 88 & $250-300^{\circ} \mathrm{C}$ \\
\hline \multirow[t]{5}{*}{369} & 40 & 49 & 2.3 & B NRM-AF150 & 18 & W & 33 & postcooling \\
\hline & 329 & -81 & 3.7 & B AF200-AF400 & 236 & SE & 162 & $150-200^{\circ} \mathrm{Oe}$ \\
\hline & 182 & -83 & 0 & S AF400-AF600 & or, opposite & & & \\
\hline & & & & & 56 & NW & 198 & \\
\hline & & & & & 212 & SE & 18 & $400^{\circ} \mathrm{Oe}$ \\
\hline 371 & 339 & 43 & 4.5 & B NRM-TD500 & 188 & $\mathrm{E}$ & 21 & postcooling \\
\hline & 342 & 68 & 1.2 & B TD500-TD650 & 57 & NW & 28 & $500^{\circ} \mathrm{C}$ \\
\hline 372 & 222 & -50 & 5851 & F NRM-AF400 & 290 & S-SW & 176 & postcooling \\
\hline & & & & & or, opposite & & & \\
\hline & & & & & 110 & N-NE & 184 & \\
\hline 375 & 333 & 38 & 0 & B AF050-AF100 & 191 & E & 29 & $<50^{\circ} \mathrm{Oe}$ \\
\hline & 231 & 54 & 2.5 & B AF150-AF400 & 91 & $\mathrm{~N}$ & 67 & $100-150^{\circ} \mathrm{Oe}$ \\
\hline 376 & 18 & 50 & 2.2 & B NRM-TD150 & 8 & W & 14 & postcooling \\
\hline & 133 & 50 & 2.3 & B TD250-TD450 & 75 & $\mathrm{~N}$ & 67 & $150-250^{\circ} \mathrm{C}$ \\
\hline & 13 & -38 & 2 & B TD500-TD600 & 236 & SE & 172 & $450-500^{\circ} \mathrm{C}$ \\
\hline & & & & & or, opposite & & & \\
\hline & & & & & 56 & NW & 188 & \\
\hline
\end{tabular}


Table A6-2, continued

\begin{tabular}{|c|c|c|c|c|c|c|c|c|}
\hline \multicolumn{5}{|c|}{ Identified Vectors } & \multicolumn{4}{|c|}{ Reconstructed Vector Rotations } \\
\hline $\begin{array}{l}\text { Sample } \\
\text { (AM-) }\end{array}$ & Declination & Inclination & MAD or $\kappa$ & Range & Strike & $\begin{array}{l}\text { Direction } \\
\text { of rotation }\end{array}$ & $\begin{array}{l}\text { Magnitude } \\
\text { of rotation }\end{array}$ & Threshold \\
\hline \multicolumn{9}{|c|}{ Square 37, Level 22} \\
\hline \multirow[t]{2}{*}{457} & 342 & 47 & 4.5 & B NRM-TD500 & 2 & W & 17 & postcooling \\
\hline & 119 & 67 & 1.9 & B TD500-TD600 & 54 & NW & 67 & $500^{\circ} \mathrm{C}$ \\
\hline \multirow[t]{2}{*}{459} & 14 & 4 & 0 & S NRM-TD350 & 307 & SW & 52 & postcooling \\
\hline & 186 & 58 & 1943 & F TD350-TD500 & 102 & $\mathrm{~N}$ & 109 & $350^{\circ} \mathrm{C}$ \\
\hline \multirow[t]{5}{*}{461} & 3 & 54 & 4.1 & B NRM-TD150 & & & $<5$ & postcooling \\
\hline & 16 & 6 & 1.4 & B TD250-TD350 & 303 & SW & 52 & $150-250^{\circ} \mathrm{C}$ \\
\hline & 162 & -36 & 1.4 & B TD500-TD650 & 61 & SE & 167 & $350<\mathrm{t}<500^{\circ} \mathrm{C}$ \\
\hline & & & & & or, opposite & & & \\
\hline & & & & & 241 & NW & 193 & \\
\hline 463 & 277 & 42 & 1631 & F NRM-AF400 & 142 & NE & 65 & postcooling \\
\hline \multirow[t]{3}{*}{464} & 359 & 63 & 7 & B NRM-TD150 & 93 & $\mathrm{~N}$ & 12 & postcooling \\
\hline & 132 & 48 & 4.3 & B TD250-TD500 & 62 & NW & 69 & $150-250^{\circ} \mathrm{C}$ \\
\hline & 54 & -32 & 2.3 & B TD550-TD650 & 40 & NW & 136 & $500-550^{\circ} \mathrm{C}$ \\
\hline \multicolumn{9}{|c|}{ Square 37, Level 22-Base } \\
\hline \multirow[t]{2}{*}{760} & 59 & 55 & 1.9 & B NRM-AF200 & 35 & NW & 42 & postcooling \\
\hline & 23 & 37 & 1.9 & B AF200-AF400 & 273 & $S$ & 30 & $200^{\circ} \mathrm{Oe}$ \\
\hline 761 & 249 & 23 & 971 & F NRM-AF400 & 130 & NE & 98 & postcooling \\
\hline \multirow[t]{2}{*}{762} & 27 & -68 & 0 & S AF100-AF150 & 242 & SE & 130 & $<100^{\circ} \mathrm{Oe}$ \\
\hline & 98 & -81 & 0.6 & B AF150-AF400 & 206 & SE & 26 & $150^{\circ} \mathrm{Oe}$ \\
\hline \multicolumn{9}{|c|}{ Square 37, Level 24} \\
\hline \multirow[t]{2}{*}{963} & 43 & 50 & 6.4 & B AF100-AF200 & 22 & W-NW & 34 & $<100^{\circ} \mathrm{Oe}$ \\
\hline & $\sim 38$ & $<5$ & 0 & S AF400-ORIGIN & $340 ?$ & W-SW? & $57 ?$ & $200<\mathrm{t}<400^{\circ} \mathrm{Oe}$ \\
\hline \multirow[t]{3}{*}{964} & 351 & 54 & 1.8 & B TD100-TD200 & 144 & $\mathrm{NE}$ & 8 & postcooling \\
\hline & 265 & 23 & 2.2 & B TD200-TD400 & 142 & NE & 82 & $200^{\circ} \mathrm{C}$ \\
\hline & 345 & -6 & 2.1 & B TD450-TD650 & 180 & $\mathrm{E}$ & 122 & $400-450^{\circ} \mathrm{C}$ \\
\hline \multicolumn{9}{|c|}{ Square 38, Level 20} \\
\hline \multirow[t]{2}{*}{330} & 341 & 54 & 1.4 & B TD100-TD200 & 104 & $\mathrm{~N}$ & 16 & postcooling \\
\hline & 204 & -11 & 1.2 & B TD500-TD575 & 337 & W-SW & 128 & $200<\mathrm{t}<500^{\circ} \mathrm{C}$ \\
\hline \multirow[t]{2}{*}{332} & 344 & 56 & 6.7 & B NRM-AF150 & 146 & $\mathrm{NE}$ & 14 & postcooling \\
\hline & 198 & 66 & 3.3 & B AF150-AF400 & 86 & $\mathrm{~N}$ & 55 & $150^{\circ} \mathrm{Oe}$ \\
\hline \multirow[t]{2}{*}{333} & 357 & 40 & 7.8 & B NRM-TD200 & & & $\sim 10$ & postcooling \\
\hline & 94 & 19 & 3.4 & B TD350-TD550 & 40 & NW & 107 & $200<\mathrm{t}<350^{\circ} \mathrm{C}$ \\
\hline 335 & 353 & 36 & 1724 & F NRM-AF400 & 239 & SE & 15 & postcooling \\
\hline 336 & 8 & 29 & 2096 & F NRM-AF400 & 296 & SW & 24 & postcooling \\
\hline \multirow[t]{5}{*}{337} & 7 & 50 & 3.2 & B TD100-TD250 & & & $<7$ & postcooling \\
\hline & 204 & -21 & 4.1 & B TD300-TD400 & 106 & $\mathrm{~N}$ & 150 & $250-300^{\circ} \mathrm{C}$ \\
\hline & 160 & 9 & 3 & B TD400-TD550 & or, opposite & & & \\
\hline & & & & & 286 & $S$ & 210 & \\
\hline & & & & & 4 & W & 68 & $400^{\circ} \mathrm{C}$ \\
\hline Square $38, \mathrm{Lc}$ & vel 21-A & & & & & & & \\
\hline 425 & 59 & -48 & 4.4 & B AF150-AF400 & 27 & NW & 175 & $<150^{\circ} \mathrm{Oe}$ \\
\hline & & & & & or, opposite & & & \\
\hline & & & & & 207 & SE & 185 & \\
\hline 427 & 349 & 72 & 5 & B TD100-TD300 & 100 & $\mathrm{~N}$ & 23 & postcooling \\
\hline & 55 & 8 & 1 & B TD500-TD600 & 5 & W & 106 & $300<\mathrm{t}<500^{\circ} \mathrm{C}$ \\
\hline 428 & 8 & 52 & 2 & B AF075-AF150 & & & $<8$ & $<75^{\circ} \mathrm{Oe}$ \\
\hline & 25 & 33 & 4.8 & B AF200-AF400 & 330 & SW & 26 & $150-200^{\circ} \mathrm{Oe}$ \\
\hline 430 & 339 & 18 & 4.2 & B TD100-TD400 & 214 & SE & 43 & postcooling \\
\hline & 171 & 36 & 1.2 & B TD400-TD650 & 258 & $S$ & 126 & $400^{\circ} \mathrm{C}$ \\
\hline
\end{tabular}


Table A6-2, continued

\begin{tabular}{|c|c|c|c|c|c|c|c|c|}
\hline \multicolumn{5}{|c|}{ Identified Vectors } & \multicolumn{4}{|c|}{ Reconstructed Vector Rotations } \\
\hline $\begin{array}{l}\text { Sample } \\
\text { (AM-) }\end{array}$ & Declination & Inclination & MAD or $\kappa$ & Range & Strike & $\begin{array}{c}\text { Direction } \\
\text { of rotation }\end{array}$ & $\begin{array}{l}\text { Magnitude } \\
\text { of rotation }\end{array}$ & Threshold \\
\hline 432 & 348 & 26 & 1120 & F NRM-TD600 & 231 & SE & 28 & postcooling \\
\hline 434 & 0 & 28 & 2425 & F NRM-AF600 & 270 & $S$ & 22 & postcooling \\
\hline \multirow[t]{2}{*}{435} & 8 & 41 & 1.5 & B AF100-AF200 & 316 & SW & 12 & $<100^{\circ} \mathrm{Oe}$ \\
\hline & 21 & 55 & 4.4 & B AF200-AF400 & 70 & $\mathrm{~N}-\mathrm{NW}$ & 16 & $200^{\circ} \mathrm{Oe}$ \\
\hline 436 & 87 & 13 & 4.1 & B NRM-AF600 & 32 & NW & 99 & postcooling \\
\hline \multicolumn{9}{|c|}{ Square 38, Level 22} \\
\hline \multirow[t]{2}{*}{603} & 344 & 18 & 1.5 & B AF100-AF200 & 227 & SE & 39 & $<100^{\circ} \mathrm{Oe}$ \\
\hline & 354 & 11 & 2.6 & B AF200-AF400 & 308 & SW & 13 & $200^{\circ} \mathrm{Oe}$ \\
\hline 604 & 322 & 50 & 4494 & F NRM-TD450 & 160 & E-NE & 32 & postcooling \\
\hline \multirow{3}{*}{632} & 285 & -41 & 3047 & F NRM-AF600 & 148 & NE & 166 & postcooling \\
\hline & & & & & or, opposite & & & \\
\hline & & & & & 328 & SW & 194 & \\
\hline 633 & 266 & -6 & 12081 & F NRM-AF400 & 144 & NE & 124 & postcooling \\
\hline \multirow[t]{2}{*}{635} & 352 & 33 & 4.7 & B AF100-AF200 & 240 & SE & 19 & $<100^{\circ} \mathrm{Oe}$ \\
\hline & 9 & 15 & 4.7 & B AF200-AF400 & 316 & SW & 27 & $200^{\circ} \mathrm{Oe}$ \\
\hline 636 & 211 & 3 & 370 & F NRM-AF400 & 108 & $\mathrm{~N}$ & 132 & postcooling \\
\hline \multirow[t]{2}{*}{637} & 52 & 52 & 1 & B AF050-AF150 & 28 & NW & 40 & $<50 \mathrm{Oe}$ \\
\hline & 150 & 56 & 3 & B AF200-AF600 & 108 & $\mathrm{~N}$ & 54 & $150-200 \mathrm{Oe}$ \\
\hline \multirow[t]{3}{*}{638} & 351 & 36 & 2.7 & B TD100-TD300 (MINUS 250) & 232 & SE & 17 & postcooling \\
\hline & 344 & 21 & 2.2 & B TD350-TD500 & 219 & SE & 19 & $300-350^{\circ} \mathrm{C}$ \\
\hline & 279 & 34 & 0.8 & B TD575-TD650 & 122 & NE & 62 & $500-575^{\circ} \mathrm{C}$ \\
\hline 640 & 353 & 45 & 3486 & F NRM-AF400 & 213 & SE & 8 & postcooling \\
\hline 643 & 20 & 42 & 3909 & F NRM-AF400 & 348 & W & 21 & postcooling \\
\hline 644 & 337 & 44 & 10214 & F NRM-AF400 & 183 & $\mathrm{E}$ & 22 & postcooling \\
\hline 645 & 250 & 47 & 768 & F NRM-AF400 & 125 & NE & 73 & postcooling \\
\hline \multicolumn{9}{|c|}{ Square 38, Level 22-Base } \\
\hline 711 & 7 & 23 & 2.6 & B NRM-AF400 & 292 & S-SW & 29 & postcooling \\
\hline 712 & 359 & 41 & 2172 & F NRM-AF400 & 279 & S & 9 & postcooling \\
\hline 714 & 8 & 62 & 1.5 & B NRM-AF400 & 70 & N-NW & 14 & postcooling \\
\hline 715 & 354 & 58 & 1734 & F NRM-AF400 & 114 & $\mathrm{~N}-\mathrm{NE}$ & 9 & postcooling \\
\hline \multirow[t]{2}{*}{716} & 334 & 49 & 2.5 & B NRM-AF150 & 170 & $\mathrm{E}$ & 22 & postcooling \\
\hline & 318 & 43 & 3.1 & B AF150-AF400 & 166 & E & 16 & $150^{\circ} \mathrm{Oe}$ \\
\hline \multirow[t]{2}{*}{717} & 343 & 55 & 1.9 & B NRM-AF100 & 148 & NE & 14 & postcooling \\
\hline & 84 & 64 & 1.7 & B AF200-AF600 & 39 & NW & 54 & $100-200^{\circ} \mathrm{Oe}$ \\
\hline 718 & 261 & 33 & 3528 & F NRM-AF400 & 138 & NE & 82 & postcooling \\
\hline 719 & 254 & 18 & 4673 & F NRM-AF400 & 136 & $\mathrm{NE}$ & 102 & postcooling \\
\hline 720 & 1 & 36 & 1.5 & B AF050-AF400 & 277 & S & 14 & $<50^{\circ} \mathrm{Oe}$ \\
\hline \multirow[t]{2}{*}{721} & 197 & 5 & 3.5 & B NRM-AF100 & 99 & $\mathrm{~N}$ & 125 & postcooling \\
\hline & 186 & 18 & 0.7 & B AF150-AF400 & 331 & SW & 20 & $100-150^{\circ} \mathrm{Oe}$ \\
\hline \multirow[t]{3}{*}{722} & 195 & -28 & 1210 & F NRM-AF400 & 98 & $\mathrm{~N}$ & 158 & postcooling \\
\hline & & & & & or, opposite & & & \\
\hline & & & & & 278 & $\mathrm{~S}$ & 202 & \\
\hline \multirow[t]{2}{*}{723} & 332 & 10 & 9.5 & B NRM-AF100 & 205 & E-SE & 58 & postcooling \\
\hline & 327 & -66 & 4.1 & B AF150-AF400 & 177 & $\mathrm{E}$ & 108 & $100-150^{\circ} \mathrm{Oe}$ \\
\hline 730 & 210 & 39 & 648 & $\mathrm{~F}$ AF150-AF400 & 106 & $\mathrm{~N}$ & 90 & $<150^{\circ} \mathrm{Oe}$ \\
\hline 731 & 185 & 7 & 882 & F NRM-AF400 & 92 & $\mathrm{~N}$ & 123 & postcooling \\
\hline 732 & 358 & 49 & 456 & F NRM-AF400 & & & $<2$ & postcooling \\
\hline 733 & 201 & -24 & 5875 & F NRM-AF400 & 102 & $\mathrm{~N}$ & 153 & postcooling \\
\hline 734 & 290 & 48 & 468 & F NRM-AF400 & 146 & NE & 54 & postcooling \\
\hline \multirow[t]{2}{*}{735} & 58 & 17 & 10.9 & B NRM-AF100 & 9 & W & 77 & postcooling \\
\hline & 108 & -38 & 3.7 & B AF200-AF400 & 50 & NW & 80 & $100-200^{\circ} \mathrm{Oe}$ \\
\hline
\end{tabular}


Table A6-2, continued

\begin{tabular}{|c|c|c|c|c|c|c|c|c|}
\hline & & & entified Vect & & & Reconstruct & ed Vector Ro & tations \\
\hline $\begin{array}{l}\text { Sample } \\
\text { (AM-) }\end{array}$ & Declination & Inclination & MAD or $\kappa$ & Range & Strike & $\begin{array}{l}\text { Direction } \\
\text { of rotation }\end{array}$ & $\begin{array}{l}\text { Magnitude } \\
\text { of rotation }\end{array}$ & Threshold \\
\hline Square $38, \mathrm{Le}$ & vel 23 & & & & & & & \\
\hline 859 & 121 & -30 & 1207 & F NRM-TD650 & 55 & NW & 157 & postcooling \\
\hline & & & & & or, opposite & & & \\
\hline & & & & & 235 & SE & 203 & \\
\hline 861 & 346 & 41 & 0 & S NRM-TD100 & 204 & E-SE & 16 & postcooling \\
\hline & 256 & 14 & 2.3 & B TD200-TD600 & 131 & $\mathrm{NE}$ & 94 & $100-200^{\circ} \mathrm{C}$ \\
\hline & 204 & 36 & 0 & S TD600-TD650 & 33 & NW & 61 & $600^{\circ} \mathrm{C}$ \\
\hline 862 & 7 & 51 & 9.4 & B TD100-TD200 & & & $<5$ & postcooling \\
\hline & 352 & -9 & 1.7 & B TD250-TD500 & 239 & SE & 67 & $200-250^{\circ} \mathrm{C}$ \\
\hline & 43 & 27 & 2.2 & B TD550-TD600 & 27 & NW & 83 & $500-550^{\circ} \mathrm{C}$ \\
\hline 863 & 12 & 61 & 4.4 & B NRM-TD250 (MINUS 150) & 59 & NW & 14 & postcooling \\
\hline 864 & 334 & 56 & 1.4 & B AF050-AF150 & 149 & $\mathrm{NE}$ & 20 & $<50^{\circ} \mathrm{Oe}$ \\
\hline & 323 & 26 & 1.9 & B AF200-AF400 & 200 & E-SE & 40 & $150-200 \mathrm{Oe}$ \\
\hline 865 & 28 & 49 & 5.7 & B AF050-AF150 & 10 & $\mathrm{~W}$ & 24 & $<50^{\circ} \mathrm{Oe}$ \\
\hline & 46 & -22 & 2.5 & B AF300-AF600 & 2 & W & 100 & $150<\mathrm{t}<300^{\circ} \mathrm{Oe}$ \\
\hline 867 & 353 & 43 & 391 & F NRM-AF400 & 222 & SE & 10 & postcooling \\
\hline 868 & 11 & 61 & 6753 & F NRM-AF400 & 60 & NW & 14 & postcooling \\
\hline 869 & 335 & 41 & 71758 & F NRM-AF400 & 186 & $\mathrm{E}$ & 26 & postcooling \\
\hline 870 & 334 & 28 & 2.5 & B TD250-TD350 & 202 & E-SE & 37 & $<250^{\circ} \mathrm{C}$ \\
\hline & 197 & 64 & 0.5 & B TD500-TD650 & 73 & $\mathrm{~N}$ & 84 & $350<\mathrm{t}<500^{\circ} \mathrm{C}$ \\
\hline 874 & 348 & 49 & 2.2 & В TD250-TD400 & & & $<2$ & $<250^{\circ} \mathrm{C}$ \\
\hline & 10 & 58 & 0.1 & B TD500-TD650 & 30 & NW & 19 & $400-500^{\circ} \mathrm{C}$ \\
\hline 875 & 325 & 60 & 1126 & F AF050-AF400 & 140 & NE & 26 & $<50^{\circ} \mathrm{Oe}$ \\
\hline 876 & 349 & 62 & 558 & F NRM-AF400 & 115 & N-NE & 14 & postcooling \\
\hline 877 & 357 & 41 & 1.3 & B NRM-AF200 & 250 & S-SE & 9 & postcooling \\
\hline & 353 & 61 & 0 & S AF300-AF400 & 90 & $\mathrm{~N}$ & 19 & $200-300^{\circ} \mathrm{Oe}$ \\
\hline 878 & 11 & 53 & 701 & F NRM-AF400 & 22 & W-NW & 10 & postcooling \\
\hline 879 & 330 & 52 & 522 & F NRM-TD500 & 159 & E-NE & 24 & postcooling \\
\hline Square $38, \mathrm{Le}$ & vel 23-Base & & & & & & & \\
\hline 939 & 41 & 38 & 519 & F NRM-AF400 & 5 & W & 43 & postcooling \\
\hline 940 & 343 & 50 & 4711 & F NRM-AF400 & 6 & W & 14 & postcooling \\
\hline 941 & 344 & 56 & 1.7 & B NRM-AF100 & 144 & $\mathrm{NE}$ & 14 & postcooling \\
\hline & 283 & 30 & 2.2 & B AF200-AF400 & 152 & NE & 61 & $100-200^{\circ} \mathrm{Oe}$ \\
\hline 943 & 341 & 39 & 0 & B AF050-AF100 & 200 & E-SE & 22 & $<50^{\circ} \mathrm{Oe}$ \\
\hline & 329 & -17 & 2 & B AF150-AF300 & 200 & E-SE & 72 & $100-150^{\circ} \mathrm{Oe}$ \\
\hline 944 & 102 & 64 & 2052 & F AF050-AF400 & 60 & NW & 54 & $<50^{\circ} \mathrm{Oe}$ \\
\hline Square 38, Le & vel 24 & & & & & & & \\
\hline 1196 & 51 & -35 & 1.2 & B AF150-AF400 & 26 & NW & 180 & $<150^{\circ} \mathrm{Oe}$ \\
\hline & & & & & or, opposite & & & \\
\hline & & & & & 206 & SE & 180 & \\
\hline 1197 & 344 & 38 & 3.1 & B AF050-AF300 (MINUS 100) & 207 & SE & 20 & $<50^{\circ} \mathrm{Oe}$ \\
\hline 1198 & 7 & 59 & 1.3 & B AF050-AF150 & & & $<10$ & $<50^{\circ} \mathrm{Oe}$ \\
\hline & 13 & 49 & 2.2 & B AF150-AF300 & 304 & SW & 11 & $150^{\circ} \mathrm{Oe}$ \\
\hline & $>21$ & $<18$ & 0 & S AF400-ORIGIN & 306 & SW & $34+$ & $300-400^{\circ} \mathrm{Oe}$ \\
\hline 1199 & 18 & 43 & 1.7 & B NRM-AF100 & 347 & $\mathrm{w}$ & 19 & postcooling \\
\hline & 25 & -21 & 2 & B AF200-AF400 & 335 & W-SW & 81 & $100-200^{\circ} \mathrm{Oe}$ \\
\hline 1200 & 348 & 50 & 5.3 & B AF050-AF150 & & & $<5$ & $<50^{\circ} \mathrm{Oe}$ \\
\hline & 34 & 33 & 0 & S AF300-AF400 & 354 & W & 50 & $150<\mathrm{t}<300^{\circ} \mathrm{Oe}$ \\
\hline 1201 & 354 & 43 & 2.6 & B NRM-AF400 & 226 & SE & 9 & postcooling \\
\hline 1202 & 335 & 43 & 1.7 & B NRM-AF150 & 182 & $\mathrm{E}$ & 24 & postcooling \\
\hline & 267 & -12 & 0 & S AF300-AF400 & 144 & NE & 111 & \\
\hline
\end{tabular}


Table A6-2, continued

\begin{tabular}{|c|c|c|c|c|c|c|c|c|}
\hline & & & entified Vect & & & Reconstruct & ed Vector Rc & tations \\
\hline $\begin{array}{l}\text { Sample } \\
\text { (AM-) }\end{array}$ & Declination & Inclination & MAD or $\kappa$ & Range & Strike & $\begin{array}{c}\text { Direction } \\
\text { of rotation }\end{array}$ & $\begin{array}{l}\text { Magnitude } \\
\text { of rotation }\end{array}$ & Threshold \\
\hline 1203 & 347 & 56 & 2755 & F NRM-AF400 & 140 & NE & 12 & postcooling \\
\hline 1204 & 3 & 25 & 563 & F NRM-TD600 & 282 & S & 25 & postcooling \\
\hline 1205 & 339 & 67 & 0 & B AF050-AF100 & 66 & N-NW & 19 & $<50^{\circ} \mathrm{Oe}$ \\
\hline & 336 & 85 & 0.1 & B AF200-AF400 & 116 & NE & 21 & $100-200^{\circ} \mathrm{Oe}$ \\
\hline 1206 & 345 & 89 & 3.6 & B AF100-AF200 & 90 & $\mathrm{~N}$ & 39 & $<100^{\circ} \mathrm{Oe}$ \\
\hline & 19 & 51 & 0.7 & B AF200-AF400 & 302 & SW & 31 & $200^{\circ} \mathrm{Oe}$ \\
\hline & $<4$ & $\sim 49$ & 0 & S AF400-ORIGIN & $\sim 246$ & $\sim \mathrm{S}-\mathrm{SE}$ & $\sim 13$ & $400^{\circ} \mathrm{Oe}$ \\
\hline 1207 & 358 & 40 & 4.8 & B TD300-TD450 & & & $\sim 10$ & $<300^{\circ} \mathrm{C}$ \\
\hline & 22 & -9 & 2.3 & B TD450-TD550 & 339 & W-SW & 81 & $450^{\circ} \mathrm{C}$ \\
\hline & 27 & -31 & 0 & B TD550-TD600 & 2 & W & 36 & $550^{\circ} \mathrm{C}$ \\
\hline 1208 & 355 & 55 & 3.2 & B NRM-TD300 & & & $<5$ & postcooling \\
\hline & 271 & -51 & 1.7 & B TD450-TD550 & 135 & NE & 175 & $300<\mathrm{t}<450^{\circ} \mathrm{C}$ \\
\hline & & & & & or, opposite & & & \\
\hline & & & & & 315 & SW & 185 & \\
\hline 1209 & 360 & 48 & 1.5 & B TD200-TD400 (MINUS 250) & & & $<2$ & $<200^{\circ} \mathrm{C}$ \\
\hline 1210 & 172 & 6 & 605 & F NRM-AF400 & 86 & $\mathrm{~N}$ & 125 & postcooling \\
\hline 1211 & 35 & 63 & 4.5 & B NRM-AF100 & 47 & NW & 26 & postcooling \\
\hline & 186 & 36 & 2.1 & B AF200-AF400 & 103 & $\mathrm{~N}$ & 79 & $100-200^{\circ} \mathrm{Oe}$ \\
\hline 1212 & 351 & 43 & 3.5 & B NRM-AF100 & 212 & SE & 10 & postcooling \\
\hline & 235 & -55 & 2.1 & B AF200-AF400 & 302 & SW & 180 & $100-200^{\circ} \mathrm{Oe}$ \\
\hline & & & & & or, opposite & & & \\
\hline & & & & & 122 & NE & 180 & \\
\hline Square $38, \mathrm{~L}$ & evel 25-B & & & & & & & \\
\hline 1235 & 335 & 70 & 2.8 & B AF050-AF400 & 113 & N-NE & 24 & $<50^{\circ} \mathrm{Oe}$ \\
\hline$\overline{\text { Square } 39, \mathrm{~L}}$ & evel 21-A & & & & & & & \\
\hline 386 & 0 & 40 & 1 & B NRM-TD150 & 270 & $\mathrm{~S}$ & 10 & postcooling \\
\hline & 340 & 28 & 4.2 & B TD150-TD300 & 196 & $\mathrm{E}$ & 27 & $150^{\circ} \mathrm{C}$ \\
\hline & 64 & -42 & 1 & B TD400-TD650 & 198 & E & 177 & $300-400^{\circ} \mathrm{C}$ \\
\hline & & & & & or, opposite & & & \\
\hline & & & & & 18 & W & 183 & \\
\hline 387 & 280 & 20 & 985 & F NRM-AF600 & 153 & $\mathrm{NE}$ & 87 & postcooling \\
\hline 389 & 2 & 52 & 4.9 & B TD100-TD200 & & & $<5$ & postcooling \\
\hline & 327 & 74 & 5.3 & B TD350-TD450 & 114 & N-NE & 27 & $200<\mathrm{t}<350^{\circ} \mathrm{C}$ \\
\hline & 181 & 64 & 0 & S TD500-TD550 & 78 & $\mathrm{~N}$ & 41 & $450-500^{\circ} \mathrm{C}$ \\
\hline & 330 & 52 & 0.1 & B TD575-TD650 & 236 & SE & 68 & $550-575^{\circ} \mathrm{C}$ \\
\hline 391 & 351 & 43 & 4.5 & B NRM-AF100 & 214 & SE & 11 & postcooling \\
\hline & 257 & 2 & 3 & B AF300-AF600 & 137 & NE & 110 & $100<\mathrm{t}<300^{\circ} \mathrm{Oe}$ \\
\hline Square $39, \mathrm{~L}$ & evel 22 & & & & & & & \\
\hline 614 & 346 & 33 & 4.3 & B AF050-AF150 & 219 & SE & 22 & $<50^{\circ} \mathrm{Oe}$ \\
\hline & 322 & 23 & 1 & B AF200-AF400 & 172 & $\mathrm{E}$ & 33 & $150-200^{\circ} \mathrm{Oe}$ \\
\hline 624 & 325 & 76 & 1.9 & B NRM-TD150 & 108 & $\mathrm{~N}$ & 30 & postcooling \\
\hline & 302 & 29 & 6.4 & B TD200-TD350 (MINUS 250) & 182 & E & 64 & $150-200^{\circ} \mathrm{C}$ \\
\hline & 351 & 25 & 2.1 & B TD350-TD450 & 254 & $S$ & 46 & $350^{\circ} \mathrm{C}$ \\
\hline & 151 & 85 & 6.6 & B TD500-TD575 & 24 & W & 92 & $450-500^{\circ} \mathrm{C}$ \\
\hline 625 & 0 & 56 & 6.6 & B AF100-AF200 & & & $<5$ & $<100^{\circ} \mathrm{Oe}$ \\
\hline 626 & 10 & 6 & 1455 & F NRM-AF400 & 299 & SW & 47 & postcooling \\
\hline 628 & 332 & -12 & 0.4 & B AF200-AF600 & 205 & E-SE & 86 & $<200^{\circ} \mathrm{Oe}$ \\
\hline$\overline{\text { Square } 39, \mathrm{Lc}}$ & evel 22-Base & & & & & & & \\
\hline 706 & 354 & 11 & 2.1 & B NRM-AF400 & 252 & $S$ & 40 & postcooling \\
\hline 707 & 208 & -24 & 426 & F NRM-AF600 & 106 & $\mathrm{~N}$ & 105 & postcooling \\
\hline 708 & 345 & 30 & 2192 & F NRM-AF400 & 220 & SE & 26 & postcooling \\
\hline
\end{tabular}


Table A6-2, continued

\begin{tabular}{|c|c|c|c|c|c|c|c|c|}
\hline \multicolumn{5}{|c|}{ Identified Vectors } & \multicolumn{4}{|c|}{ Reconstructed Vector Rotations } \\
\hline $\begin{array}{l}\text { Sample } \\
\text { (AM-) }\end{array}$ & Declination & Inclination & MAD or $\kappa$ & Range & Strike & $\begin{array}{l}\text { Direction } \\
\text { of rotation }\end{array}$ & $\begin{array}{l}\text { Magnitude } \\
\text { of rotation }\end{array}$ & Threshold \\
\hline 709 & 344 & 40 & 1828 & F NRM-AF400 & 198 & $\mathrm{E}$ & 18 & postcooling \\
\hline 710 & 325 & 27 & 1353 & F NRM-AF400 & 188 & $\mathrm{E}$ & 46 & postcooling \\
\hline \multicolumn{9}{|c|}{ Square 39, Level 23} \\
\hline \multirow[t]{3}{*}{871} & 347 & 29 & 4.7 & B TD100-TD350 & 224 & SE & 26 & postcooling \\
\hline & 186 & 64 & 1.2 & B TD400-TD550 & 81 & $\mathrm{~N}$ & 86 & $350-400^{\circ} \mathrm{C}$ \\
\hline & 152 & 68 & 1 & B TD550-TD650 & 354 & W & 18 & $550^{\circ} \mathrm{C}$ \\
\hline 904 & 355 & 62 & 1.1 & B AF050-AF400 & 103 & $\mathrm{~N}$ & 13 & $<50^{\circ} \mathrm{Oe}$ \\
\hline \multicolumn{9}{|c|}{ Square 39, Level 24} \\
\hline 990 & 0 & 13 & 981 & F NRM-AF400 & 270 & $S$ & 37 & postcooling \\
\hline \multirow[t]{5}{*}{993} & 357 & 57 & 3.9 & B NRM-TD300 & & & $<7$ & postcooling \\
\hline & 338 & 30 & 0.5 & B TD300-TD400 & 222 & SE & 32 & $300^{\circ} \mathrm{C}$ \\
\hline & 167 & -68 & 1.9 & B TD500-TD600 & 297 & SW & 160 & $400-500^{\circ} \mathrm{C}$ \\
\hline & & & & & or, opposite & & & \\
\hline & & & & & 117 & NE & 190 & \\
\hline \multicolumn{9}{|c|}{ Square 41, Level 28} \\
\hline \multirow[t]{7}{*}{571} & 22 & 45 & 2.2 & B TD100-TD200 & 354 & W & 20 & postcooling \\
\hline & 233 & -40 & 4.7 & B TD250-TD350 & 287. & S & 174 & $200-250^{\circ} \mathrm{C}$ \\
\hline & 172 & -50 & 0.6 & B TD350-TD450 & or, opposite & & & \\
\hline & 232 & -37 & 4.9 & B TD450-TD550 & 107 & $\mathrm{~N}$ & 186 & \\
\hline & 279 & -8 & 0.8 & B TD575-TD650 & 19 & W & 54 & $350^{\circ} \mathrm{C}$ \\
\hline & & & & & 206 & SE & 53 & $450^{\circ} \mathrm{C}$ \\
\hline & & & & & 163 & E & 68 & $550-575^{\circ} \mathrm{C}$ \\
\hline \multicolumn{9}{|c|}{ Square 42, Level 27} \\
\hline \multirow[t]{2}{*}{498} & 356 & 55 & 4.9 & B NRM-TD200 & & & $<5$ & postcooling \\
\hline & 327 & 58 & 4338 & F TD200-TD550 & 152 & NE & 20 & $200^{\circ} \mathrm{C}$ \\
\hline 574 & 4 & 49 & 2062 & F AF050-AF400 & & & $<5$ & $<50^{\circ} \mathrm{Oe}$ \\
\hline \multicolumn{9}{|c|}{ Square 42, Level 29} \\
\hline \multirow[t]{3}{*}{881} & 32 & 42 & 0 & S NRM-TD250 & 2 & W & 30 & postcooling \\
\hline & 76 & 48 & 3 & B TD250-TD500 & 67 & $\mathrm{~N}-\mathrm{NW}$ & 33 & $250^{\circ} \mathrm{C}$ \\
\hline & 11 & 24 & 1.2 & B TD550-TD600 & 254 & $S$ & 56 & $500-550^{\circ} \mathrm{C}$ \\
\hline \multicolumn{9}{|c|}{ Square 45, Level 18} \\
\hline 109 & 3 & 46 & 3.4 & B TD150-TD300 & & & $<5$ & $<150^{\circ} \mathrm{C}$ \\
\hline 109 & 276 & 50 & 2.8 & B TD575-TD650 & 139 & NE & 66 & $300<\mathrm{t}<575^{\circ} \mathrm{C}$ \\
\hline \multicolumn{9}{|c|}{ Square 48, Level 19} \\
\hline \multirow[t]{4}{*}{222} & 18 & 46 & 2.2 & B NRM-TD200 (MINUS 150) & 358 & W & 17 & postcooling \\
\hline & 173 & -26 & 0.3 & В TD350-TD600 & 81 & $\mathrm{~N}$ & 154 & $200<\mathrm{t}<350^{\circ} \mathrm{C}$ \\
\hline & & & & & or, opposite & & & \\
\hline & & & & & 261 & $S$ & 206 & \\
\hline 225 & 201 & 31 & 518 & F NRM-AF400 & 100 & $\mathrm{~N}$ & 99 & postcooling \\
\hline \multicolumn{9}{|c|}{ Square 48, Level 20} \\
\hline \multirow[t]{4}{*}{295} & 348 & 53 & 6.3 & B NRM-TD150 & 152 & NE & 10 & postcooling \\
\hline & 66 & 10 & 3.8 & B TD200-TD300 & 15 & W & 101 & $150-200^{\circ} \mathrm{C}$ \\
\hline & 248 & 34 & 1.7 & В TD300-TD400 & 124 & NE & 134 & $300^{\circ} \mathrm{C}$ \\
\hline & 66 & 73 & 3.9 & В TD500-TD600 & 182 & E & 97 & $400-500^{\circ} \mathrm{C}$ \\
\hline 296 & 351 & 24 & 1.7 & B AF200-AF400 & 240 & SE & 28 & $<200 \mathrm{Oe}$ \\
\hline \multicolumn{9}{|c|}{ Square 49, Level 20} \\
\hline 404 & 339 & 27 & 3.8 & B NRM-AF150 (MINUS AF050) & 210 & SE & 35 & postcooling \\
\hline & 314 & -6 & 1.5 & B AF200-AF400 & 178 & E & 52 & $150-200 \mathrm{Oe}$ \\
\hline 406 & 358 & 19 & 1557 & F NRM-AF400 & 263 & $S$ & 30 & postcooling \\
\hline 407 & 83 & -57 & 2.3 & B AF300-AF650 & 47 & NW & 53 & $<300^{\circ} \mathrm{Oe}$ \\
\hline 408 & 354 & 51 & 7.3 & B NRM-TD150 & & & $<5$ & postcooling \\
\hline
\end{tabular}


Table A6-2, continued

\begin{tabular}{|c|c|c|c|c|c|c|c|c|}
\hline & & & entified Vect & & & Reconstruct & ed Vector Ro & tations \\
\hline $\begin{array}{l}\text { Sample } \\
\text { (AM-) }\end{array}$ & Declination & Inclination & MAD or $\kappa$ & Range & Strike & $\begin{array}{l}\text { Direction } \\
\text { of rotation }\end{array}$ & $\begin{array}{l}\text { Magnitude } \\
\text { of rotation }\end{array}$ & Threshold \\
\hline & 9 & - & 0.9 & B TD200-TD600 & 184 & $\mathrm{E}$ & 176 & $150-200^{\circ} \mathrm{C}$ \\
\hline & & & & & or, opposite & & & \\
\hline & & & & & 4 & W & 184 & \\
\hline Square 50, Le & vel 20 & & & & & & & \\
\hline 276 & 334 & 42 & 1343 & F NRM-AF400 & 183 & E & 26 & postcooling \\
\hline 289 & 50 & 27 & 2.1 & B TD250-TD550 & 7 & W & 57 & $<250^{\circ} \mathrm{C}$ \\
\hline & 15 & -5 & 2.5 & B TD550-TD600 & 311 & SW & 53 & $550^{\circ} \mathrm{C}$ \\
\hline$\overline{\text { Square } 50, \mathrm{Le}}$ & vel 21 & & & & & & & \\
\hline 444 & 352 & 49 & 0.7 & B NRM-AF400 & & & $<3$ & postcooling \\
\hline & 160 & -26 & 2.4 & B AF600-AF1000 & 75 & $\mathrm{~N}$ & 156 & $400<\mathrm{t}<600^{\circ} \mathrm{Oe}$ \\
\hline & & & & & or, opposite & & & \\
\hline & & & & & 255 & $S$ & 204 & \\
\hline 445 & 329 & 37 & 541 & F NRM-TD575 & 185 & $\mathrm{E}$ & 34 & postcooling \\
\hline$\overline{\text { Square } 50, \mathrm{Le}}$ & vel 22 & & & & & & & \\
\hline 569 & 25 & 59 & 1.1 & B AF050-AF 150 & 39 & W-SW & 20 & $<50^{\circ} \mathrm{Oe}$ \\
\hline & 35 & 35 & 2.5 & B AF200-AF400 & 337 & NW & 21 & $150-200^{\circ} \mathrm{Oe}$ \\
\hline 755 & 5 & 49 & 2.7 & $\mathrm{~B} A F 100-\mathrm{AF} 200$ & & & $\sim 5$ & $<100^{\circ} \mathrm{Oe}$ \\
\hline & 61 & 33 & 0 & S AF300-AF400 & 20 & W-NW & 59 & $200-300^{\circ} \mathrm{Oe}$ \\
\hline 756 & 356 & 46 & 2.4 & B NRM-TD150 & & & $<5$ & postcooling \\
\hline & 347 & 28 & 2 & B TD150-TD400 & 230 & SE & 22 & $150^{\circ} \mathrm{C}$ \\
\hline & 147 & -16 & 4.1 & В TD450-TD600 & 71 & $\mathrm{~N}$ & 170 & $400-450^{\circ} \mathrm{C}$ \\
\hline & & & & & or, opposite & & & \\
\hline & & & & & 251 & S & 190 & \\
\hline 757 & 0 & 56 & 1.6 & B AF050-AF200 & 90 & $\mathrm{~N}$ & 6 & $<50^{\circ} \mathrm{Oe}$ \\
\hline & 340 & 59 & 1.7 & B AF200-AF400 & 154 & $\mathrm{NE}$ & 15 & $200^{\circ} \mathrm{Oe}$ \\
\hline 758 & 354 & -3 & 1132 & F NRM-AF400 & 254 & S & 53 & postcooling \\
\hline$\overline{\text { Square } 50, \mathrm{Le}}$ & vel 23 & & & & & & & \\
\hline 928 & 248 & 39 & 3.3 & B AF100-AF200 & 127 & NE & 81 & $<100^{\circ} \mathrm{Oe}$ \\
\hline & 208 & 0 & 0 & S AF300-AF400 & 87 & $\mathrm{~N}$ & 53 & $200-300^{\circ} \mathrm{Oe}$ \\
\hline$\overline{\text { Square } 50, \mathrm{Le}}$ & vel 25 & & & & & & & \\
\hline 1024 & 257 & 39 & 3.2 & B AF025-AF100 & 132 & $\mathrm{NE}$ & 78 & postcooling \\
\hline & 287 & -58 & 0.5 & B AF200-AF400 & 133 & NE & 118 & $100-200^{\circ} \mathrm{Oe}$ \\
\hline 1025 & 2 & 49 & 2 & B NRM-AF150 & & & $<3$ & postcooling \\
\hline & $\sim 284$ & 11 & 0 & S AF400-ORIGIN & 156 & E-NE & 98 & $150<\mathrm{t}<400^{\circ} \mathrm{Oe}$ \\
\hline$\overline{\text { Square } 50, \mathrm{Le}}$ & vel 25-B & & & & & & & \\
\hline 1018 & 316 & 44 & 4.6 & B TD150-TD250 & 166 & E & 39 & $<150 \mathrm{C}$ \\
\hline & 305 & -16 & 2.9 & B TD300-TD400 & 173 & $\mathrm{E}$ & 83 & $350-300 \mathrm{C}$ \\
\hline & 280 & -45 & 1.3 & B TD450-TD650 & 116 & NE & 38 & $400-450 \mathrm{C}$ \\
\hline 1020 & 356 & 53 & 2.2 & B NRM-TD500 & & & $<5$ & postcooling \\
\hline & 50 & 21 & 4.1 & B TD500-TD650 & 360 & $\mathrm{~W}$ & 67 & $500 \mathrm{C}$ \\
\hline$\overline{\text { Square } 51, \mathrm{Le}}$ & vel 21 & & & & & & & \\
\hline 437 & 39 & 64 & 3.2 & B TD100-TD300 (MINUS 150) & 48 & NW & 28 & postcooling \\
\hline & 62 & 44 & 2.9 & B TD400-TD500 & 6 & $\mathrm{~W}$ & 31 & $300-400 \mathrm{C}$ \\
\hline & 243 & 88 & 2.7 & B TD550-TD650 & 160 & E-NE & 61 & $500-550^{\circ} \mathrm{C}$ \\
\hline 439 & 342 & 37 & 3.7 & B TD100-TD350 & 206 & SE & 23 & postcooling \\
\hline & 349 & -29 & 2.6 & B TD550-TD600 & 222 & SE & 74 & $350<\mathrm{t}<550^{\circ} \mathrm{C}$ \\
\hline 442 & 359 & 39 & 4 & B NRM-TD400 & 264 & S & 11 & postcooling \\
\hline & 198 & 15 & 1.8 & B TD500-TD650 & 100 & $\mathrm{~N}$ & 126 & $400-500^{\circ} \mathrm{C}$ \\
\hline$\overline{\text { Square 51, Le }}$ & vel 22 & & & & & & & \\
\hline 582 & 62 & 33 & 851 & F NRM-TD550 & 8 & W & 62 & postcooling \\
\hline 584 & 290 & 68 & 1466 & $\mathrm{~F}$ AF150-AF400 & 124 & NE & 40 & $<150^{\circ} \mathrm{Oe}$ \\
\hline
\end{tabular}


Table A6-2, continued

\begin{tabular}{|c|c|c|c|c|c|c|c|c|}
\hline & & & entified Vect & & & Reconstruc & ed Vector Ro & tations \\
\hline $\begin{array}{l}\text { Sample } \\
\text { (AM-) }\end{array}$ & Declination & Inclination & MAD or $\kappa$ & Range & Strike & $\begin{array}{l}\text { Direction } \\
\text { of rotation }\end{array}$ & $\begin{array}{l}\text { Magnitude } \\
\text { of rotation }\end{array}$ & Threshold \\
\hline 586 & 347 & 8 & 3.1 & B AF050-AF400 & 235 & SE & 46 & $<50^{\circ} \mathrm{Oe}$ \\
\hline Square 51, Le & vel 22-Base & & & & & & & \\
\hline 751 & 332 & 26 & 2.2 & B AF100-AF400 & 200 & E-SE & 41 & $<100^{\circ} \mathrm{Oe}$ \\
\hline 753 & 348 & 60 & 2.9 & B NRM-TD500 & 124 & NE & 13 & postcooling \\
\hline & 89 & -42 & 2.5 & B TD500-TD650 & 49 & NW & 179 & $500^{\circ} \mathrm{C}$ \\
\hline & & & & & or, opposite & & & \\
\hline & & & & & 229 & SE & 181 & \\
\hline Square 51, Le & vel 23 & & & & & & & \\
\hline 920 & 356 & 37 & 3415 & F NRM-AF400 & 250 & S-SE & 13 & postcooling \\
\hline 921 & 6 & 45 & 3.7 & B AF $150-A F 400$ & 322 & SW & 8 & $<150^{\circ} \mathrm{Oe}$ \\
\hline 924 & 347 & 40 & 3 & B NRM-TD600 & 209 & SE & 16 & postcooling \\
\hline 925 & 346 & 52 & 802 & F NRM-AF400 & 161 & $\mathrm{E}$ & 11 & postcooling \\
\hline$\overline{\text { Square } 51, \mathrm{Le}}$ & vel 24 & & & & & & & \\
\hline 1213 & 223 & 43 & 718 & F NRM-AF400 & 112 & N-NE & 83 & postcooling \\
\hline 1214 & 355 & 48 & 3.2 & B TD100-TD400 (MINUS 250) & & & $<5$ & postcooling \\
\hline & 313 & 0 & 2.2 & B TD450-TD550 & 181 & $\mathrm{E}$ & 83 & $400-450^{\circ} \mathrm{C}$ \\
\hline & 296 & 43 & 0 & S TD550-TD600 & 30 & NW & 55 & $550^{\circ} \mathrm{C}$ \\
\hline 1215 & 8 & 58 & 3.2 & B NRM-AF400 & 59 & NW & 10 & postcooling \\
\hline 1216 & 46 & 39 & 1.9 & B AF050-400 (MINUS 100) & 10 & W & 45 & $<50^{\circ} \mathrm{Oe}$ \\
\hline 1217 & 357 & 49 & 0.8 & B AF100-AF200 & & & $<2$ & $<100^{\circ} \mathrm{Oe}$ \\
\hline & $>21$ & $<-19$ & 0 & S AF400-ORIGIN & 328 & SW & 89 & $200<\mathrm{t}<400^{\circ} \mathrm{Oe}$ \\
\hline 1218 & 356 & 48 & 952 & F NRM-AF400 & & & $<5$ & postcooling \\
\hline 1219 & 357 & 46 & 3.8 & B NRM-AF400 & & & $<5$ & postcooling \\
\hline 1220 & 2 & 56 & 1553 & F NRM-AF400 (MINUS 100) & & & $\sim 7$ & postcooling \\
\hline 1221 & 345 & 52 & 3751 & F NRM-AF400 & 162 & $\mathrm{E}$ & 12 & postcooling \\
\hline 1222 & 336 & 61 & 1755 & F NRM-AF400 & 136 & NE & 20 & postcooling \\
\hline Square 51, Le & vel 25 & & & & & & & \\
\hline 1233 & 346 & 49 & 1 & B AF150-AF400 & 178 & $\mathrm{E}$ & 12 & $<150^{\circ} \mathrm{Oe}$ \\
\hline 1236 & 249 & 73 & 2.6 & B AF100-AF200 & 108 & $\mathrm{~N}$ & 50 & $<100^{\circ} \mathrm{Oe}$ \\
\hline & 207 & 59 & 2.5 & B AF200-AF400 & 82 & $\mathrm{~N}$ & 21 & $200^{\circ} \mathrm{Oe}$ \\
\hline 1238 & 18 & 51 & 1781 & F AF050-AF400 & 11 & W & 15 & $<50^{\circ} \mathrm{Oe}$ \\
\hline 1239 & 344 & 68 & 5.8 & B NRM-TD150 & 108 & $\mathrm{~N}$ & 20 & postcooling \\
\hline & 161 & 2 & 2.1 & B TD250-TD600 & 76 & $\mathrm{~N}$ & 111 & $150-250^{\circ} \mathrm{C}$ \\
\hline Square 51, Le & vel 26 & & & & & & & \\
\hline 1151 & 243 & 46 & 1542 & F NRM-AF400 & 122 & NE & 75 & postcooling \\
\hline 1152 & 355 & 48 & 2.1 & B NRM-AF100 (MINUS AF025) & & & $<5$ & postcooling \\
\hline & 357 & 5 & 1.5 & B AF150-AF300 & 274 & $\mathrm{~S}$ & 43 & $100-150^{\circ} \mathrm{Oe}$ \\
\hline 1260 & 4 & 50 & 2.2 & B NRM-TD200 & & & $<5$ & postcooling \\
\hline & 146 & 30 & 2.4 & B TD300-TD500 & 70 & N-NW & 98 & $200-300^{\circ} \mathrm{C}$ \\
\hline & 122 & -20 & 3.8 & B TD550-TD650 & 48 & NW & 59 & $500-550^{\circ} \mathrm{C}$ \\
\hline$\overline{\text { Square } 52, \mathrm{Le}}$ & vel 21 & & & & & & & \\
\hline 207 & 20 & 41 & 2.6 & B TD100-TD200 & 345 & W & 22 & postcooling \\
\hline & 287 & 8 & 0.4 & B TD400-TD650 & 160 & $\mathrm{E}$ & 120 & $200<\mathrm{t}<400^{\circ} \mathrm{C}$ \\
\hline 209 & 347 & 68 & 0 & S NRM-TD300 & 107 & $\mathrm{~N}$ & 19 & postcooling \\
\hline & 53 & -44 & 1.1 & B TD400-TD575 & 222 & SE & 166 & $300-400^{\circ} \mathrm{C}$ \\
\hline & 66 & -86 & 0 & S TD575-TD650 & or, opposite & & & \\
\hline & & & & & 42 & NW & 194 & \\
\hline & & & & & 97 & $\mathrm{~N}$ & 53 & $575^{\circ} \mathrm{C}$ \\
\hline 211 & 355 & 42 & 1.6 & B NRM-TD200 (MINUS 150) & 233 & SE & 9 & postcooling \\
\hline & 298 & 28 & 1.7 & B TD300-TD650 & 159 & E-NE & 62 & $200-300^{\circ} \mathrm{C}$ \\
\hline 213 & 0 & 51 & 4.7 & B NRM-TD150 & & & $<2$ & postcooling \\
\hline
\end{tabular}


Table A6-2, continued

\begin{tabular}{|c|c|c|c|c|c|c|c|c|}
\hline \multicolumn{5}{|c|}{ Identified Vectors } & \multicolumn{4}{|c|}{ Reconstructed Vector Rotations } \\
\hline \multirow[t]{5}{*}{$\begin{array}{c}\text { Sample } \\
\text { (AM-) }\end{array}$} & Declination & Inclination & MAD or $\kappa$ & Range & Strike & $\begin{array}{l}\text { Direction } \\
\text { of rotation }\end{array}$ & $\begin{array}{l}\text { Magnitude } \\
\text { of rotation }\end{array}$ & Threshold \\
\hline & 290 & -10 & 4.4 & B TD250-TD400 & 162 & $\mathrm{E}$ & 116 & $150-250^{\circ} \mathrm{C}$ \\
\hline & 130 & 67 & 1.2 & B TD450-TD650 & 42 & NW & 161 & $400-450^{\circ} \mathrm{C}$ \\
\hline & & & & & or, opposite & & & \\
\hline & & & & & 222 & SE & 199 & \\
\hline \multirow[t]{3}{*}{214} & 18 & 40 & 2.8 & B NRM-AF150 & 341 & W & 20 & postcooling \\
\hline & 42 & 47 & 2.7 & B AF150-AF300 & 51 & NW & 20 & $150^{\circ} \mathrm{Oe}$ \\
\hline & $\sim 182$ & $<35$ & 0 & S AF400-ORIGIN & $102 ?$ & $\mathrm{~N}$ ? & $92 ?$ & $300-400^{\circ} \mathrm{Oe}$ \\
\hline \multirow[t]{5}{*}{216} & 358 & 59 & 2.7 & B TD100-TD200 & 97 & $\mathrm{~N}$ & 10 & postcooling \\
\hline & 265 & 4 & 0 & S TD350-TD400 & 145 & NE & 110 & $200<\mathrm{t}<350^{\circ} \mathrm{C}$ \\
\hline & 69 & -35 & 6.8 & B TD500-TD600 & 112 & N-NE & 158 & $400-500^{\circ} \mathrm{C}$ \\
\hline & & & & & or, opposite & & & \\
\hline & & & & & 292 & S-SW & 202 & \\
\hline \multirow[t]{5}{*}{217} & 345 & 64 & 3.7 & B NRM-TD300 & 116 & NE & 17 & postcooling \\
\hline & 2 & -33 & 1 & B TD450-TD550 & 200 & E-SE & 141 & $300<\mathrm{t}<450^{\circ} \mathrm{C}$ \\
\hline & 110 & -47 & 0 & S TD550-ORIGIN & or, opposite & & & \\
\hline & & & & & 20 & W-NW & 219 & \\
\hline & & & & & 153 & NE & 100 & $550^{\circ} \mathrm{C}$ \\
\hline \multirow[t]{2}{*}{246} & 329 & 21 & 0 & S NRM-AF100 & 198 & $\mathrm{E}$ & 49 & postcooling \\
\hline & 326 & -41 & 0.6 & B AF200-AF400 & 185 & E & 84 & $100-200^{\circ} \mathrm{Oe}$ \\
\hline \multicolumn{9}{|c|}{ Square 52, Level 22} \\
\hline \multirow[t]{4}{*}{342} & 355 & 47 & 3.7 & B NRM-TD300 (MINUS 150) & & & $<5$ & postcooling \\
\hline & 44 & -53 & 3.6 & B TD450-TD600 & 207 & SE & 165 & $300<\mathrm{t}<450^{\circ} \mathrm{C}$ \\
\hline & & & & & or, opposite & & & \\
\hline & & & & & 27 & NW & 195 & \\
\hline 343 & 340 & 37 & 1911 & F NRM-AF400 & 202 & E-SE & 24 & postcooling \\
\hline \multirow[t]{5}{*}{344} & 8 & 62 & 4.6 & B TD100-TD200 & 69 & $\mathrm{~N}-\mathrm{NW}$ & 14 & postcooling \\
\hline & 238 & -26 & 1.4 & B TD300-TD400 & 128 & NE & 154 & $200-300^{\circ} \mathrm{C}$ \\
\hline & 347 & -22 & 1.8 & В TD450-TD600 & or, opposite & & & \\
\hline & & & & & 308 & SW & 206 & \\
\hline & & & & & 148 & NE & 122 & $400-450^{\circ} \mathrm{C}$ \\
\hline 347 & 38 & 46 & 1.3 & B AF $100-A F 400$ & 12 & W & 33 & $<100^{\circ} \mathrm{Oe}$ \\
\hline 348 & 349 & 61 & 5.1 & B NRM-TD550 & 118 & NE & 14 & postcooling \\
\hline 349 & 43 & 17 & 4 & B NRM-TD200 & 356 & W & 63 & postcooling \\
\hline \multirow[t]{4}{*}{351} & 342 & 46 & 5 & B TD150-TD400 & 184 & $\mathrm{E}$ & 17 & $<150^{\circ} \mathrm{C}$ \\
\hline & 259 & -37 & 3.9 & B TD500-TD600 & 140 & NE & 142 & $400-500^{\circ} \mathrm{C}$ \\
\hline & & & & & or, opposite & & & \\
\hline & & & & & 320 & SW & 218 & \\
\hline \multirow[t]{3}{*}{353} & 23 & 66 & 3.4 & B NRM-TD200 & 60 & NW & 21 & postcooling \\
\hline & 317 & 18 & 3.5 & B TD200-TD350 & 188 & $\mathrm{E}$ & 88 & $200^{\circ} \mathrm{C}$ \\
\hline & 271 & -8 & 3439 & F TD400-TD550 & 116 & NE & 55 & $350-400^{\circ} \mathrm{C}$ \\
\hline 354 & 322 & 82 & 0.5 & B AF150-AF400 & 98 & $\mathrm{~N}$ & 35 & $<150^{\circ} \mathrm{Oe}$ \\
\hline \multicolumn{9}{|c|}{ Square 52, Level 23-Middle } \\
\hline \multirow[t]{3}{*}{537} & 10 & 50 & 4.5 & B NRM-AF100 & 4 & W & 8 & postcooling \\
\hline & 76 & 41 & 5.9 & B AF100-AF200 & 35 & NW & 55 & $100^{\circ} \mathrm{Oe}$ \\
\hline & 138 & 27 & 0 & B AF300-AF400 & 98 & $\mathrm{~N}$ & 53 & $200-300^{\circ} \mathrm{Oe}$ \\
\hline \multirow[t]{2}{*}{539} & 21 & 43 & 4 & B NRM-AF150 & 350 & W & 21 & postcooling \\
\hline & 21 & 29 & 1.1 & B AF200-AF400 & 310 & SW & 16 & $150-200^{\circ} \mathrm{Oe}$ \\
\hline \multirow[t]{2}{*}{540} & 51 & 41 & 1.8 & B AF050-AF200 & 16 & W & 46 & $<50^{\circ} \mathrm{Oe}$ \\
\hline & 68 & 26 & 3 & B AF200-AF400 & 28 & NW & 26 & $200^{\circ} \mathrm{Oe}$ \\
\hline \multirow[t]{2}{*}{541} & 3 & 55 & 4.9 & B NRM-TD400 (MINUS 200) & & & $<3$ & postcooling \\
\hline & 341 & 35 & 1.8 & B TD450-TD650 & 213 & SE & 29 & $400-450^{\circ} \mathrm{C}$ \\
\hline
\end{tabular}


Table A6-2, continued

\begin{tabular}{|c|c|c|c|c|c|c|c|c|}
\hline \multicolumn{5}{|c|}{ Identified Vectors } & \multicolumn{4}{|c|}{ Reconstructed Vector Rotations } \\
\hline $\begin{array}{l}\text { Sample } \\
(\text { AM-) }\end{array}$ & Declination & Inclination & MAD or $\kappa$ & Range & Strike & $\begin{array}{l}\text { Direction } \\
\text { of rotation }\end{array}$ & $\begin{array}{l}\text { Magnitude } \\
\text { of rotation }\end{array}$ & Threshold \\
\hline \multirow[t]{2}{*}{544} & 5 & 64 & 2.5 & B NRM-AF100 & 80 & $\mathrm{~N}$ & 13 & postcooling \\
\hline & 55 & 56 & 1.1 & B AF200-AF400 & 21 & W-NW & 34 & $100-200^{\circ} \mathrm{Oe}$ \\
\hline \multirow[t]{2}{*}{546} & 298 & 31 & 5.8 & B NRM-AF100 & 162 & $\mathrm{E}$ & 63 & postcooling \\
\hline & 268 & -5 & 1.1 & B AF150-AF300 & 134 & NE & 54 & $100-150^{\circ} \mathrm{Oe}$ \\
\hline \multirow[t]{2}{*}{549} & 301 & 73 & 2.3 & B AF050-AF150 & 116 & NE & 36 & $<50^{\circ} \mathrm{Oe}$ \\
\hline & -87 & 62 & 15643 & F AF200-AF400 & 148 & NE & 18 & $150-200^{\circ} \mathrm{Oe}$ \\
\hline \multirow[t]{2}{*}{550} & 331 & 41 & 2.1 & B NRM-AF150 & 182 & $\mathrm{E}$ & 30 & postcooling \\
\hline & 313 & 30 & 0.7 & B AF200-AF400 & 167 & $\mathrm{E}$ & 22 & $150-200^{\circ} \mathrm{Oe}$ \\
\hline \multirow[t]{2}{*}{553} & 44 & 43 & 2.7 & B NRM-AF150 & 13 & W & 39 & postcooling \\
\hline & 57 & 29 & 0.8 & B AF200-AF400 & 13 & W & 22 & $150-200^{\circ} \mathrm{Oe}$ \\
\hline \multirow[t]{3}{*}{554} & 332 & 76 & 6 & B NRM-TD350 (MINUS 150 \& & 104 & $\mathrm{~N}$ & 29 & postcooling \\
\hline & 201 & 77 & 1.6 & B TD400-TD550 & 84 & $\mathrm{~N}$ & 25 & $350-400^{\circ} \mathrm{C}$ \\
\hline & 184 & 66 & 1.9 & B TD550-TD650 & 69 & N-NW & 10 & $550^{\circ} \mathrm{C}$ \\
\hline \multirow[t]{2}{*}{555} & 284 & 38 & 3.9 & B NRM-AF100 & 149 & NE & 66 & postcooling \\
\hline & 195 & 32 & 2.6 & B AF200-AF400 & 64 & NW & 74 & $100-200^{\circ} \mathrm{Oe}$ \\
\hline \multirow[t]{2}{*}{556} & 7 & 57 & 0.9 & B NRM-AF100 & 58 & NW & 9 & postcooling \\
\hline & 324 & 43 & 0.7 & B AF200-AF400 & 182 & E & 40 & $100-200^{\circ} \mathrm{Oe}$ \\
\hline \multirow[t]{2}{*}{557} & 359 & 72 & 4 & B NRM-AF400 & 90 & $\mathrm{~N}$ & 22 & postcooling \\
\hline & $>116$ & $<71$ & 0 & S AF400-ORIGIN & $?$ & $?$ & $?$ & $>400^{\circ} \mathrm{Oe}$ \\
\hline \multirow[t]{2}{*}{559} & 30 & 21 & 5.8 & B AF050-AF150 & 341 & W & 47 & $<50^{\circ} \mathrm{Oe}$ \\
\hline & 42 & -3 & 4.4 & B AF200-AF400 & 358 & W & 36 & $150-200^{\circ} \mathrm{Oe}$ \\
\hline \multirow[t]{2}{*}{562} & 58 & 40 & 3.2 & B NRM-AF150 & 20 & W-NW & 54 & postcooling \\
\hline & 54 & 28 & 1.6 & B AF200-AF400 & 348 & W & 16 & $150-200^{\circ} \mathrm{Oe}$ \\
\hline \multirow[t]{3}{*}{563} & 290 & -6 & 8.9 & B NRM-AF150 & 162 & E & 113 & postcooling \\
\hline & 207 & -41 & 1.4 & B AF200-AF400 & 98 & $\mathrm{~N}$ & 80 & $150-200 \mathrm{Oe}$ \\
\hline & $<174$ & -36 & 0 & S AF400-ORIGIN & 94 & $\mathrm{~N}$ & 28 & $400 \mathrm{Oe}$ \\
\hline \multicolumn{9}{|c|}{ Square 52, Level 23} \\
\hline 588 & 345 & 16 & 2.8 & B NRM-TD650 & 227 & SE & 40 & postcooling \\
\hline \multirow[t]{3}{*}{698} & 31 & 49 & 3.5 & B NRM-TD200 (MINUS 150) & 12 & W & 26 & postcooling \\
\hline & 332 & 60 & 1.7 & B TD200-TD550 & 162 & $\mathrm{E}$ & 45 & $200^{\circ} \mathrm{C}$ \\
\hline & 299 & 48 & 1.7 & B TD550-TD600 & 160 & E-NE & 29 & $550^{\circ} \mathrm{C}$ \\
\hline \multirow[t]{2}{*}{821} & 67 & 52 & 2.8 & B NRM-AF100 & 35 & NW & 49 & postcooling \\
\hline & 93 & -32 & 0.8 & B AF200-AF400 & 38 & NW & 105 & $100-200^{\circ} \mathrm{Oe}$ \\
\hline \multirow[t]{2}{*}{822} & 6 & 42 & 0 & S NRM-AF100 & 312 & SW & 9 & postcooling \\
\hline & 26 & -20 & 2.1 & B AF200-AF400 & 331 & SW & 82 & $100-200^{\circ} \mathrm{Oe}$ \\
\hline 823 & 358 & 48 & 3.9 & B NRM-TD200 & & & $<2$ & postcooling \\
\hline & 338 & 37 & 1.4 & B TD250-TD650 & 195 & E & 25 & $200-250^{\circ} \mathrm{C}$ \\
\hline 825 & 358 & 53 & 1.7 & B NRM-TD150 & & & $<5$ & postcooling \\
\hline & 169 & -25 & 0.9 & B TD250-TD650 & 82 & $\mathrm{~N}$ & 152 & $150-200^{\circ} \mathrm{C}$ \\
\hline & & & & & or, opposite & & & \\
\hline & & & & & 262 & $S$ & 208 & \\
\hline 826 & 146 & 36 & 2164 & F NRM-AF400 & 72 & $\mathrm{~N}$ & 92 & postcooling \\
\hline 829 & 4 & 55 & 2.5 & B NRM-TD200 & & & $<5$ & postcooling \\
\hline & 353 & 23 & 4.7 & B TD300-TD450 & 245 & S-SE & 35 & $200-300^{\circ} \mathrm{C}$ \\
\hline & 330 & 10 & 1 & B TD500-TD650 & 182 & $\mathrm{E}$ & 30 & $450-500^{\circ} \mathrm{C}$ \\
\hline 830 & 308 & 46 & 1.5 & B NRM-TD250 & 158 & E-NE & 44 & postcooling \\
\hline & 15 & -67 & 0.9 & B TD350-TD600 & 316 & SW & 70 & $250-350^{\circ} \mathrm{C}$ \\
\hline 832 & 356 & 49 & 4.8 & B NRM-TD450 & & & $<4$ & postcooling \\
\hline & 122 & 19 & 0 & S TD500-TD550 & 54 & NW & 107 & $450-500^{\circ} \mathrm{C}$ \\
\hline 833 & 359 & 45 & 12850 & F NRM-AF400 & & & $<5$ & postcooling \\
\hline 834 & 34 & 58 & 632 & F NRM-TD450 & 34 & NW & 25 & postcooling \\
\hline
\end{tabular}


Table A6-2, continued

\begin{tabular}{|c|c|c|c|c|c|c|c|c|}
\hline \multicolumn{5}{|c|}{ Identified Vectors } & \multicolumn{4}{|c|}{ Reconstructed Vector Rotations } \\
\hline $\begin{array}{c}\text { Sample } \\
\text { (AM-) }\end{array}$ & Declination & Inclination & MAD or $\kappa$ & Range & Strike & $\begin{array}{l}\text { Direction } \\
\text { of rotation }\end{array}$ & $\begin{array}{l}\text { Magnitude } \\
\text { of rotation }\end{array}$ & Threshold \\
\hline & 90 & 56 & 0.6 & B TD500-TD575 & 61 & NW & 34 & $450-500^{\circ} \mathrm{C}$ \\
\hline 835 & 359 & 50 & 2.3 & B AF050-AF400 & & & $<1$ & $<50^{\circ} \mathrm{Oe}$ \\
\hline 836 & 350 & 48 & 1.1 & B NRM-AF400 & 189 & E & 9 & postcooling \\
\hline 838 & 13 & 41 & 556 & F NRM-TD600 & 332 & SW & 16 & postcooling \\
\hline 839 & 4 & 74 & 1824 & F NRM-AF400 & 86 & $\mathrm{~N}$ & 24 & postcooling \\
\hline \multirow[t]{3}{*}{840} & 343 & 65 & 3.8 & B NRM-AF150 & 118 & NE & 19 & postcooling \\
\hline & 2 & 68 & 1.1 & B AF150-AF400 & 7 & $\mathrm{~W}$ & 11 & $150^{\circ} \mathrm{Oe}$ \\
\hline & $>27$ & $\sim 68$ & 0 & S AF400-ORIGIN & 12 & W & 13 & $400^{\circ} \mathrm{Oe}$ \\
\hline 841 & 213 & 37 & 1.8 & B AF100-AF400 & 108 & $\mathrm{~N}$ & 92 & $<100^{\circ} \mathrm{Oe}$ \\
\hline \multirow[t]{3}{*}{842} & 311 & -39 & 2.1 & B AF150-AF400 & 167 & $\mathrm{E}$ & 154 & $<150^{\circ} \mathrm{Oe}$ \\
\hline & & & & & or, opposit & & & \\
\hline & & & & & 347 & W & 206 & \\
\hline 843 & 334 & 49 & 2.2 & B AF050-AF400 & 170 & $\mathrm{E}$ & 22 & $<50^{\circ} \mathrm{Oe}$ \\
\hline \multirow[t]{2}{*}{844} & 352 & 49 & 3 & B NRM-AF100 & & & $<2$ & postcooling \\
\hline & 347 & 17 & 3.5 & B AF150-AF400 & 247 & S-SE & 32 & $100-150^{\circ} \mathrm{Oe}$ \\
\hline 846 & 350 & 39 & 300 & F NRM-TD600 & 222 & SE & 16 & postcooling \\
\hline \multicolumn{9}{|c|}{ Square 52, Level 23-Base } \\
\hline 909 & 349 & 62 & 697 & F NRM-AF400 & 113 & $\mathrm{~N}-\mathrm{NE}$ & 13 & postcooling \\
\hline 910 & 29 & 27 & 1454 & F NRM-AF800 & 342 & W & 40 & postcooling \\
\hline \multirow[t]{2}{*}{912} & 340 & 29 & 6.7 & B TD150-TD400 (MINUS 350) & 211 & SE & 31 & $<150 \mathrm{C}$ \\
\hline & 102 & 52 & 1.5 & B TD500-TD650 & 48 & NW & 97 & $400-500 \mathrm{C}$ \\
\hline 914 & 339 & 38 & 2092 & F NRM-AF400 & 198 & E & 25 & postcooling \\
\hline \multicolumn{9}{|c|}{ Square 52, Level 24-Middle } \\
\hline 958 & 343 & 41 & 196 & F NRM-TD550 & 199 & $\mathrm{E}$ & 18 & postcooling \\
\hline \multirow[t]{3}{*}{959} & 3 & 52 & 4.4 & B NRM-TD250 (MINUS 100) & & & $<3$ & postcooling \\
\hline & 344 & 30 & 2.9 & B TD300-TD400 & 218 & SE & 30 & $250-300^{\circ} \mathrm{C}$ \\
\hline & 358 & -26 & 0.5 & B TD500-TD600 & 242 & SE & 61 & $400-500^{\circ} \mathrm{C}$ \\
\hline 962 & 359 & 77 & 36 & F NRM-TD550 & 91 & $\mathrm{~N}$ & 27 & postcooling \\
\hline 968 & 356 & 60 & 105 & F TD150-TD500 & 104 & $\mathrm{~N}$ & 10 & $<150^{\circ} \mathrm{C}$ \\
\hline \multirow[t]{2}{*}{970} & 13 & 56 & 2.1 & B AF100-AF200 & 40 & NW & 12 & $<100^{\circ} \mathrm{Oe}$ \\
\hline & 66 & -23 & 0 & S AF400-AF600 & 20 & W-NW & 129 & $200<\mathrm{t}<400^{\circ} \mathrm{Oe}$ \\
\hline \multirow[t]{3}{*}{971} & 359 & 49 & 2.1 & B TD200-TD300 & & & $<2$ & $<200^{\circ} \mathrm{Oe}$ \\
\hline & 325 & 68 & 4.4 & B TD350-TD500 & 119 & $\mathrm{NE}$ & 27 & $300-350^{\circ} \mathrm{C}$ \\
\hline & 219 & 56 & 1.8 & B TD550-TD650 & 100 & $\mathrm{~N}$ & 46 & $500-550^{\circ} \mathrm{C}$ \\
\hline \multicolumn{9}{|c|}{ Square 52, Level 24} \\
\hline 1030 & 344 & 41 & 6397 & F NRM-AF400 & 201 & E-SE & 18 & postcooling \\
\hline 1031 & 0 & 43 & 1786 & F NRM-AF400 & 280 & S & 7 & postcooling \\
\hline \multirow[t]{2}{*}{1032} & 352 & 49 & 0.4 & B AF100-AF200 & & & $<2$ & $<100^{\circ} \mathrm{Oe}$ \\
\hline & $<309$ & $<41$ & 0 & S AF400-ORIGIN & 160 & E-NE & 40 & $200<\mathrm{t}<400^{\circ} \mathrm{Oe}$ \\
\hline \multirow[t]{2}{*}{1033} & 323 & 73 & 3 & B AF050-AF200 & 112 & $\mathrm{~N}-\mathrm{NE}$ & 29 & $<50^{\circ} \mathrm{Oe}$ \\
\hline & 266 & 78 & 1.5 & B AF200-AF400 & 93 & $\mathrm{~N}$ & 15 & $200^{\circ} \mathrm{Oe}$ \\
\hline 1035 & 328 & 62 & 3493 & F NRM-AF400 & 134 & NE & 24 & postcooling \\
\hline \multirow[t]{2}{*}{1036} & 349 & 53 & 2.9 & B NRM-TD575 & & & $<3$ & postcooling \\
\hline & 354 & 27 & 2.7 & B TD575-TD650 & 273 & S & 28 & $575^{\circ} \mathrm{C}$ \\
\hline 1037 & 324 & 40 & 6681 & F NRM-AF400 & 177 & $\mathrm{E}$ & 36 & postcooling \\
\hline \multirow[t]{2}{*}{1040} & 35 & 41 & 5.3 & B AF050-AF150 & 3 & W & 33 & $<50^{\circ} \mathrm{Oe}$ \\
\hline & $\sim 95$ & $<7$ & 0 & S AF400-ORIGIN & 44 & NW & 75 & $150<\mathrm{t}<400^{\circ} \mathrm{Oe}$ \\
\hline 1042 & 2 & 33 & 175 & F NRM-AF400 & 278 & $S$ & 17 & postcooling \\
\hline \multirow[t]{3}{*}{1043} & 317 & 67 & 3.5 & B AF050-AF150 & 127 & $\mathrm{NE}$ & 30 & $<50^{\circ} \mathrm{Oe}$ \\
\hline & 148 & -66 & 1.7 & B AF300-AF600 & 91 & $\mathrm{~N}$ & 176 & $150<\mathrm{t}<300^{\circ} \mathrm{Oe}$ \\
\hline & & & & & or, opposit & & & \\
\hline
\end{tabular}


Table A6-2, continued

\begin{tabular}{|c|c|c|c|c|c|c|c|c|}
\hline \multicolumn{5}{|c|}{ Identified Vectors } & \multicolumn{4}{|c|}{ Reconstructed Vector Rotations } \\
\hline $\begin{array}{l}\text { Sample } \\
\text { (AM-) }\end{array}$ & Declination & Inclination & MAD or $\kappa$ & Range & Strike & $\begin{array}{c}\text { Direction } \\
\text { of rotation }\end{array}$ & $\begin{array}{l}\text { Magnitude } \\
\text { of rotation }\end{array}$ & Threshold \\
\hline \multirow{3}{*}{1047} & & & & & 271 & $\mathrm{~S}$ & 184 & \\
\hline & 12 & 45 & 6.7 & В TD250-TD500 & 345 & $\mathrm{~W}$ & 12 & $<250^{\circ} \mathrm{C}$ \\
\hline & 51 & 67 & 0.5 & В TD575-TD650 & 78 & $\mathrm{~N}$ & 30 & $500-575^{\circ} \mathrm{C}$ \\
\hline \multirow[t]{2}{*}{1048} & 328 & 59 & 5.7 & B AF025-AF400 & 142 & $\mathrm{NE}$ & 25 & postcooling \\
\hline & $<290$ & $<31$ & 0 & S AF400-ORIGIN & 162 & $\mathrm{E}$ & 48 & $400^{\circ} \mathrm{Oe}$ \\
\hline \multirow[t]{2}{*}{1050} & 0 & 58 & 3.6 & B TD100-TD450 & 90 & $\mathrm{~N}$ & 8 & postcooling \\
\hline & 148 & 7 & 0.8 & B TD550-TD600 & 61 & NW & 113 & $450-550^{\circ} \mathrm{C}$ \\
\hline \multirow[t]{3}{*}{1051} & 1 & 53 & 1.9 & B NRM-AF150 & & & $<3$ & postcooling \\
\hline & 172 & -12 & 0 & S AF300-AF400 & 85 & $\mathrm{~N}$ & 139 & $150<\mathrm{t}<300^{\circ} \mathrm{Oe}$ \\
\hline & $<139$ & $\sim-5$ & 0 & S AF400-ORIGIN & $?$ & $?$ & $?$ & $>400^{\circ} \mathrm{Oe}$ \\
\hline \multirow[t]{4}{*}{1052} & 360 & 43 & 1.4 & B AF100-AF200 & 270 & $S$ & 7 & $<100^{\circ} \mathrm{Oe}$ \\
\hline & $\sim 110$ & $\sim-36$ & 0 & S AF400-ORIGIN & $\sim 52$ & $\sim \mathrm{NW}$ & $\sim 161$ & $200<\mathrm{t}<400^{\circ} \mathrm{Oe}$ \\
\hline & & & & & or, opposite & & & \\
\hline & & & & & $\sim 232$ & $\sim \mathrm{SE}$ & $\sim 199$ & \\
\hline \multirow[t]{2}{*}{1054} & 334 & 51 & 2.7 & B AF050-AF200 & 163 & $\mathrm{E}$ & 22 & $<50 \mathrm{Oe}$ \\
\hline & $>290$ & $<14$ & 0 & S AF400-ORIGIN & 160 & E-NE & 75 & $200<\mathrm{t}<400 \mathrm{Oe}$ \\
\hline 1055 & 360 & 41 & 2 & B TD100-TD600 & 270 & $\mathrm{~S}$ & 9 & postcooling \\
\hline \multirow[t]{2}{*}{1057} & 1 & 50 & 1.3 & B AF050-AF300 & & & $<1$ & $<50^{\circ} \mathrm{Oe}$ \\
\hline & $\sim 15$ & $\sim 80$ & 0 & B AF400-ORIGIN & 85 & $\mathrm{~N}$ & 30 & $300-400^{\circ} \mathrm{Oe}$ \\
\hline \multicolumn{9}{|c|}{ Square 52, Level 25} \\
\hline \multirow[t]{3}{*}{1083} & 0 & 56 & 3.2 & B AF025-AF100 & & & $<6$ & postcooling \\
\hline & 15 & 81 & 0 & S AF200-AF300 & 86 & $\mathrm{~N}$ & 25 & $100-200^{\circ} \mathrm{Oe}$ \\
\hline & $\sim 133$ & 68 & 0 & S AF400-ORIGIN & 60 & NW & 30 & $300-400^{\circ} \mathrm{Oe}$ \\
\hline \multirow[t]{3}{*}{1085} & 10 & 40 & 0 & S NRM-TD300 & 139 & $\mathrm{NE}$ & 15 & postcooling \\
\hline & 91 & 60 & 5.4 & B TD300-TD550 & 68 & $\mathrm{~N}-\mathrm{NW}$ & 54 & $300^{\circ} \mathrm{C}$ \\
\hline & 86 & 2 & 0 & B TD550-TD600 & 18 & $\mathrm{~W}$ & 66 & $500^{\circ} \mathrm{C}$ \\
\hline 1086 & 344 & 56 & 4.2 & B AF100-AF400 & 142 & $\mathrm{NE}$ & 13 & $<100^{\circ} \mathrm{Oe}$ \\
\hline \multirow[t]{2}{*}{1090} & 188 & 84 & 2.9 & B AF050-AF150 & 136 & $\mathrm{NE}$ & 52 & $<50^{\circ} \mathrm{Oe}$ \\
\hline & 229 & 40 & 3 & B AF200-AF400 & 90 & $\mathrm{~N}$ & 46 & $150-200^{\circ} \mathrm{Oe}$ \\
\hline 1091 & 0 & 51 & 2244 & F NRM-TD550 & & & $<1$ & postcooling \\
\hline \multirow[t]{6}{*}{1092} & 335 & 57 & 5.2 & B NRM-TD300 & 144 & $\mathrm{NE}$ & 20 & postcooling \\
\hline & 70 & 51 & 0.158 & S TD350-TD400 & 20 & W-NW & 66 & $300-350^{\circ} \mathrm{C}$ \\
\hline & 24 & -26 & 1.3 & B TD450-TD550 & 10 & $\mathrm{~W}$ & 123 & $400-450^{\circ} \mathrm{C}$ \\
\hline & 161 & 24 & 2.7 & B TD550-TD600 & 118 & NE & 170 & $550^{\circ} \mathrm{C}$ \\
\hline & & & & & or, opposite & & & \\
\hline & & & & & 298 & SW & 190 & \\
\hline \multirow[t]{2}{*}{1093} & 358 & 64 & 5.8 & B NRM-TD300 (MINUS 200) & 94 & $\mathrm{~N}$ & 14 & postcooling \\
\hline & 3 & 21 & 2.3 & B TD450-TD600 & 276 & $\mathrm{~S}$ & 45 & $300<\mathrm{t}<450^{\circ} \mathrm{C}$ \\
\hline 1108 & 10 & 61 & 1736 & F NRM-AF400 & 62 & NW & 13 & postcooling \\
\hline \multirow[t]{2}{*}{1111} & 19 & 48 & 3.7 & B TD100-TD300 & 2 & W & 17 & postcooling \\
\hline & 288 & 24 & 3.3 & B TD500-TD650 & 159 & E-NE & 97 & $300<\mathrm{t}<500^{\circ} \mathrm{C}$ \\
\hline \multicolumn{9}{|c|}{ Square 53, Level 23 Middle } \\
\hline 532 & 3 & 47 & 1.3 & B TD100-TD600 & & & $<4$ & postcooling \\
\hline
\end{tabular}


TABLE A6-3

Archeomagnetic Interpretation of Vectoral Data Samples Not Illustrated or Discussed in Chapter 27

\begin{tabular}{|c|c|c|c|c|c|}
\hline \multicolumn{3}{|l|}{ Cooling Context } & \multirow{2}{*}{\multicolumn{3}{|c|}{ Lowest Temperature of Movement }} \\
\hline \multicolumn{3}{|c|}{ A cooled in place } & & & $*$ no discernible movement \\
\hline \multicolumn{3}{|c|}{ cooled near find position } & \multicolumn{3}{|c|}{$\mathrm{X}$ unknown (AF demagnetized) } \\
\hline \multicolumn{3}{|c|}{ out-of-place: cooling location } & \multicolumn{3}{|c|}{$\mathrm{V}$ possible viscous magnetization } \\
\hline \multicolumn{3}{|c|}{ out-of-place: unknown cooling } & \multicolumn{3}{|c|}{$\mathrm{L}$ less or equal to $250^{\circ} \mathrm{C}$} \\
\hline \multicolumn{3}{|c|}{ E uncertain / unknown } & \multicolumn{3}{|c|}{$\mathrm{M}$ between 250 and $450^{\circ} \mathrm{C}$} \\
\hline & & & greater than 450 & & \\
\hline Square & Level & $\begin{array}{l}\text { Sample Number } \\
\text { (AM-) }\end{array}$ & Cooling Context & $\begin{array}{c}\text { Lowest Temperature } \\
\text { of Movement }\end{array}$ & $\begin{array}{c}\text { Number of Discernible } \\
\text { Movements while Cooling }\end{array}$ \\
\hline 20 & 19 & 0299 & B & $\mathrm{L}$ & 1 \\
\hline 20 & 19 & 0300 & A & * & 0 \\
\hline 20 & 19 & 0301 & B & L-M & 2 \\
\hline 20 & 19 & 0302 & $\mathrm{C}$ & $X$ & $1+$ \\
\hline 20 & 19 & 0304 & $\mathrm{C}$ & L-M & 1 \\
\hline 20 & 19 & 0306 & $\mathrm{D}$ & $*$ & $0+$ \\
\hline 28-West & 27-B & 1174 & A & $\mathrm{X}$ & 1 \\
\hline 34 & 21 & 0422 & E & $\mathrm{H}$ & $1+$ \\
\hline 34 & 21 & 0423 & D & $*$ & 0 \\
\hline 45 & 18 & 0109 & A & $\mathrm{M}-\mathrm{H}$ & $1-2$ \\
\hline
\end{tabular}


TABLE A6-4

Samples Collected but not Analyzed Individual Features and Burned Rock Midden 1 (Square 100)

\begin{tabular}{|c|c|c|c|c|c|c|c|}
\hline $\begin{array}{l}\text { Feature } \\
\text { Number }\end{array}$ & $\begin{array}{l}\text { Sample Number } \\
\text { (AM-) }\end{array}$ & Square & Level & $\begin{array}{l}\text { Feature } \\
\text { Number }\end{array}$ & $\begin{array}{l}\text { Sample Number } \\
\text { (AM-) }\end{array}$ & Square & Level \\
\hline \multirow[t]{2}{*}{201} & 0041 & 14 & 5 & & 0307 & 27 & 22 \\
\hline & 0042 & 14 & 5 & & 0309 (see 0501) & 27 & 22 \\
\hline \multirow[t]{2}{*}{201} & 0033 & 21 & 7 & & 0310 & 27 & 22 \\
\hline & 0034 & 21 & 7 & 226 & 0156 & 46 & 20-B \\
\hline \multirow[t]{11}{*}{201} & 0009 & 18 & 8 & & 0157 & 46 & $20-B$ \\
\hline & 0010 & 18 & 8 & 227 & 0226 & 30 & 20-B \\
\hline & 0015 (see 0014) & 20 & 8 & & 0230 & 30 & $21-B$ \\
\hline & 0016 (see 0014) & 20 & 8 & & & 30 & $21-B$ \\
\hline & 0017 & 21 & 6 & 228 & 0339 (see 0635) & 38 & $21-B$ \\
\hline & 0020 (see 0019) & 21 & 6 & 230 & 0395 & 39 & $21-B$ \\
\hline & 0021 & 21 & 6 & & 0396 & 39 & $21-B$ \\
\hline & 0036 & 22 & 7 & & 0621 (see 0622) & 39 & 22 \\
\hline & 0037 & 22 & 7 & & 0700 & 39 & 22-Base \\
\hline & 0029 & 19 & 8 & & 0702 & 39 & 22-Base \\
\hline & 0031 & 19 & 8 & & 0705 & 39 & 22-Base \\
\hline \multirow[t]{6}{*}{204} & 0062 & 20 & $11-B$ & $230 ?$ & 0908 & 39 & 23 \\
\hline & 0045 & 22 & 8 & 233 & 0470 & 20 & $25-\mathrm{B}$ \\
\hline & 0046 & 22 & 8 & & 0471 & 20 & $25-B$ \\
\hline & 0049 & 22 & 8 & & 0474 & 20 & $25-B$ \\
\hline & 0052 & 15 & 5 & & 0475 & 20 & $25-B$ \\
\hline & & 15 & 5 & 234 & 0466 & 30 & 28 \\
\hline $206 ?$ & 0050 & 16 & 5 & & 0566 (see 0567$)$ & 30 & 30 \\
\hline \multirow{3}{*}{$207 ?$} & 0055 & 14 & $6-\mathrm{A}$ & 235 & 0609 (see 0610) & 32 & $28-B$ \\
\hline & 0057 & 14 & $6-\mathrm{A}$ & 236 & 0674 & 33 & 29 \\
\hline & 0059 & 14 & $6-\mathrm{A}$ & & 0675 & 33 & 29 \\
\hline \multirow[t]{3}{*}{208} & 0076 & 16 & 7 & & 0676 & 48 & 29 \\
\hline & 0074 & 17 & 7 & & 0681 (see $0672 / 0682)$ & 29 & \\
\hline & 0075 & 17 & 7 & 237 & 0670 & 34 & 23 \\
\hline \multirow[t]{2}{*}{211} & 0079 & 17 & 8-B & $237 ?$ & 0667 & 49 & 23 \\
\hline & 0080 & 17 & $8-\mathrm{B}$ & 239 & 0915 & 34 & 26 \\
\hline \multirow[t]{2}{*}{212} & 0081 & 37 & $13-\mathrm{B}$ & & 0917 & 34 & 26 \\
\hline & 0092 (see 0093) & 37 & $13-\mathrm{B}$ & 240 & 0889 & 27 & 27 \\
\hline \multirow[t]{5}{*}{213} & 0087 & 13 & 11-B & & 0890 & 27 & 27 \\
\hline & 0088 & 13 & $11-\mathrm{B}$ & $240 ?$ & 0887 & 27 & 27 \\
\hline & 0089 & 13 & $11-B$ & & 0888 & 27 & 27 \\
\hline & 0090 & 13 & $11-\mathrm{B}$ & & 0997 & 27 & 27 \\
\hline & 0091 & 13 & $11-\mathrm{B}$ & & 0999 & 27 & 28 \\
\hline \multirow[t]{2}{*}{214} & 0082 & 16 & 10 & & 1082 & 27 & 29 \\
\hline & 0086 (see 0085) & 16 & 10 & 241 & 0898 & 35 & $26-\mathrm{B}$ \\
\hline 216 & 0095 & 22 & $12-\mathrm{B}$ & & 0900 & 35 & $26-B$ \\
\hline 217 & 0096 & 33 & 17 & 242 & 0891 & 20 & 28 \\
\hline 218 & 0099 & 19 & $14-\mathrm{A}$ & & 0892 & 20 & 28 \\
\hline \multirow[t]{2}{*}{222} & 0100 & 37 & 16 & 246 & 1058 & 34 & 31 \\
\hline & 0103 & 37 & 16 & & 1062 & 34 & 31 \\
\hline \multirow[t]{3}{*}{223} & 0162 & 34 & 19 & & 1097 & 34 & 31 \\
\hline & 0165 & 34 & 19 & & 1099 & 34 & 31 \\
\hline & 0166 & 34 & 19 & & 1103 & 34 & 31 \\
\hline \multirow[t]{2}{*}{$223 ?$} & 0169 & 49 & 19 & & 1104 & 42 & 32 \\
\hline & 0170 & 49 & 19 & 247 & 1081 & 34 & 31 \\
\hline \multirow[t]{7}{*}{224} & 0113 & 12 & 18 & 248 & 1076 & 53 & 28 \\
\hline & 0114 & 12 & 18 & & 1123 & 53 & 28 \\
\hline & 0140 & 12 & 19 & $248 ?$ & 1140 & 52 & 29 \\
\hline & 0263 & 27 & 22 & $249 ?$ & 1262 & 51 & 26 \\
\hline & 0265 & 27 & 22 & & 1267 & 51 & $28-\mathrm{B}$ \\
\hline & 0268 & 27 & 22 & 250 & 1115 & 50 & 30 \\
\hline & 0269 & 27 & 22 & & 1117 & 50 & 29 \\
\hline
\end{tabular}


Table Appendix 6-4, continued

\begin{tabular}{|c|c|c|c|c|c|c|c|}
\hline Feature Number & $\begin{array}{c}\text { Sample Number } \\
\text { (AM-) }\end{array}$ & Square & Level & Feature Number & $\begin{array}{c}\text { Sample Number } \\
\text { (AM-) }\end{array}$ & Square & Level \\
\hline & 1119 & 50 & 29 & \multirow{5}{*}{ Nonfeature } & 0066 & 12 & 6 \\
\hline & 1125 & 37 & 30 & & 0067 & 12 & 6 \\
\hline & 1127 & 37 & 30 & & 0068 & 12 & 6 \\
\hline $252 ?$ & 1177 & 46 & 43 & & 0748 & 12 & 31 \\
\hline 254 & 1173 & 28-West & $31-\mathrm{B}$ & & 0749 & 12 & 31 \\
\hline 255 & 1183 & 59 & 42 & \multirow[t]{3}{*}{ Nonfeature } & 0023 & 13 & 4 \\
\hline 259 & 1224 & 35 & 46 & & 0024 & 13 & 4 \\
\hline & 1225 & 35 & 47 & & 0025 & 13 & 4 \\
\hline & 1227 & 35 & 47 & \multirow[t]{3}{*}{ Nonfeature } & 0069 & 13 & 6 \\
\hline & 1229 & 35 & 47 & & 0070 & 13 & 6 \\
\hline & 1192 & 35 & 45 & & 0071 & 13 & 6 \\
\hline $259 ?$ & 1230 & 35 & 48 & \multirow[t]{3}{*}{ Nonfeature } & 0026 & 14 & 3 \\
\hline 260 & 1241 & 52 & 42-B & & 0027 & 14 & 3 \\
\hline & 1243 & 52 & 42-B & & 0028 & 14 & 3 \\
\hline & 1245 & 52 & $42-B$ & \multirow{2}{*}{ Nonfeature } & 0001 & 16 & 1 \\
\hline & 1247 & 52 & 42-B & & 0002 & 16 & 1 \\
\hline & 1249 & $52 / 39$ & $42-B$ & \multirow[t]{3}{*}{ Nonfeature } & 0005 & 17 & 1 \\
\hline & 1250 & 52 & 42-B & & 0006 & 17 & 1 \\
\hline & 1252 & 39 & 42 & & 0007 & 17 & 1 \\
\hline \multirow[t]{3}{*}{261} & 1257 & 20 & 54 & \multirow[t]{2}{*}{ Nonfeature } & 0072 & 19 & 10 \\
\hline & 1258 & 20 & 54 & & 0073 & 19 & 10 \\
\hline & 1259 & 20 & 54 & \multirow[t]{2}{*}{ Nonfeature } & 0003 & 22 & 1 \\
\hline 262 & 1263 & 27 & 51-B & & 0004 & 22 & 1 \\
\hline \multirow[t]{5}{*}{ Burned Rock Midden 1} & 0594 & 100 & 2 & Nonfeature & 1150 & 26 & 39 \\
\hline & 0595 & 100 & 2 & Nonfeature & 1160 & 26 & 40 \\
\hline & 0597 & 100 & 2 & Nonfeature & 1094 & 27 & 31 \\
\hline & 0599 & 100 & 2 & Nonfeature & 1138 & 27 & 33 \\
\hline & 0600 & 100 & 2 & & 1139 & 27 & 33 \\
\hline \multirow[t]{6}{*}{ Burned Rock Midden 1} & 0646 & 100 & 3 & Nonfeature & 1161 & 27 & 34 \\
\hline & 0650 & 100 & 3 & Nonfeature & 1178 & 33 & 28 \\
\hline & 0651 & 100 & 3 & Nonfeature & 1188 & 28 & 41 \\
\hline & 0652 & 100 & 3 & Nonfeature & 0110 & 30 & 18 \\
\hline & 0657 & 100 & 3 & Nonfeature & 0966 & 34 & 27 \\
\hline & 0658 & 100 & 3 & Nonfeature & 0967 & 34 & 28 \\
\hline \multirow[t]{6}{*}{ Burned Rock Midden 1} & 0683 & 100 & 4 & Nonfeature & 0995 & 34 & 29 \\
\hline & 0686 & 100 & 4 & & 0996 & 49 & 29 \\
\hline & 0689 & 100 & 4 & Nonfeature & 1016 & 35 & 28 \\
\hline & 0691 & 100 & 4 & & 1021 & 35 & 28 \\
\hline & 0693 & 100 & 4 & Nonfeature & 1232 & 35 & 50 \\
\hline & 0695 & 100 & 4 & Nonfeature & 1129 & 37 & 31 \\
\hline \multirow[t]{3}{*}{ Burned Rock Midden 1} & 0736 & 100 & 5 & Nonfeature & 1137 & 37 & 32 \\
\hline & 0741 & 100 & 5 & Nonfeature & 1162 & 39 & 30 \\
\hline & 0746 & 100 & 5 & & 1163 & & \\
\hline \multirow[t]{3}{*}{ Burned Rock Midden 1} & 0808 & 100 & 6 & Nonfeature & 1268 & 39 & 53 \\
\hline & 0813 & 100 & 6 & Nonfeature & 0218 & 46 & 22 \\
\hline & 0814 & 100 & 6 & Nonfeature & 0994 & 46 & 35 \\
\hline Burned Rock Midden 1 & 0848 & 100 & 7 & Nonfeature & 1120 & 46 & 37 \\
\hline & 0851 & 100 & 7 & Nonfeature & 0106 & 47 & 18 \\
\hline & 0854 & 100 & 7 & Nonfeature & 1159 & 52 & 30 \\
\hline & 0856 & 100 & 7 & Nonfeature & 1223 & 52 & 40 \\
\hline Burned Rock Midden 1 & 0946 & 100 & 8 & Nonfeature & & 53 & 51 \\
\hline & 0950 & 100 & 8 & Nonfeature & 1176 & 57 & 46 \\
\hline & 0951 & 100 & 8 & Nonfeature & 1190 & 57 & 49 \\
\hline & 0952 & 100 & 8 & & 1191 & 57 & 49 \\
\hline & 0954 & 100 & 8 & Nonfeature & 1231 & 57 & 51 \\
\hline Burned Rock Midden 1 & 0984 & 100 & 9 & Nonfeature & 1149 & 58 & 41 \\
\hline & 0986 & 100 & 9 & Nonfeature & 1193 & 59 & 43 \\
\hline Burned Rock Midden 1 & 1002 & 100 & 10 & & & & \\
\hline & 1003 & 100 & 10 & & & & \\
\hline & 1006 & 100 & 10 & & & & \\
\hline Burned Rock Midden 1 & 1172 & 100 & 11 & & & & \\
\hline
\end{tabular}


TABLE A6-5

Samples Collected but not Analyzed Features 231, 181, and 245

\begin{tabular}{|c|c|c|c|c|c|c|c|c|}
\hline $\begin{array}{c}\text { Sample } \\
\text { Number (AM-) }\end{array}$ & Square & Level & $\begin{array}{c}\text { Sample } \\
\text { Number (AM-) }\end{array}$ & Square & Level & $\begin{array}{c}\text { Sample } \\
\text { Number (AM-) }\end{array}$ & Square & Level \\
\hline 0298 & 20 & 19 & 0511 & 28 & 22-Middle & 0465 & 37 & 22 \\
\hline 0303 & 20 & 19 & 0514 & 28 & 22-Middle & 0965 & 37 & 24 \\
\hline 0305 & 20 & 19 & 0516 & 28 & 22-Middle & 1022 & 37 & 26 \\
\hline 0378 & 20 & 24 & 0517 & 28 & 22-Middle & 1023 & 37 & 26 \\
\hline 0379 & 20 & 24 & 0520 & 28 & 22-Middle & 0331 & 38 & 20 \\
\hline 0385 & 20 & 24 & 0523 & 28 & 22-Middle & 0334 & 38 & 20 \\
\hline 0783 & 20 & 27 & 0526 & 28 & 22-Middle & 0338 & 38 & 20 \\
\hline 0234 & 25 & 22 & 0790 & 28 & 22 & 0424 & 38 & 21-A \\
\hline 0236 & 25 & 22 & 0792 & 28 & 22 & 0426 & 38 & 21-A \\
\hline 0311 & 25 & 24 & 0796 & 28 & 22 & 0429 & 38 & $21-\mathrm{A}$ \\
\hline 0314 & 25 & 24 & 0798 & 28 & 22 & 0431 & 38 & $21-\mathrm{A}$ \\
\hline 0410 & 25 & 25 & 0799 & 28 & 22 & 0433 & 38 & 21-A \\
\hline 0454 & 25 & 26 & 0800 & 28 & 22 & 0605 & 38 & 22 \\
\hline 0143 & 26 & 21 & 0802 & 28 & 22 & 0630 & 38 & 22 \\
\hline 0145 & 26 & 21 & 0804 & 28 & 22 & 0631 & 38 & 22 \\
\hline 0183 & 26 & 22 & 0975 & 28 & 24 & 0634 & 38 & 22 \\
\hline 0188 & 26 & 22 & 0979 & 28 & 24 & 0639 & 38 & 22 \\
\hline 0190 & 26 & 22 & 0981 & 28 & 24 & 0641 & 38 & 22 \\
\hline 0192 & 26 & 22 & 0983 & 28 & 24 & 0642 & 38 & 22 \\
\hline 0271 & 26 & 24 & 1144 & 28 & 24-Base & 0713 & 38 & 22 \\
\hline 0272 & 26 & 24 & 1146 & 28 & 24-Base & 0729 & 38 & 22 \\
\hline 0273 & 26 & 24 & 1148 & 28 & 24-Base & 0858 & 38 & 23 \\
\hline 0274 & 26 & 24 & 1011 & 28 & 25 & 0860 & 38 & 23 \\
\hline 0447 & 26 & 26 & 1014 & 28 & 25 & 0866 & 38 & 23 \\
\hline 0448 & 26 & 26 & 1153 & 28 & 25 & 0872 & 38 & 23 \\
\hline 0450 & 26 & 26 & 1155 & 28 & 25 & 0873 & 38 & 23 \\
\hline 0452 & 26 & 26 & 1065 & 28 & 26 & 0902 & 38 & 23 \\
\hline 0453 & 26 & 26 & 1067 & 28 & 26 & 0942 & 38 & 23 \\
\hline 0493 & 26 & 27 & 1070 & 28 & 26 & 0945 & 38 & 23 \\
\hline 0575 & 26 & 27 & 1080 & 28 & 26 & 1234 & 38 & $25-B$ \\
\hline 0576 & 26 & 27 & 1175 & 28-East & $27 \mathrm{~B}$ & 0388 & 39 & $21-\mathrm{A}$ \\
\hline 0579 & 26 & 27 & 1166 & 28-West & 26 & 0390 & 39 & $21-A$ \\
\hline 0765 & 26 & 28 & 110 & 30 & 18 & 0392 & 39 & $21-\mathrm{A}$ \\
\hline 0767 & 26 & 28 & 0247 & 33 & 19 & 0615 & 39 & 22 \\
\hline 0770 & 26 & 28 & 0253 & 33 & 19 & 0616 & 39 & 22 \\
\hline 0782 & 26 & 28 & 0297 & 33 & 20 & 0627 & 39 & 22 \\
\hline 0883 & 26 & 29 & 0363 & 33 & 22 & 0629 & 39 & 22 \\
\hline 0885 & 26 & 29 & 0399 & 34 & 20 & 0903 & 39 & 23 \\
\hline 0126 & 27 & 20 & 0402 & 34 & 20 & 0905 & 39 & 23 \\
\hline 0129 & 27 & 20 & 0421 & 34 & 21 & 0988 & 39 & 24 \\
\hline 0175 & 27 & 21 & 0479 & 34 & 22 & 0989 & 39 & 24 \\
\hline 0178 & 27 & 21 & 0726 & 34 & 24 & 0991 & 39 & 24 \\
\hline 0661 & 27 & 25 & 0220 & 35 & 20 & 0991 & 39 & 24 \\
\hline 0664 & 27 & 25 & 0238 & 35 & 20 & 0992 & 39 & 24 \\
\hline 0774 & 27 & 26 & 0242 & 35 & 20 & 0456 & 41 & 26 \\
\hline 0777 & 27 & 26 & 0244 & 35 & 20 & 0419 & 42 & 26 \\
\hline 0134 & 28 & 19 & 0293 & 35 & 20 & 0420 & 42 & 26 \\
\hline 0137 & 28 & 19 & 0294 & 35 & 20 & 0497 & 42 & 27 \\
\hline 0195 & 28 & 20-Middle & 0356 & 35 & 21 & 0573 & 42 & 27 \\
\hline 0197 & 28 & 20-Middle & 0358 & 35 & 21 & 0880 & 42 & 29 \\
\hline 0198 & 28 & 20-Middle & 0359 & 35 & 21 & 0780 & 43 & 26 \\
\hline 0200 & 28 & 20-Middle & 0485 & 35 & 22 & 0781 & 43 & 26 \\
\hline 0201 & 28 & 20-Middle & 0487 & 35 & 22 & 0527 & 44 & 22-Middle \\
\hline 0205 & 28 & 20-Middle & 0490 & 35 & 22 & 0528 & 44 & 22-Middle \\
\hline 0255 & 28 & 20-Base & 0816 & 35 & 24 & 0529 & 44 & 22-Middle \\
\hline 0256 & 28 & 20-Base & 0818 & 35 & 24 & 0786 & 44 & 22 \\
\hline 0257 & 28 & 20-Base & 0278 & 37 & 20 & 0467 & 46 & 27 \\
\hline 0259 & 28 & 20-Base & 0282 & 37 & 20 & 0468 & 46 & 27 \\
\hline 0261 & 28 & 20-Base & 0283 & 37 & 20 & 0106 & 47 & 18 \\
\hline 0315 & 28 & 21 & 0285 & 37 & 20 & 0223 & 48 & 19 \\
\hline 0317 & 28 & 21 & 0367 & 37 & 21 & 0224 & 48 & 19 \\
\hline 0319 & 28 & 21 & 0370 & 37 & 21 & 0478 & 48 & 27 \\
\hline 0322 & 28 & 21 & 0373 & 37 & 21 & 0403 & 49 & 20 \\
\hline 0324 & 28 & 21 & 0374 & 37 & 21 & 0405 & 49 & 20 \\
\hline 0327 & 28 & 21 & 0458 & 37 & 22 & 0067 & 49 & 23 \\
\hline 0328 & 28 & 21 & 0460 & 37 & 22 & 0724 & 49 & 24 \\
\hline 0507 & 28 & 22-Middle & 0462 & 37 & 22 & 0932 & 49 & 27 \\
\hline
\end{tabular}


Table A6-5, continued

\begin{tabular}{|c|c|c|c|c|c|c|c|c|}
\hline $\begin{array}{c}\text { Sample } \\
\text { Number (AM-) }\end{array}$ & Square & Level & $\begin{array}{c}\text { Sample } \\
\text { Number (AM-) }\end{array}$ & Square & Level & $\begin{array}{c}\text { Sample } \\
\text { Number (AM-) }\end{array}$ & Square & Level \\
\hline 0933 & 49 & 27 & 1261 & 51 & 26 & 0824 & 52 & 23 \\
\hline 0275 & 50 & 20 & 0149 & 52 & 20 & 0827 & 52 & 23 \\
\hline 0290 & 50 & 20 & 0150 & 52 & 20 & 0828 & 52 & 23 \\
\hline 0411 & 50 & 21 & 0151 & 52 & 20 & 0831 & 52 & 23 \\
\hline 0412 & 50 & 21 & 0152 & 52 & 20 & 0837 & 52 & 23 \\
\hline 0413 & 50 & 21 & 0153 & 52 & 20 & 0845 & 52 & 23 \\
\hline 0414 & 50 & 21 & 0154 & 52 & 20 & 0847 & 52 & 23 \\
\hline 0415 & 50 & 21 & 0206 & 52 & 21 & 0911 & 52 & 23-Base \\
\hline 0416 & 50 & 21 & 0208 & 52 & 21 & 0913 & 52 & 23-Base \\
\hline 0417 & 50 & 21 & 0210 & 52 & 21 & 0957 & 52 & 24-Middle \\
\hline 0443 & 50 & 21 & 0212 & 52 & 21 & 0960 & 52 & 24-Middle \\
\hline 0568 & 50 & 22 & 0215 & 52 & 21 & 0961 & 52 & 24-Middle \\
\hline 0570 & 50 & 22 & 0441 & 52 & 21-Base & & 52 & 24-Middle \\
\hline 0759 & 50 & 22 & 0341 & 52 & 22 & 0969 & 52 & 24-Middle \\
\hline 0929 & 50 & 23 & 0345 & 52 & 22 & 0972 & 52 & 24-Middle \\
\hline 0930 & 50 & 23 & 0346 & 52 & 22 & 1034 & 52 & 24 \\
\hline 0931 & 50 & 23 & 0350 & 52 & 22 & 1038 & 52 & 24 \\
\hline 1017 & 50 & $25-\mathrm{B}$ & 0352 & 52 & 22 & 1039 & 52 & 24 \\
\hline 1019 & 50 & $25-\mathrm{B}$ & 0533 & 52 & 22-Middle & 1041 & 52 & 24 \\
\hline 1026 & 50 & 25 & 0534 & 52 & 22-Middle & 1044 & 52 & 24 \\
\hline 1027 & 50 & 25 & 0535 & 52 & 22-Middle & 1045 & 52 & 24 \\
\hline 0438 & 51 & 21 & 0536 & 52 & 22-Middle & 1046 & 52 & 24 \\
\hline 0440 & 51 & 21 & 0538 & 52 & 22-Middle & 1049 & 52 & 24 \\
\hline 0583 & 51 & 22 & 0542 & 52 & 22-Middle & 1053 & 52 & 24 \\
\hline 0585 & 51 & 22 & 0543 & 52 & 22-Middle & 1056 & 52 & 24 \\
\hline 0587 & 51 & 22 & 0545 & 52 & 22-Middle & 1087 & 52 & 25 \\
\hline 0589 & 51 & 22 & 0547 & 52 & 22-Middle & 1088 & 52 & 25 \\
\hline 0590 & 51 & 22 & 0548 & 52 & 22-Middle & 1084 & 52 & 25 \\
\hline 0750 & 51 & 22 & 0551 & 52 & 22-Middle & 1089 & 52 & 25 \\
\hline 0752 & 51 & 22 & 0552 & 52 & 22-Middle & 1109 & 52 & 25 \\
\hline 0754 & 51 & 22 & 0558 & 52 & 22-Middle & 1110 & 52 & 25 \\
\hline 0922 & 51 & 23 & 0560 & 52 & 22-Middle & 1112 & 52 & 25 \\
\hline 0923 & 51 & 23 & 0561 & 52 & 22-Middle & 0530 & 53 & 23-Middle \\
\hline 0926 & 51 & 23 & 0564 & 52 & 22-Middle & 0531 & 53 & 23-Middle \\
\hline 0927 & 51 & 23 & 0565 & 52 & 22-Middle & & & \\
\hline 1237 & 51 & 25 & 0820 & 52 & 23 & & & \\
\hline
\end{tabular}


APPENDIX 7: DESCRIPTIONS OF MICROMORPHOLOGICAL THIN SECTIONS

by Paul Goldberg 


\section{INTRODUCTION}

This appendix supplements the discussion of micromorphological analysis presented in Chapter 29. It provides selected, summary descriptions of 156 micromorphological samples, including 88 thin-section slides from geologic columns and 68 thin-sections and/or polished blocks from feature contexts (the distinction between thin-section and block samples is explained in the methods section of Chapter 29). Provenience details for all samples are listed in Table 29-2 in Chapter 29.

The descriptions of the geologic thin-sections are presented first. They include 82 samples collected from three sampling columns (Squares 12, 20, and 100) during the TARL excavations and 6 samples collected from Square E20/S72 during the TxDOT excavations. The TARL thin-sections were made from intact blocks (collected in situ) while the TxDOT slides were made from loose sediment collected as bulk matrix samples.

The 68 feature samples represent 39 cultural or natural features identified in the TxDOT and TARL excavations. Most of the samples are from burned rock features, but the series also includes 10 samples from Burial 2, 6 samples from two pits (Features 168,169), and 4 samples from probable animal burrows (Features 228, 249 [2 samples], and 252). The samples include 22 collected as intact blocks during the TARL excavations and 46 made from bulk matrix collected in either the TxDOT or TARL excavations. Both block and slide descriptions are presented for many of the feature samples, though only slides are described for 8 samples and only blocks are described for 11 . The micromorphological samples supplement other feature data presented in Chapter 26 (see individual feature descriptions), and most of the interpretive discussion of these samples is presented in that chapter.

\section{GEOLOGICSAMPLES}

\section{Sampling Column 100 from Square 12}

\section{Unit IIIc}

WL-92-102: This consists predominantly of snail shells with many subangular and subrounded limestone fragments. Some bone fragments and chert grains were also observed. The matrix is comprised of reddish brown calcareous clay and the sample is relatively clay rich. There are some incipient clay coatings, but these are very poorly developed.

WL-92-104: This thin section is composed of subrounded limestone clasts, some bone, and charcoal in a calcareous clay matrix. The matrix shows signs of extensive bioturbation by earthworms, resulting in numerous individual and welded clasts. This has an extreme excremental fabric. Locally are domains of noncalcareous, reddish brown clay which appears to have been heated. Heating is also evident by the presence of calcined limestone grains and the presence of individual rhombs of calcareous ash. One coprolite grain was found and consists of pale yellowish phosphatic material with a few inclusions of fine quartz silt. The fine fraction is comprised of numerous finely divided microcontrasted particles which probably are responsible for providing the dark color of this deposit (Unit IIII) in the field. Some reddish brown sand-sized pieces of vegetal matter are mixed in with the matrix. Locally, irregular vugs and shells are stained with yellowish brown iron hypocoatings. This sample has a very cultural aspect as shown by the abundance of bone, fine organic matter, and burned fragments of snail shells and limestone. Burning is also shown by the presence of ash crystals dispersed throughout the matrix.

WL-92-105: This is similar to Sample 92-104 in having a cultural aspect, as expressed by the presence of a number of fragments of bone and charcoal. Some of the charcoal grains display within the cell structure rhomb-shaped oxalate crystals; the latter are also dispersed within the matrix. Localized in the slide are individual grain aggregates composed of reddish brown clay with inclusions of quartz silt. Overall the sample has a spongy fabric, with numerous earthworms casts, many of which are welded. Both this sample and WL-92-104 contain numerous phytoliths. In sum, this sample is associated with anthropogenic inputs that have been modified by post-depositional processes, here in the form of bioturbation by earthworms (see Figure 29-2).

\section{Unit IIIb}

WL-92-106: Although this sample is from Unit IIIb, it does not appear to be significantly different from the overlying samples in Unit IIII. Overall this resembles those above it in Unit IIIc. It is composed of calcareous clay with abundant snail shell fragments that have been heated; many earthworm casts are present, and most are individual casts and not welded. The sediments looks quite fresh and the excrements appear to maintain their original shape. Scattered throughout the organic-rich matrix are a number of individual rhombs of calcareous ash. However no signs of in situ burning were observed because of extensive bioturbation. The sample has a spongy fabric with numerous voids and vugs. Locally visible are noncalcareous clayey domains and reddish vegetal fragments. The latter appear to have been broken by turbation within the soil.

WL-92-107: This sample is similar to Sample 92-106, but seems slightly more compact, and earthworm casts are locally better welded together. Abundant snail shells occur and ash rhombs appear to be more easily distinguished (possibly due to slightly better thin section). Some bone and possible eggshell fragments were observed, as well as some heating of the snail shells and rock fragments. The matrix abounds in finely divided organic matter, some of which is the bright red type. In sum, this looks like an originally ashy 
deposit that has been substantially modified by biological reworking. Some noncalcareous domains can be found. The porosity is generally spongy, with numerous vugs and planes, and some fissures. Some hackberry seeds were noted.

WL-92-108: This sample is very similar to others in Unit IIIb (particularly Sample WL-92-107). One bright orange red silty clay grain with quartz inclusions was observed suggesting heating of this material. Two fragments of brownish black charred material with oxalate rhombs were observed. It is possible that this sample is slightly richer in organic matter but this is difficult to state definitively.

WL-92-109: This sample is similar to others in the unit. There appear to be relatively numerous noncalcareous domains or domains that are composed of reddish clay that do not appear to have been heated. Several fragments of eggshell were observed, some possibly heated. Bone fragments are present. Numerous rhombs of ash occur throughout the sample and appear to be among the most abundant in any of the samples; some charcoal occurs as very small, silt-sized fragments. Some very curious rounded sand-sized grains were observed that are yellowish brown in plane polarized light (PPL) and isotropic in cross polarized light (XPL); it is not clear what they are, but coprolite cannot be ruled out. Earthworm casts occur as both individual and welded casts resulting in a crumbly to granular microstructure, and locally the microstructure is more massive where it borders on subangular blocky.

WL-92-110: This contains abundant snail shells and rock fragments, including a few pieces of bone. However, most notable here is the presence of calcined limestone rock fragments. Only one or two pieces were observed, but this was the stratigraphically highest sample where burned grains were found. Burned snails were also visible, but there were only few. Traces of non-calcareous domains were also observed, but these are generally rare. Some ash rhombs were clearly visible but most are well integrated into the bioturbated matrix. The fabric is quite spongy, with numerous vugs and vesicles and some fissures. Earthworm casts are abundant and many are locally welded, but overall the matrix has a granular, as well as spongy microstructure. This sample is laterally about $1 \mathrm{~m}$ or less from a prominent burned rock feature and the granular fabric may be due to bioturbation of organic-rich sediments that are associated with this feature. The presence of poorly developed hypocoatings (see Figure 29-1a, b) suggest some weak pedogenesis, and this level appears to represent an incipient A-horizon.

WL-92-111: This sample appears to represent a slight departure from others in Unit IIIlb. Although limestone clasts and snail shells are as abundant as samples above it and many fragments are partially or totally calcined, we see here incipient hypocoatings and the formation of secondary calcium carbonate. The hypocoatings tend to occur around circular voids, suggesting that they are associated with biologically produced pores, such as roots. In addition, this sample is slightly more compact than the ones above it. The microstructure varies from crumbly to locally granular and subangular to subrounded blocky; it is locally spongy as well. Bones are also present and some appear to be heated. Notable is a phosphatic grain strongly resembling a coprolite. Some noncalcareous domains are visible, but these are less abundant than in the overlying samples. One possible ostracode fragment was observed, although this could actually be part of a shell remnant. Ash rhombs still occur but are more difficult to detect because the matrix seems slightly more calcareous. In any case, the sample has a strong cultural input as shown by the ash rhombs and burned fragments of snail shells and rocks. Charcoal is not evident, although some finely comminuted, silt-sized pieces are incorporated into the matrix.

\section{Unit IIIa}

WL-92-112: Like Sample WL-92-111, this shows signs of secondary carbonate mobilization in the form of carbonate hypocoatings that here are only slightly better developed than in Sample WL-92-111. Cultural manifestations are evident in a number of bone fragments. Some eggshell fragments were also observed. The hypocoatings appear to be associated with rounded pores as in Sample WL-92-111. Overall, the microstructure is complex, ranging from slightly spongy to granular with pores and irregular vugs; some individual earthworm casts are visible but most seem to be welded. This sample is altogether more aged than the samples in Units IIIb and IIIc, and also appears to be somewhat more calcareous. One limestone clast shows partial calcination on its outer surface. Some domains of more reddish, noncalcareous clay are present, but these are very localized; one appears to be associated with a void in which the carbonate seems to have been removed; a snail shell fragment next to this void is also decalcified, showing that this is a secondary phenomenon. Ash rhombs appear disseminated throughout the matrix.

WL-92-113: This sample is slightly more compact than overlying sediments and displays a well-developed excremental fabric in which earthworm casts are very abundant; these are individualized for the most part, but some are locally welded. Chert fragments were observed, and these are generally sand sized. This is one of the few samples that shows a granular-sized fragment of ashy vegetal residue; ash rhombs are dispersed throughout the matrix. Bone splinters seem to be smaller than elsewhere. Weakly developed, noncalcareous domains appear to be relatively more abundant than in Units IIIla and IIIlb. Carbonate hypocoatings are clearly more prominent and are associated with pores, vugs, and channels; they are thicker than in overlying samples and thus suggest that this sample is deeper within an extant profile. In other words, this sample could come from within a Bw-horizon or incipient Bk-horizon. Charcoal and burned shells and limestone clasts point to burning. Some calcined 
shell fragments were observed. Finely divided red vegetal fragments are well worked into the matrix. In one location, a void showed some partial decalcification, perhaps related to roots. This sample exhibits a relative abundance of eggshells.

WL-92-114: This sample is much like Sample WL-92113 and contains numerous cultural features: bone fragments, shell (some of which has been heated), charcoal, and some limestone clasts, which are anomalously red or reddish. Some eggshell also appears to be present. Also pronounced in this sample are a number of noncalcareous zones that are comprised of dusty clay with silt quartz inclusions; these also appear to have some very localized dustings of carbonate. In this sample, it seems that the noncalcareous domains are due to decalcification of the matrix, since they often strongly resemble micropassage features, suggesting association with biological activity. In fact, many of these domains are enriched in flecks of organic matter in comparison to the surrounding matrix. Other evidence of biological activity is shown by the excremental fabric which is expressed by both individual and coalesced earthworm casts. As a consequence, the sample has a very vugy to spongy and locally granular microstructure, and ash rhombs are worked into the matrix. Numerous snail shell fragments show signs of having been heated. It is interesting, however, that no secondary carbonate was observed in this sample, in contrast to Sample WL-92-111, which is near the top of Unit IIII. This indicates that the secondary carbonate must be tied to a soil-forming phase that occurred at the end of accumulation of Unit IIIa and is not associated with rhizolith formation, which is prominent in Units I and II.

WL-92-115: This sample is very similar to Sample WL92-114. It contains some bone fragments but less than in Sample WL-92-114, eggshell fragments, and a grain of a weathered intrusive rock, obviously a manuport. Many of the limestone clasts show internal flecks of bright reddish iron, similar to that found in the rocks in Feature 168, and could be of a similar origin. Some calcareous grains appear to have calcrete coatings around them, suggesting they are derived from some caliche upland cap. Burning is indicated by pieces of charcoal, burned shell and isolated rhombs of ash dispersed through the matrix. Some moderately developed calcareous hypocoatings in this sample are similar to those found at the top of Unit IIIa. The microstructure is variable, ranging from vugy to spongy and granular. Some noncalcareous domains are present, but these are less abundant than in Sample WL-92-114.

WL-92-116: This sample is somewhat more calcareous than overlying ones, although it does not differ significantly from them. The sample is somewhat more compact, although several individualized earthworm casts, can still be observed; many casts, however, are coalesced and welded. This sample appears to have a more aged look where the casts are less fresh and distinct than in samples from Unit IIIc and Unit IIIb. In addition to numerous vugs are localized vesicles which commonly exhibit poorly developed hypocoatings, less than in Sample WL-92-111. The upper part of the sample shows a large noncalcareous area composed of reddish yellow brown clay containing abundant organic material. One area exhibits a concentration of ash rhombs that has been disturbed by burrowing. Elsewhere rhombs of ash are diffused throughout the matrix. This microfeature seems to be related to borrowing activity. Some voids contain a few remains of what appear to be roots.

\section{Unit II}

WL-92-118: The differences between Units II and III are reflected in this sample. The major difference is shown by the aged appearance of the earthworm casts, which here are less individualized but commonly welded. More obvious is the degree of development of carbonate hypocoatings which are quite abundant and thick in this sample. They tend to be associated with rounded elliptical voids and vesicles, perhaps suggesting roots of grassy vegetation.

The sample also has a diminished cultural appearance with many fewer bone fragments, although burned calcareous vegetal fragments can be seen. Little charcoal was noted. Noncalcareous domains are localized and seem to be less abundant than in Sample WL-92-116. Ash rhombs are actually quite visible in this sample and like elsewhere, are worked into the matrix by biological activity. Some eggshell fragments are also noted (see Figure 29-1c, d).

WL-92-119: This also shows a general calcareous appearance with numerous hypocoatings that are quite thick and associated with voids, particularly vesicles and circular vugs. It strongly resembles Sample WL-92-118. Some bone and calcareous vegetal fragments occur. Ash rhombs are as elsewhere; localized domains of noncalcareous red brown clay are present. The excremental microstructure is expressed by individual worm casts, although most casts are welded producing overall a granular to subrounded blocky appearance. Much of the more massive areas of the matrix are perforated by pores with hypocoatings.

WL-92-120: This sample, like others in Unit II is quite compact and also exhibits an aged appearance. It is quite cemented, and hypocoatings are well developed, especially around vesicles and vugs. In some of the voids are aciculate needles of felt-like calcite. The hypocoatings and the degree of secondary calcification increase with depth. The microstructure is variable being vugy to slightly subrounded blocky. Some pieces of charcoal were observed, but bone is absent. Several noncalcareous domains enriched in fine organic matter are present and appear to be associated with micropassage features. Some calcititic vegetal fragments occur throughout the matrix as do ash rhombs. Some micropassage features are clearly expressed by lighter and darker bedding of matrix material. Finally, some of the snail shells and limestone clasts show signs of having been heated (see Figure 29-1e, f). 


\section{Unit Id}

WL-92-121: The siltier nature of Unit I is reflected here in the relatively low proportion of lithic fragments. The matrix is also relatively compact. Although extensively bioturbated, most of the casts are welded together and the voids are complex, being packing voids, vugs, and some vesicles within aggregates. Hypocoatings are well developed to the extent that the impregnation of calcite is not just confined to the void but permeates much of the entire matrix. In other words, much of the sample seems to be infused with secondary carbonate. Many of the voids show felt-like masses of aciculate carbonate. Cultural features here are much less prominent: an occasional burned shell fragment or finely divided dark brown shreds of organic matter. A few pieces of calcareous vegetal matter also occur. No bones were observed, but some ash rhombs occur throughout the matrix. In sum, this sample seems to represent a stable surface, perhaps with grassy vegetation, whose pores permitted the accumulation of secondary carbonate. A spongy fabric begins to be visible.

WL-92-122: This is much different from the samples in Unit III and II and postdepositional features are more developed than in other Unit Id samples. The most striking aspect is the spongy, porous microstructure that is produced by numerous vesicles and pelletal carbonate. It almost appears as if carbonate hypocoatings form and then break off, become rounded, perhaps by pedoturbation and then become integrated into the matrix. Dispersed throughout the slide are areas that exhibit reddish brown clay containing less carbonate than the matrix. Some calcareous vegetal fragments occur along with some ash rhombs but the latter are less common than above. Some bone occurs as well (see Figure 29-5a, b).

WL-92-123: This sample exhibits the uppermost appearance of iron and manganese staining in Column 100 and takes the form of millimeter-sized irregular impregnations of the matrix. These are scattered sporadically throughout the slide and are not common. Carbonates are abundant with numerous thick hypocoatings around vesicles, vugs, and shells. The matrix between vugs is calcareous but does not appear to be impregnated with calcite; felt-like masses of aciculate calcite occur in vugs. Noncalcareous domains in this sample appear to represent areas of decalcification, although they tend to be richer in dark, fine-grained organic matter inclusions, thus suggesting a biological origin. The matrix is bioturbated and exhibits a spongy, vugy microstructure with numerous vugs and channels. Ash rhombs are present but seem to be more difficult to recognize with so much calcite in the sample (see Figure 29-5c).

\section{Unit Isi}

WL-92-124: This sample from Unit Isi is more calcareous than the ones from overlying units; hypocoatings are widespread to the point that it appears that much of the matrix has been injected with secondary carbonate along vesicles/root systems. The hypocoatings are quite complex and are difficult to describe. They often seem to coalesce, which results in a locally spongy fabric; elsewhere where hypocoatings and vesicles are fewer, the microstructure is subangular blocky, as opposed to more open structures in overlying units. Snail shells seem to be fewer in this sample, and rock fragments similarly seem reduced in comparison to Unit III and Unit II samples. One grain of fresh glauconite was observed. Some charcoal or charred vegetal matter occurs, but rhombs of ash can be discerned only with difficulty. In addition, some shreds of bone can be found, but they are quite rare. Iron and manganese staining is more prevalent here indicating increase with depth. These stains are about the same size as in the overlying Sample WL-92123 , but they are more abundant. Some snail shells appear to have been heated. Finally, noncalcified domains are rare, and where present, are richer in fine organic matter.

WL-92-125: This sample is similar to Sample WL-92124 , above. It contains however, numerous reddish brown noncalcareous domains, which have more organic matter than elsewhere. They also are redder and more clayey than in Units II and III. The microstructure is here more vesicular than above, but also vugy. Several sand-sized pieces of brown organic matter were found, a number of which show oxalate crystals preserved within them. It is possible that this burned brown matter with oxalate crystals could correspond to the zone in which the onion bulbs were retrieved or in which the burned trees were found. One large splinter of bone was present, but bones are very uncommon. Iron/ manganese staining is more widespread with depth in the unit and stained zones are larger. Numerous vesicles in this sample produce a spongy fabric. One hackberry seed was observed.

WL-92-126: This sample strongly resembles Sample WL-92-125 and likewise comes from the Leanne soil. However, calcareous domains here are not restricted to hypocoatings and are also present as micritic impregnations of the matrix; these impregnations are up to several millimeters across and resemble incipient carbonate nodules. The sediment has an excremental, compacted, spongy fabric, as well as numerous vesicles. A number of the limestone grains seem to have fine micritic coatings suggesting rolling in colluviation or turbation in place. There are numerous sandsized specks of iron/manganese, which are widely distributed throughout the slide. Finally, the formation of hypocoatings is complex and seems to have the following sequence:

Hypocoatings $P$ impregnation of matrix $P$ shrinking of carbonate due to drying (??) P break-up of nodule P incorporation of broken nodule into matrix $P$ clotted micrite matrix (see Figure 29-5f, g).

WL-92-127: Overall, this sample continues the trend of greater iron staining with depth. The iron staining is 
diffuse and takes the form of broad impregnations and not flecks. Snail shells are rare and tend to be fragmented; one eggshell fragment was noted. Overall there is very little organic matter in the sample. No bone was found. Some ostracodes seem to appear here. Rhombs of ash, if present are difficult to isolate because of the abundance of secondary micrite; however, some still seem to be present. Some brown diffuse organic matter does show some rhombs within the tissues. The sediment is quite porous and exhibits a spongy fabric, with numerous vesicles vugs and associated hypocoatings. Carbonate precipitation is extensive and the hypocoatings are very complex with repeated phases of precipitation, disruption, and renewed precipitation. Close examination of the microstratigraphic relationships demonstrate that iron and carbonate precipitation seem to be roughly contemporaneous.

WL-92-128: This sample is quite calcareous, with numerous coalesced hypocoatings. It is also quite vugy, with numerous vesicles. Secondary mottling is represented by diffuse iron impregnations and not localized splotches. Some of the secondary iron does appear to stain the most recent carbonate impregnated voids, again indicating that the iron precipitation alternated with that of carbonate formation, both being roughly co-eval. Shell fragments are rare, although one whole gastropod appears in the section. There is no bone or other evidence of cultural features, such as evidence of burning. There is scarcely any fine organic matter in the matrix, which seems generally clean.

Sample 92-128 was partially decalcified in order to observe a "pre-diagenetic" window into the sediments. Observations show that it is difficult to decalcify the sample completely because only the layer closest to the exposed surface appears to be attacked by $\mathrm{HCl}$. Moreover, it seems to some extant that the areas most impregnated with iron are initially more clay rich, since some underlying birefringence can be observed in these areas. Finally, most of the sample is comprised initially or before calcification of rounded clayey, quartz silt aggregates that appear to be a result of bioturbation by worms. In other words, it seems that these samples, i.e., floodplain sediments, were undergoing bioturbation just after deposition by Brushy Creek.

WL-92-129: This sample is quite calcareous, with numerous vugs, complex hypocoatings, and intensive speckly iron impregnations; it seems quite massive, with spongy, vugy, and fine crack microstructure. Some snail and limestone clasts occur but these are generally rare. One bone fragment was observed, but the sediment is generally noncultural. As elsewhere in the unit, iron seems to pre- and postdate the precipitation of carbonate (see Figure 29-4a, b).

WL-92-133: These sediments are similar to others above it in Unit Isi but seem more calcareous. Complex voids and vugs point to several phases of repeated carbonate deposition in the form of hypocoatings. The latest phase of carbonate precipitation in vesicles and vugs and channels is very clearly later than the phase of massive yellow-brown iron staining; there do not appear to be iron stains that postdate the carbonate hypocoating phase in this sample.

In these lower, fine-grained, calcareous samples from Unit Isi, it is quite difficult to recognize the original fluvial sediments because of the extensive diagenesis. Some limestone clasts and snails are present and some quartz silt, but there is so much cementation that it is difficult to observe them. It is assumed that these grains and clasts were derived from Brushy Creek. The matrix is quite massive, but locally vugy and possibly angular blocky; there are only a few vesicles and more planes or fissures here in the lower sediments. One bone fragment was found.

WL-92-134: This sample is quite gravelly as was noted in the field. Many of the centimeter-sized rock clasts are composed of biomicrite with many shell fragments. In addition, the matrix is quite calcareous and stained with iron. It is quite compact and the microstructure is a subangular or subrounded blocky structure with numerous vugs. Finally, the latest phase of carbonate hypocoatings appears to postdate the formation of massive iron impregnations.

WL-92-135: This sample is generally similar to others of the lower part of Unit Isi where the microstructure is defined by planes and fissures, and intrapedal pores are quite vesicular and vugy, with numerous, well-developed hypocoatings. It is very calcareous. One bone fragment was observed. It appears that the original matrix is not present but has been completely altered diagenetically with repeated intervals of calcite precipitation around vesicles and voids. Some sand-sized aggregates appear to be material similar to Unit Icl: brown-stained calcite with abundant shreds of brown, finely comminuted organic matter.

WL-92-136: This looks much like Sample WL-92-135. Partial decalcification of the slide by $\mathrm{HCl}$ shows possible individual silt-sized particles composed of calcite or limestone. Iron staining is abundant. Porosity is mostly in the form of vugs and vesicles that perforate a massive calcareous matrix that is locally differentiated by fissures. Limestone clasts vary from millimeter to centimeter sized, and are generally rounded.

WL-92-137: This is generally similar to Sample WL-92135 but is perhaps somewhat more vugy with localized spongy fabric. Much of the matrix appears to have been repeatedly broken in place and recemented. Vugs and vesicles commonly are either perforating massive, cemented matrix or occur at the end of finer fissures and chambers, suggesting a relationship among them.

WL-92-138: This sample is less stoney, but finer grained than the material immediately above it. It is quite homogeneous and massive overall with subangular blocky peds and a locally spongy fabric. Extensive cementation occurs, and as elsewhere, the latest phase seems to postdate the bulk of iron precipitation. Some areas appear as though the matrix cracked during a drying phase, whereas elsewhere there are circular areas that are quite spongy and show complex hypocoatings. Staining is exhibited by diffuse iron 
mottles, although locally they occur more as denser speckly impregnations.

WL-92-139: This sample is very similar to others in the lower part of Unit Isi, being fine grained with relatively few stones. Here, however there seems to be a better development of a clear subangular blocky structure that was less evident in overlying samples. Locally, the microstructure is vugy to spongy, with vesicles and vugs perforating the peds. One shred of sand-sized bone and one small piece of tooth were observed near the top.

WL-92-140 and 92-141: These are generally fine grained and overall identical to others in this part of the profile. Again, the microstructure is quite massive with numerous fissures leading to chambers and vugs. There are massive impregnations of iron, with fissures and vesicles perforating a massive matrix, which is locally subangular blocky. Pedality is not well developed.

\section{Sampling Column 200 from Square 20}

\section{Unit IIIb}

WL-92-203: This sample is remarkable for its generally compact nature, which is most likely due to the fact that it is situated roughly at the top of the profile, just below the surface scraped by the earlier excavations. It is likely that the heavy machinery employed at this time severely compacted the underlying substrate. Consequently, voids are represented essentially by fissures with little interaggregate void space. Several bones are visible, as well as some eggshell fragments; numerous snail shells also occur. Rounded rock fragments are relatively rare. Some charcoal was observed, ranging from hundreds of microns up to a few millimeters in size. The charcoal ranges from angular pieces to a few well rounded ones.

Although the matrix is generally calcareous, several noncalcareous domains occur. These are generally composed of reddish brown clay that are typically richer in finely comminuted organic matter, which is quite abundant in this sample. The most striking feature of this sample is the occurrence of large chamber fillings composed of masses of fibrous and felt-like accumulations of calcite. Some of these fillings clearly display ash rhombs, as well as calcareous vegetal matter; ash rhombs are common and distributed throughout the compacted matrix. Elsewhere the fillings are associated with fibrous concentric fillings of rounded voids that seem to be root pores; in fact, one long fissure with these massive coatings and fillings also appears to exhibit remains of modern roots.

WL-92-204: This sample is much more typical to samples from Unit III. This is shown by the marked excremental fabric embodied by abundant earthworm casts. Many of these are individual casts, but most seem welded or coalesced, perhaps still reflecting compaction associated with the TxDOT excavation. Compositionally, this sample exhib- its elements characteristic of Unit III: abundant snail and bone fragments and isolated pieces of charcoal.

Noncalcareous domains are present and represented by bright reddish brown clay with quartz silt; these are not particularly abundant, however. The few that are visible, are slightly reddish brown, indicative of their having been heated. Reddish brown (recent) organic matter tends to occur in isolated pockets. Rock fragments of limestone are relatively rare but are generally well rounded.

The microstructure is vugy with some vesicles; most porosity, however is produced by intercast voids. A few eggshell fragments were observed, which are generally fine sand sized. Ash rhombs occur as individual grains well incorporated into the matrix. A calcined vegetal ash fragment was observed, again indicating evidence of burning.

WL-92-205: In this sample, an excremental fabric is very well developed to the extent that the entire sample is comprised of individual and slightly compact earthworm casts; locally the matrix is quite compact. This has resulted in quite a granular fabric with many irregular vugs, chambers, and some channels and vesicles.

As in Sample WL-92-204, limestone clasts are not abundant, although snails are; some bone splinters were observed, as well as flint chips. A few of the limestone grains appear to have been heated.

Numerous shreds of reddish brown plant tissues were detected; they are larger pieces than those in Sample WL92-204. Some of them are clearly related to roots or root tissues, presumably modern ones, since many of these fragments appear to be associated with channels. Several noncalcareous domains occur here and again appear to be slightly enriched in fine organic matter, suggesting an earthworm-related origin.

This sample appears to be somewhat more calcareous than the one above it, although no secondary carbonates such as hypocoatings were observed. Because the sample has been so extensively homogenized by earthworm activity, ash rhombs are well worked into the matrix and difficult to isolate.

WL-92-206: This sample is quite similar to Sample WL92-205, exhibiting a total excremental fabric. Numerous snail shells occur, some of which are burned. Limestone fragments are quite rare and range from angular coarse to rounded fine-sand-sized grains; some showing signs of heating. Noncalcareous domains are relatively common; similarly there are a few large grains composed of dark reddish brown clay with quartz silt and pieces of organic matter; one shows crude stratification in the clay. Bone fragments are relatively rare.

As in other samples from Unit IIIb, the microstructure is quite vugy and almost spongy, resulting from extensive bioturbation; some areas are more compact, and these display fissures instead of earthworm casts. Ash rhombs are scattered throughout the matrix, as well as finely divided organic matter including red amber fragments. 
WL-92-207: Overall, this is virtually identical to Sample WL-92-206. Bone is slightly more abundant in this sample and organic matter somewhat lower.

WL-92-208: This sample is slightly different from others in Unit IIIb. Although it has been extremely bioturbated, extensive fissures and more massive areas can be recognized, as well as vugs; there is a relative increase in the abundance of vesicles.

Snails are common and limestone grains are slightly more abundant than in the overlying samples. Noteworthy, however is the occurrence of calcined rock fragments and snails and a curious grain composed of silt-sized pieces of carbonates in an isotropic matrix. The origin of this grain is not clear but likely relates to burning activities.This sample is slightly more aged than the ones above it. Ash rhombs and fine organic matter are dispersed throughout. One calcareous vegetal fragment was observed (see Figure 29-3).

WL-92-209: This sample also appears slightly more aged than many of the others in Unit IIIb. Both individual and welded casts occur but here there is a marked increase in vesicles. Moreover, these vesicles exhibit incipient hypocoatings, the stratigraphically highest in the sampling column, and they are in the same stratigraphic position (very base of Unit IIIb/top of Unit IIIa) as those observed in Square 12 described above. Compositionally, this sample is similar to others. Snail shells and stone fragments are relatively abundant, and the latter commonly show signs of having been burned. Some red brown amber fragments of organic matter occur locally in small concentrations. Bone is relatively scarce, and ash rhombs are dispersed throughout the matrix. Organic matter decreases with depth and occurs mostly within the bioturbated matrix. The microstructure is vugy to vesicular; locally it tends to be somewhat more massive where it is broken by fine fissures; earthworm casts are also quite prominent locally.

\section{Unit IIIa}

WL-92-210: This sample is quite compact, and although individual worm casts are present, most are compressed. Also, porosity is expressed as fissures and planes, resulting in a subangular blocky microstructure; vugs are the next most important void type. Although some vesicles are evident, none seems to exhibit any hypocoatings. Snails are quite abundant. Hypocoatings are barely visible. Some burned shells were observed as well as some very finely divided organic matter which is well integrated into the matrix. Isolated individual ash rhombs could be seen.

WL-92-211: This sample is quite similar to Sample WL92-210, being generally compact and with many welded worm casts. However, the sample is slightly more vugy, with a slight increase in vesicles, some of which display incipient hypocoatings. Overall this sample has quite an aged appearance, again similar to its stratigraphic counterpart in Square 12 (Sample WL-92-111). Some bone fragments and many snail shells can be seen, as well as very finely comminuted organic matter; ash rhombs seem to be slightly more abundant. These components, coupled with the fragments of bone and some burned shell, imply a slightly more cultural aspect to this sample. The incipient hypocoatings are probably tied to pedogenesis associated with the Stiba soil.

WL-92-212: This sample is quite reminiscent of Sample WL-92-211, with a generally subangular blocky, fissured microstructure, although locally it is quite vugy. Rudimentary hypocoatings, but noticeably better developed than in the overlying sample, are presumably related to a greater depth within the B-horizon of the Stiba soil. Locally the matrix is quite compact. Snail shells are reduced in number, and only a few pieces of bone were observed. One very calcined millimeter-sized rock fragment was noted. Finegrained organic matter within the matrix is common. One sand-sized piece of yellow phosphatic material (coprolite?] was observed.

WL-92-213: The microstructure of this sample is noticeably different from the ones above it. Overall the microstructure is subangular blocky, but the sample exhibits more irregular vugs and vesicles than overlying samples. Vesicles tend to be associated with notably better-developed hypocoatings, which are relatively more numerous and better developed (thicker). Numerous snail shells and round rock fragments occur. Noncalcareous domains appear to be slightly more pronounsed in this sample. Isolated ash rhombs and bone fragments occur, and two rock fragments appear to have been heated (see Figure 29-4c).

WL-92-214: Overall, this sample is similar to Sample WL-92-113, varying from subangular blocky to vugy microstructure; localized welded worm casts were observed. Hypocoatings are comparable to those in Sample WL-92113 but they seem to be somewhat more complex, with several vesicles coalescing to produce locally a spongy porosity. Notable in this sample is the presence of millimeter-sized calcined limestone fragments. These could be associated with Feature 233. Some calcareous vegetal fragments also attest to burning.

\section{Unit II}

WL-92-215: This sample is not on unlike Sample WL92-214, being generally compact with a subangular blocky structure and locally perforated by vugs and vesicles. The sample has an aged look to it, and many casts are compressed and welded. Hypocoating development, however, is less than in the samples from Unit IIIa above, and tend to be somewhat localized. This sample is relatively rich in bone, and sand-sized pieces of charcoal also occur, in addition to a few eggshell fragments. Thus, this sample has a relatively strong cultural component. It also includes some bright red aggregates of clay with silt inclusions that have probably been burned. There are also a number of ash rhombs. A few calcareous vegetal fragments were also noted. This sample 
is also considerably stonier than the ones above it.

WL-92-216: This sample is quite similar to Sample WL92-215, although the hypocoatings are more numerous and better developed here. Since these tend to be associated with vesicles, the porosity is somewhat different from that in the samples above, being somewhat spongy and more open; it appears as an incipient clotted fabric. As in Sample WL92-215, bone fragments are relatively common. This is reasonable in light of the presence of numerous burned rocks at this level.

WL-92-217: Notable in this sample is the relative abundance of bone and charcoal pieces which are up to a few hundred microns across. There is an overall pinkish hue to the sediments, which is a trait common to burned units from features. There are also relatively abundant noncalcareous domains in this sample, and most of these show enrichment in fine organic matter. One clump of ashy silt was observed. The porosity in this sample is higher than the ones above it and results from interaggregate voids produced by worms, as well as numerous vugs and vesicles. Hypocoatings, however, are much less marked here than in the samples above, suggesting that this layer is below any affected by pedogenesis. In sum, this is a major cultural level, little modified by secondary carbonate precipitation, although earthworm burrowing is common.

WL-92-219: This sample is quite rich in bone fragments, some of which are quite fragile. Overall the sample is quite dense, with many fissures producing a subangular blocky structure; numerous vugs and vesicles also impart a vugy appearance to this sample. Locally, there are abundant charcoal fragments which are generally of fine sand size. Hypocoatings are well developed here and tend to be quite thick; where the hypocoatings coalesce, they produce a clotted and spongy fabric. Also important here is the uppermost occurrence in this sampling column $(\sim 95.10 \mathrm{~m})$ of iron/ manganese stains, which takes the form of localized sandsized impregnations and flecks.

WL-92-221: This sample contains a number of fresh, centimeter-sized rock fragments. Overall, this is similar to Sample WL-92-219, but the iron staining is more pervasive and takes the form of diffuse impregnations rather than localized fleck-like concentrations. This finding matches the field observations. Hypocoatings are also somewhat better developed than in samples of Unit III, and in this sample they clearly postdate the iron-staining phase. The porosity tends to be more open with depth and is characterized by numerous vug chambers, fissures, and channels.

\section{Unit Id}

WL-92-223: This sample spans the Unit II/Unit Id boundary. Unit 2 sediment is composed of angular chips of centimeter-sized gravels that overlie Unit I sediment, which is much finer. The upper part of the slide is comprised of stoney silt that has a vugy and vesicular microstructure, and vesicles are commonly associated with hypocoatings that are moderately well developed; they appear to postdate a faintly iron-stained matrix. Staining, however, is not well developed. Some voids show concentration of root tissues which could be relatively recent. Some charred organic matter is recognizable in this upper part of the slide.

The lower part of the slide (Unit I) is somewhat different than the upper part and characterized by more-extensive and thicker hypocoatings and overall greater degree of calcification. (This also matches field observations which indicate a reduction in the abundance of rhizoliths in Unit II in comparison to Unit Id.) Iron staining is also more prominent. Both parts of the slide exhibit a small number of burned fragments of snail shell and stone. Noncalcareous domains are scattered throughout the slide. All in all, a minor unconformity exists between Units Id and II, as represented by the degree of hypocoating development and thickness and overall degree of calcification.

\section{Unit Isi}

WL-92-224: This sample is quite different from those in overlying units. It is extensively iron stained in the form of concentrated blobs and flecks. It is also more calcareous with not only hypocoatings but also incipient nodules that are up to two millimeters across. The microstructure also is cracked, with fine subangular blocky peds delineated by numerous fine fissures. In addition, pieces of charred or humified organic matter occur; some of these are up to two millimeters long, although most are finer, silt-sized shreds. The microstructure is also locally vugy and vesicular; where vesicles converge or overlap the carbonate hypocoatings have a clotted appearance. This clotted appearance becomes increasingly pronounced below this sample.

WL-92-225: This is from the Leanne soil and is marked by the extensive development of both dark massive flecks of iron which are localized within the slide or more diffuse impregnations of the matrix throughout the slide area. In addition, extensive calcification is very well developed and is expressed as dense millimeter-sized carbonate nodules, hypocoatings in voids, and clotted carbonate aggregates near complex vugs. It is clear that this sample marks a conspicuous increase in secondary calcification in comparison with samples above it. This was noted also in the field. Organic matter is present only as very fine silt-sized flecks of reddish and yellowish brown stringers; these tend to be particularly dispersed throughout the slide but not in areas associated with secondary carbonate. Finally, it appears that much of the hypocoatings and carbonate nodules are not stained by iron and therefore seem to have formed later than the phase of iron precipitation. Snail shell fragments are relatively scarce, as are clasts of limestone. The microstructure is complex, being composed of subangular blocky peds with numerous fissures, vugs and chambers, and channels; the latter appear to be particularly associated with 
hypocoatings. One burned snail shell fragment and two pieces of bone were observed. Ash rhombs are difficult to recognize in light of the calcareous nature of this sample.

WL-92-226: This sample is overall similar to the one above it. The carbonate nodules are more strongly developed, being both more massive, with sharper boundaries in relation to the matrix, and are commonly cracked. The cracks have been filled with microsparite, and many appear to have irregular solution cavities or vugs within them. Hypocoatings are also present but are relatively few in number. Locally are areas with clotted carbonate microfabrics. Dispersed throughout much of the matrix are very fine siltsized pieces and shreds of organic material; this presumably imparts the darker color that the Leanne soil has in the field. Iron staining is in the form of diffuse impregnations, as well as fleck like concentrations. Again, carbonate precipitation seems to postdate the formation of secondary iron.

WL-92-227: This sample exhibits extensive development of secondary carbonate in the form of complex hypocoatings, as well as dense micritic nodules that are commonly cracked and reveal effects of dissolution along cracks and voids. Many of the nodules seem to have arcuate fissures within them. Dense flecks of iron and more diffuse iron stains are present, but these appear to have formed prior to the phase of carbonate accumulation. One bone fragment was observed in this predominantly fine grained sediment. As in other samples of the Leanne soil, the matrix shows very fine-grained pieces of yellow-brown organic matter. The sample overall has a fine subangular blocky structure that is punctuated with several vugs and vesicles, the latter being associated with the hypocoatings. Some reddish brown aggregates were found; some ash rhombs were also visible (see Figure 29-5d, e).

WL-92-228: This sample superficially resembles Sample WL-92-227 but with some exceptions. Iron staining is extensive as diffuse stains throughout the slide. Several of the massive carbonate nodules (popcorn carbonates) exhibit yellow-brown iron staining. Hypocoatings, however, are not stained, suggesting a different timing of the different carbonate precipitation events. In addition, hypocoatings seem to be more isolated or well defined, whereby the carbonates are locally confined to vesicles and not large-scale impregnations. However, there are also some areas that are widely cemented with carbonate. Many of the nodules show arcuate fissures or are somewhat fragmented; these arcuate fissures are reminiscent of desiccation features. Some isolated snail shell fragments could be recognized as in the field. In addition, there seem to be some ostracodes. Most notable, however is the abundance of very fine, silt-sized fragments of organic matter. These are more abundant than in overlying samples from the Leanne soil, and their abundance here could reflect the proximity to the underlying swamp or cienega. Thus, microscopically this sample has affinities with both Units Isi and Icl. The microstructure here is quite complex and is expressed by many vugs, fis- sures, planes, and chambers, which result in a generally open fabric.

WL-92-229: Overall, this is quite similar to Sample WL92-228 but exhibits a notable increase in finely comminuted and disseminated organic matter associated with the cienega and Leanne soil; the organic matter imparts almost a pinkish brown color to the matrix, a characteristic of the cienega deposits. The matrix is extensively iron stained but the hypocoatings are not. Some ostracode fragments were observed.

\section{Unit Icl}

WL-92-230: This sample displays a marked increase in both rounded oyster fragments derived from the bedrock, as well as ostracode fragments. As above, the matrix contains fine-grained organic matter, but less than in Sample WL-92229; iron staining is pervasive. Hypocoatings are localized, and associated with individual vesicles, some of which are coalesced; they are not iron stained. This sample shows several popcorn carbonates, which typically are cracked, possibly associated with desiccation and shrinking and cracking. These nodules do not appear to be extensively stained with iron, although in some, the outer edges do exhibit some iron staining. The microstructure is quite vugy and associated which numerous vesicles and coalesced vesicles. One sand-sized, dark brown piece of charcoal or organic matter was found. One burned shell was also observed.

WL-92-231: This sample is very similar to Sample WL92-230 which overlies it. The matrix exhibits abundant finely comminuted organic matter and abundant iron staining. Larger pieces of dark shreds of sand-sized organic/charcoal material was also observed. This seems to be typical of the cienega deposits. Again, hypocoatings are not stained nor are the nodules. Here the hypocoatings still exhibit some traces of organic matter, whereas samples above the hypocoatings are cleaner and with much less organic matter. The microstructure is for the most part cracked with subangular blocky peds that are punctuated by vugs and vesicles.

WL-92-232: This sample has numerous well-developed popcorn carbonates that are extensively cracked and are locally iron stained, although the bulk of any given nodule is generally not stained. The nodules tend to have numerous vugs and concentric fractures, some of which are filled with microsparite. Elsewhere, hypocoatings are more localized and not very well developed, i.e., the coatings are relatively thin. Numerous ostracodes occur in this sample. The microstructure overall is subangular blocky and with more massive and coarser peds than in overlying samples. Iron staining is abundant and in the form of diffuse concentrations as well as flecks. Fine-grained organic fragments are also present in this sample which was collected from the center of the cienega (see Figure 29-5h). 
WL-92-233: This sample, similar to Sample WL-92-232 above, is quite fractured, and shows numerous fine cracks and fissures. Iron staining occurs as above. Nodules are quite prominent and are locally stained.

WL-92-234: This sample is again similar to others in Unit Icl. In addition, abundant finely disseminated organic matter occurs within a calcareous matrix that is extensively iron stained. The matrix has a pale brown tinge to it which seems to result from both organic matter and perhaps also the type of carbonate. The latter seems to have a peculiar morphology and is reminiscent of carbonate associated with springs. In sum, this carbonate could be related to some kind of spring deposit with abundant organic matter. Some silt-sized bone fragments occur. Iron staining is very marked as in other samples from the lower part of the sampling column. The peds have a subrounded aspect to them suggesting some kind of contraction and perhaps rotation of the peds in place.

WL-92-235: This sample is very compact sediment with numerous fissures and craze planes. It is virtually identical to Sample WL-92-234.

WL-92-236: This lowest sample in Square 20 is not unlike the ones above it. It is quite compact with subangular blocky structure and massive peds, with numerous planes and fissures. Intra-pedal positions show some vugs and vesicles; the latter however, occur in abundance much lower than in overlying samples. Overall this sample has a very compacted aspect. Iron staining is very extensive, both as intense and diffuse impregnations. Organic matter is scattered throughout the slide as fine silt-sized pieces. However, there are several coarser fragments in this sample, more so than is generally the case. Hypocoatings are present but not very well defined as such. Rather, the carbonate is so abundant that much of the sample is impregnated with secondary carbonate that appears to have diffused from the voids. Carbonate nodules are also present locally and have a clotted aspect. Many nodules appear to be a result of several repeated phases of carbonate precipitation. Moreover, different zones of these nodules appear to be more stained with iron than others. This differential staining also suggests that these carbonate nodules formed intermittently with the precipitation of the iron. All in all, however, many parts of the nodules are not iron stained and therefore appear in part to postdate the bulk of iron precipitation. This sample would appear to be still within the cienega.

\section{Sampling Column 300 from Square 100}

\section{Unit IIIc}

WL-92-300: This sample is similar to Unit III sediments, particularly the upper, fresher part. It is characterized by extensively bioturbated, organic-rich, granular, calcareous silty clay that contains abundant fragments of bone and snail shells, as well as a number of grains of charcoal. The sample is quite calcareous, with numerous centimeter-sized rock fragments that are commonly burned, and smaller, rounded sand-sized grains that are well mixed with the clayey organic-rich aggregates. This mixing and the generally open granular fabric is due to earthworm activity as in the other deposits from burned rock features.

WL-92-301: This sample is overall quite similar to Sample WL-92-300 but exhibits a slightly greater proportion of rock fragments that show extensive signs of heating. Calcareous and noncalcareous domains of the matrix are evident, again due to intensive mixing by earthworms.

WL-92-302: This sample from the base of the burned rock feature is clearly more calcareous and aged than overlying samples. Shell and rock fragments are moderately abundant, and many of the latter show signs of having been intensively heated. Porosity is produced mostly from individual and coalesced earthworm casts; vesicles are rare. Bone fragments are relatively common, as are finely comminuted organic matter and calcined vegetal matter that have been well integrated into the matrix by earthworm activity. Interesting is the presence of poorly developed, incipient hypocoatings associated with circular voids from which some calcium carbonate has been mobilized into the matrix. In sum, this is predominantly a cultural deposit that has been reworked by earthworms and slightly influenced by secondary carbonate movement.

\section{Unit Y}

WL-92-303: In the field, this was collected from Unit Y, which is described as a transition zone between the burned rock feature described above and the calcareous, silty units below. The anthropogenic character of this sample in thin section is manifested in an abundance of finely divided organic matter, rhombic ash crystals, and burned snail shell and rock fragments. Snail fragments are relatively common, whereas bones are rare. The sediment has been extensively burrowed by earthworms, but most of the casts are coalesced, calcareous, and overall have an aged appearance; some fresh, individualized casts are present and these contain reddish amber organic matter, possibly of modern origin. Numerous noncalcareous domains could be recognized. Hypocoatings are better developed than in Sample WL-93302 and are associated with a greater abundance of vesicles than in overlying samples. The hypocoatings are similar in morphology and development to those at the base of Unit IIIb or the top of Unit IIIa in Squares 12 and 20; they are not as well as developed as those in Unit II from these excavation squares.

WL-92-304: This sample is more calcareous and possibly less porous than those above. Moreover, the earthworm casts are noticeably more welded in appearance, and locally the structure is more massive. Stone and snail shell fragments are numerous but most do not appear to have been burned. Similarly, the matrix contains some finely divided 
organic matter but in lower proportions than in the feature deposits above. Hypocoating development and abundance is similar to that in Sample WL-92-303. The sample appears transitional between Unit III and Unit II in the excavated area.

WL-92-305: This is similar to Sample WL-92-304 but contains abundant broken pieces of charcoal and organic matter that have been worked into the matrix. In addition, the matrix is locally quite compact, and individual worm casts are quite compacted; in these compacted areas the matrix is massive and fissured. Vesicles and hypocoatings are similar to those above. This sample also is transitional to Units II and III.

WL-92-306: This sample differs somewhat from the ones above it. It is much more massive, and porosity is much reduced and is expressed as vugs, intergranular voids, and vesicles; the latter are associated with dense hypocoatings. Organic matter is somewhat reduced with regard to Sample WL-92-305 and is similarly broken and worked into the matrix by biological activity. There are a moderate number of millimeter-sized stones, several of which have coatings of calcareous silt. These coatings point to down-slope movement of the grains. Some of the snail shell fragments show evidence of having been heated. Ultimately, the sample appears to be anthropogenic in origin but has been modified by bioturbation, compaction and secondary carbonate precipitation (see Figure 29-1h).

\section{Unit X}

WL-92-309: This sample is compositionally similar to Sample WL-92-306 above it. However, it is somewhat more porous, with an increased quantity of vugs and vesicles that produce a slightly spongy aspect to the fabric, similar to that found within sediments from the base of Unit II (e.g., Sample WL-92-120). However, the presence of traces of bone, some fine charcoal and ash crystals do indicate anthropogenic inputs.

WL-92-311: This sample is clearly different from the samples above it, as is shown by the distinctly spongy fabric. Similar types of fabrics occur within the sediments from the very base of Unit II (Sample WL-92-221 in Square 20) or the uppermost part of Unit Id (e.g., Samples WL-92-121 and WL-92-122 in Square 12). Although the matrix is quite dense, it is still possible to observe welded worm casts. Moreover, there are several well-developed hypocoatings which partly coalesce to produce the observed spongy fabric. Some noncalcareous domains are present, probably produced by earthworm activity. Organic matter and other anthropogenic indicators are absent.

WL-92-312: This is virtually identical to Sample WL92-311 and again exhibits characteristics of the sediments from the top of Unit I. One eggshell fragment was observed.

WL-92-314: This contains numerous millimeter-sized limestone fragments in a massive matrix that is punctuated by vugs and vesicles. So much of the matrix is calcareous that it is difficult to make out individual hypocoatings. This feature is similar to the sediments in Unit Isi.

WL-92-315: This sample is quite calcareous and a shift here is noted to more of a fissured microstructure developed in a massive, dense, calcareous matrix which is punctuated with numerous vesicles. The calcareous matrix makes it difficult to recognize individual hypocoatings. Within the fissures are fillings of felt-like masses of needle carbonate. Similar needle carbonates were found in Samples WL-92121, WL-92-122, and WL-92-123 (base of Unit II, Unit Id). A moderate amount of millimeter- to centimeter-sized rock fragments occur.

WL-92-316: This is somewhat similar to Sample WL92-315 but is slightly stonier, with an increase of rounded limestone grains. Moreover, it has a slightly more open fabric that has a more excremental nature than Sample WL$92-315$, and many aggregates and casts are welded. There is a noticeable drop in vesicles, and hypocoatings are visible although less evident than in overlying samples. One ostracode was observed. This sample looks like it is composed of a calcareous mud slurry containing rounded rock fragments. WL-92-317: This is identical to Sample WL-92316 , with several rock fragments and an open, excremental fabric; the calibre and number of stones is approximately the same.

WL-92-319 and WL-92-320: These samples are virtually identical to Samples WL-92-315 and WL-92-316. As in Sample WL-92-317, it has a clear excremental fabric.

\section{Thin Sections Made from TxDOT Bulk Matrix Samples Collected from Square E20/S72 (North Wall)}

WL-94-S1: Id or Isi-c?; grayish/yellowish brown color; small amount of bone; charcoal flecks; dark reddish brown iron staining (isolated domains); locally abundant shreds of organic material; looks like Leanne soil but not as dark; some gastropod shell fragments; locally extensive hypocoatings; no evidence of burning; some of the limestone clasts have micritic rinds (which could be due to movement along a slope?).

WL-94-S2: Probably Isi-c?; color is similar to Sample S1 but slightly darker, possibly because thin section is thicker; has a lot more fossil shell fragments than S1 and more noncalcareous domains; very bioturbated; locally extensive hypocoatings (but more root-like); the same or slightly less organic material than $\mathrm{S} 1$; some bone (traces, not much); no evidence of burning; charcoal flecks (no more than ca. $130: \mathrm{m})$.

WL-94-S3: Probably Isi-c?; some bioturbation; clay illuviation; heated snail shell fragment?; some grains show iron staining; some organic matter but less than S1 and S2; does not really look like Leanne soil, but more like Isi; could be Leanne soil with less of an anthropogenic contribution of organic matter? 
WL-94-S4: Possibly upper portion of Icl; illuviated clay filling a void (why in this sample and none of the others?); some organic material but not as much as WL-94-S1-S2; has overall grayish yellow look (like Icl); organic material is very finely divided (more typical of Icl); possible that the clay coatings are not related to soil formation but represent flooding of the cienega (low energy, backed-up slackwater); some areas of noncalcified matrix; hypocoatings are less prominent in this sample, fewer circular voids; calcified root tissues.

WL-94-S5: Definitely Icl; grayish tinge to matrix with much iron-staining; abundant finely divided organic material; fresh grain of feldspar; no ostracodes or bone observed; some vesicles and chambers/channels but hypocoatings not particularly well developed.

WL-94-S6: Definitely Icl but possibly near the bottom; similar in color to WL-94-S5; increase in the intensity and amount of iron staining; much more organic matter than WL94-S5; hypocoatings as in WL-94-S5; no illuviation; possible ostracode; no bone observed.

\section{FEATURESAMPLES}

\section{2-1993 Series of Feature Samples (Collected In-situ During TARL Excavations)}

\section{Feature 181}

WL-92-F2, Block: Relatively abundant charcoal (or dark organic matter). Sample totally churned up by earthworms.

WL-92-F2, Slide: Burned stones and some burned snails. Finely divided pieces of charcoal, broken up by earthworms. A good many bones. Perhaps some crystals of ash worked into matrix, although isolated. Definitely evidence of burning and not limited to burned limestone. Particles larger than $1 \mathrm{~mm}$ show burning and a few smaller than $1 \mathrm{~mm}$. Sample altered by bioturbation. No oxidized sediment.

WL-92-F4, Block: Churned by worms throughout. Looks similar to WL-92-F2. Not much charcoal/organic matter, but sample is very small.

WL-92-F4, Slide: Burned stone, one prominent one, anyway. Some bone. Lots of earthworm activity. No charcoal apparent. Snails do not appear burned, nor do bones. One piece of ash, and another rhombic piece of ash. Some individual ash crystals. Same amount of burning as in WL92-F2. Red organic fragments that look like freshly disrupted, modern organic matter. Burning mostly restricted to larger particles.

WL-92-F5, Block: Earthworm activity throughout. Some charcoal/dark organic matter.

WL-92-F5, SlideCLooks like Unit II because of iron staining. Earthworm activity prominent. Some hackberry seeds. Some snails, some burned, one severely burned shell. Burning apparent in stones. But less burning than WL-92F2 and WL-92-F4. More stones than WL-92-F2, WL-92-F4, but fewer are burned. Reddish plant tissues incorporated into matrix by burrowing, probably intrusive. Sediment not burned or oxidized. A few ash crystals that look like ashy residues from plants. Much very fine charred organic matter. No charcoal, probably were broken up by worms. Overall is similar to WL-92-F2 and WL-92-F4, except for more red matter. Less bone than in WL-92-F2 and WL-92-F4.

WL-92-F6, Block: Earthworm churned. Some tiny pieces of charcoal or dark organic matter. Does not look oxidized. Some recent roots. Some snail shells.

WL-92-F6, Slide: Outer edge of one of stones is completely calcined from intense burning. Other stones also calcined. Higher temperature indicated by stones than in WL-92-F2, WL-92-F4, WL-92-F5. Lots of snails, none looks burned. Rare bone. Burned ashy vegetal matter that has retained morphology. Burrowing obscures everything. No charcoal. Many individual ash crystals. Only traces of reddish plant matter. Overall looks like burned material broken up by worms. One burned stone is $1 \mathrm{~cm}$ in diameter.

WL-92-F7, Block: Earthworm activity, as in other Feature 181 samples. A little charcoal or dark organic matter. Domains of gray ashy deposits.

WL-92-F7, Slide: Burned soil of reddish color but only one piece, probably a dismantled piece of hearth, just below where fire is; soil is oxidized. Some bone, not burned. Highly calcined piece of limestone. A lot of sediment is now calcified, including snails and eggshell, but more pinkish and therefore heated. Many sand-sized calcined limestone grains (200:m). More reddish clay at higher magnification. Ashy charred or humified organic matter but finely divided and broken up and worked into matrix. Some ash crystals and ashy residues. Definitely evidence for fire/burning. No large pieces of charcoal but some finely divided ones. More burning than other Feature 181 samples. More snails are burned, and this sample displays burned soil not seen in the other samples. Some bone, but only fragments. No chert visible.

\section{Feature 232}

WL-92-F32, Slide: No evidence of burning is evident in this slide. It looks like typical unburned Unit II sediment.

\section{Feature 236}

WL-92-F3, Slide: Burned stones calcined on the outside. Iron staining, like Unit II. Burned bone. Many clayey domains that may have some original clay within; matrix looks less calcareous than usual. Some pinkish areas that look burned but are isolated; they are remnants of original material. Burrowing obscures whether matrix is in situ or not. Some pink iron-tinged limestone, as in Feature 245, which is probably the same as red limestone with gray margin. No ashy $\mathrm{CaCO}_{3}$. Charcoal is broken up, but overall there is less charcoal than other samples. A few ash crystals. Some reddened burned soil. 
WL-92-F11, Block: Uniform looking sample, more compacted; more aged than Feature 181 and Feature 245. A piece of charcoal or dark organic matter that is broken up. Bioturbation still evident. A small amount of reddish soil, but not obvious.

WL-92-F11, Slide: Ashy vegetal residue. Some eggshell. A possible ostracode. Some areas that are slightly reddened. Some charcoal, broken up. A grain of plagioclase. A spongy fabric, which is a postdepositional effect. A burned bone; not many bones overall. One burned limestone apparent with heating evident, but not calcined; one piece that is calcined.

\section{Feature 243}

WL-92-F12, Block: The lower $2 / 3$ of the block is pinkish, bright red burned sediment that is perforated by numerous earthworm tubes. Some charcoal or dark organic matter was observed but it was mostly broken by burrowing activity. Relatively abundant snail shells. Fair amount of bone. Some pieces of stone are grayish and look burned.

WL-92-F12, Slide: This sample exhibits clear evidence of in situ burning but the microstratification of the feature is especially visible in the polished block and in the thin section slide under lower magnification (10X). Like the block, the lower $2 / 3$ of the slide is distinctly redder in color. Several fragments of intensely burned, calcined limestone and burned bone were observed. Other manifestations of burning include numerous ash rhombs, bright red aggregates of clay with silt inclusions, and numerous fragments of dark brownish black organic matter/charred material. This material has been broken up and reworked into the matrix by extensive earthworm activity; this is especially clear in the polished block. Ash rhombs occur both within tissues of organic matter and also occur individually and have been reworked into the matrix by biological activity. The bright red aggregates are concentrated in the upper portion of the sample (perhaps at or near the extant surface?).

Many of the voids show calcareous hypocoatings (this sample must be near the top of Unit II). The voids are complex and consist of fissures, vugs, and vesicles, the latter exhibiting the hypocoatings.

\section{Feature 245}

WL-92-F8, Block: Secondary $\mathrm{CaCO}_{3}$ in voids. Very bioturbated. Some bones. There are traces of reddened soil as in WL-92-F7, but churned by bioturbation.

WL-92-F8, Slide: Some stones highly heated, that is calcined. Lots of calcined stones from intense burning. More burned than Feature 181 samples. Slightly reddened areas which are burned oxidized soil. Burned bone. Burning in all particle sizes. Must be close to fire because of calcined rock and burned soil. Is most likely in situ. Bioturbation prominent. Little charcoal. Ashy vegetal residues. Scattered ash crystals. Many snail shells.

WL-92-F14, Block: Same bioturbation as others. Gray fire-altered stones. Definite reddening of matrix from heating but bioturbated so not possible to make out original fabric. What remains are domains of heated soil. Some snail shells. Some charcoal or dark organic matter broken up and reworked into sediment.

WL-92-F14, Slide: Many calcined limestone fragments. Some large pieces of charcoal, but broken up. Clearly ash crystals. A piece of fire-reddened oxidized earth (these firereddened samples are noncalcareous; the $\mathrm{CaCO}_{3}$ in samples are from earthworms). Some bone, not burned. Not as much burned soil as WL-92-F8; has a few smaller pieces instead. Not possible to determine if in situ because of bioturbation. Burned limestone and clumps of burned earth. Charred plant matter with oxalates. A sand-sized grain of plagioclase, possibly from Central Mineral Region. Sample near burning source. Similar to WL-92-F8 in evidence of burning.

WL-92-F17, Block: Burned in situ. Perforations by numerous earthworm burrows. Burning evident in large amount of reddened oxidized soil. Some charcoal or dark organic matter broken up by bioturbation.

WL-92-F17, Slide: Large area of reddened burned soil, with in situ burning. A number of calcined limestone fragments. Many ash crystals. Not much bone, one probably heat altered, one not burned. More burning than other Feature 245 samples. Definitely is burned substrate. One reddened noncalcareous fragment surrounded by pinkish calcite-rich matrix. Not much charcoal but mostly broken up. All particle sizes are burned. No ashy residues apparent.

WL-92-F18, Block: One very large calcined limestone fragment, burned gray with white calcined rim, is evidence for intense burning. Small clumps of burned matrix scattered throughout. Lots of shells. Some charcoal or dark organic matter, much broken up by worm activity.

WL-92-F18, Slide: Calcination of large burned limestone fragment. Jumble of reddened fire-heated soil matrix that has been reworked by earthworms. Lots of ashy residues. One piece of pink limestone, an iron-rich stone, perhaps oxidized from heating. Some calcined snail shells, possibly calcined bone? Some charcoal or dark organic matter, fine-grained. Burning in all particle sizes. Mostly in situ burning.

WL-92-F19, Block: Earthworm activity prominent. Localized reddened soil clumps from heating.

WL-92-F19, Slide: Stones do not appear burned, not as much as other samples. A few pieces of calcined limestone. Localized reddened oxidized areas, churned up by earthworms. Pinkish limestone with iron elements, but not necessarily oxidized by this fire. Some ashy vegetal residues. A few pieces of eggshell. No charcoal. All particle sizes burned. Many snails; some bone, not burned; some ash crystals. Cannot determine if in situ. Not as burned as other samples. 
WL-92-F20, Block: Reddened soil perforated by earthworm casts. Possibly burned in situ. Some charcoal or dark organic matter but broken down by burrowing. Red ironstained limestone.

WL-92-F20, Slide: Pieces of charcoal have been burrowed through, some with original oxalates. Appears similar to Unit II, since matrix looks more compacted, more calcareous. A large grain of calcined limestone, but overall few. One grain with evidence of intense burning. One piece of chert. One large piece of ashy vegetal residue. A few pink limestone grains containing iron. One large piece of bone stained with iron or some other element. Not possible to determine if in situ burning. All particle sizes show burning. No ashy crystals. Less visibly burned than other samples. Not much reddened oxidized soil.

W.L-92-F21, Block: Much reddened burned oxidized soil. Earthworm activity prominent. Fine charcoal or dark organic matter broken up by earthworms.

WL-92-F21, Slide: Similar to WL-92-F20. Not many burned rocks; a few are calcined, especially where reddish soil is prominent in top half of thin section.. Localized domains of reddish soil but not as pronounced as on the block. Many snail shells. One chert grain. Much very fine charcoal-like organic matter, chopped up and worked into matrix. Some eggshell? No ashy residue apparent. Some bone not burned. Some pinkish limestone.

WL-92-F25, Block: Only part of sample is reddened, not all of it. Like other Feature 245 samples, perforated by earthworms, with charcoal or dark organic matter broken up by bioturbation.

WL-92-F25, Slide: Similar to Sample WL-92-F12 (Feature 243) both in composition and structure. This is another sample that exhibits clear evidence of in situ burning primarily in the form of abundant, burned (rubified/oxidized) sediment. At the very top are extremely burned, calcined limestone fragments (although fragments of snail shell adjacent to them are not burned). Some bone occurs but it does not appear to be burned (no evidence of heating observed). Reddish brown clay/silt aggregates are distributed throughout and some of them have a bright red color (indicative of burning). There is not much organic material in this sample. Some small shreds of dark brownish black organic matter were observed but they occurred in much lower density than observed in similar Sample WL-92-F12. The organic material has been worked into the matrix through bioturbation. A few isolated ash rhombs were noted. Carbonate hypocoatings and coatings in large voids display felt-like masses of aciculate crystals.

\section{Feature 249}

WL-92-F23, Slide: A large piece of burned, rubified limestone ( $3 \mathrm{~cm}$ in diameter) occurred in this sample as well as some rubified, burned matrix and some bright reddish clayey aggregates (bright reddish color is indicative of burn- ing). There are also many ash rhombs and much dark organic matter that may represent charred plant remains. There are also some burned snail shells, a burned shell fragment that may be eggshell, and a lot of unburned bone. The abundance of burned material in this sample and the rubified sediment suggest that the burning occurred in or near the sampled area.

WL-92-F30, Slide: A number of rubified and calcined limestone fragments are evident in this sample. A few pieces of burned snail shell were also observed as well as some unburned bone.

\section{Feature 252}

WL-92-F22, Slide (1): This sample is similar to WL-92F22(2) except it contains large popcorn carbonate samples that obscure many features in the slide.

WL-92-F22, Slide (2): This sample is heavily calcified (like typical Isi), but contains some very fine-grained organic matter that is locally concentrated. This type of organic matter is characteristic of the Leanne soil and the local concentrations reflect secondary processes such as bioturbation and calcification. One unburned bone fragment was also observed.

\section{Feature 256}

WL-92-F26, Slide: No evidence of burning observed. Slide is not very good but it looks like it is a typical Leanne soil sample.

\section{Feature 260}

WL-92-F29, Slide: Much fine organic matter (typical of Leanne soil). No evidence of burning observed. A possible ostracode was observed.

\section{4-1995 Series of Feature Samples from Bags of Loose Sediment Collected During Both the TxDOT and TARL Excavations}

\section{Feature 104}

WL-95-3, Block: Several burned stones were observed along with some circular gray patches that look like ash. There is evidence of abundant earthworm activity. There may be traces of oxidized, burned soil but it is difficult to determine because of bioturbation. There is some iron staining. A number of snail shells and some bone were also observed.

WL-95-3, Slide: The primary indications of burning in this sample are a few burned (partially calcined) limestone fragments and traces of rubified matrix that have been broken up by biological activity and extensive secondary cementation. A few isolated ash rhombs were observed, but 
they are generally difficult to distinguish due to the extensive calcification that pervades the sample. There is much finely shredded organic matter that has been worked into the matrix through bioturbation. Hypocoatings are quite thick and their degree of development is similar to that found in Unit II (this sample was probably collected from Unit X). Overall, the sample has a very spongy to vugy microstructure.

\section{Feature 155}

WL-95-24, Block: Bright, orange-brown color that may represent oxidation associated with burning. Some of the small limestone grains exhibit a dark gray color (possibly burned?). Small pieces of charcoal or organic matter that are worked into the matrix through bioturbation. Snails evident but no bone observed. Occasional ashy domains are evident.

WL-95-24, Slide: The bright orange color observed in the block more likely represents iron staining than oxidation from burning. This is a very stoney sample but none of the rocks exhibit clear evidence of burning The possibly burned limestone grains observed in the block did not appear burned in the slide (dark gray color probably not due to burning). A large calcareous, "ashed" vegetal fragment was observed along with scattered ash rhombs that are worked into the matrix. Hypocoatings are localized but they tend to be relatively thick (which is typical of upper Unit II). There is some incipient iron staining (mostly flecks). A small amount of dark brownish black organic matter is worked into the matrix along with a few isolated pieces of unburned bone (but these materials are not abundant).

\section{Feature 157}

WL-95-20, Block: Not a good impregnation. One large rosy and gray piece of burned limestone. Some shells. No reddened soil apparent. Charcoal dust. This sample was not thin sectioned.

\section{Feature 166}

WL-94-F1, Slide: Definitely reddened soil. Much recent reddish organic matter worked into the matrix. Unusual soil concretion. Some calcining of the limestone but minor. Some ashy remnants. Some evidence of burning in all particles. Some fine charcoal or charred material. Limestone has caliche crust that looks like plaster. One chert grain.

WL-94-F2, Slide: A lot of iron-stained grains. Grains of calcrete? No burned limestone. Some pinkish limestone. Not much charcoal. Very finely divided organic matter. Some ashy vegetal relict. Overall not much evidence for burning. No reddened burned soil. One possibly burned grain? One rhomb of ash.

\section{Feature 168}

WL-93-Pi1: Quite spongy; many voids and hypocoatings; some organic material but not much; localized areas that are richer in finely divided organic material; the hypocoatings are coated with thin dusty brown coatings that formed after the hypocoatings; abundance of iron staining; looks like either Isi or Leanne soil.

WL-93-Pi2: Looks like mixture of both Isi and Icl (but more Icl than anything else); no ostracodes noted; only a trace of the dusty clay void coatings; some hypocoatings; some iron staining, but not well developed like Isi; stony; one piece of bone.

WL-93-Pi3(1): Not a very good thin section; ironstained aggregates of Isi mixed in with what looks like Icl; not very much organic material in the pit fill; looks more like Isi than anything (low organic content and lots of iron staining).

WL-93-Pi3(2): Not a very good thin section; not very much organic material except in occasional pockets or domains; lots of iron-staining (mostly orange); mostly looks like Isi with possible admixture of Icl (thin section too poor to say much).

WL-93-Pi6: (Sample collected outside Feature 168 pit on 6/30/83). Many rock fragments, snail shell (possibly heated/burned); one small patch of noncalcareous clay (400 :m long); a few dusty clay void coatings (ca. 20 :m thick), a few infillings of dusty brown clay; organic matter is relatively sparse; considerable iron staining and some localized burrowing; the presence of individual iron stained aggregates indicates iron staining took place before the burrowing; this sample looks like Isi.

\section{Feature 169}

WL-93-Pi4: (Collected from dark brown zone at base of pit containing 2 limestone rocks). Slide is slightly too thick; limestone fragment (1 $\mathrm{cm}$ across) stained pink from hematite/iron oxide; some type of ash/vegetal fragment; part of the matrix is also stained red (hematite?); appears to be Isi with iron staining; unidentified bright orange fragments (5 :m across) which particularly occur in the voids; these orange things almost look like spores (?); fair amount of organic material; tiny grain of quartz with hematite staining (45 :m across); possible ostracode; bone fragment.

WL-93-Pi5: (Collected from central portion of pit fill in south half of pit). Matrix has localized areas which are stained red or pink, presumably from hematite/iron oxide?; limestone fragment with one small pink area that probably represents burning (probably not very intensive burning because little of the grain has been calcined); other limestone fragments that show evidence of mild heating are not pink; a few fine pieces of charcoal; one void shows calcified roots; looks like there are individual rhombs of ash that have been worked into the matrix through mixing/bioturbation?; lots of shreds 
of organic material; looks like Leanne soil more than anything else.

WL-93-Pi7: (Collected primarily from outer margins of pit fill in south half of feature). Not as pink as WL-93-Pi5; nonlocal weathered rock fragment (biosparite?); no limestone fragments with evidence of burning (no pink); large void with bright orange root (?) material; chert grain; partially dissolved bone fragment; lots of tiny bone fragments (10-50 :m); fair amount of organic matter; a few ash rhombs mixed in with charcoal; domains of noncalcareous clay; local patches of bright orange iron staining; orange-stained silt with organic matter looks like Leanne soil more than anything else; faint trace of dusty brown clay void coatings; this sample differs from the other Feature 169 samples because it exhibits very little evidence of the pink iron-oxide staining.

\section{Feature 176}

WL-95-4, Block: Very dense fabric. Very compact. Some of the earthworm casts are made of red, oxidized sediment but the larger patches of burned sediment that the casts are derived from are not visible. Isolated pieces of charcoal (large enough pieces that some structure is visible in thin section). Gray patches similar to ash. There are several bone fragments (not possible to determine if burned). Some modern roots. Some snail shells (do not look particularly burned).

WL-95-4, Slide: This sample was collected from a level that was ascribed to either Unit IIIc or IIIb. The evidence observed in the thin-section suggests it is more likely IIIb because the earthworm casts do not look very fresh, i.e., they tend to be welded, rather than individual casts. There is a slight indication of hypocoating development which does not occur in IIIc. Overall the sample has more of an aged appearance than typical IIIc samples.

The evidence of burning is very subtle in this sample. There are traces of rubified sediment that apparently represent isolated remnants of larger areas of burned sediment that were extensively burrowed. There are several dispersed ash crystals and at least one burned, calcined snail shell. A few very small burned (partially calcined) limestone fragments were also observed. There are also a few calcareous, "ashed" vegetal fragments.

Feature 185

WL-95-22, Block: Very fine-grained matrix. A piece of charcoal or dark organic matter. No limestone apparent. No reddened soil. Nothing burned. This sample was not thin sectioned.

\section{Feature 187}

WL-95-23, Block: Lots of fine charcoal or dark organic matter. No remnants of burned soil apparent, or even of pink limestone. Does not appear very burned nor very cultural. Much iron staining. Some black flecks, possibly manganese staining.
WL-95-23, Slide: This sample contains much silt and fine sand-sized calcite grains. These grains have been cemented by secondary carbonates which also take the form of hypocoatings in vesicles. There is much iron staining. This sample also has local concentrations of very finely divided organic matter. It also includes a few ash rhombs and at least one possible ostracode was noted. The granular nature of the calcite is reminiscent of spring-like deposition.

\section{Feature 204}

WL-95-5, Block: A piece of calcined limestone. Overall grains are small, so difficult to infer anything. Not much charcoal (or dark organic matter); what there is, is very fine. A few pink-stained limestone fragments. Does not appear burned.

WL-95-5, Slide: No rubified sediment was observed but there are a number of ash rhombs scattered throughout the sample along with finely divided dark brown organic material (not charcoal). There are also several pieces of calcareous, "ashy" vegetal material. There are several bone fragments (unburned) and a few unburned snail shells. There are a few limestone fragments but none appear burned. Although there is no definitive evidence of in situ burning, the ash rhombs and ashed vegetal material are indicative of burning.

\section{Feature 206}

WL-95-6, Block: This sample exhibits much finely divided charcoal or dark organic matter. It appears burned overall and includes some possibly calcined limestone. Some reddened burned soil was also observed.

WL-95-6, Slide: This sample consists primarily of ash and calcareous, "ashy" vegetal material (much higher ash content than other Wilson-Leonard thin-sections). Many ash rhombs are worked into the matrix along with a lot of finely divided organic matter. A few unburned bone splinters are present as well as unburned snail shells and a few pieces of chert. No burned limestone was observed. A possible burned eggshell (?) fragment was also observed.

\section{Feature 209}

WL-95-25, Block: This sample is made of many small clumps impregnated together. Some of them are gray and ashy looking. It looks like there is a burned fossil shell fragment (from the limestone). Very finely divided charcoal or dark organic matter worked into the matrix through bioturbation.

WL-95-25, Slide: This sample is typical of lower portion of Unit IIIb with the presence of incipient hypocoatings associated with vesicles. The dark color observed in the field is expressed in the sample as an abundance of finely 
comminuted dark organic matter that is well worked into the calcareous matrix by earthworms. One unburned bone fragment was noted. A few ash rhombs are readily visible and others are scattered throughout the matrix.

\section{Feature 213}

WL-95-7, Block: Some burned soil and pink limestone. Very fine charcoal or dark organic matter worked into matrix.

WL-95-7, Slide: This sample was made from several small dried clumps of sediment that were impregnated together. Although many of these clumps exhibit a pinkish hue that may represent in situ burning, the clumps are too small for a definitive assessment. One of the clumps contains a void with hypocoatings. A number of snail shells are present and some have been heated (they are not calcined but they are altered by fire). Several unburned bone fragments are present. Calcareous ashy vegetal material and ash rhombs are also present. The sample exhibits evidence of lots of biological reworking (worms, etc.). Although this sample does not provide definitive evidence of in situ burning, the pinkish color and ashy material suggest burning probably occurred at or near this location.

\section{Feature 216}

WL-95-26, Block: This sample is made of several small clumps impregnated together. Some gray limestone pieces that may be burned. Some ashy domains. Not much charcoal or dark organic matter. No oxidized sediment. This sample was not thin sectioned.

\section{Feature 220}

WL-95-27, Block: This sample is made of a lot of small clumps impregnated together. This has a dark color (darker than most of these samples) with much charcoal or dark organic matter (isolated zones with a lot more dark material). Lighter areas that are pinkish and may be oxidized burned sediment. One burned snail shell. Marbled, ashy looking swirls.

WL-95-27, Slide: This sample is provenienced to either Unit IIII or IIIa, but the slide looks more like Unit IIIa due to the moderate development of hypocoatings in voids. This is matched by the more massive nature of the matrix which shows relatively few individual earthworm casts and mostly welded ones (sample is much more aged). A bright reddish brown clayey aggregate was observed that probably represented burned sediment. Large pieces of dark yellowish brown organic matter were also observed in relatively greater abundance than seen in many other slides. This material is probably burned plant material and it is also coarser than the organic material seen in other slides. A few ash rhombs, some unburned bone, and a burned snail shell were also noted.

\section{Feature 222}

WL-95-29, Block: This sample is made of several small clumps impregnated together. Burned limestone fragment that may have a calcined rind. A lot of fine charcoal or dark organic matter. This sample was not thin sectioned.

\section{Feature 224}

WL-95-9, Block: Not much charcoal/organic matter. Burned limestone, some extensively burned. Soil does not look burned. Fine aggregates. Some orange-pink limestone. No reddened soil, but heavily perforated by earthworms.

WL-95-9, Slide: There is limited evidence of burning in this sample. This includes a clump of sediment that has a reddish pink hue; a burned bone fragment; a partially heataltered (not calcined) limestone fragment; a heated snail shell fragment; a few ash rhombs; and calcareous ashy vegetal material. An unburned tooth fragment was also observed. Although this sample does not provide definitive evidence of in situ burning, the pinkish color and ashy material suggest burning probably occurred at or near this location.

\section{Feature 226}

WL-95-10, Block: Charcoal/organic matter(?) worked into matrix. Some pinkish grains. One clump of burned soil.

WL-95-10, Slide: Sample looks much like Unit II (compact, stoney, lots of snails; well-developed hypocoatings; relatively little organic material). There is a very small amount of finely divided organic material worked into the matrix but this may not be charcoal. Not much evidence of burning (no pink sediment, no charcoal, no ash rhombs, no burned stone) but there is some calcareous ashy vegetal material. A few very, very small bone fragments were observed, but they were too small to tell if they were burned.

\section{Feature 227}

WL-95-11, Block: This is not a very good sample. It is made of many small clumps that were impregnated together. There are small flecks of organic matter/charcoal that are worked into the matrix through bioturbation. A clump of what may be ash or ashy sediment (much grayer). No bone. Several snails (do not appear burned). Possibly some slightly pinker areas (not super evident). This sample was not thin sectioned.

\section{Feature 228}

WL-95-30, Block: This sample is made of several small clumps impregnated together. Burned bone or tooth. Many gray (burned?) limestone fragments that may be calcined rind. Not much charcoal. Marbled, ashy looking domains.

WL-95-30, Slide: A relatively large ( $3 \mathrm{~mm}$ in diameter) limestone fragment showed extensive heating and calcination. 
A mass of recrystallized ash ( $1 \mathrm{~mm}$ in diameter) was adhered to one surface. This is expressed as poorly differentiated mass of porous calcium carbonate that is perforated by a few roots. The thickness of the slide and the fineness of the calcite makes recognition of individual ash crystals very difficult. Several pinkish, burned limestone fragments were also observed.

\section{Feature 230}

WL-95-16, Block: Poorly impregnated sample. It is composed of several small clumps that were impregnated together. There are very fine pieces of charcoal or dark organic matter that are worked into the matrix through bioturbation. There are some grayish ashy clumps. One piece of bone. Small areas of lighter, slightly orange sediment may represent burned, oxidized sediment. This sample was not thin sectioned.

\section{Feature 233}

WL-95-12, Block: Some pinkish limestone. Very fine grains. Very fine charcoal/organic matter(?). Some evidence for burning. A piece of calcined(?) limestone. Many snail shells. No burned soil apparent.

WL-95-12, Slide: There are some partially calcined, burned limestone fragments present. No rubified sediment evident but there are quite a few ash rhombs worked into the matrix. There are several calcareous ashy vegetal fragments and a few burned snail shells or burned limestone fragments. There are also some poorly preserved bone fragments. This sample looks more clayey than most samples (browner in color).

\section{Feature 237}

WL-95-31, Block: This sample is made of several small clumps impregnated together. Several small areas of burned, oxidized (reddish) sediment broken up by bioturbation. Some fine bits of charcoal or dark organic matter. Some grayer zones that might be ashy but too broken up to tell in the block. This sample was not thin sectioned.

\section{Feature 239}

WL-95-17, Block: Composed of several small clumps that were poorly impregnated. One gray rock that looks like it might be heated. One clump with charcoal or dark organic matter worked into it. No evidence of oxidized sediment. This sample was not thin sectioned.

\section{Feature 241}

WL-95-18, Block: Poor sample, composed of small clumps that were impregnated together. Small charcoal or dark organic matter and possibly ashy, gray domains look like they have been worked into the matrix through bioturbation. No evidence of oxidized sediment observed. Many snail shells (like most of these samples). No bone. This sample was not thin sectioned.

\section{Feature 246}

WL-95-14, Block: Some possibly calcined limestone. The charcoal (or dark organic matter) is broken up. Some areas of reddened burned soil. Some pinkish stained limestone that could be from heating.

\section{Feature 248}

WL-95-19, Block: One large clump but mostly the sample is made of small pieces impregnated together. Burned seed. Very bioturbated by earthworms. Pieces of charcoal or dark organic matter broken by earthworms. Some of the sediment looks pinkish or orange (probably burned, oxidized). No iron staining. Ashy domains. Bright yellow grains that represent weathered limestone.

WL-95-19, Slide: Some domains of pinkish, oxidized sediment are apparent. Other evidence of burning includes some definite charcoal or dark organic matter pieces, some burned snail shells, and possible traces of ash rhombs. Some pieces of unburned bone are also present.

\section{Feature 255}

WL-95-15, Block: Small piece of charcoal. Much manganese. Some snail shells. Some iron staining. No limestone apparent, but perhaps one burned grain. Not much evidence of burning.

WL-95-15, Slide: This sample exhibits much iron staining and much secondary carbonate. No clear evidence of burning. There are some fine shreds of brownish black organic material worked into the matrix but not possible to determine whether it is charcoal. One aggregate has a pinkish red hue that looks as if it may have been heated (it looks different from the yellowish iron-stained sediment). Possible ash rhombs but matrix is too calcareous to distinguish ash easily.

\section{Feature 262}

WL-95-1, Block: Good example of Isi. It is very iron stained. There are some very finely divided dark flecks which could be organic matter, charcoal, or manganese. If the dark material is carbonized plant material, it probably is not woody charcoal (more likely burned grass or some other nonvascular plant). No bone observed. No definitive evidence of burning.

WL-95-1, Slide: No evidence of burning was observed. Much fine organic matter is distributed throughout the sample 
but none of it appears to be carbonized. There is extensive iron staining.

WL-95-2, Block: Very similar to Block WL-95-1 so no thin section was made from this block. This samples is also from Unit Isi (very iron stained) but there are some grayish domains that are reminiscent of Unit Icl. There are also the same dark flecks as in Block 1 but there are some larger pieces that are clearly plant matter (exhibit vegetal structure). Cannot determine if this is carbonized. No bone observed.

\section{Burial 2}

WL-93-B1: (Collected from pelvis block; matrix remaining after bone removed; sample selected from intact clod); very compact (possibly tamped down), but with large chambers and smaller voids and vesicles; looks like compressed version of WL-93-B7; relatively few hypocoatings (less than WL-93-B7) perhaps because sample was from under the body(?); one clump of noncalcified silty clay which could contain some ash crystals; one bone fragment; one ostracode.

WL-93-B2: (Collected from rib block; matrix remaining after bone removed; looks as if matrix became wet and then artificially clumped together); very compact (possibly tamped down); relatively few hypocoatings; iron-rich grains (Isi) mixed into the calcareous matrix; fair amount of bone; not much organic material.

WL-93-B3: (Sample collected under limestone rock found in upper portion of burial pit; base of rock at TxDOT elevation $94.885 \mathrm{~m}$ or TARL elevation $94.225 \mathrm{~m}$ ). This sample is similar to WL-93-B6 (characteristics of both Icl and Leanne soil; possibly at or near contact), but looks more like Leanne soil than Icl (seems to be mostly Leanne soil with some inclusions of $\mathrm{Icl}$ ); many microcontrasted particles; very spongy, several vesicles; one broken piece of charcoal ca. $1.5 \mathrm{~mm}$ long (rarely find pieces of charcoal this size in Icl); overall, the organic matter is fairly coarse which is generally more characteristic of Leanne soil than Icl; the areas that are more characteristic of Icl include much fine-grained organic matter and have a more grayish color; dusty brown, impure void coatings 15 to 30 :m thick (coatings are fairly faint); these coatings look similar to those that develop below slaking crusts; however, they are weakly developed (subtle) suggesting short period of accumulation; some of the void coatings look like they are comprised of finely divided organic matter that was translocated from a surface; must be fairly close to a former surface (lots of biological activity indicated by burrows, roots).

WL-93-B4: (Sample collected under groundstone/chopper found in burial pit). Very porous with many voids; considerable bioturbation; abundant hypocoatings; many rock fragments; some bone fragments; modest amount of finely divided organic matter that is quite localized (probably as a result of bioturbation); faint traces of void coatings with one circular void with a 40 :m thick coating of dusty brown clay (void coatings are similar to those in WL-93-B3 but not as common); lesser development of void coatings in this sample (compared to WL-93-B3) might be due to protective action of stone under which sample was collected; clay coatings seem to postdate the hypocoatings; in general, sample looks quite similar to Leanne soil, much iron staining, even bone is iron stained; yellow staining suggests some of the phosphate may be leaching into the matrix from the bone.

WL-93-B5(1): (Sample collected outside and west of burial pit). Lots of voids; hypocoatings not as well developed as in Burial 2 pit fill samples; dark reddish brown, dusty clay void coatings that are better developed than in Sample WL-93-B4; some are up to 60 :m thick; some are more limpid clay coatings but these are thinner (ca. 10 :m thick); not too much organic matter; abundant iron staining; most similar to Isi.

WL-93-B5(2): (Sample collected outside and west of burial pit). Similar to WL-93-B5(1) but more organic matter; dusty clay void coatings like previous sample but dusty clay fillings can be found between grains and aggregates as well as in void coatings; sample has very disrupted appearance and is very biologically reworked; probably near surface that has been broken up: then fine silt and clay have been worked into the interstitial voids; almost looks like a microbreccia of Isi with the interstices filled with organicrich dusty clay.

WL-93-B6: (Collected just outside of/east of Burial 2). One poorly preserved bone fragment; a few ostracodes; moderate amount of finely divided organic matter; moderately abundant hypocoatings and a generally spongy fabric; slight evidence of dusty brown void coatings 5 :m thick; very similar to WL-94-S4 (TxDOT soil zone 15) but not quite as gray; could be edge of cienega (Icl), but also has some aspects of Leanne soil, being more brownish in color and organic matter tends to be slightly coarser than in Icl; roughly a $65 \%$ probability of being Icl and 35\% Isi-c?; most likely at/ or near the Isi-c/Icl contact.

WL-93-B7: (Pit fill). Probable mixture of Isi and Icl; has grayish tinge of Icl but has rounded grains of iron-rich sediment that look like Isi; looks like they filled pit with mixture of Isi and Icl which was then cemented by calcium carbonateCthere are hypocoatings (and numerous vesicles) that penetrate both of these types of sediment; faintest dusty brown void coatingCresembles material beneath a slaking crust; these dusty coatings seem to be formed after the calcareous hypocoatings; elsewhere there are some reddish brown clay void coatings that are 5 to 15 :m thick (these look more like the void coatings in WL-94-S4); in one area of the slide, there is a ca. 1-mm size aggregate of dark brown, humified organic matter (appears as one object that has been partially broken up).

WL-93-B8: (Pit fill). Definitely has localized areas with a peculiar reddish brown tinge; part of this color is due to iron staining but probably also some reddish clay present; 
elsewhere there is more grayish brown material that is similar to Icl; organic matter occurs in both the reddish brown and grayish areas; one bone fragment noted; several matrix aggregates, some of which are welded together, are composed of both the reddish and grayish materials (one clast that was half and half); again this would suggest that the pit fill is composed of both Isi and Icl.

WL-93-B9: (Vial of pit fill; Munsell Zone 2 on plan map 1B). Poor sample (quite small); slight dusty coatings on the voids and in-fillings; much organic matter; grayish color; a number of voids with hypocoatings; one of the fragments has a slaking crust; looks like either Leanne soil or Icl.

WL-93-B10: (Vial of pit fill; Munsell Zone 3 on plan map 1B). Appears to be a mixture of Icl and Leanne soil; unusual piece of decayed vegetation(?) which has stained the surrounding matrix a pinkish beige color and left behind some possible ash crystals; thin dusty brown clay void coatings (sparse); some hypocoatings; some bone present and some appears to stain the surrounding matrix a yellowish color. 
ISBN 1-887072-28-4 (Volume IV)

ISBN 1-887072-24-1 (5 Volume Set) 